U.S. Department of the Interior

U.S. Geological Survey

\title{
Physical, Chemical, and Biological Data for Selected Streams in Chester County, Pennsylvania, 1981-94
}

by Andrew G. Reif

Open-File Report 99-216

prepared in cooperation with the

CHESTER COUNTY WATER RESOURCES AUTHORITY 


\section{U.S. DEPARTMENT OF THE INTERIOR \\ BRUCE BABBITT, Secretary}

\section{U.S. GEOLOGICAL SURVEY}

Charles G. Groat, Director

Copies of this report may be purchased from:

U.S. Geological Survey

Branch of Information Services

Box 25286, Building 810

Denver, Colorado 80225-0286
Copies are also available from:

Chester County Water Resources Authority 601 Westtown Road

Suite 270

P.O. Box 2747

Government Services Center

West Chester, Pennnsylvania 19380-0990 


\section{CONTENTS}

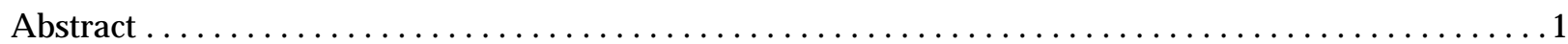

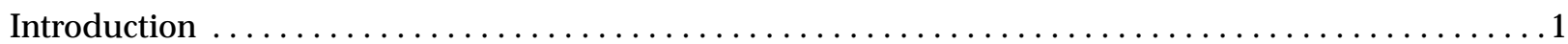

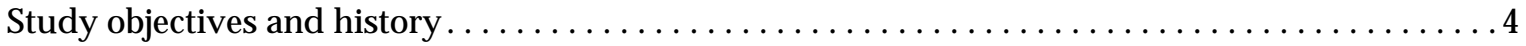

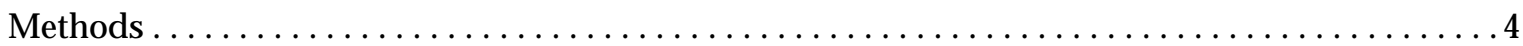

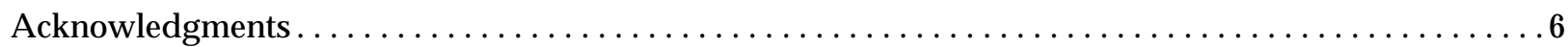

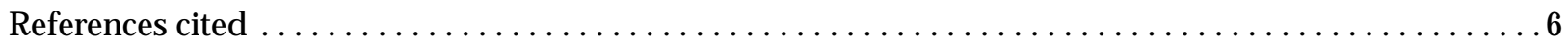

\section{ILLUSTRATION}

Figure 1. Map showing location of sampling sites in Chester County, Pa. . . . . . . . . . . 2

\section{TABLES}

Table 1. Sampling sites, station numbers, names, drainage areas, and period of record $\ldots \ldots \ldots \ldots 3$

2. List of taxonomic references used to identify macroinvertebrate samples $\ldots \ldots \ldots \ldots \ldots \ldots$

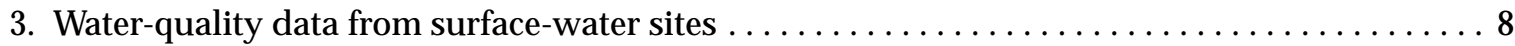

4. Results of stream-bottom sediment sampling .......................... 240

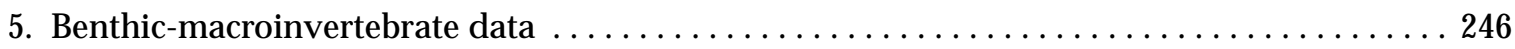

6. Brillouin's diversity index, maximum diversity, minimum diversity, and relative

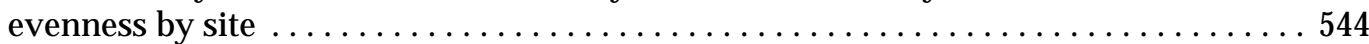

7. Median, mean, standard deviation, and standard error values of Brillouin's

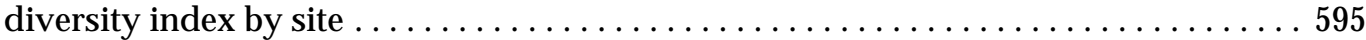

8. Alphabetic checklist of taxa reported from Chester County Biological Monitoring Network $1981-94$. . . . . . . . . . . . . . . . . . . . . . . . . . . 597

9. Systematic checklist of taxa reported from Chester County Biological

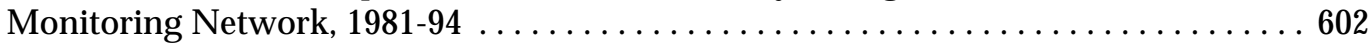




\section{CONVERSION FACTORS AND ABBREVIATED WATER-QUALITY UNITS}

Multiply

inch (in.)

square mile $\left(\mathrm{mi}^{2}\right)$

cubic foot per second $\left(\mathrm{ft}^{3} / \mathrm{s}\right)$

degree Fahrenheit $\left({ }^{\circ} \mathrm{F}\right)$
By

2.54

2.590

0.02832

${ }^{\circ} \mathrm{C}=5 / 9\left({ }^{\circ} \mathrm{F}-32\right)$
To obtain

centimeter

square kilometer

cubic meter per second

degree Celsius

Abbreviated water-quality units used in this report:

micrograms per kilogram $(\mu \mathrm{g} / \mathrm{kg})$

micrograms per liter $(\mu \mathrm{g} / \mathrm{L})$

microsiemens per centimeter $(\mu \mathrm{S} / \mathrm{cm})$

milligram per liter $(\mathrm{mg} / \mathrm{L})$

millimeter (mm)

grams per kilogram $(\mathrm{g} / \mathrm{kg})$ 


\title{
PHYSICAL, CHEMICAL, AND BIOLOGICAL DATA FOR SELECTED STREAMS IN CHESTER COUNTY, PENNSYLVANIA, 1981-94
}

\author{
By Andrew G. Reif
}

\begin{abstract}
Physical, chemical, and biological data were collected at 51 sampling sites in Chester County, Pa., from 1970 through 1994 as part of the Stream Conditions of Chester County Program. This report presents data collected from 1981 through 1994. Physical data include water temperature, instantaneous stream discharge, $\mathrm{pH}$, alkalinity, specific conductance, and dissolved oxygen. Chemical data include laboratory determinations of nutrients, major ions, and selected metals in whole water samples and selected metals, pesticides, gross polychlorinated biphenyls (PCB's), gross polychlorinated napthalenes (PCN's), and total carbon in stream-bottom sediment samples. The biological data consists of benthic macroinvertebrate population analyses and diversity indices. Chester County is undergoing rapid urbanization as agricultural lands are converted to residential, commercial, and industrial areas. The purpose of the Stream Conditions of Chester County Program is to further the understanding of stream habitat and chemical changes in response to this urbanization.
\end{abstract}

\section{INTRODUCTION}

Chester County, in the southeast corner of Pennsylvania near Philadelphia (fig. 1), is undergoing rapid urbanization as agricultural lands are converted to residential, commercial, and industrial areas. The Stream Conditions of Chester County Program was developed by the U.S. Geological Survey (USGS) and the Chester County Water Resources Authority (CCWRA) to evaluate stream-water quality and to further the understanding of stream changes in response to urbanization (Lium, 1977, p. 6). This report presents physical, chemical, and biological data collected at 51 sites from 1981 through 1994 as part of the Stream Conditions of Chester County Program (table 1). The physical, chemical, and biological data from the Stream Conditions of Chester County Program from 1969 through 1980 are presented in a report by Moore (1989).

The streams included in the Stream Conditions of Chester County Program drain nearly 95 percent of the county (fig. 1). Valley Creek, Pickering Creek, Stony Run, Pigeon Creek, and French Creek are tributaries to the Schuylkill River. Darby, Crum, Ridley, and Chester Creeks are tributaries to the Delaware River. Buck Run, Doe Run, Indian Run, and Valley Creek are tributaries to the Brandywine Creek. The Red Clay Creek, White Clay Creek, and the Brandywine Creek are tributaries to the Christina River, which is a tributary to the Delaware River. Big Elk Creek flows into the Chesapeake Bay. Octoraro Creek is a tributary to the Susquehanna River. All streams sampled originate within the boundaries of Chester County, except for the headwaters of the West Branch Brandywine, French, and Octoraro Creeks. 


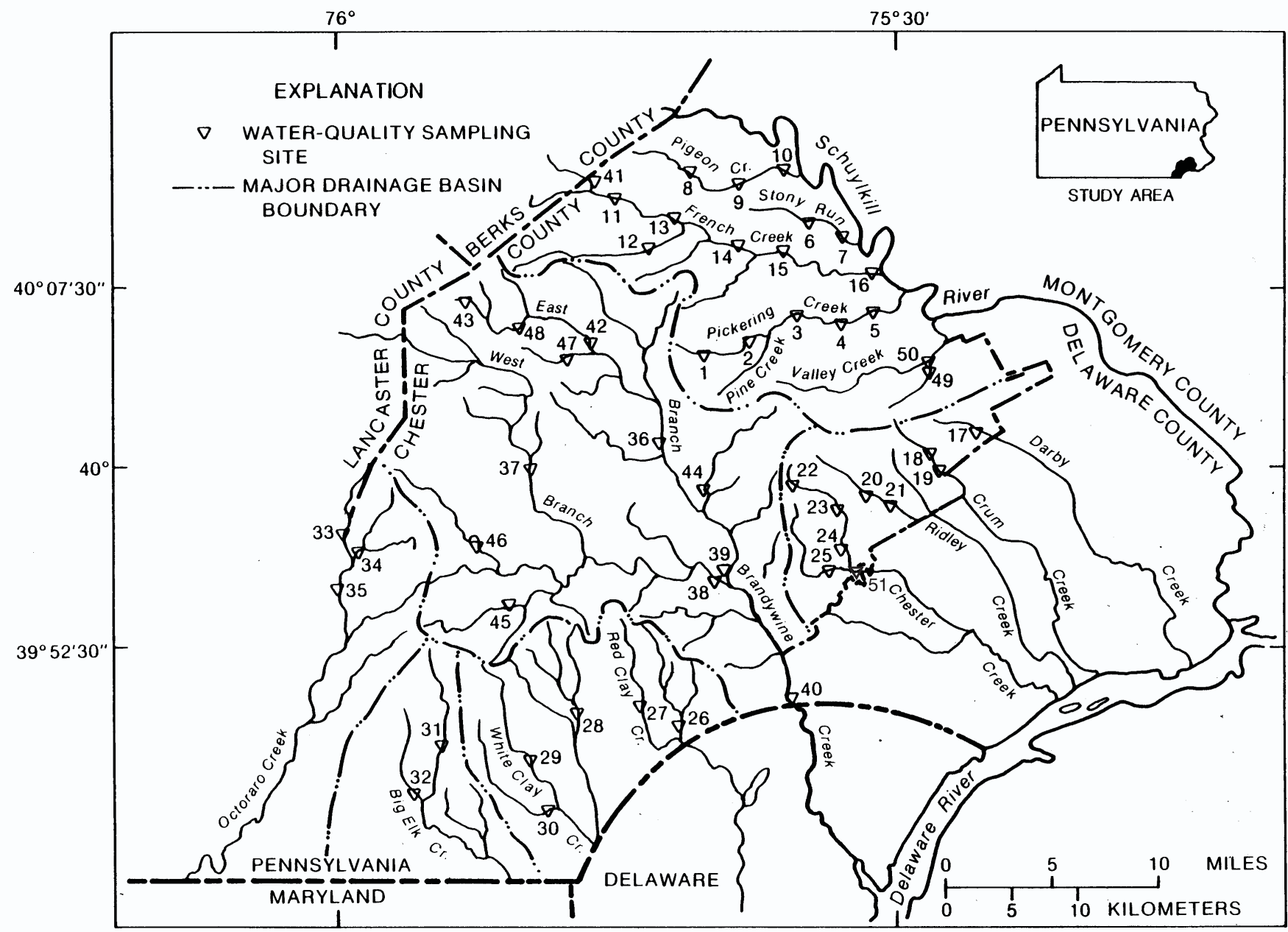

Figure 1. Location of sampling sites in Chester County, Pa. 
Table 1. Sampling sites, station numbers, names, drainage areas, and period of record

$[-$, no data $]$

\begin{tabular}{|c|c|c|c|c|c|c|}
\hline \multirow{2}{*}{$\begin{array}{l}\text { Station } \\
\text { number }\end{array}$} & \multirow{2}{*}{$\begin{array}{c}\text { Site } \\
\text { number }\end{array}$} & \multirow[b]{2}{*}{ Name } & \multirow{2}{*}{$\begin{array}{l}\text { Drain- } \\
\text { age } \\
\text { area }\end{array}$} & \multicolumn{3}{|c|}{ Period of record } \\
\hline & & & & Biological & Chemical & $\begin{array}{l}\text { Bottom } \\
\text { sediment }\end{array}$ \\
\hline 01472054 & 8 & Pigeon Creek near Bucktown & 4.20 & $1970-82$ & $1969-82$ & - \\
\hline 01472065 & 9 & Pigeon Creek at Porters Mill & 6.97 & $1970-82$ & $1969-82$ & - \\
\hline 01472080 & 10 & Pigeon Creek near Parker Ford & 12.0 & $1970-94$ & $1969-94$ & 1985 \\
\hline 01472109 & 6 & Stony Run near Spring City & 2.00 & $1970-94$ & $1969-94$ & 1985 \\
\hline 01472110 & 7 & Stony Run at Spring City & 4.07 & $1970-82$ & $1969-82$ & - \\
\hline 01472126 & 41 & French Creek at Trythall & 5.06 & 1982 & $1970-82$ & - \\
\hline 01472129 & 11 & French Creek near Knauertown & 11.7 & $1972-82$ & $1969-82$ & - \\
\hline 01472138 & 13 & French Creek near Coventryville & 19.9 & $1970-94$ & $1969-94$ & 1986 \\
\hline 01472140 & 12 & South Branch French Creek at Coventryville & 12.4 & $1970-94$ & $1969-94$ & 1985 \\
\hline 01472154 & 14 & French Creek near Pughtown & 46.1 & $1970-94$ & $1969-94$ & 1985 \\
\hline 01472157 & 15 & French Creek near Phoenixville & 59.1 & 1970-94 & $1969-94$ & 1994 \\
\hline 014721612 & 16 & French Creek at Railroad Bridge at Phoenixville & 70.7 & $1980-94$ & $1970-94$ & 1985,1994 \\
\hline 01472170 & 1 & Pickering Creek near Eagle & 3.09 & $1970-94$ & $1969-94$ & 1987 \\
\hline 01472174 & 2 & Pickering Creek near Chester Springs & 5.98 & $1970-94$ & $1969-94$ & 1986 \\
\hline 014721854 & 3 & Pickering Creek at Merlin & 21.2 & 1970-94 & $1969-94$ & 1986 \\
\hline 014721884 & 4 & Pickering Creek at Charlestown Road at Charlestown & 27.5 & 1972-94 & 1969-94 & 1985 \\
\hline 01472190 & 5 & Pickering Creek near Phoenixville & 31.4 & 1970-94 & 1969-94 & 1986, 1994 \\
\hline 01473167 & 49 & Little Valley Creek at Howellville & 6.45 & $1973-94$ & $1970-94$ & $1986,87,93$ \\
\hline 01473168 & 50 & Valley Creek near Valley Forge & 12.7 & 1973-94 & $1970-94$ & 1985,1993 \\
\hline 01475300 & 17 & Darby Creek at Waterloo Mills near Devon & 5.15 & 1970-94 & $1969-94$ & - \\
\hline 01475830 & 18 & Crum Creek near Paoli & 6.16 & $1970-82$ & $1969-82$ & - \\
\hline 01475840 & 19 & Crum Creek at Whitehorse & 10.1 & 1970-94 & 1969-94 & 1986 \\
\hline 01476430 & 20 & Ridley Creek at Goshenville & 4.22 & $1970-94$ & $1969-94$ & 1985 \\
\hline 01476435 & 21 & Ridley Creek at Dutton Mill near West Chester & 9.71 & $1970-94$ & $1969-94$ & 1986 \\
\hline 01476790 & 22 & East Branch Chester Creek at Green Hill & .63 & $1970-94$ & $1969-94$ & 1986 \\
\hline 01476830 & 23 & East Branch Chester Creek at Milltown & 5.77 & $1970-94$ & $1969-94$ & 1986 \\
\hline 01476835 & 24 & East Branch Chester Creek at Westtown & 10.4 & 1970-94 & $1969-94$ & 1985,1994 \\
\hline 01476840 & 25 & $\begin{array}{l}\text { Goose Creek Tributary to East Branch Chester Creek near } \\
\text { West Chester }\end{array}$ & 4.28 & $\begin{array}{l}1975-82 \\
1988-94\end{array}$ & $\begin{array}{l}1970-82 \\
1988-94\end{array}$ & 1988,1993 \\
\hline 01476848 & 51 & $\begin{array}{l}\text { East Branch Chester Creek below Goose Creek near } \\
\text { West Chester }\end{array}$ & 19.2 & 1983-94 & 1970-94 & 1986,1994 \\
\hline 01478120 & 28 & East Branch White Clay Creek near Avondale & 11.3 & 1970-94 & $1970-94$ & 1985,1993 \\
\hline 01478190 & 29 & Middle Branch White Clay Creek near Wickerton & 9.94 & 1970-94 & $1970-94$ & 1986,1993 \\
\hline 01478220 & 30 & West Branch White Clay Creek near Chesterville & 9.92 & $1970-94$ & $1970-94$ & 1985,1993 \\
\hline 01479680 & 27 & West Branch Red Clay Creek at Kennett Square & 9.79 & $1970-94$ & $1970-94$ & $1983,86,93$ \\
\hline 01479800 & 26 & East Branch Red Clay Creek near Five Point & 10.2 & $1970-94$ & $1970-94$ & 1985,1993 \\
\hline 01480434 & 37 & West Branch Brandywine Creek at Rock Run & 37.3 & 1970-94 & 1970-94 & - \\
\hline 01480629 & 46 & Buck Run at Doe Run & 22.6 & 1973-94 & 1971-94 & 1985 \\
\hline 01480632 & 45 & Doe Run at Springdell & 11.8 & 1973-94 & $1971-94$ & 1986 \\
\hline 01480640 & 38 & West Branch Brandywine Creek at Wawaset & 134 & $1970-94$ & $1970-94$ & 1985,1993 \\
\hline 01480647 & 43 & East Branch Brandywine Creek near Struble Dam & 4.36 & 1973-82 & $1971-82$ & - \\
\hline 01480648 & 48 & East Branch Brandywine Creek near Cupola & 5.98 & 1973-94 & $1971-94$ & 1986 \\
\hline 01480653 & 42 & East Branch Brandywine Creek at Glenmoore & 16.5 & 1973-94 & 1971-94 & 1985 \\
\hline 01480656 & 47 & Indian Run near Springton & 4.26 & 1974-94 & $1971-94$ & 1986 \\
\hline 01480700 & 36 & East Branch Brandywine Creek near Downingtown & 60.6 & $1970-94$ & $1970-94$ & 1985 \\
\hline 01480903 & 44 & Valley Creek at Mullsteins Meadows near Downingtown & 16.1 & 1973-94 & $1971-94$ & 1985 \\
\hline 01480950 & 39 & East Branch Brandywine Creek at Wawaset & 123 & 1979-94 & $1970-94$ & 1986,1993 \\
\hline 01481030 & 40 & Brandywine Creek near Chadds Ford & 291 & 1972-94 & $1970-94$ & 1985 \\
\hline 01494900 & 31 & East Branch Big Elk Creek at Elkview & 11.1 & $1970-94$ & $1970-94$ & 1986, 1994 \\
\hline 01494950 & 32 & West Branch Big Elk Creek near Oxford & 10.0 & $1970-94$ & $1970-94$ & 1985,1994 \\
\hline 01578340 & 33 & East Branch Octoraro Creek at Christiana & 11.8 & $1970-94$ & $1970-94$ & 1994 \\
\hline 01578343 & 34 & Valley Creek at Atglen & 10.5 & 1970-94 & $1970-94$ & 1985 \\
\hline 01578345 & 35 & East Branch Octoraro Creek at Steelville & 32.9 & $1970-82$ & $1970-82$ & - \\
\hline
\end{tabular}




\section{Study Objectives and History}

The major goal of the Stream Conditions of Chester County Program is to assess the water quality of streams in the county and to further the understanding of stream changes in response to urbanization. The physical, chemical, and biological data presented in this report were collected in support of this goal.

The investigation began in the fall of 1969 with a reconnaissance of the county to determine the general conditions of streams and land-use patterns. In 1970, the reconnaissance served as a guide to establish a chemical and biological water-quality network of 40 sites in 13 stream basins. The sites were established on the basis of equal cumulative square miles of drainage area within the basin (Lium, 1977). The sites were established away from any known source of pollution so that the water quality of the overall stream could be assessed. During 1970-72, samples were collected in the spring and fall. In 1971, 10 new stations were added to the chemical sampling program. In 1973, these 10 stations were added to the biological sampling program and sampling was reduced to once a year in the fall. In 1979, qualitative sampling was replaced by quantitative sampling at sites 16 and 39. In 1982, nine stations (sites 7, 8, 9, 11, $18,25,35,41$, and 43) were dropped from the network, and in 1983, one station (site 51) was added. In 1988 , site 25 was reestablished, bringing the current number of active stations to 43 .

\section{Methods}

Biological samples consisted of benthic macroinvertebrates collected from a riffle area. During each visit, benthic macroinvertebrates were sampled by collecting 10 rocks ( $45-90 \mathrm{~mm}$ in diameter) at random (Lium, 1974). All invertebrates from the rocks were composited in a container and stored in 70 percent isopropyl alcohol for later identification. A complete description of the sampling technique is described in a report by Moore (1987, p. 7). Benthic-macroinvertebrate samples were analyzed at the U.S. Geological Survey office in Malvern, Pa. Benthic-macroinvertebrates were identified to the lowest taxonomic level possible. A voucher collection of identified organisms is located at the USGS, Water Resources Division, Malvern, Pa. A list of taxonomic references that the identifications were based on is given in table 2.

Brillouin's diversity index, maximum diversity, minimum diversity, and evenness were calculated for each benthic macroinvertebrate sample (table 6). Mean and median Brillouin's diversity index along with the standard deviation and standard error of the mean were calculated for each site (table 7). Brillouin's diversity index can be calculated by the following formula:

$$
\mathrm{H}=(\mathrm{C} / \mathrm{N}) \log _{10}\left(\mathrm{~N} ! / \mathrm{N}_{1} ! \mathrm{N}_{2} ! \ldots . . \mathrm{N}_{\mathrm{s}} !\right)
$$

where $\mathrm{H}$ is diversity,

C is 3.3219 ,

$\mathrm{N}$ is total number of individuals, $\mathrm{s}$ is number of taxa, and $\mathrm{N}_{\mathrm{i}}(\mathrm{i}=1,2, \ldots ., \mathrm{s})$ is number of individuals in the $\mathrm{i}^{\text {th }}$ taxa. 
Table 2. List of taxonomic references used to identify macroinvertebrate samples

\begin{tabular}{ll}
\hline \multicolumn{1}{c}{ Taxonomic Group } & \multicolumn{1}{c}{ Reference } \\
\hline Turbellaria & Pennak, 1989 \\
Nematoda & Pennak, 1989 \\
Nemertea & Pennak, 1989 \\
Gastropoda & Harman and Berg, 1971 \\
Bivalvia & Harman and Berg, 1971 \\
Annelida & Pennak, 1989 \\
Acariformes & Pennak, 1989 \\
Crustacea & Pennak, 1989 \\
Ephemeroptera & Edmunds and others, 1976 \\
Odonata & Brigham, and others, 1982; Merritt and Cummins, 1996 \\
Plecoptera & Brigham, and others, 1982; Merritt and Cummins, 1996 \\
Megaloptera & Brigham, and others, 1982; Merritt and Cummins, 1996 \\
Neuroptera & Brigham, and others, 1982; Merritt and Cummins, 1996 \\
Trichoptera & Brigham, and others, 1982; Wiggins, 1996 \\
Lepidoptera & Brigham, 1982; Merritt and Cummins, 1996 \\
Coleoptera & Brown, 1976 \\
Hymenoptera & Brigham, 1982; Merritt and Cummins, 1996 \\
Diptera & Brigham, 1982; Merritt and Cummins, 1996 \\
\hline
\end{tabular}

Brillouin's diversity index is based on the different kinds of organisms (taxa) present in a community and their relative abundance. In general, diversity is high if a community has many taxa and their abundance are evenly distributed; diversity is low if the taxa are few and their abundance are unevenly distributed (Moore, 1987). Brillouin's diversity can range from zero to infinity but usually is below 5.0. Brillouin's diversity values below 1.0 are associated with waters receiving heavy levels of organic wastes. Brillouin's diversity values between 1.0 and 3.0 are associated with waters receiving moderate levels of organic wastes, and Brillouin's diversity values between 3.0 and 5.0 are associated with waters receiving little or no organic wastes (Wilhm and Dorris, 1968; Wilhm, 1970). Brillouin's diversity measures the effect of community stress and not pollution directly. Community stress may be the result of many factors, including organic or toxic pollution, physical stress, or lack of habitat. Other information can be obtained from the number of taxa present in a community and their relative abundance. The maximum diversity $\left(\mathrm{H}_{\max }\right)$ exists when all individuals are distributed as evenly as possible among the taxa. The minimum diversity $\left(\mathrm{H}_{\mathrm{min}}\right)$ exists when all individuals are distributed as unevenly as possible among the taxa. Evenness (e) describes the observed degree of uniformity of the distribution of individuals among the taxa in the collection. Evenness values between 0.5 and 1.0 generally indicate a balanced community (Moore, 1987). The maximum diversity $\left(\mathrm{H}_{\max }\right)$, minimum diversity $\left(\mathrm{H}_{\min }\right)$, and evenness (e) can be calculated by use of the following formulas:

$$
\begin{aligned}
& \mathrm{H}_{\max }=\mathrm{C} / \mathrm{N}\left\{\log _{10}(\mathrm{~N} !)-\mathrm{s}\left(\log _{10}\right)[(\mathrm{N} / \mathrm{s}) !]\right\} \\
& \mathrm{H}_{\min }=\mathrm{C} / \mathrm{N}\left(\log _{10}(\mathrm{~N} !)-\log _{10}\{[\mathrm{~N}-(\mathrm{s}-1)] !\}\right) \\
& \mathrm{e}=\mathrm{H}-\mathrm{H}_{\min } / \mathrm{H}_{\max }-\mathrm{H}_{\min }
\end{aligned}
$$


Surface-water samples for chemical analysis were collected in conjunction with the biological samples by use of techniques described by Brown and others (1970, p. 5). Chemical samples collected from 1981 through 1984 were analyzed at the USGS National Water Quality Laboratory in Atlanta, Ga. Surface-water samples collected from 1985 through 1994 were analyzed at the USGS National Water Quality Laboratory in Arvada, Colo. Whole water samples were analyzed for nutrients, major ions, and selected metals. Selected metals analyzed and reported from whole water samples are arsenic, barium, beryllium, cadmium, chromium, cobalt, iron, copper, lead, lithium, manganese, mercury, nickel, silver, strontium, vanadium, and zinc.

Stream-bottom sediment samples were collected from 1985 through 1987 and from 1993 through 1994. Samples were collected by hand from the top 6 to $12 \mathrm{in}$. of sediment with a polyethylene scoop and sieved through a 2-mm polyethylene sieve to remove gravel. The sediment was washed through the sieve with native water and collected in a polyethylene collection basin. The samples were homogenized and then transferred to clean glass or polyethylene containers and placed on ice for shipment to the USGS National Water Quality Laboratory. Stream-bottom sediment samples were analyzed for selected metals, pesticides, gross polychlorinated biphenyls ( $\left.\mathrm{PCB}^{\prime} \mathrm{s}\right)$, gross polychlorinated napthalenes ( $\mathrm{PCN}$ 's), and total carbon. Selected metals analyzed and reported from stream-bottom sediment samples are arsenic, cadmium, chromium, iron, copper, lead, manganese, mercury, and zinc.

\section{ACKNOWLEDGMENTS}

The cooperation of the Chester County Board of Commissioners and the Chester County Water Resources Authority is gratefully acknowledged. Special thanks are extended to David C. Yaeck and Irene B. Brooks, former Executive Directors of the Chester County Water Resources Authority, for their interest and support throughout the program's history. The author also would like to thank Dr. Richard McLean for his assistance throughout the years. The author also recognizes Michael D. Bilger and J. Kent Crawford (U.S. Geological Survey) for their review of this report. Technical support was provided by Kim Otto and Terriann Preston (U.S. Geological Survey). 


\section{REFERENCES CITED}

Brigham, A.R., Brigham, W.U., and Gnilka, A., eds., 1982, Aquatic insects and oligochaetes of North and South Carolina: Mahomet, Ill., Midwest Aquatic Enterprises, 837 p.

Brown, Eugene, Skougstad, M.W., and Fishman, M.J., 1970, Methods for collection and analysis of water samples for dissolved minerals and gases: U.S. Geological Survey Techniques of Water-Resources Investigations, book 5, chap. A1, $160 \mathrm{p}$.

Brown, H.P., 1976, Aquatic dryopoid beetles (Coleoptera) of the United States: U.S. Environmental Protection Agency, Water Pollution Control Research Series 18050 ELD04/72, 82 p.

Edmunds, G.F., Jensen, S.L., and Berner, L., 1976, Mayflies of North and Central America: Minneapolis, Minn., University of Minnesota Press, 330 p.

Harman, W.N., and Berg, C.O., 1971, The freshwater snails of central New York with illustrated keys to the genera and species: Search Agriculture, v. 1, no. 4, 68 p.

Lium, B.W., 1974, Some biological aspects of pools and riffles in gravel bed streams in Western United States: U.S. Geological Journal of Research, v. 2, no. 3, p. 379-384.

1977, Limnological studies of the major streams in Chester County, Pennsylvania: U.S. Geological Survey Open-File Report 77-462, 37 p.

Merritt, R.W., and Cummins, K.W., eds., 1996, An introduction to the aquatic insects of North America (3d ed): Dubuque, Iowa, Kendall Hunt Publishing Company, 722 p.

Moore, C.R., 1987, Determination of benthic-invertebrate indices and water-quality trends of selected streams in Chester County, Pennsylvania, 1969-80: U.S. Geological Survey Water-Resources Investigations Report 85-4177, 62 p. 1989, Physical, chemical, and biological data for selected streams in Chester County, Pennsylvania, 1969-80: U.S. Geological Survey Open-File Report 85-686, 289 p.

Pennak, R.W., 1989, Fresh-water invertebrates of the United States (2d ed.): New York, John Wiley and Sons, $803 \mathrm{p}$.

Wiggins, G.B., 1996, Larvae of the North American caddisfly genera (Trichoptera): Toronto, University of Toronto, $401 \mathrm{p}$.

Wilhm, J.L, 1970, Range of Diversity index in benthic macro-invertebrate populations: Water Pollution Control Federation Journal, v. 42, no. 5, p. R221-R251.

Wilhm, J.L. and Dorris, T.C., 1968, Biological parameters for water quality criteria: Bioscience, v. 18, p. 477481. 
Table 3. Water-quality data from surface-water sites

$\mu \mathrm{S} / \mathrm{CM}$, microsiemens per centimeter at 25 degrees Celsius

DEG C, degrees Celsius

NTU, nephelometric turbidity units

MG/L, milligrams per liter

AC-FT, acre foot

$\mu \mathrm{G} / \mathrm{L}$, micrograms per liter

ND, compound not detected

$<$, less than

一, no data 
Table 3. Water-quality data from surface-water sites

01472054 - Pigeon Creek near Bucktown, Pa. (Site 8)

\begin{tabular}{|c|c|c|c|c|c|c|c|c|c|c|}
\hline DATE & TIME & $\begin{array}{c}\text { DIS- } \\
\text { CHARGE, } \\
\text { INST. } \\
\text { (CUBIC } \\
\text { FEET } \\
\text { PER } \\
\text { SECOND) } \\
(00061)\end{array}$ & $\begin{array}{c}\text { SPE- } \\
\text { CIFIC } \\
\text { CON- } \\
\text { DUCT- } \\
\text { ANCE } \\
(\mu \mathrm{S} / \mathrm{CM}) \\
(00095)\end{array}$ & $\begin{array}{c}\text { PH } \\
\text { WATER } \\
\text { WHOLE } \\
\text { FIELD } \\
\text { (STAND- } \\
\text { ARD } \\
\text { UNITS) } \\
(00400)\end{array}$ & $\begin{array}{l}\text { TEMPER- } \\
\text { ATURE } \\
\text { WATER } \\
(\text { DEG C) } \\
(00010)\end{array}$ & $\begin{array}{c}\text { OXYGEN, } \\
\text { DIS- } \\
\text { SOLVED } \\
(\text { MG /L) } \\
(00300)\end{array}$ & $\begin{array}{l}\text { HARD- } \\
\text { NESS } \\
\text { TOTAL } \\
(\mathrm{MG} / \mathrm{L} \\
\mathrm{AS} \\
\left.\mathrm{CACO}_{3}\right) \\
(00900)\end{array}$ & $\begin{array}{c}\text { CALCIUM } \\
\text { DIS- } \\
\text { SOLVED } \\
\text { (MG/L } \\
\text { AS CA) } \\
(00915)\end{array}$ & $\begin{array}{l}\text { MAGNE- } \\
\text { SIUM, } \\
\text { DIS- } \\
\text { SOLVED } \\
\text { (MG/L } \\
\text { AS MG) } \\
(00925)\end{array}$ & $\begin{array}{l}\text { SODIUM, } \\
\text { DIS- } \\
\text { SOLVED } \\
\text { (MG/L } \\
\text { AS NA } \\
(00930)\end{array}$ \\
\hline $\begin{array}{l}\text { CT } 1981 \\
21 \ldots \\
\text { CT } 1982\end{array}$ & 1645 & - & 126 & 7.6 & 10.5 & 10.4 & 41 & 11 & 3.3 & 6.9 \\
\hline DATE & $\begin{array}{l}\text { SODIUM } \\
\text { PERCENT } \\
\text { (00932) }\end{array}$ & $\begin{array}{c}\text { SODIUM } \\
\text { AD- } \\
\text { SORP- } \\
\text { TION } \\
\text { RATIO } \\
(00931)\end{array}$ & $\begin{array}{c}\text { POTAS- } \\
\text { SIUM, } \\
\text { DIS- } \\
\text { SOLVED } \\
\text { (MG/L } \\
\text { AS K) } \\
(00935)\end{array}$ & $\begin{array}{c}7.4 \\
\text { ALKA- } \\
\text { LINITY, } \\
\text { WAT WH } \\
\text { TOT FET } \\
\text { FIELD } \\
(\mathrm{MG} / \mathrm{L} \text { AS } \\
\text { CACO }) \\
(00410)\end{array}$ & $\begin{array}{l}\text { SULFATE, } \\
\text { DIS- } \\
\text { SOLVED } \\
(\mathrm{MG} / \mathrm{L} \\
\left.\mathrm{AS} \mathrm{SO}_{4}\right) \\
(00945)\end{array}$ & $\begin{array}{l}\text { CHLO- } \\
\text { RIDE, } \\
\text { DIS- } \\
\text { SOLVED } \\
\text { (MG/L } \\
\text { AS CL) } \\
(00940)\end{array}$ & $\begin{array}{c}\text { FLUO- } \\
\text { RIDE, } \\
\text { DIS- } \\
\text { SOLVED } \\
(M G / L \\
\text { AS F) } \\
(00950)\end{array}$ & $\begin{array}{l}\text { SILICA, } \\
\text { DIS- } \\
\text { SOLVED } \\
(\mathrm{MG} / \mathrm{L} \\
\mathrm{AS} \\
\left.\mathrm{SIO}_{2}\right) \\
(00955)\end{array}$ & $\begin{array}{c}3.3 \\
\text { SOLIDS, } \\
\text { RESIDUE } \\
\text { AT } 180 \\
\text { DEG. C } \\
\text { DIS- } \\
\text { SOLVED } \\
\text { (MG/L) } \\
(70300)\end{array}$ & $\begin{array}{c}5.8 \\
\text { SOLIDS, } \\
\text { SUM OF } \\
\text { CONSTI- } \\
\text { TUENTS, } \\
\text { DIS- } \\
\text { SOLVED } \\
\text { (MG/L) } \\
(70301)\end{array}$ \\
\hline $\begin{array}{c}\text { СТ } 1981 \\
21 \ldots \\
\text { СТ } 1982 \\
29 \ldots\end{array}$ & 26 & 0.5 & 1.2 & - & 22 & 5.3 & $<0.10$ & 14 & 81 & - \\
\hline DATE & $\begin{array}{c}\text { SOLIDS, } \\
\text { DIS- } \\
\text { SOLVED } \\
\text { (TONS } \\
\text { PER } \\
\text { AC-FT) } \\
(70303)\end{array}$ & $\begin{array}{l}\text { SOLIDS, } \\
\text { DIS- } \\
\text { SOLVED } \\
\text { (TONS } \\
\text { PER } \\
\text { DAY) } \\
(70302)\end{array}$ & $\begin{array}{l}\text { NITRO- } \\
\text { GEN, } \\
\text { NITRATE } \\
\text { TOTAL } \\
\text { (MG/L } \\
\text { AS N) } \\
(00620)\end{array}$ & $\begin{array}{l}\text { NITRO- } \\
\text { GEN, } \\
\text { NITRITE } \\
\text { DIS- } \\
\text { SOLVED } \\
\text { (MG/L } \\
\text { AS N) } \\
(00613)\end{array}$ & $\begin{array}{c}\text { NITRO- } \\
\text { GEN, } \\
\mathrm{NO}_{2}+\mathrm{NO}_{3} \\
\text { DIS- } \\
\text { SOLVED } \\
\text { (MG/L } \\
\text { AS N) } \\
(00631)\end{array}$ & $\begin{array}{c}\text { NITRO- } \\
\text { GEN, } \\
\text { AMMONIA } \\
\text { DIS- } \\
\text { SOLVED } \\
\text { (MG/L } \\
\text { AS N) } \\
(00608)\end{array}$ & $\begin{array}{c}\text { NITRO- } \\
\text { GEN, } \\
\text { AMMONIA } \\
\text { DIS- } \\
\text { SOLVED } \\
\text { (MG/L } \\
\left.\text { AS NH }{ }_{4}\right) \\
(71846)\end{array}$ & $\begin{array}{l}\text { NITRO- } \\
\text { GEN, } \\
\text { ORGANIC } \\
\text { TOTAL } \\
\text { (MG/L } \\
\text { AS N) } \\
(00605)\end{array}$ & $\begin{array}{c}\text { NITRO- } \\
\text { GEN, } \\
\text { ORGANIC } \\
\text { DIS- } \\
\text { SOLVED } \\
(\text { MG/L } \\
\text { AS N) } \\
(00607)\end{array}$ & $\begin{array}{c}\text { NITRO- } \\
\text { GEN, AM- } \\
\text { MONIA + } \\
\text { ORGANIC } \\
\text { TOTAL } \\
\text { (MG/L } \\
\text { AS N) } \\
(00625)\end{array}$ \\
\hline $\begin{array}{c}\text { СТ } 1981 \\
21 \ldots \\
\text { СТ } 1982 \\
29 \ldots\end{array}$ & 0.11 & - & 0.620 & $<0.010$ & 680 & .150 & .19 & 0.33 & 0.44 & 0.46 \\
\hline DATE & $\begin{array}{c}\text { NITRO- } \\
\text { GEN, AM- } \\
\text { MONIA + } \\
\text { ORGANIC } \\
\text { DIS. } \\
(\text { MG/L } \\
\text { AS N) } \\
(00623)\end{array}$ & $\begin{array}{c}\text { NITRO- } \\
\text { GEN, } \\
\text { TOTAL } \\
(\text { MG/L } \\
\text { AS N) } \\
(00600)\end{array}$ & $\begin{array}{c}\text { NITRO- } \\
\text { GEN, } \\
\text { DIS- } \\
\text { SOLVED } \\
\text { (MG/L } \\
\text { AS N) } \\
(00602)\end{array}$ & $\begin{array}{c}\text { PHOS- } \\
\text { PHORUS, } \\
\text { TOTAL } \\
(\text { MG /L } \\
\text { AS P) } \\
(00665)\end{array}$ & $\begin{array}{c}\text { PHOS- } \\
\text { PHORUS, } \\
\text { TOTAL } \\
(\mathrm{MG} / \mathrm{L} \\
\text { AS PO }) \\
(71886)\end{array}$ & $\begin{array}{c}\text { PHOS- } \\
\text { PHORUS, } \\
\text { DIS- } \\
\text { SOLVED } \\
\text { (MG /L } \\
\text { AS P) } \\
(00666)\end{array}$ & $\begin{array}{l}\text { PHOS- } \\
\text { PHORUS } \\
\text { ORTHO, } \\
\text { DIS- } \\
\text { SOLVED } \\
(\text { MG/L } \\
\text { A.S P) } \\
(00671)\end{array}$ & $\begin{array}{l}\text { PHOS- } \\
\text { PHATE, } \\
\text { ORTHO, } \\
\text { DIS- } \\
\text { SOLVED } \\
(\mathrm{MG} / \mathrm{L} \\
\text { A.S PO }) \\
(00660)\end{array}$ & $\begin{array}{c}\text { ARSENIC, } \\
\text { DIS- } \\
\text { SOLVED } \\
(\mu \mathrm{G} / \mathrm{L} \\
\text { AS AS }) \\
(01000)\end{array}$ & $\begin{array}{c}\text { CADMIUM, } \\
\text { DIS- } \\
\text { SOLVED } \\
(\mu \mathrm{G} / \mathrm{L} \\
\text { AS CD }) \\
(01025)\end{array}$ \\
\hline $\begin{array}{c}\text { ОСт } 1981 \\
21 \ldots \\
\text { ОСт } 1982\end{array}$ & 0.59 & 1.1 & 1.3 & 0.080 & .25 & 030 & .030 & .09 & 1 & 4.0 \\
\hline DATE & $\begin{array}{c}\text { CHRO- } \\
\text { MIUM, } \\
\text { DIS- } \\
\text { SOLVED } \\
(\mu \mathrm{G} / \mathrm{L} \\
\text { AS CR) } \\
(01030)\end{array}$ & $\begin{array}{c}\text { COBALT, } \\
\text { DIS- } \\
\text { SOLVED } \\
(\mu \mathrm{G} / \mathrm{L} \\
\mathrm{AS} \mathrm{CO}) \\
(01035)\end{array}$ & $\begin{array}{l}\text { COPPER, } \\
\text { DIS- } \\
\text { SOLVED } \\
(\mu \mathrm{G} / \mathrm{L} \\
\text { AS CU) } \\
(01040)\end{array}$ & $\begin{array}{c}\text { IRON, } \\
\text { DIS- } \\
\text { SOLVED } \\
(\mu \mathrm{G} / \mathrm{L} \\
\text { AS FE) } \\
(01046)\end{array}$ & $\begin{array}{c}\text { LEAD, } \\
\text { DIS- } \\
\text { SOLVED } \\
(\mu \mathrm{G} / \mathrm{L} \\
\text { AS PB) } \\
(01049)\end{array}$ & $\begin{array}{c}\text { MANGA- } \\
\text { NESE, } \\
\text { DIS- } \\
\text { SOLVED } \\
(\mu \mathrm{G} / \mathrm{L} \\
\text { AS MN) } \\
(01056)\end{array}$ & $\begin{array}{c}\text { MERCURY, } \\
\text { DIS- } \\
\text { SOLVED } \\
(\mu \mathrm{G} / \mathrm{L} \\
\text { AS HG) } \\
(71890)\end{array}$ & $\begin{array}{l}\text { NICKEL, } \\
\text { DIS- } \\
\text { SOLVED } \\
(\mu G / L \\
\text { AS NI) } \\
(01065)\end{array}$ & $\begin{array}{c}\text { ZINC, } \\
\text { DIS- } \\
\text { SOLVED } \\
(\mu \mathrm{G} / \mathrm{L} \\
\text { AS } \quad \mathrm{ZN}) \\
(01090)\end{array}$ & $\begin{array}{c}<1.0 \\
\text { METHY- } \\
\text { LENE } \\
\text { BLUE } \\
\text { ACTIVE } \\
\text { SUB- } \\
\text { STANCE } \\
(\text { MG } / \text { L) } \\
(38260)\end{array}$ \\
\hline
\end{tabular}

OCT 1981

$21 \ldots$

OCT 1982

29 ...

$\begin{array}{rrrrrrrrrr}<1 & <1 & 1 & 86 & <1 & 34 & 0.1 & 1 & 4 & - \\ <1 & 1 & 2 & 86 & <1 & 32 & <.1 & 1 & <4 & 0.02\end{array}$


Table 3. Water-quality data from surface-water sites-Continued

01472065 - Pigeon Creek at Porters Mill, Pa. (Site 9)

\begin{tabular}{|c|c|c|c|c|c|c|c|c|c|c|}
\hline DATE & TIME & $\begin{array}{c}\text { DIS- } \\
\text { CHARGE, } \\
\text { INST. } \\
\text { (CUBIC } \\
\text { FEET } \\
\text { PER } \\
\text { SECOND) } \\
(00061)\end{array}$ & $\begin{array}{l}\text { SPE- } \\
\text { CIFIC } \\
\text { CON- } \\
\text { DUCT- } \\
\text { ANCE } \\
(\mu \mathrm{S} / \mathrm{CM}) \\
(00095)\end{array}$ & $\begin{array}{c}\text { PH } \\
\text { WATER } \\
\text { WHOLE } \\
\text { FIELD } \\
\text { (STAND- } \\
\text { ARD } \\
\text { UNITS) } \\
(00400)\end{array}$ & $\begin{array}{l}\text { TEMPER- } \\
\text { ATURE } \\
\text { WATER } \\
(\text { DEG C) } \\
(00010)\end{array}$ & $\begin{array}{c}\text { OXYGEN, } \\
\text { DIS- } \\
\text { SOLVED } \\
(\text { MG } / \text { L) } \\
(00300)\end{array}$ & $\begin{array}{l}\text { HARD- } \\
\text { NESS } \\
\text { TOTAL } \\
(\mathrm{MG} / \mathrm{L} \\
\mathrm{AS} \\
\left.\mathrm{CACO}_{3}\right) \\
(00900)\end{array}$ & $\begin{array}{l}\text { CALCIUM } \\
\text { DIS- } \\
\text { SOLVED } \\
(\text { MG/L } \\
\text { AS CA) } \\
(00915)\end{array}$ & $\begin{array}{c}\text { MAGNE- } \\
\text { SIUM, } \\
\text { DIS- } \\
\text { SOLVED } \\
\text { (MG/L } \\
\text { AS MG) } \\
(00925)\end{array}$ & $\begin{array}{l}\text { SODIUM, } \\
\text { DIS- } \\
\text { SOLVED } \\
\text { (MG/L } \\
\text { AS NA) } \\
(00930)\end{array}$ \\
\hline $\begin{array}{c}\text { CT } 1981 \\
20 \ldots \\
\text { CT } 1982\end{array}$ & 1530 & - & 138 & 7.8 & 8.5 & 12.1 & 48 & 13 & 3.8 & 7.2 \\
\hline $29 \ldots$ & $\begin{array}{l}\text { SODIUM } \\
\text { PERCENT } \\
(00932)\end{array}$ & $\begin{array}{l}\text { SODIUM } \\
\text { AD- } \\
\text { SORP- } \\
\text { TION } \\
\text { RATIO } \\
(00931)\end{array}$ & $\begin{array}{l}\text { POTAS- } \\
\text { SIUM, } \\
\text { DIS- } \\
\text { SOLVED } \\
(\text { MG/L } \\
\text { AS K) } \\
(00935)\end{array}$ & $\begin{array}{l}\text { ALKA- } \\
\text { LINITY } \\
\text { WAT WH } \\
\text { TOT FET } \\
\text { FIELD } \\
(\mathrm{MG} / \mathrm{L} \\
\text { AS CACO }) \\
(00410)\end{array}$ & $\begin{array}{l}\text { SULFATE, } \\
\text { DIS- } \\
\text { SOLVED } \\
(\mathrm{MG} / \mathrm{L} \\
\left.\mathrm{AS} \mathrm{SO}_{4}\right) \\
(00945)\end{array}$ & $\begin{array}{c}\text { CHLO- } \\
\text { RIDE, } \\
\text { DIS- } \\
\text { SOLVED } \\
\text { (MG/L } \\
\text { AS CL) } \\
(00940)\end{array}$ & $\begin{array}{c}\text { FLUO- } \\
\text { RIDE, } \\
\text { DIS- } \\
\text { SOLVED } \\
\text { (MG/L } \\
\text { AS F) } \\
(00950)\end{array}$ & $\begin{array}{c}\text { SILICA, } \\
\text { DIS- } \\
\text { SOLVED } \\
\text { (MG/L } \\
\text { AS } \\
\left.\mathrm{SIO}_{2}\right) \\
(00955)\end{array}$ & $\begin{array}{c}\text { SOLIDS, } \\
\text { RESIDUE } \\
\text { AT } 180 \\
\text { DEG.C } \\
\text { DIS- } \\
\text { SOLVED } \\
(\mathrm{MG} / \mathrm{L}) \\
(70300)\end{array}$ & $\begin{array}{l}\text { SOLIDS, } \\
\text { SUM OF } \\
\text { CONSTI- } \\
\text { TUENTS, } \\
\text { DIS- } \\
\text { SOLVED } \\
\text { (MG/L) } \\
(70301)\end{array}$ \\
\hline $\begin{array}{c}\text { DCT } 1981 \\
20 \ldots \\
\text { DCT } 1982 \\
29 \ldots\end{array}$ & 24 & 0.5 & 1.5 & - & 17 & 6.2 & $\begin{array}{l}<0.10 \\
<.10\end{array}$ & 17 & 85 & - \\
\hline DATE & $\begin{array}{c}\text { SOLIDS, } \\
\text { DIS- } \\
\text { SOLVED } \\
\text { (TONS } \\
\text { PER } \\
\text { AC-FT) } \\
(70303)\end{array}$ & $\begin{array}{c}\text { SOLIDS, } \\
\text { DIS- } \\
\text { SOLVED } \\
\text { (TONS } \\
\text { PER } \\
\text { DAY) } \\
\text { (70302) }\end{array}$ & $\begin{array}{l}\text { NITRO- } \\
\text { GEN, } \\
\text { NITRATE } \\
\text { TOTAL } \\
\text { (MG/L } \\
\text { AS N) } \\
(00620)\end{array}$ & $\begin{array}{c}\text { NITRO- } \\
\text { GEN, } \\
\text { NITRITE } \\
\text { DIS- } \\
\text { SOLVED } \\
\text { (MG/L } \\
\text { AS N) } \\
(00613)\end{array}$ & $\begin{array}{c}\text { NITRO- } \\
\text { GEN, } \\
\mathrm{NO}_{2}+\mathrm{NO}_{3} \\
\text { DIS- } \\
\text { SOLVED } \\
(\mathrm{MG} / \mathrm{L} \\
\mathrm{AS} \mathrm{N}) \\
(00631)\end{array}$ & $\begin{array}{c}\text { NITRO- } \\
\text { GEN, } \\
\text { AMMONIA } \\
\text { DIS- } \\
\text { SOLVED } \\
\text { (MG/L } \\
\text { AS N) } \\
(00608)\end{array}$ & $\begin{array}{c}\text { NITRO- } \\
\text { GEN, } \\
\text { AMMONIA } \\
\text { DIS- } \\
\text { SOLVED } \\
(\mathrm{MG} / \mathrm{L} \\
\left.\mathrm{AS} \mathrm{NH} \mathrm{NH}_{4}\right) \\
(71846)\end{array}$ & $\begin{array}{l}\text { NITRO- } \\
\text { GEN, } \\
\text { ORGANIC } \\
\text { TOTAL } \\
\text { (MG/L } \\
\text { AS N) } \\
(00605)\end{array}$ & $\begin{array}{c}\text { NITRO- } \\
\text { GEN, } \\
\text { ORGANIC } \\
\text { DIS- } \\
\text { SOLVED } \\
(\text { MG/L } \\
\text { AS N) } \\
(00607)\end{array}$ & $\begin{array}{c}\text { NITRO- } \\
\text { GEN, AM- } \\
\text { MONIA + } \\
\text { ORGANIC } \\
\text { TOTAL } \\
\text { (MG/L } \\
\text { AS N) } \\
(00625)\end{array}$ \\
\hline $\begin{array}{c}\text { OCT } 1981 \\
20 \ldots \\
\text { OCT } 1982 \\
29 \ldots\end{array}$ & 0.12 & 0.57 & 1.00 & $<0.010$ & 0.980 & 0.100 & 0.13 & 0.19 & 0.71 & 0.25 \\
\hline DATE & $\begin{array}{l}\text { NITRO- } \\
\text { GEN, AM- } \\
\text { MONIA + } \\
\text { ORGANIC } \\
\text { DIS. } \\
(\text { MG/L } \\
\text { AS N) } \\
(00623)\end{array}$ & $\begin{array}{c}\text { NITRO- } \\
\text { GEN, } \\
\text { TOTAL } \\
\text { (MG/L } \\
\text { AS N) } \\
(006000)\end{array}$ & $\begin{array}{c}\text { NITRO- } \\
\text { GEN, } \\
\text { DIS- } \\
\text { SOLVED } \\
\text { (MG/L } \\
\text { AS N) } \\
(00602)\end{array}$ & $\begin{array}{c}\text { PHOS- } \\
\text { PHORUS, } \\
\text { TOTAL } \\
\text { (MG /L } \\
\text { AS P) } \\
(00665)\end{array}$ & $\begin{array}{l}\text { PHOS- } \\
\text { PHORUS, } \\
\text { TOTAL } \\
(\mathrm{MG} / \mathrm{L} \\
\text { AS PO }) \\
(71886)\end{array}$ & $\begin{array}{l}\text { PHOS- } \\
\text { PHORUS, } \\
\text { DIS- } \\
\text { SOLVED } \\
(\text { MG / L } \\
\text { AS P) } \\
(00666)\end{array}$ & $\begin{array}{l}\text { PHOS- } \\
\text { PHORUS, } \\
\text { ORTHO, } \\
\text { DIS- } \\
\text { SOLVED } \\
\text { (MG/L } \\
\text { AS P) } \\
(00671)\end{array}$ & $\begin{array}{l}\text { PHOS- } \\
\text { PHATE, } \\
\text { ORTHO, } \\
\text { DIS- } \\
\text { SOLVED } \\
(\mathrm{MG} / \mathrm{L} \\
\text { AS PO }) \\
(00660)\end{array}$ & $\begin{array}{c}\text { ARSENIC, } \\
\text { DIS- } \\
\text { SOLVED } \\
(\mu \mathrm{G} / \mathrm{L} \\
\text { AS AS) } \\
(01000)\end{array}$ & $\begin{array}{l}\text { CADMIUM, } \\
\text { DIS- } \\
\text { SOLVED } \\
(\mu \mathrm{G} / \mathrm{L} \\
\text { AS CD }) \\
(01025)\end{array}$ \\
\hline $\begin{array}{c}\text { ОСТ } 1981 \\
20 \ldots \\
\text { ОСТ } 1982 \\
29 \ldots\end{array}$ & 0.81 & 1.2 & $\begin{array}{l}1.8 \\
1.8\end{array}$ & 0.040 & 0.12 & 0.020 & $\begin{array}{r}0.020 \\
.020\end{array}$ & 0.06 & 2 & $<1.0$ \\
\hline DATE & $\begin{array}{l}\text { CHRO- } \\
\text { MIUM, } \\
\text { DIS- } \\
\text { SOLVED } \\
(\mu \mathrm{G} / \mathrm{L} \\
\text { AS CR) } \\
(01030)\end{array}$ & $\begin{array}{c}\text { COBALT, } \\
\text { DIS- } \\
\text { SOLVED } \\
(\mu \mathrm{G} / \mathrm{L} \\
\text { AS CO) } \\
(01035)\end{array}$ & $\begin{array}{l}\text { COPPER, } \\
\text { DIS- } \\
\text { SOLVED } \\
(\mu \mathrm{G} / \mathrm{L} \\
\text { AS CU) } \\
(01040)\end{array}$ & $\begin{array}{l}\text { IRON, } \\
\text { DIS- } \\
\text { SOLVED } \\
(\mu \mathrm{G} / \mathrm{L} \\
\text { AS FE) } \\
(01046)\end{array}$ & $\begin{array}{c}\text { LEAD, } \\
\text { DIS- } \\
\text { SOLVED } \\
(\mu \mathrm{G} / \mathrm{L} \\
\text { AS PB) } \\
(01049)\end{array}$ & $\begin{array}{c}\text { MANGA- } \\
\text { NESE, } \\
\text { DIS- } \\
\text { SOLVED } \\
(\mu \mathrm{G} / \mathrm{L} \\
\text { AS MN }) \\
(01056)\end{array}$ & $\begin{array}{l}\text { MERCURY, } \\
\text { DIS- } \\
\text { SOLVED } \\
(\mu \mathrm{G} / \mathrm{L} \\
\text { AS HG) } \\
(71890)\end{array}$ & $\begin{array}{l}\text { NICKEL, } \\
\text { DIS- } \\
\text { SOLVED } \\
(\mu \mathrm{G} / \mathrm{L} \\
\text { AS NI) } \\
(01065)\end{array}$ & $\begin{array}{c}\text { ZINC, } \\
\text { DIS- } \\
\text { SOLVED } \\
(\mu \mathrm{G} / \mathrm{L} \\
\text { AS ZN) } \\
(01090)\end{array}$ & $\begin{array}{l}\text { METHY- } \\
\text { LENE } \\
\text { BLUE } \\
\text { ACTIVE } \\
\text { SUB- } \\
\text { STANCE } \\
\text { (MG/L) } \\
(38260)\end{array}$ \\
\hline
\end{tabular}

OCT 1981

$20 \ldots$

ОСТ 1982

$29 \ldots$

$\begin{array}{lllll}<1 & <1 & 3 & 64 & 1 \\ <1 & 1 & 2 & 35 & <1\end{array}$

1
$<1$

$\begin{array}{ll}15 & 0.1 \\ 9 & <.1\end{array}$

1

$<1$

$$
<4
$$$$
<4
$$

0.02 
Table 3. Water-quality data from surface-water sites-Continued

01472080 - Pigeon Creek near Parker Ford, Pa. (Site 10)

\begin{tabular}{|c|c|c|c|c|c|c|c|c|c|c|c|}
\hline & & DIS- & & $\mathrm{PH}$ & & & & & HARD- & & \\
\hline & & CHARGE, & $\mathrm{SPE}-$ & WATER & & & & HARD- & NESS & & MAGNE- \\
\hline & & INST. & CIFIC & WHOLE & & & & NESS & NONCARB & CALCIUM & SIUM, \\
\hline & & (CUBIC) & $\mathrm{CON}-$ & FIELD & TEMPER- & TUR- & OXYGEN, & TOTAL & WH WAT & DIS- & DIS- \\
\hline & & FEET & DUCT- & (STAND- & ATURE & BID- & DIS- & (MG /L & TOT FLD & SOLVED & SOLVED \\
\hline DATE & TIME & PER & ANCE & ARD & WATER & ITY & SOLVED & AS & (MG/L AS & (MG /L & (MG/L \\
\hline & & SECOND) & $(\mu \mathrm{S} / \mathrm{CM})$ & UNITS) & (DEG C) & (NTU) & (MG/L) & $\left.\mathrm{CACO}_{3}\right)$ & $\left.\mathrm{CACO}_{3}\right)$ & AS CA) & AS MG) \\
\hline & & $(00061)$ & $(00095)$ & $(00400)$ & $(00010)$ & $(00076)$ & $(00300)$ & $(00900)$ & $(00902)$ & $(00915)$ & $(00925)$ \\
\hline
\end{tabular}

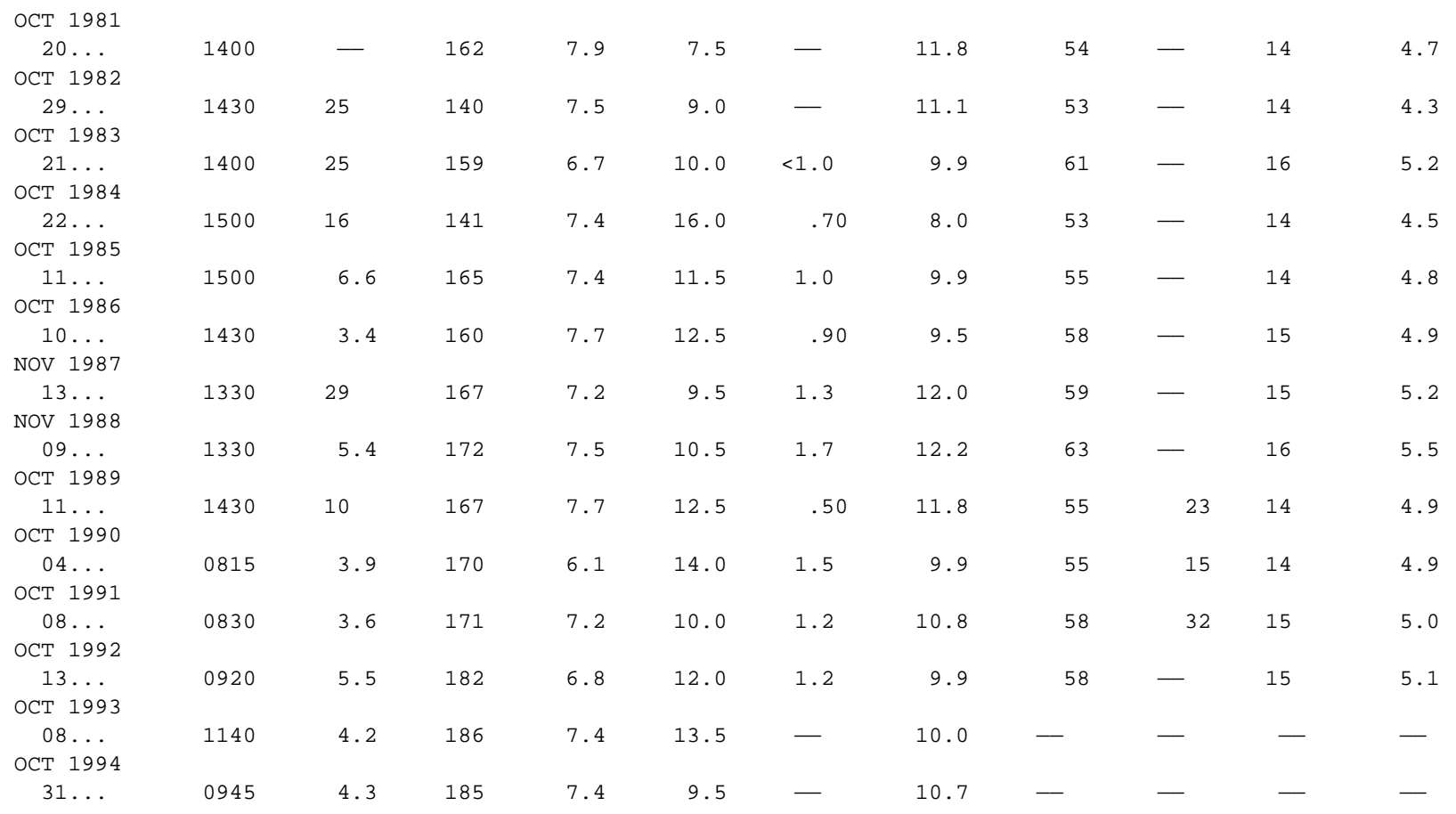


Table 3. Water-quality data from surface-water sites-Continued

01472080 - Pigeon Creek near Parker Ford, Pa. (Site 10)—Continued

\begin{tabular}{|c|c|c|c|c|c|c|c|c|c|c|c|}
\hline & & & & POTAS- & $\begin{array}{l}\text { ALKA- } \\
\text { LINITY }\end{array}$ & $\begin{array}{l}\text { ALKA- } \\
\text { LINITY }\end{array}$ & & $1-$ & - & & $\begin{array}{l}\text { SOLIDS, } \\
\text { RESIDUE }\end{array}$ \\
\hline & SODIUM, & & SODIUM & SIUM, & WAT WH & WAT WH & SULFATE, & RIDE, & RIDE， & DIS & AT 180 \\
\hline & DIS- & & $\mathrm{AD}-$ & DIS- & TOT FET & TOT IT & DIS- & DIS- & DIS- & SOLVED & DEG. C \\
\hline & $\begin{array}{l}\text { SOLVED } \\
\text { (MG/L }\end{array}$ & & SORP- & $\begin{array}{l}\text { SOLVED } \\
\text { (MG/L }\end{array}$ & $\begin{array}{l}\text { FIELD } \\
\text { (MG/L AS }\end{array}$ & $\begin{array}{l}\text { FIELD } \\
\text { (MG/I AS }\end{array}$ & $\begin{array}{l}\text { SOLVED } \\
\text { (MG/L }\end{array}$ & SOLVED & SOLVED & (MG / L & $\begin{array}{r}\text { DIS- } \\
\text { SOLVED }\end{array}$ \\
\hline & AS NA) & PERCENT & RATIO & AS K) & $\begin{array}{l}(\mathrm{MG} / \mathrm{L} \mathrm{AS} \\
\left.\mathrm{CACO}_{3}\right)\end{array}$ & $\left.\mathrm{CACO}_{3}\right)$ & $\left.\mathrm{AS} \quad \mathrm{SO}_{4}\right)$ & AS CL) & AS F) & $\begin{array}{l}\mathrm{ASS} \\
\left.\mathrm{SIO}_{2}\right)\end{array}$ & (MG/L) \\
\hline & 10930) & & 1) & 0935) & 410) & 19) & $(00945)$ & $(00940)$ & 00950) & $(00955)$ & (7) \\
\hline
\end{tabular}

\begin{tabular}{|c|c|c|c|c|c|c|c|c|c|c|c|}
\hline $\begin{array}{c}\text { OCT } 1981 \\
20 \ldots \\
\text { OCT } 1982\end{array}$ & 8.4 & 24 & 0.5 & 2.1 & - & - & 19 & 8.7 & $<0.10$ & 18 & 101 \\
\hline $29 \ldots$ & 6.8 & 21 & .4 & 1.5 & 32 & - & 18 & 6.9 & $<.10$ & 17 & 103 \\
\hline $\begin{array}{c}\text { OCT } 1983 \\
21 \ldots\end{array}$ & 8.8 & 23 & .5 & 1.8 & 38 & - & 22 & 8.1 & - & 17 & 112 \\
\hline $\begin{array}{c}22 \ldots 84 \\
\text { OCT } 1985\end{array}$ & 6.8 & 21 & .4 & 1.7 & 36 & - & 18 & 7.6 & - & 15 & 91 \\
\hline $\begin{array}{c}11 \ldots \\
\text { OCT } 1986\end{array}$ & 7.6 & 23 & .4 & 1.7 & 40 & - & 22 & 8.8 & - & 17 & 101 \\
\hline $\begin{array}{c}10 \ldots \\
\text { NOV } 1987\end{array}$ & 7.8 & 22 & .4 & 1.8 & 44 & - & 23 & 8.2 & - & 18 & 114 \\
\hline $\begin{array}{c}13 \ldots \\
\text { NOV } 1988\end{array}$ & 8.7 & 23 & .5 & 2.5 & 37 & - & 22 & 15 & - & 15 & 126 \\
\hline $\begin{array}{c}09 \ldots \\
\text { OCT } 1989\end{array}$ & 8.3 & 22 & .5 & 1.8 & 54 & - & 24 & 9.3 & - & 16 & - \\
\hline $\begin{array}{c}11 \ldots \\
\text { OCT } 1990\end{array}$ & 8.5 & 24 & .5 & 1.8 & 32 & - & 18 & 9.1 & - & 17 & - \\
\hline $\begin{array}{c}04 \ldots \\
\text { ОСТ } 1991\end{array}$ & 8.0 & 23 & .5 & 1.5 & 40 & - & 18 & 9.8 & $<.10$ & 18 & - \\
\hline $\begin{array}{c}08 \ldots \\
\text { OCT } 1992\end{array}$ & 7.7 & 22 & .4 & 1.8 & 26 & - & 17 & 9.9 & .10 & 17 & - \\
\hline $\begin{array}{c}13 \ldots \\
\text { OCT } 1993\end{array}$ & 8.4 & 23 & .5 & 2.3 & - & 29 & 21 & 11 & $<.10$ & 16 & - \\
\hline $\begin{array}{c}08 \ldots \\
\text { OCT } 1994\end{array}$ & - & - & - & - & - & 39 & - & - & - & - & - \\
\hline
\end{tabular}


Table 3. Water-quality data from surface-water sites-Continued

01472080 - Pigeon Creek near Parker Ford, Pa. (Site 10)—Continued

\begin{tabular}{|c|c|c|c|c|c|c|c|c|c|c|c|}
\hline DATE & $\begin{array}{l}\text { SOLIDS, } \\
\text { SUM OF } \\
\text { CONSTI- } \\
\text { TUENTS, } \\
\text { DIS- } \\
\text { SOLVED } \\
(\text { MG/L) } \\
(70301)\end{array}$ & $\begin{array}{c}\text { SOLIDS, } \\
\text { DIS- } \\
\text { SOLVED } \\
\text { (TONS } \\
\text { PER } \\
\text { AC-FT) } \\
(70303)\end{array}$ & $\begin{array}{l}\text { SOLIDS, } \\
\text { DIS- } \\
\text { SOLVED } \\
\text { (TONS } \\
\text { PER } \\
\text { DAY) } \\
(70302)\end{array}$ & $\begin{array}{l}\text { NITRO- } \\
\quad \text { GEN, } \\
\text { NITRATE } \\
\text { TOTAL } \\
\text { (MG/L } \\
\text { AS N) } \\
(00620)\end{array}$ & $\begin{array}{l}\text { NITRO- } \\
\text { GEN, } \\
\text { NITRATE } \\
\text { DIS- } \\
\text { SOLVED } \\
\text { (MG/L } \\
\text { AS N) } \\
(00618)\end{array}$ & $\begin{array}{c}\text { NITRO- } \\
\text { GEN, } \\
\text { NITRATE } \\
\text { DIS- } \\
\text { SOLVED } \\
(\mathrm{MG} / \mathrm{L} \\
\left.\mathrm{AS} \mathrm{NO}_{3}\right) \\
(71851)\end{array}$ & $\begin{array}{l}\text { NITRO- } \\
\text { GEN, } \\
\text { NITRITE } \\
\text { DIS- } \\
\text { SOLVED } \\
\text { (MG/L } \\
\text { AS N) } \\
(00613)\end{array}$ & $\begin{array}{c}\text { NITRO- } \\
\text { GEN, } \\
\mathrm{NO}_{2}+\mathrm{NO}_{3} \\
\text { DIS- } \\
\text { SOLVED } \\
(\mathrm{MG} / \mathrm{L} \\
\mathrm{AS} \mathrm{N}) \\
(00631)\end{array}$ & $\begin{array}{c}\text { NITRO- } \\
\text { GEN, } \\
\text { AMMONIA } \\
\text { DIS- } \\
\text { SOLVED } \\
\text { (MG/L } \\
\text { AS N) } \\
(00608)\end{array}$ & $\begin{array}{c}\text { NITRO- } \\
\text { GEN, } \\
\text { AMMONIA } \\
\text { DIS- } \\
\text { SOLVED } \\
\text { (MG/L } \\
\left.\text { AS } \mathrm{NH}_{4}\right) \\
(71846)\end{array}$ & $\begin{array}{l}\text { NITRO- } \\
\text { GEN, } \\
\text { ORGANIC } \\
\text { TOTAL } \\
\text { (MG/L } \\
\text { AS N) } \\
(00605)\end{array}$ \\
\hline $\begin{array}{c}\text { OCT } 1981 \\
20 \ldots\end{array}$ & - & 0.14 & - & 1.40 & - & - & $<0.010$ & 1.50 & 0.010 & 0.01 & 0.45 \\
\hline OCT 1982 & & & & & & & & & & & \\
\hline $\begin{array}{c}29 \ldots \\
\text { OCT } 1983\end{array}$ & 95 & .14 & 6.95 & 1.70 & - & - & $<.010$ & 1.70 & .010 & .01 & - \\
\hline $\begin{array}{c}21 \ldots \\
\text { OCT } 1984\end{array}$ & 109 & .15 & 7.56 & 1.56 & 1.56 & 6.9 & .040 & 1.60 & $<.010$ & - & - \\
\hline $\begin{array}{c}22 \ldots \\
\text { OCT } 1985\end{array}$ & 97 & .12 & 3.93 & 1.56 & 1.56 & 6.9 & .040 & 1.60 & .060 & .08 & - \\
\hline $\begin{array}{c}11 \ldots \\
\text { OCT } 1986\end{array}$ & 109 & .14 & 1.80 & 2.10 & - & - & $<.010$ & 2.10 & .010 & .01 & - \\
\hline $\begin{array}{c}10 \ldots \\
\text { NOV } 1987\end{array}$ & 112 & .16 & 1.03 & 1.60 & - & - & $<.010$ & 1.60 & $<.010$ & - & .40 \\
\hline $\begin{array}{c}13 \ldots \\
\text { NOV } 1988\end{array}$ & 116 & .17 & 9.87 & 2.20 & - & - & $<.010$ & 2.20 & $<.010$ & - & .50 \\
\hline $\begin{array}{c}09 \ldots \\
\text { OCT } 1989\end{array}$ & 122 & .17 & 1.78 & 2.00 & - & 一 & $<.010$ & 2.00 & .020 & .03 & .28 \\
\hline $\begin{array}{c}11 \ldots \\
\text { OCT } 1990\end{array}$ & 105 & .14 & 2.84 & 2.79 & 2.79 & 12 & .010 & 2.80 & .010 & .01 & .39 \\
\hline $\begin{array}{c}04 \ldots \\
\text { OCT } 1991\end{array}$ & 109 & .15 & 1.15 & 2.40 & - & - & $<.010$ & 2.40 & .020 & .03 & .28 \\
\hline $\begin{array}{c}08 \ldots \\
\text { OCT } 1992\end{array}$ & 98 & .13 & .96 & 2.00 & - & - & $<.010$ & 2.00 & $<.010$ & - & - \\
\hline $\begin{array}{c}13 \ldots \\
\text { OCT } 1993\end{array}$ & 105 & .14 & 1.56 & 1.90 & - & - & $<.010$ & 1.90 & .030 & .04 & .27 \\
\hline $\begin{array}{c}08 \ldots \\
\text { OCT } 1994\end{array}$ & - & - & - & 2.30 & - & - & $<.010$ & 2.30 & .020 & .03 & - \\
\hline $31 \ldots$ & - & - & - & 1.90 & - & - & $<.010$ & 1.90 & .020 & .03 & - \\
\hline
\end{tabular}


Table 3. Water-quality data from surface-water sites-Continued

01472080 - Pigeon Creek near Parker Ford, Pa. (Site 10)—Continued

\begin{tabular}{|c|c|c|c|c|c|c|c|c|c|c|c|}
\hline & $\begin{array}{r}\text { NITRO- } \\
\text { GEN, } \\
\text { ORGANIC }\end{array}$ & $\begin{array}{l}\text { NITRO- } \\
\text { GEN, AM- } \\
\text { MONIA + }\end{array}$ & $\begin{array}{l}\text { NITRO- } \\
\text { GEN, AM- } \\
\text { MONIA + }\end{array}$ & NITRO- & $\begin{array}{c}\text { NITRO- } \\
\text { GEN, }\end{array}$ & $E n$ & & $\begin{array}{r}\text { PHOS- } \\
\text { PHORUS }\end{array}$ & $\begin{array}{c}\text { PHOS- } \\
\text { PHORUS, } \\
\text { ORTHO, }\end{array}$ & $\begin{array}{l}\text { PHOS- } \\
\text { PHATE, } \\
\text { ORTHO, }\end{array}$ & ARSENIC, \\
\hline & DIS- & ORGANIC & ORGANIC & GEN, & DIS- & HORUS & HORUS & DIS- & DIS- & DIS- & DIS- \\
\hline & $\begin{array}{r}\text { SOLVED } \\
\text { (MG/L }\end{array}$ & $\begin{array}{l}\text { TOTAL } \\
\text { (MG/L }\end{array}$ & $\begin{array}{l}\text { DIS. } \\
\text { (MG/L }\end{array}$ & $\begin{array}{l}\text { TOTAL } \\
\text { (MG / L }\end{array}$ & $\begin{array}{c}\text { SOLVED } \\
(\mathrm{MG} / \mathrm{L}\end{array}$ & $\begin{array}{l}\text { TOTAL } \\
\quad(\mathrm{MG} / \mathrm{L}\end{array}$ & $\begin{array}{l}\text { TOTAL } \\
\text { (MG/L }\end{array}$ & $\begin{array}{l}\text { SOLVED } \\
\text { (MG/L }\end{array}$ & $\begin{array}{r}\text { SOLVED } \\
(\mathrm{MG} / \mathrm{L}\end{array}$ & $\begin{array}{l}\text { SOLVED } \\
(\mathrm{MG} / \mathrm{L}\end{array}$ & $\begin{array}{l}\text { SOLVED } \\
(\mu \mathrm{G} / \mathrm{L}\end{array}$ \\
\hline & $\begin{array}{r}A S N) \\
(00607)\end{array}$ & $\begin{array}{c}\text { AS N }) \\
(00625)\end{array}$ & $\begin{array}{c}\text { AS N }) \\
(00623)\end{array}$ & $\begin{array}{c}\text { AS N) } \\
(00600)\end{array}$ & $\begin{array}{c}\text { AS N }) \\
(00602)\end{array}$ & $\begin{array}{l}\text { AS P ) } \\
(00665)\end{array}$ & $\begin{array}{c}\left.\mathrm{AS} \mathrm{PO}_{4}\right) \\
(71886)\end{array}$ & $\begin{array}{l}\text { AS P) } \\
(00666)\end{array}$ & $\begin{array}{l}\text { AS P) } \\
(00671)\end{array}$ & $\begin{array}{c}\left.\text { AS } \mathrm{PO}_{4}\right) \\
(00660)\end{array}$ & $\begin{array}{l}\text { AS AS) } \\
(01000)\end{array}$ \\
\hline
\end{tabular}

\begin{tabular}{|c|c|c|c|c|c|c|c|c|c|c|c|}
\hline $\begin{array}{c}20 \ldots \\
\text { OCT } 1982\end{array}$ & 0.38 & 0.50 & 0.39 & 1.9 & 1.9 & 0.050 & 0.15 & 0.040 & 0.040 & 0.12 & 1 \\
\hline $\begin{array}{c}29 \ldots \\
\text { OCT } 1983\end{array}$ & .69 & - & .70 & - & 2.4 & - & - & .040 & .030 & .09 & 1 \\
\hline $\begin{array}{c}21 \ldots \\
\text { OCT } 1984\end{array}$ & - & - & .40 & - & 2.0 & .060 & .18 & .050 & .050 & .15 & - \\
\hline $\begin{array}{c}22 \ldots \\
\text { OCT } 1985\end{array}$ & .64 & - & .70 & - & 2.3 & .030 & - & .060 & .070 & .21 & - \\
\hline $\begin{array}{c}11 \ldots \\
\text { OCT } 1986\end{array}$ & .59 & - & .60 & - & 2.7 & .050 & .15 & .040 & .020 & .06 & - \\
\hline $\begin{array}{c}10 \ldots \\
\text { NOV } 1987\end{array}$ & - & .40 & .30 & 2.0 & 1.9 & .060 & - & .050 & .030 & .09 & - \\
\hline $\begin{array}{c}13 \ldots \\
\text { NOV } 1988\end{array}$ & - & .50 & $<.20$ & 2.7 & - & .080 & - & .050 & .030 & .09 & - \\
\hline $\begin{array}{c}09 \ldots \\
\text { OCT } 1989\end{array}$ & .28 & .30 & .30 & 2.3 & 2.3 & .050 & - & .040 & .030 & .09 & - \\
\hline $\begin{array}{c}11 \ldots \\
\text { OCT } 1990\end{array}$ & .39 & .40 & .40 & 3.2 & 3.2 & .050 & - & .030 & .030 & .09 & - \\
\hline $\begin{array}{c}04 \ldots \\
\text { OCT } 1991\end{array}$ & .28 & .30 & .30 & 2.7 & 2.7 & .050 & - & $<.040$ & .030 & .09 & - \\
\hline $\begin{array}{c}08 \ldots \\
\text { OCT } 1992\end{array}$ & - & $<.20$ & .10 & - & 2.1 & .060 & - & .040 & .040 & .12 & - \\
\hline $\begin{array}{c}13 \ldots \\
\text { OCT } 1993\end{array}$ & .27 & .30 & .30 & 2.2 & 2.2 & .090 & - & .080 & .070 & .21 & - \\
\hline $\begin{array}{r}08 \ldots \\
\mathrm{OCT} \quad 1994\end{array}$ & - & - & - & - & - & - & - & - & .050 & .15 & - \\
\hline $31 \ldots$ & - & - & - & - & - & - & - & - & .030 & .09 & 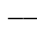 \\
\hline
\end{tabular}


Table 3. Water-quality data from surface-water sites-Continued

01472080 - Pigeon Creek near Parker Ford, Pa. (Site 10)—Continued

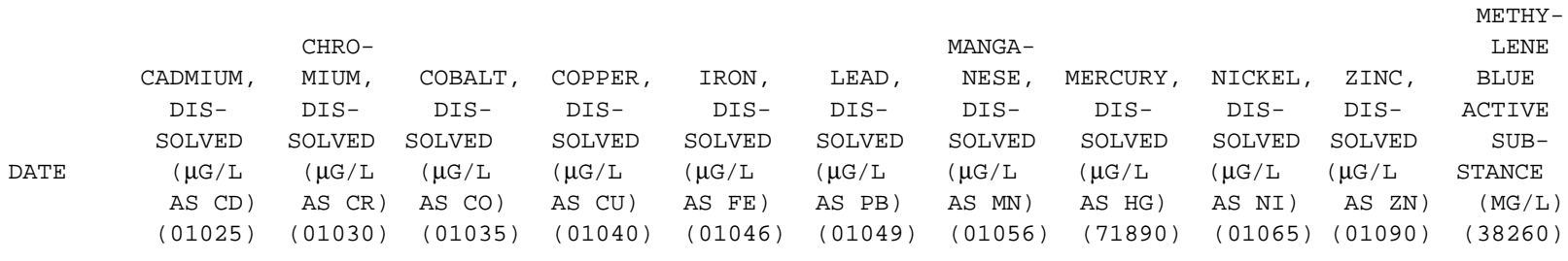

\begin{tabular}{|c|c|c|c|c|c|c|c|c|c|c|c|}
\hline $\begin{array}{c}\text { OCT } 1981 \\
20 \ldots \\
\text { OCT } 1982\end{array}$ & $<1.0$ & $<1$ & $<1$ & 4 & 83 & 1 & 18 & $<0.1$ & 3 & 6 & - \\
\hline $\begin{array}{c}29 \ldots \\
\text { OCT } 1983\end{array}$ & $<1.0$ & $<1$ & $<1$ & $<1$ & 40 & $<1$ & 9 & $<.1$ & 1 & $<4$ & 0.02 \\
\hline $\begin{array}{c}21 \ldots \\
\text { OCT } 1984\end{array}$ & - & - & - & - & 87 & - & 20 & - & - & - & - \\
\hline $\begin{array}{c}22 \ldots \\
\text { OCT } 1985\end{array}$ & - & - & - & - & 51 & - & 12 & - & - & - & - \\
\hline $\begin{array}{c}11 \ldots \\
\text { ОСТ } 1986\end{array}$ & - & - & - & - & 43 & - & 15 & - & - & - & - \\
\hline $\begin{array}{c}10 \ldots \\
\text { NoV } 1987\end{array}$ & - & - & - & - & 64 & - & 19 & - & - & - & - \\
\hline $\begin{array}{c}13 \ldots \\
\text { Nov } 1988\end{array}$ & - & - & - & - & 85 & - & 47 & - & - & - & - \\
\hline $\begin{array}{c}09 \ldots \\
\text { ОСТ } 1989\end{array}$ & - & - & - & - & 56 & - & 17 & - & - & - & - \\
\hline $\begin{array}{c}11 \ldots \\
\text { ОСт } 1990\end{array}$ & - & - & - & - & 53 & - & 26 & - & - & - & - \\
\hline $\begin{array}{c}04 \ldots \\
\text { ОСТ } 1991\end{array}$ & - & - & - & - & 36 & - & 16 & - & - & - & - \\
\hline $\begin{array}{c}08 \ldots \\
\text { ОСт } 1992\end{array}$ & - & - & - & - & 51 & - & 17 & - & - & - & - \\
\hline $\begin{array}{c}13 \ldots \\
\text { OCT } 1993\end{array}$ & - & - & - & - & 68 & - & 23 & - & - & - & - \\
\hline $\begin{array}{c}08 \ldots \\
\text { OCT } 1994\end{array}$ & - & - & - & - & - & - & - & - & - & - & - \\
\hline $31 \ldots$ & - & - & - & - & - & - & - & - & - & - & - \\
\hline
\end{tabular}


Table 3. Water-quality data from surface-water sites-Continued

01472109 Stony Run near Spring City, Pa. (Site 6)

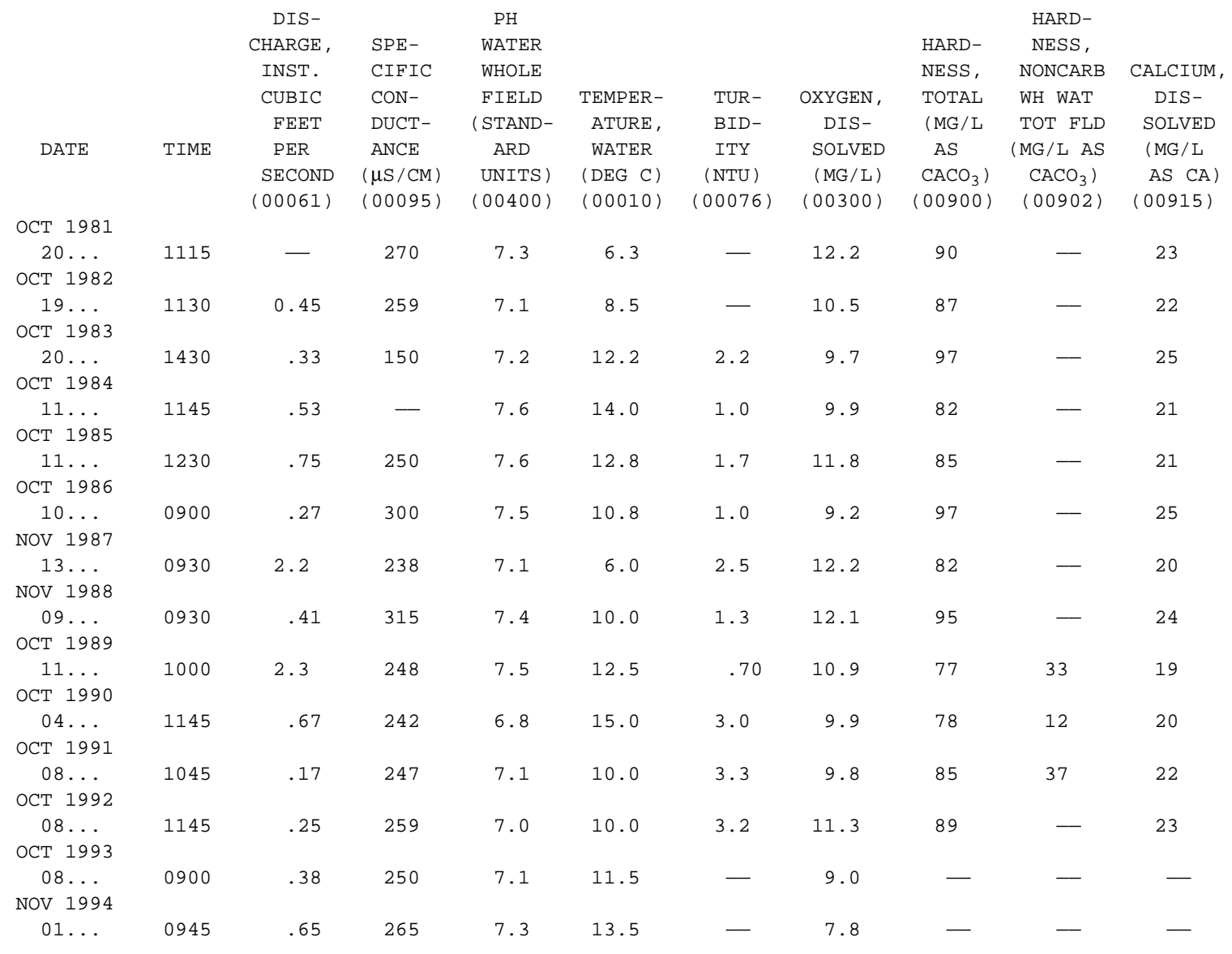


Table 3. Water-quality data from surface-water sites-Continued

01472109 Stony Run near Spring City, Pa. (Site 6)—Continued

\begin{tabular}{|c|c|c|c|c|c|c|c|c|c|c|c|c|}
\hline \multirow{4}{*}{ DATE } & MAGNE- & & & & $P$ & $\begin{array}{c}\text { ANC } \\
\text { WATER }\end{array}$ & $\begin{array}{c}\text { ANC } \\
\text { WATER }\end{array}$ & & CHI & FLL & , & $\begin{array}{l}\text { SOLIDS, } \\
\text { RESIDUE }\end{array}$ \\
\hline & $\begin{array}{r}\text { SIUM, } \\
\text { DIS- }\end{array}$ & $\begin{array}{c}\text { SODIUM, } \\
\text { DIS- }\end{array}$ & & $\begin{array}{c}\text { SODIUM } \\
\text { AD- }\end{array}$ & $\begin{array}{l}\text { SIUM, } \\
\text { DIS- }\end{array}$ & $\begin{array}{c}\text { UNF LTRD } \\
\text { FET }\end{array}$ & $\begin{array}{l}\text { UNFLTRD } \\
\text { IT }\end{array}$ & $\begin{array}{l}\text { SULFATE, } \\
\text { DIS- }\end{array}$ & $\begin{array}{l}\text { RIDE, } \\
\text { DIS- }\end{array}$ & $\begin{array}{l}\text { RIDE, } \\
\text { DIS- }\end{array}$ & $\begin{array}{c}\text { DIS- } \\
\text { SOLVED }\end{array}$ & $\begin{array}{l}\text { AT } 180 \\
\text { DEG. C }\end{array}$ \\
\hline & $\begin{array}{l}\text { SOLVED } \\
\text { (MG/L }\end{array}$ & $\begin{array}{l}\text { SOLVED } \\
\text { (MG/L }\end{array}$ & & $\begin{array}{l}\text { SORP- } \\
\text { TION }\end{array}$ & $\begin{array}{l}\text { SOLVED } \\
\text { (MG/L }\end{array}$ & $\begin{array}{c}\text { FIELD } \\
\text { MG/L AS }\end{array}$ & $\begin{array}{c}\text { FIELD } \\
\text { MG/L AS }\end{array}$ & $\begin{array}{r}\text { SOLVED } \\
(\mathrm{MG} / \mathrm{L}\end{array}$ & SOLVED & SOLVED & $(\mathrm{MG} / \mathrm{L}$ & $\begin{array}{c}\text { DIS- } \\
\text { SOLVED }\end{array}$ \\
\hline & $\begin{array}{c}\text { AS MG) } \\
(00925)\end{array}$ & $\begin{array}{r}\text { AS NA) } \\
(00930)\end{array}$ & PERCENT & $\begin{array}{l}\text { RATIO } \\
(00931)\end{array}$ & $\begin{array}{l}\text { AS K) } \\
(00935)\end{array}$ & $\begin{array}{l}\mathrm{CACO}_{3} \\
(00410)\end{array}$ & $\begin{array}{l}\mathrm{CACO}_{3} \\
(00419)\end{array}$ & $\begin{array}{c}\left.\mathrm{AS} \mathrm{SO}_{4}\right) \\
(00945)\end{array}$ & $\begin{array}{l}\text { AS CL) } \\
(00940)\end{array}$ & $\begin{array}{l}\text { AS F) } \\
(00950)\end{array}$ & $\begin{array}{l}\left.\mathrm{AIO}_{2}\right) \\
(00955)\end{array}$ & $\begin{array}{l}\text { (MG/L) } \\
(70300)\end{array}$ \\
\hline
\end{tabular}

\begin{tabular}{|c|c|c|c|c|c|c|c|c|c|c|c|c|}
\hline $\begin{array}{c}\text { OCT } 1981 \\
20 \ldots \\
\text { OCT } 1982\end{array}$ & 7.8 & 22 & 33 & 1 & 4.9 & - & - & 27 & 32 & $<0.10$ & 18 & 178 \\
\hline $\begin{array}{c}19 \ldots \\
\text { OCT } 1983\end{array}$ & 7.7 & 15 & 27 & .8 & 2.4 & 47 & - & 25 & 22 & $<.10$ & 19 & 274 \\
\hline $\begin{array}{c}20 \ldots \\
\text { OCT } 1984\end{array}$ & 8.3 & 15 & 23 & .7 & 8.9 & 56 & - & 37 & 27 & - & 17 & 203 \\
\hline $\begin{array}{c}09 \ldots \\
\text { OCT } 1985\end{array}$ & 7.1 & 14 & 26 & .7 & 3.2 & 48 & - & 24 & 19 & - & 17 & 145 \\
\hline $\begin{array}{c}11 \ldots \\
\text { ОСт } 1986\end{array}$ & 7.8 & 13 & 24 & .6 & 4.0 & 54 & - & 26 & 22 & - & 17 & 156 \\
\hline $\begin{array}{c}10 \ldots \\
\text { NOV } 1987\end{array}$ & 8.4 & 21 & 31 & .9 & 4.5 & 72 & - & 22 & 35 & - & 20 & 244 \\
\hline $\begin{array}{c}13 \ldots \\
\text { NOV } 1988\end{array}$ & 7.8 & 13 & 24 & .6 & 5.0 & 44 & - & 26 & 24 & - & 15 & 175 \\
\hline $\begin{array}{c}09 \ldots \\
\text { OCT } 1989\end{array}$ & 8.6 & 22 & 32 & 1 & 4.7 & 62 & - & 25 & 34 & - & 17 & - \\
\hline $\begin{array}{c}11 \ldots \\
\text { OCT } 1990\end{array}$ & 7.2 & 12 & 24 & .6 & 3.0 & 44 & - & 24 & 20 & - & 15 & - \\
\hline $\begin{array}{c}04 \ldots \\
\text { OCT } 1991\end{array}$ & 6.9 & 12 & 24 & .6 & 2.3 & 66 & - & 21 & 18 & $<.10$ & 17 & - \\
\hline $\begin{array}{c}08 \ldots \\
\text { OCT } 1992\end{array}$ & 7.4 & 11 & 21 & .5 & 3.4 & 48 & - & 22 & 18 & $<.10$ & 18 & - \\
\hline $\begin{array}{c}08 \ldots \\
\text { OCT } 1993\end{array}$ & 7.6 & 12 & 22 & .6 & 3.0 & - & 40 & 23 & 22 & $<.10$ & 18 & - \\
\hline $\begin{array}{c}08 \ldots \\
\text { NOV } 1994\end{array}$ & - & - & - & - & - & - & 54 & - & - & - & - & - \\
\hline $01 \ldots$ & - & - & - & - & - & - & 54 & - & 19 & - & - & - \\
\hline
\end{tabular}


Table 3. Water-quality data from surface-water sites-Continued

01472109 Stony Run near Spring City, Pa. (Site 6)—Continued

\begin{tabular}{|c|c|c|c|c|c|c|c|c|c|c|c|}
\hline ATE & $\begin{array}{l}\text { SOLIDS, } \\
\text { SUM OF } \\
\text { CONSTI- } \\
\text { TUENTS, } \\
\text { DIS- } \\
\text { SOLVED }\end{array}$ & $\begin{array}{l}\text { SOLIDS, } \\
\text { DIS- } \\
\text { SOLVED } \\
\text { (TONS } \\
\text { PER }\end{array}$ & $\begin{array}{l}\text { SOLIDS, } \\
\text { DIS- } \\
\text { SOLVED } \\
\text { (TONS } \\
\text { PER }\end{array}$ & $\begin{array}{l}\text { NITRO- } \\
\text { GEN, } \\
\text { NITRATE } \\
\text { TOTAL } \\
\text { (MG/L }\end{array}$ & $\begin{array}{l}\text { NITRO- } \\
\text { GEN, } \\
\text { NITRATE } \\
\text { DIS- } \\
\text { SOLVED } \\
\text { (MG/L }\end{array}$ & $\begin{array}{l}\text { NITRO- } \\
\text { GEN, } \\
\text { NITRATE } \\
\text { DIS- } \\
\text { SOLVED } \\
\text { (MG/L }\end{array}$ & $\begin{array}{l}\text { NITRO- } \\
\text { GEN, } \\
\text { NITRITE } \\
\text { DIS- } \\
\text { SOLVED } \\
\text { (MG/L }\end{array}$ & $\begin{array}{l}\mathrm{NITRO}- \\
\text { GEN, } \\
\mathrm{NO}_{2}+\mathrm{NO}_{3} \\
\text { DIS- } \\
\text { SOLVED } \\
\text { (MG/L }\end{array}$ & $\begin{array}{l}\text { NITRO- } \\
\text { GEN, } \\
\text { AMMONIA } \\
\text { DIS- } \\
\text { SOLVED } \\
\text { (MG/L }\end{array}$ & $\begin{array}{l}\text { NITRO- } \\
\text { GEN, } \\
\text { AMMONIA } \\
\text { DIS- } \\
\text { SOLVED } \\
\text { (MG/L }\end{array}$ & $\begin{array}{c}\text { NITRO- } \\
\text { GEN, } \\
\text { ORGANIC } \\
\text { TOTAL } \\
\text { (MG/L }\end{array}$ \\
\hline & $\begin{array}{l}(\mathrm{MG} / \mathrm{L}) \\
(70301)\end{array}$ & $\begin{array}{l}\mathrm{AC}-\mathrm{FT}) \\
(70303)\end{array}$ & $\begin{array}{l}\text { DAY) } \\
(70302)\end{array}$ & $\begin{array}{c}\text { AS N) } \\
(00620)\end{array}$ & $\begin{array}{c}\text { AS N) } \\
(00618)\end{array}$ & $\begin{array}{l}\left.\mathrm{AS} \quad \mathrm{NO}_{3}\right) \\
(71851)\end{array}$ & $\begin{array}{l}\text { AS N) } \\
(00613)\end{array}$ & $\begin{array}{l}\text { AS N) } \\
(00631)\end{array}$ & $\begin{array}{l}\text { AS N) } \\
(00608)\end{array}$ & $\begin{array}{l}\left.\mathrm{AS} \quad \mathrm{NH}_{4}\right) \\
(71846)\end{array}$ & $\begin{array}{l}\text { AS N) } \\
(00605)\end{array}$ \\
\hline
\end{tabular}

\begin{tabular}{|c|c|c|c|c|c|c|c|c|c|c|c|}
\hline $\begin{array}{c}\text { OCT } 1981 \\
20 \ldots \\
\text { OCT } 1982\end{array}$ & - & 0.24 & - & 3.40 & - & - & $<0.010$ & 3.10 & 0.070 & 0.09 & 0.88 \\
\hline $\begin{array}{c}19 \ldots \\
\text { OCT } 1983\end{array}$ & 163 & .37 & 0.33 & - & 4.90 & 22 & .010 & 4.90 & .010 & .01 & - \\
\hline $\begin{array}{c}20 \ldots \\
\text { OCT } 1984\end{array}$ & 186 & .28 & .18 & - & 3.00 & 13 & .050 & 3.00 & .090 & .12 & - \\
\hline $\begin{array}{c}09 \ldots \\
\text { OCT } 1985\end{array}$ & 155 & .20 & .21 & - & 4.55 & 20 & .050 & 4.60 & .070 & .09 & - \\
\hline $\begin{array}{c}11 \ldots \\
\text { OCT } 1986\end{array}$ & 161 & .21 & .32 & - & 3.87 & 17 & .030 & 3.90 & .020 & .03 & .78 \\
\hline $\begin{array}{c}10 \ldots \\
\text { NOV } 1987\end{array}$ & 190 & .33 & .18 & - & 2.38 & 11 & .020 & 2.40 & $<.010$ & - & - \\
\hline $\begin{array}{c}13 \ldots \\
\text { NOV } 1988\end{array}$ & 157 & .24 & 1.04 & - & 4.39 & 19 & .010 & 4.40 & .130 & .17 & .87 \\
\hline $\begin{array}{c}09 \ldots \\
\text { OCT } 1989\end{array}$ & 188 & .26 & .21 & - & 3.37 & 15 & .030 & 3.40 & .040 & .05 & .36 \\
\hline $\begin{array}{c}11 \ldots \\
\text { OCT } 1990\end{array}$ & 150 & .20 & .93 & - & 5.27 & 23 & .030 & 5.30 & .020 & .03 & .48 \\
\hline $\begin{array}{c}04 \ldots \\
\text { OCT } 1991\end{array}$ & 156 & .21 & .28 & - & 4.29 & 19 & .010 & 4.30 & .020 & .03 & .38 \\
\hline $\begin{array}{c}08 \ldots \\
\text { OCT } 1992\end{array}$ & 146 & .20 & .07 & - & - & - & $<.010$ & 3.40 & $<.010$ & - & - \\
\hline $\begin{array}{r}08 \ldots \\
\text { OCT } 193\end{array}$ & 151 & .20 & .10 & - & 3.99 & 18 & .010 & 4.00 & .050 & .06 & .45 \\
\hline $\begin{array}{c}08 \ldots \\
\text { NOV } 1994\end{array}$ & - & - & - & - & 3.98 & 18 & .020 & 4.00 & .040 & .05 & - \\
\hline $01 \ldots$ & - & - & - & - & 3.68 & 16 & .020 & 3.70 & $<.015$ & - & - \\
\hline
\end{tabular}


Table 3. Water-quality data from surface-water sites-Continued

01472109 Stony Run near Spring City, Pa. (Site 6)—Continued

\begin{tabular}{|c|c|c|c|c|c|c|c|c|c|c|c|}
\hline & $\begin{array}{l}\text { NITRO- } \\
\text { GEN }\end{array}$ & $\begin{array}{r}\text { NITRO- } \\
\text { GEN, AM- }\end{array}$ & $\begin{array}{r}\text { NITRO- } \\
\text { GEN, AM- }\end{array}$ & & NITRO- & & & $\mathrm{PHO}$ & $\begin{array}{c}\text { PHOS- } \\
\text { PHORUS, }\end{array}$ & $\begin{array}{l}\text { PHOS- } \\
\text { PHATE }\end{array}$ & \\
\hline \multirow[t]{2}{*}{ DATE } & $\begin{array}{l}\text { ORGANIC } \\
\text { DIS- } \\
\text { SOLVED } \\
\text { (MG/L }\end{array}$ & $\begin{array}{c}\text { MONIA + } \\
\text { ORGANIC } \\
\text { TOTAL } \\
\text { (MG/L }\end{array}$ & $\begin{array}{l}\text { MONIA + } \\
\text { ORGANIC } \\
\text { DIS. } \\
\text { (MG/L }\end{array}$ & $\begin{array}{c}\text { NITRO- } \\
\text { GEN, } \\
\text { TOTAL } \\
\text { (MG/L }\end{array}$ & $\begin{array}{c}\text { GEN, } \\
\text { DIS- } \\
\text { SOLVED } \\
\text { (MG/L }\end{array}$ & $\begin{array}{l}\text { PHOS- } \\
\text { PHORUS, } \\
\text { TOTAL } \\
\quad(\text { MG } / \text { L }\end{array}$ & $\begin{array}{l}\text { PHOS- } \\
\text { PHORUS, } \\
\text { TOTAL } \\
\text { (MG / L }\end{array}$ & $\begin{array}{l}\text { PHORUS, } \\
\text { DIS- } \\
\text { SOLVED } \\
\text { (MG/L }\end{array}$ & $\begin{array}{l}\text { ORTHO, } \\
\text { DIS- } \\
\text { SOLVED } \\
\text { (MG/L }\end{array}$ & $\begin{array}{c}\text { ORTHO, } \\
\text { DIS- } \\
\text { SOLVED } \\
\text { (MG/L }\end{array}$ & $\begin{array}{c}\text { ARSENIC, } \\
\text { DIS- } \\
\text { SOLVED } \\
(\mu \mathrm{G} / \mathrm{L}\end{array}$ \\
\hline & $\begin{array}{c}\text { AS N) } \\
(00607)\end{array}$ & $\begin{array}{l}\text { AS N) } \\
(00625)\end{array}$ & $\begin{array}{c}\text { AS N) } \\
(00623)\end{array}$ & $\begin{array}{c}\text { AS N) } \\
(00600)\end{array}$ & $\begin{array}{c}\text { AS N) } \\
(00602)\end{array}$ & $\begin{array}{c}\text { AS P) } \\
(00665)\end{array}$ & $\begin{array}{l}\left.\mathrm{AS} \mathrm{PO}_{4}\right) \\
(71886)\end{array}$ & $\begin{array}{l}\text { AS P) } \\
(00666)\end{array}$ & $\begin{array}{l}\text { AS P) } \\
(00671)\end{array}$ & $\begin{array}{c}\left.\mathrm{AS} \mathrm{PO}_{4}\right) \\
(00660)\end{array}$ & $\begin{array}{l}\text { AS AS) } \\
(01000)\end{array}$ \\
\hline
\end{tabular}

OCT 1981

$20 \ldots$

OCT 1982

$19 \ldots$

OCT 1983

$20 \ldots$

ОСТ 1984

$09 \ldots$

ОСТ 1985

$11 \ldots$

ОСТ 1986

$10 \ldots$

NOV 1987

$13 \ldots$

NOV 1988

$09 \ldots$

OCT 1989

$11 \ldots$

OCT 1990

$04 \ldots$

$4 \cdot 3$

4.1

0.500

1.5

$0.260 \quad 0.230$

0.71

(01000)

OCT 1991

$08 .$.

1.7

1.7

6.6

-

$-$

$.060 \quad .050$

.15

$1.2-$

1.3

4.3

.270

$\begin{array}{lll}.83 & .220 \quad .210\end{array}$

.64

$.33-$

.40

5.0

.140

$-$

$.100 \quad .100$

.31

$.58 \quad .80$

.60

4.7

4.5

.160

.49

$.130 \quad .110$

.34

$-\quad .50 \quad .40$

2.9

2

.160

$-\quad .120 \quad .110$

.34

$\begin{array}{lll}.47 & 1.0 & .60\end{array}$

5.4

5.0

.180

$-\quad .140 \quad .080$

.25

$.56 \quad .40$

.60

3.8

4.

.290

- $\quad .240 \quad .220$

.67

$.58 \quad .50$

.60

5.8

5.

.090

\begin{tabular}{l}
$-.060 \quad .060$ \\
\hline
\end{tabular}

.18

$.48 \quad .40$

.50

4.7

4.8

.050

$-\quad<.060 \quad .050$

.15

OCT 1992

$08 \ldots$

- .20

.30

3.6

$3.7 \quad .100$

-

$.050 \quad .060$

.18

.40

4.5

$4.4 \quad .100$

-
$-\quad .070 \quad .070$

.21

CT 1993

$.35 \quad .50$

$01 \ldots$ 
Table 3. Water-quality data from surface-water sites-Continued

01472109 Stony Run near Spring City, Pa. (Site 6)—Continued

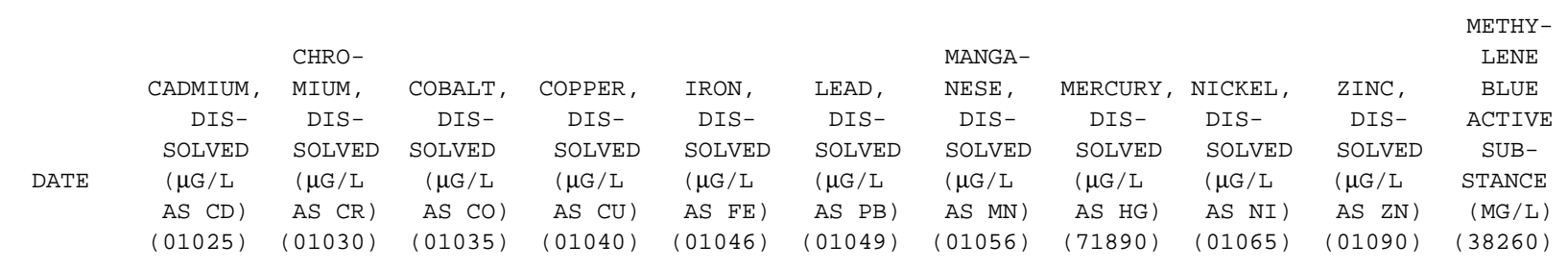

\begin{tabular}{|c|c|c|c|c|c|c|c|c|c|c|c|}
\hline OCT 1981 & & & & & & & & & & & \\
\hline $\begin{array}{c}20 \ldots \\
\text { OCT } 1982\end{array}$ & $<1.0$ & $<1.0$ & $<1.0$ & 3.0 & 150 & 1.0 & 57 & $<0.1$ & 6.0 & 6.0 & - \\
\hline $\begin{array}{c}19 \ldots \\
\text { OCT } 1983\end{array}$ & $<1.0$ & $<1.0$ & 1.0 & 3.0 & 12 & $<1.0$ & 17 & .1 & $<1.0$ & 7.0 & 0.05 \\
\hline $\begin{array}{c}20 \ldots \\
\text { OCT } 1984\end{array}$ & - & - & - & - & 89 & - & 54 & - & - & - & - \\
\hline $\begin{array}{c}09 \ldots \\
\text { OCT } 1985\end{array}$ & - & - & - & - & 35 & - & 44 & - & - & - & - \\
\hline $\begin{array}{c}11 \ldots \\
\text { OCT } 1986\end{array}$ & - & - & - & - & 44 & - & 70 & - & - & - & - \\
\hline $\begin{array}{c}10 \ldots \\
\text { NOV } 1987\end{array}$ & - & - & - & - & 62 & - & 57 & - & - & - & - \\
\hline $\begin{array}{c}13 \ldots \\
\text { NOV } 1988\end{array}$ & - & - & - & - & 130 & - & 110 & - & - & - & - \\
\hline $\begin{array}{c}09 \ldots \\
\text { OCT } 1989\end{array}$ & - & - & - & - & 83 & - & 75 & - & - & - & - \\
\hline $\begin{array}{c}11 \ldots \\
\text { OCT } 1990\end{array}$ & - & - & - & - & 42 & - & 32 & - & - & - & - \\
\hline $\begin{array}{c}04 \ldots \\
\text { OCT } 1991\end{array}$ & - & - & - & - & 17 & - & 47 & - & - & - & - \\
\hline $\begin{array}{c}08 \ldots \\
\text { OCT } 1992\end{array}$ & - & - & - & - & 33 & - & 28 & 一 & - & - & - \\
\hline $\begin{array}{c}08 \ldots \\
\text { OCT } 1993\end{array}$ & - & - & - & - & 23 & - & 31 & - & - & - & - \\
\hline $\begin{array}{c}08 \ldots \\
\text { NOV } 1994\end{array}$ & - & - & - & - & - & - & - & - & - & - & - \\
\hline $01 \ldots$ & - & - & - & - & - & - & - & - & - & - & - \\
\hline
\end{tabular}


Table 3. Water-quality data from surface-water sites-Continued

01472110 Stony Run at Spring City, Pa. (Site 7)

\begin{tabular}{|c|c|c|c|c|c|c|c|c|c|c|c|}
\hline DATE & TIME & $\begin{array}{c}\text { DIS- } \\
\text { CHARGE, } \\
\text { INST. } \\
\text { (CUBIC } \\
\text { FEET } \\
\text { PER } \\
\text { SECOND) } \\
(00061)\end{array}$ & $\begin{array}{l}\text { SPE- } \\
\text { CIFIC } \\
\text { CON- } \\
\text { DUCT- } \\
\text { ANCE } \\
(\mu \mathrm{S} / \mathrm{CM}) \\
(00095)\end{array}$ & $\begin{array}{l}\text { PH } \\
\text { WATER } \\
\text { WHOLE } \\
\text { FIELD } \\
\text { (STAND- } \\
\text { ARD } \\
\text { UNITS) } \\
(00400)\end{array}$ & $\begin{array}{l}\text { TEMPER- } \\
\text { ATURE } \\
\text { WATER } \\
(\text { DEG C) } \\
(00010)\end{array}$ & $\begin{array}{l}\text { OXYGEN, } \\
\text { DIS- } \\
\text { SOLVED } \\
\text { (MG/L) } \\
(00300)\end{array}$ & $\begin{array}{c}\text { HARD- } \\
\text { NESS, } \\
\text { TOTAL } \\
(\mathrm{MG} / \mathrm{L} \\
\mathrm{AS} \\
\left.\mathrm{CACO}_{3}\right) \\
(00900)\end{array}$ & $\begin{array}{l}\text { CALCIUM, } \\
\text { DIS- } \\
\text { SOLVED } \\
\text { (MG/L } \\
\text { AS CA) } \\
(00915)\end{array}$ & $\begin{array}{l}\text { MAGNE- } \\
\text { SIUM, } \\
\text { DIS- } \\
\text { SOLVED } \\
\text { (MG/L } \\
\text { AS MG) } \\
(00925)\end{array}$ & $\begin{array}{l}\text { SODIUM, } \\
\text { DIS- } \\
\text { SOLVED } \\
\text { (MG/L } \\
\text { AS NA) } \\
(00930)\end{array}$ & $\begin{array}{l}\text { SODIUM } \\
\text { PERCENT } \\
(00932)\end{array}$ \\
\hline $\begin{array}{c}\text { OCT } 1981 \\
20 \ldots \\
\text { OCT } 1982\end{array}$ & 0915 & - & 260 & 7.0 & 5.0 & 8.1 & 86 & 22 & 7.6 & 17 & 29 \\
\hline $19 \ldots$ & $\begin{array}{c}\text { SODIUM } \\
\text { AD- } \\
\text { SORP- } \\
\text { TION } \\
\text { RATIO } \\
(00931)\end{array}$ & $\begin{array}{l}\text { POTAS- } \\
\text { SIUM, } \\
\text { DIS- } \\
\text { SOLVED } \\
\text { (MG/L } \\
\text { AS K) } \\
(00935)\end{array}$ & $\begin{array}{l}\text { ALKA- } \\
\text { LINITY } \\
\text { WAT WH } \\
\text { TOT FET } \\
\text { FIELD } \\
(\mathrm{MG} / \mathrm{L} \text { AS } \\
\left.\mathrm{CACO}_{3}\right) \\
(00410)\end{array}$ & $\begin{array}{l}\text { SULFATE, } \\
\text { DIS- } \\
\text { SOLVED } \\
(\mathrm{MG} / \mathrm{L} \\
\left.\mathrm{AS} \mathrm{SO}_{4}\right) \\
(00945)\end{array}$ & $\begin{array}{c}\text { CHLO- } \\
\text { RIDE, } \\
\text { DIS- } \\
\text { SOLVED } \\
(M G / L \\
\text { AS CL) } \\
(00940)\end{array}$ & $\begin{array}{l}\text { FLUO- } \\
\text { RIDE, } \\
\text { DIS- } \\
\text { SOLVED } \\
\text { (MG/L } \\
\text { AS F) } \\
(00950)\end{array}$ & $\begin{array}{l}\text { SILICA, } \\
\text { DIS- } \\
\text { SOLVED } \\
(\mathrm{MG} / \mathrm{L} \\
\mathrm{AS} \\
\left.\mathrm{SIO}_{2}\right) \\
(00955)\end{array}$ & $\begin{array}{l}\text { SOLIDS, } \\
\text { RESIDUE } \\
\text { AT } 180 \\
\text { DEG. C } \\
\text { DIS- } \\
\text { SOLVED } \\
(\mathrm{MG} / \mathrm{L}) \\
(70300)\end{array}$ & $\begin{array}{l}7.3 \\
\\
\text { SOLIDS, } \\
\text { SUM OF } \\
\text { CONSTI- } \\
\text { TUENTS, } \\
\text { DIS- } \\
\text { SOLVED } \\
\text { (MG/L) } \\
\text { (70301) }\end{array}$ & $\begin{array}{l}\text { SOLIDS, } \\
\text { DIS- } \\
\text { SOLVED } \\
\text { (TONS } \\
\text { PER } \\
\text { AC-FT) } \\
(70303)\end{array}$ & $\begin{array}{l}\text { SOLIDS, } \\
\text { DIS- } \\
\text { SOLVED } \\
\text { (TONS } \\
\text { PER } \\
\text { DAY) } \\
\text { (70302) }\end{array}$ \\
\hline $\begin{array}{c}\text { OCT } 1981 \\
20 \ldots \\
\text { OCT } 1982 \\
19 \ldots\end{array}$ & 0.8 & 4.9 & - & 30 & 23 & $\begin{array}{r}<0.10 \\
<.10\end{array}$ & 14 & 159 & - & 0.22 & - \\
\hline DATE & $\begin{array}{c}\text { NITRO- } \\
\text { GEN, } \\
\text { NITRATE } \\
\text { TOTAL } \\
\text { (MG/L } \\
\text { AS N) } \\
(00620)\end{array}$ & $\begin{array}{l}\text { NITRO- } \\
\text { GEN, } \\
\text { NITRATE } \\
\text { DIS- } \\
\text { SOLVED } \\
\text { (MG/L } \\
\text { AS N) } \\
(00618)\end{array}$ & $\begin{array}{l}\text { NITRO- } \\
\text { GEN, } \\
\text { NITRATE } \\
\text { DIS- } \\
\text { SOLVED } \\
(\mathrm{MG} / \mathrm{L} \\
\left.\mathrm{AS} \mathrm{NO})_{3}\right) \\
(71851)\end{array}$ & $\begin{array}{l}\text { NITRO- } \\
\text { GEN, } \\
\text { NITRITE } \\
\text { DIS- } \\
\text { SOLVED } \\
\text { (MG/L } \\
\text { AS N) } \\
(00613)\end{array}$ & $\begin{array}{c}\mathrm{NITRO}- \\
\text { GEN, } \\
\mathrm{NO}_{2}+\mathrm{NO}_{3} \quad \mathrm{~A} \\
\text { DIS- } \\
\mathrm{SOLVED} \\
(\mathrm{MG} / \mathrm{L} \\
\mathrm{AS} \mathrm{N}) \\
(00631)\end{array}$ & $\begin{array}{l}\text { NITRO- } \\
\text { GEN, } \\
\text { AMMONIA } \\
\text { DIS- } \\
\text { SOLVED } \\
\text { (MG/L } \\
\text { AS N) } \\
(00608)\end{array}$ & $\begin{array}{c}\text { NITRO- } \\
\text { GEN, } \\
\text { AMMONIA } \\
\text { DIS- } \\
\text { SOLVED } \\
\text { (MG/L } \\
\left.\text { AS NH } \text { NH }_{4}\right) \\
(71846)\end{array}$ & $\begin{array}{l}\text { NITRO- } \\
\text { GEN, OF } \\
\text { ORGANIC } \\
\text { TOTAL } \\
\text { (MG/L } \\
\text { AS N) } \\
(00605) \quad(\end{array}$ & $\begin{array}{l}\text { NITRO- } \\
\text { GEN, } \\
\text { ORGANIC } \\
\text { DIS- } \\
\text { SOLVED } \\
\text { (MG/L } \\
\text { AS N) } \\
(00607) \quad(\end{array}$ & $\begin{array}{l}\text { NITRO- } \\
\text { GEN, AM- } \\
\text { MONIA + } \\
\text { ORGANIC } \\
\text { TOTAL } \\
\text { (MG/L } \\
\text { AS N) } \\
(00625)\end{array}$ & \\
\hline $\begin{array}{c}\text { OCT } 1981 \\
20 \ldots \\
\text { OCT } 1982 \\
19 \ldots\end{array}$ & 3.31 & 3.61 & 16 & 0.090 & 3.70 & 0.430 & 0.55 & $\begin{array}{l}0.53 \\
-\end{array}$ & $\begin{array}{l}0.87 \\
2.2\end{array}$ & $\begin{array}{l}0.75 \\
-\end{array}$ & \\
\hline DATE & $\begin{array}{l}\text { NITRO- } \\
\text { GEN, AM- } \\
\text { MONIA + } \\
\text { ORGANIC } \\
\text { DIS. } \\
\text { (MG/L } \\
\text { AS N) } \\
(00623)\end{array}$ & $\begin{array}{c}\text { NITRO- } \\
\text { GEN, } \\
\text { TOTAL } \\
(\text { MG/L } \\
\text { AS N) } \\
(00600)\end{array}$ & $\begin{array}{l}\text { NITRO- } \\
\text { GEN, } \\
\text { DIS- } \\
\text { SOLVED } \\
\text { (MG / L } \\
\text { AS N) } \\
(00602)\end{array}$ & $\begin{array}{l}\text { PHOS- } \\
\text { PHORUS, P } \\
\text { TOTAL } \\
\text { (MG/L } \\
\text { AS P) } \\
(00665)\end{array}$ & $\begin{array}{c}\text { PHOS- } \\
\text { PHORUS, } \\
\text { TOTAL } \\
(\mathrm{MG} / \mathrm{L} \\
\text { AS PO }) \\
(71886)\end{array}$ & $\begin{array}{c}\text { PHOS- } \\
\text { PHORUS, } \\
\text { DIS- } \\
\text { SOLVED } \\
\text { (MG/L } \\
\text { AS P) } \\
(00666)\end{array}$ & $\begin{array}{l}\text { PHOS- } \\
\text { PHORUS } \\
\text { ORTHO, } \\
\text { DIS- } \\
\text { SOLVED } \\
(\text { MG / L } \\
\text { AS P) } \\
(00671)\end{array}$ & $\begin{array}{l}\text { PHOS- } \\
\text { PHATE, } \\
\text { ORTHO, } \\
\text { DIS- } \\
\text { SOLVED } \\
(\text { MG/L } \\
\text { AS PO }) \\
(00660)\end{array}$ & $\begin{array}{l}\text { ARSENIC, } \\
\text { DIS- } \\
\text { SOLVED } \\
(\mu \mathrm{G} / \mathrm{L} \\
\text { AS AS) } \\
(01000)\end{array}$ & $\begin{array}{l}\text { CADMIUM, } \\
\text { DIS- } \\
\text { SOLVED } \\
(\mu \mathrm{G} / \mathrm{L} \\
\text { AS CD }) \\
(01025)\end{array}$ & \\
\hline $\begin{array}{c}\text { OCT } 1981 \\
20 \ldots \\
\text { OCT } 1982 \\
19 \ldots\end{array}$ & 2.3 & $\begin{array}{l}4.1 \\
-\end{array}$ & 7.1 & $\begin{array}{c}0.210 \\
-\end{array}$ & $\begin{array}{l}0.64 \\
-\end{array}$ & $\begin{array}{r}0.190 \\
.150\end{array}$ & $\begin{array}{r}0.170 \\
.150\end{array}$ & $\begin{array}{r}0.52 \\
.46\end{array}$ & 1 & $\begin{array}{r}3.0 \\
<1.0\end{array}$ & \\
\hline DATE & $\begin{array}{c}\text { CHRO- } \\
\text { MIUM, } \\
\text { DIS- } \\
\text { SOLVED } \\
(\mu \mathrm{H} / \mathrm{L} \\
\text { AS CR) } \\
(01030)\end{array}$ & $\begin{array}{c}\text { COBALT, } \\
\text { DIS- } \\
\text { SOLVED } \\
(\mu \mathrm{G} / \mathrm{L} \\
\text { AS CO }) \\
(01035)\end{array}$ & $\begin{array}{c}\text { COPPER, } \\
\text { DIS- } \\
\text { SOLVED } \\
(\mu \mathrm{G} / \mathrm{L} \\
\text { AS CU }) \\
(01040)\end{array}$ & $\begin{array}{c}\text { IRON, } \\
\text { DIS- } \\
\text { SOLVED } \\
(\mu \mathrm{G} / \mathrm{L} \\
\mathrm{AS} \mathrm{FE}) \\
(01046)\end{array}$ & $\begin{array}{c}\text { LEAD, } \\
\text { DIS- } \\
\text { SOLVED } \\
(\mu \mathrm{G} / \mathrm{L} \\
\mathrm{AS} \mathrm{PB}) \\
(01049)\end{array}$ & $\begin{array}{c}\text { MANGA- } \\
\text { NESE, } \\
\text { DIS- } \\
\text { SOLVED } \\
(\mu \mathrm{G} / \mathrm{L} \\
\text { AS MN) } \\
(01056)\end{array}$ & $\begin{array}{l}\text { MERCURY } \\
\text { DIS- } \\
\text { SOLVED } \\
(\mu \mathrm{G} / \mathrm{L} \\
\text { AS HG) } \\
(71890)\end{array}$ & $\begin{array}{c}\text { YICKEL } \\
\text { DIS- } \\
\text { SOLVED } \\
(\mu \mathrm{G} / \mathrm{L} \\
\text { AS NI) } \\
(01065)\end{array}$ & $\begin{array}{c}\text { L, } \quad \text { ZINC, } \\
\text { DIS- } \\
\text { SOLVED } \\
(\mu \mathrm{G} / \mathrm{L} \\
\text { AS ZN }) \\
(01090)\end{array}$ & $\begin{array}{c}\text { METHY- } \\
\text { LENE } \\
\text { BLUE } \\
\text { ACTIVE } \\
\text { SUB- } \\
\text { STANCE } \\
\text { (MG/L) } \\
(38260)\end{array}$ & \\
\hline $\begin{array}{c}\text { OCT } 1981 \\
20 \ldots \\
\text { OCT } 1982 \\
19 \ldots\end{array}$ & $<1$ & 1 & 4 & 39 & $<1$ & 10 & $<0.1$ & $<1$ & $<4$ & 0.10 & \\
\hline
\end{tabular}


Table 3. Water-quality data from surface-water sites-Continued

01472126 - French Creek at Trythall, Pa. (Site 41)

\begin{tabular}{|c|c|c|c|c|c|c|c|c|c|c|}
\hline DATE & 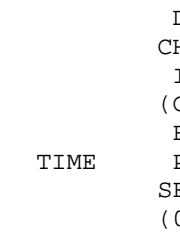 & $\begin{array}{l}\text { DIS- } \\
\text { HARGE, } \\
\text { INST. } \\
\text { (CUBIC } \\
\text { FEET } \\
\text { PER } \\
\text { ECOND) } \\
(00061)\end{array}$ & $\begin{array}{l}\text { SPE- } \\
\text { CIFIC } \\
\text { CON- } \\
\text { DUCT- } \\
\text { ANCE } \\
(\mu \mathrm{S} / \mathrm{CM}) \\
(00095)\end{array}$ & $\begin{array}{l}\text { PH } \\
\text { WATER } \\
\text { WHOLE } \\
\text { FIELD } \\
\text { (STAND- } \\
\text { ARD } \\
\text { UNITS) } \\
(00400)\end{array}$ & $\begin{array}{c}\text { TEMPER- } \\
\text { ATURE } \\
\text { WATER } \\
(\text { DEG C) } \\
(00010)\end{array}$ & $\begin{array}{l}\text { OXYGEN, } \\
\text { DIS- } \\
\text { SOLVED } \\
(\mathrm{MG} / \mathrm{L}) \\
(00300)\end{array}$ & $\begin{array}{l}\text { HARD- } \\
\text { NESS } \\
\text { TOTAL } \\
(\mathrm{MG} / \mathrm{L} \\
\mathrm{AS} \\
\left.\mathrm{CACO}_{3}\right) \\
(00900)\end{array}$ & $\begin{array}{l}\text { M } \\
\text { CALCIUM, } \\
\text { DIS- } \\
\text { SOLVED } \\
\text { (MG/L } \\
\text { AS CA) } \\
(00915)\end{array}$ & $\begin{array}{l}\text { MAGNE- } \\
\text { SIUM, } \\
\text { DIS- } \\
\text { SOLVED } \\
\text { (MG/L } \\
\text { AS MG) } \\
(00925)\end{array}$ & $\begin{array}{l}\text { SODIUM, } \\
\text { DIS- } \\
\text { SOLVED } \\
(\text { MG / L } \\
\text { AS NA) } \\
(00930)\end{array}$ \\
\hline $\begin{array}{c}\text { OCT } 1981 \\
22 \ldots \\
\text { ОСт } 1982\end{array}$ & 1045 & - & 75 & 7.0 & 9.0 & 10.1 & 26 & 6.9 & 2.1 & 4.0 \\
\hline $26 \ldots$ & $\begin{array}{l}\text { SODIUM } \\
\text { PERCENT } \\
\text { (00932) }\end{array}$ & $\begin{array}{l}\text { SODIUM } \\
\text { AD- } \\
\text { SORP- } \\
\text { TION } \\
\text { RATIO } \\
(00931)\end{array}$ & $\begin{array}{l}\text { POTAS- } \\
\text { SIUM, } \\
\quad \text { DIS- } \\
\text { SOLVED } \\
\text { (MG/L } \\
\text { AS K) } \\
(00935)\end{array}$ & $\begin{array}{l}6.4 \\
\\
\text { ALKA- } \\
\text { LINITY } \\
\text { WAT WH } \\
\text { TOT FET } \\
\text { FIELD } \\
(\mathrm{MG} / \mathrm{L} \text { AS } \\
\left.\text { CACO })_{3}\right) \\
(00410)\end{array}$ & $\begin{array}{l}\text { SULFATE, } \\
\text { DIS- } \\
\text { SOLVED } \\
(\mathrm{MG} / \mathrm{L} \\
\left.\mathrm{AS} \mathrm{SO}_{4}\right) \\
(00945)\end{array}$ & $\begin{array}{c}\text { CHLO- } \\
\text { RIDE, } \\
\text { DIS- } \\
\text { SOLVED } \\
\text { (MG/L } \\
\text { AS CL) } \\
(00940)\end{array}$ & $\begin{array}{l}\text { FLUO- } \\
\text { RIDE, } \\
\text { DIS- } \\
\text { SOLVED } \\
(M G / L \\
\text { AS F) } \\
(00950)\end{array}$ & $\begin{array}{l}\text { SILICA, } \\
\text { DIS- } \\
\text { SOLVED } \\
(\mathrm{MG} / \mathrm{L} \\
\mathrm{AS} \\
\left.\mathrm{SIO}_{2}\right) \\
(00955)\end{array}$ & $\begin{array}{l}\text { SOLIDS, } \\
\text { RESIDUE } \\
\text { AT } 180 \\
\text { DEG. C } \\
\text { DIS- } \\
\text { SOLVED } \\
(\mathrm{MG} / \mathrm{L}) \\
(70300)\end{array}$ & $\begin{array}{l}\text { SOLIDS, } \\
\text { SUM OF } \\
\text { CONSTI- } \\
\text { TUENTS, } \\
\text { DIS- } \\
\text { SOLVED } \\
(\text { MG/L) } \\
(70301)\end{array}$ \\
\hline $\begin{array}{c}\text { OCT } 1981 \\
22 \ldots \\
\text { OCT } 1982 \\
26\end{array}$ & 24 & 0.3 & 1.0 & - & 6.2 & 2.7 & $\begin{array}{r}<0.10 \\
<.10\end{array}$ & $\begin{array}{l}6.6 \\
10\end{array}$ & 43 & - \\
\hline DATE & $\begin{array}{c}\text { SOLIDS, } \\
\text { DIS- } \\
\text { SOLVED } \\
\text { (TONS } \\
\text { PER } \\
\text { AC-FT) } \\
(70303)\end{array}$ & $\begin{array}{c}\text { SOLIDS, } \\
\text { DIS- } \\
\text { SOLVED } \\
\text { (TONS } \\
\text { PER } \\
\text { DAY) } \\
(70302)\end{array}$ & $\begin{array}{c}\text { NITRO- } \\
\text { GEN, } \\
\text { NITRATE } \\
\text { TOTAL } \\
\text { (MG/L } \\
\text { AS N) } \\
(00620)\end{array}$ & $\begin{array}{l}\text { NITRO- } \\
\text { GEN, } \\
\text { NITRITE } \\
\text { DIS- } \\
\text { SOLVED } \\
(\text { MG/L } \\
\text { AS N) } \\
(00613)\end{array}$ & $\begin{array}{l}\mathrm{NITRO}- \\
\text { GEN, } \\
\mathrm{NO}_{2}+\mathrm{NO}_{3} \\
\mathrm{DIS}- \\
\text { SOLVED } \\
(\mathrm{MG} / \mathrm{L} \\
\mathrm{AS} \mathrm{N}) \\
(00631)\end{array}$ & $\begin{array}{l}\text { NITRO- } \\
\text { GEN, } \\
\text { AMMONIA } \\
\text { DIS- } \\
\text { SOLVED } \\
\text { (MG/L } \\
\text { AS N) } \\
(00608)\end{array}$ & $\begin{array}{c}\text { NITRO- } \\
\text { GEN, } \\
\text { AMMONIA } \\
\text { DIS- } \\
\text { SOLVED } \\
(\mathrm{MG} / \mathrm{L} \\
\left.\mathrm{AS} \mathrm{NH} \mathrm{N}_{4}\right) \\
(71846)\end{array}$ & $\begin{array}{l}\text { NITRO- } \\
\text { GEN, } \\
\text { ORGANIC } \\
\text { TOTAL } \\
(\mathrm{MG} / \mathrm{L} \\
\text { AS N) } \\
(00605)\end{array}$ & $\begin{array}{c}\text { NITRO- } \\
\text { GEN, } \\
\text { ORGANIC } \\
\text { DIS- } \\
\text { SOLVED } \\
\text { (MG/L } \\
\text { AS N) } \\
(00607)\end{array}$ & $\begin{array}{c}\text { NITRO- } \\
\text { GEN, AM- } \\
\text { MONIA + } \\
\text { ORGANIC } \\
\text { TOTAL } \\
\text { (MG/L } \\
\text { AS N) } \\
(00625)\end{array}$ \\
\hline $\begin{array}{c}\text { OCT } 1981 \\
22 \ldots \\
\text { OCT } 1982 \\
26 \ldots\end{array}$ & 0.06 & - & 0.080 & $<0.010$ & $\begin{array}{r}0.090 \\
.130\end{array}$ & $\begin{array}{r}0.080 \\
.030\end{array}$ & 0.10 & 0.22 & $\begin{array}{r}0.62 \\
.77\end{array}$ & $\begin{array}{l}0.25 \\
-\end{array}$ \\
\hline DATE & $\begin{array}{c}\text { NITRO- } \\
\text { GEN, AM- } \\
\text { MONIA + } \\
\text { ORGANIC } \\
\text { DIS. } \\
(\text { MG / } \\
\text { AS N) } \\
(00623)\end{array}$ & $\begin{array}{l}\text { NITRO- } \\
\text { GEN, } \\
\text { TOTAL } \\
(\text { MG/L } \\
\text { AS N) } \\
(006000)\end{array}$ & $\begin{array}{c}\text { NITRO- } \\
\text { GEN, } \\
\text { DIS- } \\
\text { SOLVED } \\
\text { (MG/L } \\
\text { AS N) } \\
(00602)\end{array}$ & $\begin{array}{c}\text { PHOS- } \\
\text { PHORUS, } \\
\text { TOTAL } \\
\text { (MG/L } \\
\text { AS P) } \\
(00665)\end{array}$ & $\begin{array}{l}\text { PHOS- } \\
\text { PHORUS, } \\
\text { DIS- } \\
\text { SOLVED } \\
\text { (MG/L } \\
\text { AS P) } \\
(00666)\end{array}$ & $\begin{array}{c}\text { PHOS- } \\
\text { PHORUS } \\
\text { ORTHO, } \\
\text { DIS- } \\
\text { SOLVED } \\
\text { (MG /L } \\
\text { AS P) } \\
(00671)\end{array}$ & $\begin{array}{l}\text { PHOS- } \\
\text { PHATE, } \\
\text { ORTHO, } \\
\text { DIS- } \\
\text { SOLVED } \\
(\mathrm{MG} / \mathrm{L} \\
\left.\text { AS PO } \mathrm{PO}_{4}\right) \\
(00660)\end{array}$ & $\begin{array}{c} \\
\text { ARSENIC, } \\
\text { DIS- } \\
\text { SOLVED } \\
(\mu \mathrm{G} / \mathrm{L} \\
\text { AS AS) } \\
(01000)\end{array}$ & $\begin{array}{l}\text { CADMIUM, } \\
\text { DIS- } \\
\text { SOLVED } \\
(\mu \mathrm{G} / \mathrm{L} \\
\text { AS CD }) \\
(01025)\end{array}$ & $\begin{array}{l}\text { CHRO- } \\
\text { MIUM, } \\
\text { DIS- } \\
\text { SOLVED } \\
(\mu \mathrm{G} / \mathrm{L} \\
\text { AS CR }) \\
(01030)\end{array}$ \\
\hline $\begin{array}{c}\text { OCT } 1981 \\
22 \ldots \\
\text { OCT } 1982 \\
26 \ldots\end{array}$ & $\begin{array}{r}0.70 \\
.80\end{array}$ & 0.33 & $\begin{array}{r}0.79 \\
.93\end{array}$ & $\begin{array}{c}<0.010 \\
-\end{array}$ & $\begin{array}{r}0.010 \\
.020\end{array}$ & $\begin{array}{r}0.020 \\
.010\end{array}$ & $\begin{array}{r}0.06 \\
.03\end{array}$ & $<1$ & $\begin{array}{r}1.0 \\
<1.0\end{array}$ & $\begin{array}{l}<1 \\
<1\end{array}$ \\
\hline & DATE & $\begin{array}{c}\text { COBALT, } \\
\text { DIS- } \\
\text { SOLVED } \\
(\mu \mathrm{G} / \mathrm{L} \\
\text { AS CO) } \\
(01035)\end{array}$ & $\begin{array}{l}\text { COPPER, } \\
\text { DIS- } \\
\text { SOLVED } \\
(\mu \mathrm{G} / \mathrm{L} \\
\mathrm{AS} \mathrm{CU}) \\
(01040)\end{array}$ & $\begin{array}{c}\text { IRON, } \\
\text { DIS- } \\
\text { SOLVED } \\
(\mu \mathrm{G} / \mathrm{L} \\
\text { AS FE) } \\
(01046)\end{array}$ & $\begin{array}{c}\text { LEAD, } \\
\text { DIS- } \\
\text { SOLVED } \\
(\mu \mathrm{G} / \mathrm{L} \\
\text { AS PB) } \\
(01049)\end{array}$ & $\begin{array}{c}\text { MANGA- } \\
\text { NESE, } \\
\text { DIS- } \\
\text { SOLVED } \\
(\mu \mathrm{G} / \mathrm{L} \\
\text { AS MN) } \\
(01056)\end{array}$ & $\begin{array}{c}\text { MERCURY, } \\
\text { DIS- } \\
\text { SOLVED } \\
(\mu \mathrm{G} / \mathrm{L} \\
\text { AS HG) } \\
(71890)\end{array}$ & $\begin{array}{c}\text { NICKEL, } \\
\text { DIS- } \\
\text { SOLVED } \\
(\mu \mathrm{G} / \mathrm{L} \\
\text { AS NI) } \\
(01065)\end{array}$ & $\begin{array}{c}\text { ZINC, } \\
\text { DIS- } \\
\text { SOLVED } \\
(\mu \mathrm{G} / \mathrm{L} \\
\text { AS ZN) } \\
(01090)\end{array}$ & $\begin{array}{l}\text { METHY- } \\
\text { LENE } \\
\text { BLUE } \\
\text { ACTIVE } \\
\text { SUB- } \\
\text { STANCE } \\
\text { (MG/L) } \\
(38260)\end{array}$ \\
\hline & $\begin{array}{rr}\text { OCT } 1981 \\
22 \ldots \\
\text { OCT } 1982\end{array}$ & $<1$ & 3 & 130 & 1 & 52 & $<0.1$ & 1 & 7 & - \\
\hline & $26 \ldots$ & $<1$ & 2 & 320 & 1 & 55 & $<.1$ & 1 & 7 & 0.02 \\
\hline
\end{tabular}


Table 3. Water-quality data from surface-water sites-Continued

01472129 - French Creek near Knauertown, Pa. (Site 11)

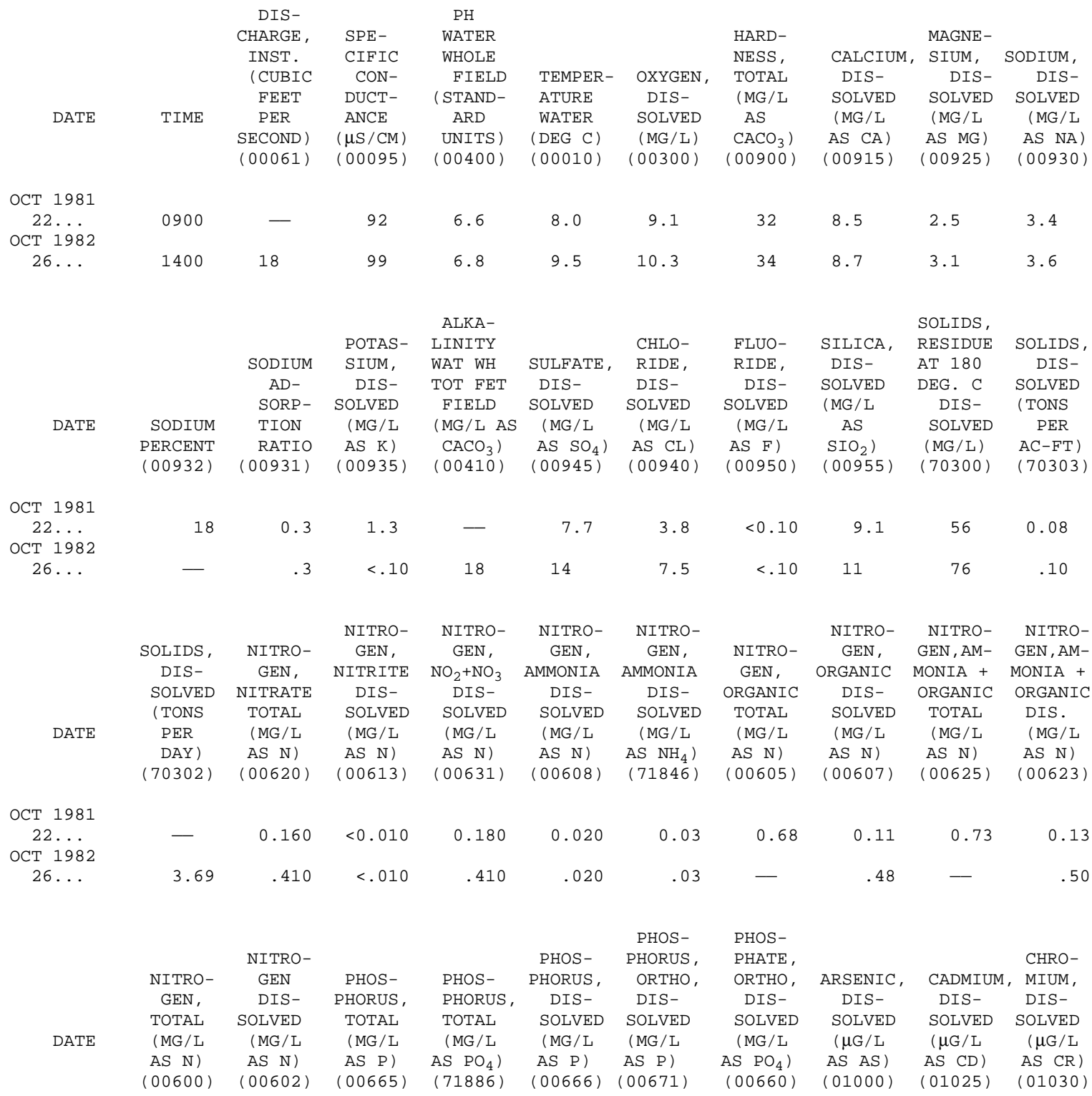

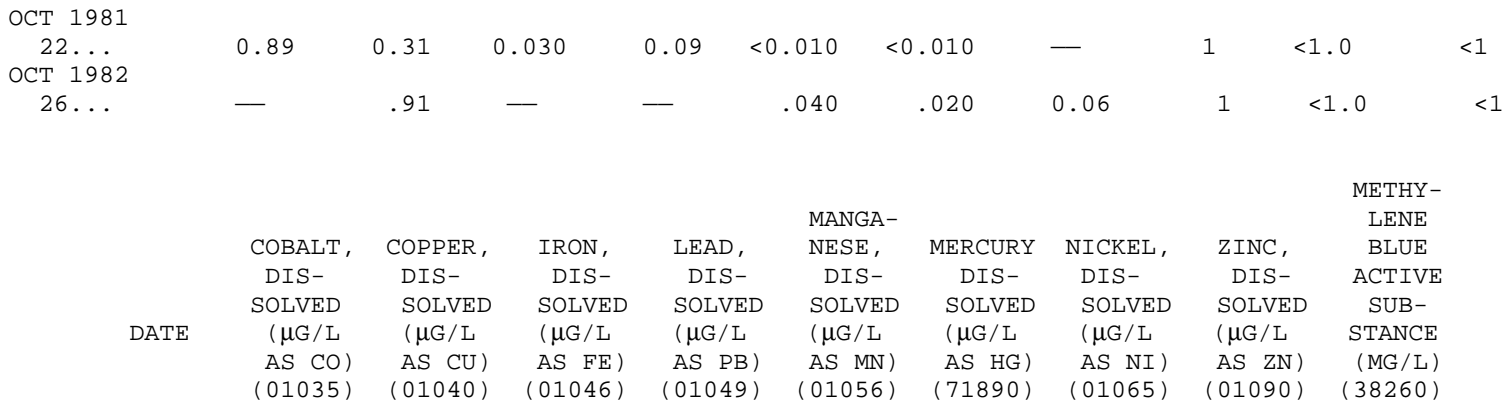

OCT 1981

$22 \ldots$

OCT 1982

$26 \ldots$

$\begin{array}{lll}<1 & 3 & 160 \\ <1 & 2 & 350\end{array}$

350 $\begin{array}{lll}1 & 51 & <0.1 \\ <1 & 52 & <.1\end{array}$

2

$\begin{array}{cc}6 & - \\ 10 & 0.03\end{array}$ 
Table 3. Water-quality data from surface-water sites-Continued

01472138 - French Creek near Coventryville, Pa. (Site 13)

\begin{tabular}{|c|c|c|c|c|c|c|c|c|c|c|c|}
\hline DATE & TIME & $\begin{array}{l}\text { DIS- } \\
\text { CHARGE, } \\
\text { INST. } \\
\text { (CUBIC } \\
\text { FEET } \\
\text { PER } \\
\text { SECOND) } \\
(00061)\end{array}$ & $\begin{array}{l}\text { SPE- } \\
\text { CIFIC } \\
\text { CON- } \\
\text { DUCT- } \\
\text { ANCE } \\
(\mu \mathrm{S} / \mathrm{CM}) \\
(00095)\end{array}$ & $\begin{array}{c}\text { PH } \\
\text { WATER } \\
\text { WHOLE } \\
\text { FIELD } \\
\text { (STAND- } \\
\text { ARD } \\
\text { UNITS) } \\
(00400)\end{array}$ & $\begin{array}{l}\text { TEMPER- } \\
\text { ATURE } \\
\text { WATER } \\
(\text { DEG C) } \\
(00010)\end{array}$ & $\begin{array}{l}\text { TUR- } \\
\text { BID- } \\
\text { ITY } \\
(\text { NTU) } \\
(00076)\end{array}$ & $\begin{array}{l}\text { OXYGEN, } \\
\text { DIS- } \\
\text { SOLVED } \\
(M G / L) \\
(00300)\end{array}$ & $\begin{array}{c}\text { HARD- } \\
\text { NESS, } \\
\text { TOTAL } \\
(\mathrm{MG} / \mathrm{L} \\
\mathrm{AS} \\
\left.\mathrm{CACO}_{3}\right) \\
(00900)\end{array}$ & $\begin{array}{l}\text { HARD- } \\
\text { NESS, } \\
\text { NONCARB } \\
\text { WH WAT } \\
\text { TOT FLD } \\
(\mathrm{MG} / \mathrm{L} \text { AS } \\
\left.\mathrm{CACO}_{3}\right) \\
(00902)\end{array}$ & $\begin{array}{l}\text { CALCIUM, } \\
\text { DIS- } \\
\text { SOLVED } \\
(\text { MG/L } \\
\text { AS CA) } \\
(00915)\end{array}$ & $\begin{array}{l}\text { MAGNE- } \\
\text { SIUM, } \\
\text { DIS- } \\
\text { SOLVED } \\
(\text { MG/L } \\
\text { AS MG) } \\
(00925)\end{array}$ \\
\hline ОСТ 1981 & & & & & & & & & & & \\
\hline $\begin{array}{c}21 \ldots \\
\text { NOV } 1982\end{array}$ & 1345 & - & 154 & 7.8 & 7.5 & - & 10.2 & 58 & - & 15 & 5.0 \\
\hline $\begin{array}{c}04 \ldots \\
\text { OCT } 1983\end{array}$ & 1015 & 7.3 & 140 & 7.3 & 15.0 & - & 7.2 & 58 & - & 15 & 5.1 \\
\hline $\begin{array}{c}18 \ldots \\
\text { OCT } 1984\end{array}$ & 1330 & 9.5 & 125 & 7.4 & 13.0 & 1.8 & 9.5 & 47 & - & 12 & 4.2 \\
\hline $\begin{array}{c}10 \ldots \\
\text { OCT } 1985\end{array}$ & 1430 & 10 & 125 & 7.7 & 13.0 & .50 & 10.6 & 47 & - & 12 & 4.1 \\
\hline $\begin{array}{c}10 \ldots \\
\text { OCT } 1986\end{array}$ & 0830 & 11 & 125 & 7.2 & 8.5 & 1.0 & 9.9 & 47 & - & 12 & 4.2 \\
\hline $\begin{array}{c}22 \ldots \\
\text { OCT } 1987\end{array}$ & 0900 & 5.0 & 145 & 7.5 & 10.0 & 1.4 & 7.1 & 54 & - & 14 & 4.7 \\
\hline $\begin{array}{c}16 \ldots \\
\text { OCT } 1988\end{array}$ & 1000 & 10 & 122 & 7.2 & 10.0 & .70 & 11.2 & 48 & - & 12 & 4.3 \\
\hline $\begin{array}{c}20 \ldots \\
\text { OCT } 1989\end{array}$ & 0930 & 7.3 & 145 & 6.7 & 9.0 & .90 & 11.0 & 56 & - & 14 & 5.0 \\
\hline $\begin{array}{c}23 \ldots \\
\text { NOV } 1990\end{array}$ & 1030 & 32 & 123 & 7.3 & 9.5 & 1.0 & 11.8 & 44 & 12 & 11 & 4.0 \\
\hline $\begin{array}{c}16 \ldots \\
\text { OCT } 1991\end{array}$ & 0900 & 16 & 132 & 6.8 & 6.5 & 1.3 & 12.4 & 49 & 3 & 12 & 4.6 \\
\hline $\begin{array}{c}09 \ldots \\
\text { ОСТ } 1992\end{array}$ & 0930 & 6.8 & 146 & 7.1 & 10.0 & 2.5 & 10.6 & 54 & 17 & 14 & 4.6 \\
\hline $\begin{array}{c}15 \ldots \\
\text { OCT } 1993\end{array}$ & 0900 & 9.8 & 145 & 7.4 & 11.5 & 0.90 & 10.5 & 54 & - & 14 & 4.6 \\
\hline $\begin{array}{c}14 \ldots \\
\text { OCT } 1994\end{array}$ & 0945 & 16 & 127 & 7.1 & 8.0 & - & 10.7 & - & - & - & - \\
\hline $27 \ldots$ & 1155 & 10 & 148 & 7.5 & 8.5 & - & 11.1 & - & - & - & - \\
\hline
\end{tabular}


Table 3. Water-quality data from surface-water sites-Continued

01472138 - French Creek near Coventryville, Pa. (Site 13)—Continued

\begin{tabular}{|c|c|c|c|c|c|c|c|c|c|c|c|}
\hline DATE & $\begin{array}{c}\text { SODIUM, } \\
\text { DIS- } \\
\text { SOLVED } \\
(\text { MG/L } \\
\text { AS NA) } \\
(00930)\end{array}$ & $\begin{array}{c}\text { SODIUM } \\
\text { PERCENT } \\
(00932)\end{array}$ & $\begin{array}{c}\text { SODIUM } \\
\text { AD- } \\
\text { SORP- } \\
\text { TION } \\
\text { RATIO } \\
(00931)\end{array}$ & $\begin{array}{c}\text { POTAS- } \\
\text { SIUM, } \\
\text { DIS- } \\
\text { SOLVED } \\
\text { (MG/L } \\
\text { AS K) } \\
(00935)\end{array}$ & $\begin{array}{c}\text { ALKA- } \\
\text { LINITY } \\
\text { WAT WH } \\
\text { TOT FET } \\
\text { FIELD } \\
(\mathrm{MG} / \mathrm{L} \text { AS } \\
\left.\mathrm{CACO}_{3}\right) \\
(00410)\end{array}$ & 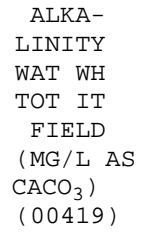 & $\begin{array}{c}\text { SULFATE, } \\
\text { DIS- } \\
\text { SOLVED } \\
(\mathrm{MG} / \mathrm{L} \\
\left.\mathrm{AS} \mathrm{SO}_{4}\right) \\
(00945)\end{array}$ & $\begin{array}{c}\text { CHLO- } \\
\text { RIDE, } \\
\text { DIS- } \\
\text { SOLVED } \\
\text { (MG/L } \\
\text { AS CL) } \\
(00940)\end{array}$ & $\begin{array}{c}\text { FLUO- } \\
\text { RIDE, } \\
\text { DIS- } \\
\text { SOLVED } \\
(\text { MG /L } \\
\text { AS F) } \\
(00950)\end{array}$ & $\begin{array}{l}\text { SILICA, } \\
\text { DIS- } \\
\text { SOLVED } \\
\text { (MG/L } \\
\text { AS } \\
\left.\mathrm{SIO}_{2}\right) \\
(00955)\end{array}$ & $\begin{array}{c}\text { SOLIDS, } \\
\text { RESIDUE } \\
\text { AT } 180 \\
\text { DEG. C } \\
\text { DIS- } \\
\text { SOLVED } \\
(\mathrm{MG} / \mathrm{L}) \\
(70300)\end{array}$ \\
\hline OCT 1981 & & & & & & & & & & & \\
\hline $\begin{array}{c}21 \ldots \\
\text { NOV } 1982\end{array}$ & 6.0 & 18 & 0.3 & 1.9 & - & - & 11 & 9.4 & $<0.10$ & 15 & 86 \\
\hline $\begin{array}{c}04 \ldots \\
\text { OCT } 1983\end{array}$ & 5.5 & 17 & .3 & 1.4 & 48 & - & 12 & 8.1 & $<.10$ & 15 & 94 \\
\hline $\begin{array}{c}18 \ldots \\
\text { ОСТ } 1984\end{array}$ & 6.1 & 21 & .4 & 1.6 & 38 & - & 14 & 8.2 & - & 16 & 100 \\
\hline $\begin{array}{c}10 \ldots \\
\text { OCT } 1985\end{array}$ & 5.0 & 18 & .3 & 1.2 & 42 & - & 9.4 & 6.9 & - & 16 & 81 \\
\hline $\begin{array}{c}10 \ldots \\
\text { OCT } 1986\end{array}$ & 5.1 & 18 & .3 & 1.4 & 40 & - & 16 & 7.4 & - & 15 & 83 \\
\hline $\begin{array}{c}22 \ldots \\
\text { OCT } 1987\end{array}$ & 5.7 & 18 & .3 & 1.5 & 50 & - & 11 & 8.3 & - & 16 & 104 \\
\hline $\begin{array}{c}16 \ldots \\
\text { ОСт } 1988\end{array}$ & 5.3 & 19 & .3 & 1.4 & 44 & - & 15 & 6.6 & - & 15 & 81 \\
\hline $\begin{array}{c}20 \ldots \\
\text { OCT } 1989\end{array}$ & 5.6 & 18 & .3 & 1.4 & 46 & - & 13 & 8.2 & - & 16 & - \\
\hline $\begin{array}{c}23 \ldots \\
\mathrm{NOV} 1990\end{array}$ & 5.2 & 20 & .3 & 1.5 & 32 & - & 13 & 6.2 & - & 15 & - \\
\hline $\begin{array}{c}16 \ldots \\
\text { ОСт } 1991\end{array}$ & 5.9 & 20 & .4 & 1.3 & 46 & - & 13 & 7.3 & .30 & 18 & - \\
\hline $\begin{array}{c}09 \ldots \\
\text { ОСт } 1992\end{array}$ & 5.5 & 18 & .3 & 1.4 & 37 & - & 11 & 8.1 & .10 & 16 & - \\
\hline $\begin{array}{c}15 \ldots \\
\text { OCT } 1993\end{array}$ & 6.0 & 19 & .4 & 1.6 & - & 54 & 15 & 8.7 & $<.10$ & 17 & - \\
\hline $\begin{array}{c}14 \ldots \\
\text { OCT } 1994\end{array}$ & - & - & - & - & - & 26 & - & - & - & - & - \\
\hline $27 \ldots$ & - & - & - & - & - & 40 & - & 8.7 & - & - & - \\
\hline
\end{tabular}


01472138 - French Creek near Coventryville, Pa. (Site 13)—Continued

\begin{tabular}{|c|c|c|c|c|c|c|c|c|c|c|c|}
\hline DATE & $\begin{array}{l}\text { SOLIDS, } \\
\text { SUM OF } \\
\text { CONSTI- } \\
\text { TUENTS, } \\
\text { DIS- } \\
\text { SOLVED } \\
\text { (MG/L) } \\
(70301)\end{array}$ & $\begin{array}{c}\text { SOLIDS, } \\
\text { DIS- } \\
\text { SOLVED } \\
\text { (TONS } \\
\text { PER } \\
\text { AC-FT) } \\
(70303)\end{array}$ & $\begin{array}{c}\text { SOLIDS, } \\
\text { DIS- } \\
\text { SOLVED } \\
\text { (TONS } \\
\text { PER } \\
\text { DAY) } \\
(70302)\end{array}$ & $\begin{array}{l}\text { NITRO- } \\
\text { GEN, } \\
\text { NITRATE } \\
\text { TOTAL } \\
\text { (MG/L } \\
\text { AS N) } \\
(00620)\end{array}$ & $\begin{array}{l}\text { NITRO- } \\
\text { GEN, } \\
\text { NITRATE } \\
\text { DIS- } \\
\text { SOLVED } \\
\text { (MG/L } \\
\text { AS N) } \\
(00618)\end{array}$ & $\begin{array}{c}\text { NITRO- } \\
\text { GEN, } \\
\text { NITRATE } \\
\text { DIS- } \\
\text { SOLVED } \\
(\mathrm{MG} / \mathrm{L} \\
\left.\text { AS NO }{ }_{3}\right) \\
(71851)\end{array}$ & $\begin{array}{c}\text { NITRO- } \\
\text { GEN, } \\
\text { NITRITE } \\
\text { DIS- } \\
\text { SOLVED } \\
\text { (MG/L } \\
\text { AS N) } \\
(00613)\end{array}$ & $\begin{array}{c}\text { NITRO- } \\
\text { GEN, } \\
\mathrm{NO}_{2}+\mathrm{NO}_{3} \\
\text { DIS- } \\
\text { SOLVED } \\
(\mathrm{MG} / \mathrm{L} \\
\mathrm{AS} \mathrm{N}) \\
(00631)\end{array}$ & $\begin{array}{c}\text { NITRO- } \\
\text { GEN, } \\
\text { AMMONIA } \\
\text { DIS- } \\
\text { SOLVED } \\
\text { (MG/L } \\
\text { AS N) } \\
(00608)\end{array}$ & $\begin{array}{c}\text { NITRO- } \\
\text { GEN, } \\
\text { AMMONIA } \\
\text { DIS- } \\
\text { SOLVED } \\
(\mathrm{MG} / \mathrm{L} \\
\left.\text { AS } \mathrm{NH}_{4}\right) \\
(71846)\end{array}$ & $\begin{array}{l}\text { NITRO- } \\
\text { GEN, } \\
\text { ORGANIC } \\
\text { TOTAL } \\
(\text { MG/L } \\
\text { AS N) } \\
(00605)\end{array}$ \\
\hline OCT 1981 & & & & & & & & & & & \\
\hline $\begin{array}{c}21 \ldots \\
\text { NOV } 1982\end{array}$ & - & 0.12 & - & 0.270 & - & - & $<0.010$ & 0.290 & 0.040 & 0.05 & 0.30 \\
\hline $\begin{array}{c}04 \ldots \\
\text { OCT } 1983\end{array}$ & 92 & .13 & 1.86 & .330 & - & - & $<.010$ & .330 & .010 & .01 & - \\
\hline $\begin{array}{c}18 \ldots \\
\text { OCT } 1984\end{array}$ & 89 & .14 & 2.57 & .810 & 0.810 & 3.6 & .050 & .860 & .120 & .15 & - \\
\hline $\begin{array}{c}10 \ldots \\
\text { OCT } 1985\end{array}$ & 83 & .11 & 2.19 & .770 & - & - & $<.010$ & .770 & .020 & .03 & - \\
\hline $\begin{array}{c}10 \ldots \\
\text { OCT } 1986\end{array}$ & 89 & .11 & 2.47 & .780 & - & - & $<.010$ & .780 & .020 & .03 & .48 \\
\hline $\begin{array}{c}22 \ldots \\
\text { OCT } 1987\end{array}$ & 95 & .14 & 1.40 & .720 & - & - & $<.010$ & .720 & $<.010$ & - & .40 \\
\hline $\begin{array}{c}16 \ldots \\
\text { OCT } 1988\end{array}$ & 90 & .11 & 2.19 & .800 & - & - & $<.010$ & .800 & .020 & .03 & .48 \\
\hline $\begin{array}{c}20 \ldots \\
\text { OCT } 1989\end{array}$ & 94 & .13 & 1.85 & .640 & - & - & $<.010$ & .640 & .010 & .01 & .29 \\
\hline $\begin{array}{c}23 \ldots \\
\text { NOV } 1990\end{array}$ & 79 & .11 & 6.86 & .900 & - & - & $<.010$ & .900 & $<.010$ & - & - \\
\hline $\begin{array}{c}16 \ldots \\
\text { OCT } 1991\end{array}$ & 95 & .13 & 4.06 & 1.10 & - & - & $<.010$ & 1.10 & .050 & .06 & - \\
\hline $\begin{array}{c}09 \ldots \\
\text { OCT } 1992\end{array}$ & 86 & .12 & 1.58 & .630 & - & - & $<.010$ & .630 & $<.010$ & - & - \\
\hline $\begin{array}{c}15 \ldots \\
\text { OCT } 1993\end{array}$ & 103 & .14 & 2.72 & .710 & - & - & $<.010$ & .710 & .020 & .03 & - \\
\hline $\begin{array}{c}14 \ldots \\
\text { OCT } 1994\end{array}$ & - & - & - & .460 & - & - & $<.010$ & .460 & .020 & .03 & - \\
\hline $27 \ldots$ & - & - & - & .420 & - & - & $<.010$ & .420 & .020 & .03 & - \\
\hline
\end{tabular}


Table 3. Water-quality data from surface-water sites-Continued

01472138 - French Creek near Coventryville, Pa. (Site 13)—Continued

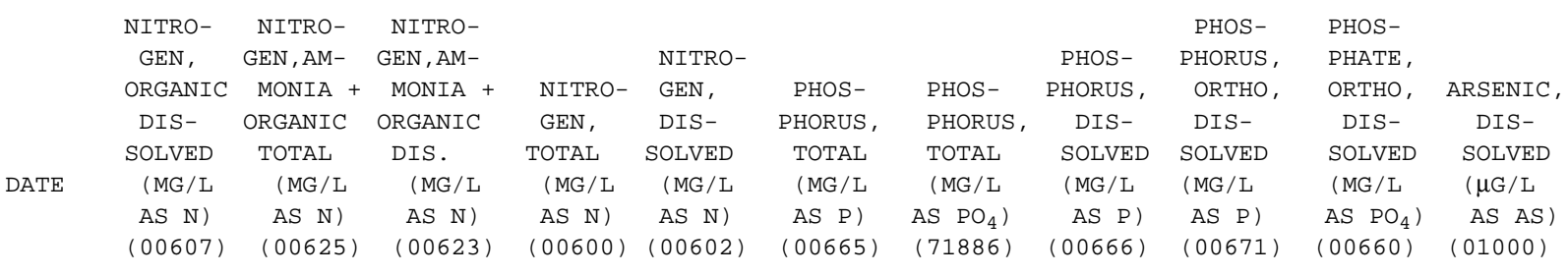

\begin{tabular}{|c|c|c|c|c|c|c|c|c|c|c|c|}
\hline $\begin{array}{c}\text { OCT } 1981 \\
21 \ldots \\
\text { NOV } 1982\end{array}$ & 0.28 & 0.31 & 0.32 & 0.59 & 0.61 & 0.020 & 0.06 & $<0.010$ & $<0.010$ & - & 1 \\
\hline $\begin{array}{c}04 \ldots \\
\text { OCT } 1983\end{array}$ & .29 & - & .30 & - & .63 & - & - & .010 & $<.010$ & - & $<1$ \\
\hline $\begin{array}{c}18 \ldots \\
\text { OCT } 1984\end{array}$ & .48 & - & .60 & - & 1.5 & .020 & .06 & .020 & .010 & .03 & - \\
\hline $\begin{array}{c}10 \ldots \\
\text { OCT } 1985\end{array}$ & .28 & - & .30 & - & 1.1 & .040 & - & .020 & .020 & .06 & - \\
\hline $\begin{array}{c}10 \ldots \\
\text { ОСТ } 1986\end{array}$ & .28 & .50 & .30 & 1.3 & 1.1 & .020 & .06 & .030 & $<.010$ & - & - \\
\hline $\begin{array}{c}22 \ldots \\
\text { ОСТ } 1987\end{array}$ & - & .40 & .50 & 1.1 & 1.2 & .030 & - & $<.010$ & .010 & .03 & - \\
\hline $\begin{array}{c}16 \ldots \\
\text { OCT } 1988\end{array}$ & .18 & .50 & .20 & 1.3 & 1.0 & .010 & - & $<.010$ & $<.010$ & - & - \\
\hline $\begin{array}{c}20 \ldots \\
\text { OCT } 1989\end{array}$ & .19 & .30 & .20 & .94 & .84 & .010 & - & .010 & $<.010$ & - & - \\
\hline $\begin{array}{c}23 \ldots \\
\text { NOV } 1990\end{array}$ & - & $<.20$ & .30 & - & 1.2 & .030 & - & .010 & .040 & .12 & - \\
\hline $\begin{array}{c}16 \ldots \\
\text { OCT } 1991\end{array}$ & .25 & $<.20$ & .30 & - & 1.4 & $<.010$ & - & $<.010$ & $<.010$ & - & - \\
\hline $\begin{array}{c}09 \ldots \\
\text { OCT } 1992\end{array}$ & - & $<.20$ & - & - & - & .030 & - & $<.010$ & .010 & .03 & - \\
\hline $\begin{array}{c}15 \ldots \\
\text { OCT } 1993\end{array}$ & - & $<.20$ & $<.20$ & - & - & .030 & - & .020 & .020 & .06 & - \\
\hline $\begin{array}{c}14 \ldots \\
\text { OCT } 1994\end{array}$ & - & - & - & - & - & - & - & - & $<.010$ & - & - \\
\hline $27 \ldots$ & - & - & - & - & - & - & - & - & .010 & .03 & - \\
\hline
\end{tabular}


Table 3. Water-quality data from surface-water sites-Continued

01472138 - French Creek near Coventryville, Pa. (Site 13)—Continued

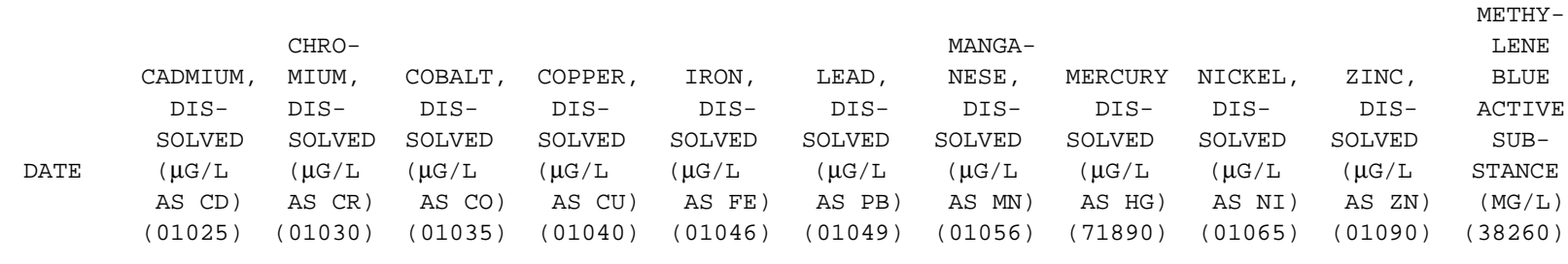

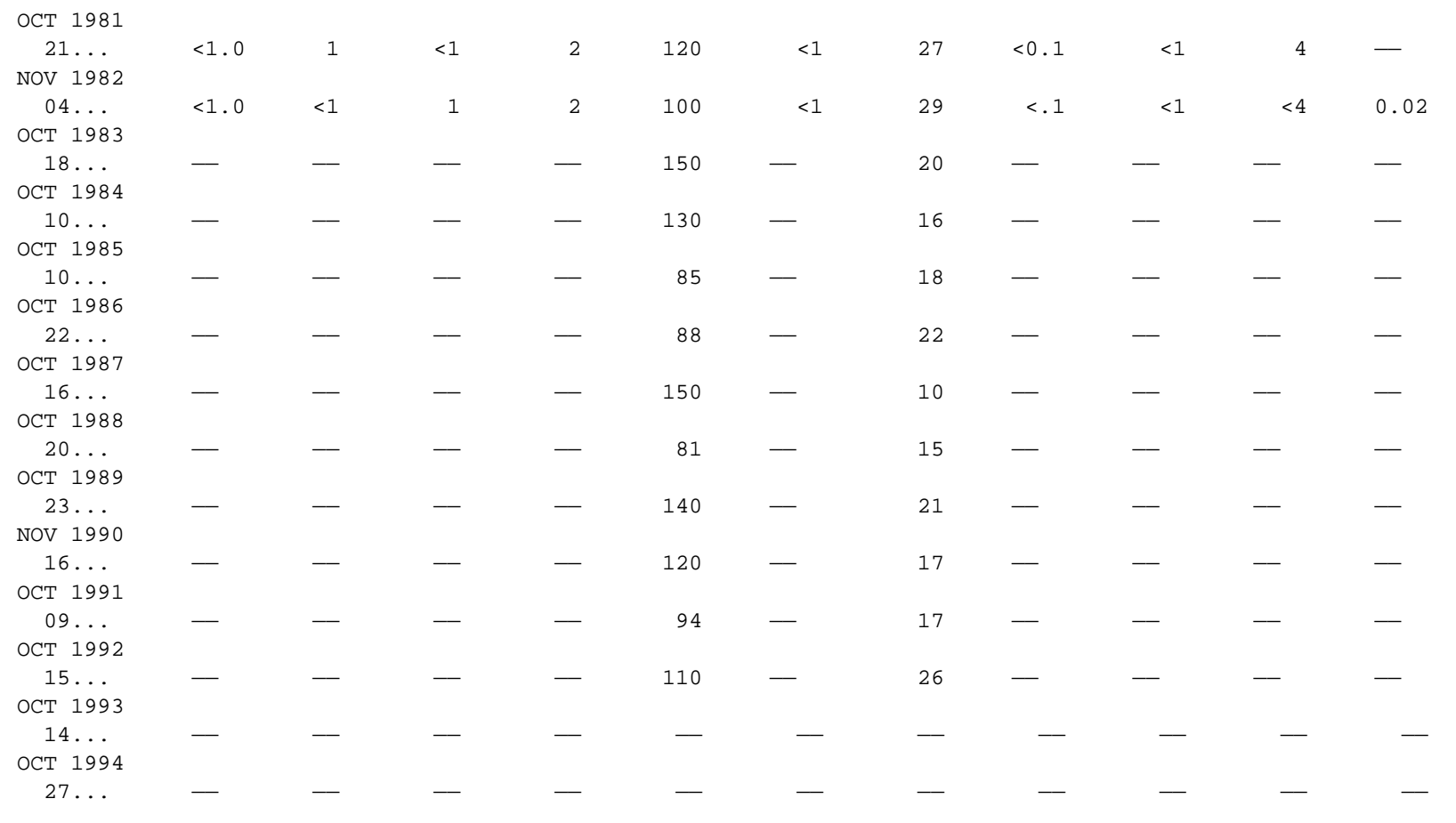


Table 3. Water-quality data from surface-water sites-Continued

01472140 - South Branch French Creek at Coventryville, Pa. (Site 12)

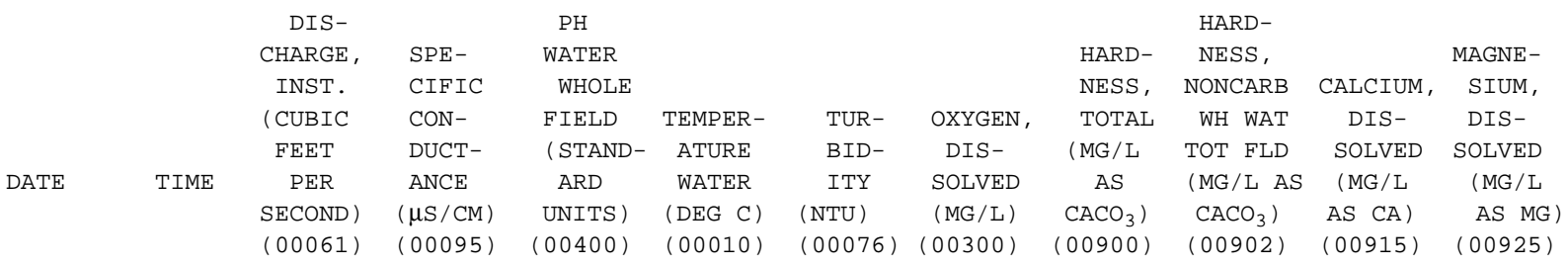

\begin{tabular}{|c|c|c|c|c|c|c|c|c|c|c|c|}
\hline $\begin{array}{c}\text { OCT } 1981 \\
21 \ldots \\
\text { NOV } 1982\end{array}$ & 1500 & - & 182 & 8.5 & 10.5 & - & 13.8 & 63 & - & 17 & 5.1 \\
\hline $\begin{array}{c}04 \ldots \\
\text { OCT } 1983\end{array}$ & 1315 & 6.9 & 161 & 8.0 & 17.0 & - & 10.6 & 64 & - & 17 & 5.3 \\
\hline $\begin{array}{c}18 \ldots \\
\text { OCT } 1984\end{array}$ & 1500 & 4.7 & 181 & 8.1 & 14.5 & $<1.0$ & 10.4 & 70 & - & 19 & 5.4 \\
\hline $\begin{array}{c}10 \ldots \\
\text { OCT } 1985\end{array}$ & 1600 & 7.8 & 185 & 8.1 & 15.0 & .40 & 10.6 & 68 & - & 18 & 5.5 \\
\hline $\begin{array}{c}10 \ldots \\
\text { OCT } 1986\end{array}$ & 1130 & 7.7 & 195 & 7.4 & 9.5 & .90 & 12.6 & 70 & - & 18 & 6.0 \\
\hline $\begin{array}{c}22 \ldots \\
\text { OCT } 1987\end{array}$ & 1230 & 4.4 & 180 & 8.0 & 12.0 & .30 & 12.8 & 68 & - & 18 & 5.5 \\
\hline $\begin{array}{c}16 \ldots \\
\text { OCT } 1988\end{array}$ & 1400 & 7.6 & 190 & 7.7 & 13.5 & .60 & 12.8 & 70 & - & 18 & 6.0 \\
\hline $\begin{array}{c}20 \ldots \\
\text { OCT } 1989\end{array}$ & 1330 & 5.5 & 198 & 7.1 & 10.0 & .60 & 12.1 & 73 & - & 19 & 6.1 \\
\hline $\begin{array}{c}23 \ldots \\
\text { NOV } 1990\end{array}$ & 1430 & 19 & 188 & 7.2 & 12.5 & 1.5 & 9.3 & 66 & 10 & 17 & 5.6 \\
\hline $\begin{array}{c}16 \ldots \\
\text { OCT } 1991\end{array}$ & 1150 & 9.6 & 196 & 6.9 & 7.5 & 1.5 & 12.8 & 70 & 17 & 18 & 6.0 \\
\hline $\begin{array}{c}09 \ldots \\
\text { OCT } 1992\end{array}$ & 1130 & 4.5 & 203 & 7.2 & 10.5 & .50 & 12.4 & 71 & 32 & 19 & 5.8 \\
\hline $\begin{array}{c}15 \ldots \\
\text { OCT } 1993\end{array}$ & 1215 & 5.6 & 208 & 7.2 & 13.0 & .90 & 12.4 & 71 & - & 19 & 5.8 \\
\hline $\begin{array}{c}14 \ldots \\
\text { OCT } 1994\end{array}$ & 1240 & 8.3 & 196 & 7.3 & 8.0 & - & 11.7 & - & - & - & - \\
\hline $27 \ldots$ & 1420 & 6.0 & 202 & 8.1 & 9.0 & - & 12.9 & - & - & - & - \\
\hline
\end{tabular}


Table 3. Water-quality data from surface-water sites-Continued

01472140 - South Branch French Creek at Coventryville, Pa. (Site 12)—Continued

\begin{tabular}{|c|c|c|c|c|c|c|c|c|c|c|c|}
\hline DATE & $\begin{array}{l}\text { SODIUM, } \\
\text { DIS- } \\
\text { SOLVED } \\
\text { (MG/L } \\
\text { AS NA) } \\
(00930)\end{array}$ & $\begin{array}{c}\text { SODIUM } \\
\text { PERCENT } \\
(00932)\end{array}$ & $\begin{array}{c}\text { SODIUM } \\
\text { AD- } \\
\text { SORP- } \\
\text { TION } \\
\text { RATIO } \\
(00931)\end{array}$ & $\begin{array}{l}\text { POTAS- } \\
\text { SIUM, } \\
\text { DIS- } \\
\text { SOLVED } \\
(\text { MG/L } \\
\text { AS K) } \\
(00935)\end{array}$ & $\begin{array}{l}\text { ALKA- } \\
\text { LINITY } \\
\text { WAT WH } \\
\text { TOT FET } \\
\text { FIELD } \\
(\mathrm{MG} / \mathrm{L} \text { AS } \\
\left.\mathrm{CACO}_{3}\right) \\
(00410)\end{array}$ & $\begin{array}{l}\text { ALKA- } \\
\text { LINITY } \\
\text { WAT WH } \\
\text { TOT IT } \\
\text { FIELD } \\
(\mathrm{MG} / \mathrm{L} \text { AS } \\
\left.\mathrm{CACO}_{3}\right) \\
(00419)\end{array}$ & $\begin{array}{l}\text { SULFATE, } \\
\text { DIS- } \\
\text { SOLVED } \\
(\mathrm{MG} / \mathrm{L} \\
\left.\mathrm{AS} \mathrm{SO}_{4}\right) \\
(00945)\end{array}$ & $\begin{array}{l}\text { CHLO- } \\
\text { RIDE, } \\
\text { DIS- } \\
\text { SOLVED } \\
(M G / L \\
\text { AS CL) } \\
(00940)\end{array}$ & $\begin{array}{c}\text { FLUO- } \\
\text { RIDE, } \\
\text { DIS- } \\
\text { SOLVED } \\
(M G / L \\
\text { AS F) } \\
(00950)\end{array}$ & $\begin{array}{l}\text { SILICA, } \\
\text { DIS- } \\
\text { SOLVED } \\
(\mathrm{MG} / \mathrm{L} \\
\mathrm{AS} \\
\left.\mathrm{SIO}_{2}\right) \\
(00955)\end{array}$ & $\begin{array}{l}\text { SOLIDS } \\
\text { RESIDUE } \\
\text { AT } 180 \\
\text { DEG. C } \\
\text { DIS- } \\
\text { SOLVED } \\
(\mathrm{MG} / \mathrm{L}) \\
(70300)\end{array}$ \\
\hline OCT 1981 & & & & & & & & & & & \\
\hline $\begin{array}{c}21 \ldots \\
\text { NOV } 1982\end{array}$ & 8.3 & 21 & 0.5 & 2.8 & - & - & 15 & 12 & $<0.10$ & 19 & 105 \\
\hline $\begin{array}{c}04 \ldots \\
\text { OCT } 1983\end{array}$ & 7.4 & 19 & .4 & 2.2 & 43 & - & 15 & 12 & $<.10$ & 18 & 116 \\
\hline $\begin{array}{c}18 \ldots \\
\text { OCT } 1984\end{array}$ & 7.0 & 17 & .4 & 2.2 & 50 & - & 17 & 12 & - & 20 & 137 \\
\hline $\begin{array}{c}10 \ldots \\
\text { OCT } 1985\end{array}$ & 7.6 & 19 & .4 & 1.9 & 48 & - & 16 & 12 & - & 19 & 121 \\
\hline $\begin{array}{c}10 \ldots \\
\text { OCT } 1986\end{array}$ & 7.9 & 19 & .4 & 2.3 & 50 & - & 20 & 14 & - & 19 & 126 \\
\hline $\begin{array}{c}22 \ldots \\
\text { OCT } 1987\end{array}$ & 7.4 & 19 & .4 & 2.1 & 51 & - & 16 & 12 & - & 18 & 128 \\
\hline $\begin{array}{c}16 \ldots \\
\text { OCT } 1988\end{array}$ & 8.2 & 20 & .4 & 2.2 & 46 & - & 15 & 13 & - & 17 & 121 \\
\hline $\begin{array}{c}20 \ldots \\
\text { OCT } 1989\end{array}$ & 7.4 & 18 & .4 & 2.0 & 44 & - & 17 & 13 & - & 18 & - \\
\hline $\begin{array}{c}23 \ldots \\
\text { NOV } 1990\end{array}$ & 7.3 & 19 & .4 & 2.4 & 56 & - & 16 & 11 & - & 19 & - \\
\hline $\begin{array}{c}16 \ldots \\
\text { OCT } 1991\end{array}$ & 7.6 & 19 & .4 & 2.1 & 53 & - & 21 & 17 & .10 & 20 & - \\
\hline $\begin{array}{c}09 \ldots \\
\text { OCT } 1992\end{array}$ & 7.4 & 18 & .4 & 2.2 & 39 & - & 14 & 15 & .20 & 19 & - \\
\hline $\begin{array}{c}15 \ldots \\
\text { OCT } 1993\end{array}$ & 7.2 & - & .4 & $<.10$ & - & 60 & 18 & 13 & .10 & 18 & - \\
\hline $\begin{array}{c}14 \ldots \\
\text { OCT } 1994\end{array}$ & - & - & - & - & - & 42 & - & - & - & - & - \\
\hline $27 \ldots$ & - & - & - & - & - & 38 & - & 17 & - & - & - \\
\hline
\end{tabular}


Table 3. Water-quality data from surface-water sites-Continued

01472140 - South Branch French Creek at Coventryville, Pa. (Site 12)-Continued

\begin{tabular}{|c|c|c|c|c|c|c|c|c|c|c|c|}
\hline & $\begin{array}{l}\text { SOLIDS, } \\
\text { SUM OF }\end{array}$ & SOLIDS, & SOLIDS, & NITRO- & $\begin{array}{l}\text { NITRO- } \\
\text { GEN, }\end{array}$ & $\begin{array}{l}\text { NITRO- } \\
\text { GEN, }\end{array}$ & $\begin{array}{l}\text { NITRO- } \\
\text { GEN, }\end{array}$ & $\begin{array}{c}\text { NITRO- } \\
\text { GEN, } \\
\mathrm{NO}_{2}+\mathrm{NO}_{3}\end{array}$ & $\begin{array}{c}\text { NITRO- } \\
\text { GEN, } \\
\text { AMMONIA }\end{array}$ & $\begin{array}{c}\text { NITRO- } \\
\text { GEN, } \\
\text { AMMONIA }\end{array}$ & $\begin{array}{l}\text { NITRO- } \\
\text { GEN }\end{array}$ \\
\hline & $\begin{array}{l}\text { CONSTI- } \\
\text { TUENTS, }\end{array}$ & $\begin{array}{c}\text { DIS- } \\
\text { SOLVED }\end{array}$ & $\begin{array}{c}\text { DIS- } \\
\text { SOLVED }\end{array}$ & $\begin{array}{c}\text { GEN, } \\
\text { NITRATE }\end{array}$ & $\begin{array}{c}\text { NITRATE } \\
\text { DIS- }\end{array}$ & $\begin{array}{c}\text { NITRATE } \\
\text { DIS- }\end{array}$ & $\begin{array}{l}\text { NITRITE } \\
\text { DIS- }\end{array}$ & $\begin{array}{c}\mathrm{NO}_{2}+\mathrm{NO}_{3} \\
\text { DIS- }\end{array}$ & $\begin{array}{c}\text { AMMONIA } \\
\text { DIS- }\end{array}$ & $\begin{array}{l}\text { AMMONIA } \\
\text { DIS- }\end{array}$ & $\begin{array}{c}\text { GEN, } \\
\text { ORGANIC }\end{array}$ \\
\hline & DIS- & (TONS & (TONS & TOTAL & SOLVED & SOLVED & SOLVED & SOLVED & SOLVED & SOLVED & TOTAL \\
\hline \multirow[t]{3}{*}{ DATE } & SOLVED & PER & PER & $(\mathrm{MG} / \mathrm{L}$ & (MG / L & $(\mathrm{MG} / \mathrm{L}$ & $(\mathrm{MG} / \mathrm{L}$ & (MG / L & (MG /L & (MG /L & $(\mathrm{MG} / \mathrm{L}$ \\
\hline & (MG / L ) & $\mathrm{AC}-\mathrm{FT}$ ) & DAY) & AS N) & AS N) & $\left.\mathrm{AS} \quad \mathrm{NO}_{3}\right)$ & AS N) & AS N) & AS N) & A.S $\quad \mathrm{NH}_{4}$ ) & AS N) \\
\hline & $(70301)$ & $(70303)$ & $(70302)$ & $(00620)$ & $(00618)$ & $(71851)$ & $(00613)$ & $(00631)$ & $(00608)$ & $(71846)$ & $(00605)$ \\
\hline
\end{tabular}

\begin{tabular}{|c|c|c|c|c|c|c|c|c|c|c|c|}
\hline $\begin{array}{c}\text { OCT } 1981 \\
21 \ldots \\
\text { NOV } 1982\end{array}$ & - & 0.14 & - & 2.00 & - & - & $<0.010$ & 2.00 & 0.020 & 0.03 & 0.23 \\
\hline $\begin{array}{r}04 \ldots \\
\text { OCT } 1983\end{array}$ & 112 & .16 & 2.17 & 1.99 & 1.99 & 8.8 & .010 & 2.00 & $<.010$ & .01 & - \\
\hline $\begin{array}{r}18 \ldots \\
\text { OCT } 1984\end{array}$ & 125 & .19 & 1.74 & 2.80 & - & - & $<.010$ & 2.80 & .020 & .03 & - \\
\hline $\begin{array}{c}10 \ldots \\
\text { OCT } 1985\end{array}$ & 124 & .16 & 2.55 & 3.40 & - & - & $<.010$ & 3.40 & .040 & .05 & - \\
\hline $\begin{array}{c}10 \ldots \\
\text { OCT } 1986\end{array}$ & 132 & .17 & 2.62 & 3.40 & - & - & $<.010$ & 3.40 & .010 & .01 & .49 \\
\hline $\begin{array}{c}22 \ldots \\
\text { OCT } 1987\end{array}$ & 122 & .17 & 1.52 & 2.80 & - & - & $<.010$ & 2.80 & .010 & .01 & 1.2 \\
\hline $\begin{array}{c}16 \ldots \\
\text { OCT } 1988\end{array}$ & 123 & .16 & 2.48 & 3.60 & - & - & $<.010$ & 3.60 & .020 & .03 & .38 \\
\hline $\begin{array}{c}20 \ldots \\
\text { OCT } 1989\end{array}$ & 123 & .17 & 1.83 & 3.20 & - & - & $<.010$ & 3.20 & .020 & .03 & .38 \\
\hline $\begin{array}{c}23 \ldots \\
\text { NOV } 1990\end{array}$ & 127 & .17 & 6.50 & 3.30 & - & - & $<.010$ & 3.30 & .010 & .01 & - \\
\hline $\begin{array}{c}16 \ldots \\
\text { OCT } 1991\end{array}$ & 141 & .19 & 3.64 & 3.80 & - & - & $<.010$ & 3.80 & .050 & .06 & .65 \\
\hline $\begin{array}{c}09 \ldots \\
\text { OCT } 1992\end{array}$ & 120 & .16 & 1.45 & 3.20 & - & - & $<.010$ & 3.20 & $<.010$ & - & - \\
\hline $\begin{array}{c}15 \ldots \\
\text { OCT } 1993\end{array}$ & - & - & - & 2.60 & - & - & $<.010$ & 2.60 & .010 & .01 & .19 \\
\hline $\begin{array}{c}14 \ldots \\
\text { OCT } 1994\end{array}$ & - & - & - & 2.30 & - & - & $<.010$ & 2.30 & .020 & .03 & - \\
\hline $27 \ldots$ & - & - & - & 2.50 & - & - & $<.010$ & 2.50 & $<.015$ & - & - \\
\hline
\end{tabular}


Table 3. Water-quality data from surface-water sites-Continued

01472140 - South Branch French Creek at Coventryville, Pa. (Site 12)—Continued

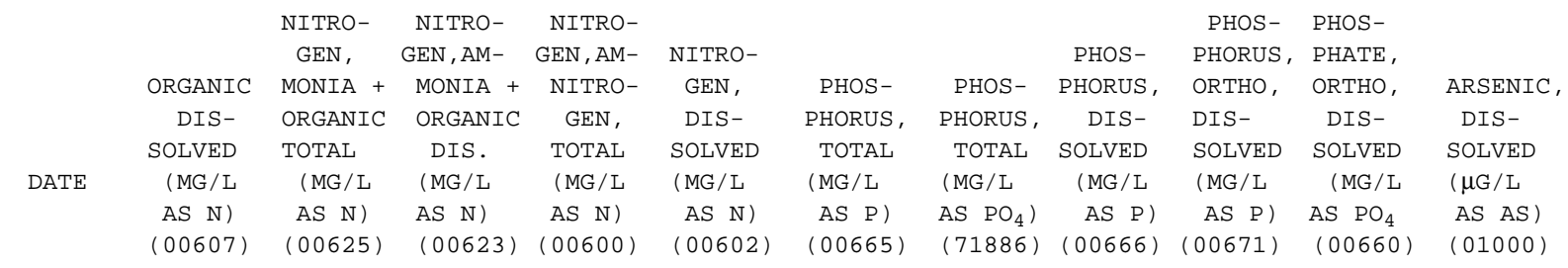

\begin{tabular}{|c|c|c|c|c|c|c|c|c|c|c|c|}
\hline $\begin{array}{c}\text { OCT } 1981 \\
21 \ldots \\
\text { NOV } 1982\end{array}$ & 0.21 & 0.24 & 0.23 & 2.2 & 2.2 & 0.040 & 0.12 & $<0.010$ & $<0.010$ & - & 2 \\
\hline $\begin{array}{c}04 \ldots \\
\text { OCT } 1983\end{array}$ & - & - & .10 & - & 2.1 & - & - & .020 & .010 & 0.03 & $<1$ \\
\hline $\begin{array}{c}18 \ldots \\
\text { OCT } 1984\end{array}$ & .28 & - & .30 & - & 3.1 & .040 & .12 & .040 & $<.010$ & - & - \\
\hline $\begin{array}{c}10 \ldots \\
\text { OCT } 1985\end{array}$ & .46 & - & .50 & - & 3.9 & .050 & - & .030 & .020 & .06 & 一 \\
\hline $\begin{array}{c}10 \ldots \\
\text { OCT } 1986\end{array}$ & .29 & .50 & .30 & 3.9 & 3.7 & .020 & .06 & .020 & .020 & .06 & 一 \\
\hline $\begin{array}{c}22 \ldots \\
\text { OCT } 1987\end{array}$ & 1.2 & 1.2 & 1.2 & 4.0 & 4.0 & $<.010$ & - & $<.010$ & .010 & .03 & - \\
\hline $\begin{array}{c}16 \ldots \\
\text { OCT } 1988\end{array}$ & .38 & .40 & .40 & 4.0 & 4.0 & $<.010$ & - & $<.010$ & $<.010$ & - & - \\
\hline $\begin{array}{c}20 \ldots \\
\text { OCT } 1989\end{array}$ & .38 & .40 & .40 & 3.6 & 3.6 & .010 & - & .010 & $<.010$ & - & - \\
\hline $\begin{array}{c}23 \ldots \\
\text { NOV } 1990\end{array}$ & .49 & $<.20$ & .50 & - & 3.8 & .040 & - & .030 & .020 & .06 & - \\
\hline $\begin{array}{c}16 \ldots \\
\text { OCT } 1991\end{array}$ & .35 & .70 & .40 & 4.5 & 4.2 & .030 & - & $<.010$ & .010 & .03 & - \\
\hline $\begin{array}{c}09 \ldots \\
\text { OCT } 1992\end{array}$ & - & $<.20$ & - & - & - & .030 & - & $<.010$ & $<.010$ & - & - \\
\hline $\begin{array}{c}15 \ldots \\
\text { OCT } 1993\end{array}$ & .19 & .20 & .20 & 2.8 & 2.8 & .040 & - & .020 & .020 & .06 & 一 \\
\hline $\begin{array}{c}14 \ldots \\
\text { OCT } 1994\end{array}$ & - & - & - & - & - & - & - & - & .020 & .06 & - \\
\hline $27 \ldots$ & - & - & - & - & - & - & - & - & .010 & .03 & - \\
\hline
\end{tabular}


Table 3. Water-quality data from surface-water sites-Continued

01472140 - South Branch French Creek at Coventryville, Pa. (Site 12)—Continued

METHY-
LENE

\begin{tabular}{|c|c|c|c|c|c|c|c|c|c|c|c|}
\hline $\begin{array}{c}\text { OCT } 1981 \\
21 \ldots \\
\text { NOV } 1982\end{array}$ & $<1.0$ & $<1$ & $<1$ & & 53 & $<1$ & 9 & $<0.1$ & $<1$ & $<4$ & - \\
\hline $\begin{array}{c}04 \ldots \\
\text { OCT } 1983\end{array}$ & $<1.0$ & $<1$ & $<1$ & & 66 & 1 & 10 & $<.1$ & $<1$ & $<4$ & 0.03 \\
\hline $18 \ldots$ & - & - & - & - & 72 & - & 10 & - & - & - & - \\
\hline $\begin{array}{c}\text { OCT } 1984 \\
10 \ldots\end{array}$ & - & - & - & - & 69 & - & 11 & - & - & - & - \\
\hline $\begin{array}{c}10 \ldots \\
\text { OCT } 1986\end{array}$ & - & - & - & - & 65 & - & 14 & - & - & - & - \\
\hline $\begin{array}{c}22 \ldots \\
\text { OCT } 1987\end{array}$ & - & - & - & - & 35 & - & 6 & - & - & - & - \\
\hline $\begin{array}{c}16 \ldots \\
\text { OCT } 1988\end{array}$ & - & - & - & - & 77 & - & 11 & - & - & - & - \\
\hline $\begin{array}{c}20 \ldots \\
\text { OCT } 1989\end{array}$ & - & - & - & - & 62 & - & 8 & - & - & - & - \\
\hline $\begin{array}{c}23 \ldots \\
\text { NOV } 1990\end{array}$ & - & - & - & - & 140 & - & 33 & - & - & - & - \\
\hline $\begin{array}{cc}16 \ldots \\
\text { OCT } 1991\end{array}$ & - & - & - & - & 100 & - & 20 & - & - & - & - \\
\hline $\begin{array}{c}09 \ldots \\
\text { OCT } 1992\end{array}$ & - & - & - & - & 69 & - & 11 & - & - & - & - \\
\hline $\begin{array}{c}15 \ldots \\
\text { OCT } 1993\end{array}$ & - & - & - & - & 130 & - & 15 & - & - & - & - \\
\hline $\begin{array}{c}14 \ldots \\
\text { OCT } 1994\end{array}$ & - & - & - & - & - & - & - & - & - & - & - \\
\hline $27 \ldots$ & - & - & - & - & - & - & - & - & - & - & - \\
\hline
\end{tabular}


Table 3. Water-quality data from surface-water sites-Continued

01472154 - French Creek near Pughtown, Pa. (Site 14)

\begin{tabular}{|c|c|c|c|c|c|c|c|c|c|c|c|}
\hline & & DIS- & & $\mathrm{PH}$ & & & & & HARD- & & \\
\hline & & CHARGE, & $\mathrm{SPE}-$ & WATER & & & & HARD- & NESS, & & MAGNE- \\
\hline & & INST. & CIFIC & WHOLE & & & & NESS, & NONCARB & CALCIUM, & SIUM, \\
\hline & & (CUBIC & $\mathrm{CON}-$ & FIELD & TEMPER- & TUR- & OXYGEN, & TOTAL & WH WAT & DIS- & DIS- \\
\hline & & FEET & DUCT- & (STAND- & ATURE & BID- & DIS- & (MG / L & TOT FLD & SOLVED & SOLVED \\
\hline DATE & TIME & PER & ANCE & ARD & WATER & ITY & SOLVED & AS & (MG/L AS & (MG /L & (MG / L \\
\hline & & SECOND) & $(\mu \mathrm{S} / \mathrm{CM})$ & UNITS) & (DEG C) & (NTU) & $(\mathrm{MG} / \mathrm{L})$ & $\left.\mathrm{CACO}_{3}\right)$ & $\left.\mathrm{CACO}_{3}\right)$ & AS CA) & AS MG) \\
\hline & & $(00061)$ & $(00095)$ & $(00400)$ & $(00010)$ & $(00076)$ & $(00300)$ & $(00900)$ & $(00902)$ & $(00915)$ & $(00925)$ \\
\hline
\end{tabular}

\begin{tabular}{|c|c|c|c|c|c|c|c|c|c|c|c|}
\hline $\begin{array}{c}21 \ldots \\
\text { NOV } 1982\end{array}$ & 1130 & - & 164 & 7.1 & 6.5 & - & 11.1 & 57 & - & 15 & 4.8 \\
\hline $\begin{array}{c}02 \ldots \\
\text { OCT } 1983\end{array}$ & 1400 & 19 & 140 & 7.8 & 14.5 & - & 9.6 & 57 & - & 15 & 4.7 \\
\hline $\begin{array}{c}20 \ldots \\
\text { OCT } 1984\end{array}$ & 1015 & 30 & 147 & 7.1 & 11.0 & 1.9 & 9.6 & 56 & - & 15 & 4.6 \\
\hline $\begin{array}{c}10 \ldots \\
\text { OCT } 1985\end{array}$ & 1200 & 23 & 150 & 7.7 & 13.0 & .60 & 11.0 & 56 & - & 15 & 4.6 \\
\hline $\begin{array}{c}11 \ldots \\
\text { OCT } 1986\end{array}$ & 0900 & 24 & 155 & 7.3 & 11.0 & .90 & 10.2 & 55 & - & 14 & 4.8 \\
\hline $\begin{array}{c}31 \ldots \\
\text { OCT } 1987\end{array}$ & 0900 & 17 & 160 & 7.5 & 9.0 & .70 & 9.4 & 62 & - & 16 & 5.3 \\
\hline $\begin{array}{c}14 \ldots \\
\text { OCT } 1988\end{array}$ & 1000 & 28 & 147 & 7.4 & 9.0 & .40 & 12.2 & 57 & - & 15 & 4.8 \\
\hline $\begin{array}{c}21 \ldots \\
\text { OCT } 1989\end{array}$ & 0930 & 16 & 163 & 7.5 & 8.5 & .90 & 11.2 & 62 & - & 16 & 5.3 \\
\hline $\begin{array}{c}24 \ldots \\
\text { NOV } 1990\end{array}$ & 0930 & 60 & 149 & 7.2 & 9.0 & 1.1 & 12.1 & 51 & 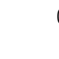 & 13 & 4.6 \\
\hline $\begin{array}{c}15 \ldots \\
\text { OCT } 1991\end{array}$ & 0830 & 35 & 165 & 7.0 & 4.0 & 1.1 & 12.9 & 55 & 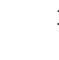 & 14 & 4.9 \\
\hline $\begin{array}{c}15 \ldots \\
\text { OCT } 1992\end{array}$ & 0900 & 15 & 168 & 7.0 & 10.0 & 1.0 & 10.4 & 60 & 2 & 16 & 4.9 \\
\hline $\begin{array}{c}14 \ldots \\
\text { OCT } 1993\end{array}$ & 1045 & 20 & 159 & 7.2 & 11.0 & 3.3 & 11.0 & 61 & - & 16 & 5.0 \\
\hline $\begin{array}{c}15 \ldots \\
\text { OCT } 1994\end{array}$ & 1100 & 24 & 160 & 7.1 & 9.5 & - & 10.8 & - & - & - & - \\
\hline $27 \ldots$ & 0905 & 20 & 168 & 7.4 & 8.5 & - & 10.9 & - & - & - & - \\
\hline
\end{tabular}


Table 3. Water-quality data from surface-water sites-Continued

01472154 - French Creek near Pughtown, Pa. (Site 14)-Continued

\begin{tabular}{|c|c|c|c|c|c|c|c|c|c|c|}
\hline & & & & $\begin{array}{l}\text { ALKA- } \\
\text { LINITY }\end{array}$ & $\begin{array}{r}\text { ALKA- } \\
\text { LINITY }\end{array}$ & & HL & - & $S$ & $\begin{array}{l}\text { SOLIDS, } \\
\text { RESIDUE }\end{array}$ \\
\hline & & SODIUM & SIUM, & WAT WH & WAT WH & SULFATE, & RIDE， & RIDE, & DIS- & AT 180 \\
\hline $\begin{array}{c} \\
\text { SODIUM, } \\
\text { DIS- }\end{array}$ & & $A D-$ & DIS- & TOT FET & TOT IT & DIS- & DIS- & DIS- & SOLVED & DEG. C \\
\hline SOLVED & & SORP- & SOLVED & FIELD & FIELD & SOLVED & SOLVED & SOLVED & (MG / L & DIS- \\
\hline (MG/L & SODIUM & TION & (MG/L & (MG/L AS & (MG/L AS & (MG/L & $(\mathrm{MG} / \mathrm{L}$ & (MG/L & AS & SOLVED \\
\hline AS NA) & PERCENT & RATIO & AS K) & $\left.\mathrm{CACO}_{3}\right)$ & $\left.\mathrm{CACO}_{3}\right)$ & $\left.\mathrm{AS} \quad \mathrm{SO}_{4}\right)$ & AS CL) & AS F) & $\left.\mathrm{SIO}_{2}\right)$ & (MG/L) \\
\hline$(00930)$ & $(00932)$ & (00931) & $(00935)$ & $(00410)$ & $(00419)$ & $(00945)$ & $(00940)$ & $(00950)$ & $(00955)$ & $(70300)$ \\
\hline
\end{tabular}

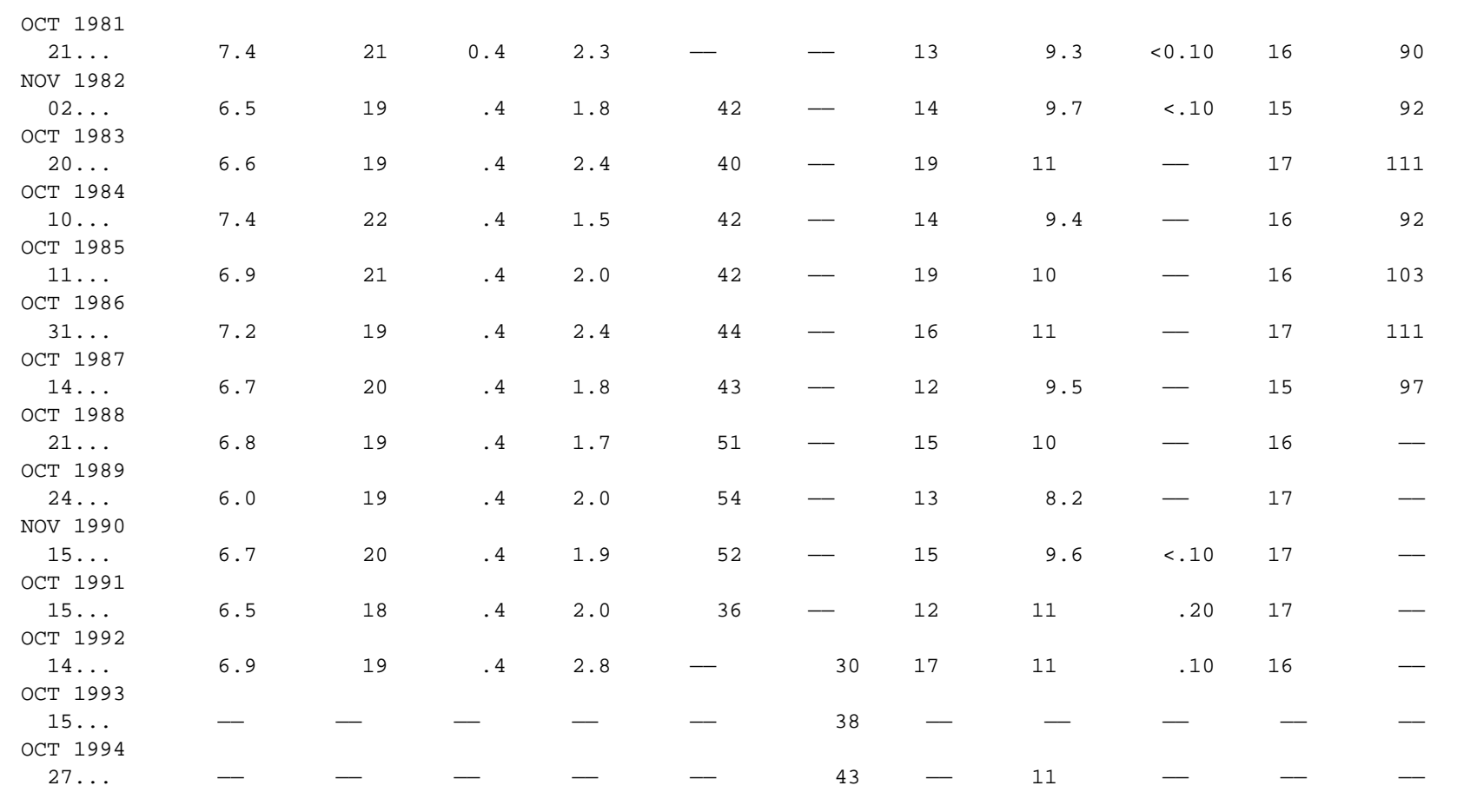


Table 3. Water-quality data from surface-water sites-Continued

01472154 - French Creek near Pughtown, Pa. (Site 14)—Continued

\begin{tabular}{|c|c|c|c|c|c|c|c|c|c|c|c|}
\hline DATE & $\begin{array}{l}\text { SOLIDS, } \\
\text { SUM OF } \\
\text { CONSTI- } \\
\text { TUENTS, } \\
\text { DIS- } \\
\text { SOLVED } \\
(\text { MG/L) } \\
(70301)\end{array}$ & $\begin{array}{c}\text { SOLIDS, } \\
\text { DIS- } \\
\text { SOLVED } \\
\text { (TONS } \\
\text { PER } \\
\text { AC-FT) } \\
(70303)\end{array}$ & $\begin{array}{c}\text { SOLIDS, } \\
\text { DIS- } \\
\text { SOLVED } \\
\text { (TONS } \\
\text { PER } \\
\text { DAY) } \\
(70302)\end{array}$ & $\begin{array}{l}\text { NITRO- } \\
\text { GEN, } \\
\text { NITRATE } \\
\text { TOTAL } \\
\text { (MG/L } \\
\text { AS N) } \\
(00620)\end{array}$ & $\begin{array}{l}\text { NITRO- } \\
\text { GEN, } \\
\text { NITRATE } \\
\text { DIS- } \\
\text { SOLVED } \\
\text { (MG/L } \\
\text { AS N) } \\
(00618)\end{array}$ & $\begin{array}{c}\text { NITRO- } \\
\text { GEN, } \\
\text { NITRATE } \\
\text { DIS- } \\
\text { SOLVED } \\
(\mathrm{MG} / \mathrm{L} \\
\text { AS NO } \\
(71851)\end{array}$ & $\begin{array}{l}\text { NITRO- } \\
\text { GEN, } \\
\text { NITRITE } \\
\text { DIS- } \\
\text { SOLVED } \\
\text { (MG/L } \\
\text { AS N) } \\
(00613)\end{array}$ & $\begin{array}{c}\text { NITRO- } \\
\text { GEN, } \\
\mathrm{NO}_{2}+\mathrm{NO}_{3} \\
\text { DIS- } \\
\text { SOLVED } \\
(\mathrm{MG} / \mathrm{L} \\
\mathrm{AS} \mathrm{N}) \\
(00631)\end{array}$ & $\begin{array}{c}\text { NITRO- } \\
\text { GEN, } \\
\text { AMMONIA } \\
\text { DIS- } \\
\text { SOLVED } \\
\text { (MG/L } \\
\text { AS N) } \\
(00608)\end{array}$ & $\begin{array}{c}\text { NITRO- } \\
\text { GEN, } \\
\text { AMMONIA } \\
\text { DIS- } \\
\text { SOLVED } \\
(\mathrm{MG} / \mathrm{L} \\
\left.\mathrm{AS} \mathrm{NH}_{4}\right) \\
(71846)\end{array}$ & $\begin{array}{l}\text { NITRO- } \\
\text { GEN, } \\
\text { ORGANIC } \\
\text { TOTAL } \\
\text { (MG/L } \\
\text { AS N) } \\
(00605)\end{array}$ \\
\hline OCT 1981 & & & & & & & & & & & \\
\hline $\begin{array}{c}21 \ldots \\
\text { NOV } 1982\end{array}$ & - & 0.12 & - & 0.700 & - & - & $<0.010$ & 0.710 & 0.030 & 0.04 & 0.36 \\
\hline $\begin{array}{c}02 \ldots \\
\text { OCT } 1983\end{array}$ & 96 & .13 & 4.72 & .930 & 0.930 & 4.1 & .010 & .940 & .040 & .05 & - \\
\hline $\begin{array}{c}20 \ldots \\
\text { OCT } 1984\end{array}$ & 105 & .15 & 8.99 & 1.17 & 1.17 & 5.2 & .030 & 1.20 & $<.010$ & - & - \\
\hline $\begin{array}{c}10 \ldots \\
\text { OCT } 1985\end{array}$ & 101 & .13 & 5.71 & 1.80 & - & - & $<.010$ & 1.80 & .040 & .05 & - \\
\hline $\begin{array}{c}11 \ldots \\
\text { OCT } 1986\end{array}$ & 105 & .14 & 6.67 & 1.70 & - & - & $<.010$ & 1.70 & .010 & .01 & .69 \\
\hline $\begin{array}{c}31 \ldots \\
\text { OCT } 1987\end{array}$ & 105 & .15 & 5.15 & .800 & - & - & $<.010$ & .800 & .050 & .06 & .25 \\
\hline $\begin{array}{c}14 \ldots \\
\text { OCT } 1988\end{array}$ & 98 & .13 & 7.33 & 1.60 & - & - & $<.010$ & 1.60 & .020 & .03 & .38 \\
\hline $\begin{array}{c}21 \ldots \\
\text { OCT } 1989\end{array}$ & 108 & .15 & 4.67 & 1.50 & - & - & $<.010$ & 1.50 & .020 & .03 & .18 \\
\hline $\begin{array}{c}24 \ldots \\
\text { NOV } 1990\end{array}$ & 103 & .14 & 16.8 & 1.60 & - & - & $<.010$ & 1.60 & $<.010$ & - & .40 \\
\hline $\begin{array}{c}15 \ldots \\
\text { OCT } 1991\end{array}$ & 108 & .15 & 10.3 & 1.80 & - & - & $<.010$ & 1.80 & .050 & .06 & - \\
\hline $\begin{array}{c}15 \ldots \\
\text { OCT } 1992\end{array}$ & 98 & .13 & 4.03 & 1.40 & - & - & $<.010$ & 1.40 & .030 & .04 & - \\
\hline $\begin{array}{c}14 \ldots \\
\text { OCT } 1993\end{array}$ & 98 & .13 & 5.21 & 1.10 & - & - & $<.010$ & 1.10 & .030 & .04 & .37 \\
\hline $\begin{array}{c}15 \ldots \\
\text { OCT } 1994\end{array}$ & - & - & - & 1.20 & - & - & $<.010$ & 1.20 & .020 & .03 & - \\
\hline $27 \ldots$ & - & - & - & .950 & - & - & $<.010$ & .950 & $<.015$ & - & - \\
\hline
\end{tabular}


Table 3. Water-quality data from surface-water sites-Continued

01472154 - French Creek near Pughtown, Pa. (Site 14)-Continued

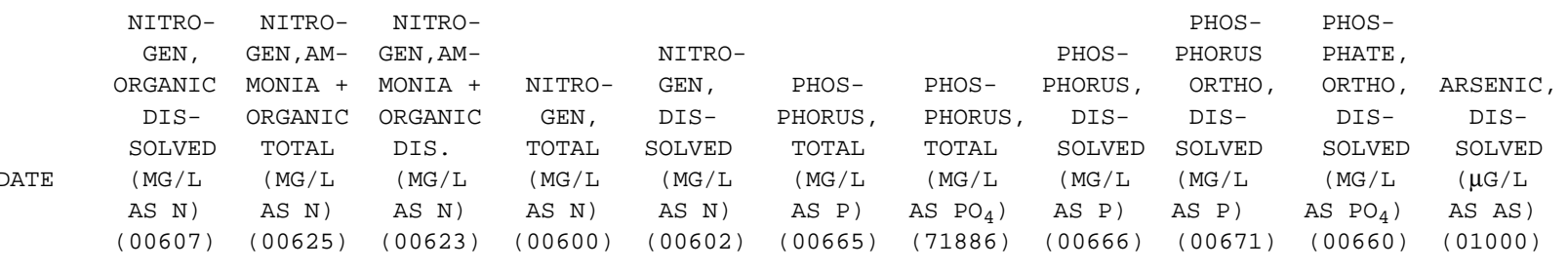

\begin{tabular}{|c|c|c|c|c|c|c|c|c|c|c|}
\hline $\begin{array}{c}21 \ldots \\
\text { NOV } 1982\end{array}$ & 0.43 & 0.39 & 0.46 & 1.1 & 1.2 & 0.040 & 0.12 & $<0.010$ & $<0.010$ & - \\
\hline $\begin{array}{c}02 \ldots \\
\text { OCT } 1983\end{array}$ & .26 & - & .30 & - & 1.2 & - & - & .020 & $<.010$ & - \\
\hline $\begin{array}{c}20 \ldots \\
\text { OCT } 1984\end{array}$ & - & - & .60 & - & 1.8 & .040 & .12 & .020 & .020 & 0.06 \\
\hline $\begin{array}{c}10 \ldots \\
\text { OCT } 1985\end{array}$ & .16 & - & .20 & - & 2.0 & .080 & - & .080 & .040 & .12 \\
\hline $\begin{array}{c}11 \ldots \\
\text { OCT } 1986\end{array}$ & .29 & .70 & .30 & 2.4 & 2.0 & .020 & .06 & .010 & $<.010$ & - \\
\hline $\begin{array}{c}31 \ldots \\
\text { OCT } 1987\end{array}$ & .65 & .30 & .70 & 1.1 & 1.5 & .020 & - & .010 & $<.010$ & - \\
\hline $\begin{array}{c}14 \ldots \\
\text { ОСТ } 1988\end{array}$ & .28 & .40 & .30 & 2.0 & 1.9 & .010 & - & $<.010$ & $<.010$ & - \\
\hline $\begin{array}{c}21 \ldots \\
\text { ОСТ } 1989\end{array}$ & .18 & .20 & .20 & 1.7 & 1.7 & .010 & - & .010 & $<.010$ & - \\
\hline $\begin{array}{c}24 \ldots \\
\text { NOV } 1990\end{array}$ & - & .40 & $<.20$ & 2.0 & - & .030 & - & .020 & .020 & .06 \\
\hline $\begin{array}{c}15 \ldots \\
\text { OCT } 1991\end{array}$ & .25 & $<.20$ & .30 & - & 2.1 & .030 & - & .020 & $<.010$ & - \\
\hline $\begin{array}{c}15 \ldots \\
\text { OCT } 1992\end{array}$ & - & $<.20$ & $<.20$ & - & - & .070 & - & .020 & $<.010$ & - \\
\hline $\begin{array}{c}14 \ldots \\
\text { OCT } 1993\end{array}$ & .47 & .40 & .50 & 1.5 & 1.6 & .060 & - & .030 & .020 & .06 \\
\hline $\begin{array}{c}15 \ldots \\
\text { OCT } 1994\end{array}$ & - & - & - & - & - & - & - & - & .010 & .03 \\
\hline $27 \ldots$ & - & - & - & - & - & - & - & - & $<.010$ & - \\
\hline
\end{tabular}


Table 3. Water-quality data from surface-water sites-Continued

01472154 - French Creek near Pughtown, Pa. (Site 14)—Continued

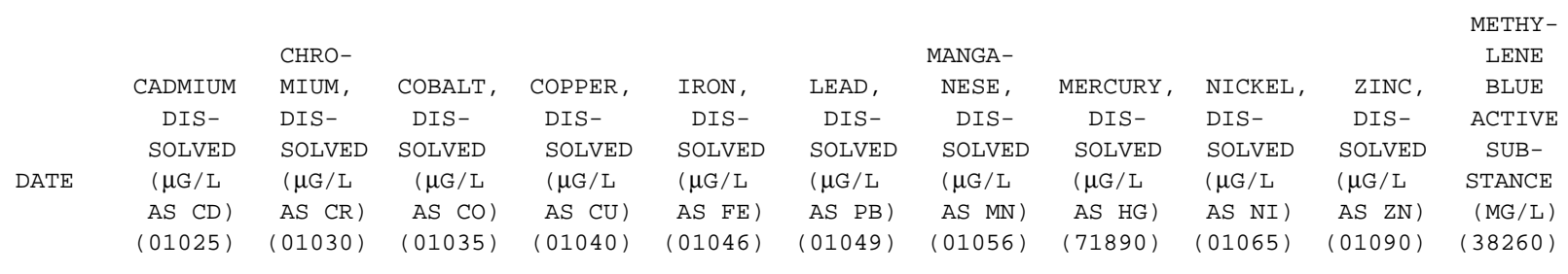

\begin{tabular}{|c|c|c|c|c|c|c|c|c|c|c|c|}
\hline $\begin{array}{c}\text { OCT } 1981 \\
21 \ldots\end{array}$ & 1.0 & 4 & $<1$ & 4 & 110 & 2 & 23 & $<0.1$ & $<1$ & 5 & - \\
\hline NOV 1982 & & & & & & & & & & & \\
\hline $\begin{array}{c}02 \ldots \\
\text { OCT } 1983\end{array}$ & $<1.0$ & $<1$ & $<1$ & 1 & 65 & 1 & 12 & $<0.1$ & $<1$ & $<4$ & 0.02 \\
\hline $\begin{array}{c}20 \ldots \\
\text { OCT } 1984\end{array}$ & - & - & - & - & 120 & - & 16 & - & - & - & - \\
\hline $\begin{array}{c}10 \ldots \\
\text { ОСт } 1985\end{array}$ & - & - & - & - & 61 & - & 8 & - & - & - & - \\
\hline $\begin{array}{c}11 \ldots \\
\text { ОСТ } 1986\end{array}$ & - & - & - & - & 57 & - & 8 & - & - & - & - \\
\hline $\begin{array}{c}31 \ldots \\
\text { OCT } 1987\end{array}$ & - & - & - & - & 83 & - & 14 & - & - & - & - \\
\hline $\begin{array}{c}14 \ldots \\
\text { OCT } 1988\end{array}$ & - & - & - & - & 110 & - & 10 & - & - & - & - \\
\hline $\begin{array}{c}21 \ldots \\
\text { OCT } 1989\end{array}$ & - & - & - & - & 53 & - & 9 & - & - & - & - \\
\hline $\begin{array}{c}24 \ldots \\
\text { NOV } 1990\end{array}$ & - & - & - & - & 120 & - & 22 & - & - & - & - \\
\hline $\begin{array}{c}15 \ldots \\
\text { ОСТ } 1991\end{array}$ & - & - & - & - & 140 & - & 19 & - & - & - & - \\
\hline $\begin{array}{c}15 \ldots \\
\text { OCT } 1992\end{array}$ & - & - & - & - & 94 & - & 14 & - & - & - & - \\
\hline $14 \ldots$ & - & - & - & - & 140 & - & 18 & - & - & - & - \\
\hline $\begin{array}{c}\text { OCT } 1993 \\
15 \ldots\end{array}$ & - & - & - & - & - & - & - & - & - & - & - \\
\hline $\begin{array}{c}\text { OCT } 1994 \\
27 \ldots\end{array}$ & - & - & - & - & - & - & - & - & - & - & - \\
\hline
\end{tabular}


Table 3. Water-quality data from surface-water sites-Continued

01472157 - French Creek near Phoenixville, Pa. (Site 15)

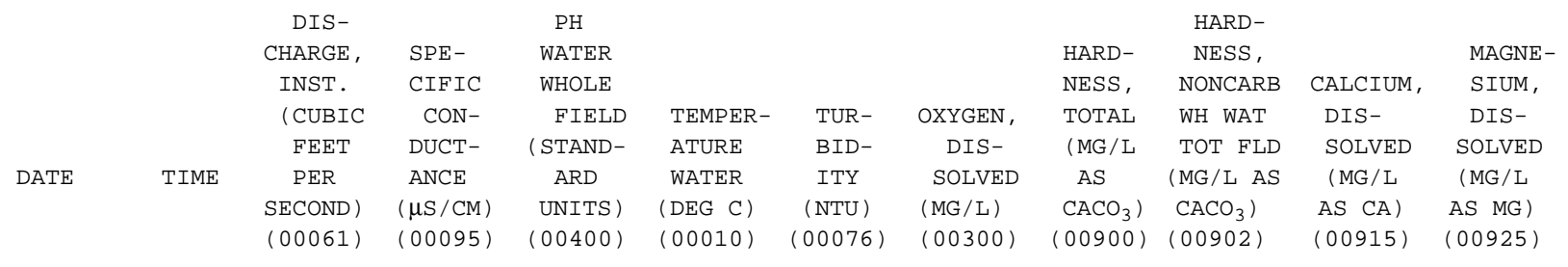

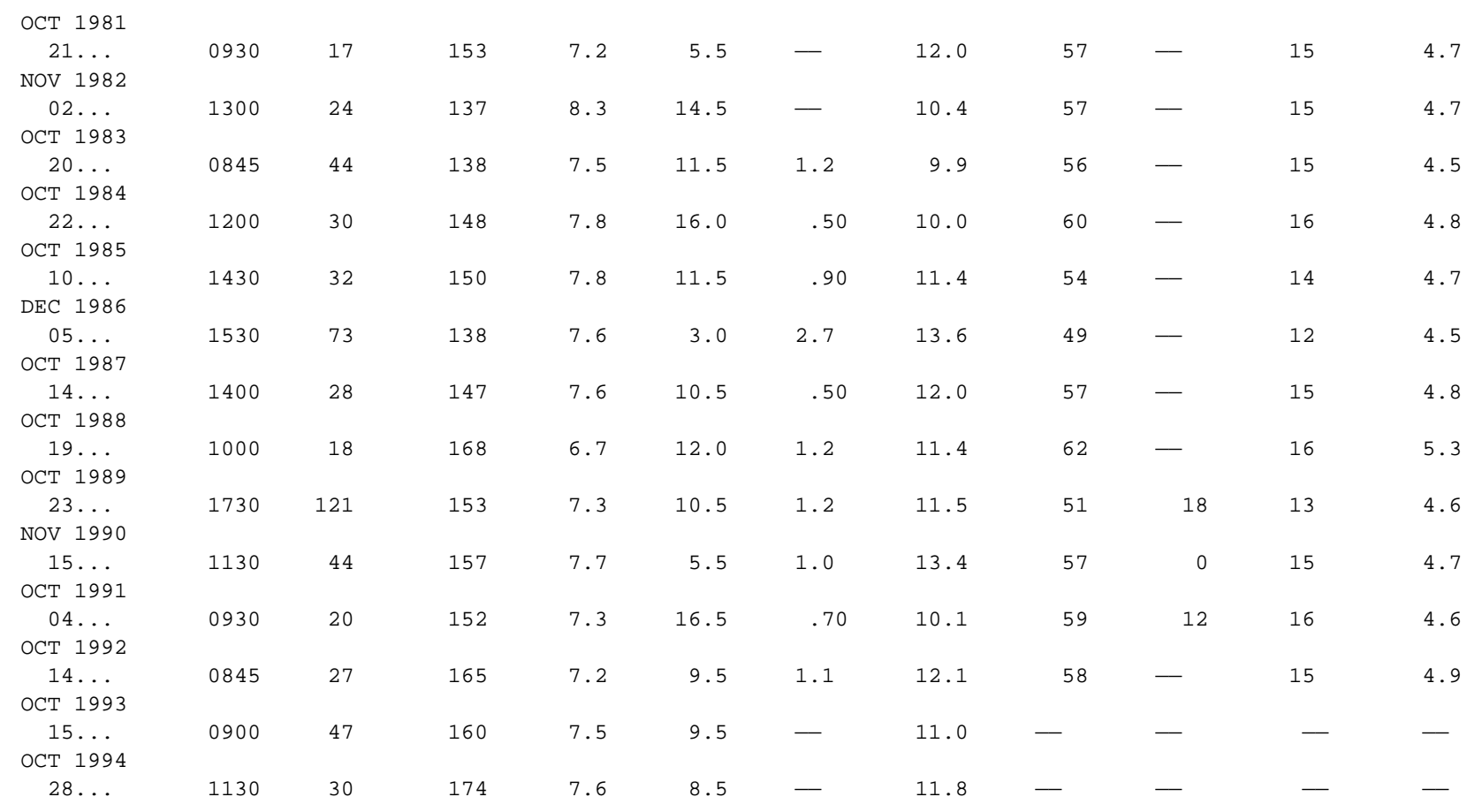


Table 3. Water-quality data from surface-water sites-Continued

01472157 - French Creek near Phoenixville, Pa. (Site 15)—Continued

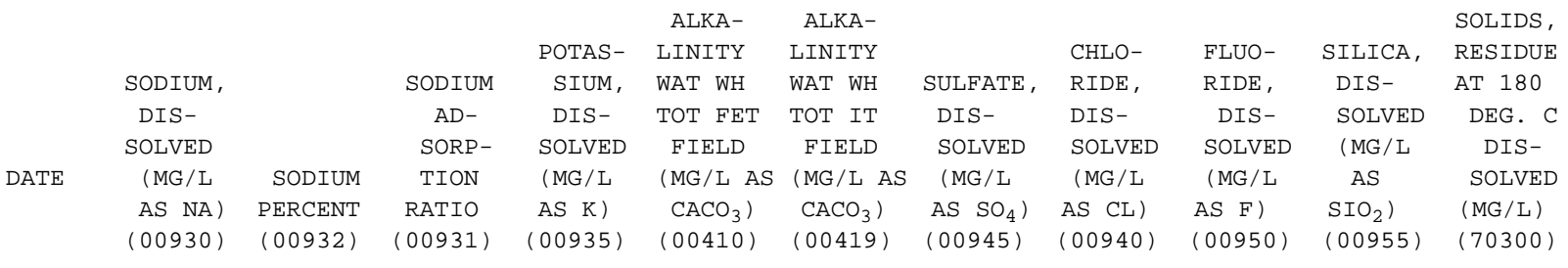

\begin{tabular}{|c|c|c|c|c|c|c|c|c|c|c|c|}
\hline $\begin{array}{c}\text { OCT } 1981 \\
21 \ldots \\
\text { NOV } 1982\end{array}$ & 7.4 & 21 & 0.4 & 2.0 & - & - & 13 & 9.0 & $<0.10$ & 16 & 92 \\
\hline $\begin{array}{c}02 \ldots \\
\text { OCT } 1983\end{array}$ & 6.4 & 19 & .4 & 1.6 & 40 & - & 14 & 9.4 & $<.10$ & 15 & 95 \\
\hline $\begin{array}{c}20 \ldots \\
\text { OCT } 1984\end{array}$ & 6.4 & 19 & .4 & 2.2 & 38 & - & 19 & 9.9 & - & 17 & 109 \\
\hline $\begin{array}{c}22 \ldots \\
\text { OCT } 1985\end{array}$ & 6.0 & 17 & .3 & 1.9 & 46 & - & 13 & 9.7 & - & 15 & 103 \\
\hline $\begin{array}{c}10 \ldots \\
\operatorname{DEC} 1986\end{array}$ & 6.6 & 20 & .4 & 1.9 & 40 & - & 18 & 9.2 & - & 17 & 101 \\
\hline $\begin{array}{c}05 \ldots \\
\text { OCT } 1987\end{array}$ & 6.2 & 21 & .4 & 1.8 & 36 & - & 18 & 8.8 & - & 15 & 98 \\
\hline $\begin{array}{c}14 \ldots \\
\text { OCT } 1988\end{array}$ & 6.6 & 19 & .4 & 1.8 & 42 & - & 12 & 9.3 & - & 15 & 97 \\
\hline $\begin{array}{c}19 \ldots \\
\text { OCT } 1989\end{array}$ & 6.6 & 18 & .4 & 1.7 & 45 & - & 15 & 10 & - & 16 & - \\
\hline $\begin{array}{c}23 \ldots \\
\text { NOV } 1990\end{array}$ & 7.4 & 23 & .4 & 2.0 & 33 & - & 14 & 9.4 & - & 16 & - \\
\hline $\begin{array}{c}15 \ldots \\
\text { OCT } 1991\end{array}$ & 6.4 & 19 & .4 & 1.9 & 60 & - & 15 & 10 & $<.10$ & 17 & - \\
\hline $\begin{array}{c}04 \ldots \\
\text { OCT } 1992\end{array}$ & 6.6 & 19 & .4 & 1.8 & 47 & - & 13 & 11 & .20 & 16 & - \\
\hline $\begin{array}{c}14 \ldots \\
\text { OCT } 1993\end{array}$ & 6.7 & 19 & .4 & 2.8 & - & 28 & 16 & 11 & .10 & 15 & - \\
\hline $\begin{array}{c}15 \ldots \\
\text { OCT } 1994\end{array}$ & - & - & - & - & - & 41 & - & - & - & - & - \\
\hline $28 \ldots$ & - & - & - & - & - & 48 & - & 12 & - & - & - \\
\hline
\end{tabular}


Table 3. Water-quality data from surface-water sites-Continued

01472157 - French Creek near Phoenixville, Pa. (Site 15)—Continued

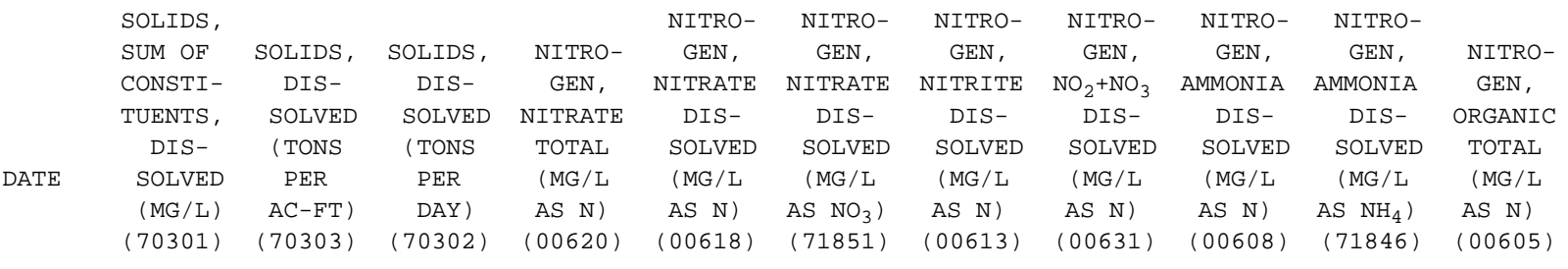

\begin{tabular}{|c|c|c|c|c|c|c|c|c|c|c|c|}
\hline $\begin{array}{c}\text { OCT } 1981 \\
21 \ldots \\
\text { NOV } 1982\end{array}$ & - & 0.13 & - & 0.770 & - & - & $<0.010$ & 0.770 & 0.050 & 0.06 & 0.24 \\
\hline $02 \ldots$ & 94 & .13 & 6.05 & .950 & .950 & 4.2 & .010 & .960 & .010 & .01 & - \\
\hline OCT 1983 & & & & & & & & & & & \\
\hline $\begin{array}{c}20 \ldots \\
\text { OCT } 1984\end{array}$ & 102 & .15 & 12.9 & 1.07 & 1.07 & 4.7 & .030 & 1.10 & $<.010$ & - & - \\
\hline $\begin{array}{c}22 \ldots \\
\text { OCT } 1985\end{array}$ & 99 & .14 & 8.34 & 1.07 & 1.07 & 4.7 & .030 & 1.10 & .040 & .05 & - \\
\hline $\begin{array}{c}10 \ldots \\
\text { DEC } 1986\end{array}$ & 103 & .14 & 8.73 & 1.60 & - & - & $<.010$ & 1.60 & .020 & .03 & .28 \\
\hline $\begin{array}{c}05 \ldots \\
\text { OCT } 1987\end{array}$ & 96 & .13 & 19.3 & 1.70 & - & - & $<.010$ & 1.70 & .020 & .03 & .28 \\
\hline $\begin{array}{c}14 \ldots \\
\text { OCT } 1988\end{array}$ & 96 & .13 & 7.33 & 1.50 & - & - & $<.010$ & 1.50 & .020 & .03 & .48 \\
\hline $\begin{array}{c}19 \ldots \\
\text { OCT } 1989\end{array}$ & 104 & .14 & 5.05 & 1.40 & - & - & $<.010$ & 1.40 & .070 & .09 & .23 \\
\hline $\begin{array}{c}23 \ldots \\
\text { NOV } 1990\end{array}$ & 94 & .13 & 3.8 & 1.80 & - & - & $<.010$ & 1.80 & .010 & .01 & .39 \\
\hline $\begin{array}{c}15 \ldots \\
\text { OCT } 1991\end{array}$ & 114 & .16 & 13.6 & 1.80 & - & 一 & $<.010$ & 1.80 & .050 & .06 & .15 \\
\hline $\begin{array}{c}04 \ldots \\
\text { OCT } 1992\end{array}$ & 104 & .14 & 5.63 & 1.40 & - & 一 & $<.010$ & 1.40 & $<.010$ & - & - \\
\hline $\begin{array}{c}14 \ldots \\
\text { OCT } 1993\end{array}$ & 93 & .13 & 6.83 & 1.10 & - & - & $<.010$ & 1.10 & .020 & .03 & .28 \\
\hline $\begin{array}{c}15 \ldots \\
\text { OCT } 1994\end{array}$ & - & - & - & 1.20 & - & - & $<.010$ & 1.20 & .020 & .03 & - \\
\hline $28 \ldots$ & - & - & - & 1.00 & - & - & $<.010$ & 1.00 & $<.015$ & - & - \\
\hline
\end{tabular}


Table 3. Water-quality data from surface-water sites-Continued

01472157 - French Creek near Phoenixville, Pa. (Site 15)—Continued

\begin{tabular}{|c|c|c|c|c|c|c|c|c|c|c|c|}
\hline & $\begin{array}{c}\text { NITRO- } \\
\text { GEN, } \\
\text { ORGANIC }\end{array}$ & $\begin{array}{l}\text { NITRO- } \\
\text { GEN, AM- } \\
\text { MONIA + }\end{array}$ & $\begin{array}{l}\text { NITRO- } \\
\text { GEN, AM- } \\
\text { MONIA + }\end{array}$ & NITRO- & $\begin{array}{c}\text { NITRO- } \\
\text { GEN }\end{array}$ & PHOS- & $\mathrm{PHO}$ & $\begin{array}{l}\text { PHOS- } \\
\text { PHORUS, }\end{array}$ & $\begin{array}{r}\text { PHOS- } \\
\text { PHORUS } \\
\text { ORTHO, }\end{array}$ & $\begin{array}{l}\text { PHOS- } \\
\text { PHATE, } \\
\text { ORTHO, }\end{array}$ & ARSENIC, \\
\hline $\mathrm{TE}$ & $\begin{array}{l}\text { DIS- } \\
\text { SOLVED } \\
(\mathrm{MG} / \mathrm{L}\end{array}$ & $\begin{array}{c}\text { ORGANIC } \\
\text { TOTAL } \\
\text { (MG/L }\end{array}$ & $\begin{array}{l}\text { ORGANIC } \\
\text { DIS. } \\
\text { (MG/L }\end{array}$ & $\begin{array}{c}\text { GEN, } \\
\text { TOTAL } \\
\text { (MG/L }\end{array}$ & $\begin{array}{l}\text { DIS- } \\
\text { SOLVED } \\
\text { (MG/L }\end{array}$ & $\begin{array}{c}\text { PHORUS, } \\
\text { TOTAL } \\
\text { (MG/L }\end{array}$ & $\begin{array}{l}\text { PHORUS, } \\
\text { TOTAL } \\
\text { (MG/L }\end{array}$ & $\begin{array}{l}\text { DIS- } \\
\text { SOLVED } \\
\text { (MG/L }\end{array}$ & $\begin{array}{l}\text { DIS- } \\
\text { SOLVED } \\
\text { (MG/L }\end{array}$ & $\begin{array}{c}\text { DIS- } \\
\text { SOLVED } \\
\text { (MG/L }\end{array}$ & $\begin{array}{c}\text { DIS- } \\
\text { SOLVED } \\
(\mu \mathrm{G} / \mathrm{L}\end{array}$ \\
\hline & $\begin{array}{c}\text { AS N) } \\
(00607)\end{array}$ & $\begin{array}{c}\text { AS N) } \\
(00625)\end{array}$ & $\begin{array}{l}\text { AS N) } \\
(00623)\end{array}$ & $\begin{array}{l}A S N) \\
(00600)\end{array}$ & $\begin{array}{l}\text { AS N) } \\
(00602)\end{array}$ & $\begin{array}{c}\text { AS P) } \\
(00665)\end{array}$ & $\begin{array}{l}\text { AS PO4) } \\
(71886)\end{array}$ & $\begin{array}{l}\text { AS P ) } \\
(00666)\end{array}$ & $\begin{array}{l}\text { AS P) } \\
(00671)\end{array}$ & $\begin{array}{l}\left.\mathrm{AS} \mathrm{PO}_{4}\right) \\
(00660)\end{array}$ & $\begin{array}{c}\text { AS AS) } \\
(01000)\end{array}$ \\
\hline
\end{tabular}

\begin{tabular}{|c|c|c|c|c|c|c|c|c|c|c|}
\hline $\begin{array}{c}21 \ldots \\
\text { NOV } 1982\end{array}$ & 0.24 & 0.32 & 0.29 & 1.1 & 1.1 & $<0.010$ & - & $<0.010$ & $<0.010$ & - \\
\hline $\begin{array}{c}02 \ldots \\
\text { OCT } 1983\end{array}$ & .79 & - & .80 & - & 1.8 & - & - & $<.010$ & $<.010$ & - \\
\hline $\begin{array}{c}20 \ldots \\
\text { OCT } 1984\end{array}$ & - & - & .40 & - & 1.5 & .030 & 0.09 & .030 & .020 & 0.06 \\
\hline $\begin{array}{c}22 \ldots \\
\text { OCT } 1985\end{array}$ & .26 & - & .30 & - & 1.4 & $<.010$ & - & .030 & .010 & .03 \\
\hline $\begin{array}{c}10 \ldots \\
\mathrm{DEC} 1986\end{array}$ & .28 & .30 & .30 & 1.9 & 1.9 & .020 & .06 & .020 & .010 & .03 \\
\hline $\begin{array}{c}05 \ldots \\
\mathrm{OCT} \quad 1987\end{array}$ & .48 & .30 & .50 & 2.0 & 2.2 & .030 & - & .020 & .010 & .03 \\
\hline $\begin{array}{c}14 \ldots \\
\text { OCT } 1988\end{array}$ & .38 & .50 & .40 & 2.0 & 1.9 & $<.010$ & - & $<.010$ & $<.010$ & - \\
\hline $\begin{array}{c}19 \ldots \\
\text { OCT } 1989\end{array}$ & .23 & .30 & .30 & 1.7 & 1.7 & .020 & - & .020 & $<.010$ & - \\
\hline $\begin{array}{c}23 \ldots \\
\text { NOV } 1990\end{array}$ & .39 & .40 & .40 & 2.2 & 2.2 & .040 & - & .020 & .030 & .09 \\
\hline $\begin{array}{c}15 \ldots \\
\text { OCT } 1991\end{array}$ & .15 & .20 & .20 & 2.0 & 2.0 & .020 & - & $<.010$ & $<.010$ & - \\
\hline $\begin{array}{c}04 \ldots \\
\text { OCT } 1992\end{array}$ & - & $<.20$ & - & - & - & .030 & - & $<.010$ & .010 & .03 \\
\hline $\begin{array}{c}14 \ldots \\
\text { OCT } 1993\end{array}$ & .28 & .30 & .30 & 1.4 & 1.4 & .030 & - & .030 & .020 & .06 \\
\hline $\begin{array}{c}15 \ldots \\
\text { OCT } 1994\end{array}$ & - & - & - & - & - & - & - & - & .020 & .06 \\
\hline $28 \ldots$ & - & - & - & - & - & - & - & - & $<.010$ & - \\
\hline
\end{tabular}


Table 3. Water-quality data from surface-water sites-Continued

01472157 - French Creek near Phoenixville, Pa. (Site 15)—Continued

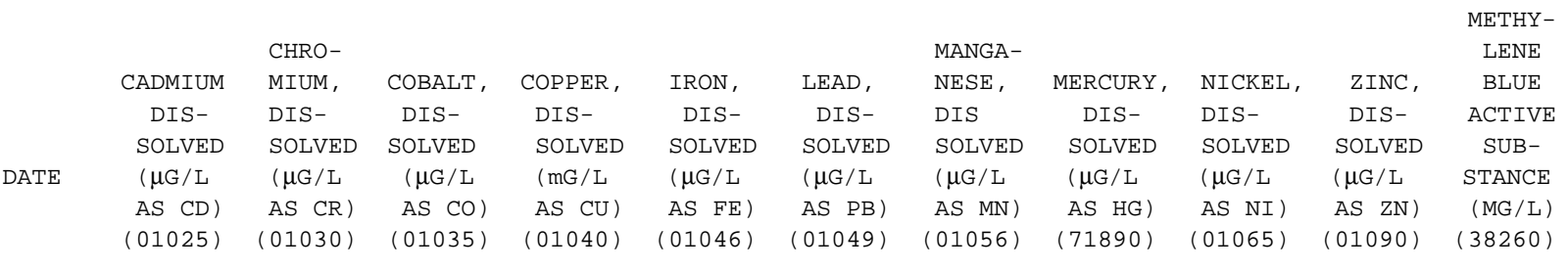

\begin{tabular}{|c|c|c|c|c|c|c|c|c|c|c|c|}
\hline $\begin{array}{c}\text { OCT } 1981 \\
21 \ldots\end{array}$ & $<1.0$ & $<1$ & $<1$ & 2 & 97 & $<1$ & 6 & $<0.1$ & 1 & 4 & - \\
\hline NoV 1982 & & & & & & & & & & & \\
\hline $\begin{array}{c}02 \ldots \\
\text { ОСТ } 1983\end{array}$ & $<1.0$ & $<1$ & $<1$ & 1 & 51 & $<1$ & 4 & $<.1$ & $<1$ & $<4$ & 0.01 \\
\hline $20 \ldots$ & - & - & - & - & 100 & - & 6 & - & - & - & - \\
\hline $\begin{array}{c}\text { OCT } 1984 \\
22 \ldots \\
\text { OCT } 1985\end{array}$ & - & - & - & - & 42 & - & 3 & - & - & - & - \\
\hline $\begin{array}{c}10 \ldots \\
\text { DEC } 1986\end{array}$ & - & - & - & - & 53 & - & 4 & - & - & - & - \\
\hline $\begin{array}{c}05 \ldots \\
\text { OCT } 1987\end{array}$ & - & - & - & - & 110 & - & 16 & - & - & - & - \\
\hline $\begin{array}{c}14 \ldots \\
\text { OCT } 1988\end{array}$ & - & - & - & - & 93 & - & 6 & - & - & - & - \\
\hline $\begin{array}{c}19 \ldots \\
\text { OCT } 1989\end{array}$ & - & - & - & - & 38 & - & 4 & - & - & - & - \\
\hline $\begin{array}{c}23 \ldots \\
\text { NOV } 1990\end{array}$ & - & - & - & - & 120 & - & 12 & - & - & - & - \\
\hline $\begin{array}{c}15 \ldots \\
\text { ОСТ } 1991\end{array}$ & - & - & - & - & 120 & - & 8 & - & - & - & - \\
\hline $\begin{array}{c}04 \ldots \\
\text { OCT } 1992\end{array}$ & - & - & - & - & 72 & - & 5 & - & - & - & - \\
\hline $\begin{array}{c}14 \ldots \\
\text { OCT } 1993\end{array}$ & - & - & - & - & 120 & - & 6 & - & - & - & - \\
\hline $15 \ldots$ & - & - & - & - & - & - & - & - & - & - & - \\
\hline $28 \ldots$ & - & - & - & - & - & - & - & - & - & - & - \\
\hline
\end{tabular}


Table 3. Water-quality data from surface-water sites-Continued

014721612 - French Creek at Railroad Bridge at Phoenixville, Pa. (Site 16)

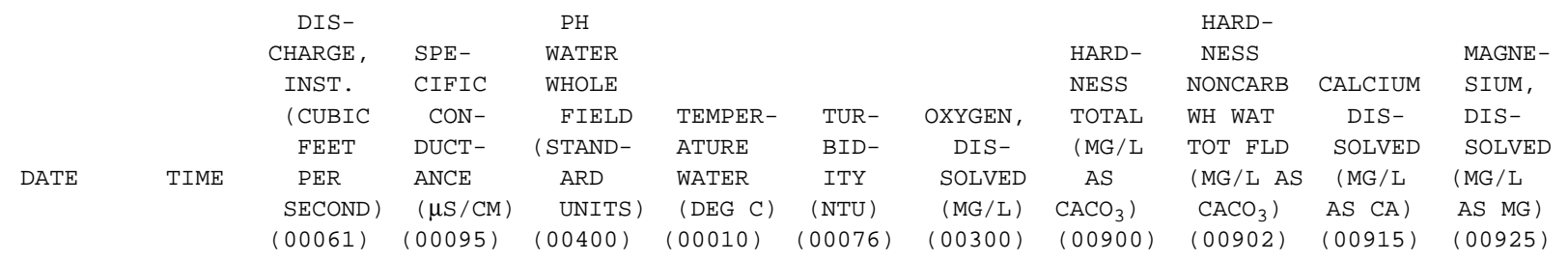

\begin{tabular}{|c|c|c|c|c|c|c|c|c|c|c|c|}
\hline $\begin{array}{c}\text { OCT } 1981 \\
23 \ldots \\
\text { NOV } 1982\end{array}$ & 1200 & - & 468 & 4.3 & 17.0 & - & 9.1 & 130 & - & 38 & 9.0 \\
\hline $\begin{array}{c}02 \ldots \\
\text { OCT } 1983\end{array}$ & 1045 & 30 & 189 & 8.0 & 14.0 & - & 10.7 & 75 & - & 20 & 6.0 \\
\hline $\begin{array}{c}20 \ldots \\
\text { OCT } 1984\end{array}$ & 1230 & 52 & 185 & 7.8 & 13.0 & 1.5 & 10.5 & 67 & - & 18 & 5.4 \\
\hline $\begin{array}{c}10 \ldots \\
\text { OCT } 1985\end{array}$ & 0900 & 35 & 200 & 7.8 & 14.0 & .80 & 10.6 & 78 & - & 21 & 6.2 \\
\hline $\begin{array}{c}09 \ldots \\
\text { OCT } 1986\end{array}$ & 1500 & 43 & 225 & 7.3 & 10.0 & 1.5 & 11.8 & 80 & - & 21 & 6.8 \\
\hline $\begin{array}{c}31 \ldots \\
\text { OCT } 1987\end{array}$ & 1200 & 24 & 220 & 8.0 & 12.0 & .90 & 10.4 & 86 & - & 23 & 6.9 \\
\hline $\begin{array}{c}13 \ldots \\
\text { OCT } 1988\end{array}$ & 0930 & 39 & 188 & 7.5 & 10.0 & .60 & 12.2 & 75 & - & 20 & 6.0 \\
\hline $\begin{array}{c}19 \ldots \\
\text { OCT } 1989\end{array}$ & 1500 & 35 & 232 & 7.2 & 13.5 & 1.1 & 11.5 & 87 & - & 23 & 7.2 \\
\hline $\begin{array}{c}24 \ldots \\
\text { NOV } 1990\end{array}$ & 1430 & 123 & 189 & 7.3 & 11.5 & 1.0 & 11.9 & 66 & 22 & 17 & 5.8 \\
\hline $\begin{array}{c}15 \ldots \\
\text { OCT } 1991\end{array}$ & 1400 & 51 & 197 & 7.4 & 7.5 & 4.5 & 13.1 & 69 & 13 & 18 & 5.8 \\
\hline $\begin{array}{c}21 \ldots \\
\text { OCT } 1992\end{array}$ & 0915 & 27 & 212 & 7.2 & 7.5 & 2.3 & 12.1 & 78 & 18 & 21 & 6.2 \\
\hline $\begin{array}{c}13 \ldots \\
\text { OCT } 1993\end{array}$ & 1200 & 45 & 202 & 7.1 & 12.5 & 1.5 & 11.3 & 71 & - & 19 & 5.8 \\
\hline $\begin{array}{c}18 \ldots \\
\text { OCT } 1994\end{array}$ & 0800 & 35 & 218 & 7.2 & 13.5 & - & 10.1 & - & - & - & - \\
\hline $28 \ldots$ & 0830 & 31 & 219 & 7.8 & 8.0 & - & 11.4 & - & - & - & - \\
\hline
\end{tabular}


Table 3. Water-quality data from surface-water sites-Continued

014721612 - French Creek at Railroad Bridge at Phoenixville, Pa. (Site 16)—Continued

\begin{tabular}{|c|c|c|c|c|c|c|c|c|c|c|}
\hline DATE & $\begin{array}{l}\text { SODIUM, } \\
\text { DIS- } \\
\text { SOLVED } \\
\text { (MG/L } \\
\text { AS NA) } \\
(00930)\end{array}$ & $\begin{array}{r}\text { SODIUM } \\
\text { PERCENT } \\
\text { (00932) }\end{array}$ & $\begin{array}{c}\text { SODIUM } \\
\text { AD- } \\
\text { SORP } \\
\text { TION } \\
\text { RATIO } \\
(00931)\end{array}$ & $\begin{array}{c}\text { POTAS- } \\
\text { SIUM, } \\
\text { DIS- } \\
\text { (SOLVED } \\
(\text { MG /L } \\
\text { AS K) } \\
(00935)\end{array}$ & $\begin{array}{l}\text { ALKA- } \\
\text { LINITY } \\
\text { WAT WH } \\
\text { TOT FET } \\
\text { FIELD } \\
(\mathrm{MG} / \mathrm{L} \\
\text { AS CACO }) \\
(00410)\end{array}$ & $\begin{array}{l}\text { ALKA- } \\
\text { LINITY } \\
\text { WAT WH } \\
\text { TOT IT } \\
\text { FIELD } \\
(\mathrm{MG} / \mathrm{L} \\
\text { AS CACO }) \\
(00419)\end{array}$ & $\begin{array}{l}\text { SULFATE, } \\
\text { DIS- } \\
\text { SOLVED } \\
(\mathrm{MG} / \mathrm{L} \\
\left.\mathrm{AS} \mathrm{SO}_{4}\right) \\
(00945)\end{array}$ & $\begin{array}{c}\text { CHLO- } \\
\text { RIDE, } \\
\text { DIS- } \\
\text { SOLVED } \\
\text { (MG/L } \\
\text { AS CL) } \\
(00940)\end{array}$ & $\begin{array}{c}\text { FLUO- } \\
\text { RIDE, } \\
\text { DIS- } \\
\text { SOLVED } \\
(\text { MG / L } \\
\text { AS F) } \\
(00950)\end{array}$ & $\begin{array}{l}\text { SILICA, } \\
\text { DIS- } \\
\text { SOLVED } \\
(\mathrm{MG} / \mathrm{L} \\
\mathrm{AS} \\
\left.\mathrm{SIO}_{2}\right) \\
(00955)\end{array}$ \\
\hline OCT 1981 & & & & & & & & & & \\
\hline $\begin{array}{c}23 \ldots \\
\text { NOV } 1982\end{array}$ & 27 & 30 & 1 & 4.1 & - & - & 76 & 36 & 1.5 & 11 \\
\hline $\begin{array}{c}02 \ldots \\
\text { OCT } 1983\end{array}$ & 9.2 & 21 & .5 & 2.0 & 52 & - & 21 & 12 & $<.10$ & 14 \\
\hline $\begin{array}{c}20 \ldots \\
\text { ОСТ } 1984\end{array}$ & 9.2 & 22 & .5 & 2.5 & 50 & - & 22 & 14 & - & 16 \\
\hline $\begin{array}{c}10 \ldots \\
\text { OCT } 1985\end{array}$ & 9.3 & 20 & .5 & 1.9 & 54 & - & 22 & 13 & - & 15 \\
\hline $\begin{array}{c}09 \ldots \\
\text { OCT } 1986\end{array}$ & 11 & 22 & .5 & 2.6 & 52 & - & 26 & 15 & - & 16 \\
\hline $\begin{array}{c}31 \ldots \\
\text { OCT } 1987\end{array}$ & 10 & 20 & .5 & 2.9 & 62 & - & 24 & 14 & - & 16 \\
\hline $\begin{array}{c}13 \ldots \\
\text { OCT } 1988\end{array}$ & 8.6 & 19 & .4 & 2.1 & 56 & - & 18 & 12 & - & 16 \\
\hline $\begin{array}{c}19 \ldots \\
\text { OCT } 1989\end{array}$ & 11 & 21 & .5 & 2.1 & 58 & - & 24 & 15 & - & 15 \\
\hline $\begin{array}{c}24 \ldots \\
\text { NOV } 1990\end{array}$ & 8.1 & 20 & .4 & 2.1 & 44 & - & 19 & 10 & - & 17 \\
\hline $\begin{array}{c}15 \ldots \\
\text { ОСТ } 1991\end{array}$ & 8.8 & 21 & .5 & 2.1 & 56 & - & 20 & 13 & .10 & 16 \\
\hline $\begin{array}{c}21 \ldots \\
\text { OCT } 1992\end{array}$ & 9.5 & 20 & .5 & 2.7 & 60 & - & 23 & 16 & .10 & 15 \\
\hline $\begin{array}{c}13 \ldots \\
\text { OCT } 1993\end{array}$ & 8.2 & 19 & .4 & 3.0 & - & 35 & 20 & 13 & .10 & 16 \\
\hline $\begin{array}{c}18 \ldots \\
\text { OCT } 1994\end{array}$ & - & - & - & - & - & 47 & - & - & - & - \\
\hline $28 \ldots$ & - & - & - & - & - & 48 & - & 15 & - & - \\
\hline
\end{tabular}


Table 3. Water-quality data from surface-water sites-Continued

014721612 - French Creek at Railroad Bridge at Phoenixville, Pa. (Site 16)—Continued

\begin{tabular}{|c|c|c|c|c|c|c|c|c|c|c|}
\hline DATE & $\begin{array}{l}\text { SOLIDS, } \\
\text { RESIDUE } \\
\text { AT } 180 \\
\text { DEG. C } \\
\text { DIS- } \\
\text { SOLVED } \\
(\mathrm{MG} / \mathrm{L}) \\
(70300)\end{array}$ & $\begin{array}{l}\text { SOLIDS, } \\
\text { SUM OF } \\
\text { CONSTI- } \\
\text { TUENTS, } \\
\text { DIS- } \\
\text { SOLVED } \\
(\text { MG/L) } \\
(70301)\end{array}$ & $\begin{array}{c}\text { SOLIDS, } \\
\text { DIS- } \\
\text { SOLVED } \\
\text { (TONS } \\
\text { PER } \\
\text { AC-FT) } \\
(70303)\end{array}$ & $\begin{array}{c}\text { SOLIDS, } \\
\text { DIS- } \\
\text { SOLVED } \\
\text { (TONS } \\
\text { PER } \\
\text { DAY) } \\
(70302)\end{array}$ & $\begin{array}{l}\text { NITRO- } \\
\text { GEN, } \\
\text { NITRATE } \\
\text { TOTAL } \\
\text { (MG/L } \\
\text { AS N) } \\
(00620)\end{array}$ & $\begin{array}{c}\text { NITRO- } \\
\text { GEN, } \\
\text { NITRATE } \\
\text { DIS- } \\
\text { SOLVED } \\
\text { (MG/L } \\
\text { AS N) } \\
(00618)\end{array}$ & $\begin{array}{c}\text { NITRO- } \\
\text { GEN, } \\
\text { NITRATE } \\
\text { DIS- } \\
\text { SOLVED } \\
(\mathrm{MG} / \mathrm{L} \\
\left.\text { AS } \mathrm{NO}_{3}\right) \\
(71851)\end{array}$ & $\begin{array}{l}\text { NITRO- } \\
\text { GEN, } \\
\text { NITRITE } \\
\text { DIS- } \\
\text { SOLVED } \\
(\text { MG/L } \\
\text { AS N) } \\
(00613)\end{array}$ & $\begin{array}{c}\text { NITRO- } \\
\text { GEN, } \\
\text { NO2+NO3 } \\
\text { DIS- } \\
\text { SOLVED } \\
\text { (MG/L } \\
\text { AS N) } \\
(00631)\end{array}$ & $\begin{array}{c}\text { NITRO- } \\
\text { GEN, } \\
\text { AMMONIA } \\
\text { DIS- } \\
\text { SOLVED } \\
\text { (MG/L } \\
\text { AS N) } \\
(00608)\end{array}$ \\
\hline OCT 1981 & & & & & & & & & & \\
\hline $\begin{array}{c}23 \ldots \\
\text { NOV } 1982\end{array}$ & 323 & - & 0.44 & - & 14.0 & 14.0 & 62 & 0.020 & 14.0 & 0.140 \\
\hline $\begin{array}{c}02 \ldots \\
\text { OCT } 1983\end{array}$ & 124 & 120 & .17 & 10.0 & .910 & .910 & 4.0 & .010 & .920 & $<.010$ \\
\hline $\begin{array}{c}20 \ldots \\
\text { OCT } 1984\end{array}$ & 134 & 123 & .18 & 18.8 & 1.17 & 1.17 & 5.2 & .030 & 1.20 & $<.010$ \\
\hline $\begin{array}{c}10 \ldots \\
\text { OCT } 1985\end{array}$ & 127 & 129 & .17 & 12.0 & 1.70 & - & - & $<.010$ & 1.70 & .020 \\
\hline $\begin{array}{c}09 \ldots \\
\text { OCT } 1986\end{array}$ & 139 & 138 & .19 & 16.1 & 1.78 & 1.78 & 7.9 & .020 & 1.80 & .030 \\
\hline $\begin{array}{c}31 \ldots \\
\text { OCT } 1987\end{array}$ & 147 & 138 & .20 & 9.49 & .810 & - & - & $<.010$ & .810 & .050 \\
\hline $\begin{array}{c}13 \ldots \\
\text { OCT } 1988\end{array}$ & 121 & 124 & .16 & 12.7 & 1.60 & - & - & $<.010$ & 1.60 & .030 \\
\hline $\begin{array}{c}19 \ldots \\
\text { OCT } 1989\end{array}$ & - & 139 & .19 & 13.1 & 1.40 & - & - & $<.010$ & 1.40 & .030 \\
\hline $\begin{array}{c}24 \ldots \\
\text { NOV } 1990\end{array}$ & - & 115 & .16 & 38.4 & 2.20 & - & - & $<.010$ & 2.20 & .010 \\
\hline $\begin{array}{c}15 \ldots \\
\text { OCT } 1991\end{array}$ & - & 126 & .17 & 17.3 & 1.80 & - & - & $<.010$ & 1.80 & .060 \\
\hline $\begin{array}{c}21 \ldots \\
\text { OCT } 1992\end{array}$ & - & 135 & .18 & 9.78 & 1.20 & - & - & $<.010$ & 1.20 & .030 \\
\hline $\begin{array}{c}13 \ldots \\
\text { OCT } 1993\end{array}$ & - & 111 & .15 & 13.5 & 1.00 & - & - & $<.010$ & 1.00 & .020 \\
\hline $\begin{array}{c}18 \ldots \\
\text { OCT } 1994\end{array}$ & - & - & - & - & 1.40 & - & - & $<.010$ & 1.40 & .030 \\
\hline $28 \ldots$ & - & 一 & - & - & 1.00 & 一 & - & $<.010$ & 1.00 & $<.015$ \\
\hline
\end{tabular}


Table 3. Water-quality data from surface-water sites-Continued

014721612 - French Creek at Railroad Bridge at Phoenixville, Pa. (Site 16)—Continued

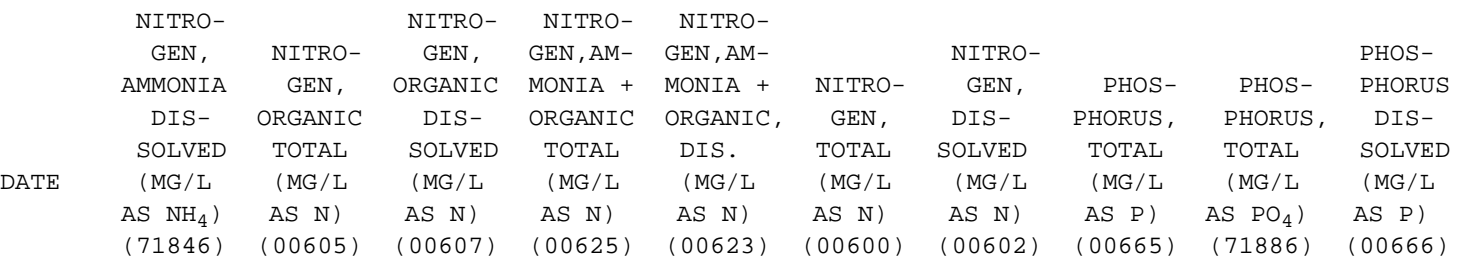

\begin{tabular}{|c|c|c|c|c|c|c|c|c|c|c|}
\hline $\begin{array}{c}23 \ldots \\
\text { NOV } 1982\end{array}$ & 0.18 & 0.42 & 0.36 & 0.49 & 0.50 & 14 & 15 & 0.310 & 0.95 & 0.280 \\
\hline $02 \ldots$ & .01 & - & - & - & .50 & - & 1.4 & - & - & .010 \\
\hline $\begin{array}{c}\text { OCT } 1983 \\
20 \ldots \\
\text { OCT } 1984\end{array}$ & - & - & - & - & .50 & - & 1.7 & .030 & .09 & .020 \\
\hline $\begin{array}{c}10 \ldots \\
\text { OCT } 1985\end{array}$ & .03 & - & .18 & - & .20 & - & 1.9 & .030 & - & .020 \\
\hline $\begin{array}{c}09 \ldots \\
\text { OCT } 1986\end{array}$ & .04 & - & .37 & - & .40 & - & 2.2 & .050 & .15 & .030 \\
\hline $\begin{array}{c}31 \ldots \\
\text { OCT } 1987\end{array}$ & .06 & .45 & .45 & .50 & .50 & 1.3 & 1.3 & .020 & - & .020 \\
\hline $\begin{array}{c}13 \ldots \\
\text { OCT } 1988\end{array}$ & .04 & .27 & .27 & .30 & .30 & 1.9 & 1.9 & .010 & - & $<.010$ \\
\hline $\begin{array}{c}19 \ldots \\
\text { ОСТ } 1989\end{array}$ & .04 & .57 & .47 & .60 & .50 & 2.0 & 1.9 & .010 & - & .010 \\
\hline $\begin{array}{c}24 \ldots \\
\text { NOV } 1990\end{array}$ & .01 & .19 & .29 & .20 & .30 & 2.4 & 2.5 & .040 & - & .020 \\
\hline $\begin{array}{c}15 \ldots \\
\text { ОСТ } 1991\end{array}$ & .08 & .24 & .44 & .30 & .50 & 2.1 & 2.3 & .030 & - & $<.010$ \\
\hline $\begin{array}{c}21 \ldots \\
\text { OCT } 1992\end{array}$ & .04 & .27 & .17 & .30 & .20 & 1.5 & 1.4 & .040 & - & .020 \\
\hline $\begin{array}{c}13 \ldots \\
\text { ост } 1993\end{array}$ & .03 & .28 & .28 & .30 & .30 & 1.3 & 1.3 & .040 & 一 & .040 \\
\hline $\begin{array}{c}18 \ldots \\
\text { OCT } 1994\end{array}$ & .04 & - & - & - & - & - & - & - & - & - \\
\hline $28 \ldots$ & - & - & - & - & - & - & - & - & - & - \\
\hline
\end{tabular}


Table 3. Water-quality data from surface-water sites-Continued

014721612 - French Creek at Railroad Bridge at Phoenixville, Pa. (Site 16)—Continued

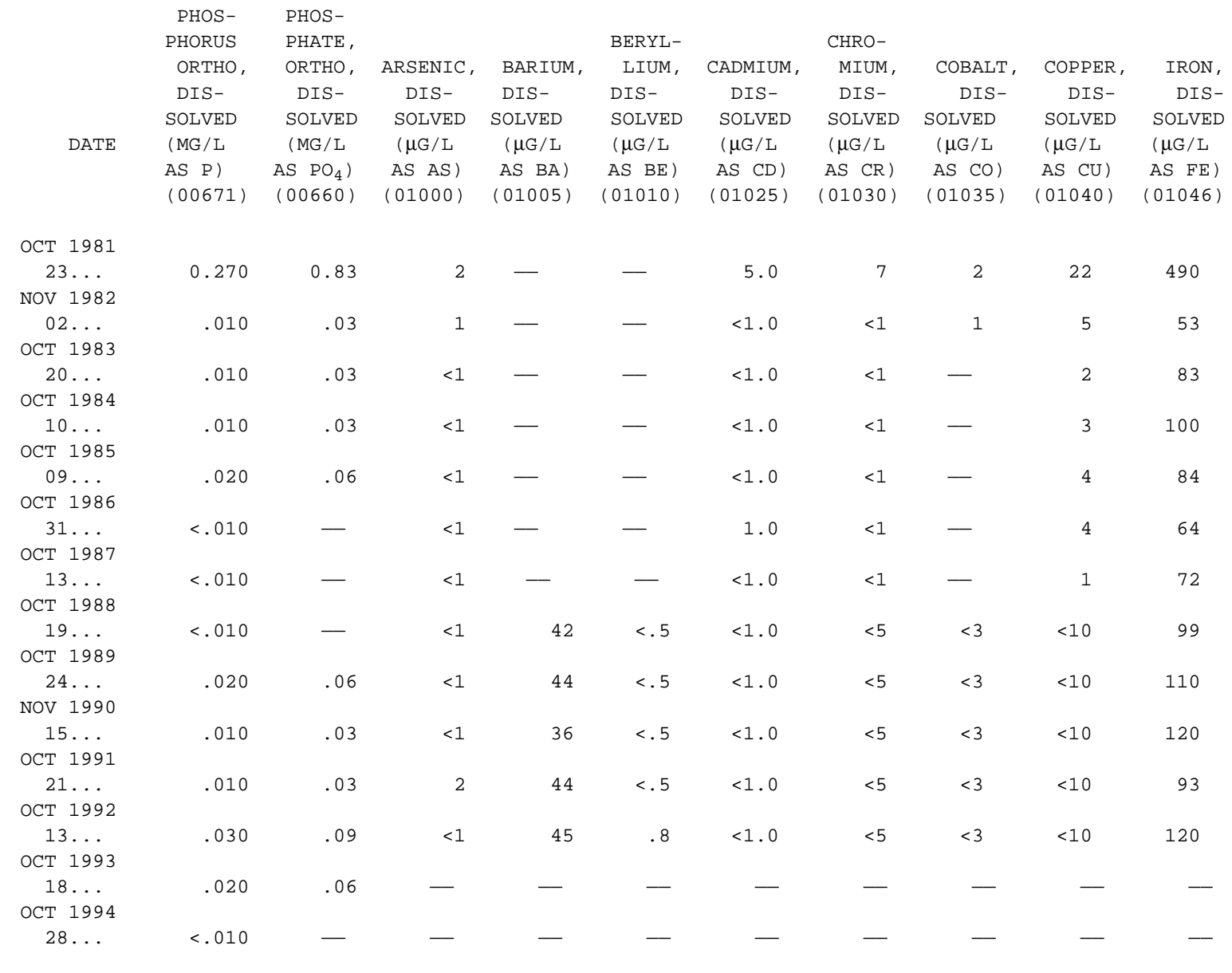


Table 3. Water-quality data from surface-water sites-Continued

014721612 - French Creek at Railroad Bridge at Phoenixville, Pa. (Site 16)—Continued

\begin{tabular}{|c|c|c|c|c|c|c|c|c|c|c|}
\hline DATE & $\begin{array}{c}\text { LEAD, } \\
\text { DIS- } \\
\text { SOLVED } \\
(\mu \mathrm{G} / \mathrm{L} \\
\text { AS PB) } \\
(01049)\end{array}$ & $\begin{array}{c}\text { LITHIUM, } \\
\text { DIS- } \\
\text { SOLVED } \\
(\mu \mathrm{G} / \mathrm{L} \\
\text { AS LI) } \\
(01130)\end{array}$ & $\begin{array}{c}\text { MANGA- } \\
\text { NESE, } \\
\text { DIS- } \\
\text { SOLVED } \\
(\mu \mathrm{G} / \mathrm{L} \\
\text { AS MN) } \\
(01056)\end{array}$ & $\begin{array}{c}\text { MERCURY, } \\
\text { DIS- } \\
\text { SOLVED } \\
(\mu \mathrm{G} / \mathrm{L} \\
\text { AS HG) } \\
(71890)\end{array}$ & $\begin{array}{c}\text { NICKEL, } \\
\text { DIS- } \\
\text { SOLVED } \\
(\mu \mathrm{G} / \mathrm{L} \\
\text { AS NI) } \\
(01065)\end{array}$ & $\begin{array}{c}\text { SILVER, } \\
\text { DIS- } \\
\text { SOLVED } \\
(\mu \mathrm{G} / \mathrm{L} \\
\text { AS AG) } \\
(01075)\end{array}$ & $\begin{array}{c}\text { STRON- } \\
\text { TIUM, } \\
\text { DIS- } \\
\text { SOLVED } \\
(\mu \mathrm{G} / \mathrm{L} \\
\text { AS SR) } \\
(01080)\end{array}$ & $\begin{array}{c}\text { VANA- } \\
\text { DIUM, } \\
\text { DIS- } \\
\text { SOLVED } \\
(\mu \mathrm{G} / \mathrm{L} \\
\text { AS V) } \\
(01085)\end{array}$ & $\begin{array}{c}\text { ZINC, } \\
\text { DIS- } \\
\text { SOLVED } \\
(\mu \mathrm{G} / \mathrm{L} \\
\text { AS ZN }) \\
(01090)\end{array}$ & $\begin{array}{c}\text { METHY- } \\
\text { LENE } \\
\text { BLUE } \\
\text { ACTIVE } \\
\text { SUB- } \\
\text { STANCE } \\
\text { (MG/L) } \\
(38260)\end{array}$ \\
\hline ОСТ 1981 & & & & & & & & & & \\
\hline $\begin{array}{c}23 \ldots \\
\text { NOV } 1982\end{array}$ & 200 & - & 12,000 & 0.7 & 6 & - & - & - & 320 & 0.20 \\
\hline $\begin{array}{c}02 \ldots \\
\text { OCT } 1983\end{array}$ & $<1$ & - & 40 & $<.1$ & $<1$ & - & - & - & $<4$ & .02 \\
\hline $\begin{array}{c}20 \ldots \\
\text { OCT } 1984\end{array}$ & 2 & - & 21 & $<.1$ & 1 & $<1.0$ & - & - & $<3$ & - \\
\hline $\begin{array}{c}10 \ldots \\
\text { OCT } 1985\end{array}$ & 5 & - & 39 & $<.1$ & 2 & $<1.0$ & - & - & $<3$ & - \\
\hline $\begin{array}{c}09 \ldots \\
\text { OCT } 1986\end{array}$ & 5 & - & 58 & $<.1$ & 2 & $<1.0$ & - & - & 24 & - \\
\hline $\begin{array}{c}31 \ldots \\
\text { OCT } 1987\end{array}$ & $<5$ & - & 29 & $<.1$ & 3 & $<1.0$ & - & - & 9 & - \\
\hline $\begin{array}{c}13 \ldots \\
\text { OCT } 1988\end{array}$ & $<5$ & - & 26 & $<.1$ & $<1$ & $<1.0$ & - & - & 3 & - \\
\hline $\begin{array}{c}19 \ldots \\
\text { OCT } 1989\end{array}$ & $<10$ & $<4$ & 30 & .2 & $<10$ & $<1.0$ & 120 & $<6$ & $<3$ & - \\
\hline $\begin{array}{c}24 \ldots \\
\text { NOV } 1990\end{array}$ & $<10$ & $<4$ & 23 & $<.1$ & $<10$ & $<1.0$ & 83 & $<6$ & 9 & - \\
\hline $\begin{array}{c}15 \ldots \\
\text { OCT } 1991\end{array}$ & $<10$ & 4 & 33 & $<.1$ & $<10$ & $<1.0$ & 86 & $<6$ & $<3$ & - \\
\hline $\begin{array}{c}21 \ldots \\
\text { OCT } 1992\end{array}$ & $<10$ & $<4$ & 32 & - & $<10$ & $<1.0$ & 100 & $<6$ & 4 & - \\
\hline $\begin{array}{c}13 \ldots \\
\text { OCT } 1993\end{array}$ & $<10$ & $<4$ & 29 & $<.1$ & $<10$ & $<1.0$ & 94 & $<6$ & 4 & - \\
\hline $\begin{array}{c}18 \ldots \\
\text { ОСТ } 1994\end{array}$ & - & - & - & - & - & - & - & - & - & - \\
\hline $28 \ldots$ & - & - & - & - & - & - & - & - & - & - \\
\hline
\end{tabular}


Table 3. Water-quality data from surface-water sites-Continued

01472170 - Pickering Creek near Eagle, Pa. (Site 1)

\begin{tabular}{|c|c|c|c|c|c|c|c|c|c|c|c|}
\hline & & DIS- & & PH & & & & & HARD- & & \\
\hline & & CHARGE, & SPE- & WATER & & & & HARD- & NESS & & MAGNE- \\
\hline & & INST. & CIFIC & WHOLE & & & & NESS, & NONCARB & CALCIUM, & SIUM, \\
\hline & & (CUBIC & $\mathrm{CON}-$ & FIELD & TEMPER- & TUR- & OXYGEN， & TOTAL & WH WAT & DIS- & DIS- \\
\hline & & FEET & DUCT- & (STAND- & ATURE & BID- & DIS- & (MG /L & TOT FLD & SOLVED & SOLVED \\
\hline DATE & TIME & PER & ANCE & ARD & WATER & ITY & SOLVED & AS & (MG/L AS & (MG / L & (MG / L \\
\hline & & SECOND) & $(\mu \mathrm{S} / \mathrm{CM})$ & UNITS) & (DEG C) & (NTU) & (MG /L) & $\left.\mathrm{CACO}_{3}\right)$ & $\left.\mathrm{CACO}_{3}\right)$ & AS CA) & AS MG) \\
\hline & & $(00061)$ & $(00095)$ & $(00400)$ & $(00010)$ & $(00076)$ & $(00300)$ & $(00900)$ & $(00902)$ & $(00915)$ & $(00925)$ \\
\hline
\end{tabular}

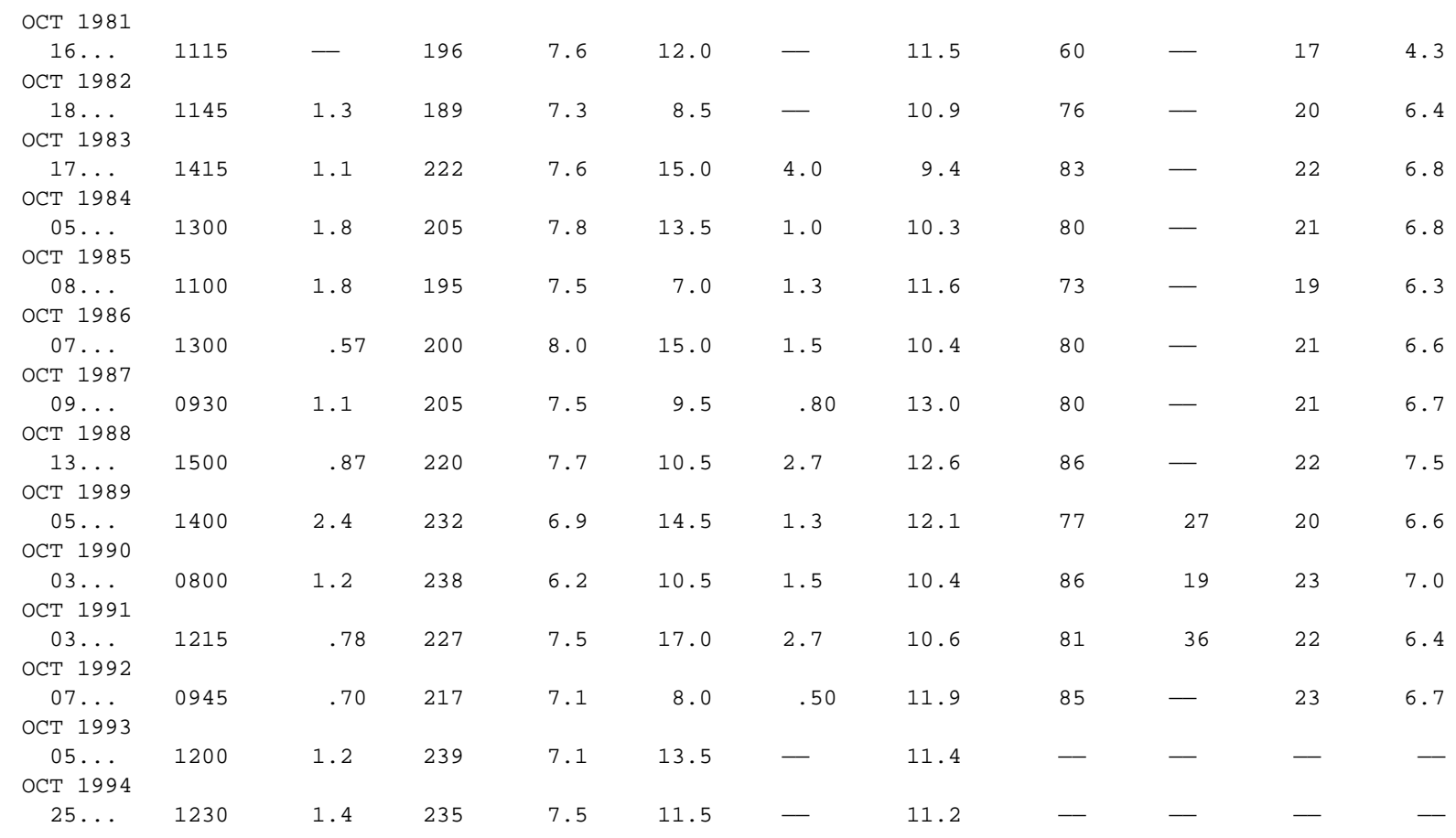


Table 3. Water-quality data from surface-water sites-Continued

01472170 - Pickering Creek near Eagle, Pa. (Site 1)—Continued

\begin{tabular}{|c|c|c|c|c|c|c|c|c|c|c|c|}
\hline & & & & POTAS- & $\begin{array}{l}\text { ALKA- } \\
\text { LINITY }\end{array}$ & $\begin{array}{l}\text { ALKA- } \\
\text { LINITY }\end{array}$ & & CHLO- & FLUO- & SILICA, & $\begin{array}{l}\text { SOLIDS, } \\
\text { RESIDUE }\end{array}$ \\
\hline & SODIUM, & & SODIUM & SIUM, & WAT WH & WAT WH & SULFATE, & RIDE, & RIDE, & DIS- & AT 180 \\
\hline & DIS- & & $\mathrm{AD}-$ & DIS- & TOT FET & TOT IT & DIS- & DIS- & DIS- & SOLVED & DEG. C \\
\hline & SOLVED & & SORP- & SOLVED & FIELD & FIELD & SOLVED & SOLVED & SOLVED & (MG / L & DIS- \\
\hline ATE & (MG/L & SODIUM & TION & (MG/L & (MG/L AS & (MG/L AS & (MG /L & (MG/L & (MG/L & AS & SOLVED \\
\hline & AS NA) & PERCENT & RATIO & AS K) & $\left.\mathrm{CACO}_{3}\right)$ & $\left.\mathrm{CACO}_{3}\right)$ & AS $\left.\quad \mathrm{SO}_{4}\right)$ & AS CL) & AS F) & $\left.\mathrm{SIO}_{2}\right)$ & $(\mathrm{MG} / \mathrm{L})$ \\
\hline & $(00930)$ & $(00932)$ & $(00931)$ & (00935) & $(00410)$ & $(00419)$ & $(00945)$ & $(00940)$ & $(00950)$ & $(00955)$ & $(70300)$ \\
\hline
\end{tabular}

\begin{tabular}{|c|c|c|c|c|c|c|c|c|c|c|c|}
\hline $\begin{array}{c}16 \ldots \\
\text { OCT } 1982\end{array}$ & 6.2 & 18 & 0.3 & 1.9 & - & - & 12 & 18 & $<0.10$ & 17 & 120 \\
\hline $\begin{array}{c}18 \ldots \\
\text { OCT } 1983\end{array}$ & 6.7 & 15 & .3 & 2.6 & 44 & - & 13 & 21 & $<.10$ & 21 & 154 \\
\hline $\begin{array}{c}17 \ldots \\
\text { OCT } 1984\end{array}$ & 7.1 & 15 & .3 & 2.8 & 48 & - & 15 & 24 & - & 22 & $16^{\circ}$ \\
\hline $\begin{array}{c}05 \ldots \\
\text { OCT } 1985\end{array}$ & 8.8 & 19 & .4 & 1.8 & 42 & - & 15 & 24 & - & 20 & 13 \\
\hline $\begin{array}{c}08 \ldots \\
\text { OCT } 1986\end{array}$ & 7.4 & 17 & .4 & 2.0 & 42 & - & 18 & 18 & - & 20 & 132 \\
\hline $\begin{array}{c}07 \ldots \\
\text { ОСТ } 1987\end{array}$ & 7.9 & 17 & .4 & 1.9 & 56 & - & 15 & 19 & - & 22 & 150 \\
\hline $\begin{array}{c}09 \ldots \\
\text { OCT } 1988\end{array}$ & 8.8 & 19 & .4 & 2.0 & 51 & - & 14 & 21 & - & 20 & 138 \\
\hline $\begin{array}{c}13 \ldots \\
\text { OCT } 1989\end{array}$ & 8.1 & 17 & .4 & 1.7 & 53 & - & 16 & 23 & - & 21 & - \\
\hline $\begin{array}{c}05 \ldots \\
\text { OCT } 1990\end{array}$ & 7.4 & 17 & .4 & 2.0 & 50 & - & 14 & 21 & - & 19 & - \\
\hline $\begin{array}{c}03 \ldots \\
\text { OCT } 1991\end{array}$ & 8.3 & 17 & .4 & 1.8 & 67 & - & 15 & 24 & .10 & 20 & - \\
\hline $\begin{array}{c}03 \ldots \\
\text { OCT } 1992\end{array}$ & 7.8 & 17 & .4 & 1.8 & 45 & - & 13 & 25 & .20 & 20 & - \\
\hline $\begin{array}{c}07 \ldots \\
\text { ОСТ } 1993\end{array}$ & 7.6 & 16 & .4 & 1.7 & - & 38 & 14 & 21 & .10 & 21 & - \\
\hline $\begin{array}{c}05 \ldots \\
\text { ОСТ } 1994\end{array}$ & - & - & - & - & - & 49 & - & - & - & - & - \\
\hline $25 \ldots$ & - & - & - & - & - & 48 & - & 26 & - & - & \\
\hline
\end{tabular}


Table 3. Water-quality data from surface-water sites-Continued

01472170 - Pickering Creek near Eagle, Pa. (Site 1)—Continued

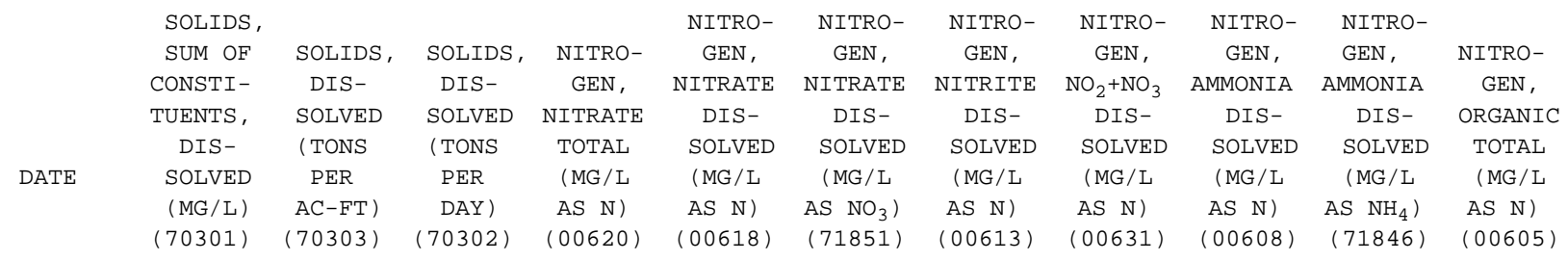

\begin{tabular}{|c|c|c|c|c|c|c|c|c|c|c|c|}
\hline $\begin{array}{c}\text { OCT } 1981 \\
16 \ldots \\
\text { OCT } 1982\end{array}$ & - & 0.16 & - & 1.49 & 1.49 & 6.6 & 0.010 & 1.50 & 0.050 & 0.06 & 0.37 \\
\hline $18 \ldots$ & 127 & .21 & .52 & 2.09 & 2.09 & 9.3 & .010 & 2.10 & .050 & .06 & - \\
\hline ОСт 1983 & & & & & & & & & & & \\
\hline $\begin{array}{c}17 \ldots \\
\text { ОСТ } 1984\end{array}$ & 141 & .23 & .50 & 2.64 & 2.64 & 12 & .060 & 2.70 & .130 & .17 & - \\
\hline $\begin{array}{c}05 \ldots \\
\text { OCT } 1985\end{array}$ & 135 & .19 & .67 & 2.80 & - & - & $<.010$ & 2.80 & .060 & .08 & - \\
\hline $\begin{array}{c}08 \ldots \\
\text { ОСТ } 1986\end{array}$ & 126 & .18 & .64 & 2.20 & - & - & $<.010$ & 2.20 & .050 & .06 & - \\
\hline $\begin{array}{c}07 \ldots \\
\text { ОСТ } 1987\end{array}$ & 136 & .20 & .23 & 1.89 & 1.89 & 8.4 & .010 & 1.90 & .020 & .03 & .98 \\
\hline $\begin{array}{c}09 \ldots \\
\text { OCT } 1988\end{array}$ & 133 & .19 & .41 & 1.90 & - & - & $<.010$ & 1.90 & .020 & .03 & .38 \\
\hline $\begin{array}{c}13 \ldots \\
\text { OCT } 1989\end{array}$ & 142 & .19 & .33 & 2.40 & - & - & $<.010$ & 2.40 & .010 & .01 & .29 \\
\hline $\begin{array}{c}05 \ldots \\
\text { OCT } 1990\end{array}$ & 132 & .18 & .85 & 2.59 & 2.59 & 11 & .010 & 2.60 & .020 & .03 & .38 \\
\hline $\begin{array}{c}03 \ldots \\
\text { ОСТ } 1991\end{array}$ & 149 & .20 & .46 & 2.20 & - & - & $<.010$ & 2.20 & .010 & .01 & .19 \\
\hline $\begin{array}{c}03 \ldots \\
\text { OCT } 1992\end{array}$ & 131 & .18 & .28 & 1.80 & - & - & $<.010$ & 1.80 & $<.010$ & - & - \\
\hline $\begin{array}{c}07 \ldots \\
\text { OCT } 1993\end{array}$ & 127 & .17 & .24 & 2.10 & - & - & $<.010$ & 2.10 & .020 & .03 & - \\
\hline $\begin{array}{c}05 \ldots \\
\text { OCT } 1994\end{array}$ & - & - & - & 2.20 & - & - & $<.010$ & 2.20 & .020 & .03 & - \\
\hline $25 \ldots$ & - & - & - & 1.90 & - & - & $<.010$ & 1.90 & $<.015$ & - & - \\
\hline
\end{tabular}


Table 3. Water-quality data from surface-water sites-Continued

01472170 - Pickering Creek near Eagle, Pa. (Site 1)—Continued

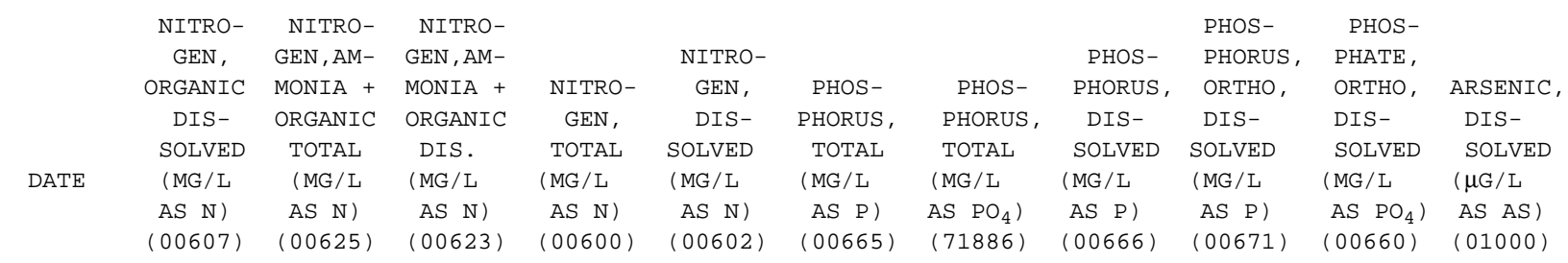

\begin{tabular}{|c|c|c|c|c|c|c|c|c|c|c|c|}
\hline $\begin{array}{c}16 \ldots \\
\text { OCT } 1982\end{array}$ & 0.27 & 0.46 & 0.32 & 2.0 & 1.8 & 0.030 & 0.09 & 0.010 & 0.010 & 0.03 & 2 \\
\hline $\begin{array}{c}18 \ldots \\
\text { ОСТ } 1983\end{array}$ & .35 & - & .40 & - & 2.5 & - & - & .040 & .020 & .06 & 1 \\
\hline $\begin{array}{c}17 \ldots \\
\text { OCT } 1984\end{array}$ & .87 & - & 1.0 & - & 3.7 & .050 & .15 & .030 & .040 & .12 & - \\
\hline $\begin{array}{c}05 \ldots \\
\text { OCT } 1985\end{array}$ & .14 & - & .20 & - & 3.0 & .030 & - & $<.010$ & .010 & .03 & - \\
\hline $\begin{array}{c}08 \ldots \\
\text { OCT } 1986\end{array}$ & .55 & - & .60 & - & 2.8 & .030 & .09 & .020 & .020 & .06 & - \\
\hline $\begin{array}{c}07 \ldots \\
\text { OCT } 1987\end{array}$ & .58 & 1.0 & .60 & 2.9 & 2.5 & .020 & - & .020 & .010 & .03 & - \\
\hline $\begin{array}{c}09 \ldots \\
\text { ОСТ } 1988\end{array}$ & - & .40 & $<.20$ & 2.3 & - & .010 & - & $<.010$ & $<.010$ & - & - \\
\hline $\begin{array}{c}13 \ldots \\
\text { OCT } 1989\end{array}$ & .29 & .30 & .30 & 2.7 & 2.7 & .010 & - & .010 & $<.010$ & - & - \\
\hline $\begin{array}{c}05 \ldots \\
\text { ОСТ } 1990\end{array}$ & .48 & .40 & .50 & 3.0 & 3.1 & .020 & - & $<.010$ & $<.010$ & - & - \\
\hline $\begin{array}{c}03 \ldots \\
\text { OCT } 1991\end{array}$ & .29 & .20 & .30 & 2.4 & 2.5 & $<.010$ & - & $<.010$ & $<.010$ & - & - \\
\hline $\begin{array}{c}03 \ldots \\
\text { OCT } 1992\end{array}$ & - & $<.20$ & .10 & - & 1.9 & .030 & - & $<.010$ & $<.010$ & - & - \\
\hline $\begin{array}{c}07 \ldots \\
\text { OCT } 1993\end{array}$ & - & $<.20$ & $<.20$ & - & - & .020 & - & $<.010$ & $<.010$ & - & - \\
\hline $\begin{array}{c}05 \ldots \\
\text { ОСТ } 1994\end{array}$ & - & - & - & - & - & - & - & - & $<.010$ & - & - \\
\hline $25 \ldots$ & - & - & - & - & - & - & - & - & $<.010$ & - & - \\
\hline
\end{tabular}


Table 3. Water-quality data from surface-water sites-Continued

01472170 - Pickering Creek near Eagle, Pa. (Site 1)—Continued

\begin{tabular}{|c|c|c|c|c|c|c|c|c|c|c|c|}
\hline \multirow{6}{*}{ DATE } & & CHRO- & & & & & MANGA- & & & & $\begin{array}{l}\text { METHY- } \\
\text { LENE }\end{array}$ \\
\hline & CADMIUM, & MIUM, & COBALT, & COPPER, & IRON, & LEAD, & NESE, & MERCURY, & NICKEL, & ZINC, & BLUE \\
\hline & $\begin{array}{c}\text { DIS- } \\
\text { SOLVED }\end{array}$ & $\begin{array}{l}\text { DIS- } \\
\text { SOLVED }\end{array}$ & $\begin{array}{c}\text { DIS- } \\
\text { SOLVED }\end{array}$ & $\begin{array}{l}\text { DIS- } \\
\text { SOIFD }\end{array}$ & DIS- & DIS- & $\begin{array}{l}\text { DIS- } \\
\text { SOIVFD }\end{array}$ & DIS- & DIS- & DIS- & ACT IVE \\
\hline & $\begin{array}{l}S O L V E D \\
(\mu G / L\end{array}$ & $\begin{array}{l}S O L V E D \\
(\mu G / L\end{array}$ & $\begin{array}{c}S O L V E D \\
(\mu G / L\end{array}$ & $\begin{array}{l}S O L V E D \\
(\mu \mathrm{G} / \mathrm{L}\end{array}$ & $\begin{array}{l}S O L V E D \\
(\mu \mathrm{G} / \mathrm{L}\end{array}$ & $\begin{array}{l}\text { SOLVED } \\
(\mu \mathrm{G} / \mathrm{L}\end{array}$ & $\begin{array}{l}\text { SOLVED } \\
(\mu \mathrm{G} / \mathrm{L}\end{array}$ & $(\mu \mathrm{G} / \mathrm{L}$ & $\begin{array}{l}S O L V E D \\
(\mu \mathrm{G} / \mathrm{L}\end{array}$ & $\begin{array}{l}S O L V E D \\
(\mu \mathrm{G} / \mathrm{L}\end{array}$ & STANCE \\
\hline & $\mathrm{AS} \quad \mathrm{CD}$ ) & AS $\quad$ CR) & A.S $\mathrm{CO})$ & AS CU) & AS FE) & AS PB) & AS MN) & AS HG) & AS NI) & AS $\quad \mathrm{ZN})$ & $(\mathrm{MG} / \mathrm{L})$ \\
\hline & $(01025)$ & $(01030)$ & $(01035)$ & $(01040)$ & $(01046)$ & $(01049)$ & $(01056)$ & $(71890)$ & $(01065)$ & $(01090)$ & $(38260)$ \\
\hline
\end{tabular}

\begin{tabular}{|c|c|c|c|c|c|c|c|c|c|c|c|}
\hline $\begin{array}{c}\text { OCT } 1981 \\
16 \ldots\end{array}$ & 1.0 & $<1$ & 2 & 5 & 110 & $<1$ & 50 & $<0.1$ & & 10 & - \\
\hline ОСТ 1982 & & & & & & & & & & & \\
\hline $18 \ldots$ & $<1.0$ & $<1$ & $<1$ & $<1$ & 100 & $<1$ & 50 & $<.1$ & & $<4$ & 0.02 \\
\hline $\begin{array}{c}17 \ldots \\
\text { OCT } 1984\end{array}$ & - & - & - & - & 170 & - & 56 & - & - & - & - \\
\hline $\begin{array}{c}05 \ldots \\
\text { OCT } 1985\end{array}$ & - & - & - & - & 93 & - & 35 & - & - & - & - \\
\hline $\begin{array}{c}08 \ldots \\
\text { OCT } 1986\end{array}$ & - & - & - & - & 95 & - & 54 & - & - & - & - \\
\hline $\begin{array}{c}07 \ldots \\
\text { OCT } 1987\end{array}$ & - & - & - & - & 110 & - & 23 & - & - & - & - \\
\hline $\begin{array}{c}09 \ldots \\
\text { OCT } 1988\end{array}$ & - & - & - & - & 110 & - & 43 & - & - & - & - \\
\hline $\begin{array}{c}13 \ldots \\
\text { OCT } 1989\end{array}$ & - & - & 一 & - & 100 & - & 23 & - & - & - & - \\
\hline $\begin{array}{c}05 \ldots \\
\text { OCT } 1990\end{array}$ & - & - & - & - & 180 & - & 48 & - & - & - & - \\
\hline $\begin{array}{c}03 \ldots \\
\text { OCT } 1991\end{array}$ & - & - & - & - & 100 & - & 43 & - & - & - & - \\
\hline $\begin{array}{c}03 \ldots \\
\text { OCT } 1992\end{array}$ & - & - & - & - & 150 & - & 28 & - & - & - & - \\
\hline $\begin{array}{c}07 \ldots \\
\text { OCT } 1993\end{array}$ & - & - & - & - & 110 & - & 36 & - & - & - & - \\
\hline $\begin{array}{c}05 \ldots \\
\text { OCT } 1994\end{array}$ & - & - & - & - & - & - & - & - & - & - & - \\
\hline $25 \ldots$ & - & - & - & - & - & - & - & - & - & - & - \\
\hline
\end{tabular}


Table 3. Water-quality data from surface-water sites-Continued

01472174 - Pickering Creek near Chester Springs, Pa. (Site 2)

\begin{tabular}{|c|c|c|c|c|c|c|c|c|c|c|}
\hline \multirow{6}{*}{ DATE } & & \multirow{3}{*}{$\begin{array}{l}\text { DIS- } \\
\text { CHARGE, } \\
\text { INST. } \\
\text { CUBIC } \\
\text { FEET }\end{array}$} & & & & & HARD- & HARD- & \\
\hline & & & $\begin{array}{c}\text { CIFIC } \\
\text { CON- }\end{array}$ & $\begin{array}{l}\text { WHOLE } \\
\text { FIELD }\end{array}$ & TEMPER- & & OXYGEN, & $\begin{array}{l}\text { NESS, } \\
\text { TOTAL }\end{array}$ & $\begin{array}{c}\text { NONCARB } \\
\text { WH WAT }\end{array}$ & $\begin{array}{c}\text { CALCIUM, } \\
\text { DIS- }\end{array}$ \\
\hline & & & DUCT- & (STAND- & ATURE & BID- & DIS- & $\begin{array}{l}\text { TOTAL } \\
\text { (MG/L }\end{array}$ & TOT FLD & SOLVED \\
\hline & TIME & PER & ANCE & ARD & WATER & ITY & SOLVED & AS & (MG/L AS & (MG /L \\
\hline & & SECOND & $(\mu \mathrm{S} / \mathrm{CM})$ & UNITS) & $(\mathrm{DEG} \quad \mathrm{C})$ & (NTU) & (MG / L) & $\left.\mathrm{CACO}_{3}\right)$ & $\left.\mathrm{CACO}_{3}\right)$ & AS CA) \\
\hline & & $(00061)$ & $(00095)$ & $(00400)$ & $(00010)$ & $(00076)$ & $(00300)$ & $(00900)$ & $(00902)$ & $(00915)$ \\
\hline
\end{tabular}

\begin{tabular}{|c|c|c|c|c|c|c|c|c|c|c|}
\hline $16 \ldots$ & 0915 & - & 191 & 7.2 & 9.0 & - & 10.8 & 55 & - & 17 \\
\hline ОСТ 1982 & & & & & & & & & & \\
\hline $18 \ldots$ & 0930 & 3.5 & 190 & 6.6 & 5.8 & - & 10.2 & 73 & - & 20 \\
\hline OCT 1983 & & & & & & & & & & \\
\hline $18 \ldots$ & 1045 & 2.6 & 195 & 7.5 & 13.0 & 1.0 & 8.6 & 81 & - & 23 \\
\hline OCT 1984 & & & & & & & & & & \\
\hline $05 \ldots$ & 0900 & 4.0 & 200 & 7.7 & 9.5 & .60 & 10.7 & 77 & - & 21 \\
\hline OCT 1985 & & & & & & & & & & \\
\hline $08 \ldots$ & 0815 & 5.1 & 212 & 7.4 & 6.0 & 1.1 & 11.0 & 72 & - & 19 \\
\hline ОСТ 1986 & & & & & & & & & & \\
\hline $07 \ldots$ & 0900 & 2.1 & 195 & 7.6 & 10.0 & .50 & 9.9 & 79 & - & 22 \\
\hline ОСТ 1987 & & & & & & & & & & \\
\hline $09 \ldots$ & 1400 & 2.7 & 195 & 7.5 & 12.0 & .70 & 10.7 & 76 & - & 21 \\
\hline OCT 1988 & & & & & & & & & & \\
\hline $13 \ldots$ & 1000 & 2.7 & 201 & 7.6 & 8.0 & 1.6 & 11.8 & 80 & - & 22 \\
\hline ОСТ 1989 & & & & & & & & & & \\
\hline $05 \ldots$ & 0915 & 7.3 & 195 & 7.3 & 10.5 & 1.1 & 10.6 & 74 & 28 & 20 \\
\hline OCT 1990 & & & & & & & & & & \\
\hline $03 \ldots$ & 1030 & 2.9 & 213 & 6.6 & 11.5 & 1.0 & 10.7 & 76 & 11 & 21 \\
\hline ОСТ 1991 & & & & & & & & & & \\
\hline $03 \ldots$ & 0900 & 1.9 & 211 & 7.2 & 16.0 & 1.4 & 9.1 & 78 & 24 & 22 \\
\hline ОСТ 1992 & & & & & & & & & & \\
\hline $08 \ldots$ & 0830 & 1.6 & 215 & 7.1 & 8.5 & .60 & 11.5 & 84 & - & 24 \\
\hline ОСТ 1993 & & & & & & & & & & \\
\hline $07 \ldots$ & 0900 & 2.5 & 220 & 7.3 & 10.5 & - & 10.7 & - & - & - \\
\hline СТ 1994 & & & & & & & & & & \\
\hline $25 \ldots$ & 0945 & 4.3 & 224 & 7.0 & 10.5 & - & 10.5 & - & - & 一 \\
\hline
\end{tabular}


Table 3. Water-quality data from surface-water sites-Continued

01472174 - Pickering Creek near Chester Springs, Pa. (Site 2)—Continued

\begin{tabular}{|c|c|c|c|c|c|c|c|c|c|c|c|c|}
\hline & MA & & & & & $\begin{array}{c}\text { ANC } \\
\text { WATER }\end{array}$ & $\begin{array}{c}\text { ANC } \\
\text { WATER }\end{array}$ & & & & & $\begin{array}{l}\text { SOLIDS, } \\
\text { RESIDUE }\end{array}$ \\
\hline & $\begin{array}{l}\text { SIUM, } \\
\text { DIS- }\end{array}$ & $\begin{array}{l}\text { SODIUM, } \\
\text { DIS- }\end{array}$ & & SODIUM & $\begin{array}{l}\text { SIUM, } \\
\text { DIS- }\end{array}$ & $\begin{array}{l}\text { UNF LTRD } \\
\text { FET }\end{array}$ & UNFLTRD & $\begin{array}{l}\text { SULFATE, } \\
\text { DIS- }\end{array}$ & RI & RIDE, & $\begin{array}{r}\text { DI } \\
\text { SOI }\end{array}$ & $\begin{array}{l}\text { AT } 180 \\
\text { DEG C C }\end{array}$ \\
\hline & $\begin{array}{l}\text { SOLVED } \\
\text { (MG/L }\end{array}$ & $\begin{array}{r}\text { SOLVED } \\
\text { (MG/L }\end{array}$ & & $\begin{array}{l}\text { SORP- } \\
\text { TION }\end{array}$ & $\begin{array}{l}\text { SOLVED } \\
\text { (MG/L }\end{array}$ & $\begin{array}{c}\text { FIELD } \\
\text { (MG/L AS }\end{array}$ & $\begin{array}{l}\text { FIELD } \\
\text { (MG/L AS }\end{array}$ & $\begin{array}{l}\text { SOLVED } \\
\text { (MG/L }\end{array}$ & $\begin{array}{l}\text { SOLVED } \\
\text { (MG/L }\end{array}$ & $\begin{array}{l}\text { SOLVED } \\
\text { (MG/L }\end{array}$ & $\begin{array}{l}\text { SOLVED } \\
\text { (MG/L } \\
\text { AS }\end{array}$ & $\begin{array}{r}\text { DIS- } \\
\text { SOLVED }\end{array}$ \\
\hline & $\begin{array}{l}\text { AS MG) } \\
(00925)\end{array}$ & $\begin{array}{l}\text { AS NA) } \\
(00930)\end{array}$ & $\begin{array}{l}\text { PERCENT } \\
\text { (00932) }\end{array}$ & $\begin{array}{r}\text { RATIO } \\
(00931)\end{array}$ & $\begin{array}{l}\text { AS K) } \\
(00935)\end{array}$ & $\begin{array}{r}\left.\mathrm{CACO}_{3}\right) \\
(00410)\end{array}$ & $\begin{array}{l}\left.\mathrm{CACO}_{3}\right) \\
(00419)\end{array}$ & $\begin{array}{l}\left.\mathrm{AS} \mathrm{SO}_{4}\right) \\
(00945)\end{array}$ & $\begin{array}{l}\text { AS CL) } \\
(00940)\end{array}$ & $\begin{array}{l}\text { AS F) } \\
(00950)\end{array}$ & $\begin{array}{l}\left.\mathrm{SIO}_{2}\right) \\
(00955)\end{array}$ & $\begin{array}{c}\text { (MG/L) } \\
(70300\end{array}$ \\
\hline
\end{tabular}

OCT 1981

\begin{tabular}{|c|c|c|c|c|c|c|c|c|c|c|c|c|}
\hline $16 \ldots$ & 3.1 & 6.1 & 19 & 0.4 & 2.5 & - & - & 13 & 16 & $<0.10$ & 16 & 121 \\
\hline $\begin{array}{c}\text { ОСТ } 1982 \\
18 \ldots\end{array}$ & 5.5 & 6.2 & 15 & 3 & 12 & 50 & - & 15 & 12 & $<10$ & 20 & 130 \\
\hline OCT 1983 & 3.3 & 0.2 & 13 & (.3) & 1.2 & 50 & & 13 & 12 & & & \\
\hline $18 \ldots$ & 5.8 & 6.7 & 15 & .3 & 2.2 & 54 & - & 16 & 17 & - & 19 & 148 \\
\hline $\begin{array}{c}05 \ldots \\
\text { OCT } 1985\end{array}$ & 6.0 & 8.1 & 18 & .4 & 1.9 & 52 & - & 16 & 16 & - & 18 & 127 \\
\hline $\begin{array}{c}08 \ldots \\
\text { ост } 1986\end{array}$ & 6.0 & 7.2 & 17 & .4 & 2.3 & 48 & - & 20 & 12 & - & 18 & 134 \\
\hline $\begin{array}{c}07 \ldots \\
\text { ОСт } 1987\end{array}$ & 5.9 & 7.4 & 16 & .4 & 2.2 & 56 & - & 16 & 12 & - & 21 & 146 \\
\hline $\begin{array}{c}09 \ldots \\
\text { ОСТ } 1988\end{array}$ & 5.8 & 8.5 & 19 & .4 & 2.2 & 54 & - & 14 & 16 & - & 18 & 127 \\
\hline $\begin{array}{c}13 \ldots \\
\text { OCT } 1989\end{array}$ & 6.2 & 7.7 & 17 & .4 & 1.7 & 56 & - & 16 & 15 & - & 17 & - \\
\hline $\begin{array}{c}05 \ldots \\
\text { OCT } 1990\end{array}$ & 5.9 & 7.0 & 17 & .4 & 1.9 & 46 & - & 15 & 14 & - & 17 & - \\
\hline $\begin{array}{c}03 \ldots \\
\text { ОСТ } 1991\end{array}$ & 5.7 & 7.4 & 17 & .4 & 1.9 & 65 & - & 14 & 17 & $<.10$ & 18 & - \\
\hline $\begin{array}{c}03 \ldots \\
\text { OCT } 1992\end{array}$ & 5.5 & 7.1 & 16 & .4 & 1.9 & 54 & - & 14 & 17 & .20 & 17 & - \\
\hline $\begin{array}{c}08 \ldots \\
\text { OCT } 1993\end{array}$ & 5.9 & 7.1 & 15 & .3 & 1.8 & - & 55 & 15 & 15 & .10 & 20 & - \\
\hline $\begin{array}{c}07 \ldots \\
\text { OCT } 1994\end{array}$ & - & - & - & - & - & - & 52 & - & - & - & - & - \\
\hline $25 \ldots$ & - & - & - & - & - & - & 47 & - & 19 & - & - & - \\
\hline
\end{tabular}


Table 3. Water-quality data from surface-water sites-Continued

01472174 - Pickering Creek near Chester Springs, Pa. (Site 2)—Continued

\begin{tabular}{|c|c|c|c|c|c|c|c|c|c|c|c|}
\hline DATE & $\begin{array}{l}\text { SOLIDS, } \\
\text { SUM OF } \\
\text { CONSTI- } \\
\text { TUENTS, } \\
\text { DIS- } \\
\text { SOLVED } \\
\text { (MG/L) } \\
(70301)\end{array}$ & $\begin{array}{c}\text { SOLIDS, } \\
\text { DIS- } \\
\text { SOLVED } \\
\text { (TONS } \\
\text { PER } \\
\text { AC-FT) } \\
(70303)\end{array}$ & $\begin{array}{c}\text { SOLIDS, } \\
\text { DIS- } \\
\text { SOLVED } \\
\text { (TONS } \\
\text { PER } \\
\text { DAY) } \\
(70302)\end{array}$ & $\begin{array}{c}\text { NITRO- } \\
\text { GEN, } \\
\text { NITRATE } \\
\text { TOTAL } \\
\text { (MG/L } \\
\text { AS N) } \\
(00620)\end{array}$ & $\begin{array}{l}\text { NITRO- } \\
\text { GEN, } \\
\text { NITRATE } \\
\text { DIS- } \\
\text { SOLVED } \\
\text { (MG/L } \\
\text { AS N) } \\
(00618)\end{array}$ & $\begin{array}{l}\text { NITRO- } \\
\text { GEN, } \\
\text { NITRATE } \\
\text { DIS- } \\
\text { SOLVED } \\
\text { (MG/L } \\
\left.\text { AS NO } \text { NO }_{3}\right) \\
(71851)\end{array}$ & $\begin{array}{l}\text { NITRO- } \\
\text { GEN, } \\
\text { NITRITE } \\
\text { DIS- } \\
\text { SOLVED } \\
\text { (MG/L } \\
\text { AS N) } \\
(00613)\end{array}$ & $\begin{array}{c}\text { NITRO- } \\
\text { GEN, } \\
\mathrm{NO}_{2}+\mathrm{NO}_{3} \\
\text { DIS- } \\
\text { SOLVED } \\
(\mathrm{MG} / \mathrm{L} \\
\mathrm{AS} \mathrm{N}) \\
(00631)\end{array}$ & $\begin{array}{c}\text { NITRO- } \\
\text { GEN, } \\
\text { AMMONIA } \\
\text { DIS- } \\
\text { SOLVED } \\
\text { (MG/L } \\
\text { AS N) } \\
(00608)\end{array}$ & $\begin{array}{c}\text { NITRO- } \\
\text { GEN, } \\
\text { AMMONIA } \\
\text { DIS- } \\
\text { SOLVED } \\
\text { (MG/L } \\
\left.\text { AS NH } \text { N }_{4}\right) \\
(71846)\end{array}$ & $\begin{array}{l}\text { NITRO- } \\
\text { GEN, } \\
\text { ORGANIC } \\
\text { TOTAL } \\
\text { (MG/L } \\
\text { AS N) } \\
(00605)\end{array}$ \\
\hline OCT 1981 & & & & & & & & & & & \\
\hline $\begin{array}{c}16 \ldots \\
\text { OCT } 1982\end{array}$ & - & 0.16 & - & 1.70 & 1.70 & 7.5 & 0.010 & 1.70 & 0.020 & 0.03 & 0.23 \\
\hline $\begin{array}{c}18 \ldots \\
\text { OCT } 1983\end{array}$ & 120 & .18 & 1.25 & - & 2.20 & 9.7 & .020 & 2.20 & .030 & .04 & - \\
\hline $\begin{array}{c}18 \ldots \\
\text { OCT } 1984\end{array}$ & 133 & .20 & 1.04 & - & 2.30 & 10 & .040 & 2.30 & .110 & .14 & - \\
\hline $\begin{array}{c}05 \ldots \\
\text { ОСТ } 1985\end{array}$ & 131 & .17 & 1.37 & - & - & - & $<.010$ & 2.80 & .050 & .06 & - \\
\hline $\begin{array}{c}08 \ldots \\
\text { OCT } 1986\end{array}$ & 123 & .18 & 1.85 & - & - & - & $<.010$ & 2.10 & .030 & .04 & - \\
\hline $\begin{array}{c}07 \ldots \\
\text { OCT } 1987\end{array}$ & 128 & .20 & .83 & - & 1.69 & 7.5 & .010 & 1.70 & .040 & .05 & .96 \\
\hline $\begin{array}{c}09 \ldots \\
\text { OCT } 1988\end{array}$ & 126 & .17 & .93 & - & - & - & $<.010$ & 1.70 & .020 & .03 & .38 \\
\hline $\begin{array}{c}13 \ldots \\
\text { ОСТ } 1989\end{array}$ & 129 & .17 & .94 & - & - & - & $<.010$ & 2.10 & .030 & .04 & - \\
\hline $\begin{array}{c}05 \ldots \\
\text { OCT } 1990\end{array}$ & 120 & .16 & 2.36 & - & 2.49 & 11 & .010 & 2.50 & .020 & .03 & .18 \\
\hline $\begin{array}{c}03 \ldots \\
\text { OCT } 1991\end{array}$ & 133 & .18 & 1.03 & - & - & - & $<.010$ & 2.00 & .020 & .03 & .38 \\
\hline $\begin{array}{c}03 \ldots \\
\text { OCT } 1992\end{array}$ & 125 & .17 & .66 & - & - & - & $<.010$ & 1.80 & $<.010$ & - & - \\
\hline $\begin{array}{c}08 \ldots \\
\text { OCT } 1993\end{array}$ & 132 & .18 & .57 & - & - & - & $<.010$ & 2.20 & .020 & .03 & - \\
\hline $\begin{array}{c}07 \ldots \\
\text { OCT } 1994\end{array}$ & - & - & - & - & - & - & $<.010$ & 2.10 & .020 & .03 & - \\
\hline $25 \ldots$ & - & - & - & - & - & - & $<.010$ & 1.70 & $<.015$ & - & - \\
\hline
\end{tabular}


Table 3. Water-quality data from surface-water sites-Continued

01472174 - Pickering Creek near Chester Springs, Pa. (Site 2)—Continued

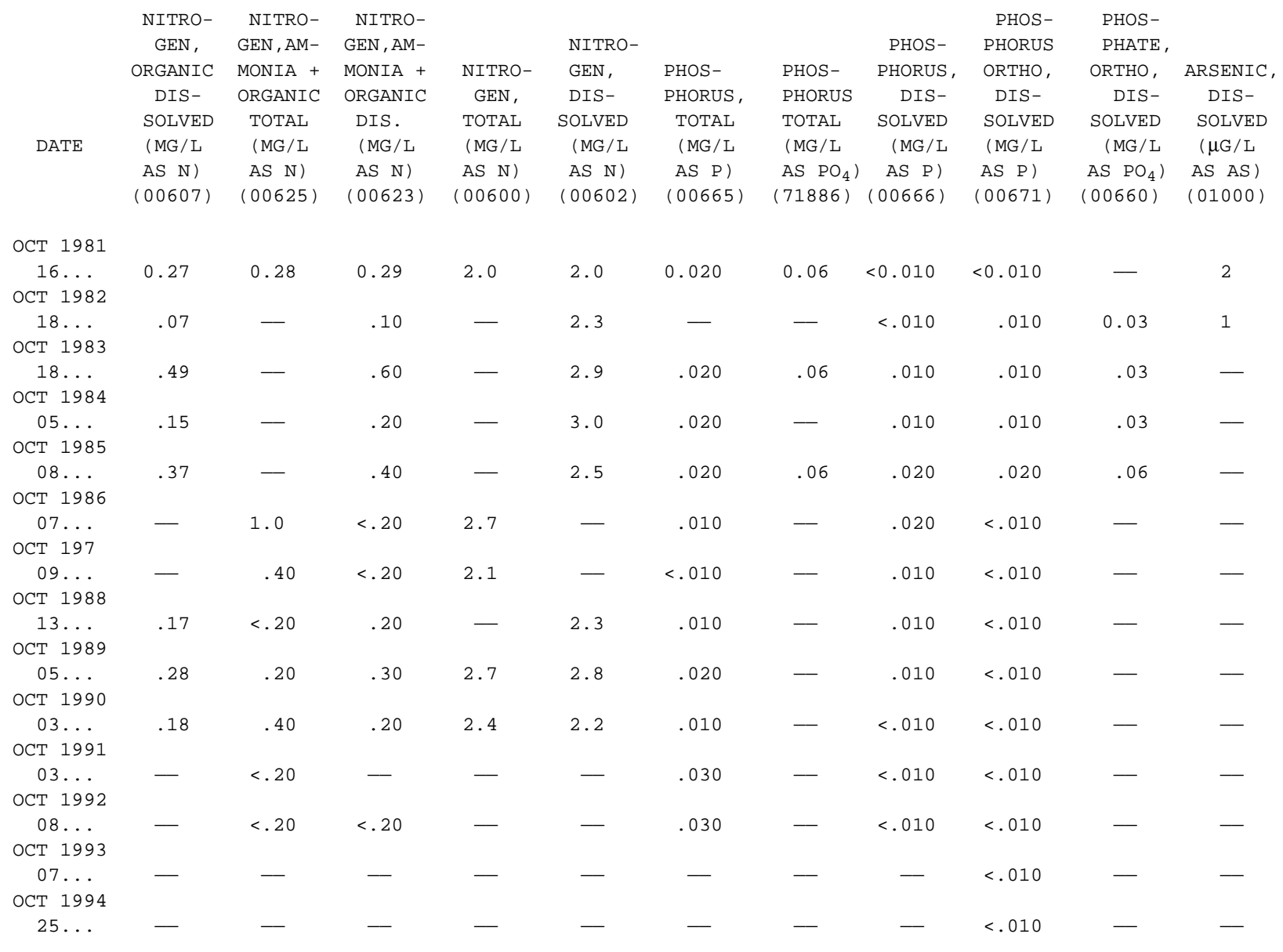


Table 3. Water-quality data from surface-water sites-Continued

01472174 - Pickering Creek near Chester Springs, Pa. (Site 2)—Continued

\begin{tabular}{|c|c|c|c|c|c|c|c|c|c|c|c|}
\hline DATE & $\begin{array}{c}\text { CADMIUM } \\
\text { DIS- } \\
\text { SOLVED } \\
(\mu \mathrm{G} / \mathrm{L} \\
\text { AS CD }) \\
(01025)\end{array}$ & $\begin{array}{l}\text { CHRO- } \\
\text { MIUM, } \\
\text { DIS- } \\
\text { SOLVED } \\
(\mu \mathrm{G} / \mathrm{L} \\
\text { AS CR) } \\
(01030)\end{array}$ & $\begin{array}{c}\text { COBALT, } \\
\text { DIS- } \\
\text { SOLVED } \\
(\mu \mathrm{G} / \mathrm{L} \\
\text { AS CO) } \\
(01035)\end{array}$ & $\begin{array}{l}\text { COPPER, } \\
\text { DIS- } \\
\text { SOLVED } \\
(\mu \mathrm{G} / \mathrm{L} \\
\text { AS CU) } \\
(01040)\end{array}$ & $\begin{array}{c}\text { IRON, } \\
\text { DIS- } \\
\text { SOLVED } \\
(\mu \mathrm{G} / \mathrm{L} \\
\text { AS FE) } \\
(01046)\end{array}$ & $\begin{array}{c}\text { LEAD, } \\
\text { DIS- } \\
\text { SOLVED } \\
(\mu \mathrm{G} / \mathrm{L} \\
\text { AS PB) } \\
(01049)\end{array}$ & $\begin{array}{l}\text { MANGA- } \\
\text { NESE, } \\
\text { DIS- } \\
\text { SOLVED } \\
(\mu \mathrm{G} / \mathrm{L} \\
\text { AS MN) } \\
(01056)\end{array}$ & $\begin{array}{l}\text { MERCURY, } \\
\text { DIS- } \\
\text { SOLVED } \\
(\mu \mathrm{G} / \mathrm{L} \\
\text { AS HG) } \\
(71890)\end{array}$ & $\begin{array}{l}\text { NICKEL, } \\
\text { DIS- } \\
\text { SOLVED } \\
(\mu \mathrm{G} / \mathrm{L} \\
\text { AS NI) } \\
(01065)\end{array}$ & $\begin{array}{c}\text { ZINC, } \\
\text { DIS- } \\
\text { SOLVED } \\
(\mu \mathrm{G} / \mathrm{L} \\
\text { AS ZN) } \\
(01090)\end{array}$ & $\begin{array}{l}\text { METHY- } \\
\text { LENE } \\
\text { BLUE } \\
\text { ACTIVE } \\
\text { SUB- } \\
\text { STANCE } \\
\text { (MG/L) } \\
(38260)\end{array}$ \\
\hline OCT 1981 & & & & & & & & & & & \\
\hline $\begin{array}{c}16 \ldots \\
\text { OCT } 1982\end{array}$ & 1.0 & $<1.0$ & 2.0 & 4.0 & 110 & $<1.0$ & 20 & $<0.1$ & 3.0 & $<10$ & - \\
\hline $\begin{array}{c}18 \ldots \\
\text { OCT } 1983\end{array}$ & $<1.0$ & 1.0 & $<1.0$ & $<1.0$ & 80 & $<1.0$ & 15 & $<.1$ & 2.0 & $<4.0$ & 0.02 \\
\hline $\begin{array}{c}18 \ldots \\
\text { OCT } 1984\end{array}$ & - & - & - & - & 78 & - & 18 & - & - & - & - \\
\hline $\begin{array}{c}05 \ldots \\
\text { OCT } 1985\end{array}$ & - & - & - & - & 67 & - & 33 & - & - & - & - \\
\hline $\begin{array}{c}08 \ldots \\
\text { OCT } 1986\end{array}$ & - & - & - & - & 89 & - & 34 & - & - & - & - \\
\hline $\begin{array}{c}07 \ldots \\
\text { OCT } 1987\end{array}$ & - & - & - & - & 110 & - & 25 & - & - & - & - \\
\hline $\begin{array}{c}09 \ldots \\
\text { OCT } 1988\end{array}$ & - & - & - & - & 120 & - & 25 & - & - & - & - \\
\hline $\begin{array}{c}13 \ldots \\
\text { OCT } 1989\end{array}$ & - & - & - & - & 72 & - & 17 & - & - & - & - \\
\hline $\begin{array}{c}05 \ldots \\
\text { OCT } 1990\end{array}$ & - & - & - & - & 85 & - & 32 & - & - & - & - \\
\hline $\begin{array}{c}03 \ldots \\
\text { OCT } 1991\end{array}$ & - & - & - & - & 78 & - & 21 & - & - & - & - \\
\hline $\begin{array}{c}03 \ldots \\
\text { OCT } 1992\end{array}$ & - & - & - & - & 85 & - & 15 & - & - & - & - \\
\hline $\begin{array}{c}08 \ldots \\
\text { OCT } 1993\end{array}$ & - & - & - & - & 99 & - & 20 & - & - & - & - \\
\hline $\begin{array}{c}07 \ldots \\
\text { OCT } 1994\end{array}$ & - & - & - & - & - & - & - & - & - & - & - \\
\hline $25 \ldots$ & - & - & - & - & - & - & - & - & - & - & - \\
\hline
\end{tabular}


Table 3. Water-quality data from surface-water sites-Continued

014721854 - Pickering Creek at Merlin, Pa. (Site 3)

\begin{tabular}{|c|c|c|c|c|c|c|c|c|c|c|c|c|}
\hline & & DIS- & & $\mathrm{PH}$ & & & & & HARD- & & & \\
\hline & & CHARGE, & SPE- & WATER & & & & HARD - & NESS, & & MAGNE- & \\
\hline & & INST. & CIFIC & WHOLE & & & & NESS, & NONCARB & CALCIUM, & SIUM, & SODIUM, \\
\hline & & (CUBIC & $\mathrm{CON}-$ & FIELD & TEMPER- & TUR- & OXYGEN, & TOTAL & WH WAT & DIS- & DIS- & DIS- \\
\hline & & FEET & DUCT- & (STAND- & ATURE & BID- & DIS- & (MG / L & TOT FLD & SOLVED & SOLVED & SOLVED \\
\hline DATE & TIME & PER & ANCE & ARD & WATER & ITY & SOLVED & AS & (MG/L AS & (MG / L & $(\mathrm{MG} / \mathrm{L}$ & (MG / L \\
\hline & & SECOND) & $(\mu \mathrm{S} / \mathrm{CM})$ & UNITS) & $(\mathrm{DEG} \quad \mathrm{C})$ & (NTU) & (MG/L) & $\left.\mathrm{CACO}_{3}\right)$ & $\mathrm{CACO}_{3}$ ) & AS CA) & AS $\quad$ MG) & AS NA) \\
\hline & & $(00061)$ & $(00095)$ & $(00400)$ & $(00010)$ & $(00076)$ & $(00300)$ & $(00900)$ & $(00902)$ & (00915) & $(00925)$ & $(00930)$ \\
\hline
\end{tabular}

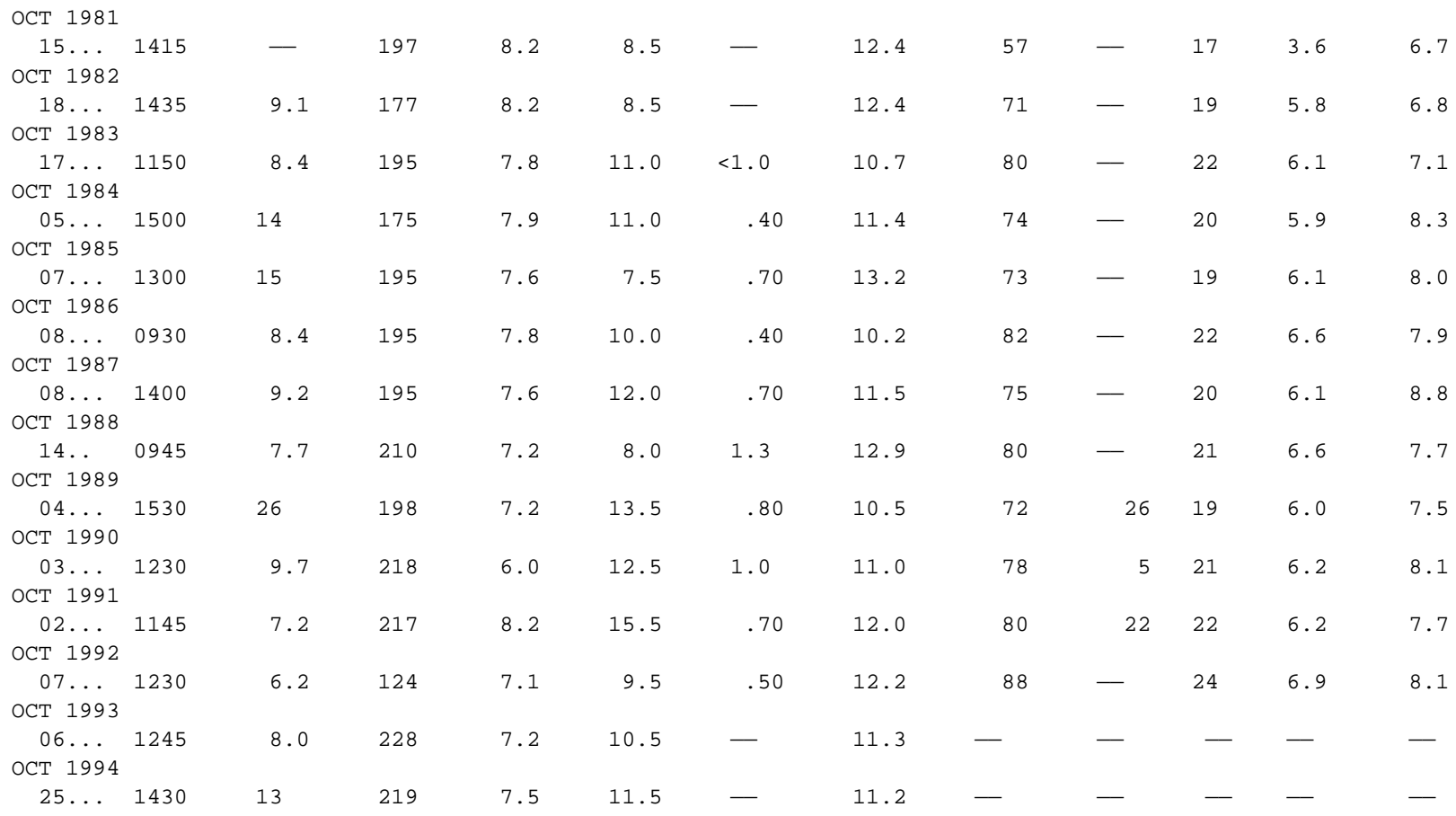


Table 3. Water-quality data from surface-water sites-Continued

014721854 - Pickering Creek at Merlin, Pa. (Site 3)—Continued

\begin{tabular}{|c|c|c|c|c|c|c|c|c|c|c|c|}
\hline & & & POTAS- & $\begin{array}{l}\text { ALKA- } \\
\text { LINITY }\end{array}$ & $\begin{array}{l}\text { ALKA- } \\
\text { LINITY }\end{array}$ & & CHLO- & FLUO- & SILICA, & $\begin{array}{l}\text { SOLIDS, } \\
\text { RESIDUE }\end{array}$ & $\begin{array}{l}\text { SOLIDS, } \\
\text { SUM OF }\end{array}$ \\
\hline & & SODIUM & SIUM, & WAT WH & WAT WH & SULFATE, & RIDE, & RIDE， & DIS- & $\mathrm{AT} 180$ & CONSTI- \\
\hline & & AD- & DIS- & TOT FET & TOT IT & DIS- & DIS- & DIS- & SOLVED & DEG. C & TUENTS, \\
\hline \multirow{3}{*}{ DATE } & SODIUM & $\begin{array}{l}\text { SORP } \\
\text { TION }\end{array}$ & $\begin{array}{l}\text { SOLVED } \\
\text { (MG/L }\end{array}$ & $\begin{array}{l}\text { FIELD } \\
\text { (MG/L AS }\end{array}$ & $\begin{array}{l}\text { FIELD } \\
\text { (MG/L AS }\end{array}$ & $\begin{array}{ll} & \text { SOLVED } \\
\text { S } & \text { (MG/L }\end{array}$ & $\begin{array}{l}\text { SOLVED } \\
\text { (MG/L }\end{array}$ & $\begin{array}{l}\text { SOLVED } \\
\text { (MG/L }\end{array}$ & $\begin{array}{l}\text { (MG / L } \\
\text { AS }\end{array}$ & $\begin{array}{c}\text { DIS- } \\
\text { SOLVED }\end{array}$ & $\begin{array}{l}\text { DIS- } \\
\text { SOLVED }\end{array}$ \\
\hline & PERCENT & RATIC & AS K) & $\left.\mathrm{CACO}_{3}\right)$ & $\left.\mathrm{CACO}_{3}\right)$ & AS $\mathrm{SO}_{4}$ ) & AS CL) & AS F) & $\mathrm{SIO}_{2}$ & (MG/L) & (MG/L) \\
\hline & $(00932)$ & $(00931)$ & $(00935)$ & $(00410)$ & (00419) & $(00945)$ & $(00940)$ & $(00950)$ & $(00955)$ & $(70300)$ & (70301 \\
\hline
\end{tabular}

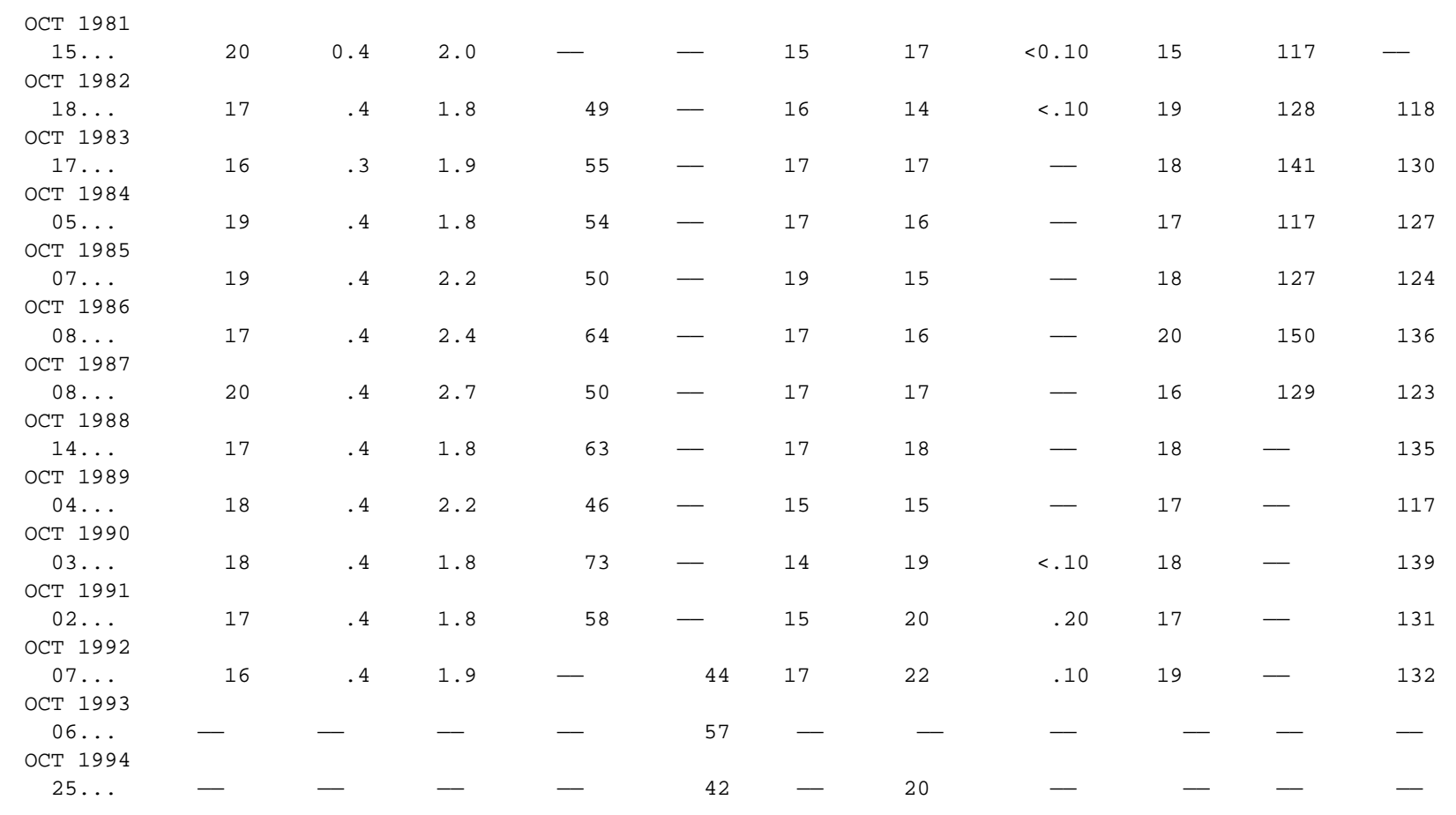


Table 3. Water-quality data from surface-water sites-Continued

014721854 - Pickering Creek at Merlin, Pa. (Site 3)—Continued

\begin{tabular}{|c|c|c|c|c|c|c|c|c|c|c|c|}
\hline DATE & $\begin{array}{c}\text { SOLIDS, } \\
\text { DIS- } \\
\text { SOLVED } \\
\text { (TONS } \\
\text { PER } \\
\text { AC-FT) } \\
(70303)\end{array}$ & $\begin{array}{c}\text { SOLIDS, } \\
\text { DIS- } \\
\text { SOLVED } \\
\text { (TONS } \\
\text { PER } \\
\text { DAY) } \\
(70302)\end{array}$ & $\begin{array}{c}\text { NITRO- } \\
\text { GEN, } \\
\text { NITRATE } \\
\text { TOTAL } \\
\text { (MG/L } \\
\text { AS N) } \\
(00620)\end{array}$ & $\begin{array}{c}\text { NITRO- } \\
\text { GEN, } \\
\text { NITRATE } \\
\text { DIS- } \\
\text { SOLVED } \\
\text { (MG/L } \\
\text { AS N) } \\
(00618)\end{array}$ & $\begin{array}{c}\text { NITRO- } \\
\text { GEN, } \\
\text { NITRATE } \\
\text { DIS- } \\
\text { SOLVED } \\
\text { (MG/L } \\
\left.\text { AS NO }{ }_{3}\right) \\
(71851)\end{array}$ & $\begin{array}{l}\text { NITRO- } \\
\text { GEN, } \\
\text { NITRITE } \\
\text { DIS- } \\
\text { SOLVED } \\
\text { (MG/L } \\
\text { AS N) } \\
(00613)\end{array}$ & $\begin{array}{c}\text { NITRO- } \\
\text { GEN, } \\
\mathrm{NO}_{2}+\mathrm{NO}_{3} \\
\text { DIS- } \\
\text { SOLVED } \\
(\mathrm{MG} / \mathrm{L} \\
\mathrm{AS} \mathrm{N}) \\
(00631)\end{array}$ & $\begin{array}{c}\text { NITRO- } \\
\text { GEN, } \\
\text { AMMONIA } \\
\text { DIS- } \\
\text { SOLVED } \\
\text { (MG/L } \\
\text { AS N) } \\
(00608)\end{array}$ & $\begin{array}{c}\text { NITRO- } \\
\text { GEN, } \\
\text { AMMONIA } \\
\text { DIS- } \\
\text { SOLVED } \\
\text { (MG/L } \\
\text { AS NH4) } \\
(71846)\end{array}$ & $\begin{array}{l}\text { NITRO- } \\
\text { GEN, } \\
\text { ORGANIC } \\
\text { TOTAL } \\
\text { (MG/L } \\
\text { AS N) } \\
(00605)\end{array}$ & $\begin{array}{c}\text { NITRO- } \\
\text { GEN, } \\
\text { ORGANIC } \\
\text { DIS- } \\
\text { SOLVED } \\
\text { (MG/L } \\
\text { AS N) } \\
(00607)\end{array}$ \\
\hline CT 1981 & & & & & & & & & & & \\
\hline $\begin{array}{c}15 \ldots \\
\text { OCT } 1982\end{array}$ & 0.16 & - & 1.09 & 1.09 & 4.8 & 0.010 & 1.10 & 0.020 & 0.03 & 0.17 & 0.21 \\
\hline $\begin{array}{c}18 \ldots \\
\text { OCT } 1983\end{array}$ & .17 & 3.15 & 1.38 & 1.38 & 6.1 & .020 & 1.40 & .020 & .03 & - & - \\
\hline $\begin{array}{c}17 \ldots \\
\text { ОСТ } 1984\end{array}$ & .19 & 3.20 & 1.65 & 1.65 & 7.3 & .050 & 1.70 & .170 & .22 & - & .13 \\
\hline $\begin{array}{c}05 \ldots \\
\text { OCT } 1985\end{array}$ & .16 & 4.42 & 1.90 & - & - & $<.010$ & 1.90 & .070 & .09 & - & .53 \\
\hline $\begin{array}{c}07 \ldots \\
\text { OCT } 1986\end{array}$ & .17 & 5.14 & 1.50 & - & - & $<.010$ & 1.50 & .020 & .03 & .48 & .38 \\
\hline $\begin{array}{c}08 \ldots \\
\text { OCT } 1987\end{array}$ & .20 & 3.40 & 1.20 & - & - & $<.010$ & 1.20 & $<.010$ & - & .30 & - \\
\hline $\begin{array}{c}08 \ldots \\
\text { OCT } 1988\end{array}$ & .18 & 3.20 & 1.10 & - & - & $<.010$ & 1.10 & .030 & .04 & .37 & .37 \\
\hline $\begin{array}{c}14 \ldots \\
\text { OCT } 1989\end{array}$ & .18 & 2.80 & 1.50 & - & - & $<.010$ & 1.50 & .010 & .01 & .29 & - \\
\hline $\begin{array}{c}04 \ldots \\
\text { OCT } 1990\end{array}$ & .16 & 8.22 & 1.70 & - & - & $<.010$ & 1.70 & .020 & .03 & - & .28 \\
\hline $\begin{array}{c}03 \ldots \\
\text { OCT } 1991\end{array}$ & .19 & 3.62 & 1.50 & - & - & $<.010$ & 1.50 & .010 & .01 & .29 & .39 \\
\hline $\begin{array}{c}02 \ldots \\
\text { OCT } 1992\end{array}$ & .18 & 2.55 & 1.40 & - & - & $<.010$ & 1.40 & $<.010$ & - & - & - \\
\hline $\begin{array}{c}07 \ldots \\
\text { OCT } 1993\end{array}$ & .18 & 2.20 & 1.40 & - & - & $<.010$ & 1.40 & .020 & .03 & - & - \\
\hline $\begin{array}{c}06 \ldots \\
\text { OCT } 1994\end{array}$ & - & - & 1.60 & - & - & $<.010$ & 1.60 & .010 & .01 & - & - \\
\hline $25 \ldots$ & - & - & 1.00 & - & - & $<.010$ & 1.00 & $<.015$ & - & - & - \\
\hline
\end{tabular}


Table 3. Water-quality data from surface-water sites-Continued

014721854 - Pickering Creek at Merlin, Pa. (Site 3)—Continued

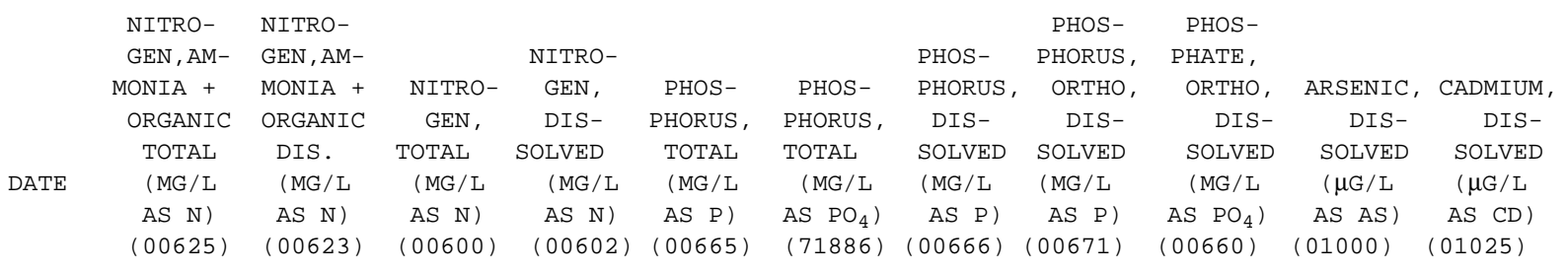

\begin{tabular}{|c|c|c|c|c|c|c|c|c|c|c|c|}
\hline $\begin{array}{c}15 \ldots \\
\text { OCT } 1982\end{array}$ & 0.22 & 0.23 & 1.3 & 1.3 & 0.020 & 0.06 & $<0.010$ & $<0.010$ & - & 2 & 1.0 \\
\hline $\begin{array}{c}18 \ldots \\
\mathrm{OCT} 1983\end{array}$ & - & $<.10$ & - & - & - & - & .050 & .020 & 0.06 & 1 & $<1.0$ \\
\hline $\begin{array}{c}17 \ldots \\
\text { OCT } 1984\end{array}$ & - & .30 & - & 2.0 & .010 & .03 & .010 & $<.010$ & - & - & - \\
\hline $\begin{array}{c}05 \ldots \\
\text { OCT } 1985\end{array}$ & - & .60 & - & 2.5 & .030 & - & $<.010$ & .020 & .06 & - & - \\
\hline $\begin{array}{c}07 \ldots \\
\text { OCT } 1986\end{array}$ & .50 & .40 & 2.0 & 1.9 & .020 & .06 & .020 & .010 & .03 & - & - \\
\hline $\begin{array}{c}08 \ldots \\
\text { OCT } 1987\end{array}$ & .30 & .20 & 1.5 & 1.4 & .070 & - & .010 & $<.010$ & - & $<1$ & $<1.0$ \\
\hline $\begin{array}{c}08 \ldots \\
\text { ОСТ } 1988\end{array}$ & .40 & .40 & 1.5 & 1.5 & .010 & - & .010 & $<.010$ & - & - & - \\
\hline $\begin{array}{c}14 \ldots \\
\text { OCT } 1989\end{array}$ & .30 & $<.20$ & 1.8 & - & .020 & - & .010 & $<.010$ & - & - & - \\
\hline $\begin{array}{c}04 \ldots \\
\text { OCT } 1990\end{array}$ & $<.20$ & .30 & - & 2.0 & .030 & - & .020 & .020 & .06 & - & - \\
\hline $\begin{array}{c}03 \ldots \\
\text { OCT } 1991\end{array}$ & .30 & .40 & 1.8 & 1.9 & $<.010$ & - & $<.010$ & $<.010$ & - & - & - \\
\hline $\begin{array}{c}02 \ldots \\
\text { OCT } 1992\end{array}$ & $<.20$ & - & - & - & .020 & - & $<.010$ & .010 & .03 & - & - \\
\hline $\begin{array}{c}07 \ldots \\
\text { OCT } 1993\end{array}$ & $<.20$ & $<.20$ & - & - & .020 & - & $<.010$ & $<.010$ & - & - & - \\
\hline $\begin{array}{c}06 \ldots \\
\text { OCT } 1994\end{array}$ & - & - & - & - & - & - & - & $<.010$ & - & - & - \\
\hline $25 \ldots$ & - & - & - & - & - & - & - & $<.010$ & - & - & - \\
\hline
\end{tabular}


Table 3. Water-quality data from surface-water sites-Continued

014721854 - Pickering Creek at Merlin, Pa. (Site 3)-Continued

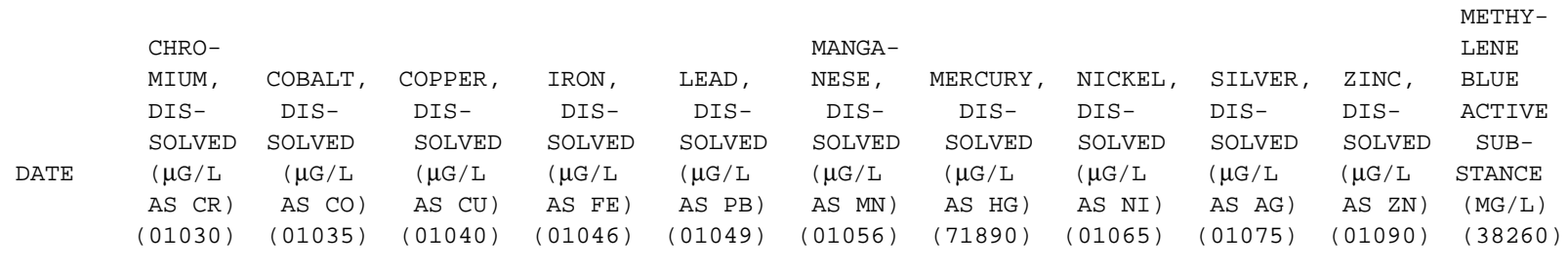

\begin{tabular}{|c|c|c|c|c|c|c|c|c|c|c|c|}
\hline $\begin{array}{c}\text { OCT } 1981 \\
15 \ldots \\
\text { OCT } 1982\end{array}$ & $<1$ & 2 & 3 & 100 & $<1$ & 10 & $<0.1$ & 2 & - & 10 & - \\
\hline $\begin{array}{c}18 \ldots \\
\text { OCT } 1983\end{array}$ & $<1$ & $<1$ & $<1$ & 63 & $<1$ & 11 & $<.1$ & 2 & - & $<4$ & 0.02 \\
\hline $\begin{array}{c}17 \ldots \\
\text { ОСТ } 1984\end{array}$ & - & - & - & 76 & - & 15 & - & - & - & - & - \\
\hline $\begin{array}{c}05 \ldots \\
\text { ОСт } 1985\end{array}$ & - & - & - & 59 & - & 18 & - & - & - & - & - \\
\hline $\begin{array}{c}07 \ldots \\
\text { OCT } 1986\end{array}$ & - & - & - & 72 & - & 22 & - & - & - & - & - \\
\hline $\begin{array}{c}08 \ldots \\
\text { ОСт } 1987\end{array}$ & $<1$ & - & 1 & 84 & $<5$ & 10 & - & 2 & $<1.0$ & $<3$ & - \\
\hline $\begin{array}{c}08 \ldots \\
\text { ОСт } 1988\end{array}$ & - & - & - & 79 & - & 13 & - & - & - & - & - \\
\hline $\begin{array}{c}14 \ldots \\
\text { ОСт } 1989\end{array}$ & - & - & - & 63 & - & 10 & - & - & - & - & - \\
\hline $\begin{array}{c}04 \ldots \\
\text { ОСТ } 1990\end{array}$ & - & - & - & 130 & - & 25 & - & - & - & - & - \\
\hline $\begin{array}{c}03 \ldots \\
\text { ОСт } 1991\end{array}$ & - & - & - & 67 & - & 14 & - & - & - & - & - \\
\hline $\begin{array}{c}02 \ldots \\
\text { ОСт } 1992\end{array}$ & - & - & - & 180 & - & 14 & - & - & - & - & - \\
\hline $\begin{array}{c}07 \ldots \\
\text { Ост } 1993\end{array}$ & - & - & - & 77 & - & 17 & - & - & - & - & - \\
\hline $\begin{array}{c}06 \ldots \\
\text { ОСТ } 1994\end{array}$ & - & - & - & - & - & - & - & - & - & - & - \\
\hline $25 \ldots$ & - & - & - & - & - & - & - & - & - & - & - \\
\hline
\end{tabular}


Table 3. Water-quality data from surface-water sites-Continued

014721884 - Pickering Creek at Charlestown Road Bridge at Charlestown, Pa. (Site 4)

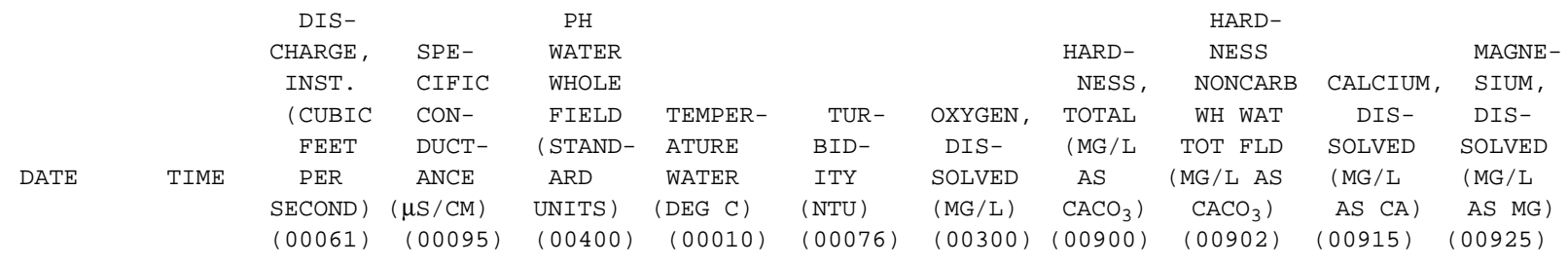

\begin{tabular}{|c|c|c|c|c|c|c|c|c|c|c|c|}
\hline $\begin{array}{c}\text { OCT } 1981 \\
15 \ldots \\
\text { OCT } 1982\end{array}$ & 0930 & - & 200 & 7.9 & 7.5 & - & 13.0 & 59 & - & 17 & 4.0 \\
\hline $\begin{array}{c}19 \ldots \\
\text { OCT } 1983\end{array}$ & 1345 & 13 & 192 & 7.5 & 9.5 & - & 11.4 & 79 & - & 21 & 6.4 \\
\hline $\begin{array}{c}17 \ldots \\
\text { OCT } 1984\end{array}$ & 0850 & 11 & 185 & 8.1 & 13.0 & $<1.0$ & 1.5 & 81 & - & 22 & 6.3 \\
\hline $\begin{array}{c}09 \ldots \\
\text { OCT } 1985\end{array}$ & 0930 & 17 & 190 & 8.0 & 12.0 & .50 & 1.8 & 75 & - & 20 & 6.1 \\
\hline $\begin{array}{c}07 \ldots \\
\text { OCT } 1986\end{array}$ & 0845 & 22 & 205 & 7.4 & 4.0 & 1.0 & 12.7 & 73 & - & 19 & 6.2 \\
\hline $\begin{array}{c}06 \ldots \\
\text { OCT } 1987\end{array}$ & 0930 & 11 & 210 & 7.6 & 15.5 & .80 & 8.7 & 83 & - & 22 & 6.7 \\
\hline $\begin{array}{c}08 \ldots \\
\text { OCT } 1988\end{array}$ & 0930 & 13 & 200 & 7.3 & 11.0 & .70 & 11.4 & 76 & - & 20 & 6.4 \\
\hline $\begin{array}{c}12 \ldots \\
\text { OCT } 1989\end{array}$ & 0930 & 11 & 220 & 7.1 & 1.5 & 1.2 & 11.6 & 80 & - & 21 & 6.7 \\
\hline $\begin{array}{c}04 \ldots \\
\text { OCT } 1990\end{array}$ & 1105 & 33 & 202 & 7.6 & 12.5 & 1.3 & 10.5 & 73 & 24 & 19 & 6.1 \\
\hline $\begin{array}{c}02 \ldots \\
\text { OCT } 1991\end{array}$ & 0930 & 13 & 189 & 7.5 & 13.5 & .40 & 10.4 & 82 & 30 & 22 & 6.5 \\
\hline $\begin{array}{c}02 \ldots \\
\text { OCT } 1992\end{array}$ & 0830 & 8.1 & 218 & 7.6 & 14.5 & 1.0 & 9.6 & 80 & 17 & 22 & 6.2 \\
\hline $\begin{array}{c}06 \ldots \\
\text { OCT } 1993\end{array}$ & 1000 & 7.6 & 222 & 6.9 & 9.5 & .40 & 12.4 & 84 & - & 23 & 6.5 \\
\hline $\begin{array}{c}06 \ldots \\
\text { OCT } 1994\end{array}$ & 0900 & 10 & 232 & 7.3 & 9.5 & - & 11.2 & - & - & - & - \\
\hline $26 \ldots$ & 1245 & 15 & 230 & 7.1 & 9.5 & - & 11.9 & - & - & - & - \\
\hline
\end{tabular}


Table 3. Water-quality data from surface-water sites-Continued

014721884 - Pickering Creek at Charlestown Road Bridge at Charlestown, Pa. (Site 4)—Continued

\begin{tabular}{|c|c|c|c|c|c|c|c|c|c|c|c|}
\hline & & & & POTAS- & $\begin{array}{l}\text { ALKA- } \\
\text { LINITY }\end{array}$ & $\begin{array}{l}\text { ALKA- } \\
\text { LINITY }\end{array}$ & & CHLO- & FLUO- & SILICA, & $\begin{array}{l}\text { SOLIDS, } \\
\text { RESIDUE }\end{array}$ \\
\hline & SODIUM, & & SODIUM & SIUM, & WAT WH & WAT WH & SULFATE, & RIDE, & RIDE, & DIS- & AT 180 \\
\hline & DIS- & & $\mathrm{AD}-$ & DIS- & TOT FET & TOT IT & DIS- & DIS- & DIS- & SOLVED & DEG. C \\
\hline & SOLVED & & SORP- & SOLVED & FIELD & FIELD & SOLVED & SOLVED & SOLVED & (MG / L & DIS- \\
\hline DATE & (MG / L & SODIUM & TION & (MG / L & (MG/L AS & (MG/L AS & (MG / L & (MG /L & (MG / L & AS & SOLVED \\
\hline & AS NA) & PERCENT & RATIO & $A S \mathrm{~K})$ & $\left.\mathrm{CACO}_{3}\right)$ & $\left.\mathrm{CACO}_{3}\right)$ & $\left.\mathrm{AS} \quad \mathrm{SO}_{4}\right)$ & AS CL) & AS F) & $\left.\mathrm{SIO}_{2}\right)$ & (MG/L) \\
\hline & $(00930)$ & $(00932)$ & $(00931)$ & $(00935)$ & $(00410)$ & $(00419)$ & $(00945)$ & $(00940)$ & $(00950)$ & $(00955)$ & $(70300)$ \\
\hline
\end{tabular}

\begin{tabular}{|c|c|c|c|c|c|c|c|c|c|c|c|}
\hline $\begin{array}{c}\text { OCT } 1981 \\
15 \ldots \\
\text { OCT } 1982\end{array}$ & 7.0 & 20 & 0.4 & 1.9 & - & - & 16 & 18 & 0.10 & 14 & 165 \\
\hline $\begin{array}{c}19 \ldots \\
\text { OCT } 1983\end{array}$ & 7.5 & 17 & .4 & 1.5 & 49 & - & 16 & 18 & $<.10$ & 20 & 126 \\
\hline $\begin{array}{c}17 \ldots \\
\text { OCT } 1984\end{array}$ & 7.6 & 17 & .4 & 2.0 & 54 & - & 18 & 19 & - & 18 & 132 \\
\hline $\begin{array}{c}09 \ldots \\
\text { OCT } 1985\end{array}$ & 9.0 & 20 & .5 & 1.7 & 52 & - & 17 & 17 & - & 17 & 121 \\
\hline $\begin{array}{c}07 \ldots \\
\text { OCT } 1986\end{array}$ & 8.0 & 19 & .4 & 2.2 & 50 & - & 20 & 16 & - & 18 & 125 \\
\hline $\begin{array}{c}06 \ldots \\
\text { OCT } 1987\end{array}$ & 8.7 & 18 & .4 & 2.7 & 58 & - & 18 & 17 & - & 20 & 156 \\
\hline $\begin{array}{c}08 \ldots \\
\text { OCT } 1988\end{array}$ & 8.5 & 19 & .4 & 2.8 & 53 & - & 17 & 18 & - & 18 & 130 \\
\hline $\begin{array}{c}12 \ldots \\
\text { OCT } 1989\end{array}$ & 7.9 & 17 & .4 & 2.0 & 66 & - & 17 & 18 & - & 17 & - \\
\hline $\begin{array}{c}04 \ldots \\
\text { OCT } 1990\end{array}$ & 8.1 & 19 & .4 & 2.2 & 49 & - & 15 & 15 & - & 18 & - \\
\hline $\begin{array}{c}02 \ldots \\
\text { OCT } 1991\end{array}$ & 9.0 & 19 & .4 & 2.0 & 52 & - & 21 & 20 & $<.10$ & 18 & - \\
\hline $\begin{array}{c}02 \ldots \\
\text { OCT } 1992\end{array}$ & 8.0 & 17 & .4 & 1.8 & 63 & - & 16 & 22 & .20 & 18 & - \\
\hline $\begin{array}{c}06 \ldots \\
\text { OCT } 1993\end{array}$ & 8.4 & 17 & .4 & 1.9 & - & 46 & 17 & 22 & .10 & 18 & - \\
\hline $\begin{array}{c}\text { O6... } \\
\text { OCT } 1994\end{array}$ & - & - & - & - & - & 54 & - & - & - & - & - \\
\hline $26 \ldots$ & - & - & - & - & - & 44 & - & 21 & - & - & - \\
\hline
\end{tabular}


Table 3. Water-quality data from surface-water sites-Continued

014721884 - Pickering Creek at Charlestown Road Bridge at Charlestown, Pa. (Site 4)-Continued

\begin{tabular}{|c|c|c|c|c|c|c|c|c|c|c|c|}
\hline & $\begin{array}{l}\text { SOLIDS, } \\
\text { SUM OF } \\
\text { CONSTI- }\end{array}$ & $\begin{array}{c}\text { SOLIDS, } \\
\text { DIS- }\end{array}$ & $\begin{array}{c}\text { SOLIDS, } \\
\text { DIS- }\end{array}$ & $\begin{array}{c}\text { NITRO- } \\
\text { GEN, }\end{array}$ & $\begin{array}{c}\text { NITRO- } \\
\text { GEN, } \\
\text { NITRATE }\end{array}$ & $\begin{array}{c}\text { NITRO- } \\
\text { GEN, } \\
\text { NITRATE }\end{array}$ & $\begin{array}{c}\text { NITRO- } \\
\text { GEN, } \\
\text { NITRITE }\end{array}$ & $\begin{array}{c}\text { NITRO- } \\
\text { GEN } \\
\mathrm{NO}_{2}+\mathrm{NO}_{3}\end{array}$ & $\begin{array}{c}\text { NITRO- } \\
\text { GEN, } \\
\text { AMMONIA }\end{array}$ & $\begin{array}{c}\text { NITRO- } \\
\text { GEN, } \\
\text { AMMONIA }\end{array}$ & $\begin{array}{l}\text { NITRO- } \\
\text { GEN, }\end{array}$ \\
\hline & TUENTS, & SOLVED & SOLVED & NITRATE & DIS- & DIS- & DIS- & DIS- & DIS- & DIS- & ORGANIC \\
\hline & DIS- & (TONS & (TONS & TOTAL & SOLVED & SOLVED & SOLVED & SOLVED & SOLVED & SOLVED & TOTAL \\
\hline \multirow[t]{3}{*}{ DATE } & SOLVED & PER & PER & (MG /L & (MG/L & (MG/L & (MG /L & (MG/L & (MG/L & (MG/L & (MG/L \\
\hline & (MG / L) & $\mathrm{AC}-\mathrm{FT}$ ) & DAY) & AS N) & AS N) & $\mathrm{AS} \quad \mathrm{NO}_{3}$ ) & AS N) & AS N) & AS N) & AS $\quad \mathrm{NH}_{4}$ ) & $\begin{array}{l}\text { AS N) } \\
(00605)\end{array}$ \\
\hline & $(70301)$ & (70303) & $(70302)$ & $(00620)$ & $(00618)$ & (71851) & $(00613)$ & $(00631)$ & $(00608)$ & $(71846)$ & $(00605)$ \\
\hline
\end{tabular}

\begin{tabular}{|c|c|c|c|c|c|c|c|c|c|c|c|}
\hline $\begin{array}{c}\text { OCT } 1981 \\
15 \ldots \\
\text { OCT } 1982\end{array}$ & - & 0.22 & - & 0.980 & 0.990 & 4.4 & 0.010 & 1.00 & 0.020 & 0.03 & 0.11 \\
\hline $\begin{array}{c}19 \ldots \\
\text { OCT } 1983\end{array}$ & 127 & .17 & 4.35 & 1.49 & 1.49 & 6.6 & .010 & 1.50 & $<.010$ & .01 & - \\
\hline $\begin{array}{c}17 \ldots \\
\text { OCT } 1984\end{array}$ & 133 & .18 & 3.92 & 1.56 & 1.56 & 6.9 & .040 & 1.60 & .120 & .15 & - \\
\hline $\begin{array}{c}09 \ldots \\
\text { OCT } 1985\end{array}$ & 128 & .16 & 5.55 & 1.90 & - & - & $<.010$ & 1.90 & .080 & .10 & - \\
\hline $\begin{array}{c}07 \ldots \\
\text { OCT } 1986\end{array}$ & 126 & .17 & 7.43 & 1.40 & - & - & $<.010$ & 1.40 & .030 & .04 & - \\
\hline $\begin{array}{c}06 \ldots \\
\text { OCT } 1987\end{array}$ & 134 & .21 & 4.63 & .960 & .960 & 4.2 & .010 & .970 & $<.010$ & - & .50 \\
\hline $\begin{array}{c}08 \ldots \\
\text { OCT } 1988\end{array}$ & 128 & .18 & 4.56 & 1.30 & - & - & $<.010$ & 1.30 & .020 & .03 & .48 \\
\hline $\begin{array}{c}12 \ldots \\
\text { OCT } 1989\end{array}$ & 135 & .18 & 4.02 & 1.40 & - & - & $<.010$ & 1.40 & .010 & .01 & - \\
\hline $\begin{array}{c}04 \ldots \\
\text { OCT } 1990\end{array}$ & 120 & .16 & 1.7 & 1.50 & - & - & $<.010$ & 1.50 & .020 & .03 & .28 \\
\hline $\begin{array}{c}02 \ldots \\
\text { OCT } 1991\end{array}$ & 136 & .19 & 4.64 & 1.50 & - & - & $<.010$ & 1.50 & .040 & .05 & .26 \\
\hline $\begin{array}{c}02 \ldots \\
\text { OCT } 1992\end{array}$ & 138 & .19 & 3.02 & 1.40 & - & - & $<.010$ & 1.40 & $<.010$ & - & - \\
\hline $\begin{array}{c}06 \ldots \\
\text { OCT } 1993\end{array}$ & 130 & .18 & 2.67 & 1.20 & - & - & $<.010$ & 1.20 & .010 & .01 & - \\
\hline $\begin{array}{c}06 \ldots \\
\text { OCT } 1994\end{array}$ & - & - & - & 1.50 & - & - & $<.010$ & 1.50 & .020 & .03 & - \\
\hline $26 \ldots$ & - & - & - & 1.10 & - & - & $<.010$ & 1.10 & $<.015$ & - & - \\
\hline
\end{tabular}


Table 3. Water-quality data from surface-water sites-Continued

014721884 - Pickering Creek at Charlestown Road Bridge at Charlestown, Pa. (Site 4)—Continued

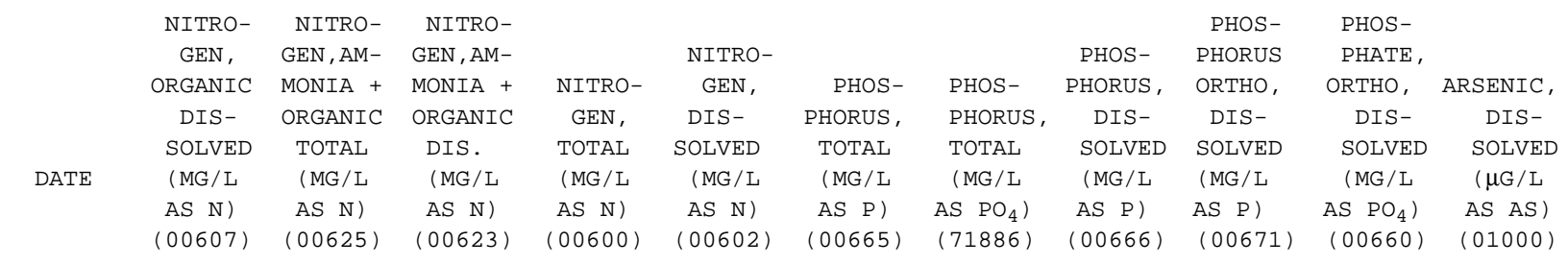

\begin{tabular}{|c|c|c|c|c|c|c|c|c|c|c|c|}
\hline $\begin{array}{c}\text { OCT } 1981 \\
15 \ldots \\
\text { OCT } 1982\end{array}$ & - & 0.20 & $<0.10$ & 1.2 & - & 0.010 & 0.03 & $<0.010$ & $<0.010$ & - & 3 \\
\hline $\begin{array}{c}19 \ldots \\
\text { OCT } 1983\end{array}$ & - & - & .90 & - & 2.4 & - & - & .010 & $<.010$ & - & 1 \\
\hline $\begin{array}{c}17 \ldots \\
\text { OCT } 1984\end{array}$ & 0.28 & - & .40 & - & 2.0 & .010 & .03 & .020 & $<.010$ & - & - \\
\hline $\begin{array}{c}09 \ldots \\
\text { OCT } 1985\end{array}$ & .22 & - & .30 & - & 2.2 & .020 & - & .010 & .020 & 0.06 & - \\
\hline $\begin{array}{c}07 \ldots \\
\text { OCT } 1986\end{array}$ & .47 & - & .50 & - & 1.9 & .020 & .06 & .020 & .020 & .06 & - \\
\hline $\begin{array}{c}06 \ldots \\
\text { OCT } 1987\end{array}$ & - & .50 & $<.20$ & 1.5 & - & .020 & - & .020 & .010 & .03 & - \\
\hline $\begin{array}{c}08 \ldots \\
\text { OCT } 1988\end{array}$ & - & .50 & $<.20$ & 1.8 & - & .010 & - & .010 & $<.010$ & - & - \\
\hline $\begin{array}{c}12 \ldots \\
\text { OCT } 1989\end{array}$ & - & $<.20$ & $<.20$ & - & - & .020 & - & .010 & $<.010$ & - & - \\
\hline $\begin{array}{c}04 \ldots \\
\text { OCT } 1990\end{array}$ & .38 & .30 & .40 & 1.8 & 1.9 & .030 & - & .010 & .010 & .03 & - \\
\hline $\begin{array}{c}02 \ldots \\
\text { OCT } 1991\end{array}$ & .26 & .30 & .30 & 1.8 & 1.8 & .010 & - & .010 & $<.010$ & - & - \\
\hline $\begin{array}{c}02 \ldots \\
\text { OCT } 1992\end{array}$ & - & $<.20$ & - & - & - & .030 & - & $<.010$ & $<.010$ & - & - \\
\hline $\begin{array}{c}06 \ldots \\
\text { OCT } 1993\end{array}$ & - & $<.20$ & $<.20$ & - & - & .010 & - & .010 & $<.010$ & - & - \\
\hline $\begin{array}{c}06 \ldots \\
\text { OCT } 1994\end{array}$ & - & - & - & - & - & - & - & - & $<.010$ & - & - \\
\hline $26 \ldots$ & - & - & - & - & - & - & - & - & $<.010$ & - & - \\
\hline
\end{tabular}


Table 3. Water-quality data from surface-water sites-Continued

014721884 - Pickering Creek at Charlestown Road Bridge at Charlestown, Pa. (Site 4)-Continued

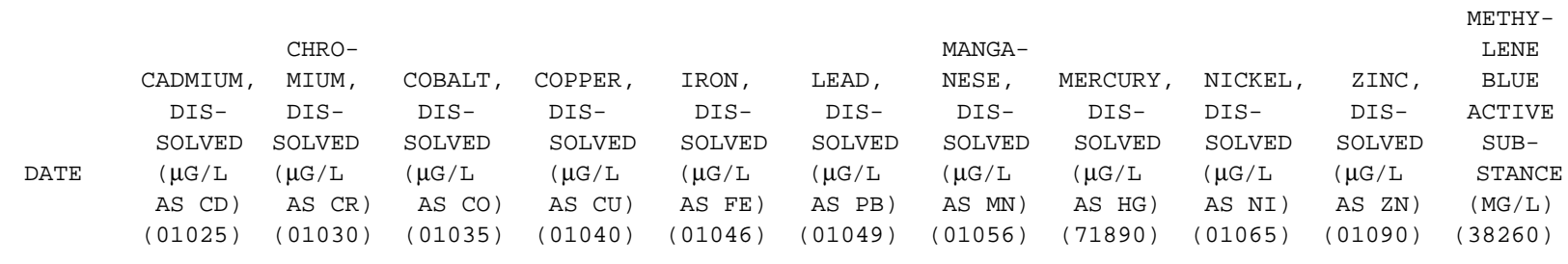

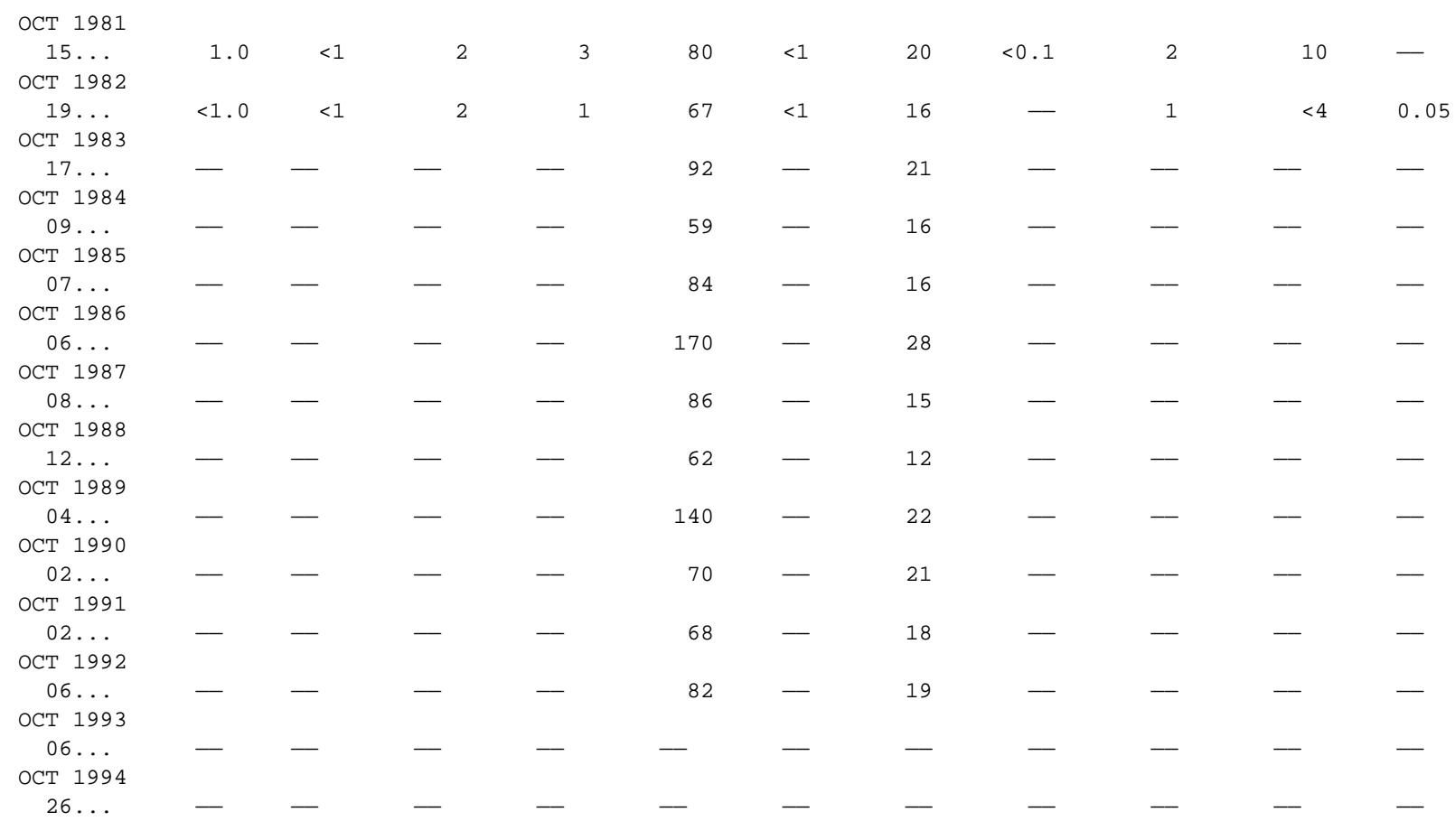


Table 3. Water-quality data from surface-water sites-Continued

01472190 - Pickering Creek near Phoenixville, Pa. (Site 5)

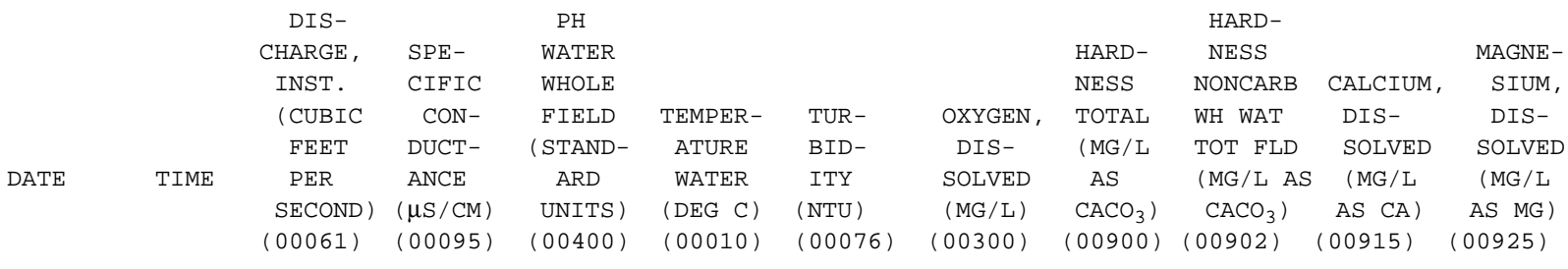

\begin{tabular}{|c|c|c|c|c|c|c|c|c|c|c|c|}
\hline $\begin{array}{c}\text { OCT } 1981 \\
15 \ldots \\
\text { NOV } 1982\end{array}$ & 1130 & - & 201 & 8.1 & 7.0 & - & 13.3 & 51 & - & 15 & 3.2 \\
\hline $\begin{array}{c}02 \ldots \\
\text { OCT } 1983\end{array}$ & 0845 & 16 & 194 & 7.6 & 13.0 & - & 9.9 & 80 & - & 21 & 6.6 \\
\hline $\begin{array}{c}18 \ldots \\
\text { OCT } 1984\end{array}$ & 0830 & - & 202 & 7.5 & 12.5 & $<1.0$ & 9.9 & 85 & - & 23 & 6.7 \\
\hline $\begin{array}{c}22 \ldots \\
\text { OCT } 1985\end{array}$ & 0930 & 23 & 206 & 7.8 & 16.0 & .50 & 9.3 & 83 & - & 22 & 6.7 \\
\hline $\begin{array}{c}08 \ldots \\
\text { OCT } 1986\end{array}$ & 1430 & 22 & 205 & 7.8 & 8.0 & .80 & 10.5 & 74 & - & 19 & 6.4 \\
\hline $\begin{array}{c}06 \ldots \\
\text { OCT } 1987\end{array}$ & 1400 & 11 & 215 & 8.1 & 15.0 & .50 & 9.8 & 83 & - & 22 & 6.9 \\
\hline $\begin{array}{c}13 \ldots \\
\text { OCT } 1988\end{array}$ & 1345 & 11 & 205 & 7.8 & 10.5 & .50 & 12.3 & 80 & - & 21 & 6.7 \\
\hline $\begin{array}{c}12 \ldots \\
\text { OCT } 1989\end{array}$ & 1400 & 11 & 225 & 7.8 & 10.5 & .60 & 12.4 & 85 & - & 22 & 7.2 \\
\hline $\begin{array}{c}06 \ldots \\
\text { OCT } 1990\end{array}$ & 1530 & 35 & 215 & 7.5 & 15.5 & .70 & 7.4 & 76 & 19 & 20 & 6.4 \\
\hline $\begin{array}{c}12 \ldots \\
\text { OCT } 1991\end{array}$ & 0815 & 14 & 272 & 6.8 & 18.5 & 2.9 & 9.3 & 86 & 12 & 23 & 7.0 \\
\hline $\begin{array}{c}07 \ldots \\
\text { OCT } 1992\end{array}$ & 0845 & 10 & 245 & 7.0 & 12.5 & .70 & 10.6 & 86 & 28 & 23 & 7.0 \\
\hline $\begin{array}{c}06 \ldots \\
\text { OCT } 1993\end{array}$ & 0745 & 7.1 & 225 & 7.3 & 9.0 & .40 & 11.8 & 89 & - & 24 & 7.0 \\
\hline $\begin{array}{c}07 \ldots \\
\text { ОСТ } 1994\end{array}$ & 1215 & 12 & 230 & 7.4 & 12.0 & - & 11.7 & - & - & - & - \\
\hline $26 \ldots$ & 0945 & 18 & 232 & 8.1 & 8.5 & - & 12.0 & - & - & - & - \\
\hline
\end{tabular}


Table 3. Water-quality data from surface-water sites-Continued

01472190 - Pickering Creek near Phoenixville, Pa. (Site 5)—Continued

\begin{tabular}{|c|c|c|c|c|c|c|c|c|c|c|c|}
\hline & & & & POTAS- & $\begin{array}{l}\text { ALKA- } \\
\text { LINITY }\end{array}$ & $\begin{array}{l}\text { ALKA- } \\
\text { LINITY }\end{array}$ & & $\begin{array}{l}\text { CHLO- } \\
\text { RIDE }\end{array}$ & $\begin{array}{l}\text { FLUO- } \\
\text { RIDE, }\end{array}$ & $\begin{array}{l}\text { SILICA, } \\
\text { DIS- }\end{array}$ & $\begin{array}{l}\text { SOLIDS, } \\
\text { RESIDUE } \\
\text { AT } 180\end{array}$ \\
\hline & $\begin{array}{l}\text { SODIUM, } \\
\text { DIS- }\end{array}$ & & $\begin{array}{l}\text { SODIUM } \\
\text { AD- }\end{array}$ & $\begin{array}{l}\text { SIUM, } \\
\text { DIS- }\end{array}$ & $\begin{array}{l}\text { WAT WH } \\
\text { TOT FET }\end{array}$ & $\begin{array}{l}\text { WAT WH } \\
\text { TOT IT }\end{array}$ & $\begin{array}{l}\text { SULFATE, } \\
\text { DIS- }\end{array}$ & $\begin{array}{l}\text { RIDE, } \\
\text { DIS- }\end{array}$ & $\begin{array}{l}\text { RIDE, } \\
\text { DIS- }\end{array}$ & $\begin{array}{l}\text { DIS- } \\
\text { SOLVED }\end{array}$ & $\begin{array}{l}\text { AT } 180 \\
\text { DEG. C }\end{array}$ \\
\hline ATE & $\begin{array}{l}\text { SOLVED } \\
\text { (MG/L }\end{array}$ & SODIUM & $\begin{array}{l}\text { SORP- } \\
\text { TION }\end{array}$ & $\begin{array}{l}\text { SOLVED } \\
\text { (MG/L }\end{array}$ & $\begin{array}{l}\text { FIELD } \\
\text { (MG/L AS }\end{array}$ & $\begin{array}{l}\text { FIELD } \\
\text { (MG/L }\end{array}$ & $\begin{array}{c}\text { SOLVED } \\
\text { (MG/L }\end{array}$ & $\begin{array}{l}\text { SOLVED } \\
\text { (MG/L }\end{array}$ & $\begin{array}{l}\text { SOLVED } \\
\text { (MG/L }\end{array}$ & $\begin{array}{l}\text { (MG /L } \\
\text { AS }\end{array}$ & $\begin{array}{l}\text { DIS- } \\
\text { SOLVED }\end{array}$ \\
\hline & AS NA) & PERCENT & RATIO & AS K) & $\left.\mathrm{CACO}_{3}\right)$ & AS $\left.\mathrm{CACO}_{3}\right)$ & $\left.\mathrm{AS} \quad \mathrm{SO}_{4}\right)$ & AS CL) & AS F) & $\left.\mathrm{SIO}_{2}\right)$ & (MG/L) \\
\hline & $(00930)$ & $(00932)$ & $(00931)$ & $(00935)$ & $(00410)$ & $(00419)$ & $(00945)$ & $(00940)$ & $(00950)$ & $(00955)$ & $(70300)$ \\
\hline
\end{tabular}

\begin{tabular}{|c|c|c|c|c|c|c|c|c|c|c|c|}
\hline $\begin{array}{c}15 \ldots \\
\text { NoV } 1982\end{array}$ & 7.2 & 23 & 0.4 & 2.1 & - & - & 16 & 18 & $<0.10$ & 14 & 139 \\
\hline $\begin{array}{c}02 \ldots \\
\text { OCT } 1983\end{array}$ & 7.6 & 17 & .4 & 2.2 & 52 & - & 18 & 16 & $<.10$ & 17 & 127 \\
\hline $\begin{array}{c}18 \ldots \\
\text { OCT } 1984\end{array}$ & 8.5 & 17 & .4 & 2.0 & 48 & - & 19 & 19 & - & 18 & 148 \\
\hline $\begin{array}{c}22 \ldots \\
\text { OCT } 1985\end{array}$ & 7.8 & 17 & .4 & 2.3 & 56 & - & 18 & 20 & - & 17 & 126 \\
\hline $\begin{array}{c}08 \ldots \\
\text { OCT } 1986\end{array}$ & 8.2 & 19 & .4 & 2.3 & 54 & - & 21 & 16 & - & 18 & 131 \\
\hline $\begin{array}{c}06 \ldots \\
\text { OCT } 1987\end{array}$ & 8.9 & 18 & .4 & 2.7 & 68 & - & 19 & 16 & - & 20 & 152 \\
\hline $\begin{array}{c}13 \ldots \\
\text { OCT } 1988\end{array}$ & 8.9 & 19 & .4 & 2.2 & 50 & - & 17 & 18 & - & 18 & 135 \\
\hline $\begin{array}{c}12 \ldots \\
\text { OCT } 1989\end{array}$ & 8.8 & 18 & .4 & 2.1 & 60 & - & 19 & 19 & - & 17 & - \\
\hline $\begin{array}{c}06 \ldots \\
\text { OCT } 1990\end{array}$ & 8.2 & 18 & .4 & 2.2 & 57 & - & 17 & 16 & - & 18 & - \\
\hline $\begin{array}{c}12 \ldots \\
\text { ОСТ } 1991\end{array}$ & 9.3 & 18 & .4 & 3.1 & 74 & - & 18 & 20 & $<.10$ & 19 & - \\
\hline $\begin{array}{c}07 \ldots \\
\text { OCT } 1992\end{array}$ & 8.7 & 17 & .4 & 2.5 & 58 & - & 18 & 19 & $<.10$ & 17 & - \\
\hline $\begin{array}{c}06 \ldots \\
\text { OCT } 1993\end{array}$ & 8.6 & 17 & .4 & 2.0 & - & 43 & 18 & 21 & .10 & 18 & - \\
\hline $\begin{array}{c}07 \ldots \\
\text { OCT } 1994\end{array}$ & - & - & - & - & - & 58 & - & - & - & - & - \\
\hline $26 \ldots$ & - & - & - & - & - & 71 & - & 22 & - & - & - \\
\hline
\end{tabular}


Table 3. Water-quality data from surface-water sites-Continued

01472190 - Pickering Creek near Phoenixville, Pa. (Site 5)—Continued

\begin{tabular}{|c|c|c|c|c|c|c|c|c|c|c|c|}
\hline & $\begin{array}{l}\text { SOLIDS, } \\
\text { SUM OF } \\
\text { CONSTI- }\end{array}$ & $\begin{array}{c}\text { SOLIDS, } \\
\text { DIS- }\end{array}$ & $\begin{array}{c}\text { SOLIDS, } \\
\text { DIS- }\end{array}$ & $\begin{array}{c}\text { NITRO- } \\
\text { GEN }\end{array}$ & $\begin{array}{c}\text { NITRO- } \\
\text { GEN, } \\
\text { NITRATE }\end{array}$ & $\begin{array}{c}\text { NITRO- } \\
\text { GEN, } \\
\text { NITRATE }\end{array}$ & $\begin{array}{c}\text { NITRO- } \\
\text { GEN, } \\
\text { NITRITE }\end{array}$ & $\begin{array}{c}\mathrm{NITRO}- \\
\text { GEN, } \\
\mathrm{NO}_{2}+\mathrm{NO}_{3}\end{array}$ & $\begin{array}{c}\text { NITRO- } \\
\text { GEN, } \\
\text { AMMONIA }\end{array}$ & $\begin{array}{c}\text { NITRO- } \\
\text { GEN, } \\
\text { AMMONIA }\end{array}$ & $\begin{array}{l}\text { NITRO- } \\
\text { GEN, }\end{array}$ \\
\hline \multirow{4}{*}{ ATE } & TUENTS, & SOLVED & SOLVED & NITRATE & DIS- & DIS- & DIS- & DIS- & DIS- & DIS- & ORGANIC \\
\hline & $\begin{array}{c}\text { DIS- } \\
\text { SOLVED }\end{array}$ & $\begin{array}{l}\text { ( TONS } \\
\text { PER }\end{array}$ & $\begin{array}{l}\text { (TONS } \\
\text { PER }\end{array}$ & $\begin{array}{l}\text { TOTAL } \\
\text { (MG/L }\end{array}$ & $\begin{array}{l}\text { SOLVED } \\
\text { (MG/L }\end{array}$ & $\begin{array}{l}\text { SOLVED } \\
\text { (MG/L }\end{array}$ & $\begin{array}{l}\text { SOLVED } \\
\text { (MG/L }\end{array}$ & $\begin{array}{l}\text { SOLVED } \\
(\mathrm{MG} / \mathrm{L}\end{array}$ & $\begin{array}{l}\text { SOLVED } \\
\text { (MG/L }\end{array}$ & $\begin{array}{l}\text { SOLVED } \\
\text { (MG/L }\end{array}$ & $\begin{array}{l}\text { TOTAL } \\
\text { (MG/L }\end{array}$ \\
\hline & (MG / L) & $\mathrm{AC}-\mathrm{FT}$ ) & DAY) & AS N) & AS N) & AS $\mathrm{NO}_{3}$ ) & AS N) & AS N) & AS N) & $\mathrm{AS} \quad \mathrm{NH}_{4}$ ) & AS N) \\
\hline & $(70301)$ & $(70303)$ & $(70302)$ & $(00620)$ & $(00618)$ & $(71851)$ & $(00613)$ & $(00631)$ & $(00608)$ & $(71846)$ & $(00605)$ \\
\hline
\end{tabular}

\begin{tabular}{|c|c|c|c|c|c|c|c|c|c|c|c|}
\hline $\begin{array}{c}15 \ldots \\
\text { NOV } 1982\end{array}$ & - & 0.19 & - & 0.880 & 0.900 & 4.0 & 0.010 & 0.910 & 0.050 & 0.06 & 0.31 \\
\hline $02 \ldots$ & 125 & .17 & 5.49 & 1.10 & - & - & $<.010$ & 1.10 & $<.010$ & .01 & - \\
\hline OCT 1983 & & & & & & & & & & & \\
\hline $\begin{array}{c}18 \ldots \\
\text { OCT } 1984\end{array}$ & 132 & .20 & - & 1.46 & 1.46 & 6.5 & .040 & 1.50 & .140 & .18 & - \\
\hline $\begin{array}{c}22 \ldots \\
\text { OCT } 1985\end{array}$ & 133 & .17 & 7.82 & 1.16 & 1.16 & 5.1 & .040 & 1.20 & .070 & .09 & - \\
\hline $\begin{array}{c}08 \ldots \\
\text { OCT } 1986\end{array}$ & 130 & .18 & 7.78 & 1.50 & - & - & $<.010$ & 1.50 & .020 & .03 & .48 \\
\hline $\begin{array}{c}06 \ldots \\
\text { OCT } 1987\end{array}$ & 140 & .21 & 4.51 & .840 & - & - & $<.010$ & .840 & $<.010$ & - & - \\
\hline $\begin{array}{c}13 \ldots \\
\text { OCT } 1988\end{array}$ & 128 & .18 & 4.01 & 1.30 & - & - & $<.010$ & 1.30 & .010 & .01 & .49 \\
\hline $\begin{array}{c}12 \ldots \\
\text { OCT } 1989\end{array}$ & 137 & .19 & 4.07 & 1.30 & - & - & $<.010$ & 1.30 & $<.010$ & - & .20 \\
\hline $\begin{array}{c}06 \ldots \\
\text { OCT } 1990\end{array}$ & 130 & .18 & 12.3 & 1.80 & - & - & $<.010$ & 1.80 & .020 & .03 & .48 \\
\hline $\begin{array}{c}12 \ldots \\
\text { OCT } 1991\end{array}$ & 148 & .20 & 5.47 & .900 & - & - & $<.010$ & .900 & .020 & .03 & .38 \\
\hline $\begin{array}{c}07 \ldots \\
\text { OCT } 1992\end{array}$ & 135 & .18 & 3.75 & 1.10 & - & - & $<.010$ & 1.10 & $<.010$ & - & - \\
\hline $\begin{array}{c}06 \ldots \\
\text { OCT } 1993\end{array}$ & 130 & .18 & 2.49 & 1.20 & - & - & $<.010$ & 1.20 & $<.010$ & - & - \\
\hline $\begin{array}{c}07 \ldots \\
\text { OCT } 1994\end{array}$ & - & - & - & 1.50 & - & - & $<.010$ & 1.50 & .010 & .01 & - \\
\hline $26 \ldots$ & - & - & - & .980 & - & - & $<.010$ & .980 & $<.015$ & - & - \\
\hline
\end{tabular}


Table 3. Water-quality data from surface-water sites-Continued

01472190 - Pickering Creek near Phoenixville, Pa. (Site 5)—Continued

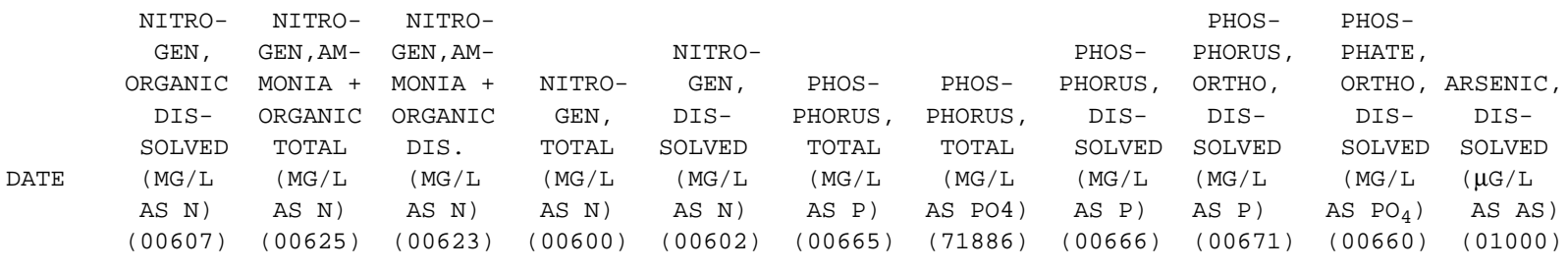

\begin{tabular}{|c|c|c|c|c|c|c|c|c|c|c|}
\hline $\begin{array}{c}\text { OCT } 1981 \\
15 \ldots \\
\text { NOV } 1982\end{array}$ & 0.07 & 0.37 & 0.12 & 1.3 & 1.0 & $<0.010$ & - & $<0.010$ & $<0.010$ & - \\
\hline $\begin{array}{c}02 \ldots \\
\text { ОСт } 1983\end{array}$ & - & - & .80 & - & 1.9 & - & - & .020 & $<.010$ & - \\
\hline $\begin{array}{c}18 \ldots \\
\text { OCT } 1984\end{array}$ & .26 & - & .40 & - & 1.9 & .020 & 0.06 & .010 & $<.010$ & - \\
\hline $\begin{array}{c}22 \ldots \\
\text { ОСТ } 1985\end{array}$ & .13 & - & .20 & - & 1.4 & $<.010$ & - & .040 & .010 & 0.03 \\
\hline $\begin{array}{c}08 \ldots \\
\text { OCT } 1986\end{array}$ & .48 & .50 & .50 & 2.0 & 2.0 & .020 & .06 & .020 & .010 & .03 \\
\hline $\begin{array}{c}06 \ldots \\
\text { OCT } 1987\end{array}$ & - & $<.20$ & .40 & - & 1.2 & .030 & - & .020 & .010 & .03 \\
\hline $\begin{array}{c}13 \ldots \\
\text { OCT } 1988\end{array}$ & - & .50 & $<.20$ & 1.8 & - & $<.010$ & - & $<.010$ & $<.010$ & - \\
\hline $\begin{array}{c}12 \ldots \\
\text { OCT } 1989\end{array}$ & - & .20 & .20 & 1.5 & 1.5 & .010 & - & .010 & $<.010$ & - \\
\hline $\begin{array}{c}06 \ldots \\
\text { OCT } 1990\end{array}$ & - & .50 & $<.20$ & 2.3 & - & .030 & - & .010 & .010 & .03 \\
\hline $\begin{array}{c}12 \ldots \\
\text { OCT } 1991\end{array}$ & .18 & .40 & .20 & 1.3 & 1.1 & .040 & - & .010 & $<.050$ & - \\
\hline $\begin{array}{c}07 \ldots \\
\text { ОСТ } 1992\end{array}$ & - & $<.20$ & - & - & - & .020 & - & $<.010$ & $<.010$ & - \\
\hline $\begin{array}{c}06 \ldots \\
\text { OCT } 1993\end{array}$ & - & $<.20$ & $<.20$ & - & - & $<.010$ & - & .020 & $<.010$ & - \\
\hline $\begin{array}{c}07 \ldots \\
\text { ОСТ } 1994\end{array}$ & - & - & - & - & - & - & - & - & $<.010$ & - \\
\hline $26 \ldots$ & - & - & - & - & - & - & - & - & $<.010$ & - \\
\hline
\end{tabular}


Table 3. Water-quality data from surface-water sites-Continued

01472190 - Pickering Creek near Phoenixville, Pa. (Site 5)—Continued

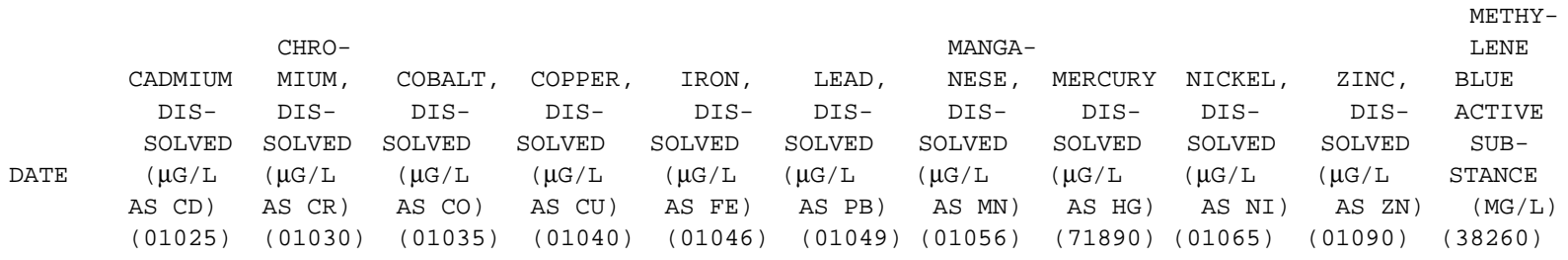

\begin{tabular}{|c|c|c|c|c|c|c|c|c|c|c|c|}
\hline $\begin{array}{c}15 \ldots \\
\text { NOV } 1982\end{array}$ & 1.0 & $<1$ & & & 70 & $<1$ & 1 & $<0.1$ & 5 & 2 & - \\
\hline $02 \ldots$ & $<1.0$ & $<1$ & $<$ & & 54 & $<1$ & & $<.1$ & $<1$ & $<4$ & 0.03 \\
\hline $\begin{array}{c}\text { OCT } 1983 \\
18 \ldots\end{array}$ & - & - & - & - & 53 & - & & - & - & - & - \\
\hline $\begin{array}{c}\text { OCT } 1984 \\
22 \ldots\end{array}$ & - & - & - & - & 48 & - & & - & - & - & - \\
\hline $\begin{array}{c}\text { OCT } 1985 \\
08 \ldots \\
\text { OCT } 1986\end{array}$ & - & - & - & - & 53 & - & & - & - & - & - \\
\hline $\begin{array}{c}06 \ldots \\
\text { OCT } 1987\end{array}$ & - & - & - & - & 100 & - & & - & - & - & - \\
\hline $\begin{array}{c}13 \ldots \\
\text { OCT } 1988\end{array}$ & - & - & - & - & 57 & - & & - & - & - & - \\
\hline $\begin{array}{c}12 \ldots \\
\text { OCT } 1989\end{array}$ & - & - & - & - & 43 & - & & - & - & - & - \\
\hline $\begin{array}{c}06 \ldots \\
\text { ОСТ } 1990\end{array}$ & - & - & - & - & 91 & - & & - & - & - & - \\
\hline $\begin{array}{c}12 \ldots \\
\text { ОСТ } 1991\end{array}$ & - & - & - & - & 47 & - & & - & - & - & - \\
\hline $\begin{array}{c}07 \ldots \\
\text { OCT } 1992\end{array}$ & - & - & - & - & 49 & - & & - & - & - & - \\
\hline $\begin{array}{c}06 \ldots \\
\text { OCT } 1993\end{array}$ & - & - & - & - & 55 & - & & - & - & - & - \\
\hline $\begin{array}{c}07 \ldots \\
\text { OCT } 1994\end{array}$ & - & - & - & - & - & - & - & - & - & - & - \\
\hline $26 \ldots$ & - & - & - & - & - & - & - & - & - & - & - \\
\hline
\end{tabular}


Table 3. Water-quality data from surface-water sites-Continued

01473167 - Little Valley Creek at Howellville, Pa. (Site 49)

\begin{tabular}{|c|c|c|c|c|c|c|c|c|c|c|}
\hline & & DIS- & & $\mathrm{PH}$ & & & & & HARD - & \\
\hline & & CHARGE, & SPE- & WATER & & & & HARD- & NESS & \\
\hline & & CUBIC & $\mathrm{CON}-$ & FIELD & TEMP ER- & TUR- & OXYGEN, & TOTAL & WH WAT & DIS- \\
\hline $\mathrm{ATE}$ & TIME & PER & $\mathrm{ANCE}$ & ARD & WATER & ITY & SOLVED & AS & (MG/L AS & (MG/L \\
\hline & & SECOND & $(\mu \mathrm{S} / \mathrm{CM})$ & UNITS) & $(\mathrm{DEG} C)$ & (NTU) & (MG /L) & $\left.\mathrm{CACO}_{3}\right)$ & $\left.\mathrm{CACO}_{3}\right)$ & AS CA) \\
\hline & & $(00061)$ & $(00095)$ & $(00400)$ & $(00010)$ & $(00076)$ & $(00300)$ & $(00900)$ & $(00902)$ & (00915) \\
\hline
\end{tabular}

\begin{tabular}{|c|c|c|c|c|c|c|c|c|c|c|}
\hline $\begin{array}{c}16 \ldots \\
\text { OCT } 1982\end{array}$ & 1515 & - & 533 & 8.6 & 14.0 & - & 13.4 & 210 & - & 56 \\
\hline $\begin{array}{c}15 \ldots \\
\text { OCT } 1983\end{array}$ & 0930 & 4.8 & 466 & 8.2 & 12.2 & - & 10.4 & 210 & - & 56 \\
\hline $\begin{array}{c}21 \ldots \\
\text { OCT } 1984\end{array}$ & 0900 & 4.0 & 503 & 7.8 & 9.0 & $<1.0$ & 10.7 & 230 & - & 59 \\
\hline $\begin{array}{c}09 \ldots \\
\text { OCT } 1985\end{array}$ & 1500 & 6.0 & 480 & 8.8 & 14.0 & .40 & 10.9 & 210 & - & 56 \\
\hline $\begin{array}{c}09 \ldots \\
\text { NOV } 1986\end{array}$ & 0830 & 5.9 & 515 & 7.5 & 7.2 & .40 & 12.0 & 240 & - & 63 \\
\hline $\begin{array}{c}07 \ldots \\
\text { NOV } 1987\end{array}$ & 0900 & 7.1 & 480 & 7.9 & 9.3 & 1.0 & 11.5 & 230 & - & 58 \\
\hline $\begin{array}{c}16 \ldots \\
\text { OCT } 1988\end{array}$ & 1330 & 9.6 & 495 & 8.1 & 11.5 & .20 & 12.0 & 220 & - & 58 \\
\hline $\begin{array}{c}26 \ldots \\
\text { NOV } 1989\end{array}$ & 0930 & 4.6 & 550 & 7.7 & 10.0 & 1.3 & 11.8 & 230 & - & 60 \\
\hline $\begin{array}{c}06 \ldots \\
\text { NOV } 1990\end{array}$ & 0945 & 8.4 & 530 & 7.8 & 11.0 & .30 & 11.4 & 220 & 59 & 57 \\
\hline $\begin{array}{c}14 \ldots \\
\text { OCT } 1991\end{array}$ & 0900 & 5.5 & 510 & 6.9 & 6.5 & .30 & 12.7 & 220 & 51 & 58 \\
\hline $\begin{array}{c}28 \ldots \\
\text { OCT } 1992\end{array}$ & 0915 & - & 570 & 7.6 & 13.0 & .60 & 10.8 & 240 & 59 & 64 \\
\hline $\begin{array}{c}05 \ldots \\
\text { NOV } 1993\end{array}$ & 0910 & 3.1 & 279 & 7.2 & 12.0 & .20 & 10.8 & 240 & - & 63 \\
\hline $\begin{array}{c}18 \ldots \\
\text { NOV } 1994\end{array}$ & 0915 & 4.4 & 520 & 8.1 & 10.5 & - & 11.4 & - & - & - \\
\hline $07 \ldots$ & 0900 & 3.5 & 650 & 7.9 & 10.5 & - & 11.2 & - & - & - \\
\hline
\end{tabular}


Table 3. Water-quality data from surface-water sites-Continued

01473167 - Little Valley Creek at Howellville, Pa. (Site 49)—Continued

\begin{tabular}{|c|c|c|c|c|c|c|c|c|c|c|c|c|}
\hline & & & & & & $\begin{array}{l}\text { ANC } \\
\text { WATER }\end{array}$ & $\begin{array}{l}\text { ANC } \\
\text { WATER }\end{array}$ & & & & & SIDUE \\
\hline & SIUM, & SODIUM, & & SODIUM & SIUM, & UNF LTRD & UNFLT & SULFATE, & RII & RIDE, & & AT 180 \\
\hline & $\begin{array}{l}\text { OLVED } \\
\text { (MG/L }\end{array}$ & $\begin{array}{r}\text { SOLVED } \\
\text { (MG/L }\end{array}$ & & $\begin{array}{l}\text { AD- } \\
\text { SORP- } \\
\text { TION }\end{array}$ & $\begin{array}{l}\text { SOLVED } \\
\text { (MG/L }\end{array}$ & $\begin{array}{c}\text { FIELD } \\
\text { (MG/L AS }\end{array}$ & $\begin{array}{l}\text { FIELD } \\
\text { (MG/L }\end{array}$ & $\begin{array}{l}\text { SOLVED } \\
\text { (MG/L }\end{array}$ & & & AS & $\begin{array}{r}\text { DIS- } \\
\text { SOLVED }\end{array}$ \\
\hline & $\begin{array}{l}\text { AS MG) } \\
(00925)\end{array}$ & $\begin{array}{l}\text { AS NA) } \\
(00930)\end{array}$ & $\begin{array}{l}\text { PERCENT } \\
\text { (00932) }\end{array}$ & $\begin{array}{l}\text { RATIO } \\
\text { (00931) }\end{array}$ & $\begin{array}{c}\text { AS K) } \\
(00935)\end{array}$ & $\begin{array}{r}\left.\mathrm{CACO}_{3}\right) \\
(00410)\end{array}$ & $\begin{array}{c}\left.\mathrm{AS} \mathrm{CACO}_{3}\right) \\
(00419)\end{array}$ & $\begin{array}{l}\left.\mathrm{AS} \mathrm{SO}_{4}\right) \\
(00945)\end{array}$ & $\begin{array}{c}\text { AS CL) } \\
(00940)\end{array}$ & $\begin{array}{l}\text { AS F) } \\
(00950)\end{array}$ & $\begin{array}{c}\left.\mathrm{SIO}_{2}\right) \\
(00955)\end{array}$ & $\begin{array}{l}(M G / L) \\
(70300)\end{array}$ \\
\hline
\end{tabular}

\begin{tabular}{|c|c|c|c|c|c|c|c|c|c|c|c|c|}
\hline $\begin{array}{c}\text { OCT } 1981 \\
16 \ldots \\
\text { OCT } 1982\end{array}$ & 18 & 24 & 19 & 0.7 & 2.4 & - & - & 39 & 45 & 0.20 & 5.6 & 298 \\
\hline $\begin{array}{c}15 \ldots \\
\text { ОСТ } 1983\end{array}$ & 18 & 23 & 19 & .7 & 1.5 & 170 & - & 34 & 44 & .20 & 7.5 & 323 \\
\hline $\begin{array}{c}21 \ldots \\
\text { OCT } 1984\end{array}$ & 19 & 24 & 19 & .7 & 2.2 & 200 & - & 34 & 47 & - & 7.5 & 342 \\
\hline $\begin{array}{c}09 \ldots \\
\text { OCT } 1985\end{array}$ & 18 & 25 & 20 & .7 & 2.1 & 174 & - & 34 & 41 & - & 7.6 & 297 \\
\hline $\begin{array}{c}20 \ldots \\
\text { NOV } 1986\end{array}$ & 20 & 26 & 19 & .7 & 2.1 & 176 & - & 35 & 50 & - & 8.2 & 313 \\
\hline $\begin{array}{c}07 \ldots \\
\text { NOV } 1987\end{array}$ & 20 & 25 & 19 & .7 & 2.2 & 178 & - & 32 & 44 & - & 7.9 & 316 \\
\hline $\begin{array}{c}16 \ldots \\
\text { OCT } 1988\end{array}$ & 19 & 26 & 20 & .8 & 2.3 & 178 & - & 35 & 48 & - & 7.5 & 302 \\
\hline $\begin{array}{c}26 \ldots \\
\text { NOV } 1989\end{array}$ & 20 & 26 & 19 & .7 & 2.4 & 178 & - & 33 & 47 & - & 8.3 & - \\
\hline $\begin{array}{c}06 \ldots \\
\text { NOV } 1990\end{array}$ & 19 & 26 & 20 & .8 & 2.0 & 162 & - & 31 & 44 & - & 6.8 & - \\
\hline $\begin{array}{c}14 \ldots \\
\text { OCT } 1991\end{array}$ & 18 & 23 & 18 & .7 & 2.3 & 168 & - & 29 & 45 & $<.10$ & 7.7 & - \\
\hline $\begin{array}{c}28 \ldots \\
\text { OCT } 1992\end{array}$ & 20 & 26 & 19 & .7 & 2.4 & 183 & - & 35 & 49 & .10 & 7.4 & - \\
\hline $\begin{array}{c}26 \ldots \\
\text { NOV } 1993\end{array}$ & 20 & 25 & 18 & .7 & 2.2 & - & 248 & 33 & 50 & .10 & 7.3 & - \\
\hline $\begin{array}{c}18 \ldots \\
\text { NOV } 1994\end{array}$ & - & - & - & - & - & - & 155 & 29 & 42 & .10 & - & - \\
\hline $07 \ldots$ & - & - & - & - & - & - & 175 & - & 53 & - & - & - \\
\hline
\end{tabular}


Table 3. Water-quality data from surface-water sites-Continued

01473167 - Little Valley Creek at Howellville, Pa. (Site 49)—Continued

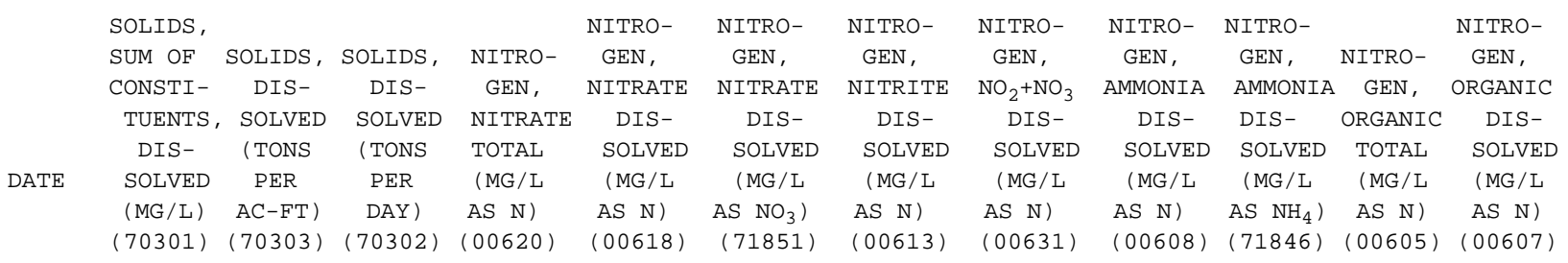

\begin{tabular}{|c|c|c|c|c|c|c|c|c|c|c|c|c|}
\hline $\begin{array}{c}\text { OCT } 1981 \\
16 \ldots \\
\text { OCT } 1982\end{array}$ & - & 0.41 & - & 2.30 & 2.30 & 10 & 0.010 & 2.30 & 0.020 & 0.03 & 0.26 & 0.30 \\
\hline $15 \ldots$ & 298 & .44 & 4.16 & - & 2.60 & 12 & .020 & 2.60 & .060 & .08 & - & .04 \\
\hline OCT 1983 & & & & & & & & & & & & \\
\hline $\begin{array}{c}21 \ldots \\
\text { OCT } 1984\end{array}$ & 323 & .47 & 3.69 & - & 2.40 & 10 & .040 & 2.40 & $<.010$ & - & - & - \\
\hline $\begin{array}{c}09 \ldots \\
\text { OCT } 1985\end{array}$ & 300 & .40 & 4.81 & - & - & - & $<.010$ & 2.70 & .030 & .04 & - & .27 \\
\hline $\begin{array}{c}09 \ldots \\
\text { NOV } 1986\end{array}$ & 322 & .43 & 4.99 & - & - & - & $<.010$ & 2.70 & .030 & .04 & .87 & .17 \\
\hline $\begin{array}{c}07 \ldots \\
\text { NOV } 1987\end{array}$ & 306 & .43 & 6.06 & - & - & - & $<.010$ & 2.20 & .010 & .01 & - & .59 \\
\hline $\begin{array}{c}16 \ldots \\
\text { OCT } 1988\end{array}$ & 314 & .41 & 7.83 & - & - & - & $<.010$ & 2.50 & $<.010$ & - & - & - \\
\hline $\begin{array}{c}26 \ldots \\
\text { NOV } 1989\end{array}$ & 314 & .43 & 3.90 & - & - & - & $<.010$ & 2.40 & .020 & .03 & - & - \\
\hline $\begin{array}{c}06 \ldots \\
\text { NOV } 1990\end{array}$ & 294 & .40 & 6.67 & - & - & - & $<.010$ & 2.50 & .020 & .03 & - & - \\
\hline $\begin{array}{c}14 \ldots \\
\text { OCT } 1991\end{array}$ & 295 & .40 & 4.37 & - & - & - & $<.010$ & 2.40 & .050 & .06 & - & - \\
\hline $\begin{array}{c}28 \ldots \\
\text { OCT } 1992\end{array}$ & 322 & .44 & - & - & - & - & $<.010$ & 1.90 & .020 & .03 & - & - \\
\hline $\begin{array}{c}05 \ldots \\
\text { NOV } 1993\end{array}$ & 359 & .49 & 3.00 & - & - & - & $<.010$ & 2.10 & $<.010$ & - & - & - \\
\hline $\begin{array}{c}18 \ldots \\
\text { NOV } 1994\end{array}$ & - & - & - & - & - & - & $<.010$ & 2.00 & .020 & .03 & - & - \\
\hline $07 \ldots$ & - & - & - & - & - & - & $<.010$ & 1.90 & $<.015$ & - & - & - \\
\hline
\end{tabular}


Table 3. Water-quality data from surface-water sites-Continued

01473167 - Little Valley Creek at Howellville, Pa. (Site 49)—Continued

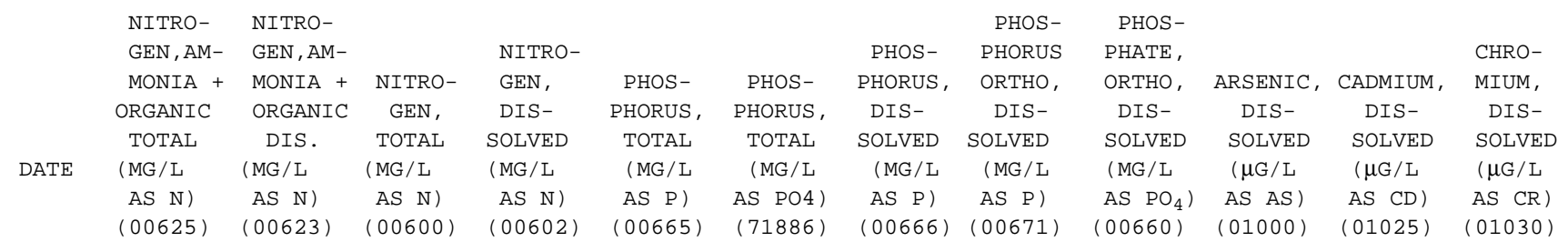

\begin{tabular}{|c|c|c|c|c|c|c|c|c|c|c|c|c|}
\hline $16 \ldots$ & 0.31 & 0.32 & 2.6 & 2.6 & 0.030 & 0.09 & 0.010 & $<0.010$ & - & 3 & 1.0 & $<1.0$ \\
\hline $\begin{array}{c}\text { OCT } 1982 \\
15 \ldots\end{array}$ & - & .10 & - & 2.7 & - & - & $<.010$ & .010 & 0.03 & 1 & $<1.0$ & 1.0 \\
\hline OCT 1983 & & & & & & & & & & & & \\
\hline $\begin{array}{c}21 \ldots \\
\text { OCT } 1984\end{array}$ & - & .30 & - & 2.7 & .030 & .09 & .020 & .020 & .06 & 1 & $<1.0$ & $<1.0$ \\
\hline $\begin{array}{c}09 \ldots \\
\text { ОСТ } 1985\end{array}$ & - & .30 & - & 3.0 & .050 & - & .020 & .020 & .06 & $<1$ & $<1.0$ & $<1.0$ \\
\hline $\begin{array}{c}09 \ldots \\
\text { NOV } 1986\end{array}$ & .90 & .20 & 3.6 & 2.9 & .020 & .06 & .010 & .010 & .03 & $<1$ & $<1.0$ & $<1.0$ \\
\hline $\begin{array}{c}07 \ldots \\
\text { NOV } 1987\end{array}$ & $<.20$ & .60 & - & 2.8 & .020 & - & .010 & $<.010$ & - & $<1$ & $<1.0$ & $<1.0$ \\
\hline $\begin{array}{c}16 \ldots \\
\text { OCT } 1988\end{array}$ & $<.20$ & $<.20$ & - & 一 & .020 & - & $<.010$ & $<.010$ & - & $<1$ & $<1.0$ & $<1.0$ \\
\hline $\begin{array}{c}26 \ldots \\
\text { NOV } 1989\end{array}$ & $<.20$ & $<.20$ & 一 & 一 & .020 & - & .020 & .010 & .03 & $<1$ & $<1.0$ & $<5.0$ \\
\hline $\begin{array}{c}06 \ldots \\
\text { NOV } 1990\end{array}$ & $<.20$ & $<.20$ & - & 一 & .010 & - & $<.010$ & .010 & .03 & $<1$ & 1.0 & $<5.0$ \\
\hline $\begin{array}{cc}14 \ldots \\
\text { OCT } & 1991\end{array}$ & $<.20$ & $<.20$ & - & - & $<.010$ & - & $<.010$ & $<.010$ & - & $<1$ & $<1.0$ & $<5.0$ \\
\hline $\begin{array}{c}28 \ldots \\
\text { OCT } 1992\end{array}$ & $<.20$ & $<.20$ & - & 一 & $<.010$ & - & $<.010$ & $<.010$ & - & 1 & $<1.0$ & $<5.0$ \\
\hline $\begin{array}{c}05 \ldots \\
\text { NOV } 1993\end{array}$ & $<.20$ & $<.20$ & 一 & 一 & $<.010$ & - & $<.010$ & $<.010$ & - & $<1$ & $<1.0$ & $<5.0$ \\
\hline $\begin{array}{c}18 \ldots \\
\text { NOV } 1994\end{array}$ & - & - & - & - & - & - & - & $<.010$ & - & - & - & - \\
\hline $07 \ldots$ & - & - & - & - & - & - & - & $<.010$ & - & - & - & - \\
\hline
\end{tabular}


Table 3. Water-quality data from surface-water sites-Continued

01473167 - Little Valley Creek at Howellville, Pa. (Site 49)—Continued

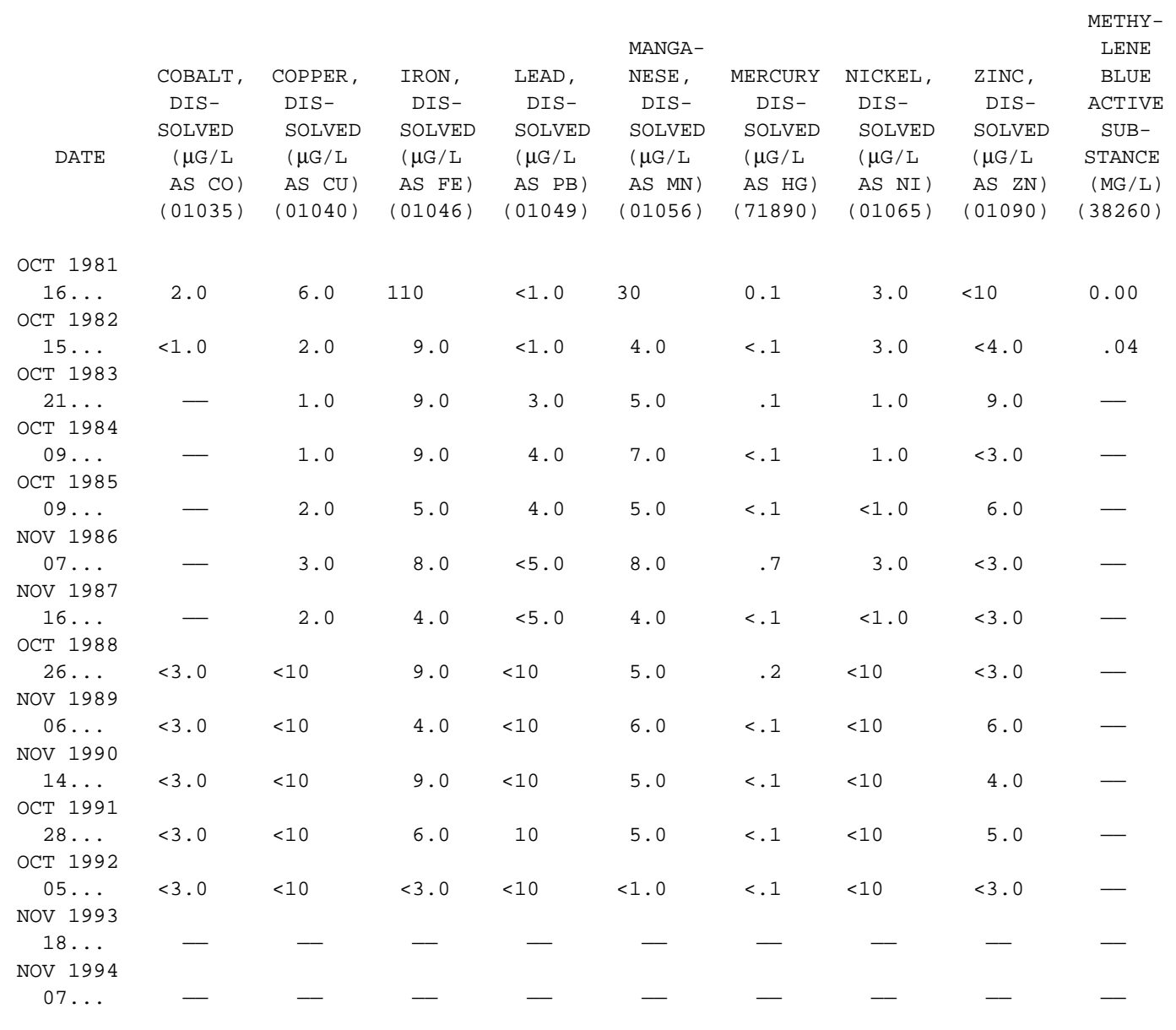


Table 3. Water-quality data from surface-water sites-Continued

01473168 - Valley Creek near Valley Forge, Pa. (Site 50)

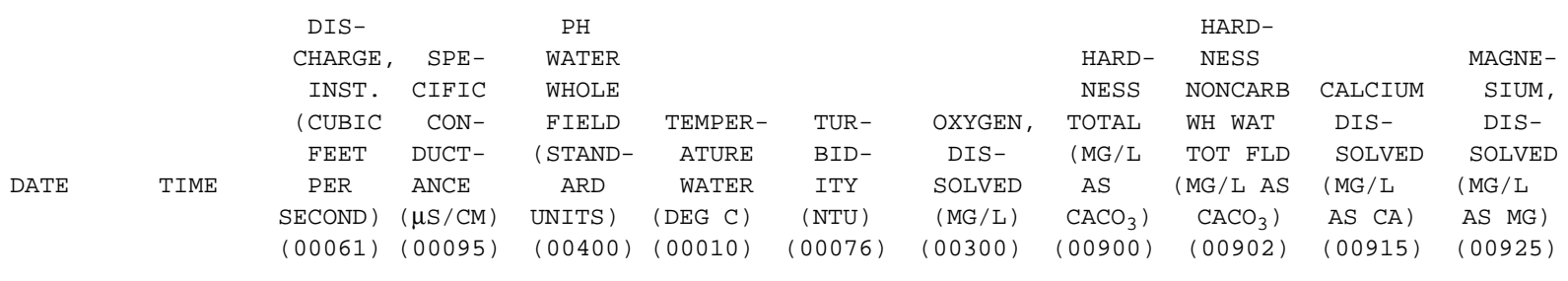

\begin{tabular}{|c|c|c|c|c|c|c|c|c|c|c|c|}
\hline $\begin{array}{c}16 \ldots \\
\text { OCT } 1982\end{array}$ & 1400 & - & 615 & 8.4 & 12.5 & - & 12.3 & 260 & - & 47 & 35 \\
\hline $\begin{array}{c}15 \ldots \\
\text { OCT } 1983\end{array}$ & 1200 & 18 & 498 & 8.3 & 12.0 & - & 10.5 & 230 & - & 45 & 29 \\
\hline $\begin{array}{c}21 \ldots \\
\text { OCT } 1984\end{array}$ & 1100 & 3.2 & 538 & 8.2 & 10.0 & 4.0 & 10.8 & 240 & - & 47 & 30 \\
\hline $\begin{array}{c}09 \ldots \\
\text { OCT } 1985\end{array}$ & 1630 & 17 & 535 & 9.2 & 14.0 & .70 & 11.1 & 240 & - & 46 & 30 \\
\hline $\begin{array}{c}09 \ldots \\
\text { NOV } 1986\end{array}$ & 1030 & 10 & 550 & 7.8 & 9.0 & 1.0 & 12.0 & 250 & - & 49 & 30 \\
\hline $\begin{array}{c}07 \ldots \\
\text { NOV } 1987\end{array}$ & 1300 & 15 & 498 & 8.3 & 9.0 & 1.1 & 11.6 & 240 & - & 46 & 31 \\
\hline $\begin{array}{c}16 \ldots \\
\text { OCT } 1988\end{array}$ & 1000 & 13 & 515 & 7.9 & 9.0 & .20 & 12.6 & 250 & - & 48 & 31 \\
\hline $\begin{array}{c}26 \ldots \\
\text { NOV } 1989\end{array}$ & 1345 & 9.8 & 518 & 7.9 & 9.5 & 2.2 & 12.1 & 250 & - & 47 & 32 \\
\hline $\begin{array}{c}06 \ldots \\
\text { NOV } 1990\end{array}$ & 1445 & 17 & 585 & 8.2 & 11.5 & .60 & 11.9 & 250 & 39 & 50 & 31 \\
\hline $\begin{array}{c}14 \ldots \\
\text { OCT } 1991\end{array}$ & 1130 & 12 & 595 & 6.9 & 6.5 & 2.5 & 13.2 & 250 & 65 & 50 & 31 \\
\hline $\begin{array}{c}28 \ldots \\
\text { OCT } 1992\end{array}$ & 1200 & 8.2 & 562 & 8.1 & 14.0 & 2.0 & 11.0 & 250 & 27 & 49 & 32 \\
\hline $\begin{array}{c}05 \ldots \\
\text { NOV } 1993\end{array}$ & 1215 & 9.3 & 308 & 7.2 & 12.5 & .30 & 11.6 & 250 & - & 47 & 31 \\
\hline $\begin{array}{c}18 \ldots \\
\text { NOV } 1994\end{array}$ & 1230 & 11 & 602 & 8.3 & 11.0 & - & 11.8 & - & - & - & - \\
\hline $07 \ldots$ & 1130 & 14 & 580 & 7.9 & 11.5 & - & 11.1 & - & - & - & - \\
\hline
\end{tabular}


Table 3. Water-quality data from surface-water sites-Continued

01473168 - Valley Creek near Valley Forge, Pa. (Site 50)—Continued

\begin{tabular}{|c|c|c|c|c|c|c|c|c|c|c|}
\hline DATE & $\begin{array}{l}\text { SODIUM, } \\
\text { DIS- } \\
\text { SOLVED } \\
\text { (MG/L } \\
\text { AS NA) } \\
(00930)\end{array}$ & $\begin{array}{l}\text { SODIUM } \\
\text { PERCENT } \\
(00932)\end{array}$ & $\begin{array}{c}\text { SODIUM } \\
\text { AD- } \\
\text { SORP- } \\
\text { TION } \\
\text { RATIO } \\
(00931)\end{array}$ & $\begin{array}{l}\text { POTAS- } \\
\text { SIUM, } \\
\text { DIS- } \\
\text { SOLVED } \\
\text { (MG/L } \\
\text { AS K) } \\
(00935)\end{array}$ & $\begin{array}{l}\text { ALKA- } \\
\text { LINITY } \\
\text { WAT WH } \\
\text { TOT FET } \\
\text { FIELD } \\
(\mathrm{MG} / \mathrm{L} \text { AS } \\
\left.\mathrm{CACO}_{3}\right) \\
(00410)\end{array}$ & $\begin{array}{l}\text { ALKA- } \\
\text { LINITY } \\
\text { WAT WH } \\
\text { TOT IT } \\
\text { FIELD } \\
(\mathrm{MG} / \mathrm{L} \text { AS } \\
\left.\mathrm{CACO}_{3}\right) \\
(00419)\end{array}$ & $\begin{array}{l}\text { SULFATE, } \\
\text { DIS- } \\
\text { SOLVED } \\
(\mathrm{MG} / \mathrm{L} \\
\left.\mathrm{AS} \mathrm{SO} \mathrm{SO}_{4}\right) \\
(00945)\end{array}$ & $\begin{array}{l}\text { CHLO- } \\
\text { RIDE, } \\
\text { DIS- } \\
\text { SOLVED } \\
\text { (MG/L } \\
\text { AS CL) } \\
(00940)\end{array}$ & $\begin{array}{l}\text { FLUO- } \\
\text { RIDE, } \\
\text { DIS- } \\
\text { SOLVED } \\
(\text { MG/L } \\
\text { AS F) } \\
(00950)\end{array}$ & $\begin{array}{l}\text { SILICA, } \\
\text { DIS- } \\
\text { SOLVED } \\
(\mathrm{MG} / \mathrm{L} \\
\mathrm{AS} \\
\left.\mathrm{SIO}_{2}\right) \\
(00955)\end{array}$ \\
\hline OCT 1981 & & 18 & 0.7 & 3 & 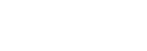 & & 37 & 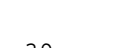 & 10 & 6.6 \\
\hline OCT 1982 & & & & 3.1 & & & (1 & (39 & 20.10 & 0.0 \\
\hline $\begin{array}{c}15 \ldots \\
\text { OCT } 1983\end{array}$ & 27 & 20 & .8 & 2.4 & 200 & - & 35 & 41 & $<.10$ & 8.0 \\
\hline $\begin{array}{c}21 \ldots \\
\text { OCT } 1984\end{array}$ & 25 & 18 & .7 & 2.9 & 212 & - & 31 & 42 & - & 7.7 \\
\hline $\begin{array}{c}09 \ldots \\
\text { OCT } 1985\end{array}$ & 29 & 21 & .8 & 3.0 & 214 & - & 31 & 42 & - & 7.7 \\
\hline $\begin{array}{c}09 \ldots \\
\text { NOV } 1986\end{array}$ & 25 & 18 & .7 & 3.0 & 216 & - & 30 & 43 & - & 8.0 \\
\hline $\begin{array}{c}07 \ldots \\
\text { NOV } 1987\end{array}$ & 23 & 17 & .6 & 3.0 & 200 & - & 33 & 36 & - & 8.2 \\
\hline $\begin{array}{c}16 \ldots \\
\text { OCT } 1988\end{array}$ & 25 & 18 & .7 & 3.5 & 211 & - & 30 & 42 & - & 6.9 \\
\hline $\begin{array}{c}26 \ldots \\
\text { NOV } 1989\end{array}$ & 26 & 18 & .7 & 3.4 & 214 & - & 31 & 43 & - & 8.1 \\
\hline $\begin{array}{c}06 \ldots \\
\text { NOV } 1990\end{array}$ & 27 & 19 & .7 & 3.1 & 214 & - & 29 & 39 & - & 6.5 \\
\hline $\begin{array}{c}14 \ldots \\
\text { OCT } 1991\end{array}$ & 26 & 18 & .7 & 3.5 & 188 & - & 28 & 45 & $<.10$ & 8.0 \\
\hline $\begin{array}{c}28 \ldots \\
\text { OCT } 1992\end{array}$ & 26 & 18 & .7 & 3.6 & 227 & - & 30 & 41 & .10 & 7.2 \\
\hline $\begin{array}{c}05 \ldots \\
\text { NOV } 1993\end{array}$ & 23 & 17 & .6 & 3.2 & - & 183 & 28 & 45 & .10 & 7.8 \\
\hline $\begin{array}{c}18 \ldots \\
\text { NOV } 1994\end{array}$ & - & - & - & - & - & 214 & 26 & 41 & $<.10$ & - \\
\hline $07 \ldots$ & - & - & - & - & - & 192 & - & 46 & - & - \\
\hline
\end{tabular}


Table 3. Water-quality data from surface-water sites-Continued

01473168 - Valley Creek near Valley Forge, Pa. (Site 50)—Continued

\begin{tabular}{|c|c|c|c|c|c|c|c|c|c|c|}
\hline DATE & $\begin{array}{c}\text { SOLIDS, } \\
\text { RESIDUE } \\
\text { AT } 180 \\
\text { DEG. C } \\
\text { DIS- } \\
\text { SOLVED } \\
(\mathrm{MG} / \mathrm{L}) \\
(70300)\end{array}$ & $\begin{array}{l}\text { SOLIDS, } \\
\text { SUM OF } \\
\text { CONSTI- } \\
\text { TUENTS, } \\
\text { DIS- } \\
\text { SOLVED } \\
\text { (MG/L) } \\
(70301)\end{array}$ & $\begin{array}{c}\text { SOLIDS, } \\
\text { DIS- } \\
\text { SOLVED } \\
\text { (TONS } \\
\text { PER } \\
\text { AC-FT) } \\
(70303)\end{array}$ & $\begin{array}{c}\text { SOLIDS, } \\
\text { DIS- } \\
\text { SOLVED } \\
\text { (TONS } \\
\text { PER } \\
\text { DAY) } \\
(70302)\end{array}$ & $\begin{array}{c}\text { NITRO- } \\
\text { GEN, } \\
\text { NITRATE } \\
\text { TOTAL } \\
\text { (MG/L } \\
\text { AS N) } \\
(00620)\end{array}$ & $\begin{array}{l}\text { NITRO- } \\
\text { GEN, } \\
\text { NITRATE } \\
\text { DIS- } \\
\text { SOLVED } \\
\text { (MG/L } \\
\text { AS N) } \\
(00618)\end{array}$ & $\begin{array}{c}\text { NITRO- } \\
\text { GEN, } \\
\text { NITRATE } \\
\text { DIS- } \\
\text { SOLVED } \\
\text { (MG/L } \\
\left.\text { AS NO })_{3}\right) \\
(71851)\end{array}$ & $\begin{array}{c}\text { NITRO- } \\
\text { GEN, } \\
\text { NITRITE } \\
\text { DIS- } \\
\text { SOLVED } \\
\text { (MG/L } \\
\text { AS N) } \\
(00613)\end{array}$ & $\begin{array}{c}\text { NITRO- } \\
\text { GEN, } \\
\mathrm{NO}_{2}+\mathrm{NO}_{3} \\
\text { DIS- } \\
\text { SOLVED } \\
(\mathrm{MG} / \mathrm{L} \\
\mathrm{AS} \mathrm{N}) \\
(00631)\end{array}$ & $\begin{array}{c}\text { NITRO- } \\
\text { GEN, } \\
\text { AMMONIA } \\
\text { DIS- } \\
\text { SOLVED } \\
\text { (MG/L } \\
\text { AS N) } \\
(00608)\end{array}$ \\
\hline OCT 1981 & & & & & & & & & & \\
\hline $\begin{array}{c}16 \ldots \\
\text { OCT } 1982\end{array}$ & 309 & - & 0.42 & - & 1.78 & 1.68 & 7.4 & 0.020 & 1.70 & 0.080 \\
\hline $\begin{array}{c}15 \ldots \\
\text { OCT } 1983\end{array}$ & 311 & 316 & .42 & 15.3 & 1.87 & 1.87 & 8.3 & .030 & 1.90 & .050 \\
\hline $\begin{array}{c}21 \ldots \\
\text { OCT } 1984\end{array}$ & 325 & 321 & .44 & 2.81 & 1.75 & 1.75 & 7.7 & .050 & 1.80 & $<.010$ \\
\hline $\begin{array}{c}09 \ldots \\
\text { OCT } 1985\end{array}$ & 311 & 327 & .42 & 14.3 & 2.17 & 2.17 & 9.6 & .030 & 2.20 & .050 \\
\hline $\begin{array}{c}09 \ldots \\
\text { NOV } 1986\end{array}$ & 315 & 328 & .43 & 8.51 & 2.17 & 2.17 & 9.6 & .030 & 2.20 & .050 \\
\hline $\begin{array}{c}07 \ldots \\
\text { NOV } 1987\end{array}$ & 305 & 310 & .41 & 12.4 & 2.08 & 2.08 & 9.2 & .020 & 2.10 & .070 \\
\hline $\begin{array}{c}16 \ldots \\
\text { OCT } 1988\end{array}$ & 313 & 323 & .43 & 11.0 & 2.20 & - & - & $<.010$ & 2.20 & $<.010$ \\
\hline $\begin{array}{c}26 \ldots \\
\text { NOV } 1989\end{array}$ & - & 330 & .45 & 8.72 & 2.37 & 2.37 & 10 & .030 & 2.40 & .070 \\
\hline $\begin{array}{c}06 \ldots \\
\text { NOV } 1990\end{array}$ & 一 & 326 & .44 & 14.9 & 2.58 & 2.58 & 11 & .020 & 2.60 & .020 \\
\hline $\begin{array}{c}14 \ldots \\
\text { OCT } 1991\end{array}$ & - & 317 & .43 & 1.3 & 2.78 & 2.78 & 12 & .020 & 2.80 & .110 \\
\hline $\begin{array}{c}28 \ldots \\
\text { OCT } 1992\end{array}$ & - & 334 & .45 & 7.39 & 1.90 & - & - & $<.010$ & 1.90 & .020 \\
\hline $\begin{array}{c}05 \ldots \\
\text { NOV } 1993\end{array}$ & - & 304 & .41 & 7.63 & 2.00 & - & - & $<.010$ & 2.00 & .010 \\
\hline $\begin{array}{c}18 \ldots \\
\text { NOV } 1994\end{array}$ & - & - & - & - & 2.18 & 2.18 & 9.6 & .020 & 2.20 & .030 \\
\hline $07 \ldots$ & - & - & - & - & 1.90 & - & - & $<.010$ & 1.90 & $<.015$ \\
\hline
\end{tabular}


Table 3. Water-quality data from surface-water sites-Continued

01473168 - Valley Creek near Valley Forge, Pa. (Site 50)—Continued

\begin{tabular}{|c|c|c|c|c|c|c|c|c|c|c|}
\hline DATE & $\begin{array}{c}\text { NITRO- } \\
\text { GEN, } \\
\text { AMMONIA } \\
\text { DIS- } \\
\text { SOLVED } \\
\text { (MG/L } \\
\text { AS NH4) } \\
(71846)\end{array}$ & $\begin{array}{c}\text { NITRO- } \\
\text { GEN, } \\
\text { ORGANIC } \\
\text { TOTAL } \\
(\text { MG/L } \\
\text { AS N) } \\
(00605)\end{array}$ & $\begin{array}{c}\text { NITRO- } \\
\text { GEN, } \\
\text { ORGANIC } \\
\text { DIS- } \\
\text { SOLVED } \\
\text { (MG/L } \\
\text { AS N) } \\
(00607)\end{array}$ & $\begin{array}{l}\text { NITRO- } \\
\text { GEN, AM- } \\
\text { MONIA + } \\
\text { ORGANIC } \\
\text { TOTAL } \\
\text { (MG/L } \\
\text { AS N) } \\
(00625)\end{array}$ & $\begin{array}{l}\text { NITRO- } \\
\text { GEN, AM- } \\
\text { MONIA + } \\
\text { ORGANIC } \\
\text { DIS. } \\
\text { (MG/L } \\
\text { AS N) } \\
(00623)\end{array}$ & $\begin{array}{c}\text { NITRO- } \\
\text { GEN, } \\
\text { TOTAL } \\
\text { (MG/L } \\
\text { AS N) } \\
(00600)\end{array}$ & $\begin{array}{c}\text { NITRO- } \\
\text { GEN, } \\
\text { DIS- } \\
\text { SOLVED } \\
\text { (MG/L } \\
\text { AS N) } \\
(00602)\end{array}$ & $\begin{array}{c}\text { PHOS- } \\
\text { PHORUS, } \\
\text { TOTAL } \\
\text { (MG/L } \\
\text { AS P) } \\
(00665)\end{array}$ & $\begin{array}{c}\text { PHOS- } \\
\text { PHORUS, } \\
\text { TOTAL } \\
(\mathrm{MG} / \mathrm{L} \\
\left.\text { AS } \mathrm{PO}_{4}\right) \\
(71886)\end{array}$ & $\begin{array}{c}\text { PHOS- } \\
\text { PHORUS, } \\
\text { DIS- } \\
\text { SOLVED } \\
(\text { MG/L } \\
\text { AS P ) } \\
(00666)\end{array}$ \\
\hline OCT 1981 & & & & & & & & & & \\
\hline $\begin{array}{c}16 \ldots \\
\text { OCT } 1982\end{array}$ & 0.10 & 0.35 & 0.03 & 0.50 & 0.11 & 2.3 & 1.8 & 0.020 & 0.06 & 0.010 \\
\hline $\begin{array}{c}15 \ldots \\
\text { OCT } 1983\end{array}$ & .06 & - & .35 & - & .40 & - & 2.3 & - & - & .010 \\
\hline $\begin{array}{c}21 \ldots \\
\text { OCT } 1984\end{array}$ & - & - & - & - & .20 & - & 2.0 & .030 & .09 & .010 \\
\hline $\begin{array}{c}09 \ldots \\
\text { ОСТ } 1985\end{array}$ & .06 & - & .25 & - & .30 & - & 2.5 & .020 & - & .010 \\
\hline $\begin{array}{c}09 \ldots \\
\text { NOV } 1986\end{array}$ & .06 & - & .35 & - & .40 & - & 2.6 & .030 & .09 & .020 \\
\hline $\begin{array}{c}07 \ldots \\
\text { NOV } 1987\end{array}$ & .09 & .43 & .43 & .50 & .50 & 2.6 & 2.6 & .020 & - & .020 \\
\hline $\begin{array}{c}16 \ldots \\
\text { OCT } 1988\end{array}$ & - & .40 & - & .40 & $<.20$ & 2.6 & - & .020 & - & $<.010$ \\
\hline $\begin{array}{c}26 \ldots \\
\text { NOV } 1989\end{array}$ & .09 & .13 & .33 & .20 & .40 & 2.6 & 2.8 & .030 & - & .020 \\
\hline $\begin{array}{c}06 \ldots \\
\text { NOV } 1990\end{array}$ & .03 & .48 & .18 & .50 & .20 & 3.1 & 2.8 & $<.010$ & - & $<.010$ \\
\hline $\begin{array}{c}14 \ldots \\
\text { OCT } 1991\end{array}$ & .14 & .49 & .49 & .60 & .60 & 3.4 & 3.4 & .040 & - & .020 \\
\hline $\begin{array}{c}28 \ldots \\
\text { ОСт } 1992\end{array}$ & .03 & - & - & $<.20$ & $<.20$ & - & - & .030 & - & $<.010$ \\
\hline $\begin{array}{c}05 \ldots \\
\text { NOV } 1993\end{array}$ & .01 & - & - & $<.20$ & $<.20$ & - & - & $<.010$ & - & .020 \\
\hline $\begin{array}{c}18 \ldots \\
\text { NOV } 1994\end{array}$ & .04 & - & - & - & - & - & - & - & - & - \\
\hline $07 \ldots$ & - & - & - & - & - & - & - & - & - & - \\
\hline
\end{tabular}


Table 3. Water-quality data from surface-water sites-Continued

01473168 - Valley Creek near Valley Forge, Pa. (Site 50)—Continued

\begin{tabular}{|c|c|c|c|c|c|c|c|c|c|}
\hline $\begin{array}{r}\text { PHOS- } \\
\text { PHORUS }\end{array}$ & $\begin{array}{l}\text { PHOS- } \\
\text { PHATE, }\end{array}$ & & & BERYL- & & CHRO- & & & \\
\hline $\begin{array}{l}\text { ORTHO, } \\
\text { DIS- } \\
\text { SOLVED }\end{array}$ & $\begin{array}{l}\text { ORTHO, } \\
\text { DIS- } \\
\text { SOLVED }\end{array}$ & $\begin{array}{c}\text { ARSENIC, } \\
\text { DIS- } \\
\text { SOLVED }\end{array}$ & $\begin{array}{l}\text { BARIUM, } \\
\text { DIS- } \\
\text { SOLVED }\end{array}$ & $\begin{array}{l}\text { LIUM, } \\
\text { DIS- } \\
\text { SOLVED }\end{array}$ & $\begin{array}{l}\text { CADMIUM, } \\
\text { DIS- } \\
\text { SOLVED }\end{array}$ & $\begin{array}{l}\text { MIUM, } \\
\text { DIS- } \\
\text { SOLVED }\end{array}$ & $\begin{array}{l}\text { COBALT, } \\
\text { DIS- } \\
\text { SOLVED }\end{array}$ & $\begin{array}{l}\text { COPPER, } \\
\text { DIS- } \\
\text { SOLVED }\end{array}$ & $\begin{array}{l}\text { IRON, } \\
\text { DIS- } \\
\text { SOLVED }\end{array}$ \\
\hline (MG/L & (MG / L & $(\mu \mathrm{G} / \mathrm{L}$ & $(\mu \mathrm{G} / \mathrm{L}$ & $(\mu \mathrm{G} / \mathrm{L}$ & $(\mu \mathrm{G} / \mathrm{L}$ & $(\mu \mathrm{G} / \mathrm{L}$ & $(\mu \mathrm{G} / \mathrm{L}$ & $(\mu \mathrm{G} / \mathrm{L}$ & $(\mu \mathrm{G} / \mathrm{L}$ \\
\hline $\begin{array}{l}\text { AS P) } \\
(00671)\end{array}$ & $\begin{array}{c}\left.\text { AS } \mathrm{PO}_{4}\right) \\
(00660)\end{array}$ & $\begin{array}{c}\text { AS AS) } \\
(01000)\end{array}$ & $\begin{array}{c}\text { AS BA) } \\
(01005)\end{array}$ & $\begin{array}{c}A S \text { BE) } \\
(01010)\end{array}$ & $\begin{array}{c}\text { AS CD) } \\
(01025)\end{array}$ & $\begin{array}{c}\text { AS CR) } \\
(01030)\end{array}$ & $\begin{array}{c}\text { AS CO) } \\
(01035)\end{array}$ & $\begin{array}{c}\text { AS CU) } \\
(01040)\end{array}$ & $\begin{array}{c}\text { AS FE) } \\
(01046)\end{array}$ \\
\hline
\end{tabular}

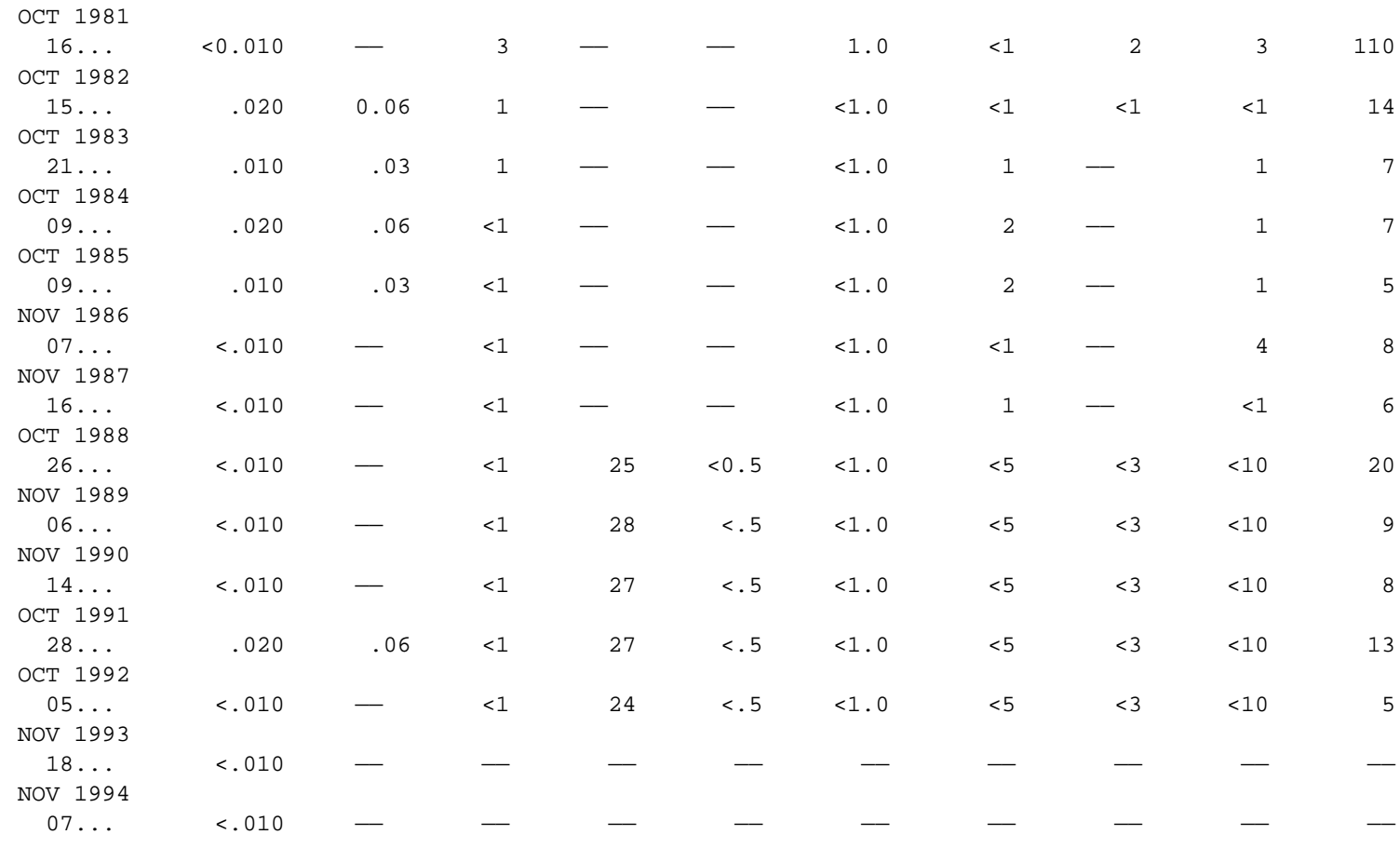


Table 3. Water-quality data from surface-water sites-Continued

01473168 - Valley Creek near Valley Forge, Pa. (Site 50)—Continued

\begin{tabular}{|c|c|c|c|c|c|c|c|c|c|c|}
\hline & & & MANGA- & & & & STRON- & VANA- & & $\begin{array}{c}\text { METHY- } \\
\text { LENE }\end{array}$ \\
\hline & LEAD, & LITHIUM, & $\mathrm{NESE}$ & MERCURY, & NICKEL, & SILVER, & TIUM, & DIUM, & ZINC, & BLUE \\
\hline & DIS- & DIS- & DIS- & DIS- & DIS- & DIS- & DIS- & DIS- & DIS- & ACTIVE \\
\hline & SOLVED & SOLVED & SOLVED & SOLVED & SOLVED & SOLVED & SOLVED & SOLVED & SOLVED & SUB- \\
\hline DATE & $(\mu \mathrm{G} / \mathrm{L}$ & $(\mu \mathrm{G} / \mathrm{L}$ & $(\mu \mathrm{G} / \mathrm{L}$ & $(\mu \mathrm{G} / \mathrm{L}$ & $(\mu \mathrm{G} / \mathrm{L}$ & $(\mu \mathrm{G} / \mathrm{L}$ & $(\mu \mathrm{G} / \mathrm{L}$ & $(\mu \mathrm{G} / \mathrm{L}$ & $(\mu \mathrm{G} / \mathrm{L}$ & STANCE \\
\hline & $A S \quad P B)$ & AS LI) & AS MN) & AS HG) & AS NI) & AS $A G$ ) & AS SR) & AS V) & AS ZN) & (MG/L) \\
\hline & $(01049)$ & $(01130)$ & $(01056)$ & $(71890)$ & $(01065)$ & $(01075)$ & $(01080)$ & (01085) & $(01090)$ & $(38260)$ \\
\hline
\end{tabular}

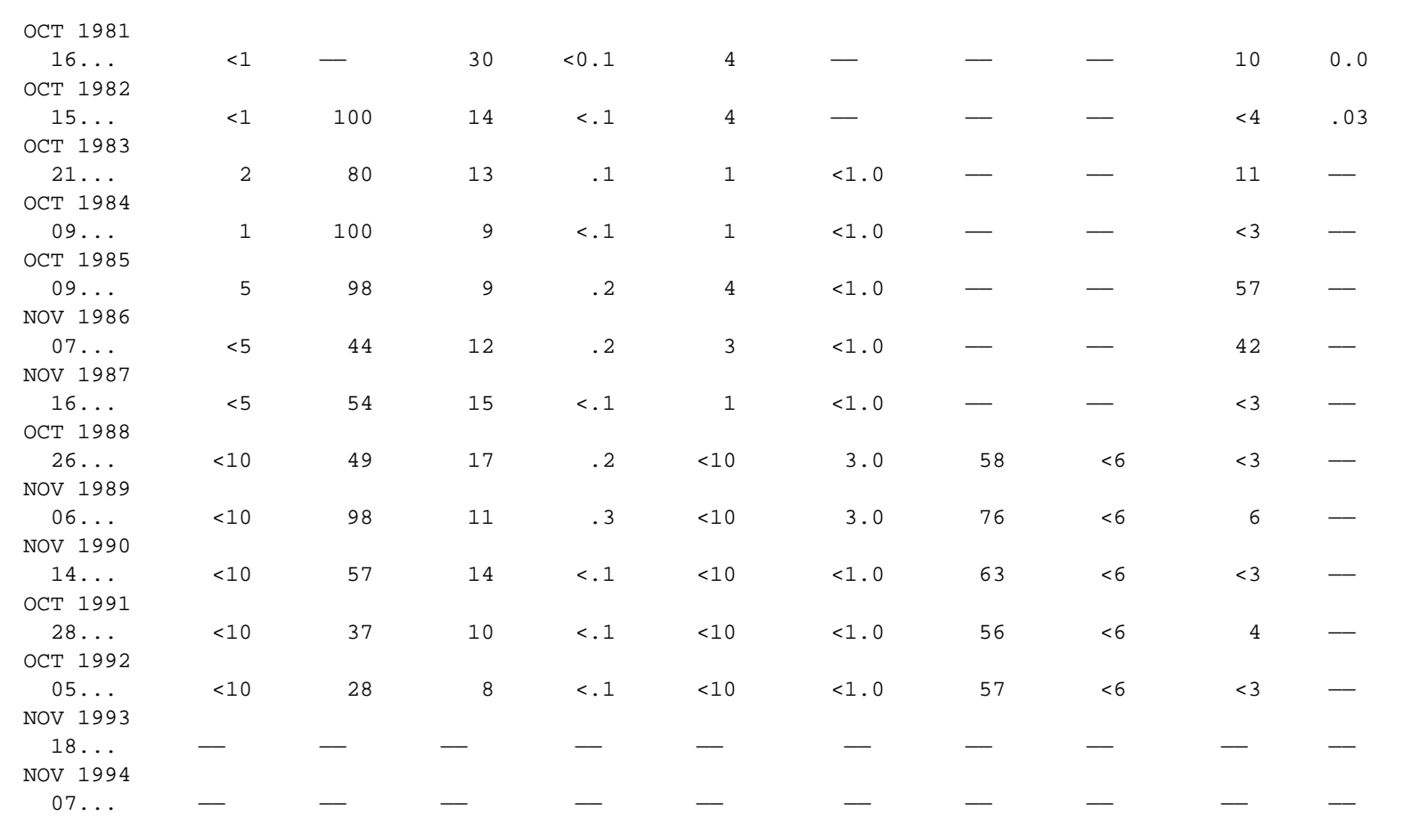


Table 3. Water-quality data from surface-water sites-Continued

01475300 - Darby Creek at Waterloo Mills near Devon, Pa. (Site 17)

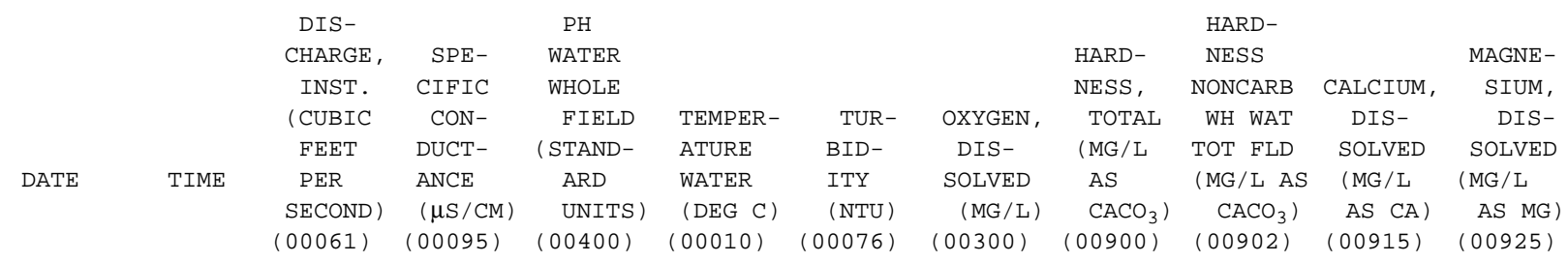

\begin{tabular}{|c|c|c|c|c|c|c|c|c|c|c|c|}
\hline $\begin{array}{c}\text { OCT } 1981 \\
19 \ldots \\
\text { OCT } 1982\end{array}$ & 1530 & - & 230 & 7.0 & 10.0 & - & 10.0 & 93 & - & 22 & 9.3 \\
\hline $\begin{array}{c}13 \ldots \\
\text { OCT } 1983\end{array}$ & 0915 & 2.8 & 266 & 6.9 & 13.0 & - & 9.5 & 99 & - & 23 & 10 \\
\hline $\begin{array}{c}27 \ldots \\
\text { OCT } 1984\end{array}$ & 1430 & 3.8 & 235 & 7.5 & 10.0 & 1.3 & 9.5 & 99 & - & 24 & 9.5 \\
\hline $\begin{array}{c}15 \ldots \\
\text { OCT } 1985\end{array}$ & 1000 & 3.0 & 250 & 7.5 & 12.5 & .40 & 10.0 & 100 & - & 24 & 10 \\
\hline $\begin{array}{c}31 \ldots \\
\text { NOV } 1986\end{array}$ & 1400 & 2.2 & 272 & 7.4 & 10.5 & .40 & 11.0 & 99 & - & 23 & 10 \\
\hline $\begin{array}{c}14 \ldots \\
\text { OCT } 1987\end{array}$ & 1400 & 3.5 & 235 & 7.7 & 4.5 & 6.9 & 12.1 & 97 & - & 23 & 9.6 \\
\hline $\begin{array}{c}15 \ldots \\
\text { OCT } 1988\end{array}$ & 1100 & 2.5 & 190 & 7.5 & 10.5 & .40 & 12.1 & 95 & - & 22 & 9.8 \\
\hline $\begin{array}{c}18 \ldots \\
\text { OCT } 1989\end{array}$ & 1500 & 3.0 & 267 & 7.1 & 14.5 & 1.0 & 9.9 & 96 & - & 22 & 10 \\
\hline $\begin{array}{c}25 \ldots \\
\text { NOV } 1990\end{array}$ & 1745 & 5.6 & 258 & 7.4 & 13.0 & .80 & 9.6 & 96 & 30 & 22 & 10 \\
\hline $\begin{array}{c}02 \ldots \\
\text { OCT } 1991\end{array}$ & 1245 & 2.7 & 262 & 6.7 & 12.5 & .60 & 11.8 & 97 & 33 & 23 & 9.6 \\
\hline $\begin{array}{c}29 \ldots \\
\text { OCT } 1992\end{array}$ & 1200 & 4.3 & 280 & 7.1 & 12.5 & 1.2 & 10.1 & 100 & 29 & 24 & 10 \\
\hline $\begin{array}{c}21 \ldots \\
\text { OCT } 1993\end{array}$ & 1150 & 4.2 & 278 & 7.3 & 10.0 & 2.5 & 11.6 & 100 & - & 25 & 10 \\
\hline $\begin{array}{c}18 \ldots \\
\text { OCT } 1994\end{array}$ & 1130 & 3.8 & 302 & 7.4 & 14.0 & - & 10.1 & - & - & - & - \\
\hline $04 \ldots$ & 1300 & 5.4 & 315 & 7.9 & 13.5 & - & 10.0 & - & - & - & - \\
\hline
\end{tabular}


Table 3. Water-quality data from surface-water sites-Continued

01475300 - Darby Creek at Waterloo Mills near Devon, Pa. (Site 17)—Continued

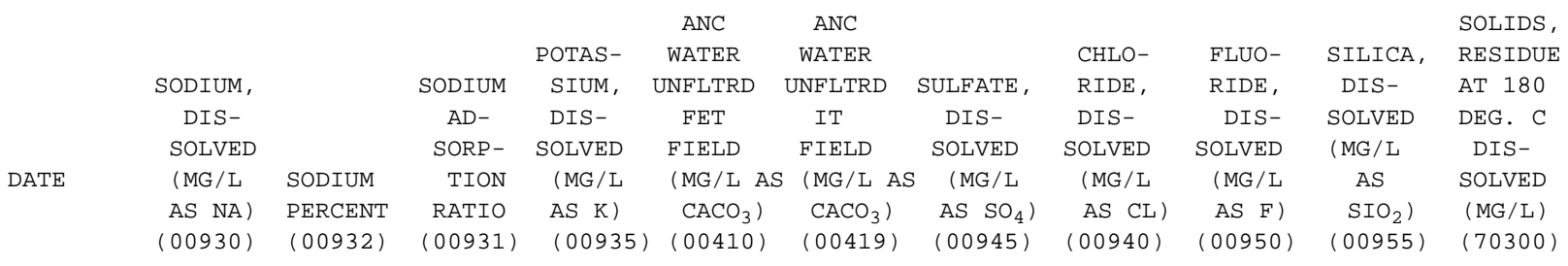

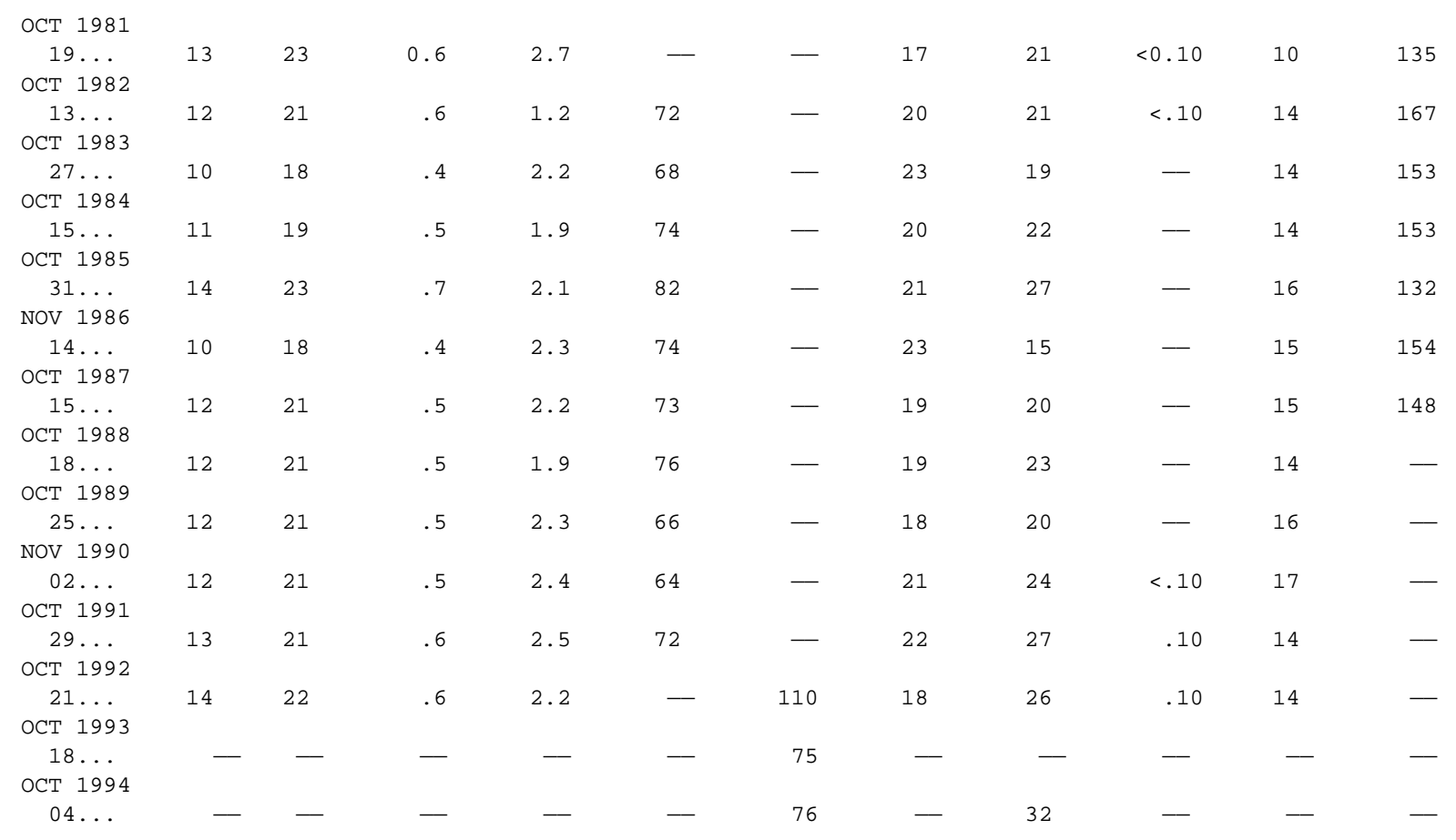


Table 3. Water-quality data from surface-water sites-Continued

01475300 - Darby Creek at Waterloo Mills near Devon, Pa. (Site 17)—Continued

\begin{tabular}{|c|c|c|c|c|c|c|c|c|c|c|c|}
\hline DATE & $\begin{array}{l}\text { SOLIDS, } \\
\text { SUM OF } \\
\text { CONSTI- } \\
\text { TUENTS, } \\
\text { DIS- } \\
\text { SOLVED } \\
(\mathrm{MG} / \mathrm{L}) \\
(70301)\end{array}$ & $\begin{array}{c}\text { SOLIDS, } \\
\text { DIS- } \\
\text { SOLVED } \\
\text { (TONS } \\
\text { PER } \\
\text { AC-FT) } \\
(70303)\end{array}$ & $\begin{array}{c}\text { SOLIDS, } \\
\text { DIS- } \\
\text { SOLVED } \\
\text { (TONS } \\
\text { PER } \\
\text { DAY) } \\
(70302)\end{array}$ & $\begin{array}{l}\text { NITRO- } \\
\text { GEN, } \\
\text { NITRATE } \\
\text { DIS- } \\
\text { SOLVED } \\
\text { (MG/L } \\
\text { AS N) } \\
(00618)\end{array}$ & $\begin{array}{c}\text { NITRO- } \\
\text { GEN, } \\
\text { NITRATE } \\
\text { DIS- } \\
\text { SOLVED } \\
(\mathrm{MG} / \mathrm{L} \\
\text { AS NO } \\
(71851)\end{array}$ & $\begin{array}{l}\text { NITRO- } \\
\text { GEN, } \\
\text { NITRITE } \\
\text { DIS- } \\
\text { SOLVED } \\
\text { (MG/L } \\
\text { AS N) } \\
(00613)\end{array}$ & $\begin{array}{c}\text { NITRO- } \\
\text { GEN, } \\
\mathrm{NO}_{2}+\mathrm{NO}_{3} \\
\text { DIS- } \\
\text { SOLVED } \\
(\mathrm{MG} / \mathrm{L} \\
\mathrm{AS} \mathrm{N}) \\
(00631)\end{array}$ & $\begin{array}{c}\text { NITRO- } \\
\text { GEN, } \\
\text { AMMONIA } \\
\text { DIS- } \\
\text { SOLVED } \\
\text { (MG/L } \\
\text { AS N) } \\
(00608)\end{array}$ & $\begin{array}{c}\text { NITRO- } \\
\text { GEN, } \\
\text { AMMONIA } \\
\text { DIS- } \\
\text { SOLVED } \\
(\text { MG/L } \\
\left.\text { AS } \mathrm{NH}_{4}\right) \\
(71846)\end{array}$ & $\begin{array}{l}\text { NITRO- } \\
\text { GEN, } \\
\text { ORGANIC } \\
\text { TOTAL } \\
\text { (MG/L } \\
\text { AS N) } \\
(00605)\end{array}$ & $\begin{array}{c}\text { NITRO- } \\
\text { GEN, } \\
\text { ORGANIC } \\
\text { DIS- } \\
\text { SOLVED } \\
\text { (MG/L } \\
\text { AS N) } \\
(00607)\end{array}$ \\
\hline OCT 1981 & & & & & & & & & & & \\
\hline $\begin{array}{c}19 \ldots \\
\text { OCT } 1982\end{array}$ & - & 0.18 & - & 1.30 & 5.8 & 0.010 & 1.30 & 0.040 & 0.05 & 0.68 & 0.54 \\
\hline $\begin{array}{c}13 \ldots \\
\text { OCT } 1983\end{array}$ & 152 & .23 & 1.26 & 1.60 & 7.1 & .020 & 1.60 & .020 & .03 & - & .08 \\
\hline $\begin{array}{c}27 \ldots \\
\text { OCT } 1984\end{array}$ & 150 & .21 & 1.57 & - & - & $<.010$ & 1.60 & $<.010$ & - & - & - \\
\hline $\begin{array}{c}15 \ldots \\
\text { OCT } 1985\end{array}$ & 154 & .21 & 1.24 & 1.37 & 6.1 & .030 & 1.40 & .060 & .08 & - & .14 \\
\hline $\begin{array}{c}31 \ldots \\
\text { NOV } 1986\end{array}$ & 169 & .18 & .78 & 1.39 & 6.2 & .010 & 1.40 & .020 & .03 & .38 & .28 \\
\hline $\begin{array}{c}14 \ldots \\
\text { OCT } 1987\end{array}$ & 149 & .21 & 1.46 & - & - & $<.010$ & 1.50 & .050 & .06 & .55 & .55 \\
\hline $\begin{array}{c}15 \ldots \\
\text { OCT } 1988\end{array}$ & 151 & .20 & 1.00 & - & - & $<.010$ & 1.70 & .020 & .03 & .28 & .18 \\
\hline $\begin{array}{c}18 \ldots \\
\text { OCT } 1989\end{array}$ & 153 & .21 & 1.24 & - & - & $<.010$ & 1.30 & $<.010$ & - & - & - \\
\hline $\begin{array}{c}25 \ldots \\
\text { NOV } 1990\end{array}$ & 140 & .20 & 2.24 & - & - & $<.010$ & 1.80 & .020 & .03 & .28 & .28 \\
\hline $\begin{array}{c}02 \ldots \\
\text { OCT } 1991\end{array}$ & 155 & .21 & 1.13 & 1.58 & 7.0 & .020 & 1.60 & $<.010$ & - & - & - \\
\hline $\begin{array}{c}29 \ldots \\
\text { OCT } 1992\end{array}$ & 162 & .22 & 1.88 & - & - & $<.010$ & 1.30 & $<.010$ & - & - & - \\
\hline $\begin{array}{c}21 \ldots \\
\text { OCT } 1993\end{array}$ & 182 & .25 & 2.06 & - & - & $<.010$ & 1.50 & $<.010$ & - & - & - \\
\hline $\begin{array}{c}18 \ldots \\
\text { OCT } 1994\end{array}$ & - & - & - & - & - & $<.010$ & 1.70 & .020 & .03 & - & - \\
\hline $04 \ldots$ & - & - & - & 1.89 & 8.4 & .010 & 1.90 & .020 & .03 & - & - \\
\hline
\end{tabular}


Table 3. Water-quality data from surface-water sites-Continued

01475300 - Darby Creek at Waterloo Mills near Devon, Pa. (Site 17)—Continued

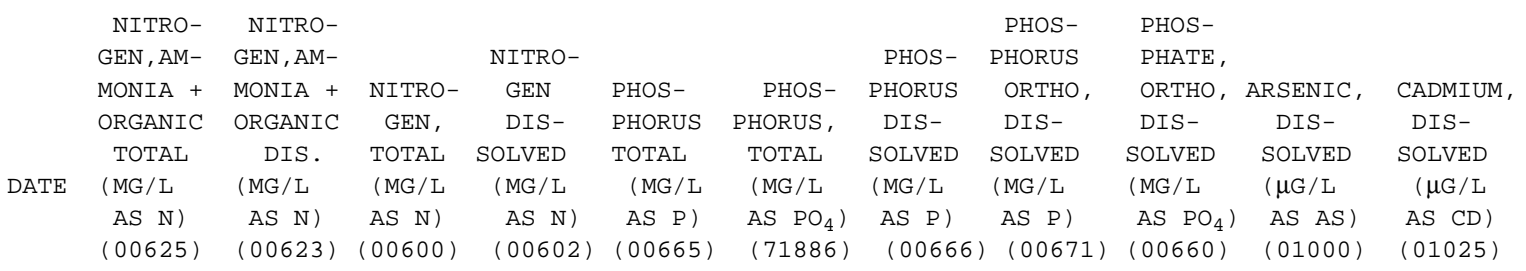

\begin{tabular}{|c|c|c|c|c|c|c|c|c|c|c|c|}
\hline $\begin{array}{c}\text { OCT } 1981 \\
19 \ldots \\
\text { OCT } 1982\end{array}$ & 0.70 & 0.58 & 2.0 & 1.9 & 0.110 & 0.34 & 0.040 & 0.030 & 0.09 & 1 & $<1.0$ \\
\hline $13 \ldots$ & - & .10 & - & 1.7 & - & - & .030 & .020 & .06 & 1 & $<1.0$ \\
\hline OCT 1983 & & & & & & & & & & & \\
\hline $\begin{array}{c}27 \ldots \\
\text { OCT } 1984\end{array}$ & - & .50 & - & 2.1 & .030 & .09 & .020 & .010 & .03 & - & - \\
\hline $\begin{array}{c}15 \ldots \\
\text { OCT } 1985\end{array}$ & - & .20 & - & 1.6 & .010 & - & .010 & .020 & .06 & - & - \\
\hline $\begin{array}{c}31 \ldots \\
\text { NOV } 1986\end{array}$ & .40 & .30 & 1.8 & 1.7 & .030 & .09 & .020 & .010 & .03 & - & - \\
\hline $\begin{array}{c}14 \ldots \\
\text { OCT } 1987\end{array}$ & .60 & .60 & 2.1 & 2.1 & .070 & - & .020 & .010 & .03 & - & - \\
\hline $\begin{array}{c}15 \ldots \\
\text { OCT } 1988\end{array}$ & .30 & .20 & 2.0 & 1.9 & .010 & - & $<.010$ & $<.010$ & - & - & - \\
\hline $\begin{array}{c}18 \ldots \\
\text { OCT } 1989\end{array}$ & .40 & .40 & 1.7 & 1.7 & .020 & - & .020 & $<.010$ & - & - & - \\
\hline $\begin{array}{c}25 \ldots \\
\text { NOV } 1990\end{array}$ & .30 & .30 & 2.1 & 2.1 & .030 & - & .030 & .020 & .06 & - & - \\
\hline $\begin{array}{c}02 \ldots \\
\text { OCT } 1991\end{array}$ & .40 & .40 & 2.0 & 2.0 & .020 & - & $<.010$ & .020 & .06 & - & - \\
\hline $\begin{array}{c}29 \ldots \\
\text { OCT } 1992\end{array}$ & .20 & $<.20$ & 1.5 & - & .030 & - & .010 & $<.010$ & - & - & - \\
\hline $\begin{array}{c}21 \ldots \\
\text { OCT } 1993\end{array}$ & .20 & $<.20$ & 1.7 & - & .040 & - & .010 & $<.010$ & - & - & - \\
\hline $\begin{array}{c}18 \ldots \\
\text { OCT } 1994\end{array}$ & - & - & - & - & - & - & - & .010 & .03 & - & - \\
\hline $04 \ldots$ & - & - & - & - & - & - & - & .010 & .03 & - & - \\
\hline
\end{tabular}


Table 3. Water-quality data from surface-water sites-Continued

01475300 - Darby Creek at Waterloo Mills near Devon, Pa. (Site 17)—Continued

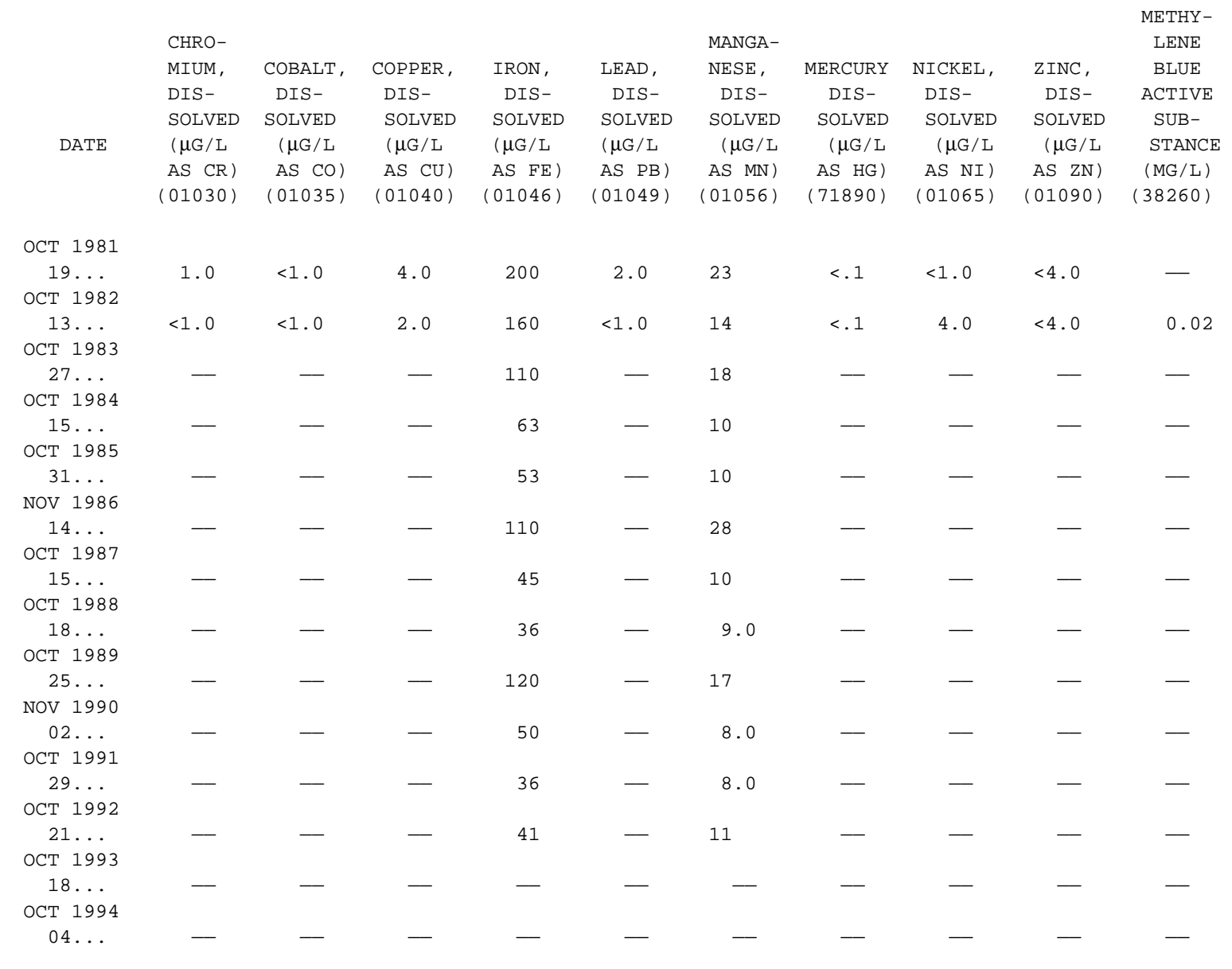


Table 3. Water-quality data from surface-water sites-Continued

01475840 - Crum Creek at Whitehorse, Pa. (Site 19)

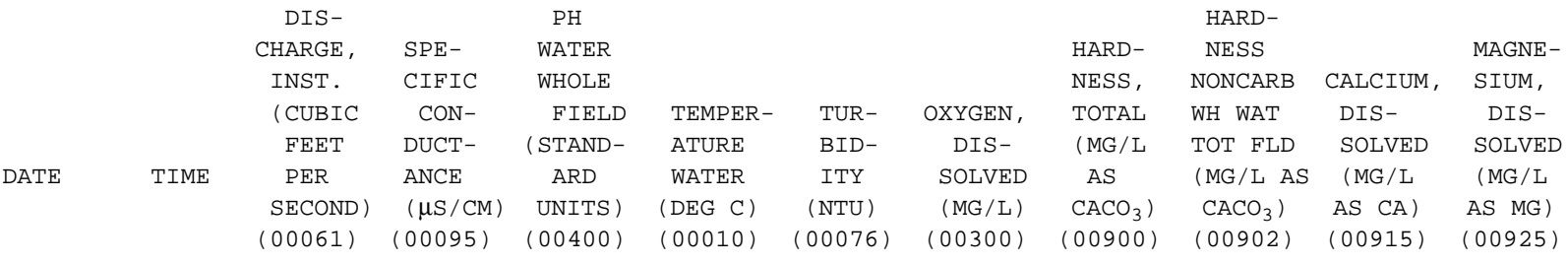

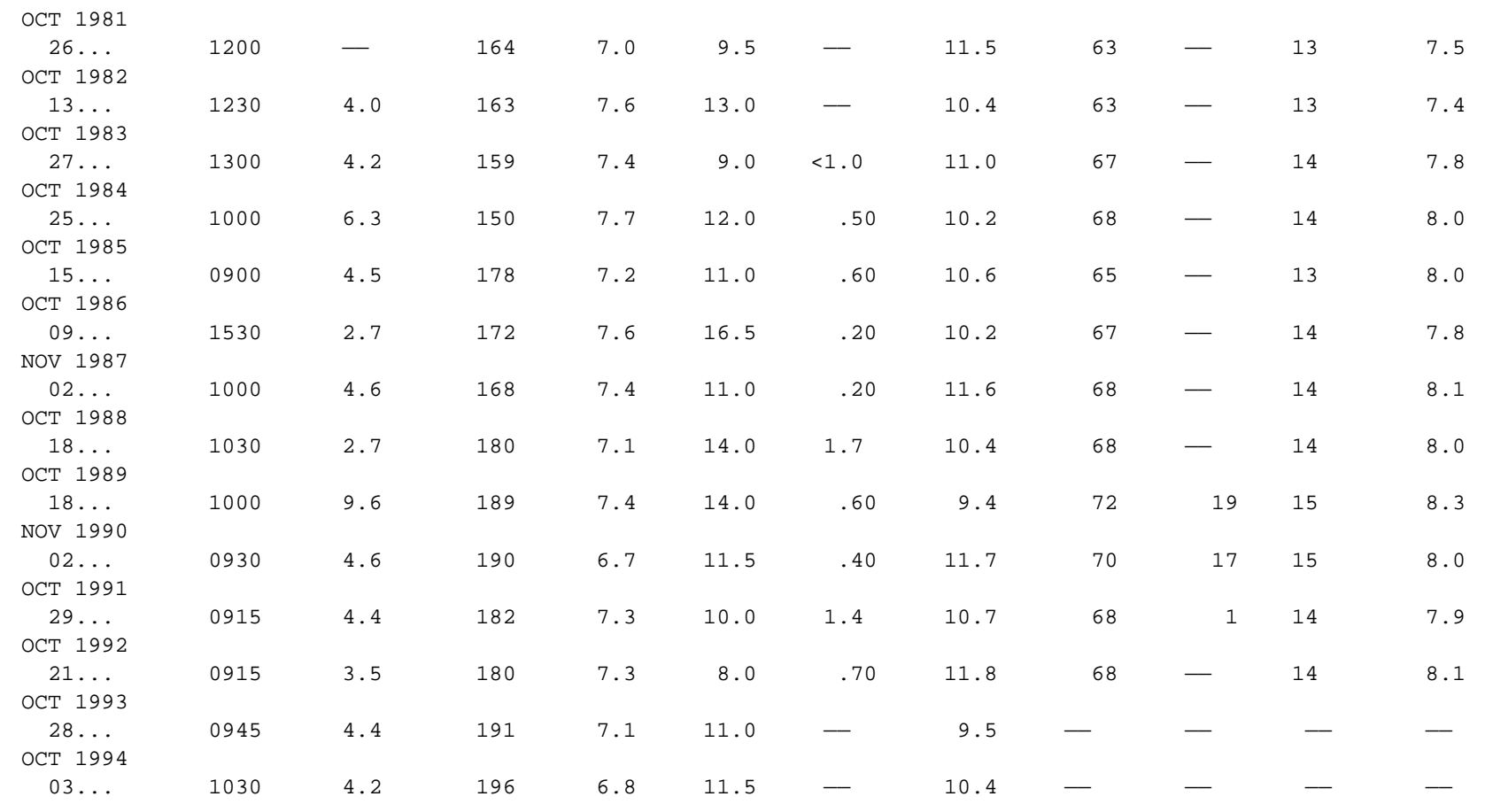


Table 3. Water-quality data from surface-water sites-Continued

01475840 - Crum Creek at Whitehorse, Pa. (Site 19)—Continued

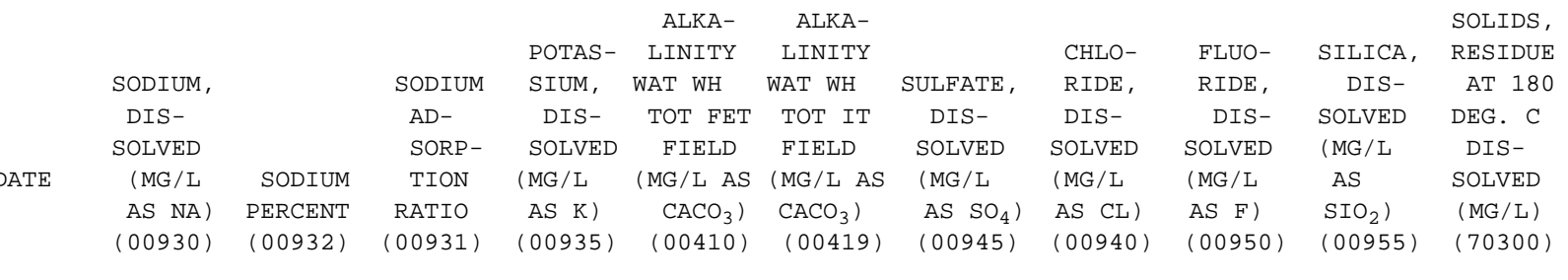

\begin{tabular}{|c|c|c|c|c|c|c|c|c|c|c|c|}
\hline $\begin{array}{c}26 \ldots \\
\text { OCT } 1982\end{array}$ & 7.1 & 19 & 0.4 & 2.1 & - & - & 12 & 9.6 & $<0.10$ & 16 & 97 \\
\hline $\begin{array}{c}13 \ldots \\
\text { OCT } 1983\end{array}$ & 6.6 & 18 & .4 & .90 & 50 & - & 10 & 9.9 & $<.10$ & 17 & 111 \\
\hline $\begin{array}{c}27 \ldots \\
\text { OCT } 1984\end{array}$ & 7.0 & 18 & .4 & 1.8 & 42 & - & 18 & 12 & - & 17 & 113 \\
\hline $\begin{array}{c}25 \ldots \\
\text { OCT } 1985\end{array}$ & 7.5 & 19 & .4 & 2.2 & 56 & - & 12 & 11 & - & 16 & 109 \\
\hline $\begin{array}{c}15 \ldots \\
\text { OCT } 1986\end{array}$ & 7.4 & 19 & .4 & 1.9 & 54 & - & 14 & 13 & - & 15 & 108 \\
\hline $\begin{array}{c}09 \ldots \\
\text { NOV } 1987\end{array}$ & 7.0 & 18 & .4 & 1.9 & 54 & - & 12 & 11 & - & 18 & 136 \\
\hline $\begin{array}{c}02 \ldots \\
\text { OCT } 1988\end{array}$ & 7.2 & 18 & .4 & 2.0 & 73 & - & 13 & 15 & - & 17 & 110 \\
\hline $\begin{array}{c}18 \ldots \\
\text { OCT } 1989\end{array}$ & 7.4 & 19 & .4 & 1.7 & 59 & - & 12 & 13 & - & 15 & - \\
\hline $\begin{array}{c}02 \ldots \\
\text { OCT } 1991\end{array}$ & 7.6 & 19 & .4 & 1.8 & 53 & - & 11 & 14 & .10 & 17 & - \\
\hline $\begin{array}{c}29 \ldots \\
\text { OCT } 1992\end{array}$ & 7.0 & 18 & .4 & 2.3 & 67 & - & 11 & 18 & .20 & 16 & - \\
\hline $\begin{array}{c}21 \ldots \\
\text { OCT } 1993\end{array}$ & 7.0 & 18 & .4 & 1.9 & - & 47 & 10 & 15 & .10 & 17 & - \\
\hline $\begin{array}{c}28 \ldots \\
\text { OCT } 1994\end{array}$ & - & - & - & - & - & 48 & - & - & - & - & - \\
\hline $03 \ldots$ & - & - & - & - & - & 30 & - & 17 & - & - & - \\
\hline
\end{tabular}


Table 3. Water-quality data from surface-water sites-Continued

01475840 - Crum Creek at Whitehorse, Pa. (Site 19)—Continued

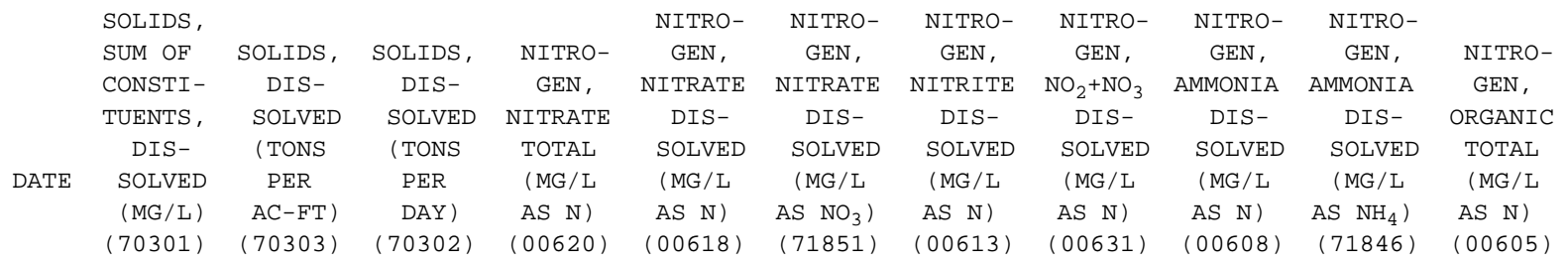

\begin{tabular}{|c|c|c|c|c|c|c|c|c|c|c|c|}
\hline $\begin{array}{c}\text { OCT } 1981 \\
26 \ldots \\
\text { OCT } 1982\end{array}$ & - & 0.13 & - & 1.08 & - & - & $<0.010$ & 1.10 & 0.020 & 0.03 & 0.28 \\
\hline $13 \ldots$ & 101 & .15 & 1.18 & 1.40 & - & - & $<.010$ & 1.40 & .020 & .03 & - \\
\hline $\begin{array}{c}27 \ldots \\
\text { OCT } 1984\end{array}$ & 109 & .15 & 1.28 & 1.40 & - & - & $<.010$ & 1.40 & $<.010$ & - & - \\
\hline $\begin{array}{c}25 \ldots \\
\text { OCT } 1985\end{array}$ & 108 & .15 & 1.85 & .860 & - & - & $<.010$ & .860 & .020 & .03 & - \\
\hline $\begin{array}{c}15 \ldots \\
\text { OCT } 1986\end{array}$ & 111 & .15 & 1.31 & 1.50 & - & - & $<.010$ & 1.50 & .020 & .03 & - \\
\hline $\begin{array}{c}09 \ldots \\
\text { NOV } 1987\end{array}$ & 109 & .18 & .99 & .990 & 0.990 & 4.4 & .010 & 1.00 & $<.010$ & - & - \\
\hline $\begin{array}{c}02 \ldots \\
\text { OCT } 1988\end{array}$ & 126 & .15 & 1.37 & 1.20 & - & - & $<.010$ & 1.20 & .030 & .04 & .47 \\
\hline $\begin{array}{c}18 \ldots \\
\text { OCT } 1989\end{array}$ & 113 & .15 & .82 & 1.40 & - & - & $<.010$ & 1.40 & $<.010$ & - & .40 \\
\hline $\begin{array}{c}18 \ldots \\
\text { NOV } 1990\end{array}$ & 115 & .16 & 2.98 & 1.39 & 1.39 & 6.2 & .010 & 1.40 & .020 & .03 & .38 \\
\hline $\begin{array}{c}02 \ldots \\
\text { OCT } 1991\end{array}$ & 113 & .15 & 1.41 & 1.50 & - & - & $<.010$ & 1.50 & .020 & .03 & .58 \\
\hline $\begin{array}{c}29 \ldots \\
\text { OCT } 1992\end{array}$ & 120 & .16 & 1.43 & .830 & - & - & $<.010$ & .830 & .020 & .03 & .18 \\
\hline $\begin{array}{c}21 \ldots \\
\text { OCT } 1993\end{array}$ & 107 & .15 & 1.01 & 1.19 & 1.19 & 5.3 & .010 & 1.20 & .010 & .01 & .19 \\
\hline $\begin{array}{c}28 \ldots \\
\text { OCT } 1994\end{array}$ & - & - & - & 1.20 & - & - & $<.010$ & 1.20 & .010 & .01 & - \\
\hline $03 \ldots$ & - & - & - & 1.40 & - & - & $<.010$ & 1.40 & $<.015$ & - & - \\
\hline
\end{tabular}


Table 3. Water-quality data from surface-water sites-Continued

01475840 - Crum Creek at Whitehorse, Pa. (Site 19)—Continued

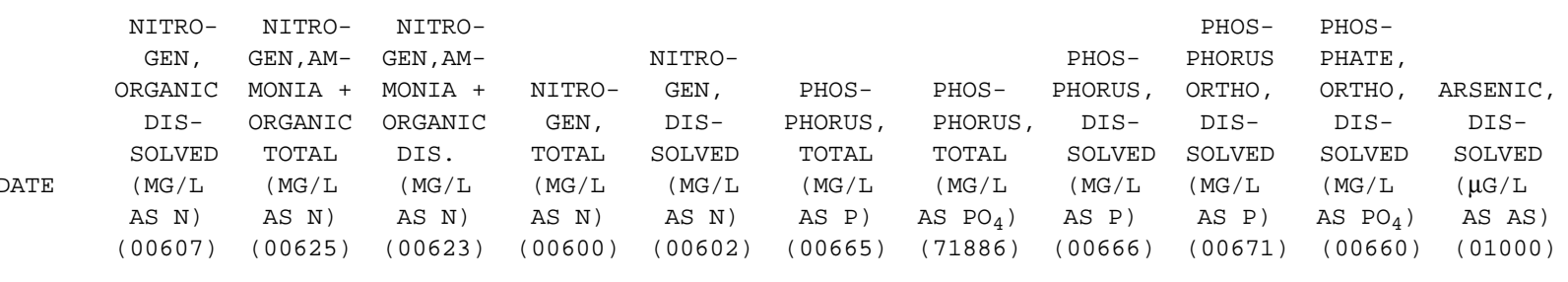

\begin{tabular}{|c|c|c|c|c|c|c|c|c|c|c|}
\hline $\begin{array}{c}26 \ldots \\
\text { OCT } 1982\end{array}$ & 0.95 & 0.30 & 0.97 & 1.4 & 2.1 & 0.030 & 0.09 & 0.030 & 0.010 & 0.03 \\
\hline $\begin{array}{c}13 \ldots \\
\text { OCT } 1983\end{array}$ & .18 & - & .20 & - & 1.6 & - & - & .060 & .020 & .06 \\
\hline $\begin{array}{c}27 \ldots \\
\text { OCT } 1984\end{array}$ & - & - & .90 & - & 2.3 & .030 & .09 & .010 & $<.010$ & - \\
\hline $\begin{array}{c}25 \ldots \\
\text { OCT } 1985\end{array}$ & .18 & - & .20 & - & 1.1 & $<.010$ & - & $<.010$ & $<.010$ & - \\
\hline $\begin{array}{c}15 \ldots \\
\text { OCT } 1986\end{array}$ & .38 & - & .40 & - & 1.9 & .010 & .03 & .010 & .010 & .03 \\
\hline $\begin{array}{c}09 \ldots \\
\text { NOV } 1987\end{array}$ & - & $<.20$ & $<.20$ & - & - & .020 & - & .020 & .010 & .03 \\
\hline $\begin{array}{c}02 \ldots \\
\mathrm{OCT} \quad 1988\end{array}$ & - & .50 & $<.20$ & 1.7 & - & .010 & - & .010 & .010 & .03 \\
\hline $\begin{array}{c}18 \ldots \\
\text { ОСТ } 1989\end{array}$ & - & .40 & .40 & 1.8 & 1.8 & .010 & - & .010 & $<.010$ & - \\
\hline $\begin{array}{c}18 \ldots \\
\text { NOV } 1990\end{array}$ & .28 & .40 & .30 & 1.8 & 1.7 & .030 & - & .030 & .020 & .06 \\
\hline $\begin{array}{c}02 \ldots \\
\text { OCT } 1991\end{array}$ & .38 & .60 & .40 & 2.1 & 1.9 & .030 & - & .020 & .030 & .09 \\
\hline $\begin{array}{c}29 \ldots \\
\text { OCT } 1992\end{array}$ & - & .20 & $<.20$ & 1.0 & - & .010 & - & $<.010$ & .020 & .06 \\
\hline $\begin{array}{c}21 \ldots \\
\text { OCT } 1993\end{array}$ & .29 & .20 & .30 & 1.4 & 1.5 & .030 & - & .020 & .020 & .06 \\
\hline $\begin{array}{c}28 \ldots \\
\text { OCT } 1994\end{array}$ & - & - & - & - & - & - & - & - & $<.010$ & - \\
\hline $03 \ldots$ & - & - & - & - & - & - & - & - & $<.010$ & - \\
\hline
\end{tabular}


Table 3. Water-quality data from surface-water sites-Continued

01475840 - Crum Creek at Whitehorse, Pa. (Site 19)—Continued

\begin{tabular}{|c|c|c|c|c|c|c|c|c|c|c|c|}
\hline & & CHRO- & & & & & MANGA- & & & & $\begin{array}{l}\text { METHY- } \\
\text { LENE }\end{array}$ \\
\hline \multirow{5}{*}{ DATE } & $\begin{array}{l}\text { CADMIUM, } \\
\text { DIS- }\end{array}$ & $\begin{array}{l}\text { MIUM, } \\
\text { DIS- }\end{array}$ & $\begin{array}{c}\text { COBALT, } \\
\text { DIS- }\end{array}$ & $\begin{array}{c}\text { COPPER, } \\
\text { DIS- }\end{array}$ & $\begin{array}{l}\text { IRON, } \\
\text { DIS- }\end{array}$ & $\begin{array}{l}\text { LEAD, } \\
\text { DIS- }\end{array}$ & $\begin{array}{r}\text { NESE } \\
\text { DIS- }\end{array}$ & $\begin{array}{c}\text { MERCURY, } \\
\text { DIS- }\end{array}$ & $\begin{array}{l}\text { NICKEL, } \\
\text { DIS- }\end{array}$ & $\begin{array}{r}\text { ZINC, } \\
\text { DIS- }\end{array}$ & $\begin{array}{c}\text { BLUE } \\
\text { ACTIVE }\end{array}$ \\
\hline & SOLVED & SOLVED & SOLVED & SOLVED & SOLVED & SOLVED & SOLVED & SOLVED & SOLVED & SOLVED & SUB- \\
\hline & $(\mu \mathrm{G} / \mathrm{L}$ & $(\mu \mathrm{G} / \mathrm{L}$ & $(\mu \mathrm{G} / \mathrm{L}$ & $(\mu \mathrm{G} / \mathrm{L}$ & $(\mu \mathrm{G} / \mathrm{L}$ & $(\mu \mathrm{G} / \mathrm{L}$ & $(\mu \mathrm{G} / \mathrm{L}$ & $(\mu \mathrm{G} / \mathrm{L}$ & $(\mu \mathrm{G} / \mathrm{L}$ & $(\mu \mathrm{G} / \mathrm{L}$ & STANCE \\
\hline & AS CD) & AS (R) & AS $(0)$ & AS CU) & AS FE) & AS PB) & AS MN) & AS HG) & AS NI) & AS $\quad \mathrm{ZN})$ & (MG/L) \\
\hline & $(01025)$ & $(01030)$ & $(01035)$ & $(01040)$ & $(01046)$ & $(01049)$ & $(01056)$ & $(71890)$ & $(01065)$ & $(01090)$ & $(38260)$ \\
\hline
\end{tabular}

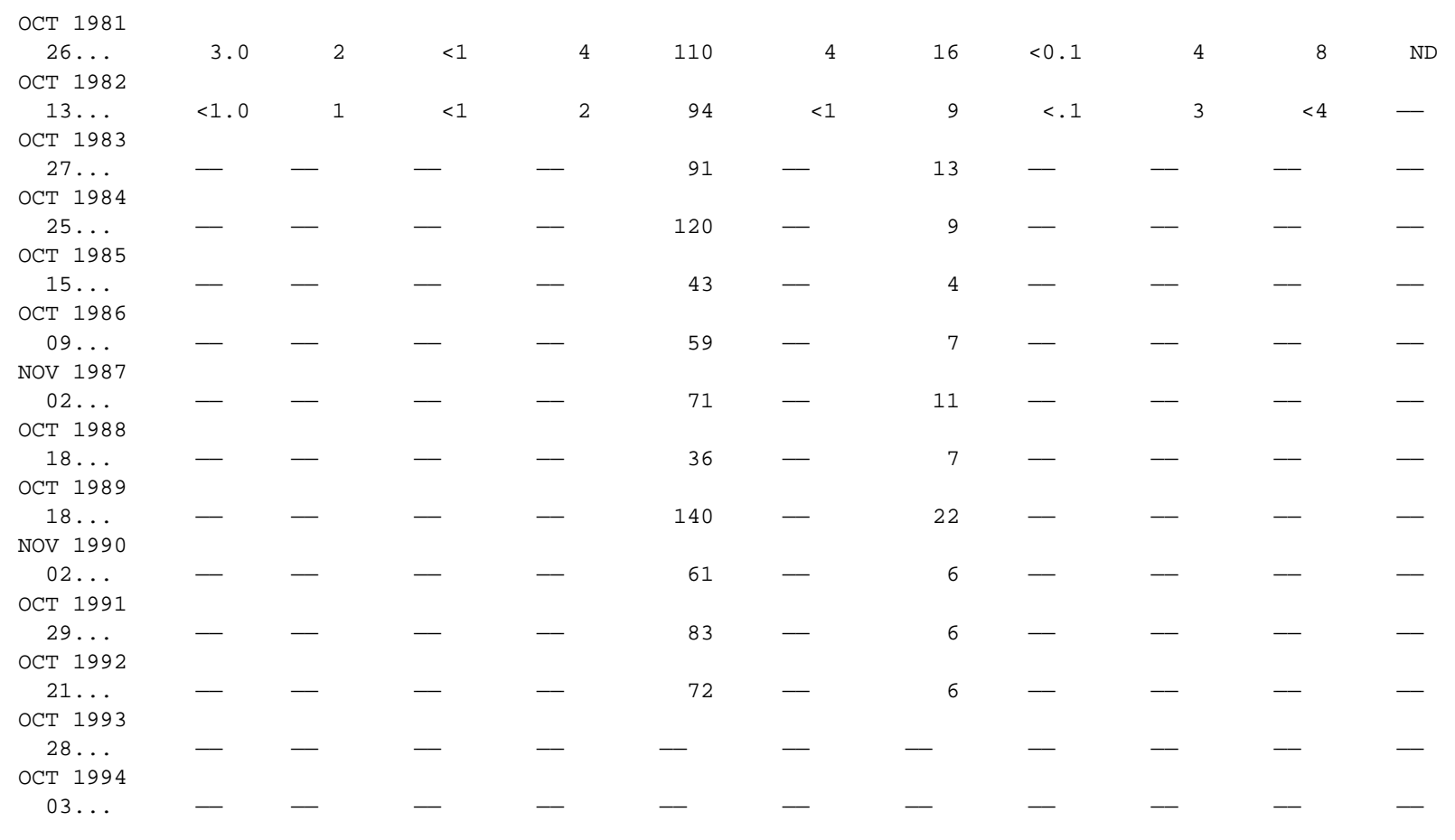


Table 3. Water-quality data from surface-water sites-Continued

01476430 - Ridley Creek at Goshenville, Pa. (Site 20)

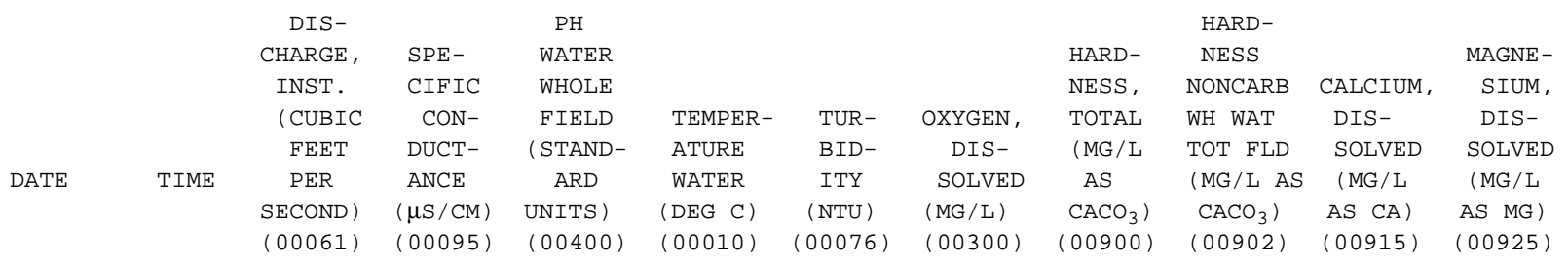

\begin{tabular}{|c|c|c|c|c|c|c|c|c|c|c|c|}
\hline $\begin{array}{c}\text { NOV } 1981 \\
05 \ldots \\
\text { OCT } 1982\end{array}$ & 1445 & - & 168 & 7.7 & 10.0 & - & 11.2 & 63 & - & 13 & 7.4 \\
\hline $\begin{array}{c}14 \ldots \\
\text { OCT } 1983\end{array}$ & 1000 & 2.0 & 194 & 7.5 & 13.0 & - & 9.1 & 63 & - & 13 & 7.4 \\
\hline $\begin{array}{c}27 \ldots \\
\text { OCT } 1984\end{array}$ & 1045 & 3.1 & 196 & 6.7 & 9.0 & 4.2 & 10.5 & 70 & - & 15 & 8.0 \\
\hline $\begin{array}{c}25 \ldots \\
\text { OCT } 1985\end{array}$ & 1400 & 2.7 & 199 & 7.5 & 14.0 & .50 & 8.8 & 72 & - & 15 & 8.3 \\
\hline $\begin{array}{c}15 \ldots \\
\text { OCT } 1986\end{array}$ & 1230 & 3.3 & 205 & 7.2 & 12.0 & 1.5 & 11.9 & 69 & - & 14 & 8.2 \\
\hline $\begin{array}{c}09 \ldots \\
\text { OCT } 1987\end{array}$ & 1230 & 1.5 & 235 & 7.8 & 16.0 & .40 & 10.0 & 85 & - & 18 & 9.8 \\
\hline $\begin{array}{c}26 \ldots \\
\text { OCT } 1988\end{array}$ & 1100 & 2.6 & 315 & 7.5 & 10.5 & .60 & 10.5 & 100 & - & 21 & 12 \\
\hline $\begin{array}{c}25 \ldots \\
\text { NOV } 1989\end{array}$ & 0930 & 3.5 & 224 & 7.4 & 10.0 & 2.8 & 10.5 & 77 & - & 16 & 9.1 \\
\hline $\begin{array}{c}14 \ldots \\
\text { OCT } 1990\end{array}$ & 0900 & 5.4 & 231 & 7.5 & 10.5 & .80 & 12.2 & 75 & 25 & 15 & 9.1 \\
\hline $\begin{array}{c}30 \ldots \\
\text { NOV } 1991\end{array}$ & 0900 & 2.4 & 249 & 6.4 & 7.0 & .50 & 12.0 & 89 & 37 & 19 & 10 \\
\hline $\begin{array}{c}06 \ldots \\
\text { OCT } 1992\end{array}$ & 0915 & 2.3 & 237 & 7.4 & 5.0 & .70 & 13.2 & 86 & 17 & 18 & 10 \\
\hline $\begin{array}{c}20 \ldots \\
\text { OCT } 1993\end{array}$ & 0845 & 2.2 & 250 & 6.6 & 7.5 & 2.0 & 10.4 & 84 & - & 17 & 10 \\
\hline $\begin{array}{c}25 \ldots \\
\text { OCT } 1994\end{array}$ & 1210 & 2.9 & 252 & 7.2 & 11.5 & - & 9.8 & - & - & - & - \\
\hline $07 \ldots$ & 1300 & 2.2 & 242 & 7.7 & 12.5 & - & 10.6 & - & - & - & - \\
\hline
\end{tabular}


Table 3. Water-quality data from surface-water sites-Continued

01476430 - Ridley Creek at Goshenville, Pa. (Site 20)—Continued

\begin{tabular}{|c|c|c|c|c|c|c|c|c|c|c|c|}
\hline & & & & POTAS- & $\begin{array}{l}\text { ALKA- } \\
\text { LINITY }\end{array}$ & $\begin{array}{l}\text { ALKA- } \\
\text { LINITY }\end{array}$ & & CHLO- & FLUO- & SILICA, & $\begin{array}{l}\text { SOLIDS, } \\
\text { RESIDUE }\end{array}$ \\
\hline & SODIUM, & & SODIUM & SIUM, & WAT WH & WAT WH & SULFATE, & RIDE, & RIDE, & DIS- & AT 180 \\
\hline \multirow{5}{*}{ DATE } & DIS- & & AD- & DIS- & TOT FET & TOT IT & DIS- & DIS- & DIS- & SOLVED & DEG. C \\
\hline & SOLVED & & SORP- & SOLVED & FIELD & FIELD & SOLVED & SOLVED & SOLVED & (MG / L & DIS- \\
\hline & (MG / L & SODIUM & TION & (MG / L & (MG /L AS & (MG / L AS & (MG /L & (MG / L & (MG / L & AS & SOLVED \\
\hline & AS NA) & PERCENT & RATIO & AS K) & $\left.\mathrm{CACO}_{3}\right)$ & $\left.\mathrm{CACO}_{3}\right)$ & AS $\left.\mathrm{SO}_{4}\right)$ & A.S CL) & AS F) & $\left.\mathrm{SIO}_{2}\right)$ & (MG/L) \\
\hline & $(00930)$ & $(00932)$ & (00931) & $(00935)$ & $(00410)$ & $(00419)$ & $(00945)$ & $(00940)$ & $(00950)$ & $(00955)$ & $(70300)$ \\
\hline
\end{tabular}

\begin{tabular}{|c|c|c|c|c|c|c|c|c|c|c|c|}
\hline NOV 1981 & & & & & & & & & & & \\
\hline $\begin{array}{c}05 \ldots \\
\text { OCT } 1982\end{array}$ & 10 & 25 & 0.5 & 1.7 & - & - & 15 & 16 & $<0.10$ & 12 & 105 \\
\hline $14 \ldots$ & 11 & 27 & .6 & 1.8 & 38 & - & 14 & 17 & $<.10$ & 9.7 & 119 \\
\hline OCT 1983 & & & & & & & & & & & \\
\hline $27 \ldots$ & 12 & 26 & .6 & 2.2 & 40 & - & 20 & 19 & - & 10 & 126 \\
\hline ОСТ 1984 & & & & & & & & & & & \\
\hline $25 \ldots$ & 11 & 24 & .6 & 2.2 & 48 & - & 17 & 18 & - & 11 & 128 \\
\hline OCT 1985 & & & & & & & & & & & \\
\hline $15 \ldots$ & 11 & 25 & .6 & 1.8 & 42 & - & 18 & 21 & - & 9.3 & 115 \\
\hline OCT 1986 & & & & & & & & & & & \\
\hline $09 \ldots$ & 13 & 24 & .6 & 1.9 & 58 & - & 16 & 22 & - & 11 & 140 \\
\hline OCT 1987 & & & & & & & & & & & \\
\hline $26 \ldots$ & 26 & 34 & 1 & 4.4 & 85 & - & 24 & 35 & - & 10 & 200 \\
\hline OCT 1988 & & & & & & & & & & & \\
\hline $25 \ldots$ & 12 & 25 & .6 & 2.3 & 57 & - & 16 & 20 & - & 9.4 & - \\
\hline NOV 1989 & & & & & & & & & & & \\
\hline $14 \ldots$ & 12 & 25 & .6 & 1.6 & 50 & - & 14 & 21 & - & 8.9 & - \\
\hline OCT 1990 & & & & & & & & & & & \\
\hline $30 \ldots$ & 14 & 25 & .6 & 2.2 & 52 & - & 17 & 25 & $<.10$ & 9.8 & - \\
\hline NOV 1991 & & & & & & & & & & & \\
\hline $06 \ldots$ & 14 & 26 & .7 & 2.0 & 69 & - & 18 & 29 & .10 & 10 & - \\
\hline OCT 1992 & & & & & & & & & & & \\
\hline $20 \ldots$ & 14 & 26 & .7 & 2.0 & - & 59 & 15 & 25 & $<.10$ & 9.7 & - \\
\hline OCT 1993 & & & & & & & & & & & \\
\hline $25 \ldots$ & - & - & - & - & - & 57 & - & - & - & - & - \\
\hline OCT 1994 & & & & & & & & & & & \\
\hline $07 \ldots$ & - & - & - & - & - & 53 & - & 32 & - & - & - \\
\hline
\end{tabular}


Table 3. Water-quality data from surface-water sites-Continued

01476430 - Ridley Creek at Goshenville, Pa. (Site 20)—Continued

\begin{tabular}{|c|c|c|c|c|c|c|c|c|c|c|c|}
\hline & $\begin{array}{l}\text { SOLIDS, } \\
\text { SUM OF } \\
\text { CONSTI- }\end{array}$ & $\begin{array}{c}\text { SOLIDS, } \\
\text { DIS- }\end{array}$ & $\begin{array}{c}\text { SOLIDS, } \\
\text { DIS- }\end{array}$ & $\begin{array}{l}\text { NITRO- } \\
\text { GEN }\end{array}$ & $\begin{array}{c}\text { NITRO- } \\
\text { GEN, } \\
\text { NITRATE }\end{array}$ & $\begin{array}{c}\text { NITRO- } \\
\text { GEN, } \\
\text { NITRATE }\end{array}$ & $\begin{array}{l}\text { NITRO- } \\
\text { GEN, } \\
\text { NITRITE }\end{array}$ & $\begin{array}{c}\text { NITRO- } \\
\text { GEN, } \\
\mathrm{NO}_{2}+\mathrm{NO}_{3}\end{array}$ & $\begin{array}{c}\text { NITRO- } \\
\text { GEN, } \\
\text { AMMONIA }\end{array}$ & $\begin{array}{c}\text { NITRO- } \\
\text { GEN, } \\
\text { AMMONIA }\end{array}$ & $\begin{array}{l}\text { NITRO- } \\
\text { GEN, }\end{array}$ \\
\hline & TUENTS, & SOLVED & SOLVED & NITRATE & DIS- & DIS- & DIS- & DIS- & DIS- & DIS- & ORGANIC \\
\hline & DIS- & (TONS & (TONS & TOTAL & SOLVED & SOLVED & SOLVED & SOLVED & SOLVED & SOLVED & TOTAL \\
\hline \multirow[t]{3}{*}{ DATE } & SOLVED & PER & PER & (MG / L & (MG / L & (MG / L & (MG /L & (MG /L & (MG /L & (MG / L & (MG / L \\
\hline & (MG/L) & $\mathrm{AC}-\mathrm{FT}$ ) & DAY) & AS N) & AS N) & $\mathrm{AS} \quad \mathrm{NO}_{3}$ ) & AS N) & AS N) & AS N) & $\left.\mathrm{AS} \quad \mathrm{NH}_{4}\right)$ & AS N) \\
\hline & $(70301)$ & (70303) & $(70302)$ & $(00620)$ & $(00618)$ & (71851) & $(00613)$ & $(00631)$ & $(00608)$ & $(71846)$ & $(00605)$ \\
\hline
\end{tabular}

NOV 1981

$05 \ldots$

OCT 1982

$14 \ldots$

OCT 1983

$27 \ldots$

OCT 1984

$25 \ldots$

OCT 1985

$15 \ldots$

OCT 1986

$09 \ldots$

OCT 1987

$26 \ldots$

OCT 1988

$25 \ldots$

NOV 1989

$14 \ldots$

OCT 1990

$30 \ldots$

NOV 1991

$06 \ldots$

OCT 1992

$20 \ldots$
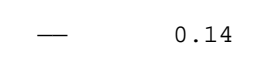

$-\quad 2.10$

-

- $\quad<0.010$

$1.90<0.010$

0.01

0.36

$109 \quad .16$

0.64

2.58

$2.58 \quad 11$

$.020 \quad 2.60$

.100

.13

$121 \quad .17$

1.05

2.40

-

$-\quad<.010$

$2.40<.010$

$119 \quad .17$

.93

1.70

120

1.02

2.59

-

$-\quad<.010$

1.70

.050

.06

$134 \quad .19$

.57

1.59

1.59

11

.010

2.60

.010

.01

.39

$193 \quad .27$

$1.40 \quad 1.69$

1.69

$7.0 \quad .010$

1.60

$<.010$

.30

$129 \quad .17$

1.22

2.08

2.08

$7.5 \quad .010$

1.70

.030

.97

$125 \quad .17$

$1.82 \quad 2.99$

2.99

$9.2 \quad .020$

2.10

.050

.04

.35

$140 \quad .19$

.90

2.47

2.47

13

.010

3.00

.020

.000 .03

154

.21

.95

2.50

11

.030

2. 50

.020

$.03 \quad .78$

139

.19

.82

2.28

$-\quad-\quad<.010$

2.50

.010

.01

$2.28 \quad 10 \quad .020$

2.30

.010

.01

.19

OCT 1994

$07 \ldots$

$2.08 \quad 2.08$

$9.2 \quad .020$

2.10

.030

.04

2.60

$<.010$

2.60 
Table 3. Water-quality data from surface-water sites-Continued

01476430 - Ridley Creek at Goshenville, Pa. (Site 20)—Continued

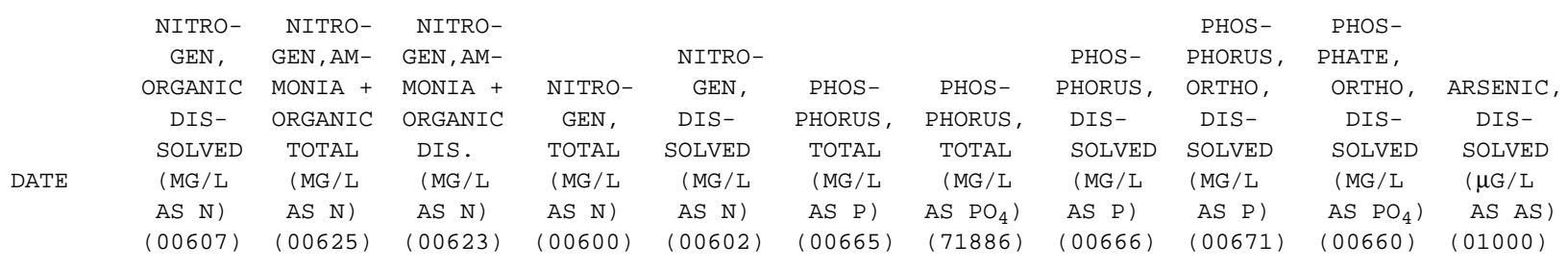

\begin{tabular}{|c|c|c|c|c|c|c|c|c|c|c|c|}
\hline $\begin{array}{c}\text { NOV } 1981 \\
05 \ldots \\
\text { OCT } 1982\end{array}$ & - & 0.36 & 0.35 & 2.5 & 2.3 & 0.070 & 0.21 & 0.070 & 0.050 & 0.15 & ND \\
\hline $\begin{array}{c}14 \ldots \\
\text { OCT } 1983\end{array}$ & 0.30 & - & .40 & - & 3.0 & - & - & .100 & .080 & .25 & 1 \\
\hline $\begin{array}{c}27 \ldots \\
\text { OCT } 1984\end{array}$ & - & - & 1.2 & - & 3.6 & .130 & .40 & .100 & .110 & .34 & - \\
\hline $\begin{array}{c}25 \ldots \\
\text { OCT } 1985\end{array}$ & .35 & - & .40 & - & 2.1 & .080 & - & .050 & .050 & .15 & - \\
\hline $\begin{array}{c}15 \ldots \\
\text { OCT } 1986\end{array}$ & .19 & .40 & .20 & 3.0 & 2.8 & .080 & .25 & .070 & .060 & .18 & - \\
\hline $\begin{array}{c}09 \ldots \\
\text { OCT } 1987\end{array}$ & - & .30 & $<.20$ & 1.9 & - & .060 & - & .050 & .040 & .12 & - \\
\hline $\begin{array}{c}26 \ldots \\
\text { OCT } 1988\end{array}$ & .27 & 1.0 & .30 & 2.7 & 2.0 & .740 & - & .810 & .680 & 2.1 & - \\
\hline $\begin{array}{c}25 \ldots \\
\text { NOV } 1989\end{array}$ & .35 & .40 & .40 & 2.5 & 2.5 & .060 & - & .040 & .040 & .12 & - \\
\hline $\begin{array}{c}14 \ldots \\
\text { OCT } 1990\end{array}$ & .28 & .40 & .30 & 3.4 & 3.3 & .060 & - & .030 & .040 & .12 & - \\
\hline $\begin{array}{c}30 \ldots \\
\text { NOV } 1991\end{array}$ & .48 & .80 & .50 & 3.3 & 3.0 & .080 & - & .070 & .090 & .28 & - \\
\hline $\begin{array}{c}06 \ldots \\
\text { OCT } 1992\end{array}$ & - & $<.20$ & $<.20$ & - & - & .060 & - & .050 & .050 & .15 & - \\
\hline $\begin{array}{c}20 \ldots \\
\text { OCT } 1993\end{array}$ & .19 & .20 & .20 & 2.5 & 2.5 & .080 & - & .110 & .060 & .18 & - \\
\hline $\begin{array}{c}25 \ldots \\
\text { OCT } 1994\end{array}$ & - & - & - & - & - & - & - & - & .050 & .15 & - \\
\hline $07 \ldots$ & - & - & - & - & - & - & - & - & .040 & .12 & - \\
\hline
\end{tabular}


Table 3. Water-quality data from surface-water sites-Continued

01476430 - Ridley Creek at Goshenville, Pa. (Site 20)—Continued

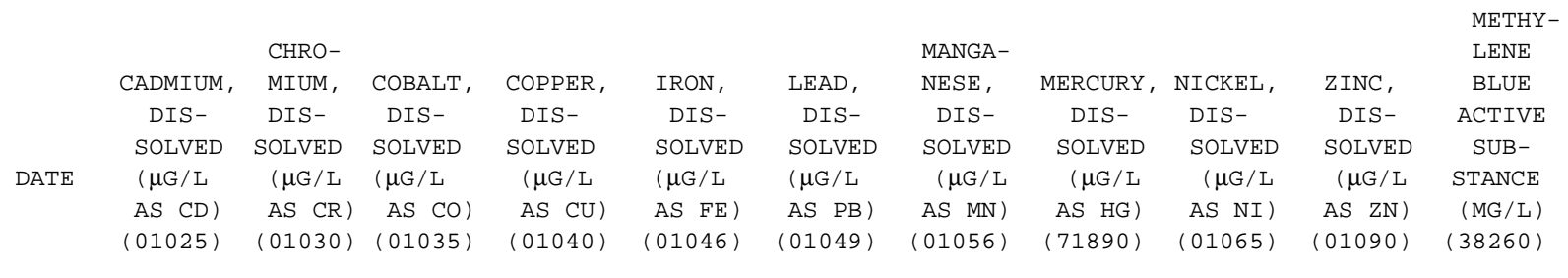

\begin{tabular}{|c|c|c|c|c|c|c|c|c|c|c|c|}
\hline $\begin{array}{c}\text { NOV } 1981 \\
05 \ldots \\
\text { OCT } 1982\end{array}$ & $<1.0$ & $<1$ & 2 & $<1$ & 97 & $<1$ & 22 & 0.1 & 2 & $<4$ & $\mathrm{ND}$ \\
\hline $\begin{array}{c}14 \ldots \\
\text { OCT } 1983\end{array}$ & $<1.0$ & $<1$ & $<1$ & 1 & 51 & 1 & 11 & $<.1$ & 5 & $<4$ & 0.03 \\
\hline $\begin{array}{c}27 \ldots \\
\text { OCT } 1984\end{array}$ & - & - & - & - & 82 & - & 28 & - & - & - & - \\
\hline $\begin{array}{c}25 \ldots \\
\text { Ост } 1985\end{array}$ & - & - & - & - & 100 & - & 19 & - & - & - & - \\
\hline $\begin{array}{c}15 \ldots \\
\text { OCT } 1986\end{array}$ & - & - & - & - & 44 & - & 13 & - & - & - & - \\
\hline $\begin{array}{c}09 \ldots \\
\text { ОСТ } 1987\end{array}$ & - & - & - & - & 39 & - & 11 & - & - & - & - \\
\hline $\begin{array}{c}26 \ldots \\
\text { OCT } 1988\end{array}$ & - & - & - & - & 39 & - & 25 & - & - & - & - \\
\hline $\begin{array}{c}25 \ldots \\
\text { NOV } 1989\end{array}$ & - & - & - & - & 93 & - & 23 & - & - & - & - \\
\hline $\begin{array}{c}14 \ldots \\
\text { Ост } 1990\end{array}$ & - & - & - & - & 63 & - & 29 & - & - & - & - \\
\hline $\begin{array}{c}30 \ldots \\
\text { NOV } 1991\end{array}$ & - & - & - & - & 58 & - & 23 & - & - & - & - \\
\hline $\begin{array}{c}06 \ldots \\
\text { ОСт } 1992\end{array}$ & - & - & - & - & 54 & - & 16 & - & - & - & - \\
\hline $\begin{array}{c}20 \ldots \\
\text { OCT } 1993\end{array}$ & - & - & - & - & 66 & - & 21 & - & - & - & - \\
\hline $\begin{array}{c}25 \ldots \\
\text { OCT } 1994\end{array}$ & - & - & - & - & - & - & - & - & - & - & - \\
\hline $07 \ldots$ & - & - & - & - & - & - & - & - & - & - & - \\
\hline
\end{tabular}


Table 3. Water-quality data from surface-water sites-Continued

01476435 - Ridley Creek at Dutton Mill near West Chester, Pa. (Site 21)

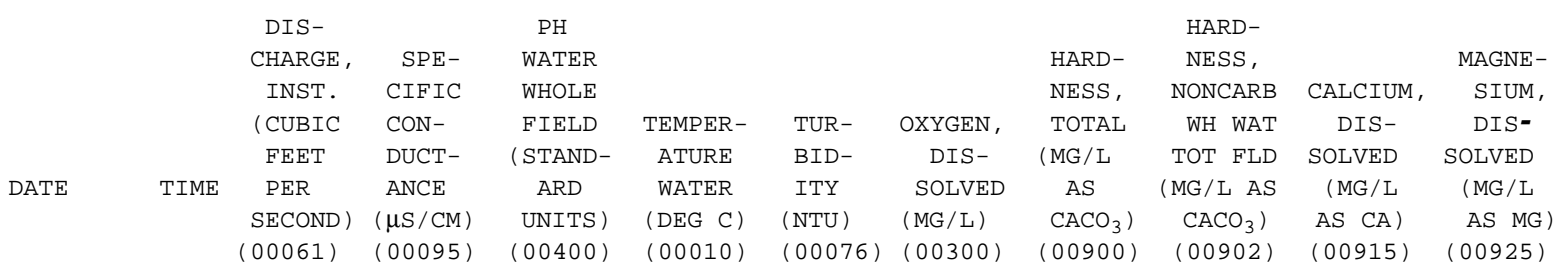

\begin{tabular}{|c|c|c|c|c|c|c|c|c|c|c|c|}
\hline $\begin{array}{c}\text { NOV } 1981 \\
05 \ldots\end{array}$ & 1300 & - & 165 & 7.8 & 9.5 & - & 11.4 & 63 & - & 13 & 7.4 \\
\hline $14 \ldots$ & 1330 & 4.9 & 180 & 8.1 & 15.0 & - & 10.4 & 58 & - & 12 & 6.8 \\
\hline $\begin{array}{c}27 \ldots \\
\text { OCT } 1984\end{array}$ & 0900 & 11 & 187 & 7.2 & 7.0 & 1.9 & 10.7 & 67 & - & 14 & 7.8 \\
\hline $\begin{array}{c}15 \ldots \\
\text { OCT } 1985\end{array}$ & 1330 & 8.7 & 185 & 8.4 & 13.0 & .70 & 12.7 & 64 & - & 13 & 7.6 \\
\hline $\begin{array}{c}15 \ldots \\
\text { OCT } 1986\end{array}$ & 1430 & 10 & 190 & 7.6 & 12.5 & 1.2 & 12.2 & 65 & - & 13 & 7.9 \\
\hline $\begin{array}{c}09 \ldots \\
\text { OCT } 1987\end{array}$ & 0900 & 5.7 & 215 & 7.5 & 13.5 & .70 & 8.8 & 81 & - & 17 & 9.3 \\
\hline $\begin{array}{c}15 \ldots \\
\text { OCT } 1988\end{array}$ & 1430 & 7.8 & 218 & 7.9 & 12.5 & .70 & 13.2 & 74 & - & 15 & 8.8 \\
\hline $\begin{array}{c}25 \ldots \\
\text { NOV } 1989\end{array}$ & 1430 & 5.0 & 231 & 7.3 & 11.5 & 1.9 & 11.0 & 77 & - & 16 & 9.0 \\
\hline $\begin{array}{c}14 \ldots \\
\text { OCT } 1990\end{array}$ & 1345 & 12 & 220 & 7.8 & 13.5 & 3.4 & 12.5 & 70 & 24 & 14 & 8.4 \\
\hline $\begin{array}{c}30 \ldots \\
\text { NOV } 1991\end{array}$ & 1145 & 6.2 & 251 & 6.6 & 8.5 & 1.1 & 12.3 & 83 & 17 & 18 & 9.3 \\
\hline $\begin{array}{c}06 \ldots \\
\text { OCT } 1992\end{array}$ & 1215 & 4.9 & 252 & 7.4 & 6.0 & 1.3 & 13.5 & 70 & 6 & 20 & 4.9 \\
\hline $\begin{array}{c}20 \ldots \\
\text { OCT } 1993\end{array}$ & 1215 & 5.0 & 254 & 6.7 & 8.5 & .80 & 12.8 & 82 & - & 17 & 9.7 \\
\hline $\begin{array}{c}25 \ldots \\
\text { OCT } 1994\end{array}$ & 0930 & 7.8 & 270 & 7.4 & 9.5 & - & 10.5 & - & - & - & - \\
\hline $07 \ldots$ & 0900 & 5.0 & 265 & 7.4 & 10.0 & - & 10.8 & - & - & - & - \\
\hline
\end{tabular}


Table 3. Water-quality data from surface-water sites-Continued

01476435 - Ridley Creek at Dutton Mill near West Chester, Pa. (Site 21)—Continued

\begin{tabular}{|c|c|c|c|c|c|c|c|c|c|c|c|}
\hline \multirow{6}{*}{ DATE } & & \multirow[b]{2}{*}{$\begin{array}{c}\text { SODIUM } \\
\text { AD- }\end{array}$} & POTAS- & $\begin{array}{l}\text { ALKA- } \\
\text { LINITY }\end{array}$ & $\begin{array}{l}\text { ALKA- } \\
\text { LINITY }\end{array}$ & & CHLO- & FLUO- & SILICA, & $\begin{array}{l}\text { SOLIDS, } \\
\text { RESIDUE }\end{array}$ \\
\hline & $\begin{array}{l}\text { SODIUM, } \\
\text { DIS- }\end{array}$ & & & $\begin{array}{l}\text { SIUM, } \\
\text { DIS- }\end{array}$ & $\begin{array}{l}\text { WAT WH } \\
\text { TOT FET }\end{array}$ & $\begin{array}{l}\text { WAT WH } \\
\text { TOT IT }\end{array}$ & $\begin{array}{l}\text { SULFATE, } \\
\text { DIS- }\end{array}$ & $\begin{array}{l}\text { RIDE, } \\
\text { DIS- }\end{array}$ & $\begin{array}{c}\text { RIDE, } \\
\text { DIS- }\end{array}$ & $\begin{array}{l}\text { DIS- } \\
\text { SOLVED }\end{array}$ & $\begin{array}{l}\text { AT } 180 \\
\text { DEG. C }\end{array}$ \\
\hline & SOLVED & & SORP- & SOLVED & FIELD & FIELD & SOLVED & SOLVED & SOLVED & (MG/L & DIS- \\
\hline & (MG/L & SODIUM & TION & (MG/L & (MG/L AS & (MG/L AS & (MG /L & (MG / L & (MG /L & AS & SOLVED \\
\hline & AS NA) & PERCENT & RATIO & AS K) & $\left.\mathrm{CACO}_{3}\right)$ & $\left.\mathrm{CACO}_{3}\right)$ & AS $\quad \mathrm{SO}_{4}$ ) & AS CL) & AS F) & $\left.\mathrm{SIO}_{2}\right)$ & (MG/L) \\
\hline & $(00930)$ & $(00932)$ & (00931) & (00935) & $(00410)$ & $(00419)$ & $(00945)$ & $(00940)$ & $(00950)$ & $(00955)$ & $(70300)$ \\
\hline
\end{tabular}

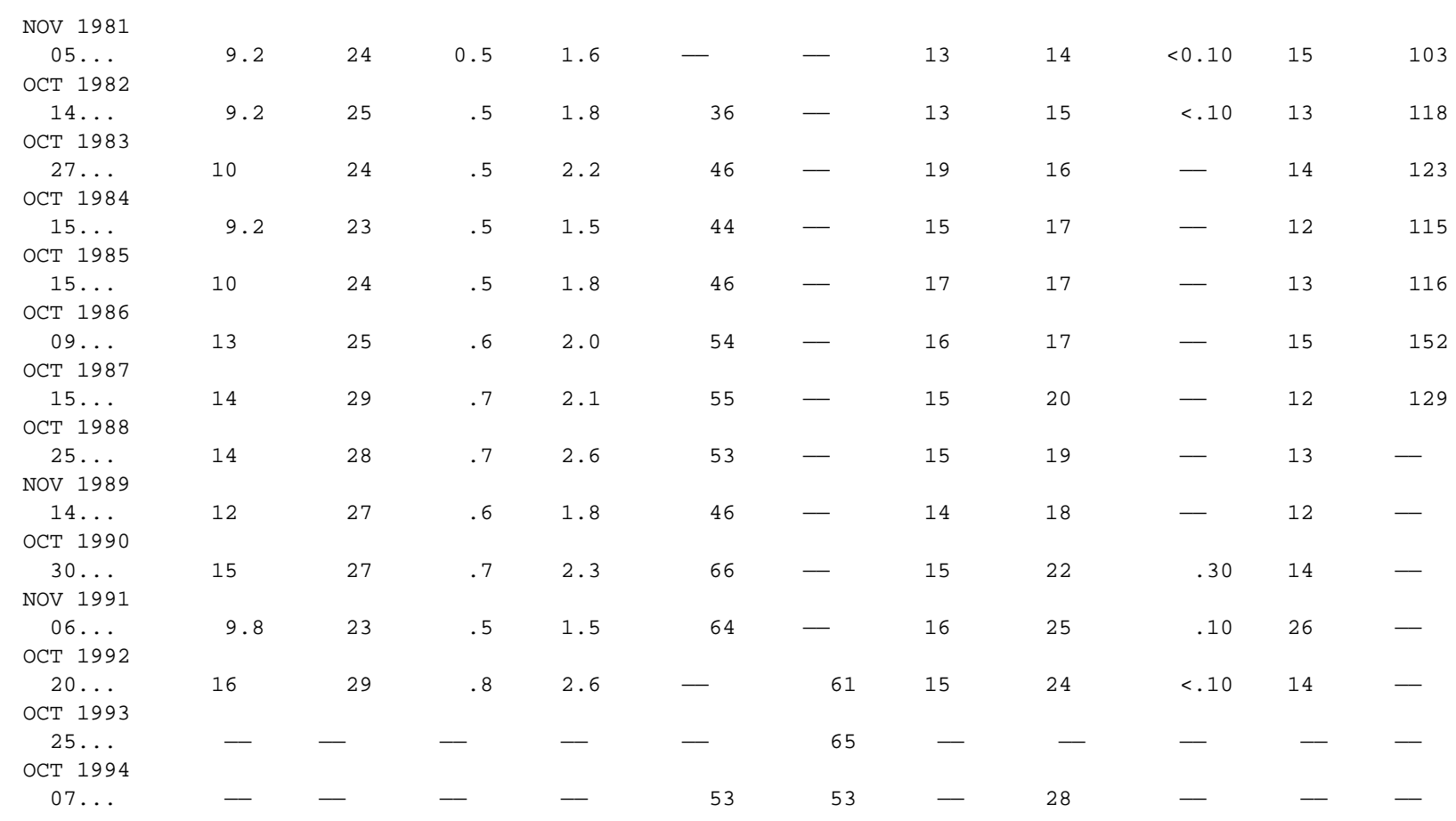


Table 3. Water-quality data from surface-water sites-Continued

01476435 - Ridley Creek at Dutton Mill near West Chester, Pa. (Site 21)—Continued

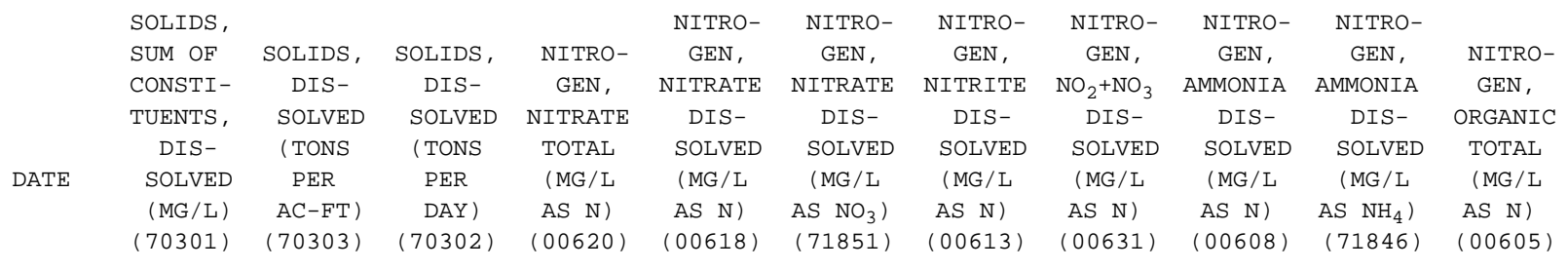

\begin{tabular}{|c|c|c|c|c|c|c|c|c|c|c|c|}
\hline $\begin{array}{c}\text { NOV } 1981 \\
05 \ldots \\
\text { OCT } 1982\end{array}$ & - & 0.14 & - & 2.28 & 2.28 & 10 & 0.020 & 2.30 & $<0.010$ & 0.01 & 0.36 \\
\hline $14 \ldots$ & 103 & .16 & 1.56 & 2.29 & 2.29 & 10 & .010 & 2.30 & .020 & .03 & - \\
\hline $\begin{array}{c}27 \ldots \\
\text { OCT } 1984\end{array}$ & 122 & .17 & 3.65 & 2.40 & - & - & $<.010$ & 2.40 & $<.010$ & - & - \\
\hline $\begin{array}{c}15 \ldots \\
\text { OCT } 1985\end{array}$ & 113 & .16 & 2.70 & 2.57 & 2.57 & 11 & .030 & 2.60 & .070 & .09 & - \\
\hline $\begin{array}{c}15 \ldots \\
\text { OCT } 1986\end{array}$ & 120 & .16 & 3.13 & 2.89 & 2.89 & 13 & .010 & 2.90 & .010 & .01 & .59 \\
\hline $\begin{array}{c}09 \ldots \\
\text { OCT } 1987\end{array}$ & 133 & .21 & 2.34 & 2.50 & - & - & $<.010$ & 2.50 & $<.010$ & - & .50 \\
\hline $\begin{array}{c}15 \ldots \\
\text { OCT } 1988\end{array}$ & 138 & .18 & 2.72 & 3.90 & - & - & $<.010$ & 3.90 & .020 & .03 & .58 \\
\hline $\begin{array}{c}25 \ldots \\
\text { NOV } 1989\end{array}$ & 138 & .19 & 1.86 & 3.70 & - & - & $<.010$ & 3.70 & .050 & .06 & .35 \\
\hline $\begin{array}{c}14 \ldots \\
\text { OCT } 1990\end{array}$ & 124 & .17 & 4.01 & 3.49 & 3.49 & 15 & .010 & 3.50 & .010 & .01 & .49 \\
\hline $\begin{array}{c}30 \ldots \\
\text { NOV } 1991\end{array}$ & 155 & .21 & 2.58 & 4.08 & 4.08 & 18 & .020 & 4.10 & .030 & .04 & .87 \\
\hline $\begin{array}{c}06 \ldots \\
\text { OCT } 1992\end{array}$ & 159 & .22 & 2.10 & 3.70 & - & - & $<.010$ & 3.70 & .020 & .03 & .18 \\
\hline $\begin{array}{c}20 \ldots \\
\text { OCT } 1993\end{array}$ & 153 & .21 & 2.06 & 3.79 & 3.79 & 17 & .010 & 3.80 & $<.010$ & - & .30 \\
\hline $\begin{array}{c}25 \ldots \\
\text { OCT } 1994\end{array}$ & - & - & - & 2.98 & 2.98 & 13 & .020 & 3.00 & .060 & .08 & - \\
\hline $07 \ldots$ & - & - & - & 3.40 & - & - & $<.010$ & 3.40 & $<.015$ & - & - \\
\hline
\end{tabular}


Table 3. Water-quality data from surface-water sites-Continued

01476435 - Ridley Creek at Dutton Mill near West Chester, Pa. (Site 21)—Continued

\begin{tabular}{|c|c|c|c|c|c|c|c|c|c|c|c|}
\hline & $\begin{array}{c}\text { NITRO- } \\
\text { GEN }\end{array}$ & $\begin{array}{l}\text { NITRO- } \\
\text { GEN, AM- }\end{array}$ & $\begin{array}{l}\text { NITRO- } \\
\text { GEN, AM- }\end{array}$ & & NITRO- & & & PHOS- & $\begin{array}{c}\text { PHOS- } \\
\text { PHORUS, }\end{array}$ & $\begin{array}{c}\text { PHOS- } \\
\text { PHATE, }\end{array}$ & \\
\hline \multirow{4}{*}{ DATE } & ORGANIC & MONIA + & MONIA + & NITRO- & GEN, & PHOS- & PHOS- & PHORUS, & ORTHO, & ORTHO, & ARSENIC, \\
\hline & $\begin{array}{l}\text { DIS- } \\
\text { SOLVED } \\
\text { (MG/L }\end{array}$ & $\begin{array}{c}\text { ORGANIC } \\
\text { TOTAL } \\
\text { (MG/L }\end{array}$ & $\begin{array}{l}\text { ORGANIC } \\
\text { DIS. } \\
\text { (MG/L }\end{array}$ & $\begin{array}{r}\text { GEN, } \\
\text { TOTAL } \\
(\mathrm{MG} / \mathrm{L}\end{array}$ & $\begin{array}{c}\text { DIS- } \\
\text { SOLVED } \\
\text { (MG/L }\end{array}$ & $\begin{array}{l}\text { PHORUS, } \\
\text { TOTAL } \\
\text { (MG/L }\end{array}$ & $\begin{array}{l}\text { PHORUS, } \\
\text { TOTAL } \\
\text { (MG/L }\end{array}$ & $\begin{array}{l}\text { DIS- } \\
\text { SOLVED } \\
\text { (MG/L }\end{array}$ & $\begin{array}{l}\text { DIS- } \\
\text { SOLVED } \\
\text { (MG/L }\end{array}$ & $\begin{array}{c}\text { DIS- } \\
\text { SOLVED } \\
\text { (MG/L }\end{array}$ & $\begin{array}{c}\text { DIS- } \\
\text { SOLVED } \\
(\mu \mathrm{G} / \mathrm{L}\end{array}$ \\
\hline & AS N) & AS N) & AS N) & AS N) & AS N) & AS P) & AS $\mathrm{PO}_{4}$ ) & AS P) & AS P) & $\left.\mathrm{AS} \quad \mathrm{PO}_{4}\right)$ & AS AS) \\
\hline & $(00607)$ & $(00625)$ & $(00623)$ & $(00600)$ & $(00602)$ & $(00665)$ & $(71886)$ & $(00666)$ & $(00671)$ & $(00660)$ & $(01000)$ \\
\hline
\end{tabular}

\begin{tabular}{|c|c|c|c|c|c|c|c|c|c|c|c|}
\hline $\begin{array}{c}\text { NOV } 1981 \\
05 \ldots \\
\text { OCT } 1982\end{array}$ & - & 0.36 & 0.39 & 2.7 & 2.7 & 0.050 & 0.15 & 0.050 & 0.030 & 0.09 & 1 \\
\hline $\begin{array}{c}14 \ldots \\
\text { OCT } 1983\end{array}$ & 0.28 & - & .30 & - & 2.6 & - & - & .040 & .070 & .21 & 1 \\
\hline $\begin{array}{c}27 \ldots \\
\text { OCT } 1984\end{array}$ & - & - & .50 & - & 2.9 & .070 & .21 & .050 & .050 & .15 & - \\
\hline $\begin{array}{c}15 \ldots \\
\text { OCT } 1985\end{array}$ & .23 & - & .30 & - & 2.9 & .030 & - & .030 & .030 & .09 & - \\
\hline $\begin{array}{c}15 \ldots \\
\text { OCT } 1986\end{array}$ & .19 & .60 & .20 & 3.5 & 3.1 & .110 & .34 & .100 & .090 & .28 & - \\
\hline $\begin{array}{c}09 \ldots \\
\text { OCT } 1987\end{array}$ & - & .50 & $<.20$ & 3.0 & - & .150 & - & .140 & .130 & .40 & - \\
\hline $\begin{array}{c}15 \ldots \\
\text { OCT } 1988\end{array}$ & .38 & .60 & .40 & 4.5 & 4.3 & .290 & - & .270 & .250 & .77 & - \\
\hline $\begin{array}{c}25 \ldots \\
\text { NOV } 1989\end{array}$ & .35 & .40 & .40 & 4.1 & 4.1 & .350 & - & .330 & .310 & .95 & - \\
\hline $\begin{array}{c}14 \ldots \\
\text { OCT } 1990\end{array}$ & .29 & .50 & .30 & 4.0 & 3.8 & .200 & - & .140 & .140 & .43 & - \\
\hline $\begin{array}{c}30 \ldots \\
\text { NOV } 1991\end{array}$ & .57 & .90 & .60 & 5.0 & 4.7 & .280 & - & .260 & .270 & .83 & - \\
\hline $\begin{array}{c}06 \ldots \\
\text { OCT } 1992\end{array}$ & - & .20 & $<.20$ & 3.9 & - & .340 & - & .360 & .290 & .89 & - \\
\hline $\begin{array}{c}20 \ldots \\
\text { OCT } 1993\end{array}$ & - & .30 & .20 & 4.1 & 4.0 & .370 & - & .330 & .320 & .98 & - \\
\hline $\begin{array}{c}25 \ldots \\
\text { OCT } 1994\end{array}$ & - & - & - & - & - & - & - & - & .190 & .58 & - \\
\hline $07 \ldots$ & - & - & - & - & - & - & - & - & .220 & .67 & - \\
\hline
\end{tabular}


Table 3. Water-quality data from surface-water sites-Continued

01476435 - Ridley Creek at Dutton Mill near West Chester, Pa. (Site 21)—Continued

\begin{tabular}{|c|c|c|c|c|c|c|c|c|c|c|c|}
\hline \multirow{4}{*}{ DATE } & & CHRO- & & & & & MANGA- & & & & $\begin{array}{l}\text { METHY- } \\
\text { LENE }\end{array}$ \\
\hline & $\begin{array}{c}\text { CADMIUM, } \\
\text { DIS- } \\
\text { SOLVED } \\
(\mu \mathrm{G} / \mathrm{L}\end{array}$ & $\begin{array}{l}\text { MIUM, } \\
\text { DIS- } \\
\text { SOLVED } \\
(\mu \mathrm{G} / \mathrm{L}\end{array}$ & $\begin{array}{c}\text { COBALT, } \\
\text { DIS- } \\
\text { SOLVED } \\
(\mu \mathrm{G} / \mathrm{L}\end{array}$ & $\begin{array}{l}\text { COPPER, } \\
\text { DIS- } \\
\text { SOLVED } \\
(\mu \mathrm{G} / \mathrm{L}\end{array}$ & $\begin{array}{c}\text { IRON, } \\
\text { DIS- } \\
\text { SOLVED } \\
(\mu \mathrm{G} / \mathrm{L}\end{array}$ & $\begin{array}{c}\text { LEAD, } \\
\text { DIS- } \\
\text { SOLVED } \\
(\mu \mathrm{G} / \mathrm{L}\end{array}$ & $\begin{array}{c}\text { NESE, } \\
\text { DIS- } \\
\text { SOLVED } \\
(\mu \mathrm{G} / \mathrm{L}\end{array}$ & $\begin{array}{c}\text { MERCURY, } \\
\text { DIS- } \\
\text { SOLVED } \\
(\mu \mathrm{G} / \mathrm{L}\end{array}$ & $\begin{array}{l}\text { NICKEL, } \\
\text { DIS- } \\
\text { SOLVED } \\
(\mu \mathrm{G} / \mathrm{L}\end{array}$ & $\begin{array}{c}\text { ZINC, } \\
\text { DIS- } \\
\text { SOLVED } \\
(\mu \mathrm{G} / \mathrm{L}\end{array}$ & $\begin{array}{c}\text { BLUE } \\
\text { ACTIVE } \\
\text { SUB- } \\
\text { STANCE }\end{array}$ \\
\hline & AS CD) & AS CR) & AS $(O)$ & $\mathrm{AS} \quad \mathrm{CU})$ & AS FE) & $A S \quad P B)$ & AS MN) & AS HG) & AS NI) & AS ZN) & $(\mathrm{MG} / \mathrm{L})$ \\
\hline & $(01025)$ & $(01030)$ & $(01035)$ & $(01040)$ & $(01046)$ & $(01049)$ & $(01056)$ & $(71890)$ & $(01065)$ & $(01090)$ & $(38260)$ \\
\hline
\end{tabular}

\begin{tabular}{|c|c|c|c|c|c|c|c|c|c|c|c|}
\hline $\begin{array}{c}\text { NOV } 1981 \\
05 \ldots \\
\text { OCT } 1982\end{array}$ & $<1.0$ & $<1$ & $<1$ & $<1$ & 100 & $<1$ & 27 & 0.1 & & $<4$ & ND \\
\hline $\begin{array}{c}14 \ldots \\
\text { OCT } 1983\end{array}$ & $<1.0$ & 4 & $<1$ & $<1$ & 86 & $<1$ & 18 & $<.1$ & & $<4$ & 0.04 \\
\hline $\begin{array}{c}27 \ldots \\
\text { OCT } 1984\end{array}$ & - & - & - & - & 98 & - & 42 & - & - & - & - \\
\hline $\begin{array}{c}15 \ldots \\
\text { OCT } 1985\end{array}$ & - & - & - & - & 79 & - & 19 & - & - & - & - \\
\hline $\begin{array}{c}15 \ldots \\
\text { OCT } 1986\end{array}$ & - & - & - & - & 45 & - & 18 & - & - & - & - \\
\hline $\begin{array}{c}09 \ldots \\
\text { OCT } 1987\end{array}$ & - & - & - & - & 68 & - & 26 & - & - & - & - \\
\hline $\begin{array}{c}15 \ldots \\
\text { OCT } 1988\end{array}$ & - & - & - & - & 40 & - & 21 & - & - & - & - \\
\hline $\begin{array}{c}25 \ldots \\
\text { NOV } 1989\end{array}$ & - & - & - & - & 100 & - & 36 & - & - & - & - \\
\hline $\begin{array}{c}14 \ldots \\
\text { OCT } 1990\end{array}$ & - & - & - & - & 66 & - & 25 & - & - & - & - \\
\hline $\begin{array}{c}30 \ldots \\
\text { NOV } 1991\end{array}$ & - & - & - & - & 55 & - & 27 & - & - & - & - \\
\hline $\begin{array}{c}06 \ldots \\
\text { OCT } 1992\end{array}$ & - & - & - & - & 30 & - & 32 & - & - & - & - \\
\hline $\begin{array}{c}20 \ldots \\
\text { OCT } 1993\end{array}$ & - & - & - & - & 65 & - & 26 & - & - & - & - \\
\hline $\begin{array}{c}25 \ldots \\
\text { OCT } 1994\end{array}$ & - & - & - & - & - & - & - & - & - & - & - \\
\hline $07 \ldots$ & - & - & - & - & - & - & - & - & - & - & - \\
\hline
\end{tabular}


Table 3. Water-quality data from surface-water sites-Continued

01476790 - East Branch Chester Creek at Green Hill, Pa. (Site 22)

\begin{tabular}{|c|c|c|c|c|c|c|c|c|c|c|}
\hline & DIS- & & $\mathrm{PH}$ & & & & & HARD - & & \\
\hline & CHARGE, & SPE- & WATER & & & & HARD - & NESS & & MAGNE- \\
\hline & INST. & CIFIC & WHOLE & & & & NESS, & NONCARB & CALCIUM, & SIUM, \\
\hline \multirow{5}{*}{ TIME } & (CUBIC & $\mathrm{CON}-$ & FIELD & TEMPER- & TUR- & OXYGEN, & TOTAL & WH WAT & DIS- & DIS- \\
\hline & FEET & DUCT- & (STAND- & ATURE & BID- & DIS- & (MG / L & TOT FLD & SOLVED & SOLVED \\
\hline & PER & ANCE & ARD & WATER & ITY & SOLVED & AS & (MG/L AS & (MG / L & $(\mathrm{MG} / \mathrm{L}$ \\
\hline & SECOND) & $(\mu \mathrm{S} / \mathrm{CM})$ & UNITS) & $(\mathrm{DEG} C$ ) & (NTU) & (MG/L) & $\left.\mathrm{CACO}_{3}\right)$ & $\left.\mathrm{CACO}_{3}\right)$ & AS CA) & AS MG) \\
\hline & $(00061)$ & $(00095)$ & $(00400)$ & $(00010)$ & $(00076)$ & $(00300)$ & $(00900)$ & $(00902)$ & $(00915)$ & $(00925)$ \\
\hline
\end{tabular}

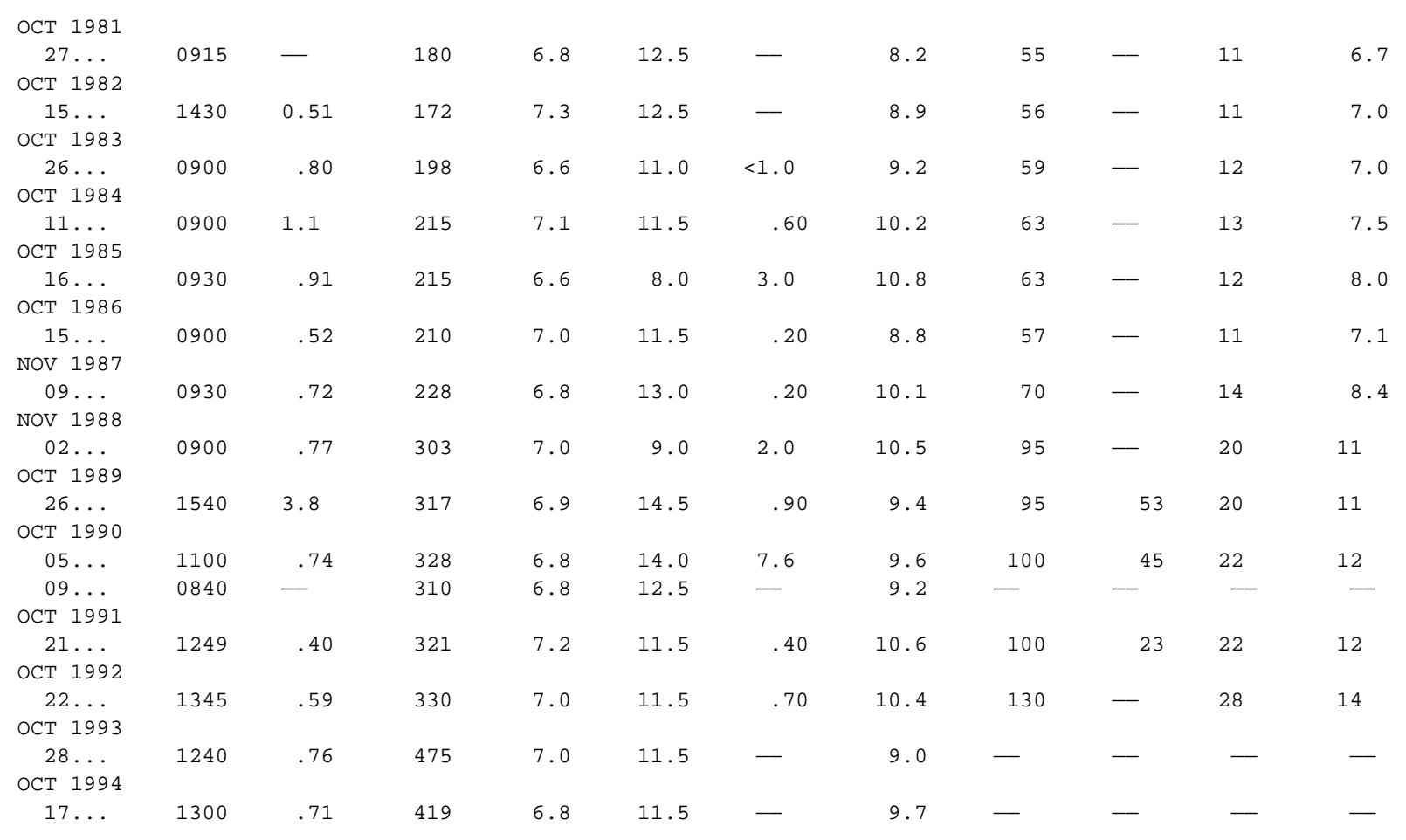


Table 3. Water-quality data from surface-water sites-Continued

01476790 - East Branch Chester Creek at Green Hill, Pa. (Site 22)—Continued

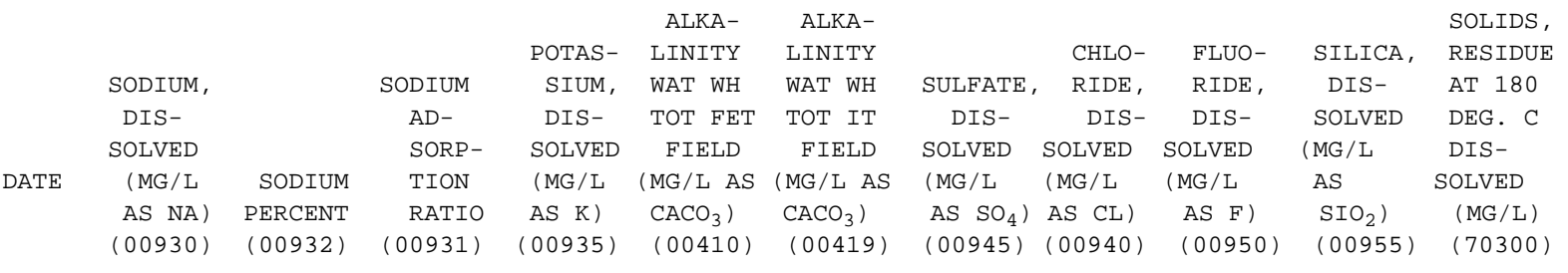

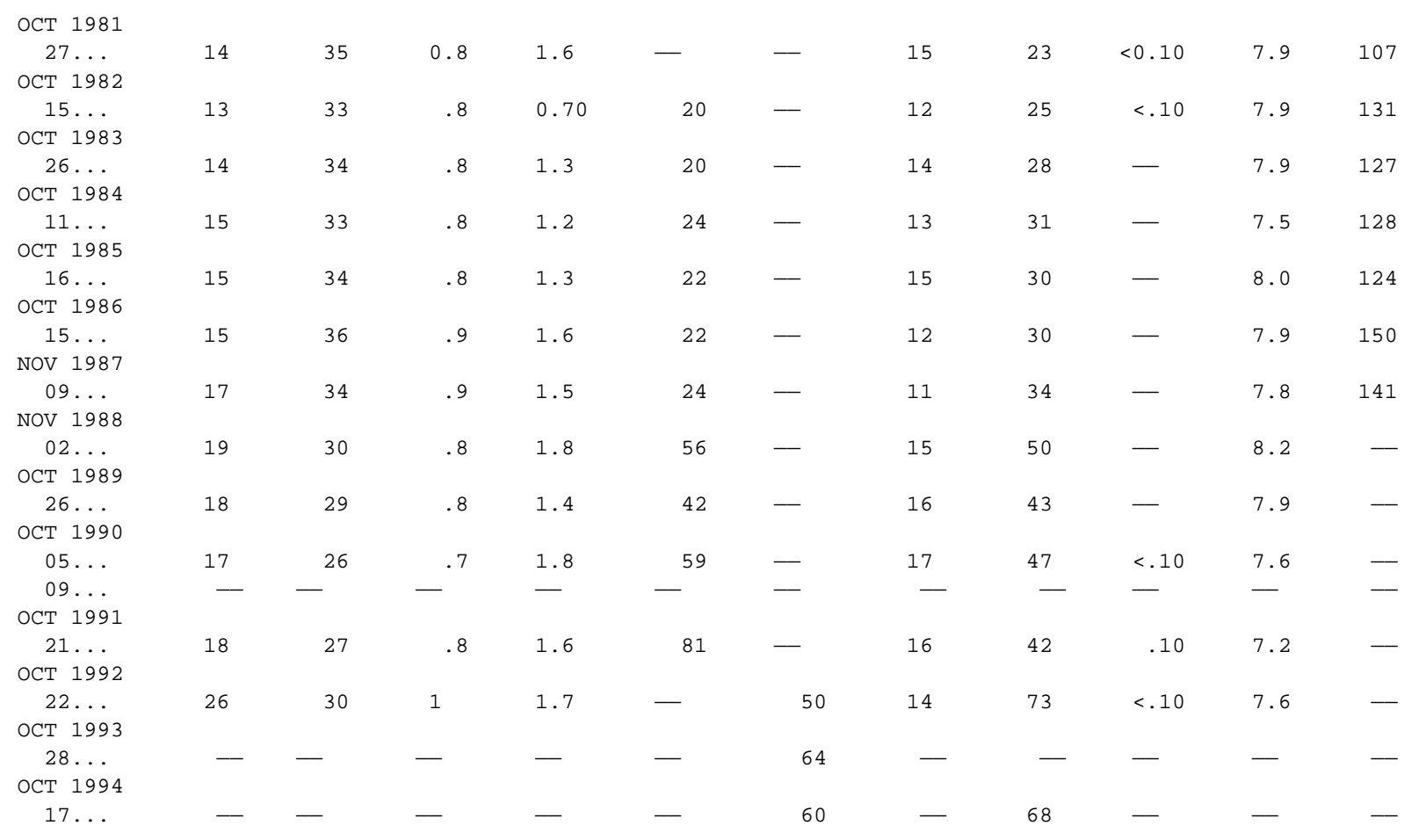


Table 3. Water-quality data from surface-water sites-Continued

01476790 - East Branch Chester Creek at Green Hill, Pa. (Site 22)—Continued

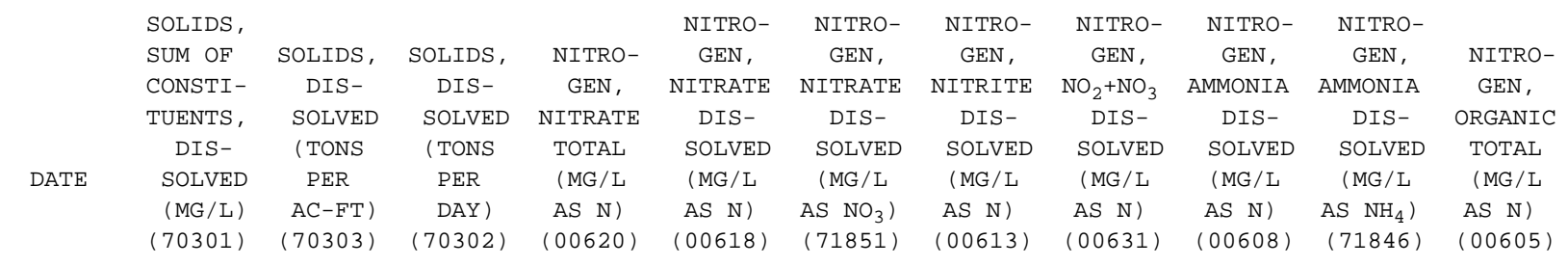

\begin{tabular}{|c|c|c|c|c|c|c|c|c|c|c|c|}
\hline $\begin{array}{c}\text { ОСТ } 1981 \\
27 \ldots\end{array}$ & - & 0.15 & - & 4.60 & - & - & $<0.010$ & 4.60 & 0.010 & 0.01 & 0.59 \\
\hline OCT 1982 & & & & & & & & & & & \\
\hline $\begin{array}{c}15 \ldots \\
\text { OCT } 1983\end{array}$ & 113 & .18 & 0.18 & 5.38 & 5.38 & 24 & .020 & 5.40 & .020 & .03 & - \\
\hline $\begin{array}{c}26 \ldots \\
\text { OCT } 1984\end{array}$ & 119 & .17 & .27 & 5.01 & 5.01 & 22 & .090 & 5.10 & $<.010$ & - & - \\
\hline $\begin{array}{c}11 \ldots \\
\text { OCT } 1985\end{array}$ & 125 & .17 & .38 & 5.00 & - & - & $<.010$ & 5.00 & .030 & .04 & - \\
\hline $\begin{array}{c}16 \ldots \\
\text { ОСТ } 1986\end{array}$ & 127 & .17 & .30 & 5.49 & 5.49 & 24 & .010 & 5.50 & .020 & .03 & .28 \\
\hline $\begin{array}{c}15 \ldots \\
\text { NOV } 1987\end{array}$ & 123 & .20 & .21 & 5.80 & - & - & $<.010$ & 5.80 & $<.010$ & - & .70 \\
\hline $\begin{array}{c}09 \ldots \\
\text { NOV } 1988\end{array}$ & 132 & .19 & .27 & 5.30 & - & - & $<.010$ & 5.30 & .020 & .03 & .58 \\
\hline $\begin{array}{c}02 \ldots \\
\text { OCT } 1989\end{array}$ & 180 & .24 & .37 & 4.80 & - & - & $<.010$ & 4.80 & $<.010$ & - & .40 \\
\hline $\begin{array}{c}26 \ldots \\
\text { OCT } 1990\end{array}$ & 164 & .22 & 1.68 & 4.70 & - & - & $<.010$ & 4.70 & .040 & .05 & .36 \\
\hline $05 \ldots$ & 179 & .24 & .36 & 4.30 & - & - & $<.010$ & 4.30 & .040 & .05 & .26 \\
\hline $\begin{array}{c}09 \ldots \\
\text { OCT } 1991\end{array}$ & - & - & - & - & - & - & - & - & - & - & - \\
\hline $\begin{array}{c}21 \ldots \\
\text { OCT } 1992\end{array}$ & 187 & .25 & .20 & 4.30 & - & - & $<.010$ & 4.30 & .020 & .03 & - \\
\hline $\begin{array}{c}22 \ldots \\
\text { ОСт } 1993\end{array}$ & 213 & .29 & .34 & 4.28 & 4.28 & 19 & .020 & 4.30 & $<.010$ & - & - \\
\hline $\begin{array}{c}28 \ldots \\
\text { OCT } 1994\end{array}$ & - & - & - & 3.80 & - & - & $<.010$ & 3.80 & .010 & .01 & - \\
\hline $17 \ldots$ & - & - & - & 4.00 & - & 一 & $<.010$ & 4.00 & .020 & .03 & - \\
\hline
\end{tabular}


Table 3. Water-quality data from surface-water sites-Continued

01476790 - East Branch Chester Creek at Green Hill, Pa. (Site 22)—Continued

\begin{tabular}{|c|c|c|c|c|c|c|c|c|c|c|c|}
\hline DATE & $\begin{array}{l}\text { NITRO- } \\
\text { GEN, } \\
\text { ORGANIC } \\
\text { DIS- } \\
\text { SOLVED } \\
\text { (MG/L } \\
\text { AS N) } \\
(00607)\end{array}$ & $\begin{array}{c}\text { NITRO- } \\
\text { GEN, AM- } \\
\text { MONIA + } \\
\text { ORGANIC } \\
\text { TOTAL } \\
(\text { MG/L } \\
\text { AS N) } \\
(00625)\end{array}$ & $\begin{array}{l}\text { NITRO- } \\
\text { GEN, AM- } \\
\text { MONIA + } \\
\text { ORGANIC } \\
\text { DIS. } \\
(\text { MG/L } \\
\text { AS N) } \\
(00623)\end{array}$ & $\begin{array}{c}\text { NITRO- } \\
\text { GEN, } \\
\text { TOTAL } \\
\text { (MG/L } \\
\text { AS N) } \\
(00600)\end{array}$ & $\begin{array}{c}\text { NITRO- } \\
\text { GEN, } \\
\text { DIS- } \\
\text { SOLVED } \\
\text { (MG/L } \\
\text { AS N) } \\
(00602)\end{array}$ & $\begin{array}{c}\text { PHOS- } \\
\text { PHORUS, } \\
\text { TOTAL } \\
(\text { MG/L } \\
\text { AS P) } \\
(00665)\end{array}$ & $\begin{array}{c}\text { PHOS- } \\
\text { PHORUS, } \\
\text { TOTAL } \\
(\mathrm{MG} / \mathrm{L} \\
\text { AS PO }) \\
(71886)\end{array}$ & $\begin{array}{c}\text { PHOS- } \\
\text { PHORUS, } \\
\text { DIS- } \\
\text { SOLVED } \\
(\text { MG / L } \\
\text { AS P) } \\
(00666)\end{array}$ & $\begin{array}{c}\text { PHOS- } \\
\text { PHORUS } \\
\text { ORTHO, } \\
\text { DIS- } \\
\text { SOLVED } \\
\text { (MG/L } \\
\text { AS P) } \\
(00671)\end{array}$ & $\begin{array}{l}\text { PHOS- } \\
\text { PHATE, } \\
\text { ORTHO, } \\
\text { DIS- } \\
\text { SOLVED } \\
(\mathrm{MG} / \mathrm{L} \\
\text { AS PO }) \\
(00660)\end{array}$ & $\begin{array}{c}\text { ARSENIC, } \\
\text { DIS- } \\
\text { SOLVED } \\
(\mu \mathrm{G} / \mathrm{L} \\
\text { AS AS) } \\
(01000)\end{array}$ \\
\hline OCT 1981 & & & & & & & & & & & \\
\hline $\begin{array}{c}27 \ldots \\
\text { OCT } 1982\end{array}$ & 0.69 & 0.60 & 0.70 & 5.2 & 5.3 & 0.020 & 0.06 & $<0.010$ & 0.010 & 0.03 & 1 \\
\hline $\begin{array}{c}15 \ldots \\
\text { OCT } 1983\end{array}$ & .18 & - & .20 & - & 5.6 & - & - & .050 & $<.010$ & - & $<1$ \\
\hline $\begin{array}{c}26 \ldots \\
\text { OCT } 1984\end{array}$ & - & - & .40 & - & 5.5 & .040 & .12 & .040 & .040 & .12 & - \\
\hline $\begin{array}{c}11 \ldots \\
\text { OCT } 1985\end{array}$ & .17 & - & .20 & - & 5.2 & .020 & - & .020 & .010 & .03 & - \\
\hline $\begin{array}{c}16 \ldots \\
\text { OCT } 1986\end{array}$ & .28 & .30 & .30 & 5.8 & 5.8 & $<.010$ & - & $<.010$ & .010 & .03 & - \\
\hline $\begin{array}{c}15 \ldots \\
\text { NOV } 1987\end{array}$ & - & .70 & .90 & 6.5 & 6.7 & .030 & - & .020 & $<.010$ & - & - \\
\hline $\begin{array}{c}09 \ldots \\
\text { NOV } 1988\end{array}$ & - & .60 & $<.20$ & 5.9 & - & .010 & - & $<.010$ & $<.010$ & - & - \\
\hline $\begin{array}{c}02 \ldots \\
\text { ОСТ } 1989\end{array}$ & - & .40 & .40 & 5.2 & 5.2 & .010 & - & $<.010$ & $<.010$ & - & 一 \\
\hline $\begin{array}{c}26 \ldots \\
\text { OCT } 1990\end{array}$ & .76 & .40 & .80 & 5.1 & 5.5 & .020 & - & .010 & .020 & .06 & - \\
\hline $\begin{array}{l}05 \ldots \\
09 \ldots\end{array}$ & $\stackrel{.36}{-}^{.36}$ & $\stackrel{.30}{-}^{.30}$ & $\underbrace{.40}$ & $\begin{array}{l}4.6 \\
-\end{array}$ & $\begin{array}{l}4.7 \\
-\end{array}$ & $\begin{array}{l}.020 \\
-\end{array}$ & - & $\begin{array}{l}.020 \\
-\end{array}$ & $\begin{array}{l}.020 \\
-\end{array}$ & $\stackrel{.06}{-}^{.06}$ & - \\
\hline $\begin{array}{c}\text { ОСТ } 1991 \\
21 \ldots \\
\text { ОСТ } 1992\end{array}$ & - & $<.20$ & $<.20$ & - & - & $<.010$ & - & $<.010$ & .020 & .06 & - \\
\hline $\begin{array}{c}22 \ldots \\
\text { OCT } 1993\end{array}$ & - & $<.20$ & $<.20$ & - & - & .030 & - & .020 & .010 & .03 & - \\
\hline $\begin{array}{c}28 \ldots \\
\text { OCT } 1994\end{array}$ & - & - & - & - & - & - & - & - & $<.010$ & - & - \\
\hline $17 \ldots$ & - & - & - & - & - & - & - & - & .020 & .06 & - \\
\hline
\end{tabular}


Table 3. Water-quality data from surface-water sites-Continued

01476790 - East Branch Chester Creek at Green Hill, Pa. (Site 22)—Continued

\begin{tabular}{|c|c|c|c|c|c|c|c|c|c|c|c|}
\hline DATE & $\begin{array}{c}\text { CADMIUM } \\
\text { DIS- } \\
\text { SOLVED } \\
(\mu \mathrm{G} / \mathrm{L} \\
\mathrm{AS} \quad \mathrm{CD}) \\
(01025)\end{array}$ & $\begin{array}{l}\text { CHRO- } \\
\text { MIUM, } \\
\text { DIS- } \\
\text { SOLVED } \\
(\mu G / L \\
\text { AS CR) } \\
(01030)\end{array}$ & $\begin{array}{c}\text { COBALT, } \\
\text { DIS- } \\
\text { SOLVED } \\
(\mu \mathrm{G} / \mathrm{L} \\
\text { AS CO) } \\
(01035)\end{array}$ & $\begin{array}{l}\text { COPPER, } \\
\text { DIS- } \\
\text { SOLVED } \\
(\mu \mathrm{G} / \mathrm{L} \\
\text { AS CU) } \\
(01040)\end{array}$ & $\begin{array}{c}\text { IRON, } \\
\text { DIS- } \\
\text { SOLVED } \\
(\mu \mathrm{G} / \mathrm{L} \\
\text { AS FE) } \\
(01046)\end{array}$ & $\begin{array}{c}\text { LEAD, } \\
\text { DIS- } \\
\text { SOLVED } \\
(\mu \mathrm{G} / \mathrm{L} \\
\text { AS PB) } \\
(01049)\end{array}$ & $\begin{array}{l}\text { MANGA- } \\
\text { NESE, } \\
\text { DIS- } \\
\text { SOLVED } \\
(\mu \mathrm{G} / \mathrm{L} \\
\text { AS MN) } \\
(01056)\end{array}$ & $\begin{array}{l}\text { MERCURY, } \\
\text { DIS- } \\
\text { SOLVED } \\
(\mu \mathrm{G} / \mathrm{L} \\
\text { AS HG) } \\
(71890)\end{array}$ & $\begin{array}{l}\text { NICKEL, } \\
\text { DIS- } \\
\text { SOLVED } \\
(\mu \mathrm{G} / \mathrm{L} \\
\text { AS NI) } \\
(01065)\end{array}$ & $\begin{array}{l}\text { ZINC, } \\
\text { DIS- } \\
\text { SOLVED } \\
(\mu \mathrm{G} / \mathrm{L} \\
\mathrm{AS} \quad \mathrm{ZN}) \\
(01090)\end{array}$ & $\begin{array}{l}\text { METHY- } \\
\text { LENE } \\
\text { BLUE } \\
\text { ACTIVE } \\
\text { SUB- } \\
\text { STANCE } \\
\text { (MG/L) } \\
(38260)\end{array}$ \\
\hline ОСт 1981 & & & & & & & & & & & \\
\hline $\begin{array}{c}27 \ldots \\
\text { OCT } 1982\end{array}$ & 2.0 & 3 & $<1$ & 2 & 32 & $<1$ & 20 & 0.2 & 2 & 8 & ND \\
\hline $\begin{array}{c}15 \ldots \\
\text { OCT } 1983\end{array}$ & $<1.0$ & 1 & $<1$ & $<1$ & 8 & $<1$ & 8 & $<.1$ & 5 & 5 & 0.05 \\
\hline $\begin{array}{c}26 \ldots \\
\text { OCT } 1984\end{array}$ & - & - & - & - & 23 & - & 18 & - & - & - & - \\
\hline $\begin{array}{c}11 \ldots \\
\text { OCT } 1985\end{array}$ & - & - & - & - & 13 & - & 10 & - & - & - & - \\
\hline $\begin{array}{c}16 \ldots \\
\text { OCT } 1986\end{array}$ & - & - & - & - & 13 & - & 16 & - & - & - & - \\
\hline $\begin{array}{c}15 \ldots \\
\text { NOV } 1987\end{array}$ & - & - & - & - & 17 & - & 12 & - & - & - & - \\
\hline $\begin{array}{c}09 \ldots \\
\text { NOV } 1988\end{array}$ & - & - & - & - & 15 & - & 9 & - & - & - & - \\
\hline $\begin{array}{c}02 \ldots \\
\text { OCT } 1989\end{array}$ & - & - & - & - & 25 & - & 13 & - & - & - & - \\
\hline $\begin{array}{c}26 \ldots \\
\text { OCT } 1990\end{array}$ & - & - & - & - & 24 & - & 170 & - & - & - & - \\
\hline $\begin{array}{l}05 \ldots \\
09 \ldots\end{array}$ & - & - & - & - & $-^{5}$ & - & $\begin{array}{c}67 \\
-\end{array}$ & - & - & - & - \\
\hline OCT 1991 & & & & & & & & & & & \\
\hline $\begin{array}{c}21 \ldots \\
\text { OCT } 1992\end{array}$ & - & - & - & - & 10 & - & 170 & - & - & - & - \\
\hline $\begin{array}{c}22 \ldots \\
\text { OCT } 1993\end{array}$ & - & - & - & - & 6 & - & 17 & - & - & - & - \\
\hline $\begin{array}{c}28 \ldots \\
\text { OCT } 1994\end{array}$ & - & - & - & - & - & - & - & - & - & - & - \\
\hline $17 \ldots$ & - & - & - & - & - & - & - & - & - & - & - \\
\hline
\end{tabular}


Table 3. Water-quality data from surface-water sites-Continued

01476830 - East Branch Chester Creek at Milltown, Pa. (Site 23)

\begin{tabular}{|c|c|c|c|c|c|c|c|c|c|c|c|}
\hline & & DIS- & & $\mathrm{PH}$ & & & & & HARD - & & \\
\hline & & CHARGE, & SPE- & WATER & & & & HARD- & NESS, & & MAGNE- \\
\hline & & INST. & CIFIC & WHOLE & & & & NESS, & NONCARB & CALCIUM, & SIUM, \\
\hline & & (CUBIC & $\mathrm{CON}-$ & FIELD & TEMPER- & TUR- & OXYGEN, & TOTAL & WH WAT & DIS- & DIS- \\
\hline & & FEET & DUCT- & (STAND- & ATURE & BID- & DIS- & (MG / L & TOT FLD & SOLVED & SOLVED \\
\hline DATE & TIME & PER & ANCE & ARD & WATER & ITY & SOLVED & AS & (MG/L AS & $(\mathrm{MG} / \mathrm{L}$ & (MG / L \\
\hline & & SECOND) & $(\mu \mathrm{S} / \mathrm{CM})$ & UNITS) & $(\mathrm{DEG} \quad \mathrm{C})$ & (NTU) & (MG/L) & $\mathrm{CACO}_{3}$ ) & $\left.\mathrm{CACO}_{3}\right)$ & AS CA) & AS MG) \\
\hline & & $(00061)$ & $(00095)$ & $(00400)$ & $(00010)$ & $(00076)$ & $(00300)$ & $(00900)$ & $(00902)$ & $(00915)$ & $(00925)$ \\
\hline
\end{tabular}

\begin{tabular}{|c|c|c|c|c|c|c|c|c|c|c|c|}
\hline $\begin{array}{c}\text { OCT } 1981 \\
27 \ldots\end{array}$ & 1100 & - & 223 & 7.3 & 13.5 & - & 9.4 & 87 & - & 19 & 9.5 \\
\hline $\begin{array}{c}\mathrm{OCT} 1982 \\
22 \ldots\end{array}$ & 1030 & 1.4 & 256 & 7.5 & 95 & - & 11.4 & 96 & - & & 10 \\
\hline ОСТ 1983 & & & & & & & & & & & \\
\hline $\begin{array}{c}26 \ldots \\
\text { OCT } 1984\end{array}$ & 1100 & 1.9 & 235 & 7.1 & 12.0 & 1.2 & 10.7 & 100 & - & 23 & 11 \\
\hline $\begin{array}{c}11 \ldots \\
\text { OCT } 1985\end{array}$ & 1100 & 3.7 & 268 & 7.9 & 15.0 & .60 & 11.1 & 100 & - & 23 & 11 \\
\hline $\begin{array}{c}16 \ldots \\
\text { OCT } 1986\end{array}$ & 1300 & 4.2 & 250 & 7.4 & 12.5 & .70 & 11.2 & 96 & - & 22 & 10 \\
\hline $\begin{array}{c}15 \ldots \\
\text { NOV } 1987\end{array}$ & 1330 & 1.7 & 240 & 7.5 & 15.0 & 2.6 & 9.6 & 94 & - & 21 & 10 \\
\hline $\begin{array}{c}09 \ldots \\
\text { NOV } 1988\end{array}$ & 1245 & 2.5 & 262 & 7.3 & 13.0 & .50 & 11.4 & 110 & - & 23 & 12 \\
\hline $\begin{array}{c}02 \ldots \\
\text { OCT } 1989\end{array}$ & 1330 & 7.6 & 280 & 7.7 & 8.5 & 1.5 & 11.8 & 100 & - & 22 & 11 \\
\hline $\begin{array}{c}26 \ldots \\
\text { OCT } 1990\end{array}$ & 1300 & 6.3 & 281 & 7.3 & 14.0 & 3.0 & 9.9 & 100 & 41 & 23 & 11 \\
\hline $\begin{array}{c}05 \ldots \\
\text { OCT } 1991\end{array}$ & 0830 & 2.1 & 324 & 6.8 & 13.5 & 1.0 & 9.0 & 120 & 29 & 27 & 13 \\
\hline $\begin{array}{c}21 \ldots \\
\text { OCT } 1992\end{array}$ & 1430 & 2.5 & 298 & 7.4 & 11.0 & 2.9 & 11.7 & 110 & 30 & 27 & 11 \\
\hline $\begin{array}{c}23 \ldots \\
\text { OCT } 1993\end{array}$ & 0945 & 2.5 & 314 & 7.6 & 8.5 & .70 & 11.8 & 120 & - & 28 & 13 \\
\hline $\begin{array}{c}26 \ldots \\
\text { OCT } 1994\end{array}$ & 1415 & 2.1 & 315 & 7.4 & 12.0 & - & 10.8 & - & - & - & - \\
\hline $21 \ldots$ & 1400 & 4.0 & 302 & 7.0 & 15.0 & - & 10.4 & - & - & - & - \\
\hline
\end{tabular}


Table 3. Water-quality data from surface-water sites-Continued

01476830 - East Branch Chester Creek at Milltown, Pa. (Site 23)—Continued

\begin{tabular}{|c|c|c|c|c|c|c|c|c|c|c|c|}
\hline DATE & $\begin{array}{l}\text { SODIUM, } \\
\text { DIS- } \\
\text { SOLVED } \\
(\text { MG/L } \\
\text { AS NA) } \\
(00930)\end{array}$ & $\begin{array}{l}\text { SODIUM } \\
\text { PERCENT } \\
(00932)\end{array}$ & $\begin{array}{l}\text { SODIUM } \\
\text { AD- } \\
\text { SORP- } \\
\text { TION } \\
\text { RATIO } \\
(00931)\end{array}$ & $\begin{array}{c}\text { POTAS- } \\
\text { SIUM, } \\
\text { DIS- } \\
\text { SOLVED } \\
\text { (MG/L } \\
\text { AS K) } \\
(00935)\end{array}$ & $\begin{array}{l}\text { ALKA- } \\
\text { LINITY } \\
\text { WAT WH } \\
\text { TOT FET } \\
\text { FIELD } \\
(\mathrm{MG} / \mathrm{L} \text { AS } \\
\left.\mathrm{CACO}_{3}\right) \\
(00410)\end{array}$ & $\begin{array}{l}\text { ALKA- } \\
\text { LINITY } \\
\text { WAT WH } \\
\text { TOT IT } \\
\text { FIELD } \\
(\mathrm{MG} / \mathrm{L} \text { AS } \\
\left.\mathrm{CACO}_{3}\right) \\
(00419)\end{array}$ & $\begin{array}{l}\text { SULFATE, } \\
\text { DIS- } \\
\text { SOLVED } \\
(\mathrm{MG} / \mathrm{L} \\
\left.\mathrm{AS} \mathrm{SO}_{4}\right) \\
(00945)\end{array}$ & $\begin{array}{c}\text { CHLO- } \\
\text { RIDE, } \\
\text { DIS- } \\
\text { SOLVED } \\
\text { (MG/L } \\
\text { AS CL) } \\
(00940)\end{array}$ & $\begin{array}{c}\text { FLUO- } \\
\text { RIDE, } \\
\text { DIS- } \\
\text { SOLVED } \\
(\mathrm{MG} / \mathrm{L} \\
\text { AS F) } \\
(00950)\end{array}$ & $\begin{array}{l}\text { SILICA, } \\
\text { DIS- } \\
\text { SOLVED } \\
\text { (MG/L } \\
\text { AS } \\
\left.\mathrm{SIO}_{2}\right) \\
(00955)\end{array}$ & $\begin{array}{c}\text { SOLIDS, } \\
\text { RESIDUE } \\
\text { AT } 180 \\
\text { DEG. C } \\
\text { DIS- } \\
\text { SOLVED } \\
\text { (MG/L) } \\
(70300)\end{array}$ \\
\hline OCT 1981 & & & & & & & & & & & \\
\hline $\begin{array}{c}27 \ldots \\
\text { OCT } 1982\end{array}$ & 11 & 21 & 0.5 & 3.8 & - & - & 26 & 21 & $<0.10$ & 12 & 136 \\
\hline $\begin{array}{c}22 \ldots \\
\text { ОСТ } 1983\end{array}$ & 8.1 & 15 & .4 & 2.7 & 68 & - & 18 & 17 & $<.10$ & 19 & 151 \\
\hline $\begin{array}{c}26 \ldots \\
\text { OCT } 1984\end{array}$ & 8.8 & 15 & .4 & 3.2 & 66 & - & 25 & 17 & - & 18 & 161 \\
\hline $\begin{array}{c}11 \ldots \\
\text { ОСт } 1985\end{array}$ & 11 & 18 & .5 & 2.9 & 72 & - & 21 & 24 & - & 14 & 156 \\
\hline $\begin{array}{c}16 \ldots \\
\text { OCT } 1986\end{array}$ & 11 & 19 & .5 & 2.6 & 58 & - & 21 & 21 & - & 12 & 144 \\
\hline $\begin{array}{c}15 \ldots \\
\text { NOV } 1987\end{array}$ & 8.5 & 16 & .4 & 4.9 & 72 & - & 22 & 19 & - & 17 & 178 \\
\hline $\begin{array}{c}09 \ldots \\
\text { NOV } 1988\end{array}$ & 11 & 18 & .5 & 2.6 & 74 & - & 19 & 27 & - & 12 & 165 \\
\hline $\begin{array}{c}02 \ldots \\
\text { OCT } 1989\end{array}$ & 13 & 21 & .6 & 2.7 & 76 & - & 24 & 31 & - & 6.5 & - \\
\hline $\begin{array}{c}26 \ldots \\
\text { OCT } 1990\end{array}$ & 11 & 18 & .5 & 2.4 & 62 & - & 20 & 26 & - & 13 & - \\
\hline $\begin{array}{c}05 \ldots \\
\text { ОСТ } 1991\end{array}$ & 13 & 19 & .5 & 2.6 & 92 & - & 21 & 35 & $<.10$ & 13 & - \\
\hline $\begin{array}{c}21 \ldots \\
\text { ОСт } 1992\end{array}$ & 9.3 & 14 & .4 & 5.2 & 83 & - & 34 & 18 & .10 & 15 & - \\
\hline $\begin{array}{c}23 \ldots \\
\text { ОСТ } 1993\end{array}$ & 13 & 18 & .5 & 2.3 & - & 68 & 21 & 36 & .10 & 14 & - \\
\hline $\begin{array}{c}26 \ldots \\
\text { OCT } 1994\end{array}$ & - & - & - & - & - & 72 & - & - & - & - & - \\
\hline $21 \ldots$ & - & - & - & - & - & 65 & - & 44 & - & - & - \\
\hline
\end{tabular}


Table 3. Water-quality data from surface-water sites-Continued

01476830 - East Branch Chester Creek at Milltown, Pa. (Site 23)—Continued

\begin{tabular}{|c|c|c|c|c|c|c|c|c|c|c|c|}
\hline DATE & $\begin{array}{l}\text { SOLIDS, } \\
\text { SUM OF } \\
\text { CONSTI- } \\
\text { TUENTS, } \\
\text { DIS- } \\
\text { SOLVED } \\
(\mathrm{MG} / \mathrm{L}) \\
(70301)\end{array}$ & $\begin{array}{c}\text { SOLIDS, } \\
\text { DIS- } \\
\text { SOLVED } \\
\text { (TONS } \\
\text { PER } \\
\text { AC-FT) } \\
(70303)\end{array}$ & $\begin{array}{l}\text { SOLIDS, } \\
\text { DIS- } \\
\text { SOLVED } \\
\text { (TONS } \\
\text { PER } \\
\text { DAY) } \\
(70302)\end{array}$ & $\begin{array}{l}\text { NITRO- } \\
\text { GEN, } \\
\text { NITRATE } \\
\text { TOTAL } \\
\text { (MG/L } \\
\text { AS N) } \\
(00620)\end{array}$ & $\begin{array}{l}\text { NITRO- } \\
\text { GEN, } \\
\text { NITRATE } \\
\text { DIS- } \\
\text { SOLVED } \\
\text { (MG/L } \\
\text { AS N) } \\
(00618)\end{array}$ & $\begin{array}{l}\text { NITRO- } \\
\text { GEN, } \\
\text { NITRATE } \\
\text { DIS- } \\
\text { SOLVED } \\
(\mathrm{MG} / \mathrm{L} \\
\left.\mathrm{AS} \mathrm{NO} \mathrm{N}_{3}\right) \\
(71851)\end{array}$ & $\begin{array}{l}\text { NITRO- } \\
\text { GEN, } \\
\text { NITRITE } \\
\text { DIS- } \\
\text { SOLVED } \\
\text { (MG/L } \\
\text { AS N) } \\
(00613)\end{array}$ & $\begin{array}{c}\text { NITRO- } \\
\text { GEN, } \\
\mathrm{NO}_{2}+\mathrm{NO}_{3} \\
\text { DIS- } \\
\text { SOLVED } \\
(\mathrm{MG} / \mathrm{L} \\
\mathrm{AS} \mathrm{N}) \\
(00631)\end{array}$ & $\begin{array}{c}\text { NITRO- } \\
\text { GEN, } \\
\text { AMMONIA } \\
\text { DIS- } \\
\text { SOLVED } \\
\text { (MG/L } \\
\text { AS N) } \\
(00608)\end{array}$ & $\begin{array}{c}\text { NITRO- } \\
\text { GEN, } \\
\text { AMMONIA } \\
\text { DIS- } \\
\text { SOLVED } \\
(\text { MG/L } \\
\left.\text { AS NH }{ }_{4}\right) \\
(71846)\end{array}$ & $\begin{array}{l}\text { NITRO- } \\
\text { GEN, } \\
\text { ORGANIC } \\
\text { TOTAL } \\
\text { (MG/L } \\
\text { A. N) } \\
(00605)\end{array}$ \\
\hline $\begin{array}{c}\text { СТ } 1981 \\
27 \ldots \\
\text { СТ } 1982\end{array}$ & - & 0.18 & - & 1.17 & - & - & $<0.010$ & 1.50 & 0.080 & 0.10 & 0.49 \\
\hline $\begin{array}{c}22 \ldots \\
\text { OCT } 1983\end{array}$ & 147 & .21 & 0.57 & 2.09 & 2.09 & 9.3 & .010 & 2.10 & $<.010$ & .01 & - \\
\hline $\begin{array}{c}26 \ldots \\
\text { OCT } 1984\end{array}$ & 156 & .22 & .83 & 2.20 & - & - & $<.010$ & 2.20 & $<.010$ & - & - \\
\hline $\begin{array}{c}11 \ldots \\
\mathrm{CT} \quad 1985\end{array}$ & 162 & .21 & 1.56 & 2.58 & 2.58 & 11 & .020 & 2.60 & .020 & .03 & - \\
\hline $\begin{array}{c}16 \ldots \\
\text { ОСТ } 1986\end{array}$ & 144 & .20 & 1.63 & 2.16 & 2.16 & 9.6 & .040 & 2.20 & .030 & .04 & .47 \\
\hline $\begin{array}{c}15 \ldots \\
\text { NOV } 1987\end{array}$ & 154 & .24 & .82 & 1.79 & 1.79 & 7.9 & .010 & 1.80 & $<.010$ & - & 1.0 \\
\hline $\begin{array}{c}09 \ldots \\
\text { IOV } 1988\end{array}$ & 160 & .22 & 1.11 & 2.10 & - & - & $<.010$ & 2.10 & .030 & .04 & .37 \\
\hline $\begin{array}{c}02 \ldots \\
\text { СТ } 1989\end{array}$ & 163 & .22 & 3.34 & 1.58 & 1.58 & 7.0 & .020 & 1.60 & .040 & .05 & .56 \\
\hline $\begin{array}{c}26 \ldots \\
\text { ОСТ } 1990\end{array}$ & 156 & .21 & 2.65 & 2.68 & 2.68 & 12 & .020 & 2.70 & .030 & .04 & .57 \\
\hline $\begin{array}{c}05 \ldots \\
\text { OCT } 1991\end{array}$ & 189 & .26 & 1.05 & 1.98 & 1.98 & 8.8 & .020 & 2.00 & .020 & .03 & .38 \\
\hline $\begin{array}{c}21 \ldots \\
\text { OCT } 1992\end{array}$ & 181 & .25 & 1.22 & 2.48 & 2.48 & 11 & .020 & 2.50 & .020 & .03 & - \\
\hline $\begin{array}{c}23 \ldots \\
\text { ОСт } 1993\end{array}$ & 178 & .24 & 1.20 & 2.08 & 2.08 & 9.2 & .020 & 2.10 & $<.010$ & - & .30 \\
\hline $\begin{array}{c}26 \ldots \\
\text { CT } 1994\end{array}$ & - & - & - & 3.10 & - & - & $<.010$ & 3.10 & .020 & .03 & - \\
\hline $21 \ldots$ & - & - & - & 1.70 & - & - & $<.010$ & 1.70 & .020 & .03 & - \\
\hline
\end{tabular}


Table 3. Water-quality data from surface-water sites-Continued

01476830 - East Branch Chester Creek at Milltown, Pa. (Site 23)—Continued

\begin{tabular}{|c|c|c|c|c|c|c|c|c|c|c|c|}
\hline DATE & $\begin{array}{l}\text { NITRO- } \\
\text { GEN, } \\
\text { ORGANIC } \\
\text { DIS- } \\
\text { SOLVED } \\
\text { (MG/L } \\
\text { AS N) } \\
(00607)\end{array}$ & $\begin{array}{l}\text { NITRO- } \\
\text { GEN, AM- } \\
\text { MONIA + } \\
\text { ORGANIC } \\
\text { TOTAL } \\
\text { (MG/L } \\
\text { AS N) } \\
(00625)\end{array}$ & $\begin{array}{l}\text { NITRO- } \\
\text { GEN, AM- } \\
\text { MONIA + } \\
\text { ORGANIC } \\
\text { DIS. } \\
\text { (MG/L } \\
\text { AS N) } \\
(00623)\end{array}$ & $\begin{array}{c}\text { NITRO- } \\
\text { GEN, } \\
\text { TOTAL } \\
(\mathrm{MG} / \mathrm{L} \\
\text { AS N) } \\
(00600)\end{array}$ & $\begin{array}{c}\text { NITRO- } \\
\text { GEN, } \\
\text { DIS- } \\
\text { SOLVED } \\
\text { (MG/L } \\
\text { AS N) } \\
(00602)\end{array}$ & $\begin{array}{c}\text { PHOS- } \\
\text { PHORUS, } \\
\text { TOTAL } \\
(\text { MG / L } \\
\text { AS P) } \\
(00665)\end{array}$ & $\begin{array}{c}\text { PHOS- } \\
\text { PHORUS, } \\
\text { TOTAL } \\
(\mathrm{MG} / \mathrm{L} \\
\left.\mathrm{AS} \mathrm{PO}_{4}\right) \\
(71886)\end{array}$ & $\begin{array}{c}\text { PHOS- } \\
\text { PHORUS, } \\
\text { DIS- } \\
\text { SOLVED } \\
(\text { MG /L } \\
\text { AS P) } \\
(00666)\end{array}$ & $\begin{array}{c}\text { PHOS- } \\
\text { PHORUS, } \\
\text { ORTHO, } \\
\text { DIS- } \\
\text { SOLVED } \\
\text { (MG/L } \\
\text { AS P) } \\
(00671)\end{array}$ & $\begin{array}{c}\text { PHOS- } \\
\text { PHATE, } \\
\text { ORTHO, } \\
\text { DIS- } \\
\text { SOLVED } \\
(\mathrm{MG} / \mathrm{L} \\
\text { AS PO }) \\
(00660)\end{array}$ & $\begin{array}{r}\text { ARSEN } \\
\text { DIS } \\
\text { SOLV } \\
(\mu \mathrm{G} / \\
\text { AS AS } \\
10100\end{array}$ \\
\hline OCT 1981 & & & & & & & & & & & \\
\hline $\begin{array}{c}27 \ldots \\
\text { OCT } 1982\end{array}$ & 0.43 & 0.55 & 0.51 & 1.7 & 2.0 & 0.060 & 0.18 & 0.020 & $<0.010$ & - & 1 \\
\hline $\begin{array}{c}22 \ldots \\
\text { OCT } 1983\end{array}$ & - & - & 2.3 & - & 4.4 & - & - & .030 & .010 & 0.03 & 1 \\
\hline $\begin{array}{c}26 \ldots \\
\text { OCT } 1984\end{array}$ & - & - & 1.3 & - & 3.5 & .060 & .18 & .030 & .050 & .15 & - \\
\hline $\begin{array}{c}11 \ldots \\
\text { OCT } 1985\end{array}$ & .28 & - & .30 & - & 2.9 & .020 & - & .020 & .010 & .03 & - \\
\hline $\begin{array}{c}16 \ldots \\
\text { OCT } 1986\end{array}$ & .27 & .50 & .30 & 2.7 & 2.5 & .020 & .06 & .010 & .010 & .03 & - \\
\hline $\begin{array}{c}15 \ldots \\
\text { NOV } 1987\end{array}$ & - & 1.0 & .90 & 2.8 & 2.7 & .070 & - & .040 & .020 & .06 & - \\
\hline $\begin{array}{c}09 \ldots \\
\text { NOV } 1988\end{array}$ & .27 & .40 & .30 & 2.5 & 2.4 & .020 & - & .020 & .010 & .03 & - \\
\hline $\begin{array}{c}02 \ldots \\
\text { OCT } 1989\end{array}$ & .56 & .60 & .60 & 2.2 & 2.2 & .030 & - & .010 & $<.010$ & - & - \\
\hline $\begin{array}{c}26 \ldots \\
\text { OCT } 1990\end{array}$ & .37 & .60 & .40 & 3.3 & 3.1 & .050 & - & $<.010$ & $<.010$ & - & - \\
\hline $\begin{array}{c}05 \ldots \\
\text { OCT } 1991\end{array}$ & .38 & .40 & .40 & 2.4 & 2.4 & $<.020$ & - & $<.010$ & $<.010$ & - & - \\
\hline $\begin{array}{c}21 \ldots \\
\text { OCT } 1992\end{array}$ & - & $<.20$ & $<.20$ & - & - & .020 & - & $<.010$ & .030 & .09 & - \\
\hline $\begin{array}{c}23 \ldots \\
\text { OCT } 1993\end{array}$ & - & .30 & $<.20$ & 2.4 & - & .020 & - & .020 & $<.010$ & - & - \\
\hline $\begin{array}{c}26 \ldots \\
\text { OCT } 1994\end{array}$ & - & - & - & - & - & - & - & - & .020 & .06 & - \\
\hline $21 \ldots$ & - & - & - & - & - & - & - & - & .020 & .06 & - \\
\hline
\end{tabular}


Table 3. Water-quality data from surface-water sites-Continued

01476830 - East Branch Chester Creek at Milltown, Pa. (Site 23)—Continued

\begin{tabular}{|c|c|c|c|c|c|c|c|c|c|c|}
\hline & CHRO- & & & & & MANGA- & & & & $\begin{array}{c}\text { METHY- } \\
\text { LENE }\end{array}$ \\
\hline CADMIUM & MIUM, & COBALT, & COPPER, & IRON, & LEAD, & NESE, & MERCURY, & NICKEL, & ZINC, & BLUE \\
\hline DIS- & DIS- & DIS- & DIS- & DIS- & DIS- & DIS- & DIS- & DIS- & DIS- & ACTIVE \\
\hline $\begin{array}{l}\text { SOLVED } \\
(\mu \mathrm{G} / \mathrm{L}\end{array}$ & $\begin{array}{l}\text { SOLVED } \\
(\mu \mathrm{G} / \mathrm{L}\end{array}$ & $\begin{array}{c}\text { SOLVED } \\
(\mu \mathrm{G} / \mathrm{L}\end{array}$ & $\begin{array}{l}\text { SOLVED } \\
(\mu \mathrm{G} / \mathrm{L}\end{array}$ & $\begin{array}{l}\text { SOLVED } \\
(\mu \mathrm{G} / \mathrm{L}\end{array}$ & $\begin{array}{l}\text { SOLVED } \\
(\mu \mathrm{G} / \mathrm{L}\end{array}$ & $\begin{array}{l}\text { SOLVED } \\
(\mu \mathrm{G} / \mathrm{L}\end{array}$ & $\begin{array}{l}\text { SOLVED } \\
(\mu \mathrm{G} / \mathrm{L}\end{array}$ & $\begin{array}{l}\text { SOLVED } \\
(\mu \mathrm{G} / \mathrm{L}\end{array}$ & $\begin{array}{l}\text { SOLVED } \\
(\mu \mathrm{G} / \mathrm{L}\end{array}$ & $\begin{array}{r}\text { SUB- } \\
\text { STANCE }\end{array}$ \\
\hline AS CD) & AS (R) & AS $(\mathrm{CO})$ & AS CU) & AS FE) & AS $\quad \mathrm{PB}$ ) & AS MN) & AS HG) & AS NI) & AS $\mathrm{ZN}$ ) & (MG / L) \\
\hline$(01025)$ & $(01030)$ & $(01035)$ & $(01040)$ & $(01046)$ & $(01049)$ & $(01056)$ & $(71890)$ & $(01065)$ & $(01090)$ & $(38260)$ \\
\hline
\end{tabular}

\begin{tabular}{|c|c|c|c|c|c|c|c|c|c|c|c|}
\hline $\begin{array}{c}\text { OCT } 1981 \\
27 \ldots \\
\text { OCT } 1982\end{array}$ & 3.0 & $<1$ & $<1$ & 2 & 380 & $<1$ & 40 & $<0.1$ & 2 & $<4$ & 0.0 \\
\hline $\begin{array}{c}22 \ldots \\
\text { OCT } 1983\end{array}$ & $<1.0$ & $<1$ & 1 & 1 & 45 & $<1$ & 33 & - & $<1$ & $<4$ & .03 \\
\hline $\begin{array}{c}26 \ldots \\
\text { OCT } 1984\end{array}$ & - & - & - & - & 110 & - & 49 & - & - & - & - \\
\hline $\begin{array}{c}11 \ldots \\
\text { OCT } 1985\end{array}$ & - & - & - & - & 57 & - & 24 & - & - & - & - \\
\hline $\begin{array}{c}16 \ldots \\
\text { OCT } 1986\end{array}$ & - & - & - & - & 50 & - & 20 & - & - & - & - \\
\hline $\begin{array}{c}15 \ldots \\
\text { NOV } 1987\end{array}$ & - & - & - & - & 79 & - & 40 & - & - & - & - \\
\hline $\begin{array}{c}09 \ldots \\
\text { NOV } 1988\end{array}$ & - & - & - & - & 61 & - & 19 & - & - & - & - \\
\hline $\begin{array}{c}02 \ldots \\
\text { ОСТ } 1989\end{array}$ & - & - & - & - & 58 & - & 25 & - & - & - & - \\
\hline $\begin{array}{c}26 \ldots \\
\text { ОСт } 1990\end{array}$ & - & - & - & - & 59 & - & 40 & - & - & - & - \\
\hline $\begin{array}{c}05 \ldots \\
\text { ОСТ } 1991\end{array}$ & - & - & - & - & 34 & - & 22 & - & - & - & - \\
\hline $\begin{array}{c}21 \ldots \\
\text { OCT } 1992\end{array}$ & - & - & - & - & 71 & - & 37 & - & - & - & - \\
\hline $\begin{array}{c}23 \ldots \\
\text { OCT } 1993\end{array}$ & - & - & - & - & 34 & - & 13 & - & - & - & - \\
\hline $26 \ldots$ & - & - & - & - & - & - & - & - & - & - & - \\
\hline $\begin{array}{c}\text { OCT } 1994 \\
21 \ldots\end{array}$ & - & - & - & - & - & - & - & - & - & - & - \\
\hline
\end{tabular}


Table 3. Water-quality data from surface-water sites-Continued

01476835 - East Branch Chester Creek at Westtown, Pa. (Site 24)

\begin{tabular}{|c|c|c|c|c|c|c|c|c|c|c|c|}
\hline & & DIS- & & $\mathrm{PH}$ & & & & & HARD- & & \\
\hline & & CHARGE, & SPE- & WATER & & & & HARD- & NESS, & & MAGNE- \\
\hline & & INST. & CIFIC & WHOLE & & & & NESS, & NONCARB & CALCIUM, & SIUM, \\
\hline & & (CUBIC & $\mathrm{CON}-$ & FIELD & TEMPER- & TUR- & OXYGEN, & TOTAL & WH WAT & DIS- & DIS- \\
\hline & & FEET & DUCT- & (STAND- & ATURE & BID- & DIS- & (MG /L & TOT FLD & SOLVED & SOLVED \\
\hline DATE & TIME & PER & ANCE & ARD & WATER & ITY & SOLVED & AS & (MG/L AS & (MG /L & (MG/L \\
\hline & & SECOND) & $(\mu \mathrm{S} / \mathrm{CM})$ & UNITS) & (DEG C) & (NTU) & $(M G / L)$ & $\left.\mathrm{CACO}_{3}\right)$ & $\left.\mathrm{CACO}_{3}\right)$ & AS CA) & AS MG) \\
\hline & & $(00061)$ & $(00095)$ & $(00400)$ & $(00010)$ & $(00076)$ & $(00300)$ & $(00900)$ & $(00902)$ & $(00915)$ & $(00925)$ \\
\hline
\end{tabular}

\begin{tabular}{|c|c|c|c|c|c|c|c|c|c|c|c|}
\hline $\begin{array}{c}27 \ldots \\
\text { OCT } 1982\end{array}$ & 1215 & - & 226 & 7.5 & 13.5 & - & 10.3 & 85 & - & 19 & 9.1 \\
\hline $\begin{array}{c}22 \ldots \\
\text { OCT } 1983\end{array}$ & 1315 & 2.8 & 284 & 7.1 & 9.5 & - & 10.5 & 99 & - & 23 & 10 \\
\hline $\begin{array}{c}26 \ldots \\
\text { OCT } 1984\end{array}$ & 1300 & 5.3 & - & - & - & 2.9 & - & 85 & - & 20 & 8.6 \\
\hline $\begin{array}{c}11 \ldots \\
\text { OCT } 1985\end{array}$ & 1400 & 6.0 & 280 & 7.8 & 16.0 & .90 & 10.0 & 99 & - & 23 & 10 \\
\hline $\begin{array}{c}16 \ldots \\
\text { OCT } 1986\end{array}$ & 1530 & 5.9 & 270 & 7.3 & 13.0 & 1.2 & 9.8 & 100 & - & 23 & 11 \\
\hline $\begin{array}{c}16 \ldots \\
\text { NOV } 1987\end{array}$ & 0900 & 3.9 & 250 & 7.5 & 10.0 & 2.0 & 9.5 & 96 & - & 22 & 9.9 \\
\hline $\begin{array}{c}05 \ldots \\
\text { NOV } 1988\end{array}$ & 0930 & 5.7 & 280 & 7.1 & 13.5 & .40 & 10.2 & 110 & - & 25 & 12 \\
\hline $\begin{array}{c}03 \ldots \\
\text { OCT } 1989\end{array}$ & 0845 & 6.3 & 280 & 7.5 & 8.0 & 3.1 & 11.4 & 100 & - & 22 & 11 \\
\hline $\begin{array}{c}26 \ldots \\
\text { OCT } 1990\end{array}$ & 0915 & 13 & 296 & 7.3 & 11.5 & 1.0 & 11.0 & 99 & 37 & 23 & 10 \\
\hline $\begin{array}{c}25 \ldots \\
\text { OCT } 1991\end{array}$ & 1330 & 7.6 & 298 & 6.8 & 14.0 & 4.0 & 10.0 & 110 & 38 & 24 & 11 \\
\hline $\begin{array}{c}22 \ldots \\
\text { OCT } 1992\end{array}$ & 1130 & 4.5 & 321 & 7.4 & 10.0 & 2.0 & 10.4 & 110 & 45 & 25 & 11 \\
\hline $\begin{array}{c}22 \ldots \\
\text { OCT } 1993\end{array}$ & 1130 & 3.8 & 330 & 7.2 & 9.5 & 5.1 & 10.8 & 110 & - & 25 & 12 \\
\hline $\begin{array}{c}26 \ldots \\
\text { OCT } 1994\end{array}$ & 1200 & 6.6 & 302 & 7.2 & 12.0 & - & 9.7 & - & - & - & - \\
\hline $21 \ldots$ & 0900 & 5.0 & 260 & 7.1 & 12.5 & - & 8.6 & - & - & - & - \\
\hline
\end{tabular}


Table 3. Water-quality data from surface-water sites-Continued

01476835 - East Branch Chester Creek at Westtown, Pa. (Site 24)—Continued

\begin{tabular}{|c|c|c|c|c|c|c|c|c|c|c|}
\hline DATE & $\begin{array}{l}\text { SODIUM, } \\
\text { DIS- } \\
\text { SOLVED } \\
\text { (MG/L } \\
\text { AS NA) } \\
(00930)\end{array}$ & $\begin{array}{r}\text { SODIUM } \\
\text { PERCENT } \\
\text { (00932) }\end{array}$ & $\begin{array}{c}\text { SODIUM } \\
\text { AD- } \\
\text { SORP- } \\
\text { TION } \\
\text { RATIO } \\
(00931)\end{array}$ & $\begin{array}{c}\text { POTAS- } \\
\text { SIUM, } \\
\text { DIS- } \\
\text { SOLVED } \\
\text { (MG/L } \\
\text { AS K) } \\
(00935)\end{array}$ & $\begin{array}{l}\text { ALKA- } \\
\text { LINITY } \\
\text { WAT WH } \\
\text { TOT FET } \\
\text { FIELD } \\
(\mathrm{MG} / \mathrm{L} \text { AS } \\
\left.\mathrm{CACO}_{3}\right) \\
(00410)\end{array}$ & $\begin{array}{l}\text { ALKA- } \\
\text { LINITY } \\
\text { WAT WH } \\
\text { TOT IT } \\
\text { FIELD } \\
(\mathrm{MG} / \mathrm{L} \text { AS } \\
\left.\mathrm{CACO}_{3}\right) \\
(00419)\end{array}$ & $\begin{array}{l}\text { SULFATE, } \\
\text { DIS- } \\
\text { SOLVED } \\
(\mathrm{MG} / \mathrm{L} \\
\left.\mathrm{AS} \mathrm{SO})_{4}\right) \\
(00945)\end{array}$ & $\begin{array}{c}\text { CHLO- } \\
\text { RIDE, } \\
\text { DIS- } \\
\text { SOLVED } \\
(\text { MG /L } \\
\text { AS CL) } \\
(00940)\end{array}$ & $\begin{array}{l}\text { FLUO- } \\
\text { RIDE, } \\
\text { DIS- } \\
\text { SOLVED } \\
(M G / L \\
\text { AS F) } \\
(00950)\end{array}$ & $\begin{array}{l}\text { SILICA, } \\
\text { DIS- } \\
\text { SOLVED } \\
(\mathrm{MG} / \mathrm{L} \\
\mathrm{AS} \\
\left.\mathrm{SIO}_{2}\right) \\
(00955)\end{array}$ \\
\hline OCT 1981 & & & & & & & & & & \\
\hline $\begin{array}{c}27 \ldots \\
\text { OCT } 1982\end{array}$ & 12 & 23 & 0.6 & 3.5 & - & - & 27 & 21 & 0.10 & 14 \\
\hline $\begin{array}{c}22 \ldots \\
\text { OCT } 1983\end{array}$ & 13 & 22 & .6 & 2.7 & 69 & - & 23 & 22 & $<.10$ & 17 \\
\hline $\begin{array}{c}26 \ldots \\
\text { OCT } 1984\end{array}$ & 11 & 21 & .5 & 3.5 & - & - & 26 & 19 & - & 13 \\
\hline $\begin{array}{c}11 \ldots \\
\text { OCT } 1985\end{array}$ & 13 & 22 & .6 & 3.2 & 64 & - & 24 & 25 & - & 14 \\
\hline $\begin{array}{c}16 \ldots \\
\text { OCT } 1986\end{array}$ & 13 & 21 & .6 & 3.4 & 60 & - & 24 & 24 & - & 17 \\
\hline $\begin{array}{c}16 \ldots \\
\text { NOV } 1987\end{array}$ & 13 & 22 & .6 & 3.9 & 68 & - & 23 & 23 & - & 15 \\
\hline $\begin{array}{c}05 \ldots \\
\text { NOV } 1988\end{array}$ & 13 & 20 & .5 & 3.3 & 74 & - & 21 & 28 & - & 13 \\
\hline $\begin{array}{c}03 \ldots \\
\text { OCT } 1989\end{array}$ & 12 & 20 & .5 & 3.1 & 68 & - & 24 & 26 & - & 13 \\
\hline $\begin{array}{c}26 \ldots \\
\text { OCT } 1990\end{array}$ & 11 & 19 & .5 & 2.9 & 62 & - & 21 & 27 & - & 15 \\
\hline $\begin{array}{c}25 \ldots \\
\text { OCT } 1991\end{array}$ & 13 & 20 & .6 & 3.7 & 67 & - & 17 & 26 & .30 & 15 \\
\hline $\begin{array}{c}22 \ldots \\
\text { OCT } 1992\end{array}$ & 14 & 21 & .6 & 3.4 & 63 & - & 23 & 33 & .10 & 14 \\
\hline $\begin{array}{c}22 \ldots \\
\text { OCT } 1993\end{array}$ & 13 & 20 & .5 & 3.0 & - & 64 & 22 & 35 & .10 & 15 \\
\hline $\begin{array}{c}26 \ldots \\
\text { ОСТ } 1994\end{array}$ & - & - & - & - & - & 65 & - & - & - & - \\
\hline $21 \ldots$ & - & - & - & - & - & 66 & - & 43 & - & - \\
\hline
\end{tabular}


Table 3. Water-quality data from surface-water sites-Continued

01476835 - East Branch Chester Creek at Westtown, Pa. (Site 24)-Continued

\begin{tabular}{|c|c|c|c|c|c|c|c|c|c|c|}
\hline DATE & $\begin{array}{l}\text { SOLIDS, } \\
\text { RESIDUE } \\
\text { AT } 180 \\
\text { DEG. C } \\
\text { DIS- } \\
\text { SOLVED } \\
(\mathrm{MG} / \mathrm{L}) \\
(70300)\end{array}$ & $\begin{array}{l}\text { SOLIDS, } \\
\text { SUM OF } \\
\text { CONSTI- } \\
\text { TUENTS, } \\
\text { DIS- } \\
\text { SOLVED } \\
(\text { MG/L) } \\
(70301)\end{array}$ & $\begin{array}{c}\text { SOLIDS, } \\
\text { DIS- } \\
\text { SOLVED } \\
\text { (TONS } \\
\text { PER } \\
\text { AC-FT) } \\
(70303)\end{array}$ & $\begin{array}{c}\text { SOLIDS, } \\
\text { DIS- } \\
\text { SOLVED } \\
\text { (TONS } \\
\text { PER } \\
\text { DAY) } \\
(70302)\end{array}$ & $\begin{array}{l}\text { NITRO- } \\
\text { GEN, } \\
\text { NITRATE } \\
\text { TOTAL } \\
\text { (MG/L } \\
\text { AS N) } \\
(00620)\end{array}$ & $\begin{array}{c}\text { NITRO- } \\
\text { GEN, } \\
\text { NITRATE } \\
\text { DIS- } \\
\text { SOLVED } \\
\text { (MG/L } \\
\text { AS N) } \\
(00618)\end{array}$ & $\begin{array}{c}\text { NITRO- } \\
\text { GEN, } \\
\text { NITRATE } \\
\text { DIS- } \\
\text { SOLVED } \\
(\mathrm{MG} / \mathrm{L} \\
\left.\text { AS } \mathrm{NO}_{3}\right) \\
(71851)\end{array}$ & $\begin{array}{l}\text { NITRO- } \\
\text { GEN, } \\
\text { NITRITE } \\
\text { DIS- } \\
\text { SOLVED } \\
(\text { MG/L } \\
\text { AS N) } \\
(00613)\end{array}$ & $\begin{array}{c}\text { NITRO- } \\
\text { GEN, } \\
\mathrm{NO}_{2}+\mathrm{NO}_{3} \\
\text { DIS- } \\
\text { SOLVED } \\
(\mathrm{MG} / \mathrm{L} \\
\mathrm{AS} \mathrm{N}) \\
(00631)\end{array}$ & $\begin{array}{c}\text { NITRO- } \\
\text { GEN, } \\
\text { AMMONIA } \\
\text { DIS- } \\
\text { SOLVED } \\
\text { (MG/L } \\
\text { AS N) } \\
(00608)\end{array}$ \\
\hline OCT 1981 & & & & & & & & & & \\
\hline $\begin{array}{c}27 \ldots \\
\text { OCT } 1982\end{array}$ & 141 & - & 0.19 & - & 1.80 & - & - & $<0.010$ & 1.70 & 0.020 \\
\hline $\begin{array}{c}22 \ldots \\
\text { OCT } 1983\end{array}$ & 153 & 164 & .21 & 1.14 & 2.47 & 2.47 & 11 & .030 & 2.50 & .100 \\
\hline $\begin{array}{c}26 \ldots \\
\text { ОСТ } 1984\end{array}$ & 150 & - & - & - & - & - & - & - & - & - \\
\hline $\begin{array}{c}11 \ldots \\
\text { OCT } 1985\end{array}$ & 165 & 165 & .22 & 2.67 & 2.89 & 2.89 & 13 & .010 & 2.90 & .080 \\
\hline $\begin{array}{c}16 \ldots \\
\text { OCT } 1986\end{array}$ & 160 & 167 & .22 & 2.55 & 3.27 & 3.27 & 14 & .030 & 3.30 & .110 \\
\hline $\begin{array}{c}16 \ldots \\
\text { NOV } 1987\end{array}$ & 183 & 161 & .25 & 1.93 & 2.08 & 2.08 & 9.2 & .020 & 2.10 & .040 \\
\hline $\begin{array}{c}05 \ldots \\
\text { NOV } 1988\end{array}$ & 174 & 173 & .24 & 2.68 & 2.69 & 2.69 & 12 & .010 & 2.70 & .080 \\
\hline $\begin{array}{c}03 \ldots \\
\text { OCT } 1989\end{array}$ & - & 162 & .22 & 2.76 & 2.10 & - & - & $<.010$ & 2.10 & .070 \\
\hline $\begin{array}{c}26 \ldots \\
\text { OCT } 1990\end{array}$ & - & 162 & .22 & 5.67 & 3.09 & 3.09 & 14 & .010 & 3.10 & .020 \\
\hline $\begin{array}{c}25 \ldots \\
\text { ОСТ } 1991\end{array}$ & - & 163 & .22 & 3.34 & 2.57 & 2.57 & 11 & .030 & 2.60 & .090 \\
\hline $\begin{array}{c}22 \ldots \\
\text { OCT } 1992\end{array}$ & - & 175 & .24 & 2.13 & 2.89 & 2.89 & 13 & .010 & 2.90 & .030 \\
\hline $\begin{array}{c}22 \ldots \\
\text { OCT } 1993\end{array}$ & - & 177 & .24 & 1.82 & 2.89 & 2.89 & 13 & .010 & 2.90 & .010 \\
\hline $\begin{array}{c}26 \ldots \\
\text { OCT } 1994\end{array}$ & - & - & - & - & 3.90 & - & - & $<.010$ & 3.90 & .030 \\
\hline $21 \ldots$ & - & - & - & - & 2.30 & - & - & $<.010$ & 2.30 & $<.015$ \\
\hline
\end{tabular}


Table 3. Water-quality data from surface-water sites-Continued

01476835 - East Branch Chester Creek at Westtown, Pa. (Site 24)—Continued

\begin{tabular}{|c|c|c|c|c|c|c|c|c|c|c|}
\hline DATE & $\begin{array}{c}\text { NITRO- } \\
\text { GEN, } \\
\text { AMMONIA } \\
\text { DIS- } \\
\text { SOLVED } \\
(\mathrm{MG} / \mathrm{L} \\
\left.\text { AS NH})_{4}\right) \\
(71846)\end{array}$ & $\begin{array}{l}\text { NITRO- } \\
\text { GEN, } \\
\text { ORGANIC } \\
\text { TOTAL } \\
\text { (MG/L } \\
\text { AS N) } \\
(00605)\end{array}$ & $\begin{array}{l}\text { NITRO- } \\
\text { GEN, } \\
\text { ORGANIC } \\
\text { DIS- } \\
\text { SOLVED } \\
\text { (MG/L } \\
\text { AS N) } \\
(00607)\end{array}$ & $\begin{array}{l}\text { NITRO- } \\
\text { GEN, AM- } \\
\text { MONIA + } \\
\text { ORGANIC } \\
\text { TOTAL } \\
(\text { MG/L } \\
\text { AS N) } \\
(00625)\end{array}$ & $\begin{array}{l}\text { NITRO- } \\
\text { GEN, AM- } \\
\text { MONIA + } \\
\text { ORGANIC } \\
\text { DIS. } \\
\text { (MG/L } \\
\text { AS N) } \\
(00623)\end{array}$ & $\begin{array}{c}\text { NITRO- } \\
\text { GEN, } \\
\text { TOTAL } \\
(\text { MG/L } \\
\text { AS N) } \\
(00600)\end{array}$ & $\begin{array}{l}\text { NITRO- } \\
\text { GEN, } \\
\text { DIS- } \\
\text { SOLVED } \\
\text { (MG/L } \\
\text { AS N) } \\
(00602)\end{array}$ & $\begin{array}{c}\text { PHOS- } \\
\text { PHORUS, } \\
\text { TOTAL } \\
\text { (MG/L } \\
\text { AS P) } \\
(00665)\end{array}$ & 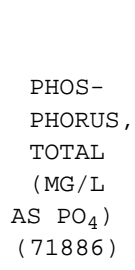 & $\begin{array}{c}\text { PHOS- } \\
\text { PHORUS, } \\
\text { DIS- } \\
\text { SOLVED } \\
\text { (MG / L } \\
\text { AS P) } \\
(00666)\end{array}$ \\
\hline $\begin{array}{c}\text { OCT } 1981 \\
27\end{array}$ & & & & & & & & & & \\
\hline $\begin{array}{cc}27 \ldots \\
\text { ОСт } 1982\end{array}$ & 0.03 & 0.86 & 0.66 & 0.90 & 0.68 & 2.7 & 2.4 & 0.280 & 0.86 & 0.250 \\
\hline $\begin{array}{c}22 \ldots \\
\text { OCT } 1983\end{array}$ & .13 & - & .60 & - & .70 & - & 3.2 & - & - & .100 \\
\hline $\begin{array}{c}26 \ldots \\
\text { ОСТ } 1984\end{array}$ & - & - & - & - & - & - & - & - & - & - \\
\hline $\begin{array}{c}11 \ldots \\
\text { OCT } 1985\end{array}$ & .10 & - & .22 & - & .30 & - & 3.2 & .390 & - & .370 \\
\hline $\begin{array}{c}16 \ldots \\
\text { OCT } 1986\end{array}$ & .14 & .59 & .59 & .70 & .70 & 4.0 & 4.0 & .460 & 1.4 & .410 \\
\hline $\begin{array}{c}16 \ldots \\
\text { NOV } 1987\end{array}$ & .05 & .66 & .36 & .70 & .40 & 2.8 & 2.5 & .300 & - & .280 \\
\hline $\begin{array}{c}05 \ldots \\
\text { NOV } 1988\end{array}$ & .10 & .42 & .52 & .50 & .60 & 3.2 & 3.3 & .260 & - & .250 \\
\hline $\begin{array}{c}03 \ldots \\
\text { OCT } 1989\end{array}$ & .09 & .43 & .43 & .50 & .50 & 2.6 & 2.6 & .200 & - & .170 \\
\hline $\begin{array}{c}26 \ldots \\
\text { OCT } 1990\end{array}$ & .03 & .28 & .28 & .30 & .30 & 3.4 & 3.4 & .190 & - & .160 \\
\hline $\begin{array}{c}25 \ldots \\
\text { OCT } 1991\end{array}$ & .12 & .71 & .61 & .80 & .70 & 3.4 & 3.3 & .270 & - & .210 \\
\hline $\begin{array}{c}22 \ldots \\
\text { OCT } 1992\end{array}$ & .04 & .47 & .17 & .50 & .20 & 3.4 & 3.1 & .340 & - & .260 \\
\hline $\begin{array}{c}22 \ldots \\
\text { OCT } 1993\end{array}$ & .01 & .89 & .39 & .90 & .40 & 3.8 & 3.3 & .370 & - & .250 \\
\hline $\begin{array}{c}26 \ldots \\
\text { OCT } 1994\end{array}$ & .04 & - & - & - & - & - & - & - & - & - \\
\hline $21 \ldots$ & - & - & - & - & - & - & - & - & - & - \\
\hline
\end{tabular}


Table 3. Water-quality data from surface-water sites-Continued

01476835 - East Branch Chester Creek at Westtown, Pa. (Site 24)—Continued

\begin{tabular}{|c|c|c|c|c|c|c|c|c|c|c|}
\hline DATE & $\begin{array}{c}\text { PHOS- } \\
\text { PHORUS, } \\
\text { ORTHO, } \\
\text { DIS- } \\
\text { SOLVED } \\
\text { (MG/L } \\
\text { AS P) } \\
(00671)\end{array}$ & $\begin{array}{l}\text { PHOS- } \\
\text { PHATE, } \\
\text { ORTHO, } \\
\text { DIS- } \\
\text { SOLVED } \\
(\mathrm{MG} / \mathrm{L} \\
\text { AS PO }) \\
(00660)\end{array}$ & $\begin{array}{c}\text { ARSENIC, } \\
\text { DIS- } \\
\text { SOLVED } \\
(\mu \mathrm{G} / \mathrm{L} \\
\text { AS AS) } \\
(01000)\end{array}$ & $\begin{array}{l}\text { BARIUM, } \\
\text { DIS- } \\
\text { SOLVED } \\
(\mu \mathrm{G} / \mathrm{L} \\
\text { AS BA) } \\
(01005)\end{array}$ & $\begin{array}{l}\text { BERYL- } \\
\text { LIUM, } \\
\text { DIS- } \\
\text { SOLVED } \\
(\mu \mathrm{G} / \mathrm{L} \\
\text { AS BE) } \\
(01010)\end{array}$ & $\begin{array}{c}\text { CADMIUM, } \\
\text { DIS- } \\
\text { SOLVED } \\
(\mu \mathrm{G} / \mathrm{L} \\
\text { AS CD }) \\
(01025)\end{array}$ & $\begin{array}{l}\text { CHRO- } \\
\text { MIUM, } \\
\text { DIS- } \\
\text { SOLVED } \\
(\mu \mathrm{G} / \mathrm{L} \\
\text { AS CR) } \\
(01030)\end{array}$ & $\begin{array}{l}\text { COBALT, } \\
\text { DIS- } \\
\text { SOLVED } \\
(\mu \mathrm{G} / \mathrm{L} \\
\text { AS CO) } \\
(01035)\end{array}$ & $\begin{array}{l}\text { COPPER, } \\
\text { DIS- } \\
\text { SOLVED } \\
(\mu \mathrm{G} / \mathrm{L} \\
\text { AS CU) } \\
(01040)\end{array}$ & $\begin{array}{c}\text { IRON, } \\
\text { DIS- } \\
\text { SOLVED } \\
(\mu \mathrm{G} / \mathrm{L} \\
\text { AS FE) } \\
(01046)\end{array}$ \\
\hline CT 1981 & & & & & & & & & & \\
\hline $\begin{array}{c}27 \ldots \\
\text { ост } 1982\end{array}$ & 0.230 & 0.71 & 1 & - & - & 3.0 & $<1$ & $<1$ & 4 & 330 \\
\hline $\begin{array}{c}22 \ldots \\
\text { OCT } 1983\end{array}$ & .070 & .21 & 1 & - & - & $<1.0$ & $<1$ & 1 & 2 & 59 \\
\hline $\begin{array}{c}26 \ldots \\
\text { OCT } 1984\end{array}$ & - & - & 1 & - & - & $<1.0$ & $<1$ & - & 4 & 66 \\
\hline $\begin{array}{c}11 \ldots \\
\text { OCT } 1985\end{array}$ & .360 & 1.1 & $<1$ & - & - & $<1.0$ & $<1$ & - & $<1$ & 55 \\
\hline $\begin{array}{c}16 \ldots \\
\text { OCT } 1986\end{array}$ & .390 & 1.2 & $<1$ & - & - & $<1.0$ & $<1$ & - & 2 & 35 \\
\hline $\begin{array}{c}16 \ldots \\
\text { NOV } 1987\end{array}$ & .270 & .83 & $<1$ & - & - & 1.0 & $<1$ & - & 3 & 75 \\
\hline $\begin{array}{c}05 \ldots \\
\text { NOV } 1988\end{array}$ & .220 & .67 & $<1$ & - & - & $<1.0$ & $<1$ & - & 2 & 78 \\
\hline $\begin{array}{c}03 \ldots \\
\text { OCT } 1989\end{array}$ & .160 & .49 & $<1$ & 46 & $<0.5$ & $<1.0$ & $<5$ & $<3$ & $<10$ & 130 \\
\hline $\begin{array}{c}26 \ldots \\
\text { OCT } 1990\end{array}$ & .140 & .43 & $<1$ & 50 & $<.5$ & $<1.0$ & $<5$ & $<3$ & $<10$ & 97 \\
\hline $\begin{array}{c}25 \ldots \\
\text { OCT } 1991\end{array}$ & .210 & .64 & $<1$ & 47 & $<.5$ & $<1.0$ & $<5$ & $<3$ & $<10$ & 63 \\
\hline $\begin{array}{c}22 \ldots \\
\text { OCT } 1992\end{array}$ & .230 & .71 & $<1$ & 47 & $<.5$ & $<1.0$ & $<5$ & $<3$ & $<10$ & 87 \\
\hline $\begin{array}{c}22 \ldots \\
\text { OCT } 1993\end{array}$ & .200 & .61 & - & 53 & $<.5$ & $<1.0$ & $<5$ & $<3$ & $<10$ & 83 \\
\hline $\begin{array}{c}26 \ldots \\
\text { OCT } 1994\end{array}$ & .330 & 1.0 & - & - & - & - & - & - & - & - \\
\hline $21 \ldots$ & .140 & .43 & - & - & - & - & - & - & - & - \\
\hline
\end{tabular}


Table 3. Water-quality data from surface-water sites-Continued

01476835 - East Branch Chester Creek at Westtown, Pa. (Site 24)—Continued

\begin{tabular}{|c|c|c|c|c|c|c|c|c|c|c|}
\hline DATE & $\begin{array}{c}\text { LEAD, } \\
\text { DIS- } \\
\text { SOLVED } \\
(\mu \mathrm{G} / \mathrm{L} \\
\text { AS PB) } \\
(01049)\end{array}$ & $\begin{array}{c}\text { LITHIUM, } \\
\text { DIS- } \\
\text { SOLVED } \\
(\mu \mathrm{G} / \mathrm{L} \\
\text { AS LI) } \\
(01130)\end{array}$ & $\begin{array}{l}\text { MANGA- } \\
\text { NESE, } \\
\text { DIS- } \\
\text { SOLVED } \\
(\mu \mathrm{G} / \mathrm{L} \\
\text { AS MN) } \\
(01056)\end{array}$ & $\begin{array}{c}\text { MERCURY, } \\
\text { DIS- } \\
\text { SOLVED } \\
(\mu \mathrm{G} / \mathrm{L} \\
\text { AS HG) } \\
(71890)\end{array}$ & $\begin{array}{l}\text { NICKEL, } \\
\text { DIS- } \\
\text { SOLVED } \\
(\mu G / L \\
\text { AS NI) } \\
(01065)\end{array}$ & $\begin{array}{c}\text { SILVER, } \\
\text { DIS- } \\
\text { SOLVED } \\
(\mu \mathrm{G} / \mathrm{L} \\
\text { AS AG) } \\
(01075)\end{array}$ & $\begin{array}{c}\text { STRON- } \\
\text { TIUM, } \\
\text { DIS- } \\
\text { SOLVED } \\
(\mu \mathrm{G} / \mathrm{L} \\
\text { AS SR) } \\
(01080)\end{array}$ & $\begin{array}{c}\text { VANA- } \\
\text { DIUM, } \\
\text { DIS- } \\
\text { SOLVED } \\
(\mu \mathrm{G} / \mathrm{L} \\
\text { AS V) } \\
(01085)\end{array}$ & $\begin{array}{r}\text { ZINC, } \\
\text { DIS- } \\
\text { SOLVED } \\
(\mu \mathrm{G} / \mathrm{L} \\
\mathrm{AS} \quad \mathrm{ZN}) \\
(01090)\end{array}$ & $\begin{array}{c}\text { METHY- } \\
\text { LENE } \\
\text { BLUE } \\
\text { ACTIVE } \\
\text { SUB- } \\
\text { STANCE } \\
\text { (MG/L) } \\
(38260)\end{array}$ \\
\hline OCT 1981 & & & & & & & & & & \\
\hline $\begin{array}{c}27 \ldots \\
\text { OCT } 1982\end{array}$ & $<1$ & - & 56 & 0.2 & 2 & - & - & - & $<4$ & ND \\
\hline $\begin{array}{c}22 \ldots \\
\text { OCT } 1983\end{array}$ & $<1$ & - & 100 & .4 & 3 & - & - & - & $<4$ & 0.04 \\
\hline $\begin{array}{c}26 \ldots \\
\text { OCT } 1984\end{array}$ & 2 & - & 69 & .1 & 2 & $<1.0$ & - & - & 6 & - \\
\hline $\begin{array}{c}11 \ldots \\
\text { OCT } 1985\end{array}$ & 2 & - & 29 & $<.1$ & 3 & $<1.0$ & - & - & $<3$ & - \\
\hline $\begin{array}{c}16 \ldots \\
\text { OCT } 1986\end{array}$ & $<1$ & - & 33 & $<.1$ & $<1$ & $<1.0$ & - & - & 15 & - \\
\hline $\begin{array}{c}16 \ldots \\
\text { NOV } 1987\end{array}$ & $<5$ & - & 54 & $<1.0$ & 2 & $<1.0$ & - & - & $<3$ & - \\
\hline $\begin{array}{c}05 \ldots \\
\text { NOV } 1988\end{array}$ & $<5$ & - & 41 & $<.1$ & $<1$ & $<1.0$ & - & - & 4 & - \\
\hline $\begin{array}{c}03 \ldots \\
\text { OCT } 1989\end{array}$ & $<10$ & 6 & 39 & .6 & $<10$ & $<1.0$ & 120 & $<6$ & 5 & - \\
\hline $\begin{array}{c}26 \ldots \\
\text { OCT } 1990\end{array}$ & $<10$ & 5 & 45 & .2 & $<10$ & $<1.0$ & 120 & $<6$ & 14 & - \\
\hline $\begin{array}{c}25 \ldots \\
\text { OCT } 1991\end{array}$ & $<10$ & 6 & 39 & $<.1$ & $<10$ & $<1.0$ & 130 & $<6$ & 5 & - \\
\hline $\begin{array}{c}22 \ldots \\
\text { OCT } 1992\end{array}$ & $<10$ & 7 & 46 & $<.1$ & $<10$ & $<1.0$ & 130 & $<6$ & 9 & - \\
\hline $\begin{array}{c}22 \ldots \\
\text { OCT } 1993\end{array}$ & $<10$ & $<4$ & 47 & $<.1$ & $<10$ & $<1.0$ & 150 & $<6$ & 8 & - \\
\hline $\begin{array}{c}26 \ldots \\
\text { OCT } 1994\end{array}$ & - & - & - & - & - & - & - & - & - & - \\
\hline $21 \ldots$ & - & - & - & - & - & - & - & - & - & - \\
\hline
\end{tabular}


Table 3. Water-quality data from surface-water sites-Continued

01476840 - Goose Creek Tributary to East Branch Chester Creek near West Chester, Pa. (Site 25)

\begin{tabular}{|c|c|c|c|c|c|c|c|c|c|c|}
\hline & DIS- & & $\mathrm{PH}$ & & & & & HARD- & & \\
\hline & HARGE， & SPE- & WATER & & & & HARD- & NESS, & & MAGNE- \\
\hline & INST. & CIFIC & WHOLE & & & & NESS, & NONCARB & CALCIUM, & SIUM, \\
\hline & (CUBIC & $\mathrm{CON}-$ & FIELD & TEMPER- & TUR- & OXYGEN, & TOTAL & WH WAT & DIS- & DIS- \\
\hline & FEET & $\begin{array}{l}\text { DUCT- } \\
\text { ANCE }\end{array}$ & $\begin{array}{c}\text { (STAND- } \\
\text { ARD }\end{array}$ & ATURE & BID- & $\begin{array}{l}\text { DIS- } \\
\text { SOLVED }\end{array}$ & (MG / L & TOT FLD & SOLVED & $\begin{array}{l}\text { SOLVED } \\
\text { (MG/L }\end{array}$ \\
\hline & SECOND) & $\begin{array}{l}\text { ANCE } \\
(\mu \mathrm{S} / \mathrm{CM})\end{array}$ & $\begin{array}{l}\text { ARD } \\
\text { UNITS) }\end{array}$ & $\begin{array}{l}\text { WATER } \\
(\text { DEG C) }\end{array}$ & $\begin{array}{l}\text { ITY } \\
\text { (NTU) }\end{array}$ & $\begin{array}{l}\text { SOLVED } \\
(M G / L)\end{array}$ & $\begin{array}{c}\mathrm{AS} \\
\left.\mathrm{CACO}_{3}\right)\end{array}$ & $\begin{array}{l}(\mathrm{MG} / \mathrm{L} \mathrm{AS} \\
\left.\mathrm{CACO}_{3}\right)\end{array}$ & AS CA) & AS MG) \\
\hline & $(00061)$ & $(00095)$ & $(00400)$ & $(00010)$ & $(00076)$ & $(00300)$ & $(00900)$ & $(00902)$ & $(00915)$ & $(00925)$ \\
\hline
\end{tabular}

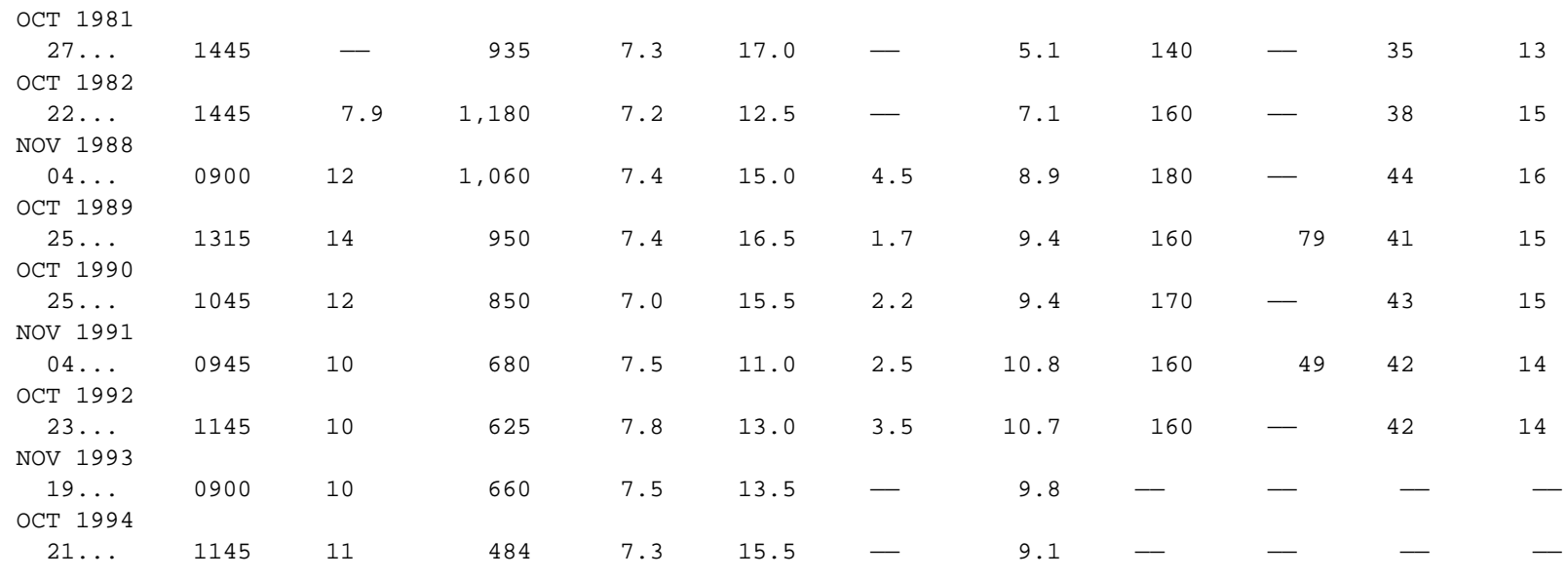

\begin{tabular}{|c|c|c|c|c|c|c|c|c|c|c|}
\hline DATE & $\begin{array}{l}\text { SODIUM, } \\
\text { DIS- } \\
\text { SOLVED } \\
\text { (MG / L } \\
\text { AS NA) } \\
(00930)\end{array}$ & $\begin{array}{r}\text { SODIUM } \\
\text { PERCENT } \\
\text { (00932) }\end{array}$ & $\begin{array}{l}\text { SODIUM } \\
\text { AD- } \\
\text { SORP- } \\
\text { TION } \\
\text { RATIO } \\
\text { (00931) }\end{array}$ & $\begin{array}{c}\text { POTAS- } \\
\text { SIUM, } \\
\text { DIS- } \\
\text { SOLVED } \\
(\text { MG /L } \\
\text { AS K) } \\
(00935)\end{array}$ & $\begin{array}{l}\text { ALKA- } \\
\text { LINITY } \\
\text { WAT WH } \\
\text { TOT FET } \\
\text { FIELD } \\
(\mathrm{MG} / \mathrm{L} \text { AS } \\
\left.\mathrm{CACO}_{3}\right) \\
(00410)\end{array}$ & $\begin{array}{l}\text { ALKA- } \\
\text { LINITY } \\
\text { WAT WH } \\
\text { TOT IT } \\
\text { FIELD } \\
(\mathrm{MG} / \mathrm{L} \text { AS } \\
\left.\mathrm{CACO}_{3}\right) \\
(00419)\end{array}$ & $\begin{array}{l}\text { SULFATE, } \\
\text { DIS- } \\
\text { SOLVED } \\
(\mathrm{MG} / \mathrm{L} \\
\left.\mathrm{AS} \mathrm{SO})_{4}\right) \\
(00945)\end{array}$ & $\begin{array}{l}\text { CHLO- } \\
\text { RIDE, } \\
\text { DIS- } \\
\text { SOLVED } \\
(\text { MG/L } \\
\text { AS CL) } \\
(00940)\end{array}$ & $\begin{array}{c}\text { FLUO- } \\
\text { RIDE, } \\
\text { DIS- } \\
\text { SOLVED } \\
(\mathrm{MG} / \mathrm{L} \\
\text { AS F) } \\
(00950)\end{array}$ & $\begin{array}{l}\text { SILICA, } \\
\text { DIS- } \\
\text { SOLVED } \\
(\mathrm{MG} / \mathrm{L} \\
\mathrm{AS} \\
\left.\mathrm{SIO}_{2}\right) \\
(00955)\end{array}$ \\
\hline $\begin{array}{c}\text { СТ } 1981 \\
27 \ldots\end{array}$ & 120 & 58 & 4 & 36 & - & - & - & 140 & 0.20 & 22 \\
\hline OCT 1982 & & & & & & & & & & \\
\hline $\begin{array}{c}22 \ldots \\
\text { NOV } 1988\end{array}$ & 110 & 53 & 4 & 43 & 130 & - & 130 & 160 & .10 & 23 \\
\hline $\begin{array}{c}04 \ldots \\
\text { OCT } 1989\end{array}$ & 130 & 56 & 4 & 39 & 106 & - & 180 & 110 & - & 21 \\
\hline $\begin{array}{c}25 \ldots \\
\text { OCT } 1990\end{array}$ & 85 & 43 & 3 & 64 & 85 & - & 160 & 84 & - & 21 \\
\hline $\begin{array}{c}25 \ldots \\
\text { NOV } 1991\end{array}$ & 80 & 44 & 3 & 41 & 73 & - & 120 & 86 & .30 & 20 \\
\hline $\begin{array}{c}04 \ldots \\
\text { OCT } 1992\end{array}$ & 63 & 44 & 2 & 9.6 & 114 & - & 50 & 94 & .40 & 17 \\
\hline $\begin{array}{c}23 \ldots \\
\text { NOV } 1993\end{array}$ & 45 & 36 & 2 & 9.4 & - & 82 & 41 & 82 & .50 & 17 \\
\hline $\begin{array}{c}19 \ldots \\
\text { OCT } 1994\end{array}$ & - & - & - & - & - & 73 & 47 & 83 & .40 & - \\
\hline $21 \ldots$ & - & - & - & - & - & 67 & - & 96 & - & - \\
\hline
\end{tabular}


Table 3. Water-quality data from surface-water sites—Continued

01476840 - Goose Creek Tributary to East Branch Chester Creek near West Chester, Pa. (Site 25)—Continued

\begin{tabular}{|c|c|c|c|c|c|c|c|c|c|c|}
\hline DATE & $\begin{array}{l}\text { SOLIDS, } \\
\text { RESIDUE } \\
\text { AT } 180 \\
\text { DEG. C } \\
\text { DIS- } \\
\text { SOLVED } \\
(\mathrm{MG} / \mathrm{L}) \\
(70300)\end{array}$ & $\begin{array}{l}\text { SOLIDS, } \\
\text { SUM OF } \\
\text { CONSTI- } \\
\text { TUENTS, } \\
\text { DIS- } \\
\text { SOLVED } \\
(\mathrm{MG} / \mathrm{L}) \\
(70301)\end{array}$ & $\begin{array}{c}\text { SOLIDS, } \\
\text { DIS- } \\
\text { SOLVED } \\
\text { (TONS } \\
\text { PER } \\
\text { AC-FT) } \\
(70303)\end{array}$ & $\begin{array}{c}\text { SOLIDS, } \\
\text { DIS- } \\
\text { SOLVED } \\
\text { (TONS } \\
\text { PER } \\
\text { DAY) } \\
\text { (70302) }\end{array}$ & $\begin{array}{c}\text { NITRO- } \\
\text { GEN, } \\
\text { NITRATE } \\
\text { TOTAL } \\
\text { (MG/L } \\
\text { AS N) } \\
(00620)\end{array}$ & $\begin{array}{l}\text { NITRO- } \\
\text { GEN, } \\
\text { NITRATE } \\
\text { DIS- } \\
\text { SOLVED } \\
\text { (MG/L } \\
\text { AS N) } \\
(00618)\end{array}$ & $\begin{array}{c}\text { NITRO- } \\
\text { GEN, } \\
\text { NITRATE } \\
\text { DIS- } \\
\text { SOLVED } \\
(\mathrm{MG} / \mathrm{L} \\
\left.\mathrm{AS} \mathrm{NO})_{3}\right) \\
(71851)\end{array}$ & $\begin{array}{l}\text { NITRO- } \\
\text { GEN, } \\
\text { NITRITE } \\
\text { DIS- } \\
\text { SOLVED } \\
(\text { MG/L } \\
\text { AS N) } \\
(00613)\end{array}$ & $\begin{array}{c}\text { NITRO- } \\
\text { GEN, } \\
\mathrm{NO}_{2}+\mathrm{NO}_{3} \\
\text { DIS- } \\
\text { SOLVED } \\
(\mathrm{MG} / \mathrm{L} \\
\mathrm{AS} \mathrm{N}) \\
(00631)\end{array}$ & $\begin{array}{c}\text { NITRO- } \\
\text { GEN, } \\
\text { AMMONIA } \\
\text { DIS- } \\
\text { SOLVED } \\
\text { (MG/L } \\
\text { AS N) } \\
(00608)\end{array}$ \\
\hline OCT 1981 & & & & & & & & & & \\
\hline $\begin{array}{c}27 \ldots \\
\text { OCT } 1982\end{array}$ & 761 & - & 1.03 & - & 6.66 & 6.36 & 28 & 0.340 & 6.70 & 8.50 \\
\hline $\begin{array}{c}22 \ldots \\
\text { NOV } 1988\end{array}$ & 586 & 676 & .80 & 12.4 & 7.30 & 7.30 & 32 & .200 & 7.50 & 23.0 \\
\hline $\begin{array}{c}\text { O4... } \\
\text { ОСТ } 1989\end{array}$ & - & 704 & .96 & 22.2 & 19.6 & 19.6 & 87 & .360 & 2.0 & 2.00 \\
\hline $\begin{array}{c}25 \ldots \\
\text { OCT } 1990\end{array}$ & - & 609 & .83 & 23.0 & 17.7 & 17.7 & 79 & .260 & 18.0 & .280 \\
\hline $\begin{array}{c}25 \ldots \\
\text { NOV } 1991\end{array}$ & - & 539 & .73 & 17.5 & 17.9 & 17.9 & 79 & .080 & 18.0 & .250 \\
\hline $\begin{array}{c}04 \ldots \\
\text { ОСТ } 1992\end{array}$ & - & 387 & .53 & 11.0 & 5.46 & 5.46 & 24 & .040 & 5.50 & .050 \\
\hline $\begin{array}{c}23 \ldots \\
\text { NOV } 1993\end{array}$ & - & 365 & .50 & 1.2 & 13.0 & 13.0 & 57 & .040 & 13.0 & .040 \\
\hline $\begin{array}{c}19 \ldots \\
\text { OCT } 1994\end{array}$ & - & - & - & - & 17.0 & 17.0 & 75 & .040 & 17.0 & .060 \\
\hline $21 \ldots$ & - & - & - & - & 16.9 & 16.9 & 75 & .150 & 17.0 & .090 \\
\hline
\end{tabular}

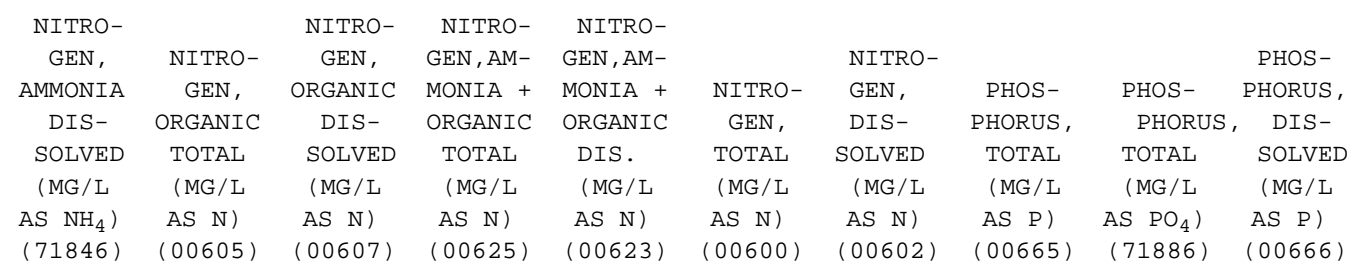

\begin{tabular}{|c|c|c|c|c|c|c|c|c|c|c|}
\hline $\begin{array}{c}\text { OCT } 1981 \\
27 \ldots\end{array}$ & 11 & 11 & 15 & 20 & 23 & 27 & 30 & 9.10 & 28 & 740 \\
\hline OCT 1982 & & & & & & & & & & \\
\hline $\begin{array}{c}22 \ldots \\
\text { NOV } 1988\end{array}$ & 30 & - & 5.0 & - & 28 & - & 36 & - & - & 5.40 \\
\hline $\begin{array}{c}04 \ldots \\
\text { OCT } 1989\end{array}$ & 2.6 & 2.2 & 2.2 & 4.2 & 4.2 & 24 & 24 & 3.70 & - & 3.40 \\
\hline $\begin{array}{c}25 \ldots \\
\text { OCT } 1990\end{array}$ & .36 & 2.1 & 1.9 & 2.4 & 2.2 & 20 & 20 & 3.60 & - & 3.30 \\
\hline $\begin{array}{c}25 \ldots \\
\text { NOV } 1991\end{array}$ & .32 & 1.8 & 1.5 & 2.1 & 1.8 & 20 & 20 & 3.50 & - & 3.20 \\
\hline $\begin{array}{c}04 \ldots \\
\text { OCT } 1992\end{array}$ & .06 & 1.0 & .85 & 1.1 & .90 & 6.6 & 6.4 & 3.10 & - & 3.00 \\
\hline $\begin{array}{c}23 \ldots \\
\text { NOV } 1993\end{array}$ & .05 & .76 & .66 & .80 & .70 & 14 & 14 & 2.60 & - & 2.40 \\
\hline $\begin{array}{c}19 \ldots \\
\text { OCT } 1994\end{array}$ & .08 & - & - & - & - & - & - & - & - & - \\
\hline $21 \ldots$ & .12 & - & - & - & - & - & - & - & - & - \\
\hline
\end{tabular}


Table 3. Water-quality data from surface-water sites-Continued

01476840 - Goose Creek Tributary to East Branch Chester Creek near West Chester, Pa. (Site 25)—Continued

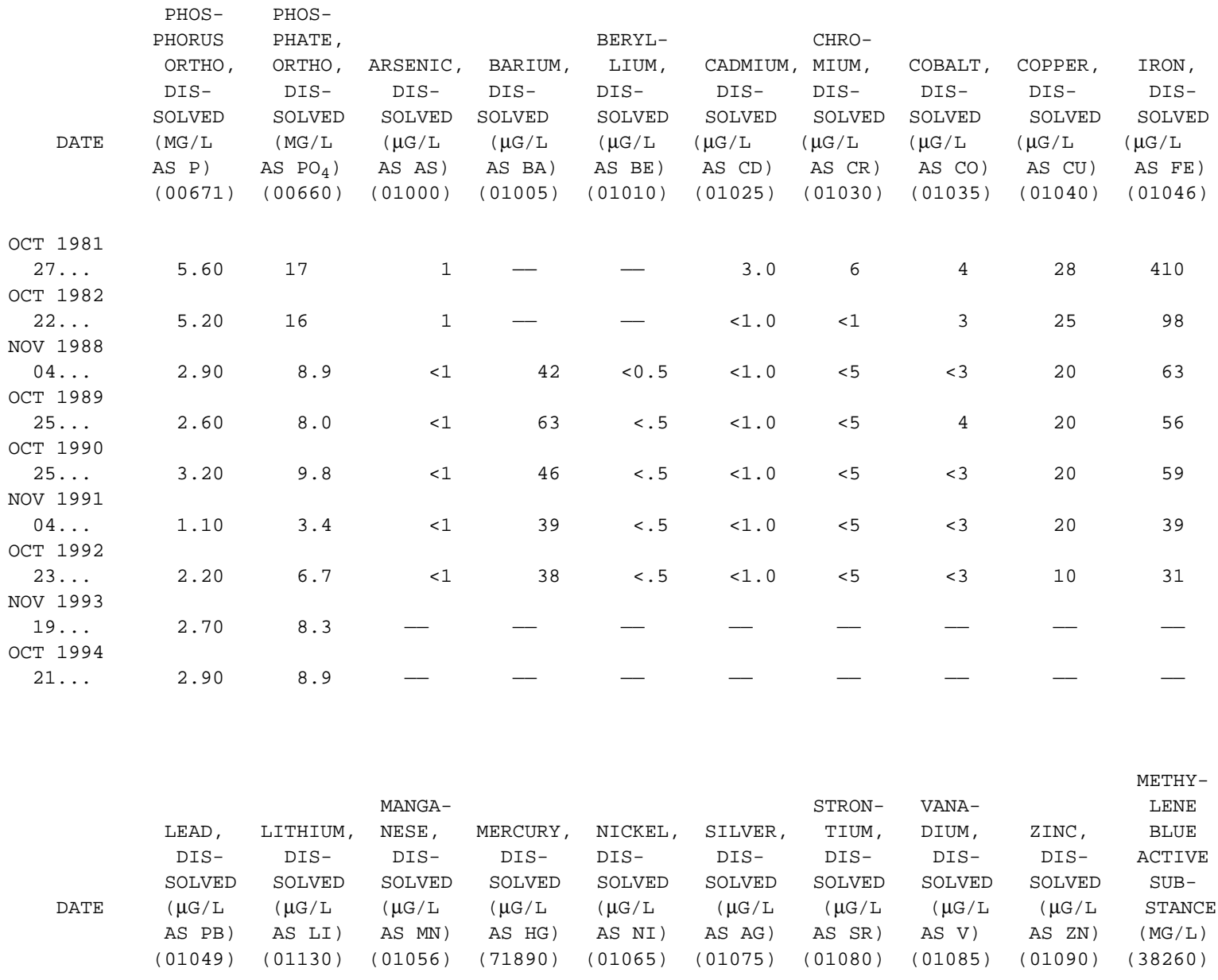

ОСт 1981

$27 \ldots$

OCT 1982

$22 \ldots$

NOV 1988

$04 \ldots$

OCT 1989

$25 \ldots$

OCT 1990

$25 \ldots$

NOV 1991

$04 \ldots$

ОСт 1992

$23 \ldots$

NOV 1993

$19 . .$.

OCT 1994

21 ...

$\begin{array}{rrrrrrrrrr}5 & - & 48,000 & 83 & 4 & - & - & - & 320 & 0.30 \\ <1 & - & 150 & - & 7 & - & - & - & 52 & .42 \\ <10 & 24 & 76 & <.1 & <10 & <1.0 & 180 & <6 & 35 & - \\ <10 & 22 & 56 & .1 & <10 & <1.0 & 180 & <6 & 50 & - \\ <10 & 38 & 51 & <.1 & <10 & <1.0 & 170 & <6 & 38 & - \\ <10 & 38 & 18 & .2 & 10 & <1.0 & 170 & <6 & 30 & - \\ <10 & 41 & 26 & <.1 & <10 & <1.0 & 170 & <6 & 38 & - \\ - & - & - & - & - & - & - & - & - & -\end{array}$


Table 3. Water-quality data from surface-water sites-Continued

01476848 - East Branch Chester Creek below Goose Creek near West Chester, Pa. (Site 51)—Continued

\begin{tabular}{|c|c|c|c|c|c|c|c|c|c|c|c|c|}
\hline \multirow{5}{*}{ DATE } & & \multirow{3}{*}{$\begin{array}{c}\text { DIS- } \\
\text { CHARGE, } \\
\text { INST. } \\
\text { (CUBIC } \\
\text { FEET }\end{array}$} & \multicolumn{3}{|c|}{$\mathrm{PH}$} & \multicolumn{7}{|c|}{ HARD- } \\
\hline & & & $\begin{array}{r}\text { SPE- } \\
\text { CIFIC }\end{array}$ & $\begin{array}{l}\text { WATER } \\
\text { WHOLE }\end{array}$ & & & & $\begin{array}{l}\text { HARD- } \\
\text { NESS }\end{array}$ & $\begin{array}{c}\text { NESS, } \\
\text { NONCARB }\end{array}$ & CALCIUM, & $\begin{array}{l}\text { MAGNE- } \\
\text { SIUM, }\end{array}$ & SODIUM, \\
\hline & TIME & & $\begin{array}{l}\text { CON- } \\
\text { DUCT- } \\
\text { ANCE }\end{array}$ & $\begin{array}{l}\text { FIELD } \\
\text { (STAND- } \\
\text { ARD }\end{array}$ & $\begin{array}{l}\text { TEMPER- } \\
\text { ATURE } \\
\text { WATER }\end{array}$ & $\begin{array}{l}\text { TUR- } \\
\text { BID- } \\
\text { ITY }\end{array}$ & $\begin{array}{l}\text { OXYGEN, } \\
\text { DIS- } \\
\text { SOLVED }\end{array}$ & $\begin{array}{l}\text { TOTAL } \\
\text { (MG/L } \\
\text { AS }\end{array}$ & $\begin{array}{r}\text { WH WAT } \\
\text { TOT FLD } \\
\text { (MG/L AS }\end{array}$ & $\begin{array}{c}\text { DIS- } \\
\text { SOLVED } \\
\text { (MG/L }\end{array}$ & $\begin{array}{l}\text { DIS- } \\
\text { SOLVED } \\
\text { (MG/L }\end{array}$ & $\begin{array}{l}\text { DIS- } \\
\text { SOLVED } \\
\text { (MG/L }\end{array}$ \\
\hline & & SECOND) & $(\mu \mathrm{S} / \mathrm{CM})$ & UNITS) & (DEG C) & (NTU) & $(\mathrm{MG} / \mathrm{L})$ & $\left.\mathrm{CACO}_{3}\right)$ & $\left.\mathrm{CACO}_{3}\right)$ & AS CA) & AS MG) & AS NA) \\
\hline & & $(00061)$ & $(00095)$ & $(00400)$ & $(00010)$ & $(00076)$ & $(00300)$ & $(00900)$ & $(00902)$ & (00915) & $(00925)$ & $(00930)$ \\
\hline
\end{tabular}

\begin{tabular}{|c|c|c|c|c|c|c|c|c|c|c|c|c|}
\hline $26 \ldots$ & 1445 & 18 & 560 & 5.7 & 14.0 & 4.6 & 7.9 & 130 & - & 31 & 12 & 43 \\
\hline $\begin{array}{c}\text { OCT } 1984 \\
11 \ldots\end{array}$ & 1530 & 21 & 625 & 8.0 & 18.0 & .90 & 11.4 & 120 & - & 30 & 12 & 76 \\
\hline OCT 1985 & & & & & & & & & & & & \\
\hline $\begin{array}{c}28 \ldots \\
\text { OCT } 1986\end{array}$ & 1530 & 16 & 550 & 6.5 & 12.0 & 2.4 & 7.7 & 130 & - & 32 & 13 & 53 \\
\hline $\begin{array}{c}16 \ldots \\
\text { NOV } 1987\end{array}$ & 1300 & 28 & 650 & 7.7 & 14.0 & 1.4 & 9.1 & 130 & - & 32 & 12 & 84 \\
\hline $\begin{array}{c}05 \ldots \\
\text { NOV } 1988\end{array}$ & 1300 & 18 & 620 & 7.5 & 15.0 & 1.7 & 8.2 & 140 & - & 35 & 13 & 66 \\
\hline $\begin{array}{c}03 \ldots \\
\text { OCT } 1989\end{array}$ & 1300 & 18 & 780 & 7.4 & 11.0 & 1.9 & 11.2 & 140 & - & 34 & 13 & 82 \\
\hline $\begin{array}{c}25 \ldots \\
\text { OCT } 1990\end{array}$ & 0945 & 31 & 500 & 7.4 & 11.5 & 1.2 & 1.4 & 120 & 60 & 29 & 12 & 33 \\
\hline $\begin{array}{c}25 \ldots \\
\text { OCT } 1991\end{array}$ & 0900 & 20 & 590 & 6.5 & 11.5 & 2.0 & 8.8 & 130 & 56 & 32 & 12 & 48 \\
\hline $\begin{array}{c}22 \ldots \\
\text { OCT } 1992\end{array}$ & 0900 & 12 & 465 & 7.5 & 9.5 & 1.4 & 10.3 & 130 & 55 & 32 & 12 & 35 \\
\hline $\begin{array}{c}22 \ldots \\
\text { OCT } 1993\end{array}$ & 0930 & 12 & 480 & 7.6 & 9.0 & .60 & 11.3 & 120 & - & 30 & 12 & 9.4 \\
\hline $\begin{array}{c}26 \ldots \\
\text { OCT } 1994\end{array}$ & 0945 & 20 & 448 & 7.4 & 12.0 & - & 9.5 & - & - & - & - & - \\
\hline $17 \ldots$ & 0945 & 12 & 530 & 7.3 & 9.5 & - & 10.5 & - & - & - & - & - \\
\hline
\end{tabular}


Table 3. Water-quality data from surface-water sites-Continued

01476848 - East Branch Chester Creek below Goose Creek near West Chester, Pa. (Site 51)

\begin{tabular}{|c|c|c|c|c|c|c|c|c|c|c|c|c|}
\hline DATE & $\begin{array}{l}\text { S } \\
\text { SODIUM } \\
\text { PERCENT } \\
(00932)\end{array}$ & $\begin{array}{l}\text { SODIUM } \\
\text { AD- } \\
\text { SORP- } \\
\text { TION } \\
\text { RATIO } \\
(00931)\end{array}$ & $\begin{array}{l}\text { POTAS- } \\
\text { SIUM, } \\
\text { DIS- } \\
\text { SOLVED } \\
\text { (MG/L } \\
\text { AS K) } \\
(00935)\end{array}$ & $\begin{array}{c}\text { ALKA- } \\
\text { LINITY } \\
\text { WAT WH } \\
\text { TOT FET } \\
\text { FIELD } \\
(\mathrm{MG} / \mathrm{L} \text { AS } \\
\left.\mathrm{CACO}_{3}\right) \\
(00410)\end{array}$ & $\begin{array}{l}\text { ALKA- } \\
\text { LINITY } \\
\text { WAT WH } \\
\text { TOT IT } \\
\text { FIELD } \\
(\mathrm{MG} / \mathrm{L} \text { AS } \\
\left.\mathrm{CACO}_{3}\right) \\
(00419)\end{array}$ & 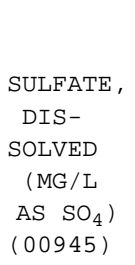 & $\begin{array}{c}\text { CHLO- } \\
\text { RIDE, } \\
\text { DIS- } \\
\text { SOLVED } \\
(M G / L \\
\text { AS CL) } \\
(00940)\end{array}$ & $\begin{array}{c}\text { FLUO- } \\
\text { RIDE, } \\
\text { DIS- } \\
\text { SOLVED } \\
(\mathrm{MG} / \mathrm{L} \\
\text { AS F) } \\
(00950)\end{array}$ & $\begin{array}{l}\text { SILICA, } \\
\text { DIS- } \\
\text { SOLVED } \\
(\mathrm{MG} / \mathrm{L} \\
\mathrm{AS} \\
\left.\mathrm{SIO}_{2}\right) \\
(00955)\end{array}$ & $\begin{array}{l}\text { SOLIDS, } \\
\text { RESIDUE } \\
\text { AT 180 } \\
\text { DEG. C } \\
\text { DIS- } \\
\text { SOLVED } \\
(\mathrm{MG} / \mathrm{L}) \\
(70300)\end{array}$ & $\begin{array}{l}\text { SOLIDS, } \\
\text { SUM OF } \\
\text { CONSTI- } \\
\text { TUENTS, } \\
\text { DIS- } \\
\text { SOLVED } \\
(\mathrm{MG} / \mathrm{L}) \\
(70301)\end{array}$ & $\begin{array}{c}\text { SOLIDS, } \\
\text { DIS- } \\
\text { SOLVED } \\
\text { (TONS } \\
\text { PER } \\
\text { AC-FT) } \\
(70303)\end{array}$ \\
\hline СТ 1983 & & & & & & & & & & & & \\
\hline $\begin{array}{c}26 \ldots \\
\text { OCT } 1984\end{array}$ & 39 & 2 & 15 & 26 & - & 58 & 66 & - & 18 & 352 & 366 & 0.48 \\
\hline $\begin{array}{c}11 \ldots \\
\text { OCT } 1985\end{array}$ & 55 & 3 & 9.0 & 106 & - & 75 & 74 & - & 19 & 392 & 393 & .53 \\
\hline $\begin{array}{c}28 \ldots \\
\text { OCT } 1986\end{array}$ & 45 & 2 & 7.2 & 90 & - & 79 & 59 & - & 19 & 326 & 348 & .44 \\
\hline $\begin{array}{c}16 \ldots \\
\text { NOV } 1987\end{array}$ & 57 & 3 & 8.9 & 114 & - & 120 & 62 & - & 18 & 540 & 444 & .73 \\
\hline $\begin{array}{c}05 \ldots \\
\text { NOV } 1988\end{array}$ & 45 & 2 & 26 & 114 & - & 99 & 61 & - & 17 & 407 & 417 & .55 \\
\hline $\begin{array}{c}03 \ldots \\
\text { OCT } 1989\end{array}$ & 51 & 3 & 27 & 90 & - & 140 & 69 & - & 17 & - & 495 & .67 \\
\hline $\begin{array}{c}25 \ldots \\
\text { OCT } 1990\end{array}$ & 33 & 1 & 21 & 62 & - & 60 & 42 & - & 18 & - & 287 & .39 \\
\hline $\begin{array}{c}25 \ldots \\
\text { OCT } 1991\end{array}$ & 39 & 2 & 25 & 74 & - & 85 & 52 & 0.30 & 17 & - & 357 & .49 \\
\hline $\begin{array}{cc}22 \ldots \\
\text { OCT } 1992\end{array}$ & 36 & 1 & 6.4 & 75 & - & 36 & 52 & .20 & 17 & - & 279 & .38 \\
\hline $\begin{array}{c}22 \ldots \\
\text { OCT } 1993\end{array}$ & 14 & .4 & 3.9 & - & 62 & 36 & 21 & .10 & 15 & - & 210 & .29 \\
\hline $\begin{array}{c}26 \ldots \\
\text { OCT } 1994\end{array}$ & - & - & - & - & 70 & - & - & - & - & - & - & - \\
\hline $17 \ldots$ & - & - & - & - & 76 & - & 67 & - & - & - & - & - \\
\hline
\end{tabular}


Table 3. Water-quality data from surface-water sites-Continued

01476848 - East Branch Chester Creek below Goose Creek near West Chester, Pa. (Site 51)—Continued

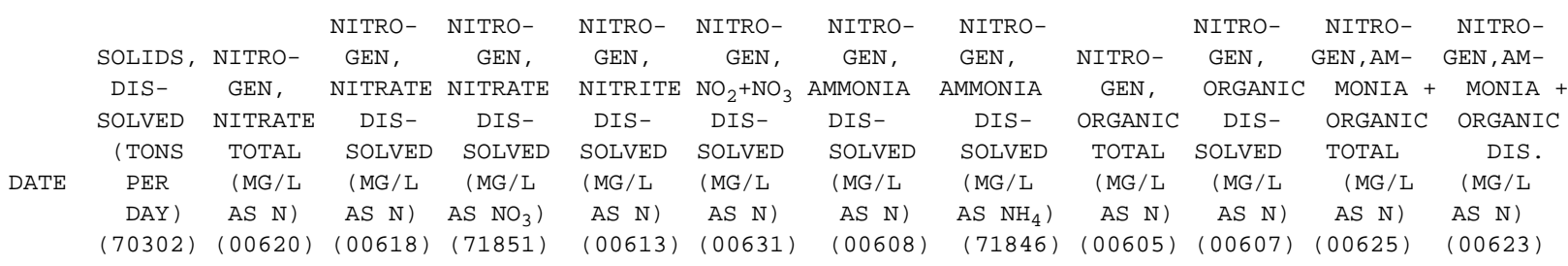

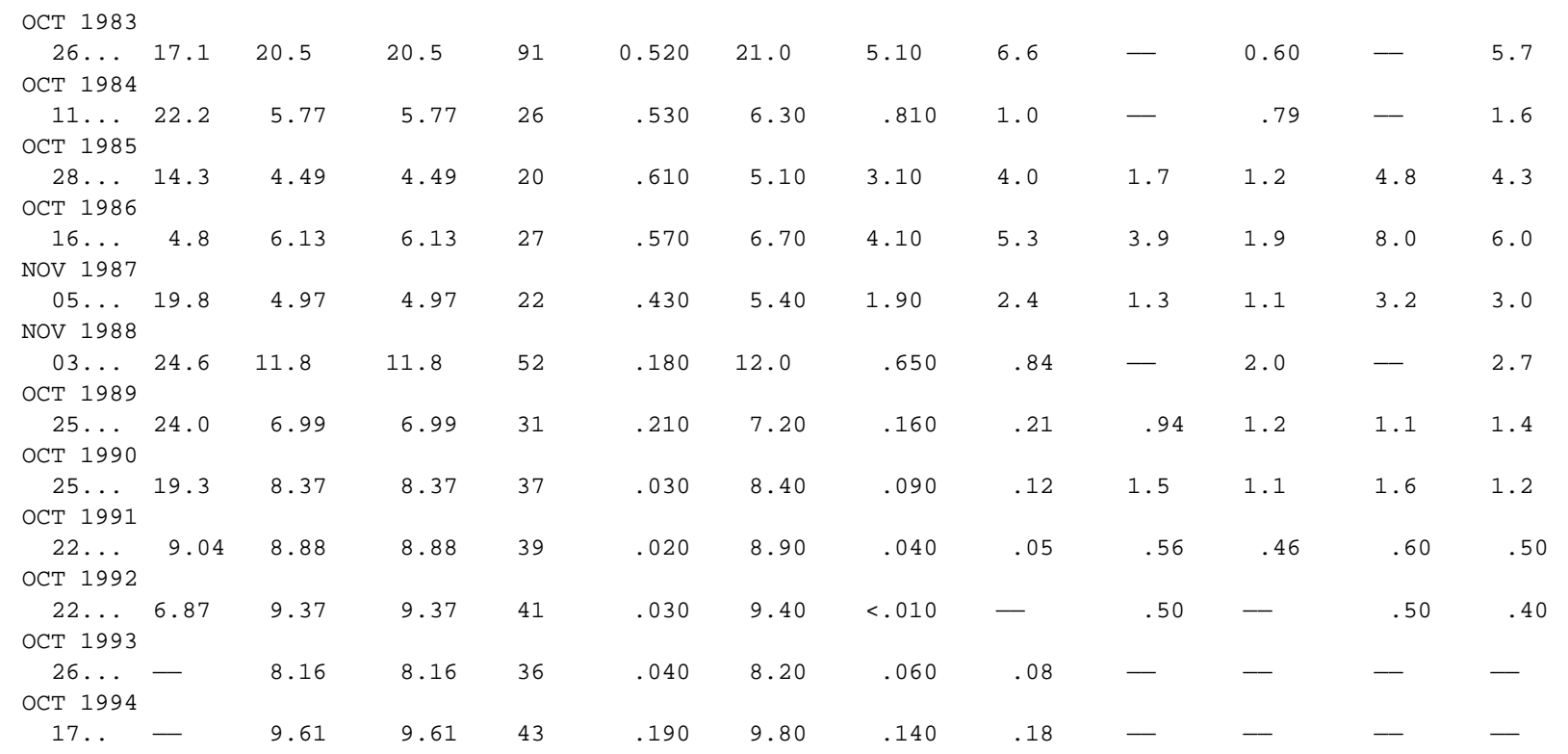


Table 3. Water-quality data from surface-water sites-Continued

01476848 - East Branch Chester Creek below Goose Creek near West Chester, Pa. (Site 51)—Continued

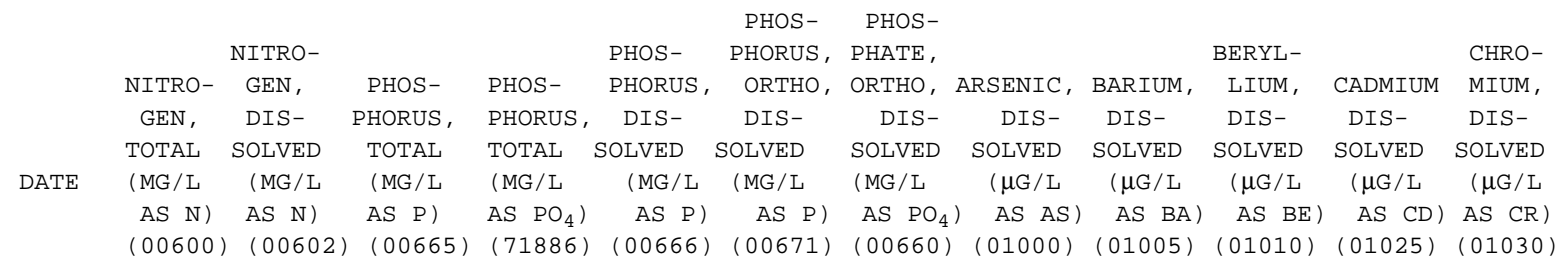

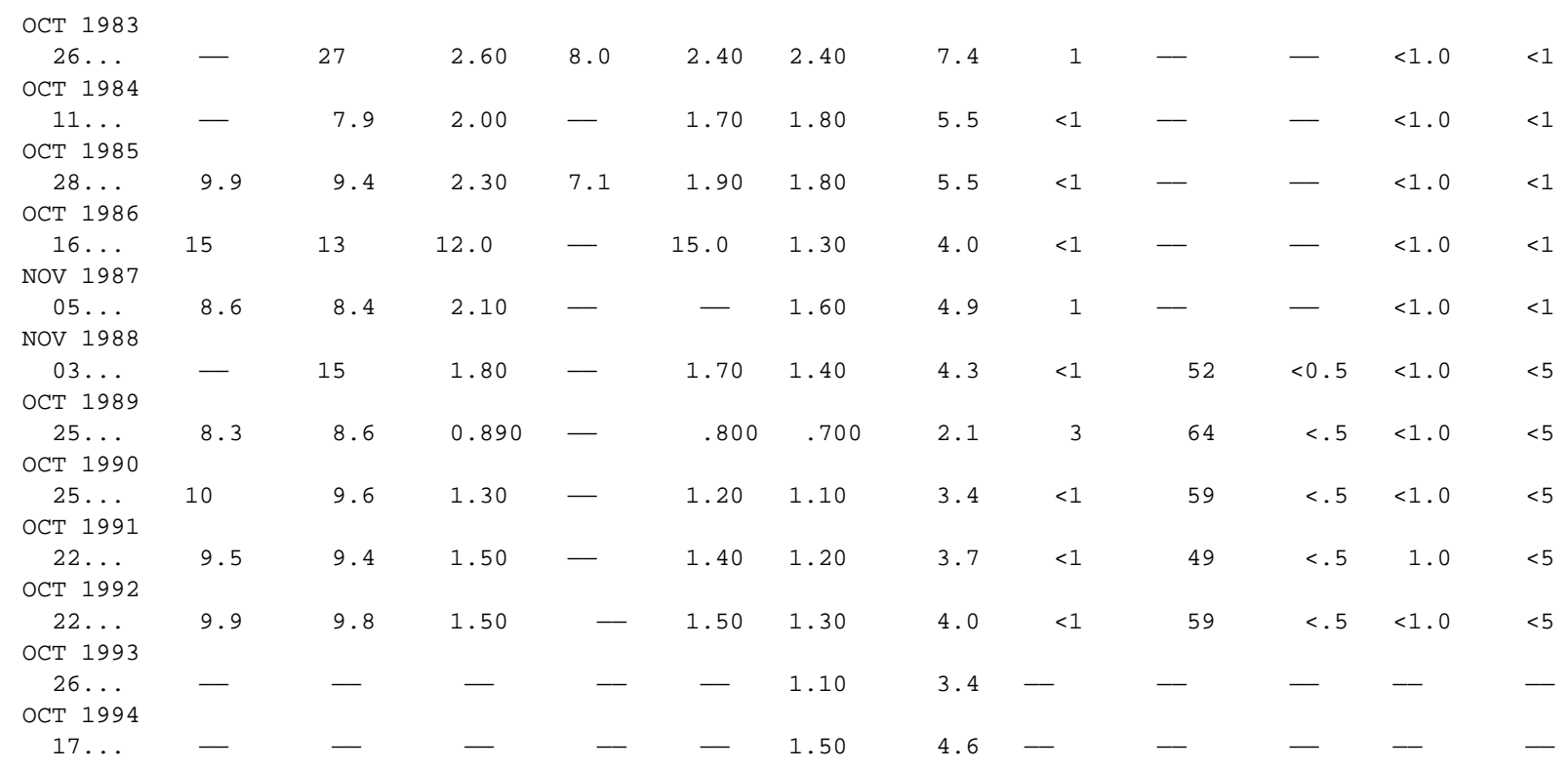


Table 3. Water-quality data from surface-water sites-Continued

01476848 - East Branch Chester Creek below Goose Creek near West Chester, Pa. (Site 51)—Continued

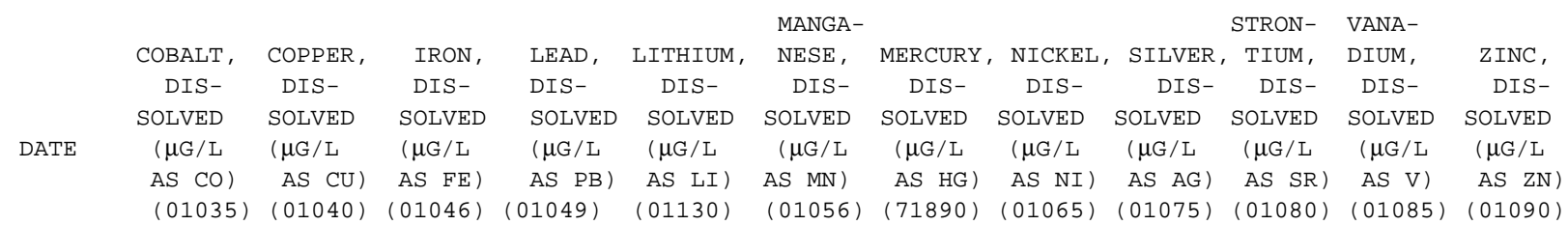


Table 3. Water-quality data from surface-water sites-Continued

01478120 - East Branch White Clay Creek at Avondale, Pa. (Site 28)

\begin{tabular}{|c|c|c|c|c|c|c|c|c|c|c|c|}
\hline & & DIS- & & $\mathrm{PH}$ & & & & & HARD- & & \\
\hline & & CHARGE, & SPE- & WATER & & & & HARD- & NESS, & & MAGNE- \\
\hline & & INST. & CIFIC & WHOLE & & & & NESS, & NONCARB & CALCIUM, & SIUM, \\
\hline & & (CUBIC & $\mathrm{CON}-$ & FIELD & TEMPER- & TUR- & OXYGEN, & TOTAL & WH WAT & DIS- & DIS- \\
\hline & & FEET & DUCT- & (STAND- & ATURE & BID- & DIS- & (MG / L & TOT FLD & SOLVED & SOLVED \\
\hline DATE & TIME & PER & ANCE & ARD & WATER & ITY & SOLVED & AS & (MG/L AS & (MG /L & (MG/I \\
\hline & & SECOND) & $(\mu \mathrm{S} / \mathrm{CM})$ & UNITS) & (DEG C) & (NTU) & (MG/L) & $\left.\mathrm{CACO}_{3}\right)$ & $\left.\mathrm{CACO}_{3}\right)$ & AS CA) & AS MG) \\
\hline & & $(00061)$ & $(00095)$ & $(00400)$ & $(00010)$ & $(00076)$ & $(00300)$ & $(00900)$ & $(00902)$ & $(00915)$ & $(00925)$ \\
\hline
\end{tabular}

\begin{tabular}{|c|c|c|c|c|c|c|c|c|c|c|c|}
\hline $\begin{array}{c}\text { OCT } 1981 \\
30 \ldots \\
\text { OCT } 1982\end{array}$ & 1345 & - & 294 & 8.3 & 10.5 & - & 12.0 & 140 & - & 32 & 14 \\
\hline $20 \ldots$ & 1345 & 4.6 & 314 & 8.2 & 11.0 & - & 12.4 & 150 & - & 35 & 15 \\
\hline NOV 1983 & & & & & & & & & & & \\
\hline $\begin{array}{c}01 \ldots \\
\text { OCT } 1984\end{array}$ & 1330 & 6.3 & 303 & 8.1 & 8.5 & 1.2 & 12.5 & 140 & - & 34 & 14 \\
\hline $\begin{array}{c}19 \ldots \\
\text { OCT } 1985\end{array}$ & 1430 & 9.9 & 298 & 8.3 & 14.5 & .70 & 11.9 & 130 & - & 32 & 13 \\
\hline $\begin{array}{c}25 \ldots \\
\text { OCT } 1986\end{array}$ & 1330 & 7.9 & 305 & 7.8 & 11.5 & 1.0 & 12.3 & 130 & - & 31 & 12 \\
\hline $\begin{array}{c}30 \ldots \\
\text { NOV } 1987\end{array}$ & 1430 & 5.6 & 315 & 8.2 & 13.0 & .40 & 11.8 & 150 & - & 35 & 15 \\
\hline $\begin{array}{c}17 \ldots \\
\text { NOV } 1988\end{array}$ & 0830 & 7.7 & 308 & 8.0 & 9.5 & .30 & 12.4 & 150 & - & 35 & 15 \\
\hline $\begin{array}{c}08 \ldots \\
\text { OCT } 1989\end{array}$ & 1500 & 6.6 & 335 & 7.7 & 9.5 & 1.5 & 12.5 & 150 & - & 35 & 15 \\
\hline $\begin{array}{c}31 \ldots \\
\text { NOV } 1990\end{array}$ & 1545 & 15 & 319 & 8.0 & 16.0 & .60 & 10.5 & 140 & 57 & 33 & 14 \\
\hline $\begin{array}{c}01 \ldots \\
\text { NOV } 1991\end{array}$ & 0845 & 7.0 & 336 & 6.5 & 9.5 & .70 & 12.4 & 150 & 50 & 36 & 15 \\
\hline $\begin{array}{c}14 \ldots \\
\text { NOV } 1992\end{array}$ & 0900 & 5.1 & 330 & 7.6 & 6.5 & 1.0 & 12.2 & 150 & 53 & 35 & 15 \\
\hline $\begin{array}{c}16 \ldots \\
\text { NOV } 1993\end{array}$ & 0930 & 7.5 & 355 & 7.9 & 4.0 & .80 & 13.5 & 150 & - & 34 & 15 \\
\hline $\begin{array}{c}24 \ldots \\
\text { NOV } 1994\end{array}$ & 0900 & 6.8 & 337 & 7.6 & 5.5 & - & 12.2 & - & - & - & - \\
\hline $03 \ldots$ & 0840 & 4.6 & 345 & 7.7 & 8.0 & - & 10.8 & 一 & - & - & - \\
\hline
\end{tabular}


Table 3. Water-quality data from surface-water sites-Continued

01478120 - East Branch White Clay Creek at Avondale, Pa. (Site 28)—Continued

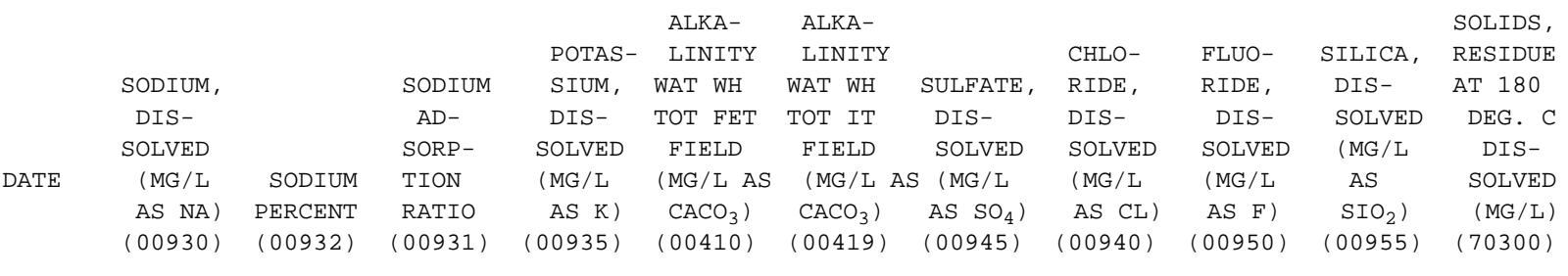

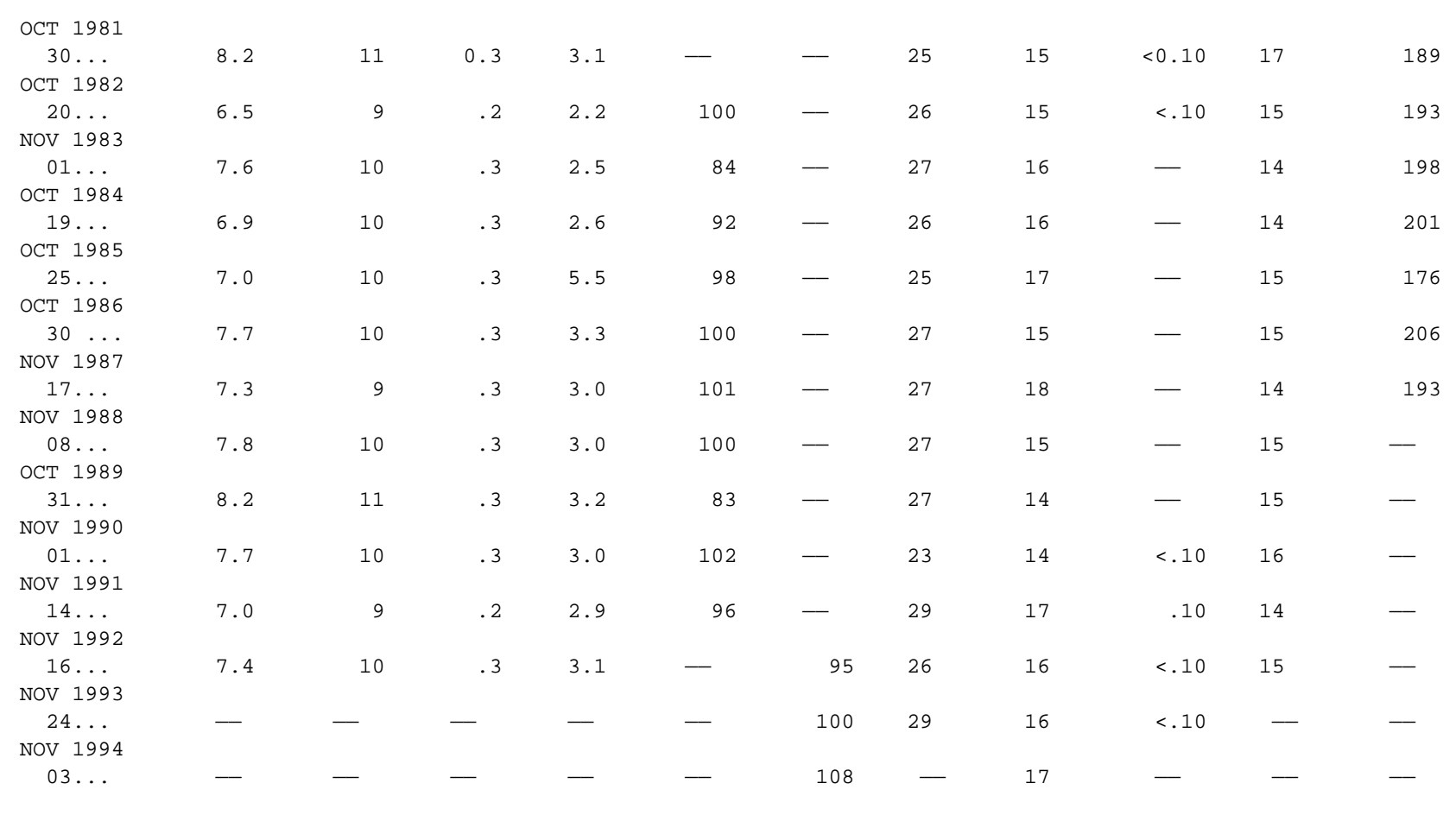


Table 3. Water-quality data from surface-water sites-Continued

01478120 - East Branch White Clay Creek at Avondale, Pa. (Site 28)—Continued

\begin{tabular}{|c|c|c|c|c|c|c|c|c|c|c|c|}
\hline DATE & $\begin{array}{l}\text { SOLIDS, } \\
\text { SUM OF } \\
\text { CONSTI- } \\
\text { TUENTS, } \\
\text { DIS- } \\
\text { SOLVED } \\
(\mathrm{MG} / \mathrm{L}) \\
(70301)\end{array}$ & $\begin{array}{c}\text { SOLIDS, } \\
\text { DIS- } \\
\text { SOLVED } \\
\text { (TONS } \\
\text { PER } \\
\text { AC-FT) } \\
(70303)\end{array}$ & $\begin{array}{c}\text { SOLIDS, } \\
\text { DIS- } \\
\text { SOLVED } \\
\text { (TONS } \\
\text { PER } \\
\text { DAY) } \\
(70302)\end{array}$ & $\begin{array}{l}\text { NITRO- } \\
\text { GEN, } \\
\text { NITRATE } \\
\text { TOTAL } \\
\text { (MG/L } \\
\text { AS N) } \\
(00620)\end{array}$ & $\begin{array}{c}\text { NITRO- } \\
\text { GEN, } \\
\text { NITRATE } \\
\text { DIS- } \\
\text { SOLVED } \\
\text { (MG/L } \\
\text { AS N) } \\
(00618)\end{array}$ & $\begin{array}{c}\text { NITRO- } \\
\text { GEN, } \\
\text { NITRATE } \\
\text { DIS- } \\
\text { SOLVED } \\
\text { (MG/L } \\
\text { AS NO3) } \\
\text { (71851) }\end{array}$ & $\begin{array}{l}\text { NITRO- } \\
\text { GEN, } \\
\text { NITRITE } \\
\text { DIS- } \\
\text { SOLVED } \\
\text { (MG/L } \\
\text { AS N) } \\
(00613)\end{array}$ & $\begin{array}{c}\text { NITRO- } \\
\text { GEN, } \\
\mathrm{NO}_{2}+\mathrm{NO}_{3} \\
\text { DIS- } \\
\text { SOLVED } \\
(\mathrm{MG} / \mathrm{L} \\
\mathrm{AS} \mathrm{N}) \\
(00631)\end{array}$ & $\begin{array}{c}\text { NITRO- } \\
\text { GEN, } \\
\text { AMMONIA } \\
\text { DIS- } \\
\text { SOLVED } \\
(\text { MG/L } \\
\text { AS N) } \\
(00608)\end{array}$ & $\begin{array}{c}\text { NITRO- } \\
\text { GEN, } \\
\text { AMMONIA } \\
\text { DIS- } \\
\text { SOLVED } \\
(\mathrm{MG} / \mathrm{L} \\
\left.\mathrm{AS} \mathrm{NH_{4 }}\right) \\
(71846)\end{array}$ & $\begin{array}{l}\text { NITRO- } \\
\text { GEN, } \\
\text { ORGANIC } \\
\text { TOTAL } \\
\text { (MG/L } \\
\text { AS N) } \\
(00605)\end{array}$ \\
\hline OCT 1981 & & & & & & & & & & & \\
\hline $\begin{array}{c}30 \ldots \\
\text { OCT } 1982\end{array}$ & - & 0.26 & - & 3.49 & 3.59 & 16 & 0.010 & 3.60 & $<0.010$ & 0.01 & 0.46 \\
\hline $\begin{array}{c}20 \ldots \\
\text { NOV } 1983\end{array}$ & 195 & .26 & 2.42 & 4.59 & 4.59 & 20 & .010 & 4.60 & .020 & .03 & - \\
\hline $\begin{array}{c}01 \ldots \\
\text { ОСТ } 1984\end{array}$ & 187 & .27 & 3.37 & 4.79 & 4.79 & 21 & .010 & 4.80 & .060 & .08 & - \\
\hline $\begin{array}{c}19 \ldots \\
\text { OCT } 1985\end{array}$ & 187 & .27 & 5.37 & 4.66 & 4.66 & 21 & .040 & 4.70 & .040 & .05 & - \\
\hline $\begin{array}{c}25 \ldots \\
\text { OCT } 1986\end{array}$ & 188 & .24 & 3.75 & 3.78 & 3.78 & 17 & .020 & 3.80 & .040 & .05 & .86 \\
\hline $\begin{array}{c}30 \ldots \\
\text { NOV } 1987\end{array}$ & 196 & .28 & 3.11 & 4.09 & 4.09 & 18 & .010 & 4.10 & .010 & .01 & .49 \\
\hline $\begin{array}{c}17 \ldots \\
\text { NOV } 1988\end{array}$ & 199 & .26 & 4.01 & 4.40 & - & - & $<.010$ & 4.40 & $<.010$ & - & .40 \\
\hline $\begin{array}{c}08 \ldots \\
\text { OCT } 1989\end{array}$ & 197 & .27 & 3.52 & 4.40 & - & - & $<.010$ & 4.40 & .040 & .05 & .36 \\
\hline $\begin{array}{c}31 \ldots \\
\text { NOV } 1990\end{array}$ & 185 & .25 & 7.50 & 4.70 & - & - & $<.010$ & 4.70 & $<.010$ & - & .70 \\
\hline $\begin{array}{c}01 \ldots \\
\text { NOV } 1991\end{array}$ & 199 & .27 & 3.74 & 5.28 & 5.28 & 23 & .020 & 5.30 & .020 & .03 & .78 \\
\hline $\begin{array}{c}14 \ldots \\
\text { NOV } 1992\end{array}$ & 200 & .27 & 2.78 & 5.00 & - & - & $<.010$ & 5.00 & .010 & .01 & .29 \\
\hline $\begin{array}{c}16 \ldots \\
\text { NOV } 1993\end{array}$ & 196 & .27 & 3.97 & 5.07 & 5.07 & 22 & .030 & 5.10 & $<.010$ & - & .30 \\
\hline $\begin{array}{c}24 \ldots \\
\text { NOV } 1994\end{array}$ & - & - & - & 4.89 & 4.89 & 22 & .010 & 4.90 & .020 & .03 & - \\
\hline $03 \ldots$ & - & - & - & 3.89 & 3.89 & 17 & .010 & 3.90 & $<.015$ & - & - \\
\hline
\end{tabular}


Table 3. Water-quality data from surface-water sites-Continued

01478120 - East Branch White Clay Creek at Avondale, Pa. (Site 28)-Continued

\begin{tabular}{|c|c|c|c|c|c|c|c|c|c|c|c|}
\hline \multirow{3}{*}{ DATE } & $\begin{array}{l}\text { NITRO- } \\
\text { GEN }\end{array}$ & $\begin{array}{r}\text { NITRO- } \\
\text { GEN, AM- }\end{array}$ & $\begin{array}{r}\text { NITRO- } \\
\text { GEN, AM- }\end{array}$ & & NITRO- & & & 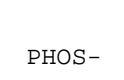 & $\begin{array}{l}\text { PHOS- } \\
\text { PHORUS }\end{array}$ & $\begin{array}{l}\text { PHOS- } \\
\text { PHATE, }\end{array}$ & \\
\hline & $\begin{array}{c}\text { ORGANIC } \\
\text { DIS- } \\
\text { SOLVED } \\
\text { (MG/L }\end{array}$ & $\begin{array}{c}\text { MONIA + } \\
\text { ORGANIC } \\
\text { TOTAL } \\
\text { (MG/L }\end{array}$ & $\begin{array}{l}\text { MONIA + } \\
\text { ORGANIC } \\
\text { DIS. } \\
\text { (MG/L }\end{array}$ & $\begin{array}{c}\text { NITRO- } \\
\text { GEN, } \\
\text { TOTAL } \\
\text { (MG/L }\end{array}$ & $\begin{array}{c}\text { GEN, } \\
\text { DIS- } \\
\text { SOLVED } \\
\text { (MG/L }\end{array}$ & $\begin{array}{c}\text { PHOS- } \\
\text { PHORUS, } \\
\text { TOTAL } \\
\text { (MG/L }\end{array}$ & $\begin{array}{l}\text { PHOS- } \\
\text { PHORUS, } \\
\text { TOTAL } \\
\text { (MG/L }\end{array}$ & $\begin{array}{c}\text { PHORUS, } \\
\text { DIS- } \\
\text { SOLVED } \\
\text { (MG/L }\end{array}$ & $\begin{array}{l}\text { ORTHO, } \\
\text { DIS- } \\
\text { SOLVED } \\
\text { (MG/L }\end{array}$ & $\begin{array}{r}\text { ORTHO, } \\
\text { DIS- } \\
\text { SOLVED } \\
\text { (MG/L }\end{array}$ & $\begin{array}{c}\text { ARSENIC, } \\
\text { DIS- } \\
\text { SOLVED } \\
(\mu \mathrm{G} / \mathrm{L}\end{array}$ \\
\hline & $\begin{array}{c}\text { AS N) } \\
(00607)\end{array}$ & $\begin{array}{c}\text { AS N) } \\
(00625)\end{array}$ & $\begin{array}{l}\text { AS N) } \\
(00623)\end{array}$ & $\begin{array}{l}\text { AS N }) \\
(00600)\end{array}$ & $\begin{array}{c}\text { AS N) } \\
(00602)\end{array}$ & $\begin{array}{l}\text { AS P) } \\
(00665)\end{array}$ & $\begin{array}{l}\left.\mathrm{AS} \mathrm{PO}_{4}\right) \\
(71886)\end{array}$ & $\begin{array}{l}\text { AS P) } \\
(00666)\end{array}$ & $\begin{array}{l}\text { AS P) } \\
(00671)\end{array}$ & $\begin{array}{c}\left.\mathrm{AS} \mathrm{PO}_{4}\right) \\
(00660)\end{array}$ & $\begin{array}{l}\text { AS AS) } \\
(01000)\end{array}$ \\
\hline
\end{tabular}

\begin{tabular}{|c|c|c|c|c|c|c|c|c|c|c|c|}
\hline $\begin{array}{c}30 \ldots \\
\text { OCT } 1982\end{array}$ & - & 0.46 & 0.49 & 4.0 & 4.1 & 0.060 & 0.18 & 0.050 & 0.040 & 0.12 & ND \\
\hline $20 \ldots$ & 0.18 & - & .20 & - & 4.8 & - & - & .040 & .020 & .06 & 1 \\
\hline NOV 1983 & & & & & & & & & & & \\
\hline $\begin{array}{c}01 \ldots \\
\text { OCT } 1984\end{array}$ & .34 & - & .40 & - & 5.2 & .030 & .09 & .030 & .010 & .03 & 一 \\
\hline $\begin{array}{c}19 \ldots \\
\text { OCT } 1985\end{array}$ & .36 & - & .40 & - & 5.1 & .010 & - & .020 & .020 & .06 & - \\
\hline $\begin{array}{c}25 \ldots \\
\text { OCT } 1986\end{array}$ & .46 & .90 & .50 & 4.7 & 4.3 & .050 & .15 & .030 & .030 & .09 & - \\
\hline $\begin{array}{c}30 \ldots \\
\text { NOV } 1987\end{array}$ & .49 & .50 & .50 & 4.6 & 4.6 & .030 & - & .020 & .020 & .06 & - \\
\hline $\begin{array}{c}17 \ldots \\
\text { NOV } 1988\end{array}$ & - & .40 & $<.20$ & 4.8 & - & .040 & - & .020 & .010 & .03 & - \\
\hline $\begin{array}{c}08 \ldots \\
\text { OCT } 1989\end{array}$ & .26 & .40 & .30 & 4.8 & 4.7 & .030 & - & .020 & .010 & .03 & - \\
\hline $\begin{array}{c}31 \ldots \\
\text { NOV } 1990\end{array}$ & - & .70 & .60 & 5.4 & 5.3 & .030 & - & .020 & .020 & .06 & - \\
\hline $\begin{array}{c}01 \ldots \\
\text { NOV } 1991\end{array}$ & .58 & .80 & .60 & 6.1 & 5.9 & .020 & - & $<.010$ & .030 & .09 & - \\
\hline $\begin{array}{c}14 \ldots \\
\text { NOV } 1992\end{array}$ & .19 & .30 & .20 & 5.3 & 5.2 & .020 & - & .010 & .020 & .06 & - \\
\hline $\begin{array}{c}16 \ldots \\
\text { NOV } 1993\end{array}$ & - & .30 & .20 & 5.4 & 5.3 & .040 & - & .030 & .020 & .06 & - \\
\hline $\begin{array}{c}24 \ldots \\
\text { NOV } 1994\end{array}$ & - & - & - & - & - & - & - & - & $<.010$ & - & - \\
\hline $03 \ldots$ & - & - & - & - & - & - & - & - & .020 & .06 & - \\
\hline
\end{tabular}


Table 3. Water-quality data from surface-water sites-Continued

01478120 - East Branch White Clay Creek at Avondale, Pa. (Site 28)—Continued

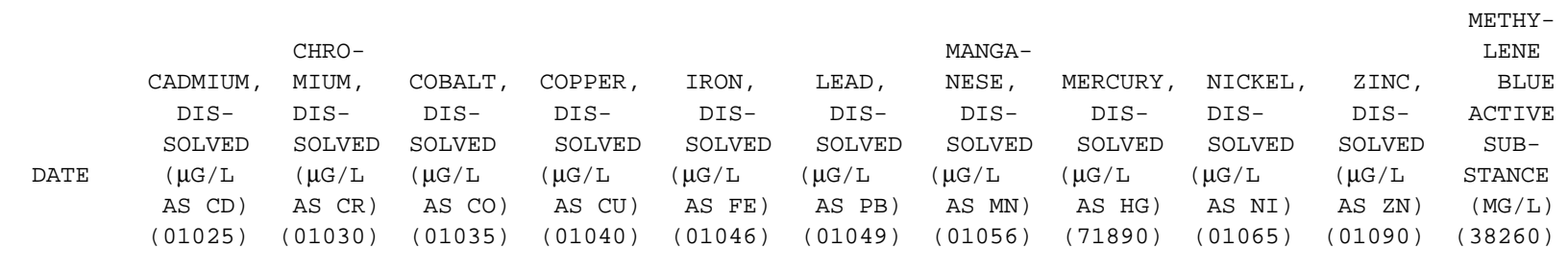

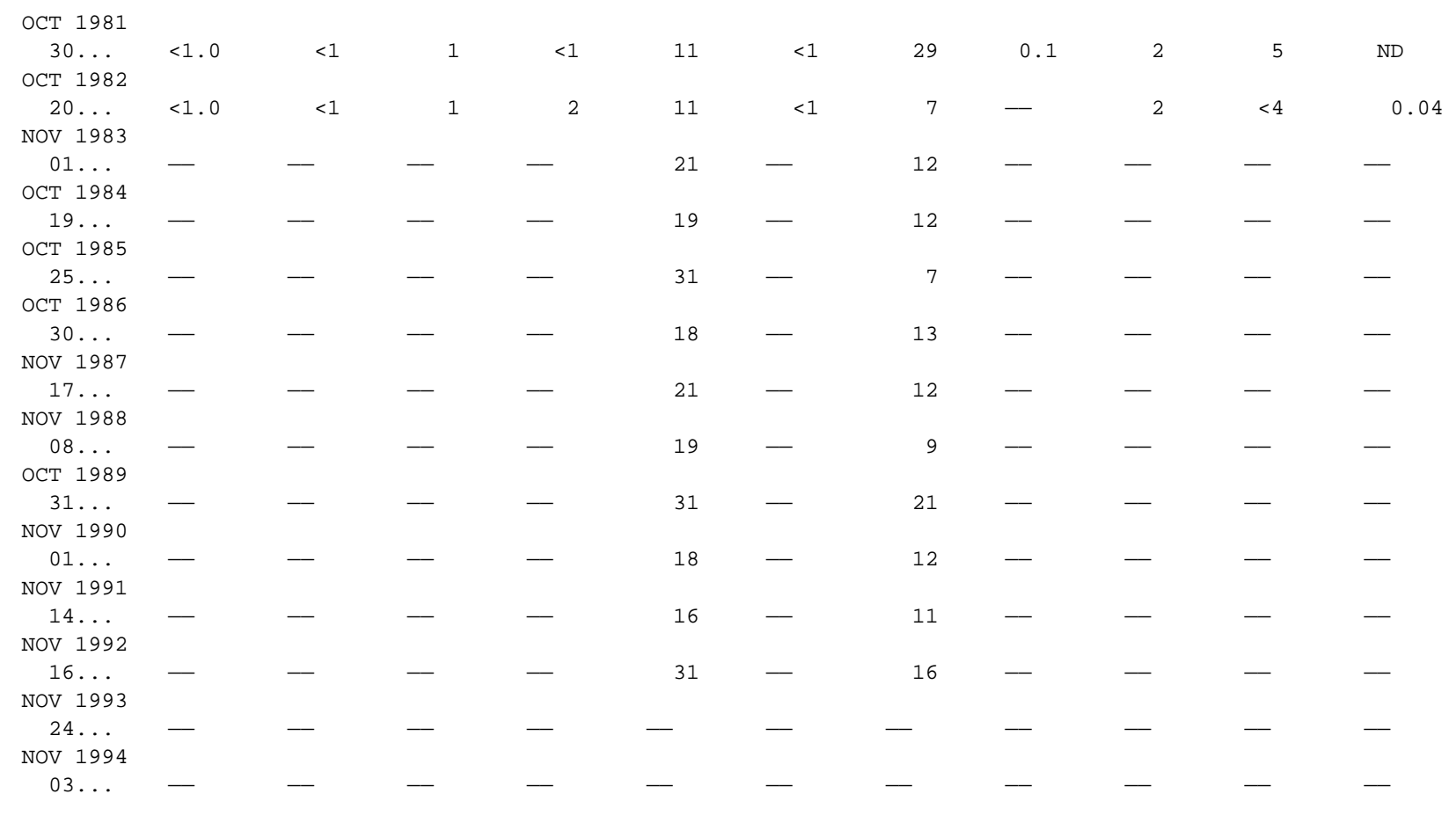


Table 3. Water-quality data from surface-water sites-Continued

01478190 - Middle Branch White Clay Creek at Wickerton, Pa. (Site 29)

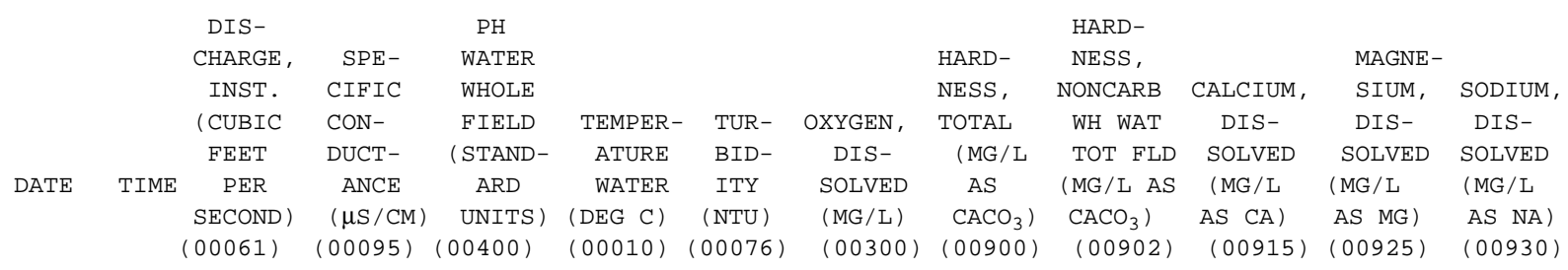

\begin{tabular}{|c|c|c|c|c|c|c|c|c|c|c|c|c|}
\hline $\begin{array}{c}29 \ldots \\
\text { OCT } 1982\end{array}$ & 1430 & - & 193 & 7.5 & 10.0 & - & 9.3 & 70 & - & 17 & 6.8 & 7.0 \\
\hline $\begin{array}{c}20 \ldots \\
\text { NOV } 1983\end{array}$ & 1115 & 3.3 & 210 & 7.2 & 9.5 & - & 10.6 & 75 & - & 17 & 7.8 & 10 \\
\hline $\begin{array}{c}02 \ldots \\
\text { OCT } 1984\end{array}$ & 0830 & 4.7 & 192 & 8.0 & 8.0 & 1.3 & 10.5 & 74 & - & 17 & 7.6 & 9.0 \\
\hline $\begin{array}{c}18 \ldots \\
\text { OCT } 1985\end{array}$ & 1530 & 6.8 & 195 & 7.6 & 15.0 & .90 & 9.9 & 70 & - & 16 & 7.4 & 7.4 \\
\hline $\begin{array}{c}25 \ldots \\
\operatorname{DEC} 1986\end{array}$ & 0830 & 6.8 & 215 & 7.0 & 10.5 & 1.6 & 8.5 & 73 & - & 17 & 7.4 & 8.4 \\
\hline $\begin{array}{c}02 \ldots \\
\text { OCT } 1987\end{array}$ & 1300 & 8.8 & 190 & 7.6 & 6.0 & 2.2 & 11.8 & 70 & - & 16 & 7.2 & 7.4 \\
\hline $\begin{array}{c}29 \ldots \\
\text { OCT } 1988\end{array}$ & 0900 & 7.1 & 200 & 7.3 & 9.0 & .60 & 11.3 & 73 & - & 17 & 7.5 & 7.8 \\
\hline $\begin{array}{c}31 \ldots \\
\text { OCT } 1989\end{array}$ & 0830 & 5.6 & 240 & 6.7 & 6.0 & 1.5 & 12.2 & 88 & - & 20 & 9.3 & 10 \\
\hline $\begin{array}{c}31 \ldots \\
\text { NOV } 1990\end{array}$ & 0900 & 12 & 219 & 7.3 & 14.5 & .70 & 9.8 & 75 & 28 & 17 & 7.8 & 8.6 \\
\hline $\begin{array}{c}09 \ldots \\
\text { NOV } 1991\end{array}$ & 0900 & 5.5 & 231 & 6.8 & 5.5 & 1.4 & 13.4 & 87 & 29 & 20 & 8.9 & 9.9 \\
\hline $\begin{array}{c}13 \ldots \\
\text { NOV } 1992\end{array}$ & 0930 & 3.7 & 235 & 7.4 & 6.5 & 1.6 & 12.1 & 82 & 47 & 19 & 8.4 & 9.7 \\
\hline $\begin{array}{c}12 \ldots \\
\text { NOV } 1993\end{array}$ & 1000 & 5.5 & 236 & 7.5 & 10.5 & .40 & 11.3 & 82 & - & 19 & 8.4 & 9.9 \\
\hline $\begin{array}{c}24 \ldots \\
\text { NOV } 1994\end{array}$ & 1230 & 5.9 & 236 & 8.0 & 8.0 & - & 15.0 & - & - & - & - & - \\
\hline $08 \ldots$ & 1305 & 4.3 & 260 & 6.8 & 10.5 & - & 12.8 & - & - & - & - & - \\
\hline
\end{tabular}


Table 3. Water-quality data from surface-water sites-Continued

01478190 - Middle Branch White Clay Creek at Wickerton, Pa. (Site 29)—Continued

\begin{tabular}{|c|c|c|c|c|c|c|c|c|c|c|c|}
\hline \multirow{6}{*}{ DATE } & & & POTAS- & $\begin{array}{l}\text { ALKA- } \\
\text { LINITY }\end{array}$ & $\begin{array}{l}\text { ALKA- } \\
\text { LINITY }\end{array}$ & & CHLO- & FLUO- & SILICA, & $\begin{array}{l}\text { SOLIDS, } \\
\text { RESIDUE }\end{array}$ & $\begin{array}{l}\text { SOLIDS, } \\
\text { SUM OF }\end{array}$ \\
\hline & & SODIUM & SIUM, & WAT WH & WAT WH & SULFATE, & RIDE， & RIDE， & DIS- & AT 180 & CONSTI- \\
\hline & & $\begin{array}{c}\text { AD- } \\
\text { SORP- }\end{array}$ & $\begin{array}{c}\text { DIS- } \\
\text { SOLVED }\end{array}$ & $\begin{array}{c}\text { TOT FET } \\
\text { FIELD }\end{array}$ & $\begin{array}{r}\text { TOT IT } \\
\text { FIELD }\end{array}$ & $\begin{array}{l}\text { DIS- } \\
\text { SOLVED }\end{array}$ & $\begin{array}{l}\text { DIS- } \\
\text { SOLVED }\end{array}$ & $\begin{array}{l}\text { DIS- } \\
\text { SOLVED }\end{array}$ & $\begin{array}{l}\text { SOLVED } \\
\text { (MG/L }\end{array}$ & $\begin{array}{c}\text { DEG. C } \\
\text { DIS- }\end{array}$ & $\begin{array}{c}\text { TUENTS, } \\
\text { DIS- }\end{array}$ \\
\hline & SODIUM & TION & (MG / L & (MG/L AS & (MG/L AS & (MG/L & $(\mathrm{MG} / \mathrm{L}$ & $(\mathrm{MG} / \mathrm{L}$ & AS & SOLVED & SOLVED \\
\hline & PERCENT & RATIO & AS K) & $\left.\mathrm{CACO}_{3}\right)$ & $\left.\mathrm{CACO}_{3}\right)$ & AS $\left.\mathrm{SO}_{4}\right)$ & AS CL) & AS F) & $\mathrm{SIO}_{2}$ ) & $(\mathrm{MG} / \mathrm{L})$ & $(\mathrm{MG} / \mathrm{L})$ \\
\hline & $(00932)$ & $(00931)$ & $(00935)$ & $(00410)$ & $(00419)$ & $(00945)$ & $(00940)$ & $(00950)$ & $(00955)$ & $(70300)$ & $(70301)$ \\
\hline
\end{tabular}

\begin{tabular}{|c|c|c|c|c|c|c|c|c|c|c|c|}
\hline $\begin{array}{c}29 \ldots \\
\text { OCT } 1982\end{array}$ & 16 & 0.4 & 5.7 & - & - & 18 & 13 & $<0.10$ & 15 & 129 & - \\
\hline $20 \ldots$ & 22 & .5 & 2.9 & 44 & - & 15 & 15 & $<.10$ & 15 & 141 & 133 \\
\hline NOV 1983 & & & & & & & & & & & \\
\hline $\begin{array}{c}02 \ldots \\
\text { OCT } 1984\end{array}$ & 20 & .5 & 3.1 & 42 & - & 16 & 15 & - & 14 & 134 & 131 \\
\hline $\begin{array}{c}18 \ldots \\
\text { OCT } 1985\end{array}$ & 18 & .4 & 3.0 & 38 & - & 15 & 15 & - & 13 & 131 & 123 \\
\hline $\begin{array}{c}25 \ldots \\
\operatorname{DEC} 1986\end{array}$ & 19 & .4 & 5.2 & 48 & - & 19 & 17 & - & 13 & 134 & 138 \\
\hline $\begin{array}{c}02 \ldots \\
\text { OCT } 1987\end{array}$ & 18 & .4 & 3.4 & 40 & - & 18 & 17 & - & 16 & 119 & 131 \\
\hline $\begin{array}{c}29 \ldots \\
\text { OCT } 1988\end{array}$ & 17 & .4 & 6.4 & 44 & - & 18 & 18 & - & 14 & 138 & 133 \\
\hline $\begin{array}{c}31 \ldots \\
\text { OCT } 1989\end{array}$ & 19 & .5 & 3.4 & 60 & - & 17 & 16 & - & 15 & - & 154 \\
\hline $\begin{array}{c}31 \ldots \\
\text { NOV } 1990\end{array}$ & 19 & .4 & 3.6 & 47 & - & 15 & 14 & - & 14 & - & 132 \\
\hline $\begin{array}{c}09 \ldots \\
\text { NOV } 1991\end{array}$ & 19 & .5 & 3.7 & 58 & - & 17 & 16 & $<.10$ & 14 & - & 151 \\
\hline $\begin{array}{c}13 \ldots \\
\text { NOV } 1992\end{array}$ & 19 & .5 & 4.8 & 35 & - & 19 & 18 & .10 & 15 & - & 140 \\
\hline $\begin{array}{c}12 \ldots \\
\text { NOV } 1993\end{array}$ & 20 & .5 & 3.9 & - & 43 & 17 & 16 & .10 & 16 & - & 144 \\
\hline $\begin{array}{c}24 \ldots \\
\text { NOV } 1994\end{array}$ & - & - & - & - & 60 & 19 & 17 & $<.10$ & - & - & - \\
\hline $08 \ldots$ & - & - & - & - & 51 & - & 18 & - & - & - & - \\
\hline
\end{tabular}


Table 3. Water-quality data from surface-water sites-Continued

01478190 - Middle Branch White Clay Creek at Wickerton, Pa. (Site 29)—Continued

\begin{tabular}{|c|c|c|c|c|c|c|c|c|c|c|c|}
\hline DATE & $\begin{array}{c}\text { SOLIDS, } \\
\text { DIS- } \\
\text { SOLVED } \\
\text { (TONS } \\
\text { PER } \\
\text { AC-FT) } \\
(70303)\end{array}$ & $\begin{array}{c}\text { SOLIDS, } \\
\text { DIS- } \\
\text { SOLVED } \\
\text { (TONS } \\
\text { PER } \\
\text { DAY) } \\
(70302)\end{array}$ & $\begin{array}{l}\text { NITRO- } \\
\text { GEN, } \\
\text { NITRATE } \\
\text { TOTAL } \\
\text { (MG/L } \\
\text { AS N) } \\
(00620)\end{array}$ & $\begin{array}{c}\text { NITRO- } \\
\text { GEN, } \\
\text { NITRATE } \\
\text { DIS- } \\
\text { SOLVED } \\
(\text { MG/L } \\
\text { AS N) } \\
(00618)\end{array}$ & $\begin{array}{c}\text { NITRO- } \\
\text { GEN, } \\
\text { NITRATE } \\
\text { DIS- } \\
\text { SOLVED } \\
(\mathrm{MG} / \mathrm{L} \\
\left.\mathrm{AS} \mathrm{NO})_{3}\right) \\
(71851)\end{array}$ & $\begin{array}{c}\text { NITRO- } \\
\text { GEN, } \\
\text { NITRITE } \\
\text { DIS- } \\
\text { SOLVED } \\
\text { (MG/L } \\
\text { AS N) } \\
(00613)\end{array}$ & $\begin{array}{c}\text { NITRO- } \\
\text { GEN, } \\
\mathrm{NO}_{2}+\mathrm{NO}_{3} \\
\text { DIS- } \\
\text { SOLVED } \\
(\mathrm{MG} / \mathrm{L} \\
\mathrm{AS} \mathrm{N}) \\
(00631)\end{array}$ & $\begin{array}{c}\text { NITRO- } \\
\text { GEN, } \\
\text { AMMONIA } \\
\text { DIS- } \\
\text { SOLVED } \\
(\text { MG/L } \\
\text { AS N) } \\
(00608)\end{array}$ & $\begin{array}{c}\text { NITRO- } \\
\text { GEN, } \\
\text { AMMONIA } \\
\text { DIS- } \\
\text { SOLVED } \\
(\mathrm{MG} / \mathrm{L} \\
\left.\text { AS NH})_{4}\right) \\
(71846)\end{array}$ & $\begin{array}{l}\text { NITRO- } \\
\text { GEN, } \\
\text { ORGANIC } \\
\text { TOTAL } \\
\text { (MG/L } \\
\text { AS N) } \\
(00605)\end{array}$ & $\begin{array}{c}\text { NITRO- } \\
\text { GEN, } \\
\text { ORGANIC } \\
\text { DIS- } \\
\text { SOLVED } \\
\text { (MG/L } \\
\text { AS N) } \\
(00607)\end{array}$ \\
\hline OCT 1981 & & & & & & & & & & & \\
\hline $\begin{array}{c}29 \ldots \\
\text { OCT } 1982\end{array}$ & 0.18 & - & 2.94 & 2.75 & 12 & 0.050 & 2.80 & 0.180 & 0.23 & 0.79 & 1.1 \\
\hline $\begin{array}{c}20 \ldots \\
\text { NOV } 1983\end{array}$ & .19 & 1.27 & 5.11 & 5.11 & 23 & .090 & 5.20 & .070 & .09 & - & .73 \\
\hline $\begin{array}{c}02 \ldots \\
\text { OCT } 1984\end{array}$ & .18 & 1.70 & 5.09 & 5.09 & 23 & .110 & 5.20 & .390 & .50 & - & .41 \\
\hline $\begin{array}{c}18 \ldots \\
\text { OCT } 1985\end{array}$ & .18 & 2.41 & 5.02 & 5.02 & 22 & .080 & 5.10 & .060 & .08 & - & .74 \\
\hline $\begin{array}{c}25 \ldots \\
\text { DEC } 1986\end{array}$ & .18 & 2.46 & 4.68 & 4.68 & 21 & .120 & 4.80 & .120 & .15 & .98 & .58 \\
\hline $\begin{array}{c}02 \ldots \\
\text { OCT } 1987\end{array}$ & .16 & 2.83 & 4.67 & 4.67 & 21 & .030 & 4.70 & .300 & .39 & .60 & .70 \\
\hline $\begin{array}{c}29 \ldots \\
\text { OCT } 1988\end{array}$ & .19 & 2.65 & 3.63 & 3.63 & 16 & .070 & 3.70 & .400 & .52 & .80 & .60 \\
\hline $\begin{array}{c}31 \ldots \\
\text { OCT } 1989\end{array}$ & .21 & 2.32 & 5.58 & 5.58 & 25 & .120 & 5.70 & .630 & .81 & .67 & .37 \\
\hline $\begin{array}{c}31 \ldots \\
\text { NOV } 1990\end{array}$ & .18 & 4.28 & 5.30 & - & - & $<.010$ & 5.30 & .020 & .03 & .28 & .58 \\
\hline $\begin{array}{c}09 \ldots \\
\text { NOV } 1991\end{array}$ & .21 & 2.25 & 5.79 & 5.79 & 26 & .010 & 5.80 & .170 & .22 & .83 & .73 \\
\hline $\begin{array}{c}13 \ldots \\
\text { NOV } 1992\end{array}$ & .19 & 1.40 & 5.60 & - & - & $<.010$ & 5.60 & .020 & .03 & .38 & .38 \\
\hline $\begin{array}{c}12 \ldots \\
\text { NOV } 1993\end{array}$ & .20 & 2.13 & 6.06 & 6.06 & 27 & .040 & 6.10 & .040 & .05 & .26 & .26 \\
\hline $\begin{array}{c}24 \ldots \\
\text { NOV } 1994\end{array}$ & - & - & 5.99 & 5.99 & 27 & .010 & 6.00 & .020 & .03 & - & - \\
\hline $08 \ldots$ & - & - & 6.29 & 6.29 & 28 & .010 & 6.30 & $<.015$ & - & - & - \\
\hline
\end{tabular}


Table 3. Water-quality data from surface-water sites-Continued

01478190 - Middle Branch White Clay Creek at Wickerton, Pa. (Site 29)—Continued

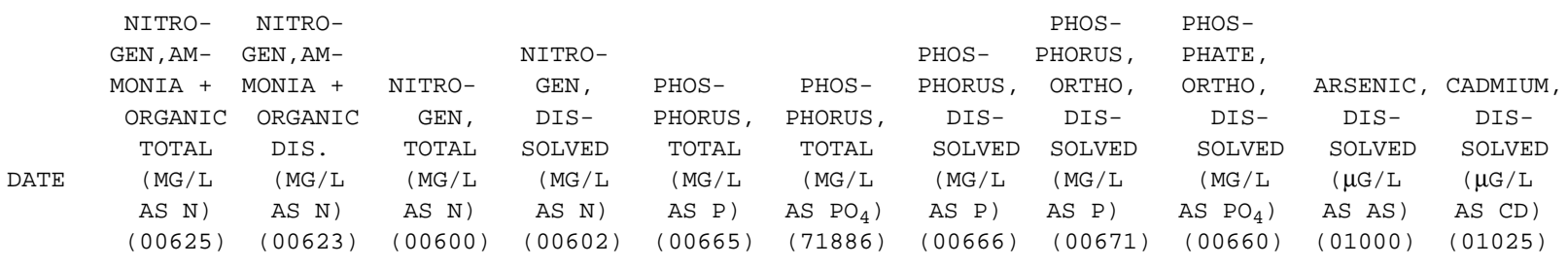

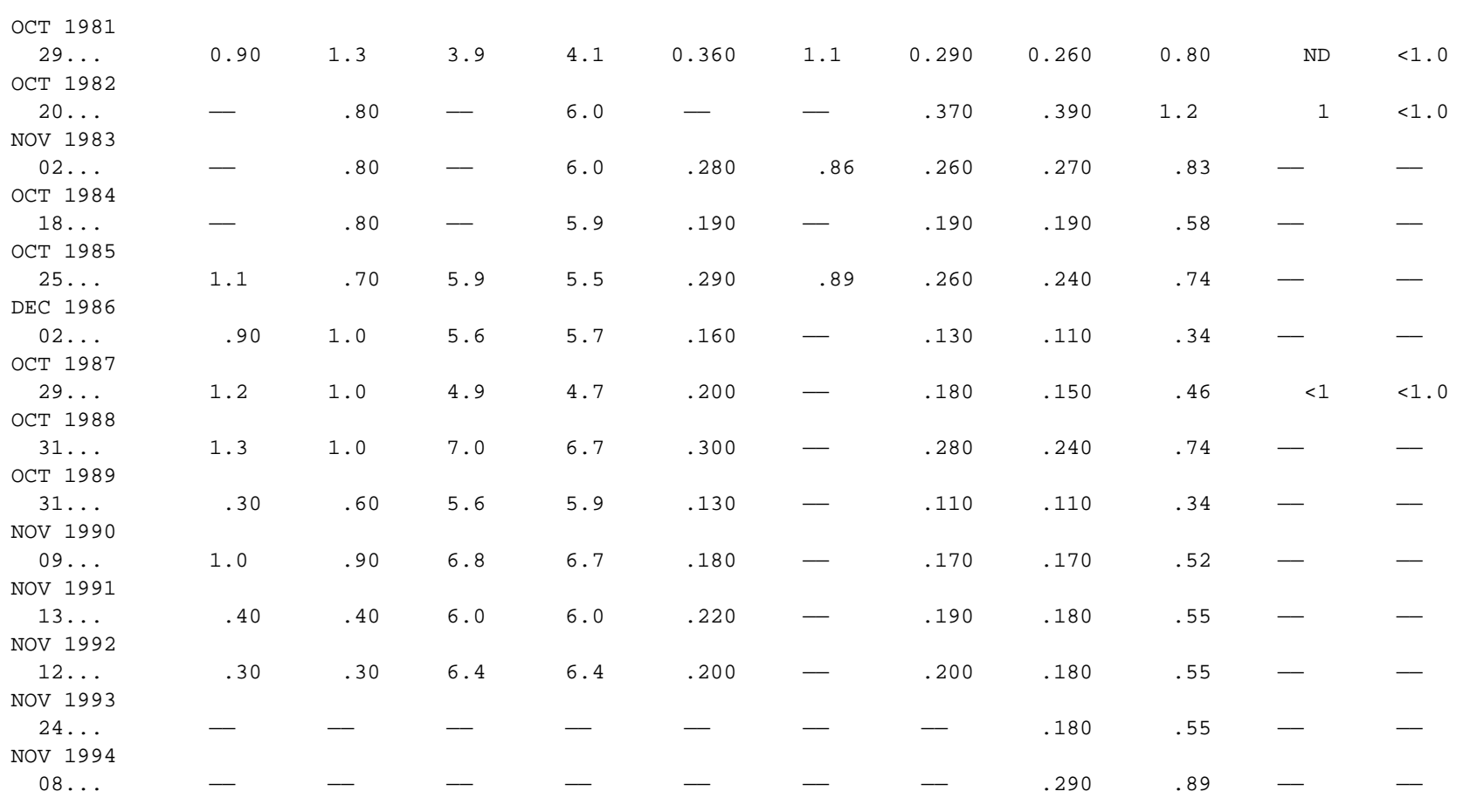


Table 3. Water-quality data from surface-water sites-Continued

01478190 - Middle Branch White Clay Creek at Wickerton, Pa. (Site 29)—Continued

\begin{tabular}{|c|c|c|c|c|c|c|c|c|c|c|c|}
\hline DATE & $\begin{array}{l}\text { CHRO- } \\
\text { MIUM, } \\
\text { DIS- } \\
\text { SOLVED } \\
(\mu \mathrm{G} / \mathrm{L} \\
\text { AS CR) } \\
(01030)\end{array}$ & $\begin{array}{l}\text { COBALT, } \\
\text { DIS- } \\
\text { SOLVED } \\
(\mu \mathrm{G} / \mathrm{L} \\
\text { AS CO) } \\
(01035)\end{array}$ & $\begin{array}{l}\text { COPPER, } \\
\text { DIS- } \\
\text { SOLVED } \\
(\mu \mathrm{G} / \mathrm{L} \\
\text { AS CU) } \\
(01040)\end{array}$ & $\begin{array}{c}\text { IRON, } \\
\text { DIS- } \\
\text { SOLVED } \\
(\mu \mathrm{G} / \mathrm{L} \\
\text { AS FE) } \\
(01046)\end{array}$ & $\begin{array}{c}\text { LEAD, } \\
\text { DIS- } \\
\text { SOLVED } \\
(\mu \mathrm{G} / \mathrm{L} \\
\mathrm{AS} \mathrm{PB}) \\
(01049)\end{array}$ & $\begin{array}{c}\text { MANGA- } \\
\text { NESE, } \\
\text { DIS- } \\
\text { SOLVED } \\
(\mu \mathrm{G} / \mathrm{L} \\
\text { AS MN) } \\
(01056)\end{array}$ & $\begin{array}{c}\text { MERCURY, } \\
\text { DIS- } \\
\text { SOLVED } \\
(\mu \mathrm{G} / \mathrm{L} \\
\text { AS HG) } \\
(71890)\end{array}$ & $\begin{array}{l}\text { NICKEL, } \\
\text { DIS- } \\
\text { SOLVED } \\
(\mu \mathrm{G} / \mathrm{L} \\
\text { AS NI) } \\
(01065)\end{array}$ & $\begin{array}{c}\text { SILVER, } \\
\text { DIS- } \\
\text { SOLVED } \\
(\mu \mathrm{G} / \mathrm{L} \\
\mathrm{AS} \text { AG) } \\
(01075)\end{array}$ & $\begin{array}{c}\text { ZINC, } \\
\text { DIS- } \\
\text { SOLVED } \\
(\mu \mathrm{G} / \mathrm{L} \\
\text { AS } \mathrm{ZN}) \\
(01090)\end{array}$ & $\begin{array}{c}\text { METHY- } \\
\text { LENE } \\
\text { BLUE } \\
\text { ACTIVE } \\
\text { SUB- } \\
\text { STANCE } \\
\text { (MG/L) } \\
(38260)\end{array}$ \\
\hline OCT 1981 & & & & & & & & & & & \\
\hline $\begin{array}{c}29 \ldots \\
\text { OCT } 1982\end{array}$ & $<1$ & $<1$ & 2 & 220 & $<1$ & 95 & 0.4 & 3 & - & $<4$ & 0.10 \\
\hline $\begin{array}{c}20 \ldots \\
\text { NOV } 1983\end{array}$ & $<1$ & 1 & 2 & 21 & $<1$ & 14 & $<.1$ & $<1$ & - & $<4$ & .08 \\
\hline $\begin{array}{c}02 \ldots \\
\text { ОСТ } 1984\end{array}$ & - & - & - & 62 & - & 32 & - & - & - & - & - \\
\hline $\begin{array}{c}18 \ldots \\
\text { OCT } 1985\end{array}$ & - & - & - & 48 & - & 20 & - & - & - & - & - \\
\hline $\begin{array}{c}25 \ldots \\
\text { DEC } 1986\end{array}$ & - & - & - & 37 & - & 10 & - & - & - & - & - \\
\hline $\begin{array}{c}02 \ldots \\
\text { OCT } 1987\end{array}$ & - & - & - & 58 & - & 54 & - & - & - & - & - \\
\hline $\begin{array}{c}29 \ldots \\
\text { OCT } 1988\end{array}$ & $<1$ & - & 1 & 84 & $<5$ & 47 & $<.1$ & $<1$ & $<1.0$ & 4 & - \\
\hline $\begin{array}{c}31 \ldots \\
\text { OCT } 1989\end{array}$ & - & - & - & 56 & - & 32 & - & - & - & - & - \\
\hline $\begin{array}{c}31 \ldots \\
\text { NOV } 1990\end{array}$ & - & - & - & 66 & - & 23 & - & - & - & - & - \\
\hline $\begin{array}{c}09 \ldots \\
\text { NOV } 1991\end{array}$ & - & - & - & 52 & - & 20 & - & - & - & - & - \\
\hline $\begin{array}{c}13 \ldots \\
\text { NOV } 1992\end{array}$ & - & - & - & 42 & - & 15 & - & - & - & - & - \\
\hline $\begin{array}{c}12 \ldots \\
\text { NOV } 1993\end{array}$ & - & - & - & 60 & - & 20 & - & - & - & - & - \\
\hline $\begin{array}{c}24 \ldots \\
\text { NOV } 1994\end{array}$ & - & - & - & - & - & - & - & - & - & - & - \\
\hline $08 \ldots$ & - & - & - & - & - & - & - & - & - & - & - \\
\hline
\end{tabular}


Table 3. Water-quality data from surface-water sites-Continued

01478220 - West Branch White Clay Creek near Chesterville (Site 30)

\begin{tabular}{|c|c|c|c|c|c|c|c|c|c|c|c|}
\hline & & DIS- & & $\mathrm{PH}$ & & & & & HARD- & & \\
\hline & & CHARGE, & SPE- & WATER & & & & HARD- & NESS, & & MAGNE- \\
\hline & & INST. & CIFIC & WHOLE & & & & NESS, & NONCARB & CALCIUM, & SIUM, \\
\hline & & (CUBIC & $\mathrm{CON}-$ & FIELD & TEMPER- & TUR- & OXYGEN, & TOTAL & WH WAT & DIS- & DIS- \\
\hline & & FEET & DUCT- & (STAND- & ATURE & BID- & DIS- & (MG/L & TOT FLD & SOLVED & SOLVED \\
\hline DATE & TIME & PER & ANCE & ARD & WATER & ITY & SOLVED & AS & (MG/L AS & (MG/L & (MG/L \\
\hline & & SECOND) & $(\mu \mathrm{S} / \mathrm{CM})$ & UNITS) & (DEG C) & (NTU) & (MG/L) & $\left.\mathrm{CACO}_{3}\right)$ & $\left.\mathrm{CACO}_{3}\right)$ & AS CA) & AS MG) \\
\hline & & $(00061)$ & $(00095)$ & $(00400)$ & $(00010)$ & $(00076)$ & $(00300)$ & $(00900)$ & $(00902)$ & (00915) & $(00925)$ \\
\hline
\end{tabular}

\begin{tabular}{|c|c|c|c|c|c|c|c|c|c|c|c|}
\hline $\begin{array}{c}29 \ldots \\
\text { ост } 1982\end{array}$ & 1330 & - & 167 & 7.6 & 9.5 & - & 10.4 & 56 & - & 14 & 5.2 \\
\hline $\begin{array}{c}20 \ldots \\
\text { NOV } 1983\end{array}$ & 0945 & 3.3 & 145 & 7.6 & 8.5 & - & 10.3 & 49 & - & 12 & 4.6 \\
\hline $\begin{array}{c}02 \ldots \\
\text { OCT } 1984\end{array}$ & 1015 & 4.3 & 144 & 7.3 & 7.0 & 1.6 & 12.0 & 49 & - & 12 & 4.7 \\
\hline $\begin{array}{c}18 \ldots \\
\text { OCT } 1985\end{array}$ & 1400 & 5.4 & 150 & 7.6 & 15.0 & .50 & 10.4 & 49 & - & 12 & 4.6 \\
\hline $\begin{array}{c}25 \ldots \\
\text { NOV } 1986\end{array}$ & 1100 & 6.2 & 165 & 7.1 & 11.0 & .60 & 11.5 & 51 & - & 12 & 5.0 \\
\hline $\begin{array}{c}25 \ldots \\
\text { OCT } 1987\end{array}$ & 1100 & 9.8 & 160 & 7.5 & 6.0 & 1.4 & 12.7 & 52 & - & 12 & 5.3 \\
\hline $\begin{array}{c}29 \ldots \\
\text { OCT } 1988\end{array}$ & 1230 & 7.6 & 160 & 7.4 & 10.0 & .70 & 11.9 & 54 & - & 13 & 5.3 \\
\hline $\begin{array}{c}31 \ldots \\
\text { OCT } 1989\end{array}$ & 1300 & 4.1 & 168 & 7.3 & 7.5 & 1.9 & 13.2 & 55 & - & 13 & 5.5 \\
\hline $\begin{array}{c}31 \ldots \\
\text { NOV } 1990\end{array}$ & 1220 & 13 & 169 & 7.3 & 15.5 & .50 & 9.4 & 53 & 0 & 13 & 5.1 \\
\hline $\begin{array}{c}09 \ldots \\
\text { NOV } 1991\end{array}$ & 1115 & 4.1 & 177 & 7.4 & 5.5 & .40 & 14.1 & 54 & 6 & 13 & 5.3 \\
\hline $\begin{array}{c}13 \ldots \\
\text { NOV } 1992\end{array}$ & 1145 & 3.9 & 184 & 7.3 & 7.0 & 1.4 & 12.9 & 58 & 34 & 14 & 5.6 \\
\hline $\begin{array}{c}16 \ldots \\
\text { NOV } 1993\end{array}$ & 1235 & 6.3 & 175 & 7.2 & 4.5 & .40 & 13.7 & 55 & - & 13 & 5.4 \\
\hline $\begin{array}{c}23 \ldots \\
\text { NOV } 1994\end{array}$ & 0945 & 5.6 & 180 & 7.3 & 3.5 & - & 13.0 & - & - & - & - \\
\hline $03 \ldots$ & 1150 & 3.0 & 198 & 7.8 & 9.5 & - & 12.4 & - & - & - & - \\
\hline
\end{tabular}


Table 3. Water-quality data from surface-water sites-Continued

01478220 - West Branch White Clay Creek near Chesterville (Site 30)—Continued

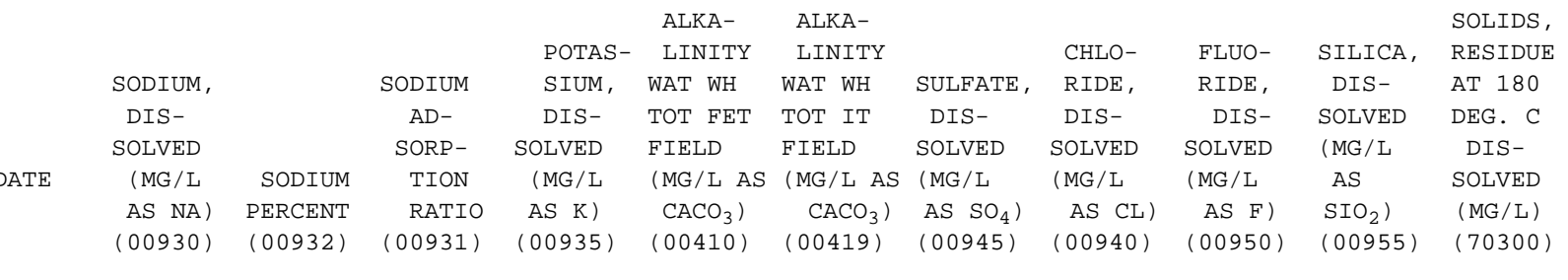

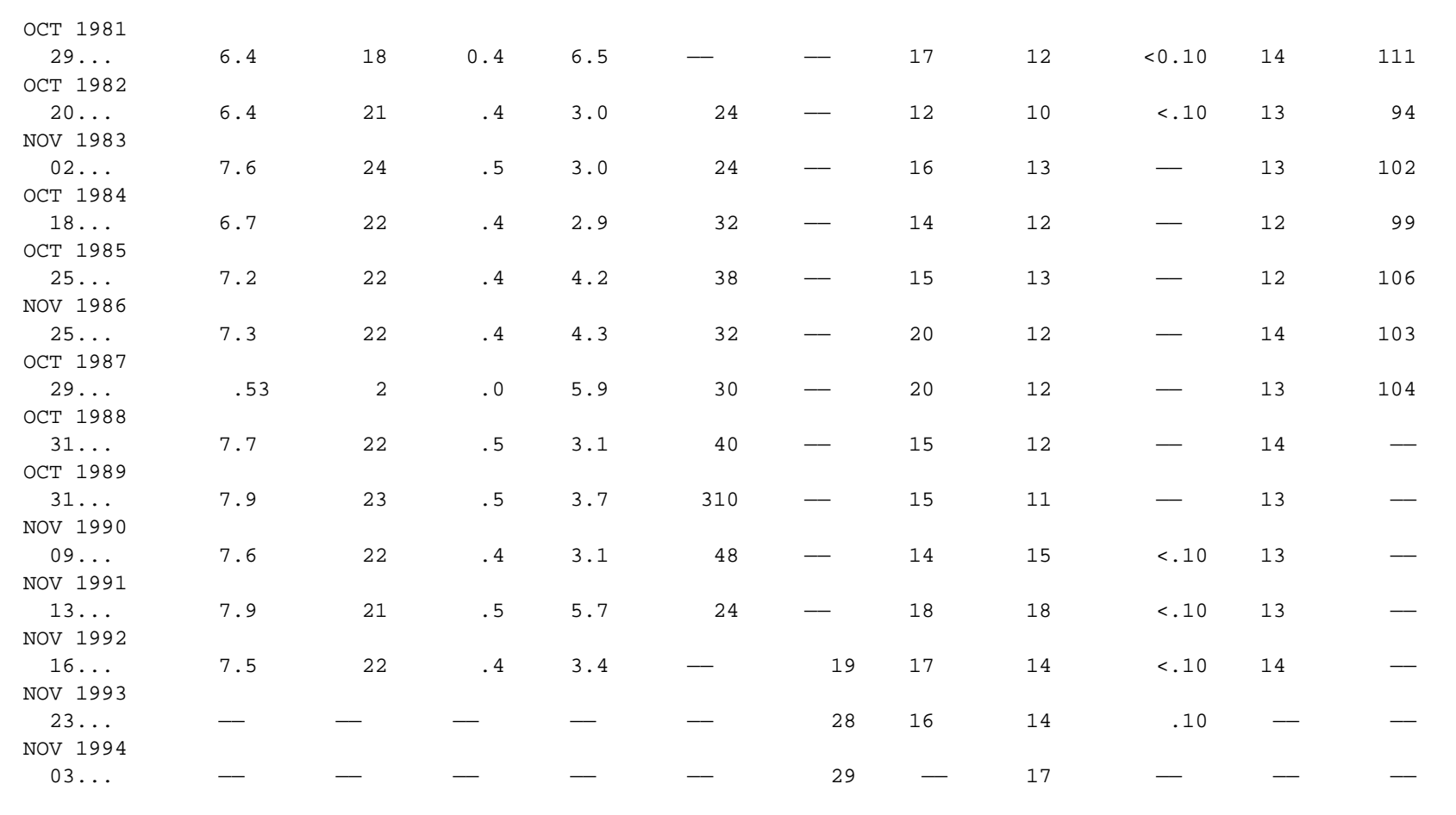


Table 3. Water-quality data from surface-water sites-Continued

01478220 - West Branch White Clay Creek near Chesterville (Site 30)—Continued

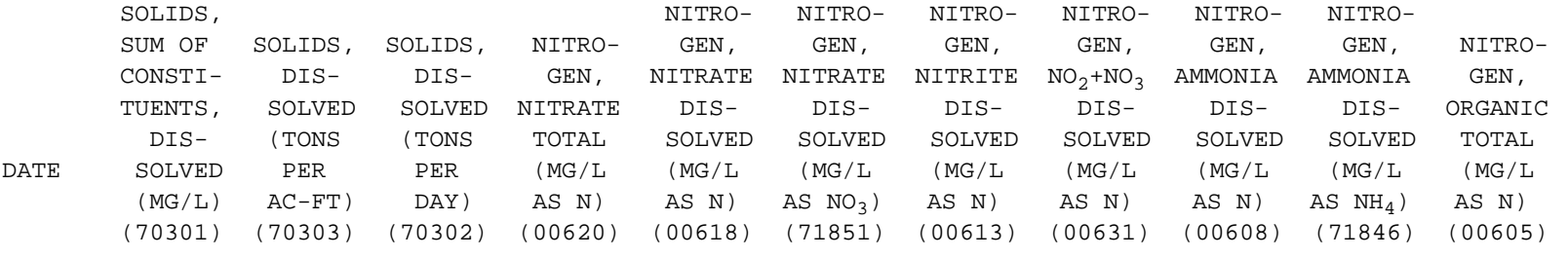

\begin{tabular}{|c|c|c|c|c|c|c|c|c|c|c|c|}
\hline $29 \ldots$ & - & 0.15 & - & 1.89 & 1.89 & 8.4 & 0.010 & 1.90 & $<0.010$ & 0.01 & 0.62 \\
\hline $20 \ldots$ & 87 & .13 & 0.83 & 2.60 & - & - & $<.010$ & 2.60 & .030 & .04 & - \\
\hline NOV 1983 & & & & & & & & & & & \\
\hline $\begin{array}{c}02 \ldots \\
\text { OCT } 1984\end{array}$ & 99 & .14 & 1.18 & 3.49 & 3.49 & 15 & .010 & 3.50 & .030 & .04 & - \\
\hline $\begin{array}{c}18 \ldots \\
\text { OCT } 1985\end{array}$ & 100 & .13 & 1.44 & 3.56 & 3.56 & 16 & .040 & 3.60 & .060 & .08 & - \\
\hline $\begin{array}{c}25 \ldots \\
\text { NOV } 1986\end{array}$ & 104 & .14 & 1.77 & 2.89 & 2.89 & 13 & .010 & 2.90 & .030 & .04 & .57 \\
\hline $\begin{array}{c}25 \ldots \\
\text { OCT } 1987\end{array}$ & 109 & .14 & 2.73 & 3.19 & 3.19 & 14 & .010 & 3.20 & .040 & .05 & .26 \\
\hline $\begin{array}{c}29 \ldots \\
\text { OCT } 1988\end{array}$ & 100 & .14 & 2.13 & 2.70 & - & - & $<.010$ & 2.70 & .060 & .08 & .34 \\
\hline $\begin{array}{c}31 \ldots \\
\text { OCT } 1989\end{array}$ & 111 & .15 & 1.23 & 3.80 & - & - & $<.010$ & 3.80 & .010 & .01 & .49 \\
\hline $\begin{array}{c}31 \ldots \\
\text { NOV } 1990\end{array}$ & 270 & .37 & 9.48 & 3.50 & - & - & $<.010$ & 3.50 & $<.010$ & - & .40 \\
\hline $\begin{array}{c}09 \ldots \\
\text { NOV } 1991\end{array}$ & 117 & .16 & 1.28 & 3.90 & - & - & $<.010$ & 3.90 & .050 & .06 & .45 \\
\hline $\begin{array}{c}13 \ldots \\
\text { NOV } 1992\end{array}$ & 112 & .15 & 1.18 & 3.50 & - & - & $<.010$ & 3.50 & .040 & .05 & .56 \\
\hline $\begin{array}{c}16 \ldots \\
\text { NOV } 1993\end{array}$ & 103 & .14 & 1.75 & 3.87 & 3.87 & 17 & .030 & 3.90 & $<.010$ & - & - \\
\hline $\begin{array}{c}23 \ldots \\
\text { NOV } 1994\end{array}$ & - & - & - & 4.00 & - & - & $<.010$ & 4.00 & .010 & .01 & - \\
\hline $03 \ldots$ & - & - & - & 2.79 & 2.79 & 12 & .010 & 2.80 & $<.015$ & - & - \\
\hline
\end{tabular}


Table 3. Water-quality data from surface-water sites-Continued

01478220 - West Branch White Clay Creek near Chesterville (Site 30)—Continued

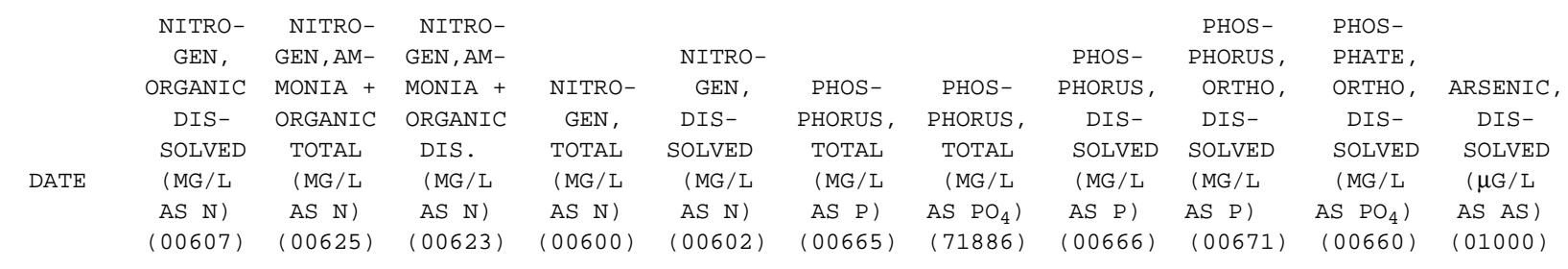

\begin{tabular}{|c|c|c|c|c|c|c|c|c|c|c|c|}
\hline $\begin{array}{c}\text { OCT } 1981 \\
29 \ldots \\
\text { OCT } 1982\end{array}$ & - & 0.62 & 0.63 & 2.5 & 2.5 & 0.070 & 0.21 & 0.080 & 0.050 & 0.15 & 1 \\
\hline $20 \ldots$ & 0.77 & - & .80 & - & 3.4 & - & - & .020 & $<.010$ & - & 1 \\
\hline NOV 1983 & & & & & & & & & & & \\
\hline $\begin{array}{c}02 \ldots \\
\text { OCT } 1984\end{array}$ & .47 & - & .50 & - & 4.0 & .030 & .09 & .020 & $<.010$ & - & - \\
\hline $\begin{array}{c}18 \ldots \\
\text { OCT } 1985\end{array}$ & .34 & - & .40 & - & 4.0 & $<.010$ & - & .010 & .020 & .06 & - \\
\hline $\begin{array}{c}25 \ldots \\
\text { NOV } 1986\end{array}$ & .37 & .60 & .40 & 3.5 & 3.3 & .010 & .03 & $<.010$ & .010 & .03 & - \\
\hline $\begin{array}{c}25 \ldots \\
\text { OCT } 1987\end{array}$ & .46 & .30 & .50 & 3.5 & 3.7 & .050 & - & .040 & .030 & .09 & - \\
\hline $\begin{array}{c}29 \ldots \\
\text { OCT } 1988\end{array}$ & .14 & .40 & .20 & 3.1 & 2.9 & .040 & - & .020 & .010 & .03 & - \\
\hline $\begin{array}{c}31 \ldots \\
\text { OCT } 1989\end{array}$ & - & .50 & $<.20$ & 4.3 & - & .020 & - & .010 & $<.010$ & - & - \\
\hline $\begin{array}{c}31 \ldots \\
\text { NOV } 1990\end{array}$ & - & .40 & .40 & 3.9 & 3.9 & .020 & - & .010 & .010 & .03 & - \\
\hline $\begin{array}{c}09 \ldots \\
\text { NOV } 1991\end{array}$ & .35 & .50 & .40 & 4.4 & 4.3 & $<.010$ & - & $<.010$ & $<.010$ & - & - \\
\hline $\begin{array}{c}13 \ldots \\
\text { NOV } 1992\end{array}$ & .36 & .60 & .40 & 4.1 & 3.9 & .030 & - & .010 & $<.010$ & - & - \\
\hline $\begin{array}{c}16 \ldots \\
\text { NOV } 1993\end{array}$ & - & $<.20$ & $<.20$ & - & - & .020 & - & .030 & .010 & .03 & - \\
\hline $\begin{array}{c}23 \ldots \\
\text { NOV } 1994\end{array}$ & - & - & - & - & - & - & - & - & $<.010$ & - & - \\
\hline $03 \ldots$ & - & - & - & - & - & - & - & - & $<.010$ & - & - \\
\hline
\end{tabular}


Table 3. Water-quality data from surface-water sites-Continued

01478220 - West Branch White Clay Creek near Chesterville (Site 30)—Continued

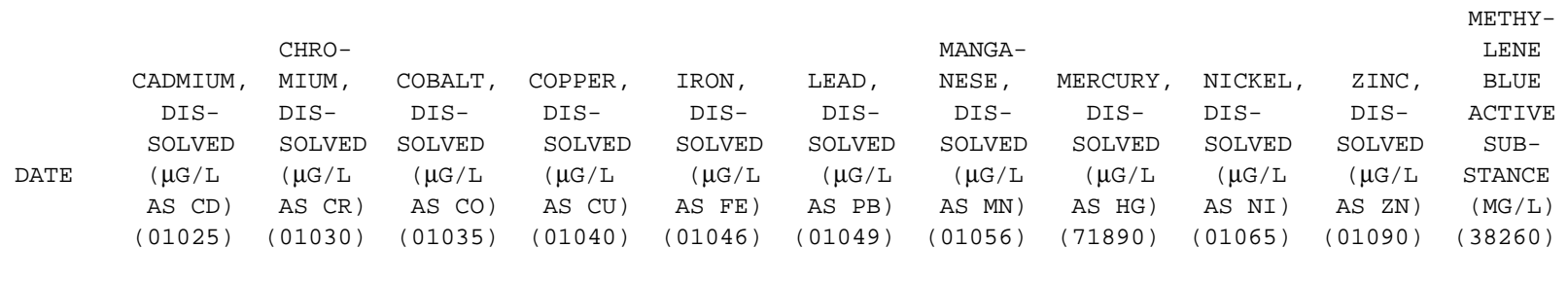

OCT 1981

$$
29 \ldots
$$

OCT 1982

$20 \ldots$

NOV 1983

$$
<1.0 \quad 1 \quad<1
$$

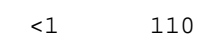

$<1$

200

0.1

2

$<4$

ND

$<1.0<1$

42

35

$<1$

22

$-$

$<1$

$<4$

0.08

$02 \ldots$

OCT 1984

$18 \ldots$

OCT 1985

25 ...

NOV 1986

$25 \ldots$

OCT 1987

$29 .$.

OCT 1988

$31 \ldots$

OCT 1989

$31 \ldots$

NOV 1990

$09 \ldots$

NOV 1991

13 ...

NOV 1992

$16 \ldots$

NOV 1993

23 ...

NOV 1994

$03 \ldots$ 
Table 3. Water-quality data from surface-water sites-Continued

01479680 - West Branch Red Clay Creek at Kennett Square, Pa. (Site 27)

\begin{tabular}{|c|c|c|c|c|c|c|c|c|c|c|c|}
\hline & & DIS- & & $\mathrm{PH}$ & & & & & HARD - & & \\
\hline & & CHARGE, & SPE- & WATER & & & & HARD - & NESS & & MAGNE- \\
\hline & & INST. & CIFIC & WHOLE & & & & NESS, & NONCARB & CALCIUM, & SIUM, \\
\hline & & (CUBIC & $\mathrm{CON}-$ & FIELD & TEMPER- & TUR- & OXYGEN, & TOTAL & WH WAT & DIS- & DIS- \\
\hline & & FEET & DUCT- & (STAND- & ATURE & BID- & DIS- & (MG / L & TOT FLD & SOLVED & SOLVED \\
\hline DATE & TIME & PER & ANCE & ARD & WATER & ITY & SOLVED & AS & (MG/L AS & (MG / L & (MG / L \\
\hline & & SECOND) & $(\mu \mathrm{S} / \mathrm{CM})$ & UNITS) & $(\mathrm{DEG} C)$ & (NTU) & (MG/L) & $\left.\mathrm{CACO}_{3}\right)$ & $\left.\mathrm{CACO}_{3}\right)$ & AS CA) & AS MG) \\
\hline & & $(00061)$ & $(00095)$ & $(00400)$ & $(00010)$ & $(00076)$ & $(00300)$ & $(00900)$ & $(00902)$ & $(00915)$ & $(00925)$ \\
\hline
\end{tabular}

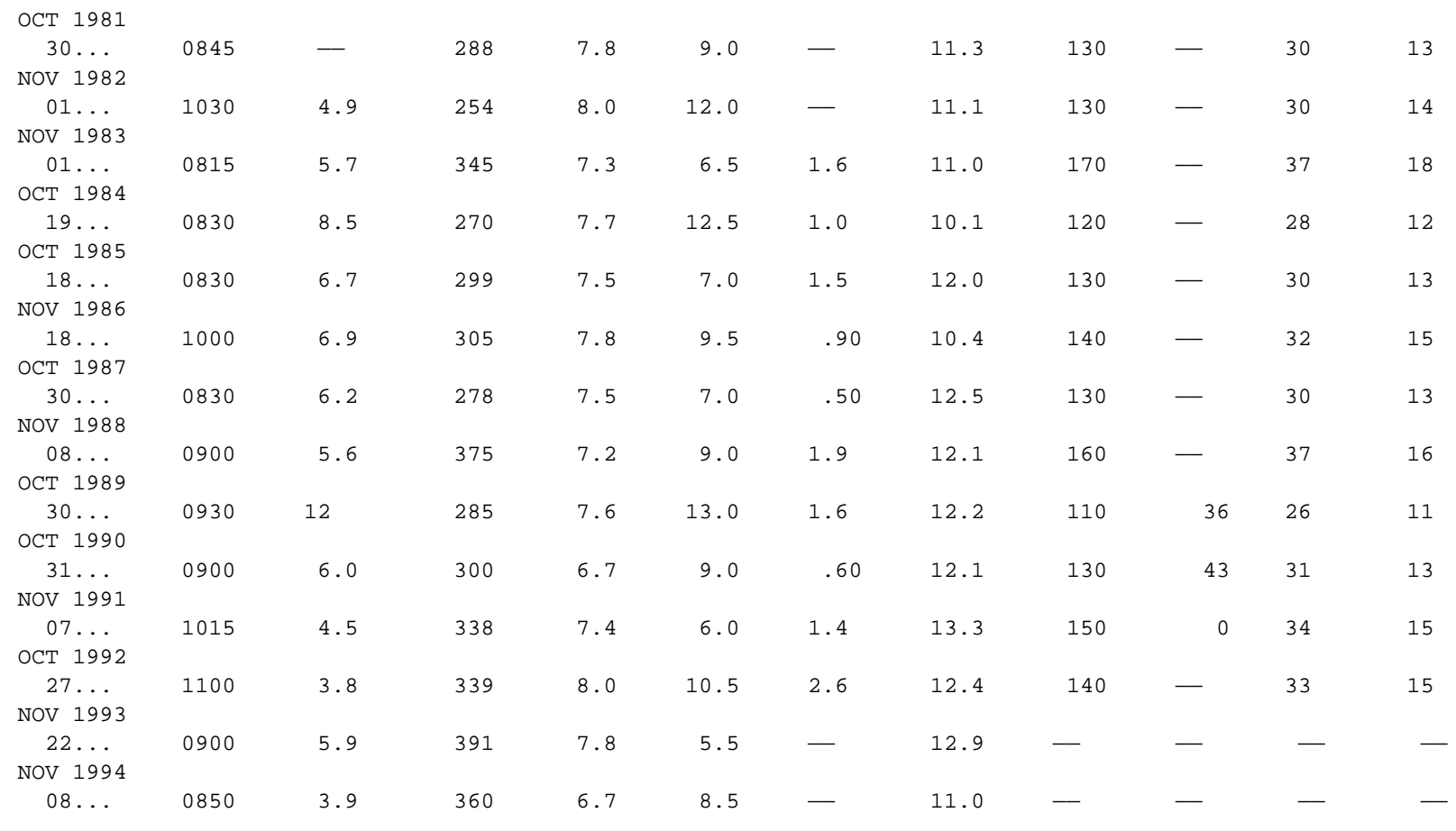


Table 3. Water-quality data from surface-water sites-Continued

01479680 - West Branch Red Clay Creek at Kennett Square, Pa. (Site 27)—Continued

\begin{tabular}{|c|c|c|c|c|c|c|c|c|c|c|}
\hline & & & & POTAS- & $\begin{array}{r}\text { ALKA- } \\
\text { LINITY }\end{array}$ & $\begin{array}{l}\text { ALKA- } \\
\text { LINITY }\end{array}$ & & 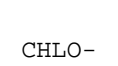 & FI & SII \\
\hline & SOD IUM, & & SODIUM & SIUM, & WAT WH & WAT WH & SULFATE, & RIDE, & RIDE, & DIS- \\
\hline & DIS- & & $\mathrm{AD}-$ & DIS- & TOT FET & TOT IT & DIS- & DIS- & DIS- & SOLVED \\
\hline & SOLVED & & SORP- & SOLVED & FIELD & FIELD & SOLVED & SOLVED & SOLVED & (MG / L \\
\hline $\mathrm{ATE}$ & (MG / L & SODIUM & TION & (MG / L & (MG/L AS & (MG/L AS & (MG / L & (MG / L & (MG / L & AS \\
\hline & AS NA) & PERCENT & RATIO & AS K) & $\left.\mathrm{CACO}_{3}\right)$ & $\left.\mathrm{CACO}_{3}\right)$ & AS $\left.\quad \mathrm{SO}_{4}\right)$ & AS CL) & AS F) & $\mathrm{SIO}_{2}$ ) \\
\hline & $(00930)$ & (00932) & $(00931)$ & $(00935)$ & $(00410)$ & $(00419)$ & $(00945)$ & $(00940)$ & $(00950)$ & $(00955)$ \\
\hline
\end{tabular}

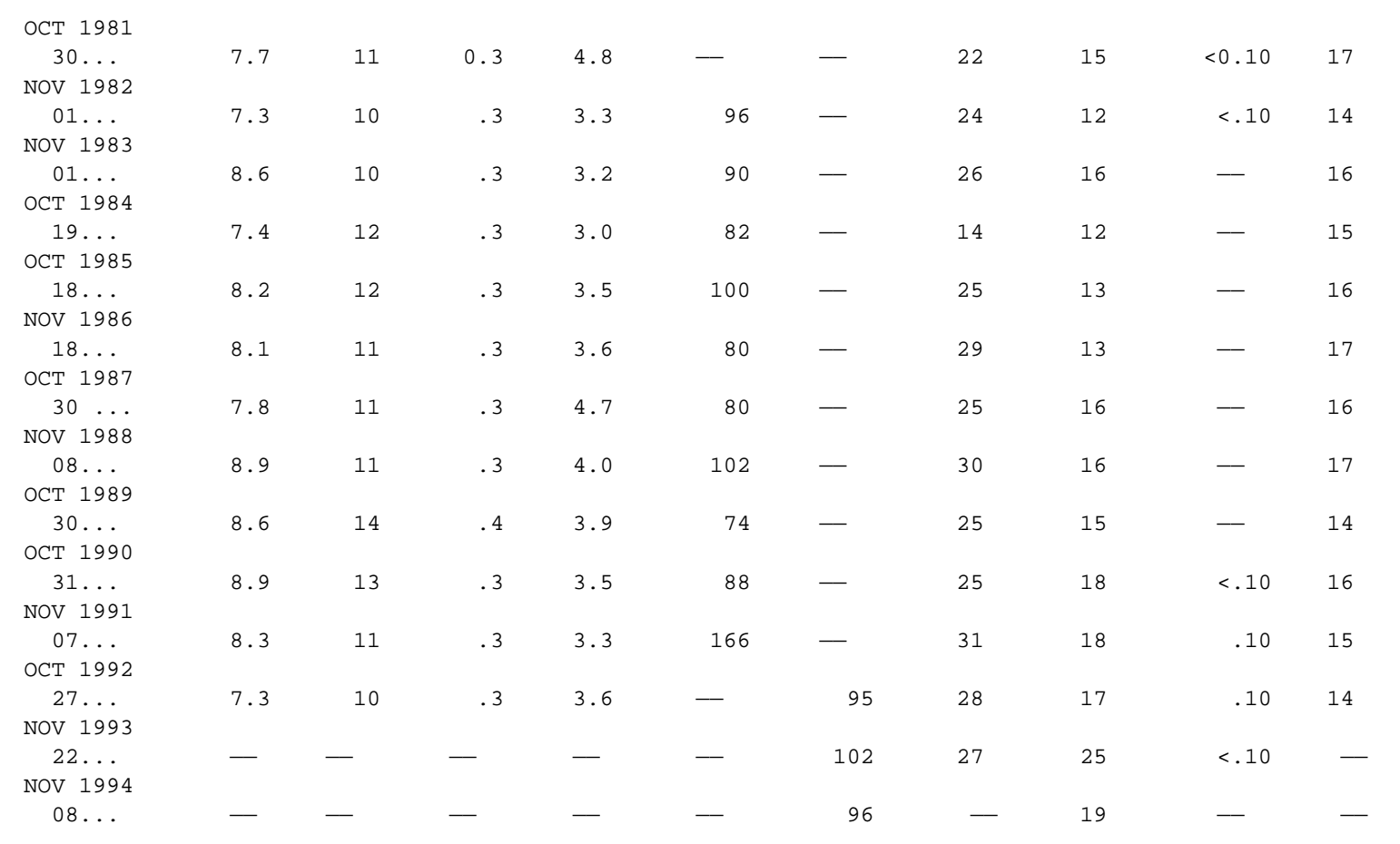


Table 3. Water-quality data from surface-water sites-Continued

01479680 - West Branch Red Clay Creek at Kennett Square, Pa. (Site 27)—Continued

\begin{tabular}{|c|c|c|c|c|c|c|c|c|c|c|}
\hline DATE & $\begin{array}{l}\text { SOLIDS, } \\
\text { RESIDUE } \\
\text { AT } 180 \\
\text { DEG. C } \\
\text { DIS- } \\
\text { SOLVED } \\
(\mathrm{MG} / \mathrm{L}) \\
(70300)\end{array}$ & $\begin{array}{l}\text { SOLIDS, } \\
\text { SUM OF } \\
\text { CONSTI- } \\
\text { TUENTS, } \\
\text { DIS- } \\
\text { SOLVED } \\
(\text { MG/L) } \\
(70301)\end{array}$ & $\begin{array}{c}\text { SOLIDS, } \\
\text { DIS- } \\
\text { SOLVED } \\
\text { (TONS } \\
\text { PER } \\
\text { AC-FT) } \\
(70303)\end{array}$ & $\begin{array}{c}\text { SOLIDS, } \\
\text { DIS- } \\
\text { SOLVED } \\
\text { (TONS } \\
\text { PER } \\
\text { DAY) } \\
(70302)\end{array}$ & $\begin{array}{l}\text { NITRO- } \\
\text { GEN, } \\
\text { NITRATE } \\
\text { TOTAL } \\
\text { (MG/L } \\
\text { AS N) } \\
(00620)\end{array}$ & $\begin{array}{c}\text { NITRO- } \\
\text { GEN, } \\
\text { NITRATE } \\
\text { DIS- } \\
\text { SOLVED } \\
\text { (MG/L } \\
\text { AS N) } \\
(00618)\end{array}$ & $\begin{array}{c}\text { NITRO- } \\
\text { GEN, } \\
\text { NITRATE } \\
\text { DIS- } \\
\text { SOLVED } \\
(\mathrm{MG} / \mathrm{L} \\
\left.\text { AS } \mathrm{NO}_{3}\right) \\
(71851)\end{array}$ & $\begin{array}{l}\text { NITRO- } \\
\text { GEN, } \\
\text { NITRITE } \\
\text { DIS- } \\
\text { SOLVED } \\
(\text { MG/L } \\
\text { AS N) } \\
(00613)\end{array}$ & $\begin{array}{c}\text { NITRO- } \\
\text { GEN, } \\
\mathrm{NO}_{2}+\mathrm{NO}_{3} \\
\text { DIS- } \\
\text { SOLVED } \\
(\mathrm{MG} / \mathrm{L} \\
\mathrm{AS} \mathrm{N}) \\
(00631)\end{array}$ & $\begin{array}{c}\text { NITRO- } \\
\text { GEN, } \\
\text { AMMONIA } \\
\text { DIS- } \\
\text { SOLVED } \\
\text { (MG/L } \\
\text { AS N) } \\
(00608)\end{array}$ \\
\hline OCT 1981 & & & & & & & & & & \\
\hline $\begin{array}{c}30 \ldots \\
\text { NOV } 1982\end{array}$ & 184 & - & 0.25 & - & 3.69 & 3.69 & 16 & 0.010 & 3.70 & $<0.010$ \\
\hline $\begin{array}{c}01 \ldots \\
\text { NOV } 1983\end{array}$ & 176 & 179 & .24 & 2.33 & 3.68 & 3.68 & 16 & .020 & 3.70 & $<.010$ \\
\hline $\begin{array}{c}01 \ldots \\
\text { OCT } 1984\end{array}$ & 215 & 201 & .29 & 3.31 & 5.00 & - & - & $<.010$ & 5.00 & .060 \\
\hline $\begin{array}{c}19 \ldots \\
\text { OCT } 1985\end{array}$ & 170 & 161 & .23 & 3.90 & 4.55 & 4.55 & 20 & .050 & 4.60 & .050 \\
\hline $\begin{array}{c}18 \ldots \\
\text { NOV } 1986\end{array}$ & 171 & 188 & .23 & 3.09 & 4.29 & 4.29 & 19 & .010 & 4.30 & .050 \\
\hline $\begin{array}{c}18 \ldots \\
\text { OCT } 1987\end{array}$ & 202 & 187 & .27 & 3.76 & 4.80 & - & - & $<.010$ & 4.80 & .060 \\
\hline $\begin{array}{c}30 \ldots \\
\text { NOV } 1988\end{array}$ & 181 & 179 & .25 & 3.03 & 4.20 & - & - & $<.010$ & 4.20 & .050 \\
\hline $\begin{array}{c}08 \ldots \\
\text { OCT } 1989\end{array}$ & - & 211 & .29 & 3.19 & 4.68 & 4.68 & 21 & .020 & 4.70 & .040 \\
\hline $\begin{array}{c}30 \ldots \\
\text { OCT } 1990\end{array}$ & - & 169 & .23 & 5.48 & 4.69 & 4.69 & 21 & .010 & 4.70 & .030 \\
\hline $\begin{array}{c}31 \ldots \\
\text { NOV } 1991\end{array}$ & - & 194 & .26 & 3.14 & 5.58 & 5.58 & 25 & .020 & 5.60 & .280 \\
\hline $\begin{array}{c}07 \ldots \\
\text { OCT } 1992\end{array}$ & - & 249 & .34 & 3.03 & 5.60 & - & - & $<.010$ & 5.60 & .030 \\
\hline $\begin{array}{c}27 \ldots \\
\text { NOV } 1993\end{array}$ & - & 197 & .27 & 2.02 & 4.87 & 4.87 & 22 & .030 & 4.90 & .020 \\
\hline $\begin{array}{c}22 \ldots \\
\text { NOV } 1994\end{array}$ & - & - & - & - & 4.98 & 4.98 & 22 & .020 & 5.00 & .040 \\
\hline $08 \ldots$ & - & - & - & - & 4.60 & - & - & $<.010$ & 4.60 & $<.015$ \\
\hline
\end{tabular}


Table 3. Water-quality data from surface-water sites-Continued

01479680 - West Branch Red Clay Creek at Kennett Square, Pa. (Site 27)—Continued

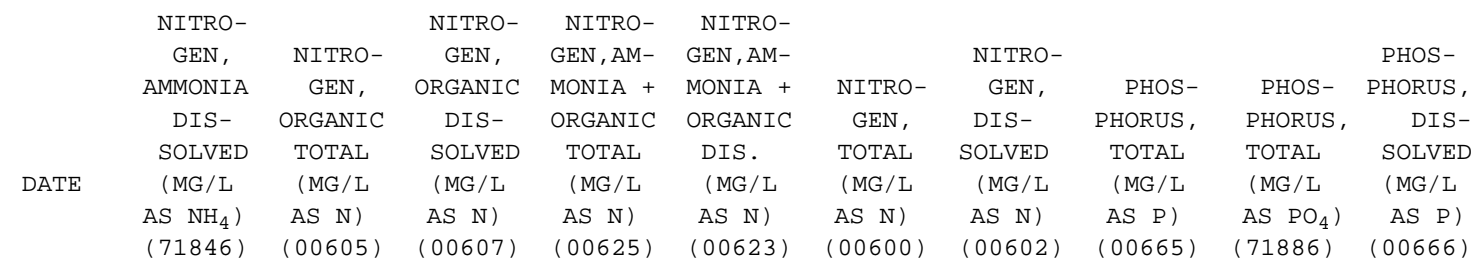

\begin{tabular}{|c|c|c|c|c|c|c|c|c|c|c|}
\hline $\begin{array}{c}\text { OCT } 1981 \\
30 \ldots \\
\text { NOV } 1982\end{array}$ & 0.01 & 0.87 & - & 0.89 & 0.49 & 4.6 & 4.2 & 0.090 & 0.28 & 0.080 \\
\hline $\begin{array}{c}01 \ldots \\
\text { NOV } 1983\end{array}$ & .01 & - & - & - & .30 & - & 4.0 & - & - & .030 \\
\hline $\begin{array}{c}01 \ldots \\
\text { ОСт } 1984\end{array}$ & .08 & - & 1.0 & - & 1.1 & - & 6.1 & .050 & .15 & .040 \\
\hline $\begin{array}{c}19 \ldots \\
\text { OCT } 1985\end{array}$ & .06 & - & .35 & - & .40 & - & 5.0 & .030 & - & .030 \\
\hline $\begin{array}{c}18 \ldots \\
\text { NOV } 1986\end{array}$ & .06 & .35 & .35 & .40 & .40 & 4.7 & 4.7 & .030 & .09 & .030 \\
\hline $\begin{array}{c}18 \ldots \\
\text { OCT } 1987\end{array}$ & .08 & .94 & .64 & 1.0 & .70 & 5.8 & 5.5 & .060 & - & .030 \\
\hline $\begin{array}{c}30 \ldots \\
\text { NOV } 1988\end{array}$ & .06 & .25 & - & .30 & $<.20$ & 4.5 & - & .040 & - & .020 \\
\hline $\begin{array}{c}08 \ldots \\
\text { ОСТ } 1989\end{array}$ & .05 & .46 & .46 & .50 & .50 & 5.2 & 5.2 & .040 & - & .030 \\
\hline $\begin{array}{c}30 \ldots \\
\text { OCT } 1990\end{array}$ & .04 & .27 & .27 & .30 & .30 & 5.0 & 5.0 & .030 & - & .020 \\
\hline $\begin{array}{c}31 \ldots \\
\text { NOV } 1991\end{array}$ & .36 & .92 & .82 & 1.2 & 1.1 & 6.8 & 6.7 & .180 & - & .120 \\
\hline $\begin{array}{c}07 \ldots \\
\text { OCT } 1992\end{array}$ & .04 & - & .17 & $<.20$ & .20 & - & 5.8 & .040 & - & .030 \\
\hline $\begin{array}{c}27 \ldots \\
\text { NOV } 1993\end{array}$ & .03 & .38 & .48 & .40 & .50 & 5.3 & 5.4 & .080 & - & .060 \\
\hline $\begin{array}{c}22 \ldots \\
\text { NOV } 1994\end{array}$ & .05 & - & - & - & - & - & - & - & - & - \\
\hline $08 \ldots$ & - & - & - & - & - & - & - & - & - & - \\
\hline
\end{tabular}


Table 3. Water-quality data from surface-water sites-Continued

01479680 - West Branch Red Clay Creek at Kennett Square, Pa. (Site 27)—Continued

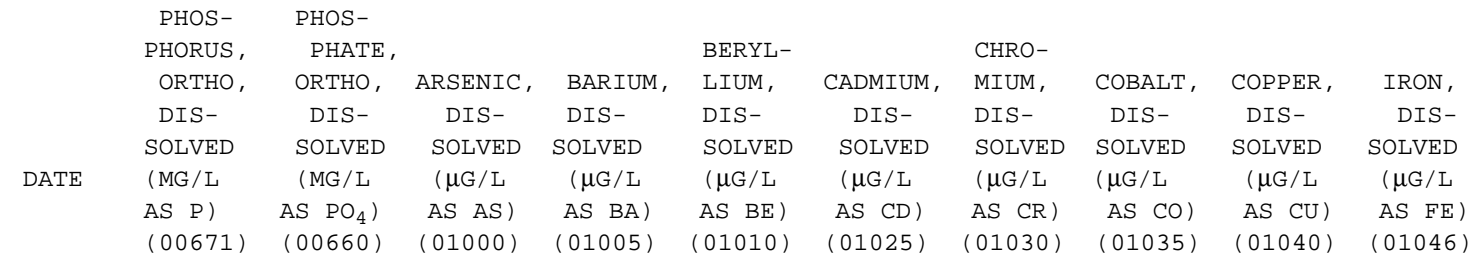

\begin{tabular}{|c|c|c|c|c|c|c|c|c|c|c|}
\hline $\begin{array}{c}30 \ldots \\
\text { NOV } 1982\end{array}$ & 0.080 & 0.25 & $<1$ & - & - & $<1.0$ & 3 & $<1$ & 2 & 78 \\
\hline $01 \ldots$ & .030 & .09 & 1 & - & - & $<1.0$ & $<1$ & $<1$ & 2 & 37 \\
\hline $\begin{array}{c}01 \ldots \\
\text { OCT } 1984\end{array}$ & .020 & .06 & 1 & - & - & $<1.0$ & $<1$ & $<1$ & 1 & 40 \\
\hline $\begin{array}{c}19 \ldots \\
\text { ОСТ } 1985\end{array}$ & .030 & .09 & $<1$ & - & - & $<1.0$ & 2 & - & 1 & 51 \\
\hline $\begin{array}{c}18 \ldots \\
\text { NOV } 1986\end{array}$ & .030 & .09 & $<1$ & - & - & $<1.0$ & $<1$ & - & $<1$ & 24 \\
\hline $\begin{array}{c}18 \ldots \\
\text { OCT } 1987\end{array}$ & .020 & .06 & $<1$ & - & - & $<1.0$ & $<1$ & - & $<1$ & 33 \\
\hline $\begin{array}{cc}3 & \ldots \\
\text { NOV } & 1988\end{array}$ & .020 & .06 & $<1$ & - & - & $<1.0$ & $<1$ & - & 1 & 43 \\
\hline $\begin{array}{c}08 \ldots \\
\text { OCT } 1989\end{array}$ & .030 & .09 & $<1$ & 44 & $<0.5$ & $<1.0$ & $<5$ & $<3$ & $<10$ & 40 \\
\hline $\begin{array}{c}30 \ldots \\
\text { OCT } 1990\end{array}$ & .020 & .06 & $<1$ & 45 & $<.5$ & $<1.0$ & $<5$ & $<3$ & $<10$ & 53 \\
\hline $\begin{array}{c}31 \ldots \\
\text { NOV } 1991\end{array}$ & .120 & .37 & $<1$ & 42 & $<.5$ & $<1.0$ & $<5$ & $<3$ & $<10$ & 50 \\
\hline $\begin{array}{c}07 \ldots \\
\text { OCT } 1992\end{array}$ & .030 & .09 & $<1$ & 40 & $<.5$ & $<1.0$ & $<5$ & $<3$ & $<10$ & 26 \\
\hline $\begin{array}{c}27 \ldots \\
\text { NOV } 1993\end{array}$ & .060 & .18 & $<1$ & 41 & $<.5$ & $<1.0$ & $<5$ & $<3$ & $<10$ & 23 \\
\hline $\begin{array}{c}22 \ldots \\
\text { NOV } 1994\end{array}$ & .040 & .12 & - & - & - & - & - & - & - & - \\
\hline $08 \ldots$ & $<.010$ & - & - & - & - & - & - & - & - & - \\
\hline
\end{tabular}


Table 3. Water-quality data from surface-water sites-Continued

01479680 - West Branch Red Clay Creek at Kennett Square, Pa. (Site 27)—Continued

\begin{tabular}{|c|c|c|c|c|c|c|c|c|c|c|}
\hline DATE & $\begin{array}{c}\text { LEAD, } \\
\text { DIS- } \\
\text { SOLVED } \\
(\mu \mathrm{G} / \mathrm{L} \\
\text { AS PB) } \\
(01049)\end{array}$ & $\begin{array}{c}\text { LITHIUM, } \\
\text { DIS- } \\
\text { SOLVED } \\
(\mu \mathrm{G} / \mathrm{L} \\
\text { AS LI) } \\
(01130)\end{array}$ & $\begin{array}{l}\text { MANGA- } \\
\text { NESE, } \\
\text { DIS- } \\
\text { SOLVED } \\
(\mu \mathrm{G} / \mathrm{L} \\
\text { AS MN) } \\
(01056)\end{array}$ & $\begin{array}{c}\text { MERCURY, } \\
\text { DIS- } \\
\text { SOLVED } \\
(\mu \mathrm{G} / \mathrm{L} \\
\text { AS HG) } \\
(71890)\end{array}$ & $\begin{array}{l}\text { NICKEL, } \\
\text { DIS- } \\
\text { SOLVED } \\
(\mu \mathrm{G} / \mathrm{L} \\
\text { AS NI) } \\
(01065)\end{array}$ & $\begin{array}{l}\text { SILVER, } \\
\text { DIS- } \\
\text { SOLVED } \\
(\mu \mathrm{G} / \mathrm{L} \\
\text { AS AG) } \\
(01075)\end{array}$ & $\begin{array}{c}\text { STRON- } \\
\text { TIUM, } \\
\text { DIS- } \\
\text { SOLVED } \\
(\mu \mathrm{G} / \mathrm{L} \\
\text { AS SR) } \\
(01080)\end{array}$ & $\begin{array}{c}\text { VANA- } \\
\text { DIUM, } \\
\text { DIS- } \\
\text { SOLVED } \\
(\mu \mathrm{G} / \mathrm{L} \\
\text { AS V) } \\
(01085)\end{array}$ & $\begin{array}{r}\text { ZINC, } \\
\text { DIS- } \\
\text { SOLVED } \\
(\mu \mathrm{G} / \mathrm{L} \\
\mathrm{AS} \quad \mathrm{ZN}) \\
(01090)\end{array}$ & $\begin{array}{l}\text { METHY- } \\
\text { LENE } \\
\text { BLUE } \\
\text { ACTIVE } \\
\text { SUB- } \\
\text { STANCE } \\
\text { (MG/L) } \\
(38260)\end{array}$ \\
\hline ОСТ 1981 & & & & & & & & & & \\
\hline $\begin{array}{c}30 \ldots \\
\text { NOV } 1982\end{array}$ & $<1$ & - & 130 & $<0.1$ & 4 & - & - & - & $<4$ & 0.10 \\
\hline $\begin{array}{c}01 \ldots \\
\text { NOV } 1983\end{array}$ & $<1$ & - & 32 & $<.1$ & $<1$ & - & - & - & $<4$ & .04 \\
\hline $\begin{array}{c}01 \ldots \\
\text { OCT } 1984\end{array}$ & $<1$ & - & 31 & .2 & $<1$ & $<1.0$ & - & - & 5 & - \\
\hline $\begin{array}{c}19 \ldots \\
\text { OCT } 1985\end{array}$ & 2 & - & 40 & $<.1$ & 2 & $<1.0$ & - & - & 6 & - \\
\hline $\begin{array}{c}18 \ldots \\
\text { NOV } 1986\end{array}$ & $<1$ & - & 30 & $<.1$ & $<1$ & $<1.0$ & - & - & 7 & - \\
\hline $\begin{array}{c}18 \ldots \\
\text { OCT } 1987\end{array}$ & 5 & - & 42 & $<.1$ & 1 & $<1.0$ & - & - & 5 & - \\
\hline $\begin{array}{c}30 \ldots \\
\text { NOV } 1988\end{array}$ & $<5$ & - & 46 & $<.1$ & 4 & $<1.0$ & - & - & $<3$ & - \\
\hline $\begin{array}{c}08 \ldots \\
\text { OCT } 1989\end{array}$ & $<10$ & 42 & 32 & 1.8 & $<10$ & $<1.0$ & 96 & $<6$ & 20 & - \\
\hline $\begin{array}{c}30 \ldots \\
\text { OCT } 1990\end{array}$ & $<10$ & $<4$ & 48 & .5 & $<10$ & 3.0 & 110 & $<6$ & $<3$ & - \\
\hline $\begin{array}{c}31 \ldots \\
\text { NOV } 1991\end{array}$ & $<10$ & $<4$ & 35 & $<.1$ & $<10$ & $<1.0$ & 100 & $<6$ & 4 & - \\
\hline $\begin{array}{c}07 \ldots \\
\text { OCT } 1992\end{array}$ & $<10$ & 5 & 22 & $<.1$ & $<10$ & 1.0 & 96 & $<6$ & $<3$ & - \\
\hline $\begin{array}{c}27 \ldots \\
\text { NOV } 1993\end{array}$ & $<10$ & $<4$ & 25 & $<.1$ & $<10$ & $<1.0$ & 99 & $<6$ & 5 & - \\
\hline $\begin{array}{c}22 \ldots \\
\text { NOV } 1994\end{array}$ & - & - & - & - & - & - & - & - & - & - \\
\hline $08 \ldots$ & - & - & - & - & - & - & - & - & - & - \\
\hline
\end{tabular}


Table 3. Water-quality data from surface-water sites-Continued

01479800 - East Branch Red Clay Creek near Five Point, Pa. (Site 26)

\begin{tabular}{|c|c|c|c|c|c|c|c|c|c|c|c|}
\hline & & DIS- & & $\mathrm{PH}$ & & & & & HARD- & & \\
\hline & & CHARGE, & $\mathrm{SPE}-$ & WATER & & & & HARD- & NESS & & MAGNE- \\
\hline & & INST. & CIFIC & WHOLE & & & & NESS, & NONCARB & CALCIUM, & SIUM, \\
\hline & & (CUBIC & $\mathrm{CON}-$ & FIELD & TEMPER- & TUR- & OXYGEN, & TOTAL & WH WAT & DIS- & DIS- \\
\hline & & FEET & DUCT- & (STAND- & ATURE & BID- & DIS- & (MG / L & TOT FLD & SOLVED & SOLVED \\
\hline DATE & TIME & PER & ANCE & $\mathrm{ARD}$ & WATER & ITY & SOLVED & AS & (MG/L AS & (MG / L & (MG / L \\
\hline & & SECOND) & $(\mu \mathrm{S} / \mathrm{CM})$ & UNITS) & $(\mathrm{DEG} C)$ & (NTU) & $(\mathrm{MG} / \mathrm{L})$ & $\mathrm{CACO}_{3}$ ) & $\left.\mathrm{CACO}_{3}\right)$ & AS CA) & AS MG) \\
\hline & & $(00061)$ & $(00095)$ & $(00400)$ & $(00010)$ & $(00076)$ & $(00300)$ & $(00900)$ & $(00902)$ & (00915) & $(00925)$ \\
\hline
\end{tabular}

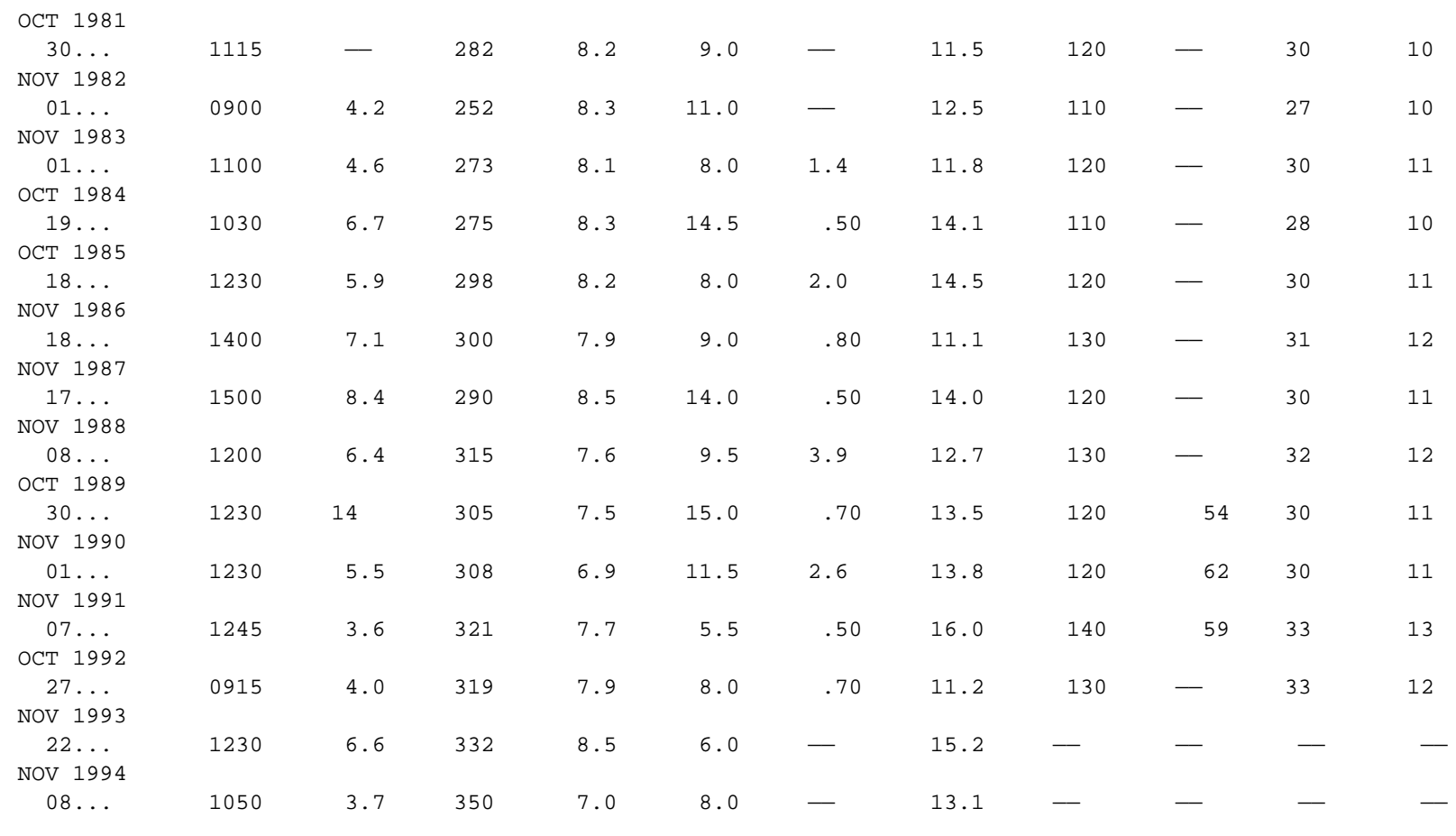


Table 3. Water-quality data from surface-water sites-Continued

01479800 - East Branch Red Clay Creek near Five Point, Pa. (Site 26)—Continued

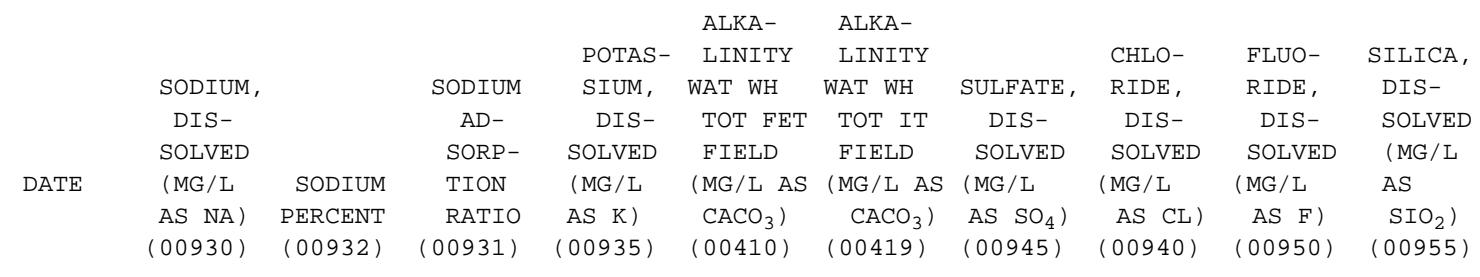

\begin{tabular}{|c|c|c|c|c|c|c|c|c|c|c|}
\hline $\begin{array}{c}\text { OCT } 1981 \\
30 \ldots \\
\text { NOV } 1982\end{array}$ & 9.8 & 15 & 0.4 & 6.7 & - & - & 29 & 19 & $<0.10$ & 18 \\
\hline $\begin{array}{c}01 \ldots \\
\text { NOV } 1983\end{array}$ & 9.3 & 15 & .4 & 3.7 & 72 & - & 30 & 16 & $<.10$ & 14 \\
\hline $01 \ldots$ & 12 & 17 & .5 & 4.7 & 86 & - & 37 & 21 & - & 17 \\
\hline $\begin{array}{c}\text { OCT } 1984 \\
19 \ldots\end{array}$ & 9.2 & 15 & .4 & 3.8 & 66 & - & 34 & 19 & - & 15 \\
\hline $\begin{array}{c}\text { OCT } 1985 \\
18 \ldots \\
\text { NOV } 1986\end{array}$ & 10 & 15 & .4 & 4.2 & 74 & - & 33 & 17 & - & 17 \\
\hline $\begin{array}{c}18 \ldots \\
\text { NOV } 1987\end{array}$ & 10 & 14 & .4 & 5.5 & 66 & - & 46 & 16 & - & 19 \\
\hline $\begin{array}{c}17 \ldots \\
\text { NOV } 1988\end{array}$ & 12 & 17 & .5 & 4.2 & 67 & - & 36 & 23 & - & 15 \\
\hline $\begin{array}{c}08 \ldots \\
\text { OCT } 1989\end{array}$ & 11 & 15 & .4 & 5.5 & 70 & - & 50 & 17 & - & 17 \\
\hline $\begin{array}{c}30 \ldots \\
\text { NOV } 1990\end{array}$ & 10 & 15 & .4 & 4.0 & 66 & - & 35 & 17 & - & 17 \\
\hline $\begin{array}{c}01 \ldots \\
\text { NOV } 1991\end{array}$ & 9.9 & 15 & .4 & 3.6 & 58 & - & 33 & 19 & .30 & 16 \\
\hline $\begin{array}{c}07 \ldots \\
\text { OCT } 1992\end{array}$ & 11 & 15 & .4 & 3.8 & 77 & - & 42 & 23 & .10 & 15 \\
\hline $\begin{array}{c}27 \ldots \\
\text { NOV } 1993\end{array}$ & 35 & 35 & 1 & 6.7 & - & 66 & 34 & 61 & .30 & 16 \\
\hline $\begin{array}{c}22 \ldots \\
\text { NOV } 1994\end{array}$ & - & - & - & - & - & 136 & 37 & 20 & $<.10$ & - \\
\hline $08 \ldots$ & - & - & - & - & - & 85 & - & 25 & - & - \\
\hline
\end{tabular}


Table 3. Water-quality data from surface-water sites-Continued

01479800 - East Branch Red Clay Creek near Five Point, Pa. (Site 26)—Continued

\begin{tabular}{|c|c|c|c|c|c|c|c|c|c|c|}
\hline DATE & $\begin{array}{c}\text { SOLIDS, } \\
\text { RESIDUE } \\
\text { AT } 180 \\
\text { DEG. C } \\
\text { DIS- } \\
\text { SOLVED } \\
(\mathrm{MG} / \mathrm{L}) \\
(70300)\end{array}$ & $\begin{array}{l}\text { SOLIDS, } \\
\text { SUM OF } \\
\text { CONSTI- } \\
\text { TUENTS, } \\
\text { DIS- } \\
\text { SOLVED } \\
\text { (MG/L) } \\
(70301)\end{array}$ & $\begin{array}{c}\text { SOLIDS, } \\
\text { DIS- } \\
\text { SOLVED } \\
\text { (TONS } \\
\text { PER } \\
\text { AC-FT) } \\
(70303)\end{array}$ & $\begin{array}{c}\text { SOLIDS, } \\
\text { DIS- } \\
\text { SOLVED } \\
\text { (TONS } \\
\text { PER } \\
\text { DAY) } \\
(70302)\end{array}$ & $\begin{array}{c}\text { NITRO- } \\
\text { GEN, } \\
\text { NITRATE } \\
\text { TOTAL } \\
\text { (MG/L } \\
\text { AS N) } \\
(00620)\end{array}$ & $\begin{array}{c}\text { NITRO- } \\
\text { GEN, } \\
\text { NITRATE } \\
\text { DIS- } \\
\text { SOLVED } \\
\text { (MG/L } \\
\text { AS N) } \\
(00618)\end{array}$ & $\begin{array}{c}\text { NITRO- } \\
\text { GEN, } \\
\text { NITRATE } \\
\text { DIS- } \\
\text { SOLVED } \\
(\mathrm{MG} / \mathrm{L} \\
\left.\mathrm{AS} \mathrm{NO})_{3}\right) \\
(71851)\end{array}$ & $\begin{array}{c}\text { NITRO- } \\
\text { GEN, } \\
\text { NITRITE } \\
\text { DIS- } \\
\text { SOLVED } \\
\text { (MG/L } \\
\text { AS N) } \\
(00613)\end{array}$ & $\begin{array}{c}\mathrm{NITRO}- \\
\text { GEN, } \\
\mathrm{NO}_{2}+\mathrm{NO}_{3} \\
\text { DIS- } \\
\text { SOLVED } \\
(\mathrm{MG} / \mathrm{L} \\
\mathrm{AS} \mathrm{N}) \\
(00631)\end{array}$ & $\begin{array}{c}\text { NITRO- } \\
\text { GEN, } \\
\text { AMMONIA } \\
\text { DIS- } \\
\text { SOLVED } \\
\text { (MG/L } \\
\text { AS N) } \\
(00608)\end{array}$ \\
\hline OCT 1981 & & & & & & & & & & \\
\hline $\begin{array}{c}30 \ldots \\
\text { NOV } 1982\end{array}$ & 187 & - & 0.25 & - & 2.48 & 2.58 & 11 & 0.020 & 2.60 & $<0.010$ \\
\hline $\begin{array}{c}01 \ldots \\
\text { NOV } 1983\end{array}$ & 159 & 165 & .22 & 1.80 & 2.68 & 2.68 & 12 & .020 & 2.70 & $<.010$ \\
\hline $\begin{array}{c}01 \ldots \\
\text { ОСТ } 1984\end{array}$ & 187 & 203 & .25 & 2.32 & 4.08 & 4.08 & 18 & .020 & 4.10 & .070 \\
\hline $\begin{array}{c}19 \ldots \\
\text { OCT } 1985\end{array}$ & 168 & 176 & .23 & 3.04 & 3.85 & 3.85 & 17 & .050 & 3.90 & .040 \\
\hline $\begin{array}{c}18 \ldots \\
\text { NOV } 1986\end{array}$ & 174 & 182 & .24 & 2.77 & 3.49 & 3.49 & 15 & .010 & 3.50 & .030 \\
\hline $\begin{array}{c}18 \ldots \\
\text { NOV } 1987\end{array}$ & 206 & 198 & .28 & 3.95 & 4.27 & 4.27 & 19 & .030 & 4.30 & .040 \\
\hline $\begin{array}{c}17 \ldots \\
\text { NOV } 1988\end{array}$ & 203 & 187 & .28 & 4.60 & 3.60 & - & - & $<.010$ & 3.60 & $<.010$ \\
\hline $\begin{array}{c}08 \ldots \\
\text { ОСТ } 1989\end{array}$ & - & 200 & .27 & 3.46 & 2.99 & 2.99 & 13 & .010 & 3.00 & .020 \\
\hline $\begin{array}{c}30 \ldots \\
\text { NOV } 1990\end{array}$ & - & 181 & .25 & 6.85 & 3.88 & 3.88 & 17 & .020 & 3.90 & $<.010$ \\
\hline $\begin{array}{c}01 \ldots \\
\text { NOV } 1991\end{array}$ & - & 176 & .24 & 2.61 & 4.08 & 4.08 & 18 & .020 & 4.10 & $<.010$ \\
\hline $\begin{array}{c}07 \ldots \\
\text { OCT } 1992\end{array}$ & - & 204 & .28 & 1.98 & 3.70 & - & - & $<.010$ & 3.70 & .020 \\
\hline $\begin{array}{c}27 \ldots \\
\text { NOV } 1993\end{array}$ & - & 252 & .34 & 2.72 & 3.19 & 3.19 & 14 & .010 & 3.20 & $<.010$ \\
\hline $\begin{array}{c}22 \ldots \\
\text { NOV } 1994\end{array}$ & - & - & - & - & 3.58 & 3.58 & 16 & .020 & 3.60 & .020 \\
\hline $08 \ldots$ & - & - & - & - & 2.70 & - & - & $<.010$ & 2.70 & $<.015$ \\
\hline
\end{tabular}


Table 3. Water-quality data from surface-water sites-Continued

01479800 - East Branch Red Clay Creek near Five Point, Pa. (Site 26)—Continued

\begin{tabular}{|c|c|c|c|c|c|c|c|c|c|c|}
\hline \multirow{6}{*}{ ATE } & $\begin{array}{l}\text { NITRO- } \\
\text { GEN, }\end{array}$ & & $\begin{array}{c}\text { NITRO- } \\
\text { GEN, }\end{array}$ & $\begin{array}{l}\text { NITRO- } \\
\text { GEN, AM- }\end{array}$ & $\begin{array}{r}\text { NITRO- } \\
\text { GEN, AM- }\end{array}$ & & & & & \\
\hline & MMONIA & GEN & RGANIC & ONIA + & MONIA + & NITRO- & GEI & PHOS- & $\mathrm{PHC}$ & HO \\
\hline & DIS- & [C & DIS- & ORGE & ORGANIC & GEN， & S- & , & , & D \\
\hline & SOLVED & TOTAI & SOLVED & TOTAL & DIS. & TOTA & SOLVED & TOTAL & TO & SOLVED \\
\hline & (MG /L & (MG/ & (MG/L & (MG/L & (MG/L & (MG / L & (MG/L & (MG / L & (MG/L & (MG /L \\
\hline & $\begin{array}{c}\left.\mathrm{AS} \quad \mathrm{NH}_{4}\right) \\
(71846)\end{array}$ & $\begin{array}{l}\text { AS N) } \\
(00605)\end{array}$ & $\begin{array}{l}\text { AS N) } \\
(00607)\end{array}$ & $\begin{array}{l}\text { AS N) } \\
(00625)\end{array}$ & $\begin{array}{l}\text { AS N) } \\
(00623)\end{array}$ & $\begin{array}{l}\text { AS N) } \\
(00600)\end{array}$ & $\begin{array}{l}\text { AS N) } \\
(00602)\end{array}$ & $\begin{array}{l}\text { AS P) } \\
(00665)\end{array}$ & $\begin{array}{l}\left.\mathrm{AS} \mathrm{PO}_{4}\right) \\
(71886)\end{array}$ & $\begin{array}{l}\text { AS P) } \\
(00666)\end{array}$ \\
\hline
\end{tabular}

\begin{tabular}{|c|c|c|c|c|c|c|c|c|c|c|}
\hline $\begin{array}{c}30 \ldots \\
\text { NOV } 1982\end{array}$ & 0.01 & 0.74 & - & 0.74 & 0.57 & 3.2 & 3.2 & 0.080 & 0.25 & 0.060 \\
\hline $\begin{array}{c}01 \ldots \\
\text { NOV } 1983\end{array}$ & .01 & - & - & - & .70 & - & 3.4 & - & - & .030 \\
\hline $\begin{array}{c}01 \ldots \\
\text { OCT } 1984\end{array}$ & .09 & - & 0.73 & - & .80 & - & 4.9 & .100 & .31 & .080 \\
\hline $\begin{array}{c}19 \ldots \\
\text { OCT } 1985\end{array}$ & .05 & - & .66 & - & .70 & - & 4.6 & .050 & - & .060 \\
\hline $\begin{array}{c}18 \ldots \\
\text { NOV } 1986\end{array}$ & .04 & .57 & .57 & .60 & .60 & 4.1 & 4.1 & .060 & .18 & .050 \\
\hline $\begin{array}{c}18 \ldots \\
\text { NOV } 1987\end{array}$ & .05 & .56 & .26 & .60 & .30 & 4.9 & 4.6 & .020 & - & .050 \\
\hline $\begin{array}{c}17 \ldots \\
\text { NOV } 1988\end{array}$ & - & .20 & - & .20 & .20 & 3.8 & 3.8 & .070 & - & .050 \\
\hline $\begin{array}{c}08 \ldots \\
\text { OCT } 1989\end{array}$ & .03 & .48 & .48 & .50 & .50 & 3.5 & 3.5 & .070 & - & .050 \\
\hline $\begin{array}{c}30 \ldots \\
\text { NOV } 1990\end{array}$ & - & .70 & - & .70 & .30 & 4.6 & 4.2 & .030 & - & .020 \\
\hline $\begin{array}{c}01 \ldots \\
\text { NOV } 1991\end{array}$ & - & .70 & - & .70 & .60 & 4.8 & 4.7 & .050 & - & .030 \\
\hline $\begin{array}{c}07 \ldots \\
\text { OCT } 1992\end{array}$ & .03 & .28 & .28 & .30 & .30 & 4.0 & 4.0 & .020 & - & .030 \\
\hline $\begin{array}{c}27 \ldots \\
\text { NOV } 1993\end{array}$ & - & .20 & - & .20 & .20 & 3.4 & 3.4 & .030 & - & .010 \\
\hline $\begin{array}{c}22 \ldots \\
\text { NOV } 1994\end{array}$ & .03 & - & - & - & - & - & - & - & - & - \\
\hline $08 \ldots$ & - & - & - & - & - & - & - & - & - & - \\
\hline
\end{tabular}


Table 3. Water-quality data from surface-water sites-Continued

01479800 - East Branch Red Clay Creek near Five Point, Pa. (Site 26)—Continued

\begin{tabular}{|c|c|c|c|c|c|c|c|c|c|c|}
\hline DATE & $\begin{array}{l}\text { PHOS- } \\
\text { PHORUS, } \\
\text { ORTHO, } \\
\text { DIS- } \\
\text { SOLVED } \\
(\text { MG/L } \\
\text { AS P) } \\
(00671)\end{array}$ & $\begin{array}{l}\text { PHOS- } \\
\text { PHATE, } \\
\text { ORTHO, } \\
\text { DIS- } \\
\text { SOLVED } \\
(\mathrm{MG} / \mathrm{L} \\
\left.\text { AS PO })_{4}\right) \\
(00660)\end{array}$ & $\begin{array}{c}\text { ARSENIC, } \\
\text { DIS- } \\
\text { SOLVED } \\
(\mu \mathrm{G} / \mathrm{L} \\
\text { AS AS) } \\
(01000)\end{array}$ & $\begin{array}{l}\text { BARIUM, } \\
\text { DIS- } \\
\text { SOLVED } \\
(\mu \mathrm{G} / \mathrm{L} \\
\text { AS BA) } \\
(01005)\end{array}$ & $\begin{array}{l}\text { BERYL- } \\
\text { LIUM, } \\
\text { DIS- } \\
\text { SOLVED } \\
(\mu \mathrm{G} / \mathrm{L} \\
\text { AS BE) } \\
(01010)\end{array}$ & $\begin{array}{l}\text { CADMIUM, } \\
\text { DIS- } \\
\text { SOLVED } \\
(\mu \mathrm{G} / \mathrm{L} \\
\text { AS CD }) \\
(01025)\end{array}$ & $\begin{array}{l}\text { CHRO- } \\
\text { MIUM, } \\
\text { DIS- } \\
\text { SOLVED } \\
(\mu \mathrm{G} / \mathrm{L} \\
\text { AS CR) } \\
(01030)\end{array}$ & $\begin{array}{l}\text { COBALT, } \\
\text { DIS- } \\
\text { SOLVED } \\
(\mu \mathrm{G} / \mathrm{L} \\
\text { AS CO) } \\
(01035)\end{array}$ & $\begin{array}{l}\text { COPPER, } \\
\text { DIS- } \\
\text { SOLVED } \\
(\mu \mathrm{G} / \mathrm{L} \\
\text { AS CU) } \\
(01040)\end{array}$ & $\begin{array}{l}\text { IRON, } \\
\text { DIS- } \\
\text { SOLVED } \\
(\mu \mathrm{G} / \mathrm{L} \\
\text { AS FE) } \\
(01046)\end{array}$ \\
\hline OCT 1981 & & & & & & & & & & \\
\hline $\begin{array}{c}30 \ldots \\
\text { NOV } 1982\end{array}$ & 0.050 & 0.15 & ND & - & - & $<1.0$ & 2 & $<1$ & $<1$ & 58 \\
\hline $\begin{array}{c}01 \ldots \\
\text { NOV } 1983\end{array}$ & .020 & .06 & $<1$ & - & - & $<1.0$ & $<1$ & 1 & 1 & 40 \\
\hline $\begin{array}{c}01 \ldots \\
\text { OCT } 1984\end{array}$ & .080 & .25 & 1 & - & - & $<1.0$ & $<1$ & - & 2 & 55 \\
\hline $\begin{array}{c}19 \ldots \\
\text { OCT } 1985\end{array}$ & .060 & .18 & $<1$ & - & - & $<1.0$ & $<1$ & - & 1 & 36 \\
\hline $\begin{array}{c}18 \ldots \\
\text { NOV } 1986\end{array}$ & .050 & .15 & $<1$ & - & - & $<1.0$ & $<1$ & - & $<1$ & 18 \\
\hline $\begin{array}{c}18 \ldots \\
\text { NOV } 1987\end{array}$ & .030 & .09 & $<1$ & - & - & $<1.0$ & $<1$ & - & 4 & 48 \\
\hline $\begin{array}{c}17 \ldots \\
\text { NOV } 1988\end{array}$ & .030 & .09 & $<1$ & - & - & $<1.0$ & $<1$ & - & 1 & 26 \\
\hline $\begin{array}{c}08 \ldots \\
\text { OCT } 1989\end{array}$ & .040 & .12 & $<1$ & 54 & $<0.5$ & $<1.0$ & $<5$ & $<3$ & $<10$ & 65 \\
\hline $\begin{array}{c}30 \ldots \\
\text { NOV } 1990\end{array}$ & .020 & .06 & $<1$ & 53 & $<.5$ & $<1.0$ & $<5$ & $<3$ & $<10$ & 42 \\
\hline $\begin{array}{c}01 \ldots \\
\text { NOV } 1991\end{array}$ & .030 & .09 & $<1$ & 49 & $<.5$ & $<1.0$ & $<5$ & $<3$ & $<10$ & 33 \\
\hline $\begin{array}{c}07 \ldots \\
\text { OCT } 1992\end{array}$ & .010 & .03 & $<1$ & 52 & $<.5$ & $<1.0$ & $<5$ & $<3$ & $<10$ & 26 \\
\hline $\begin{array}{c}27 \ldots \\
\text { NOV } 1993\end{array}$ & .010 & .03 & $<1$ & 51 & $<.5$ & $<1.0$ & $<5$ & $<3$ & 10 & 49 \\
\hline $\begin{array}{c}22 \ldots \\
\text { NOV } 1994\end{array}$ & .050 & .15 & - & - & - & - & - & - & - & - \\
\hline $08 \ldots$ & $<.010$ & - & - & - & - & - & - & - & - & - \\
\hline
\end{tabular}


Table 3. Water-quality data from surface-water sites-Continued

01479800 - East Branch Red Clay Creek near Five Point, Pa. (Site 26)—Continued

\begin{tabular}{|c|c|c|c|c|c|c|c|c|c|c|}
\hline & & & MANGA- & & & & STRON- & VANA- & & $\begin{array}{c}\text { METHY- } \\
\text { LENE }\end{array}$ \\
\hline & LEAD, & LITHIUM, & NESE, & MERCURY, & NICKEL, & SILVER, & TIUM, & DIUM, & ZINC, & BLUE \\
\hline & DIS- & DIS- & DIS- & DIS- & DIS- & DIS- & DIS- & DIS- & DIS- & ACTIVE \\
\hline & SOLVED & SOLVED & SOLVED & SOLVED & SOLVED & SOLVED & SOLVED & SOLVED & SOLVED & SUB- \\
\hline $\mathrm{ATE}$ & $(\mu \mathrm{G} / \mathrm{L}$ & $(\mu \mathrm{G} / \mathrm{L}$ & $(\mu \mathrm{G} / \mathrm{L}$ & $(\mu \mathrm{G} / \mathrm{L}$ & $(\mu \mathrm{G} / \mathrm{L}$ & $(\mu \mathrm{G} / \mathrm{L}$ & $(\mu \mathrm{G} / \mathrm{L}$ & $(\mu \mathrm{G} / \mathrm{L}$ & $(\mu \mathrm{G} / \mathrm{L}$ & STANCE \\
\hline & $A S \quad P B)$ & AS LI) & AS MN) & AS HG) & AS NI) & AS AG) & AS SR) & AS V) & AS ZN) & (MG/L) \\
\hline & $(01049)$ & $(01130)$ & $(01056)$ & $(71890)$ & $(01065)$ & $(01075)$ & $(01080)$ & (01085) & $(01090)$ & $(38260)$ \\
\hline
\end{tabular}

\begin{tabular}{|c|c|c|c|c|c|c|c|c|c|c|}
\hline $\begin{array}{c}30 \ldots \\
\text { NOV } 1982\end{array}$ & $<1$ & - & 62 & 0.3 & 1 & - & - & - & $<4$ & ND \\
\hline $\begin{array}{c}01 \ldots \\
\text { NOV } 1983\end{array}$ & $<1$ & - & 21 & $<.1$ & $<1$ & - & - & - & $<4$ & 0.05 \\
\hline $\begin{array}{c}01 \ldots \\
\text { OCT } 1984\end{array}$ & 1 & - & 27 & .2 & 1 & $<1.0$ & - & - & 5 & - \\
\hline $\begin{array}{c}19 \ldots \\
\text { OCT } 1985\end{array}$ & $<1$ & - & 17 & $<.1$ & 1 & $<1.0$ & - & - & $<3$ & - \\
\hline $\begin{array}{c}18 \ldots \\
\text { NOV } 1986\end{array}$ & $<1$ & - & 6 & $<.1$ & $<1$ & $<1.0$ & - & - & 9 & - \\
\hline $\begin{array}{c}18 \ldots \\
\text { NOV } 1987\end{array}$ & $<5$ & - & 36 & $<.1$ & 3 & $<1.0$ & - & - & 4 & - \\
\hline $\begin{array}{c}17 \ldots \\
\text { NOV } 1988\end{array}$ & $<5$ & - & 19 & $<.1$ & 1 & $<1.0$ & - & - & $<3$ & - \\
\hline $\begin{array}{c}08 \ldots \\
\text { OCT } 1989\end{array}$ & $<10$ & 5 & 33 & $<.1$ & $<10$ & $<1.0$ & 130 & $<6$ & 11 & - \\
\hline $\begin{array}{c}30 \ldots \\
\text { NOV } 1990\end{array}$ & $<10$ & $<4$ & 19 & .1 & $<10$ & $<1.0$ & 130 & $<6$ & $<3$ & - \\
\hline $\begin{array}{c}01 \ldots \\
\text { NOV } 1991\end{array}$ & $<10$ & 6 & 15 & $<.1$ & $<10$ & $<1.0$ & 130 & $<6$ & $<3$ & - \\
\hline $\begin{array}{c}07 \ldots \\
\text { OCT } 1992\end{array}$ & $<10$ & 5 & 9 & $<.1$ & $<10$ & $<1.0$ & 130 & $<6$ & 13 & - \\
\hline $\begin{array}{c}27 \ldots \\
\text { NOV } 1993\end{array}$ & $<10$ & 24 & 17 & $<.1$ & $<10$ & $<1.0$ & 170 & $<6$ & 23 & - \\
\hline $\begin{array}{c}22 \ldots \\
\text { NOV } 1994\end{array}$ & - & - & - & - & - & - & - & - & & - \\
\hline $08 \ldots$ & - & - & - & - & - & - & - & - & - & - \\
\hline
\end{tabular}


Table 3. Water-quality data from surface-water sites-Continued

01480434 - West Branch Brandywine Creek at Rock Run, Pa. (Site 37)

\begin{tabular}{|c|c|c|c|c|c|c|c|c|c|c|c|}
\hline & & & & & & & & & & & \\
\hline & & DIS- & SPE- & $\begin{array}{l}\mathrm{PH} \\
\text { WATER }\end{array}$ & & & & HARD & HARD- & & \\
\hline & & INST. & CIFIC & WHOLE & & & & NESS, & NONCARB & CALCIUM, & SIUM, \\
\hline & & (CUBIC & $\mathrm{CON}-$ & FIELD & TEMPER- & TUR- & OXYGEN, & TOTAL & WH WAT & DIS- & DIS- \\
\hline ATE & & FEET & DUCT- & $\begin{array}{c}\text { (STAND- } \\
\text { ARD }\end{array}$ & ATURE & BID- & DIS- & (MG / L & $\begin{array}{l}\text { TOT FLD } \\
\text { (MG/L AS }\end{array}$ & $\begin{array}{r}\text { SOLVED } \\
\text { (MG/L }\end{array}$ & $\begin{array}{l}\text { SOLVED } \\
\text { (MG/L }\end{array}$ \\
\hline AlE & 11ME & SECOND) & $(\mu \mathrm{S} / \mathrm{CM})$ & $\begin{array}{l}\text { ARD } \\
\text { UNITS) }\end{array}$ & $\begin{array}{l}\text { WATER } \\
\text { (DEG C) }\end{array}$ & $\begin{array}{l}11 Y \\
\text { (NTU) }\end{array}$ & $\begin{array}{l}\text { SOLVED } \\
\text { (MG/L) }\end{array}$ & $\left.\mathrm{CACO}_{3}\right)$ & $\begin{array}{l}(\mathrm{MG} / \mathrm{L} \mathrm{AS} \\
\left.\mathrm{CACO}_{3}\right)\end{array}$ & $\begin{array}{l}\text { (MG } / L \\
\text { AS CA) }\end{array}$ & $\begin{array}{l}(\mathrm{MG} / \mathrm{L} \\
\mathrm{AS} \quad \mathrm{MG})\end{array}$ \\
\hline & & $(00061)$ & $(00095)$ & $(00400)$ & $(00010)$ & $(00076)$ & $(00300)$ & $(00900)$ & $(00902)$ & $(00915)$ & $(00925)$ \\
\hline
\end{tabular}

\begin{tabular}{|c|c|c|c|c|c|c|c|c|c|c|c|}
\hline $\begin{array}{c}\text { NOV } 1981 \\
02 \ldots\end{array}$ & 1545 & - & 198 & 8.0 & 12.0 & - & 11.4 & 76 & - & 19 & 7.0 \\
\hline OCT 1982 & & & & & & & & & & & \\
\hline $27 \ldots$ & 1535 & 22 & 196 & 7.5 & 10.5 & - & 12.3 & 76 & - & 19 & 6.9 \\
\hline NOV 1983 & & & & & & & & & & & \\
\hline $\begin{array}{c}04 \ldots \\
\text { ОСТ } 1984\end{array}$ & 0915 & 19 & 198 & 7.4 & 8.5 & 1.5 & - & 81 & - & 20 & 7.5 \\
\hline $\begin{array}{c}30 \ldots \\
\text { OCT } 1985\end{array}$ & 1430 & 38 & 200 & 7.5 & 15.5 & 4.1 & 9.8 & 70 & - & 17 & 6.7 \\
\hline $21 \ldots$ & 1200 & 19 & 200 & 7.4 & 8.0 & .60 & 12.0 & 75 & - & 18 & 7.2 \\
\hline NOV 1986 & & & & & & & & & & & \\
\hline $\begin{array}{c}17 \ldots \\
\text { оСт } 1987\end{array}$ & 1500 & 17 & 210 & 7.7 & 8.5 & .70 & 11.2 & 82 & - & 20 & 7.9 \\
\hline $\begin{array}{c}22 \ldots \\
\text { OCT } 1988\end{array}$ & 1100 & 23 & 200 & 7.5 & 9.5 & .50 & 12.7 & 79 & - & 19 & 7.6 \\
\hline $\begin{array}{c}05 \ldots \\
\text { OCT } 1989\end{array}$ & 1430 & 17 & 220 & 7.8 & 15.5 & 1.4 & 11.4 & 80 & - & 19 & 7.9 \\
\hline $\begin{array}{c}10 \ldots \\
\text { ОСт } 1990\end{array}$ & 1500 & 38 & 214 & 7.5 & 1.5 & .70 & 9.5 & 78 & 30 & 19 & 7.5 \\
\hline $\begin{array}{c}16 \ldots \\
\text { NOV } 1991\end{array}$ & 1130 & 22 & 232 & 7.1 & 14.0 & 1.0 & 1.3 & 82 & 20 & 20 & 7.7 \\
\hline $\begin{array}{c}18 \ldots \\
\text { OCT } 1992\end{array}$ & 1300 & 14 & 220 & 7.4 & 5.0 & .60 & 15.2 & 80 & 31 & 20 & 7.4 \\
\hline $30 \ldots$ & 1100 & 19 & 234 & 7.2 & 1.5 & .90 & 11.8 & 85 & - & 21 & 7.8 \\
\hline NOV 1993 & & & & & & & & & & & \\
\hline $15 \ldots$ & 1330 & 31 & 205 & 8.2 & 13.5 & - & 11.3 & - & - & - & - \\
\hline ОСТ 1994 & & & & & & & & & & & \\
\hline $13 \ldots$ & 1120 & 14 & 238 & 7.6 & 9.0 & - & 12.3 & - & - & - & - \\
\hline
\end{tabular}


Table 3. Water-quality data from surface-water sites-Continued

01480434 - West Branch Brandywine Creek at Rock Run, Pa. (Site 37)—Continued

\begin{tabular}{|c|c|c|c|c|c|c|c|c|c|c|c|}
\hline & & & & POTAS- & $\begin{array}{l}\text { ALKA- } \\
\text { LINITY }\end{array}$ & $\begin{array}{l}\text { ALKA- } \\
\text { LINITY }\end{array}$ & & CHLO- & FLUO- & SILICA, & $\begin{array}{l}\text { SOLIDS, } \\
\text { RESIDUE }\end{array}$ \\
\hline & SODIUM, & & SODIUM & SIUM, & WAT WH & WAT WH & SULFATE, & RIDE, & RIDE, & DIS- & $\mathrm{AT} 180$ \\
\hline & DIS- & & $\mathrm{AD}-$ & DIS- & TOT FET & TOT IT & DIS- & DIS- & DIS- & SOLVED & DEG. C \\
\hline & SOLVED & & SORP - & SOLVED & FIELD & FIELD & SOLVED & SOLVED & SOLVED & (MG/L & DIS- \\
\hline ATE & (MG / L & SODIUM & TION & (MG/L & (MG/L AS & (MG/L AS & (MG / L & (MG / L & (MG / L & AS & SOLVED \\
\hline & AS NA) & PERCENT & RATIO & AS K) & $\left.\mathrm{CACO}_{3}\right)$ & $\left.\mathrm{CACO}_{3}\right)$ & AS $\mathrm{SO}_{4}$ ) & AS CL) & AS F) & $\left.\mathrm{SIO}_{2}\right)$ & $(\mathrm{MG} / \mathrm{L})$ \\
\hline & $(00930)$ & $(00932)$ & $(00931)$ & $(00935)$ & $(00410)$ & $(00419)$ & $(00945)$ & $(00940)$ & $(00950)$ & $(00955)$ & $(70300)$ \\
\hline
\end{tabular}

\begin{tabular}{|c|c|c|c|c|c|c|c|c|c|c|c|}
\hline $\begin{array}{c}\text { NOV } 1981 \\
02 \ldots \\
\text { OCT } 1982\end{array}$ & 7.6 & 17 & 0.4 & 4.3 & - & - & 20 & 16 & $<0.10$ & 12 & 125 \\
\hline $27 \ldots$ & 6.6 & 15 & .3 & 3.0 & 46 & - & 16 & 14 & $<.10$ & 14 & 119 \\
\hline $\begin{array}{c}\text { NOV } 1983 \\
04 \ldots\end{array}$ & 7.9 & 17 & .4 & 3.5 & 48 & - & 21 & 17 & - & 15 & 140 \\
\hline OCT 1984 & & & & & & & & & & & \\
\hline $\begin{array}{c}30 \ldots \\
\text { OCT } 1985\end{array}$ & 6.6 & 15 & .3 & 7.4 & 42 & - & 20 & 13 & - & 13 & 137 \\
\hline $\begin{array}{c}21 \ldots \\
\text { NOV } 1986\end{array}$ & 8.0 & 18 & .4 & 3.0 & 50 & - & 18 & 16 & - & 13 & 118 \\
\hline $\begin{array}{c}17 \ldots \\
\text { OCT } 1987\end{array}$ & 8.1 & 17 & .4 & 3.5 & 34 & - & 22 & 13 & - & 18 & 145 \\
\hline $\begin{array}{c}22 \ldots \\
\text { OCT } 1988\end{array}$ & 8.1 & 18 & .4 & 3.3 & 51 & - & 19 & 15 & - & 14 & 127 \\
\hline $\begin{array}{c}05 \ldots \\
\text { OCT } 1989\end{array}$ & 7.6 & 16 & .4 & 4.9 & 55 & - & 20 & 16 & - & 14 & - \\
\hline $\begin{array}{c}10 \ldots \\
\text { OCT } 1990\end{array}$ & 8.0 & 18 & .4 & 2.6 & 48 & - & 17 & 15 & - & 16 & - \\
\hline $\begin{array}{c}16 \ldots \\
\text { NOV } 1991\end{array}$ & 8.1 & 17 & .4 & 4.8 & 62 & - & 17 & 16 & $<.10$ & 16 & - \\
\hline $\begin{array}{c}18 \ldots \\
\text { OCT } 1992\end{array}$ & 9.0 & 19 & .4 & 2.6 & 49 & - & 22 & 21 & $<.10$ & 12 & - \\
\hline $\begin{array}{c}30 \ldots \\
\text { NOV } 1993\end{array}$ & 9.5 & 19 & .4 & 3.4 & - & 58 & 19 & 17 & $<.10$ & 14 & - \\
\hline $\begin{array}{c}15 \ldots \\
\text { OCT } 1994\end{array}$ & - & - & - & - & - & 47 & 18 & 16 & .10 & - & - \\
\hline $13 \ldots$ & - & - & - & - & - & 52 & - & - & - & - & - \\
\hline
\end{tabular}


Table 3. Water-quality data from surface-water sites-Continued

01480434 - West Branch Brandywine Creek at Rock Run, Pa. (Site 37)—Continued

\begin{tabular}{|c|c|c|c|c|c|c|c|c|c|c|c|}
\hline & $\begin{array}{l}\text { SOLIDS, } \\
\text { SUM OF }\end{array}$ & SOLIDS, & SOLIDS, & NITRO- & $\begin{array}{c}\text { NITRO- } \\
\text { GEN, }\end{array}$ & $\begin{array}{c}\text { NITRO- } \\
\text { GEN }\end{array}$ & $\begin{array}{c}\text { NITRO- } \\
\text { GEN, }\end{array}$ & $\begin{array}{c}\text { NITRO- } \\
\text { GEN, }\end{array}$ & $\begin{array}{c}\text { NITRO- } \\
\text { GEN, }\end{array}$ & $\begin{array}{l}\text { NITRO- } \\
\text { GEN, }\end{array}$ & NITRO- \\
\hline & CONSTI- & DIS- & DIS- & GEN, & NITRATE & NITRATE & NITRITE & $\mathrm{NO}_{2}+\mathrm{NO}_{3}$ & AMMONIA & AMMONIA & GEN, \\
\hline & TUENTS, & SOLVED & SOLVED & NITRATE & DIS- & DIS- & DIS- & DIS- & DIS- & DIS- & ORGANIC \\
\hline & DIS- & (TONS & (TONS & TOTAL & SOLVED & SOLVED & SOLVED & SOLVED & SOLVED & SOLVED & TOTAL \\
\hline \multirow[t]{3}{*}{ DATE } & SOLVED & PER & PER & (MG / L & (MG / L & (MG / L & (MG / L & (MG / L & (MG / L & (MG / L & (MG / L \\
\hline & (MG/L) & $\mathrm{AC}-\mathrm{FT}$ ) & DAY) & AS N) & AS N) & AS $\left.\quad \mathrm{NO}_{3}\right)$ & AS N) & AS N) & AS N) & AS $\mathrm{NH}_{4}$ ) & AS $N$ ) \\
\hline & $(70301)$ & $(70303)$ & $(70302)$ & $(00620)$ & $(00618)$ & $(71851)$ & $(00613)$ & $(00631)$ & $(00608)$ & $(71846)$ & $(00605)$ \\
\hline
\end{tabular}

NOV 1981

$02 \ldots$

OCT 1982

$27 \ldots$

NOV 1983

$04 \ldots$

OCT 1984

$30 \ldots$

OCT 1985

$21 \ldots$

NOV 1986

$17 \ldots$

OCT 1987

$22 \ldots$

OCT 1988

$05 \ldots$

OCT 1989

$10 \ldots$

OCT 1990

16 ...

NOV 1991

$18 \ldots$

OCT 1992

$30 \ldots$

NOV 1993

$15 \ldots$

OCT 1994

\begin{tabular}{|c|c|c|c|c|c|c|c|c|c|c|}
\hline 一 & 0.17 & - & 1.40 & - & - & $<0.010$ & 1.40 & $<0.010$ & 0.01 & 0.43 \\
\hline 118 & .16 & 7.20 & 2.50 & - & - & $<.010$ & 2.50 & .010 & .01 & - \\
\hline 117 & .19 & 14.1 & 1.70 & - & - & $<.010$ & 1.70 & .030 & .04 & - \\
\hline 129 & .20 & 6.66 & 3.60 & - & - & $<.010$ & 3.60 & $<.010$ & - & - \\
\hline 130 & .17 & 7.89 & 2.90 & - & - & $<.010$ & 2.90 & .020 & .03 & .78 \\
\hline 136 & .18 & 6.24 & 3.00 & - & - & $<.010$ & 3.00 & .020 & .03 & .58 \\
\hline 138 & .19 & 8.18 & 2.39 & 2.39 & 11 & .010 & 2.40 & .030 & .04 & .57 \\
\hline 137 & .19 & 5.17 & 3.00 & - & - & $<.010$ & 3.00 & .020 & .03 & - \\
\hline 141 & .19 & 7.40 & 3.29 & 3.29 & 15 & .010 & 3.30 & .020 & .03 & - \\
\hline - & - & - & 3.29 & 3.29 & 15 & .010 & 3.30 & .010 & .01 & - \\
\hline- & - & - & 3.10 & - & - & $<.010$ & 3.10 & $<.015$ & - & - \\
\hline
\end{tabular}


Table 3. Water-quality data from surface-water sites-Continued

01480434 - West Branch Brandywine Creek at Rock Run, Pa. (Site 37)—Continued

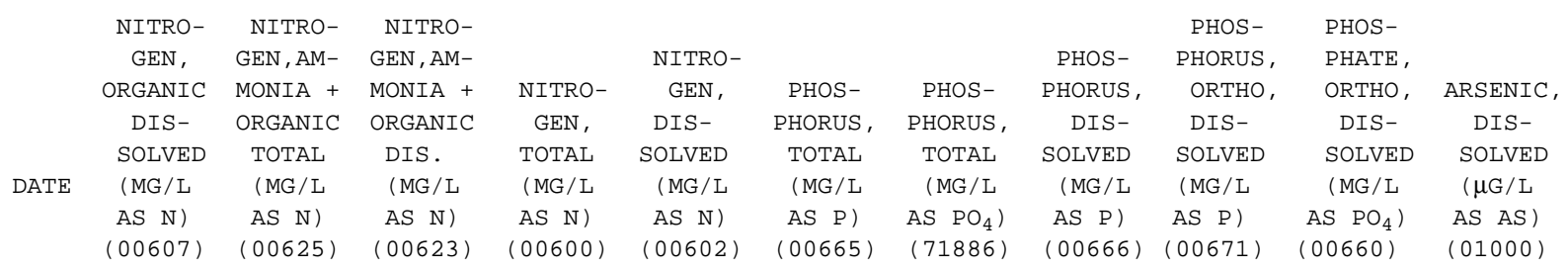

NOV 1981

$\begin{array}{llllllllllll}02 \ldots & - & 0.43 & 0.31 & 1.8 & 0.7 & 0.010 & 0.03 & 0.030 & <0.010 & -\quad\end{array}$

OCT 1982

$27 \ldots$

NOV 1983

$04 \ldots$

OCT 1984

$30 \ldots$

OCT 1985

$21 \ldots$

NOV 1986

$17 \ldots$

OCT 1987

$22 \ldots$

OCT 1988

$05 \ldots$

OCT 1989

$10 \ldots$

OCT 1990

$16 \ldots$

NOV 1991

$18 \ldots$

$0.59-$

.60

$-$

3.

$.48 \quad-\quad .50$

$-$

$3.1-$

$.77-$

.80

$3.5 \quad .050$

$-$

$2.5 \quad .150$

.15

.030

$<.010$

-

ND

$\begin{array}{lll}.38 & .60 & .40\end{array}$

3.5

3.3

.050

$-$

.040

.020

.06

$<1$

\begin{tabular}{l}
$<.20 \quad .60$ \\
\hline
\end{tabular}

4.2

.070

.15

.070

.090

.28

.040

.040

.12

$\begin{array}{lll}.58 & .80 \quad .60\end{array}$

3.7

3.5

.040

$-$

.060

$\begin{array}{lll}.58 & .60 \quad .60\end{array}$

3.6

3.6

.070

$-$

.060

.040

.12

$\begin{array}{lll}.28 & .40 \quad .30\end{array}$

4.3

4.2

.040

$-$

.060

$.030 \quad .09=$

$.47 \quad .60$

.50

3.0

2.9

.060

$-$

.030

.040

.12

OCT 1992

$30 \ldots$

NOV 1993

$15 \ldots$

OCT 1994

$13 \ldots$ 
Table 3. Water-quality data from surface-water sites-Continued

01480434 - West Branch Brandywine Creek at Rock Run, Pa. (Site 37)—Continued

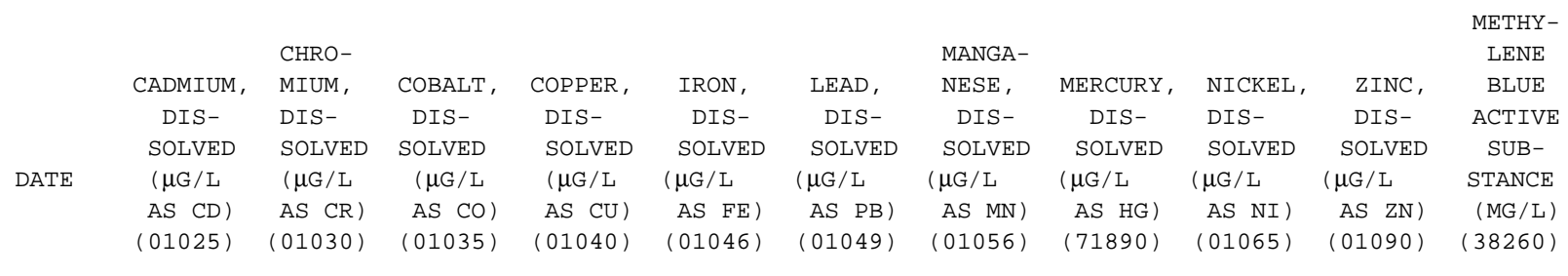

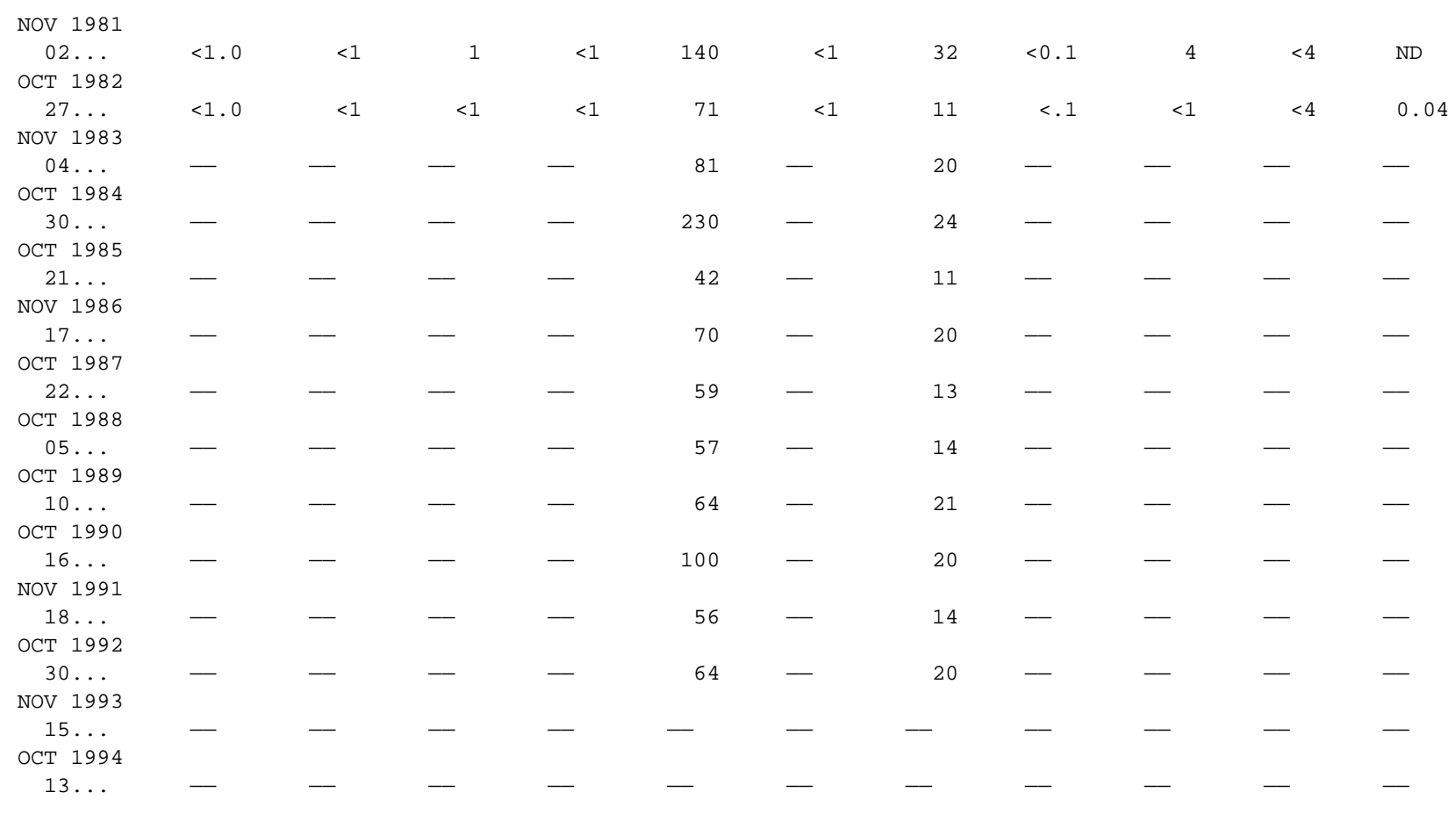


Table 3. Water-quality data from surface-water sites-Continued

01480629 - Buck Run at Doe Run, Pa. (Site 46)

\begin{tabular}{|c|c|c|c|c|c|c|c|c|c|c|c|}
\hline & & DIS- & & $\mathrm{PH}$ & & & & & HARD- & & \\
\hline & & CHARGE, & SPE- & WATER & & & & HARD- & NESS & & MAGNE- \\
\hline & & INST. & CIFIC & WHOLE & & & & NESS, & NONCARB & CALCIUM, & SIUM, \\
\hline & & (CUBIC & $\mathrm{CON}-$ & FIELD & TEMPER- & TUR- & OXYGEN, & TOTAL & WH WAT & DIS- & DIS- \\
\hline & & FEET & DUCT- & (STAND- & ATURE & BID- & DIS- & (MG / L & TOT FLD & SOLVED & SOLVED \\
\hline $\mathrm{ATE}$ & TIME & PER & ANCE & ARD & WATER & ITY & SOLVED & AS & (MG/L AS & (MG / L & (MG / L \\
\hline & & SECOND) & $(\mu \mathrm{S} / \mathrm{CM})$ & UNITS) & $(\mathrm{DEG} C)$ & (NTU) & (MG/L) & $\left.\mathrm{CACO}_{3}\right)$ & $\left.\mathrm{CACO}_{3}\right)$ & AS CA) & AS $\quad \mathrm{MG})$ \\
\hline & & $(00061)$ & $(00095)$ & $(00400)$ & $(00010)$ & $(00076)$ & $(00300)$ & $(00900)$ & $(00902)$ & $(00915)$ & $(00925)$ \\
\hline
\end{tabular}

\begin{tabular}{|c|c|c|c|c|c|c|c|c|c|c|c|}
\hline $\begin{array}{c}05 \ldots \\
\text { OCT } 1982\end{array}$ & 1000 & - & 206 & - & 7.5 & - & 11.7 & 82 & - & 21 & 7.1 \\
\hline $\begin{array}{c}28 \ldots \\
\text { OCT } 1983\end{array}$ & 0930 & 11 & 195 & 7.6 & 7.0 & - & 13.5 & 78 & - & 20 & 6.9 \\
\hline $\begin{array}{c}28 \ldots \\
\text { OCT } 1984\end{array}$ & 1230 & 11 & 214 & 7.5 & 9.0 & 1.2 & 11.4 & 83 & - & 21 & 7.4 \\
\hline $\begin{array}{c}31 \ldots \\
\text { OCT } 1985\end{array}$ & 0900 & 18 & 220 & 7.3 & 14.0 & 1.1 & 10.5 & 80 & - & 20 & 7.2 \\
\hline $\begin{array}{c}29 \ldots \\
\text { OCT } 1986\end{array}$ & 0945 & 11 & 260 & 7.3 & 9.0 & 1.0 & 12.2 & 86 & - & 22 & 7.6 \\
\hline $\begin{array}{c}30 \ldots \\
\text { NOV } 1987\end{array}$ & 0800 & 8.6 & 215 & 7.4 & 11.0 & 1.0 & 9.6 & 79 & - & 20 & 7.0 \\
\hline $\begin{array}{c}19 \ldots \\
\text { NOV } 1988\end{array}$ & 0900 & 15 & 228 & 7.1 & 9.0 & .50 & 12.0 & 87 & - & 22 & 7.8 \\
\hline $\begin{array}{c}14 \ldots \\
\text { NOV } 1989\end{array}$ & 0830 & 15 & 240 & 7.6 & 7.0 & 2.5 & 13.2 & 92 & - & 23 & 8.3 \\
\hline $\begin{array}{c}07 \ldots \\
\text { OCT } 1990\end{array}$ & 0845 & 19 & 223 & 7.6 & 8.5 & 1.1 & 12.8 & 78 & 39 & 19 & 7.5 \\
\hline $\begin{array}{c}17 \ldots \\
\text { OCT } 1991\end{array}$ & 1130 & 12 & 237 & 6.9 & 12.5 & 1.8 & 10.9 & 80 & 20 & 20 & 7.4 \\
\hline $\begin{array}{c}31 \ldots \\
\text { OCT } 1992\end{array}$ & 0845 & 8.2 & 239 & 7.8 & 8.5 & .60 & 11.1 & 83 & 42 & 21 & 7.3 \\
\hline $\begin{array}{c}16 \ldots \\
\text { NOV } 1993\end{array}$ & 1240 & 13 & 250 & 7.1 & 14.0 & .80 & 11.1 & 90 & - & 23 & 7.8 \\
\hline $\begin{array}{c}08 \ldots \\
\text { NOV } 1994\end{array}$ & 1240 & 13 & 242 & 7.7 & 6.0 & - & 14.0 & - & - & - & - \\
\hline $14 \ldots$ & 0935 & 11 & 244 & 6.7 & 8.5 & - & 11.5 & - & - & - & - \\
\hline
\end{tabular}


Table 3. Water-quality data from surface-water sites-Continued

01480629 - Buck Run at Doe Run, Pa. (Site 46)—Continued

\begin{tabular}{|c|c|c|c|c|c|c|c|c|c|c|c|}
\hline & & & & POTAS- & $\begin{array}{l}\text { ALKA- } \\
\text { LINITY }\end{array}$ & $\begin{array}{l}\text { ALKA- } \\
\text { LINITY }\end{array}$ & & $\begin{array}{l}\text { CHLO- } \\
\text { RIDF }\end{array}$ & $\begin{array}{l}\text { FLUO- } \\
\text { RIDF, }\end{array}$ & $\begin{array}{l}\text { SILICA, } \\
\text { DIS- }\end{array}$ & $\begin{array}{l}\text { SOLIDS, } \\
\text { RESIDUE } \\
\text { AT } 180\end{array}$ \\
\hline & SODIUM, & & SODIUM & $\begin{array}{l}\text { SIUM, } \\
\text { DIS- }\end{array}$ & $\begin{array}{l}\text { WAT WH } \\
\text { TOT FET }\end{array}$ & $\begin{array}{l}\text { WAT WH } \\
\text { TOT IT }\end{array}$ & SULFATE, & RIDE， & RIDE, & $\begin{array}{l}\text { DIS- } \\
\text { SOLVED }\end{array}$ & $\begin{array}{l}\text { AT } 180 \\
\text { DEG. C }\end{array}$ \\
\hline & $\begin{array}{c}\text { DIS- } \\
\text { SOLVED }\end{array}$ & & $\begin{array}{c}\text { AD- } \\
\text { SORP- }\end{array}$ & $\begin{array}{l}\text { DIS- } \\
\text { SOLVED }\end{array}$ & $\begin{array}{l}\text { TOT FET } \\
\text { FIELD }\end{array}$ & $\begin{array}{l}\text { TOT IT } \\
\text { FIELD }\end{array}$ & $\begin{array}{c}\text { DIS- } \\
\text { SOLVED }\end{array}$ & $\begin{array}{c}\text { DIS- } \\
\text { SOLVED }\end{array}$ & $\begin{array}{l}\text { DIS- } \\
\text { SOLVED }\end{array}$ & $\begin{array}{l}\text { SOLVED } \\
\text { (MG/L }\end{array}$ & $\begin{array}{l}\text { DEG. C } \\
\text { DIS- }\end{array}$ \\
\hline ATE & (MG/L & SODIUM & TION & (MG/L & (MG/L AS & (MG/L AS & (MG / L & (MG / L & (MG / L & AS & SOLVED \\
\hline & AS NA) & PERCENT & RATIO & AS K) & $\left.\mathrm{CACO}_{3}\right)$ & $\left.\mathrm{CACO}_{3}\right)$ & AS $\mathrm{SO}_{4}$ ) & AS CL) & AS F) & $\left.\mathrm{SIO}_{2}\right)$ & $(\mathrm{MG} / \mathrm{L})$ \\
\hline & $(00930)$ & $(00932)$ & $(00931)$ & (00935) & $(00410)$ & $(00419)$ & $(00945)$ & $(00940)$ & $(00950)$ & $(00955)$ & $(70300)$ \\
\hline
\end{tabular}

\begin{tabular}{|c|c|c|c|c|c|c|c|c|c|c|c|}
\hline $05 \ldots$ & 9.6 & 20 & 0.5 & 2.6 & - & - & 17 & 17 & $<0.10$ & 7.0 & 124 \\
\hline OCT 1982 & & & & & & & & & & & \\
\hline $28 \ldots$ & 8.5 & 18 & .4 & 4.0 & 40 & - & 16 & 17 & $<.10$ & 7.8 & 129 \\
\hline ОСТ 1983 & & & & & & & & & & & \\
\hline $\begin{array}{c}28 \ldots \\
\text { OCT } 1984\end{array}$ & 9.2 & 19 & .4 & 2.9 & 48 & - & 20 & 19 & - & 9.6 & 145 \\
\hline $\begin{array}{c}31 \ldots \\
\text { OCT } 1985\end{array}$ & 9.1 & 19 & .4 & 3.0 & 46 & - & 17 & 15 & - & 8.4 & 126 \\
\hline $\begin{array}{c}29 \ldots \\
\text { OCT } 1986\end{array}$ & 10 & 20 & .5 & 2.8 & 50 & - & 18 & 20 & - & 8.1 & 121 \\
\hline $\begin{array}{c}30 \ldots \\
\text { NOV } 1987\end{array}$ & 9.0 & 19 & .4 & 3.3 & 50 & - & 19 & 17 & - & 9.0 & 141 \\
\hline $\begin{array}{c}19 \ldots \\
\text { NOV } 1988\end{array}$ & 11 & 21 & .5 & 2.9 & 47 & - & 20 & 23 & - & 8.7 & 143 \\
\hline $\begin{array}{c}14 \ldots \\
\text { NOV } 1989\end{array}$ & 10 & 19 & .5 & 3.0 & 48 & - & 19 & 18 & - & 8.8 & - \\
\hline $\begin{array}{c}07 \ldots \\
\text { OCT } 1990\end{array}$ & 8.1 & 18 & .4 & 2.1 & 39 & - & 16 & 15 & - & 7.8 & - \\
\hline $\begin{array}{c}17 \ldots \\
\text { OCT } 1991\end{array}$ & 9.0 & 19 & .4 & 2.7 & 60 & - & 16 & 17 & $<.10$ & 9.7 & - \\
\hline $\begin{array}{c}31 \ldots \\
\text { ОСТ } 1992\end{array}$ & 9.2 & 19 & .4 & 3.0 & 41 & - & 21 & 21 & .10 & 7.8 & 一 \\
\hline $\begin{array}{c}16 \ldots \\
\text { NOV } 1993\end{array}$ & 9.1 & 17 & .4 & 3.1 & - & 47 & 19 & 17 & .10 & 9.1 & - \\
\hline $\begin{array}{c}08 \ldots \\
\text { NOV } 1994\end{array}$ & - & - & - & - & - & 49 & 19 & 19 & $<.10$ & - & - \\
\hline $14 \ldots$ & - & - & - & - & - & 43 & - & 19 & - & - & - \\
\hline
\end{tabular}


Table 3. Water-quality data from surface-water sites-Continued

01480629 - Buck Run at Doe Run, Pa. (Site 46)—Continued

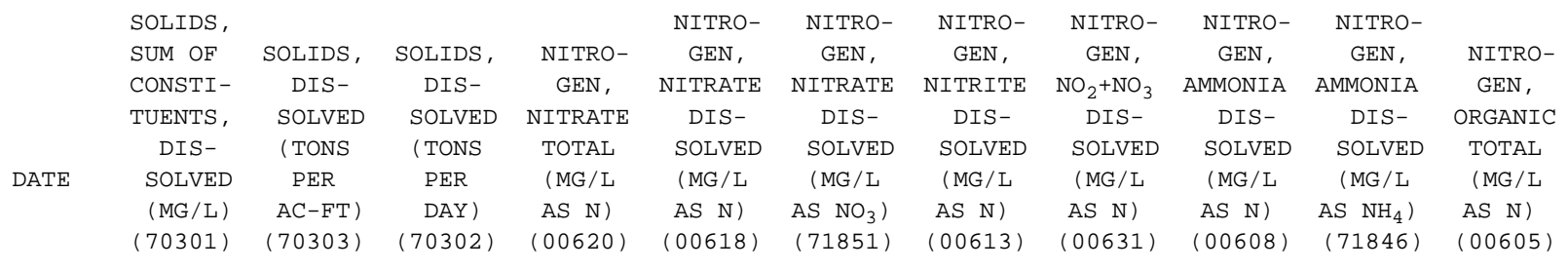

NOV 1981

$05 \ldots$

OCT 1982

$28 \ldots$

OCT 1983

$28 \ldots$

OCT 1984

$31 \ldots$

OCT 1985

$29 \ldots$

OCT 1986

$30 \ldots$

NOV 1987

$19 \ldots$

NOV 1988

$14 \ldots$

NOV 1989

$07 \ldots$

OCT 1990

$17 \ldots$

OCT 1991

$31 \ldots$

OCT 1992

$16 \ldots$

NOV 1993

$08 \ldots$

NOV 1994

\begin{tabular}{|c|c|c|c|c|c|c|c|c|c|c|}
\hline - & 0.17 & - & 3.80 & - & - & $<0.010$ & 3.90 & $<0.010$ & 0.01 & 0.48 \\
\hline 122 & .18 & 3.97 & 3.99 & 3.99 & 18 & .010 & 4.00 & $<.010$ & .01 & - \\
\hline 138 & .20 & 4.31 & 4.40 & - & - & $<.010$ & 4.40 & $<.010$ & - & - \\
\hline 125 & .17 & 6.12 & 3.90 & - & - & $<.010$ & 3.90 & .020 & .03 & - \\
\hline 139 & .16 & 3.72 & 4.49 & 4.49 & 20 & .010 & 4.50 & .030 & .04 & .27 \\
\hline 132 & .19 & 3.27 & 4.00 & - & - & $<.010$ & 4.00 & .020 & .03 & .48 \\
\hline 144 & .19 & 5.60 & 4.60 & - & - & $<.010$ & 4.60 & $<.010$ & - & .40 \\
\hline 142 & .19 & 5.76 & 5.18 & 5.18 & 23 & .020 & 5.20 & .020 & .03 & .38 \\
\hline 124 & .17 & 6.38 & 5.69 & 5.69 & 25 & .010 & 5.70 & .010 & .01 & .19 \\
\hline 138 & .19 & 4.47 & 4.59 & 4.59 & 20 & .010 & 4.60 & .020 & .03 & .88 \\
\hline 134 & .18 & 2.96 & 4.20 & - & - & $<.010$ & 4.20 & .020 & .03 & - \\
\hline 139 & .19 & 4.74 & 5.09 & 5.09 & 23 & .010 & 5.10 & .020 & .03 & .28 \\
\hline- & - & - & 5.48 & 5.48 & 24 & .020 & 5.50 & .020 & .03 & - \\
\hline- & - & - & 4.78 & 4.78 & 21 & .020 & 4.80 & $<.015$ & - & - \\
\hline
\end{tabular}


Table 3. Water-quality data from surface-water sites-Continued

01480629 - Buck Run at Doe Run, Pa. (Site 46)—Continued

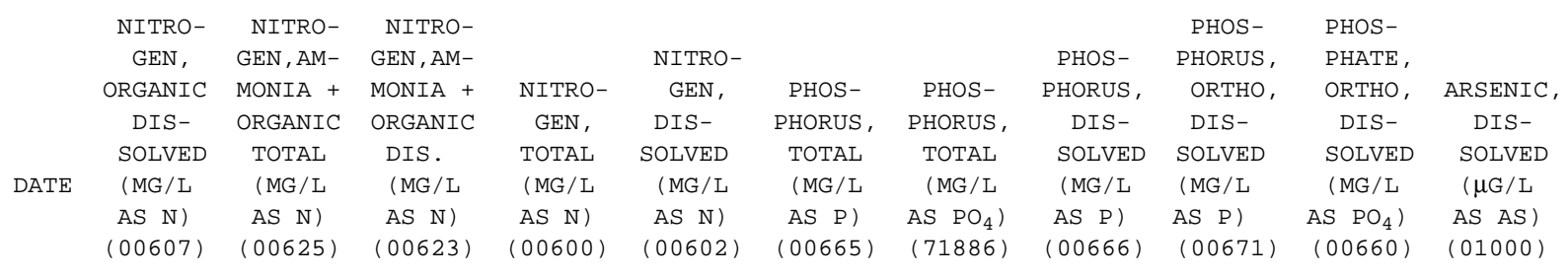

\begin{tabular}{|c|c|c|c|c|c|c|c|c|c|c|}
\hline $\begin{array}{c}\text { NOV } 1981 \\
05 \ldots \\
\text { OCT } 1982\end{array}$ & - & 0.48 & 0.53 & 4.3 & 4.4 & 0.130 & 0.40 & 0.130 & 0.110 & 0.34 \\
\hline $28 \ldots$ & - & - & .70 & - & 4.7 & - & - & .090 & .080 & .25 \\
\hline $\begin{array}{c}28 \ldots \\
\text { OCT } 1984\end{array}$ & - & - & .80 & - & 5.2 & .100 & .31 & .090 & .080 & .25 \\
\hline $\begin{array}{c}31 \ldots \\
\text { OCT } 1985\end{array}$ & 0.28 & - & .30 & - & 4.2 & .080 & - & .070 & .060 & .18 \\
\hline $\begin{array}{c}29 \ldots \\
\text { OCT } 1986\end{array}$ & .17 & .30 & .20 & 4.8 & 4.7 & .080 & .25 & .080 & .070 & .21 \\
\hline $\begin{array}{c}30 \ldots \\
\text { NOV } 1987\end{array}$ & .38 & .50 & .40 & 4.5 & 4.4 & .130 & - & .090 & .090 & .28 \\
\hline $\begin{array}{c}19 \ldots \\
\text { NOV } 1988\end{array}$ & - & .40 & .30 & 5.0 & 4.9 & .100 & - & .070 & .040 & .12 \\
\hline $\begin{array}{c}14 \ldots \\
\text { NOV } 1989\end{array}$ & .38 & .40 & .40 & 5.6 & 5.6 & .110 & - & .090 & .080 & .25 \\
\hline $\begin{array}{c}07 \ldots \\
\text { OCT } 1990\end{array}$ & .39 & .20 & .40 & 5.9 & 6.1 & .040 & - & .020 & .030 & .09 \\
\hline $\begin{array}{c}17 \ldots \\
\text { OCT } 1991\end{array}$ & .38 & .90 & .40 & 5.5 & 5.0 & .070 & - & .070 & .050 & .15 \\
\hline $\begin{array}{c}31 \ldots \\
\text { OCT } 1992\end{array}$ & - & $<.20$ & $<.20$ & - & - & .060 & - & .050 & .040 & .12 \\
\hline $\begin{array}{c}16 \ldots \\
\text { NOV } 1993\end{array}$ & .28 & .30 & .30 & 5.4 & 5.4 & .060 & - & .050 & .040 & .12 \\
\hline $\begin{array}{c}08 \ldots \\
\text { NOV } 1994\end{array}$ & - & - & - & - & - & - & - & - & .030 & .09 \\
\hline $14 \ldots$ & - & - & - & - & - & - & - & - & $<.010$ & - \\
\hline
\end{tabular}


Table 3. Water-quality data from surface-water sites-Continued

01480629 - Buck Run at Doe Run, Pa. (Site 46)—Continued

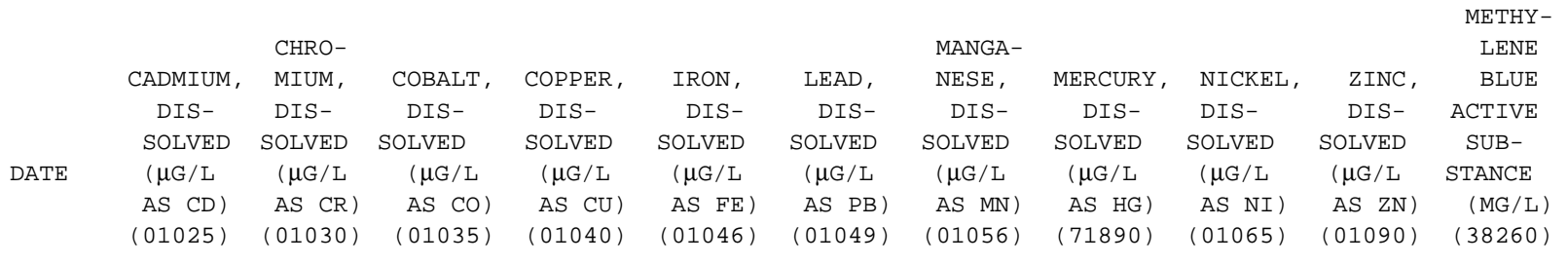

\begin{tabular}{|c|c|c|c|c|c|c|c|c|c|c|c|}
\hline $\begin{array}{c}\text { NOV } 1981 \\
05 \ldots \\
\text { OCT } 1982\end{array}$ & $<1.0$ & $<1$ & $<1$ & 3 & 54 & $<1$ & 25 & 0.7 & $<1$ & 5 & ND \\
\hline $\begin{array}{c}28 \ldots \\
\text { OCT } 1983\end{array}$ & $<1.0$ & $<1$ & 1 & 2 & 76 & $<1$ & 22 & $<.1$ & 1 & $<4$ & 0.06 \\
\hline $\begin{array}{c}28 \ldots \\
\text { OCT } 1984\end{array}$ & - & - & - & - & 62 & - & 24 & - & - & - & - \\
\hline $\begin{array}{c}31 \ldots \\
\text { ОСт } 1985\end{array}$ & - & - & - & - & 71 & - & 27 & - & - & - & - \\
\hline $\begin{array}{c}29 \ldots \\
\text { ОСт } 1986\end{array}$ & - & - & - & - & 37 & - & 13 & - & - & - & - \\
\hline $\begin{array}{c}30 \ldots \\
\text { NOV } 1987\end{array}$ & - & - & - & - & 45 & - & 13 & - & - & - & - \\
\hline $\begin{array}{c}19 \ldots \\
\text { NOV } 1988\end{array}$ & - & - & - & - & 47 & - & 36 & - & - & - & - \\
\hline $\begin{array}{c}14 \ldots \\
\text { NOV } 1989\end{array}$ & - & - & - & - & 42 & - & 19 & - & - & - & - \\
\hline $\begin{array}{c}07 \ldots \\
\text { ОСТ } 1990\end{array}$ & - & - & - & - & 42 & - & 22 & - & - & - & - \\
\hline $\begin{array}{c}17 \ldots \\
\text { ОСт } 1991\end{array}$ & - & - & - & - & 40 & - & 26 & - & - & - & - \\
\hline $\begin{array}{c}31 \ldots \\
\text { OCT } 1992\end{array}$ & - & - & - & - & 67 & - & 25 & - & - & - & - \\
\hline $\begin{array}{c}16 \ldots \\
\text { NOV } 1993\end{array}$ & - & - & - & - & 74 & - & 30 & - & - & - & - \\
\hline $\begin{array}{c}08 \ldots \\
\text { NOV } 1994\end{array}$ & - & - & - & - & - & - & - & - & - & - & - \\
\hline $14 \ldots$ & - & - & - & - & - & - & - & - & - & - & - \\
\hline
\end{tabular}


Table 3. Water-quality data from surface-water sites-Continued

01480632 - Doe Run at Springdell, Pa. (Site 45)

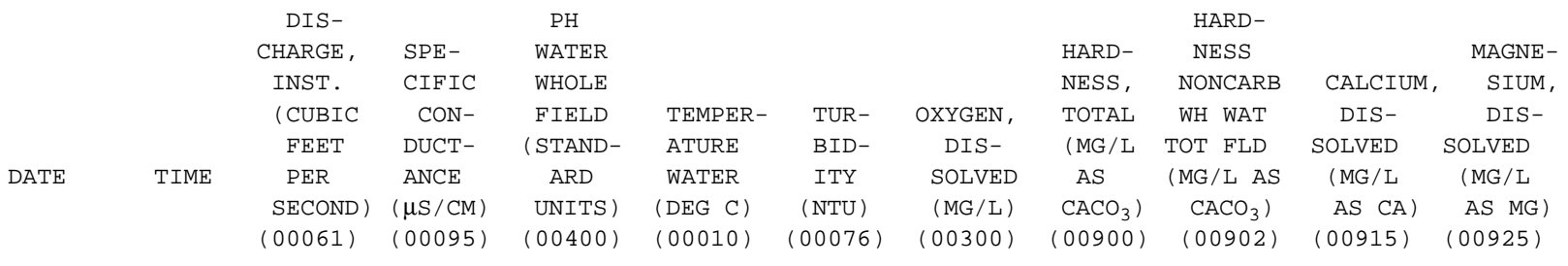

\begin{tabular}{|c|c|c|c|c|c|c|c|c|c|c|c|}
\hline $\begin{array}{c}\text { NOV } 1981 \\
05 \ldots \\
\text { OCT } 1982\end{array}$ & 0845 & - & 127 & 7.4 & 6.5 & - & 11.9 & 49 & - & 12 & 4.6 \\
\hline $28 \ldots$ & 1100 & 5.0 & 122 & 7.4 & 7.0 & - & 13.8 & 50 & - & 12 & 4.8 \\
\hline OCT 1983 & & & & & & & & & & & \\
\hline $\begin{array}{c}28 \ldots \\
\text { OCT } 1984\end{array}$ & 1345 & 5.4 & 131 & 7.3 & 10.5 & $<1.0$ & 11.5 & 50 & - & 12 & 4.9 \\
\hline $\begin{array}{c}31 \ldots \\
\text { OCT } 1985\end{array}$ & 1100 & 10 & 135 & 7.5 & 14.0 & .90 & 11.2 & 51 & - & 12 & 5.0 \\
\hline $\begin{array}{c}29 \ldots \\
\text { OCT } 1986\end{array}$ & 1530 & 6.6 & 140 & 7.4 & 9.0 & .80 & 12.9 & 51 & - & 12 & 5.0 \\
\hline $\begin{array}{c}30 \ldots \\
\text { NOV } 1987\end{array}$ & 1100 & 4.6 & 135 & 7.6 & 12.5 & .60 & 10.7 & 50 & - & 12 & 4.9 \\
\hline $\begin{array}{c}19 \ldots \\
\text { NOV } 1988\end{array}$ & 1330 & 7.2 & 140 & 7.4 & 10.5 & .50 & 12.8 & 54 & - & 13 & 5.3 \\
\hline $\begin{array}{c}14 \ldots \\
\text { NOV } 1989\end{array}$ & 1245 & 6.7 & 150 & 7.2 & 12.0 & 1.4 & 13.4 & 55 & - & 13 & 5.4 \\
\hline $\begin{array}{c}07 \ldots \\
\text { OCT } 1990\end{array}$ & 1230 & 14 & 152 & 7.6 & 11.5 & 1.5 & 12.5 & 51 & 20 & 12 & 5.2 \\
\hline $\begin{array}{c}17 \ldots \\
\text { ОСТ } 1991\end{array}$ & 0900 & 5.9 & 146 & 7.1 & 11.5 & 1.0 & 10.8 & 51 & 0 & 12 & 5.1 \\
\hline $\begin{array}{c}31 \ldots \\
\text { OCT } 1992\end{array}$ & 1045 & 4.9 & 142 & 7.0 & 10.0 & 5.7 & 11.4 & 50 & 7 & 12 & 4.8 \\
\hline $\begin{array}{c}16 \ldots \\
\text { NOV } 1993\end{array}$ & 0900 & 6.4 & 159 & 7.2 & 13.0 & .70 & 10.8 & 53 & - & 13 & 5.0 \\
\hline $\begin{array}{c}08 \ldots \\
\text { NOV } 1994\end{array}$ & 0920 & 7.1 & 150 & 7.6 & 5.0 & - & 13.4 & - & - & - & - \\
\hline $09 \ldots$ & 1140 & 5.8 & 154 & 6.5 & 11.5 & - & 12.1 & - & - & - & - \\
\hline
\end{tabular}


Table 3. Water-quality data from surface-water sites-Continued

01480632 - Doe Run at Springdell, Pa. (Site 45)—Continued

\begin{tabular}{|c|c|c|c|c|c|c|c|c|c|c|c|}
\hline DATE & $\begin{array}{l}\text { SODIUM, } \\
\text { DIS- } \\
\text { SOLVED } \\
\text { (MG/L } \\
\text { AS NA) } \\
(00930)\end{array}$ & $\begin{array}{r}\text { SODIUM } \\
\text { PERCENT } \\
\text { (00932) }\end{array}$ & $\begin{array}{c}\text { SODIUM } \\
\text { AD- } \\
\text { SORP- } \\
\text { TION } \\
\text { RATIO } \\
(00931)\end{array}$ & $\begin{array}{l}\text { POTAS- } \\
\text { SIUM, } \\
\text { DIS- } \\
\text { SOLVED } \\
\text { (MG/L } \\
\text { AS K) } \\
(00935)\end{array}$ & $\begin{array}{l}\text { ALKA- } \\
\text { LINITY } \\
\text { WAT WH } \\
\text { TOT FET } \\
\text { FIELD } \\
(\mathrm{MG} / \mathrm{L} \text { AS } \\
\left.\mathrm{CACO}_{3}\right) \\
(00410)\end{array}$ & $\begin{array}{l}\text { ALKA- } \\
\text { LINITY } \\
\text { WAT WH } \\
\text { TOT IT } \\
\text { FIELD } \\
(\mathrm{MG} / \mathrm{L} \text { AS } \\
\left.\mathrm{CACO}_{3}\right) \\
(00419)\end{array}$ & $\begin{array}{l}\text { SULFATE, } \\
\text { DIS- } \\
\text { SOLVED } \\
(\mathrm{MG} / \mathrm{L} \\
\left.\mathrm{AS} \mathrm{SO}_{4}\right) \\
(00945)\end{array}$ & $\begin{array}{l}\text { CHLO- } \\
\text { RIDE, } \\
\text { DIS- } \\
\text { SOLVED } \\
\text { (MG/L } \\
\text { AS CL) } \\
(00940)\end{array}$ & $\begin{array}{l}\text { FLUO- } \\
\text { RIDE, } \\
\text { DIS- } \\
\text { SOLVED } \\
(M G / L \\
\text { AS F) } \\
(00950)\end{array}$ & $\begin{array}{l}\text { SILICA, } \\
\text { DIS- } \\
\text { SOLVED } \\
(\mathrm{MG} / \mathrm{L} \\
\mathrm{AS} \\
\left.\mathrm{SIO}_{2}\right) \\
(00955)\end{array}$ & $\begin{array}{l}\text { SOLIDS, } \\
\text { RESIDUE } \\
\text { AT } 180 \\
\text { DEG. C } \\
\text { DIS- } \\
\text { SOLVED } \\
(\mathrm{MG} / \mathrm{L}) \\
(70300)\end{array}$ \\
\hline NOV 1981 & & & & & & & & & & & \\
\hline $\begin{array}{c}05 \ldots \\
\text { OCT } 1982\end{array}$ & 4.6 & 16 & 0.3 & 1.9 & - & - & 6.9 & 9.6 & $<0.10$ & 9.0 & 83 \\
\hline $\begin{array}{c}28 \ldots \\
\text { OCT } 1983\end{array}$ & 4.8 & 17 & .3 & 2.4 & 28 & - & 10 & 10 & $<.10$ & 9.9 & 85 \\
\hline $\begin{array}{c}28 \ldots \\
\text { OCT } 1984\end{array}$ & 5.0 & 17 & .3 & 2.1 & 28 & - & 9.9 & 11 & - & 9.8 & 92 \\
\hline $\begin{array}{c}31 \ldots \\
\text { OCT } 1985\end{array}$ & 5.3 & 18 & .3 & 2.0 & 28 & - & 9.3 & 8.7 & - & 9.2 & 82 \\
\hline $\begin{array}{c}29 \ldots \\
\text { OCT } 1986\end{array}$ & 5.2 & 18 & .3 & 2.0 & 58 & - & 9.7 & 10 & - & 9.4 & 76 \\
\hline $\begin{array}{c}30 \ldots \\
\text { NOV } 1987\end{array}$ & 4.9 & 17 & .3 & 2.6 & 32 & - & - & - & - & 10 & 93 \\
\hline $\begin{array}{c}19 \ldots \\
\text { NOV } 1988\end{array}$ & 5.7 & 18 & .3 & 2.2 & 32 & - & 11 & 16 & - & 8.9 & 90 \\
\hline $\begin{array}{c}14 \ldots \\
\text { NOV } 1989\end{array}$ & 5.3 & 16 & .3 & 3.0 & 34 & - & 11 & 11 & - & 9.0 & - \\
\hline $\begin{array}{c}07 \ldots \\
\text { OCT } 1990\end{array}$ & 5.1 & 17 & .3 & 1.7 & 31 & - & 10 & 10 & - & 9.5 & - \\
\hline $\begin{array}{c}17 \ldots \\
\text { OCT } 1991\end{array}$ & 5.1 & 17 & .3 & 2.0 & 51 & - & 7.6 & 9.6 & $<.10$ & 11 & - \\
\hline $\begin{array}{c}31 \ldots \\
\text { ОСТ } 1992\end{array}$ & 5.0 & 17 & .3 & 2.1 & 43 & - & 9.5 & 12 & $<.10$ & 10 & - \\
\hline $\begin{array}{c}16 \ldots \\
\text { NOV } 1993\end{array}$ & 5.4 & 17 & .3 & 2.2 & - & 71 & 8.7 & 11 & $<.10$ & 10 & - \\
\hline $\begin{array}{c}08 \ldots \\
\text { NOV } 1994\end{array}$ & - & - & - & - & - & 27 & 8.9 & 11 & .10 & - & - \\
\hline $09 \ldots$ & - & - & - & - & - & 25 & - & 11 & - & - & - \\
\hline
\end{tabular}


Table 3. Water-quality data from surface-water sites-Continued

01480632 - Doe Run at Springdell, Pa. (Site 45)—Continued

\begin{tabular}{|c|c|c|c|c|c|c|c|c|c|c|c|}
\hline \multirow{6}{*}{ DATE } & $\begin{array}{l}\text { SOLIDS, } \\
\text { SUM OF }\end{array}$ & $\begin{array}{l}\text { SOLIDS, } \\
\text { DIS- }\end{array}$ & SOLIDS, & & $\begin{array}{c}\text { NITRO- } \\
\text { GEN, } \\
\text { NITRATE }\end{array}$ & $\begin{array}{l}\text { NITRO- } \\
\text { GEN, }\end{array}$ & $\begin{array}{l}\text { NITRO- } \\
\text { GEN, }\end{array}$ & $\begin{array}{c}\text { NITRO- } \\
\text { GEN, } \\
\mathrm{NO}_{2}+\mathrm{NO}_{3}\end{array}$ & $\begin{array}{c}\text { NITRO- } \\
\text { GEN, } \\
\text { AMMONIA }\end{array}$ & $\begin{array}{l}\text { NITRO- } \\
\text { GEN, } \\
\text { AMMONIA }\end{array}$ & $\begin{array}{l}\text { NITRO- } \\
\text { GEN, }\end{array}$ \\
\hline & TUENTS, & SOLVED & SOLVED & NITRATE & DIS- & DIS- & DIS- & $\begin{array}{l}N_{2}+N_{3} \\
\text { DIS- }\end{array}$ & DIS- & DIS- & ORGANIC \\
\hline & DIS- & (TONS & (TONS & TOTAL & SOLVED & SOLVED & SOLVED & SOLVED & SOLVED & SOLVED & TOTAL \\
\hline & SOLVED & PER & PER & (MG / L & (MG /L & (MG/L & (MG/L & (MG/L & (MG/L & (MG /L & (MG/L \\
\hline & (MG/L) & $A C-F T)$ & DAY) & AS N) & AS N) & AS $\quad \mathrm{NO}_{3}$ ) & AS N) & AS N) & AS N) & AS $\left.\quad \mathrm{NH}_{4}\right)$ & AS N) \\
\hline & $(70301)$ & $(70303)$ & (70302) & $(00620)$ & $(00618)$ & $(71851)$ & $(00613)$ & $(00631)$ & $(00608)$ & $(71846)$ & $(00605)$ \\
\hline
\end{tabular}

\begin{tabular}{|c|c|c|c|c|c|c|c|c|c|c|c|}
\hline $\begin{array}{c}\text { NOV } 1981 \\
05 \ldots \\
\text { OCT } 1982\end{array}$ & - & 0.11 & - & 3.00 & - & - & $<0.010$ & 3.10 & $<0.010$ & 0.01 & 0.46 \\
\hline $28 \ldots$ & 84 & .12 & 1.15 & 2.90 & - & - & $<.010$ & 2.90 & $<.010$ & .01 & - \\
\hline OCT 1983 & & & & & & & & & & & \\
\hline $\begin{array}{c}28 \ldots \\
\text { OCT } 1984\end{array}$ & 88 & .13 & 1.34 & 3.80 & - & - & $<.010$ & 3.80 & $<.010$ & - & - \\
\hline $\begin{array}{c}31 \ldots \\
\text { OCT } 1985\end{array}$ & 83 & .11 & 2.21 & 3.40 & - & - & $<.010$ & 3.40 & .040 & .05 & - \\
\hline $\begin{array}{c}29 \ldots \\
\text { OCT } 1986\end{array}$ & 106 & .10 & 1.35 & 4.10 & - & - & $<.010$ & 4.10 & .020 & .03 & - \\
\hline $\begin{array}{c}30 \ldots \\
\text { NOV } 1987\end{array}$ & - & - & - & 3.30 & - & - & $<.010$ & 3.30 & .040 & .05 & 1.8 \\
\hline $\begin{array}{c}19 \ldots \\
\text { NOV } 1988\end{array}$ & 98 & .12 & 1.75 & 3.80 & - & - & $<.010$ & 3.80 & $<.010$ & - & .30 \\
\hline $\begin{array}{c}14 \ldots \\
\text { NOV } 1989\end{array}$ & 96 & .13 & 1.74 & 4.09 & 4.09 & 18 & .010 & 4.10 & .030 & .04 & .37 \\
\hline $\begin{array}{c}07 \ldots \\
\text { OCT } 1990\end{array}$ & 94 & .13 & 3.55 & 4.90 & - & - & $<.010$ & 4.90 & .030 & .04 & .27 \\
\hline $\begin{array}{cc}17 \ldots \\
\text { OCT } 1991\end{array}$ & 101 & .14 & 1.62 & 4.10 & - & - & $<.010$ & 4.10 & $<.010$ & - & .80 \\
\hline $\begin{array}{c}31 \ldots \\
\text { OCT } 1992\end{array}$ & 98 & .13 & 1.30 & 3.80 & - & - & $<.010$ & 3.80 & .010 & .01 & .19 \\
\hline $\begin{array}{c}16 \ldots \\
\text { NOV } 1993\end{array}$ & 118 & .16 & 2.03 & 4.40 & - & - & $<.010$ & 4.40 & .020 & .03 & - \\
\hline $\begin{array}{c}08 \ldots \\
\text { NOV } 1994\end{array}$ & - & - & - & 4.80 & - & - & $<.010$ & 4.80 & .020 & .03 & - \\
\hline $09 \ldots$ & - & - & - & 4.40 & - & - & $<.010$ & 4.40 & $<.015$ & - & - \\
\hline
\end{tabular}


Table 3. Water-quality data from surface-water sites-Continued

01480632 - Doe Run at Springdell, Pa. (Site 45)—Continued

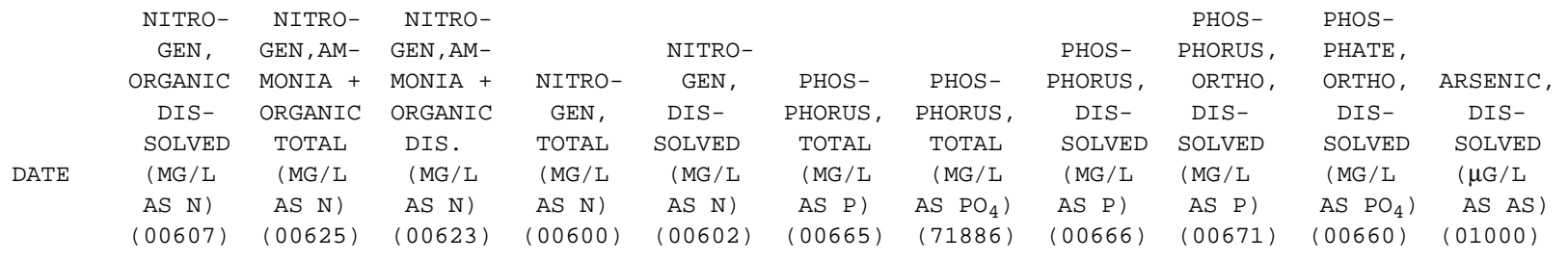

NOV 1981

$05 \ldots$

OCT 1982
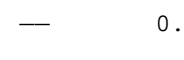

- $-\quad .30 \quad-$

$3.5 \quad 0.010$

0.03

0.020

$<0.010$

-

$3.2-$

.010

$<.010$

$-$

OCT 1983

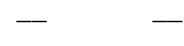

$3.9 \quad .020$

.06

.020

.010

0.03

$0.26 \quad-\quad .30 \quad-$

3.7

$<.010$

$-$

$<.010<.010$

$\begin{array}{llll}.28 & - & .30 \quad-\end{array}$

$4.4 \quad .010$

.03

.010

.010

.03

OCT 1986

$30 \ldots$

NOV 1987

$\begin{array}{llll}.66 & 1.8 & .70 & 5 .\end{array}$

$4.0 \quad .010$

.010

.010

$.03-$

$19 \ldots$

NOV 1988

$14 \ldots$

NOV 1989

$07 \ldots$

OCT 1990

$17 \ldots$

OCT 1991

$31 \ldots$

OCT 1992

$16 \ldots$

NOV 1993

$08 \ldots$

NOV 1994

$09 .$.

$\begin{array}{llll}- & .30 & .30 & 4 . \\ .77 & .40 & .80\end{array}$

.030

$-$

.010

$<.010$

$4.9 \quad .030$

$-$

.020

.010

$<.010$

.020

$5.3 \quad .030$

$-$

4.6

.020

$-$

.020

$<.010$

$<.010$

-

$<.010$

$<.010$

4. 7

.030

$-$

.030

.020

.010

.010

-

-

$.03-$

$\begin{array}{llll}.28 & <.20 \quad & .30 \quad-\end{array}$

$-\quad-$

$-$

$-$

.010 
Table 3. Water-quality data from surface-water sites-Continued

01480632 - Doe Run at Springdell, Pa. (Site 45)—Continued

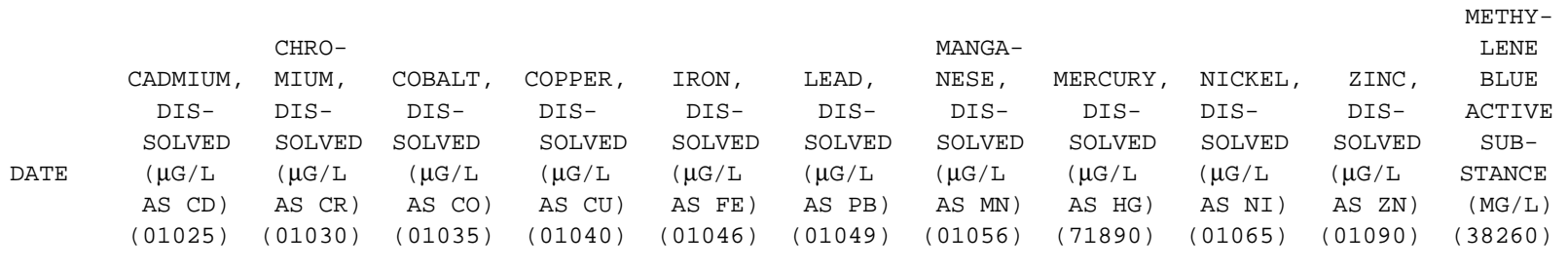

\begin{tabular}{|c|c|c|c|c|c|c|c|c|c|c|c|}
\hline $\begin{array}{c}\text { NOV } 1981 \\
05 \ldots \\
\text { OCT } 1982\end{array}$ & $<1.0$ & $<1$ & $<1$ & $<1$ & 29 & $<1$ & 14 & 0.4 & 1 & $<4$ & ND \\
\hline $\begin{array}{c}28 \ldots \\
\text { OCT } 1983\end{array}$ & $<1.0$ & $<1$ & $<1$ & 1 & 27 & $<1$ & 8 & $<.1$ & $<1$ & 6 & 0.04 \\
\hline $28 \ldots$ & - & - & - & - & 32 & - & 14 & - & - & - & - \\
\hline $\begin{array}{c}\text { OCT } 1984 \\
31 \ldots \\
\text { OCT } 1985\end{array}$ & - & - & - & - & 35 & - & 11 & - & - & - & - \\
\hline $\begin{array}{c}29 \ldots \\
\text { OCT } 1986\end{array}$ & - & - & - & - & 18 & - & 9 & - & - & - & - \\
\hline $\begin{array}{c}30 \ldots \\
\text { NOV } 1987\end{array}$ & - & - & - & - & 30 & - & 10 & - & - & - & - \\
\hline $\begin{array}{c}19 \ldots \\
\text { NOV } 1988\end{array}$ & - & - & - & - & 29 & - & 10 & - & - & - & - \\
\hline $\begin{array}{c}14 \ldots \\
\text { NOV } 1989\end{array}$ & - & - & - & - & 29 & - & 8 & - & - & - & - \\
\hline $\begin{array}{c}07 \ldots \\
\text { OCT } 1990\end{array}$ & - & - & - & - & 30 & - & 14 & - & - & - & - \\
\hline $\begin{array}{c}17 \ldots \\
\text { OCT } 1991\end{array}$ & - & - & - & - & 27 & - & 9 & - & - & - & - \\
\hline $\begin{array}{c}31 \ldots \\
\text { OCT } 1992\end{array}$ & - & - & - & - & 51 & - & 12 & - & - & - & - \\
\hline $\begin{array}{c}16 \ldots \\
\text { NOV } 1993\end{array}$ & - & - & - & - & 35 & - & 10 & - & - & - & - \\
\hline $\begin{array}{r}08 \ldots \\
\text { NOV } 1994\end{array}$ & - & - & - & - & - & - & - & - & - & - & - \\
\hline $09 \ldots$ & - & - & - & - & - & - & - & - & - & - & - \\
\hline
\end{tabular}


Table 3. Water-quality data from surface-water sites-Continued

01480640 - West Branch Brandywine Creek at Wawaset, Pa. (Site 38)

\begin{tabular}{|c|c|c|c|c|c|c|c|c|c|c|c|}
\hline & & DIS- & & $\mathrm{PH}$ & & & & & HARD - & & \\
\hline & & CHARGE, & SPE- & WATER & & & & HARD - & NESS & & MAGNE- \\
\hline & & INST. & CIFIC & WHOLE & & & & NESS, & NONCARB & CALCIUM, & SIUM, \\
\hline & & (CUBIC & $\mathrm{CON}-$ & FIELD & TEMPER- & TUR- & OXYGEN, & TOTAL & WH WAT & DIS- & DIS- \\
\hline & & FEET & DUCT- & (STAND- & ATURE & BID- & DIS- & (MG / L & TOT FLD & SOLVED & SOLVED \\
\hline DATE & TIME & PER & $\mathrm{ANCE}$ & $\mathrm{ARD}$ & WATER & ITY & SOLVED & AS & (MG/L AS & (MG/L & (MG / L \\
\hline & & SECOND) & $(\mu \mathrm{S} / \mathrm{CM})$ & UNITS) & $(\mathrm{DEG} C)$ & (NTU) & (MG/L) & $\left.\mathrm{CACO}_{3}\right)$ & $\mathrm{CACO}_{3}$ ) & AS $C A$ ) & AS MG) \\
\hline & & $(00061)$ & $(00095)$ & $(00400)$ & $(00010)$ & $(00076)$ & $(00300)$ & $(00900)$ & $(00902)$ & $(00915)$ & $(00925)$ \\
\hline
\end{tabular}

\begin{tabular}{|c|c|c|c|c|c|c|c|c|c|c|c|}
\hline $\begin{array}{c}04 \ldots \\
\text { OCT } 1982\end{array}$ & 1445 & - & 240 & 7.5 & 10.5 & - & 12.0 & 93 & - & 23 & 8.6 \\
\hline $\begin{array}{c}21 \ldots \\
\text { OCT } 1983\end{array}$ & 1530 & 59 & 238 & 7.7 & 13.0 & - & 10.9 & 86 & - & 21 & 8.1 \\
\hline $\begin{array}{c}31 \ldots \\
\text { OCT } 1984\end{array}$ & 1130 & 71 & 245 & 7.4 & 8.0 & 1.2 & 11.6 & 92 & - & 23 & 8.3 \\
\hline $\begin{array}{c}16 \ldots \\
\text { OCT } 1985\end{array}$ & 1130 & 100 & 225 & 8.2 & 13.0 & .40 & 11.4 & 84 & - & 21 & 7.6 \\
\hline $\begin{array}{c}22 \ldots \\
\text { NOV } 1986\end{array}$ & 1400 & 74 & 250 & 7.6 & 10.0 & .60 & 12.6 & 88 & - & 22 & 8.1 \\
\hline $\begin{array}{c}03 \ldots \\
\text { NOV } 1987\end{array}$ & 1130 & 51 & 245 & 7.8 & 11.0 & 1.0 & 10.3 & 92 & - & 23 & 8.4 \\
\hline $\begin{array}{c}03 \ldots \\
\text { OCT } 1988\end{array}$ & 1000 & 69 & 230 & 7.4 & 12.0 & .50 & 11.2 & 92 & - & 23 & 8.4 \\
\hline $\begin{array}{c}11 \ldots \\
\text { OCT } 1989\end{array}$ & 1030 & 57 & 258 & 7.3 & 12.0 & .30 & 11.7 & 95 & - & 23 & 9.0 \\
\hline $\begin{array}{c}13 \ldots \\
\text { OCT } 1990\end{array}$ & 1430 & 106 & 230 & 7.5 & 15.5 & .40 & 13.0 & 82 & 38 & 20 & 7.7 \\
\hline $\begin{array}{c}15 \ldots \\
\text { OCT } 1991\end{array}$ & 1100 & 79 & 258 & 6.8 & 19.0 & 2.5 & 8.4 & 88 & 0 & 22 & 7.9 \\
\hline $\begin{array}{c}30 \ldots \\
\text { OCT } 1992\end{array}$ & 0930 & 50 & 270 & 6.8 & 8.0 & .30 & 12.1 & 96 & 27 & 24 & 8.7 \\
\hline $\begin{array}{c}29 \ldots \\
\text { NOV } 1993\end{array}$ & 0915 & 56 & 270 & 7.8 & 9.0 & .90 & 11.3 & 89 & - & 22 & 8.3 \\
\hline $\begin{array}{c}15 \ldots \\
\text { OCT } 1994\end{array}$ & 0945 & 84 & 261 & 7.7 & 12.0 & - & 11.3 & - & - & - & - \\
\hline $11 \ldots$ & 1000 & 52 & 263 & 7.3 & 11.5 & - & 10.4 & - & - & - & - \\
\hline
\end{tabular}


Table 3. Water-quality data from surface-water sites-Continued

01480640 - West Branch Brandywine Creek at Wawaset, Pa. (Site 38)—Continued

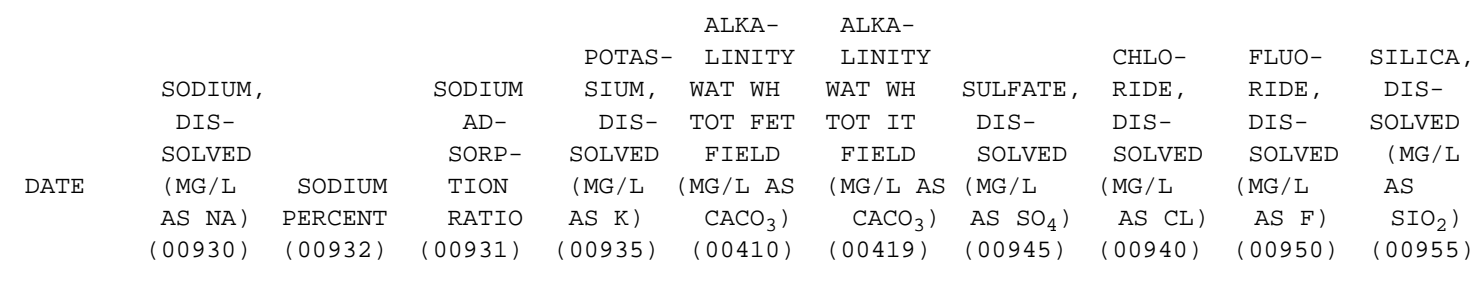

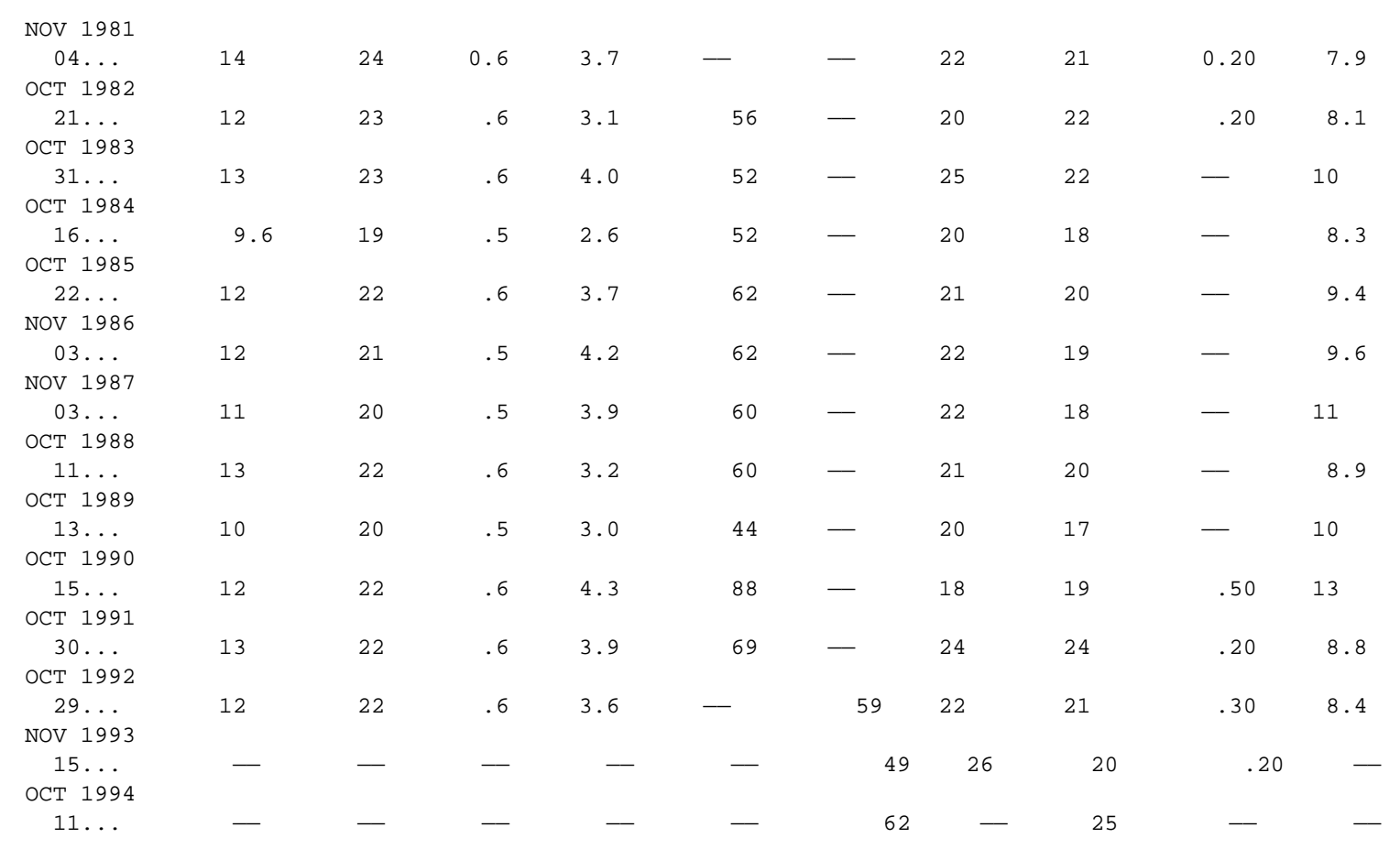


Table 3. Water-quality data from surface-water sites-Continued

01480640 - West Branch Brandywine Creek at Wawaset, Pa. (Site 38)—Continued

\begin{tabular}{|c|c|c|c|c|c|c|c|c|c|c|}
\hline & $\begin{array}{l}\text { SOLIDS, } \\
\text { RESIDUE }\end{array}$ & $\begin{array}{l}\text { SOLIDS, } \\
\text { SUM OF }\end{array}$ & SOLIDS, & SOLIDS, & NITRO- & $\begin{array}{c}\text { NITRO- } \\
\text { GEN }\end{array}$ & $\begin{array}{c}\text { NITRO- } \\
\text { GEN }\end{array}$ & $\begin{array}{c}\text { NITRO- } \\
\text { GEN }\end{array}$ & $\begin{array}{c}\text { NITRO- } \\
\text { GEN }\end{array}$ & $\begin{array}{l}\text { NITRO- } \\
\text { GEN, } \\
\text { AMMONIA }\end{array}$ \\
\hline \multirow{5}{*}{ ATE } & AT 180 & CONSTI- & DIS- & DIS- & GEN， & NITRATE & NITRATE & NITRITE & $\mathrm{NO}_{2}+\mathrm{NO}_{3}$ & $\begin{array}{c}\text { AMMONIA } \\
\text { DIS- }\end{array}$ \\
\hline & $\begin{array}{c}\text { DEG. C } \\
\text { DIS- }\end{array}$ & $\begin{array}{c}\text { TUENTS, } \\
\text { DIS- }\end{array}$ & $\begin{array}{l}\text { SOLVED } \\
\text { ( TONS }\end{array}$ & $\begin{array}{l}\text { SOLVED } \\
\text { (TONS }\end{array}$ & $\begin{array}{l}\text { NITRATE } \\
\text { TOTAL }\end{array}$ & $\begin{array}{l}\text { DIS- } \\
\text { SOLVED }\end{array}$ & $\begin{array}{l}\text { DIS- } \\
\text { SOLVED }\end{array}$ & $\begin{array}{l}\text { DIS- } \\
\text { SOLVED }\end{array}$ & $\begin{array}{l}\text { DIS- } \\
\text { SOLVED }\end{array}$ & $\begin{array}{l}\text { DIS- } \\
\text { SOLVED }\end{array}$ \\
\hline & SOLVED & SOLVED & PER & PER & (MG/L & (MG / L & (MG / L & (MG / L & (MG/L & (MG/L \\
\hline & (MG/L) & (MG/L) & $\mathrm{AC}-\mathrm{FT}$ ) & DAY) & AS N) & AS N) & AS $\left.\quad \mathrm{NO}_{3}\right)$ & AS N) & AS N) & AS N) \\
\hline & $(70300)$ & $(70301)$ & $(70303)$ & $(70302)$ & $(00620)$ & $(00618)$ & (71851) & $(00613)$ & $(00631)$ & $(00608)$ \\
\hline
\end{tabular}

\begin{tabular}{|c|c|c|c|c|c|c|c|c|c|c|}
\hline $\begin{array}{c}\text { NOV } 1981 \\
04 \ldots \\
\text { OCT } 1982\end{array}$ & 142 & - & 0.19 & - & 2.37 & 2.34 & 10 & 0.060 & 2.40 & $<0.010$ \\
\hline $21 \ldots$ & 140 & 139 & .19 & 22.3 & 2.36 & 2.36 & 10 & .040 & 2.40 & $<.010$ \\
\hline OCT 1983 & & & & & & & & & & \\
\hline $\begin{array}{c}31 \ldots \\
\text { OCT } 1984\end{array}$ & 153 & 154 & .21 & 29.3 & 3.76 & 3.76 & 17 & .040 & 3.80 & .060 \\
\hline $\begin{array}{c}16 \ldots \\
\text { OCT } 1985\end{array}$ & 135 & 135 & .18 & 36.5 & 3.55 & 3.55 & 16 & .050 & 3.60 & .070 \\
\hline $\begin{array}{c}22 \ldots \\
\text { NOV } 1986\end{array}$ & 140 & 148 & .19 & 28.0 & 3.15 & 3.15 & 14 & .050 & 3.20 & .040 \\
\hline $\begin{array}{c}03 \ldots \\
\text { NOV } 1987\end{array}$ & 152 & 148 & .21 & 2.9 & 2.69 & 2.69 & 12 & .010 & 2.70 & $<.010$ \\
\hline $\begin{array}{c}03 \ldots \\
\text { OCT } 1988\end{array}$ & 144 & 148 & .20 & 26.8 & 3.13 & 3.13 & 14 & .070 & 3.20 & .110 \\
\hline $\begin{array}{c}11 \ldots \\
\text { OCT } 1989\end{array}$ & - & 150 & .20 & 23.1 & 3.50 & - & - & $<.010$ & 3.50 & .020 \\
\hline $\begin{array}{c}13 \ldots \\
\text { OCT } 1990\end{array}$ & - & 130 & .18 & 37.3 & 3.59 & 3.59 & 16 & .010 & 3.60 & .010 \\
\hline $\begin{array}{c}15 \ldots \\
\text { OCT } 1991\end{array}$ & - & 162 & .22 & 34.6 & 2.78 & 2.78 & 12 & .020 & 2.80 & .030 \\
\hline $\begin{array}{c}30 \ldots \\
\text { OCT } 1992\end{array}$ & - & 161 & .22 & 21.7 & 2.80 & - & - & $<.010$ & 2.80 & $<.010$ \\
\hline $\begin{array}{c}29 \ldots \\
\text { NOV } 1993\end{array}$ & - & 149 & .20 & 22.7 & 3.58 & 3.58 & 16 & .020 & 3.60 & $<.010$ \\
\hline $\begin{array}{c}15 \ldots \\
\text { OCT } 1994\end{array}$ & - & - & - & - & 3.60 & - & - & $<.010$ & 3.60 & .010 \\
\hline $11 \ldots$ & - & - & - & - & 3.60 & - & - & $<.010$ & 3.60 & $<.015$ \\
\hline
\end{tabular}


Table 3. Water-quality data from surface-water sites-Continued

01480640 - West Branch Brandywine Creek at Wawaset, Pa. (Site 38)—Continued

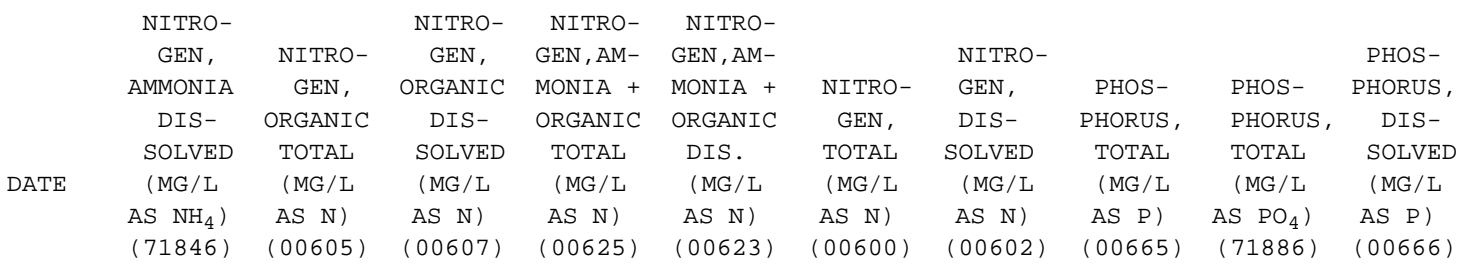

NOV 1981

$04 \ldots$

OCT 1982

$21 \ldots$

OCT 1983

$\begin{array}{lllll}0.01 & 0.49 \quad 0 & 0.49 & 0.66\end{array}$

$\begin{array}{lllllll}.01 & - & - & - & - & - & 1.7\end{array}$

3.

0.200

0.61

0.170

$31 \ldots$

OCT 1984

$16 \ldots$

OCT 1985

$22 \ldots$

NOV 1986

$03 \ldots$

NOV 1987

$03 . .$.

OCT 1988

$11 \ldots$

OCT 1989

$13 \ldots$

ОСт 1990

$15 \ldots$

ОСт 1991

$30 \ldots$

ОСт 1992

29 ..

NOV 1993

$15 \ldots$

OCT 1994

$\begin{array}{llllll}.08 & - & 0.34 & - & .40 & -\end{array}$

4.1

$-$

.140

$.09 \quad-$

4.2

170

.52

.150

$.05 \quad .76 \quad .66$

$.40-$

4.0

.130

-

.130

.76
$-\quad .80 \quad-$

.80

.70

4.0

3.9

.150

.46

.140

$.14 \quad .59 \quad .39$

.80

3.5

3.3

.190

$-$

.170

$\begin{array}{lll}.14 & .59 & .39 \\ .03 & .38 & .38\end{array}$

.50

3.9

3.7

.120

-

.100

$\begin{array}{llllll}.03 & .38 & .38 & .40 & .40\end{array}$

3.9

3.9

.150

$-$

.140

$\begin{array}{lllll}.01 & .49 & .39 & .50 & .40\end{array}$

4.1

4.0

.080

$-$

.070

$\begin{array}{lllll}.04 & .57 & .57 & .60 & .60\end{array}$

3.4

3.4

.140

$-$

.100

- $\quad .30 \quad-$

.30

$<.20$

3.1

.120

$-$

.110

$\begin{array}{llll}- & .20 \quad & -\end{array}$

.20

3.8

3.8

.110

$-$

.090

$11 \ldots$ 
Table 3. Water-quality data from surface-water sites-Continued

01480640 - West Branch Brandywine Creek at Wawaset, Pa. (Site 38)—Continued

\begin{tabular}{|c|c|c|c|c|c|c|c|c|c|c|}
\hline & $\begin{array}{c}\text { PHOS- } \\
\text { PHORUS, }\end{array}$ & $\begin{array}{l}\text { PHOS- } \\
\text { PHATE, }\end{array}$ & & & BERYL- & & CHRO- & & & \\
\hline ATE & $\begin{array}{l}\text { ORTHO, } \\
\text { DIS- } \\
\text { SOLVED } \\
\text { (MG/L }\end{array}$ & $\begin{array}{c}\text { ORTHO, } \\
\text { DIS- } \\
\text { SOLVED } \\
\text { (MG/L }\end{array}$ & $\begin{array}{c}\text { ARSENIC, } \\
\text { DIS- } \\
\text { SOLVED } \\
(\mu \mathrm{G} / \mathrm{L}\end{array}$ & $\begin{array}{l}\text { BARIUM, } \\
\text { DIS- } \\
\text { SOLVED } \\
(\mu \mathrm{G} / \mathrm{L}\end{array}$ & $\begin{array}{l}\text { LIUM, } \\
\text { DIS- } \\
\text { SOLVED } \\
(\mu \mathrm{G} / \mathrm{L}\end{array}$ & $\begin{array}{c}\text { CADMIUM, } \\
\text { DIS- } \\
\text { SOLVED } \\
(\mu \mathrm{G} / \mathrm{L}\end{array}$ & $\begin{array}{c}\text { MIUM, } \\
\text { DIS- } \\
\text { SOLVED } \\
(\mu \mathrm{G} / \mathrm{L}\end{array}$ & $\begin{array}{c}\text { COBALT, } \\
\text { DIS- } \\
\text { SOLVED } \\
(\mu \mathrm{G} / \mathrm{L}\end{array}$ & $\begin{array}{l}\text { COPPER, } \\
\text { DIS- } \\
\text { SOLVED } \\
(\mu \mathrm{G} / \mathrm{L}\end{array}$ & $\begin{array}{l}\text { IRON, } \\
\text { DIS- } \\
\text { SOLVED } \\
(\mu \mathrm{G} / \mathrm{L}\end{array}$ \\
\hline & $\begin{array}{l}\text { AS P) } \\
(00671)\end{array}$ & $\begin{array}{l}\left.\mathrm{AS} \mathrm{PO}_{4}\right) \\
(00660)\end{array}$ & $\begin{array}{c}\text { AS AS) } \\
(01000)\end{array}$ & $\begin{array}{c}\text { AS BA) } \\
(01005)\end{array}$ & $\begin{array}{c}\text { AS BE) } \\
(01010)\end{array}$ & $\begin{array}{c}\text { AS CD) } \\
(01025)\end{array}$ & $\begin{array}{c}\text { AS CR) } \\
(01030)\end{array}$ & $\begin{array}{c}\text { AS CO) } \\
(01035)\end{array}$ & $\begin{array}{c}\text { AS CU) } \\
(01040)\end{array}$ & $\begin{array}{c}\text { AS FE) } \\
(01046)\end{array}$ \\
\hline
\end{tabular}

\begin{tabular}{|c|c|c|c|c|c|c|c|c|c|c|}
\hline $04 \ldots$ & 0.150 & 0.46 & ND & - & - & $<1.0$ & $<1$ & $<1$ & 2 & 65 \\
\hline OCT 1982 & & & & & & & & & & \\
\hline $\begin{array}{c}21 \ldots \\
\text { OCT } 1983\end{array}$ & .130 & .40 & 1 & - & - & $<1.0$ & $<1$ & 1 & 3 & 50 \\
\hline $\begin{array}{c}31 \ldots \\
\text { OCT } 1984\end{array}$ & .150 & .46 & 1 & - & - & $<1.0$ & $<1$ & - & 3 & 81 \\
\hline $\begin{array}{c}16 \ldots \\
\text { OCT } 1985\end{array}$ & .130 & .40 & $<1$ & - & - & $<1.0$ & 2 & - & 1 & 46 \\
\hline $\begin{array}{c}22 \ldots \\
\text { NOV } 1986\end{array}$ & .130 & .40 & $<1$ & - & - & $<1.0$ & 1 & - & 2 & 42 \\
\hline $\begin{array}{c}03 \ldots \\
\text { NOV } 1987\end{array}$ & .140 & .43 & $<1$ & - & - & 1.0 & $<1$ & - & 3 & 65 \\
\hline $\begin{array}{c}03 \ldots \\
\text { OCT } 1988\end{array}$ & .100 & .31 & $<1$ & - & - & $<1.0$ & 2 & - & 4 & 58 \\
\hline $\begin{array}{c}11 \ldots \\
\text { OCT } 1989\end{array}$ & .120 & .37 & $<1$ & 25 & $<0.5$ & $<1.0$ & $<5$ & $<3$ & $<10$ & 35 \\
\hline $\begin{array}{c}13 \ldots \\
\text { OCT } 1990\end{array}$ & .060 & .18 & $<1$ & 25 & $<.5$ & $<1.0$ & $<5$ & $<3$ & $<10$ & 41 \\
\hline $\begin{array}{c}15 \ldots \\
\text { OCT } 1991\end{array}$ & .110 & .34 & $<1$ & 30 & $<.5$ & $<1.0$ & $<5$ & $<3$ & $<10$ & 67 \\
\hline $\begin{array}{c}30 \ldots \\
\text { OCT } 1992\end{array}$ & .090 & .28 & $<1$ & 26 & $<.5$ & 1.0 & $<5$ & $<3$ & $<10$ & 75 \\
\hline $\begin{array}{c}29 \ldots \\
\text { NOV } 1993\end{array}$ & .070 & .21 & $<1$ & 27 & $<.5$ & $<1.0$ & $<5$ & $<3$ & $<10$ & 57 \\
\hline $\begin{array}{c}15 \ldots \\
\text { OCT } 1994\end{array}$ & .040 & .12 & - & - & - & - & - & - & - & - \\
\hline $11 \ldots$ & .060 & .18 & - & - & - & - & - & - & - & - \\
\hline
\end{tabular}


Table 3. Water-quality data from surface-water sites-Continued

01480640 - West Branch Brandywine Creek at Wawaset, Pa. (Site 38)—Continued

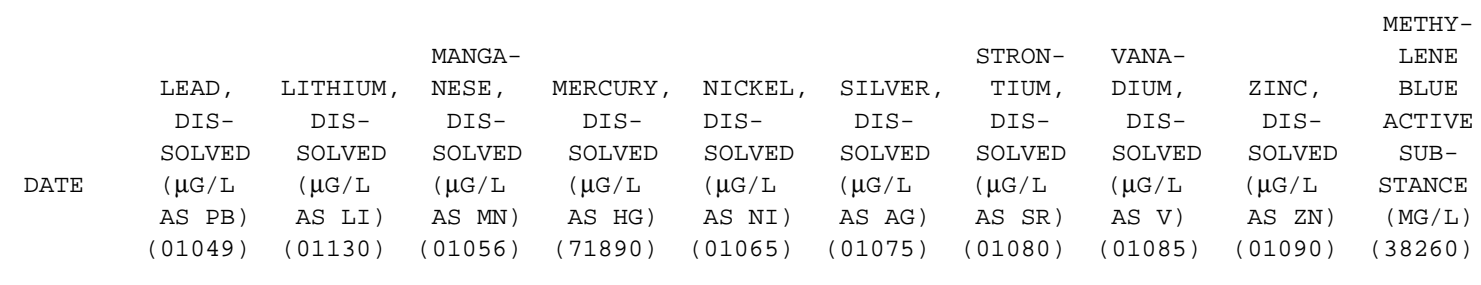

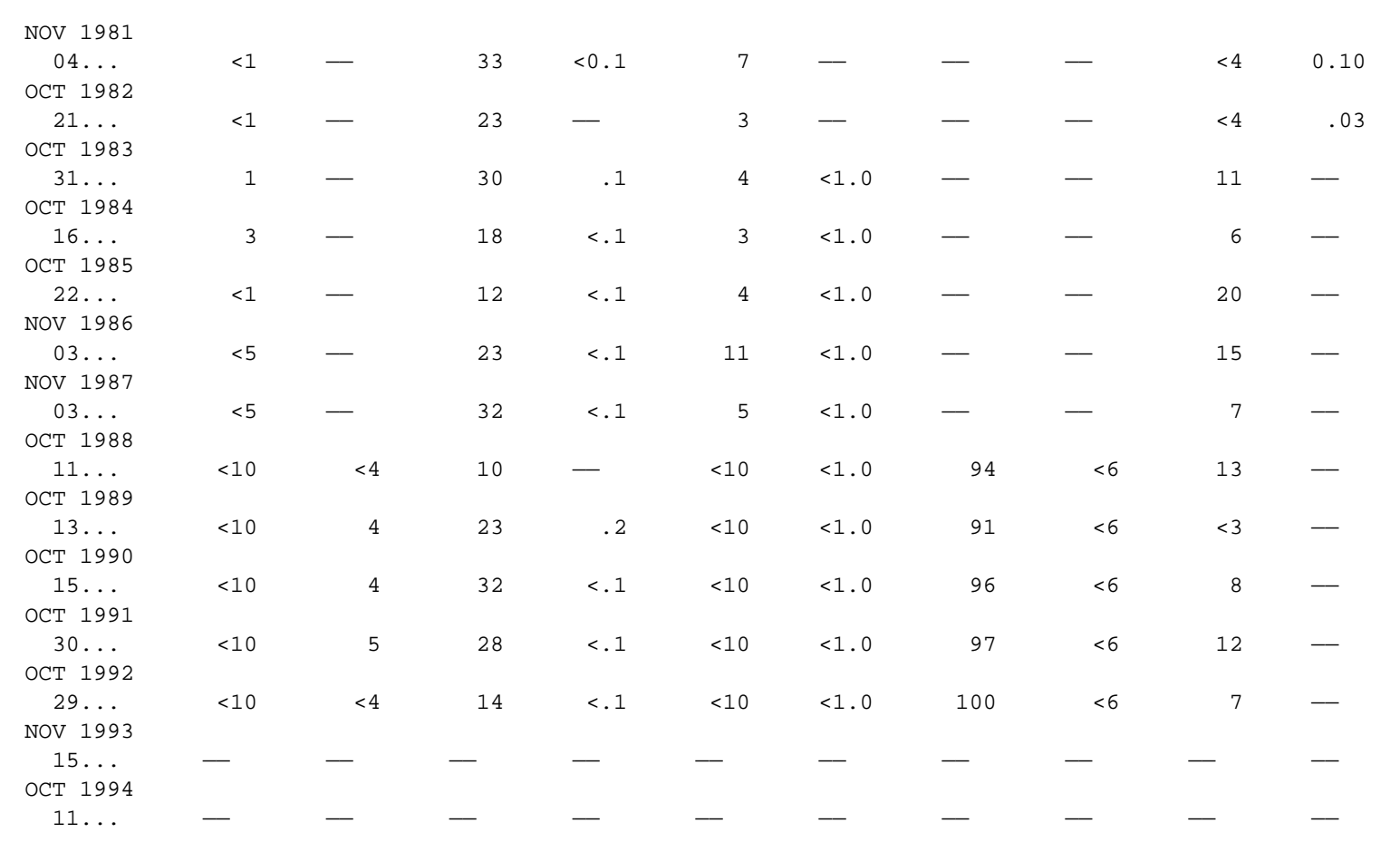


Table 3. Water-quality data from surface-water sites-Continued

01480647 - East Branch Brandywine Creek near Struble Dam, Pa. (Site 43)

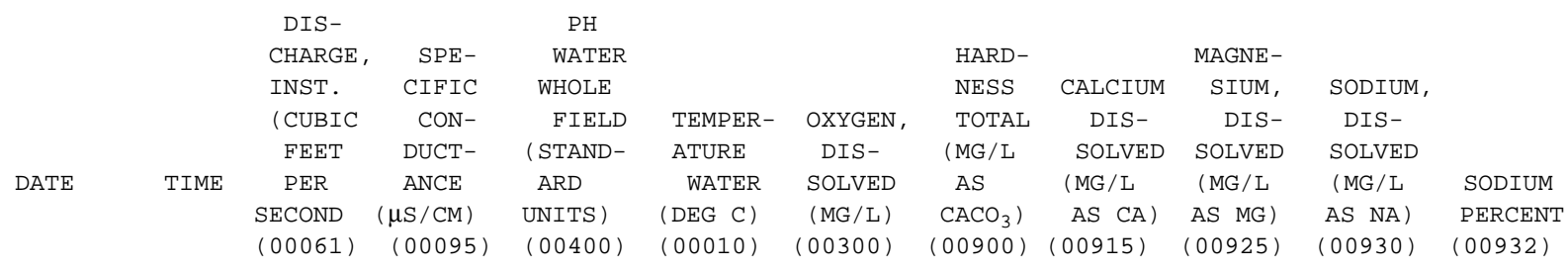

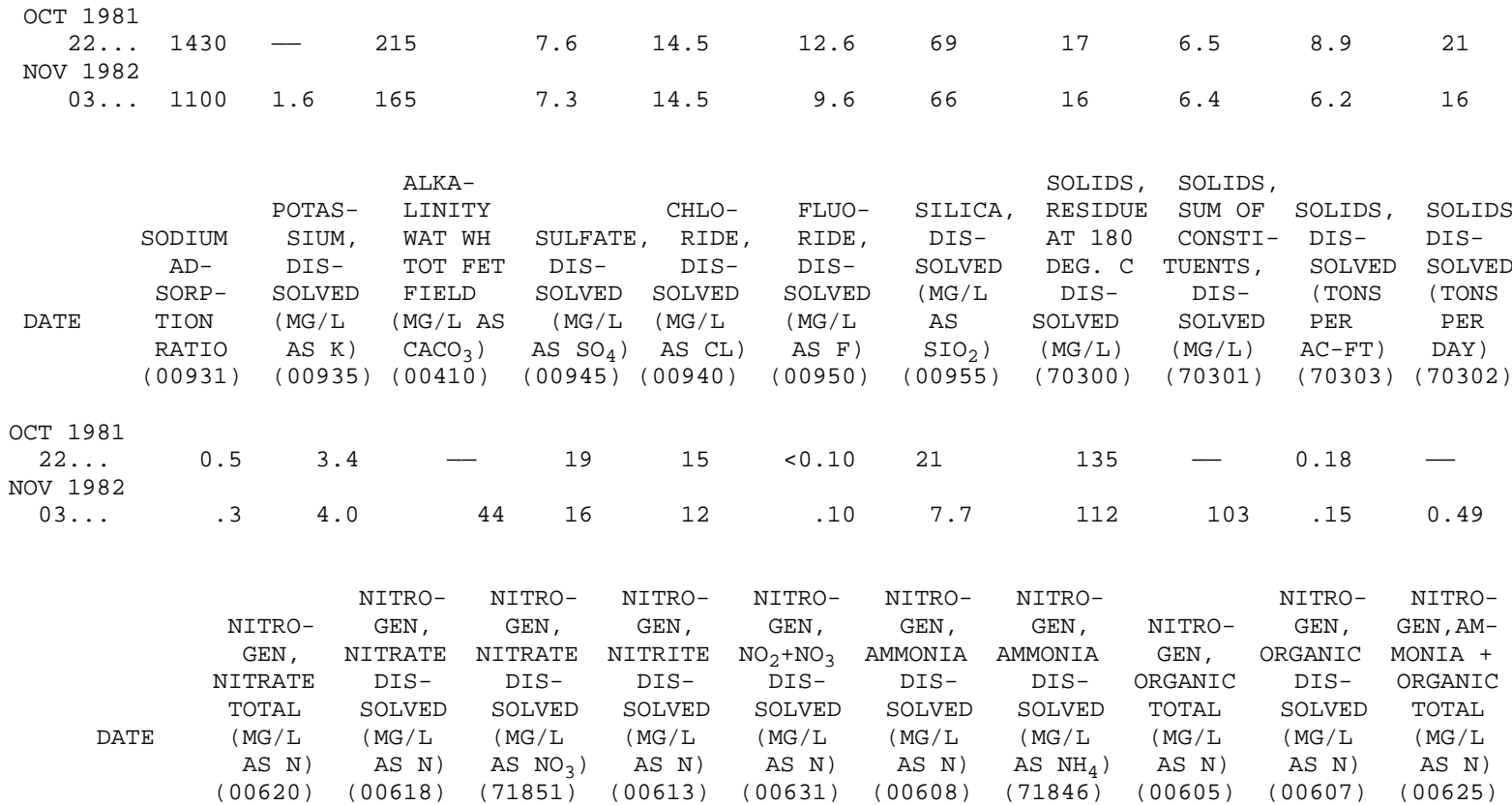

\begin{tabular}{|c|c|c|c|c|c|c|c|c|c|c|}
\hline $\begin{array}{r}22 \ldots \\
\text { NOV } 1982\end{array}$ & 3.78 & 4.19 & 19 & 0.010 & 4.20 & 0.130 & 0.17 & 1.5 & 1.3 & 1.6 \\
\hline $03 \ldots$ & 1.78 & 1.78 & 7.9 & .020 & 1.80 & .040 & .05 & - & .46 & - \\
\hline DATE & $\begin{array}{c}\text { NITRO- } \\
\text { GEN, AM } \\
\text { MONIA } \\
\text { ORGANIC } \\
\text { DIS. } \\
\text { (MG/L } \\
\text { AS N) } \\
(00623)\end{array}$ & $\begin{array}{cc}- & \\
\mathrm{M}- & \\
+ & \text { NITRO- } \\
\mathrm{C} & \text { GEN, } \\
& \text { TOTAL } \\
\text { (MG/L } \\
\text { AS N) } \\
\quad(00600)\end{array}$ & $\begin{array}{c}\text { NITRO- } \\
\text { GEN, } \\
\text { DIS- } \\
\text { SOLVED } \\
\text { (MG / L } \\
\text { AS N) } \\
(00602)\end{array}$ & $\begin{array}{l}\text { PHOS- } \\
\text { PHORUS, } \\
\text { TOTAL } \\
\text { (MG/L } \\
\text { AS P) } \\
(00665)\end{array}$ & $\begin{array}{c}\text { PHOS- } \\
\text { PHORUS, } \\
\text { TOTAL } \\
(\mathrm{MG} / \mathrm{L} \\
\mathrm{AS} \mathrm{PO}) \\
(71886)\end{array}$ & $\begin{array}{c}\text { PHOS- } \\
\text { PHORUS, } \\
\text { S, } \text { DIS } \\
\text { SOLVE } \\
(\mathrm{MG} / \mathrm{L} \\
\text { ) } \mathrm{AS} \mathrm{P}) \\
(00666)\end{array}$ & $\begin{array}{ll} & \text { PHOS- } \\
\text { S, } & \text { PHORUS } \\
\text { S, } & \text { ORTHO, } \\
\text { S- } & \text { DIS- } \\
\text { DD } & \text { SOLVED } \\
\text { L } & \text { (MG/L } \\
\text { AS P ) } \\
\text { 6) } & (00671)\end{array}$ & $\begin{array}{r}\text { PHOS- } \\
\text { PHATE, } \\
\text { ORTHO, } \\
\text { DIS- } \\
\text { SOLVED } \\
(\mathrm{MG} / \mathrm{L} \\
\left.\mathrm{AS} \mathrm{PO}_{4}\right) \\
(00660)\end{array}$ & $\begin{array}{r} \\
\text { ARSENIC, } \\
\text { DIS- } \\
\text { SOLVED } \\
(\mu \mathrm{G} / \mathrm{L} \\
\mathrm{AS} A \mathrm{~A}) \\
(01000)\end{array}$ & $\begin{array}{cr}C, & \text { CADMIUM, } \\
- & \text { DIS- } \\
D & \text { SOLVED } \\
\text { L } & (\mu G / L \\
\text { D) } & \text { AS CD }) \\
0) & (01025)\end{array}$ \\
\hline ОСТ 1981 & & & & & & & & & & \\
\hline $\begin{array}{c}22 \ldots \\
\text { NOV } 1982\end{array}$ & 1.4 & 5.4 & 5.6 & 0.090 & 0.28 & 0.050 & 0.030 & 0.09 & 1 & 3.0 \\
\hline $03 \ldots$ & .50 & - & 2.3 & - & - & .010 & $<.010$ & - & 1 & $<1.0$ \\
\hline DATE & $\begin{array}{l}\text { CHRO- } \\
\text { MIUM, } \\
\text { DIS- } \\
\text { SOLVED } \\
(\mu \mathrm{G} / \mathrm{L} \\
\text { AS CR) } \\
(01030)\end{array}$ & $\begin{array}{c}\text { COBALT, } \\
\text { DIS- } \\
\text { SOLVED } \\
(\mu \mathrm{G} / \mathrm{L} \\
\text { AS CO) } \\
(01035)\end{array}$ & $\begin{array}{l}\text { COPPER, } \\
\text { DIS- } \\
\text { SOLVED } \\
(\mu \mathrm{G} / \mathrm{L} \\
\text { AS CU }) \\
(01040)\end{array}$ & $\begin{array}{c}\text { IRON, } \\
\text { DIS- } \\
\text { SOLVED } \\
(\mu \mathrm{G} / \mathrm{L} \\
\text { AS FE) } \\
(01046)\end{array}$ & $\begin{array}{l}\text { LEAD, } \\
\text { DIS- } \\
\text { SOLVED } \\
(\mu \mathrm{G} / \mathrm{L} \\
\text { AS PB) } \\
(01049)\end{array}$ & $\begin{array}{l}\text { MANGA- } \\
\text { NESE, } \\
\text { DIS- } \\
\text { SOLVED } \\
(\mu \mathrm{G} / \mathrm{L} \\
\text { AS MN) } \\
(01056)\end{array}$ & $\begin{array}{c}\text { MERCURY, } \\
\text { DIS- } \\
\text { SOLVED } \\
(\mu \mathrm{G} / \mathrm{L} \\
\text { AS HG) } \\
(71890)\end{array}$ & $\begin{array}{l}\text { NICKEL, } \\
\text { DIS- } \\
\text { SOLVED } \\
(\mu G / L \\
\text { AS NI) } \\
(01065)\end{array}$ & $\begin{array}{c}\text { ZINC, } \\
\text { DIS- } \\
\text { SOLVED } \\
(\mu \mathrm{G} / \mathrm{L} \\
\text { AS ZN }) \\
(01090)\end{array}$ & $\begin{array}{c}\text { METHY- } \\
\text { LENE } \\
\text { BLUE } \\
\text { ACTIVE } \\
\text { SUB- } \\
\text { STANCE } \\
(\text { MG/L) } \\
(38260)\end{array}$ \\
\hline ОСТ 1981 & & & & & & & & & & \\
\hline $\begin{array}{c}22 \ldots \\
\text { NOV } 1982\end{array}$ & 5 & 1 & 20 & 610 & 1 & 140 & 0.5 & 22 & 6 & 一 \\
\hline $03 \ldots$ & $<1$ & 1 & $<1$ & 49 & $<1$ & 82 & $<.1$ & $<1$ & $<4$ & 0.03 \\
\hline
\end{tabular}


Table 3. Water-quality data from surface-water sites-Continued

01480648 - East Branch Brandywine Creek near Cupola, Pa. (Site 48)

\begin{tabular}{|c|c|c|c|c|c|c|c|c|c|c|c|}
\hline & & DIS- & & $\mathrm{PH}$ & & & & & HARD - & & \\
\hline & & CHARGE, & SPE- & WATER & & & & HARD - & NESS & & MAGNE- \\
\hline & & INST. & CIFIC & WHOLE & & & & NESS, & NONCARB & CALCIUM, & SIUM, \\
\hline & & (CUBIC & $\mathrm{CON}-$ & FIELD & TEMPER- & TUR- & OXYGEN, & TOTAL & WH WAT & DIS- & DIS- \\
\hline & & FEET & DUCT- & (STAND- & ATURE & BID- & DIS- & (MG / L & TOT FLD & SOLVED & SOLVED \\
\hline DATE & TIME & PER & ANCE & ARD & WATER & ITY & SOLVED & AS & (MG/L AS & (MG / L & (MG / L \\
\hline & & SECOND) & $(\mu \mathrm{S} / \mathrm{CM})$ & UNITS) & $(\mathrm{DEG} C)$ & (NTU) & (MG/L) & $\left.\mathrm{CACO}_{3}\right)$ & $\mathrm{CACO}_{3}$ ) & AS CA) & AS MG) \\
\hline & & $(00061)$ & $(00095)$ & $(00400)$ & $(00010)$ & $(00076)$ & $(00300)$ & $(00900)$ & $(00902)$ & $(00915)$ & $(00925)$ \\
\hline
\end{tabular}

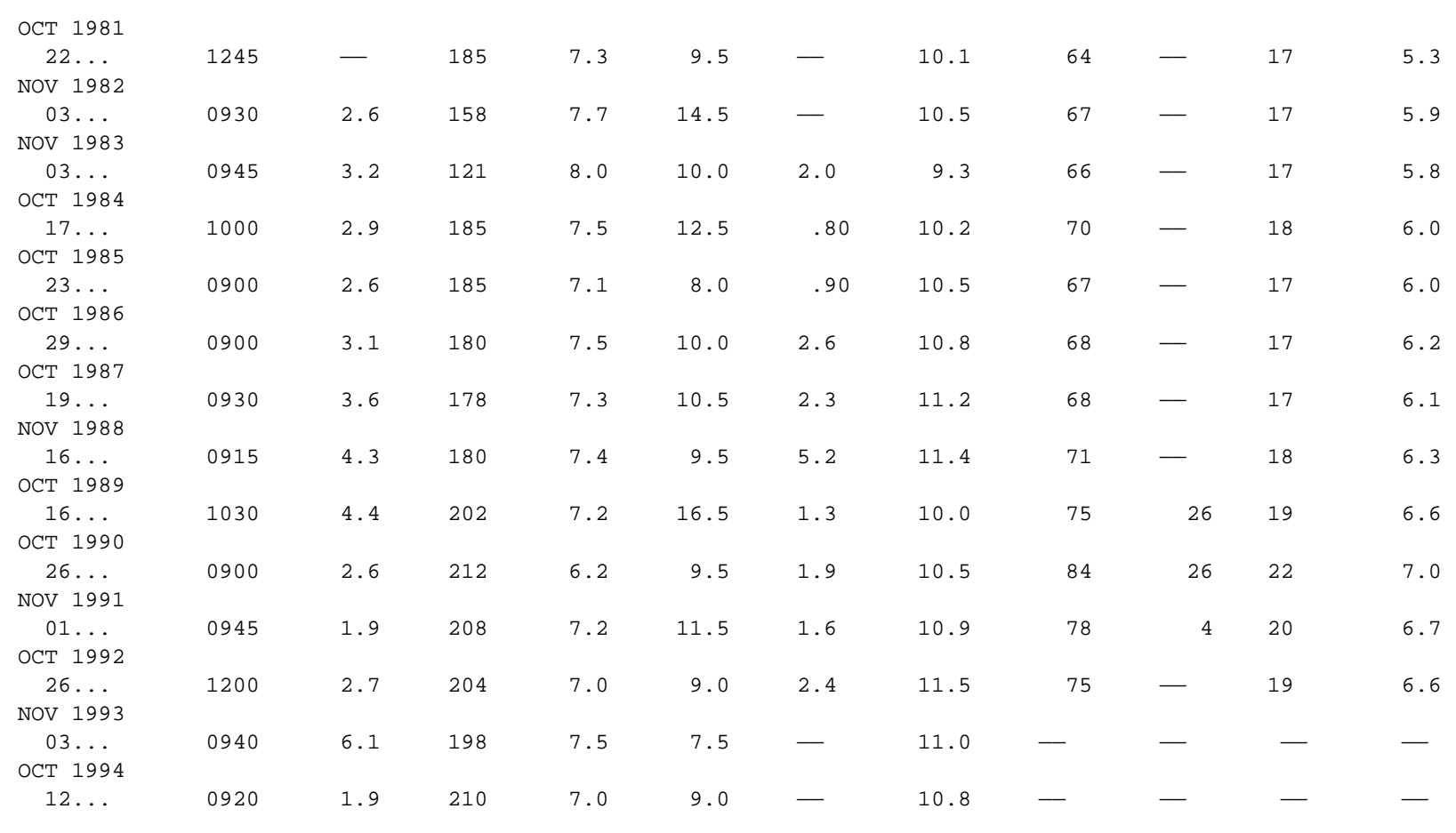


Table 3. Water-quality data from surface-water sites-Continued

01480648 - East Branch Brandywine Creek near Cupola, Pa. (Site 48)—Continued

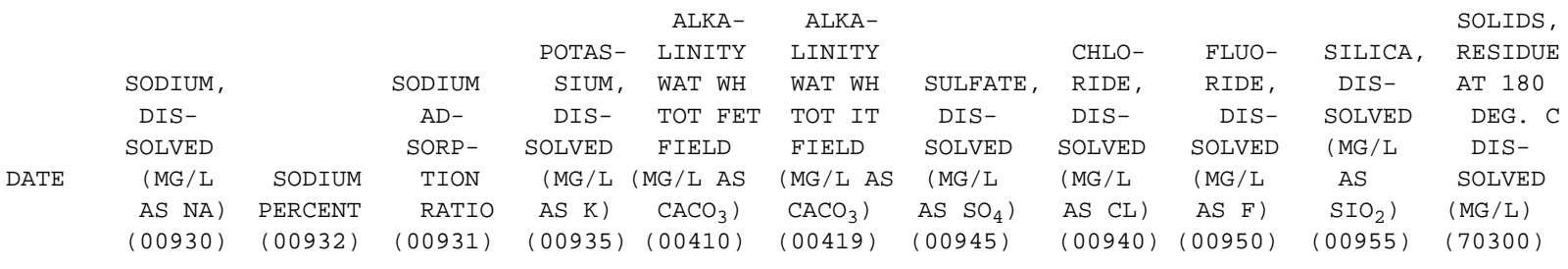

\begin{tabular}{|c|c|c|c|c|c|c|c|c|c|c|c|}
\hline $\begin{array}{c}\text { OCT } 1981 \\
22 \ldots \\
\text { NOV } 1982\end{array}$ & 8.2 & 21 & 0.4 & 2.1 & - & - & 12 & 8.7 & $<0.10$ & 24 & 112 \\
\hline $03 \ldots$ & 6.9 & 17 & .4 & 3.2 & 44 & - & 14 & 10 & .10 & 14 & 107 \\
\hline NOV 1983 & & & & & & & & & & & \\
\hline $\begin{array}{c}03 \ldots \\
\text { OCT } 1984\end{array}$ & 7.6 & 19 & .4 & 2.9 & 52 & - & 18 & 11 & - & 12 & 120 \\
\hline $\begin{array}{c}17 \ldots \\
\text { OCT } 1985\end{array}$ & 6.4 & 16 & .3 & 2.8 & 48 & - & 16 & 11 & - & 15 & 130 \\
\hline $\begin{array}{c}23 \ldots \\
\text { OCT } 1986\end{array}$ & 7.3 & 18 & .4 & 3.0 & 54 & - & 15 & 12 & - & 16 & 108 \\
\hline $\begin{array}{c}29 \ldots \\
\text { OCT } 1987\end{array}$ & 7.2 & 18 & .4 & 3.7 & 48 & - & 17 & 13 & - & 12 & 119 \\
\hline $\begin{array}{c}19 \ldots \\
\text { NOV } 1988\end{array}$ & 7.0 & 18 & .4 & 3.3 & 46 & - & 13 & 11 & - & 15 & 117 \\
\hline $\begin{array}{c}16 \ldots \\
\text { OCT } 1989\end{array}$ & 6.7 & 16 & .3 & 3.5 & 50 & - & 19 & 11 & - & 10 & - \\
\hline $\begin{array}{c}16 \ldots \\
\text { OCT } 1990\end{array}$ & 7.1 & 16 & .4 & 3.4 & 49 & - & 13 & 12 & - & 15 & - \\
\hline $\begin{array}{c}26 \ldots \\
\text { NOV } 1991\end{array}$ & 8.0 & 17 & .4 & 3.0 & 58 & - & 21 & 17 & .10 & 23 & - \\
\hline $\begin{array}{c}01 \ldots \\
\text { OCT } 1992\end{array}$ & 7.8 & 17 & .4 & 2.9 & 74 & - & 15 & 15 & $<.10$ & 16 & - \\
\hline $\begin{array}{c}26 \ldots \\
\text { NOV } 1993\end{array}$ & 7.6 & 17 & .4 & 3.0 & - & 47 & 16 & 14 & .10 & 15 & - \\
\hline $\begin{array}{c}03 \ldots \\
\text { OCT } 1994\end{array}$ & - & - & - & - & - & 50 & 16 & 12 & .20 & - & - \\
\hline $12 \ldots$ & - & - & - & - & - & 53 & - & 13 & - & - & - \\
\hline
\end{tabular}


Table 3. Water-quality data from surface-water sites-Continued

01480648 - East Branch Brandywine Creek near Cupola, Pa. (Site 48)—Continued

\begin{tabular}{|c|c|c|c|c|c|c|c|c|c|c|c|}
\hline DATE & $\begin{array}{l}\text { SOLIDS, } \\
\text { SUM OF } \\
\text { CONSTI- } \\
\text { TUENTS, } \\
\text { DIS- } \\
\text { SOLVED } \\
(\mathrm{MG} / \mathrm{L}) \\
(70301)\end{array}$ & $\begin{array}{c}\text { SOLIDS, } \\
\text { DIS- } \\
\text { SOLVED } \\
\text { (TONS } \\
\text { PER } \\
\text { AC-FT) } \\
(70303)\end{array}$ & $\begin{array}{c}\text { SOLIDS, } \\
\text { DIS- } \\
\text { SOLVED } \\
\text { (TONS } \\
\text { PER } \\
\text { DAY) } \\
(70302)\end{array}$ & $\begin{array}{l}\text { NITRO- } \\
\text { GEN, } \\
\text { NITRATE } \\
\text { TOTAL } \\
\text { (MG/L } \\
\text { AS N) } \\
(00620)\end{array}$ & $\begin{array}{l}\text { NITRO- } \\
\text { GEN, } \\
\text { NITRATE } \\
\text { DIS- } \\
\text { SOLVED } \\
(\text { MG/L } \\
\text { AS N) } \\
(00618)\end{array}$ & $\begin{array}{c}\text { NITRO- } \\
\text { GEN, } \\
\text { NITRATE } \\
\text { DIS- } \\
\text { SOLVED } \\
(\mathrm{MG} / \mathrm{L} \\
\text { AS NO } \\
(71851)\end{array}$ & $\begin{array}{l}\text { NITRO- } \\
\text { GEN, } \\
\text { NITRITE } \\
\text { DIS- } \\
\text { SOLVED } \\
\text { (MG/L } \\
\text { AS N) } \\
(00613)\end{array}$ & $\begin{array}{c}\text { NITRO- } \\
\text { GEN, } \\
\mathrm{NO}_{2}+\mathrm{NO}_{3} \\
\text { DIS- } \\
\text { SOLVED } \\
(\mathrm{MG} / \mathrm{L} \\
\mathrm{AS} \mathrm{N}) \\
(00631)\end{array}$ & $\begin{array}{c}\text { NITRO- } \\
\text { GEN, } \\
\text { AMMONIA } \\
\text { DIS- } \\
\text { SOLVED } \\
\text { (MG/L } \\
\text { AS N) } \\
(00608)\end{array}$ & $\begin{array}{c}\text { NITRO- } \\
\text { GEN, } \\
\text { AMMONIA } \\
\text { DIS- } \\
\text { SOLVED } \\
(\mathrm{MG} / \mathrm{L} \\
\left.\text { AS } \mathrm{NH}_{4}\right) \\
(71846)\end{array}$ & $\begin{array}{l}\text { NITRO- } \\
\text { GEN, } \\
\text { ORGANIC } \\
\text { TOTAL } \\
\text { (MG/L } \\
\text { AS N) } \\
(00605)\end{array}$ \\
\hline ОСТ 1981 & & & & & & & & & & & \\
\hline $\begin{array}{c}22 \ldots \\
\text { NOV } 1982\end{array}$ & - & 0.15 & - & 3.09 & - & - & $<0.010$ & 3.10 & 0.040 & 0.05 & 0.22 \\
\hline $\begin{array}{c}03 \ldots \\
\text { NOV } 1983\end{array}$ & 106 & .15 & 0.75 & 1.98 & 1.98 & 8.8 & .020 & 2.00 & $<.010$ & .01 & - \\
\hline $\begin{array}{c}03 \ldots \\
\text { ОСТ } 1984\end{array}$ & 118 & .16 & 1.04 & 2.77 & 2.77 & 12 & .030 & 2.80 & .130 & .17 & - \\
\hline $\begin{array}{c}17 \ldots \\
\text { OCT } 1985\end{array}$ & 120 & .18 & 1.02 & 3.44 & 3.44 & 15 & .060 & 3.50 & .130 & .17 & - \\
\hline $\begin{array}{c}23 \ldots \\
\text { OCT } 1986\end{array}$ & 126 & .15 & .76 & 3.79 & 3.79 & 17 & .010 & 3.80 & .050 & .06 & - \\
\hline $\begin{array}{c}29 \ldots \\
\text { OCT } 1987\end{array}$ & 113 & .16 & 1.0 & 1.80 & - & - & $<.010$ & 1.80 & $<.010$ & - & .90 \\
\hline $\begin{array}{c}19 \ldots \\
\text { NOV } 1988\end{array}$ & 115 & .16 & 1.14 & 3.39 & 3.39 & 15 & .010 & 3.40 & .030 & .04 & 1.2 \\
\hline $\begin{array}{c}16 \ldots \\
\text { ОСТ } 1989\end{array}$ & 118 & .16 & 1.37 & 2.97 & 2.97 & 13 & .030 & 3.00 & .210 & .27 & .69 \\
\hline $\begin{array}{c}16 \ldots \\
\text { OCT } 1990\end{array}$ & 122 & .17 & 1.44 & 3.57 & 3.57 & 16 & .030 & 3.60 & .020 & .03 & .78 \\
\hline $\begin{array}{c}26 \ldots \\
\text { NOV } 1991\end{array}$ & 159 & .22 & 1.13 & 5.18 & 5.18 & 23 & .020 & 5.20 & .030 & .04 & .77 \\
\hline $\begin{array}{c}01 \ldots \\
\text { OCT } 1992\end{array}$ & 144 & .20 & .74 & 3.68 & 3.68 & 16 & .021 & 3.70 & .021 & .03 & .48 \\
\hline $\begin{array}{c}26 \ldots \\
\text { NOV } 1993\end{array}$ & 124 & .17 & .90 & 3.18 & 3.18 & 14 & .020 & 3.20 & .020 & .03 & .58 \\
\hline $\begin{array}{c}03 \ldots \\
\text { OCT } 1994\end{array}$ & - & - & - & 2.47 & 2.47 & 11 & .030 & 2.50 & .180 & .23 & - \\
\hline $12 \ldots$ & - & - & - & 3.88 & 3.88 & 17 & .020 & 3.90 & .030 & .04 & - \\
\hline
\end{tabular}


Table 3. Water-quality data from surface-water sites-Continued

01480648 - East Branch Brandywine Creek near Cupola, Pa. (Site 48)—Continued

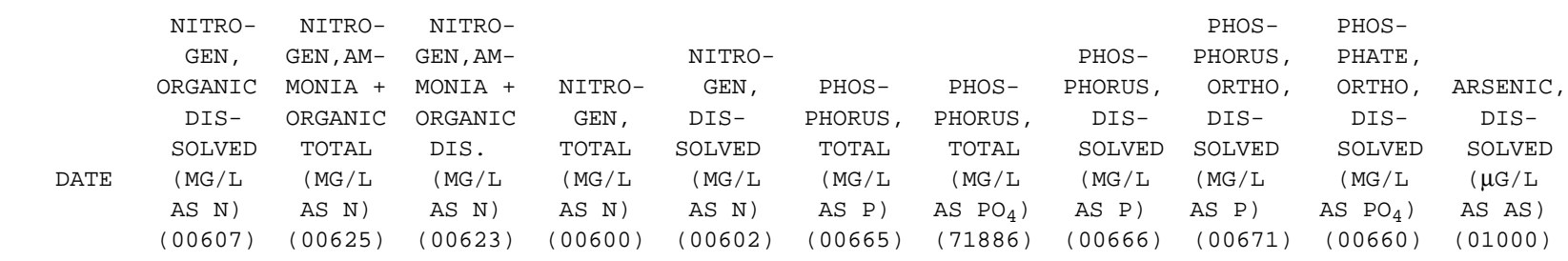

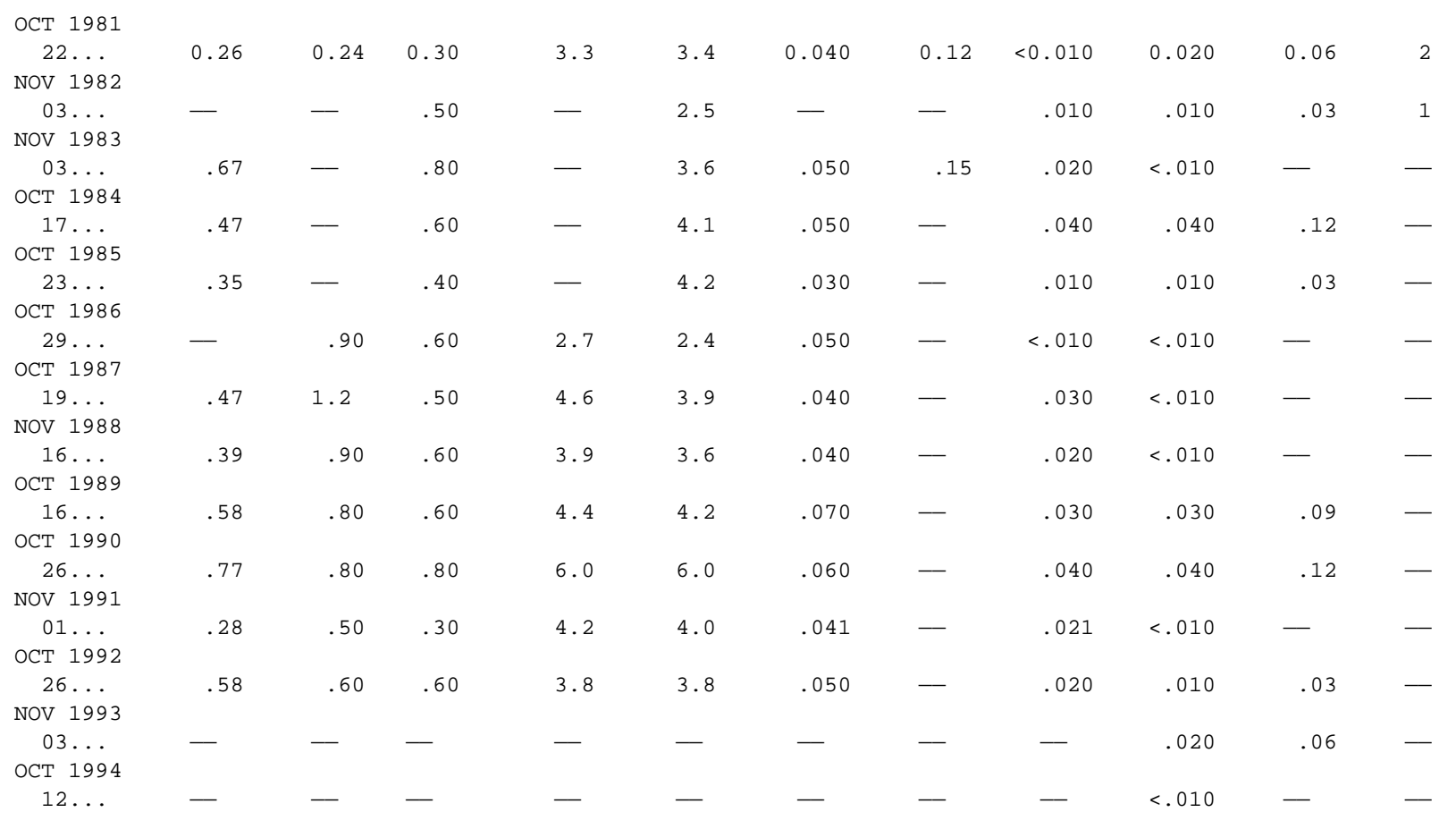


Table 3. Water-quality data from surface-water sites-Continued

01480648 - East Branch Brandywine Creek near Cupola, Pa. (Site 48)—Continued

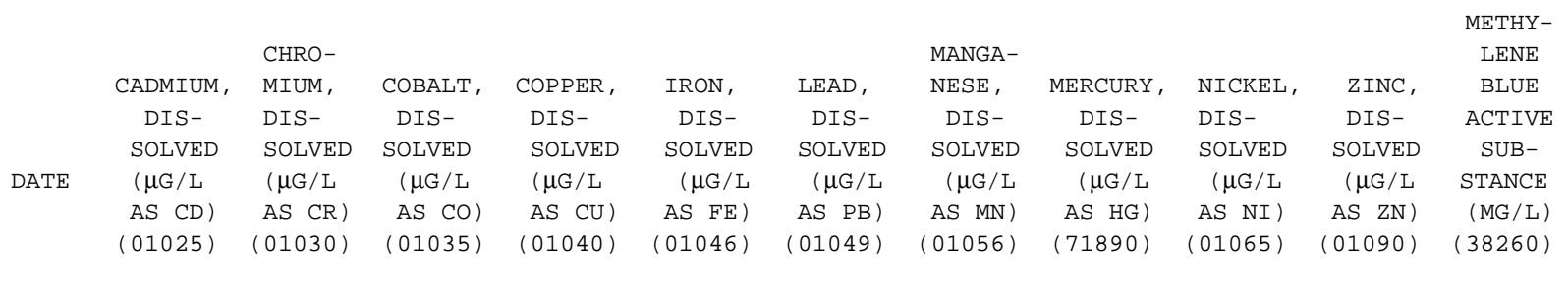

\begin{tabular}{|c|c|c|c|c|c|c|c|c|c|c|c|}
\hline $\begin{array}{c}\text { OCT } 1981 \\
22 \ldots \\
\text { NOV } 1982\end{array}$ & $<1.0$ & 2 & $<1$ & 2 & 84 & $<1$ & 25 & $<0.1$ & $<1$ & 8 & - \\
\hline $\begin{array}{c}03 \ldots \\
\text { NOV } 1983\end{array}$ & $<1.0$ & $<1$ & $<1$ & 1 & 50 & $<1$ & 39 & $<.1$ & $<1$ & $<4$ & 0.04 \\
\hline $\begin{array}{c}03 \ldots \\
\text { OCT } 1984\end{array}$ & - & - & - & - & 70 & - & 54 & - & - & - & - \\
\hline $\begin{array}{c}17 \ldots \\
\text { Ост } 1985\end{array}$ & - & - & - & - & 120 & - & 33 & - & - & - & - \\
\hline $\begin{array}{c}23 \ldots \\
\text { OCT } 1986\end{array}$ & - & - & - & - & 36 & - & 13 & - & - & - & - \\
\hline $\begin{array}{c}29 \ldots \\
\text { ОСТ } 1987\end{array}$ & - & - & - & - & 37 & - & 27 & - & - & - & - \\
\hline $\begin{array}{c}19 \ldots \\
\text { NOV } 1988\end{array}$ & - & - & - & - & 61 & - & 22 & - & - & - & - \\
\hline $\begin{array}{c}16 \ldots \\
\text { Ост } 1989\end{array}$ & - & - & - & - & 38 & - & 25 & - & - & - & - \\
\hline $\begin{array}{c}16 \ldots \\
\text { ОСт } 1990\end{array}$ & - & - & - & - & 48 & - & 28 & - & - & - & - \\
\hline $\begin{array}{c}26 \ldots \\
\text { NOV } 1991\end{array}$ & - & - & - & - & 93 & - & 52 & - & - & - & - \\
\hline $\begin{array}{c}01 \ldots \\
\text { OСТ } 1992\end{array}$ & - & - & - & - & 54 & - & 26 & - & - & - & - \\
\hline $\begin{array}{c}26 \ldots \\
\text { NOV } 1993\end{array}$ & - & - & - & - & 66 & - & 26 & - & - & - & - \\
\hline $03 \ldots$ & - & - & - & - & - & - & - & - & - & - & - \\
\hline $\begin{array}{c}12 \ldots 94 \\
12 .\end{array}$ & - & - & - & - & - & - & - & - & - & - & - \\
\hline
\end{tabular}


Table 3. Water-quality data from surface-water sites-Continued

01480653 - East Branch Brandywine Creek at Glenmoore, Pa. (Site 42)

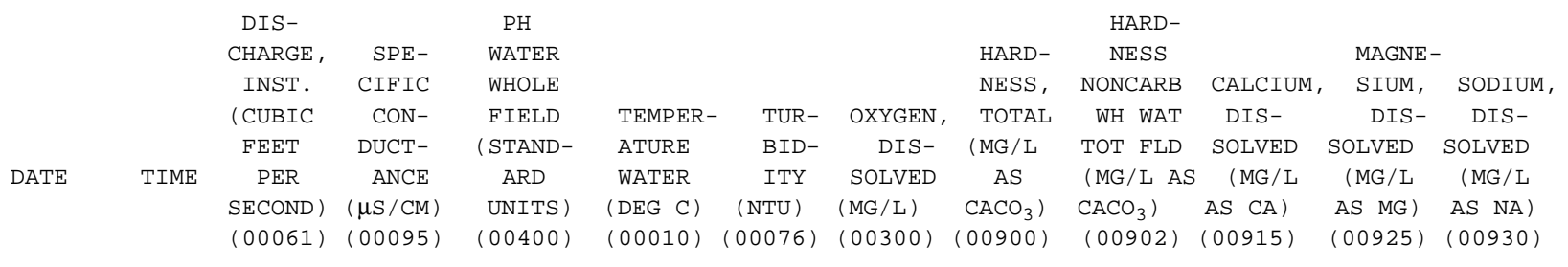

\begin{tabular}{|c|c|c|c|c|c|c|c|c|c|c|c|c|}
\hline $\begin{array}{c}02 \ldots \\
\text { NOV } 1982\end{array}$ & 1100 & - & 169 & 7.5 & 9.5 & - & 10.4 & 65 & - & 16 & 6.1 & 8.3 \\
\hline $03 \ldots$ & 1330 & 7.6 & 154 & 8.0 & 16.5 & - & 9.8 & 61 & - & 16 & 5.1 & 6.6 \\
\hline NOV 1983 & & & & & & & & & & & & \\
\hline $\begin{array}{c}03 \ldots \\
\text { ОСТ } 1984\end{array}$ & 1230 & 7.6 & 164 & 6.5 & 10.5 & 1.5 & 10.2 & 65 & - & 17 & 5.4 & 7.3 \\
\hline $\begin{array}{c}17 \ldots \\
\text { OCT } 1985\end{array}$ & 1330 & 9.2 & 178 & 7.8 & 12.5 & .70 & 11.6 & 68 & - & 18 & 5.5 & 6.8 \\
\hline $\begin{array}{c}23 \ldots \\
\mathrm{DEC} \quad 1986\end{array}$ & 1300 & 7.0 & 170 & 7.7 & 10.0 & .90 & 11.9 & 65 & - & 16 & 6.0 & 8.0 \\
\hline $\begin{array}{c}05 \ldots \\
\text { OCT } 1987\end{array}$ & 1000 & 25 & 140 & 7.6 & 3.0 & 2.6 & 13.4 & 60 & - & 15 & 5.5 & 6.7 \\
\hline $\begin{array}{c}23 \ldots \\
\text { NOV } 1988\end{array}$ & 1200 & 8.0 & 173 & 7.2 & 9.0 & .70 & 12.4 & 66 & - & 17 & 5.7 & 7.2 \\
\hline $\begin{array}{c}15 \ldots \\
\text { NOV } 1989\end{array}$ & 0900 & 12 & 178 & 7.4 & 8.0 & 2.2 & 13.4 & 66 & - & 17 & 5.7 & 7.3 \\
\hline $\begin{array}{c}01 \ldots \\
\text { OCT } 1990\end{array}$ & 1145 & 20 & 193 & 8.0 & 12.5 & .80 & 11.1 & 70 & 22 & 18 & 6.0 & 7.8 \\
\hline $\begin{array}{c}26 \ldots \\
\text { NOV } 1991\end{array}$ & 1200 & 11 & 197 & 6.4 & 10.5 & 1.7 & 11.4 & 73 & 17 & 19 & 6.1 & 7.9 \\
\hline $\begin{array}{c}01 \ldots \\
\text { NOV } 1992\end{array}$ & 1200 & 7.0 & 199 & 7.5 & 11.5 & .60 & 12.1 & 71 & 0 & 19 & 5.8 & 8.0 \\
\hline $\begin{array}{c}17 \ldots \\
\text { NOV } 1993\end{array}$ & 1230 & 13 & 180 & 7.5 & 5.5 & 2.7 & 13.5 & 69 & - & 18 & 5.9 & 7.4 \\
\hline $\begin{array}{c}04 \ldots \\
\text { ОСТ } 1994\end{array}$ & 0950 & 11 & 198 & 7.6 & 6.0 & - & 11.8 & - & - & - & - & - \\
\hline $12 \ldots$ & 1215 & 6.2 & 208 & 7.1 & 9.5 & - & 12.4 & - & - & - & - & - \\
\hline
\end{tabular}


Table 3. Water-quality data from surface-water sites-Continued

01480653 - East Branch Brandywine Creek at Glenmoore, Pa. (Site 42)—Continued

\begin{tabular}{|c|c|c|c|c|c|c|c|c|c|c|c|}
\hline & & & POTAS- & $\begin{array}{l}\text { ALKA- } \\
\text { LINITY }\end{array}$ & $\begin{array}{l}\text { ALKA- } \\
\text { LINITY }\end{array}$ & & CHLO- & FLUO- & SILICA, & $\begin{array}{l}\text { SOLIDS, } \\
\text { RESIDUE }\end{array}$ & $\begin{array}{l}\text { SOLIDS, } \\
\text { SUM OF }\end{array}$ \\
\hline & & SODIUM & SIUM, & WAT WH & WAT WH & SULFATE, & RIDE, & RIDE, & DIS- & AT 180 & CONSTI- \\
\hline & & $\mathrm{AD}-$ & DIS- & TOT FET & TOT IT & DIS- & DIS- & DIS- & SOLVED & DEG. C & TUENTS， \\
\hline & & SORP- & SOLVED & FIELD & FIELD & SOLVED & SOLVED & SOLVED & (MG / L & DIS- & DIS- \\
\hline $\mathrm{TE}$ & SODIUM & TION & (MG / L & (MG/L AS & (MG/L AS & (MG / L & (MG / L & (MG / L & AS & SOLVED & SOLVED \\
\hline & $\begin{array}{l}\text { PERCENT } \\
(00932)\end{array}$ & $\begin{array}{l}\text { RATIO } \\
(00931)\end{array}$ & $\begin{array}{l}\text { AS K) } \\
(00935)\end{array}$ & $\begin{array}{l}\left.\mathrm{CACO}_{3}\right) \\
(00410)\end{array}$ & $\begin{array}{c}\left.\mathrm{CACO}_{3}\right) \\
(00419)\end{array}$ & $\begin{array}{l}\left.\mathrm{AS} \mathrm{SO}_{4}\right) \\
(00945)\end{array}$ & $\begin{array}{c}\text { AS CL) } \\
(00940)\end{array}$ & $\begin{array}{c}A S F) \\
(00950)\end{array}$ & $\begin{array}{c}\left.\mathrm{SIO}_{2}\right) \\
(00955)\end{array}$ & $\begin{array}{r}(M G / L) \\
(70300)\end{array}$ & $\begin{array}{r}(M G / L) \\
(70301)\end{array}$ \\
\hline
\end{tabular}

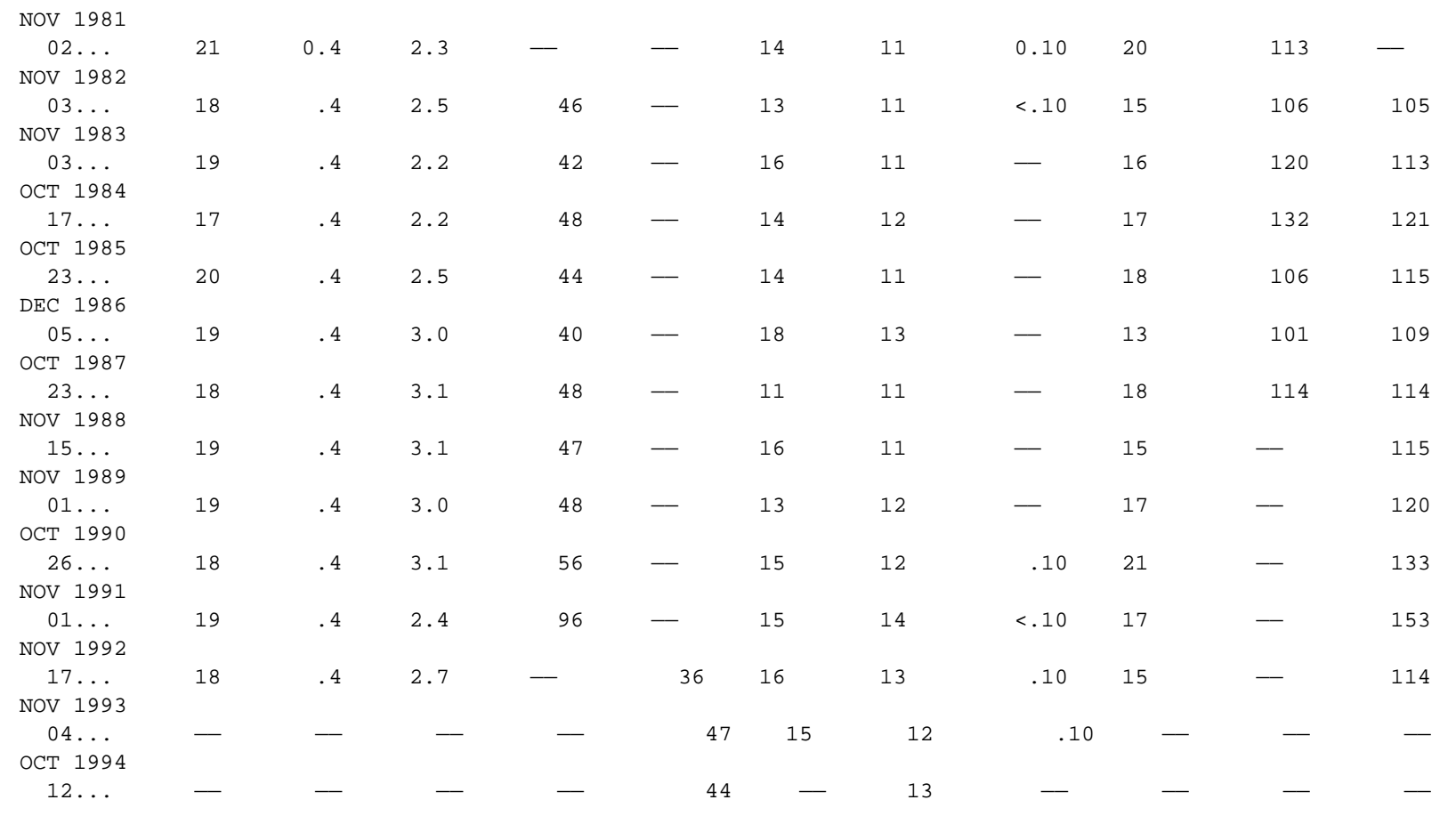


Table 3. Water-quality data from surface-water sites-Continued

01480653 - East Branch Brandywine Creek at Glenmoore, Pa. (Site 42)—Continued

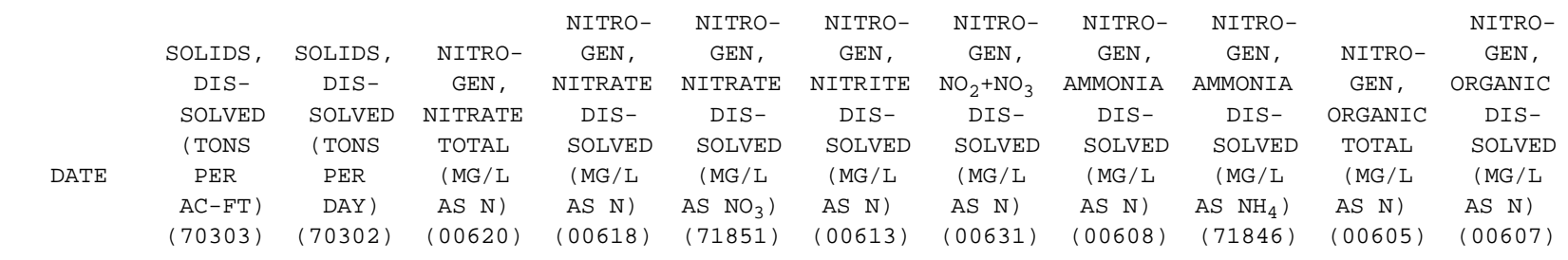

\begin{tabular}{|c|c|c|c|c|c|c|c|c|c|c|c|}
\hline $\begin{array}{c}\text { NOV } 1981 \\
02 \ldots \\
\text { NOV } 1982\end{array}$ & 0.15 & - & 1.70 & - & - & $<0.010$ & 1.70 & $<0.010$ & 0.01 & 0.48 & - \\
\hline $\begin{array}{c}03 \ldots \\
\text { NOV } 1983\end{array}$ & .14 & 2.18 & 1.89 & 1.89 & 8.4 & .010 & 1.90 & .010 & .01 & - & 0.19 \\
\hline $\begin{array}{c}03 \ldots \\
\text { OCT } 1984\end{array}$ & .16 & 2.46 & 2.90 & - & - & $<.010$ & 2.90 & .060 & .08 & - & .44 \\
\hline $\begin{array}{c}17 \ldots \\
\text { OCT } 1985\end{array}$ & .18 & 3.27 & 3.66 & 3.66 & 16 & .040 & 3.70 & .090 & .12 & - & .41 \\
\hline $\begin{array}{c}23 \ldots \\
\mathrm{DEC} \quad 1986\end{array}$ & .14 & 2.00 & 2.89 & 2.89 & 13 & .010 & 2.90 & .030 & .04 & .97 & .47 \\
\hline $\begin{array}{c}05 \ldots \\
\text { OCT } 1987\end{array}$ & .14 & 6.82 & 2.40 & - & - & $<.010$ & 2.40 & .030 & .04 & .87 & .87 \\
\hline $\begin{array}{c}23 \ldots \\
\text { NOV } 1988\end{array}$ & .16 & 2.46 & 2.80 & - & - & $<.010$ & 2.80 & .030 & .04 & .27 & .37 \\
\hline $\begin{array}{c}15 \ldots \\
\text { NOV } 1989\end{array}$ & .16 & 3.71 & 2.69 & 2.69 & 12 & .010 & 2.70 & .020 & .03 & .48 & .38 \\
\hline $\begin{array}{c}01 \ldots \\
\text { OCT } 1990\end{array}$ & .16 & 6.48 & 3.20 & - & - & $<.010$ & 3.20 & .030 & .04 & .37 & .27 \\
\hline $\begin{array}{c}26 \ldots \\
\text { NOV } 1991\end{array}$ & .18 & 3.97 & 3.28 & 3.28 & 15 & .020 & 3.30 & .020 & .03 & 1.6 & .78 \\
\hline $\begin{array}{c}01 \ldots \\
\text { NOV } 1992\end{array}$ & .21 & 2.89 & 3.20 & - & - & $<.010$ & 3.20 & .021 & .03 & - & .28 \\
\hline $\begin{array}{c}17 \ldots \\
\text { NOV } 1993\end{array}$ & .16 & 3.98 & 3.26 & 3.26 & 14 & .040 & 3.30 & .010 & .01 & .29 & .29 \\
\hline $\begin{array}{c}04 \ldots \\
\text { OCT } 1994\end{array}$ & - & - & 2.89 & 2.89 & 13 & .010 & 2.90 & .020 & .03 & - & - \\
\hline $12 \ldots$ & - & - & 3.39 & 3.39 & 15 & .010 & 3.40 & $<.015$ & - & - & - \\
\hline
\end{tabular}


Table 3. Water-quality data from surface-water sites-Continued

01480653 - East Branch Brandywine Creek at Glenmoore, Pa. (Site 42)—Continued

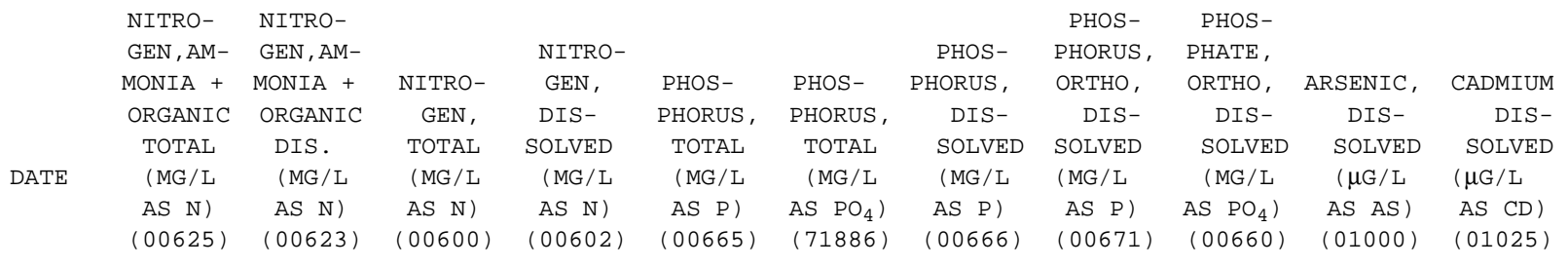

NOV 1981

$02 \ldots$

NOV 1982

$\begin{array}{llllll}0.48 & 0.59 & 2.2 & 2.3 & 0.020 & 0.06\end{array}$

0.010

0.03

ND

$<1.0$

$03 \ldots$

0.48

$.20-$

$2.1-$

- $\quad .020$

$<.010$

$-$

$1<1.0$

NOV 1983

$03 . .$.

OCT 1984

$17 \ldots$

OCT 1985

$23 \ldots$

DEC 1986

$05 \ldots$

OCT 1987

$23 \ldots$

NOV 1988

$15 \ldots$

NOV 1989

$01 \ldots$

OCT 1990

$26 \ldots$

NOV 1991

$01 \ldots$

- $.50 \quad-$

$3.4 \quad .030$

.09

.020

$<.010$

$\begin{array}{llll}4.2 & .030 \quad-030\end{array}$

.030

$3.4 \quad .020$

.06

.020

.010

$\begin{array}{llll}3.3 & .060 \quad-020\end{array}$

.010

$.90 \quad .90$

3.3

3.2

.030

$<.010$

$<.010$

$-$

$<1 \quad<1.0$

$.50 \quad .40$

3.2

3.1

.030

.020

.010

$<.010$

.010

. .30

4.6

4.5

.030

$.040 \quad-.030$

.040

$<.20 \quad .30$

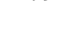

3.5

.021

$<.010$

.030

17.

NOV 1993

$04 \ldots$

OCT 1994

$12 \ldots$

.30

.30

3.6

3.6

.040

.020

$<.010$

.010

.010 
Table 3. Water-quality data from surface-water sites-Continued

01480653 - East Branch Brandywine Creek at Glenmoore, Pa. (Site 42)—Continued

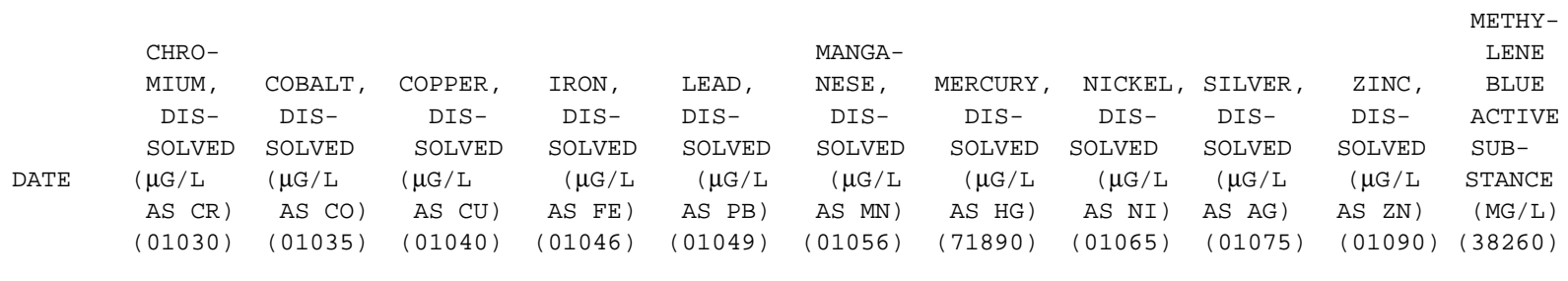

\begin{tabular}{|c|c|c|c|c|c|c|c|c|c|c|c|}
\hline $\begin{array}{c}\text { NOV } 1981 \\
02 \ldots \\
\text { NoV } 1982\end{array}$ & $<1$ & 1 & $<1$ & 77 & $<1$ & 49 & $<0.1$ & 1 & - & 6 & - \\
\hline $\begin{array}{c}03 \ldots \\
\text { Nov } 1983\end{array}$ & $<1$ & 1 & $<1$ & 55 & $<1$ & 22 & $<.1$ & $<1$ & - & $<4$ & 0.02 \\
\hline $\begin{array}{c}03 \ldots \\
\text { OCT } 1984\end{array}$ & - & - & - & 67 & - & 25 & - & - & - & - & - \\
\hline $\begin{array}{c}17 \ldots \\
\text { ОСт } 1985\end{array}$ & - & - & - & 69 & - & 16 & - & - & - & - & - \\
\hline $\begin{array}{c}23 \ldots \\
\text { DEC } 1986\end{array}$ & - & - & - & 50 & - & 11 & - & - & - & - & - \\
\hline $\begin{array}{c}05 \ldots \\
\text { OCT } 1987\end{array}$ & - & - & - & 71 & - & 18 & - & - & - & - & - \\
\hline $\begin{array}{c}23 \ldots \\
\text { NOV } 1988\end{array}$ & $<1$ & - & $<1$ & 67 & $<5$ & 11 & $<.1$ & 1 & $<1.0$ & $<3$ & - \\
\hline $\begin{array}{c}15 \ldots \\
\text { NOV } 1989\end{array}$ & - & - & - & 67 & - & 12 & - & - & - & - & - \\
\hline $\begin{array}{c}01 \ldots \\
\text { ОСт } 1990\end{array}$ & - & - & - & 92 & - & 19 & - & - & - & - & - \\
\hline $\begin{array}{c}26 \ldots \\
\text { Nov } 1991\end{array}$ & - & - & - & 100 & - & 30 & - & - & - & - & - \\
\hline $\begin{array}{c}01 \ldots \\
\text { NOV } 1992\end{array}$ & - & - & - & 65 & - & 13 & - & - & - & - & - \\
\hline $\begin{array}{c}17 \ldots \\
\text { NOV } 1993\end{array}$ & - & - & - & 77 & - & 18 & - & - & - & - & - \\
\hline $\begin{array}{c}04 \ldots \\
\text { ОСТ } 1994\end{array}$ & - & - & - & - & - & - & - & - & - & - & - \\
\hline $12 \ldots$ & - & - & - & - & - & - & - & - & - & - & - \\
\hline
\end{tabular}


Table 3. Water-quality data from surface-water sites-Continued

01480656 - Indian Run near Springton, Pa. (Site 47)

\begin{tabular}{|c|c|c|c|c|c|c|c|c|c|c|c|}
\hline & & DIS- & & $\mathrm{PH}$ & & & & & HARD- & & \\
\hline & & CHARGE, & SPE- & WATER & & & & HARD- & NESS & & MAGNE- \\
\hline & & INST. & CIFIC & WHOLE & & & & NESS, & NONCARB & CALCIUM, & SIUM, \\
\hline & & (CUBIC & $\mathrm{CON}-$ & FIELD & TEMPER- & TUR- & OXYGEN, & TOTAL & WH WAT & DIS- & DIS- \\
\hline & & FEET & DUCT- & (STAND- & ATURE & BID- & DIS- & (MG / L & TOT FLD & SOLVED & SOLVED \\
\hline DATE & TIME & PER & ANCE & ARD & WATER & ITY & SOLVED & AS & (MG/L AS & (MG / L & (MG /L \\
\hline & & SECOND ) & $(\mu \mathrm{S} / \mathrm{CM})$ & UNITS) & (DEG C) & (NTU) & (MG/L) & $\left.\mathrm{CACO}_{3}\right)$ & $\left.\mathrm{CACO}_{3}\right)$ & AS CA) & AS MG) \\
\hline & & $(00061)$ & $(00095)$ & $(00400)$ & $(00010)$ & $(00076)$ & $(00300)$ & $(00900)$ & $(00902)$ & (00915) & $(00925)$ \\
\hline
\end{tabular}

\begin{tabular}{|c|c|c|c|c|c|c|c|c|c|c|c|}
\hline NOV 1981 & & & & & & & & & & & \\
\hline $\begin{array}{c}02 \ldots \\
\text { NOV } 1982\end{array}$ & 1345 & - & 164 & 7.6 & 11.5 & - & 10.9 & 64 & - & 18 & 4.6 \\
\hline $\begin{array}{c}03 \ldots \\
\text { Nov } 1983\end{array}$ & 1500 & 1.9 & 157 & 7.9 & 15.5 & - & 9.8 & 63 & - & 18 & 4.4 \\
\hline $\begin{array}{c}03 \ldots \\
\text { OCT } 1984\end{array}$ & 1400 & 2.1 & 156 & 6.5 & 12.0 & 1.1 & 9.3 & 63 & - & 18 & 4.5 \\
\hline $\begin{array}{c}17 \ldots \\
\text { OCT } 1985\end{array}$ & 1600 & 2.7 & 170 & 7.6 & 12.0 & .50 & 9.9 & 63 & - & 18 & 4.4 \\
\hline $\begin{array}{c}23 \ldots \\
\text { OCT } 1986\end{array}$ & 1330 & .94 & 175 & 7.4 & 9.5 & .70 & 10.8 & 61 & - & 17 & 4.4 \\
\hline $\begin{array}{c}29 \ldots \\
\text { OCT } 1987\end{array}$ & 1500 & 1.8 & 185 & 7.5 & 13.0 & .40 & 9.5 & 68 & - & 19 & 4.9 \\
\hline $\begin{array}{c}19 \ldots \\
\text { NOV } 1988\end{array}$ & 1400 & 2.0 & 175 & 7.3 & 12.5 & .30 & 11.2 & 64 & - & 18 & 4.6 \\
\hline $\begin{array}{c}15 \ldots \\
\text { OCT } 1989\end{array}$ & 1300 & 2.2 & 178 & 7.4 & 10.0 & 1.4 & 12.8 & 64 & - & 18 & 4.7 \\
\hline $\begin{array}{c}16 \ldots \\
\text { NOV } 1990\end{array}$ & 1510 & 3.0 & 183 & 7.1 & 18.5 & .50 & 9.8 & 63 & 13 & 18 & 4.3 \\
\hline $\begin{array}{c}13 \ldots \\
\text { NOV } 1991\end{array}$ & 1030 & 3.7 & 160 & 7.6 & 5.5 & 1.0 & 12.6 & 57 & 17 & 16 & 4.1 \\
\hline $\begin{array}{c}05 \ldots \\
\text { OCT } 1992\end{array}$ & 1200 & 1.7 & 191 & 7.5 & 6.0 & .50 & 13.5 & 82 & 7 & 17 & 9.5 \\
\hline $\begin{array}{c}26 \ldots \\
\text { NOV } 1993\end{array}$ & 0845 & 1.7 & 202 & 6.7 & 7.0 & .60 & 11.6 & 74 & - & 21 & 5.2 \\
\hline $\begin{array}{c}02 \ldots \\
\text { OCT } 1994\end{array}$ & 1010 & 3.1 & 162 & 7.4 & 6.0 & - & 11.6 & - & - & - & - \\
\hline $14 \ldots$ & 0950 & 1.7 & 210 & 7.1 & 9.5 & - & 11.5 & - & - & - & - \\
\hline
\end{tabular}


Table 3. Water-quality data from surface-water sites-Continued

01480656 - Indian Run near Springton, Pa. (Site 47)—Continued

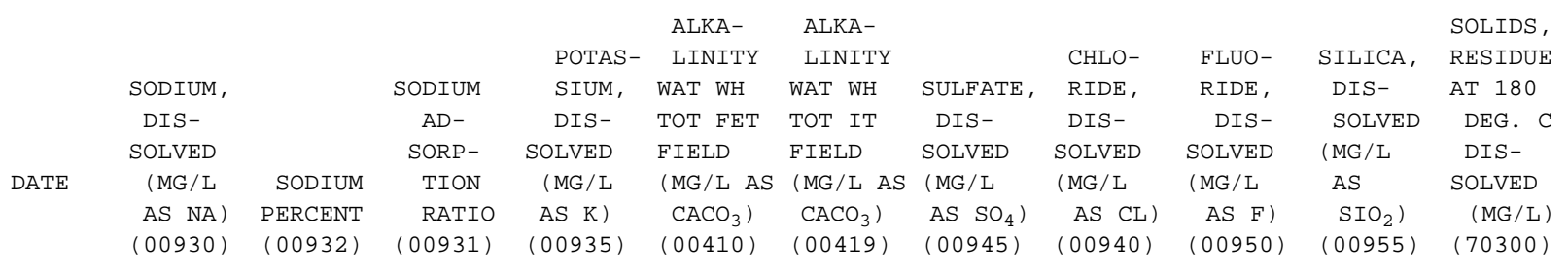

\begin{tabular}{|c|c|c|c|c|c|c|c|c|c|c|c|}
\hline $\begin{array}{c}\text { NOV } 1981 \\
02 \ldots \\
\text { NOV } 1982\end{array}$ & 8.7 & 22 & 0.5 & 1.4 & - & - & 7.6 & 9.8 & $<0.10$ & 28 & 120 \\
\hline $\begin{array}{c}03 \ldots \\
\text { NOV } 1983\end{array}$ & 8.5 & 22 & .5 & 1.6 & 57 & - & 9.0 & 9.7 & $<.10$ & 26 & 117 \\
\hline $\begin{array}{c}03 \ldots \\
\text { OCT } 1984\end{array}$ & 9.2 & 23 & .5 & 1.4 & 38 & - & 9.2 & 11 & - & 26 & 126 \\
\hline $\begin{array}{c}17 \ldots \\
\text { OCT } 1985\end{array}$ & 8.4 & 22 & .5 & 1.3 & 50 & - & 8.2 & 11 & - & 25 & 120 \\
\hline $\begin{array}{c}23 \ldots \\
\text { OCT } 1986\end{array}$ & 9.0 & 24 & .5 & 1.6 & 60 & - & 7.8 & 10 & - & 27 & 140 \\
\hline $\begin{array}{c}29 \ldots \\
\text { OCT } 1987\end{array}$ & 9.8 & 23 & .5 & 2.0 & 58 & - & 10 & 12 & - & 28 & 145 \\
\hline $\begin{array}{c}19 \ldots \\
\text { NOV } 1988\end{array}$ & 9.3 & 24 & .5 & 1.5 & 55 & - & 11 & 10 & - & 25 & 125 \\
\hline $\begin{array}{c}15 \ldots \\
\text { OCT } 1989\end{array}$ & 9.2 & 23 & .5 & 1.6 & 49 & - & 14 & 11 & - & 24 & - \\
\hline $\begin{array}{c}16 \ldots \\
\text { NOV } 1990\end{array}$ & 9.4 & 24 & .5 & 1.7 & 50 & - & 9.0 & 10 & - & 26 & - \\
\hline $\begin{array}{c}13 \ldots \\
\text { NOV } 1991\end{array}$ & 7.4 & 21 & .4 & 1.6 & 40 & - & 13 & 11 & $<.10$ & 24 & - \\
\hline $\begin{array}{c}05 \ldots \\
\text { OCT } 1992\end{array}$ & 15 & 28 & .7 & 2.3 & 75 & - & 9.4 & 14 & $<.10$ & 14 & - \\
\hline $\begin{array}{c}26 \ldots \\
\text { NOV } 1993\end{array}$ & 10 & 22 & .5 & 1.9 & - & 60 & 8.8 & 12 & .10 & 26 & - \\
\hline $\begin{array}{c}02 \ldots \\
\text { OCT } 1994\end{array}$ & - & - & - & - & - & 47 & 12 & 8.6 & .10 & - & - \\
\hline $14 \ldots$ & - & - & - & - & - & 58 & - & 13 & - & - & - \\
\hline
\end{tabular}


Table 3. Water-quality data from surface-water sites-Continued

01480656 - Indian Run near Springton, Pa. (Site 47)—Continued

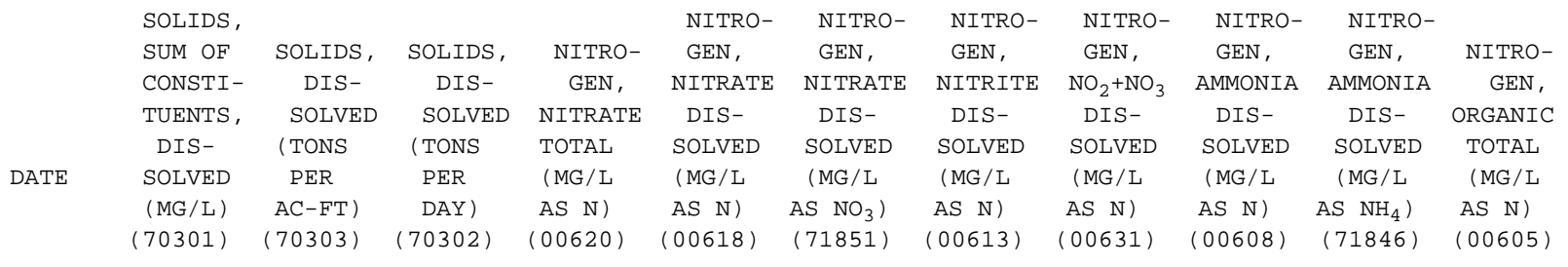

NOV 1981

$02 \ldots$

NOV 1982

$03 \ldots$
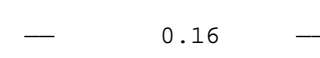

NOV 1983

$03 \ldots$

ОСТ 1984

$17 \ldots$

OCT 1985

$23 \ldots$

OCT 1986

$29 \ldots$

OCT 1987

$19 \ldots$

NOV 1988

$15 \ldots$

OCT 1989

$16 \ldots$

NOV 1990

$13 \ldots$

NOV 1991

$05 \ldots$

OCT 1992

$26 \ldots$

NOV 1993

- 0.16

$122 \quad .16$

- 2.69

$2.89 \quad 13$

0.010

2.90

$<0.010$

0.01

0.46

$118 \quad .17$

0.60

$2.19 \quad 2.19$

9.7

.010

2.20

.040

.05

.71

$\begin{array}{lll}3.38 & 3.38 & 15\end{array}$

.020

3.40

.060

.08

$\begin{array}{lll}122 & .16 & .87\end{array}$

$\begin{array}{lll}3.36 & 3.36 & 15\end{array}$

.040

3.40

.100

.13

$\begin{array}{lll}125 & .19 & .36\end{array}$

$2.69 \quad 2.69 \quad 12$

.010

2.70

.02

.03

.88

$135 \quad .20 \quad .70$

3.10

$-\quad<.010$

3.10

.020

.03

.38

$129 \quad .17$

.68

3.60

$125 \quad .17$

.74

2.88

$120 \quad .16$

.97

2.46

2.88

$<.010$

3.60

.020

.03

.28

113

1.13

2.59

2.46

.020

2.90

.030

.04

.67

.040

2.50

.020

.03

.28

141

2. $59 \quad 11$

.010

2.60

.060

.08

.24

134

.19

3.40

- $\quad<.010$

3.40

.010

.01

.19

.62

$2.98 \quad 2.98 \quad 13$

.020

3.00

$<.010$

$-$

.30

$02 \ldots$
OCT 1994

14 ... 
Table 3. Water-quality data from surface-water sites-Continued

01480656 - Indian Run near Springton, Pa. (Site 47)—Continued

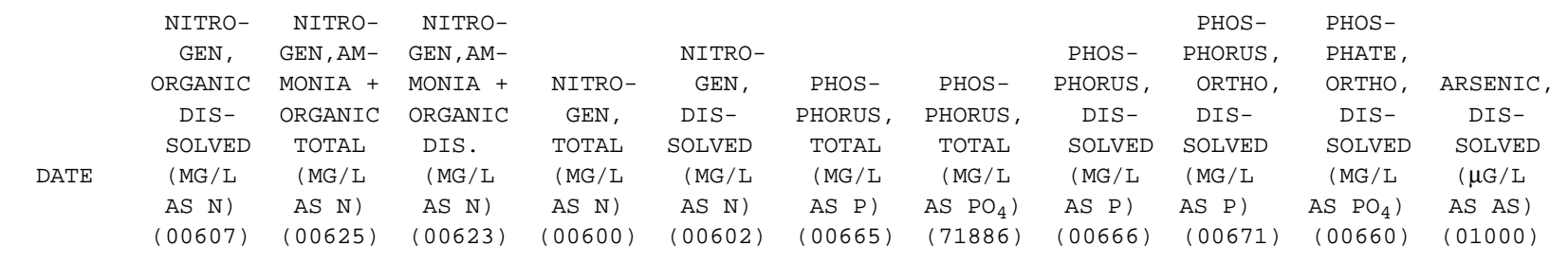

\begin{tabular}{|c|c|c|c|c|c|c|c|c|c|c|c|}
\hline $\begin{array}{c}\text { NOV } 1981 \\
02 \ldots\end{array}$ & - & 0.46 & 0.40 & 3.2 & 3.3 & 0.170 & 0.52 & 0.150 & 0.150 & 0.46 & ND \\
\hline $\begin{array}{c}03 \ldots \\
\text { NOV } 1983\end{array}$ & 0.66 & - & .70 & - & 2.9 & - & - & .320 & .340 & 1.0 & 1 \\
\hline $\begin{array}{c}03 \ldots \\
\text { OCT } 1984\end{array}$ & .74 & - & .80 & - & 4.2 & .140 & .43 & .130 & .120 & .37 & - \\
\hline $\begin{array}{c}17 \ldots \\
\text { OCT } 1985\end{array}$ & .20 & - & .30 & - & 3.7 & .140 & - & .160 & .150 & .46 & - \\
\hline $\begin{array}{c}23 \ldots \\
\text { OCT } 1986\end{array}$ & .48 & .90 & .50 & 3.6 & 3.2 & .130 & .40 & .120 & .110 & .34 & - \\
\hline $\begin{array}{c}29 \ldots \\
\text { OCT } 1987\end{array}$ & .38 & .40 & .40 & 3.5 & 3.5 & .180 & - & .120 & .120 & .37 & - \\
\hline $\begin{array}{c}19 \ldots \\
\text { NOV } 1988\end{array}$ & .18 & .30 & .20 & 3.9 & 3.8 & .090 & - & .080 & .070 & .21 & - \\
\hline $\begin{array}{c}15 \ldots \\
\text { OCT } 1989\end{array}$ & .67 & .70 & .70 & 3.6 & 3.6 & .120 & - & .110 & .100 & .31 & - \\
\hline $\begin{array}{c}16 \ldots \\
\text { NOV } 1990\end{array}$ & .28 & .30 & .30 & 2.8 & 2.8 & .060 & - & .050 & .060 & .18 & - \\
\hline $\begin{array}{c}13 \ldots \\
\text { NOV } 1991\end{array}$ & .34 & .30 & .40 & 2.9 & 3.0 & .040 & - & .030 & .040 & .12 & - \\
\hline $\begin{array}{c}05 \ldots \\
\text { ОСТ } 1992\end{array}$ & - & .20 & $<.20$ & 3.6 & - & .060 & - & .060 & .040 & .12 & - \\
\hline $\begin{array}{c}26 \ldots \\
\text { NOV } 1993\end{array}$ & - & .30 & $<.20$ & 3.3 & - & .040 & - & .030 & .020 & .06 & - \\
\hline $\begin{array}{c}02 \ldots \\
\text { OCT } 1994\end{array}$ & - & - & - & - & - & - & - & - & .030 & .09 & - \\
\hline $14 \ldots$ & - & - & - & - & - & - & - & - & .020 & .06 & - \\
\hline
\end{tabular}


Table 3. Water-quality data from surface-water sites-Continued

01480656 - Indian Run near Springton, Pa. (Site 47)—Continued

\begin{tabular}{|c|c|c|c|c|c|c|c|c|c|c|c|}
\hline \multirow{5}{*}{ DATE } & \multirow{3}{*}{$\begin{array}{l}\text { CADMIUM, } \\
\text { DIS- } \\
\text { SOLVED } \\
(\mu \mathrm{G} / \mathrm{L}\end{array}$} & CHRO- & & & & & MANGA- & \multirow[b]{2}{*}{ MERCURY, } & & \multirow[b]{2}{*}{ ZINC, } & $\begin{array}{l}\text { METHY- } \\
\text { LENE }\end{array}$ \\
\hline & & $\begin{array}{l}\text { MIUM, } \\
\text { DIS- }\end{array}$ & & & & & $\begin{array}{r}\text { NESE } \\
\text { DIS- }\end{array}$ & & & & $\begin{array}{c}\text { BLUE } \\
\text { ACTIVE }\end{array}$ \\
\hline & & $\begin{array}{c}\text { SOLVED } \\
(\mu \mathrm{G} / \mathrm{L}\end{array}$ & $\begin{array}{l}\text { SOLVED } \\
\qquad \mu \mathrm{G} / \mathrm{L}\end{array}$ & $\begin{array}{c}\text { SOLVED } \\
(\mu \mathrm{G} / \mathrm{L}\end{array}$ & $\begin{array}{c}\text { SOLVED } \\
(\mu \mathrm{G} / \mathrm{L}\end{array}$ & $\begin{array}{c}\text { SOLVED } \\
(\mu \mathrm{G} / \mathrm{L}\end{array}$ & $\begin{array}{c}\text { SOLVED } \\
(\mu \mathrm{G} / \mathrm{L}\end{array}$ & $\begin{array}{c}\text { SOLVED } \\
(\mu \mathrm{G} / \mathrm{L}\end{array}$ & $\begin{array}{c}\text { SOLVED } \\
(\mu \mathrm{G} / \mathrm{L}\end{array}$ & $\begin{array}{c}\text { SOLVED } \\
(\mu \mathrm{G} / \mathrm{L}\end{array}$ & $\begin{array}{c}\text { SUB- } \\
\text { STANCE }\end{array}$ \\
\hline & $\mathrm{AS} \quad \mathrm{CD}$ ) & AS (R) & AS CO) & $\mathrm{AS} \quad \mathrm{CU})$ & AS FE) & AS PB) & AS MN) & AS HG) & AS NI) & AS ZN) & (MG/L) \\
\hline & $(01025)$ & $(01030)$ & (01035) & $(01040)$ & $(01046)$ & (01049) & $(01056)$ & $(71890)$ & $(01065)$ & $(01090)$ & $(38260)$ \\
\hline
\end{tabular}

NOV 1981

$02 \ldots$

$<1.0 \quad 5 \quad<1$

$41<1$

11

0.1

1

$<4 \quad$ ND

NOV 1982

NOV 1983

$<1.0<1$

$<1$

5

$23<1$

3

$<.1$

$<1$

$<4$

0.03

$03 . .$.

OCT 1984

- $\quad-\quad-$

$17 \ldots$

OCT 1985

$23 \ldots$

OCT 1986

29...

OCT 1987

$19 . .$.

NOV 1988

$15 \ldots$

ОСт 1989

$16 \ldots$

NOV 1990

$13 . .$.

NOV 1991

$05 \ldots$

OCT 1992

$26 \ldots$

NOV 1993

$02 \ldots$

OCT 1994

$14 \ldots$ 
Table 3. Water-quality data from surface-water sites-Continued

01480700 - East Branch Brandywine Creek near Downingtown, Pa. (Site 36)

\begin{tabular}{|c|c|c|c|c|c|c|c|c|c|c|}
\hline & DIS- & & $\mathrm{PH}$ & & & & & HARD- & & \\
\hline & CHARGE, & SPE- & WATER & & & & HARD- & NESS & & MAGNE- \\
\hline & INST. & CIFIC & WHOLE & & & & NESS, & NONCARB & CALCIUM, & SIUM, \\
\hline & (CUBIC & $\mathrm{CON}-$ & FIELD & TEMPER- & TUR- & OXYGEN, & TOTAL & WH WAT & DIS- & DIS- \\
\hline & FEET & DUCT- & (STAND- & ATURE & BID- & DIS- & (MG/L & TOT FLD & SOLVED & SOLVED \\
\hline TIME & PER & ANCE & ARD & WATER & ITY & SOLVED & A.S & (MG/L AS & (MG / L & (MG /L \\
\hline & SECOND ) & $(\mu \mathrm{S} / \mathrm{CM})$ & UNITS) & $(\mathrm{DEG} \quad \mathrm{C})$ & (NTU) & (MG/L) & $\left.\mathrm{CACO}_{3}\right)$ & $\left.\mathrm{CACO}_{3}\right)$ & AS CA) & AS MG) \\
\hline & $00061)$ & $(00095)$ & $(00400)$ & $(00010)$ & $(00076)$ & $(00300)$ & $(00900)$ & $(00902)$ & (00915) & $(00925)$ \\
\hline
\end{tabular}

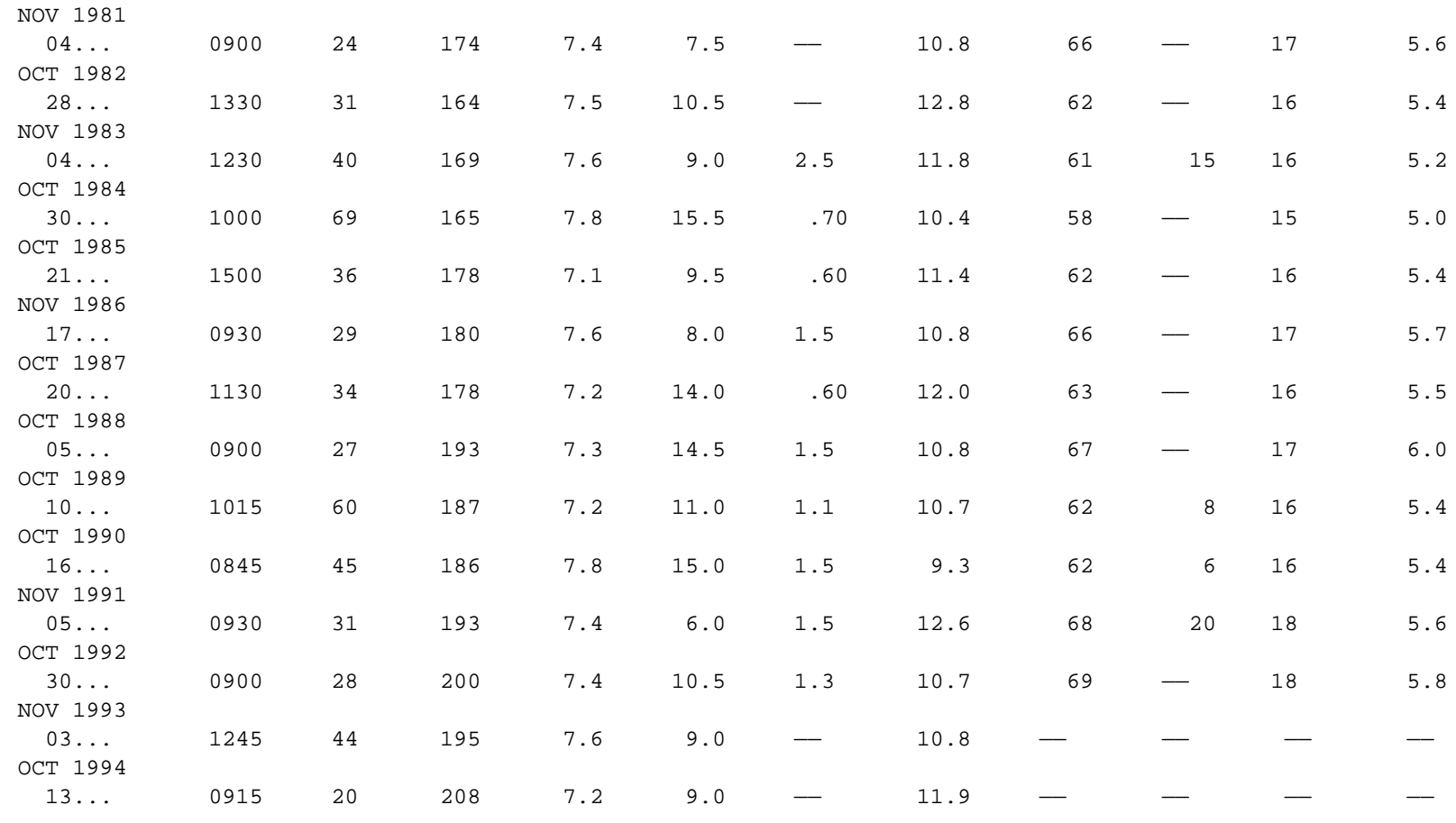


Table 3. Water-quality data from surface-water sites-Continued

01480700 - East Branch Brandywine Creek near Downingtown, Pa. (Site 36)—Continued

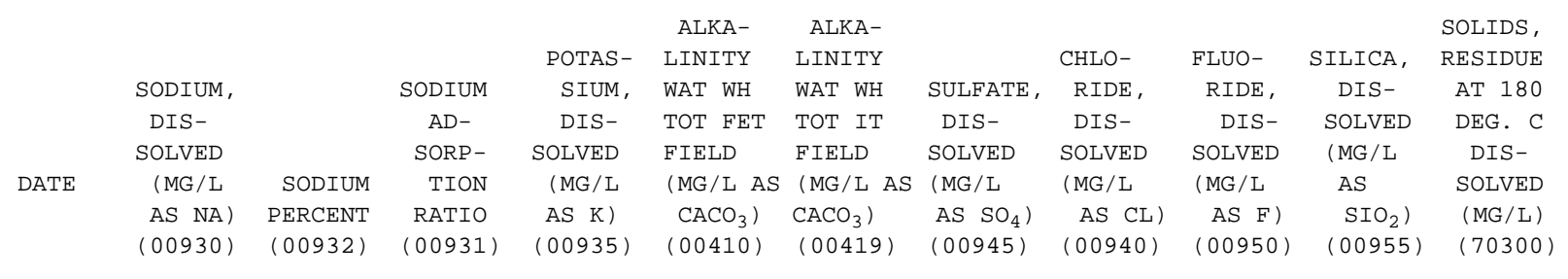

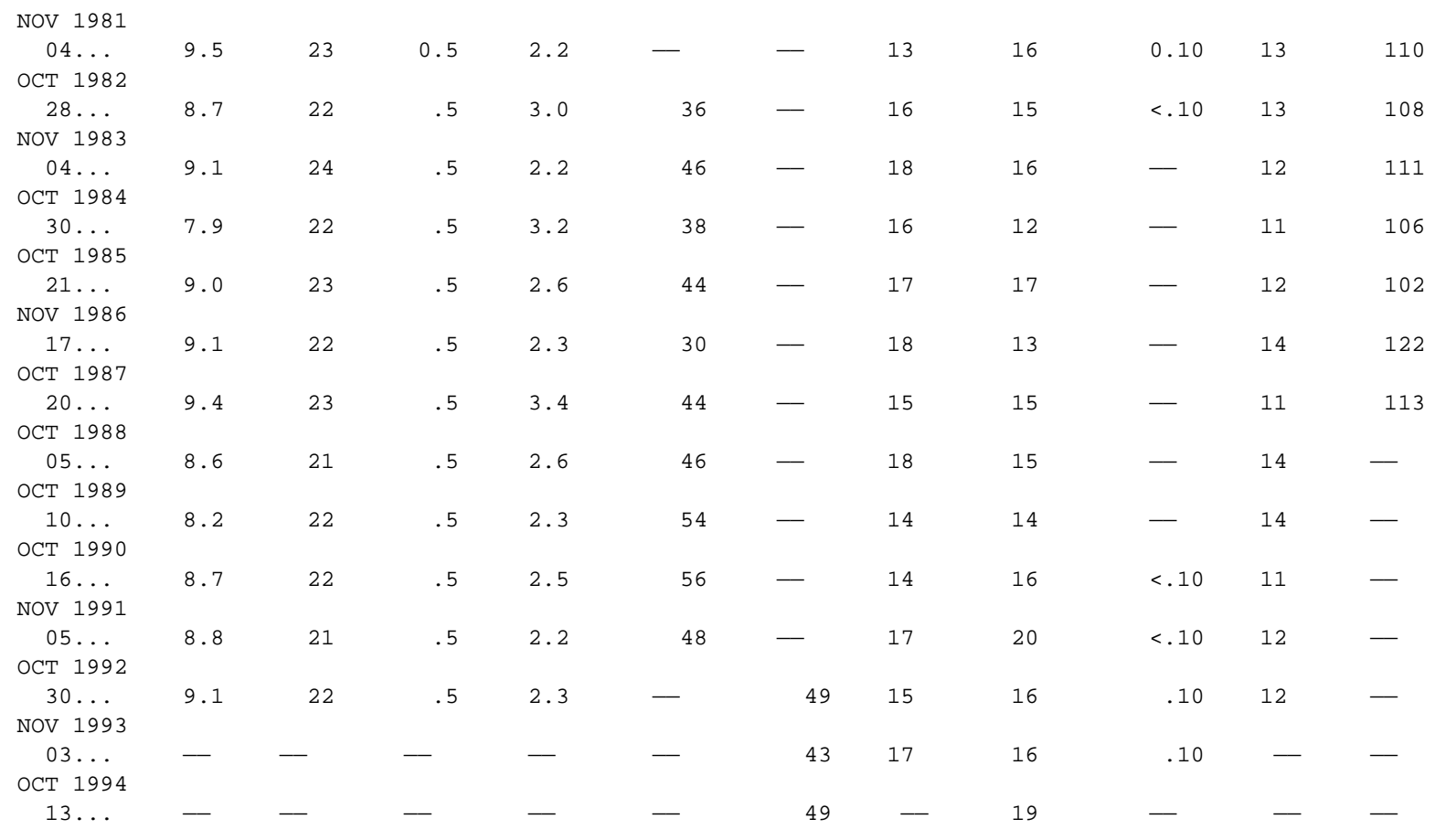


Table 3. Water-quality data from surface-water sites-Continued

01480700 - East Branch Brandywine Creek near Downingtown, Pa. (Site 36)—Continued

\begin{tabular}{|c|c|c|c|c|c|c|c|c|c|c|c|}
\hline & $\begin{array}{l}\text { SOLIDS, } \\
\text { SUM OF } \\
\text { CONSTI- }\end{array}$ & $\begin{array}{c}\text { SOLIDS, } \\
\text { DIS- }\end{array}$ & $\begin{array}{c}\text { SOLIDS, } \\
\text { DIS- }\end{array}$ & $\begin{array}{c}\text { NITRO- } \\
\text { GEN, }\end{array}$ & $\begin{array}{c}\text { NITRO- } \\
\text { GEN, } \\
\text { NITRATE }\end{array}$ & $\begin{array}{c}\text { NITRO- } \\
\text { GEN, } \\
\text { NITRATE }\end{array}$ & $\begin{array}{c}\text { NITRO- } \\
\text { GEN, } \\
\text { NITRITE }\end{array}$ & $\begin{array}{c}\mathrm{NITRO}- \\
\text { GEN, } \\
\mathrm{NO}_{2}+\mathrm{NO}_{3}\end{array}$ & $\begin{array}{c}\text { NITRO- } \\
\text { GEN, } \\
\text { AMMONIA }\end{array}$ & $\begin{array}{c}\text { NITRO- } \\
\text { GEN, } \\
\text { AMMONIA }\end{array}$ & $\begin{array}{l}\text { NITRO- } \\
\text { GEN, }\end{array}$ \\
\hline ATE & $\begin{array}{c}\text { TUENTS, } \\
\text { DIS- } \\
\text { SOLVED }\end{array}$ & $\begin{array}{c}\text { SOLVED } \\
\text { (TONS } \\
\text { PER }\end{array}$ & $\begin{array}{l}\text { SOLVED } \\
\text { (TONS } \\
\text { PER }\end{array}$ & $\begin{array}{c}\text { NITRATE } \\
\text { TOTAL } \\
\text { (MG/L }\end{array}$ & $\begin{array}{c}\text { DIS- } \\
\text { SOLVED } \\
(\mathrm{MG} / \mathrm{L}\end{array}$ & $\begin{array}{l}\text { DIS- } \\
\text { SOLVED } \\
\text { (MG/L }\end{array}$ & $\begin{array}{l}\text { DIS- } \\
\text { SOLVED } \\
\text { (MG/L }\end{array}$ & $\begin{array}{l}\text { DIS- } \\
\text { SOLVED } \\
\text { (MG/L }\end{array}$ & $\begin{array}{l}\text { DIS- } \\
\text { SOLVED } \\
\text { (MG/L }\end{array}$ & $\begin{array}{c}\text { DIS- } \\
\text { SOLVED } \\
\text { (MG/L }\end{array}$ & $\begin{array}{c}\text { ORGANIC } \\
\text { TOTAL } \\
\text { (MG/L }\end{array}$ \\
\hline & (MG / L ) & $\mathrm{AC}-\mathrm{FT}$ ) & DAY) & AS N) & AS N) & $\left.\mathrm{AS} \quad \mathrm{NO}_{3}\right)$ & AS N) & AS N) & AS N) & $\left.\mathrm{AS} \quad \mathrm{NH}_{4}\right)$ & AS N) \\
\hline & $(70301)$ & $(70303)$ & $(70302)$ & $(00620)$ & $(00618)$ & $(71851)$ & $(00613)$ & $(00631)$ & $(00608)$ & $(71846)$ & $(00605)$ \\
\hline
\end{tabular}

\begin{tabular}{|c|c|c|c|c|c|c|c|c|c|c|c|}
\hline $04 \ldots$ & - & 0.15 & - & 0.980 & 0.980 & 4.3 & 0.020 & 1.00 & 0.170 & 0.22 & 0.57 \\
\hline OCT 1982 & & & & & & & & & & & \\
\hline $28 \ldots$ & 105 & .15 & 9.04 & 1.29 & 1.29 & 5.7 & .010 & 1.30 & .060 & .08 & - \\
\hline NOV 1983 & & & & & & & & & & & \\
\hline $\begin{array}{c}04 \ldots \\
\text { OCT } 1984\end{array}$ & 113 & .15 & 12.0 & 1.49 & 1.49 & 6.6 & .010 & 1.50 & .230 & .30 & - \\
\hline $\begin{array}{c}30 \ldots \\
\text { OCT } 1985\end{array}$ & 98 & .14 & 19.7 & 1.00 & - & - & $<.010$ & 1.00 & .030 & .04 & - \\
\hline $\begin{array}{c}21 \ldots \\
\text { NOV } 1986\end{array}$ & 112 & .14 & 9.91 & 1.49 & 1.49 & 6.6 & .010 & 1.50 & .040 & .05 & - \\
\hline $\begin{array}{c}17 \ldots \\
\text { OCT } 1987\end{array}$ & 105 & .17 & 9.55 & 1.80 & - & - & $<.010$ & 1.80 & .100 & .13 & .20 \\
\hline $\begin{array}{c}20 \ldots \\
\text { OCT } 1988\end{array}$ & 109 & .15 & 1.4 & 1.60 & - & - & $<.010$ & 1.60 & .050 & .06 & .65 \\
\hline $\begin{array}{c}05 \ldots \\
\text { OCT } 1989\end{array}$ & 118 & .16 & 8.57 & 1.89 & 1.89 & 8.4 & .010 & 1.90 & $<.030$ & - & .50 \\
\hline $\begin{array}{c}10 \ldots \\
\text { OCT } 1990\end{array}$ & 116 & .16 & 18.7 & 1.99 & 1.99 & 8.8 & .010 & 2.00 & .090 & .12 & - \\
\hline $\begin{array}{c}16 \ldots \\
\text { NOV } 1991\end{array}$ & 111 & .15 & 13.4 & .900 & - & - & $<.010$ & .900 & .020 & .03 & .58 \\
\hline $\begin{array}{c}05 \ldots \\
\text { OCT } 1992\end{array}$ & 119 & .16 & 9.83 & 1.28 & 1.28 & 5.7 & .020 & 1.30 & .120 & .15 & .28 \\
\hline $\begin{array}{c}30 \ldots \\
\text { NOV } 1993\end{array}$ & 116 & .16 & 8.74 & 1.68 & 1.68 & 7.4 & .020 & 1.70 & .060 & .08 & .14 \\
\hline $\begin{array}{c}03 \ldots \\
\text { OCT } 1994\end{array}$ & - & - & - & 1.39 & 1.39 & 6.2 & .010 & 1.40 & .060 & .08 & - \\
\hline $13 \ldots$ & - & - & - & 1.89 & 1.89 & 8.4 & .010 & 1.90 & .020 & .03 & - \\
\hline
\end{tabular}


Table 3. Water-quality data from surface-water sites-Continued

01480700 - East Branch Brandywine Creek near Downingtown, Pa. (Site 36)—Continued

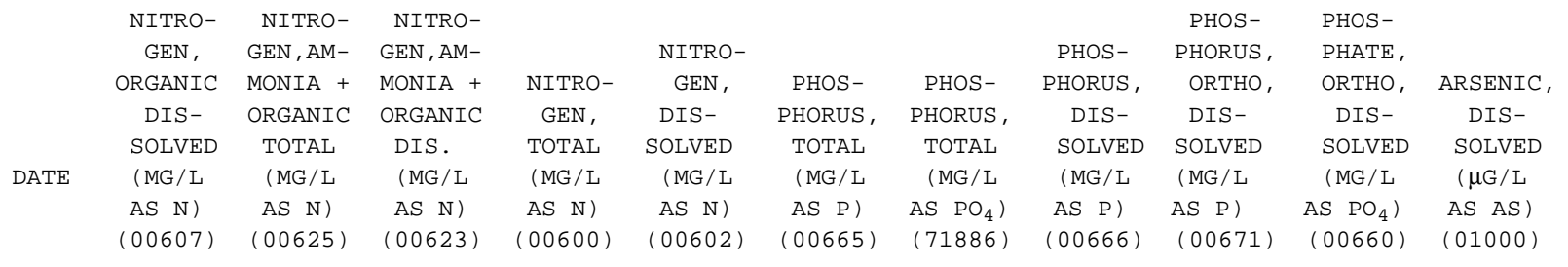

NOV 1981

$04 \ldots$

OCT 1982

\begin{tabular}{|c|c|c|c|c|c|c|c|c|c|c|}
\hline 0.56 & 0.74 & 0.73 & 1.7 & 1.7 & 0.020 & 0.06 & 0.020 & $<0.010$ & - & ND \\
\hline .24 & - & .30 & - & 1.6 & - & - & .020 & .010 & 0.03 & $<1$ \\
\hline 1.3 & - & 1.5 & - & 3.0 & .030 & .09 & .020 & $<.010$ & - & - \\
\hline .37 & - & .40 & - & 1.4 & $<.010$ & - & $<.010$ & .020 & .06 & - \\
\hline .86 & - & .90 & - & 2.4 & .020 & .06 & .010 & .010 & .03 & - \\
\hline .50 & .30 & .60 & 2.1 & 2.4 & .040 & - & .010 & $<.010$ & - & - \\
\hline .35 & .70 & .40 & 2.3 & 2.0 & .010 & - & $<.010$ & $<.010$ & - & - \\
\hline- & .50 & .50 & 2.4 & 2.4 & .010 & - & .010 & $<.010$ & - & - \\
\hline .31 & $<.20$ & .40 & - & 2.4 & .030 & - & .010 & $<.010$ & - & - \\
\hline .28 & .60 & .30 & 1.5 & 1.2 & .020 & - & $<.010$ & $<.010$ & - & - \\
\hline .18 & .40 & .30 & 1.7 & 1.6 & $<.010$ & - & $<.010$ & $<.010$ & - & - \\
\hline .14 & .20 & .20 & 1.9 & 1.9 & $<.010$ & - & .010 & $<.010$ & - & - \\
\hline- & - & - & - & - & - & - & - & .010 & .03 & - \\
\hline- & - & - & - & - & - & - & - & $<.010$ & - & - \\
\hline
\end{tabular}


Table 3. Water-quality data from surface-water sites-Continued

01480700 - East Branch Brandywine Creek near Downingtown, Pa. (Site 36)—Continued

\begin{tabular}{|c|c|c|c|c|c|c|c|c|c|c|c|}
\hline \multirow{5}{*}{ DATE } & & CHRO- & & & & & MANGA- & & & & $\begin{array}{c}\text { METHY- } \\
\text { LENE } \\
\text { BLUE }\end{array}$ \\
\hline & $\begin{array}{l}\text { CADMIUM, } \\
\text { DIS- }\end{array}$ & $\begin{array}{l}\text { MIUM, } \\
\text { DIS- }\end{array}$ & $\begin{array}{l}\text { COBALT, } \\
\text { DIS- }\end{array}$ & $\begin{array}{l}\text { COPPER, } \\
\text { DIS- }\end{array}$ & $\begin{array}{l}\text { IRON, } \\
\text { DIS- }\end{array}$ & $\begin{array}{l}\text { LEAD, } \\
\text { DIS- }\end{array}$ & $\begin{array}{l}\text { NESE, } \\
\text { DIS- }\end{array}$ & $\begin{array}{l}\text { MERCURY, } \\
\text { DIS- }\end{array}$ & $\begin{array}{l}\text { NICKEL, } \\
\text { DIS- }\end{array}$ & $\begin{array}{l}\text { ZINC, } \\
\text { DIS- }\end{array}$ & $\begin{array}{l}\text { BLUE } \\
\text { ACTIVE }\end{array}$ \\
\hline & $\begin{array}{l}\text { SOLVED } \\
(\mu \mathrm{G} / \mathrm{L}\end{array}$ & $\begin{array}{l}\text { SOLVED } \\
(\mu \mathrm{G} / \mathrm{L}\end{array}$ & $\begin{array}{r}\text { SOLVED } \\
(\mu \mathrm{G} / \mathrm{L}\end{array}$ & $\begin{array}{l}\text { SOLVED } \\
(\mu \mathrm{G} / \mathrm{L}\end{array}$ & $\begin{array}{c}\text { SOLVED } \\
(\mu \mathrm{G} / \mathrm{L}\end{array}$ & $\begin{array}{c}\text { SOLVED } \\
(\mu \mathrm{G} / \mathrm{L}\end{array}$ & $\begin{array}{l}\text { SOLVED } \\
(\mu \mathrm{G} / \mathrm{L}\end{array}$ & $\begin{array}{l}\text { SOLVED } \\
(\mu \mathrm{G} / \mathrm{L}\end{array}$ & $\begin{array}{l}\text { SOLVED } \\
(\mu \mathrm{G} / \mathrm{L}\end{array}$ & $\begin{array}{l}\text { SOLVED } \\
(\mu \mathrm{G} / \mathrm{L}\end{array}$ & $\begin{array}{c}\text { SUB- } \\
\text { STANCE }\end{array}$ \\
\hline & AS CD) & AS CR) & AS $\mathrm{CO})$ & AS CU) & AS FE) & AS PB) & AS MN) & AS HG) & AS NI) & A.S $\quad \mathrm{ZN})$ & (MG/L) \\
\hline & $(01025)$ & $(01030)$ & $(01035)$ & $(01040)$ & $(01046)$ & $(01049)$ & $(01056)$ & $(71890)$ & $(01065)$ & $(01090)$ & $(38260)$ \\
\hline
\end{tabular}

\begin{tabular}{|c|c|c|c|c|c|c|c|c|c|c|c|}
\hline $\begin{array}{c}04 \ldots \\
\text { OCT } 1982\end{array}$ & $<1.0$ & 2 & $<1$ & & 240 & $<1$ & 750 & 0.1 & 1 & $<4$ & ND \\
\hline $28 \ldots$ & $<1.0$ & $<1$ & $<1$ & & 59 & $<1$ & 74 & $<.1$ & 2 & $<4$ & 0.03 \\
\hline $\begin{array}{c}\text { NOV } 1983 \\
04 \ldots\end{array}$ & - & - & - & - & 150 & - & 140 & - & - & - & - \\
\hline $\begin{array}{c}\text { OCT } 1984 \\
30 \ldots \\
\text { OCT } 1985\end{array}$ & - & - & - & - & 71 & - & 23 & - & - & - & - \\
\hline $\begin{array}{c}21 \ldots \\
\text { NOV } 1986\end{array}$ & - & - & - & - & 54 & - & 27 & - & - & - & - \\
\hline $\begin{array}{c}17 \ldots \\
\text { OCT } 1987\end{array}$ & - & - & - & - & 120 & - & 140 & - & - & - & - \\
\hline $\begin{array}{c}20 \ldots \\
\text { OCT } 1988\end{array}$ & - & - & - & - & 87 & - & 96 & - & - & - & - \\
\hline $\begin{array}{c}05 \ldots \\
\text { OCT } 1989\end{array}$ & - & - & - & - & 290 & - & 99 & - & - & - & - \\
\hline $\begin{array}{c}10 \ldots \\
\text { OCT } 1990\end{array}$ & - & - & - & - & 190 & - & 160 & - & - & - & - \\
\hline $\begin{array}{c}16 \ldots \\
\text { NOV } 1991\end{array}$ & - & - & - & - & 87 & - & 34 & - & - & - & - \\
\hline $\begin{array}{c}05 \ldots \\
\text { ОСТ } 1992\end{array}$ & - & - & - & - & 370 & - & 350 & - & - & - & - \\
\hline $\begin{array}{c}30 \ldots \\
\text { NOV } 1993\end{array}$ & - & - & - & - & 98 & - & 240 & - & - & - & - \\
\hline $\begin{array}{c}03 \ldots \\
\text { OCT } 1994\end{array}$ & - & - & - & - & - & - & - & - & - & - & - \\
\hline $13 \ldots$ & - & - & - & - & - & - & - & - & - & - & - \\
\hline
\end{tabular}


Table 3. Water-quality data from surface-water sites-Continued

01480903 - Valley Creek at Mullsteins Meadows near Downingtown, Pa. (Site 44)

\begin{tabular}{|c|c|c|c|c|c|c|c|c|c|c|}
\hline & & DIS- & & $\mathrm{PH}$ & & & & & HARD - & \\
\hline & & CHARGE, & SPE- & WATER & & & & HARD- & NESS & \\
\hline & & (CUBIC & $\mathrm{CON}-$ & FIELD & TEMP ER- & TUR- & OXYGEN, & TOTAL & WH WAT & DIS- \\
\hline $\mathrm{ATE}$ & TIME & PER & $\mathrm{ANCE}$ & ARD & WATER & ITY & SOLVED & AS & (MG/L AS & (MG/L \\
\hline & & SECOND) & $(\mu \mathrm{S} / \mathrm{CM})$ & UNITS) & $(\mathrm{DEG} \quad \mathrm{C})$ & (NTU) & (MG / L ) & $\left.\mathrm{CACO}_{3}\right)$ & $\left.\mathrm{CACO}_{3}\right)$ & AS CA) \\
\hline & & $(00061)$ & $(00095)$ & $(00400)$ & $(00010)$ & $(00076)$ & $(00300)$ & $(00900)$ & $(00902)$ & (00915) \\
\hline
\end{tabular}

\begin{tabular}{|c|c|c|c|c|c|c|c|c|c|c|}
\hline \multicolumn{10}{|l|}{ NOV 1981} & 36 \\
\hline \multicolumn{11}{|l|}{ OCT 1982} \\
\hline $28 \ldots$ & 1445 & 7.3 & 324 & 8.4 & 10.7 & - & 12.4 & 150 & - & 33 \\
\hline \multicolumn{11}{|l|}{ OCT 1983} \\
\hline $31 \ldots$ & 1345 & 7.0 & 377 & 8.0 & 10.0 & 1.3 & 12.4 & 170 & - & 38 \\
\hline \multicolumn{11}{|l|}{ OCT 1984} \\
\hline $16 \ldots$ & 1500 & 11 & 370 & 8.7 & 14.0 & .40 & 12.8 & 150 & - & 33 \\
\hline \multicolumn{11}{|l|}{ OCT 1985} \\
\hline $31 \ldots$ & 0930 & 8.3 & 340 & 7.6 & 11.0 & .60 & 12.2 & 150 & - & 37 \\
\hline \multicolumn{11}{|l|}{ OCT 1986} \\
\hline $08 \ldots$ & 1330 & 5.5 & 345 & 8.5 & 14.5 & .40 & 12.6 & 170 & - & 35 \\
\hline \multicolumn{11}{|l|}{ NOV 1987} \\
\hline $04 \ldots$ & 1400 & 7.8 & 335 & 8.6 & 15.0 & .40 & 14.6 & 150 & - & 37 \\
\hline \multicolumn{11}{|l|}{ OCT 1988} \\
\hline $14 \ldots$ & 1530 & 12 & 321 & 7.6 & 12.0 & 1.5 & 13.4 & 130 & - & 33 \\
\hline \multicolumn{11}{|l|}{ OCT 1989} \\
\hline $06 \ldots$ & 1015 & 21 & 370 & 7.8 & 13.0 & .40 & 11.5 & 160 & 54 & 36 \\
\hline \multicolumn{11}{|l|}{ OCT 1990} \\
\hline $11 \ldots$ & 1245 & 6.1 & 390 & 6.9 & 19.0 & .50 & 10.2 & 160 & 48 & 32 \\
\hline \multicolumn{11}{|l|}{ NOV 1991} \\
\hline $18 \ldots$ & 0945 & 4.4 & 349 & 7.5 & 3.5 & 1.1 & 15.0 & 150 & 60 & 38 \\
\hline \multicolumn{11}{|l|}{ NOV 1992} \\
\hline $17 \ldots$ & 0915 & 7.4 & 329 & 7.9 & 4.5 & .70 & 14.5 & 130 & - & 34 \\
\hline \multicolumn{11}{|l|}{ NOV 1993} \\
\hline $04 \ldots$ & 1300 & 8.6 & 429 & 8.4 & 9.0 & - & 14.0 & - & - & - \\
\hline \multicolumn{11}{|l|}{ OCT 1994} \\
\hline $06 \ldots$ & 1000 & 5.4 & 390 & 8.0 & 10.0 & - & 12.0 & - & - & - \\
\hline
\end{tabular}


Table 3. Water-quality data from surface-water sites-Continued

01480903 - Valley Creek at Mullsteins Meadows near Downingtown, Pa. (Site 44)—Continued

\begin{tabular}{|c|c|c|c|c|c|c|c|c|c|c|c|}
\hline & & & & & ANC & ANC & & & & & \\
\hline MAGNE- & & & & POTA & WATER & WATER & & $\mathrm{CHLC}$ & FLU & SILICA, & RESIDUE \\
\hline SIUM, & SODIUM, & & ODIUM & SIUM & JNFLTRD & UNFLTRD & SULF & RID & RID & DI & AT 180 \\
\hline DIS- & DIS- & & $\mathrm{AD}-$ & DIS- & FET & IT & DI & DIS- & DIs & SOLVED & DEG. C \\
\hline 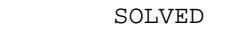 & SOLVED & & SORP- & SOLVED & FIELD & FIELD & VED & SOLVED & SOI & (MG / L & DI \\
\hline (MG /L & (MG / L & $\mathrm{s}$ & TION & (MG/L & (MG/L AS & (MG/L AS & (MG/L & (MG / L & (MG / L & AS & SOLVED \\
\hline MG) & AS NA) & ERCENT & RATIO & AS K) & $\left.\mathrm{CACO}_{3}\right)$ & $\left.\mathrm{CACO}_{3}\right)$ & AS $\left.\quad \mathrm{SO}_{4}\right)$ & AS CL) & AS F) & $\left.\mathrm{SIO}_{2}\right)$ & (MC \\
\hline (00925) & $(00930)$ & $(00932)$ & $(00931)$ & $(00935)$ & $(00410)$ & $(00419)$ & $(00945)$ & $(00940)$ & $(00950)$ & (00955) & (70300 \\
\hline
\end{tabular}

\begin{tabular}{|c|c|c|c|c|c|c|c|c|c|c|c|c|}
\hline $\begin{array}{c}04 \ldots \\
\text { OCT } 1982\end{array}$ & 13 & 11 & 14 & 0.4 & 1.7 & - & - & 29 & 20 & $<0.10$ & 6.1 & 190 \\
\hline $\begin{array}{c}28 \ldots \\
\text { OCT } 1983\end{array}$ & 17 & 10 & 12 & .4 & 2.4 & 92 & - & 33 & 19 & $<.10$ & 5.7 & 203 \\
\hline $\begin{array}{c}04 \ldots \\
\text { OCT } 1984\end{array}$ & 19 & 10 & 11 & .3 & 2.5 & 84 & - & 55 & 19 & - & 5.4 & 231 \\
\hline $\begin{array}{c}16 \ldots \\
\text { OCT } 1985\end{array}$ & 16 & 9.7 & 12 & .3 & 2.1 & 100 & - & 42 & 19 & - & 4.5 & 196 \\
\hline $\begin{array}{c}31 \ldots \\
\text { OCT } 1986\end{array}$ & 14 & 13 & 16 & .5 & 2.0 & 108 & - & 27 & 28 & - & 6.0 & 195 \\
\hline $\begin{array}{c}08 \ldots \\
\text { NOV } 1987\end{array}$ & 19 & 11 & 12 & .4 & 3.2 & 104 & - & 49 & 20 & - & 6.2 & 240 \\
\hline $\begin{array}{c}04 \ldots \\
\text { OCT } 1988\end{array}$ & 15 & 12 & 14 & .4 & 2.5 & 114 & - & 31 & 23 & - & 5.0 & 202 \\
\hline $\begin{array}{c}14 \ldots \\
\text { OCT } 1989\end{array}$ & 12 & 11 & 15 & .4 & 1.7 & 101 & - & 25 & 22 & - & 6.4 & - \\
\hline $\begin{array}{c}06 \ldots \\
\text { OCT } 1990\end{array}$ & 16 & 12 & 14 & .4 & 2.4 & 102 & - & 38 & 23 & - & 7.5 & - \\
\hline $\begin{array}{c}11 \ldots \\
\text { NOV } 1991\end{array}$ & 20 & 12 & 14 & .4 & 3.1 & 114 & - & 43 & 24 & $<.10$ & 5.8 & 220 \\
\hline $\begin{array}{c}18 \ldots \\
\text { NOV } 1992\end{array}$ & 14 & 13 & 15 & .5 & 1.8 & 93 & - & 32 & 27 & .10 & 4.1 & - \\
\hline $\begin{array}{c}17 \ldots \\
\text { NOV } 1993\end{array}$ & 12 & 13 & 17 & .5 & 1.7 & - & 82 & 27 & 25 & $<.10$ & 6.6 & - \\
\hline $\begin{array}{c}04 \ldots \\
\text { OCT } 1994\end{array}$ & - & - & - & - & - & - & 138 & 40 & 29 & $<.10$ & - & - \\
\hline $06 \ldots$ & - & - & - & - & - & 110 & 110 & - & 32 & - & - & - \\
\hline
\end{tabular}


Table 3. Water-quality data from surface-water sites-Continued

01480903 - Valley Creek at Mullsteins Meadows near Downingtown, Pa. (Site 44)—Continued

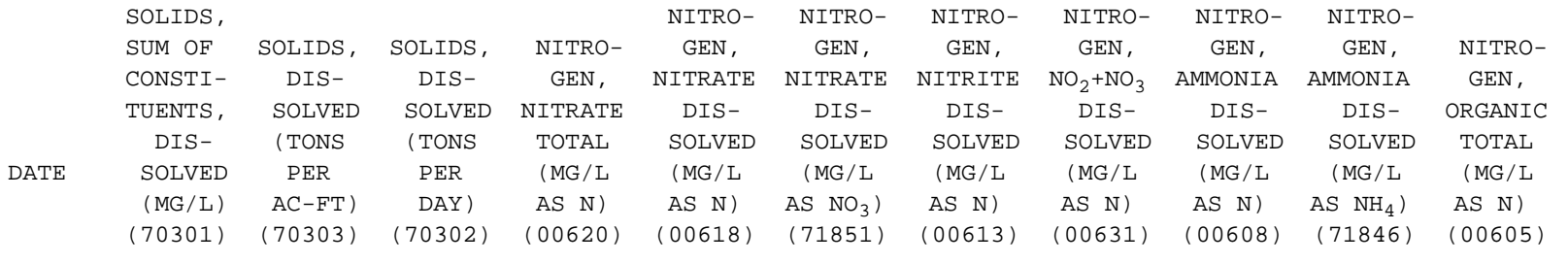

\begin{tabular}{|c|c|c|c|c|c|c|c|c|c|c|c|}
\hline $\begin{array}{c}04 \ldots \\
\text { OCT } 1982\end{array}$ & - & 0.26 & - & 2.40 & - & - & $<0.010$ & 2.20 & $<0.010$ & 0.01 & - \\
\hline $\begin{array}{c}28 \ldots \\
\text { OCT } 1983\end{array}$ & 186 & .28 & 4.01 & - & - & - & $<.010$ & 2.40 & .020 & .03 & - \\
\hline $\begin{array}{c}31 \ldots \\
\text { OCT } 1984\end{array}$ & 216 & .31 & 4.37 & - & 3.60 & 16 & .010 & 3.60 & .010 & .01 & - \\
\hline $\begin{array}{c}16 \ldots \\
\text { OCT } 1985\end{array}$ & 200 & .27 & 5.82 & - & 2.96 & 13 & .040 & 3.00 & .050 & .06 & - \\
\hline $\begin{array}{c}31 \ldots \\
\text { OCT } 1986\end{array}$ & 204 & .27 & 4.37 & - & - & - & $<.010$ & 2.70 & .010 & .01 & - \\
\hline $\begin{array}{c}08 \ldots \\
\text { NOV } 1987\end{array}$ & 217 & .33 & 3.56 & - & 2.39 & 11 & .010 & 2.40 & $<.010$ & - & - \\
\hline $\begin{array}{c}04 \ldots \\
\text { OCT } 1988\end{array}$ & 205 & .27 & 4.25 & - & - & - & $<.010$ & 2.40 & .020 & .03 & 0.88 \\
\hline $\begin{array}{c}14 \ldots \\
\text { OCT } 1989\end{array}$ & 183 & .25 & 5.92 & - & - & - & $<.010$ & 2.50 & .010 & .01 & - \\
\hline $\begin{array}{c}06 \ldots \\
\text { OCT } 1990\end{array}$ & 208 & .28 & 11.8 & - & - & - & $<.010$ & 2.70 & .010 & .01 & - \\
\hline $\begin{array}{c}11 \ldots \\
\text { NOV } 1991\end{array}$ & 219 & .30 & 3.63 & - & - & - & $<.010$ & 2.40 & $<.020$ & - & - \\
\hline $\begin{array}{c}18 \ldots \\
\text { NOV } 1992\end{array}$ & 196 & .27 & 2.35 & - & - & - & $<.010$ & 2.30 & .010 & .01 & - \\
\hline $\begin{array}{c}17 \ldots \\
\text { NOV } 1993\end{array}$ & 179 & .24 & 3.58 & - & 2.36 & 10 & .040 & 2.40 & .040 & .05 & - \\
\hline $\begin{array}{c}04 \ldots \\
\text { OCT } 1994\end{array}$ & - & - & - & - & - & - & $<.010$ & 2.00 & .020 & .03 & - \\
\hline $06 \ldots$ & - & - & - & - & - & - & $<.010$ & 2.40 & $<.015$ & - & - \\
\hline
\end{tabular}


Table 3. Water-quality data from surface-water sites-Continued

01480903 - Valley Creek at Mullsteins Meadows near Downingtown, Pa. (Site 44)—Continued

\begin{tabular}{|c|c|c|c|c|c|c|c|c|c|c|c|}
\hline & $\begin{array}{c}\text { NITRO- } \\
\text { GEN, } \\
\text { ORGANIC }\end{array}$ & $\begin{array}{l}\text { NITRO- } \\
\text { GEN, AM- } \\
\text { MONIA + }\end{array}$ & $\begin{array}{l}\text { NITRO- } \\
\text { GEN, AM- } \\
\text { MONIA + }\end{array}$ & 10 & $\begin{array}{l}\text { NITRO- } \\
\text { GEN, }\end{array}$ & & & $\begin{array}{c}\text { PHOS- } \\
\text { PHORUS, }\end{array}$ & $\begin{array}{l}\text { PHOS- } \\
\text { PHORUS } \\
\text { ORTHO, }\end{array}$ & $\begin{array}{l}\text { PHOS- } \\
\text { PHATE, } \\
\text { ORTHO, }\end{array}$ & \\
\hline & $\begin{array}{c}\text { DIS- } \\
\text { SOLVED } \\
\text { (MG / L }\end{array}$ & $\begin{array}{c}\text { ORGANIC } \\
\text { TOTAL } \\
\text { (MG/L }\end{array}$ & $\begin{array}{l}\text { ORGANIC } \\
\text { DIS. } \\
\text { (MG/L }\end{array}$ & $\begin{array}{c}\text { GEN, } \\
\text { TOTAL } \\
(\mathrm{MG} / \mathrm{L}\end{array}$ & $\begin{array}{c}\text { DIS- } \\
\text { SOLVED } \\
\text { (MG/L }\end{array}$ & $\begin{array}{c}\text { PHORUS, } \\
\text { TOTAL } \\
\text { (MG/L }\end{array}$ & $\begin{array}{l}\text { PHORUS, } \\
\text { TOTAL } \\
\text { (MG/L }\end{array}$ & $\begin{array}{c}\text { DIS- } \\
\text { SOLVED } \\
\text { (MG/L }\end{array}$ & $\begin{array}{l}\text { DIS- } \\
\text { SOLVED } \\
\text { (MG/L }\end{array}$ & $\begin{array}{r}\text { DIS- } \\
\text { SOLVED } \\
(\mathrm{MG} / \mathrm{L}\end{array}$ & $\begin{array}{r}\text { DIS- } \\
\text { SOLVED } \\
(\mu \mathrm{G} / \mathrm{L}\end{array}$ \\
\hline & $\begin{array}{c}\text { AS N) } \\
(00607)\end{array}$ & $\begin{array}{c}\text { AS N) } \\
(00625)\end{array}$ & $\begin{array}{c}\text { AS N) } \\
(00623)\end{array}$ & $\begin{array}{c}\text { AS N) } \\
(00600)\end{array}$ & $\begin{array}{c}\text { AS N) } \\
(00602)\end{array}$ & $\begin{array}{c}\text { AS P) } \\
(00665)\end{array}$ & $\begin{array}{l}\left.\text { AS } \mathrm{PO}_{4}\right) \\
(71886)\end{array}$ & $\begin{array}{l}\text { AS P ) } \\
(00666)\end{array}$ & $\begin{array}{l}\text { AS P) } \\
(00671)\end{array}$ & $\begin{array}{l}\left.\text { AS } \mathrm{PO}_{4}\right) \\
(00660)\end{array}$ & $\begin{array}{l}\text { AS AS) } \\
(01000)\end{array}$ \\
\hline
\end{tabular}

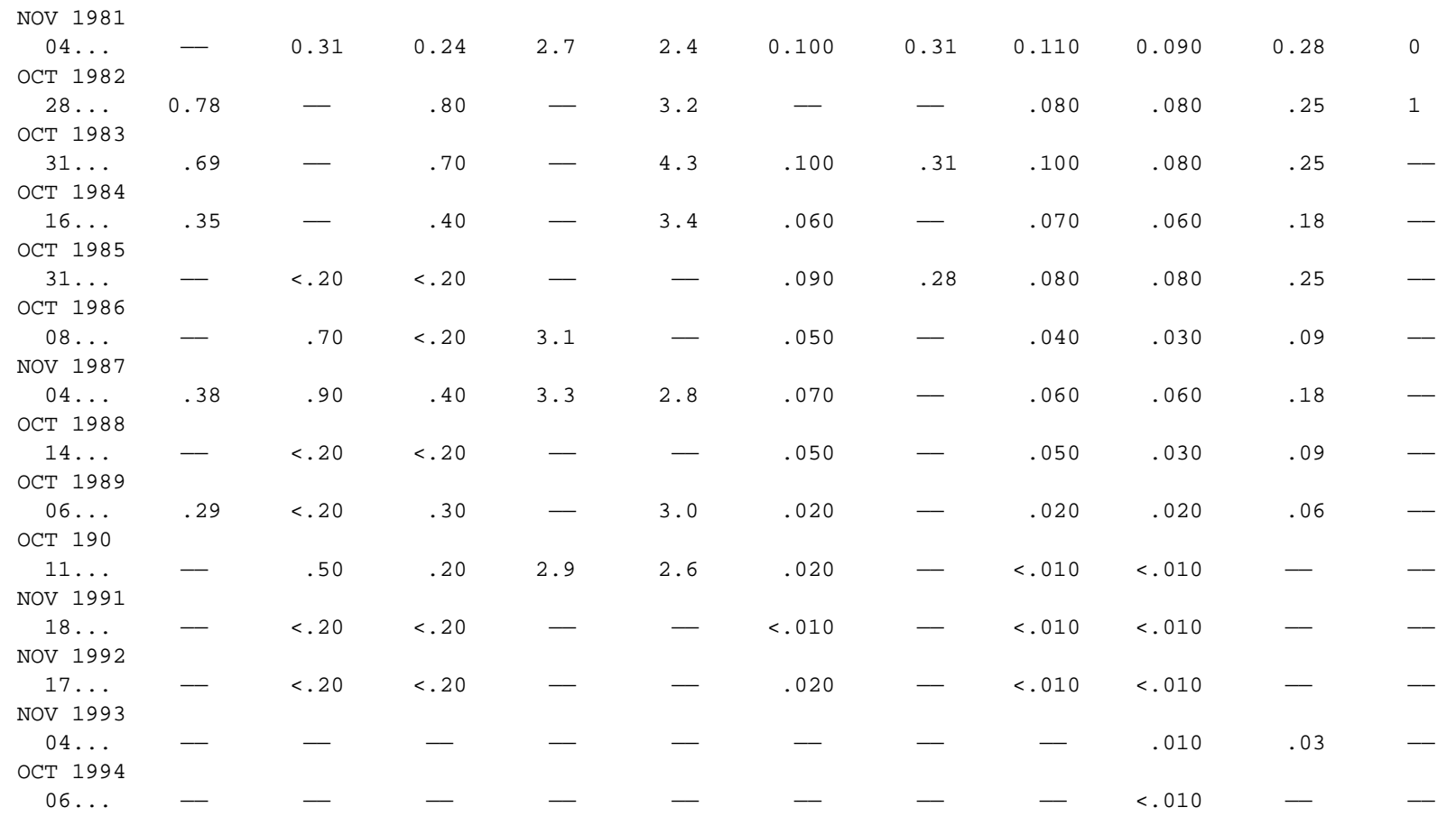


Table 3. Water-quality data from surface-water sites-Continued

01480903 - Valley Creek at Mullsteins Meadows near Downingtown, Pa. (Site 44)—Continued

\begin{tabular}{|c|c|c|c|c|c|c|c|c|c|c|c|}
\hline & & CHRO- & & & & & MANGA- & & & & $\begin{array}{l}\text { METHY- } \\
\text { LENE }\end{array}$ \\
\hline & $\begin{array}{c}\text { CADMIUM } \\
\text { DIS- }\end{array}$ & $\begin{array}{l}\text { MIUM, } \\
\text { DIS- }\end{array}$ & $\begin{array}{l}\text { COBALT, } \\
\text { DIS- }\end{array}$ & $\begin{array}{c}\text { COPPER, } \\
\text { DIS- }\end{array}$ & $\begin{array}{r}\text { IRON, } \\
\text { DIS- }\end{array}$ & $\begin{array}{l}\text { LEAD, } \\
\text { DIS- }\end{array}$ & $\begin{array}{r}\mathrm{NESE} \\
\mathrm{DIS}-\end{array}$ & $\begin{array}{c}\text { MERCURY, } \\
\text { DIS- }\end{array}$ & $\begin{array}{l}\text { NICKEL, } \\
\text { DIS- }\end{array}$ & $\begin{array}{l}\text { ZINC, } \\
\text { DIS- }\end{array}$ & $\begin{array}{c}\text { BLUE } \\
\text { ACTIVE }\end{array}$ \\
\hline DATE & $\begin{array}{l}\text { SOLVED } \\
(\mu \mathrm{G} / \mathrm{L}\end{array}$ & $\begin{array}{c}\text { SOLVED } \\
(\mu \mathrm{G} / \mathrm{L}\end{array}$ & $\begin{array}{c}\text { SOLVED } \\
(\mu \mathrm{G} / \mathrm{L}\end{array}$ & $\begin{array}{c}\text { SOLVED } \\
(\mu \mathrm{G} / \mathrm{L}\end{array}$ & $\begin{array}{c}\text { SOLVED } \\
(\mu \mathrm{G} / \mathrm{L}\end{array}$ & $\begin{array}{c}\text { SOLVED } \\
(\mu \mathrm{G} / \mathrm{L}\end{array}$ & $\begin{array}{c}\text { SOLVED } \\
(\mu \mathrm{G} / \mathrm{L}\end{array}$ & $\begin{array}{c}\text { SOLVED } \\
(\mu \mathrm{G} / \mathrm{L}\end{array}$ & $\begin{array}{c}\text { SOLVED } \\
(\mu \mathrm{G} / \mathrm{L}\end{array}$ & $\begin{array}{l}\text { SOLVED } \\
(\mu \mathrm{G} / \mathrm{L}\end{array}$ & $\begin{array}{r}\text { SUB- } \\
\text { STANCE }\end{array}$ \\
\hline & A.S CD) & AS (R) & AS $(O)$ & AS CU) & AS FE) & AS $\quad$ PB) & AS MN) & AS HG) & AS NI) & AS ZN) & (MG / L) \\
\hline & $(01025)$ & $(01030)$ & $(01035)$ & $(01040)$ & $(01046)$ & $(01049)$ & $(01056)$ & $(71890)$ & $(01065)$ & $(01090)$ & $(38260)$ \\
\hline
\end{tabular}

NOV 1981

\begin{tabular}{|c|c|c|c|c|c|c|c|c|c|c|c|}
\hline $\begin{array}{c}04 \ldots \\
\text { OCT } 1982\end{array}$ & $<1.0$ & $<1.0$ & 2.0 & $<1.0$ & 16 & $<1.0$ & 46 & 0.1 & 2.0 & $<4.0$ & ND \\
\hline $\begin{array}{c}28 \ldots \\
\text { OCT } 1983\end{array}$ & $<1.0$ & $<1.0$ & $<1.0$ & $<1.0$ & 18 & $<1.0$ & 5.0 & $<.1$ & 1.0 & $<4.0$ & 0.04 \\
\hline $\begin{array}{c}31 \ldots \\
\text { OCT } 1984\end{array}$ & - & - & - & - & 16 & - & 8.0 & - & - & - & - \\
\hline $\begin{array}{c}16 \ldots \\
\text { OCT } 1985\end{array}$ & - & - & - & - & 13 & - & 4.0 & - & - & - & - \\
\hline $\begin{array}{c}31 \ldots \\
\text { OCT } 1986\end{array}$ & - & - & - & - & 10 & - & 8.0 & - & - & - & - \\
\hline $\begin{array}{c}08 \ldots \\
\text { NOV } 1987\end{array}$ & - & - & - & - & 13 & - & 8.0 & - & - & - & - \\
\hline $\begin{array}{c}04 \ldots \\
\text { OCT } 1988\end{array}$ & - & - & - & - & 13 & - & 6.0 & - & - & - & - \\
\hline $\begin{array}{c}14 \ldots \\
\text { OCT } 1989\end{array}$ & - & - & - & - & 17 & - & 6.0 & - & - & - & - \\
\hline $\begin{array}{c}06 \ldots \\
\text { OCT } 1990\end{array}$ & - & - & - & - & 14 & - & 7.0 & - & - & - & - \\
\hline $\begin{array}{c}11 \ldots \\
\text { NOV } 1991\end{array}$ & - & $<1.0$ & - & - & 24 & - & 17 & - & - & - & - \\
\hline $\begin{array}{c}18 \ldots \\
\text { NOV } 1992\end{array}$ & - & - & - & - & 15 & - & 4.0 & - & - & - & - \\
\hline $\begin{array}{c}17 \ldots \\
\text { NOV } 1993\end{array}$ & 1.0 & $<5.0$ & $<3.0$ & $<10$ & 20 & $<10$ & 8.0 & - & $<10$ & $<3.0$ & - \\
\hline $\begin{array}{c}04 \ldots \\
\text { OCT } 1994\end{array}$ & - & - & - & - & - & - & - & - & - & - & - \\
\hline $06 \ldots$ & - & - & - & - & - & - & - & - & - & - & - \\
\hline
\end{tabular}


Table 3. Water-quality data from surface-water sites-Continued

01480950 - East Branch Brandywine Creek at Wawaset, Pa. (Site 39)

\begin{tabular}{|c|c|c|c|c|c|c|c|c|c|c|c|}
\hline & & DIS- & & $\mathrm{PH}$ & & & & & HARD- & & \\
\hline & & CHARGE, & SPE- & WATER & & & & HARD- & NESS, & & MAGNE- \\
\hline & & INST. & CIFIC & WHOLE & & & & NESS, & NONCARB & CALCIUM & SIUM, \\
\hline & & (CUBIC & $\mathrm{CON}-$ & FIELD & TEMPER- & TUR- & OXYGEN， & TOTAL & WH WAT & DIS- & DIS- \\
\hline & & FEET & DUCT- & (STAND- & ATURE & BID- & DIS- & (MG /L & TOT FLD & SOLVED & SOLVED \\
\hline ATE & TIME & PER & ANCE & ARD & WATER & ITY & SOLVED & AS & (MG/L AS & (MG /L & (MG /L \\
\hline & & SECOND) & $(\mu \mathrm{S} / \mathrm{CM})$ & UNITS) & (DEG C) & (NTU) & (MG/L) & $\left.\mathrm{CACO}_{3}\right)$ & $\left.\mathrm{CACO}_{3}\right)$ & AS CA) & AS MG) \\
\hline & & $(00061)$ & $(00095)$ & $(00400)$ & $(00010)$ & $(00076)$ & $(00300)$ & $(00900)$ & $(00902)$ & $(00915)$ & (00925) \\
\hline
\end{tabular}

\begin{tabular}{|c|c|c|c|c|c|c|c|c|c|c|c|}
\hline $\begin{array}{c}\text { NOV } 1981 \\
04 \ldots\end{array}$ & 1330 & - & 328 & 6.7 & 10.5 & - & 12.4 & 120 & - & 29 & 12 \\
\hline OCT 1982 & & & & & & & & & & & \\
\hline $21 \ldots$ & 1400 & 56 & 290 & 8.0 & 14.5 & - & 11.3 & 100 & - & 25 & 10 \\
\hline OCT 1983 & & & & & & & & & & & \\
\hline $31 \ldots$ & 0945 & 78 & 284 & 7.5 & 7.5 & 2.4 & 10.8 & 120 & - & 28 & 11 \\
\hline OCT 1984 & & & & & & & & & & & \\
\hline $16 \ldots$ & 0930 & 68 & 290 & 7.8 & 13.0 & 1.3 & 12.4 & 110 & - & 26 & 10 \\
\hline OCT 1985 & & & & & & & & & & & \\
\hline $22 \ldots$ & 0900 & 55 & 290 & 7.5 & 9.5 & 1.0 & 13.8 & 110 & - & 27 & 11 \\
\hline NOV 1986 & & & & & & & & & & & \\
\hline $03 \ldots$ & 1400 & 50 & 293 & 7.9 & 12.0 & .70 & 11.4 & 110 & - & 27 & 10 \\
\hline NOV 1987 & & & & & & & & & & & \\
\hline $04 \ldots$ & 0930 & 66 & 292 & 7.4 & 12.5 & .60 & 12.6 & 110 & - & 28 & 10 \\
\hline OCT 1988 & & & & & & & & & & & \\
\hline $06 \ldots$ & 1030 & 52 & 374 & 7.8 & 12.5 & 1.8 & 13.4 & 130 & - & 30 & 13 \\
\hline OCT 1989 & & & & & & & & & & & \\
\hline $13 \ldots$ & 0915 & 113 & 293 & 7.5 & 13.0 & .80 & 10.9 & 110 & 35 & 26 & 9.7 \\
\hline OCT 1990 & & & & & & & & & & & \\
\hline $15 \ldots$ & 1300 & 86 & 295 & 6.6 & 19.5 & 1.5 & 8.8 & 100 & 26 & 25 & 9.7 \\
\hline OCT 1991 & & & & & & & & & & & \\
\hline $30 \ldots$ & 1245 & 51 & 350 & 8.3 & 10.5 & .50 & 16.4 & 120 & 45 & 30 & 11 \\
\hline OCT 1992 & & & & & & & & & & & \\
\hline $29 \ldots$ & 1300 & 46 & 350 & 7.6 & 11.5 & .90 & 11.6 & 110 & - & 27 & 10 \\
\hline NOV 1993 & & & & & & & & & & & \\
\hline $16 \ldots$ & 1000 & 55 & 338 & 8.2 & 12.0 & - & 12.8 & - & - & - & - \\
\hline OCT 1994 & & & & & & & & & & & \\
\hline $11 \ldots$ & 1300 & 57 & 377 & 7.8 & 12.5 & - & 12.4 & - & - & - & - \\
\hline
\end{tabular}


Table 3. Water-quality data from surface-water sites-Continued

01480950 - East Branch Brandywine Creek at Wawaset, Pa. (Site 39)—Continued

\begin{tabular}{|c|c|c|c|c|c|c|c|c|c|c|}
\hline \multirow{6}{*}{ DATE } & \multirow{4}{*}{$\begin{array}{l}\text { SODIUM, } \\
\text { DIS- } \\
\text { SOLVED }\end{array}$} & & \multirow{3}{*}{$\begin{array}{c}\text { SODIUM } \\
\text { AD- }\end{array}$} & \multirow{3}{*}{$\begin{array}{c}\text { POTAS- } \\
\text { SIUM, } \\
\text { DIS- }\end{array}$} & $\begin{array}{l}\text { ALKA- } \\
\text { LINITY }\end{array}$ & $\begin{array}{l}\text { ALKA- } \\
\text { LINITY }\end{array}$ & \multirow[b]{2}{*}{ SULFATE, } & \multirow{2}{*}{$\begin{array}{l}\text { CHLO- } \\
\text { RIDE, }\end{array}$} & \multirow{2}{*}{$\begin{array}{l}\text { FLUO- } \\
\text { RIDE, }\end{array}$} & \multirow{2}{*}{$\begin{array}{l}\text { SILICA, } \\
\text { DIS- }\end{array}$} \\
\hline & & & & & WAT WH & WAT WH & & & & \\
\hline & & & & & TOT FET & TOT IT & DIS- & DIS- & DIS- & SOLVED \\
\hline & & & SORP- & $\begin{array}{r}\text { SOLVED } \\
\text { (MG/L }\end{array}$ & $\begin{array}{l}\text { FIELD } \\
\text { (MG/L AS }\end{array}$ & $\begin{array}{l}\text { FIELD } \\
\text { (MG/L AS }\end{array}$ & $\begin{array}{r}\text { SOLVED } \\
\text { (MG/L }\end{array}$ & $\begin{array}{r}\text { SOLVED } \\
\text { (MG/L }\end{array}$ & $\begin{array}{c}\text { SOLVED } \\
\text { (MG/L }\end{array}$ & (MG/L \\
\hline & $\begin{array}{l}\text { (MG/L } \\
\text { AS NA) }\end{array}$ & $\begin{array}{l}\text { SODIUM } \\
\text { PERCENT }\end{array}$ & RATIO & AS K) & $\begin{array}{c}(\mathrm{MG} / \mathrm{L} \mathrm{AS} \\
\left.\mathrm{CACO}_{3}\right)\end{array}$ & $\begin{array}{l}(\mathrm{MG} / \mathrm{L} \mathrm{AS} \\
\left.\mathrm{CACO}_{3}\right)\end{array}$ & $\left.\mathrm{AS} \quad \mathrm{SO}_{4}\right)$ & AS CL) & AS F) & $\begin{array}{c}\mathrm{AS} \\
\left.\mathrm{SIO}_{2}\right)\end{array}$ \\
\hline & $(00930)$ & $(00932)$ & $(00931)$ & $(00935)$ & $(00410)$ & $(00419)$ & $(00945)$ & $(00940)$ & $(00950)$ & $(00955)$ \\
\hline
\end{tabular}

\begin{tabular}{|c|c|c|c|c|c|c|c|c|c|c|}
\hline NOV 1981 & & & & & & & & & & \\
\hline $\begin{array}{c}04 \ldots \\
\text { OCT } 1982\end{array}$ & 20 & 26 & 0.8 & 3.4 & - & - & 29 & 24 & 0.10 & 13 \\
\hline $21 \ldots$ & 16 & 25 & .7 & 2.8 & 74 & - & 32 & 23 & .10 & 10 \\
\hline OCT 1983 & & & & & & & & & & \\
\hline $\begin{array}{c}31 \ldots \\
\text { OCT } 1984\end{array}$ & 16 & 23 & .6 & 3.1 & 84 & - & 31 & 23 & - & 11 \\
\hline $\begin{array}{c}16 \ldots \\
\text { OCT } 1985\end{array}$ & 16 & 24 & .7 & 2.7 & 82 & - & 25 & 22 & - & 9.0 \\
\hline $\begin{array}{c}22 \ldots \\
\text { NOV } 1986\end{array}$ & 16 & 23 & .7 & 3.4 & 80 & - & 28 & 25 & - & 9.7 \\
\hline $\begin{array}{c}03 \ldots \\
\text { NOV } 1987\end{array}$ & 17 & 25 & .7 & 3.9 & 84 & - & 24 & 25 & - & 10 \\
\hline $\begin{array}{c}04 \ldots \\
\text { OCT } 1988\end{array}$ & 18 & 25 & .7 & 3.8 & 85 & - & 26 & 26 & - & 12 \\
\hline $\begin{array}{c}06 \ldots \\
\text { OCT } 1989\end{array}$ & 19 & 24 & .7 & 3.7 & 94 & - & 29 & 27 & - & 11 \\
\hline $\begin{array}{c}13 \ldots \\
\text { OCT } 1990\end{array}$ & 15 & 23 & .6 & 3.3 & 70 & - & 21 & 21 & - & 12 \\
\hline $\begin{array}{c}15 \ldots \\
\text { OCT } 1991\end{array}$ & 15 & 23 & .6 & 4.0 & 77 & - & 21 & 22 & .20 & 12 \\
\hline $\begin{array}{cc}30 & \ldots \\
\text { OCT } & 1992\end{array}$ & 22 & 28 & .9 & 4.5 & 75 & - & 30 & 33 & .20 & 9.8 \\
\hline $\begin{array}{c}29 \ldots \\
\text { NOV } 1993\end{array}$ & 19 & 27 & .8 & 4.1 & - & 76 & 24 & 33 & .20 & 10 \\
\hline $\begin{array}{c}16 \ldots \\
\text { OCT } 1994\end{array}$ & - & - & - & - & - & 70 & 28 & 26 & .10 & - \\
\hline $11 \ldots$ & - & - & - & - & - & 108 & - & 37 & - & - \\
\hline
\end{tabular}


Table 3. Water-quality data from surface-water sites-Continued

01480950 - East Branch Brandywine Creek at Wawaset, Pa. (Site 39)—Continued

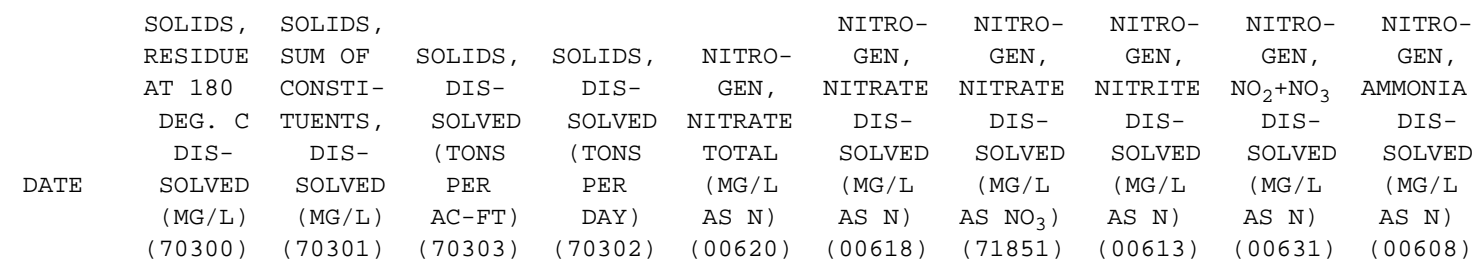

\begin{tabular}{|c|c|c|c|c|c|c|c|c|c|c|}
\hline $\begin{array}{c}\text { NOV } 1981 \\
04 \ldots \\
\text { OCT } 1982\end{array}$ & 189 & - & 0.26 & - & 2.24 & 2.04 & 9.0 & 0.160 & 2.20 & 0.490 \\
\hline $21 \ldots$ & 176 & 174 & .24 & 26.5 & 1.94 & 1.94 & 8.6 & .060 & 2.00 & .060 \\
\hline OCT 1983 & & & & & & & & & & \\
\hline $\begin{array}{c}31 \ldots \\
\text { OCT } 1984\end{array}$ & 188 & 188 & .26 & 39.6 & 2.85 & 2.85 & 13 & .050 & 2.90 & .310 \\
\hline $\begin{array}{c}16 \ldots \\
\text { OCT } 1985\end{array}$ & 175 & 175 & .24 & 32.1 & 2.91 & 2.91 & 13 & .090 & 3.00 & .070 \\
\hline $\begin{array}{c}22 \ldots \\
\text { NOV } 1986\end{array}$ & 174 & 180 & .24 & 25.8 & 2.31 & 2.31 & 10 & .090 & 2.40 & .110 \\
\hline $\begin{array}{c}03 \ldots \\
\text { NOV } 1987\end{array}$ & 186 & 180 & .25 & 25.1 & 2.23 & 2.23 & 9.9 & .070 & 2.30 & .170 \\
\hline $\begin{array}{c}04 \ldots \\
\text { OCT } 1988\end{array}$ & 182 & 188 & .25 & 32.4 & 2.58 & 2.58 & 11 & .020 & 2.60 & .050 \\
\hline $\begin{array}{c}06 \ldots \\
\text { ОСТ } 1989\end{array}$ & - & 205 & .28 & 28.8 & 3.09 & 3.09 & 14 & .010 & 3.10 & .020 \\
\hline $\begin{array}{c}13 \ldots \\
\text { OCT } 1990\end{array}$ & - & 165 & .22 & 50.5 & 3.18 & 3.18 & 14 & .020 & 3.20 & .020 \\
\hline $\begin{array}{c}15 \ldots \\
\text { OCT } 1991\end{array}$ & - & 166 & .23 & 38.8 & 2.18 & 2.18 & 9.6 & .020 & 2.20 & .040 \\
\hline $\begin{array}{c}30 \ldots \\
\text { OCT } 1992\end{array}$ & - & 201 & .27 & 27.5 & 3.19 & 3.19 & 14 & .010 & 3.20 & .010 \\
\hline $\begin{array}{c}29 \ldots \\
\text { NOV } 1993\end{array}$ & - & 190 & .26 & 23.8 & 3.57 & 3.57 & 16 & .030 & 3.60 & .090 \\
\hline $\begin{array}{c}16 \ldots \\
\text { OCT } 1994\end{array}$ & - & - & - & - & 3.67 & 3.67 & 16 & .030 & 3.70 & .050 \\
\hline $11 \ldots$ & - & - & - & - & 4.18 & 4.18 & 19 & .020 & 4.20 & .020 \\
\hline
\end{tabular}


Table 3. Water-quality data from surface-water sites-Continued

01480950 - East Branch Brandywine Creek at Wawaset, Pa. (Site 39)—Continued

\begin{tabular}{|c|c|c|c|c|c|c|c|c|c|c|}
\hline & $\begin{array}{c}\text { NITRO- } \\
\text { GEN }\end{array}$ & NITRO- & $\begin{array}{c}\text { NITRO- } \\
\text { GEN }\end{array}$ & $\begin{array}{r}\text { NITRO- } \\
\text { GEN, AM- }\end{array}$ & $\begin{array}{r}\text { NI TRO- } \\
\text { GEN, AM- }\end{array}$ & & NITRO- & & & PHOS- \\
\hline $\mathrm{TE}$ & $\begin{array}{c}\text { AMMONIA } \\
\text { DIS- } \\
\text { SOLVED } \\
\text { (MG/L }\end{array}$ & $\begin{array}{c}\text { GEN, } \\
\text { ORGANIC } \\
\text { TOTAL } \\
\text { (MG/L }\end{array}$ & $\begin{array}{c}\text { ORGANIC } \\
\text { DIS- } \\
\text { SOLVED } \\
\text { (MG/L }\end{array}$ & $\begin{array}{c}\text { MONIA + } \\
\text { ORGANIC } \\
\text { TOTAL } \\
\text { (MG/L }\end{array}$ & $\begin{array}{l}\text { MONIA + } \\
\text { ORGANIC } \\
\text { DIS. } \\
\text { (MG/L }\end{array}$ & $\begin{array}{c}\text { NITRO- } \\
\text { GEN, } \\
\text { TOTAL } \\
\text { (MG/L }\end{array}$ & $\begin{array}{c}\text { GEN, } \\
\text { DIS- } \\
\text { SOLVED } \\
\text { (MG/L }\end{array}$ & $\begin{array}{l}\text { PHOS- } \\
\text { PHORUS, } \\
\text { TOTAL } \\
\text { (MG/L }\end{array}$ & $\begin{array}{l}\text { PHOS- } \\
\text { PHORUS, } \\
\text { TOTAL } \\
\text { (MG/L }\end{array}$ & $\begin{array}{c}\text { PHORUS, } \\
\text { DIS- } \\
\text { SOLVED } \\
\text { (MG/L }\end{array}$ \\
\hline & $\begin{array}{l}\left.\mathrm{AS} \quad \mathrm{NH}_{4}\right) \\
(71846)\end{array}$ & $\begin{array}{l}\text { AS N) } \\
(00605)\end{array}$ & $\begin{array}{l}A S N) \\
(00607)\end{array}$ & $\begin{array}{l}\text { AS N) } \\
(00625)\end{array}$ & $\begin{array}{l}\text { AS N) } \\
(00623)\end{array}$ & $\begin{array}{l}\text { AS N) } \\
(00600)\end{array}$ & $\begin{array}{l}\text { AS N) } \\
(00602)\end{array}$ & $\begin{array}{l}\text { AS P) } \\
(00665)\end{array}$ & $\begin{array}{c}\left.\text { AS } \mathrm{PO}_{4}\right) \\
(71886)\end{array}$ & $\begin{array}{l}\text { A.S P) } \\
(00666)\end{array}$ \\
\hline
\end{tabular}

NOV 1981

$04 \ldots$

OCT 1982

$21 \ldots$

OCT 1983

$31 \ldots$

OCT 1984

$16 \ldots$

OCT 1985

$22 \ldots$

NOV 1986

$03 . .$.

NOV 1987

$04 \ldots$

OCT 1988

$06 \ldots$

OCT 1989

$13 . .$.

ОСТ 1990

$15 \ldots$

ОСТ 1991

$30 \ldots$

ОСТ 1992

$29 \ldots$

NOV 1993

16 ...

OCT 1994

\begin{tabular}{|c|c|c|c|c|c|c|c|c|c|}
\hline 0.63 & 1.1 & 0.71 & 1.6 & 1.2 & 4.0 & 3.4 & 0.900 & 2.8 & 0.800 \\
\hline .08 & - & 1.2 & - & 1.3 & - & 3.3 & - & - & .530 \\
\hline .40 & - & .39 & - & .70 & - & 3.6 & .520 & 1.6 & .510 \\
\hline .09 & - & .23 & - & .30 & - & 3.3 & .710 & - & .670 \\
\hline .14 & .59 & .49 & .70 & .60 & 3.1 & 3.0 & .480 & 1.5 & .450 \\
\hline .22 & .43 & .63 & .60 & .80 & 2.9 & 3.1 & .690 & - & .660 \\
\hline .06 & .65 & .55 & .70 & .60 & 3.3 & 3.2 & .530 & - & .560 \\
\hline .03 & .68 & .68 & .70 & .70 & 3.8 & 3.8 & .700 & - & .690 \\
\hline .03 & .48 & .68 & .50 & .70 & 3.7 & 3.9 & .330 & - & .320 \\
\hline .05 & .66 & .36 & .70 & .40 & 2.9 & 2.6 & .320 & - & .320 \\
\hline .01 & .39 & .29 & .40 & .30 & 3.6 & 3.5 & .350 & - & .330 \\
\hline .12 & .61 & .51 & .70 & .60 & 4.3 & 4.2 & .320 & - & .250 \\
\hline .06 & - & - & - & - & - & - & - & - & - \\
\hline .03 & - & - & - & - & - & - & - & - & - \\
\hline
\end{tabular}


Table 3. Water-quality data from surface-water sites-Continued

01480950 - East Branch Brandywine Creek at Wawaset, Pa. (Site 39)—Continued

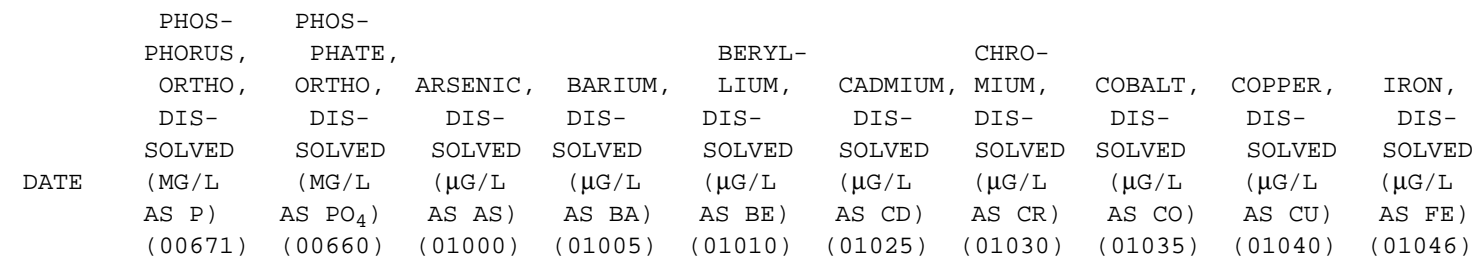

\begin{tabular}{|c|c|c|c|c|c|c|c|c|c|c|}
\hline $04 \ldots$ & 0.800 & 2.5 & 1 & - & - & $<1.0$ & $<1$ & $<1$ & 2 & 66 \\
\hline \multicolumn{11}{|l|}{ OCT 1982} \\
\hline $21 \ldots$ & .570 & 1.7 & 1 & - & - & $<1.0$ & $<1$ & 1 & 4 & 45 \\
\hline \multicolumn{11}{|l|}{ OCT 1983} \\
\hline $31 \ldots$ & .530 & 1.6 & 1 & - & - & 1.0 & $<1$ & - & 3 & 74 \\
\hline \multicolumn{11}{|l|}{ OCT 1984} \\
\hline $16 \ldots$ & .700 & 2.1 & $<1$ & - & - & $<1.0$ & 1 & - & 1 & 41 \\
\hline \multicolumn{11}{|l|}{ OCT 1985} \\
\hline $22 \ldots$ & .410 & 1.3 & $<1$ & - & - & $<1.0$ & $<1$ & - & 2 & 33 \\
\hline \multicolumn{11}{|l|}{ NOV 1986} \\
\hline $03 \ldots$ & .640 & 2.0 & $<1$ & - & - & 1.0 & $<1$ & - & 3 & 68 \\
\hline \multicolumn{11}{|l|}{ NOV 1987} \\
\hline $04 \ldots$ & .490 & 1.5 & $<1$ & - & - & $<1.0$ & 90 & - & 4 & 68 \\
\hline \multicolumn{11}{|l|}{ OCT 1988} \\
\hline $06 \ldots$ & .610 & 1.9 & $<1$ & 31 & $<0.5$ & 2.0 & 5 & $<3$ & $<10$ & 53 \\
\hline \multicolumn{11}{|l|}{ OCT 1989} \\
\hline $13 \ldots$ & .300 & .92 & $<1$ & 38 & $<.5$ & $<1.0$ & $<5$ & $<3$ & $<10$ & 99 \\
\hline \multicolumn{11}{|l|}{ OCT 1990} \\
\hline $15 \ldots$ & .340 & 1.0 & $<1$ & 35 & $<.5$ & $<1.0$ & $<5$ & $<3$ & $<10$ & 74 \\
\hline \multicolumn{11}{|l|}{ OCT 1991} \\
\hline $30 \ldots$ & .270 & .83 & $<1$ & 30 & $<.5$ & $<1.0$ & $<5$ & $<3$ & $<10$ & 130 \\
\hline \multicolumn{11}{|l|}{ OCT 1992} \\
\hline $29 \ldots$ & .240 & .74 & $<1$ & 33 & $<.5$ & $<1.0$ & $<5$ & $<3$ & $<10$ & 50 \\
\hline \multicolumn{11}{|l|}{ NOV 1993} \\
\hline $16 \ldots$ & .330 & 1.0 & - & - & - & - & - & - & - & - \\
\hline \multicolumn{11}{|l|}{ OCT 1994} \\
\hline $11 \ldots$ & .150 & .46 & - & - & - & - & - & - & - & - \\
\hline
\end{tabular}


Table 3. Water-quality data from surface-water sites-Continued

01480950 - East Branch Brandywine Creek at Wawaset, Pa. (Site 39)-Continued

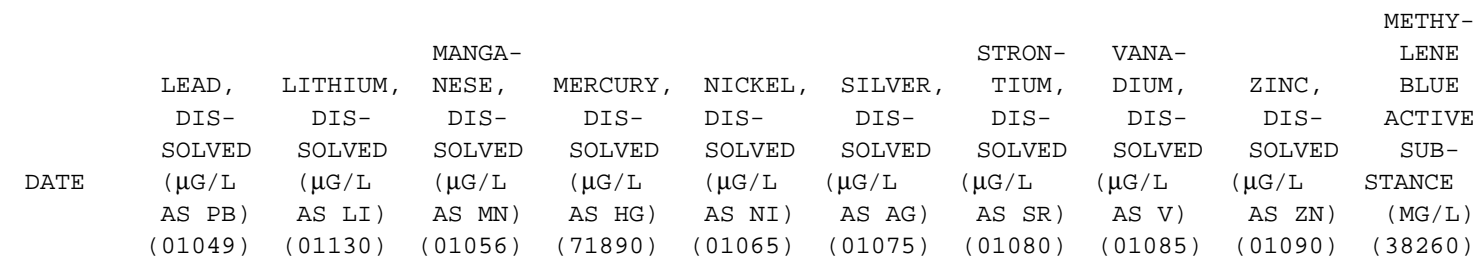

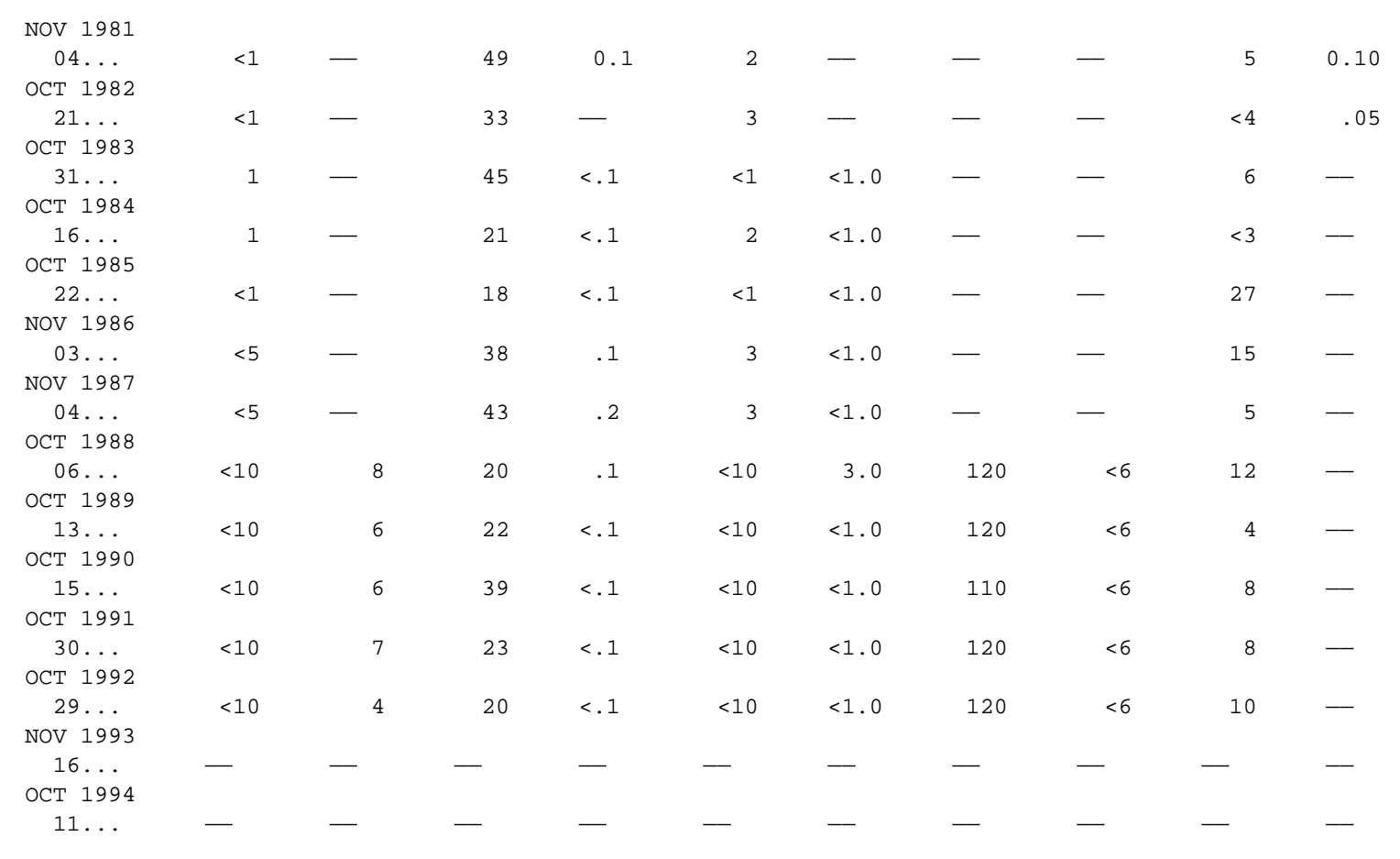


Table 3. Water-quality data from surface-water sites-Continued

01481030 - Brandywine Creek near Chadds Ford, Pa. (Site 40)

\begin{tabular}{|c|c|c|c|c|c|c|c|c|c|c|c|}
\hline & & DIS- & & PH & & & & & HARD- & & \\
\hline & & CHARGE， & SPE- & WATER & & & & HARD- & NESS & & MAGNE- \\
\hline & & $\begin{array}{l}\text { INST. } \\
\text { (CUBIC }\end{array}$ & $\begin{array}{l}\text { CIFIC } \\
\text { CON- }\end{array}$ & $\begin{array}{l}\text { WHOLE } \\
\text { FIELD }\end{array}$ & TEMPER- & & OXYGFN & $\begin{array}{l}\text { NESS, } \\
\text { TOTAL }\end{array}$ & $\begin{array}{r}\text { NONCARB } \\
\text { WH WAT }\end{array}$ & CALCIUM, & $\begin{array}{l}\text { SIUM, } \\
\text { DIS- }\end{array}$ \\
\hline & & FEET & DUCT- & (STAND- & ATURE & BID- & DIS- & (MG/L & TOT FLD & SOLVED & SOLVED \\
\hline $\mathrm{ATE}$ & TIME & PER & ANCE & ARD & WATER & ITY & SOLVED & AS & (MG/L AS & (MG/L & (MG / L \\
\hline & & SECOND) & $(\mu \mathrm{S} / \mathrm{CM})$ & UNITS) & (DEG C) & (NTU) & (MG/L) & $\left.\mathrm{CACO}_{3}\right)$ & $\left.\mathrm{CACO}_{3}\right)$ & AS CA) & AS MG) \\
\hline & & $(00061)$ & $(00095)$ & $(00400)$ & $(00010)$ & $(00076)$ & $(00300)$ & $(00900)$ & $(00902)$ & $(00915)$ & $(00925)$ \\
\hline
\end{tabular}

\begin{tabular}{|c|c|c|c|c|c|c|c|c|c|c|c|}
\hline $\begin{array}{c}\text { NOV } 1981 \\
04 \ldots \\
\text { OCT } 1982\end{array}$ & 1645 & 121 & 265 & 7.6 & 11.0 & - & 11.2 & 100 & - & 25 & 9.7 \\
\hline $\begin{array}{c}21 \ldots \\
\text { OCT } 1983\end{array}$ & 1045 & 157 & 262 & 7.5 & 12.5 & - & 10.3 & 94 & - & 23 & 8.9 \\
\hline $\begin{array}{c}31 \ldots \\
\text { OCT } 1984\end{array}$ & 1600 & 131 & 252 & 7.6 & 9.0 & 1.6 & 11.2 & 100 & - & 25 & 9.5 \\
\hline $\begin{array}{c}15 \ldots \\
\text { OCT } 1985\end{array}$ & 1600 & 165 & 230 & 8.4 & 14.0 & .60 & 12.4 & 89 & - & 22 & 8.2 \\
\hline $\begin{array}{c}30 \ldots \\
\text { DEC } 1986\end{array}$ & 1100 & 135 & 250 & 8.0 & 10.0 & .70 & 13.9 & 95 & - & 23 & 9.1 \\
\hline $\begin{array}{c}02 \ldots \\
\text { NOV } 1987\end{array}$ & 0930 & 258 & 240 & 7.8 & 5.0 & 1.8 & 11.8 & 92 & - & 22 & 8.9 \\
\hline $\begin{array}{c}20 \ldots \\
\text { OCT } 1988\end{array}$ & 1200 & 199 & 250 & 7.4 & 9.5 & .80 & 11.6 & 90 & - & 22 & 8.4 \\
\hline $\begin{array}{c}07 \ldots \\
\text { OCT } 1989\end{array}$ & 1000 & 116 & 285 & 7.6 & 12.0 & 1.5 & 10.4 & 100 & - & 24 & 10 \\
\hline $\begin{array}{c}17 \ldots \\
\text { ОСТ } 1990\end{array}$ & 1030 & 278 & 260 & 7.3 & 17.5 & .70 & 8.7 & 92 & - & 22 & 8.9 \\
\hline $\begin{array}{c}15 \ldots \\
\text { NOV } 1991\end{array}$ & 0930 & 201 & 242 & 6.8 & 19.0 & 3.7 & 7.6 & 80 & 4 & 19 & 7.8 \\
\hline $\begin{array}{c}15 \ldots \\
\text { OCT } 1992\end{array}$ & 1000 & 127 & 299 & 7.4 & 7.5 & .70 & 12.4 & 100 & 38 & 26 & 9.4 \\
\hline $\begin{array}{c}27 \ldots \\
\text { NOV } 1993\end{array}$ & 1345 & 135 & 290 & 8.4 & 10.5 & .80 & 13.9 & 98 & - & 24 & 9.2 \\
\hline $\begin{array}{c}09 \ldots \\
\text { ОСТ } 1994\end{array}$ & 0945 & 191 & 275 & 7.3 & 5.5 & - & 12.9 & - & - & - & - \\
\hline $04 \ldots$ & 1000 & 169 & 295 & 7.6 & 12.5 & - & 9.4 & - & - & - & - \\
\hline
\end{tabular}


Table 3. Water-quality data from surface-water sites-Continued

01481030 - Brandywine Creek near Chadds Ford, Pa. (Site 40)—Continued

\begin{tabular}{|c|c|c|c|c|c|c|c|c|c|c|c|}
\hline & & & & POTAS- & $\begin{array}{l}\text { ALKA- } \\
\text { LINITY }\end{array}$ & $\begin{array}{l}\text { ALKA- } \\
\text { LINITY }\end{array}$ & & CHLO- & FLUO- & SILICA, & $\begin{array}{l}\text { SOLIDS, } \\
\text { RESIDUE } \\
\text { AT } 180\end{array}$ \\
\hline & $\begin{array}{l}\text { SODIUM, } \\
\text { DIS- }\end{array}$ & & $\begin{array}{l}\text { SODIUM } \\
\text { AD- }\end{array}$ & $\begin{array}{l}\text { SIUM, } \\
\text { DIS- }\end{array}$ & $\begin{array}{l}\text { WAT WH } \\
\text { TOT FET }\end{array}$ & $\begin{array}{l}\text { WAT WH } \\
\text { TOT IT }\end{array}$ & $\begin{array}{l}\text { SULFATE, } \\
\text { DIS- }\end{array}$ & $\begin{array}{l}\text { RIDE, } \\
\text { DIS- }\end{array}$ & $\begin{array}{l}\text { RIDE, } \\
\text { DIS- }\end{array}$ & $\begin{array}{l}\text { DIS- } \\
\text { SOLVED }\end{array}$ & $\begin{array}{l}\text { AT } 180 \\
\text { DEG. C }\end{array}$ \\
\hline & SOLVED & & SORP- & SOLVED & FIELD & FIELD & SOLVED & SOLVED & SOLVED & (MG / L & DIS- \\
\hline $\mathrm{TE}$ & (MG/L & SODIUM & TION & (MG /L & (MG/L AS & (MG/L AS & (MG / L & (MG / L & (MG /L & AS & SOLVED \\
\hline & AS NA) & PERCENT & RATIO & AS K) & $\left.\mathrm{CACO}_{3}\right)$ & $\left.\mathrm{CACO}_{3}\right)$ & $\mathrm{AS} \quad \mathrm{SO}_{4}$ ) & AS CL) & AS F) & $\left.\mathrm{SIO}_{2}\right)$ & (MG /L) \\
\hline & $(00930)$ & (00932) & $(00931)$ & $(00935)$ & $(00410)$ & (00419) & $(00945)$ & $(00940)$ & $(00950)$ & (00955) & $(70300)$ \\
\hline
\end{tabular}

NOV 1981

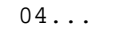

OCT 1982

$21 \ldots$

OCT 1983

$31 \ldots$

OCT 1984

$15 \ldots$

OCT 1985

$30 \ldots$

DEC 1986

$02 \ldots$

NOV 1987

$20 \ldots$

OCT 1988

$07 \ldots$

OCT 1989

$17 \ldots$

OCT 1990

$15 \ldots$

NOV 1991

$15 \ldots$

OCT 1992

$27 \ldots$

NOV 1993

$09 \ldots$

OCT 1994

$04 \ldots$

\begin{tabular}{|c|c|c|c|c|c|c|c|c|c|c|}
\hline 14 & 22 & 0.6 & 3.4 & - & - & 26 & 21 & 0.20 & 11 & 164 \\
\hline 15 & 25 & .7 & 3.0 & 62 & - & 24 & 24 & .20 & 9.8 & 161 \\
\hline 14 & 22 & .6 & 3.6 & 64 & - & 29 & 21 & - & 12 & 172 \\
\hline 11 & 21 & .5 & 2.6 & 62 & - & 22 & 18 & - & 8.8 & 143 \\
\hline 13 & 22 & .6 & 3.3 & 70 & - & 23 & 21 & - & 11 & 146 \\
\hline 11 & 20 & .5 & 3.1 & 72 & - & 25 & 23 & - & 13 & 150 \\
\hline 14 & 24 & .6 & 3.5 & 65 & - & 21 & 24 & - & 11 & 164 \\
\hline 14 & 22 & .6 & 3.3 & 78 & - & 24 & 22 & - & 10 & - \\
\hline 13 & 23 & .6 & 3.4 & 58 & - & 21 & 20 & - & 9.9 & - \\
\hline 11 & 22 & .5 & 4.5 & 76 & - & 19 & 18 & .30 & 12 & - \\
\hline 16 & 24 & .7 & 3.6 & 66 & - & 25 & 26 & .20 & 8.5 & - \\
\hline 15 & 24 & .7 & 3.7 & - & 59 & 23 & 23 & .20 & 9.3 & - \\
\hline- & - & - & - & - & 64 & 27 & 22 & .20 & - & - \\
\hline- & - & - & - & 68 & 68 & - & 26 & - & - & - \\
\hline
\end{tabular}


Table 3. Water-quality data from surface-water sites-Continued

01481030 - Brandywine Creek near Chadds Ford, Pa. (Site 40)—Continued

\begin{tabular}{|c|c|c|c|c|c|c|c|c|c|c|c|}
\hline \multirow{2}{*}{\multicolumn{2}{|c|}{$\begin{array}{l}\text { SOLIDS, } \\
\text { SUM OF } \\
\text { CONSTI- }\end{array}$}} & $\begin{array}{l}\text { DLIDS, } \\
\text { DIS- }\end{array}$ & $\begin{array}{l}\text { OLIDS, } \\
\text { DIS- }\end{array}$ & $\begin{array}{l}\text { NITRO- } \\
\text { GEN, }\end{array}$ & $\begin{array}{l}\text { NITRO- } \\
\text { GEN, } \\
\text { NITRATE }\end{array}$ & $\begin{array}{l}\text { NITRO- } \\
\text { GEN, } \\
\text { NITRATE }\end{array}$ & $\begin{array}{c}\text { NITRO- } \\
\text { GEN, } \\
\text { NITRITE }\end{array}$ & $\begin{array}{l}\text { NITRO- } \\
\text { GEN, }\end{array}$ & $\begin{array}{c}\text { NITRO- } \\
\text { GEN, } \\
\text { AMMONIA }\end{array}$ & $\begin{array}{l}\text { NITRO- } \\
\text { GEN, } \\
\text { AMMONIA }\end{array}$ & $\begin{array}{l}\text { NITRO- } \\
\text { GEN, AM- } \\
\text { MONIA + }\end{array}$ \\
\hline & & SOLVED & SOI & & & & & & & & \\
\hline \multirow{4}{*}{$\mathrm{ATE}$} & DIS- & (TONS & (TONS & то & SOL & SOL & SOI & SOLVED & SOI & SOI & \\
\hline & SOI & PER & $\mathrm{PE}$ & (MG & (MG/L & (MG /L & (MG/L & (MG/L & (MG/L & (MG /L & (MG/L \\
\hline & (MC & & DA & AS & AS $\mathrm{N}$ & AS $\quad \mathrm{NO}_{3}$ ) & AS & AS 1 & AS 1 & AS $\quad \mathrm{NH}_{4}$ ) & $\mathrm{AS}$ \\
\hline & 70301) & 0303) & (0302) & $(00620)$ & $(00618)$ & (71851 & 100613 & 100631 & (00608) & $(71846)$ & 10062 \\
\hline
\end{tabular}

\begin{tabular}{|c|c|c|c|c|c|c|c|c|c|c|c|}
\hline NOV 1981 & & & & & & & & & & & \\
\hline $\begin{array}{c}04 \ldots \\
\text { OCT } 1982\end{array}$ & - & 0.22 & - & 2.21 & 2.12 & 9.4 & 0.080 & 2.20 & 0.090 & 0.12 & 0.71 \\
\hline $21 \ldots$ & 156 & .22 & 68.2 & 2.17 & 2.17 & 9.6 & .030 & 2.20 & .010 & .01 & - \\
\hline $\begin{array}{c}\text { OCT } 1983 \\
31 \ldots\end{array}$ & 166 & .23 & 60.8 & 2.88 & 2.88 & 13 & .020 & 2.90 & .040 & .05 & - \\
\hline OCT 1984 & & $\cdot 8$ & 00.0 & 2.00 & 2.00 & & $.0<0$ & 2.00 & .070 & .00 & \\
\hline $\begin{array}{c}15 \ldots \\
\text { OCT } 1985\end{array}$ & 143 & .19 & 63.7 & 2.76 & 2.76 & 12 & .040 & 2.80 & .070 & .09 & - \\
\hline $\begin{array}{c}30 \ldots \\
\mathrm{DEC} \quad 1986\end{array}$ & 156 & .20 & 53.2 & 2.26 & 2.26 & 10 & .040 & 2.30 & .020 & .03 & .58 \\
\hline $\begin{array}{c}02 \ldots \\
\text { NOV } 1987\end{array}$ & 163 & .20 & 104 & 2.97 & 2.97 & 13 & .030 & 3.00 & .160 & .21 & .94 \\
\hline $\begin{array}{c}20 \ldots \\
\text { OCT } 1988\end{array}$ & 155 & .22 & 88.1 & 2.49 & 2.49 & 11 & .010 & 2.50 & $<.010$ & - & .50 \\
\hline $\begin{array}{c}07 \ldots \\
\text { OCT } 1989\end{array}$ & 168 & .23 & 52.7 & 3.00 & - & - & $<.010$ & 3.00 & $<.010$ & - & .40 \\
\hline $\begin{array}{c}17 \ldots \\
\text { OCT } 1990\end{array}$ & 147 & .20 & 111 & 3.08 & 3.08 & 14 & .020 & 3.10 & .020 & .03 & .58 \\
\hline $\begin{array}{c}15 \ldots \\
\text { NOV } 1991\end{array}$ & 147 & .20 & 79.8 & 1.98 & 1.98 & 8.8 & .020 & 2.00 & .050 & .06 & .55 \\
\hline $\begin{array}{c}15 \ldots \\
\text { OCT } 1992\end{array}$ & 169 & .23 & 57.9 & 3.20 & - & - & $<.010$ & 3.20 & .010 & .01 & .29 \\
\hline $\begin{array}{c}27 \ldots \\
\text { NOV } 1993\end{array}$ & 156 & .21 & 56.8 & 2.88 & 2.88 & 13 & .020 & 2.90 & $<.010$ & - & .30 \\
\hline $\begin{array}{c}09 \ldots \\
\text { OCT } 1994\end{array}$ & - & - & - & 3.19 & 3.19 & 14 & .010 & 3.20 & .010 & .01 & - \\
\hline $04 \ldots$ & - & - & - & 3.39 & 3.39 & 15 & .010 & 3.40 & $<.015$ & - & - \\
\hline
\end{tabular}


Table 3. Water-quality data from surface-water sites-Continued

01481030 - Brandywine Creek near Chadds Ford, Pa. (Site 40)—Continued

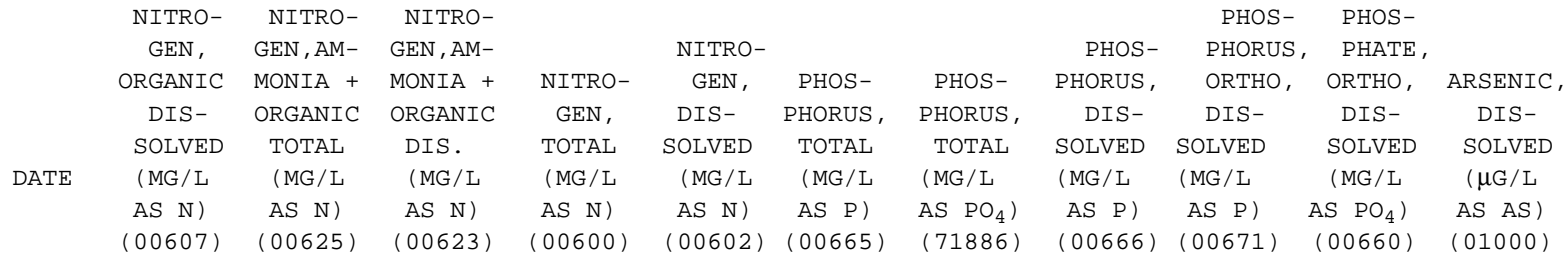

\begin{tabular}{|c|c|c|c|c|c|c|c|c|c|c|}
\hline $\begin{array}{c}04 \ldots \\
\text { ОСТ } 1982\end{array}$ & 0.58 & 0.85 & 0.67 & 3.2 & 2.9 & 0.410 & 1.3 & 0.360 & 0.330 & 1.0 \\
\hline OCT 1982 & & & & & & & & & & \\
\hline $21 \ldots$ & .39 & - & .40 & - & 2.6 & - & - & .290 & .330 & 1.0 \\
\hline $\begin{array}{c}\text { OCT } 1983 \\
31 \ldots\end{array}$ & .76 & 一 & .80 & - & 3.7 & .300 & .92 & .290 & .250 & .77 \\
\hline $\begin{array}{c}\text { OCT } 1984 \\
15 \ldots\end{array}$ & .43 & - & .50 & - & 3.3 & .250 & - & .250 & .260 & .80 \\
\hline OCT 1985 & & & & & & & & & & \\
\hline $\begin{array}{c}30 \ldots \\
\mathrm{DEC} 1986\end{array}$ & .38 & .60 & .40 & 2.9 & 2.7 & .280 & .86 & .260 & .240 & .74 \\
\hline $\begin{array}{c}02 \ldots \\
\text { NOV } 1987\end{array}$ & .34 & 1.1 & .50 & 4.1 & 3.5 & .200 & - & .160 & .130 & .40 \\
\hline $\begin{array}{c}20 \ldots \\
\text { OCT } 1988\end{array}$ & - & .50 & $<.20$ & 3.0 & - & .290 & - & .260 & .170 & .52 \\
\hline $\begin{array}{c}07 \ldots \\
\text { ОСт } 1989\end{array}$ & - & .40 & .40 & 3.4 & 3.4 & .320 & - & .310 & .260 & .80 \\
\hline $\begin{array}{c}17 \ldots \\
\text { OCT } 1990\end{array}$ & .48 & .60 & .50 & 3.7 & 3.6 & .210 & - & .170 & .170 & .52 \\
\hline $\begin{array}{c}15 \ldots \\
\text { NOV } 1991\end{array}$ & .75 & .60 & .80 & 2.6 & 2.8 & .190 & - & .140 & .150 & .46 \\
\hline $\begin{array}{c}15 \ldots \\
\text { OCT } 1992\end{array}$ & .19 & .30 & .20 & 3.5 & 3.4 & .150 & - & .130 & .120 & .37 \\
\hline $\begin{array}{c}27 \ldots \\
\text { NOV } 1993\end{array}$ & - & .30 & .20 & 3.2 & 3.1 & .110 & - & .090 & .080 & .25 \\
\hline $\begin{array}{c}09 \ldots \\
\text { OCT } 1994\end{array}$ & - & - & - & - & - & - & - & - & .110 & .34 \\
\hline $04 \ldots$ & - & - & - & - & - & - & - & - & .080 & .25 \\
\hline
\end{tabular}


Table 3. Water-quality data from surface-water sites-Continued

01481030 - Brandywine Creek near Chadds Ford, Pa. (Site 40)—Contined

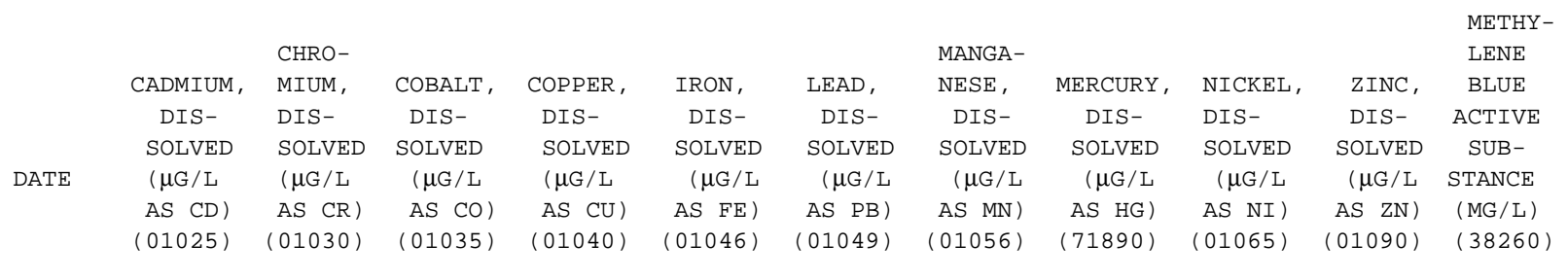

NOV 1981

$04 \ldots$

OCT 1982

$21 \ldots$

OCT 1983

$31 \ldots$

OCT 1984

$15 \ldots$

OCT 1985

$30 \ldots$

DEC 1986

$02 \ldots$

NOV 1987

$20 \ldots$

OCT 1988

$07 \ldots$

ОСт 1989

17 ...

OCT 1990

$15 \ldots$

NOV 1991

15 ...

ОСт 1992

$27 . .$.

NOV 1993

$09 . .$.

OCT 1994

\begin{tabular}{|c|c|c|c|c|c|c|c|c|c|c|}
\hline$<1.0$ & $<1$ & $<1$ & 1 & 67 & $<1$ & 56 & 0.7 & & $<4$ & - \\
\hline$<1.0$ & $<1$ & 1 & 4 & 61 & $<1$ & 37 & - & & 7 & 0.05 \\
\hline- & - & - & - & 88 & - & 47 & - & - & - & - \\
\hline- & - & - & - & 50 & - & 18 & - & - & - & - \\
\hline- & - & - & - & 46 & - & 19 & - & - & - & - \\
\hline- & - & - & - & 67 & - & 44 & - & - & - & - \\
\hline- & - & - & - & 57 & - & 40 & - & - & - & - \\
\hline- & - & - & - & 55 & - & 20 & - & - & - & - \\
\hline- & - & - & - & 69 & - & 20 & - & - & - & - \\
\hline- & - & - & - & 89 & - & 35 & - & - & - & - \\
\hline- & - & - & - & 45 & - & 18 & - & - & - & - \\
\hline- & - & - & - & 66 & - & 16 & - & - & - & - \\
\hline- & - & - & - & - & - & - & - & - & - & - \\
\hline- & - & - & - & - & - & - & - & - & - & - \\
\hline
\end{tabular}


Table 3. Water-quality data from surface-water sites-Continued

01494900 - East Branch Big Elk Creek at Elkview, Pa. (Site 31)

\begin{tabular}{|c|c|c|c|c|c|c|c|c|c|c|c|}
\hline & & DIS- & & $\mathrm{PH}$ & & & & & HARD - & & \\
\hline & & CHARGE, & SPE- & WATER & & & & HARD- & NESS & & MAGNE- \\
\hline & & INST. & CIFIC & WHOLE & & & & NESS, & NONCARB & CALCIUM, & SIUM, \\
\hline & & (CUBIC & $\mathrm{CON}-$ & FIELD & TEMP ER- & TUR- & OXYGEN, & TOTAL & WH WAT & DIS- & DIS- \\
\hline & & FEET & DUCT- & (STAND- & ATURE & BID- & DIS- & $(\mathrm{MG} / \mathrm{L}$ & TOT FLD & SOLVED & SOLVED \\
\hline $\mathrm{ATE}$ & TIME & PER & ANCE & ARD & WATER & ITY & SOLVED & AS & (MG/L AS & (MG / L & (MG / L \\
\hline & & SECOND) & $(\mu \mathrm{S} / \mathrm{CM})$ & UNITS) & $(\mathrm{DEG} C)$ & (NTU) & (MG/L) & $\left.\mathrm{CACO}_{3}\right)$ & $\left.\mathrm{CACO}_{3}\right)$ & AS CA) & AS MG) \\
\hline & & $(00061)$ & $(00095)$ & $(00400)$ & $(00010)$ & $(00076)$ & $(00300)$ & $(00900)$ & $(00902)$ & $(00915)$ & $(00925)$ \\
\hline
\end{tabular}

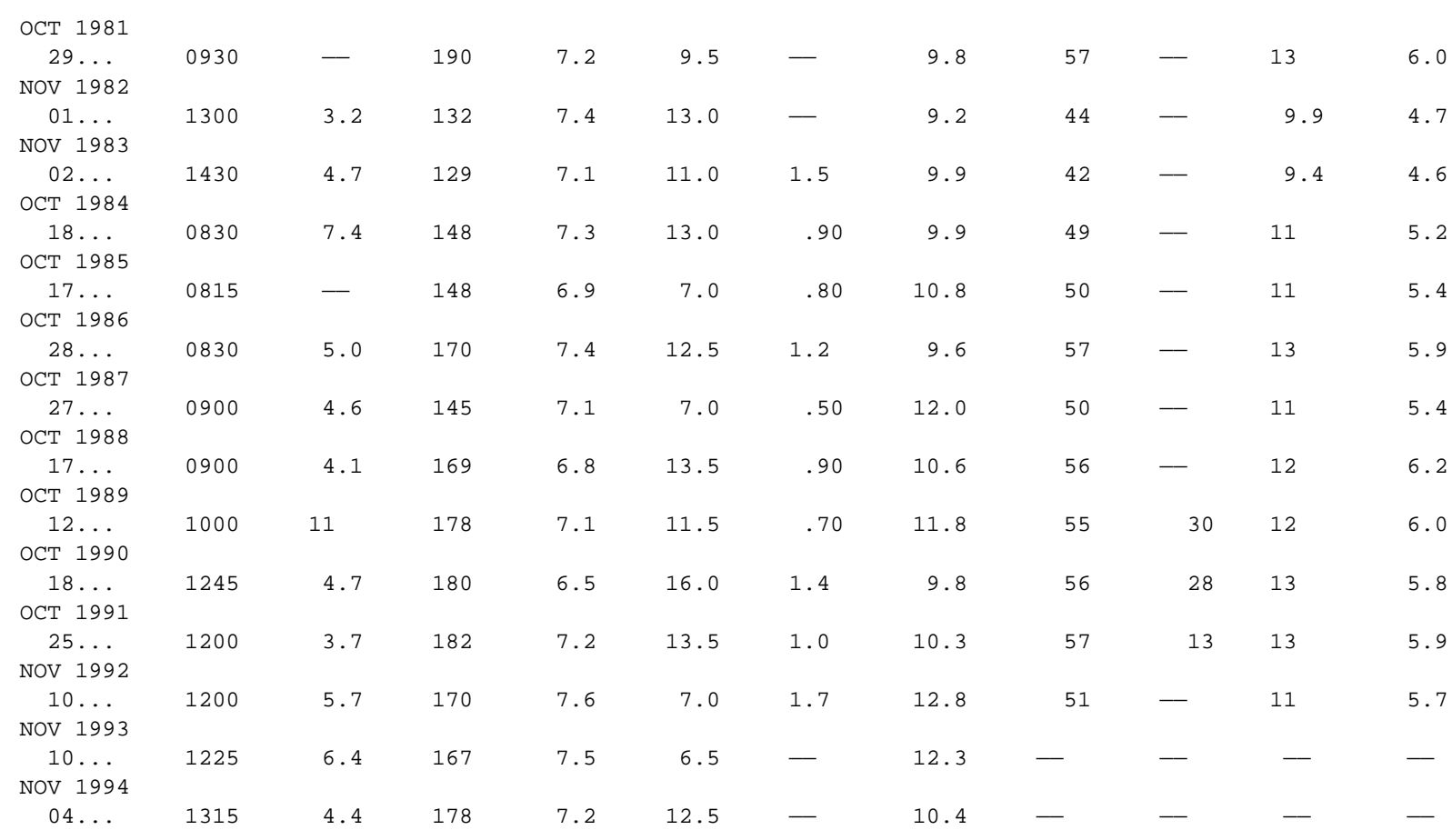


Table 3. Water-quality data from surface-water sites-Continued

01494900 - East Branch Big Elk Creek at Elkview, Pa. (Site 31)—Continued

\begin{tabular}{|c|c|c|c|c|c|c|c|c|c|c|}
\hline \multirow{2}{*}{\multicolumn{11}{|c|}{ ALKA- }} \\
\hline & & & & & & & & & & \\
\hline \multirow{6}{*}{ DATE } & \multirow{3}{*}{$\begin{array}{l}\text { SODIUM, } \\
\text { DIS- } \\
\text { SOLVED }\end{array}$} & & \multirow{3}{*}{$\begin{array}{l}\text { SODIUM } \\
\text { AD- } \\
\text { SORP- }\end{array}$} & $\begin{array}{l}\text { POTAS- } \\
\text { SIUM, }\end{array}$ & $\begin{array}{l}\text { WNITY } \\
\text { WAT WH }\end{array}$ & $\begin{array}{l}\text { LINITY } \\
\text { WAT WH }\end{array}$ & SULFATE, & $\begin{array}{l}\text { CHLO- } \\
\text { RIDE, }\end{array}$ & $\begin{array}{l}\text { RIDUO- } \\
\text { RIDE, }\end{array}$ & $\begin{array}{l}\text { SILICA, } \\
\text { DIS- }\end{array}$ \\
\hline & & & & DIS- & TOT FET & TOT IT & DIS- & DIS- & DIS- & SOLVED \\
\hline & & & & SOLVED & FIELD & FIELD & SOLVED & SOLVED & SOLVED & (MG / L \\
\hline & (MG / L & SODIUM & TION & (MG / L & (MG/L AS & (MG/L AS & (MG / L & (MG /L & (MG / L & AS \\
\hline & AS NA) & PERCENT & RATIO & AS K) & $\left.\mathrm{CACO}_{3}\right)$ & $\left.\mathrm{CACO}_{3}\right)$ & AS $\left.\mathrm{SO}_{4}\right)$ & AS CL) & AS F) & $\left.\mathrm{SIO}_{2}\right)$ \\
\hline & $(00930)$ & $(00932)$ & $(00931)$ & $(00935)$ & $(00410)$ & $(00419)$ & $(00945)$ & $(00940)$ & $(00950)$ & $(00955)$ \\
\hline
\end{tabular}

\begin{tabular}{|c|c|c|c|c|c|c|c|c|c|c|}
\hline $\begin{array}{c}\text { OCT } 1981 \\
29 \ldots \\
\text { NOV } 1982\end{array}$ & 13 & 30 & 0.7 & 7.9 & - & - & 14 & 21 & 0.10 & 14 \\
\hline $\begin{array}{c}01 \ldots \\
\text { NOV } 1983\end{array}$ & 6.7 & 23 & .4 & 3.3 & 28 & - & 8.0 & 12 & $<.10$ & 10 \\
\hline $\begin{array}{c}02 \ldots \\
\text { Ост } 1984\end{array}$ & 6.6 & 24 & .4 & 2.5 & 22 & - & 8.2 & 12 & - & 11 \\
\hline $\begin{array}{c}18 \ldots \\
\text { OCT } 1985\end{array}$ & 6.1 & 20 & .4 & 2.7 & 28 & - & 6.4 & 13 & - & 11 \\
\hline $\begin{array}{c}17 \ldots \\
\text { OCT } 1986\end{array}$ & 6.5 & 21 & .4 & 2.9 & 26 & - & 9.0 & 12 & - & 10 \\
\hline $\begin{array}{c}28 \ldots \\
\text { OCT } 1987\end{array}$ & 7.4 & 20 & .4 & 6.5 & 34 & - & 12 & 13 & - & 13 \\
\hline $\begin{array}{c}27 \ldots \\
\text { OCT } 1988\end{array}$ & 6.5 & 21 & .4 & 2.8 & 30 & - & 9.7 & 12 & - & 11 \\
\hline $\begin{array}{c}17 \ldots \\
\text { OCT } 1989\end{array}$ & 6.9 & 20 & .4 & 3.4 & 51 & - & 9.7 & 12 & - & 9.8 \\
\hline $\begin{array}{c}12 \ldots \\
\text { OCT } 1990\end{array}$ & 6.9 & 20 & .4 & 3.5 & 25 & - & 10 & 12 & - & 11 \\
\hline $\begin{array}{cc}18 \ldots \\
\text { OCT } & 1991\end{array}$ & 7.2 & 20 & .4 & 3.6 & 28 & - & 7.4 & 15 & $<.10$ & 11 \\
\hline $\begin{array}{c}25 \ldots \\
\text { NOV } 1992\end{array}$ & 7.5 & 21 & .4 & 4.3 & 44 & - & 11 & 18 & $<.10$ & 11 \\
\hline $\begin{array}{c}10 \ldots \\
\text { NOV } 1993\end{array}$ & 8.2 & 25 & .5 & 3.0 & - & 22 & 7.8 & 14 & $<.10$ & 13 \\
\hline $\begin{array}{c}10 \ldots \\
\text { NOV } 1994\end{array}$ & - & - & - & - & - & 26 & - & - & - & - \\
\hline $04 \ldots$ & - & - & - & - & - & 32 & - & 15 & - & - \\
\hline
\end{tabular}


Table 3. Water-quality data from surface-water sites-Continued

01494900 - East Branch Big Elk Creek at Elkview, Pa. (Site 31)—Continued

\begin{tabular}{|c|c|c|c|c|c|c|c|c|c|c|}
\hline DATE & $\begin{array}{c}\text { SOLIDS, } \\
\text { RESIDUE } \\
\text { AT } 180 \\
\text { DEG. C } \\
\text { DIS- } \\
\text { SOLVED } \\
(\mathrm{MG} / \mathrm{L}) \\
(70300)\end{array}$ & $\begin{array}{l}\text { SOLIDS, } \\
\text { SUM OF } \\
\text { CONSTI- } \\
\text { TUENTS, } \\
\text { DIS- } \\
\text { SOLVED } \\
(\mathrm{MG} / \mathrm{L}) \\
(70301)\end{array}$ & $\begin{array}{c}\text { SOLIDS, } \\
\text { DIS- } \\
\text { SOLVED } \\
\text { (TONS } \\
\text { PER } \\
\text { AC-FT) } \\
(70303)\end{array}$ & $\begin{array}{c}\text { SOLIDS, } \\
\text { DIS- } \\
\text { SOLVED } \\
\text { (TONS } \\
\text { PER } \\
\text { DAY) } \\
(70302)\end{array}$ & $\begin{array}{c}\text { NITRO- } \\
\text { GEN, } \\
\text { NITRATE } \\
\text { TOTAL } \\
\text { (MG/L } \\
\text { AS N) } \\
(00620)\end{array}$ & $\begin{array}{c}\text { NITRO- } \\
\text { GEN, } \\
\text { NITRATE } \\
\text { DIS- } \\
\text { SOLVED } \\
\text { (MG/L } \\
\text { AS N) } \\
(00618)\end{array}$ & $\begin{array}{c}\text { NITRO- } \\
\text { GEN, } \\
\text { NITRATE } \\
\text { DIS- } \\
\text { SOLVED } \\
(\mathrm{MG} / \mathrm{L} \\
\text { AS NO } \\
(71851)\end{array}$ & $\begin{array}{c}\text { NITRO- } \\
\text { GEN, } \\
\text { NITRITE } \\
\text { DIS- } \\
\text { SOLVED } \\
\text { (MG/L } \\
\text { AS N) } \\
(00613)\end{array}$ & $\begin{array}{c}\mathrm{NITRO}- \\
\text { GEN, } \\
\mathrm{NO}_{2}+\mathrm{NO}_{3} \\
\text { DIS- } \\
\text { SOLVED } \\
(\mathrm{MG} / \mathrm{L} \\
\mathrm{AS} \mathrm{N}) \\
(00631)\end{array}$ & $\begin{array}{c}\text { NITRO- } \\
\text { GEN, } \\
\text { AMMONIA } \\
\text { DIS- } \\
\text { SOLVED } \\
\text { (MG/L } \\
\text { AS N) } \\
(00608)\end{array}$ \\
\hline OCT 1981 & & & & & & & & & & \\
\hline $\begin{array}{c}29 \ldots \\
\text { NOV } 1982\end{array}$ & 128 & - & 0.17 & - & 3.18 & 3.07 & 14 & 0.030 & 3.10 & 0.020 \\
\hline $\begin{array}{c}01 \ldots \\
\text { NOV } 1983\end{array}$ & 85 & 90 & .12 & 0.73 & 3.97 & 3.97 & 18 & .030 & 4.00 & .060 \\
\hline $\begin{array}{c}02 \ldots \\
\text { ОСТ } 1984\end{array}$ & 92 & 88 & .13 & 1.17 & 4.36 & 4.36 & 19 & .040 & 4.40 & .210 \\
\hline $\begin{array}{c}18 \ldots \\
\text { ОСТ } 1985\end{array}$ & 92 & 97 & .13 & 1.84 & 5.35 & 5.35 & 24 & .050 & 5.40 & .120 \\
\hline $\begin{array}{c}17 \ldots \\
\text { OCT } 1986\end{array}$ & 84 & 94 & .11 & - & 4.78 & 4.78 & 21 & .020 & 4.80 & .030 \\
\hline $\begin{array}{c}28 \ldots \\
\text { OCT } 1987\end{array}$ & 115 & 113 & .16 & 1.55 & 4.68 & 4.68 & 21 & .020 & 4.70 & .020 \\
\hline $\begin{array}{c}27 \ldots \\
\text { ОСТ } 1988\end{array}$ & 90 & 99 & .12 & 1.12 & 5.09 & 5.09 & 23 & .010 & 5.10 & .030 \\
\hline $\begin{array}{c}17 \ldots \\
\text { OCT } 1989\end{array}$ & - & 119 & .16 & 1.32 & 5.98 & 5.98 & 26 & .020 & 6.00 & .030 \\
\hline $\begin{array}{c}12 \ldots \\
\text { OCT } 1990\end{array}$ & - & 107 & .15 & 3.19 & 6.26 & 6.26 & 28 & .040 & 6.30 & .210 \\
\hline $\begin{array}{c}18 \ldots \\
\text { OCT } 1991\end{array}$ & - & 109 & .15 & 1.37 & 6.18 & 6.18 & 27 & .020 & 6.20 & .010 \\
\hline $\begin{array}{c}25 \ldots \\
\text { NOV } 1992\end{array}$ & - & 125 & .17 & 1.25 & 5.98 & 5.98 & 26 & .020 & 6.00 & .020 \\
\hline $\begin{array}{c}10 \ldots \\
\text { NOV } 1993\end{array}$ & - & 101 & .14 & 1.55 & 5.47 & 5.47 & 24 & .030 & 5.50 & $<.010$ \\
\hline $\begin{array}{c}10 \ldots \\
\text { NOV } 1994\end{array}$ & - & - & - & - & 5.69 & 5.69 & 25 & .010 & 5.70 & .010 \\
\hline $04 \ldots$ & - & - & - & - & 4.88 & 4.88 & 22 & .020 & 4.90 & $<.015$ \\
\hline
\end{tabular}


Table 3. Water-quality data from surface-water sites-Continued

01494900 - East Branch Big Elk Creek at Elkview, Pa. (Site 31)—Continued

\begin{tabular}{|c|c|c|c|c|c|c|c|c|c|c|}
\hline DATE & $\begin{array}{c}\text { NITRO- } \\
\text { GEN, } \\
\text { AMMONIA } \\
\text { DIS- } \\
\text { SOLVED } \\
(\mathrm{MG} / \mathrm{L} \\
\left.\text { AS NH})_{4}\right) \\
(71846)\end{array}$ & $\begin{array}{c}\text { NITRO- } \\
\text { GEN, } \\
\text { ORGANIC } \\
\text { TOTAL } \\
\text { (MG/L } \\
\text { AS N) } \\
(00605)\end{array}$ & $\begin{array}{l}\text { NITRO- } \\
\text { GEN, } \\
\text { ORGANIC } \\
\text { DIS- } \\
\text { SOLVED } \\
\text { (MG/L } \\
\text { AS N) } \\
(00607)\end{array}$ & $\begin{array}{l}\text { NITRO- } \\
\text { GEN, AM- } \\
\text { MONIA + } \\
\text { ORGANIC } \\
\text { TOTAL } \\
\text { (MG/L } \\
\text { AS N) } \\
(00625)\end{array}$ & $\begin{array}{l}\text { NITRO- } \\
\text { GEN, AM- } \\
\text { MONIA + } \\
\text { ORGANIC } \\
\text { DIS. } \\
\text { (MG/L } \\
\text { AS N) } \\
(00623)\end{array}$ & $\begin{array}{c}\text { NITRO- } \\
\text { GEN, } \\
\text { TOTAL } \\
(\mathrm{MG} / \mathrm{L} \\
\text { AS N) } \\
(00600)\end{array}$ & $\begin{array}{l}\text { NITRO- } \\
\text { GEN, } \\
\text { DIS- } \\
\text { SOLVED } \\
\text { (MG/L } \\
\text { AS N) } \\
(00602)\end{array}$ & $\begin{array}{l}\text { PHOS- } \\
\text { PHORUS, } \\
\text { TOTAL } \\
\text { (MG/L } \\
\text { AS P) } \\
(00665)\end{array}$ & $\begin{array}{l}\text { PHOS- } \\
\text { PHORUS, } \\
\text { TOTAL } \\
(\mathrm{MG} / \mathrm{L} \\
\text { AS PO }) \\
(71886)\end{array}$ & $\begin{array}{c}\text { PHOS- } \\
\text { PHORUS, } \\
\text { DIS- } \\
\text { SOLVED } \\
\text { (MG/L } \\
\text { A.S P) } \\
(00666)\end{array}$ \\
\hline OCT 1981 & & & & & & & & & & \\
\hline $\begin{array}{c}29 \ldots \\
\text { NOV } 1982\end{array}$ & 0.03 & 0.89 & 0.79 & 0.90 & 0.81 & 4.1 & 3.9 & 0.220 & 0.67 & 0.230 \\
\hline $\begin{array}{c}01 \ldots \\
\text { NOV } 1983\end{array}$ & .08 & - & 1.1 & - & 1.2 & - & 5.2 & - & - & .180 \\
\hline $\begin{array}{c}02 \ldots \\
\text { OCT } 1984\end{array}$ & .27 & - & .89 & - & 1.1 & - & 5.5 & .130 & .40 & .120 \\
\hline $\begin{array}{c}18 \ldots \\
\text { OCT } 1985\end{array}$ & .15 & - & .28 & - & .40 & - & 5.8 & .090 & - & .090 \\
\hline $\begin{array}{c}17 \ldots \\
\text { OCT } 1986\end{array}$ & .04 & .47 & .27 & .50 & .30 & 5.3 & 5.1 & .080 & .25 & .080 \\
\hline $\begin{array}{c}28 \ldots \\
\text { ОСТ } 1987\end{array}$ & .03 & 1.5 & 1.3 & 1.5 & 1.3 & 6.2 & 6.0 & .190 & - & .180 \\
\hline $\begin{array}{c}27 \ldots \\
\text { OCT } 1988\end{array}$ & .04 & .47 & - & .50 & $<.20$ & 5.6 & - & .070 & - & .080 \\
\hline $\begin{array}{c}17 \ldots \\
\text { OCT } 1989\end{array}$ & .04 & .87 & .67 & .90 & .70 & 6.9 & 6.7 & .710 & - & .690 \\
\hline $\begin{array}{c}12 \ldots \\
\text { OCT } 1990\end{array}$ & .27 & .59 & .39 & .80 & .60 & 7.1 & 6.9 & .920 & - & .890 \\
\hline $\begin{array}{c}18 \ldots \\
\text { OCT } 1991\end{array}$ & .01 & 1.7 & .69 & 1.7 & .70 & 7.9 & 6.9 & .420 & - & .400 \\
\hline $\begin{array}{c}25 \ldots \\
\text { NOV } 1992\end{array}$ & .03 & .38 & .18 & .40 & .20 & 6.4 & 6.2 & .430 & - & .420 \\
\hline $\begin{array}{c}10 \ldots \\
\text { NOV } 1993\end{array}$ & - & .20 & - & .20 & .30 & 5.7 & 5.8 & .100 & - & .080 \\
\hline $\begin{array}{c}10 \ldots \\
\text { NOV } 1994\end{array}$ & .01 & - & - & - & - & - & - & - & - & - \\
\hline $04 \ldots$ & - & - & 一 & - & 一 & - & - & - & - & - \\
\hline
\end{tabular}


Table 3. Water-quality data from surface-water sites-Continued

01494900 - East Branch Big Elk Creek at Elkview, Pa. (Site 31)—Continued

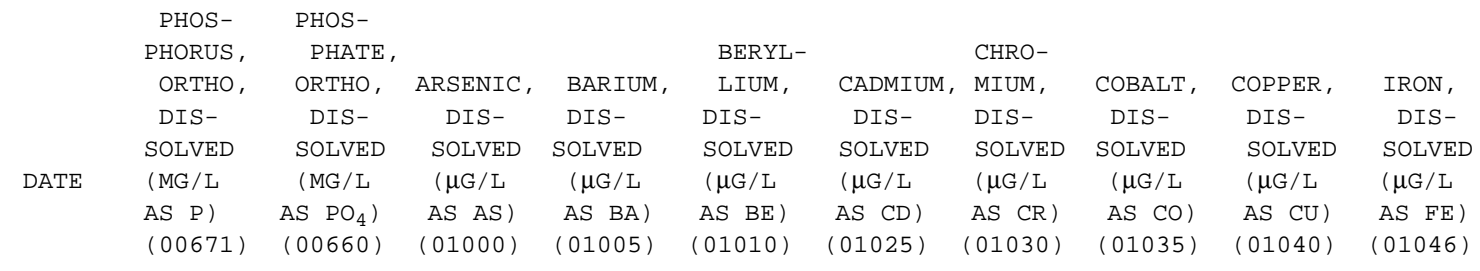

\begin{tabular}{|c|c|c|c|c|c|c|c|c|c|c|}
\hline \multicolumn{11}{|l|}{ OCT 1981} \\
\hline \multicolumn{11}{|l|}{ NOV 1982} \\
\hline $01 \ldots$ & .180 & .55 & 1 & - & - & $<1.0$ & $<1$ & $<1$ & 1 & 56 \\
\hline \multicolumn{11}{|l|}{ NOV 1983} \\
\hline $02 \ldots$ & .120 & .37 & $<1$ & - & - & $<1.0$ & $<1$ & - & 2 & 58 \\
\hline \multicolumn{11}{|l|}{ OCT 1984} \\
\hline $18 \ldots$ & .100 & .31 & $<1$ & - & - & $<1.0$ & $<1$ & - & 2 & 44 \\
\hline \multicolumn{11}{|l|}{ OCT 1985} \\
\hline $17 \ldots$ & .070 & .21 & $<1$ & - & - & $<1.0$ & $<1$ & - & $<1$ & 23 \\
\hline \multicolumn{11}{|l|}{ OCT 1986} \\
\hline $28 \ldots$ & .140 & .43 & $<1$ & - & - & 2.0 & $<1$ & - & 4 & 66 \\
\hline \multicolumn{11}{|l|}{ OCT 1987} \\
\hline $27 \ldots$ & .060 & .18 & $<1$ & - & - & $<1.0$ & $<1$ & - & 1 & 37 \\
\hline \multicolumn{11}{|l|}{ OCT 1988} \\
\hline $17 \ldots$ & .610 & 1.9 & $<1$ & 23 & $<.5$ & $<1.0$ & $<5$ & $<3$ & $<10$ & 34 \\
\hline \multicolumn{11}{|l|}{ OCT 1989} \\
\hline $12 \ldots$ & .890 & 2.7 & $<1$ & 25 & $<.5$ & $<1.0$ & $<5$ & $<3$ & $<10$ & 43 \\
\hline \multicolumn{11}{|l|}{ OCT 1990} \\
\hline $18 \ldots$ & .410 & 1.3 & $<1$ & 23 & $<.5$ & $<1.0$ & $<5$ & $<3$ & $<10$ & 27 \\
\hline \multicolumn{11}{|l|}{ OCT 1991} \\
\hline $25 \ldots$ & .370 & 1.1 & $<1$ & 24 & $<.5$ & $<1.0$ & $<5$ & $<3$ & $<10$ & 40 \\
\hline \multicolumn{11}{|l|}{ NOV 1992} \\
\hline $10 \ldots$ & .080 & .25 & $<1$ & 22 & .6 & $<1.0$ & $<5$ & $<3$ & $<10$ & 50 \\
\hline \multicolumn{11}{|l|}{ NOV 1993} \\
\hline $10 \ldots$ & .080 & .25 & - & - & - & - & - & - & - & - \\
\hline \multicolumn{11}{|l|}{ NOV 1994} \\
\hline $04 \ldots$ & .070 & .21 & - & - & - & - & - & - & - & - \\
\hline
\end{tabular}


Table 3. Water-quality data from surface-water sites-Continued

01494900 - East Branch Big Elk Creek at Elkview, Pa. (Site 31)—Continued

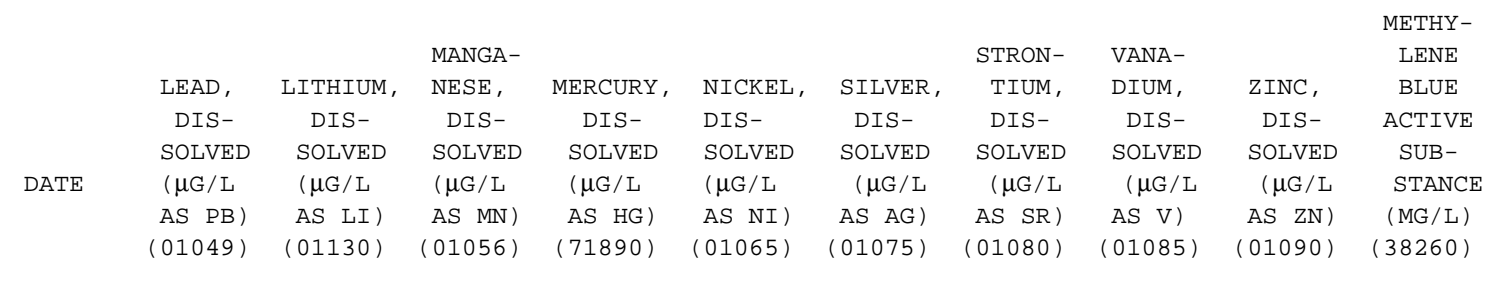

\begin{tabular}{|c|c|c|c|c|c|c|c|c|c|c|}
\hline $\begin{array}{c}\text { OCT } 1981 \\
29 \ldots \\
\text { NOV } 1982\end{array}$ & $<1$ & - & 790 & 0.1 & 3 & - & - & - & 6 & 0.10 \\
\hline $\begin{array}{l}01 \ldots \\
\text { NOV } 1983\end{array}$ & $<1$ & - & 23 & $<.1$ & $<1$ & - & - & - & $<4$ & .05 \\
\hline $\begin{array}{c}02 \ldots \\
\text { OCT } 1984\end{array}$ & $<1$ & - & 20 & .2 & $<1$ & $<1.0$ & - & - & 5 & - \\
\hline $\begin{array}{c}18 \ldots \\
\text { OCT } 1985\end{array}$ & $<1$ & - & 11 & $<.1$ & $<1$ & $<1.0$ & - & - & 6 & - \\
\hline $\begin{array}{c}17 \ldots \\
\text { OCT } 1986\end{array}$ & $<1$ & - & 9 & $<.1$ & $<1$ & $<1.0$ & - & - & 6 & - \\
\hline $\begin{array}{c}28 \ldots \\
\text { OCT } 1987\end{array}$ & $<5$ & - & 13 & $<.1$ & 3 & 1.0 & - & - & 29 & - \\
\hline $\begin{array}{c}27 \ldots \\
\text { OCT } 1988\end{array}$ & $<5$ & - & 14 & $<.1$ & 2 & $<1.0$ & - & - & 3 & - \\
\hline $\begin{array}{c}17 \ldots \\
\text { OCT } 1989\end{array}$ & $<10$ & $<$ & 13 & .2 & $<10$ & $<1.0$ & 80 & $<\epsilon$ & 27 & - \\
\hline $\begin{array}{c}12 \ldots \\
\text { OCT } 1990\end{array}$ & $<10$ & $<$ & 18 & $<.1$ & $<10$ & $<1.0$ & 82 & $<\epsilon$ & 8 & - \\
\hline $\begin{array}{c}18 \ldots \\
\text { OCT } 1991\end{array}$ & $<10$ & $<$ & 10 & .1 & $<10$ & 1.0 & 83 & $<\epsilon$ & 3 & - \\
\hline $\begin{array}{c}25 \ldots \\
\text { NOV } 1992\end{array}$ & $<10$ & & 15 & $<.1$ & $<10$ & $<1.0$ & 8 & $<\epsilon$ & 10 & - \\
\hline $\begin{array}{c}10 \ldots \\
\text { NOV } 1993\end{array}$ & $<10$ & $<$ & 25 & $<.1$ & $<10$ & $<1.0$ & 80 & $<\epsilon$ & 5 & - \\
\hline $\begin{array}{c}10 \ldots \\
\text { NOV } 1994\end{array}$ & - & - & - & - & - & - & - & - & - & - \\
\hline $04 \ldots$ & - & - & - & - & - & - & - & - & - & - \\
\hline
\end{tabular}


Table 3. Water-quality data from surface-water sites-Continued

01494950 - West Branch Big Elk Creek near Oxford, Pa. (Site 32)

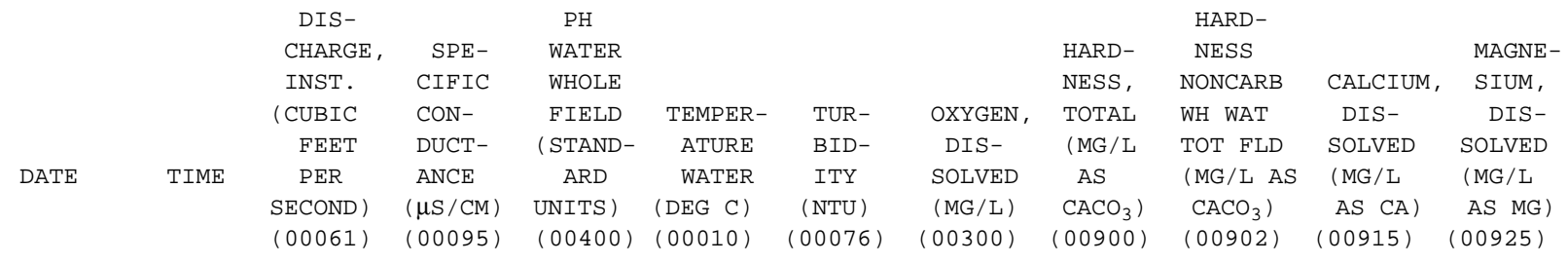

\begin{tabular}{|c|c|c|c|c|c|c|c|c|c|c|c|}
\hline $\begin{array}{c}\text { OCT } 1981 \\
29 \ldots \\
\text { NOV } 1982\end{array}$ & 1100 & - & 180 & 7.5 & 9.5 & - & 10.4 & 56 & - & 13 & 5.8 \\
\hline $\begin{array}{c}01 \ldots \\
\text { Nov } 1983\end{array}$ & 1430 & 3.4 & 146 & 7.8 & 16.5 & - & 10.4 & 46 & - & 10 & 5.2 \\
\hline $\begin{array}{c}02 \ldots \\
\text { ОСТ } 1984\end{array}$ & 1300 & 6.6 & 141 & 6.2 & 11.0 & 1.4 & 11.1 & 46 & - & 10 & 5.1 \\
\hline $\begin{array}{c}18 \ldots \\
\text { OCT } 1985\end{array}$ & 1030 & 7.0 & 155 & 7.6 & 14.0 & .80 & 11.8 & 46 & - & 10 & 5.2 \\
\hline $\begin{array}{c}17 \ldots \\
\text { OCT } 1986\end{array}$ & 1100 & 6.4 & 188 & 7.0 & 8.0 & 2.1 & 12.4 & 55 & - & 12 & 6.1 \\
\hline $\begin{array}{c}28 \ldots \\
\text { OCT } 1987\end{array}$ & 1200 & 4.9 & 200 & 7.6 & 15.5 & 2.8 & 11.1 & 56 & - & 12 & 6.3 \\
\hline $\begin{array}{c}27 \ldots \\
\text { OCT } 1988\end{array}$ & 1300 & 4.9 & 160 & 7.2 & 10.0 & .80 & 11.4 & 51 & - & 11 & 5.7 \\
\hline $\begin{array}{c}17 \ldots \\
\text { OCT } 1989\end{array}$ & 1430 & 4.7 & 201 & 7.2 & 17.0 & .80 & 12.4 & 61 & - & 13 & 6.9 \\
\hline $\begin{array}{c}12 \ldots \\
\text { OCT } 1990\end{array}$ & 1445 & 9.7 & 179 & 7.7 & 14.5 & .70 & 12.9 & 55 & 32 & 12 & 6.1 \\
\hline $\begin{array}{c}29 \ldots \\
\text { OCT } 1991\end{array}$ & 0930 & 8.9 & 191 & 7.7 & 7.5 & 2.8 & 12.1 & 60 & 18 & 13 & 6.6 \\
\hline $\begin{array}{c}25 \ldots \\
\text { NOV } 1992\end{array}$ & 0915 & 5.0 & 208 & 7.3 & 13.5 & .70 & 10.8 & 64 & 31 & 14 & 6.9 \\
\hline $\begin{array}{c}10 \ldots \\
\text { NOV } 1993\end{array}$ & 0945 & 5.7 & 210 & 7.4 & 6.5 & .60 & 13.2 & 60 & - & 13 & 6.7 \\
\hline $\begin{array}{c}10 \ldots \\
\text { NOV } 1994\end{array}$ & 1000 & 7.6 & 216 & 7.2 & 5.5 & - & 13.4 & - & - & - & - \\
\hline $04 \ldots$ & 1015 & 4.7 & 223 & 7.4 & 12.0 & - & 12.1 & - & - & - & - \\
\hline
\end{tabular}


Table 3. Water-quality data from surface-water sites-Continued

01494950 - West Branch Big Elk Creek near Oxford, Pa. (Site 32)—Continued

\begin{tabular}{|c|c|c|c|c|c|c|c|c|c|c|}
\hline \multirow{7}{*}{ DATE } & \multirow{5}{*}{$\begin{array}{l}\text { SODIUM, } \\
\text { DIS- } \\
\text { SOLVED }\end{array}$} & & \multirow{5}{*}{$\begin{array}{c}\text { SODIUM } \\
\text { AD- } \\
\text { SORP- }\end{array}$} & \multirow{6}{*}{$\begin{array}{c}\text { POTAS- } \\
\text { SIUM, } \\
\text { DIS- } \\
\text { SOLVED } \\
\text { (MG/L }\end{array}$} & \multirow{6}{*}{$\begin{array}{l}\text { ALKA- } \\
\text { LINITY } \\
\text { WAT WH } \\
\text { TOT FET } \\
\text { FIELD } \\
\text { (MG/L AS }\end{array}$} & \multirow{2}{*}{$\begin{array}{l}\text { ALKA- } \\
\text { LINITY }\end{array}$} & \multirow{4}{*}{$\begin{array}{l}\text { SULFATE， } \\
\text { DIS- }\end{array}$} & \multirow[b]{2}{*}{ CHLO- } & \multirow[b]{2}{*}{ FLUO- } & \multirow{3}{*}{$\begin{array}{l}\text { SILICA, } \\
\text { DIS- }\end{array}$} \\
\hline & & & & & & & & & & \\
\hline & & & & & & WAT WH & & RIDE, & RIDE, & \\
\hline & & & & & & TOT IT & & DIS- & DIS- & SOLVED \\
\hline & & & & & & FIELD & SOLVED & SOLVED & SOLVED & (MG / L \\
\hline & (MG/L & SODIUM & TION & & & (MG/L AS & (MG/L & (MG / L & (MG / L & AS \\
\hline & AS NA) & PERCENT & RATIO & AS K) & $\left.\mathrm{CACO}_{3}\right)$ & $\left.\mathrm{CACO}_{3}\right)$ & AS $\left.\quad \mathrm{SO}_{4}\right)$ & AS CL) & AS F) & $\mathrm{SIO}_{2}$ ) \\
\hline & $(00930)$ & $(00932)$ & $(00931)$ & $(00935)$ & $(00410)$ & $(00419)$ & $(00945)$ & $(00940)$ & $(00950)$ & $(00955)$ \\
\hline
\end{tabular}

\begin{tabular}{|c|c|c|c|c|c|c|c|c|c|c|}
\hline $\begin{array}{c}\text { OCT } 1981 \\
29 \ldots \\
\text { NOV } 1982\end{array}$ & 17 & 36 & 1 & 6.9 & - & - & 86 & 26 & $<0.10$ & 14 \\
\hline $\begin{array}{c}01 \ldots \\
\text { NOV } 1983\end{array}$ & 8.7 & 28 & .6 & 2.7 & 22 & - & 9.0 & 15 & $<.10$ & 9.1 \\
\hline $\begin{array}{c}02 \ldots \\
\text { Ост } 1984\end{array}$ & 8.3 & 27 & .5 & 2.6 & 18 & - & 9.8 & 15 & - & 10 \\
\hline $\begin{array}{c}18 \ldots \\
\text { OCT } 1985\end{array}$ & 7.4 & 25 & .5 & 2.2 & 26 & - & 7.5 & 15 & - & 9.6 \\
\hline $\begin{array}{c}17 \ldots \\
\text { OCT } 1986\end{array}$ & 9.3 & 24 & .5 & 6.3 & 30 & - & 16 & 18 & - & 9.7 \\
\hline $\begin{array}{c}28 \ldots \\
\text { OCT } 1987\end{array}$ & 9.5 & 25 & .6 & 5.8 & 29 & - & 13 & 17 & - & 12 \\
\hline $\begin{array}{c}27 \ldots \\
\text { OCT } 1988\end{array}$ & 8.9 & 26 & .5 & 2.8 & 24 & - & 11 & 16 & - & 9.0 \\
\hline $\begin{array}{c}17 \ldots \\
\text { OCT } 1989\end{array}$ & 13 & 30 & .7 & 3.2 & 34 & - & 11 & 19 & - & 9.9 \\
\hline $\begin{array}{c}12 \ldots \\
\text { OCT } 1990\end{array}$ & 9.2 & 25 & .5 & 2.7 & 23 & - & 10 & 16 & - & 9.0 \\
\hline $\begin{array}{c}29 \ldots \\
\text { OCT } 1991\end{array}$ & 9.1 & 24 & .5 & 2.8 & 42 & - & 9.1 & 19 & .20 & 13 \\
\hline $\begin{array}{c}25 \ldots \\
\text { NOV } 1992\end{array}$ & 13 & 30 & .7 & 3.3 & 33 & - & 10 & 23 & .10 & 9.6 \\
\hline $\begin{array}{c}10 \ldots \\
\text { NOV } 1993\end{array}$ & 12 & 29 & .7 & 3.6 & - & 18 & 12 & 22 & .10 & 12 \\
\hline $\begin{array}{c}10 \ldots \\
\text { NOV } 1994\end{array}$ & - & - & - & - & - & 27 & - & - & - & - \\
\hline $04 \ldots$ & - & - & - & - & - & 40 & - & 23 & - & - \\
\hline
\end{tabular}


Table 3. Water-quality data from surface-water sites-Continued

01494950 - West Branch Big Elk Creek near Oxford, Pa. (Site 32)—Continued

\begin{tabular}{|c|c|c|c|c|c|c|c|c|c|c|}
\hline & $\begin{array}{l}\text { SOLIDS, } \\
\text { RESIDUE }\end{array}$ & $\begin{array}{l}\text { SOLIDS, } \\
\text { SUM OF }\end{array}$ & SOLIDS, & SOI TRS & $x^{2}+2$ & $\begin{array}{c}\text { NITRO- } \\
\text { GEN, }\end{array}$ & $\begin{array}{c}\text { NITRO- } \\
\text { GEN, }\end{array}$ & $\begin{array}{c}\text { NITRO- } \\
\text { GEN, }\end{array}$ & $\begin{array}{c}\text { NITRO- } \\
\text { GEN, }\end{array}$ & $\begin{array}{c}\text { NITRO- } \\
\text { GEN, }\end{array}$ \\
\hline & $\begin{array}{l}\text { DEG. C } \\
\text { DIS- }\end{array}$ & $\begin{array}{c}\text { TUENTS, } \\
\text { DIS- }\end{array}$ & $\begin{array}{l}\text { SOLVED } \\
\text { (TONS }\end{array}$ & $\begin{array}{l}\text { SOLVED } \\
\text { (TONS }\end{array}$ & $\begin{array}{c}\text { NITRATE } \\
\text { TOTAL }\end{array}$ & $\begin{array}{c}\text { DIS- } \\
\text { SOLVED }\end{array}$ & $\begin{array}{c}\text { DIS- } \\
\text { SOLVED }\end{array}$ & $\begin{array}{c}\text { DIS- } \\
\text { SOLVED }\end{array}$ & $\begin{array}{c}\text { DIS- } \\
\text { SOLVED }\end{array}$ & $\begin{array}{c}\text { DIS- } \\
\text { SOLVED }\end{array}$ \\
\hline \multirow[t]{3}{*}{ DATE } & SOLVED & SOLVED & PER & PER & (MG / L & (MG / L & (MG / L & (MG / L & (MG/L & (MG / L \\
\hline & $(\mathrm{MG} / \mathrm{L})$ & $(\mathrm{MG} / \mathrm{L})$ & $\mathrm{AC}-\mathrm{FT}$ ) & DAY) & AS N) & AS N) & $\left.\mathrm{AS} \quad \mathrm{NO}_{3}\right)$ & AS N) & AS N) & AS N) \\
\hline & $(70300)$ & (70301) & $(70303)$ & $(70302)$ & $(00620)$ & $(00618)$ & (71851) & $(00613)$ & $(00631)$ & $(00608)$ \\
\hline
\end{tabular}

\begin{tabular}{|c|c|c|c|c|c|c|c|c|c|c|}
\hline $\begin{array}{c}29 \ldots \\
\text { NOV } 1982\end{array}$ & 234 & - & 0.32 & - & 3.10 & - & - & $<0.010$ & 3.10 & $<0.010$ \\
\hline $\begin{array}{c}01 \ldots \\
\text { NOV } 1983\end{array}$ & 91 & 94 & .12 & 0.84 & 4.56 & 4.56 & 20 & .040 & 4.60 & .050 \\
\hline $\begin{array}{c}02 \ldots \\
\text { OCT } 1984\end{array}$ & 104 & 94 & .14 & 1.85 & 4.88 & 4.88 & 22 & .020 & 4.90 & .030 \\
\hline $\begin{array}{c}18 \ldots \\
\text { OCT } 1985\end{array}$ & 103 & 96 & .14 & 1.95 & 5.25 & 5.25 & 23 & .050 & 5.30 & .080 \\
\hline $\begin{array}{c}17 \ldots \\
\text { OCT } 1986\end{array}$ & 106 & 118 & .14 & 1.83 & 4.98 & 4.98 & 22 & .020 & 5.00 & .050 \\
\hline $\begin{array}{c}28 \ldots \\
\text { OCT } 1987\end{array}$ & 119 & 115 & .16 & 1.57 & 4.98 & 4.98 & 22 & .020 & 5.00 & .030 \\
\hline $\begin{array}{c}27 \ldots \\
\text { OCT } 1988\end{array}$ & 102 & 104 & .14 & 1.35 & 5.48 & 5.48 & 24 & .020 & 5.50 & .020 \\
\hline $\begin{array}{c}17 \ldots \\
\text { OCT } 1989\end{array}$ & - & 120 & .16 & 1.52 & 5.09 & 5.09 & 23 & .010 & 5.10 & .020 \\
\hline $\begin{array}{c}12 \ldots \\
\text { OCT } 1990\end{array}$ & - & 103 & .14 & 2.70 & 5.38 & 5.38 & 24 & .020 & 5.40 & .010 \\
\hline $\begin{array}{c}29 \ldots \\
\text { ОСТ } 1991\end{array}$ & - & 128 & .17 & 3.09 & 6.68 & 6.68 & 30 & .020 & 6.70 & .070 \\
\hline $\begin{array}{c}25 \ldots \\
\text { NOV } 1992\end{array}$ & - & 124 & .17 & 1.66 & 5.39 & 5.39 & 24 & .010 & 5.40 & $<.010$ \\
\hline $\begin{array}{c}10 \ldots \\
\text { NOV } 1993\end{array}$ & - & 119 & .16 & 1.84 & 5.96 & 5.96 & 26 & .040 & 6.00 & $<.010$ \\
\hline $\begin{array}{c}10 \ldots \\
\text { NOV } 1994\end{array}$ & - & - & - & - & 5.99 & 5.99 & 27 & .010 & 6.00 & .020 \\
\hline $04 \ldots$ & - & - & - & - & 5.48 & 5.48 & 24 & .020 & 5.50 & .020 \\
\hline
\end{tabular}


Table 3. Water-quality data from surface-water sites-Continued

01494950 - West Branch Big Elk Creek near Oxford, Pa. (Site 32)—Continued

\begin{tabular}{|c|c|c|c|c|c|c|c|c|c|c|}
\hline DATE & $\begin{array}{c}\text { NITRO- } \\
\text { GEN, } \\
\text { AMMONIA } \\
\text { DIS- } \\
\text { SOLVED } \\
(\mathrm{MG} / \mathrm{L} \\
\left.\text { AS NH})_{4}\right) \\
(71846)\end{array}$ & $\begin{array}{l}\text { NITRO- } \\
\text { GEN, } \\
\text { ORGANIC } \\
\text { TOTAL } \\
\text { (MG/L } \\
\text { AS N) } \\
(00605)\end{array}$ & $\begin{array}{l}\text { NITRO- } \\
\text { GEN, } \\
\text { ORGANIC } \\
\text { DIS- } \\
\text { SOLVED } \\
\text { (MG/L } \\
\text { AS N) } \\
(00607)\end{array}$ & $\begin{array}{c}\text { NITRO- } \\
\text { GEN, AM- } \\
\text { MONIA + } \\
\text { ORGANIC } \\
\text { TOTAL } \\
(\text { MG/L } \\
\text { AS N) } \\
(00625)\end{array}$ & $\begin{array}{l}\text { NITRO- } \\
\text { GEN, AM- } \\
\text { MONIA + } \\
\text { ORGANIC } \\
\text { DIS. } \\
(\text { MG/L } \\
\text { AS N) } \\
(00623)\end{array}$ & $\begin{array}{c}\text { NITRO- } \\
\text { GEN, } \\
\text { TOTAL } \\
(\text { MG/L } \\
\text { AS N) } \\
(00600)\end{array}$ & $\begin{array}{c}\text { NITRO- } \\
\text { GEN, } \\
\text { DIS- } \\
\text { SOLVED } \\
\text { (MG/L } \\
\text { AS N) } \\
(00602)\end{array}$ & $\begin{array}{c}\text { PHOS- } \\
\text { PHORUS, } \\
\text { TOTAL } \\
\text { (MG/L } \\
\text { AS P) } \\
(00665)\end{array}$ & $\begin{array}{l}\text { PHOS- } \\
\text { PHORUS, } \\
\text { TOTAL } \\
(\mathrm{MG} / \mathrm{L} \\
\mathrm{AS} \mathrm{PO}) \\
(71886)\end{array}$ & $\begin{array}{c}\text { PHOS- } \\
\text { PHORUS, } \\
\text { DIS- } \\
\text { SOLVED } \\
\text { (MG/L } \\
\text { AS P) } \\
(00666)\end{array}$ \\
\hline OCT 1981 & & & & & & & & & & \\
\hline $\begin{array}{c}29 \ldots \\
\text { NOV } 1982\end{array}$ & 0.01 & 1.2 & - & 1.2 & 1.3 & 4.3 & 4.4 & 0.170 & 0.52 & 0.060 \\
\hline $\begin{array}{c}01 \ldots \\
\text { NOV } 1983\end{array}$ & .06 & - & 0.25 & - & .30 & - & 4.9 & - & - & .160 \\
\hline $\begin{array}{c}02 \ldots \\
\text { OCT } 1984\end{array}$ & .04 & - & .17 & - & .20 & - & 5.1 & .130 & .40 & .110 \\
\hline $\begin{array}{c}18 \ldots \\
\text { OCT } 1985\end{array}$ & .10 & - & .22 & - & .30 & - & 5.6 & .100 & - & .080 \\
\hline $\begin{array}{c}17 \ldots \\
\text { OCT } 1986\end{array}$ & .06 & .75 & .55 & .80 & .60 & 5.8 & 5.6 & .090 & .28 & .070 \\
\hline $\begin{array}{c}28 \ldots \\
\text { OCT } 1987\end{array}$ & .04 & .97 & .67 & 1.0 & .70 & 6.0 & 5.7 & .230 & - & .130 \\
\hline $\begin{array}{c}27 \ldots \\
\text { OCT } 1988\end{array}$ & .03 & .58 & .68 & .60 & .70 & 6.1 & 6.2 & .110 & - & .130 \\
\hline $\begin{array}{c}17 \ldots \\
\text { OCT } 1989\end{array}$ & .03 & .48 & .48 & .50 & .50 & 5.6 & 5.6 & .270 & - & .260 \\
\hline $\begin{array}{c}12 \ldots \\
\text { OCT } 1990\end{array}$ & .01 & .29 & .49 & .30 & .50 & 5.7 & 5.9 & .090 & - & .070 \\
\hline $\begin{array}{c}29 \ldots \\
\text { OCT } 1991\end{array}$ & .09 & 1.1 & .53 & 1.2 & .60 & 7.9 & 7.3 & .090 & - & .070 \\
\hline $\begin{array}{c}25 \ldots \\
\text { NOV } 1992\end{array}$ & - & .30 & - & .30 & .20 & 5.7 & 5.6 & .170 & - & .170 \\
\hline $\begin{array}{c}10 \ldots \\
\text { NOV } 1993\end{array}$ & - & .20 & - & .20 & .30 & 6.2 & 6.3 & .140 & - & .130 \\
\hline $\begin{array}{c}10 \ldots \\
\text { NOV } 1994\end{array}$ & .03 & - & - & - & - & - & - & - & - & - \\
\hline $04 \ldots$ & .03 & - & - & - & - & - & - & - & - & - \\
\hline
\end{tabular}


Table 3. Water-quality data from surface-water sites-Continued

01494950 - West Branch Big Elk Creek near Oxford, Pa. (Site 32)—Continued

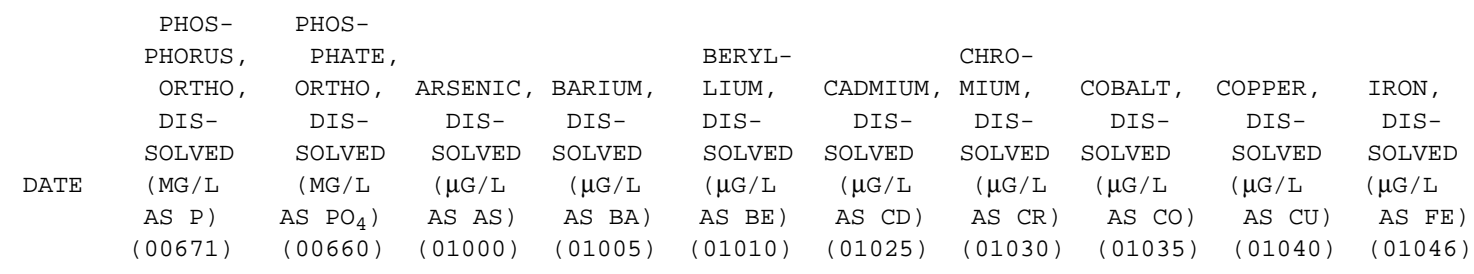

\begin{tabular}{|c|c|c|c|c|c|c|c|c|c|c|}
\hline $\begin{array}{c}29 \ldots \\
\text { NOV } 1982\end{array}$ & 0.010 & 0.03 & ND & - & - & $<1.0$ & $<1$ & 3 & 4 & 230 \\
\hline $\begin{array}{c}01 \ldots \\
\text { NOV } 1983\end{array}$ & .150 & .46 & 1 & - & - & $<1.0$ & $<1$ & $<1$ & $<1$ & 34 \\
\hline $\begin{array}{c}02 \ldots \\
\text { OCT } 1984\end{array}$ & .110 & .34 & 1 & - & - & 1.0 & $<1$ & - & 2 & 46 \\
\hline $\begin{array}{c}18 \ldots \\
\text { OCT } 1985\end{array}$ & .110 & .34 & $<1$ & - & - & $<1.0$ & 1 & - & $<1$ & 35 \\
\hline $\begin{array}{c}17 \ldots \\
\text { ОСТ } 1986\end{array}$ & .070 & .21 & $<1$ & - & - & $<1.0$ & $<1$ & - & 1 & 45 \\
\hline $\begin{array}{c}28 \ldots \\
\text { OCT } 1987\end{array}$ & .110 & .34 & $<1$ & - & - & $<1.0$ & $<1$ & - & 2 & 59 \\
\hline $\begin{array}{c}27 \ldots \\
\text { OCT } 1988\end{array}$ & .100 & .31 & $<1$ & - & - & $<1.0$ & 1 & - & $<1$ & 28 \\
\hline $\begin{array}{c}17 \ldots \\
\text { OCT } 1989\end{array}$ & .240 & .74 & $<1$ & 22 & $<.5$ & $<1.0$ & $<5$ & $<3$ & $<10$ & 27 \\
\hline $\begin{array}{c}12 \ldots \\
\text { OCT } 1990\end{array}$ & .080 & .25 & $<1$ & 21 & $<.5$ & 1.0 & $<5$ & $<3$ & $<10$ & 33 \\
\hline $\begin{array}{c}29 \ldots \\
\text { OCT } 1991\end{array}$ & .080 & .25 & $<1$ & 29 & $<.5$ & $<1.0$ & $<5$ & $<3$ & $<10$ & 37 \\
\hline $\begin{array}{c}25 \ldots \\
\text { NOV } 1992\end{array}$ & .140 & .43 & $<1$ & 32 & $<.5$ & $<1.0$ & $<5$ & $<3$ & $<10$ & 34 \\
\hline $\begin{array}{c}10 \ldots \\
\text { NOV } 1993\end{array}$ & .130 & .40 & $<1$ & 29 & $<.5$ & $<1.0$ & $<5$ & $<3$ & $<10$ & 60 \\
\hline $\begin{array}{c}10 \ldots \\
\text { NOV } 1994\end{array}$ & .110 & .34 & - & - & - & - & - & - & - & - \\
\hline $04 \ldots$ & .070 & .21 & - & - & - & - & - & - & - & - \\
\hline
\end{tabular}


Table 3. Water-quality data from surface-water sites-Continued

01494950 - West Branch Big Elk Creek near Oxford, Pa. (Site 32)—Continued

\begin{tabular}{|c|c|c|c|c|c|c|c|c|c|c|}
\hline DATE & $\begin{array}{c}\text { LEAD, } \\
\text { DIS- } \\
\text { SOLVED } \\
(\mu \mathrm{G} / \mathrm{L} \\
\text { AS PB) } \\
(01049)\end{array}$ & $\begin{array}{c}\text { LITHIUM, } \\
\text { DIS- } \\
\text { SOLVED } \\
(\mu \mathrm{G} / \mathrm{L} \\
\text { AS LI) } \\
(01130)\end{array}$ & $\begin{array}{l}\text { MANGA- } \\
\text { NESE, } \\
\text { DIS- } \\
\text { SOLVED } \\
(\mu \mathrm{G} / \mathrm{L} \\
\text { AS MN) } \\
(01056)\end{array}$ & $\begin{array}{c}\text { MERCURY, } \\
\text { DIS- } \\
\text { SOLVED } \\
(\mu \mathrm{G} / \mathrm{L} \\
\text { AS HG) } \\
(71890)\end{array}$ & $\begin{array}{c}\text { NICKEL, } \\
\text { DIS- } \\
\text { SOLVED } \\
(\mu \mathrm{G} / \mathrm{L} \\
\text { AS NI) } \\
(01065)\end{array}$ & $\begin{array}{c}\text { SILVER, } \\
\text { DIS- } \\
\text { SOLVED } \\
(\mu \mathrm{G} / \mathrm{L} \\
\text { AS AG) } \\
(01075)\end{array}$ & $\begin{array}{c}\text { STRON- } \\
\text { TIUM, } \\
\text { DIS- } \\
\text { SOLVED } \\
(\mu \mathrm{G} / \mathrm{L} \\
\text { AS SR) } \\
(01080)\end{array}$ & $\begin{array}{c}\text { VANA- } \\
\text { DIUM, } \\
\text { DIS- } \\
\text { SOLVED } \\
(\mu \mathrm{G} / \mathrm{L} \\
\text { AS V) } \\
(01085)\end{array}$ & $\begin{array}{c}\text { ZINC, } \\
\text { DIS- } \\
\text { SOLVED } \\
(\mu \mathrm{G} / \mathrm{L} \\
\text { AS } \quad \mathrm{ZN}) \\
(01090)\end{array}$ & $\begin{array}{l}\text { METHY- } \\
\text { LENE } \\
\text { BLUE } \\
\text { ACTIVE } \\
\text { SUB- } \\
\text { STANCE } \\
(\text { MG/L) } \\
(38260)\end{array}$ \\
\hline ОСт 1981 & & & & & & & & & & \\
\hline $\begin{array}{c}29 \ldots \\
\text { NOV } 1982\end{array}$ & 13 & - & 39,000 & 48 & 4 & - & - & - & 8 & 0.10 \\
\hline $\begin{array}{c}01 \ldots \\
\text { NOV } 1983\end{array}$ & $<1$ & - & 22 & $<.1$ & $<1$ & - & - & - & $<4$ & .03 \\
\hline $\begin{array}{c}02 \ldots \\
\text { OCT } 1984\end{array}$ & $<1$ & - & 17 & .7 & $<1$ & $<1.0$ & - & - & 8 & - \\
\hline $\begin{array}{c}18 \ldots \\
\text { OCT } 1985\end{array}$ & 1 & - & 17 & $<.1$ & 1 & $<1.0$ & - & - & $<3$ & - \\
\hline $\begin{array}{c}17 \ldots \\
\text { OCT } 1986\end{array}$ & 1 & - & 18 & $<.1$ & $<1$ & $<1.0$ & - & - & 6 & - \\
\hline $\begin{array}{c}28 \ldots \\
\text { OCT } 1987\end{array}$ & $<5$ & - & 32 & .3 & 3 & $<1.0$ & - & - & 20 & - \\
\hline $\begin{array}{c}27 \ldots \\
\text { ОСт } 1988\end{array}$ & $<5$ & - & 13 & $<.1$ & $<1$ & $<1.0$ & - & - & 4 & - \\
\hline $\begin{array}{c}17 \ldots \\
\text { OCT } 1989\end{array}$ & $<10$ & $<4$ & 14 & .1 & $<10$ & $<1.0$ & 98 & $<6$ & 6 & - \\
\hline $\begin{array}{c}12 \ldots \\
\text { OCT } 1990\end{array}$ & $<10$ & $<4$ & 12 & .2 & $<10$ & $<1.0$ & 89 & $<6$ & 6 & - \\
\hline $\begin{array}{c}29 \ldots \\
\text { OCT } 1991\end{array}$ & $<10$ & $<4$ & 32 & $<.1$ & $<10$ & $<1.0$ & 100 & $<6$ & $<3$ & - \\
\hline $\begin{array}{c}25 \ldots \\
\text { NOV } 1992\end{array}$ & $<10$ & 5 & 15 & $<.1$ & $<10$ & $<1.0$ & 110 & $<6$ & 6 & - \\
\hline $\begin{array}{c}10 \ldots \\
\text { NOV } 1993\end{array}$ & $<10$ & $<4$ & 22 & $<.1$ & $<10$ & $<1.0$ & 110 & $<6$ & 5 & - \\
\hline $\begin{array}{c}10 \ldots \\
\text { NOV } 1994\end{array}$ & - & - & - & - & - & - & - & - & - & - \\
\hline $04 \ldots$ & - & - & - & - & - & - & - & - & - & - \\
\hline
\end{tabular}


Table 3. Water-quality data from surface-water sites-Continued

01578340 - East Branch Octoraro Creek at Christiana, Pa. (Site 33)

\begin{tabular}{|c|c|c|c|c|c|c|c|c|c|c|c|}
\hline & & DIS- & & $\mathrm{PH}$ & & & & & HARD- & & \\
\hline & & CHARGE， & SPE- & WATER & & & & HARD- & NESS & & MAGNE- \\
\hline & & INST. & CIFIC & WHOLE & & & & NESS, & NONCARB & CALCIUM, & SIUM, \\
\hline & & (CUBIC & $\mathrm{CON}-$ & FIELD & TEMPER- & TUR- & OXYGEN， & TOTAL & WH WAT & DIS- & DIS- \\
\hline & & FEET & DUCT- & (STAND- & ATURE & BID- & DIS- & (MG /L & TOT FLD & SOLVED & SOLVED \\
\hline DATE & TIME & PER & ANCE & ARD & WATER & ITY & SOLVED & AS & (MG/L AS & (MG /L & (MG / L \\
\hline & & SECOND) & $(\mu \mathrm{S} / \mathrm{CM})$ & UNITS) & (DEG C) & (NTU) & $(\mathrm{MG} / \mathrm{L})$ & $\left.\mathrm{CACO}_{3}\right)$ & $\left.\mathrm{CACO}_{3}\right)$ & AS CA) & AS MG) \\
\hline & & $(00061)$ & $(00095)$ & $(00400)$ & $(00010)$ & $(00076)$ & $(00300)$ & $(00900)$ & $(00902)$ & $(00915)$ & $(00925)$ \\
\hline
\end{tabular}

\begin{tabular}{|c|c|c|c|c|c|c|c|c|c|c|c|}
\hline $\begin{array}{c}\text { NOV } 1981 \\
03 \ldots\end{array}$ & 0915 & - & 246 & 6.8 & 9.0 & - & 10.3 & 97 & - & 23 & 9.5 \\
\hline OCT 1982 & & & & & & & & & & & \\
\hline $27 \ldots$ & 0900 & 4.0 & 277 & 6.5 & 6.5 & - & 11.3 & 100 & 52 & 25 & 10 \\
\hline OCT 1983 & & & & & & & & & & & \\
\hline $\begin{array}{c}28 \ldots \\
\text { OCT } 1984\end{array}$ & 0830 & 6.9 & 210 & 7.0 & 7.0 & 4.8 & 10.0 & 100 & - & 24 & 10 \\
\hline $\begin{array}{c}26 \ldots \\
\text { OCT } 1985\end{array}$ & 1100 & 7.5 & 275 & 7.9 & 14.0 & 3.4 & 8.8 & 100 & - & 24 & 10 \\
\hline $\begin{array}{l}24 \ldots \\
\text { NOV } 1986\end{array}$ & 0900 & 5.3 & 265 & 7.1 & 9.5 & 2.0 & 8.4 & 100 & - & 24 & 10 \\
\hline $\begin{array}{c}20 \ldots \\
\text { NOV } 1987\end{array}$ & 0900 & 4.7 & 260 & 7.5 & 3.0 & 2.8 & 10.8 & 110 & - & 25 & 11 \\
\hline $\begin{array}{c}18 \ldots \\
\text { NOV } 1988\end{array}$ & 0900 & 11 & 265 & 7.1 & 13.5 & 3.7 & 10.6 & 100 & - & 24 & 10 \\
\hline $\begin{array}{c}07 \ldots \\
\text { ОСТ } 1989\end{array}$ & 0845 & 7.1 & 295 & 7.4 & 9.5 & 6.0 & 10.8 & 120 & - & 28 & 11 \\
\hline $\begin{array}{c}27 \ldots \\
\text { OCT } 1990\end{array}$ & 0915 & 9.1 & 290 & 7.2 & 11.0 & 3.1 & 11.0 & 110 & 66 & 26 & 11 \\
\hline $\begin{array}{c}18 \ldots \\
\text { OCT } 1991\end{array}$ & 0900 & 5.4 & 299 & 6.2 & 16.0 & 4.0 & 8.2 & 110 & 48 & 27 & 11 \\
\hline $\begin{array}{c}24 \ldots \\
\text { NOV } 1992\end{array}$ & 0900 & 4.8 & 299 & 7.3 & 13.0 & .70 & 8.0 & 110 & 70 & 26 & 11 \\
\hline $09 \ldots$ & 0915 & 5.3 & 230 & 7.5 & 3.5 & 2.1 & 13.1 & 110 & - & 26 & 11 \\
\hline OCT 1993 & & & & & & & & & & & \\
\hline $19 \ldots$ & 0930 & 7.9 & 308 & 7.2 & 12.0 & - & 9.8 & - & - & - & - \\
\hline $21 \ldots$ & 0900 & 6.0 & 312 & 7.2 & 8.5 & - & 11.4 & - & - & - & - \\
\hline
\end{tabular}


Table 3. Water-quality data from surface-water sites-Continued

01578340 - East Branch Octoraro Creek at Christiana, Pa. (Site 33)—Continued

\begin{tabular}{|c|c|c|c|c|c|c|c|c|c|c|}
\hline \multirow{6}{*}{ DATE } & \multirow{3}{*}{$\begin{array}{l}\text { SODIUM, } \\
\text { DIS- } \\
\text { SOLVED }\end{array}$} & & \multirow[b]{2}{*}{ SODIUM } & \multirow{2}{*}{$\begin{array}{r}\text { POTAS- } \\
\text { SIUM, }\end{array}$} & $\begin{array}{l}\text { ALKA- } \\
\text { LINITY }\end{array}$ & $\begin{array}{l}\text { ALKA- } \\
\text { LINITY }\end{array}$ & \multirow[b]{2}{*}{ SULFATE, } & CHLO- & \multirow[t]{2}{*}{$\begin{array}{l}\text { FLUO- } \\
\text { RIDE, }\end{array}$} & \multirow[t]{2}{*}{$\begin{array}{l}\text { SILICA, } \\
\text { DIS- }\end{array}$} \\
\hline & & & & & $\begin{array}{l}\text { WAT WH } \\
\text { TOT FET }\end{array}$ & $\begin{array}{l}\text { WAT WH } \\
\text { TOT IT }\end{array}$ & & $\begin{array}{l}\text { RIDE, } \\
\text { DIS- }\end{array}$ & & \\
\hline & & & SORP- & SOLVED & FIELD & FIELD & SOLVED & SOLVED & SOLVED & (MG/L \\
\hline & (MG/L & SODIUM & TION & (MG /L & (MG/L AS & (MG/L AS & (MG /L & (MG / L & (MG/L & AS \\
\hline & AS NA) & PERCENT & RATIO & AS K) & $\mathrm{CACO}_{3}$ ) & $\left.\mathrm{CACO}_{3}\right)$ & AS $\mathrm{SO}_{4}$ ) & AS CL) & AS F) & $\left.\mathrm{SIO}_{2}\right)$ \\
\hline & $(00930)$ & $(00932)$ & $(00931)$ & $(00935)$ & $(00410)$ & $(00419)$ & $(00945)$ & $(00940)$ & $(00950)$ & $(00955)$ \\
\hline
\end{tabular}

\begin{tabular}{|c|c|c|c|c|c|c|c|c|c|c|}
\hline $\begin{array}{c}\text { NOV } 1981 \\
03 \ldots \\
\text { OCT } 1982\end{array}$ & 8.3 & 15 & 0.4 & 4.6 & - & - & 22 & 15 & $<0.10$ & 16 \\
\hline $\begin{array}{c}27 \ldots \\
\text { OCT } 1983\end{array}$ & 8.8 & 14 & .4 & 9.6 & 52 & - & 30 & 19 & $<.10$ & 14 \\
\hline $\begin{array}{c}28 \ldots \\
\text { OCT } 1984\end{array}$ & 8.4 & 15 & .4 & 4.5 & 40 & - & 33 & 18 & - & 16 \\
\hline $\begin{array}{c}26 \ldots \\
\text { OCT } 1985\end{array}$ & 9.5 & 16 & .4 & 4.7 & 52 & - & 30 & 16 & - & 14 \\
\hline $\begin{array}{c}24 \ldots \\
\text { NOV } 1986\end{array}$ & 8.3 & 15 & .4 & 4.0 & 54 & - & 28 & 16 & - & 11 \\
\hline $\begin{array}{c}20 \ldots \\
\text { NOV } 1987\end{array}$ & 8.1 & 13 & .3 & 6.6 & 50 & - & 36 & 17 & - & 15 \\
\hline $\begin{array}{c}18 \ldots \\
\text { NOV } 1988\end{array}$ & 8.4 & 15 & .4 & 4.5 & 42 & - & 29 & 19 & - & 12 \\
\hline $\begin{array}{c}07 \ldots \\
\text { OCT } 1989\end{array}$ & 8.7 & 13 & .4 & 6.9 & 62 & - & 37 & 17 & - & 16 \\
\hline $\begin{array}{c}27 \ldots \\
\text { OCT } 1990\end{array}$ & 7.5 & 12 & .3 & 4.2 & 44 & - & 30 & 17 & - & 16 \\
\hline $\begin{array}{c}18 \ldots \\
\text { OCT } 1991\end{array}$ & 8.6 & 14 & .4 & 4.4 & 65 & - & 25 & 19 & .10 & 16 \\
\hline $\begin{array}{c}24 \ldots \\
\text { NOV } 1992\end{array}$ & 11 & 17 & .5 & 2.6 & 40 & - & 21 & 28 & .10 & 15 \\
\hline $\begin{array}{c}09 \ldots \\
\text { OCT } 1993\end{array}$ & 9.7 & 15 & .4 & 4.4 & - & 56 & 31 & 19 & $<.10$ & 17 \\
\hline $\begin{array}{c}19 \ldots \\
\text { NOV } 1994\end{array}$ & - & - & - & - & - & 46 & - & - & - & - \\
\hline $21 \ldots$ & - & - & - & - & - & 44 & - & 20 & - & - \\
\hline
\end{tabular}


Table 3. Water-quality data from surface-water sites-Continued

01578340 - East Branch Octoraro Creek at Christiana, Pa. (Site 33)-Continued

\begin{tabular}{|c|c|c|c|c|c|c|c|c|c|c|}
\hline DATE & $\begin{array}{c}\text { SOLIDS, } \\
\text { RESIDUE } \\
\text { AT } 180 \\
\text { DEG. C } \\
\text { DIS- } \\
\text { SOLVED } \\
(\mathrm{MG} / \mathrm{L}) \\
(70300)\end{array}$ & $\begin{array}{l}\text { SOLIDS, } \\
\text { SUM OF } \\
\text { CONSTI- } \\
\text { TUENTS, } \\
\text { DIS- } \\
\text { SOLVED } \\
(\text { MG/L) } \\
(70301)\end{array}$ & $\begin{array}{c}\text { SOLIDS, } \\
\text { DIS- } \\
\text { SOLVED } \\
\text { (TONS } \\
\text { PER } \\
\text { AC-FT) } \\
(70303)\end{array}$ & $\begin{array}{c}\text { SOLIDS, } \\
\text { DIS- } \\
\text { SOLVED } \\
\text { (TONS } \\
\text { PER } \\
\text { DAY) } \\
(70302)\end{array}$ & $\begin{array}{c}\text { NITRO- } \\
\text { GEN, } \\
\text { NITRATE } \\
\text { TOTAL } \\
\text { (MG/L } \\
\text { AS N) } \\
(00620)\end{array}$ & $\begin{array}{l}\text { NITRO- } \\
\text { GEN, } \\
\text { NITRATE } \\
\text { DIS- } \\
\text { SOLVED } \\
\text { (MG/L } \\
\text { AS N) } \\
(00618)\end{array}$ & $\begin{array}{c}\text { NITRO- } \\
\text { GEN, } \\
\text { NITRATE } \\
\text { DIS- } \\
\text { SOLVED } \\
(\mathrm{MG} / \mathrm{L} \\
\left.\mathrm{AS} \mathrm{NO} \mathrm{N}_{3}\right) \\
(71851)\end{array}$ & $\begin{array}{l}\text { NITRO- } \\
\text { GEN, } \\
\text { NITRITE } \\
\text { DIS- } \\
\text { SOLVED } \\
\text { (MG/L } \\
\text { AS N) } \\
(00613)\end{array}$ & $\begin{array}{c}\mathrm{NITRO}- \\
\text { GEN, } \\
\mathrm{NO}_{2}+\mathrm{NO}_{3} \\
\text { DIS- } \\
\text { SOLVED } \\
(\mathrm{MG} / \mathrm{L} \\
\mathrm{AS} \mathrm{N}) \\
(00631)\end{array}$ & $\begin{array}{c}\text { NITRO- } \\
\text { GEN, } \\
\text { AMMONIA } \\
\text { DIS- } \\
\text { SOLVED } \\
\text { (MG/L } \\
\text { AS N) } \\
(00608)\end{array}$ \\
\hline $\begin{array}{l}\text { OV } 1981 \\
03 \ldots\end{array}$ & 149 & - & 0.20 & - & 5.05 & 5.04 & 22 & 0.060 & 5.10 & 0.020 \\
\hline OCT 1982 & & & & & & & & & & \\
\hline $\begin{array}{c}27 \ldots \\
\text { OCT } 1983\end{array}$ & 177 & 170 & .24 & 1.91 & 4.85 & 4.85 & 21 & .050 & 4.90 & .070 \\
\hline $\begin{array}{c}28 \ldots \\
\text { OCT } 1984\end{array}$ & 180 & 168 & .24 & 3.35 & 6.67 & 6.67 & 30 & .030 & 6.70 & $<.010$ \\
\hline $\begin{array}{c}26 \ldots \\
\text { OCT } 1985\end{array}$ & 172 & 167 & .23 & 3.48 & 6.03 & 6.03 & 27 & .070 & 6.10 & .250 \\
\hline $\begin{array}{c}24 \ldots \\
\text { NOV } 1986\end{array}$ & 148 & 165 & .20 & 2.12 & 6.97 & 6.97 & 31 & .030 & 7.00 & .050 \\
\hline $\begin{array}{c}20 \ldots \\
\text { NOV } 1987\end{array}$ & 183 & 177 & .25 & 2.32 & 6.17 & 6.17 & 27 & .030 & 6.20 & .160 \\
\hline $\begin{array}{c}18 \ldots \\
\text { NOV } 1988\end{array}$ & 188 & 163 & .26 & 5.58 & 6.98 & 6.98 & 31 & .020 & 7.00 & $<.010$ \\
\hline $\begin{array}{c}07 \ldots \\
\text { OCT } 1989\end{array}$ & - & 193 & .26 & 3.71 & 6.96 & 6.96 & 31 & .040 & 7.00 & .050 \\
\hline $\begin{array}{c}27 \ldots \\
\text { OCT } 1990\end{array}$ & - & 179 & .24 & 4.39 & 9.07 & 9.07 & 40 & .030 & 9.10 & .020 \\
\hline $\begin{array}{c}18 \ldots \\
\text { OCT } 1991\end{array}$ & - & 186 & .25 & 2.72 & 8.06 & 8.06 & 36 & .040 & 8.10 & .030 \\
\hline $\begin{array}{c}24 \ldots \\
\text { NOV } 1992\end{array}$ & - & 177 & .24 & 2.30 & 8.64 & 8.64 & 38 & .060 & 8.70 & .040 \\
\hline $\begin{array}{c}09 \ldots \\
\text { OCT } 1993\end{array}$ & - & 192 & .26 & 2.74 & 8.85 & 8.85 & 39 & .050 & 8.90 & .040 \\
\hline $\begin{array}{c}19 \ldots \\
\text { NOV } 1994\end{array}$ & - & - & - & - & 9.78 & 9.78 & 43 & .020 & 9.80 & .030 \\
\hline $21 \ldots$ & - & - & - & - & 9.37 & 9.37 & 41 & .030 & 9.40 & $<.015$ \\
\hline
\end{tabular}


Table 3. Water-quality data from surface-water sites-Continued

01578340 - East Branch Octoraro Creek at Christiana, Pa. (Site 33)—Continued

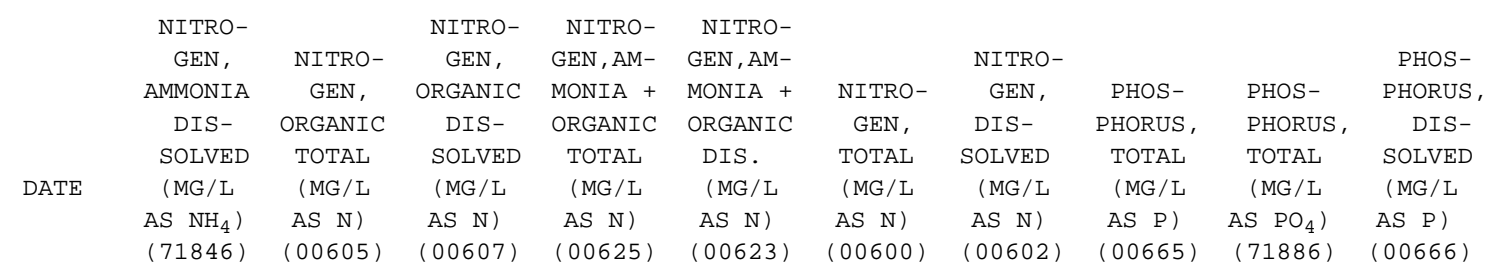

NOV 1981

$03 \ldots$

OCT 1982

0.70

0.68

5.8

5.8

0.100

0.31

0.050

$.09 \quad-$

.63

$.70-$

5.6

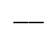

-

OCT 1983

$28 \ldots$

OCT 1984

$26 \ldots$

OCT 1985

$24 \ldots$

NOV 1986

$20 \ldots$

NOV 1987

$18 \ldots$

NOV 1988

$07 \ldots$

ОСт 1989

27 ...

ОСт 1990

18 ...

ОСт 1991

24 ...

NOV 1992

$09 . .$.

OCT 1993

$19 \ldots$

NOV 1994

$21 \ldots$ 
Table 3. Water-quality data from surface-water sites-Continued

01578340 - East Branch Octoraro Creek at Christiana, Pa. (Site 33)—Continued

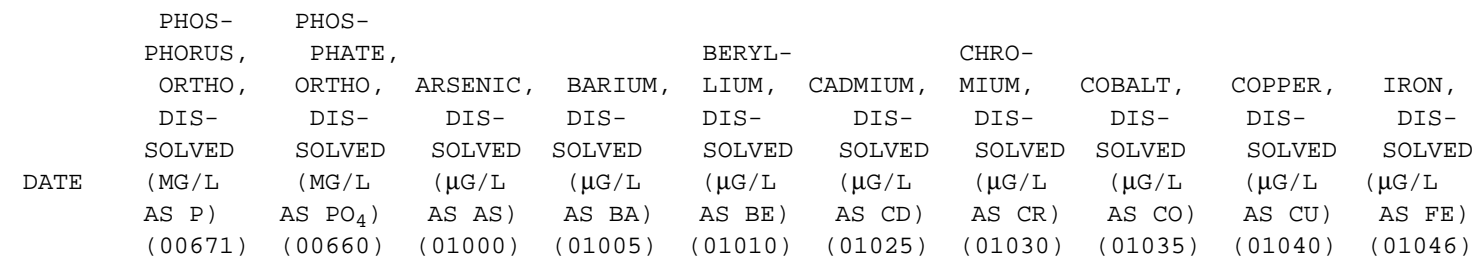

\begin{tabular}{|c|c|c|c|c|c|c|c|c|c|c|}
\hline $\begin{array}{c}\text { NOV } 1981 \\
03 \ldots \\
\text { OCT } 1982\end{array}$ & 0.040 & 0.12 & ND & - & - & $<1.0$ & $<1$ & $<1$ & $<1$ & 7 \\
\hline $\begin{array}{c}27 \ldots \\
\text { OCT } 1983\end{array}$ & .050 & .15 & $<1$ & - & - & $<1.0$ & $<1$ & 1 & 1 & 72 \\
\hline $\begin{array}{c}28 \ldots \\
\text { OCT } 1984\end{array}$ & .050 & .15 & - & - & - & - & - & - & - & 78 \\
\hline $\begin{array}{c}26 \ldots \\
\text { OCT } 1985\end{array}$ & .160 & .49 & $<1$ & - & - & $<1.0$ & $<1$ & - & 3 & 5 \\
\hline $\begin{array}{c}24 \ldots \\
\text { NOV } 1986\end{array}$ & .020 & .06 & $<1$ & - & - & $<1.0$ & $<1$ & - & $<1$ & 2 \\
\hline $\begin{array}{c}20 \ldots \\
\text { NOV } 1987\end{array}$ & .090 & .28 & $<1$ & - & - & $<1.0$ & $<1$ & - & 2 & 5 \\
\hline $\begin{array}{c}18 \ldots \\
\text { NOV } 1988\end{array}$ & .020 & .06 & $<1$ & - & - & $<1.0$ & 1 & - & 2 & 3 \\
\hline $\begin{array}{c}07 \ldots \\
\text { OCT } 1989\end{array}$ & .080 & .25 & $<1$ & 64 & $<0.5$ & $<1.0$ & $<5$ & $<3$ & $<10$ & 7 \\
\hline $\begin{array}{c}27 \ldots \\
\text { OCT } 1990\end{array}$ & .030 & .09 & $<1$ & 65 & $<.5$ & $<1.0$ & $<5$ & $<3$ & $<10$ & 4 \\
\hline $\begin{array}{c}18 \ldots \\
\text { OCT } 1991\end{array}$ & .040 & .12 & $<1$ & 67 & $<.5$ & $<1.0$ & $<5$ & $<3$ & $<10$ & 4 \\
\hline $\begin{array}{c}24 \ldots \\
\text { NOV } 1992\end{array}$ & .060 & .18 & - & - & - & - & - & - & - & 4 \\
\hline $\begin{array}{c}09 \ldots \\
\text { OCT } 1993\end{array}$ & .030 & .09 & $<1$ & 65 & $<.5$ & $<1.0$ & $<5$ & $<3$ & $<10$ & 6 \\
\hline $\begin{array}{c}19 \ldots \\
\text { NOV } 1994\end{array}$ & .030 & .09 & - & - & - & - & - & - & - & - \\
\hline $21 \ldots$ & $<.010$ & - & - & - & - & - & - & - & - & - \\
\hline
\end{tabular}


Table 3. Water-quality data from surface-water sites-Continued

01578340 - East Branch Octoraro Creek at Christiana, Pa. (Site 33)—Continued

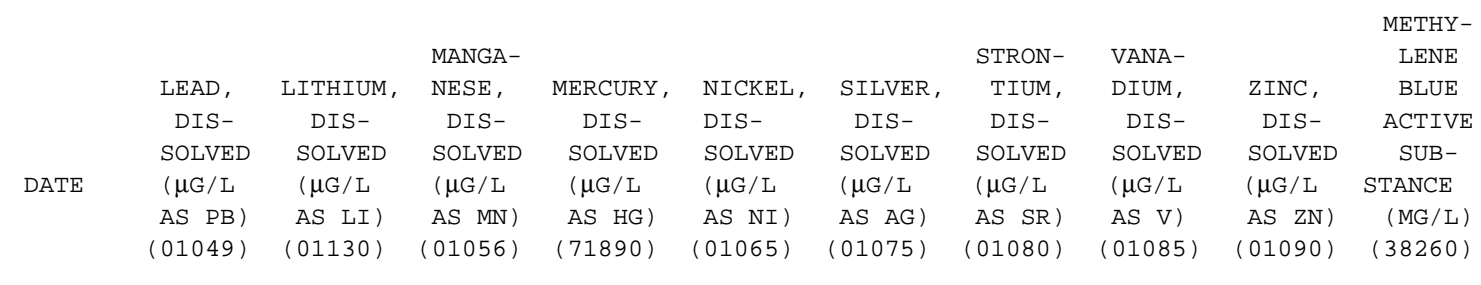

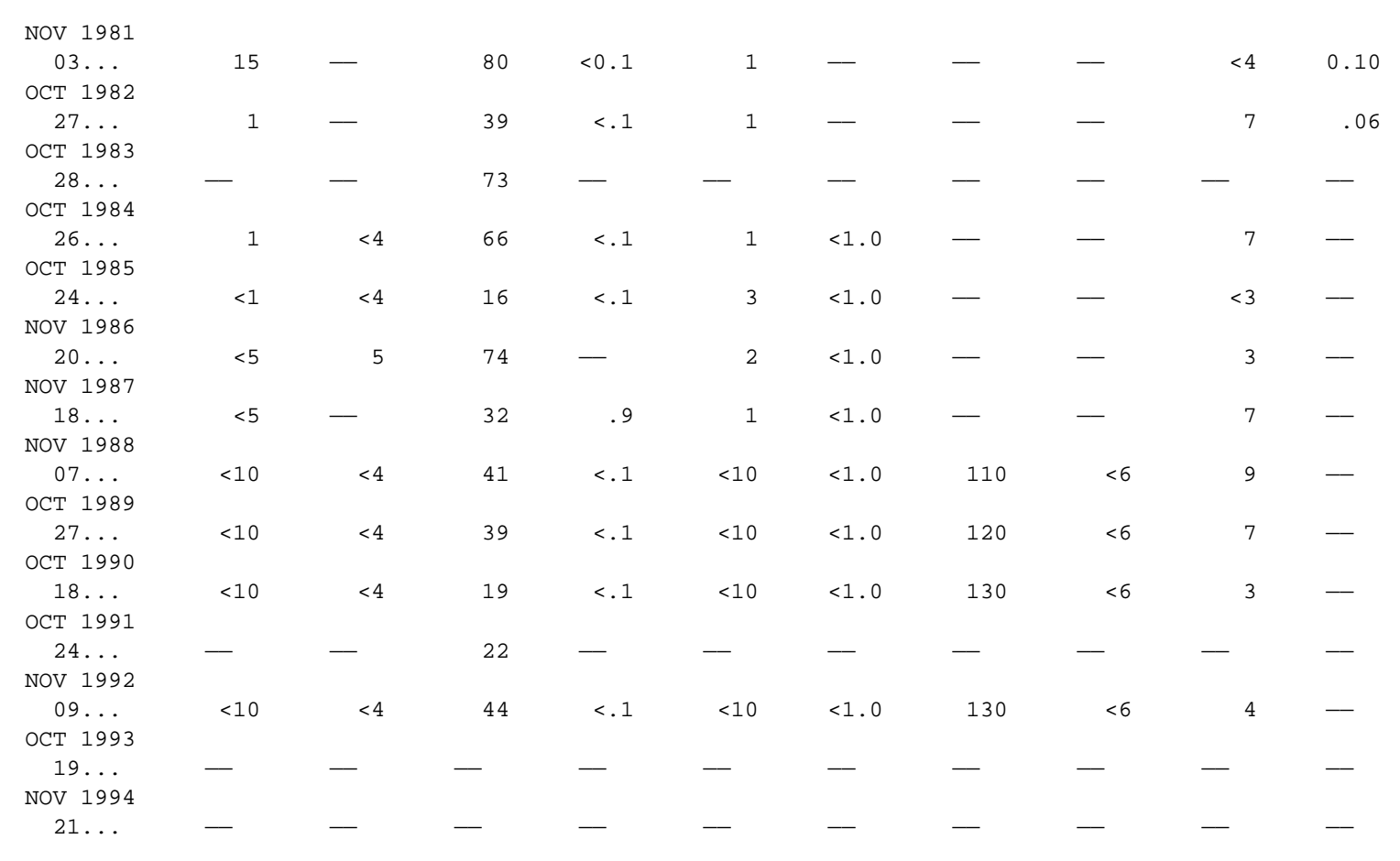


Table 3. Water-quality data from surface-water sites-Continued

01578343 - Valley Creek near Atglen, Pa. (Site 34)

\begin{tabular}{|c|c|c|c|c|c|c|c|c|c|c|c|}
\hline & & DIS- & & $\mathrm{PH}$ & & & & & HARD- & & \\
\hline & & CHARGE, & SPE- & WATER & & & & HARD- & NESS & & MAGNE- \\
\hline & & INST. & CIFIC & WHOLE & & & & NESS, & NONCARB & CALCIUM, & SIUM, \\
\hline & & $\begin{array}{r}\text { (CUBIC } \\
\text { FEET }\end{array}$ & $\begin{array}{l}\text { CON- } \\
\text { DUCT- }\end{array}$ & $\begin{array}{l}\text { FIELD } \\
\text { (STAND- }\end{array}$ & $\begin{array}{l}\text { TEMPER- } \\
\text { ATURF }\end{array}$ & $\begin{array}{l}\text { TUR- } \\
\text { BID- }\end{array}$ & OXYGEN, & $\begin{array}{l}\text { TOTAL } \\
\text { (MG/L }\end{array}$ & $\begin{array}{l}\text { WH WAT } \\
\text { TOT FLD }\end{array}$ & $\begin{array}{l}\text { DIS- } \\
\text { SOLVED }\end{array}$ & $\begin{array}{l}\text { DIS- } \\
\text { SOLVED }\end{array}$ \\
\hline DATE & TIME & PER & ANCE & ARD & WATER & ITY & SOLVED & AS & (MG/L AS & (MG /L & (MG/L \\
\hline & & SECOND ) & $(\mu \mathrm{S} / \mathrm{CM})$ & UNITS) & (DEG C) & (NTU) & (MG/L) & $\left.\mathrm{CACO}_{3}\right)$ & $\left.\mathrm{CACO}_{3}\right)$ & AS CA) & AS MG) \\
\hline & & $(00061)$ & $(00095)$ & $(00400)$ & $(00010)$ & $(00076)$ & $(00300)$ & $(00900)$ & (00902) & $(00915)$ & $(00925)$ \\
\hline
\end{tabular}

\begin{tabular}{|c|c|c|c|c|c|c|c|c|c|c|c|}
\hline $\begin{array}{c}\text { NOV } 1981 \\
03 \ldots \\
\text { OCT } 1982\end{array}$ & 1130 & - & 255 & 7.4 & 10.5 & - & 10.5 & 110 & - & 31 & 7.8 \\
\hline $27 \ldots$ & 1100 & 4.4 & 279 & 7.2 & 7.5 & - & 11.4 & 110 & - & 30 & 8.4 \\
\hline ОСТ 1983 & & & & & & & & & & & \\
\hline $\begin{array}{c}28 \ldots \\
\text { OCT } 1984\end{array}$ & 1000 & 5.9 & 266 & 7.4 & 8.5 & 1.9 & 10.5 & 110 & - & 30 & 9.0 \\
\hline $\begin{array}{c}26 \ldots \\
\text { OCT } 1985\end{array}$ & 1400 & 6.9 & 275 & 7.7 & 15.5 & 1.3 & 10.0 & 110 & - & 28 & 9.0 \\
\hline $\begin{array}{c}24 \ldots \\
\text { NOV } 1986\end{array}$ & 1100 & 6.4 & 285 & 7.6 & 10.0 & 1.3 & 9.8 & 110 & - & 30 & 9.1 \\
\hline $\begin{array}{c}20 \ldots \\
\text { NOV } 1987\end{array}$ & 1300 & 6.1 & 280 & 7.8 & 4.0 & 1.6 & 12.0 & 110 & - & 30 & 9.2 \\
\hline $\begin{array}{c}18 \ldots \\
\text { NOV } 1988\end{array}$ & 1330 & 15 & 270 & 7.4 & 14.5 & 1.6 & 11.2 & 110 & - & 30 & 9.4 \\
\hline $\begin{array}{c}07 \ldots \\
\text { OCT } 1989\end{array}$ & 1230 & 5.7 & 292 & 7.5 & 10.0 & 2.5 & 11.0 & 120 & - & 32 & 9.8 \\
\hline $\begin{array}{c}27 \ldots \\
\text { OCT } 1990\end{array}$ & 1430 & 9.0 & 295 & 7.5 & 14.5 & 1.3 & 10.8 & 110 & 53 & 29 & 9.4 \\
\hline $\begin{array}{c}18 \ldots \\
\text { OCT } 1991\end{array}$ & 1100 & 4.4 & 308 & 6.6 & 16.5 & 4.5 & 8.2 & 120 & 18 & 31 & 9.3 \\
\hline $\begin{array}{c}24 \ldots \\
\text { NOV } 1992\end{array}$ & 1100 & 3.6 & 311 & 7.5 & 13.5 & 1.5 & 9.6 & 120 & 53 & 32 & 9.7 \\
\hline $\begin{array}{c}09 \ldots \\
\text { OCT } 1993\end{array}$ & 1130 & 4.8 & 308 & 7.7 & 5.5 & .80 & 12.2 & 120 & - & 31 & 9.7 \\
\hline $\begin{array}{c}19 \ldots \\
\text { NOV } 1994\end{array}$ & 1145 & 5.9 & 328 & 7.2 & 12.5 & - & 11.8 & - & - & - & - \\
\hline $23 \ldots$ & 0900 & 5.3 & 328 & 7.4 & 5.5 & - & 11.1 & - & - & - & - \\
\hline
\end{tabular}


Table 3. Water-quality data from surface-water sites-Continued

01578343 - Valley Creek near Atglen, Pa. (Site 34)—Continued

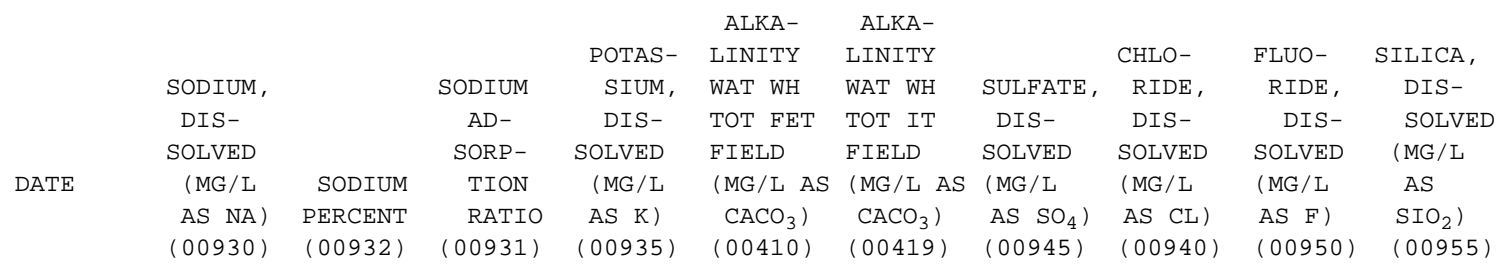

\begin{tabular}{|c|c|c|c|c|c|c|c|c|c|c|}
\hline $\begin{array}{c}\text { NOV } 1981 \\
03 \ldots\end{array}$ & 7.6 & 13 & 0.3 & 3.1 & - & - & 23 & 16 & $<0.10$ & 9.1 \\
\hline $\begin{array}{c}27 \ldots \\
\text { OCT } 1983\end{array}$ & 10 & - & .4 & $<.10$ & 64 & - & 24 & 18 & $<.10$ & 11 \\
\hline $\begin{array}{c}28 \ldots \\
\text { OCT } 1984\end{array}$ & 8.9 & 14 & .4 & 3.6 & 62 & - & 27 & 18 & - & 12 \\
\hline $\begin{array}{c}26 \ldots \\
\text { OCT } 1985\end{array}$ & 8.1 & 14 & .3 & 3.6 & 64 & - & 24 & 15 & - & 11 \\
\hline $\begin{array}{c}24 \ldots \\
\text { NOV } 1986\end{array}$ & 11 & 17 & .5 & 3.5 & 74 & - & 26 & 19 & - & 9.3 \\
\hline $\begin{array}{c}20 \ldots \\
\text { NOV } 1987\end{array}$ & 8.7 & 14 & .4 & 5.0 & 64 & - & 30 & 19 & - & 12 \\
\hline $\begin{array}{c}18 \ldots \\
\text { NOV } 1988\end{array}$ & 9.9 & 15 & .4 & 4.5 & 61 & - & 27 & 24 & - & 10 \\
\hline $\begin{array}{c}07 \ldots \\
\text { ОСт } 1989\end{array}$ & 9.9 & 15 & .4 & 5.0 & 70 & - & 28 & 17 & - & 12 \\
\hline $\begin{array}{c}27 \ldots \\
\text { OCT } 1990\end{array}$ & 7.9 & 13 & .3 & 3.5 & 58 & - & 23 & 16 & - & 11 \\
\hline $\begin{array}{c}18 \ldots \\
\text { OCT } 1991\end{array}$ & 9.0 & 14 & .4 & 3.8 & 98 & - & 22 & 19 & .10 & 11 \\
\hline $\begin{array}{c}24 \ldots \\
\text { NOV } 1992\end{array}$ & 11 & 16 & .4 & 4.0 & 67 & - & 29 & 22 & .10 & 11 \\
\hline $\begin{array}{c}09 \ldots \\
\text { ОСт } 1993\end{array}$ & 11 & 16 & .4 & 4.0 & - & 58 & 25 & 18 & $<.10$ & 12 \\
\hline $\begin{array}{c}19 \ldots \\
\text { NOV } 1994\end{array}$ & - & - & - & - & - & 66 & - & - & - & - \\
\hline $23 \ldots$ & - & - & - & - & - & 69 & - & 22 & - & - \\
\hline
\end{tabular}


Table 3. Water-quality data from surface-water sites-Continued

01578343 - Valley Creek near Atglen, Pa. (Site 34)—Continued

\begin{tabular}{|c|c|c|c|c|c|c|c|c|c|c|}
\hline & $\begin{array}{l}\text { SOLIDS, } \\
\text { RESIDUE }\end{array}$ & $\begin{array}{l}\text { SOLIDS, } \\
\text { SUM OF }\end{array}$ & SO & & & $\begin{array}{c}\text { NITRO- } \\
\text { GEN, }\end{array}$ & $\begin{array}{c}\text { NITRO- } \\
\text { GEN, }\end{array}$ & $\begin{array}{c}\text { NITRO- } \\
\text { GEN, }\end{array}$ & $\begin{array}{c}\text { NITRO- } \\
\text { GEN, }\end{array}$ & $\begin{array}{c}\text { NITRO- } \\
\text { GEN, }\end{array}$ \\
\hline & AT 180 & CONSTI- & DIS- & DIS- & GEN, & NITRATE & NITRATE & NITRITE & $\mathrm{NO}_{2}+\mathrm{NO}_{3}$ & AMMONIA \\
\hline & DEG. C & TUENTS, & SOLVED & SOLVED & NITRATE & DIS- & DIS- & DIS- & DIS- & DIS- \\
\hline & DIS- & DIS- & (TONS & ( TONS & TOTAL & SOLVED & SOLVED & SOLVED & SOLVED & $\begin{array}{l}\text { SOLVED } \\
\text { (MG/L }\end{array}$ \\
\hline & $\begin{array}{l}\text { SOLVED } \\
(M G / L)\end{array}$ & $\begin{array}{l}\text { SOLVED } \\
\text { (MG/L) }\end{array}$ & $\begin{array}{c}\text { PER } \\
\text { AC-FT) }\end{array}$ & $\begin{array}{l}\text { PER } \\
\text { DAY) }\end{array}$ & $\begin{array}{l}(\mathrm{MG} / \mathrm{L} \\
\mathrm{AS} \quad \mathrm{N})\end{array}$ & $\begin{array}{l}(\mathrm{MG} / \mathrm{L} \\
\mathrm{AS} \quad \mathrm{N})\end{array}$ & $\left.\mathrm{AS} \quad \mathrm{NO}_{3}\right)$ & AS N) & $\begin{array}{l}(\mathrm{MG} / \mathrm{L} \\
\mathrm{AS} \quad \mathrm{N})\end{array}$ & $\begin{array}{l}(\mathrm{MG} / \mathrm{L} \\
\mathrm{AS} \quad \mathrm{N})\end{array}$ \\
\hline & $(70300)$ & ( 70301$)$ & (70303) & ( 70302$)$ & $(00620)$ & $(00618)$ & $(71851)$ & $(00613)$ & $(00631)$ & 100608 \\
\hline
\end{tabular}

NOV 1981

$03 \ldots$

OCT 1982

$27 \ldots$

OCT 1983

$28 \ldots$

OCT 1984

$26 \ldots$

OCT 1985

$24 \ldots$

NOV 1986

$20 \ldots$

NOV 1987

$18 \ldots$

NOV 1988

$07 \ldots$

OCT 1989

$27 \ldots$

OCT 1990

$18 \ldots$

OCT 1991

$24 \ldots$

NOV 1992

$09 \ldots$

OCT 1993

$19 \ldots$

NOV 1994

\begin{tabular}{|c|c|c|c|c|c|c|c|c|c|}
\hline 154 & - & 0.21 & - & 4.31 & 4.32 & 19 & 0.080 & 4.40 & 0.050 \\
\hline 170 & - & .23 & 2.03 & 4.55 & 4.55 & 20 & .050 & 4.60 & .110 \\
\hline 178 & 176 & .24 & 2.84 & 6.69 & 6.69 & 30 & .010 & 6.70 & $<.010$ \\
\hline 167 & 161 & .23 & 3.11 & 5.36 & 5.36 & 24 & .040 & 5.40 & .120 \\
\hline 164 & 180 & .22 & 2.83 & 6.06 & 6.06 & 27 & .040 & 6.10 & .180 \\
\hline 162 & 175 & .22 & 2.67 & 5.07 & 5.07 & 22 & .030 & 5.10 & .160 \\
\hline 176 & 177 & .24 & 7.13 & 5.69 & 5.69 & 25 & .010 & 5.70 & .070 \\
\hline- & 182 & .25 & 2.80 & 5.65 & 5.65 & 25 & .050 & 5.70 & .160 \\
\hline- & 170 & .23 & 4.13 & 7.77 & 7.77 & 34 & .030 & 7.80 & .150 \\
\hline- & 191 & .26 & 2.27 & 5.94 & 5.94 & 26 & .060 & 6.00 & .190 \\
\hline - & 184 & .25 & 1.79 & 5.44 & 5.44 & 24 & .060 & 5.50 & .100 \\
\hline- & 178 & .24 & 2.31 & 7.24 & 7.24 & 32 & .060 & 7.30 & .120 \\
\hline- & - & - & - & 8.06 & 8.06 & 36 & .040 & 8.10 & .340 \\
\hline- & - & - & - & 6.36 & 6.36 & 28 & .040 & 6.40 & .340 \\
\hline
\end{tabular}


Table 3. Water-quality data from surface-water sites-Continued

01578343 - Valley Creek near Atglen, Pa. (Site 34)—Continued

\begin{tabular}{|c|c|c|c|c|c|c|c|c|c|c|}
\hline DATE & $\begin{array}{c}\text { NITRO- } \\
\text { GEN, } \\
\text { AMMONIA } \\
\text { DIS- } \\
\text { SOLVED } \\
(\mathrm{MG} / \mathrm{L} \\
\left.\text { AS } \mathrm{NH}_{4}\right) \\
(71846)\end{array}$ & $\begin{array}{l}\text { NITRO- } \\
\text { GEN, } \\
\text { ORGANIC } \\
\text { TOTAL } \\
\text { (MG/L } \\
\text { AS N) } \\
(00605)\end{array}$ & $\begin{array}{c}\text { NITRO- } \\
\text { GEN, } \\
\text { ORGANIC } \\
\text { DIS- } \\
\text { SOLVED } \\
(\text { MG/L } \\
\text { AS N) } \\
(00607)\end{array}$ & $\begin{array}{l}\text { NITRO- } \\
\text { GEN, AM- } \\
\text { MONIA + } \\
\text { ORGANIC } \\
\text { TOTAL } \\
(\text { MG/L } \\
\text { AS N) } \\
(00625)\end{array}$ & $\begin{array}{l}\text { NITRO- } \\
\text { GEN, AM- } \\
\text { MONIA + } \\
\text { ORGANIC } \\
\text { DIS. } \\
\text { (MG/L } \\
\text { AS N) } \\
(00623)\end{array}$ & $\begin{array}{c}\text { NITRO- } \\
\text { GEN, } \\
\text { TOTAL } \\
\text { (MG/L } \\
\text { AS N) } \\
(00600)\end{array}$ & $\begin{array}{l}\text { NITRO- } \\
\text { GEN, } \\
\text { DIS- } \\
\text { SOLVED } \\
\text { (MG/L } \\
\text { AS N) } \\
(00602)\end{array}$ & $\begin{array}{c}\text { PHOS- } \\
\text { PHORUS, } \\
\text { TOTAL } \\
\text { (MG/L } \\
\text { AS P) } \\
(00665)\end{array}$ & $\begin{array}{l}\text { PHOS- } \\
\text { PHORUS, } \\
\text { TOTAL } \\
(\mathrm{MG} / \mathrm{L} \\
\text { AS PO }) \\
(71886)\end{array}$ & $\begin{array}{c}\text { PHOS- } \\
\text { PHORUS, } \\
\text { DIS- } \\
\text { SOLVED } \\
\text { (MG/L } \\
\text { AS P) } \\
(00666)\end{array}$ \\
\hline NOV 1981 & & & & & & & & & & \\
\hline $\begin{array}{c}03 \ldots \\
\text { OCT } 1982\end{array}$ & 0.06 & 0.65 & 0.57 & 0.73 & 0.62 & 5.1 & 5.0 & 0.160 & 0.49 & 0.140 \\
\hline $\begin{array}{c}27 \ldots \\
\text { OCT } 1983\end{array}$ & .14 & - & 1.6 & - & 1.7 & - & 6.3 & - & - & .100 \\
\hline $\begin{array}{c}28 \ldots \\
\text { OCT } 1984\end{array}$ & - & - & - & - & .80 & - & 7.5 & .160 & .49 & .120 \\
\hline $\begin{array}{c}26 \ldots \\
\text { OCT } 1985\end{array}$ & .15 & - & .28 & - & .40 & - & 5.8 & .090 & - & .110 \\
\hline $\begin{array}{c}24 \ldots \\
\text { NOV } 1986\end{array}$ & .23 & 1.0 & .32 & 1.2 & .50 & 7.3 & 6.6 & .080 & .25 & .050 \\
\hline $\begin{array}{c}20 \ldots \\
\text { NOV } 1987\end{array}$ & .21 & .94 & .74 & 1.1 & .90 & 6.2 & 6.0 & .140 & - & .100 \\
\hline $\begin{array}{c}18 \ldots \\
\text { NOV } 1988\end{array}$ & .09 & .43 & .23 & .50 & .30 & 6.2 & 6.0 & .140 & - & .010 \\
\hline $\begin{array}{c}07 \ldots \\
\text { OCT } 1989\end{array}$ & .21 & .64 & .54 & .80 & .70 & 6.5 & 6.4 & .160 & - & .140 \\
\hline $\begin{array}{c}27 \ldots \\
\text { OCT } 1990\end{array}$ & .19 & .75 & .45 & .90 & .60 & 8.7 & 8.4 & .100 & - & .080 \\
\hline $\begin{array}{c}18 \ldots \\
\text { OCT } 1991\end{array}$ & .24 & .71 & .81 & .90 & 1.0 & 6.9 & 7.0 & .140 & - & .080 \\
\hline $\begin{array}{c}24 \ldots \\
\text { NOV } 1992\end{array}$ & .13 & .40 & .30 & .50 & .40 & 6.0 & 5.9 & .180 & - & .160 \\
\hline $\begin{array}{c}09 \ldots \\
\text { OCT } 1993\end{array}$ & .15 & .28 & .28 & .40 & .40 & 7.7 & 7.7 & .080 & - & .060 \\
\hline $\begin{array}{c}19 \ldots \\
\text { NOV } 1994\end{array}$ & .44 & - & - & - & - & - & - & - & - & - \\
\hline $23 \ldots$ & .44 & - & - & - & - & - & - & - & - & - \\
\hline
\end{tabular}


Table 3. Water-quality data from surface-water sites-Continued

01578343 - Valley Creek near Atglen, Pa. (Site 34)—Continued

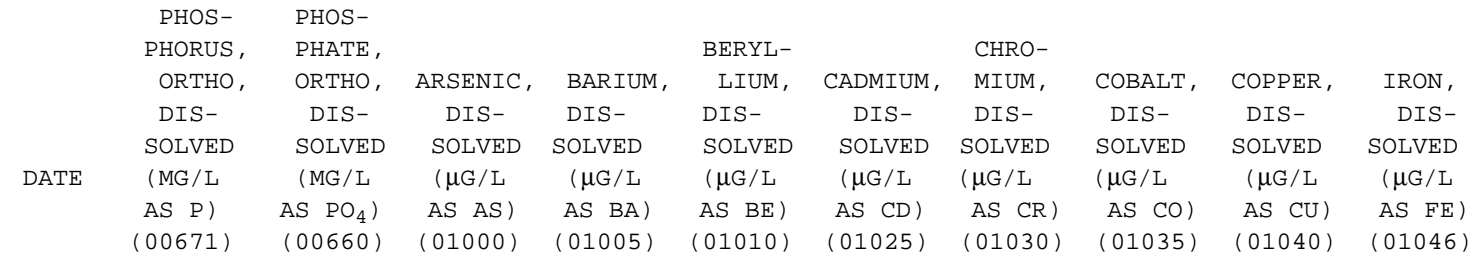

NOV 1981

$03 \ldots$

0.37

$27 \ldots$

OCT 1983

0.120

0.37

ND

1.0

$<1$

1

1

100

$28 \ldots$

ОСТ 1984

.090

.28

$<1 \quad-$

$-\quad 1.0$

$<1$

$<1$

1

53

.120

.37

$1 \quad-$

$-\quad<1.0$

$<1$

$-$

1

$26 \ldots$

OCT 1985

$24 \ldots$

NOV 1986

$20 \ldots$

NOV 1987

$18 \ldots$

NOV 1988

$07 \ldots$

OCT 1989

$27 \ldots$

OCT 1990

$18 \ldots$

ОСт 1991

$24 \ldots$

NOV 1992

$09 \ldots$

OCT 1993

$19 \ldots$

NOV 1994

.090

.28

$-\quad<1.0$

1

$1 \quad-$

1

66

.050

.15

$-$

$<1.0$

$<$

$<1 \quad-$

$-$

.080

.25

$-\quad<1.0$

$<1$

.060

.18

.110

.34

$-$

$<1.0$

$3-$

$-$

$<5$

$<3$

$<5$

$<3$

$<5$

$<3$

10

$<3$

$<5$

$<3$

1

37

23...

.060

.18

$<1 \quad 50$

$.6<1.0$

$-$

.090

.28

.090

.28 
Table 3. Water-quality data from surface-water sites-Continued

01578343 - Valley Creek near Atglen, Pa. (Site 34)—Continued

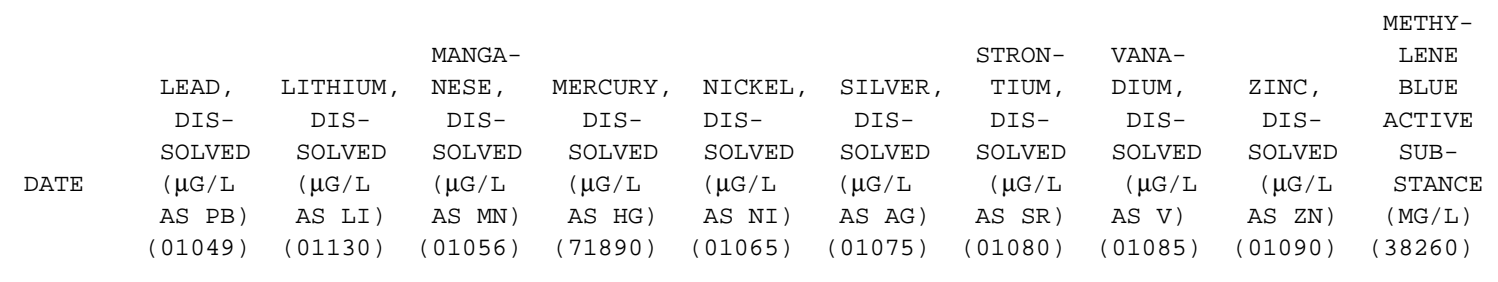

\begin{tabular}{|c|c|c|c|c|c|c|c|c|c|c|}
\hline NOV 1981 & & & & & & & & & & \\
\hline $\begin{array}{c}03 \ldots \\
\text { ОСТ } 1982\end{array}$ & 1 & - & 65 & 0.1 & 3 & - & - & - & 4 & 0.10 \\
\hline $27 \ldots$ & $<1$ & - & 33 & $<.1$ & $<1$ & - & - & - & 4 & .07 \\
\hline $\begin{array}{c}28 \ldots \\
\text { OCT } 1984\end{array}$ & 1 & - & 39 & $<.1$ & 3 & $<1.0$ & - & - & 4 & - \\
\hline $\begin{array}{c}26 \ldots \\
\text { OCT } 1985\end{array}$ & 1 & - & 25 & $<.1$ & $<1$ & $<1.0$ & - & - & 6 & - \\
\hline $\begin{array}{c}24 \ldots \\
\text { NOV } 1986\end{array}$ & $<1$ & - & 17 & $<.1$ & 4 & $<1.0$ & - & - & 4 & - \\
\hline $\begin{array}{c}20 \ldots \\
\text { NOV } 1987\end{array}$ & $<5$ & - & 47 & $<.1$ & $<1$ & $<1.0$ & - & - & 4 & - \\
\hline $\begin{array}{c}18 \ldots \\
\text { NOV } 1988\end{array}$ & $<5$ & - & 21 & $<.1$ & 2 & $<1.0$ & - & - & $<3$ & - \\
\hline $\begin{array}{c}07 \ldots \\
\text { OCT } 1989\end{array}$ & $<10$ & $<4$ & 29 & .2 & $<10$ & $<1.0$ & 140 & $<6$ & 6 & - \\
\hline $\begin{array}{c}27 \ldots \\
\text { OCT } 1990\end{array}$ & $<10$ & $<4$ & 22 & $<.1$ & $<10$ & $<1.0$ & 130 & $<6$ & 7 & - \\
\hline $\begin{array}{c}18 \ldots \\
\text { OCT } 1991\end{array}$ & $<10$ & 4 & 18 & $<.1$ & $<10$ & $<1.0$ & 140 & $<6$ & $<3$ & - \\
\hline $\begin{array}{c}24 \ldots \\
\text { NOV } 1992\end{array}$ & $<10$ & 6 & 23 & $<.1$ & $<10$ & $<1.0$ & 140 & $<6$ & 4 & - \\
\hline $\begin{array}{c}09 \ldots \\
\text { OCT } 1993\end{array}$ & $<10$ & $<4$ & 30 & $<.1$ & $<10$ & 1.0 & 140 & $<6$ & 10 & - \\
\hline $\begin{array}{c}19 \ldots \\
\text { NOV } 1994\end{array}$ & - & - & - & - & - & - & - & - & - & - \\
\hline $23 \ldots$ & - & - & - & - & - & - & - & - & - & - \\
\hline
\end{tabular}


Table 3. Water-quality data from surface-water sites-Continued

01578345 - East Branch Octoraro Creek at Steelville, Pa. (Site 35)

\begin{tabular}{|c|c|c|c|c|c|c|c|c|c|c|c|}
\hline & & DIS- & & PH & & & & & & & \\
\hline & & CHARGE， & SPE- & WATER & & & HARD- & & MAGNE- & & \\
\hline & & INST. & CIFIC & WHOLE & & & NESS & CALCIUM & SIUM, & SODIUM, & \\
\hline & & (CUBIC & $\mathrm{CON}-$ & FIELD & TEMPER- & OXYGEN， & TOTAL & DIS- & DIS- & DIS- & \\
\hline & & FEET & DUCT- & (STAND- & ATURE & DIS- & (MG /L & SOLVED & SOLVED & SOLVED & \\
\hline ATE & TIME & PER & ANCE & ARD & WATER & SOLVED & AS & (MG / L & (MG/L & (MG / L & SODIUM \\
\hline & & SECOND) & $(\mu \mathrm{S} / \mathrm{CM})$ & UNITS) & (DEG C) & (MG/L) & $\left.\mathrm{CACO}_{3}\right)$ & AS CA) & AS $\quad$ MG) & AS NA) & PERCENT \\
\hline & & $(00061)$ & $(00095)$ & $(00400)$ & $(00010)$ & $(00300)$ & $(00900)$ & $(00915)$ & $(00925)$ & $(00930)$ & $(00932)$ \\
\hline
\end{tabular}

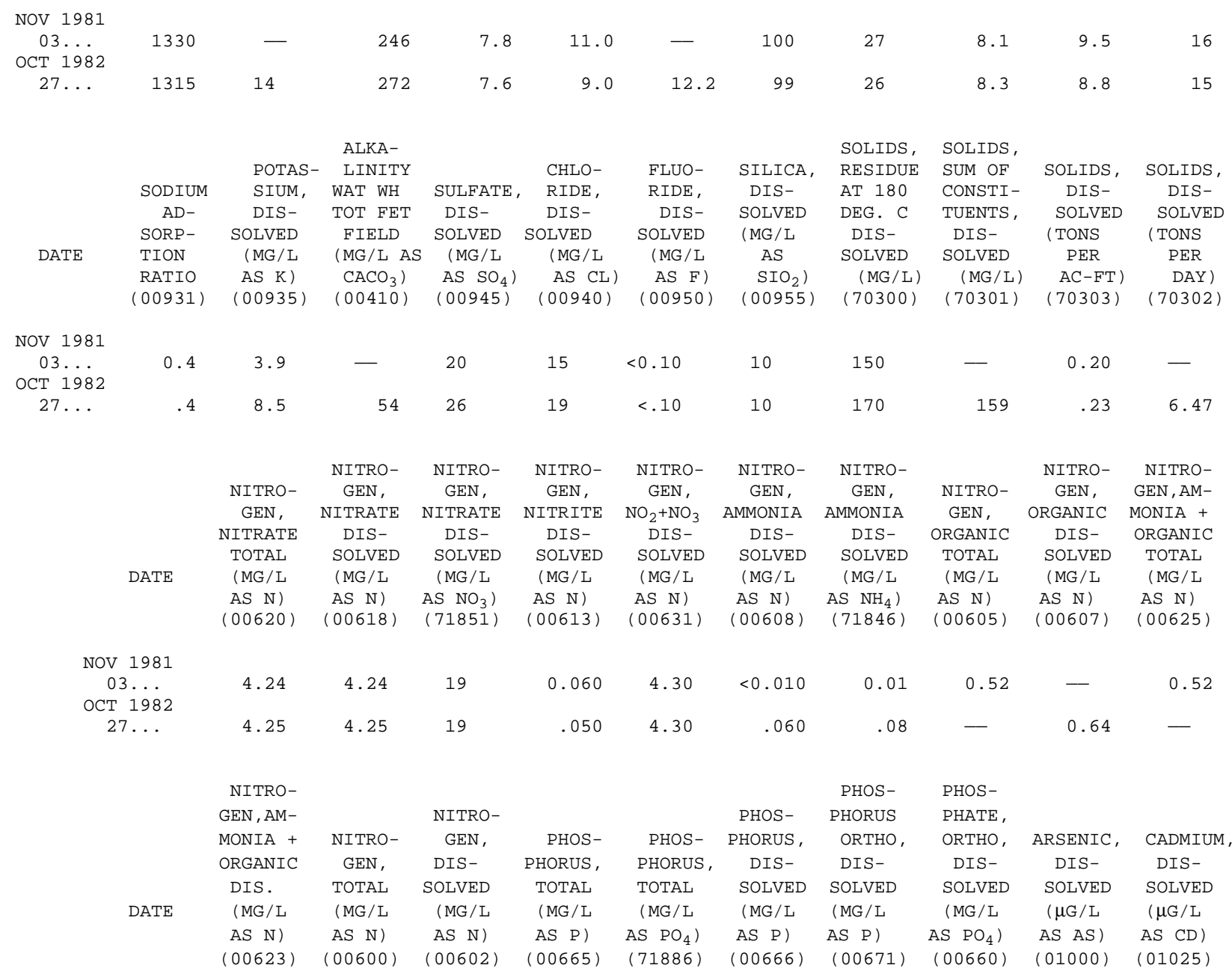

NOV 1981

$03 \ldots$

OCT 1982

$27 \ldots$

$$
\begin{array}{llll}
0.55 & 4.8 & 4.9 & 0.250 \\
.70 & - & 5.0 & -
\end{array}
$$$$
0.77
$$$$
0.220
$$$$
0.190
$$$$
.170
$$$$
0.58
$$$$
\text { ND }
$$$$
<1.0
$$$$
\text { - }
$$

$$
.180
$$$$
.52
$$$$
1
$$$$
<1.0
$$

CHRO-

MIUM

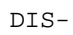

(01030)

$\begin{array}{ll}<1 & <1 \\ <1 & <1\end{array}$

$\begin{array}{lcc}\text { COPPER, } & \text { IRON, } & \text { LEAD, } \\ \text { DIS- } & \text { DIS- } & \text { DIS- } \\ \text { SOLVED } & \text { SOLVED } & \text { SOLVED } \\ (\mu \mathrm{G} / \mathrm{L} & (\mu \mathrm{G} / \mathrm{L} & (\mu \mathrm{G} / \mathrm{L} \\ \mathrm{AS} \mathrm{CU}) & \mathrm{AS} \mathrm{FE}) & \text { AS PB) } \\ (01040) & (01046) & (01049)\end{array}$

MANGA-

NESE,

DIS-

SOLVED

$(\mu \mathrm{G} / \mathrm{L}$

A.S MN)

(01056)
$<1$

$<1$

$\begin{array}{ll}21 & 0.1 \\ 13 & <.1\end{array}$

$<.1$
METHY-

LENE

MERCURY, NICKEL, ZINC, BLUE

DIS- DIS- DIS- ACTIVE

SOLVED SOLVED SOLVED SUB-

$(\mu \mathrm{G} / \mathrm{L} \quad(\mu \mathrm{G} / \mathrm{L} \quad(\mu \mathrm{G} / \mathrm{L} \quad \mathrm{STANCE}$

AS HG) AS NI) AS ZN) (MG/L)

$\begin{array}{lllllll}(71890) & (01065) & \text { (01090) } & \text { (38260) }\end{array}$
NOV 1981

OCT 1982

$27 \ldots$ 
Table 4. Results of stream-bottom sediment sampling

[Concentrations in micrograms per gram; $\mathrm{g} / \mathrm{kg}$, gram per kilogram; $\mu \mathrm{g} / \mathrm{kg}$, microgram per kilogram; PBC, polychlorinated biphenyls; PCN, polychlorinated napthalenes; <, less than; -, no data]

\begin{tabular}{|c|c|c|c|c|c|c|c|c|c|c|c|}
\hline $\begin{array}{l}\text { Station } \\
\text { number }\end{array}$ & $\begin{array}{c}\text { Site } \\
\text { number }\end{array}$ & Date & $\begin{array}{c}\text { Arsenic, } \\
\text { total }\end{array}$ & $\begin{array}{l}\text { Cad- } \\
\text { mium, } \\
\text { recover- } \\
\text { able }\end{array}$ & $\begin{array}{l}\text { Chro- } \\
\text { mium, } \\
\text { recover- } \\
\text { able }\end{array}$ & $\begin{array}{l}\text { Iron, } \\
\text { recover- } \\
\text { able }\end{array}$ & $\begin{array}{l}\text { Copper, } \\
\text { recover- } \\
\text { able }\end{array}$ & $\begin{array}{l}\text { Lead, } \\
\text { recover- } \\
\text { able }\end{array}$ & $\begin{array}{l}\text { Manga- } \\
\text { nese, } \\
\text { recover- } \\
\text { able }\end{array}$ & $\begin{array}{l}\text { Mercury, } \\
\text { recover- } \\
\text { able }\end{array}$ & $\begin{array}{l}\text { Zinc, } \\
\text { recover- } \\
\text { able }\end{array}$ \\
\hline 01472080 & 10 & $10-11-85$ & - & - & - & - & - & - & - & - & - \\
\hline 01472109 & 6 & $10-11-85$ & - & - & - & - & - & - & - & - & - \\
\hline 01472138 & 13 & $10-22-86$ & - & - & - & - & - & - & - & - & - \\
\hline 01472140 & 12 & $10-10-85$ & - & - & - & - & - & - & - & - & - \\
\hline 01472154 & 14 & $10-11-85$ & - & - & - & - & - & - & - & - & - \\
\hline 01472157 & 15 & $10-28-94$ & 1 & $<1$ & 20 & 24,000 & 20 & 30 & 590 & 0.03 & 100 \\
\hline 014721612 & 16 & $10-09-85$ & - & - & - & - & - & - & - & - & - \\
\hline 01472170 & 1 & $10-09-87$ & - & - & - & - & - & - & - & - & - \\
\hline 01472174 & 2 & $10-07-86$ & - & - & - & - & - & - & - & - & - \\
\hline 014721854 & 3 & $10-08-86$ & - & - & - & - & - & - & - & - & - \\
\hline 014721884 & 4 & $10-07-85$ & - & - & - & - & - & - & - & - & - \\
\hline \multirow[t]{3}{*}{01472190} & 5 & $10-06-86$ & - & - & - & - & - & - & - & - & - \\
\hline & & $10-26-94$ & 1 & $<1$ & 10 & 7,400 & 6 & 20 & 210 & .01 & 40 \\
\hline & & $10-28-94$ & 2 & $<1$ & 10 & 17,000 & 20 & 80 & 460 & .03 & 100 \\
\hline \multirow[t]{3}{*}{01473167} & 49 & $11-07-86$ & - & - & - & - & - & - & - & - & - \\
\hline & & $11-16-87$ & - & - & - & - & - & - & - & - & - \\
\hline & & $11-18-93$ & 6 & 1 & 40 & 28,000 & 20 & 30 & 760 & .02 & 100 \\
\hline \multirow[t]{2}{*}{01473168} & 50 & $10-09-85$ & - & - & - & - & - & - & - & - & - \\
\hline & & $11-18-93$ & 3 & 1 & 20 & 9,300 & 30 & 50 & 360 & .03 & 110 \\
\hline 01475840 & 19 & $10-09-86$ & - & - & - & - & - & - & - & - & - \\
\hline 01476430 & 20 & $10-15-85$ & - & - & - & - & - & - & - & - & - \\
\hline 01476435 & 21 & $10-09-86$ & - & - & - & - & - & - & - & - & - \\
\hline 01476790 & 22 & $10-15-86$ & - & - & - & - & - & - & - & - & - \\
\hline 01476830 & 23 & $10-15-86$ & - & - & - & - & - & - & - & - & - \\
\hline \multirow[t]{2}{*}{01476835} & 24 & $10-16-85$ & - & - & - & - & - & - & - & - & - \\
\hline & & $10-21-94$ & $<1$ & $<1$ & 20 & 14,000 & 20 & 20 & 190 & .16 & 80 \\
\hline \multirow[t]{2}{*}{01476840} & 25 & $11-04-88$ & 4 & 1 & 30 & - & 40 & 60 & - & .76 & 170 \\
\hline & & $11-19-93$ & 1 & $<1$ & 30 & 15,000 & 20 & 20 & 260 & .40 & 90 \\
\hline \multirow[t]{2}{*}{01476848} & 51 & $10-16-86$ & - & - & - & - & - & - & - & - & - \\
\hline & & $10-17-94$ & $<1$ & $<1$ & 10 & 7,300 & 9 & 20 & 70 & .34 & 50 \\
\hline \multirow[t]{2}{*}{01478120} & 28 & $10-25-85$ & - & - & - & - & - & - & - & - & - \\
\hline & & $11-24-93$ & $<1$ & $<1$ & 10 & 6,000 & 4 & 10 & 190 & $<.10$ & 20 \\
\hline \multirow[t]{2}{*}{01478190} & 29 & $12-02-86$ & - & - & - & - & - & - & - & - & - \\
\hline & & $11-24-93$ & 2 & $<1$ & 20 & 12,000 & 10 & 10 & 240 & .01 & 40 \\
\hline \multirow[t]{2}{*}{01478220} & 30 & $10-25-85$ & - & - & - & - & - & - & - & - & - \\
\hline & & $11-23-93$ & 2 & $<1$ & 20 & 15,000 & 10 & 10 & 240 & .01 & 50 \\
\hline \multirow[t]{4}{*}{01479680} & 27 & $11-01-83$ & - & - & - & - & - & - & - & - & - \\
\hline & & $11-18-86$ & - & - & - & - & - & - & - & - & - \\
\hline & & $11-22-93$ & $<1$ & $<1$ & 20 & 7,300 & 5 & 10 & 150 & .01 & 40 \\
\hline & & $10-17-94$ & $<1$ & $<1$ & 10 & 7,300 & 9 & 20 & 70 & .34 & 50 \\
\hline \multirow[t]{2}{*}{01479800} & 26 & $10-18-85$ & - & - & - & - & - & - & - & - & - \\
\hline & & $11-22-93$ & 1 & $<1$ & 20 & 10,000 & 7 & 10 & 240 & $<.10$ & 30 \\
\hline 01480629 & 46 & $10-29-85$ & - & - & - & - & - & - & - & - & - \\
\hline 01480632 & 45 & $10-30-86$ & - & - & - & - & - & - & - & - & - \\
\hline
\end{tabular}


Table 4. Results of stream-bottom sediment sampling-Continued

\begin{tabular}{cccccccccccc}
\hline $\begin{array}{c}\text { Station } \\
\text { number }\end{array}$ & $\begin{array}{c}\text { Site } \\
\text { number }\end{array}$ & Date & $\begin{array}{c}\text { Arsenic, } \\
\text { total }\end{array}$ & $\begin{array}{c}\text { Cad- } \\
\text { mium, } \\
\text { recover- } \\
\text { able }\end{array}$ & $\begin{array}{c}\text { Chro- } \\
\text { mium, } \\
\text { recover- } \\
\text { able }\end{array}$ & $\begin{array}{c}\text { Iron, } \\
\text { recover- } \\
\text { able }\end{array}$ & $\begin{array}{c}\text { Copper, } \\
\text { recover- } \\
\text { able }\end{array}$ & $\begin{array}{c}\text { Lead, } \\
\text { recover- } \\
\text { able }\end{array}$ & $\begin{array}{c}\text { Manga- } \\
\text { nese, } \\
\text { recover- } \\
\text { able }\end{array}$ & $\begin{array}{c}\text { Mercury, } \\
\text { recover- } \\
\text { able }\end{array}$ & $\begin{array}{c}\text { Zinc, } \\
\text { recover- } \\
\text { able }\end{array}$ \\
\hline 01480640 & 38 & $10-22-85$ & - & - & - & - & - & - & - & - & - \\
01480648 & 48 & $10-29-86$ & - & - & - & - & - & - & - & - & - \\
01480653 & 42 & $10-23-85$ & - & - & - & - & - & - & - & - & - \\
01480656 & 47 & $10-29-86$ & - & - & - & - & - & - & - & - & - \\
01480700 & 36 & $10-21-85$ & - & - & - & - & - & - & - & - & - \\
01480903 & 44 & $10-31-85$ & - & - & - & - & - & - & - & - & - \\
01480950 & 39 & $11-03-86$ & - & - & - & - & - & - & - & - & - \\
& & $11-16-93$ & 2 & $<1$ & 20 & 12,000 & 10 & 20 & 370 & 0.06 & 60 \\
01481030 & 40 & $10-30-85$ & - & - & - & - & - & - & - & - & - \\
01494900 & 31 & $10-28-86$ & - & - & - & - & - & - & - & - & - \\
& & $11-04-94$ & $<1$ & $<1$ & 9 & 10,000 & 6 & $<10$ & 260 & $<.01$ & 20 \\
01494950 & 32 & $10-17-85$ & - & - & - & - & - & - & - & - & - \\
& & $11-04-94$ & 2 & $<1$ & 10 & 15,000 & 10 & 20 & 540 & .02 & 50 \\
01578340 & 33 & $11-21-94$ & 2 & $<1$ & 50 & 17,000 & 20 & 30 & 360 & .03 & 100 \\
01578343 & 34 & $10-24-85$ & - & - & - & - & - & - & - & - & -
\end{tabular}


Table 4. Results of stream-bottom sediment sampling-Continued

\begin{tabular}{|c|c|c|c|c|c|c|c|c|c|c|c|}
\hline $\begin{array}{l}\text { Station } \\
\text { number }\end{array}$ & $\begin{array}{c}\text { Site } \\
\text { number }\end{array}$ & Date & $\begin{array}{c}\text { Carbon, } \\
\text { inorg + } \\
\text { organic } \\
\text { (gm/kg } \\
\text { as C) }\end{array}$ & $\begin{array}{c}\text { Aldrin, } \\
\text { total } \\
(\mu \mathrm{g} / \mathrm{kg})\end{array}$ & $\begin{array}{l}\text { Chlor- } \\
\text { dane, } \\
\text { total } \\
(\mu \mathrm{g} / \mathrm{kg})\end{array}$ & $\begin{array}{l}\text { DDD, } \\
\text { recover- } \\
\text { able } \\
(\mu \mathrm{g} / \mathrm{kg})\end{array}$ & $\begin{array}{l}\text { DDE, } \\
\text { recover- } \\
\text { able } \\
(\mu \mathrm{g} / \mathrm{kg})\end{array}$ & $\begin{array}{l}\text { DDT, } \\
\text { recover- } \\
\text { able } \\
(\mu \mathrm{g} / \mathrm{kg}) \text {, }\end{array}$ & $\begin{array}{l}\text { Dieldrin, } \\
\text { total, } \\
(\mu \mathrm{g} / \mathrm{kg})\end{array}$ & $\begin{array}{c}\text { Endo- } \\
\text { sulfan, } \\
\text { total } \\
(\mu \mathrm{g} / \mathrm{kg})\end{array}$ & $\begin{array}{c}\text { Endrin, } \\
\text { total } \\
(\mu \mathrm{g} / \mathrm{kg})\end{array}$ \\
\hline 01472080 & 10 & $10-11-85$ & - & $<0.100$ & $<1.00$ & $<0.100$ & 0.100 & $<0.100$ & $<0.100$ & $<0.100$ & $<0.100$ \\
\hline 01472109 & 6 & $10-11-85$ & - & $<.100$ & 6.00 & .400 & 1.00 & $<.100$ & .300 & $<.100$ & $<.100$ \\
\hline 01472138 & 13 & $10-22-86$ & - & $<.100$ & $<1.00$ & 1.20 & 1.10 & $<.100$ & .300 & $<.100$ & $<.100$ \\
\hline 01472140 & 12 & $10-10-85$ & - & $<.100$ & $<1.00$ & .300 & .400 & .400 & 4.80 & $<.100$ & .100 \\
\hline 01472154 & 14 & $10-11-85$ & - & $<.100$ & 6.00 & $<.100$ & .600 & $<.100$ & .100 & $<.100$ & $<.100$ \\
\hline 01472157 & 15 & $10-28-94$ & 15 & $<.100$ & $<1.00$ & .100 & .300 & .200 & $<.800$ & $<.100$ & $<.100$ \\
\hline \multirow[t]{2}{*}{014721612} & 16 & $10-09-85$ & - & $<.100$ & 5.00 & $<.100$ & $<.100$ & $<.100$ & .200 & $<.100$ & $<.100$ \\
\hline & & $10-28-94$ & 18 & $<.100$ & 24.0 & .600 & .600 & .600 & 5.40 & $<.100$ & $<.100$ \\
\hline 01472170 & 1 & $10-09-87$ & - & $<.100$ & 2.00 & .300 & .200 & $<1.00$ & $<.100$ & $<.100$ & $<.100$ \\
\hline 01472174 & 2 & $10-07-86$ & - & $<.100$ & $<1.00$ & $<.200$ & .500 & $<.100$ & $<.100$ & $<.200$ & $<.100$ \\
\hline 014721854 & 3 & $10-08-86$ & - & $<.100$ & $<1.00$ & .300 & .400 & - & $<.100$ & .100 & $<.100$ \\
\hline 014721884 & 4 & $10-07-85$ & - & $<.100$ & $<1.00$ & $<.100$ & - & $<.100$ & .100 & $<.100$ & $<.100$ \\
\hline \multirow[t]{2}{*}{01472190} & 5 & $10-06-86$ & - & $<.100$ & $<1.00$ & $<.100$ & .400 & .300 & $<.100$ & .300 & $<.100$ \\
\hline & & $10-26-94$ & 3.0 & $<.100$ & $<1.00$ & $<.100$ & $<.100$ & $<.100$ & $<.800$ & $<.100$ & $<.800$ \\
\hline \multirow[t]{3}{*}{01473167} & 49 & $11-07-86$ & - & - & - & - & - & - & - & - & - \\
\hline & & $11-16-87$ & - & $<1.0$ & 13.0 & .300 & $<1.0$ & $<1.0$ & .800 & $<.100$ & $<.100$ \\
\hline & & 11-18-93 & 17 & $<.100$ & 5.00 & .600 & $<.100$ & $<.400$ & 1.10 & .500 & $<.100$ \\
\hline \multirow[t]{2}{*}{01473168} & 50 & $10-09-85$ & - & $<.100$ & 5.00 & 1.70 & 1.70 & 3.20 & .100 & $<.100$ & $<.100$ \\
\hline & & $11-18-93$ & 30 & $<.100$ & 5.00 & 1.40 & 1.0 & 3.60 & .400 & $<.100$ & $<.100$ \\
\hline 01475840 & 19 & $10-09-86$ & - & $<.100$ & 7.00 & .100 & .300 & 2.20 & .100 & $<.100$ & $<.100$ \\
\hline 01476430 & 20 & $10-15-85$ & - & $<.100$ & 7.00 & .600 & .600 & $<.100$ & .300 & $<.100$ & $<.100$ \\
\hline 01476435 & 21 & $10-09-86$ & - & $<.100$ & $<1.00$ & .100 & .100 & $<.100$ & $<.100$ & $<.100$ & $<.100$ \\
\hline 01476790 & 22 & $10-15-86$ & - & $<.100$ & 30.0 & .800 & 1.60 & 1.30 & .500 & $<.100$ & $<.100$ \\
\hline 01476830 & 23 & $10-15-86$ & - & $<.100$ & $<1.00$ & .300 & .600 & $<.100$ & .400 & $<.100$ & $<.100$ \\
\hline \multirow[t]{2}{*}{01476835} & 24 & $10-16-85$ & - & $<.100$ & 7.00 & $<.100$ & .300 & $<.100$ & .100 & $<.100$ & $<.100$ \\
\hline & & $10-21-94$ & 17 & $<.100$ & 6.00 & .300 & .800 & .300 & .800 & $<.100$ & $<.800$ \\
\hline \multirow[t]{2}{*}{01476840} & 25 & $11-04-88$ & 20 & $<.100$ & 51.0 & 7.50 & 1.90 & 13.0 & 1.80 & $<.100$ & $<.100$ \\
\hline & & $11-19-93$ & 9.2 & $<.100$ & 10.0 & 2.30 & 1.20 & 12.0 & .200 & $<.100$ & $<.100$ \\
\hline \multirow[t]{2}{*}{01476848} & 51 & $10-16-86$ & - & $<.100$ & 110 & 5.00 & 2.10 & 1.20 & .600 & $<.100$ & $<.100$ \\
\hline & & $10-17-94$ & 5.0 & $<.100$ & 2.00 & .700 & .400 & .800 & $<.800$ & $<.100$ & $<.800$ \\
\hline \multirow[t]{2}{*}{01478120} & 28 & $10-25-85$ & - & $<.100$ & $<1.00$ & 6.30 & 2.80 & .400 & .100 & $<.100$ & $<.100$ \\
\hline & & $11-24-93$ & 7.3 & $<.100$ & $<1.00$ & $<.100$ & .900 & $<.100$ & $<.200$ & $<.100$ & $<.100$ \\
\hline \multirow[t]{2}{*}{01478190} & 29 & $12-02-86$ & - & $<.100$ & $<1.00$ & 1.10 & 1.20 & 1.30 & .100 & $<.100$ & $<.100$ \\
\hline & & $11-24-93$ & 4.4 & $<.100$ & 1.00 & $<.100$ & 1.60 & $<.100$ & $<.200$ & $<.100$ & $<.100$ \\
\hline \multirow[t]{2}{*}{01478220} & 30 & $10-25-85$ & - & $<.100$ & $<1.00$ & - & .400 & $<.100$ & $<.100$ & $<.100$ & $<.100$ \\
\hline & & $11-23-93$ & 3.4 & $<.100$ & $<1.00$ & $<.100$ & .300 & $<.100$ & $<.200$ & $<.100$ & $<.100$ \\
\hline \multirow[t]{3}{*}{01479680} & 27 & $11-01-83$ & - & $<1.00$ & $<10.0$ & 260 & - & 15.0 & 2.50 & $<1.00$ & $<1.00$ \\
\hline & & $11-18-86$ & - & $<.100$ & - & - & - & - & - & $<.100$ & $<.100$ \\
\hline & & $11-22-93$ & 5.8 & $<.100$ & 7.00 & 23.0 & 2.0 & 27.0 & .200 & $<.100$ & $<.200$ \\
\hline \multirow[t]{2}{*}{01479800} & 26 & $10-18-85$ & - & $<.100$ & 5.00 & 36.0 & 22.0 & 61.0 & $<.100$ & $<.100$ & $<.100$ \\
\hline & & $11-22-93$ & 1.9 & $<.100$ & 1.00 & 2.10 & 1.80 & 2.60 & $<.100$ & $<.100$ & $<.100$ \\
\hline 01480629 & 46 & $10-29-85$ & - & $<.100$ & $<1.00$ & $<.100$ & $<.100$ & $<.100$ & $<.100$ & $<.100$ & $<.100$ \\
\hline 01480632 & 45 & $10-30-86$ & - & $<.100$ & 4.00 & .600 & 2.10 & $<.100$ & .700 & $<.100$ & $<.100$ \\
\hline \multirow[t]{2}{*}{01480640} & 38 & $10-22-85$ & - & $<.100$ & 3.00 & .600 & .200 & $<.100$ & .100 & $<.100$ & $<.100$ \\
\hline & & $11-15-93$ & 3.4 & $<.200$ & 4.00 & 1.30 & 1.40 & 1.00 & .400 & $<.100$ & $<.100$ \\
\hline
\end{tabular}


Table 4. Results of stream-bottom sediment sampling-Continued

\begin{tabular}{|c|c|c|c|c|c|c|c|c|c|c|c|}
\hline $\begin{array}{l}\text { Station } \\
\text { number }\end{array}$ & $\begin{array}{c}\text { Site } \\
\text { number }\end{array}$ & Date & $\begin{array}{c}\text { Carbon, } \\
\text { inorg + } \\
\text { organic } \\
\text { (gm/kg } \\
\text { as C) }\end{array}$ & $\begin{array}{c}\text { Aldrin, } \\
\text { total } \\
(\mu \mathrm{g} / \mathrm{kg})\end{array}$ & $\begin{array}{l}\text { Chlor- } \\
\text { dane, } \\
\text { total } \\
(\mu \mathrm{g} / \mathrm{kg})\end{array}$ & $\begin{array}{l}\text { DDD, } \\
\text { recover- } \\
\text { able } \\
(\mu \mathrm{g} / \mathrm{kg})\end{array}$ & $\begin{array}{l}\text { DDE, } \\
\text { recover- } \\
\text { able } \\
(\mu \mathrm{g} / \mathrm{kg})\end{array}$ & $\begin{array}{l}\text { DDT, } \\
\text { recover- } \\
\text { able } \\
(\mu \mathrm{g} / \mathrm{kg}) \text {, }\end{array}$ & $\begin{array}{c}\text { Dieldrin, } \\
\text { total, } \\
(\mu \mathrm{g} / \mathrm{kg})\end{array}$ & $\begin{array}{c}\text { Endo- } \\
\text { sulfan, } \\
\text { total } \\
(\mu \mathrm{g} / \mathrm{kg})\end{array}$ & $\begin{array}{c}\text { Endrin, } \\
\text { total } \\
(\mu \mathrm{g} / \mathrm{kg})\end{array}$ \\
\hline 01480648 & 48 & $10-29-86$. & - & 0.100 & 1.00 & 0.300 & 1.80 & $<0.100$ & 0.400 & $<0.100$ & $<0.100$ \\
\hline 01480653 & 42 & $10-23-85$ & - & $<.100$ & $<1.00$ & $<.100$ & .200 & $<.100$ & $<.100$ & $<.100$ & $<.100$ \\
\hline 01480656 & 47 & $10-29-86$ & - & $<.100$ & $<1.00$ & .400 & - & $<.100$ & .400 & $<.100$ & $<.100$ \\
\hline 01480700 & 36 & $10-21-85$ & - & $<.100$ & $<1.00$ & .100 & .200 & $<.100$ & $<.100$ & $<.100$ & $<.100$ \\
\hline 01480903 & 44 & $10-31-85$ & - & $<.100$ & 4.00 & .400 & $<.100$ & $<.100$ & .300 & $<.100$ & $<.100$ \\
\hline \multirow[t]{2}{*}{01480950} & 39 & $11-03-86$ & - & $<.100$ & 32.0 & 4.40 & 4.10 & 1.30 & 3.20 & .200 & $<.100$ \\
\hline & & $11-16-93$ & 4.9 & $<.100$ & 3.00 & .200 & .500 & .300 & .200 & $<.100$ & $<.100$ \\
\hline 01481030 & 40 & $10-30-85$ & - & $<.100$ & 3.00 & 3.60 & 2.50 & $<.100$ & $<.100$ & $<.100$ & $<.100$ \\
\hline \multirow[t]{2}{*}{01494900} & 31 & $10-28-86$ & - & $<.100$ & 29.0 & 3.20 & 7.40 & .800 & .900 & $<.100$ & $<.100$ \\
\hline & & 11-04-94 & 1.5 & $<.100$ & $<1.00$ & .100 & $<.100$ & .200 & $<.400$ & $<.100$ & $<.100$ \\
\hline \multirow[t]{2}{*}{01494950} & 32 & $10-17-85$ & - & $<.100$ & 1.00 & .800 & 1.00 & 3.10 & $<.100$ & $<.100$ & $<.100$ \\
\hline & & $11-04-94$ & 10 & $<.100$ & 1.00 & .600 & .500 & .600 & $<.400$ & $<.100$ & $<.100$ \\
\hline 01578340 & 33 & $11-21-94$ & 27 & $<.100$ & 5.00 & 1.10 & 1.10 & 1.20 & $<.800$ & $<.200$ & $<.300$ \\
\hline 01578343 & 34 & $10-24-85$ & - & $<.100$ & $<1.00$ & .100 & $<.100$ & .200 & $<.100$ & $<.100$ & $<.100$ \\
\hline
\end{tabular}


Table 4. Results of stream-bottom sediment sampling-Continued

\begin{tabular}{|c|c|c|c|c|c|c|c|c|c|c|c|}
\hline $\begin{array}{l}\text { Station } \\
\text { number }\end{array}$ & $\begin{array}{c}\text { Site } \\
\text { number }\end{array}$ & Date & $\begin{array}{l}\text { Hepta- } \\
\text { chlor, } \\
\text { total } \\
(\mu \mathrm{g} / \mathrm{kg})\end{array}$ & $\begin{array}{c}\text { Hepta- } \\
\text { chlor, } \\
\text { epoxide, } \\
\text { total } \\
(\mu \mathrm{g} / \mathrm{kg})\end{array}$ & $\begin{array}{l}\text { Lindane, } \\
\text { total } \\
(\mu \mathrm{g} / \mathrm{kg})\end{array}$ & $\begin{array}{c}\text { Meth- } \\
\text { oxy- } \\
\text { chlor, } \\
\text { total } \\
(\mu \mathrm{g} / \mathrm{kg})\end{array}$ & $\begin{array}{c}\text { Mirex, } \\
\text { total } \\
(\mu \mathrm{g} / \mathrm{kg})\end{array}$ & $\begin{array}{c}\text { Per- } \\
\text { thane, } \\
\text { total } \\
(\mu \mathrm{g} / \mathrm{kg})\end{array}$ & $\begin{array}{c}\text { Toxa- } \\
\text { phene, } \\
\text { total } \\
(\mu \mathrm{g} / \mathrm{kg})\end{array}$ & $\begin{array}{c}\text { PCB, } \\
\text { total } \\
(\mu \mathrm{g} / \mathrm{kg})\end{array}$ & $\begin{array}{c}\text { PCN, } \\
\text { total } \\
(\mu \mathrm{g} / \mathrm{kg})\end{array}$ \\
\hline 01472080 & 10 & $10-11-85$ & $<0.100$ & $<0.100$ & $<0.100$ & $<0.100$ & $<0.100$ & $<1.00$ & $<10.0$ & $<1.00$ & $<1.00$ \\
\hline 01472109 & 6 & $10-11-85$ & $<.100$ & .200 & $<.100$ & $<.100$ & $<.100$ & $<1.00$ & $<10.0$ & 3.00 & $<1.00$ \\
\hline 01472138 & 13 & $10-22-86$ & $<.100$ & $<.100$ & .100 & $<.100$ & $<.100$ & $<1.00$ & $<10.0$ & $<1.00$ & $<1.00$ \\
\hline 01472140 & 12 & $10-10-85$ & $<.100$ & .400 & $<.100$ & $<.100$ & $<.100$ & $<1.00$ & $<10.0$ & $<1.00$ & $<1.00$ \\
\hline 01472154 & 14 & $10-11-85$ & $<.100$ & .100 & $<.100$ & $<.100$ & $<.100$ & $<1.00$ & $<10.0$ & 12.0 & $<1.00$ \\
\hline 01472157 & 15 & $10-28-94$ & $<.100$ & $<.100$ & $<.100$ & $<.800$ & $<.100$ & $<1.00$ & $<10.0$ & 4.00 & $<1.00$ \\
\hline \multirow[t]{2}{*}{014721612} & 16 & $10-09-85$ & $<.100$ & .100 & $<.100$ & $<.100$ & $<.100$ & $<1.00$ & $<10.0$ & 5.00 & $<1.00$ \\
\hline & & $10-28-94$ & .300 & .600 & $<.100$ & $<.800$ & $<.100$ & $<1.00$ & $<10.0$ & 18.0 & $<1.00$ \\
\hline 01472170 & 1 & $10-09-87$ & $<.100$ & $<.100$ & $<.100$ & 2.40 & $<.100$ & $<1.00$ & $<10.0$ & 3.00 & $<1.00$ \\
\hline 01472174 & 2 & $10-07-86$ & $<.100$ & $<.100$ & $<.100$ & $<.800$ & $<.100$ & $<1.00$ & $<10.0$ & $<5.00$ & $<1.00$ \\
\hline 014721854 & 3 & $10-08-86$ & $<.100$ & 3.80 & $<.100$ & $<.100$ & $<.100$ & $<1.00$ & $<10.0$ & $<1.00$ & $<1.00$ \\
\hline 014721884 & 4 & $10-07-85$ & $<.100$ & $<.100$ & $<.100$ & $<.100$ & $<.100$ & $<1.00$ & $<10.0$ & 9.00 & $<1.00$ \\
\hline \multirow[t]{2}{*}{01472190} & 5 & $10-06-86$ & $<.100$ & $<.100$ & $<.100$ & $<.100$ & .200 & $<1.00$ & $<10.0$ & $<1.00$ & $<1.00$ \\
\hline & & $10-26-94$ & $<.100$ & $<.800$ & $<.100$ & $<2.40$ & $<.100$ & $<1.00$ & $<10.0$ & 1.00 & $<1.00$ \\
\hline \multirow[t]{3}{*}{01473167} & 49 & $11-07-86$ & - & - & - & 55.0 & - & - & - & 15,000 & - \\
\hline & & $11-16-87$ & $<1.0$ & $<.100$ & $<.100$ & 13.0 & $<1.0$ & $<1.00$ & $<10.0$ & 540 & $<1.00$ \\
\hline & & $11-18-93$ & $<.100$ & $<.100$ & $<.100$ & $<.100$ & $<1.0$ & $<1.00$ & 110 & $<1.00$ & $<1.00$ \\
\hline \multirow[t]{2}{*}{01473168} & 50 & $10-09-85$ & .100 & .100 & $<.100$ & $<.100$ & $<.100$ & $<1.00$ & $<10.0$ & 18.0 & $<1.00$ \\
\hline & & $11-18-93$ & $<.100$ & $<.100$ & .100 & $<.400$ & $<.100$ & $<1.00$ & $<10.0$ & 22.0 & $<1.00$ \\
\hline 01475840 & 19 & $10-09-86$ & $<.100$ & $<.100$ & $<.100$ & $<.100$ & .700 & $<1.00$ & $<10.0$ & 7.00 & $<1.00$ \\
\hline 01476430 & 20 & $10-15-85$ & $<.100$ & .400 & .100 & $<.100$ & $<.100$ & $<1.00$ & $<10.0$ & 5.00 & $<1.00$ \\
\hline 01476435 & 21 & $10-09-86$ & $<.100$ & $<.100$ & $<.100$ & $<.100$ & $<.100$ & $<1.00$ & $<10.0$ & $<1.00$ & $<1.00$ \\
\hline 01476790 & 22 & $10-15-86$ & $<.100$ & .100 & .100 & $<.100$ & $<.100$ & $<1.00$ & $<10.0$ & 8.00 & $<1.00$ \\
\hline 01476830 & 23 & $10-15-86$ & $<.100$ & .200 & $<.100$ & $<.100$ & $<.100$ & $<1.00$ & $<10.0$ & 4.00 & $<1.00$ \\
\hline \multirow[t]{2}{*}{01476835} & 24 & $10-16-85$ & $<.100$ & .100 & .400 & $<.100$ & $<.100$ & $<1.00$ & $<10.0$ & 2.00 & $<1.00$ \\
\hline & & $10-21-94$ & $<.100$ & $<.800$ & $<.100$ & $<22.0$ & $<.100$ & $<1.00$ & $<10.0$ & 22.0 & $<1.00$ \\
\hline \multirow[t]{2}{*}{01476840} & 25 & $11-04-88$ & $<.100$ & .300 & .300 & $<1.00$ & $<.100$ & $<1.00$ & $<10.0$ & 120 & $<1.00$ \\
\hline & & $11-19-93$ & .100 & $<.100$ & .100 & $<5.00$ & $<.100$ & $<1.00$ & $<10.0$ & 16.0 & $<1.00$ \\
\hline \multirow[t]{2}{*}{01476848} & 51 & $10-16-86$ & $<.100$ & .100 & 1.00 & $<.100$ & $<.100$ & $<1.00$ & $<10.0$ & 73.0 & $<1.00$ \\
\hline & & $10-17-94$ & $<.100$ & $<.800$ & $<.100$ & $<5.20$ & $<.100$ & $<1.00$ & $<10.0$ & 10.0 & $<1.00$ \\
\hline \multirow[t]{2}{*}{01478120} & 28 & $10-25-85$ & $<.100$ & $<.100$ & $<.100$ & $<.100$ & $<.100$ & $<1.00$ & $<10.0$ & $<1.00$ & $<1.00$ \\
\hline & & $11-24-93$ & $<.100$ & $<.100$ & $<.100$ & $<.200$ & $<.100$ & $<1.00$ & $<10.0$ & $<1.00$ & $<1.00$ \\
\hline \multirow[t]{2}{*}{01478190} & 29 & $12-02-86$ & $<.100$ & $<.100$ & $<.100$ & $<.100$ & $<.100$ & $<1.00$ & $<10.0$ & 3.00 & $<1.00$ \\
\hline & & $11-24-93$ & $<.100$ & $<.100$ & $<.100$ & $<.200$ & $<.100$ & $<1.00$ & $<10.0$ & $<1.00$ & $<1.00$ \\
\hline \multirow[t]{2}{*}{01478220} & 30 & $10-25-85$ & $<.100$ & $<.100$ & $<.100$ & $<.100$ & $<.100$ & $<1.00$ & $<10.0$ & $<1.00$ & $<1.00$ \\
\hline & & $11-23-93$ & $<.100$ & $<.100$ & $<.100$ & $<.200$ & $<.100$ & $<1.00$ & $<10.0$ & $<1.00$ & $<1.00$ \\
\hline \multirow[t]{3}{*}{01479680} & 27 & $11-01-83$ & $<1.00$ & $<1.00$ & $<1.00$ & 88.0 & $<1.00$ & $<10.0$ & $<10.0$ & 5,600 & - \\
\hline & & $11-18-86$ & $<.100$ & $<.100$ & $<.100$ & $<.100$ & .100 & - & $<10.0$ & 1,400 & $<1.00$ \\
\hline & & $11-22-93$ & $<.100$ & $<.100$ & $<.100$ & $<5.00$ & $<.100$ & $<1.00$ & $<20.0$ & 550 & $<1.00$ \\
\hline \multirow[t]{2}{*}{01479800} & 26 & $10-18-85$ & - & $<.100$ & .300 & $<.100$ & $<.100$ & $<1.00$ & $<10.0$ & 38.0 & 1.00 \\
\hline & & $11-22-93$ & $<.100$ & $<.100$ & $<.100$ & $<.400$ & $<.100$ & $<1.00$ & $<10.0$ & 2.00 & $<1.00$ \\
\hline 01480629 & 46 & $10-29-85$ & $<.100$ & $<.100$ & $<.100$ & $<.400$ & $<.100$ & $<1.00$ & $<10.0$ & $<1.00$ & $<1.00$ \\
\hline 01480632 & 45 & $10-30-86$ & $<.100$ & .100 & $<.100$ & $<.100$ & $<.100$ & $<1.00$ & $<10.0$ & $<1.00$ & $<1.00$ \\
\hline \multirow[t]{2}{*}{01480640} & 38 & $10-22-85$ & $<.100$ & .100 & $<.100$ & $<.100$ & $<.100$ & $<1.00$ & $<10.0$ & 11.0 & $<1.00$ \\
\hline & & $11-15-93$ & $<.100$ & $<.100$ & $<.100$ & $<.200$ & $<.100$ & $<1.00$ & $<10.0$ & 12.0 & $<1.00$ \\
\hline
\end{tabular}


Table 4. Results of stream-bottom sediment sampling-Continued

\begin{tabular}{|c|c|c|c|c|c|c|c|c|c|c|c|}
\hline $\begin{array}{l}\text { Station } \\
\text { number }\end{array}$ & $\begin{array}{c}\text { Site } \\
\text { number }\end{array}$ & Date & $\begin{array}{l}\text { Hepta- } \\
\text { chlor, } \\
\text { total } \\
(\mu \mathrm{g} / \mathrm{kg})\end{array}$ & $\begin{array}{l}\text { Hepta- } \\
\text { chlor, } \\
\text { epoxide, } \\
\text { total } \\
(\mu \mathrm{g} / \mathrm{kg})\end{array}$ & $\begin{array}{c}\text { Lindane, } \\
\text { total } \\
(\mu \mathrm{g} / \mathrm{kg})\end{array}$ & $\begin{array}{c}\text { Meth- } \\
\text { oxy- } \\
\text { chlor, } \\
\text { total } \\
(\mu \mathrm{g} / \mathrm{kg})\end{array}$ & $\begin{array}{l}\text { Mirex } \\
\text { total } \\
(\mu \mathrm{g} / \mathrm{kg})\end{array}$ & $\begin{array}{l}\text { Per- } \\
\text { thane, } \\
\text { total } \\
(\mu \mathrm{g} / \mathrm{kg})\end{array}$ & $\begin{array}{c}\text { Toxa- } \\
\text { phene, } \\
\text { total } \\
(\mu \mathrm{g} / \mathrm{kg})\end{array}$ & $\begin{array}{c}\text { PCB, } \\
\text { total } \\
(\mu \mathrm{g} / \mathrm{kg})\end{array}$ & $\begin{array}{c}\text { PCN, } \\
\text { total } \\
(\mu \mathrm{g} / \mathrm{kg})\end{array}$ \\
\hline 01480648 & 48 & $10-29-86$ & $<0.100$ & $<0.100$ & $<0.100$ & $<0.100$ & $<0.100$ & $<1.00$ & $<10.0$ & $<1.00$ & $<1.00$ \\
\hline 01480653 & 42 & $10-23-85$ & $<.100$ & $<.100$ & $<.100$ & $<.100$ & $<.100$ & $<1.00$ & $<10.0$ & $<1.00$ & $<1.00$ \\
\hline 01480656 & 47 & $10-29-86$ & $<.100$ & $<.100$ & $<.100$ & $<.100$ & $<.100$ & $<1.00$ & $<10.0$ & 3.00 & $<1.00$ \\
\hline 01480700 & 36 & $10-21-85$ & $<.100$ & $<.100$ & $<.100$ & $<.100$ & $<.100$ & $<1.00$ & $<10.0$ & $<1.00$ & $<1.00$ \\
\hline 01480903 & 44 & $10-31-85$ & $<.100$ & $<.100$ & $<.100$ & $<.100$ & $<.100$ & $<1.00$ & $<10.0$ & 40.0 & $<1.00$ \\
\hline \multirow[t]{2}{*}{01480950} & 39 & $11-03-86$ & $<.100$ & $<.100$ & .200 & .200 & $<.100$ & $<1.00$ & $<10.0$ & 14.0 & $<1.00$ \\
\hline & & $11-16-93$ & $<.100$ & $<.100$ & $<.100$ & $<.200$ & $<.100$ & $<1.00$ & $<10.0$ & 3.00 & $<1.00$ \\
\hline 01481030 & 40 & $10-30-85$ & $<.100$ & $<.100$ & $<.100$ & $<.100$ & $<.100$ & $<1.00$ & $<10.0$ & 6.00 & $<1.00$ \\
\hline \multirow[t]{2}{*}{01494900} & 31 & $10-28-86$ & .500 & $<.100$ & $<.100$ & $<.100$ & $<.100$ & $<1.00$ & $<10.0$ & $<1.00$ & $<1.00$ \\
\hline & & $11-04-94$ & $<.100$ & $<.100$ & $<.100$ & $<4.00$ & $<.100$ & $<1.00$ & $<10.0$ & $<1.00$ & $<1.00$ \\
\hline \multirow[t]{2}{*}{01494950} & 32 & $10-17-85$ & $<.100$ & $<.100$ & $<.100$ & $<4.00$ & $<.100$ & $<1.00$ & $<10.0$ & $<1.00$ & $<1.00$ \\
\hline & & $11-04-94$ & $<.100$ & .100 & $<.100$ & $<.100$ & $<.100$ & $<1.00$ & $<10.0$ & $<1.00$ & $<1.00$ \\
\hline 01578340 & 33 & $11-21-94$ & $<.100$ & $<.100$ & $<.100$ & $<14.0$ & $<.100$ & $<1.00$ & $<10.0$ & 3.00 & $<1.00$ \\
\hline 01578343 & 34 & $10-24-85$ & $<.100$ & $<.100$ & $<.100$ & $<.100$ & $<.100$ & $<1.00$ & $<10.0$ & $<1.00$ & $<1.00$ \\
\hline
\end{tabular}


Table 5. Benthic-macroinvertebrate data

$[<$, less than; - , not found]

01472054 - Pigeon Creek near Bucktown, Pa. (Site 8)

\begin{tabular}{|c|c|c|c|c|}
\hline \multirow{3}{*}{$\begin{array}{c}\text { Date } \\
\text { Total count } \\
\text { Organism }\end{array}$} & \multirow{2}{*}{\multicolumn{2}{|c|}{$\begin{array}{c}\text { Oct. 21, } 1981 \\
822\end{array}$}} & \multirow{2}{*}{\multicolumn{2}{|c|}{$\begin{array}{c}\text { Oct. 29, } 1982 \\
975\end{array}$}} \\
\hline & & & & \\
\hline & Count & Percent & Count & Percent \\
\hline \multicolumn{5}{|l|}{ Platyhelminthes (flatworms) } \\
\hline \multicolumn{5}{|l|}{ Turbellaria } \\
\hline \multicolumn{5}{|l|}{ Tricladida } \\
\hline Planariidae & 7 & $<1$ & 1 & $<1$ \\
\hline \multicolumn{5}{|l|}{ Nemertea (proboscis worms) } \\
\hline \multicolumn{5}{|l|}{ Enopla } \\
\hline \multicolumn{5}{|l|}{ Hoplonemertea } \\
\hline \multicolumn{5}{|l|}{ Tetrastemmatidae } \\
\hline Prostoma & - & & 4 & $<1$ \\
\hline \multicolumn{5}{|l|}{ Mollusca (molluscs) } \\
\hline \multicolumn{5}{|l|}{ Gastropoda } \\
\hline \multicolumn{5}{|l|}{ Basommatophora } \\
\hline \multicolumn{5}{|l|}{ Ancylidae } \\
\hline Ferrissia & 1 & $<1$ & - & \\
\hline \multicolumn{5}{|l|}{ Physidae } \\
\hline Physa & 1 & $<1$ & - & \\
\hline \multicolumn{5}{|l|}{ Annelida (segmented worms) } \\
\hline Oligochaeta & 4 & $<1$ & 3 & $<1$ \\
\hline \multicolumn{5}{|l|}{ Arthropoda (arthropods) } \\
\hline \multicolumn{5}{|l|}{ Acariformes } \\
\hline Hydrachnidia & 2 & $<1$ & 1 & $<1$ \\
\hline \multicolumn{5}{|l|}{ Insecta } \\
\hline \multicolumn{5}{|l|}{ Ephemeroptera } \\
\hline \multicolumn{5}{|l|}{ Baetidae } \\
\hline Baetis & 13 & 2 & 12 & 1 \\
\hline Pseudocloeon & - & & 2 & $<1$ \\
\hline \multicolumn{5}{|l|}{ Ephemerellidae } \\
\hline Ephemerella & 57 & 7 & 85 & 9 \\
\hline \multicolumn{5}{|l|}{ Heptageniidae } \\
\hline Stenonema & 65 & 8 & 110 & 11 \\
\hline Isonychia & 2 & $<1$ & 5 & $<1$ \\
\hline Plecoptera & & & & \\
\hline Capniidae & & & & \\
\hline Allocapnia & 1 & $<1$ & - & \\
\hline Chloroperlidae & 1 & $<1$ & 10 & 1 \\
\hline Perlidae & & & & \\
\hline Paragnetina & - & & 1 & $<1$ \\
\hline Perlodidae & & & & \\
\hline Isoperla & - & & 1 & $<1$ \\
\hline Taeniopterygidae & & & & \\
\hline Taeniopteryx & 27 & 3 & 44 & 4 \\
\hline Megaloptera & & & & \\
\hline Corydalidae & & & & \\
\hline Nigronia & - & & 1 & $<1$ \\
\hline
\end{tabular}


Table 5. Benthic-macroinvertebrate data-Continued

01472054 - Pigeon Creek near Bucktown, Pa. (Site 8)—Continued

\begin{tabular}{|c|c|c|c|c|}
\hline \multirow{3}{*}{$\begin{array}{c}\text { Date } \\
\text { Total count } \\
\text { Organism }\end{array}$} & \multicolumn{2}{|c|}{ Oct. 21,1981} & \multicolumn{2}{|c|}{ Oct. 29, 1982} \\
\hline & \multicolumn{2}{|c|}{822} & \multicolumn{2}{|c|}{975} \\
\hline & Count & Percent & Count & Percen \\
\hline \multicolumn{5}{|l|}{ Trichoptera } \\
\hline \multicolumn{5}{|l|}{ Brachycentridae } \\
\hline Micrasema & - & & 1 & $<1$ \\
\hline \multicolumn{5}{|l|}{ Glossosomatidae } \\
\hline Glossosoma & 2 & $<1$ & 29 & 3 \\
\hline \multicolumn{5}{|l|}{ Hydropsychidae } \\
\hline Ceratopsyche & 2 & $<1$ & 18 & 2 \\
\hline Cheumatopsyche & 200 & 24 & 120 & 12 \\
\hline Hydropsyche & 240 & 29 & 190 & 19 \\
\hline \multicolumn{5}{|l|}{ Philopotamidae } \\
\hline Chimarra & 37 & 4 & 100 & 10 \\
\hline \multicolumn{5}{|l|}{ Polycentropodidae } \\
\hline Polycentropus & - & & 1 & $<1$ \\
\hline \multicolumn{5}{|l|}{ Uenoidae } \\
\hline Neophylax & 1 & $<1$ & 4 & $<1$ \\
\hline \multicolumn{5}{|l|}{ Coleoptera } \\
\hline Dytiscidae & 1 & $<1$ & - & \\
\hline \multicolumn{5}{|l|}{ Elmidae } \\
\hline Macronychus & - & & 1 & $<1$ \\
\hline Optioservus & 32 & 4 & 14 & 1 \\
\hline Oulimnius & 2 & $<1$ & - & \\
\hline Promoresia & 21 & 3 & 3 & $<1$ \\
\hline Stenelmis & 5 & $<1$ & 3 & $<1$ \\
\hline \multicolumn{5}{|l|}{ Psephenidae } \\
\hline \multicolumn{5}{|l|}{ Ectopria } \\
\hline E. nervosa & 1 & $<1$ & 1 & $<1$ \\
\hline \multicolumn{5}{|l|}{ Diptera } \\
\hline Chironomidae & 65 & 8 & 92 & 9 \\
\hline \multicolumn{5}{|l|}{ Empididae } \\
\hline Hemerodromia & 12 & 1 & 5 & $<1$ \\
\hline \multicolumn{5}{|l|}{ Simuliidae } \\
\hline Simulium & 12 & 1 & 18 & 2 \\
\hline \multicolumn{5}{|l|}{ Tipulidae } \\
\hline Antocha & 8 & 1 & 95 & 10 \\
\hline
\end{tabular}


Table 5. Benthic-macroinvertebrate data-Continued

01472065 - Pigeon Creek at Porters Mill, Pa. (Site 9)

\begin{tabular}{|c|c|c|c|c|}
\hline \multirow{3}{*}{$\begin{array}{c}\text { Date } \\
\text { Total count } \\
\text { Organism }\end{array}$} & \multirow{2}{*}{\multicolumn{2}{|c|}{$\begin{array}{c}\text { Oct. 20, } 1981 \\
482\end{array}$}} & \multirow{2}{*}{\multicolumn{2}{|c|}{$\begin{array}{c}\text { Oct. 29, } 1982 \\
918\end{array}$}} \\
\hline & & & & \\
\hline & Count & Percent & Count & Percent \\
\hline \multicolumn{5}{|l|}{ Mollusca (molluscs) } \\
\hline \multicolumn{5}{|l|}{ Gastropoda } \\
\hline \multicolumn{5}{|l|}{ Basommatophora } \\
\hline \multicolumn{5}{|l|}{ Lymnaeidae } \\
\hline Lymnaea & 1 & $<1$ & - & \\
\hline \multicolumn{5}{|l|}{ Arthropoda (arthropods) } \\
\hline \multicolumn{5}{|l|}{ Acariformes } \\
\hline Hydrachnidia & 2 & $<1$ & 4 & $<1$ \\
\hline \multicolumn{5}{|l|}{ Insecta } \\
\hline \multicolumn{5}{|l|}{ Ephemeroptera } \\
\hline \multicolumn{5}{|l|}{ Baetidae } \\
\hline Baetis & 2 & $<1$ & - & \\
\hline Pseudocloeon & - & & 4 & $<1$ \\
\hline \multicolumn{5}{|l|}{ Ephemerellidae } \\
\hline Ephemerella & 4 & $<1$ & 120 & 13 \\
\hline \multicolumn{5}{|l|}{ Heptageniidae } \\
\hline Stenonema & 58 & 12 & 150 & 16 \\
\hline \multicolumn{5}{|l|}{ Isonychiidae } \\
\hline Isonychia & 27 & 6 & 46 & 5 \\
\hline \multicolumn{5}{|l|}{ Plecoptera } \\
\hline Capniidae & - & & 1 & $<1$ \\
\hline \multicolumn{5}{|l|}{ Perlidae } \\
\hline Paragnetina & 12 & 2 & 1 & $<1$ \\
\hline \multicolumn{5}{|l|}{ Taeniopterygidae } \\
\hline Taeniopteryx & 6 & 1 & 5 & $<1$ \\
\hline \multicolumn{5}{|l|}{ Trichoptera } \\
\hline \multicolumn{5}{|l|}{ Brachycentridae } \\
\hline Micrasema & 7 & 2 & 13 & 1 \\
\hline \multicolumn{5}{|l|}{ Glossosomatidae } \\
\hline Glossosoma & 5 & 1 & 5 & $<1$ \\
\hline \multicolumn{5}{|l|}{ Goeridae } \\
\hline Goera & - & & 1 & $<1$ \\
\hline \multicolumn{5}{|l|}{ Hydropsychidae } \\
\hline Ceratopsyche & 25 & 5 & 78 & 8 \\
\hline Cheumatopsyche & 180 & 37 & 64 & 7 \\
\hline Hydropsyche & 25 & 5 & 51 & 6 \\
\hline Hydroptilidae & & & & \\
\hline Hydroptila & - & & 14 & 2 \\
\hline Leucotrichia & 2 & $<1$ & 21 & 2 \\
\hline Leptoceridae & & & & \\
\hline Oecetis & - & & 1 & $<1$ \\
\hline Philopotamidae & & & & \\
\hline Chimarra & 12 & 2 & 13 & 1 \\
\hline Psychomyiidae & & & & \\
\hline Psychomyia & 2 & $<1$ & - & \\
\hline
\end{tabular}


Table 5. Benthic-macroinvertebrate data-Continued

01472065 - Pigeon Creek at Porters Mill, Pa. (Site 9)—Continued

\begin{tabular}{|c|c|c|c|c|}
\hline \multirow{3}{*}{$\begin{array}{c}\text { Date } \\
\text { Total count } \\
\text { Organism }\end{array}$} & \multirow{2}{*}{\multicolumn{2}{|c|}{$\frac{\text { Oct. } 20,1981}{482}$}} & \multirow{2}{*}{\multicolumn{2}{|c|}{$\frac{\text { Oct. } 29,1982}{918}$}} \\
\hline & & & & \\
\hline & Count & Percent & Count & Percent \\
\hline \multicolumn{5}{|l|}{ Coleoptera } \\
\hline \multicolumn{5}{|l|}{ Elmidae } \\
\hline Optioservus & 4 & $<1$ & 3 & $<1$ \\
\hline Stenelmis & 1 & $<1$ & - & \\
\hline \multicolumn{5}{|l|}{ Psephenidae } \\
\hline Ectopria & 1 & $<1$ & - & \\
\hline Diptera & 1 & $<1$ & - & \\
\hline \multicolumn{5}{|l|}{ Athericidae } \\
\hline Atherix & - & & 1 & $<1$ \\
\hline Chironomidae & 48 & 10 & 220 & 24 \\
\hline \multicolumn{5}{|l|}{ Empididae } \\
\hline Hemerodromia & - & & 8 & $<1$ \\
\hline \multicolumn{5}{|l|}{ Simuliidae } \\
\hline Simulium & 6 & 1 & 5 & $<1$ \\
\hline \multicolumn{5}{|l|}{ Tipulidae } \\
\hline Antocha & 51 & 10 & 89 & 10 \\
\hline
\end{tabular}


Table 5. Benthic-macroinvertebrate data-Continued

$[<$, less than; - , not found]

01472080 - Pigeon Creek near Parker Ford, Pa. (Site 10)

\begin{tabular}{|c|c|c|c|c|c|c|c|c|c|c|c|c|c|c|}
\hline \multirow{3}{*}{$\begin{array}{c}\text { Date } \\
\text { Total count } \\
\text { Organism }\end{array}$} & \multirow{2}{*}{\multicolumn{2}{|c|}{$\frac{\text { Oct. } 20,1981}{2,785}$}} & \multirow{2}{*}{\multicolumn{2}{|c|}{$\begin{array}{c}\text { Oct. } 29,1982 \\
1,691\end{array}$}} & \multirow{2}{*}{\multicolumn{2}{|c|}{$\frac{\text { Oct. } 21,1983}{969}$}} & \multirow{2}{*}{\multicolumn{2}{|c|}{$\begin{array}{c}\text { Oct. 22, } 1984 \\
1,492\end{array}$}} & \multirow{2}{*}{\multicolumn{2}{|c|}{$\begin{array}{c}\text { Oct. } 11,1985 \\
1,032\end{array}$}} & \multirow{2}{*}{\multicolumn{2}{|c|}{$\frac{\text { Oct. } 10,1986}{1,133}$}} & \multirow{2}{*}{\multicolumn{2}{|c|}{$\begin{array}{c}\text { Nov. } 13,1987 \\
2,098\end{array}$}} \\
\hline & & & & & & & & & & & & & & \\
\hline & Count & Percent & Count & Percent & Count & Percent & Count & Percent & Count & Percent & Count & Percent & Count & Percent \\
\hline \multicolumn{15}{|l|}{ Platyhelminthes (flatworms) } \\
\hline \multicolumn{15}{|l|}{ Turbellaria } \\
\hline \multicolumn{15}{|l|}{ Tricladida } \\
\hline Planariidae & 11 & $<1$ & 8 & $<1$ & 5 & $<1$ & 3 & $<1$ & 1 & $<1$ & 3 & $<1$ & 5 & $<1$ \\
\hline Nematoda (nematodes) & - & & - & & - & & - & & - & & - & & 4 & $<1$ \\
\hline \multicolumn{15}{|l|}{ Nemertea (proboscis worms) } \\
\hline \multicolumn{15}{|l|}{ Enopla } \\
\hline \multicolumn{15}{|l|}{ Hoplonemertea } \\
\hline \multicolumn{15}{|l|}{ Tetrastemmatidae } \\
\hline Prostoma & - & & - & & - & & - & & - & & - & & - & \\
\hline Mollusca (molluscs) & & & & & & & & & & & & & & \\
\hline Gastropoda & & & & & & & & & & & & & & \\
\hline Basommatophora & & & & & & & & & & & & & & \\
\hline Ancylidae & & & & & & & & & & & & & & \\
\hline Ferrissia & - & & - & & - & & - & & - & & - & & - & \\
\hline Physidae & & & & & & & & & & & & & & \\
\hline Physa & - & & - & & - & & - & & - & & - & & - & \\
\hline Annelida (segmented worms) & & & & & & & & & & & & & & \\
\hline Oligochaeta & 5 & $<1$ & 3 & $<1$ & 4 & $<1$ & 1 & $<1$ & - & & - & & - & \\
\hline Tubificida & & & & & & & & & & & & & & \\
\hline Naididae & - & & - & & - & & - & & - & & - & & 65 & 3 \\
\hline Arthropoda (arthropods) & & & & & & & & & & & & & & \\
\hline Acariformes & & & & & & & & & & & & & & \\
\hline Hydrachnidia & 9 & $<1$ & 3 & $<1$ & - & & 3 & $<1$ & - & & - & & 84 & 4 \\
\hline Crustacea & & & & & & & & & & & & & & \\
\hline Cyclopoida & & & & & & & & & & & & & & \\
\hline Cyclopidae & - & & - & & - & & - & & - & & - & & 2 & $<1$ \\
\hline Amphipoda & & & & & & & & & & & & & & \\
\hline Talitridae & & & & & & & & & & & & & & \\
\hline Hyallela & & & & & & & & & & & & & & \\
\hline H. azteca & - & & - & & - & & - & & - & & - & & 1 & $<1$ \\
\hline Isopoda & & & & & & & & & & & & & & \\
\hline Asellidae & & & & & & & & & & & & & & \\
\hline Caecidotea & - & & - & & - & & - & & - & & - & & 1 & $<1$ \\
\hline Podocopa & - & & - & & - & & - & & - & & - & & - & \\
\hline Insecta & & & & & & & & & & & & & & \\
\hline Ephemeroptera & & & & & & & & & & & & & & \\
\hline Baetidae & & & & & & & & & & & & & & \\
\hline Baetis & 29 & 1 & 11 & $<1$ & - & & 1 & $<1$ & 4 & $<1$ & 19 & 2 & - & \\
\hline Pseudocloeon & 14 & $<1$ & 16 & $<1$ & 3 & $<1$ & 7 & $<1$ & - & & 7 & $<1$ & 7 & $<1$ \\
\hline Ephemerellidae & & & & & & & & & & & & & & \\
\hline Ephemerella & 79 & 3 & 84 & 5 & 5 & $<1$ & 74 & 5 & 41 & 4 & 21 & 2 & 380 & 18 \\
\hline Heptageniidae & & & & & & & & & & & & & & \\
\hline Epeorus & - & & - & & - & & - & & - & & - & & 4 & $<1$ \\
\hline Stenonema & 280 & 10 & 110 & 6 & 81 & 8 & 150 & 10 & 58 & 6 & 48 & 4 & 92 & 4 \\
\hline Isonychiidae & - & & - & & - & & - & & - & & - & & - & \\
\hline Isonychia & 57 & 2 & 13 & $<1$ & 27 & 3 & 38 & 3 & 17 & 2 & 55 & 5 & 12 & $<1$ \\
\hline Leptophlebiidae & - & & - & & - & & - & & - & & - & & - & \\
\hline Paraleptophlebia & - & & - & & - & & - & & - & & - & & - & \\
\hline Leptohyphidae & & & & & & & & & & & & & & \\
\hline Tricorythodes & - & & - & & - & & 2 & $<1$ & - & & - & & - & \\
\hline
\end{tabular}




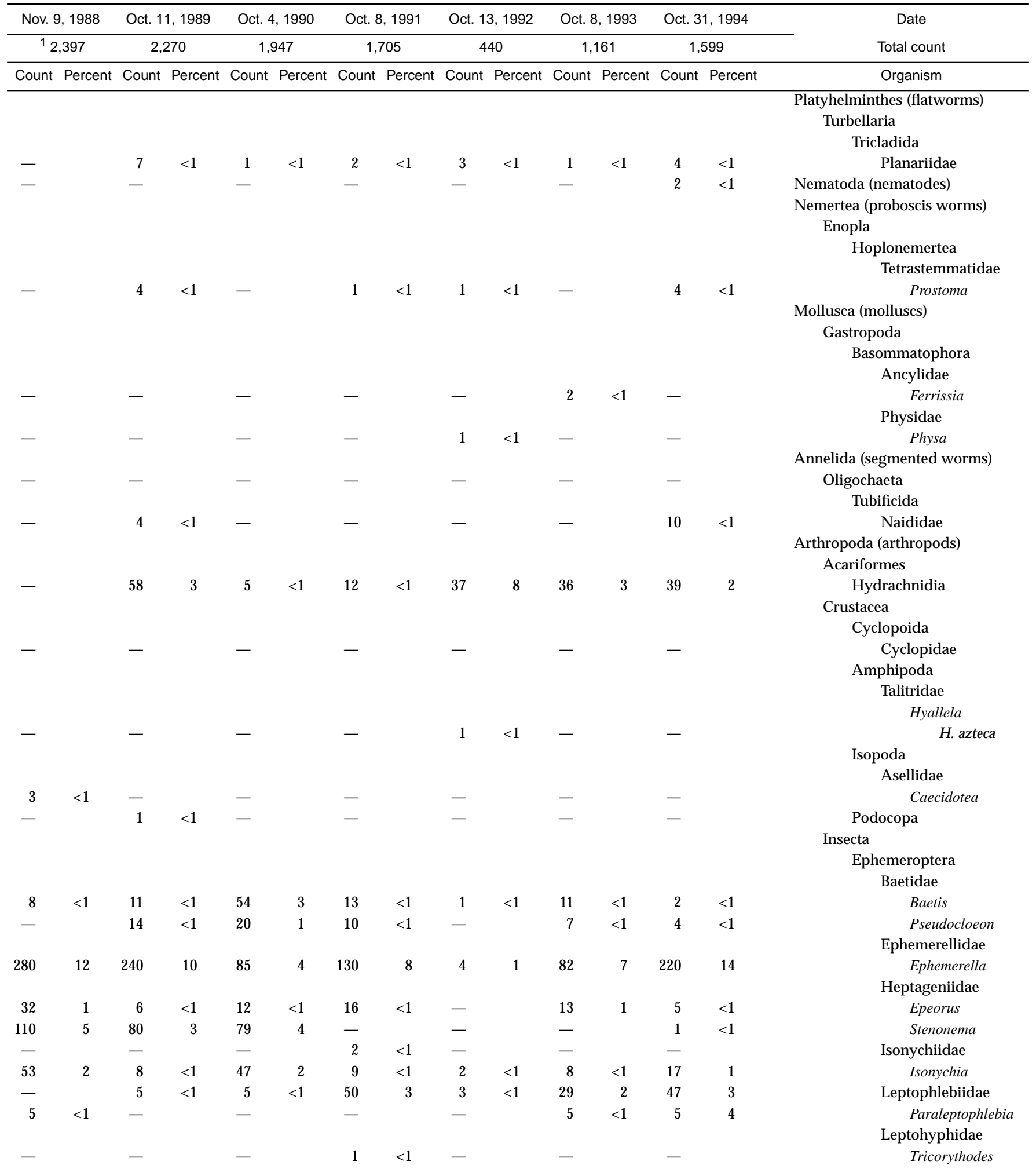


Table 5. Benthic-macroinvertebrate data-Continued

01472080 - Pigeon Creek near Parker Ford, Pa. (Site 10)—Continued

\begin{tabular}{|c|c|c|c|c|c|c|c|c|c|c|c|c|c|c|}
\hline \multirow{3}{*}{$\begin{array}{c}\text { Date } \\
\text { Total count } \\
\text { Organism }\end{array}$} & \multirow{2}{*}{\multicolumn{2}{|c|}{$\begin{array}{c}\text { Oct. } 20,1981 \\
2,785\end{array}$}} & \multirow{2}{*}{\multicolumn{2}{|c|}{$\begin{array}{c}\text { Oct. } 29,1982 \\
1,691\end{array}$}} & \multirow{2}{*}{\multicolumn{2}{|c|}{$\begin{array}{c}\text { Oct. 21, } 1983 \\
969\end{array}$}} & \multirow{2}{*}{\multicolumn{2}{|c|}{$\begin{array}{c}\text { Oct. } 22,1984 \\
1,492 \\
\end{array}$}} & \multirow{2}{*}{\multicolumn{2}{|c|}{$\begin{array}{c}\text { Oct. } 11,1985 \\
1,032\end{array}$}} & \multirow{2}{*}{\multicolumn{2}{|c|}{$\begin{array}{c}\text { Oct. } 10,1986 \\
1,133\end{array}$}} & \multirow{2}{*}{\multicolumn{2}{|c|}{$\begin{array}{c}\text { Nov. } 13,1987 \\
2,098\end{array}$}} \\
\hline & & & & & & & & & & & & & & \\
\hline & Count & Percent & Count & Percent & Count & Percent & Count & Percent & Count & Percent & Count & Percent & Count & Percent \\
\hline \multicolumn{15}{|l|}{ Plecoptera } \\
\hline Capniidae & 3 & $<1$ & - & & - & & - & & - & & - & & - & \\
\hline Allocapnia & - & & 10 & $<1$ & 2 & $<1$ & 38 & 3 & - & & - & & 14 & $<1$ \\
\hline Chloroperlidae & - & & - & & - & & - & & - & & - & & - & \\
\hline \multicolumn{15}{|l|}{ Perlidae } \\
\hline Acroneuria & 3 & $<1$ & - & & 1 & $<1$ & - & & - & & - & & - & \\
\hline Agnetina & - & & - & & - & & - & & - & & - & & - & \\
\hline Paragnetina & 6 & $<1$ & 8 & $<1$ & 4 & $<1$ & 14 & $<1$ & 2 & $<1$ & 3 & $<1$ & 4 & $<1$ \\
\hline \multicolumn{15}{|l|}{ Perlodidae } \\
\hline Isoperla & - & & - & & - & & - & & - & & - & & - & \\
\hline \multicolumn{15}{|l|}{ Taeniopterygidae } \\
\hline Strophopteryx & - & & - & & - & & - & & - & & - & & 13 & $<1$ \\
\hline Taeniopteryx & 17 & $<1$ & 23 & 1 & 2 & $<1$ & 13 & $<1$ & - & & 7 & $<1$ & 9 & $<1$ \\
\hline \multicolumn{15}{|l|}{ Hemiptera } \\
\hline \multicolumn{15}{|l|}{ Veliidae } \\
\hline Rhagovelia & 1 & $<1$ & - & & - & & 2 & $<1$ & - & & - & & - & \\
\hline \multicolumn{15}{|l|}{ Megaloptera } \\
\hline \multicolumn{15}{|l|}{ Corydalidae } \\
\hline Corydalus & 1 & $<1$ & - & & - & & - & & - & & - & & 1 & $<1$ \\
\hline \multicolumn{15}{|l|}{ Trichoptera } \\
\hline Apatania & - & & - & & - & & - & & - & & - & & 7 & $<1$ \\
\hline \multicolumn{15}{|l|}{ Brachycentridae } \\
\hline $\begin{array}{c}\text { Micrasema } \\
\text { Glossosomatidae }\end{array}$ & 17 & $<1$ & 6 & $<1$ & 9 & $<1$ & 8 & $<1$ & 17 & 2 & 110 & 10 & 82 & 4 \\
\hline $\begin{array}{l}\text { Glossosoma } \\
\text { Goeridae }\end{array}$ & 8 & $<1$ & 77 & 5 & 47 & 5 & 56 & 4 & 3 & $<1$ & 17 & 2 & 10 & $<1$ \\
\hline $\begin{array}{c}\text { Goera } \\
\text { Helicopsychidae }\end{array}$ & 7 & $<1$ & - & & - & & - & & - & & - & & 1 & $<1$ \\
\hline $\begin{array}{l}\text { Helicopsyche } \\
\text { Hydropsychidae }\end{array}$ & - & & - & & - & & - & & - & & - & & - & \\
\hline Ceratopsyche & 760 & 27 & 350 & 21 & 240 & 24 & 210 & 14 & 54 & 5 & 120 & 11 & 130 & 6 \\
\hline Cheumatopsyche & 420 & 15 & 86 & 5 & 35 & 4 & 54 & 4 & 44 & 4 & 40 & 4 & 53 & 3 \\
\hline Hydropsyche & 100 & 4 & 60 & 4 & 91 & 9 & 48 & 3 & 8 & $<1$ & 80 & 7 & 83 & 4 \\
\hline Hydroptilidae & & & & & & & & & & & & & & \\
\hline Hydroptila & 3 & $<1$ & 2 & $<1$ & 1 & $<1$ & 2 & $<1$ & - & & 1 & $<1$ & 41 & 2 \\
\hline Leucotrichia & 20 & $<1$ & 130 & 8 & 210 & 21 & 340 & 23 & 400 & 40 & 360 & 33 & 100 & 5 \\
\hline Leptoceridae & & & & & & & & & & & & & & \\
\hline $\begin{array}{c}\text { Oecetis } \\
\text { Philopotamidae }\end{array}$ & - & & - & & - & & - & & - & & - & & - & \\
\hline Chimarra & 94 & 3 & 68 & 4 & 41 & 4 & 43 & 3 & 41 & 4 & 15 & 1 & 62 & 3 \\
\hline Wormaldia & - & & - & & - & & - & & - & & - & & - & \\
\hline Polycentropodidae & & & & & & & & & & & & & & \\
\hline $\begin{array}{l}\text { Polycentropus } \\
\text { Psychomyiidae }\end{array}$ & - & & - & & 1 & $<1$ & - & & - & & - & & - & \\
\hline $\begin{array}{l}\text { Psychomyia } \\
\text { Uenoidae }\end{array}$ & - & & 2 & $<1$ & 2 & $<1$ & 9 & $<1$ & 21 & 2 & 52 & 5 & 61 & 3 \\
\hline Neophylax & - & & 6 & $<1$ & - & & - & & - & & - & & - & \\
\hline
\end{tabular}




\begin{tabular}{|c|c|c|c|c|c|c|c|c|c|c|c|c|c|c|}
\hline \multirow{2}{*}{\multicolumn{2}{|c|}{$\begin{array}{c}\text { Nov. 9, } 1988 \\
{ }^{1} 2,397\end{array}$}} & \multirow{2}{*}{\multicolumn{2}{|c|}{$\frac{\text { Oct. } 11,1989}{2,270}$}} & \multirow{2}{*}{\multicolumn{2}{|c|}{ Oct. 4, 1990}} & \multicolumn{2}{|c|}{ Oct. 8, 1991} & \multicolumn{2}{|c|}{ Oct. 13, 1992} & \multicolumn{2}{|c|}{ Oct. 8, 1993} & \multicolumn{2}{|c|}{ Oct. 31, 1994} & \multirow{3}{*}{$\begin{array}{c}\text { Date } \\
\text { Total count } \\
\text { Organism }\end{array}$} \\
\hline & & & & & & & 705 & & 40 & & 161 & 1,5 & 599 & \\
\hline Count & Percent & Count & Percent & Count & Percent & Count & Percent & Count & Percent & Count & Percent & Count & Percent & \\
\hline & & & & & & & & & & & & & & Plecoptera \\
\hline - & & - & & - & & - & & - & & - & & - & & Capniidae \\
\hline 11 & $<1$ & 2 & $<1$ & - & & - & & - & & - & & 3 & $<1$ & Allocapnia \\
\hline - & & - & & 1 & $<1$ & - & & - & & - & & - & & $\begin{array}{l}\text { Chloroperlidae } \\
\text { Perlidae }\end{array}$ \\
\hline 3 & $<1$ & 1 & $<1$ & 9 & $<1$ & - & & - & & 3 & $<1$ & 7 & $<1$ & Acroneuria \\
\hline 3 & $<1$ & 2 & $<1$ & - & & 1 & $<1$ & - & & - & & 2 & $<1$ & Agnetina \\
\hline - & & - & & - & & - & & 1 & $<1$ & 1 & $<1$ & 2 & $<1$ & $\begin{array}{l}\quad \text { Paragnetina } \\
\text { Perlodidae }\end{array}$ \\
\hline 16 & $<1$ & - & & - & & - & & - & & - & & - & & $\begin{array}{c}\text { Isoperla } \\
\text { Taeniopterygidae }\end{array}$ \\
\hline - & & - & & - & & - & & - & & - & & - & & Strophopteryx \\
\hline 8 & $<1$ & 1 & $<1$ & - & & - & & - & & - & & 1 & $<1$ & $\begin{array}{l}\text { Taeniopteryx } \\
\text { Hemiptera } \\
\text { Veliidae }\end{array}$ \\
\hline- & & 1 & $<1$ & - & & 1 & $<1$ & - & & - & & - & & $\begin{array}{l}\text { Rhagovelia } \\
\text { Megaloptera } \\
\text { Corydalidae }\end{array}$ \\
\hline- & & - & & - & & - & & - & & - & & - & & $\begin{array}{l}\text { Corydalus } \\
\text { Trichoptera } \\
\text { Apataniidae }\end{array}$ \\
\hline- & & 3 & $<1$ & 21 & 1 & 7 & $<1$ & - & & 14 & 1 & 4 & $<1$ & $\begin{array}{c}\text { Apatania } \\
\text { Brachycentridae }\end{array}$ \\
\hline 83 & 3 & 250 & 11 & 460 & 23 & 180 & 11 & 74 & 16 & 31 & 3 & 28 & 2 & $\begin{array}{c}\text { Micrasema } \\
\text { Glossosomatidae }\end{array}$ \\
\hline 3 & $<1$ & 11 & $<1$ & 21 & 1 & 9 & $<1$ & 1 & $<1$ & 3 & $<1$ & 13 & $<1$ & $\begin{array}{l}\text { Glossosoma } \\
\text { Goeridae }\end{array}$ \\
\hline 3 & $<1$ & 4 & $<1$ & 5 & $<1$ & 5 & $<1$ & 6 & 1 & 6 & $<1$ & 4 & $<1$ & $\begin{array}{c}\text { Goera } \\
\text { Helicopsychidae }\end{array}$ \\
\hline- & & - & & - & & - & & - & & 1 & $<1$ & 1 & $<1$ & $\begin{array}{l}\text { Helicopsyche } \\
\text { Hydropsychidae }\end{array}$ \\
\hline 240 & 10 & 280 & 12 & 300 & 15 & 210 & 12 & 41 & 9 & 120 & 10 & 340 & 21 & Ceratopsyche \\
\hline 99 & 4 & 60 & 3 & 32 & 2 & 14 & $<1$ & 6 & 1 & 65 & 5 & 71 & 4 & Cheumatopsyche \\
\hline 67 & 3 & 20 & $<1$ & 26 & 1 & 25 & 1 & 7 & 2 & 160 & 13 & 100 & 6 & $\begin{array}{l}\text { Hydropsyche } \\
\text { Hydroptilidae }\end{array}$ \\
\hline - & & - & & - & & 1 & $<1$ & 2 & $<1$ & 10 & $<1$ & 1 & $<1$ & Hydroptila \\
\hline 450 & 19 & 260 & 11 & 160 & 8 & 480 & 28 & 160 & 36 & 6 & $<1$ & 1 & $<1$ & $\begin{array}{l}\text { Leucotrichia } \\
\text { Leptoceridae }\end{array}$ \\
\hline- & & 1 & $<1$ & - & & - & & 4 & 1 & - & & 1 & $<1$ & $\begin{array}{c}\text { Oecetis } \\
\text { Philopotamidae }\end{array}$ \\
\hline 83 & 3 & 51 & 2 & 58 & 3 & 25 & 1 & 4 & 1 & 6 & $<1$ & 37 & 2 & Chimarra \\
\hline 5 & $<1$ & - & & - & & - & & - & & - & & - & & $\begin{array}{c}\text { Wormaldia } \\
\text { Polycentropodidae }\end{array}$ \\
\hline - & & 2 & $<1$ & - & & 3 & $<1$ & - & & 1 & $<1$ & - & & $\begin{array}{l}\text { Polycentropus } \\
\text { Psychomyiidae }\end{array}$ \\
\hline 120 & 5 & 210 & 9 & 96 & 5 & 80 & 5 & 2 & $<1$ & 4 & $<1$ & 13 & $<1$ & $\begin{array}{l}\text { Psychomyia } \\
\text { Uenoidae }\end{array}$ \\
\hline 13 & $<1$ & - & & 3 & $<1$ & - & & - & & - & & - & & Neophylax \\
\hline
\end{tabular}


Table 5. Benthic-macroinvertebrate data-Continued

01472080 - Pigeon Creek near Parker Ford, Pa. (Site 10)—Continued

\begin{tabular}{|c|c|c|c|c|c|c|c|c|c|c|c|c|c|c|}
\hline \multirow{3}{*}{$\begin{array}{c}\text { Date } \\
\text { Total count } \\
\text { Organism }\end{array}$} & \multirow{2}{*}{\multicolumn{2}{|c|}{$\begin{array}{c}\text { Oct. } 20,1981 \\
2,785\end{array}$}} & \multirow{2}{*}{\multicolumn{2}{|c|}{$\frac{\text { Oct. 29, } 1982}{1,691}$}} & \multirow{2}{*}{\multicolumn{2}{|c|}{$\frac{\text { Oct. } 21,1983}{969}$}} & \multirow{2}{*}{\multicolumn{2}{|c|}{$\begin{array}{c}\text { Oct. 22, } 1984 \\
1,492\end{array}$}} & \multirow{2}{*}{\multicolumn{2}{|c|}{$\begin{array}{c}\text { Oct. } 11,1985 \\
1,032\end{array}$}} & \multirow{2}{*}{\multicolumn{2}{|c|}{$\begin{array}{c}\text { Oct. } 10,1986 \\
1,133\end{array}$}} & \multirow{2}{*}{\multicolumn{2}{|c|}{$\frac{\text { Nov. 13, } 1987}{2,098}$}} \\
\hline & & & & & & & & & & & & & & \\
\hline & Count & Percent & Count & Percent & Count & Percent & Count & Percent & Count & Percent & Count & Percent & Count & Percent \\
\hline \multicolumn{15}{|l|}{ Coleoptera } \\
\hline Chrysomelidae & 1 & $<1$ & - & & - & & - & & - & & - & & - & \\
\hline \multicolumn{15}{|l|}{ Dryopidae } \\
\hline Helichus & - & & 1 & $<1$ & - & & - & & - & & - & & - & \\
\hline Dytiscidae & 1 & $<1$ & - & & - & & - & & - & & - & & - & \\
\hline \multicolumn{15}{|l|}{ Elmidae } \\
\hline Dubiraphia & - & & - & & - & & - & & - & & 1 & $<1$ & 2 & $<1$ \\
\hline \multicolumn{15}{|l|}{ Macronychus } \\
\hline M. glabratus & - & & 1 & $<1$ & - & & - & & - & & - & & - & \\
\hline Optioservus & 31 & 1 & 3 & $<1$ & 11 & 1 & 10 & $<1$ & 4 & 1 & 5 & $<1$ & 20 & $<1$ \\
\hline Oulimnius & - & & - & & - & & - & & 2 & $<1$ & - & & 1 & $<1$ \\
\hline Promoresia & - & & - & & - & & - & & - & & - & & - & \\
\hline Stenelmis & 6 & $<1$ & - & & - & & 7 & $<1$ & 2 & $<1$ & 1 & $<1$ & 7 & $<1$ \\
\hline Hydrophilidae & - & & - & & - & & - & & - & & - & & - & \\
\hline \multicolumn{15}{|l|}{ Psephenidae } \\
\hline Ectopria & - & & - & & - & & - & & - & & - & & - & \\
\hline E. nervosa & 1 & $<1$ & - & & - & & - & & - & & - & & 1 & $<1$ \\
\hline Psephenus & 3 & $<1$ & 1 & $<1$ & - & & - & & - & & - & & 5 & $<1$ \\
\hline Hymenoptera & - & & 1 & $<1$ & - & & 1 & $<1$ & 1 & $<1$ & - & & - & \\
\hline \multicolumn{15}{|l|}{ Diptera } \\
\hline \multicolumn{15}{|l|}{ Athericidae } \\
\hline Atherix & - & & - & & - & & - & & - & & - & & 1 & $<1$ \\
\hline Chironomidae & 700 & 25 & 460 & 27 & 93 & 9 & 240 & 16 & 240 & 24 & 91 & 8 & 390 & 19 \\
\hline \multicolumn{15}{|l|}{ Empididae } \\
\hline Hemerodromia & 7 & $<1$ & 11 & $<1$ & 1 & $<1$ & 2 & $<1$ & - & & 1 & $<1$ & 13 & $<1$ \\
\hline Ephydridae & - & & - & & - & & - & & - & & - & & - & \\
\hline \multicolumn{15}{|l|}{ Simuliidae } \\
\hline Simulium & 30 & 1 & 27 & 2 & - & & 16 & 1 & 13 & 1 & 6 & $<1$ & 110 & 5 \\
\hline \multicolumn{15}{|l|}{ Tipulidae } \\
\hline Antocha & 61 & 2 & 110 & 6 & 53 & 5 & 100 & 7 & 59 & 6 & 70 & 6 & 220 & 10 \\
\hline Dicranota & - & & - & & - & & - & & - & & - & & - & \\
\hline
\end{tabular}

${ }^{1}$ Extrapolated from a 3/8 subsample. 


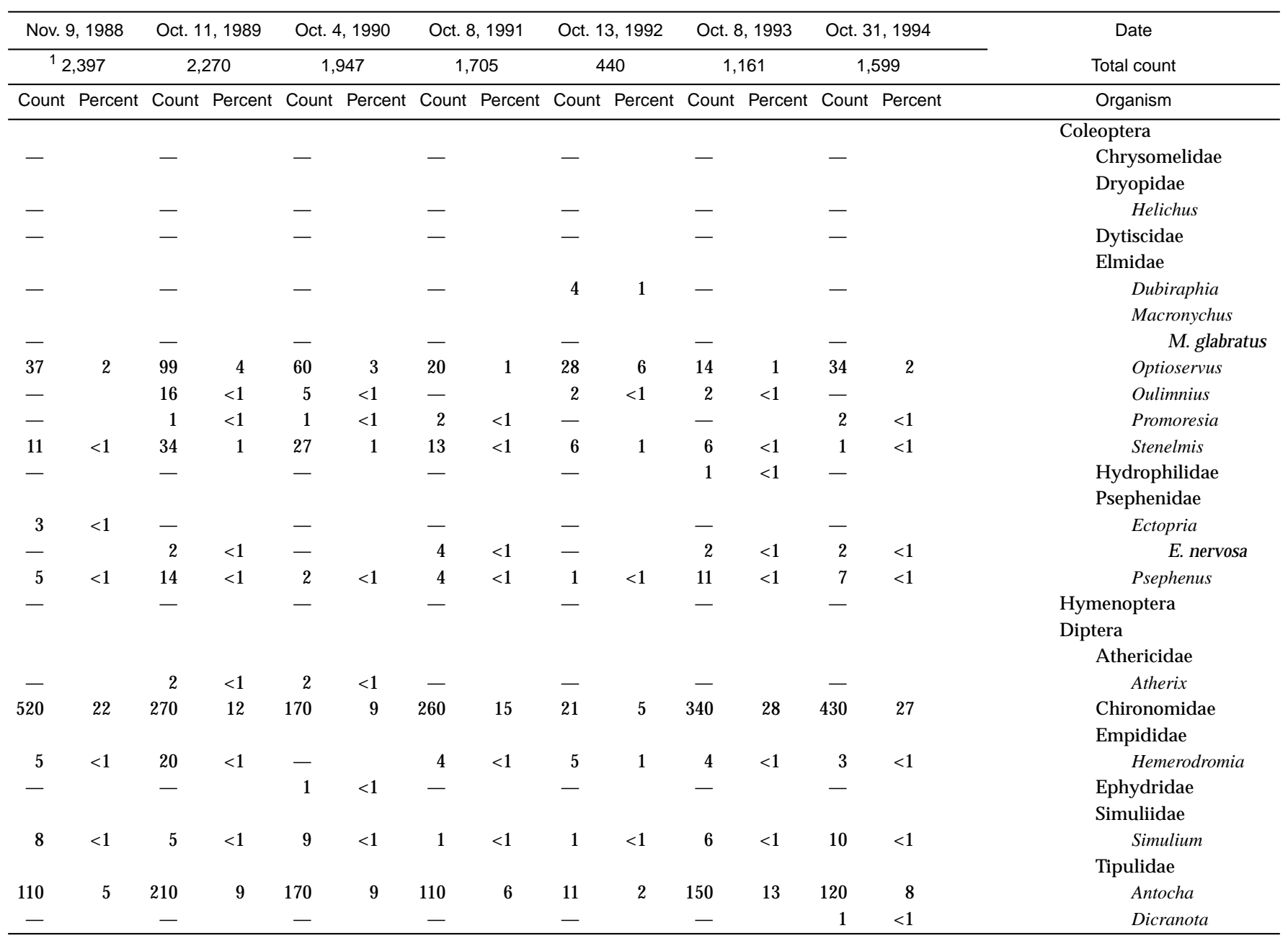


Table 5. Benthic-macroinvertebrate data-Continued

$[<$, less than; - , not found]

01472109 - Stony Run near Spring City, Pa. (Site 6)

\begin{tabular}{|c|c|c|c|c|c|c|c|c|c|c|c|c|c|c|}
\hline \multirow{3}{*}{$\begin{array}{cc}\text { Date } \\
\text { Total count }\end{array}$} & \multirow{2}{*}{\multicolumn{2}{|c|}{$\begin{array}{c}\text { Oct. } 20,1981 \\
12,760\end{array}$}} & \multirow{2}{*}{\multicolumn{2}{|c|}{$\begin{array}{c}\text { Oct. } 19,1982 \\
1,265\end{array}$}} & \multirow{2}{*}{\multicolumn{2}{|c|}{$\begin{array}{c}\text { Oct. } 20,1983 \\
2,082\end{array}$}} & \multirow{2}{*}{\multicolumn{2}{|c|}{$\begin{array}{c}\text { Oct. 9, } 1984 \\
998\end{array}$}} & \multirow{2}{*}{\multicolumn{2}{|c|}{$\frac{\text { Oct. } 11,1985}{550}$}} & \multirow{2}{*}{\multicolumn{2}{|c|}{$\begin{array}{c}\text { Oct. 10, } 1986 \\
651\end{array}$}} & \multirow{2}{*}{\multicolumn{2}{|c|}{$\begin{array}{c}\text { Nov. } 13,1987 \\
1,467\end{array}$}} \\
\hline & & & & & & & & & & & & & & \\
\hline & Count & Percent & Count & Percent & Count & Percent & Count & Percent & Count & Percent & Count & Percent & Count & Percent \\
\hline \multicolumn{15}{|l|}{ Platyhelminthes (flatworms) } \\
\hline \multicolumn{15}{|l|}{ Turbellaria } \\
\hline \multicolumn{15}{|l|}{ Tricladida } \\
\hline Planariidae & 3 & $<1$ & 9 & $<1$ & 83 & 4 & 41 & 4 & 14 & 3 & 10 & 1 & 34 & 2 \\
\hline Nematoda (nematodes) & - & & - & & - & & - & & - & & - & & 4 & $<1$ \\
\hline \multicolumn{15}{|l|}{ Nemertea (proboscis worms) } \\
\hline \multicolumn{15}{|l|}{ Enopla } \\
\hline \multicolumn{15}{|l|}{ Hoplonemertea } \\
\hline Tetrastemmatidae & & & & & & & & & & & & & & \\
\hline Prostoma & - & & - & & - & & - & & 1 & $<1$ & 1 & $<1$ & - & \\
\hline Mollusca (molluscs) & & & & & & & & & & & & & & \\
\hline Gastropoda & & & & & & & & & & & & & & \\
\hline Basommatophora & & & & & & & & & & & & & & \\
\hline Ancylidae & & & & & & & & & & & & & & \\
\hline Ferrissia & 2 & $<1$ & - & & - & & - & & - & & 1 & $<1$ & - & \\
\hline Lymnaeidae & & & & & & & & & & & & & & \\
\hline Lymnaea & - & & - & & 1 & $<1$ & - & & - & & - & & - & \\
\hline Physidae & & & & & & & & & & & & & & \\
\hline Physa & 2 & $<1$ & - & & 1 & $<1$ & - & & - & & 1 & $<1$ & 1 & $<1$ \\
\hline Planorbidae & - & & - & & - & & - & & - & & - & & - & \\
\hline Gyraulus & - & & - & & - & & - & & - & & - & & - & \\
\hline Helisoma & - & & - & & 2 & $<1$ & - & & - & & 3 & $<1$ & 1 & $<1$ \\
\hline Planorbula & - & & - & & - & & - & & - & & - & & - & \\
\hline Bivalvia & & & & & & & & & & & & & & \\
\hline Veneroida & & & & & & & & & & & & & & \\
\hline Sphaeriidae & 1 & $<1$ & - & & 11 & $<1$ & 1 & $<1$ & 4 & $<1$ & 8 & 1 & 7 & $<1$ \\
\hline Pisidium & - & & - & & - & & - & & - & & - & & - & \\
\hline Sphaerium & - & & - & & - & & - & & - & & - & & - & \\
\hline Annelida (segmented worms) & & & & & & & & & & & & & & \\
\hline Oligochaeta & 120 & 4 & - & & 83 & 4 & - & & 3 & $<1$ & - & & - & \\
\hline Lumbriculida & & & & & & & & & & & & & & \\
\hline Lumbriculidae & - & & - & & - & & - & & - & & - & & - & \\
\hline Tubificida & & & & & & & & & & & & & & \\
\hline Naididae & - & & - & & - & & 1 & $<1$ & - & & 3 & $<1$ & 140 & 9 \\
\hline Branchiobdellida & - & & - & & - & & - & & 1 & $<1$ & - & & - & \\
\hline Arthropoda (arthropods) & & & & & & & & & & & & & & \\
\hline Acariformes & & & & & & & & & & & & & & \\
\hline Hydrachnidia & - & & - & & 10 & $<1$ & - & & - & & - & & 38 & 3 \\
\hline Crustacea & & & & & & & & & & & & & & \\
\hline Cyclopoida & & & & & & & & & & & & & & \\
\hline Cyclopidae & - & & - & & - & & - & & - & & - & & 7 & $<1$ \\
\hline Amphipoda & & & & & & & & & & & & & & \\
\hline Gammaridae & & & & & & & & & & & & & & \\
\hline Gammarus & - & & - & & - & & - & & - & & - & & 2 & $<1$ \\
\hline Talitridae & & & & & & & & & & & & & & \\
\hline Hyallela & & & & & & & & & & & & & & \\
\hline H. azteca & - & & - & & 1 & $<1$ & - & & - & & - & & - & \\
\hline Isopoda & & & & & & & & & & & & & & \\
\hline Asellidae & & & & & & & & & & & & & & \\
\hline Caecidotea & - & & 1 & $<1$ & - & & - & & - & & - & & 3 & $<1$ \\
\hline Lirceus & - & & 1 & $<1$ & - & & - & & - & & - & & - & \\
\hline Podocopa & - & & - & & 5 & $<1$ & - & & 2 & $<1$ & 1 & $<1$ & 1 & $<1$ \\
\hline
\end{tabular}




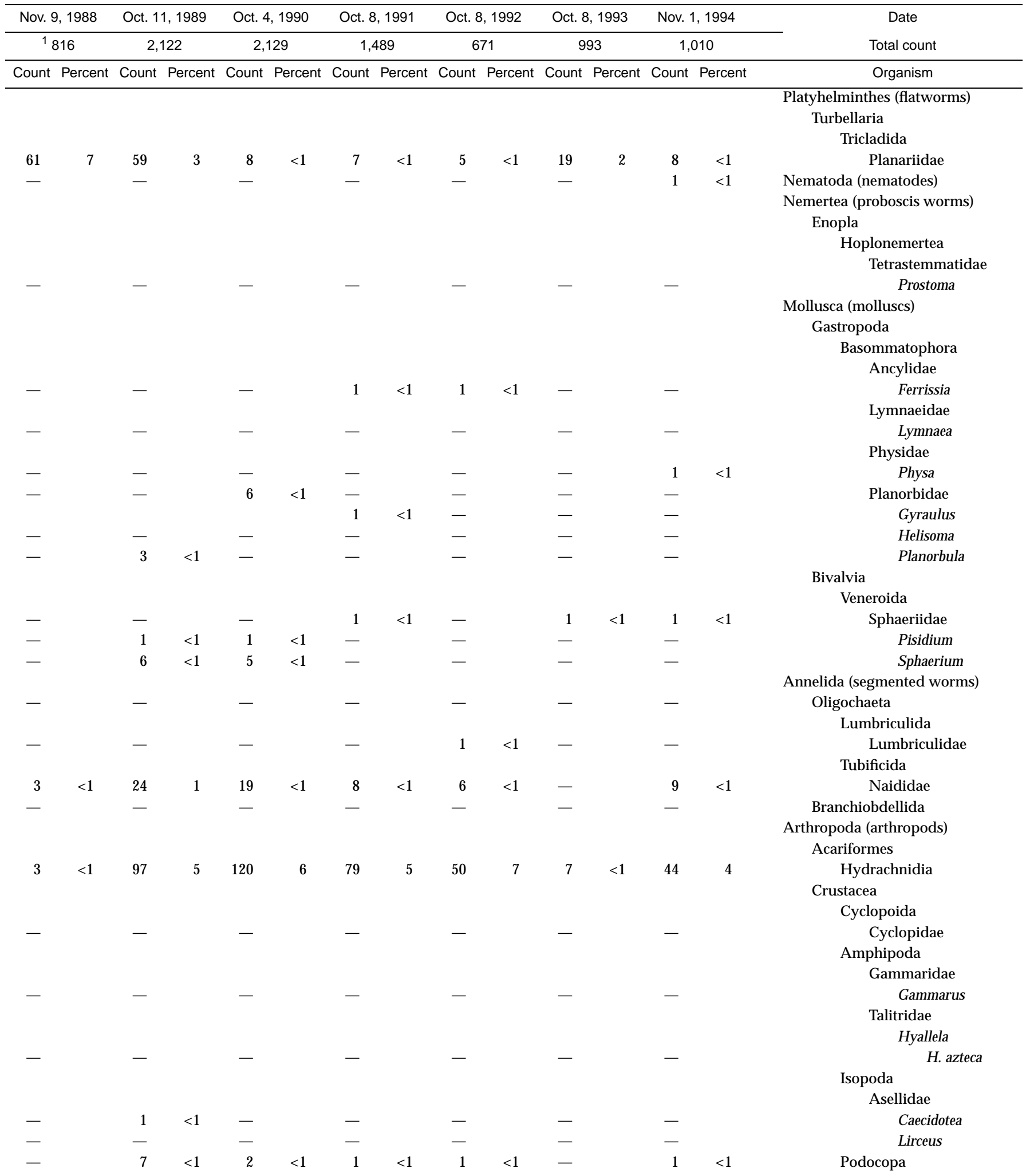


Table 5. Benthic-macroinvertebrate data-Continued

01472109 - Stony Run near Spring City, Pa. (Site 6)—Continued

\begin{tabular}{|c|c|c|c|c|c|c|c|c|c|c|c|c|c|c|}
\hline \multirow{3}{*}{$\begin{array}{c}\text { Date } \\
\text { Total count } \\
\text { Organism }\end{array}$} & \multirow{2}{*}{\multicolumn{2}{|c|}{$\begin{array}{c}\text { Oct. } 20,1981 \\
12,760\end{array}$}} & \multirow{2}{*}{\multicolumn{2}{|c|}{$\begin{array}{c}\text { Oct. } 19,1982 \\
1,265\end{array}$}} & \multirow{2}{*}{\multicolumn{2}{|c|}{$\begin{array}{c}\text { Oct. } 20,1983 \\
2,082\end{array}$}} & \multirow{2}{*}{\multicolumn{2}{|c|}{$\begin{array}{c}\text { Oct. 9, } 1984 \\
998\end{array}$}} & \multirow{2}{*}{\multicolumn{2}{|c|}{$\frac{\text { Oct. } 11,1985}{550}$}} & \multirow{2}{*}{\multicolumn{2}{|c|}{$\begin{array}{c}\text { Oct. 10,1986 } \\
651\end{array}$}} & \multirow{2}{*}{\multicolumn{2}{|c|}{$\begin{array}{c}\text { Nov. } 13,1987 \\
1,467\end{array}$}} \\
\hline & & & & & & & & & & & & & & \\
\hline & Count & Percent & Count & Percent & Count & Percent & Count & Percent & Count & Percent & Count & Percent & Count & Percent \\
\hline \multicolumn{15}{|l|}{ Insecta } \\
\hline \multicolumn{15}{|l|}{ Ephemeroptera } \\
\hline \multicolumn{15}{|l|}{ Baetidae } \\
\hline Baetis & 75 & 3 & 45 & 3 & 16 & $<1$ & 47 & 5 & 5 & $<1$ & 34 & 5 & - & \\
\hline Pseudocloeon & - & & - & & - & & 15 & 2 & - & & - & & 89 & 6 \\
\hline \multicolumn{15}{|l|}{ Caenidae } \\
\hline Caenis & 26 & $<1$ & 6 & $<1$ & 95 & 5 & 1 & $<1$ & 1 & $<1$ & 4 & $<1$ & 21 & 1 \\
\hline \multicolumn{15}{|l|}{ Ephemerellidae } \\
\hline Ephemerella & 8 & $<1$ & 5 & $<1$ & 9 & $<1$ & 4 & $<1$ & 1 & $<1$ & 2 & $<1$ & 25 & 2 \\
\hline \multicolumn{15}{|l|}{ Ephemeridae } \\
\hline Ephemera & - & & - & & 1 & $<1$ & - & & - & & - & & - & \\
\hline Heptageniidae & & & & & & & & & & & & & & \\
\hline Stenacron & - & & - & & - & & - & & - & & 5 & $<1$ & - & \\
\hline Stenonema & 94 & 3 & 120 & 9 & 43 & 2 & 67 & 7 & 5 & $<1$ & 79 & 12 & 57 & 4 \\
\hline Isonychiidae & & & & & & & & & & & & & & \\
\hline Isonychia & 7 & $<1$ & 10 & $<1$ & 7 & $<1$ & 6 & $<1$ & - & & 2 & $<1$ & 1 & $<1$ \\
\hline Leptohyphidae & & & & & & & & & & & & & & \\
\hline Tricorythodes & - & & - & & 1 & $<1$ & - & & - & & - & & - & \\
\hline Leptophlebiidae & - & & - & & - & & - & & 1 & $<1$ & 9 & 1 & - & \\
\hline Paraleptophlebia & - & & - & & - & & - & & - & & - & & - & \\
\hline Odonata & & & & & & & & & & & & & & \\
\hline Calopterygidae & & & & & & & & & & & & & & \\
\hline Hetaerina & 1 & $<1$ & - & & - & & - & & - & & - & & - & \\
\hline Coenagrionidae & & & & & & & & & & & & & & \\
\hline Argia & - & & - & & - & & - & & - & & - & & 1 & $<1$ \\
\hline Enallagma & - & & - & & - & & - & & - & & 1 & $<1$ & - & \\
\hline Plecoptera & & & & & & & & & & & & & & \\
\hline Capniidae & & & & & & & & & & & & & & \\
\hline Allocapnia & - & & - & & - & & - & & - & & - & & 2 & $<1$ \\
\hline Chloroperlidae & - & & - & & - & & - & & - & & - & & 1 & $<1$ \\
\hline Perlidae & & & & & & & & & & & & & & \\
\hline Agnetina & - & & - & & - & & - & & - & & - & & - & \\
\hline Taeniopterygidae & & & & & & & & & & & & & & \\
\hline Taeniopteryx & - & & - & & 6 & $<1$ & - & & - & & - & & - & \\
\hline Hemiptera & & & & & & & & & & & & & & \\
\hline Corixidae & - & & - & & - & & 3 & $<1$ & - & & - & & - & \\
\hline Gerridae & & & & & & & & & & & & & & \\
\hline Trepobates & - & & - & & - & & - & & - & & 1 & $<1$ & - & \\
\hline Veliidae & & & & & & & & & & & & & & \\
\hline Microvelia & - & & - & & - & & - & & - & & - & & - & \\
\hline Rhagovelia & - & & 2 & $<1$ & - & & 2 & $<1$ & - & 9 & 1 & - & & \\
\hline Megaloptera & & & & & & & & & & & & & & \\
\hline Corydalidae & & & & & & & & & & & & & & \\
\hline Corydalus & - & & - & & 1 & $<1$ & - & & - & & - & & - & \\
\hline Sialidae & & & & & & & & & & & & & & \\
\hline Sialis & 4 & $<1$ & - & & - & & - & & - & & 1 & $<1$ & - & \\
\hline Trichoptera & & & & & & & & & & & & & & \\
\hline Apataniidae & & & & & & & & & & & & & & \\
\hline Apatania & - & & - & & - & & - & & - & & - & & 29 & 2 \\
\hline Brachycentridae & & & & & & & & & & & & & & \\
\hline Micrasema & - & & - & & - & & - & & - & & - & & 3 & $<1$ \\
\hline Glossosomatidae & & & & & & & & & & & & & & \\
\hline Glossosoma & 1 & $<1$ & 3 & $<1$ & - & & - & & 2 & $<1$ & - & & - & \\
\hline
\end{tabular}




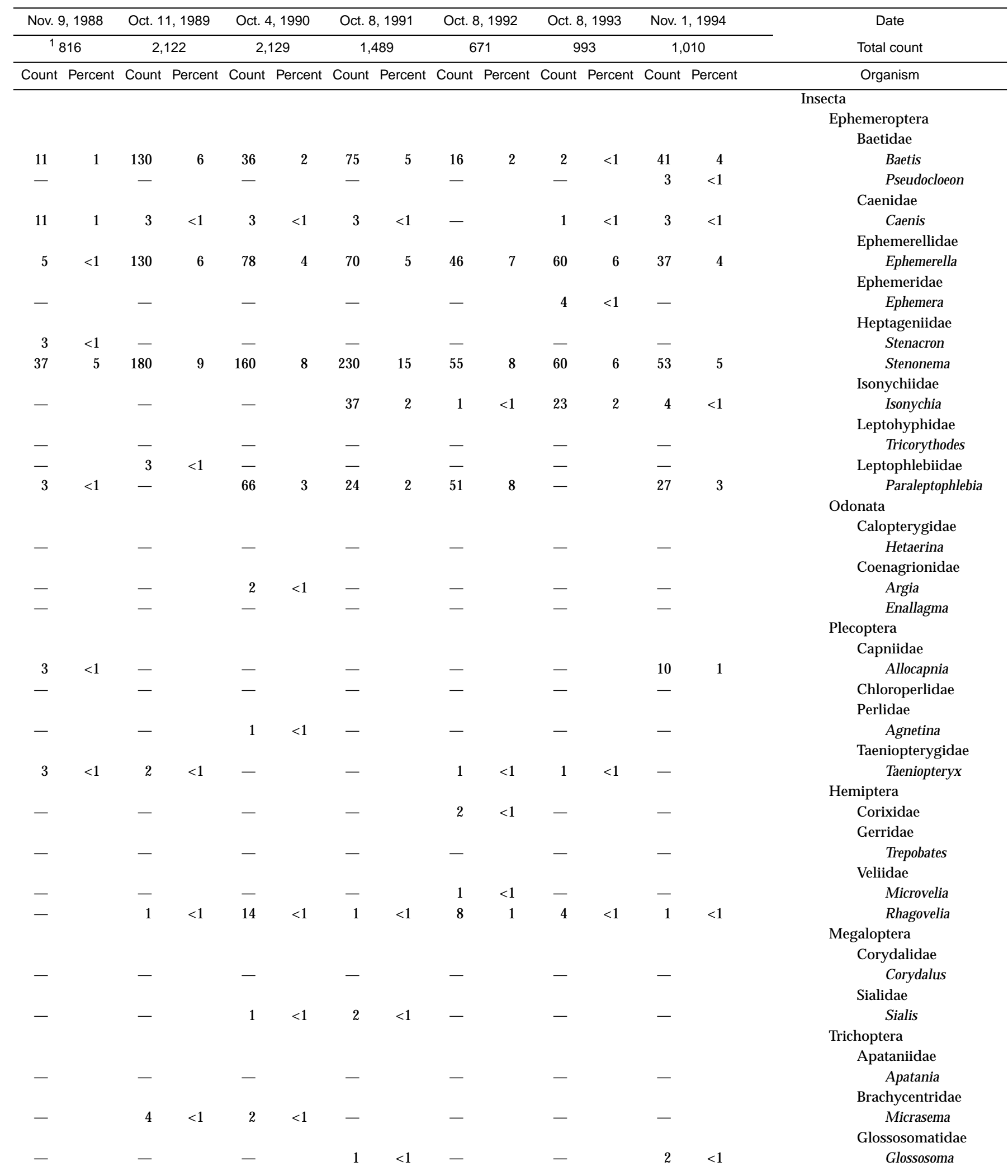


Table 5. Benthic-macroinvertebrate data-Continued

01472109 - Stony Run near Spring City, Pa. (Site 6)—Continued

\begin{tabular}{|c|c|c|c|c|c|c|c|c|c|c|c|c|c|c|}
\hline \multirow{3}{*}{$\begin{array}{c}\text { Date } \\
\text { Total count } \\
\text { Organism }\end{array}$} & \multirow{2}{*}{\multicolumn{2}{|c|}{$\begin{array}{c}\text { Oct. } 20,1981 \\
12,760\end{array}$}} & \multirow{2}{*}{\multicolumn{2}{|c|}{$\begin{array}{c}\text { Oct. } 19,1982 \\
1,265\end{array}$}} & \multirow{2}{*}{\multicolumn{2}{|c|}{$\begin{array}{c}\text { Oct. } 20,1983 \\
2,082 \\
\end{array}$}} & \multirow{2}{*}{\multicolumn{2}{|c|}{$\begin{array}{c}\text { Oct. 9, } 1984 \\
998 \\
\end{array}$}} & \multirow{2}{*}{\multicolumn{2}{|c|}{$\begin{array}{c}\text { Oct. } 11,1985 \\
550\end{array}$}} & \multirow{2}{*}{\multicolumn{2}{|c|}{$\begin{array}{c}\text { Oct. 10, } 1986 \\
651\end{array}$}} & \multirow{2}{*}{\multicolumn{2}{|c|}{$\begin{array}{c}\text { Nov. } 13,1987 \\
1,467\end{array}$}} \\
\hline & & & & & & & & & & & & & & \\
\hline & Count & Percent & Count & Percent & Count & Percent & Count & Percent & Count & Percent & Count & Percent & Count & Percent \\
\hline \multicolumn{15}{|l|}{ Trichoptera } \\
\hline \multicolumn{15}{|l|}{ Hydropsychidae } \\
\hline Ceratopsyche & 13 & $<1$ & 140 & 11 & 24 & 1 & 120 & 12 & 44 & 8 & 59 & 9 & 19 & 1 \\
\hline Cheumatopsyche & 310 & 11 & 88 & 7 & 190 & 9 & 130 & 13 & 85 & 15 & 64 & 10 & 86 & 6 \\
\hline Hydropsyche & 240 & 9 & 190 & 15 & 280 & 13 & 190 & 19 & 12 & 2 & 59 & 9 & 210 & 14 \\
\hline \multicolumn{15}{|l|}{ Hydroptilidae } \\
\hline Hydroptila & 160 & 6 & 62 & 5 & 120 & 6 & 8 & $<1$ & 2 & $<1$ & 1 & $<1$ & 12 & $<1$ \\
\hline Leucotrichia & 5 & $<1$ & 12 & $<1$ & - & & - & & - & & 5 & $<1$ & - & \\
\hline \multicolumn{15}{|l|}{ Leptoceridae } \\
\hline Mystacides & - & & - & & - & & - & & - & & - & & - & \\
\hline \multicolumn{15}{|l|}{ Philopotamidae } \\
\hline Chimarra & 35 & 1 & 9 & $<1$ & 19 & $<1$ & 4 & $<1$ & 18 & 3 & 110 & 16 & 62 & 4 \\
\hline \multicolumn{15}{|l|}{ Polycentropodidae } \\
\hline Nyctiophylax & 4 & $<1$ & 2 & $<1$ & 2 & $<1$ & - & & - & & 4 & $<1$ & - & \\
\hline Polycentropus & - & & 9 & $<1$ & 12 & $<1$ & - & & 1 & $<1$ & 2 & $<1$ & - & \\
\hline Psychomyiidae & & & & & & & & & & & & & & \\
\hline Psychomyia & 110 & 4 & 150 & 12 & 59 & 3 & 12 & 1 & - & & 1 & $<1$ & 1 & $<1$ \\
\hline Rhyacophilidae & & & & & & & & & & & & & & \\
\hline Rhyacophila & - & & - & & - & & - & & - & & - & & - & \\
\hline Uenoidae & & & & & & & & & & & & & & \\
\hline Neophylax & - & & - & & - & & - & & - & & - & & - & \\
\hline Lepidoptera & & & & & & & & & & & & & & \\
\hline Pyralidae & & & & & & & & & & & & & & \\
\hline Petrophila & - & & - & & - & & - & & - & & - & & - & \\
\hline Coleoptera & & & & & & & & & & & & & & \\
\hline Dryopidae & & & & & & & & & & & & & & \\
\hline Helichus & - & & - & & - & & - & & - & & - & & - & \\
\hline Dytiscidae & - & & 1 & $<1$ & - & & - & & - & & - & & - & \\
\hline Elmidae & & & & & & & & & & & & & & \\
\hline Ancyronyx & & & & & & & & & & & & & & \\
\hline A.variegata & - & & - & & - & & - & & - & & - & & - & \\
\hline Dubiraphia & 1 & $<1$ & 1 & $<1$ & 1 & $<1$ & - & & 1 & $<1$ & 1 & $<1$ & 4 & $<1$ \\
\hline Macronychus & - & & - & & - & & - & & - & & - & & - & \\
\hline Optioservus & 17 & $<1$ & 5 & $<1$ & 50 & 2 & 21 & 2 & 7 & 1 & 5 & $<1$ & 5 & $<1$ \\
\hline Stenelmis & 40 & 1 & 26 & 2 & 75 & 4 & 25 & 3 & 9 & 2 & 21 & 3 & 15 & 1 \\
\hline Hydrophilidae & & & & & & & & & & & & & & \\
\hline Hydrochara & - & & - & & - & & 1 & $<1$ & - & & - & & - & \\
\hline Psephenidae & & & & & & & & & & & & & & \\
\hline Ectopria & - & & - & & - & & - & & - & & 1 & $<1$ & - & \\
\hline E. nervosa & 2 & $<1$ & - & & 1 & $<1$ & 2 & $<1$ & - & & - & & - & \\
\hline Psephenus & - & & - & & 5 & $<1$ & 2 & $<1$ & - & & 1 & $<1$ & - & \\
\hline Hymenoptera & - & & - & & - & & - & & 1 & $<1$ & - & & - & \\
\hline Diptera & & & & & & & & & & & & & & \\
\hline Athericidae & & & & & & & & & & & & & & \\
\hline Atherix & - & & - & & 1 & $<1$ & - & & - & & - & & - & \\
\hline Ceratopogonidae & 1 & $<1$ & - & & - & & - & & - & & - & & - & \\
\hline Chironomidae & 910 & 33 & 220 & 17 & 770 & 37 & 140 & 14 & 320 & 57 & 120 & 18 & 390 & 26 \\
\hline Empididae & & & & & & & & & & & & & & \\
\hline Hemerodromia & 6 & $<1$ & 10 & $<1$ & 9 & $<1$ & 6 & $<1$ & 1 & $<1$ & 5 & $<1$ & 7 & $<1$ \\
\hline Muscidae & & & & & & & & & & & & & & \\
\hline Limnophora & - & & - & & - & & - & & - & & - & & - & \\
\hline Simuliidae & & & & & & & & & & & & & & \\
\hline Simulium & 540 & 19 & 110 & 8 & 39 & 2 & 78 & 8 & 8 & 2 & 6 & $<1$ & 140 & 9 \\
\hline
\end{tabular}




\begin{tabular}{|c|c|c|c|c|c|c|c|c|c|c|c|c|c|c|}
\hline \multirow{2}{*}{\multicolumn{2}{|c|}{$\begin{array}{c}\text { Nov. } 9,1988 \\
1816\end{array}$}} & \multicolumn{2}{|c|}{ Oct. 11,1989} & \multicolumn{2}{|c|}{ Oct. 4,1990} & \multicolumn{2}{|c|}{ Oct. 8,1991} & \multicolumn{2}{|c|}{ Oct. 8, 1992} & \multicolumn{2}{|c|}{ Oct. 8,1993} & \multicolumn{2}{|c|}{ Nov. 1, 1994} & \multirow{2}{*}{$\begin{array}{c}\text { Date } \\
\text { Total count }\end{array}$} \\
\hline & & & 122 & & 129 & & 489 & & 71 & 95 & 93 & & 010 & \\
\hline \multirow[t]{3}{*}{ Count } & Percent & Count & Percent & Count & Percent & Count & Percent & Count & Percent & Count & Percent & Count & Percent & Organism \\
\hline & & & & & & & & & & & & & & Trichoptera \\
\hline & & & & & & & & & & & & & & Hydropsychidae \\
\hline 100 & 12 & - & & 1 & $<1$ & 15 & 1 & 16 & 2 & - & & 27 & 3 & Ceratopsyche \\
\hline 80 & 10 & 70 & 3 & 270 & 13 & 120 & 8 & 43 & 6 & 200 & 20 & 190 & 19 & Cheumatopsyche \\
\hline \multirow[t]{2}{*}{190} & 23 & 470 & 22 & 650 & 31 & 180 & 12 & 150 & 22 & 310 & 31 & 120 & 12 & Hydropsyche \\
\hline & & & & & & & & & & & & & & Hydroptilidae \\
\hline 21 & 3 & 11 & $<1$ & 7 & $<1$ & 9 & $<1$ & 10 & 1 & 9 & $<1$ & 17 & 2 & Hydroptila \\
\hline \multirow[t]{2}{*}{ - } & & - & & - & & 3 & $<1$ & - & & - & & - & & Leucotrichia \\
\hline & & & & & & & & & & & & & & Leptoceridae \\
\hline \multirow[t]{2}{*}{-} & & 1 & $<1$ & 1 & $<1$ & 2 & $<1$ & - & & - & & - & & Mystacides \\
\hline & & & & & & & & & & & & & & Philopotamidae \\
\hline \multirow[t]{2}{*}{51} & 6 & 49 & 2 & 78 & 4 & 120 & 8 & 55 & 8 & 83 & 8 & 20 & 2 & Chimarra \\
\hline & & & & & & & & & & & & & & Polycentropodidae \\
\hline - & & 7 & $<1$ & 34 & 2 & 2 & $<1$ & 12 & 2 & 18 & 2 & 16 & 2 & Nyctiophylax \\
\hline - & & 1 & $<1$ & 1 & $<1$ & 4 & $<1$ & 7 & 1 & - & & 1 & $<1$ & Polycentropus \\
\hline & & & & & & & & & & & & & & Psychomyiidae \\
\hline 8 & 1 & 110 & 5 & 18 & $<1$ & 20 & 1 & 8 & 1 & 2 & $<1$ & 7 & $<1$ & Psychomyia \\
\hline & & & & & & & & & & & & & & Rhyacophilidae \\
\hline - & & - & & - & & 1 & $<1$ & - & & - & & - & & Rhyacophila \\
\hline & & & & & & & & & & & & & & Uenoidae \\
\hline 5 & $<1$ & 2 & $<1$ & - & & - & & - & & - & & 29 & 3 & Neophylax \\
\hline & & & & & & & & & & & & & & Lepidoptera \\
\hline & & & & & & & & & & & & & & Pyralidae \\
\hline - & & - & & - & & - & & - & & - & & 2 & $<1$ & Petrophila \\
\hline & & & & & & & & & & & & & & Coleoptera \\
\hline & & & & & & & & & & & & & & Dryopidae \\
\hline - & & 1 & $<1$ & 1 & $<1$ & - & & - & & - & & - & & Helichus \\
\hline - & & - & & - & & - & & - & & - & & - & & Dytiscidae \\
\hline & & & & & & & & & & & & & & Elmidae \\
\hline & & & & & & & & & & & & & & Ancyronyx \\
\hline - & & - & & - & & - & & - & & 2 & $<1$ & 1 & $<1$ & A.variegata \\
\hline - & & 23 & 1 & 8 & $<1$ & - & & - & & - & & 1 & $<1$ & Dubiraphia \\
\hline - & & - & & 1 & $<1$ & - & & - & & - & & - & & Macronychus \\
\hline - & & 33 & 2 & 18 & $<1$ & 41 & 3 & 39 & 6 & 2 & $<1$ & 29 & 3 & Optioservus \\
\hline 26 & 3 & 46 & 2 & 73 & 3 & 47 & 3 & 8 & 1 & 45 & 5 & 2 & $<1$ & Stenelmis \\
\hline & & & & & & & & & & & & & & Hydrophilidae \\
\hline - & & - & & - & & - & & - & & - & & - & & Hydrochara \\
\hline & & & & & & & & & & & & & & Psephenidae \\
\hline - & & - & & - & & - & & - & & - & & - & & Ectopria \\
\hline- & & - & & - & & 1 & $<1$ & 2 & $<1$ & - & & - & & E. nervosa \\
\hline - & & 1 & $<1$ & 1 & $<1$ & - & & - & & 3 & $<1$ & 1 & $<1$ & Psephenus \\
\hline - & & - & & - & & - & & - & & - & & - & & Hymenoptera \\
\hline & & & & & & & & & & & & & & Diptera \\
\hline & & & & & & & & & & & & & & Athericidae \\
\hline - & & - & & 1 & $<1$ & - & & - & & - & & - & & Atherix \\
\hline - & & - & & - & & - & & - & & - & & - & & Ceratopogonidae \\
\hline 170 & 21 & 430 & 20 & 390 & 19 & 330 & 22 & 67 & 10 & 130 & 13 & 250 & 25 & Chironomidae \\
\hline & & & & & & & & & & & & & & Empididae \\
\hline 3 & $<1$ & 42 & 2 & 19 & $<1$ & 18 & 1 & - & & 4 & $<1$ & 12 & 1 & Hemerodromia \\
\hline & & & & & & & & & & & & & & Muscidae \\
\hline - & & 1 & $<1$ & - & & - & & - & & - & & - & & Limnophora \\
\hline & & & & & & & & & & & & & & Simuliidae \\
\hline 11 & 1 & 110 & 5 & 5 & $<1$ & 2 & $<1$ & 4 & $<1$ & - & & 8 & $<1$ & Simulium \\
\hline
\end{tabular}


Table 5. Benthic-macroinvertebrate data-Continued

01472109 - Stony Run near Spring City, Pa. (Site 6)—Continued

\begin{tabular}{|c|c|c|c|c|c|c|c|c|c|c|c|c|c|c|}
\hline Date & \multicolumn{2}{|c|}{ Oct. 20, 1981} & \multicolumn{2}{|c|}{ Oct. 19, 1982} & \multicolumn{2}{|c|}{ Oct. 20, 1983} & \multicolumn{2}{|c|}{ Oct. 9, 1984} & \multicolumn{2}{|c|}{ Oct. 11, 1985} & \multicolumn{2}{|c|}{ Oct. 10, 1986} & \multicolumn{2}{|c|}{ Nov. 13, 1987} \\
\hline Total count & \multicolumn{2}{|c|}{${ }^{1} 2,760$} & \multicolumn{2}{|c|}{1,265} & \multicolumn{2}{|c|}{2,082} & \multicolumn{2}{|c|}{998} & \multicolumn{2}{|c|}{550} & \multicolumn{2}{|c|}{651} & \multicolumn{2}{|c|}{1,467} \\
\hline Organism & Count & Percent & Count & Percent & Count & Percent & Count & Percent & Count & Percent & Count & Percent & Count & Percent \\
\hline \multicolumn{15}{|l|}{ Diptera } \\
\hline \multicolumn{15}{|l|}{ Tabanidae } \\
\hline Tabanus & 1 & $<1$ & - & & - & & - & & - & & - & & - & \\
\hline \multicolumn{15}{|l|}{ Tipulidae } \\
\hline Antocha & 20 & $<1$ & 28 & 2 & 47 & 2 & 71 & 7 & 1 & $<1$ & 6 & $<1$ & 49 & 3 \\
\hline Hexatoma & - & & - & & - & & - & & - & & - & & - & \\
\hline Tipula & 1 & $<1$ & - & & 2 & $<1$ & - & & - & & 5 & $<1$ & - & \\
\hline
\end{tabular}

${ }^{1}$ Extrapolated from a 3/8 subsample. 


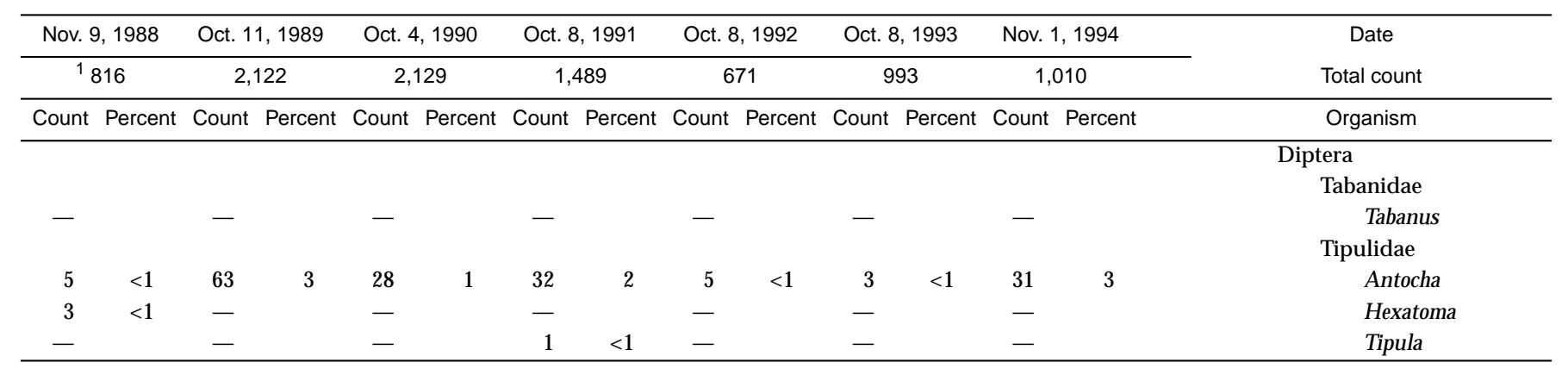


Table 5. Benthic-macroinvertebrate data-Continued

$[<$, less than; - , not found]

01472110 - Stony Run at Spring City, Pa. (Site 7)

\begin{tabular}{|c|c|c|c|c|}
\hline \multirow{3}{*}{$\begin{array}{c}\text { Date } \\
\text { Total count } \\
\text { Organism }\end{array}$} & \multirow{2}{*}{\multicolumn{2}{|c|}{$\begin{array}{c}\text { Oct. } 20,1981 \\
1,507\end{array}$}} & \multirow{2}{*}{\multicolumn{2}{|c|}{$\begin{array}{c}\text { Oct. } 19,1982 \\
1,787\end{array}$}} \\
\hline & & & & \\
\hline & Count & Percent & Count & Percent \\
\hline \multicolumn{5}{|l|}{ Platyhelminthes (flatworms) } \\
\hline \multicolumn{5}{|l|}{ Turbellaria } \\
\hline \multicolumn{5}{|l|}{ Tricladida } \\
\hline Planariidae & 110 & 7 & 120 & 7 \\
\hline \multicolumn{5}{|l|}{ Mollusca (molluscs) } \\
\hline \multicolumn{5}{|l|}{ Gastropoda } \\
\hline \multicolumn{5}{|l|}{ Basommatophora } \\
\hline \multicolumn{5}{|l|}{ Ancylidae } \\
\hline Ferrissia & 1 & $<1$ & - & \\
\hline \multicolumn{5}{|l|}{ Planorbidae } \\
\hline Helisoma & 1 & $<1$ & - & \\
\hline \multicolumn{5}{|l|}{ Bivalvia } \\
\hline \multicolumn{5}{|l|}{ Veneroida } \\
\hline Sphaeriidae & - & & 2 & $<1$ \\
\hline \multicolumn{5}{|l|}{ Annelida (segmented worms) } \\
\hline Oligochaeta & 8 & $<1$ & 30 & 2 \\
\hline \multicolumn{5}{|l|}{ Arthropoda (arthropods) } \\
\hline \multicolumn{5}{|l|}{ Acariformes } \\
\hline Hydrachnidia & - & & 1 & $<1$ \\
\hline \multicolumn{5}{|l|}{ Crustacea } \\
\hline \multicolumn{5}{|l|}{ Isopoda } \\
\hline Asellidae & 1 & $<1$ & - & \\
\hline Caecidotea & 25 & 2 & 14 & $<1$ \\
\hline \multicolumn{5}{|l|}{ Insecta } \\
\hline \multicolumn{5}{|l|}{ Ephemeroptera } \\
\hline \multicolumn{5}{|l|}{ Baetidae } \\
\hline Baetis & 52 & 3 & 130 & 7 \\
\hline \multicolumn{5}{|l|}{ Caenidae } \\
\hline Caenis & 7 & $<1$ & 1 & $<1$ \\
\hline \multicolumn{5}{|l|}{ Ephemerellidae } \\
\hline Ephemerella & 8 & $<1$ & 2 & $<1$ \\
\hline Heptageniidae & & & & \\
\hline Stenonema & 180 & 12 & 58 & 3 \\
\hline Isonychiidae & & & & \\
\hline Isonychia & 61 & 4 & 1 & $<1$ \\
\hline Odonata & & & & \\
\hline Coenagrionidae & & & & \\
\hline Argia & 12 & $<1$ & - & \\
\hline Hemiptera & & & & \\
\hline Veliidae & & & & \\
\hline Rhagovelia & - & & 1 & $<1$ \\
\hline Megaloptera & & & & \\
\hline Sialidae & & & & \\
\hline Sialis & 2 & $<1$ & - & \\
\hline
\end{tabular}


Table 5. Benthic-macroinvertebrate data-Continued

01472110 - Stony Run at Spring City, Pa. (Site 7)—Continued

\begin{tabular}{|c|c|c|c|c|}
\hline Date & \multicolumn{2}{|c|}{ Oct. 20,1981} & \multicolumn{2}{|c|}{ Oct. 19,1982} \\
\hline Total count & \multicolumn{2}{|c|}{1,507} & \multicolumn{2}{|c|}{1,787} \\
\hline Organism & Count & Percent & Count & Percent \\
\hline \multicolumn{5}{|l|}{ Trichoptera } \\
\hline \multicolumn{5}{|l|}{ Glossosomatidae } \\
\hline Glossosoma & 4 & $<1$ & 1 & $<1$ \\
\hline \multicolumn{5}{|l|}{ Hydropsychidae } \\
\hline Ceratopsyche & 4 & $<1$ & 4 & $<1$ \\
\hline Cheumatopsyche & 200 & 13 & 110 & 6 \\
\hline Hydropsyche & 230 & 15 & 150 & 8 \\
\hline \multicolumn{5}{|l|}{ Hydroptilidae } \\
\hline Hydroptila & 14 & $<1$ & 22 & 1 \\
\hline Leucotrichia & - & & 19 & 1 \\
\hline \multicolumn{5}{|l|}{ Philopotamidae } \\
\hline Chimarra & 200 & 13 & 51 & 3 \\
\hline \multicolumn{5}{|l|}{ Polycentropodidae } \\
\hline Nyctiophylax & 2 & $<1$ & - & \\
\hline Polycentropus & 6 & $<1$ & - & \\
\hline \multicolumn{5}{|l|}{ Coleoptera } \\
\hline \multicolumn{5}{|l|}{ Elmidae } \\
\hline Dubiraphia & - & & 1 & $<1$ \\
\hline Optioservus & 45 & 3 & 5 & $<1$ \\
\hline Stenelmis & 36 & 2 & 29 & 2 \\
\hline \multicolumn{5}{|l|}{ Psephenidae } \\
\hline Ectopria & 1 & $<1$ & - & \\
\hline Psephenus & 13 & $<1$ & 3 & $<1$ \\
\hline \multicolumn{5}{|l|}{ Diptera } \\
\hline \multicolumn{5}{|l|}{ Athericidae } \\
\hline Atherix & 3 & $<1$ & - & \\
\hline Chironomidae & 250 & 17 & 320 & 18 \\
\hline \multicolumn{5}{|l|}{ Empididae } \\
\hline Hemerodromia & 4 & $<1$ & 17 & $<1$ \\
\hline \multicolumn{5}{|l|}{ Simuliidae } \\
\hline Simulium & 18 & 1 & 680 & 38 \\
\hline \multicolumn{5}{|l|}{ Tabanidae } \\
\hline Tabanus & 1 & $<1$ & - & \\
\hline \multicolumn{5}{|l|}{ Tipulidae } \\
\hline Antocha & 4 & $<1$ & 14 & $<1$ \\
\hline Tipula & 4 & $<1$ & 1 & $<1$ \\
\hline
\end{tabular}


Table 5. Benthic-macroinvertebrate data-Continued

$[<$, less than; - , not found]

01472126 - French Creek at Trythall, Pa. (Site 41)

\begin{tabular}{|c|c|c|}
\hline \multirow{3}{*}{$\begin{array}{c}\text { Date } \\
\text { Total count } \\
\text { Organism }\end{array}$} & \multirow{2}{*}{\multicolumn{2}{|c|}{$\frac{\text { Oct. } 26,1982}{215}$}} \\
\hline & & \\
\hline & Count & Percent \\
\hline \multicolumn{3}{|l|}{ Nemertea (proboscis worms) } \\
\hline \multicolumn{3}{|l|}{ Enopla } \\
\hline \multicolumn{3}{|l|}{ Hoplonemertea } \\
\hline \multicolumn{3}{|l|}{ Tetrastemmatidae } \\
\hline Prostoma & 5 & 3 \\
\hline \multicolumn{3}{|l|}{ Mollusca (molluscs) } \\
\hline \multicolumn{3}{|l|}{ Gastropoda } \\
\hline \multicolumn{3}{|l|}{ Basommatophora } \\
\hline \multicolumn{3}{|l|}{ Ancylidae } \\
\hline Ferrissia & 1 & $<1$ \\
\hline \multicolumn{3}{|l|}{ Annelida (segmented worms) } \\
\hline \multicolumn{3}{|l|}{ Oligochaeta } \\
\hline \multicolumn{3}{|l|}{ Tubificida } \\
\hline Naididae & 2 & 1 \\
\hline \multicolumn{3}{|l|}{ Arthropoda (arthropods) } \\
\hline \multicolumn{3}{|l|}{ Acariformes } \\
\hline Hydrachnidia & 2 & 1 \\
\hline \multicolumn{3}{|l|}{ Insecta } \\
\hline \multicolumn{3}{|l|}{ Ephemeroptera } \\
\hline \multicolumn{3}{|l|}{ Ephemerellidae } \\
\hline Ephemerella & 10 & 5 \\
\hline \multicolumn{3}{|l|}{ Heptageniidae } \\
\hline Stenonema & 10 & 5 \\
\hline \multicolumn{3}{|l|}{ Plecoptera } \\
\hline \multicolumn{3}{|l|}{ Taeniopterygidae } \\
\hline Taeniopteryx & 32 & 15 \\
\hline \multicolumn{3}{|l|}{ Megaloptera } \\
\hline \multicolumn{3}{|l|}{ Corydalidae } \\
\hline Nigronia & 1 & $<1$ \\
\hline \multicolumn{3}{|l|}{ Trichoptera } \\
\hline Brachycentridae & & \\
\hline Brachycentrus & 3 & 2 \\
\hline Glossosomatidae & & \\
\hline Glossosoma & 3 & 2 \\
\hline Goeridae & & \\
\hline Goera & 3 & 2 \\
\hline Hydropsychidae & & \\
\hline Ceratopsyche & 2 & 1 \\
\hline Cheumatopsyche & 72 & 33 \\
\hline Hydropsyche & 11 & 5 \\
\hline Leptoceridae & & \\
\hline Oecetis & 13 & 6 \\
\hline Polycentropodidae & & \\
\hline Nyctiophylax & 1 & $<1$ \\
\hline Polycentropus & 1 & $<1$ \\
\hline
\end{tabular}


Table 5. Benthic-macroinvertebrate data-Continued

01472126 - French Creek at Trythall, Pa. (Site 41)—Continued

\begin{tabular}{|c|c|c|}
\hline Date & \multirow{2}{*}{\multicolumn{2}{|c|}{$\frac{\text { Oct. 26, } 1982}{215}$}} \\
\hline \multirow{2}{*}{$\begin{array}{c}\text { Total count } \\
\text { Organism }\end{array}$} & & \\
\hline & Count & Percent \\
\hline \multicolumn{3}{|l|}{ Coleoptera } \\
\hline \multicolumn{3}{|l|}{ Elmidae } \\
\hline Optioservus & 1 & $<1$ \\
\hline Promoresia & 1 & $<1$ \\
\hline Stenelmis & 1 & $<1$ \\
\hline \multicolumn{3}{|l|}{ Diptera } \\
\hline $\begin{array}{l}\text { Chironomidae } \\
\text { Empididae }\end{array}$ & 33 & 15 \\
\hline Hemerodromia & 5 & 3 \\
\hline \multicolumn{3}{|l|}{ Ephydridae } \\
\hline \multicolumn{3}{|l|}{ Simuliidae } \\
\hline Simulium & 1 & $<1$ \\
\hline \multicolumn{3}{|l|}{ Tipulidae } \\
\hline Tipula & 1 & $<1$ \\
\hline
\end{tabular}


Table 5. Benthic-macroinvertebrate data-Continued

$[<$, less than; - , not found]

01472129 - French Creek near Knauertown, Pa. (Site 11)

\begin{tabular}{|c|c|c|c|c|}
\hline \multirow{3}{*}{$\begin{array}{c}\text { Date } \\
\text { Total count } \\
\text { Organism }\end{array}$} & \multirow{2}{*}{\multicolumn{2}{|c|}{$\begin{array}{c}\text { Oct. } 22,1981 \\
1,078\end{array}$}} & \multirow{2}{*}{\multicolumn{2}{|c|}{$\begin{array}{c}\text { Oct. } 26,1982 \\
2,186\end{array}$}} \\
\hline & & & & \\
\hline & Count & Percent & Count & Percent \\
\hline \multicolumn{5}{|l|}{ Platyhelminthes (flatworms) } \\
\hline \multicolumn{5}{|l|}{ Turbellaria } \\
\hline \multicolumn{5}{|l|}{ Tricladida } \\
\hline Planariidae & 7 & $<1$ & 29 & 1 \\
\hline Nematoda (nematodes) & 1 & $<1$ & - & \\
\hline \multicolumn{5}{|l|}{ Nemertea (proboscis worms) } \\
\hline \multicolumn{5}{|l|}{ Enopla } \\
\hline \multicolumn{5}{|l|}{ Hoplonemertea } \\
\hline \multicolumn{5}{|l|}{ Tetrastemmatidae } \\
\hline Prostoma & - & & 3 & $<1$ \\
\hline \multicolumn{5}{|l|}{ Mollusca (molluscs) } \\
\hline \multicolumn{5}{|l|}{ Gastropoda } \\
\hline \multicolumn{5}{|l|}{ Mesogastropoda } \\
\hline \multicolumn{5}{|l|}{ Hydrobiidae } \\
\hline Amnicola & - & & 1 & $<1$ \\
\hline \multicolumn{5}{|l|}{ Annelida (segmented worms) } \\
\hline \multicolumn{5}{|l|}{ Oligochaeta } \\
\hline \multicolumn{5}{|l|}{ Tubificida } \\
\hline Naididae & 5 & $<1$ & - & \\
\hline \multicolumn{5}{|l|}{ Arthropoda (arthropods) } \\
\hline \multicolumn{5}{|l|}{ Acariformes } \\
\hline Hydrachnidia & 41 & 4 & 36 & 2 \\
\hline Crustacea & & & & \\
\hline Amphipoda & & & & \\
\hline Talitridae & & & & \\
\hline Hyallela & & & & \\
\hline H. azteca & 1 & $<1$ & 4 & $<1$ \\
\hline Insecta & & & & \\
\hline Ephemeroptera & & & & \\
\hline Baetidae & & & & \\
\hline Baetis & 38 & 3 & 27 & 1 \\
\hline Pseudocloeon & 6 & $<1$ & 6 & $<1$ \\
\hline Ephemerellidae & & & & \\
\hline Ephemerella & 55 & 5 & 55 & 3 \\
\hline Heptageniidae & & & & \\
\hline Stenonema & 42 & 4 & 60 & 3 \\
\hline Isonychiidae & & & & \\
\hline Isonychia & 15 & 1 & 10 & $<1$ \\
\hline Leptohyphidae & & & & \\
\hline Tricorythodes & 2 & $<1$ & - & \\
\hline Leptophlebiidae & & & & \\
\hline Paraleptophlebia & 1 & $<1$ & 10 & $<1$ \\
\hline Plecoptera & & & & \\
\hline Capniidae & & & & \\
\hline Allocapnia & - & & 11 & $<1$ \\
\hline Chloroperlidae & - & & 5 & $<1$ \\
\hline Perlidae & & & & \\
\hline Acroneuria & - & & 2 & $<1$ \\
\hline Paragnetina & - & & 1 & $<1$ \\
\hline Taeniopterygidae & & & & \\
\hline Strophopteryx & 23 & 2 & - & \\
\hline Taeniopteryx & 18 & 2 & 53 & 2 \\
\hline
\end{tabular}


Table 5. Benthic-macroinvertebrate data-Continued

01472129 - French Creek near Knauertown, Pa. (Site 11)—Continued

\begin{tabular}{|c|c|c|c|c|}
\hline \multirow{3}{*}{$\begin{array}{c}\text { Date } \\
\text { Total count } \\
\text { Organism }\end{array}$} & \multirow{2}{*}{\multicolumn{2}{|c|}{$\begin{array}{c}\text { Oct. 22, } 1981 \\
1,078\end{array}$}} & \multirow{2}{*}{\multicolumn{2}{|c|}{$\frac{\text { Oct. } 26,1982}{2,186}$}} \\
\hline & & & & \\
\hline & Count & Percent & Count & Percent \\
\hline \multicolumn{5}{|l|}{ Megaloptera } \\
\hline \multicolumn{5}{|l|}{ Corydalidae } \\
\hline Nigronia & 2 & $<1$ & 1 & $<1$ \\
\hline \multicolumn{5}{|l|}{ Trichoptera } \\
\hline \multicolumn{5}{|l|}{ Aptaniidae } \\
\hline Apatania & - & & 2 & $<1$ \\
\hline \multicolumn{5}{|l|}{ Brachycentridae } \\
\hline Brachycentrus & 1 & $<1$ & - & \\
\hline Micrasema & - & & 2 & $<1$ \\
\hline \multicolumn{5}{|l|}{ Glossosomatidae } \\
\hline Glossosoma & 91 & 8 & 35 & 2 \\
\hline \multicolumn{5}{|l|}{ Hydropsychidae } \\
\hline Ceratopsyche & 26 & 2 & 290 & 13 \\
\hline Cheumatopsyche & 54 & 5 & 260 & 12 \\
\hline Hydropsyche & 230 & 21 & 76 & 3 \\
\hline \multicolumn{5}{|l|}{ Hydroptilidae } \\
\hline Hydroptila & 71 & 6 & 120 & 5 \\
\hline Leucotrichia & 6 & $<1$ & - & \\
\hline \multicolumn{5}{|l|}{ Leptoceridae } \\
\hline Mystacides & - & & 5 & $<1$ \\
\hline Oecetis & 1 & $<1$ & - & \\
\hline Triaenodes & 1 & $<1$ & - & \\
\hline \multicolumn{5}{|l|}{ Philopotamidae } \\
\hline Chimarra & 71 & 6 & 120 & 5 \\
\hline \multicolumn{5}{|l|}{ Polycentropodidae } \\
\hline Nyctiophylax & - & & 1 & $<1$ \\
\hline Polycentropus & 1 & $<1$ & 1 & $<1$ \\
\hline \multicolumn{5}{|l|}{ Psychomyiidae } \\
\hline Psychomyia & 3 & $<1$ & - & \\
\hline \multicolumn{5}{|l|}{ Rhyacophilidae } \\
\hline Rhyacophila & - & & 2 & $<1$ \\
\hline \multicolumn{5}{|l|}{ Coleoptera } \\
\hline \multicolumn{5}{|l|}{ Dryopidae } \\
\hline Helichus & - & & 1 & $<1$ \\
\hline \multicolumn{5}{|l|}{ Elmidae } \\
\hline Ancyronyx & & & & \\
\hline A.variegata & - & & 1 & $<1$ \\
\hline Optioservus & 35 & 3 & 57 & 3 \\
\hline Oulimnius & 1 & $<1$ & 8 & $<1$ \\
\hline Promoresia & 6 & $<1$ & 4 & $<1$ \\
\hline Stenelmis & 9 & $<1$ & 11 & $<1$ \\
\hline Psephenidae & & & & \\
\hline Ectopria & & & & \\
\hline E. nervosa & 1 & $<1$ & - & \\
\hline Diptera & & & & \\
\hline Chironomidae & 170 & 15 & 560 & 25 \\
\hline Empididae & & & & \\
\hline Hemerodromia & 6 & $<1$ & 2 & $<1$ \\
\hline Ephydridae & - & & 1 & $<1$ \\
\hline Simuliidae & & & & \\
\hline Simulium & 12 & 1 & 270 & 12 \\
\hline Tipulidae & & & & \\
\hline Antocha & 25 & 2 & 43 & 2 \\
\hline
\end{tabular}


Table 5. Benthic-macroinvertebrate data-Continued

$[<$, less than; - , not found]

01472138 - French Creek near Coventryville, Pa. (Site 13)

\begin{tabular}{|c|c|c|c|c|c|c|c|c|c|c|c|c|c|c|}
\hline \multirow{3}{*}{$\begin{array}{c}\text { Date } \\
\text { Total count } \\
\text { Organism }\end{array}$} & \multirow{2}{*}{\multicolumn{2}{|c|}{$\frac{\text { Oct. } 21,1981}{1,542}$}} & \multirow{2}{*}{\multicolumn{2}{|c|}{$\frac{\text { Nov. 4, } 1982}{{ }^{1} 2,380}$}} & \multirow{2}{*}{\multicolumn{2}{|c|}{$\frac{\text { Oct. } 18,1983}{{ }^{1} 1,615}$}} & \multirow{2}{*}{\multicolumn{2}{|c|}{$\frac{\text { Oct. } 10,1984}{{ }^{1} 1,295}$}} & \multirow{2}{*}{\multicolumn{2}{|c|}{$\frac{\text { Oct. } 10,1985}{535}$}} & \multirow{2}{*}{\multicolumn{2}{|c|}{$\begin{array}{c}\text { Oct. 22, } 1986 \\
1,395\end{array}$}} & \multirow{2}{*}{\multicolumn{2}{|c|}{$\frac{\text { Oct. } 16,1987}{1,338}$}} \\
\hline & & & & & & & & & & & & & & \\
\hline & Count & Percent & Count & Percent & Count & Percent & Count & Percent & Count & Percent & Count & Percent & Count & Percent \\
\hline \multicolumn{15}{|l|}{ Platyhelminthes (flatworms) } \\
\hline \multicolumn{15}{|l|}{ Turbellaria } \\
\hline \multicolumn{15}{|l|}{ Tricladida } \\
\hline Planariidae & 1 & $<1$ & 5 & $<1$ & 3 & $<1$ & - & & 12 & 2 & 7 & $<1$ & - & \\
\hline Nematoda (nematodes) & - & & - & & - & & - & & - & & - & & - & \\
\hline \multicolumn{15}{|l|}{ Nemertea (proboscis worms) } \\
\hline \multicolumn{15}{|l|}{ Enopla } \\
\hline \multicolumn{15}{|l|}{ Hoplonemertea } \\
\hline Tetrastemmatidac & & & & & & & & & & & & & & \\
\hline Prostoma & - & & - & & 5 & $<1$ & - & & 1 & $<1$ & - & & - & \\
\hline Mollusca (molluscs) & & & & & & & & & & & & & & \\
\hline Gastropoda & & & & & & & & & & & & & & \\
\hline Basommatophora & & & & & & & & & & & & & & \\
\hline Ancylidae & & & & & & & & & & & & & & \\
\hline Ferrissia & 8 & $<1$ & 3 & $<1$ & 11 & $<1$ & 64 & 5 & 8 & 2 & 21 & 2 & 10 & $<1$ \\
\hline Physidae & & & & & & & & & & & & & & \\
\hline Physa & - & & - & & - & & - & & - & & - & & - & \\
\hline Planorbidae & & & & & & & & & & & & & & \\
\hline Gyraulus & - & & - & & - & & - & & - & & - & & - & \\
\hline Bivalvia & & & & & & & & & & & & & & \\
\hline Veneroida & & & & & & & & & & & & & & \\
\hline Sphaeriidae & - & & - & & - & & - & & 1 & $<1$ & - & & - & \\
\hline Pisidium & - & & 3 & $<1$ & - & & - & & - & & - & & - & \\
\hline Annelida (segmented worms) & & & & & & & & & & & & & & \\
\hline Oligochaeta & - & & - & & - & & - & & - & & - & & - & \\
\hline Lumbriculida & & & & & & & & & & & & & & \\
\hline Lumbriculidae & 15 & $<1$ & 3 & $<1$ & - & & 3 & $<1$ & 1 & $<1$ & - & & 4 & $<1$ \\
\hline Tubificida & & & & & & & & & & & & & & \\
\hline Naididae & 4 & $<1$ & 3 & $<1$ & - & & - & & - & & - & & - & \\
\hline Arthropoda (arthropods) & & & & & & & & & & & & & & \\
\hline Acariformes & & & & & & & & & & & & & & \\
\hline Hydrachnidia & 18 & 1 & - & & - & & - & & - & & 13 & $<1$ & 21 & 2 \\
\hline Crustacea & & & & & & & & & & & & & & \\
\hline Cladocera & - & & - & & - & & - & & - & & - & & - & \\
\hline Cyclopoida & - & & - & & - & & - & & - & & - & & - & \\
\hline Amphipoda & & & & & & & & & & & & & & \\
\hline Gammaridae & & & & & & & & & & & & & & \\
\hline Gammarus & - & & - & & - & & - & & - & & - & & - & \\
\hline Podocopa & - & & - & & - & & - & & - & & - & & - & \\
\hline Insecta & & & & & & & & & & & & & & \\
\hline Ephemeroptera & & & & & & & & & & & & & & \\
\hline Baetidae & & & & & & & & & & & & & & \\
\hline Baetis & 4 & $<1$ & 8 & $<1$ & 5 & $<1$ & 11 & $<1$ & 4 & $<1$ & - & & - & \\
\hline Pseudocloeon & 3 & $<1$ & - & & 13 & $<1$ & 13 & 1 & 9 & 2 & 3 & $<1$ & 10 & $<1$ \\
\hline Caenidae & & & & & & & & & & & & & & \\
\hline Caenis & 2 & $<1$ & - & & - & & - & & - & & - & & - & \\
\hline Ephemerellidae & & & & & & & & & & & & & & \\
\hline Ephemerella & 55 & 3 & 51 & 2 & 40 & 3 & 48 & 4 & 13 & 2 & 32 & 2 & 16 & 1 \\
\hline Heptageniidae & & & & & & & & & & & & & & \\
\hline Epeorus & 7 & $<1$ & 21 & $<1$ & 16 & 1 & 19 & 1 & - & & - & & 1 & $<1$ \\
\hline Stenonema & 170 & 11 & 96 & 4 & 88 & 6 & 85 & 7 & 18 & 3 & 49 & 3 & 23 & 2 \\
\hline Isonychiidae & & & & & & & & & & & & & & \\
\hline Isonychia & 91 & 6 & 43 & 2 & 43 & 3 & 56 & 4 & 6 & 1 & 65 & 5 & 13 & 1 \\
\hline
\end{tabular}




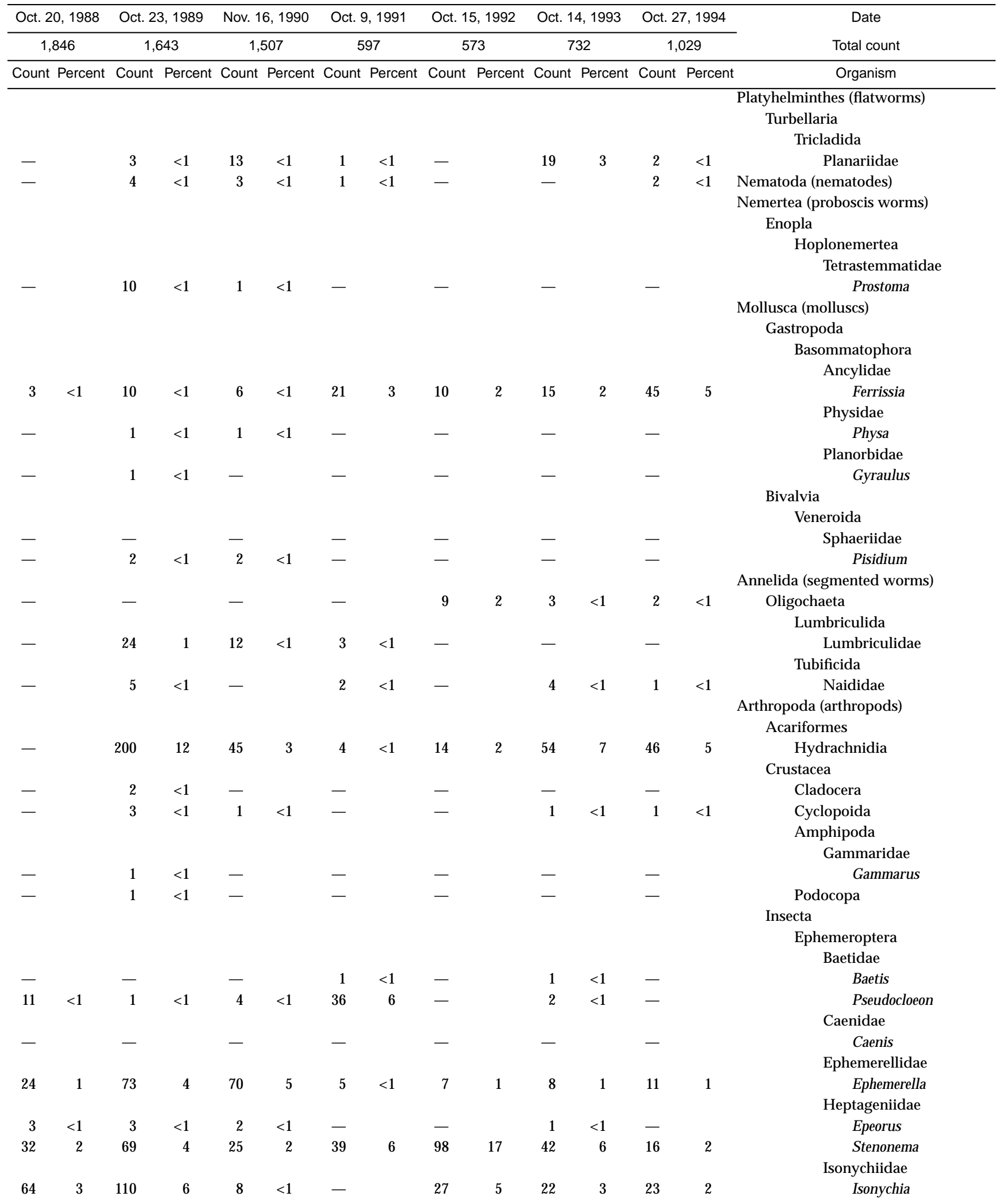


Table 5. Benthic-macroinvertebrate data-Continued

01472138 - French Creek near Coventryville, Pa. (Site 13)—Continued

\begin{tabular}{|c|c|c|c|c|c|c|c|c|c|c|c|c|c|c|}
\hline \multirow{3}{*}{$\begin{array}{c}\text { Date } \\
\text { Total count } \\
\text { Organism }\end{array}$} & \multirow{2}{*}{\multicolumn{2}{|c|}{$\begin{array}{c}\text { Oct. } 21,1981 \\
1,542\end{array}$}} & \multirow{2}{*}{\multicolumn{2}{|c|}{$\begin{array}{c}\text { Nov. 4, } 1982 \\
{ }^{1} 2,380\end{array}$}} & \multirow{2}{*}{\multicolumn{2}{|c|}{$\begin{array}{c}\text { Oct. } 18,1983 \\
{ }^{1} 1,615\end{array}$}} & \multirow{2}{*}{\multicolumn{2}{|c|}{$\begin{array}{c}\text { Oct. } 10,1984 \\
{ }^{1} 1,295\end{array}$}} & \multirow{2}{*}{\multicolumn{2}{|c|}{$\begin{array}{c}\text { Oct. } 10,1985 \\
535\end{array}$}} & \multirow{2}{*}{\multicolumn{2}{|c|}{$\begin{array}{c}\text { Oct. } 22,1986 \\
1,395\end{array}$}} & \multirow{2}{*}{\multicolumn{2}{|c|}{$\begin{array}{c}\text { Oct. } 16,1987 \\
1,338\end{array}$}} \\
\hline & & & & & & & & & & & & & & \\
\hline & Count & Percent & Count & Percent & Count & Percent & Count & Percent & Count & Percent & Count & Percent & Count & Percent \\
\hline \multicolumn{15}{|l|}{ Odonata } \\
\hline \multicolumn{15}{|l|}{ Coenagrionidae } \\
\hline Argia & - & & - & & - & & - & & - & & - & & - & \\
\hline Gomphidae & - & & - & & - & & - & & - & & - & & - & \\
\hline \multicolumn{15}{|l|}{ Ophiogomphus } \\
\hline \multicolumn{15}{|l|}{ Plecoptera } \\
\hline \multicolumn{15}{|l|}{ Capniidae } \\
\hline Allocapnia & 3 & $<1$ & 24 & 1 & 5 & $<1$ & - & & 1 & $<1$ & 1 & $<1$ & 11 & $<1$ \\
\hline Chloroperlidae & 1 & $<1$ & 5 & $<1$ & - & & 3 & $<1$ & - & & 1 & $<1$ & - & \\
\hline \multicolumn{15}{|l|}{ Perlidae } \\
\hline Acroneuria & 10 & $<1$ & - & & 3 & $<1$ & 3 & $<1$ & 1 & $<1$ & 4 & $<1$ & 1 & $<1$ \\
\hline Agnetina & 6 & $<1$ & 3 & $<1$ & - & & - & & - & & - & & - & \\
\hline Paragnetina & - & & - & & - & & - & & - & & 1 & $<1$ & 2 & $<1$ \\
\hline Taeniopterygidae & & & & & & & & & & & & & & \\
\hline Strophopteryx & 16 & 1 & 150 & 6 & 3 & $<1$ & - & & - & & - & & - & \\
\hline Taeniopteryx & 32 & 2 & 29 & 1 & 56 & 3 & 16 & 1 & 3 & $<1$ & 14 & 1 & 80 & 6 \\
\hline Hemiptera & & & & & & & & & & & & & & \\
\hline Saldidae & - & & - & & 3 & $<1$ & - & & - & & - & & - & \\
\hline Megaloptera & & & & & & & & & & & & & & \\
\hline Corydalidae & & & & & & & & & & & & & & \\
\hline Corydalus & 1 & $<1$ & - & & - & & - & & 1 & $<1$ & 1 & $<1$ & - & \\
\hline Nigronia & - & & - & & - & & - & & 1 & $<1$ & & & & \\
\hline Sialidae & & & & & & & & & & & & & & \\
\hline Sialis & - & & - & & - & & - & & - & & - & & - & \\
\hline Trichoptera & & & & & & & & & & & & & & \\
\hline Apataniidae & & & & & & & & & & & & & & \\
\hline Apatania & 19 & 1 & 11 & $<1$ & 5 & $<1$ & 3 & $<1$ & 1 & $<1$ & - & & 2 & $<1$ \\
\hline Brachycentridae & & & & & & & & & & & & & & \\
\hline Brachycentrus & - & & - & & - & & - & & 1 & $<1$ & - & & - & \\
\hline Micrasema & 170 & 11 & 72 & 3 & 130 & 8 & 3 & $<1$ & 22 & 4 & 60 & 4 & 21 & 2 \\
\hline Glossosomatidae & & & & & & & & & & & & & & \\
\hline Glossosoma & 14 & $<1$ & 29 & 1 & 24 & 2 & 32 & 2 & - & & 7 & $<1$ & 1 & $<1$ \\
\hline Protoptila & 1 & $<1$ & - & & - & & - & & - & & - & & - & \\
\hline Goeridae & & & & & & & & & & & & & & \\
\hline Goera & 5 & $<1$ & - & & 11 & $<1$ & - & & - & & - & & - & \\
\hline Helicopsychidae & & & & & & & & & & & & & & \\
\hline Helicopsyche & - & & - & & - & & - & & - & & - & & - & \\
\hline Hydropsychidae & & & & & & & & & & & & & & \\
\hline Ceratopsyche & 92 & 6 & 260 & 11 & 240 & 15 & 200 & 15 & 39 & 7 & 98 & 7 & 31 & 2 \\
\hline Cheumatopsyche & 250 & 16 & 120 & 5 & 150 & 9 & 130 & 10 & 17 & 3 & 36 & 3 & 8 & $<1$ \\
\hline Hydropsyche & 1 & $<1$ & 5 & $<1$ & 5 & $<1$ & 5 & $<1$ & 1 & $<1$ & 5 & $<1$ & 91 & 7 \\
\hline Hydroptilidae & & & & & & & & & & & & & & \\
\hline Hydroptila & 2 & $<1$ & 11 & $<1$ & 8 & $<1$ & - & & - & & - & & 5 & $<1$ \\
\hline Leucotrichia & 48 & 3 & 16 & $<1$ & 310 & 19 & 320 & 25 & 32 & 6 & 240 & 17 & 55 & 4 \\
\hline Lepidostomatidae & & & & & & & & & & & & & & \\
\hline Lepidostoma & - & & 3 & $<1$ & - & & - & & - & & - & & - & \\
\hline Leptoceridae & & & & & & & & & & & & & & \\
\hline Mystacides & - & & - & & - & & - & & - & & - & & - & \\
\hline Oecetis & - & & - & & 3 & $<1$ & - & & - & & - & & - & \\
\hline Philopotamidae & & & & & & & & & & & & & & \\
\hline Chimarra & 25 & 2 & 51 & 2 & 77 & 5 & 11 & $<1$ & 6 & 1 & 23 & 2 & 5 & $<1$ \\
\hline Dolophilodes & - & & - & & 3 & $<1$ & 3 & $<1$ & - & & 4 & $<1$ & - & \\
\hline Wormaldia & - & & - & & - & & - & & - & & - & & - & \\
\hline
\end{tabular}




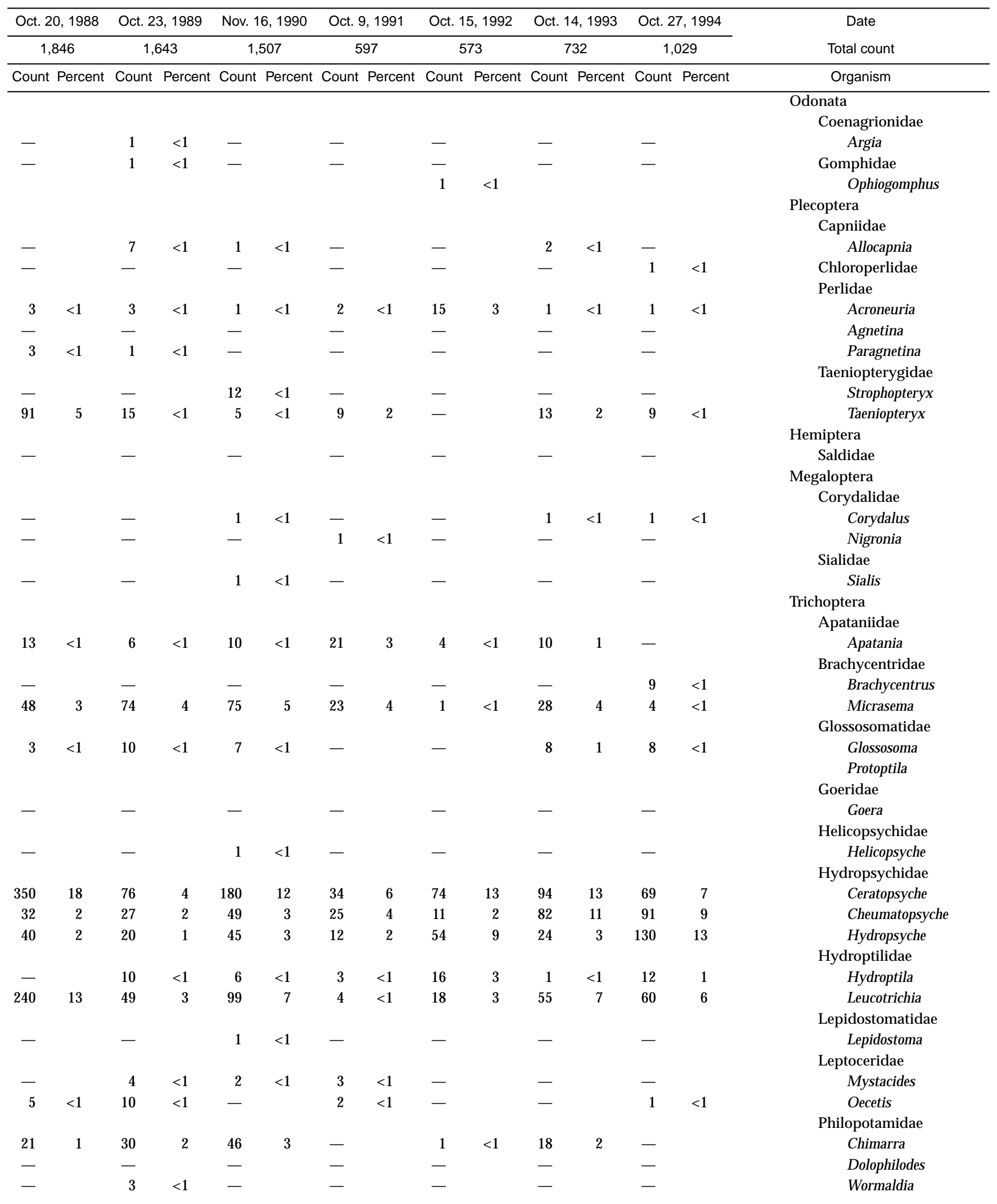


Table 5. Benthic-macroinvertebrate data-Continued

01472138 - French Creek near Coventryville, Pa. (Site 13)—Continued

\begin{tabular}{|c|c|c|c|c|c|c|c|c|c|c|c|c|c|c|}
\hline \multirow{3}{*}{$\begin{array}{c}\text { Date } \\
\text { Total count } \\
\text { Organism }\end{array}$} & \multicolumn{2}{|c|}{ Oct. 21,1981} & \multicolumn{2}{|c|}{ Nov. 4, 1982} & \multicolumn{2}{|c|}{ Oct. 18,1983} & \multicolumn{2}{|c|}{ Oct. 10, 1984} & \multicolumn{2}{|c|}{ Oct. 10,1985} & \multicolumn{2}{|c|}{ Oct. 22, 1986} & \multicolumn{2}{|c|}{ Oct. 16, 1987} \\
\hline & \multicolumn{2}{|c|}{1,542} & \multicolumn{2}{|c|}{${ }^{1} 2,380$} & \multicolumn{2}{|c|}{${ }^{1} 1,615$} & \multicolumn{2}{|c|}{${ }^{1} 1,295$} & \multicolumn{2}{|c|}{535} & \multicolumn{2}{|c|}{1,395} & \multicolumn{2}{|c|}{1,338} \\
\hline & Count & Percent & Count & Percent & Count & Percent & Count & Percent & Count & Percent & Count & Percent & Count & Percent \\
\hline \multicolumn{15}{|l|}{ Trichoptera } \\
\hline \multicolumn{15}{|l|}{ Polycentropodidae } \\
\hline Neureclipsis & - & & - & & 11 & $<1$ & - & & - & & 4 & $<1$ & 2 & $<1$ \\
\hline Nyctiophylax & 1 & $<1$ & 3 & $<1$ & 一 & & - & & - & & - & & - & \\
\hline Polycentropus & - & & - & & 3 & $<1$ & - & & - & & - & & - & \\
\hline \multicolumn{15}{|l|}{ Psychomyiidae } \\
\hline Psychomyia & 59 & 4 & 61 & 3 & 13 & $<1$ & 8 & $<1$ & 37 & 7 & 21 & 2 & 20 & 2 \\
\hline \multicolumn{15}{|l|}{ Rhyacophilidae } \\
\hline Rhyacophila & 6 & $<1$ & - & & 5 & $<1$ & 11 & $<1$ & 1 & $<1$ & 5 & $<1$ & 1 & $<1$ \\
\hline Uenoidae & & & & & & & & & & & & & & \\
\hline Neophylax & 7 & $<1$ & - & & - & & - & & - & & - & & - & \\
\hline Lepidoptera & & & & & & & & & & & & & & \\
\hline Noctuidae & - & & - & & 一 & & - & & - & & - & & - & \\
\hline Pyralidae & & & & & & & & & & & & & & \\
\hline Petrophila & 24 & 2 & 11 & $<1$ & 11 & $<1$ & - & & 1 & $<1$ & 11 & $<1$ & 1 & $<1$ \\
\hline Coleoptera & & & & & & & & & & & & & & \\
\hline Dryopidae & & & & & & & & & & & & & & \\
\hline Helichus & - & & - & & - & & - & & - & & - & & - & \\
\hline Elmidae & & & & & & & & & & & & & & \\
\hline Ancyronyx & & & & & & & & & & & & & & \\
\hline A.variegata & - & & - & & - & & - & & - & & - & & - & \\
\hline Dubiraphia & - & & - & & 一 & & - & & 1 & $<1$ & - & & - & \\
\hline Macronychus & - & & - & & - & & - & & - & & - & & - & \\
\hline Optioservus & 47 & 3 & 45 & 2 & 21 & 1 & 11 & $<1$ & 13 & 2 & 1 & $<1$ & 13 & 1 \\
\hline Oulimnius & 1 & $<1$ & 3 & $<1$ & - & & - & & 1 & $<1$ & - & & 1 & $<1$ \\
\hline Stenelmis & 7 & $<1$ & 5 & $<1$ & 16 & 1 & 11 & $<1$ & 2 & $<1$ & - & & 1 & $<1$ \\
\hline Psephenidae & & & & & & & & & & & & & & \\
\hline Psephenus & 2 & $<1$ & - & & 3 & $<1$ & - & & 2 & $<1$ & 1 & $<1$ & - & \\
\hline Hymenoptera & - & & - & & - & & - & & 2 & $<1$ & - & & - & \\
\hline Diptera & & & & & & & & & & & & & & \\
\hline Athericidae & & & & & & & & & & & & & & \\
\hline Atherix & 1 & $<1$ & - & & 一 & & - & & - & & - & & - & \\
\hline Chironomidae & 280 & 18 & 1,000 & 42 & 210 & 13 & 170 & 13 & 230 & 42 & 590 & 42 & 800 & 62 \\
\hline Empididae & & & & & & & & & & & & & & \\
\hline Chelifera & - & & - & & 一 & & - & & - & & - & & - & \\
\hline Hemerodromia & 6 & $<1$ & 11 & $<1$ & 3 & $<1$ & - & & 1 & $<1$ & 3 & $<1$ & - & \\
\hline Ephydridae & - & & - & & - & & - & & - & & - & & - & \\
\hline Simuliidae & & & & & & & & & & & & & & \\
\hline Simulium & - & & 16 & $<1$ & 8 & $<1$ & 32 & 2 & 34 & 6 & 12 & $<1$ & 55 & 4 \\
\hline Tipulidae & & & & & & & & & & & & & & \\
\hline Antocha & 27 & 2 & 200 & 8 & 51 & 3 & 24 & 2 & 11 & 2 & 62 & 4 & 33 & 3 \\
\hline Tipula & - & & - & & - & & - & & - & & - & & - & \\
\hline
\end{tabular}

\footnotetext{
${ }^{1}$ Extrapolated from a 3/8 subsample.
} 


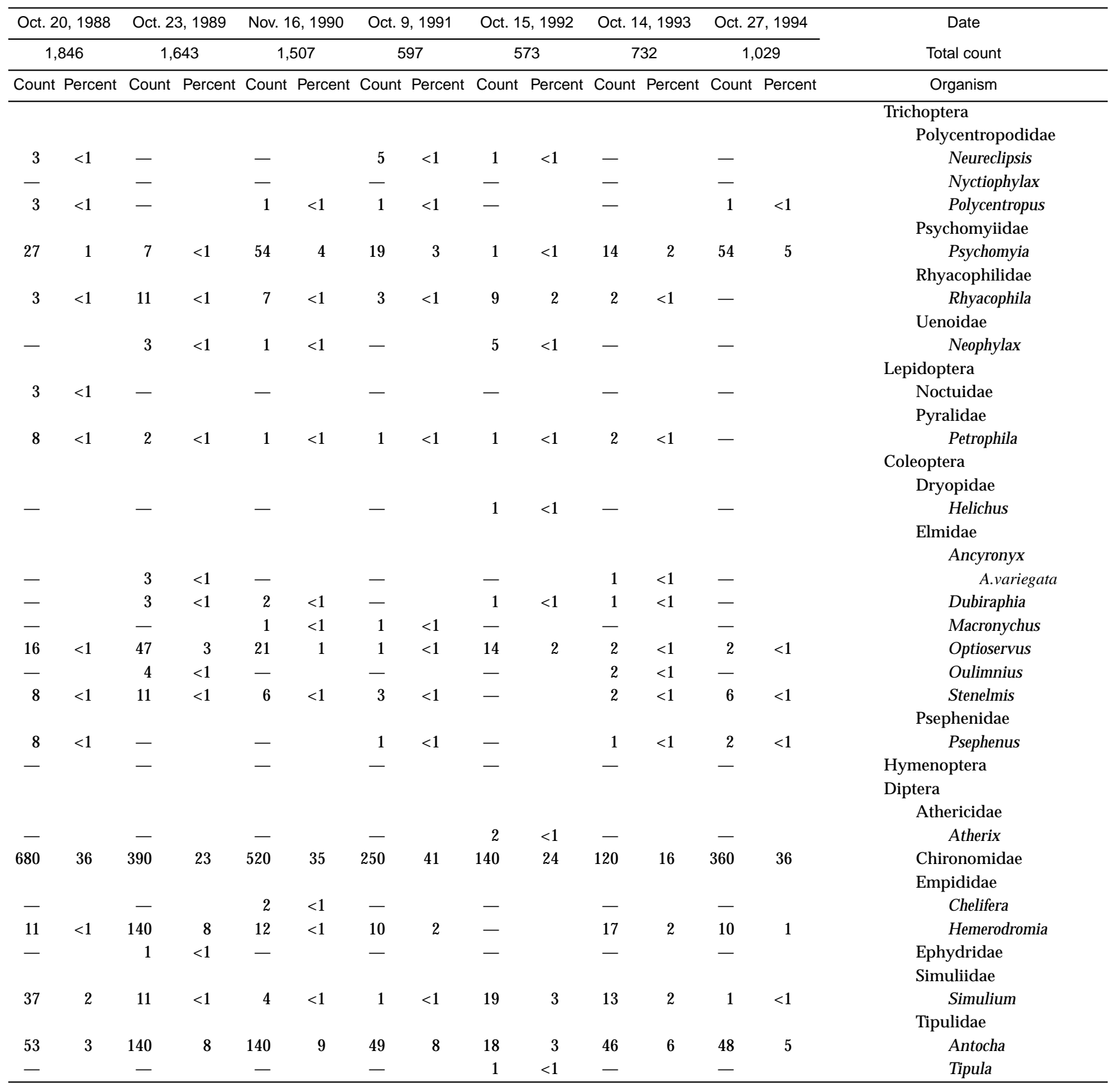


Table 5. Benthic-macroinvertebrate data-Continued

$[<$, less than; - , not found]

01472140 - South Branch French Creek at Coventryville, Pa. (Site 12)

\begin{tabular}{|c|c|c|c|c|c|c|c|c|c|c|c|c|c|c|}
\hline \multirow{3}{*}{$\begin{array}{c}\text { Date } \\
\text { Total count } \\
\text { Organism }\end{array}$} & \multirow{2}{*}{\multicolumn{2}{|c|}{$\frac{\text { Oct. } 21,1981}{{ }^{1} 1,197}$}} & \multirow{2}{*}{\multicolumn{2}{|c|}{$\frac{\text { Nov. 4, } 1982}{{ }^{1} 2,649}$}} & \multirow{2}{*}{\multicolumn{2}{|c|}{$\begin{array}{c}\text { Oct. } 18,1983 \\
{ }^{1} 1,697\end{array}$}} & \multirow{2}{*}{\multicolumn{2}{|c|}{$\frac{\text { Oct. } 10,1984}{{ }^{1} 1,563}$}} & \multirow{2}{*}{\multicolumn{2}{|c|}{$\frac{\text { Oct. 10, } 1985}{785}$}} & \multirow{2}{*}{\multicolumn{2}{|c|}{$\begin{array}{c}\text { Oct. } 22,1986 \\
1,312\end{array}$}} & \multirow{2}{*}{\multicolumn{2}{|c|}{$\frac{\text { Oct. } 16,1987}{2,014}$}} \\
\hline & & & & & & & & & & & & & & \\
\hline & Count & Percent & Count & Percent & Count & Percent & Count & Percent & Count & Percent & Count & Percent & Count & Percent \\
\hline \multicolumn{15}{|l|}{ Platyhelminthes (flatworms) } \\
\hline \multicolumn{15}{|l|}{ Turbellaria } \\
\hline \multicolumn{15}{|l|}{ Tricladida } \\
\hline Planariidae & - & & - & & 5 & $<1$ & 3 & $<1$ & 8 & 1 & 1 & $<1$ & 2 & $<1$ \\
\hline Nematoda (nematodes) & - & & - & & - & & - & & - & & - & & - & \\
\hline \multicolumn{15}{|l|}{ Nemertea (proboscis worms) } \\
\hline \multicolumn{15}{|l|}{ Enopla } \\
\hline \multicolumn{15}{|l|}{ Hoplonemertea } \\
\hline Tetrastemmatidac & & & & & & & & & & & & & & \\
\hline Prostoma & - & & - & & - & & - & & - & & - & & 1 & $<1$ \\
\hline Mollusca (molluscs) & & & & & & & & & & & & & & \\
\hline Gastropoda & & & & & & & & & & & & & & \\
\hline Basommatophora & & & & & & & & & & & & & & \\
\hline Ancylidae & & & & & & & & & & & & & & \\
\hline Ferrissia & 11 & $<1$ & - & & - & & - & & - & & - & & 4 & $<1$ \\
\hline Lymnaeidae & & & & & & & & & & & & & & \\
\hline Lymnaea & - & & - & & - & & - & & - & & - & & - & \\
\hline Physidae & & & & & & & & & & & & & & \\
\hline Physa & - & & - & & - & & - & & - & & - & & - & \\
\hline Planorbidae & & & & & & & & & & & & & & \\
\hline Gyraulus & - & & - & & - & & - & & - & & - & & - & \\
\hline Bivalvia & & & & & & & & & & & & & & \\
\hline Veneroida & & & & & & & & & & & & & & \\
\hline Sphaeriidae & - & & - & & - & & - & & - & & - & & - & \\
\hline Pisidium & - & & - & & - & & - & & - & & - & & - & \\
\hline Annelida (segmented worms) & & & & & & & & & & & & & & \\
\hline Oligochaeta & - & & - & & - & & - & & - & & - & & - & \\
\hline Lumbriculida & & & & & & & & & & & & & & \\
\hline Lumbriculidae & - & & - & & - & & - & & - & & - & & - & \\
\hline Tubificida & & & & & & & & & & & & & & \\
\hline Naididae & - & & - & & - & & - & & - & & - & & 1 & $<1$ \\
\hline Tubificidae & - & & - & & - & & - & & - & & - & & 1 & $<1$ \\
\hline Arthropoda (arthropods) & & & & & & & & & & & & & & \\
\hline Acariformes & & & & & & & & & & & & & & \\
\hline Hydrachnidia & - & & - & & - & & - & & - & & 19 & 1 & 1 & $<1$ \\
\hline Crustacea & & & & & & & & & & & & & & \\
\hline Cyclopoida & - & & - & & - & & - & & - & & - & & - & \\
\hline Podocopa & - & & - & & - & & - & & - & & - & & - & \\
\hline Insecta & & & & & & & & & & & & & & \\
\hline Ephemeroptera & & & & & & & & & & & & & & \\
\hline Baetidae & & & & & & & & & & & & & & \\
\hline Baetis & 16 & 1 & 5 & $<1$ & 3 & $<1$ & 32 & 2 & 16 & 2 & 4 & $<1$ & 27 & 1 \\
\hline Pseudocloeon & 8 & $<1$ & - & & 3 & $<1$ & 8 & $<1$ & - & & - & & 13 & $<1$ \\
\hline Caenidae & & & & & & & & & & & & & & \\
\hline Caenis & - & & - & & - & & - & & - & & - & & 1 & $<1$ \\
\hline Ephemerellidae & & & & & & & & & & & & & & \\
\hline Ephemerella & 80 & 7 & 280 & 10 & 160 & 9 & 130 & 8 & 57 & 7 & 170 & 13 & 92 & 5 \\
\hline Heptageniidae & & & & & & & & & & & & & & \\
\hline Epeorus & - & & 13 & $<1$ & 40 & 2 & 8 & $<1$ & - & & 60 & 5 & 29 & 1 \\
\hline Stenonema & 150 & 13 & 100 & 4 & 180 & 11 & 77 & 5 & 65 & 8 & 110 & 8 & 52 & 3 \\
\hline Isonychiidae & & & & & & & & & & & & & & \\
\hline Isonychia & 32 & 3 & 27 & 1 & 53 & 3 & 11 & $<1$ & 13 & 2 & 26 & 2 & 20 & 1 \\
\hline
\end{tabular}




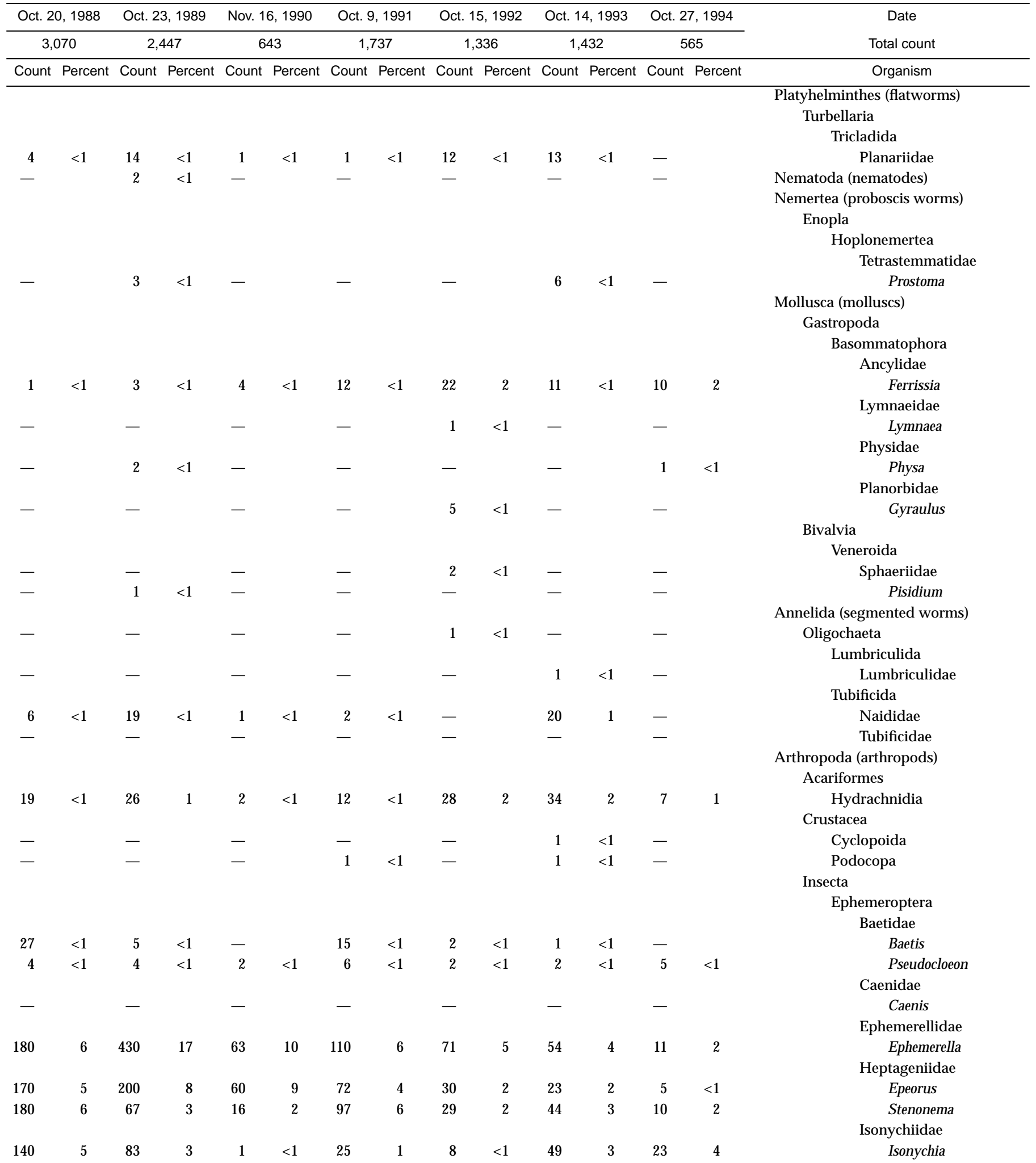


Table 5. Benthic-macroinvertebrate data—Continued

01472140 - South Branch French Creek at Coventryville, Pa. (Site 12)—Continued

\begin{tabular}{|c|c|c|c|c|c|c|c|c|c|c|c|c|c|c|}
\hline \multirow{3}{*}{$\begin{array}{c}\text { Date } \\
\text { Total count } \\
\text { Organism }\end{array}$} & \multirow{2}{*}{\multicolumn{2}{|c|}{$\begin{array}{c}\text { Oct. } 21,1981 \\
11,197\end{array}$}} & \multirow{2}{*}{\multicolumn{2}{|c|}{$\begin{array}{c}\text { Nov. } 4,1982 \\
12,649\end{array}$}} & \multirow{2}{*}{\multicolumn{2}{|c|}{$\begin{array}{c}\text { Oct. } 18,1983 \\
{ }^{1} 1,697\end{array}$}} & \multirow{2}{*}{\multicolumn{2}{|c|}{$\begin{array}{c}\text { Oct. } 10,1984 \\
{ }^{1} 1,563\end{array}$}} & \multirow{2}{*}{\multicolumn{2}{|c|}{$\begin{array}{c}\text { Oct. } 10,1985 \\
785\end{array}$}} & \multirow{2}{*}{\multicolumn{2}{|c|}{$\begin{array}{c}\text { Oct. } 22,1986 \\
1,312\end{array}$}} & \multirow{2}{*}{\multicolumn{2}{|c|}{$\begin{array}{c}\text { Oct. } 16,1987 \\
2,014\end{array}$}} \\
\hline & & & & & & & & & & & & & & \\
\hline & Count & Percent & Count & Percent & Count & Percent & Count & Percent & Count & Percent & Count & Percent & Count & Percent \\
\hline \multicolumn{15}{|l|}{ Ephemeroptera } \\
\hline Leptophlebiidae & - & & - & & - & & - & & - & & 2 & $<1$ & - & \\
\hline Paraleptophlebia & - & & - & & - & & - & & 2 & $<1$ & - & & - & \\
\hline \multicolumn{15}{|l|}{ Odonata } \\
\hline \multicolumn{15}{|l|}{ Coenagrionidae } \\
\hline Argia & - & & - & & - & & - & & - & & - & & - & \\
\hline \multicolumn{15}{|l|}{ Gomphidae } \\
\hline Gomphus & 5 & $<1$ & - & & - & & - & & - & & - & & - & \\
\hline \multicolumn{15}{|l|}{ Plecoptera } \\
\hline Capniidae & & & & & & & & & & & & & & \\
\hline Allocapnia & 5 & $<1$ & 8 & $<1$ & 5 & $<1$ & - & & - & & 1 & $<1$ & 5 & $<1$ \\
\hline Chloroperlidae & 3 & $<1$ & 59 & 2 & 11 & $<1$ & 13 & $<1$ & 9 & 1 & 11 & $<1$ & - & \\
\hline Perlidae & & & & & & & & & & & & & & \\
\hline Acroneuria & - & & - & & - & & - & & 5 & $<1$ & 2 & $<1$ & 1 & $<1$ \\
\hline Agnetina & 11 & $<1$ & - & & - & & - & & - & & - & & - & \\
\hline Paragnetina & - & & - & & - & & - & & 1 & $<1$ & 1 & $<1$ & 9 & $<1$ \\
\hline Perlodidae & & & & & & & & & & & & & & \\
\hline Isoperla & - & & - & & - & & - & & - & & - & & - & \\
\hline Taeniopterygidae & & & & & & & & & & & & & & \\
\hline Strophopteryx & - & & 13 & $<1$ & - & & - & & - & & - & & - & \\
\hline Taeniopteryx & 32 & 3 & 16 & $<1$ & 24 & 1 & 5 & $<1$ & 7 & $<1$ & 5 & $<1$ & 28 & 1 \\
\hline Megaloptera & & & & & & & & & & & & & & \\
\hline Corydalidae & & & & & & & & & & & & & & \\
\hline Corydalus & 3 & $<1$ & 3 & $<1$ & 3 & $<1$ & - & & - & & 2 & $<1$ & 1 & $<1$ \\
\hline Nigronia & 3 & $<1$ & - & & - & & - & & 1 & $<1$ & - & & - & \\
\hline Trichoptera & & & & & & & & & & & & & & \\
\hline Apataniidae & - & & - & & - & & - & & 2 & $<1$ & - & & - & \\
\hline Apatania & - & & - & & - & & - & & - & & 7 & $<1$ & 2 & $<1$ \\
\hline Brachycentridae & & & & & & & & & & & & & & \\
\hline Micrasema & 19 & 2 & 75 & 3 & 45 & 3 & 3 & $<1$ & 21 & 3 & 68 & 5 & 44 & 2 \\
\hline Glossosomatidae & & & & & & & & & & & & & & \\
\hline Culoptila & - & & - & & - & & - & & - & & - & & - & \\
\hline Glossosoma & 8 & $<1$ & 5 & $<1$ & 8 & $<1$ & 21 & 1 & 4 & $<1$ & 31 & 2 & 20 & 1 \\
\hline Protoptila & 5 & $<1$ & - & & - & & 5 & $<1$ & - & & - & & - & \\
\hline Goeridae & & & & & & & & & & & & & & \\
\hline Goera & - & & - & & 8 & $<1$ & - & & 13 & 2 & 1 & $<1$ & - & \\
\hline Helicopsychidae & & & & & & & & & & & & & & \\
\hline Helicopsyche & - & & - & & - & & - & & - & & - & & - & \\
\hline Hydropsychidae & & & & & & & & & & & & & & \\
\hline Ceratopsyche & 120 & 10 & 270 & 10 & 430 & 25 & 310 & 19 & 130 & 16 & 140 & 11 & 490 & 25 \\
\hline Cheumatopsyche & 360 & 30 & 380 & 14 & 440 & 26 & 300 & 19 & 140 & 18 & 82 & 6 & 90 & 5 \\
\hline Hydropsyche & 3 & $<1$ & 21 & $<1$ & 24 & 1 & 32 & 2 & 10 & 1 & 170 & 13 & 180 & 9 \\
\hline Macrostemum & 3 & $<1$ & 21 & $<1$ & 3 & $<1$ & 3 & $<1$ & - & & 3 & $<1$ & 5 & $<1$ \\
\hline Hydroptilidae & & & & & & & & & & & & & & \\
\hline Hydroptila & 3 & $<1$ & 21 & $<1$ & 3 & $<1$ & - & & - & & - & & 2 & $<1$ \\
\hline Leucotrichia & 3 & $<1$ & 53 & 2 & 37 & 2 & 160 & 10 & 23 & 3 & 150 & 12 & 41 & 2 \\
\hline Lepidostomatidae & & & & & & & & & & & & & & \\
\hline Lepidostoma & - & & - & & - & & - & & - & & - & & 2 & $<1$ \\
\hline Leptoceridae & & & & & & & & & & & & & & \\
\hline Mystacides & - & & - & & - & & - & & - & & - & & - & \\
\hline Oecetis & 5 & $<1$ & - & & - & & - & & 1 & $<1$ & - & & - & \\
\hline Philopotamidae & & & & & & & & & & & & & & \\
\hline Chimarra & 13 & 1 & 45 & 2 & 8 & $<1$ & 8 & $<1$ & 18 & 2 & 17 & 1 & 23 & 1 \\
\hline Dolophilodes & - & & - & & - & & - & & 1 & $<1$ & - & & - & \\
\hline Wormaldia & - & & - & & - & & - & & - & & - & & 1 & $<1$ \\
\hline
\end{tabular}




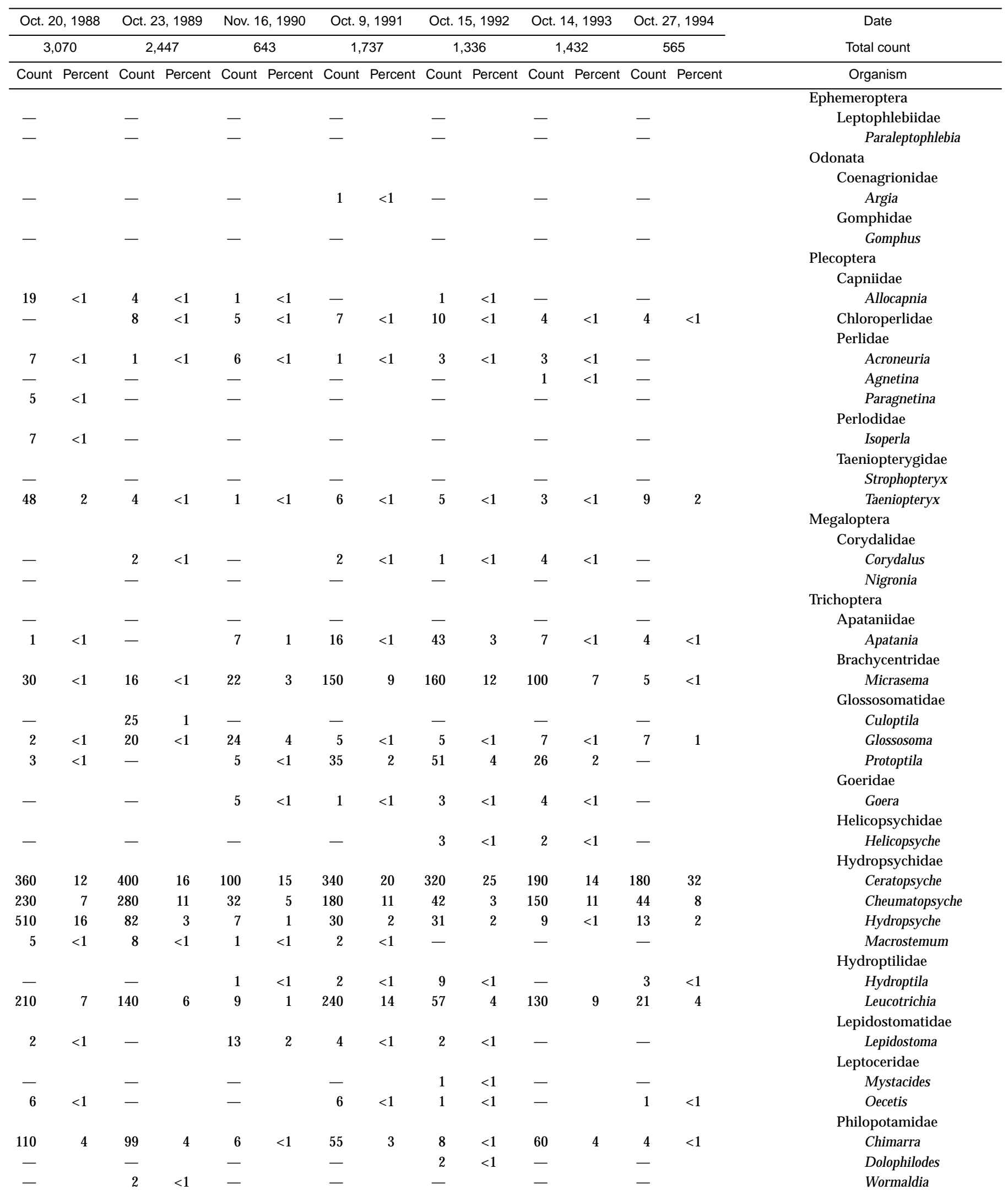


Table 5. Benthic-macroinvertebrate data—Continued

01472140 - South Branch French Creek at Coventryville, Pa. (Site 12)—Continued

\begin{tabular}{|c|c|c|c|c|c|c|c|c|c|c|c|c|c|c|}
\hline \multirow{3}{*}{$\begin{array}{c}\text { Date } \\
\text { Total count } \\
\text { Organism }\end{array}$} & \multirow{2}{*}{\multicolumn{2}{|c|}{$\begin{array}{c}\text { Oct. } 21,1981 \\
{ }^{1} 1,197\end{array}$}} & \multirow{2}{*}{\multicolumn{2}{|c|}{$\begin{array}{c}\text { Nov. } 4,1982 \\
12,649\end{array}$}} & \multirow{2}{*}{\multicolumn{2}{|c|}{$\begin{array}{c}\text { Oct. } 18,1983 \\
{ }^{1} 1,697\end{array}$}} & \multirow{2}{*}{\multicolumn{2}{|c|}{$\begin{array}{c}\text { Oct. 10, } 1984 \\
11,563\end{array}$}} & \multirow{2}{*}{\multicolumn{2}{|c|}{$\begin{array}{c}\text { Oct. } 10,1985 \\
785\end{array}$}} & \multirow{2}{*}{\multicolumn{2}{|c|}{$\begin{array}{c}\text { Oct. } 22,1986 \\
1,312\end{array}$}} & \multirow{2}{*}{\multicolumn{2}{|c|}{$\begin{array}{c}\text { Oct. } 16,1987 \\
2,014\end{array}$}} \\
\hline & & & & & & & & & & & & & & \\
\hline & Count & Percent & Count & Percent & Count & Percent & Count & Percent & Count & Percent & Count & Percent & Count & Percent \\
\hline \multicolumn{15}{|l|}{ Trichoptera } \\
\hline \multicolumn{15}{|l|}{ Polycentropodidae } \\
\hline Neureclipsis & 11 & $<1$ & - & & 5 & $<1$ & - & & - & & 1 & $<1$ & 1 & $<1$ \\
\hline Nyctiophylax & - & & 8 & $<1$ & 8 & $<1$ & 5 & $<1$ & 14 & 2 & 7 & $<1$ & 10 & $<1$ \\
\hline Polycentropus & - & & - & & - & & - & & - & & 1 & $<1$ & - & \\
\hline \multicolumn{15}{|l|}{ Psychomyiidae } \\
\hline Psychomyia & - & & 11 & $<1$ & 8 & $<1$ & 21 & 1 & 5 & $<1$ & 6 & $<1$ & 6 & $<1$ \\
\hline \multicolumn{15}{|l|}{ Rhyacophilidae } \\
\hline \multicolumn{14}{|l|}{ Uenoidae } & \\
\hline Neophylax & - & & 8 & $<1$ & - & & - & & - & & - & & - & \\
\hline \multicolumn{15}{|l|}{ Lepidoptera } \\
\hline \multicolumn{15}{|l|}{ Pyralidae } \\
\hline Petrophila & - & & - & & - & & - & & - & & 2 & $<1$ & - & \\
\hline \multicolumn{15}{|l|}{ Coleoptera } \\
\hline \multicolumn{15}{|l|}{ Elmidae } \\
\hline Dubiraphia & - & & 3 & $<1$ & 3 & $<1$ & - & & - & & - & & - & \\
\hline Optioservus & 85 & 7 & 54 & 2 & 35 & 2 & 40 & 3 & 56 & 7 & 24 & 2 & 22 & 1 \\
\hline Oulimnius & - & & 3 & $<1$ & - & & - & & 1 & $<1$ & 1 & $<1$ & - & \\
\hline Promoresia & - & & 3 & $<1$ & - & & - & & - & & 1 & $<1$ & 2 & $<1$ \\
\hline Stenelmis & 16 & 1 & 29 & 1 & 5 & $<1$ & 5 & $<1$ & 14 & 2 & 1 & $<1$ & 10 & $<1$ \\
\hline \multicolumn{15}{|l|}{ Psephenidae } \\
\hline Ectopria & - & & - & & - & & - & & - & & - & & - & \\
\hline E. nervosa & - & & 3 & $<1$ & - & & - & & - & & - & & - & \\
\hline Psephenus & - & & - & & 3 & $<1$ & - & & 3 & $<1$ & 2 & $<1$ & 3 & $<1$ \\
\hline Hymenoptera & - & & - & & - & & - & & 1 & $<1$ & - & & - & \\
\hline \multicolumn{15}{|l|}{ Diptera } \\
\hline \multicolumn{15}{|l|}{ Athericidae } \\
\hline Atherix & 5 & $<1$ & - & & - & & - & & - & & 1 & $<1$ & - & \\
\hline Chironomidae & 160 & 13 & 1,000 & 37 & 110 & 6 & 320 & 20 & 110 & 14 & 120 & 9 & 660 & 33 \\
\hline Empididae & - & & - & & - & & - & & - & & - & & - & \\
\hline Chelifera & - & & - & & - & & - & & - & & - & & - & \\
\hline Hemerodromia & 3 & $<1$ & 8 & $<1$ & - & & - & & 2 & $<1$ & - & & - & \\
\hline \multicolumn{15}{|l|}{ Simuliidae } \\
\hline Simulium & 5 & $<1$ & 11 & $<1$ & 16 & $<1$ & 19 & 1 & 22 & 3 & 16 & 1 & 100 & 5 \\
\hline \multicolumn{15}{|l|}{ Tipulidae } \\
\hline Antocha & 11 & $<1$ & 88 & 3 & 11 & $<1$ & 19 & 1 & 8 & 1 & 45 & 3 & 12 & $<1$ \\
\hline
\end{tabular}

\footnotetext{
${ }^{1}$ Extrapolated from a 3/8 subsample.
} 


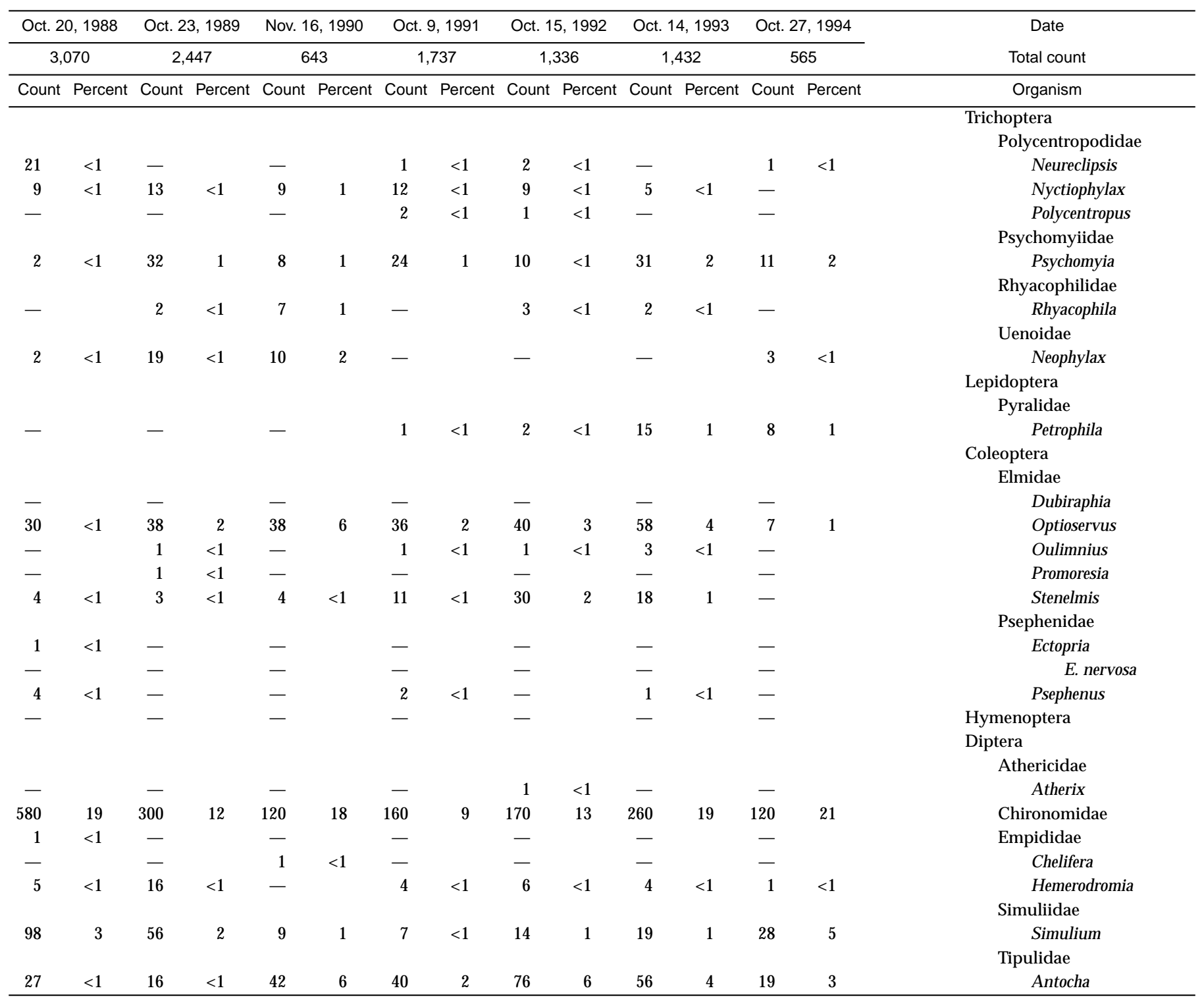


Table 5. Benthic-macroinvertebrate data-Continued

$[<$, less than; - , not found]

01472154 - French Creek near Pughtown, Pa. (Site 14)

\begin{tabular}{|c|c|c|c|c|c|c|c|c|c|c|c|c|c|c|}
\hline \multirow{3}{*}{ 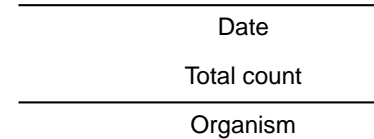 } & \multirow{2}{*}{\multicolumn{2}{|c|}{$\begin{array}{c}\text { Oct. } 21,1981 \\
1,760\end{array}$}} & \multirow{2}{*}{\multicolumn{2}{|c|}{$\begin{array}{c}\text { Nov. 2, } 1982 \\
1,543\end{array}$}} & \multirow{2}{*}{\multicolumn{2}{|c|}{$\begin{array}{c}\text { Oct. } 20,1983 \\
1,432\end{array}$}} & \multirow{2}{*}{\multicolumn{2}{|c|}{$\begin{array}{c}\text { Oct. } 10,1984 \\
1,716\end{array}$}} & \multirow{2}{*}{\multicolumn{2}{|c|}{$\frac{\text { Oct. } 11,1985}{421}$}} & \multirow{2}{*}{\multicolumn{2}{|c|}{$\frac{\text { Oct. } 31,1986}{1,416}$}} & \multirow{2}{*}{\multicolumn{2}{|c|}{$\frac{\text { Oct. } 14,1987}{1,331}$}} \\
\hline & & & & & & & & & & & & & & \\
\hline & Count & Percent & Count & Percent & Count & Percent & Count & Percent & Count & Percent & Count & Percent & Count & Percent \\
\hline \multicolumn{15}{|l|}{ Platyhelminthes (flatworms) } \\
\hline \multicolumn{15}{|l|}{ Turbellaria } \\
\hline \multicolumn{15}{|l|}{ Tricladida } \\
\hline Planariidae & 2 & $<1$ & - & & 13 & $<1$ & - & & - & & 4 & $<1$ & 1 & $<1$ \\
\hline Nematoda (nematodes) & - & & - & & - & & - & & - & & 1 & $<1$ & - & \\
\hline \multicolumn{15}{|l|}{ Nemertea (proboscis worms) } \\
\hline \multicolumn{15}{|l|}{ Enopla } \\
\hline \multicolumn{15}{|l|}{ Hoplonemertea } \\
\hline \multicolumn{15}{|l|}{ Tetrastemmatidae } \\
\hline Prostoma & - & & - & & 6 & $<1$ & - & & - & & - & & 5 & $<1$ \\
\hline Mollusca (molluscs) & & & & & & & & & & & & & & \\
\hline Gastropoda & & & & & & & & & & & & & & \\
\hline Mesogastropoda & & & & & & & & & & & & & & \\
\hline Pleuroceridae & & & & & & & & & & & & & & \\
\hline Goniobasis & - & & - & & 1 & $<1$ & - & & - & & - & & - & \\
\hline Basommatophora & & & & & & & & & & & & & & \\
\hline Ancylidae & & & & & & & & & & & & & & \\
\hline Ferrissia & 21 & 1 & 22 & 1 & 120 & 9 & - & & - & & 8 & $<1$ & 5 & $<1$ \\
\hline Physidae & & & & & & & & & & & & & & \\
\hline Physa & 1 & $<1$ & - & & 2 & $<1$ & - & & - & & - & & - & \\
\hline Planorbidae & & & & & & & & & & & & & & \\
\hline Helisoma & - & & - & & 2 & $<1$ & - & & - & & - & & - & \\
\hline Gyraulus & - & & - & & - & & - & & - & & - & & - & \\
\hline Bivalvia & & & & & & & & & & & & & & \\
\hline Veneroida & & & & & & & & & & & & & & \\
\hline Sphaeriidae & - & & - & & - & & - & & - & & - & & - & \\
\hline Annelida (segmented worms) & & & & & & & & & & & & & & \\
\hline Oligochaeta & - & & - & & - & & 3 & $<1$ & - & & - & & - & \\
\hline Lumbriculida & & & & & & & & & & & & & & \\
\hline Lumbriculidae & - & & - & & 1 & $<1$ & 1 & $<1$ & - & & - & & 1 & $<1$ \\
\hline Tubificida & & & & & & & & & & & & & & \\
\hline Naididae & - & & - & & - & & - & & - & & - & & 18 & 1 \\
\hline Tubificidae & - & & - & & - & & - & & - & & - & & - & \\
\hline Arthropoda (arthropods) & & & & & & & & & & & & & & \\
\hline Acariformes & & & & & & & & & & & & & & \\
\hline Hydrachnidia & 1 & $<1$ & 3 & $<1$ & 3 & $<1$ & - & & 1 & $<1$ & 27 & 2 & - & \\
\hline Crustacea & & & & & & & & & & & & & & \\
\hline Cyclopoida & - & & - & & - & & - & & - & & - & & - & \\
\hline Isopoda & & & & & & & & & & & & & & \\
\hline Asellidae & & & & & & & & & & & & & & \\
\hline Caecidotea & - & & - & & - & & - & & - & & - & & - & \\
\hline Podocopa & - & & - & & - & & - & & - & & - & & - & \\
\hline Insecta & & & & & & & & & & & & & & \\
\hline Ephemeroptera & & & & & & & & & & & & & & \\
\hline Baetidae & & & & & & & & & & & & & & \\
\hline Baetis & 21 & 1 & 1 & $<1$ & 24 & 2 & 19 & 1 & - & & - & & 7 & $<1$ \\
\hline Pseudocloeon & - & & - & & 2 & $<1$ & 23 & 1 & 3 & $<1$ & - & & 12 & $<1$ \\
\hline Caenidae & & & & & & & & & & & & & & \\
\hline Caenis & - & & - & & - & & - & & 4 & 1 & - & & - & \\
\hline Ephemerellidae & & & & & & & & & & & & & & \\
\hline Ephemerella & 120 & 7 & 40 & 3 & 80 & 6 & 53 & 3 & 34 & 8 & 51 & 4 & 5 & $<1$ \\
\hline
\end{tabular}




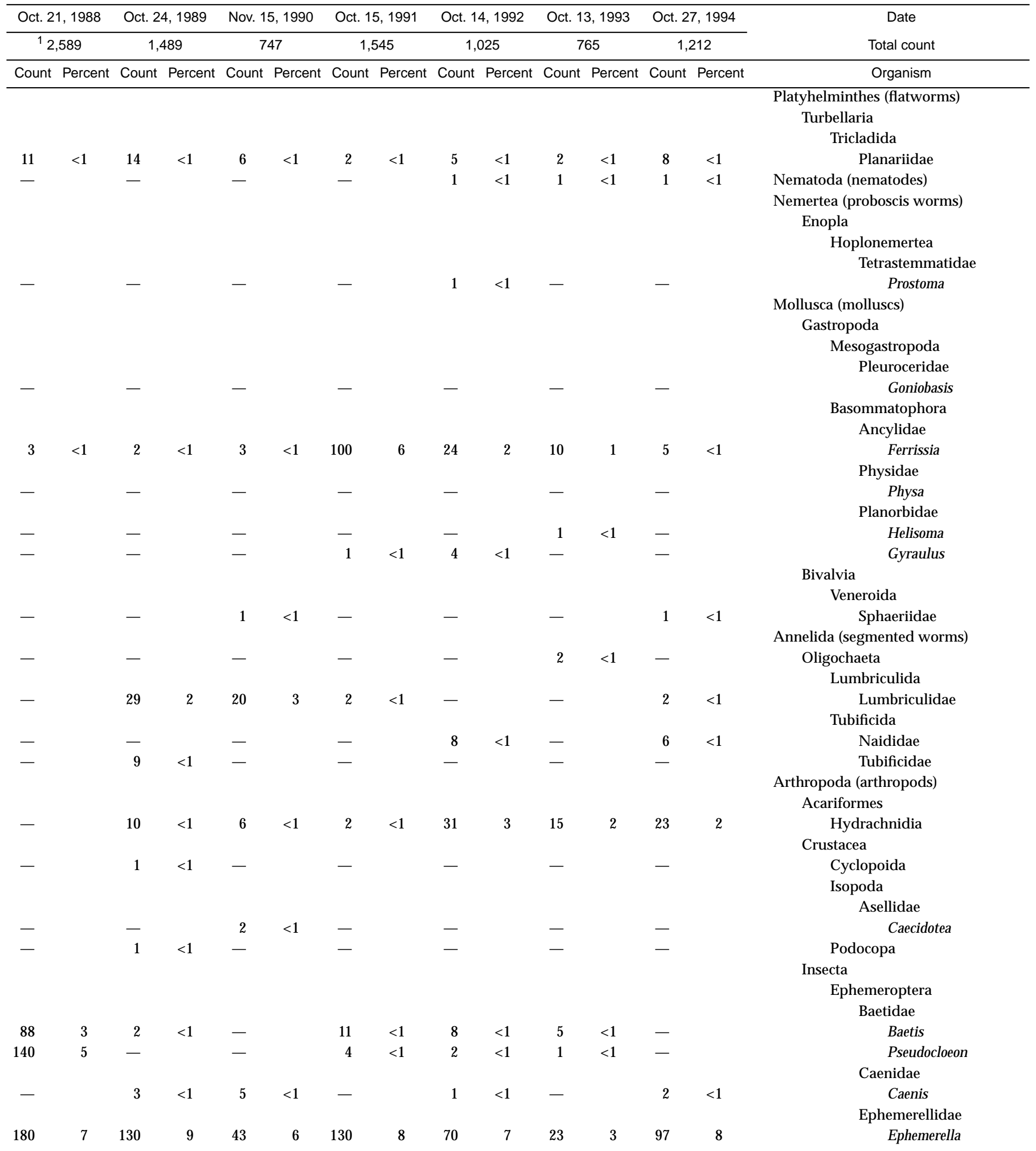


Table 5. Benthic-macroinvertebrate data-Continued

01472154 - French Creek near Pughtown, Pa. (Site 14)—Continued

\begin{tabular}{|c|c|c|c|c|c|c|c|c|c|c|c|c|c|c|}
\hline \multirow{3}{*}{$\begin{array}{c}\text { Date } \\
\text { Total count } \\
\text { Organism }\end{array}$} & \multirow{2}{*}{\multicolumn{2}{|c|}{$\begin{array}{c}\text { Oct. } 21,1981 \\
1,760\end{array}$}} & \multicolumn{2}{|c|}{ Nov. 2, 1982} & \multicolumn{2}{|c|}{ Oct. 20,1983} & \multicolumn{2}{|c|}{ Oct. 10,1984} & \multicolumn{2}{|c|}{ Oct. 11,1985} & \multicolumn{2}{|c|}{ Oct. 31,1986} & \multicolumn{2}{|c|}{ Oct. 14,1987} \\
\hline & & & & & & 432 & & 716 & & 21 & & 416 & & 331 \\
\hline & Count & Percent & Count & Percent & Count & Percent & Count & Percent & Count & Percent & Count & Percent & Count & Percent \\
\hline \multicolumn{15}{|l|}{ Ephemeroptera } \\
\hline \multicolumn{15}{|l|}{ Heptageniidae } \\
\hline Epeorus & - & & - & & - & & - & & - & & 37 & 3 & - & \\
\hline Heptagenia & - & & - & & - & & - & & - & & - & & - & \\
\hline Stenacron & - & & - & & - & & - & & - & & - & & - & \\
\hline Stenonema & 110 & 6 & 78 & 5 & 140 & 10 & 79 & 5 & 47 & 11 & 35 & 3 & 16 & 1 \\
\hline \multicolumn{15}{|l|}{ Isonychiidae } \\
\hline $\begin{array}{c}\text { Isonychia } \\
\text { Leptohyphidae }\end{array}$ & 260 & 14 & 67 & 4 & 190 & 14 & 130 & 8 & 25 & 6 & 44 & 3 & 28 & 2 \\
\hline Tricorythodes & - & & 2 & $<1$ & - & & - & & - & & - & & - & \\
\hline \multicolumn{15}{|l|}{ Odonata } \\
\hline Argia & 6 & $<1$ & 2 & $<1$ & 5 & $<1$ & - & & - & & - & & 1 & $<1$ \\
\hline \multicolumn{15}{|l|}{ Plecoptera } \\
\hline Allocapnia & - & & 2 & $<1$ & - & & 8 & $<1$ & 2 & $<1$ & - & & 12 & $<1$ \\
\hline \multicolumn{15}{|l|}{ Peltoperlidae } \\
\hline Peltoperla & - & & - & & - & & - & & - & & - & & - & \\
\hline \multicolumn{15}{|l|}{ Perlidae } \\
\hline $\begin{array}{l}\text { Acroneuria } \\
\text { Agnetina }\end{array}$ & $\begin{array}{r}2 \\
-\end{array}$ & $<1$ & - & & $\begin{array}{r}4 \\
-\end{array}$ & $<1$ & $\begin{array}{r}4 \\
-\end{array}$ & $<1$ & $\begin{array}{c}2 \\
-\end{array}$ & $<1$ & - & & - & $<1$ \\
\hline Paragnetina & 2 & $<1$ & 4 & $<1$ & 2 & $<1$ & 6 & $<1$ & - & & - & & - & \\
\hline \multicolumn{15}{|l|}{ Taeniopterygidae } \\
\hline Strophopteryx & - & & - & & - & & - & & - & & 20 & 1 & - & \\
\hline Taeniopteryx & 12 & $<1$ & 8 & $<1$ & 16 & 1 & 3 & $<1$ & 12 & 3 & 6 & $<1$ & 43 & 3 \\
\hline \multicolumn{15}{|l|}{ Hemiptera } \\
\hline $\begin{array}{l}\text { Corixidae } \\
\text { Veliidae }\end{array}$ & \multicolumn{13}{|c|}{ Veliidae } & \\
\hline Rhagovelia & - & & - & & - & & 2 & $<1$ & - & & - & & - & \\
\hline \multicolumn{15}{|l|}{ Megaloptera } \\
\hline Corydalus & 3 & $<1$ & 3 & $<1$ & 2 & $<1$ & 3 & $<1$ & 1 & $<1$ & - & & 1 & $<1$ \\
\hline Nigronia & 1 & $<1$ & - & & 1 & $<1$ & - & & - & & - & & - & \\
\hline
\end{tabular}

Neuroptera

Sisyridae

Climacia

$\begin{array}{lllll}\text { C. areolaris } & 1 & < & -\end{array}$

Trichoptera

Apataniidae

Apatania

Brachycentridae

Micrasema

Glossosomatidae

Culoptila

Glossosoma

Protoptila

Helicopsychidae Helicopsyche

Hydropsychidae Ceratopsyche Cheumatopsyche Hydropsyche Macrostemum

$\begin{array}{rrrr}9 & <1 & 5 & <1 \\ 31 & 2 & 4 & <1 \\ - & & - & \\ 7 & <1 & 10 & <1 \\ - & & - & \\ - & & - & \\ 260 & 14 & 88 & 6 \\ 300 & 17 & 260 & 16 \\ - & & - & \\ 4 & <1 & 1 & <1 \\ - & & - & \end{array}$

Potamyia 


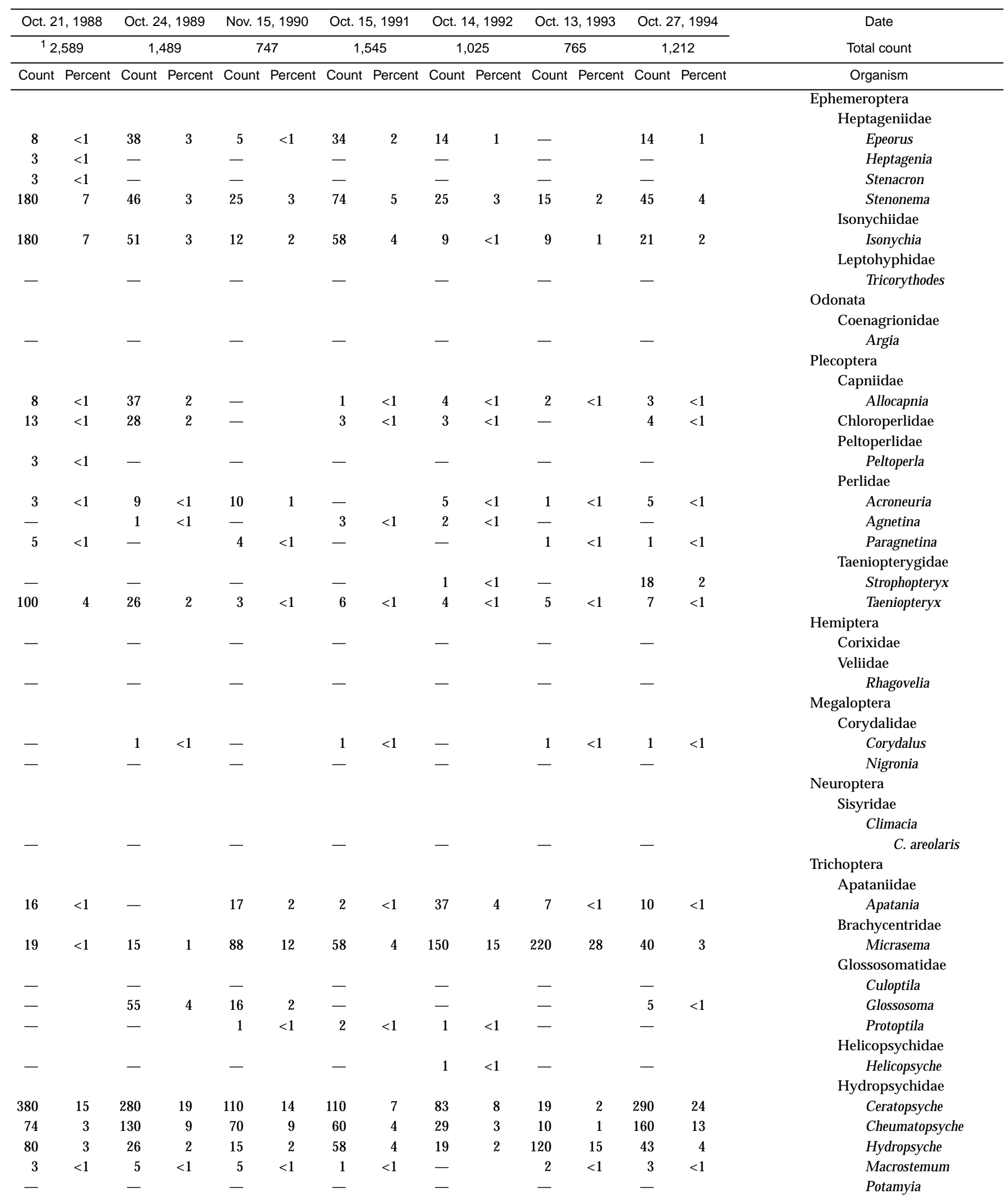


Table 5. Benthic-macroinvertebrate data-Continued

01472154 - French Creek near Pughtown, Pa. (Site 14)—Continued

\begin{tabular}{|c|c|c|c|c|c|c|c|c|c|c|c|c|c|c|}
\hline \multirow{3}{*}{$\begin{array}{c}\text { Date } \\
\text { Total count } \\
\text { Organism }\end{array}$} & \multirow{2}{*}{\multicolumn{2}{|c|}{$\begin{array}{c}\text { Oct. } 21,1981 \\
1,760\end{array}$}} & \multicolumn{2}{|c|}{ Nov. 2, 1982} & \multicolumn{2}{|c|}{ Oct. 20,1983} & \multicolumn{2}{|c|}{ Oct. 10, 1984} & \multicolumn{2}{|c|}{ Oct. 11,1985} & \multicolumn{2}{|c|}{ Oct. 31, 1986} & \multicolumn{2}{|c|}{ Oct. 14,1987} \\
\hline & & & & 543 & & 432 & & 716 & & 21 & & 416 & & 331 \\
\hline & Count & Percent & Count & Percent & Count & Percent & Count & Percent & Count & Percent & Count & Percent & Count & Percent \\
\hline \multicolumn{15}{|l|}{ Trichoptera } \\
\hline \multicolumn{15}{|l|}{ Hydroptilidae } \\
\hline Hydroptila & 3 & $<1$ & 1 & $<1$ & 6 & $<1$ & - & & - & & 2 & $<1$ & - & \\
\hline Leucotrichia & 120 & 7 & 430 & 27 & 300 & 21 & 390 & 23 & 83 & 19 & 310 & 22 & 57 & 4 \\
\hline \multicolumn{15}{|l|}{ Lepidostomatidae } \\
\hline Lepidostoma & - & & - & & - & & - & & - & & - & & - & \\
\hline \multicolumn{15}{|l|}{ Leptoceridae } \\
\hline Mystacides & - & & - & & - & & - & & - & & - & & - & \\
\hline Oecetis & - & & - & & 2 & $<1$ & - & & - & & - & & - & \\
\hline \multicolumn{15}{|l|}{ Philopotamidae } \\
\hline Chimarra & 32 & 2 & 21 & 1 & 31 & 2 & 57 & 3 & 10 & 2 & 20 & 1 & 11 & $<1$ \\
\hline Dolophilodes & - & & - & & - & & - & & - & & - & & - & \\
\hline \multicolumn{15}{|l|}{ Polycentropodidae } \\
\hline Neureclipsis & 6 & $<1$ & 3 & $<1$ & 18 & 1 & 1 & $<1$ & 1 & $<1$ & 2 & $<1$ & - & \\
\hline Polycentropus & - & & - & & - & & - & & - & & 1 & $<1$ & - & \\
\hline \multicolumn{15}{|l|}{ Psychomyiidae } \\
\hline Psychomyia & 18 & 1 & 17 & 1 & 33 & 2 & 14 & $<1$ & 2 & $<1$ & 24 & 2 & 6 & $<1$ \\
\hline \multicolumn{15}{|l|}{ Rhyacophilidae } \\
\hline Rhyacophila & - & & - & & - & & - & & - & & 1 & $<1$ & - & \\
\hline R. fuscula & 1 & $<1$ & - & & - & & - & & - & & - & & - & \\
\hline \multicolumn{15}{|l|}{ Uenoidae } \\
\hline Neophylax & 7 & $<1$ & 2 & $<1$ & - & & - & & - & & - & & - & \\
\hline Lepidoptera & & & & & & & & & & & & & & \\
\hline Pyralidae & & & & & & & & & & & & & & \\
\hline Petrophila & 12 & $<1$ & - & & 1 & $<1$ & - & & - & & 2 & $<1$ & 2 & $<1$ \\
\hline Coleoptera & & & & & & & & & & & & & & \\
\hline Elmidae & & & & & & & & & & & & & & \\
\hline Ancyronyx & & & & & & & & & & & & & & \\
\hline A.variegata & - & & - & & - & & - & & - & & - & & - & \\
\hline Optioservus & 16 & $<1$ & 1 & $<1$ & 2 & $<1$ & 6 & $<1$ & 5 & 1 & 5 & $<1$ & 22 & 2 \\
\hline Oulimnius & 1 & $<1$ & - & & - & & - & & - & & - & & - & \\
\hline Stenelmis & - & & - & & 6 & $<1$ & - & & - & & 1 & $<1$ & 1 & $<1$ \\
\hline Hydrophilidae & & & & & & & & & & & & & & \\
\hline Helophorus & - & & - & & - & & 1 & $<1$ & - & & - & & - & \\
\hline Psephenidae & & & & & & & & & & & & & & \\
\hline Psephenus & - & & - & & 1 & $<1$ & - & & - & & - & & - & \\
\hline Diptera & & & & & & & & & & & & & & \\
\hline Chironomidae & 340 & 19 & 430 & 27 & 46 & 3 & 330 & 19 & 63 & 15 & 440 & 31 & 940 & 72 \\
\hline Empididae & & & & & & & & & & & & & & \\
\hline Hemerodromia & 3 & $<1$ & 8 & $<1$ & 2 & $<1$ & 2 & $<1$ & - & & 1 & $<1$ & 1 & $<1$ \\
\hline Ephydridae & - & & - & & - & & - & & - & & - & & - & \\
\hline Simuliidae & & & & & & & & & & & & & & \\
\hline Simulium & 18 & 1 & 2 & $<1$ & 2 & $<1$ & 22 & 1 & 6 & 2 & 6 & $<1$ & 12 & $<1$ \\
\hline Tipulidae & & & & & & & & & & & & & & \\
\hline Antocha & 9 & $<1$ & 28 & 2 & 13 & $<1$ & 13 & $<1$ & 4 & 1 & 32 & 2 & 9 & $<1$ \\
\hline Tipula & - & & - & & - & & 1 & $<1$ & - & & - & & - & \\
\hline
\end{tabular}

${ }^{1}$ Extrapolated from a 3/8 subsample. 


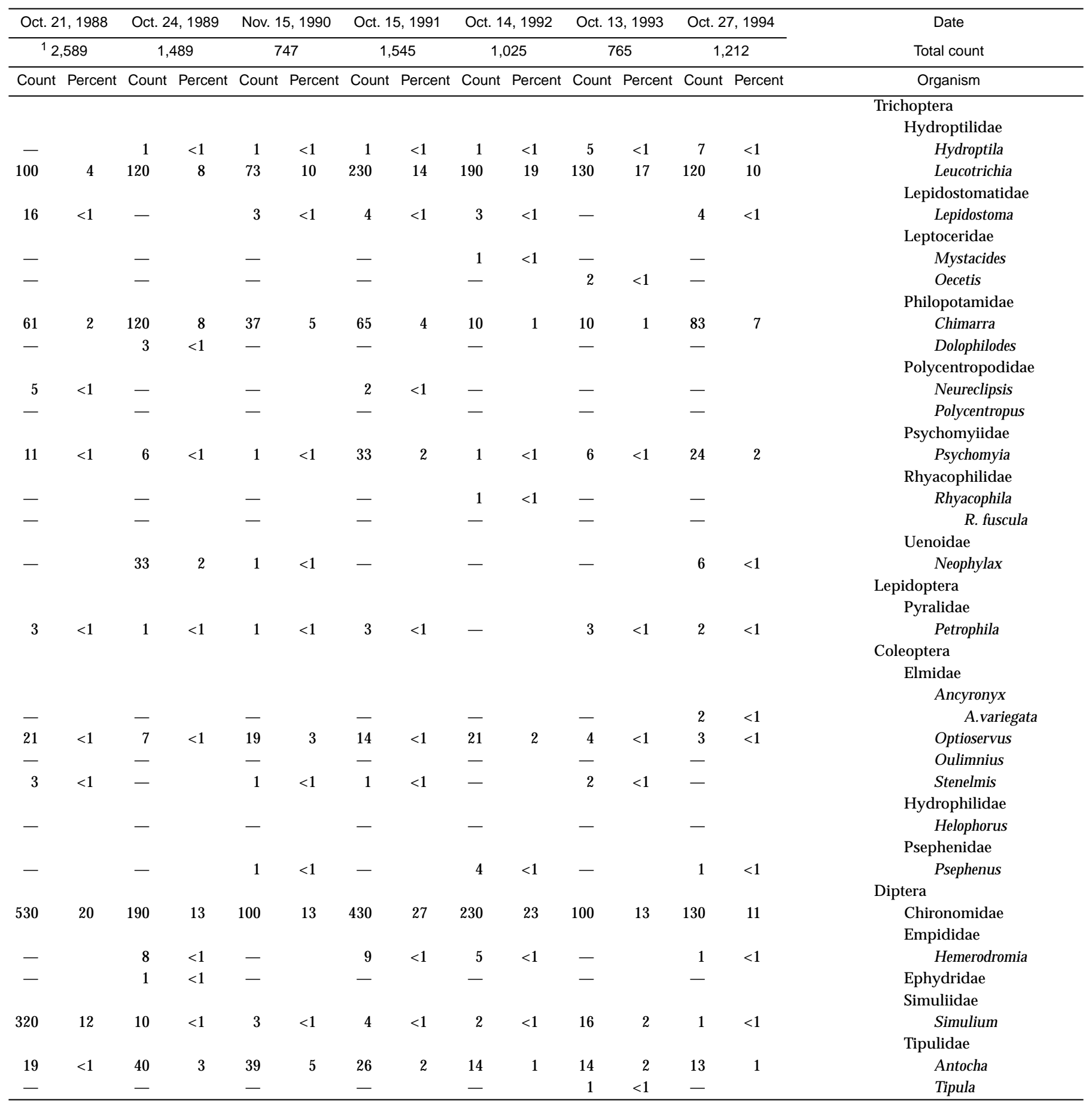


Table 5. Benthic-macroinvertebrate data-Continued

$[<$, less than; - , not found]

01472157 - French Creek near Phoenixville, Pa. (Site 15)

\begin{tabular}{|c|c|c|c|c|c|c|c|c|c|c|c|c|c|c|}
\hline \multirow{3}{*}{$\begin{array}{cc}\text { Date } \\
\text { Total count } \\
\text { Organism }\end{array}$} & \multirow{2}{*}{\multicolumn{2}{|c|}{$\frac{\text { Oct. } 21,1981}{{ }^{1} 3,427}$}} & \multirow{2}{*}{\multicolumn{2}{|c|}{$\frac{\text { Nov. 2, } 1982}{{ }^{1} 548}$}} & \multirow{2}{*}{\multicolumn{2}{|c|}{$\begin{array}{c}\text { Oct. 20, } 1983 \\
{ }^{1} 1,141\end{array}$}} & \multirow{2}{*}{\multicolumn{2}{|c|}{$\frac{\text { Oct. 10, } 1984}{{ }^{1} 821}$}} & \multirow{2}{*}{\multicolumn{2}{|c|}{$\begin{array}{c}\text { Oct. } 11,1985 \\
226\end{array}$}} & \multirow{2}{*}{\multicolumn{2}{|c|}{$\frac{\text { Dec. 5, } 1986}{712}$}} & \multirow{2}{*}{\multicolumn{2}{|c|}{$\frac{\text { Oct. } 14,1987}{600}$}} \\
\hline & & & & & & & & & & & & & & \\
\hline & Count & Percent & Count & Percent & Count & Percent & Count & Percent & Count & Percent & Count & Percent & Count & Percent \\
\hline \multicolumn{15}{|l|}{ Platyhelminthes (flatworms) } \\
\hline \multicolumn{15}{|l|}{ Turbellaria } \\
\hline \multicolumn{15}{|l|}{ Tricladida } \\
\hline Planariidae & 69 & 2 & - & & 5 & $<1$ & 5 & $<1$ & 1 & $<1$ & 5 & $<1$ & 2 & $<1$ \\
\hline \multicolumn{15}{|l|}{ Nemertea (proboscis worms) } \\
\hline \multicolumn{15}{|l|}{ Enopla } \\
\hline \multicolumn{15}{|l|}{ Hoplonemertea } \\
\hline \multicolumn{15}{|c|}{ Tetrastemmatidae } \\
\hline Prostoma & - & & - & & 3 & $<1$ & - & & - & & - & & - & \\
\hline \multicolumn{15}{|l|}{ Mollusca (molluscs) } \\
\hline Gastropoda & & & & & & & & & & & & & & \\
\hline Mesogastropoda & & & & & & & & & & & & & & \\
\hline Hydrobiidae & & & & & & & & & & & & & & \\
\hline Amnicola & - & & - & & - & & - & & 2 & 1 & 30 & 4 & 9 & 2 \\
\hline Pleuroceridae & & & & & & & & & & & & & & \\
\hline Goniobasis & - & & - & & 3 & $<1$ & - & & 4 & 2 & 1 & $<1$ & 3 & $<1$ \\
\hline Basommatophora & & & & & & & & & & & & & & \\
\hline Ancylidae & & & & & & & & & & & & & & \\
\hline Ferrissia & 11 & $<1$ & 5 & 1 & 8 & $<1$ & 8 & 1 & - & & 19 & 3 & 3 & $<1$ \\
\hline Lymnaeidae & & & & & & & & & & & & & & \\
\hline Lymnaea & 3 & $<1$ & - & & - & & - & & - & & - & & - & \\
\hline Physidae & & & & & & & & & & & & & & \\
\hline Physa & 5 & $<1$ & - & & - & & - & & 1 & $<1$ & 1 & $<1$ & - & \\
\hline Planorbidae & & & & & & & & & & & & & & \\
\hline Helisoma & 67 & 2 & - & & - & & - & & 2 & 1 & 5 & $<1$ & - & \\
\hline Gyraulus & - & & - & & - & & - & & - & & - & & - & \\
\hline Bivalvia & & & & & & & & & & & & & & \\
\hline Veneroida & & & & & & & & & & & & & & \\
\hline Sphaeriidae & - & & - & & - & & - & & - & & - & & - & \\
\hline Musculium & - & & - & & - & & - & & - & & - & & 2 & $<1$ \\
\hline Pisidium & 3 & $<1$ & - & & - & & - & & - & & - & & 1 & $<1$ \\
\hline Annelida (segmented worm & & & & & & & & & & & & & & \\
\hline Oligochaeta & - & & - & & - & & - & & - & & - & & - & \\
\hline Lumbriculida & & & & & & & & & & & & & & \\
\hline Lumbriculidae & - & & - & & - & & - & & 1 & $<1$ & 4 & $<1$ & - & \\
\hline Tubificida & & & & & & & & & & & & & & \\
\hline Naididae & - & & - & & - & & - & & - & & - & & 22 & 4 \\
\hline Tubificidae & - & & - & & - & & - & & - & & 2 & $<1$ & - & \\
\hline Hirudinea & - & & - & & - & & - & & - & & - & & 1 & $<1$ \\
\hline Arthropoda (arthropods) & & & & & & & & & & & & & & \\
\hline Acariformes & & & & & & & & & & & & & & \\
\hline Hydrachnidia & - & & - & & - & & - & & - & & 11 & 2 & - & \\
\hline Crustacea & & & & & & & & & & & & & & \\
\hline Cladocera & - & & - & & - & & - & & - & & - & & - & \\
\hline Cyclopoida & - & & - & & - & & - & & - & & - & & - & \\
\hline Amphipoda & & & & & & & & & & & & & & \\
\hline Gammaridae & & & & & & & & & & & & & & \\
\hline Gammarus & - & & - & & 3 & $<1$ & - & & - & & - & & - & \\
\hline
\end{tabular}




\begin{tabular}{|c|c|c|c|c|c|c|c|c|c|c|c|c|c|c|}
\hline Oct. 1 & 9, 1988 & Oct. 2 & 3,1989 & Nov. 1 & 5,1990 & Oct. & 1, 1991 & Oct. 1 & 4,1992 & Oct. 1 & 5,1993 & Oct. 2 & 8, 1994 & Date \\
\hline & 496 & & 03 & & 71 & & 254 & & 25 & & 87 & & 345 & Total count \\
\hline Count & Percent & Count & Percent & Count & Percent & Count & Percent & Count & Percent & Count & Percent & Count & Percent & Organism \\
\hline & & & & & & & & & & & & & & Turbellaria \\
\hline & & & & & & & & & & & & & & Tricladida \\
\hline 11 & $<1$ & 16 & 7 & 5 & 2 & 1 & $<1$ & - & & 6 & 1 & 3 & $<1$ & Planariidae \\
\hline & & & & & & & & & & & & & & Hoplonemertea \\
\hline & & & & & & & & & & & & & & Tetrastemmatidae \\
\hline - & & - & & - & & - & & 2 & $<1$ & - & & - & & Prostoma \\
\hline & & & & & & & & & & & & & & Mollusca (molluscs) \\
\hline & & & & & & & & & & & & & & Gastropoda \\
\hline & & & & & & & & & & & & & & Mesogastropoda \\
\hline & & & & & & & & & & & & & & Basommatophora \\
\hline & & & & & & & & & & & & & & Ancylidae \\
\hline 21 & $<1$ & 7 & 3 & 42 & 15 & 26 & 2 & 14 & 2 & 29 & 5 & 49 & 4 & Ferrissia \\
\hline & & & & & & & & & & & & & & Lymnaeidae \\
\hline 8 & $<1$ & - & & - & & - & & - & & - & & 10 & $<1$ & Lymnaea \\
\hline & & & & & & & & & & & & & & Physidae \\
\hline - & & - & & 4 & 2 & - & & 3 & $<1$ & 1 & $<1$ & - & & Physa \\
\hline & & & & & & & & & & & & & & Planorbidae \\
\hline - & & - & & - & & - & & - & & - & & - & & Helisoma \\
\hline 3 & $<1$ & 1 & $<1$ & 1 & $<1$ & 2 & $<1$ & 6 & $<1$ & 2 & $<1$ & 2 & $<1$ & Gyraulus \\
\hline & & & & & & & & & & & & & & Bivalvia \\
\hline & & & & & & & & & & & & & & Veneroida \\
\hline 5 & $<1$ & 10 & 5 & - & & - & & 2 & $<1$ & - & & - & & Naididae \\
\hline - & & - & & - & & - & & - & & - & & - & & Tubificidae \\
\hline - & & - & & - & & - & & - & & - & & - & & Hirudinea \\
\hline & & & & & & & & & & & & & & Arthropoda (arthropods) \\
\hline 3 & $<1$ & 8 & 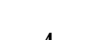 & 5 & ? & 12 & 1 & 25 & 3 & 4 & & & & Acariformes \\
\hline 3 & $<1$ & 8 & 4 & 5 & 2 & 13 & 1 & 25 & 3 & 4 & $<1$ & 50 & 5 & $\begin{array}{l}\text { Hydrachnidia } \\
\text { Crustacea }\end{array}$ \\
\hline - & & 9 & 4 & - & & - & & - & & - & & - & & Cladocera \\
\hline - & & 29 & 13 & - & & - & & - & & - & & - & & Cyclopoida \\
\hline & & & & & & & & & & & & & & Amphipoda \\
\hline & & & & & & & & & & & & & & Gammaridae \\
\hline - & & - & & - & & - & & - & & - & & - & & Gammarus \\
\hline
\end{tabular}


Table 5. Benthic-macroinvertebrate data-Continued

01472157 - French Creek near Phoenixville, Pa. (Site 15)—Continued

\begin{tabular}{|c|c|c|c|c|c|c|c|c|c|c|c|c|c|c|}
\hline \multirow{3}{*}{$\begin{array}{c}\text { Date } \\
\text { Total count } \\
\text { Organism }\end{array}$} & \multirow{2}{*}{\multicolumn{2}{|c|}{$\begin{array}{c}\text { Oct. } 21,1981 \\
{ }^{1} 3,427\end{array}$}} & \multirow{2}{*}{\multicolumn{2}{|c|}{$\begin{array}{c}\text { Nov. } 2,1982 \\
{ }^{1} 548\end{array}$}} & \multirow{2}{*}{\multicolumn{2}{|c|}{$\begin{array}{c}\text { Oct. } 20,1983 \\
11,141 \\
\end{array}$}} & \multirow{2}{*}{\multicolumn{2}{|c|}{$\begin{array}{c}\text { Oct. 10, } 1984 \\
{ }^{1} 821 \\
\end{array}$}} & \multirow{2}{*}{\multicolumn{2}{|c|}{$\begin{array}{c}\text { Oct. } 11,1985 \\
226\end{array}$}} & \multirow{2}{*}{\multicolumn{2}{|c|}{$\frac{\text { Dec. } 5,1986}{712}$}} & \multirow{2}{*}{\multicolumn{2}{|c|}{$\begin{array}{c}\text { Oct. } 14,1987 \\
600\end{array}$}} \\
\hline & & & & & & & & & & & & & & \\
\hline & Count & Percent & Count & Percent & Count & Percent & Count & Percent & Count & Percent & Count & Percent & Count & Percent \\
\hline \multicolumn{15}{|l|}{ Insecta } \\
\hline \multicolumn{15}{|l|}{ Ephemeroptera } \\
\hline \multicolumn{15}{|l|}{ Baetidae } \\
\hline Baetis & 16 & $<1$ & - & & - & & 3 & $<1$ & 5 & 2 & - & & 14 & 2 \\
\hline Pseudocloeon & 24 & $<1$ & - & & - & & 5 & $<1$ & - & & - & & - & \\
\hline \multicolumn{15}{|l|}{ Caenidae } \\
\hline Caenis & - & & - & & - & & - & & 11 & 5 & - & & 1 & $<1$ \\
\hline \multicolumn{15}{|l|}{ Ephemerellidae } \\
\hline Ephemerella & 43 & 1 & 11 & 2 & 11 & 1 & 8 & 1 & 6 & 3 & 140 & 19 & 7 & 1 \\
\hline \multicolumn{15}{|l|}{ Heptageniidae } \\
\hline Epeorus & 37 & 1 & 21 & 4 & 29 & 3 & 3 & $<1$ & - & & 77 & 11 & 1 & $<1$ \\
\hline Stenonema & 80 & 2 & 35 & 6 & 64 & 6 & 91 & 11 & 13 & 5 & 22 & 3 & 16 & 3 \\
\hline Isonychiidae & & & & & & & & & & & & & & \\
\hline Isonychia & 37 & 1 & 8 & 2 & 8 & $<1$ & 8 & 1 & 4 & 2 & 3 & $<1$ & 13 & 2 \\
\hline Leptohyphidae & & & & & & & & & & & & & & \\
\hline Tricorythodes & - & & - & & - & & - & & - & & - & & - & \\
\hline Odonata & & & & & & & & & & & & & & \\
\hline Coenagrionidae & & & & & & & & & & & & & & \\
\hline Argia & 29 & $<1$ & - & & - & & - & & - & & 3 & $<1$ & - & \\
\hline Plecoptera & & & & & & & & & & & & & & \\
\hline Capniidae & & & & & & & & & & & & & & \\
\hline Allocapnia & - & & - & & 3 & $<1$ & 13 & 2 & - & & - & & - & \\
\hline Chloroperlidae & 24 & $<1$ & 5 & 1 & 5 & $<1$ & 11 & 1 & - & & 9 & 1 & - & \\
\hline Perlidae & & & & & & & & & & & & & & \\
\hline Acroneuria & 3 & $<1$ & - & & - & & 3 & $<1$ & 1 & $<1$ & 5 & $<1$ & 2 & $<1$ \\
\hline Agnetina & 3 & $<1$ & - & & - & & - & & - & & - & & 2 & $<1$ \\
\hline Paragnetina & - & & - & & - & & - & & - & & 3 & $<1$ & - & \\
\hline Taeniopterygidae & & & & & & & & & & & & & & \\
\hline Strophopteryx & - & & - & & - & & 3 & $<1$ & - & & 3 & $<1$ & - & \\
\hline Taeniopteryx & 11 & $<1$ & 13 & 2 & 11 & 1 & 8 & 1 & 4 & 2 & - & & 2 & $<1$ \\
\hline Megaloptera & & & & & & & & & & & & & & \\
\hline Corydalidae & & & & & & & & & & & & & & \\
\hline Corydalus & - & & - & & - & & - & & - & & - & & - & \\
\hline Nigronia & - & & - & & - & & - & & - & & - & & - & \\
\hline Trichoptera & & & & & & & & & & & & & & \\
\hline Apataniidae & & & & & & & & & & & & & & \\
\hline Apatania & 13 & $<1$ & 13 & 2 & 11 & 1 & - & & 2 & 1 & 60 & 8 & 14 & 2 \\
\hline Brachycentridae & - & & - & & - & & - & & - & & 49 & 7 & 20 & 3 \\
\hline Micrasema & 220 & 6 & 8 & 2 & 85 & 8 & 11 & 1 & 18 & 8 & - & & - & \\
\hline Glossosomatidae & & & & & & & & & & & & & & \\
\hline Glossosoma & - & & 19 & 3 & - & & 64 & 8 & 31 & 13 & 3 & $<1$ & 23 & 4 \\
\hline Protoptila & 2,200 & 65 & 5 & 1 & 590 & 54 & 35 & 4 & - & & - & & - & \\
\hline Helicopsychidae & & & & & & & & & & & & & & \\
\hline Helicopsyche & - & & - & & - & & - & & - & & 21 & 3 & - & \\
\hline Hydropsychidae & & & & & & & & & & & & & & \\
\hline Ceratopsyche & 29 & $<1$ & 37 & 7 & 59 & 5 & 53 & 6 & 21 & 9 & 21 & 3 & 8 & 1 \\
\hline Cheumatopsyche & 56 & 2 & 21 & 4 & 45 & 4 & 37 & 4 & 9 & 4 & 10 & 1 & 6 & 1 \\
\hline Hydropsyche & 3 & $<1$ & 3 & $<1$ & 3 & $<1$ & - & & - & & 13 & 2 & 14 & 2 \\
\hline Macrostemum & - & & - & & - & & - & & - & & - & & - & \\
\hline Potamyia & - & & - & & - & & - & & - & & - & & 2 & $<1$ \\
\hline Hydroptilidae & & & & & & & & & & & & & & \\
\hline Hydroptila & 5 & $<1$ & - & & - & & - & & - & & - & & - & \\
\hline Leucotrichia & 24 & $<1$ & 160 & 29 & 24 & 2 & 59 & 7 & 27 & 11 & 12 & 2 & 16 & 3 \\
\hline
\end{tabular}




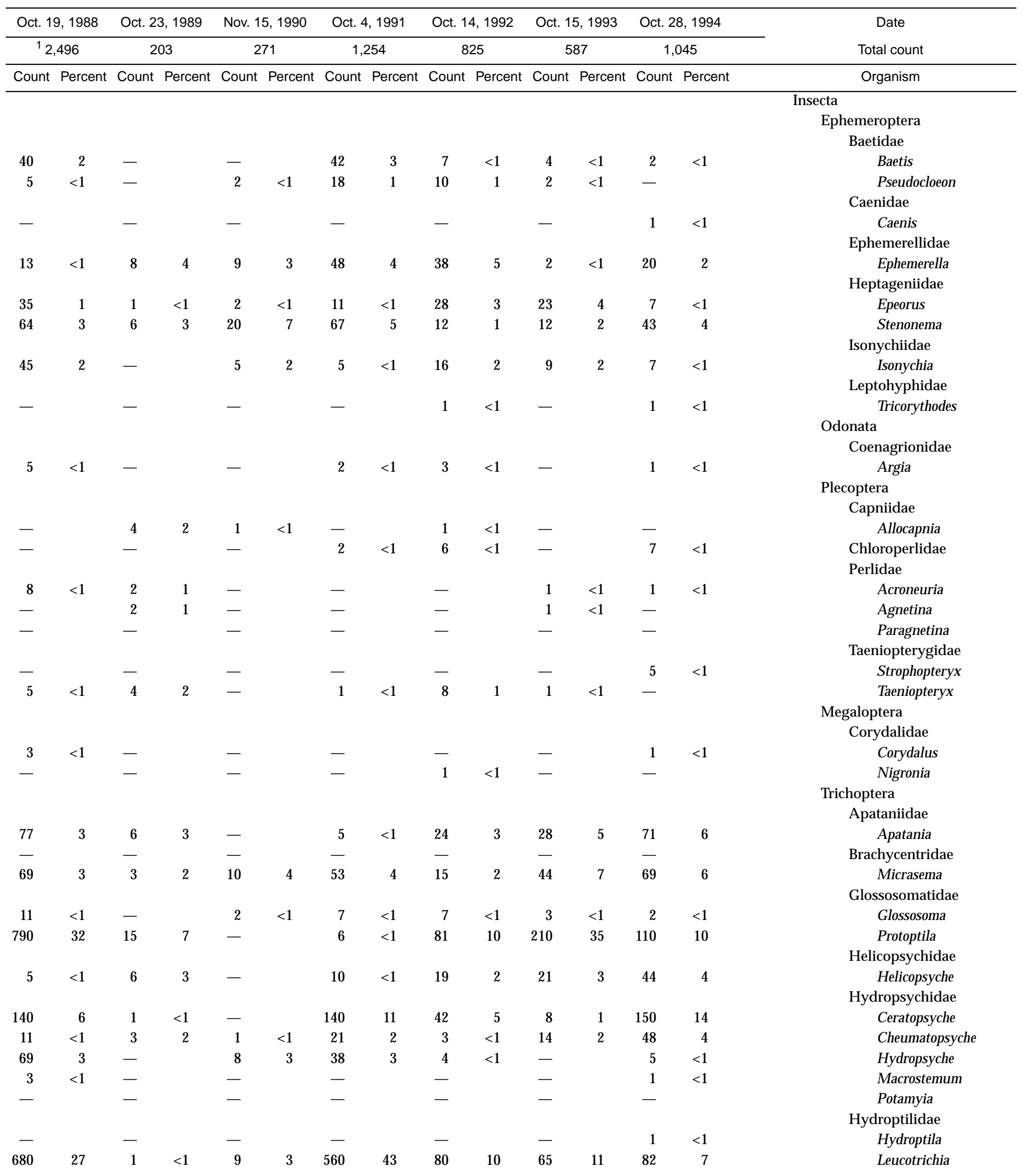


Table 5. Benthic-macroinvertebrate data-Continued

01472157 - French Creek near Phoenixville, Pa. (Site 15)—Continued

\begin{tabular}{|c|c|c|c|c|c|c|c|c|c|c|c|c|c|c|}
\hline \multirow{3}{*}{$\begin{array}{c}\text { Date } \\
\text { Total count } \\
\text { Organism }\end{array}$} & \multirow{2}{*}{\multicolumn{2}{|c|}{$\begin{array}{c}\text { Oct. } 21,1981 \\
{ }^{1} 3,427\end{array}$}} & \multirow{2}{*}{\multicolumn{2}{|c|}{$\begin{array}{c}\text { Nov. 2, } 1982 \\
{ }^{1} 548\end{array}$}} & \multirow{2}{*}{\multicolumn{2}{|c|}{$\begin{array}{c}\text { Oct. } 20,1983 \\
11,141\end{array}$}} & \multirow{2}{*}{\multicolumn{2}{|c|}{$\begin{array}{c}\text { Oct. 10, } 1984 \\
{ }^{1} 821 \\
\end{array}$}} & \multirow{2}{*}{\multicolumn{2}{|c|}{$\begin{array}{c}\text { Oct. } 11,1985 \\
226\end{array}$}} & \multirow{2}{*}{\multicolumn{2}{|c|}{$\begin{array}{c}\text { Dec. } 5,1986 \\
712\end{array}$}} & \multirow{2}{*}{\multicolumn{2}{|c|}{$\begin{array}{c}\text { Oct. } 14,1987 \\
600\end{array}$}} \\
\hline & & & & & & & & & & & & & & \\
\hline & Count & Percent & Count & Percent & Count & Percent & Count & Percent & Count & Percent & Count & Percent & Count & Percent \\
\hline \multicolumn{15}{|l|}{ Trichoptera } \\
\hline \multicolumn{15}{|l|}{ Lepidostomatidae } \\
\hline Lepidostoma & - & & - & & - & & - & & - & & - & & - & \\
\hline \multicolumn{15}{|l|}{ Leptoceridae } \\
\hline Ceraclea & - & & - & & - & & - & & - & & - & & - & \\
\hline Mystacides & - & & - & & - & & - & & - & & 1 & $<1$ & - & \\
\hline Oecetis & - & & - & & 3 & $<1$ & - & & - & & - & & - & \\
\hline \multicolumn{15}{|l|}{ Philopotamidae } \\
\hline Chimarra & 110 & 3 & 5 & 1 & 32 & 3 & 27 & 3 & 5 & 2 & 16 & 2 & 9 & 2 \\
\hline \multicolumn{15}{|l|}{ Polycentropodidae } \\
\hline Neureclipsis & - & & 3 & $<1$ & - & & - & & - & & - & & - & \\
\hline Nyctiophylax & - & & - & & - & & 5 & $<1$ & 1 & $<1$ & - & & 1 & $<1$ \\
\hline Polycentropus & - & & - & & - & & - & & - & & - & & - & \\
\hline \multicolumn{15}{|l|}{ Psychomyiidae } \\
\hline Psychomyia & - & & - & & 13 & 1 & 27 & 3 & 6 & 3 & - & & 1 & $<1$ \\
\hline \multicolumn{15}{|l|}{ Uenoidae } \\
\hline Neophylax & 160 & 5 & - & & - & & 3 & $<1$ & - & & - & & - & \\
\hline \multicolumn{15}{|l|}{ Lepidoptera } \\
\hline \multicolumn{15}{|l|}{ Pyralidae } \\
\hline Petrophila & 3 & $<1$ & - & & 8 & $<1$ & 5 & $<1$ & 2 & 1 & 2 & $<1$ & 1 & $<1$ \\
\hline Coleoptera & & & & & & & & & & & & & & \\
\hline Elmidae & & & & & & & & & & & & & & \\
\hline Microcylloepus & 3 & $<1$ & - & & - & & - & & - & & - & & - & \\
\hline Optioservus & 13 & $<1$ & 3 & $<1$ & 11 & 1 & 5 & $<1$ & 6 & 3 & 7 & 1 & 24 & 4 \\
\hline Oulimnius & - & & - & & - & & - & & - & & - & & - & \\
\hline Promoresia & - & & - & & - & & - & & - & & - & & - & \\
\hline Stenelmis & - & & - & & 3 & $<1$ & 5 & $<1$ & 4 & 2 & - & & - & \\
\hline Gyrinidae & & & & & & & & & & & & & & \\
\hline Dineutus & - & & 5 & 1 & - & & - & & - & & - & & - & \\
\hline Psephenidae & & & & & & & & & & & & & & \\
\hline Ectopria & - & & - & & - & & - & & - & & - & & - & \\
\hline E. nervosa & - & & - & & - & & - & & - & & - & & - & \\
\hline Psephenus & - & & - & & 3 & $<1$ & - & & 5 & 2 & 1 & $<1$ & 14 & 2 \\
\hline Diptera & & & & & & & & & & & & & & \\
\hline Athericidae & & & & & & & & & & & & & & \\
\hline Atherix & - & & - & & - & & - & & - & & - & & - & \\
\hline Ceratopogonidae & - & & - & & - & & - & & - & & - & & - & \\
\hline Chironomidae & 120 & 4 & 160 & 29 & 85 & 8 & 310 & 37 & 24 & 10 & 130 & 18 & 340 & 56 \\
\hline Empididae & & & & & & & & & & & & & & \\
\hline Hemerodromia & - & & - & & - & & - & & 2 & 1 & 2 & $<1$ & 1 & $<1$ \\
\hline Simuliidae & & & & & & & & & & & & & & \\
\hline Prosimulium & - & & - & & - & & - & & - & & 1 & $<1$ & - & \\
\hline Simulium & 3 & $<1$ & 3 & $<1$ & - & & 3 & $<1$ & 5 & 2 & - & & 1 & \\
\hline Tipulidae & & & & & & & & & & & & & & \\
\hline Antocha & - & & 5 & 1 & 13 & 1 & 3 & $<1$ & 3 & 1 & 18 & 3 & 4 & $<1$ \\
\hline Tipula & - & & - & & - & & - & & - & & 2 & $<1$ & - & \\
\hline
\end{tabular}

${ }^{1}$ Extrapolated from a 3/8 subsample. 


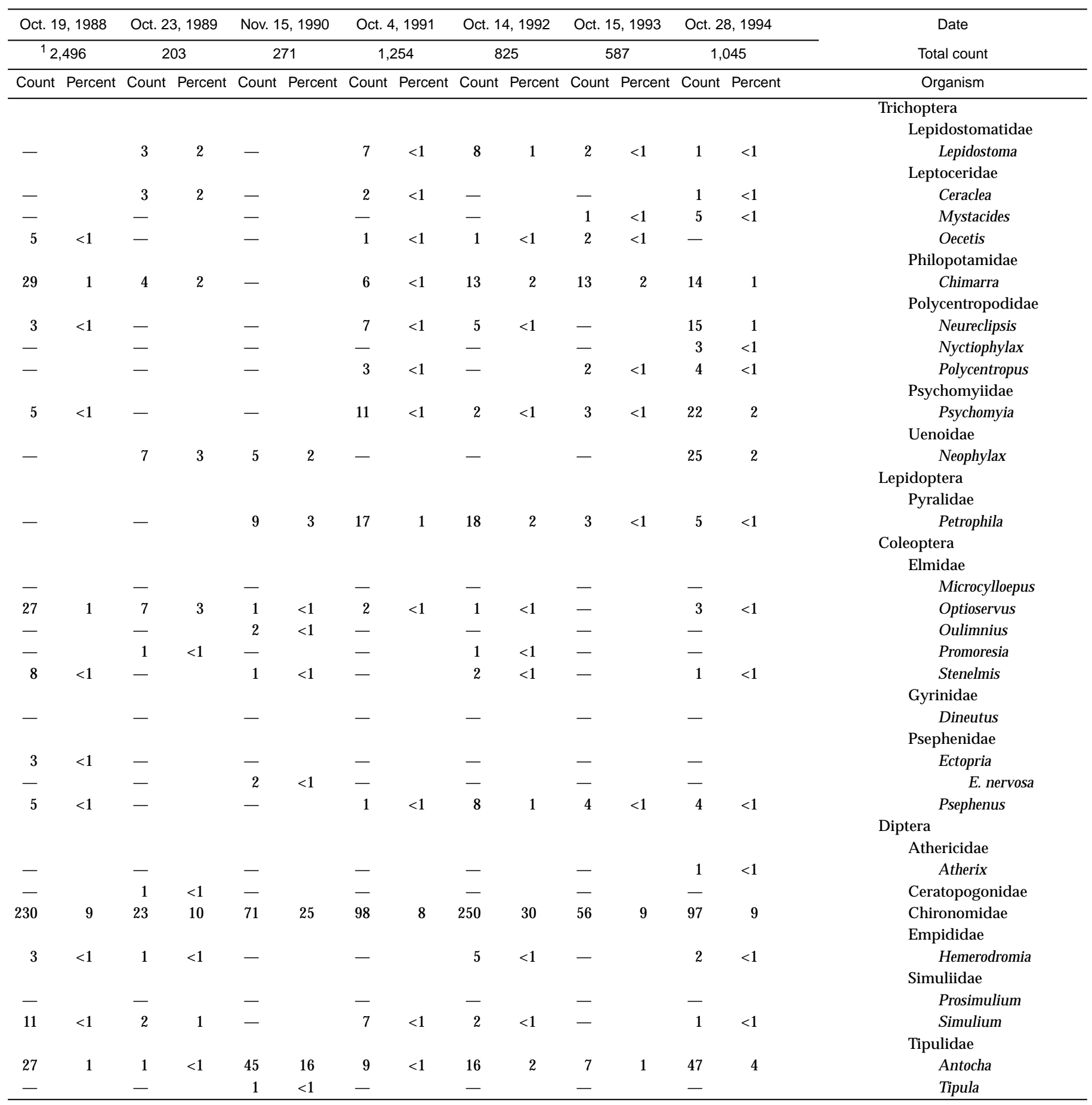


Table 5. Benthic-macroinvertebrate data-Continued

$[<$, less than; - , not found]

014721612 - French Creek at Railroad Bridge at Phoenixville, Pa. (Site 16)

\begin{tabular}{|c|c|c|c|c|c|c|c|c|c|c|c|c|c|c|}
\hline \multirow{3}{*}{$\begin{array}{cc}\text { Date } \\
\text { Total count }\end{array}$} & \multicolumn{2}{|c|}{ Oct. 23, 1981} & \multicolumn{2}{|c|}{ Nov. 2, 1982} & \multicolumn{2}{|c|}{ Oct. 20, 1983} & \multicolumn{2}{|c|}{ Oct. 10,1984} & \multicolumn{2}{|c|}{ Oct. 9, 1985} & \multicolumn{2}{|c|}{ Oct. 31, 1986} & \multicolumn{2}{|c|}{ Oct. 13,1987} \\
\hline & \multicolumn{2}{|c|}{240} & \multicolumn{2}{|c|}{619} & \multicolumn{2}{|c|}{343} & \multicolumn{2}{|c|}{2,247} & \multicolumn{2}{|c|}{72} & \multicolumn{2}{|c|}{605} & & 89 \\
\hline & Count & Percent & Count & Percent & Count & Percent & Count & Percent & Count & Percent & Count & Percent & Count & Percent \\
\hline Platyhelminthes (flatworms) & & & & & & & & & & & & & & \\
\hline Turbellaria & & & & & & & & & & & & & & \\
\hline Tricladida & & & & & & & & & & & & & & \\
\hline Planariidae & 1 & $<1$ & - & & 45 & 13 & 17 & $<1$ & 1 & 2 & 8 & 1 & 12 & 2 \\
\hline Nematoda (nematodes) & - & & - & & - & & - & & - & & 2 & $<1$ & - & \\
\hline Nemertea (proboscis worms) & & & & & & & & & & & & & & \\
\hline Enopla & & & & & & & & & & & & & & \\
\hline Hoplonemertea & & & & & & & & & & & & & & \\
\hline Tetrastemmatidae & & & & & & & & & & & & & & \\
\hline Prostoma & - & & 9 & 2 & 6 & 2 & 16 & $<1$ & - & & - & & - & \\
\hline Mollusca (molluscs) & & & & & & & & & & & & & & \\
\hline Gastropoda & & & & & & & & & & & & & & \\
\hline Mesogastropoda & & & & & & & & & & & & & & \\
\hline Hydrobiidae & & & & & & & & & & & & & & \\
\hline Amnicola & - & & - & & - & & - & & - & & - & & 3 & $<1$ \\
\hline Pleuroceridae & & & & & & & & & & & & & & \\
\hline Goniobasis & - & & - & & - & & - & & - & & - & & - & \\
\hline Basommatophora & & & & & & & & & & & & & & \\
\hline Ancylidae & & & & & & & & & & & & & & \\
\hline Ferrissia & - & & 18 & 3 & 9 & 3 & 10 & $<1$ & - & & 1 & $<1$ & 1 & $<1$ \\
\hline Lymnaeidae & & & & & & & & & & & & & & \\
\hline Lymnaea & - & & - & & 9 & 3 & - & & - & & - & & - & \\
\hline Physidae & & & & & & & & & & & & & & \\
\hline Physa & 10 & 4 & - & & 81 & 4 & 14 & $<1$ & - & & 1 & $<1$ & 1 & $<1$ \\
\hline Planorbidae & & & & & & & & & & & - & & - & \\
\hline Gyraulus & - & & - & & - & & - & & - & & - & & - & \\
\hline Helisoma & - & & - & & 23 & 7 & 1 & $<1$ & - & & - & & - & \\
\hline Bivalvia & & & & & & & & & & & & & & \\
\hline Veneroida & & & & & & & & & & & & & & \\
\hline Sphaeriidae & - & & - & & - & & - & & - & & - & & - & \\
\hline Pisidium & - & & - & & - & & - & & - & & - & & - & \\
\hline Annelida (segmented worms) & & & & & & & & & & & & & & \\
\hline Polychaeta & & & & & & & & & & & & & & \\
\hline Sabellida & & & & & & & & & & & & & & \\
\hline Sabellidae & & & & & & & & & & & & & & \\
\hline Manayunkia speciosa & - & & - & & 3 & $<1$ & - & & - & & - & & - & \\
\hline Oligochaeta & - & & - & & - & & - & & 1 & 2 & - & & - & \\
\hline Lumbriculida & & & & & & & & & & & & & & \\
\hline Lumbriculidae & 1 & $<1$ & - & & - & & - & & - & & - & & 3 & $<1$ \\
\hline Tubificida & & & & & & & & & & & & & & \\
\hline Naididae & 5 & 2 & 480 & 76 & 120 & 35 & 280 & 12 & - & & 6 & 1 & 6 & 1 \\
\hline Tubificidae & - & & 9 & 2 & 8 & 2 & 49 & 2 & - & & - & & - & \\
\hline Arthropoda (arthropods) & & & & & & & & & & & & & & \\
\hline Acariformes & & & & & & & & & & & & & & \\
\hline Hydrachnidia & - & & 3 & $<1$ & 2 & $<1$ & 1 & $<1$ & 2 & 3 & 3 & $<1$ & 12 & 2 \\
\hline Crustacea & & & & & & & & & & & & & & \\
\hline Cladocera & - & & - & & - & & 1 & $<1$ & - & & - & & - & \\
\hline Cyclopoida & - & & - & & - & & - & & - & & - & & - & \\
\hline Amphipoda & & & & & & & & & & & & & & \\
\hline Crangonyctidae & & & & & & & & & & & & & & \\
\hline Crangonyx & - & & - & & - & & - & & - & & - & & - & \\
\hline Gammaridae & & & & & & & & & & & & & & \\
\hline Gammarus & 1 & $<1$ & - & & - & & - & & - & & - & & - & \\
\hline
\end{tabular}




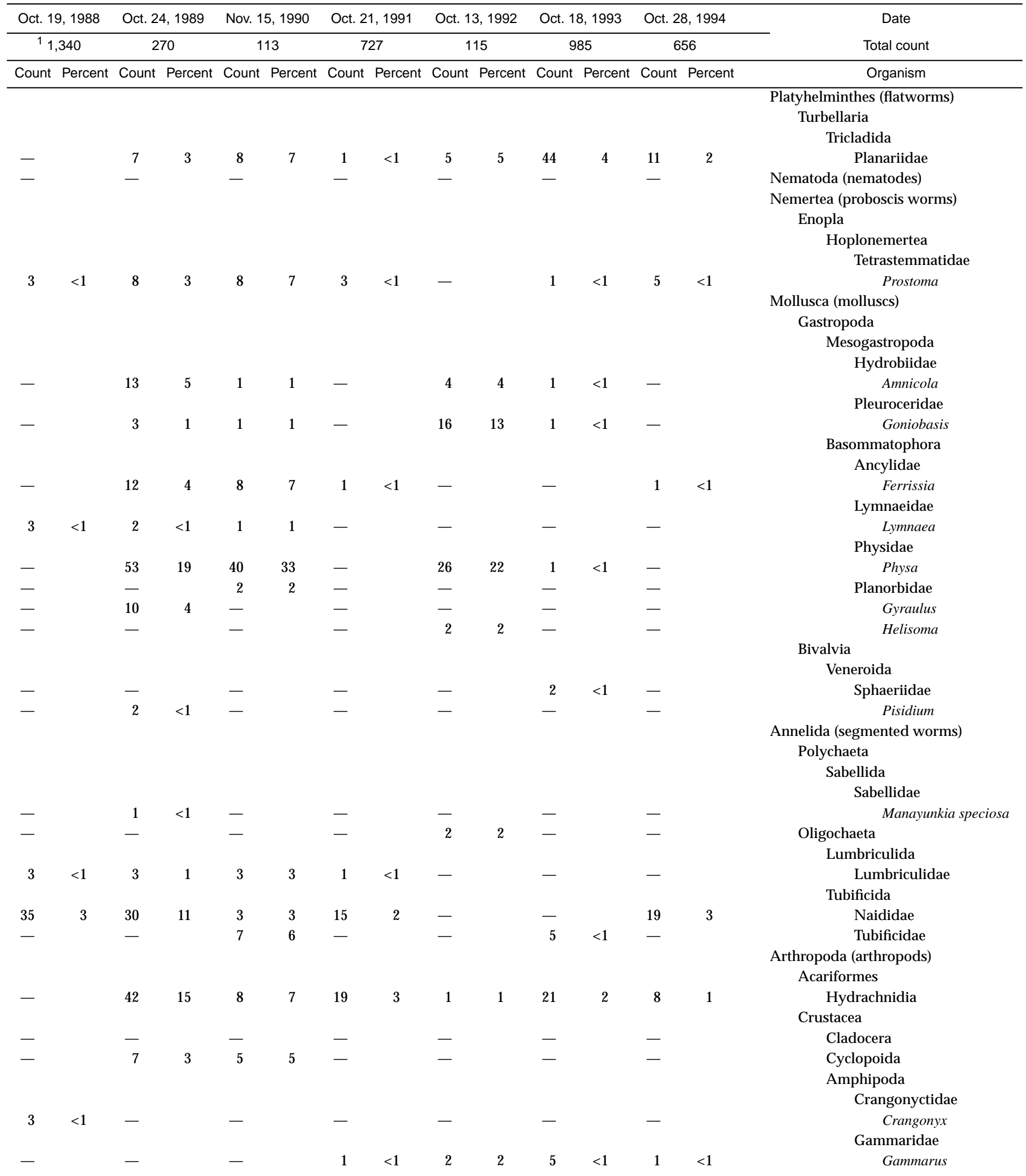


Table 5. Benthic-macroinvertebrate data—Continued

014721612 - French Creek at Railroad Bridge at Phoenixville, Pa. (Site 16)—Continued

\begin{tabular}{|c|c|c|c|c|c|c|c|c|c|c|c|c|c|c|}
\hline \multirow{3}{*}{$\begin{array}{c}\text { Date } \\
\text { Total count } \\
\text { Organism }\end{array}$} & \multirow{2}{*}{\multicolumn{2}{|c|}{$\begin{array}{c}\text { Oct. 23, } 1981 \\
240\end{array}$}} & \multicolumn{2}{|c|}{ Nov. 2, 1982} & \multicolumn{2}{|c|}{ Oct. 20,1983} & \multicolumn{2}{|c|}{ Oct. 10,1984} & \multicolumn{2}{|c|}{ Oct. 9, 1985} & \multicolumn{2}{|c|}{ Oct. 31,1986} & \multicolumn{2}{|c|}{ Oct. 13,1987} \\
\hline & & & & 19 & & 43 & 2,2 & 247 & & 72 & 6 & 05 & & 89 \\
\hline & Count & Percent & Count & Percent & Count & Percent & Count & Percent & Count & Percent & Count & Percent & Count & Percent \\
\hline \multicolumn{15}{|l|}{ Isopoda } \\
\hline \multicolumn{15}{|l|}{ Asellidae } \\
\hline Lirceus & - & & - & & - & & 5 & $<1$ & 4 & 5 & - & & - & \\
\hline \multicolumn{15}{|l|}{ Decapoda } \\
\hline Astacidae & - & & - & & - & & - & & - & & - & & - & \\
\hline Podocopa & - & & - & & - & & - & & - & & - & & - & \\
\hline \multicolumn{15}{|l|}{ Insecta } \\
\hline \multicolumn{15}{|l|}{ Ephemeroptera } \\
\hline \multicolumn{15}{|l|}{ Baetidae } \\
\hline Baetis & - & & - & & - & & 13 & $<1$ & 8 & 10 & - & & 6 & 1 \\
\hline $\begin{array}{l}\text { Pseudocloeon } \\
\text { Caenidae }\end{array}$ & \multicolumn{14}{|c|}{ Caenidae } \\
\hline \multicolumn{14}{|l|}{ Ephemerellidae } & \\
\hline $\begin{array}{c}\text { Ephemerella } \\
\text { Heptageniidae }\end{array}$ & - & & - & & - & & - & & 3 & 4 & 2 & $<1$ & 2 & $<1$ \\
\hline Epeorus & - & & - & & - & & - & & - & & - & & - & \\
\hline Stenonema & - & & - & & - & & - & & 8 & 10 & 1 & $<1$ & 7 & 2 \\
\hline \multicolumn{15}{|l|}{ Isonychiidae } \\
\hline Isonychia & - & & 1 & $<1$ & 2 & $<1$ & - & & 2 & 3 & - & & - & \\
\hline \multicolumn{14}{|l|}{ Odonata } & \\
\hline Argia & - & & 3 & $<1$ & 7 & 2 & - & & - & & 3 & $<1$ & 2 & $<1$ \\
\hline $\begin{array}{l}\text { Plecoptera } \\
\text { Capniidae }\end{array}$ & & & & & & & & & & & & & & \\
\hline $\begin{array}{l}\text { Allocapnia } \\
\text { Perlidae }\end{array}$ & - & & - & & - & & - & & - & & - & & 1 & $<1$ \\
\hline $\begin{array}{c}\text { Acroneuria } \\
\text { Taeniopterygidae }\end{array}$ & - & & - & & - & & - & & 1 & 2 & - & & - & \\
\hline Taeniopteryx & - & & - & & 1 & $<1$ & 1 & $<1$ & - & & 1 & $<1$ & 13 & 3 \\
\hline Hemiptera & & & & & & & & & & & & & & \\
\hline $\begin{array}{l}\text { Corixidae } \\
\text { Veliidae }\end{array}$ & - & & - & & - & & - & & 1 & 2 & - & & - & \\
\hline Rhagovelia & - & & 1 & $<1$ & & & & & & & & & & \\
\hline $\begin{array}{l}\text { Megaloptera } \\
\text { Corydalidae }\end{array}$ & & & & & & & & & & & & & & \\
\hline $\begin{array}{l}\text { Corydalus } \\
\text { Sialidae }\end{array}$ & - & & 1 & $<1$ & - & & - & & - & & - & & - & \\
\hline Sialis & - & & - & & - & & - & & - & & - & & - & \\
\hline $\begin{array}{l}\text { Neuroptera } \\
\text { Sisyridae }\end{array}$ & & & & & & & & & & & & & & \\
\hline Climacia & - & & 1 & $<1$ & & & & & & & & & & \\
\hline Trichoptera & & & & & & & & & & & & & & \\
\hline Apataniidae & - & & - & & - & & - & & - & & - & & - & \\
\hline $\begin{array}{c}\text { Apatania } \\
\text { Brachycentridae }\end{array}$ & - & & - & & - & & - & & - & & 1 & $<1$ & - & \\
\hline Micrasema & - & & - & & - & & - & & - & & 2 & $<1$ & - & \\
\hline Glossosomatidae & & & & & & & & & & & & & & \\
\hline Culoptila & - & & - & & - & & - & & - & & - & & - & \\
\hline Glossosoma & - & & - & & 1 & $<1$ & - & & - & & - & & - & \\
\hline Protoptila & - & & - & & - & & - & & - & & - & & - & \\
\hline Hydropsychidae & & & & & & & & & & & & & & \\
\hline Ceratopshche & 1 & $<1$ & 2 & $<1$ & 6 & 2 & - & & 6 & 8 & 2 & $<1$ & 3 & $<1$ \\
\hline Cheumatopsyche & - & & 7 & 1 & 2 & $<1$ & - & & 3 & 4 & 29 & 5 & 66 & 13 \\
\hline Hydropsyche & - & & 39 & 6 & - & & 3 & $<1$ & 1 & 2 & 230 & 38 & 11 & 2 \\
\hline
\end{tabular}




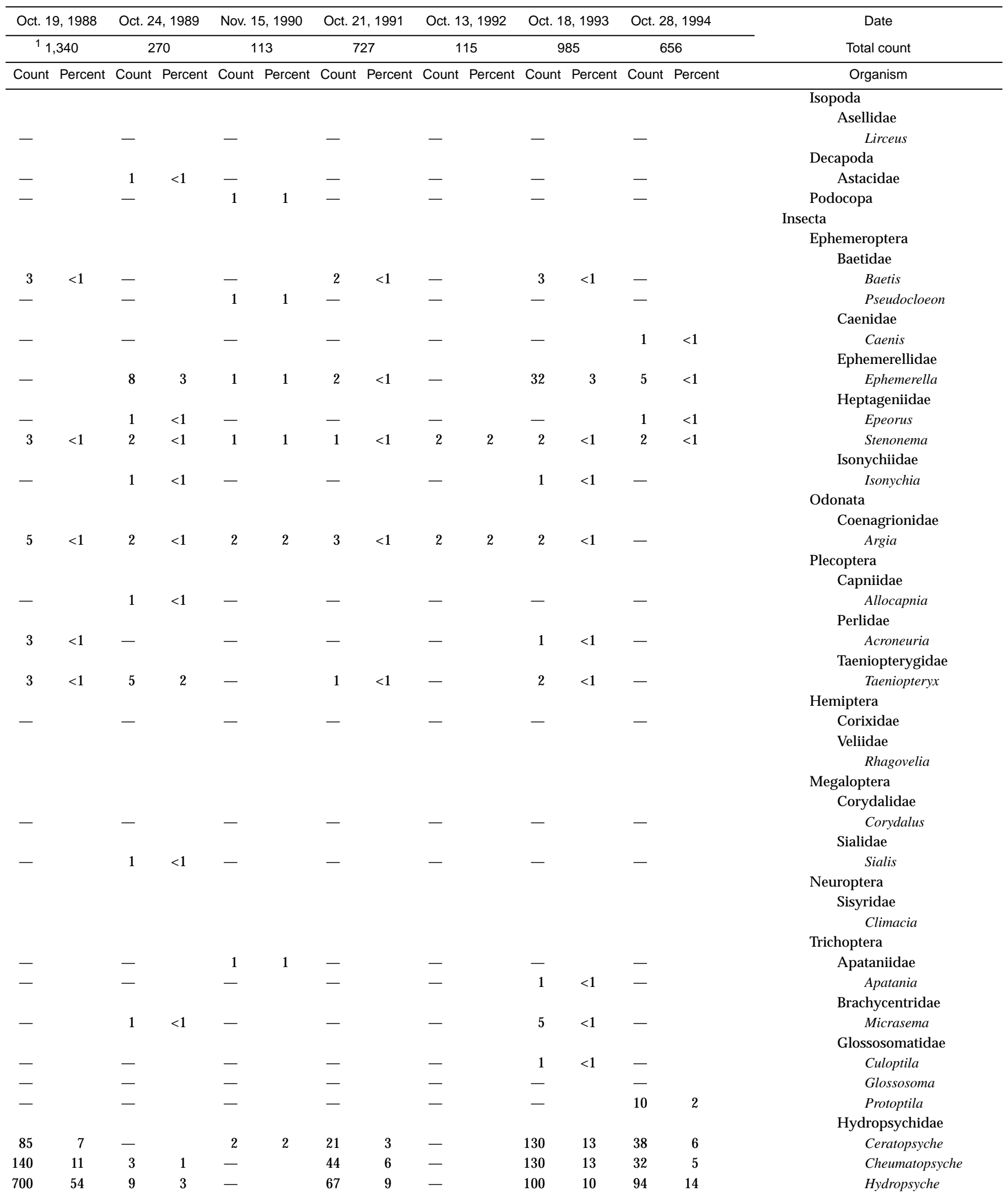


Table 5. Benthic-macroinvertebrate data—Continued

014721612 - French Creek at Railroad Bridge at Phoenixville, Pa. (Site 16)—Continued

\begin{tabular}{|c|c|c|c|c|c|c|c|c|c|c|c|c|c|c|}
\hline \multirow{3}{*}{$\begin{array}{c}\text { Date } \\
\text { Total count } \\
\text { Organism }\end{array}$} & \multirow{2}{*}{\multicolumn{2}{|c|}{$\begin{array}{c}\text { Oct. } 23,1981 \\
240\end{array}$}} & \multicolumn{2}{|c|}{ Nov. 2, 1982} & \multicolumn{2}{|c|}{ Oct. 20,1983} & \multicolumn{2}{|c|}{ Oct. 10,1984} & \multicolumn{2}{|c|}{ Oct. 9, 1985} & \multicolumn{2}{|c|}{ Oct. 31, 1986} & \multicolumn{2}{|c|}{ Oct. 13,1987} \\
\hline & & & & 19 & & 43 & & 247 & & 72 & & 05 & & 89 \\
\hline & Count & Percent & Count & Percent & Count & Percent & Count & Percent & Count & Percent & Count & Percent & Count & Percent \\
\hline \multicolumn{15}{|l|}{ Trichoptera } \\
\hline \multicolumn{15}{|l|}{ Hydroptilidae } \\
\hline Hydroptila & - & & - & & - & & - & & 1 & 2 & - & & - & \\
\hline Leucotrichia & - & & - & & - & & - & & 2 & 3 & - & & 1 & $<1$ \\
\hline \multicolumn{15}{|l|}{ Leptoceridae } \\
\hline Mystacides & - & & - & & - & & - & & - & & - & & - & \\
\hline \multicolumn{15}{|l|}{ Philopotamidae } \\
\hline Chimarra & - & & 1 & $<1$ & 2 & $<1$ & - & & - & & - & & 1 & $<1$ \\
\hline Dolophilodes & - & & - & & - & & - & & - & & - & & - & \\
\hline \multicolumn{15}{|l|}{ Polycentropodidae } \\
\hline Polycentropus & - & & - & & 1 & $<1$ & - & & - & & - & & - & \\
\hline \multicolumn{15}{|l|}{ Psychomyiidae } \\
\hline \multicolumn{15}{|l|}{ Uenoidae } \\
\hline Neophylax & - & & - & & - & & - & & - & & - & & - & \\
\hline \multicolumn{15}{|l|}{ Lepidoptera } \\
\hline \multicolumn{15}{|l|}{ Pyralidae } \\
\hline Petrophila & 1 & $<1$ & 3 & $<1$ & 1 & $<1$ & 17 & $<1$ & 1 & 2 & 89 & 15 & 21 & 4 \\
\hline Synclita & - & & - & & 1 & $<1$ & - & & - & & - & & - & \\
\hline \multicolumn{15}{|l|}{ Coleoptera } \\
\hline Curculionidae & - & & - & & - & & - & & 1 & 2 & - & & - & \\
\hline Dytiscidae & - & & - & & - & & - & & - & & - & & 1 & $<1$ \\
\hline \multicolumn{15}{|l|}{ Elmidae } \\
\hline Dubiraphia & - & & - & & - & & - & & - & & - & & 5 & 1 \\
\hline Microcylloepus & - & & - & & - & & - & & - & & - & & - & \\
\hline Optioservus & - & & 1 & $<1$ & 2 & $<1$ & - & & 3 & 4 & 15 & 2 & 49 & 10 \\
\hline Promoresia & - & & - & & - & & - & & - & & - & & - & \\
\hline Stenelmis & - & & - & & - & & - & & - & & - & & 6 & 1 \\
\hline Hydrophilidae & & & & & & & & & & & & & & \\
\hline Berosus & - & & - & & - & & - & & - & & - & & - & \\
\hline Psephenidae & & & & & & & & & & & & & & \\
\hline Psephenus & - & & - & & - & & - & & - & & - & & - & \\
\hline Hymenoptera & - & & - & & - & & - & & 1 & 2 & - & & - & \\
\hline Diptera & & & & & & & & & & & & & & \\
\hline Chironomidae & 220 & 92 & 21 & 3 & 9 & 3 & 1,800 & 78 & 21 & 26 & 200 & 33 & 230 & 46 \\
\hline Empididae & & & & & & & & & & & & & & \\
\hline $\begin{array}{l}\text { Hemerodromia } \\
\text { Psychodidae }\end{array}$ & - & & 17 & 3 & - & & 16 & $<1$ & - & & 7 & 1 & - & \\
\hline Telmatoscopus & - & & - & & - & & 2 & $<1$ & - & & - & & - & \\
\hline Simuliidae & & & & & & & & & & & & & & \\
\hline Simulium & - & & - & & - & & - & & - & & 1 & $<1$ & 26 & 5 \\
\hline Tipulidae & & & & & & & & & & & & & & \\
\hline Antocha & - & & 1 & $<1$ & - & & - & & - & & 1 & $<1$ & - & \\
\hline Tipula & - & & - & & 1 & $<1$ & 1 & $<1$ & - & & - & & - & \\
\hline
\end{tabular}

1 Extrapolated from a 3/8 subsample. 


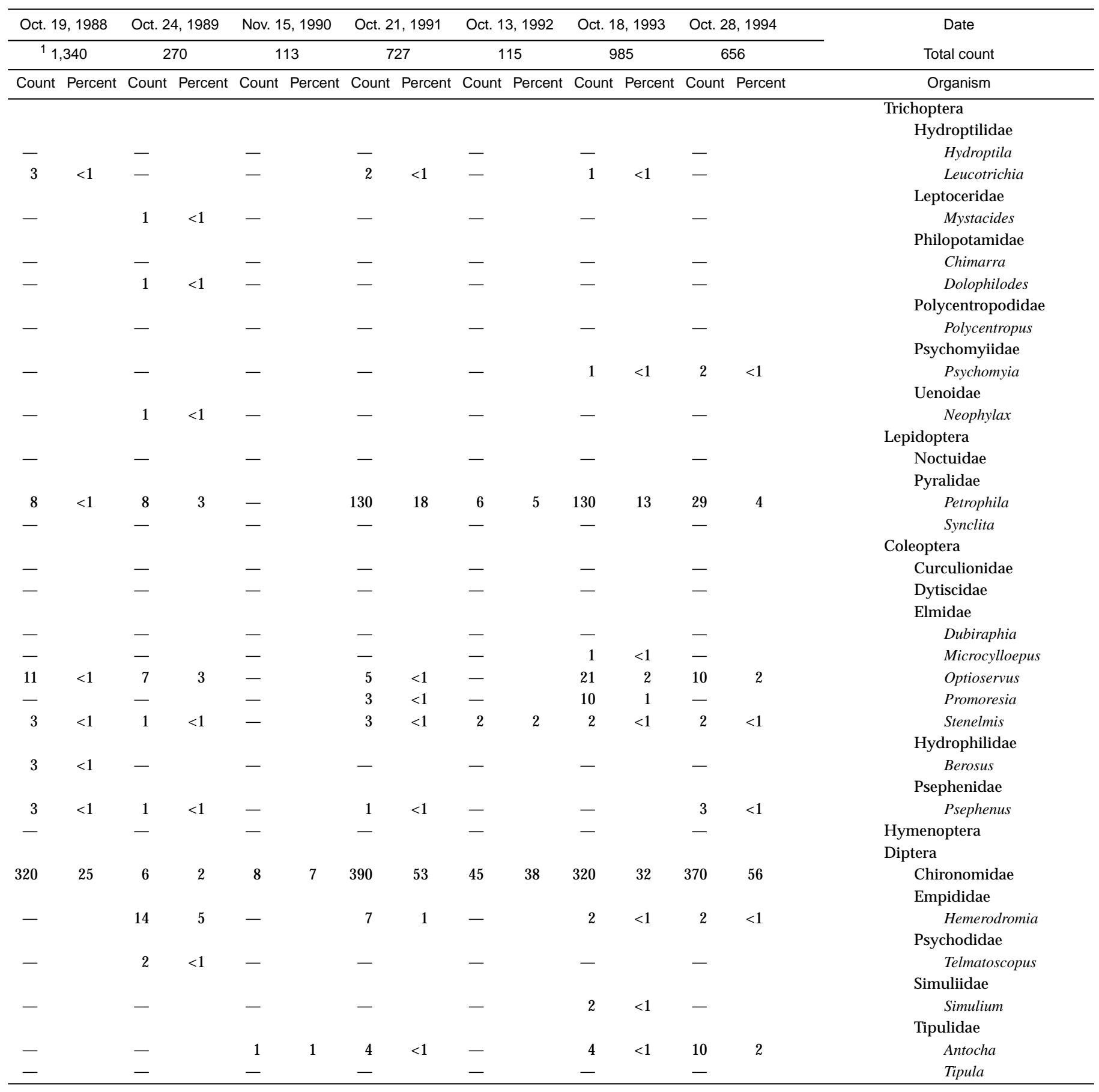


Table 5. Benthic-macroinvertebrate data-Continued

$[<$, less than; - , not found]

01472170 - Pickering Creek near Eagle, Pa. (Site 1)

\begin{tabular}{|c|c|c|c|c|c|c|c|c|c|c|c|c|c|c|}
\hline \multirow{3}{*}{$\begin{array}{cc}\text { Date } \\
\text { Total count }\end{array}$} & \multirow{2}{*}{\multicolumn{2}{|c|}{$\begin{array}{c}\text { Oct. } 16,1981 \\
11,301\end{array}$}} & \multirow{2}{*}{\multicolumn{2}{|c|}{$\frac{\text { Oct. } 18,1982}{{ }^{1} 2,643}$}} & \multirow{2}{*}{\multicolumn{2}{|c|}{$\begin{array}{c}\text { Oct. } 17,1983 \\
2,715\end{array}$}} & \multirow{2}{*}{\multicolumn{2}{|c|}{$\frac{\text { Oct. } 5,1984}{{ }^{1} 1,537}$}} & \multirow{2}{*}{\multicolumn{2}{|c|}{$\frac{\text { Oct. } 8,1985}{765}$}} & \multirow{2}{*}{\multicolumn{2}{|c|}{$\frac{\text { Oct. } 7,1986}{1,102}$}} & \multirow{2}{*}{\multicolumn{2}{|c|}{$\frac{\text { Oct. 9, } 1987}{1,431}$}} \\
\hline & & & & & & & & & & & & & & \\
\hline & Count & Percent & Count & Percent & Count & Percent & Count & Percent & Count & Percent & Count & Percent & Count & Percent \\
\hline \multicolumn{15}{|l|}{ Platyhelminthes (flatworms) } \\
\hline \multicolumn{15}{|l|}{ Turbellaria } \\
\hline \multicolumn{15}{|l|}{ Tricladida } \\
\hline Planariidae & - & & 5 & $<1$ & 6 & $<1$ & 5 & $<1$ & 15 & 2 & 19 & 2 & 15 & 1 \\
\hline \multicolumn{15}{|l|}{ Nemertea (proboscis worms) } \\
\hline \multicolumn{15}{|l|}{ Enopla } \\
\hline \multicolumn{15}{|l|}{ Hoplonemertea } \\
\hline \multicolumn{15}{|l|}{ Tetrastemmatidae } \\
\hline Prostoma & - & & - & & - & & - & & 2 & $<1$ & 3 & $<1$ & 12 & $<1$ \\
\hline Mollusca (molluscs) & & & & & & & & & & & & & & \\
\hline Gastropoda & & & & & & & & & & & & & & \\
\hline Basommatophora & & & & & & & & & & & & & & \\
\hline Ancylidae & & & & & & & & & & & & & & \\
\hline Ferrissia & - & & - & & 1 & $<1$ & - & & 3 & $<1$ & - & & - & \\
\hline Annelida (segmented worms) & & & & & & & & & & & & & & \\
\hline Oligochaeta & & & & & & & & & & & & & & \\
\hline Lumbriculida & & & & & & & & & & & & & & \\
\hline Lumbriculidae & - & & - & & - & & - & & - & & - & & - & \\
\hline Tubificida & & & & & & & & & & & & & & \\
\hline Naididae & 3 & $<1$ & 80 & 3 & 14 & $<1$ & 3 & $<1$ & 4 & $<1$ & 8 & $<1$ & 1 & $<1$ \\
\hline Tubificidae & - & & - & & - & & - & & - & & - & & - & \\
\hline Arthropoda (arthropods) & & & & & & & & & & & & & & \\
\hline Acariformes & & & & & & & & & & & & & & \\
\hline Hydrachnidia & - & & - & & 7 & $<1$ & - & & 6 & $<1$ & 1 & $<1$ & 19 & 1 \\
\hline Crustacea & & & & & & & & & & & & & & \\
\hline Cyclopoida & & & & & & & & & & & & & & \\
\hline Cyclopidae & - & & - & & - & & - & & 1 & $<1$ & - & & - & \\
\hline Isopoda & & & & & & & & & & & & & & \\
\hline Asellidae & & & & & & & & & & & & & & \\
\hline Caecidotea & - & & - & & - & & - & & 1 & $<1$ & - & & - & \\
\hline Podocopa & - & & - & & - & & - & & 1 & $<1$ & - & & - & \\
\hline Insecta & & & & & & & & & & & & & & \\
\hline Ephemeroptera & & & & & & & & & & & & & & \\
\hline Baetidae & & & & & & & & & & & & & & \\
\hline Baetis & 3 & $<1$ & 16 & $<1$ & 19 & $<1$ & 21 & 1 & 21 & 3 & 16 & 1 & 36 & 3 \\
\hline Pseudocloeon & - & & - & & 6 & $<1$ & 19 & 1 & - & & 1 & $<1$ & 2 & $<1$ \\
\hline Ephemerellidae & & & & & & & & & & & & & & \\
\hline Ephemerella & 24 & 2 & 19 & $<1$ & 49 & 2 & 51 & 3 & 7 & $<1$ & 8 & $<1$ & 29 & 2 \\
\hline Heptageniidae & & & & & & & & & & & & & & \\
\hline Epeorus & - & & - & & - & & - & & - & & - & & - & \\
\hline Heptagenia & - & & - & & - & & - & & - & & - & & - & \\
\hline Stenonema & 24 & 2 & 27 & 1 & 18 & $<1$ & 53 & 4 & 14 & 2 & 47 & 4 & 24 & 2 \\
\hline Isonychiidae & & & & & & & & & & & & & & \\
\hline Isonychia & - & & - & & 1 & $<1$ & 13 & $<1$ & - & & 3 & $<1$ & 5 & $<1$ \\
\hline Leptohyphidae & & & & & & & & & & & & & & \\
\hline Tricorythodes & - & & - & & - & & - & & - & & 1 & $<1$ & - & \\
\hline Odonata & & & & & & & & & & & & & & \\
\hline Coenagrionidae & & & & & & & & & & & & & & \\
\hline Argia & - & & - & & - & & - & & - & & - & & - & \\
\hline Ischnura & - & & - & & - & & - & & - & & - & & - & \\
\hline
\end{tabular}




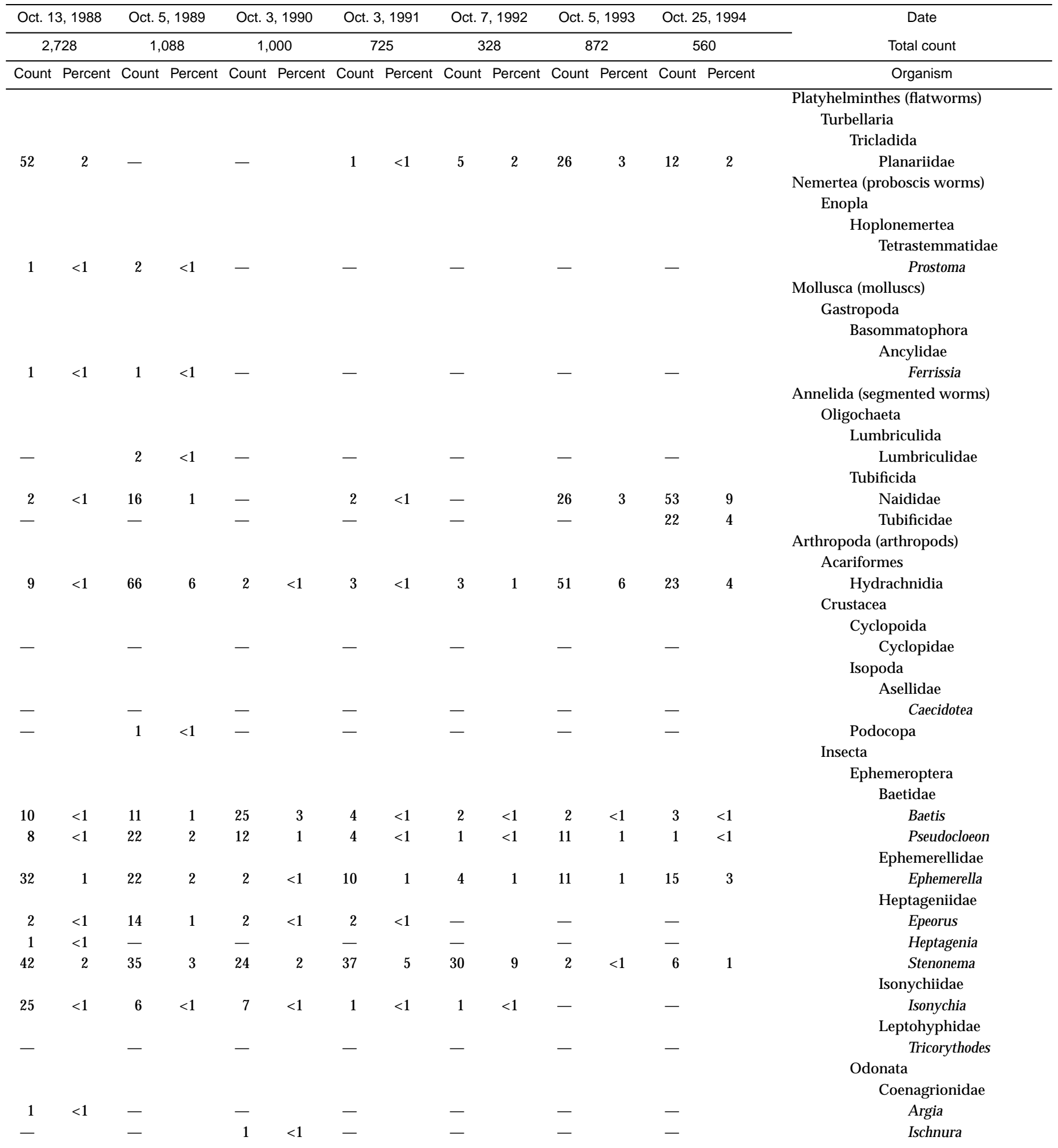


Table 5. Benthic-macroinvertebrate data-Continued

01472170 - Pickering Creek near Eagle, Pa. (Site 1)—Continued

\begin{tabular}{|c|c|c|c|c|c|c|c|c|c|c|c|c|c|c|}
\hline \multirow{3}{*}{$\begin{array}{c}\text { Date } \\
\text { Total count } \\
\text { Organism }\end{array}$} & \multirow{2}{*}{\multicolumn{2}{|c|}{$\begin{array}{c}\text { Oct. } 16,1981 \\
{ }^{1} 1,301\end{array}$}} & \multirow{2}{*}{\multicolumn{2}{|c|}{$\begin{array}{c}\text { Oct. } 18,1982 \\
{ }^{1} 2,643\end{array}$}} & \multirow{2}{*}{\multicolumn{2}{|c|}{$\begin{array}{c}\text { Oct. } 17,1983 \\
2,715\end{array}$}} & \multirow{2}{*}{\multicolumn{2}{|c|}{$\begin{array}{c}\text { Oct. } 5,1984 \\
11,537\end{array}$}} & \multirow{2}{*}{\multicolumn{2}{|c|}{$\frac{\text { Oct. } 8,1985}{765}$}} & \multirow{2}{*}{\multicolumn{2}{|c|}{$\begin{array}{c}\text { Oct. } 7,1986 \\
1,102\end{array}$}} & \multirow{2}{*}{\multicolumn{2}{|c|}{$\begin{array}{c}\text { Oct. 9, } 1987 \\
1,431\end{array}$}} \\
\hline & & & & & & & & & & & & & & \\
\hline & Count & Percent & Count & Percent & Count & Percent & Count & Percent & Count & Percent & Count & Percent & Count & Percent \\
\hline \multicolumn{15}{|l|}{ Odonata } \\
\hline \multicolumn{15}{|l|}{ Aeshnidae } \\
\hline Aeshna & - & & - & & - & & - & & - & & - & & - & \\
\hline Boyeria & - & & - & & - & & - & & - & & 1 & $<1$ & - & \\
\hline \multicolumn{15}{|l|}{ Plecoptera } \\
\hline \multicolumn{15}{|l|}{ Capniidae } \\
\hline Allocapnia & 3 & $<1$ & 11 & $<1$ & 1 & $<1$ & - & & - & & - & & - & \\
\hline \multicolumn{15}{|l|}{ Taeniopterygidae } \\
\hline Taeniopteryx & 16 & 1 & 3 & $<1$ & 9 & $<1$ & - & & 1 & $<1$ & 3 & $<1$ & 28 & 2 \\
\hline \multicolumn{15}{|l|}{ Hemiptera } \\
\hline \multicolumn{15}{|l|}{ Gerridae } \\
\hline Gerris & - & & - & & - & & 3 & $<1$ & - & & - & & - & \\
\hline \multicolumn{15}{|l|}{ Mesoveliidae } \\
\hline Mesovelia & - & & - & & - & & 3 & $<1$ & - & & - & & - & \\
\hline Veliidae & & & & & & & & & & & & & & \\
\hline Rhagovelia & - & & - & & - & & - & & - & & - & & - & \\
\hline Megaloptera & & & & & & & & & & & & & & \\
\hline Corydalidae & & & & & & & & & & & & & & \\
\hline Corydalus & - & & - & & - & & - & & - & & - & & - & \\
\hline Nigronia & 3 & $<1$ & - & & 1 & $<1$ & - & & 1 & $<1$ & 4 & $<1$ & - & \\
\hline Trichoptera & & & & & & & & & & & & & & \\
\hline Apataniidae & & & & & & & & & & & & & & \\
\hline Apatania & - & & - & & - & & - & & - & & 2 & $<1$ & - & \\
\hline Brachycentridae & & & & & & & & & & & & & & \\
\hline Micrasema & - & & - & & 3 & $<1$ & - & & - & & - & & - & \\
\hline Glossosomatidae & & & & & & & & & & & & & & \\
\hline Glossosoma & 3 & $<1$ & - & & - & & 5 & $<1$ & 3 & $<1$ & 3 & $<1$ & - & \\
\hline Goeridae & & & & & & & & & & & & & & \\
\hline Goera & - & & - & & - & & - & & - & & - & & - & \\
\hline Hydropsychidae & & & & & & & & & & & & & & \\
\hline Ceratopsyche & 40 & 3 & 160 & 6 & 100 & 4 & 230 & 15 & 130 & 17 & 230 & 21 & 77 & 6 \\
\hline Cheumatopsyche & 88 & 7 & 110 & 4 & 70 & 3 & 27 & 2 & 60 & 8 & 84 & 8 & 5 & $<1$ \\
\hline Hydropsyche & 100 & 8 & 100 & 4 & 790 & 29 & 96 & 6 & 35 & 5 & 80 & 7 & 240 & 17 \\
\hline Hydroptilidae & & & & & & & & & & & & & & \\
\hline Hydroptila & 3 & $<1$ & 5 & $<1$ & 11 & $<1$ & 3 & $<1$ & - & & 8 & $<1$ & 4 & $<1$ \\
\hline Leucotrichia & 110 & 8 & 160 & 6 & 590 & 22 & 660 & 44 & 180 & 23 & 230 & 21 & 550 & 39 \\
\hline Leptoceridae & & & & & & & & & & & & & & \\
\hline Oecetis & - & & - & & - & & - & & 1 & $<1$ & - & & - & \\
\hline Philopotamidae & & & & & & & & & & & & & & \\
\hline Chimarra & 100 & 8 & 8 & $<1$ & 31 & 1 & 3 & $<1$ & 5 & $<1$ & 36 & 3 & 29 & 2 \\
\hline Dolophilodes & - & & - & & - & & - & & - & & - & & - & \\
\hline Wormaldia & - & & - & & - & & - & & - & & - & & - & \\
\hline Polycentropodidae & & & & & & & & & & & & & & \\
\hline $\begin{array}{l}\text { Polycentropus } \\
\text { Psychomyiidae }\end{array}$ & 3 & $<1$ & 3 & $<1$ & 1 & $<1$ & - & & - & & 1 & $<1$ & 1 & $<1$ \\
\hline $\begin{array}{r}\text { Psychomyia } \\
\text { Rhyacophilidae }\end{array}$ & - & & 3 & $<1$ & 1 & $<1$ & 5 & $<1$ & 2 & $<1$ & 4 & $<1$ & 1 & $<1$ \\
\hline Rhyacophila & - & & - & & - & & - & & - & & - & & - & \\
\hline Uenoidae & & & & & & & & & & & & & & \\
\hline Neophylax & - & & - & & - & & - & & - & & - & & - & \\
\hline
\end{tabular}




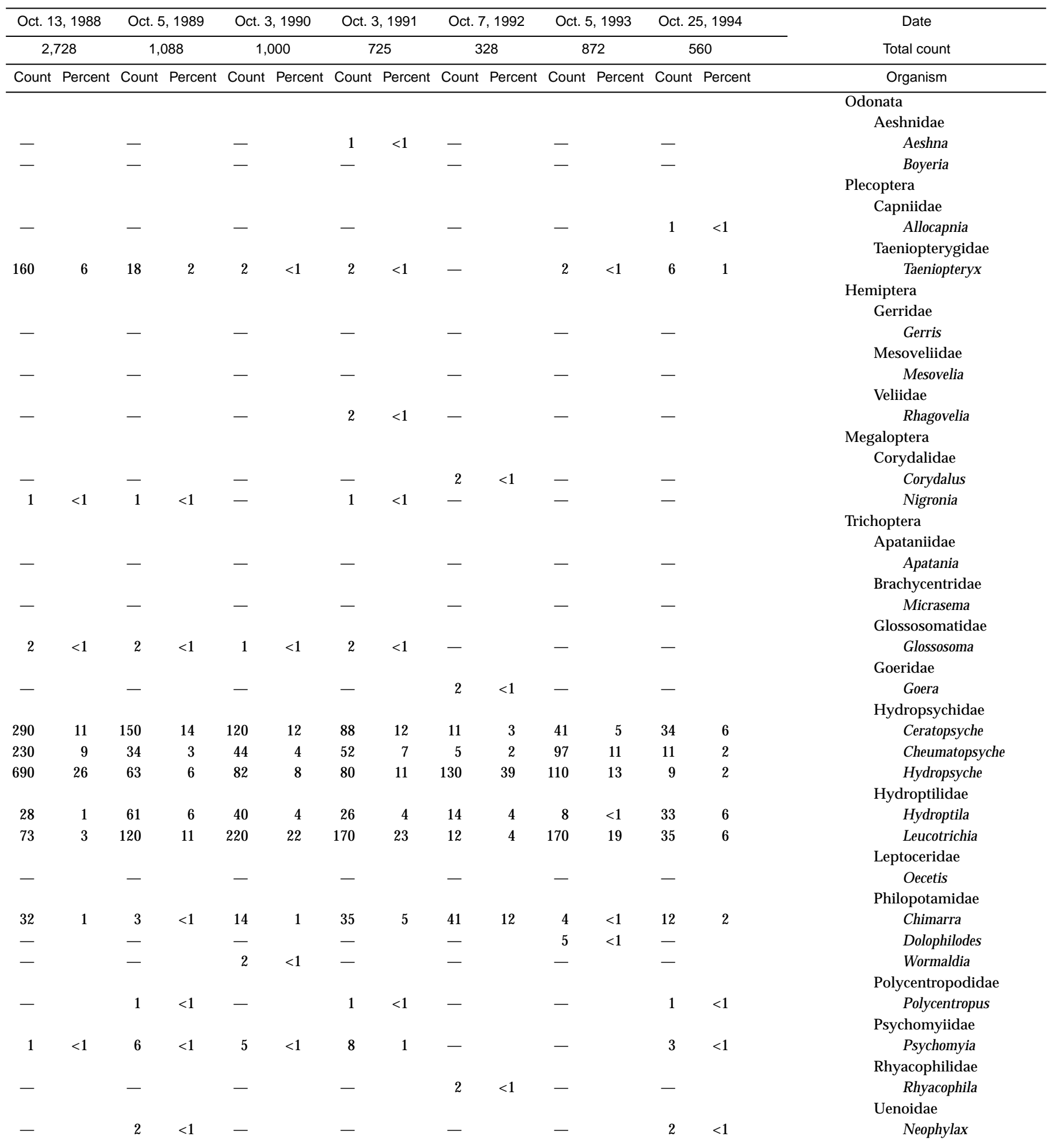


Table 5. Benthic-macroinvertebrate data-Continued

01472170 - Pickering Creek near Eagle, Pa. (Site 1)—Continued

\begin{tabular}{|c|c|c|c|c|c|c|c|c|c|c|c|c|c|c|}
\hline Date & \multicolumn{2}{|c|}{ Oct. 16, 1981} & \multicolumn{2}{|c|}{ Oct. 18, 1982} & \multicolumn{2}{|c|}{ Oct. 17,1983} & \multicolumn{2}{|c|}{ Oct. 5, 1984} & \multicolumn{2}{|c|}{ Oct. 8, 1985} & \multicolumn{2}{|c|}{ Oct. 7, 1986} & \multicolumn{2}{|c|}{ Oct. 9, 1987} \\
\hline Total count & \multicolumn{2}{|c|}{$1_{1,301}$} & \multicolumn{2}{|c|}{${ }^{1} 2,643$} & \multicolumn{2}{|c|}{2,715} & \multicolumn{2}{|c|}{11,537} & \multicolumn{2}{|c|}{765} & \multicolumn{2}{|c|}{1,102} & \multicolumn{2}{|c|}{1,431} \\
\hline Organism & Count & Percent & Count & Percent & Count & Percent & Count & Percent & Count & Percent & Count & Percent & Count & Percent \\
\hline \multicolumn{15}{|l|}{ Lepidoptera } \\
\hline \multicolumn{15}{|l|}{ Noctuidae } \\
\hline Archanara & - & & - & & - & & - & & - & & - & & - & \\
\hline \multicolumn{15}{|l|}{ Coleoptera } \\
\hline \multicolumn{15}{|l|}{ Elmidae } \\
\hline Dubiraphia & 3 & $<1$ & - & & 1 & $<1$ & - & & 1 & $<1$ & 1 & $<1$ & - & \\
\hline Optioservus & 37 & 3 & - & & 120 & 4 & 29 & 2 & 58 & 8 & 56 & 5 & 38 & 3 \\
\hline Oulimnius & - & & - & & 2 & $<1$ & - & & - & & 1 & $<1$ & 1 & $<1$ \\
\hline Stenelmis & 10 & $<1$ & 11 & $<1$ & 21 & $<1$ & 3 & $<1$ & 14 & 2 & 7 & $<1$ & 10 & $<1$ \\
\hline \multicolumn{15}{|l|}{ Psephenidae } \\
\hline \multicolumn{15}{|l|}{ Ectopria } \\
\hline E. nervosa & - & & - & & - & & - & & - & & - & & - & \\
\hline Psephenus & 8 & $<1$ & - & & 1 & $<1$ & - & & 1 & $<1$ & 6 & $<1$ & - & \\
\hline \multicolumn{15}{|l|}{ Diptera } \\
\hline \multicolumn{15}{|l|}{ Athericidae } \\
\hline Atherix & - & & - & & 4 & $<1$ & - & & - & & - & & - & \\
\hline Chironomidae & 630 & 48 & 970 & 37 & 730 & 27 & 230 & 15 & 140 & 18 & 160 & 15 & 260 & 19 \\
\hline \multicolumn{15}{|l|}{ Empididae } \\
\hline Hemerodromia & 13 & 1 & 43 & 2 & 25 & $<1$ & 8 & $<1$ & 13 & 2 & 15 & 1 & 8 & $<1$ \\
\hline Ephydridae & - & & - & & - & & - & & - & & - & & - & \\
\hline \multicolumn{15}{|l|}{ Simuliidae } \\
\hline Simulium & 13 & 1 & 820 & 32 & 26 & $<1$ & 27 & 2 & 26 & 3 & 10 & $<1$ & 10 & $<1$ \\
\hline \multicolumn{15}{|l|}{ Stratiomyidae } \\
\hline Stratiomys & - & & 3 & $<1$ & - & & - & & - & & - & & - & \\
\hline \multicolumn{15}{|l|}{ Tipulidae } \\
\hline Antocha & 64 & 5 & 83 & 3 & 56 & 2 & 40 & 3 & 16 & 2 & 53 & 5 & 26 & 2 \\
\hline Hexatoma & - & & - & & - & & - & & 2 & $<1$ & - & & - & \\
\hline Tipula & - & & 3 & $<1$ & - & & - & & - & & - & & - & \\
\hline
\end{tabular}

${ }^{1}$ Extrapolated from a 3/8 subsample. 


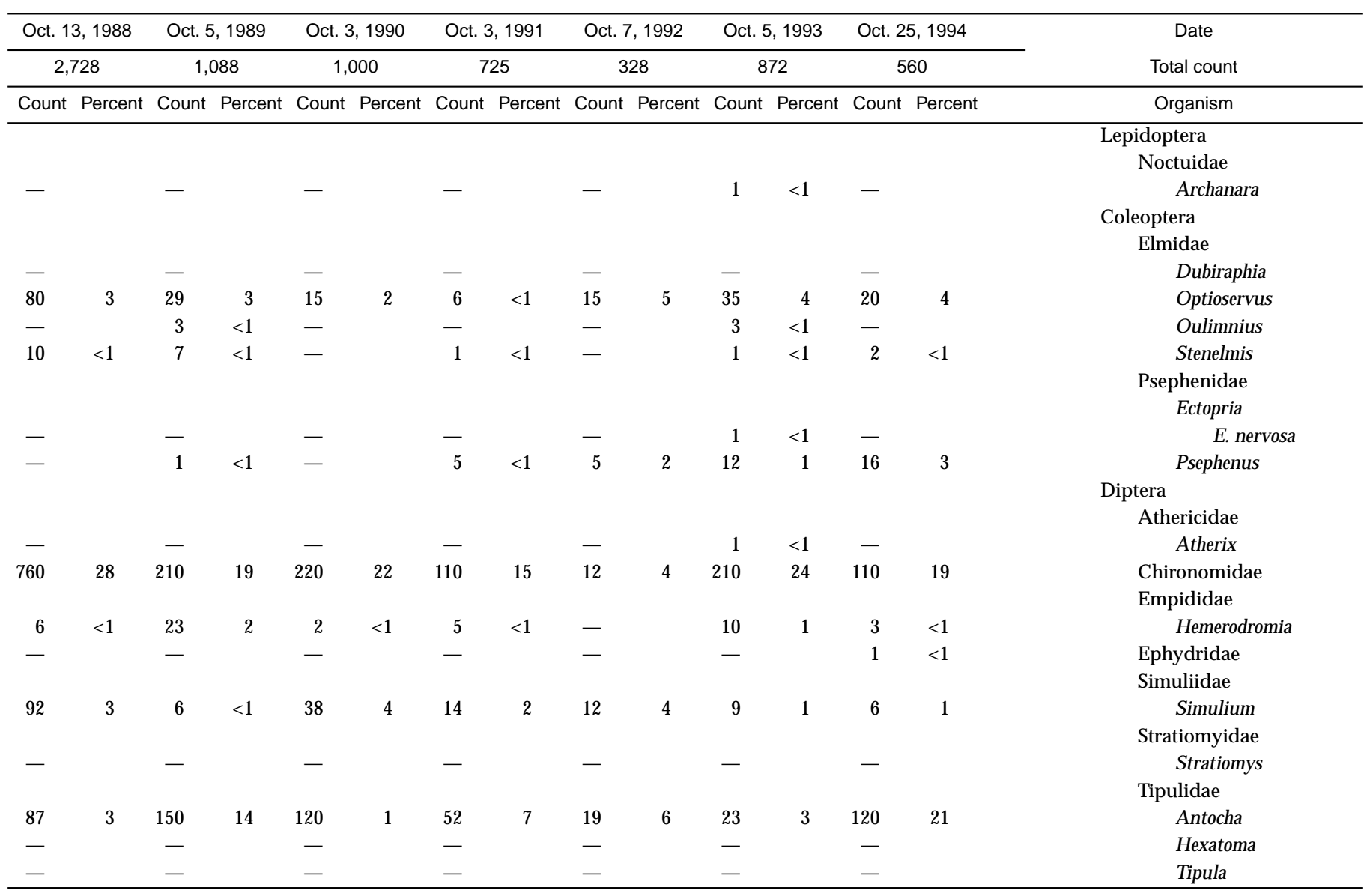


Table 5. Benthic-macroinvertebrate data-Continued

$[<$, less than; - , not found]

01472174 - Pickering Creek near Chester Springs, Pa. (Site 2)

\begin{tabular}{|c|c|c|c|c|c|c|c|c|c|c|c|c|c|c|}
\hline \multirow{3}{*}{$\begin{array}{cc}\text { Date } \\
\text { Total count }\end{array}$} & \multirow{2}{*}{\multicolumn{2}{|c|}{$\frac{\text { Oct. } 16,1981}{{ }^{1} 747}$}} & \multirow{2}{*}{\multicolumn{2}{|c|}{$\frac{\text { Oct. } 18,1982}{{ }^{1} 1,084}$}} & \multirow{2}{*}{\multicolumn{2}{|c|}{$\begin{array}{c}\text { Oct. } 18,1983 \\
526\end{array}$}} & \multirow{2}{*}{\multicolumn{2}{|c|}{$\frac{\text { Oct. } 5,1984}{{ }^{1} 1,350}$}} & \multirow{2}{*}{\multicolumn{2}{|c|}{$\frac{\text { Oct. } 8,1985}{595}$}} & \multirow{2}{*}{\multicolumn{2}{|c|}{$\begin{array}{c}\text { Oct. } 7,1986 \\
488\end{array}$}} & \multirow{2}{*}{\multicolumn{2}{|c|}{$\frac{\text { Oct. 9, } 1987}{170}$}} \\
\hline & & & & & & & & & & & & & & \\
\hline & Count & Percent & Count & Percent & Count & Percent & Count & Percent & Count & Percent & Count & Percent & Count & Percent \\
\hline \multicolumn{15}{|l|}{ Platyhelminthes (flatworms) } \\
\hline \multicolumn{15}{|l|}{ Turbellaria } \\
\hline \multicolumn{15}{|l|}{ Tricladida } \\
\hline Planariidae & 5 & $<1$ & - & & 5 & 1 & - & & 31 & 5 & 18 & 4 & 1 & $<1$ \\
\hline Nematoda (nematodes) & - & & - & & - & & - & & - & & - & & - & \\
\hline \multicolumn{15}{|l|}{ Nemertea (proboscis worms) } \\
\hline \multicolumn{15}{|l|}{ Enopla } \\
\hline \multicolumn{15}{|l|}{ Hoplonemertea } \\
\hline \multicolumn{15}{|l|}{ Tetrastemmatidae } \\
\hline Prostoma & - & & - & & - & & - & & 1 & $<1$ & - & & - & \\
\hline Mollusca (molluscs) & & & & & & & & & & & & & & \\
\hline Gastropoda & & & & & & & & & & & & & & \\
\hline Basommatophora & & & & & & & & & & & & & & \\
\hline Ancylidae & & & & & & & & & & & & & & \\
\hline Ferrissia & - & & - & & - & & - & & - & & - & & - & \\
\hline Physidae & & & & & & & & & & & & & & \\
\hline Physa & - & & 3 & $<1$ & 3 & $<1$ & - & & 1 & $<1$ & - & & 1 & $<1$ \\
\hline Planorbidae & & & & & & & & & & & & & & \\
\hline Gyraulus & - & & - & & - & & - & & - & & - & & - & \\
\hline Bivalvia & & & & & & & & & & & & & & \\
\hline Veneroida & & & & & & & & & & & & & & \\
\hline Sphaeriidae & - & & - & & - & & - & & - & & - & & - & \\
\hline Annelida (segmented worms) & & & & & & & & & & & & & & \\
\hline Oligochaeta & - & & - & & - & & - & & - & & - & & - & \\
\hline Lumbriculida & & & & & & & & & & & & & & \\
\hline Lumbriculidae & - & & - & & - & & - & & 1 & $<1$ & - & & - & \\
\hline Tubificida & & & & & & & & & & & & & & \\
\hline Naididae & 8 & 1 & 19 & 2 & - & & 3 & $<1$ & - & & 1 & $<1$ & - & \\
\hline Arthropoda (arthropods) & & & & & & & & & & & & & & \\
\hline Acariformes & & & & & & & & & & & & & & \\
\hline Hydrachnidia & - & & - & & - & & - & & 2 & $<1$ & 3 & $<1$ & - & \\
\hline Crustacea & & & & & & & & & & & & & & \\
\hline Cyclopoida & - & & - & & - & & - & & - & & - & & - & \\
\hline Insecta & & & & & & & & & & & & & & \\
\hline Ephemeroptera & & & & & & & & & & & & & & \\
\hline Baetidae & & & & & & & & & & & & & & \\
\hline Baetis & 3 & $<1$ & 3 & $<1$ & 5 & 1 & 32 & 2 & 11 & 2 & 5 & 1 & - & \\
\hline Pseudocloeon & - & & - & & - & & 11 & $<1$ & - & & 2 & $<1$ & - & \\
\hline Caenidae & & & & & & & & & & & & & & \\
\hline Caenis & - & & - & & - & & - & & - & & - & & - & \\
\hline Ephemerellidae & & & & & & & & & & & & & & \\
\hline Ephemerella & 75 & 10 & 260 & 24 & 80 & 15 & 360 & 26 & 42 & 7 & 27 & 5 & 9 & 5 \\
\hline Heptageniidae & & & & & & & & & & & & & & \\
\hline Epeorus & - & & - & & - & & - & & - & & - & & - & \\
\hline Stenonema & 13 & 2 & 99 & 9 & 48 & 9 & 61 & 4 & 17 & 3 & 27 & 5 & 11 & 6 \\
\hline Isonychiidae & & & & & & & & & & & & & & \\
\hline Isonychia & - & & - & & - & & 3 & $<1$ & - & & 1 & $<1$ & - & \\
\hline Leptohyphidae & & & & & & & & & & & & & & \\
\hline Tricorythodes & - & & 3 & $<1$ & - & & - & & - & & - & & 1 & $<1$ \\
\hline Leptophlebiidae & - & & - & & - & & - & & - & & - & & - & \\
\hline
\end{tabular}




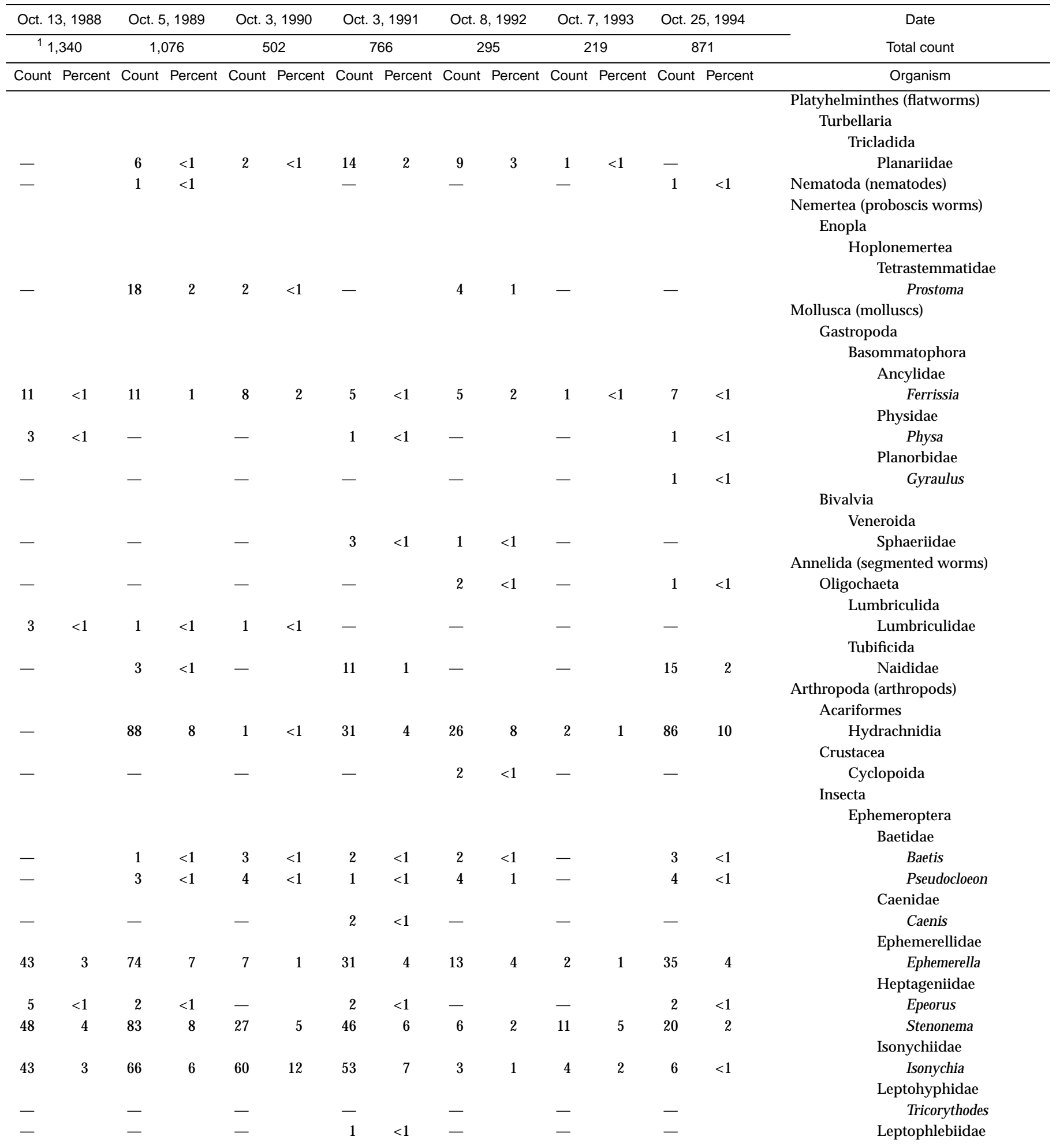


Table 5. Benthic-macroinvertebrate data-Continued

01472174 - Pickering Creek near Chester Springs, Pa. (Site 2)—Continued

\begin{tabular}{|c|c|c|c|c|c|c|c|c|c|c|c|c|c|c|}
\hline \multirow{3}{*}{$\begin{array}{c}\text { Date } \\
\text { Total count } \\
\text { Organism }\end{array}$} & \multirow{2}{*}{\multicolumn{2}{|c|}{$\begin{array}{c}\text { Oct. } 16,1981 \\
{ }^{1} 747\end{array}$}} & \multirow{2}{*}{\multicolumn{2}{|c|}{$\begin{array}{c}\text { Oct. } 18,1982 \\
11,084 \\
\end{array}$}} & \multirow{2}{*}{\multicolumn{2}{|c|}{$\begin{array}{c}\text { Oct. } 18,1983 \\
526\end{array}$}} & \multirow{2}{*}{\multicolumn{2}{|c|}{$\begin{array}{c}\text { Oct. } 5,1984 \\
11,350\end{array}$}} & \multirow{2}{*}{\multicolumn{2}{|c|}{$\begin{array}{c}\text { Oct. } 8,1985 \\
595\end{array}$}} & \multirow{2}{*}{\multicolumn{2}{|c|}{$\begin{array}{c}\text { Oct. } 7,1986 \\
488\end{array}$}} & \multirow{2}{*}{\multicolumn{2}{|c|}{$\begin{array}{c}\text { Oct. 9, } 1987 \\
170\end{array}$}} \\
\hline & & & & & & & & & & & & & & \\
\hline & Count & Percent & Count & Percent & Count & Percent & Count & Percent & Count & Percent & Count & Percent & Count & Percent \\
\hline \multicolumn{15}{|l|}{ Odonata } \\
\hline \multicolumn{15}{|l|}{ Calopterygidae } \\
\hline Calopteryx & - & & - & & - & & - & & - & & - & & - & \\
\hline Hetaerina & - & & - & & - & & - & & - & & - & & - & \\
\hline \multicolumn{15}{|l|}{ Coenagrionidae } \\
\hline Argia & - & & - & & - & & - & & - & & - & & - & \\
\hline \multicolumn{15}{|l|}{ Aeshnidae } \\
\hline Boyeria & - & & - & & - & & - & & 2 & $<1$ & - & & - & \\
\hline Gomphidae & - & & - & & - & & - & & - & & - & & - & \\
\hline Gomphus & - & & - & & - & & - & & - & & - & & - & \\
\hline \multicolumn{15}{|l|}{ Plecoptera } \\
\hline \multicolumn{15}{|l|}{ Capniidae } \\
\hline Allocapnia & 8 & 1 & 3 & $<1$ & 40 & 8 & 5 & $<1$ & 6 & 1 & 5 & 1 & - & \\
\hline Chloroperlidae & - & & - & & - & & - & & 1 & $<1$ & - & & - & \\
\hline Haploperla & - & & - & & 5 & 1 & - & & - & & - & & - & \\
\hline Perlidae & & & & & & & & & & & & & & \\
\hline Acroneuria & - & & - & & - & & - & & - & & 4 & $<1$ & - & \\
\hline Agnetina & - & & - & & - & & 3 & $<1$ & - & & - & & - & \\
\hline Paragnetina & - & & - & & - & & - & & - & & - & & - & \\
\hline Taeniopterygidae & & & & & & & & & & & & & & \\
\hline Strophopteryx & - & & - & & - & & - & & - & & - & & - & \\
\hline Taeniopteryx & 40 & 5 & 5 & $<1$ & 24 & 5 & 37 & 3 & 36 & 6 & 97 & 19 & 83 & 46 \\
\hline Hemiptera & & & & & & & & & & & & & & \\
\hline Corixidae & - & & 3 & $<1$ & - & & - & & - & & - & & - & \\
\hline Veliidae & & & & & & & & & & & & & & \\
\hline Rhagovelia & - & & - & & - & & - & & - & & - & & - & \\
\hline Megaloptera & & & & & & & & & & & & & & \\
\hline Corydalidae & & & & & & & & & & & & & & \\
\hline Nigronia & - & & - & & - & & - & & 1 & $<1$ & - & & - & \\
\hline Sialidae & & & & & & & & & & & & & & \\
\hline Sialis & - & & - & & - & & - & & - & & - & & - & \\
\hline Trichoptera & & & & & & & & & & & & & & \\
\hline Apataniidae & - & & - & & - & & - & & - & & - & & 1 & $<1$ \\
\hline Apatania & - & & - & & - & & - & & - & & - & & - & \\
\hline Brachycentridae & & & & & & & & & & & & & & \\
\hline Micrasema & - & & - & & 5 & 1 & 3 & $<1$ & - & & - & & - & \\
\hline Glossosomatidae & & & & & & & & & & & & & & \\
\hline Glossosoma & 3 & $<1$ & 5 & $<1$ & 3 & $<1$ & 27 & 2 & 12 & 2 & 11 & 2 & 2 & 1 \\
\hline Protoptila & - & & - & & 3 & $<1$ & - & & - & & - & & - & \\
\hline Goeridae & & & & & & & & & & & & & & \\
\hline Goera & 3 & $<1$ & - & & - & & - & & - & & - & & - & \\
\hline Hydropsychidae & & & & & & & & & & & & & & \\
\hline Ceratopsyche & 5 & $<1$ & 11 & 1 & 51 & 10 & 210 & 15 & 88 & 15 & 45 & 9 & 25 & 14 \\
\hline Cheumatopsyche & 29 & 4 & 48 & 4 & 48 & 9 & 200 & 14 & 230 & 38 & 30 & 6 & 13 & 7 \\
\hline Diplectrona & - & & - & & - & & - & & - & & 1 & $<1$ & - & \\
\hline Hydropsyche & - & & 5 & $<1$ & 16 & 3 & 99 & 7 & 20 & 3 & 4 & $<1$ & 3 & 2 \\
\hline Potamyia & - & & - & & - & & - & & - & & - & & 2 & 1 \\
\hline Hydroptilidae & & & & & & & & & & & & & & \\
\hline Hydroptila & 8 & 1 & 11 & 1 & - & & - & & - & & 1 & $<1$ & - & \\
\hline Leucotrichia & - & & - & & 35 & 7 & - & & - & & 1 & $<1$ & 2 & 1 \\
\hline Lepidostomatidae & & & & & & & & & & & & & & \\
\hline Lepidostoma & - & & - & & - & & - & & - & & - & & - & \\
\hline
\end{tabular}




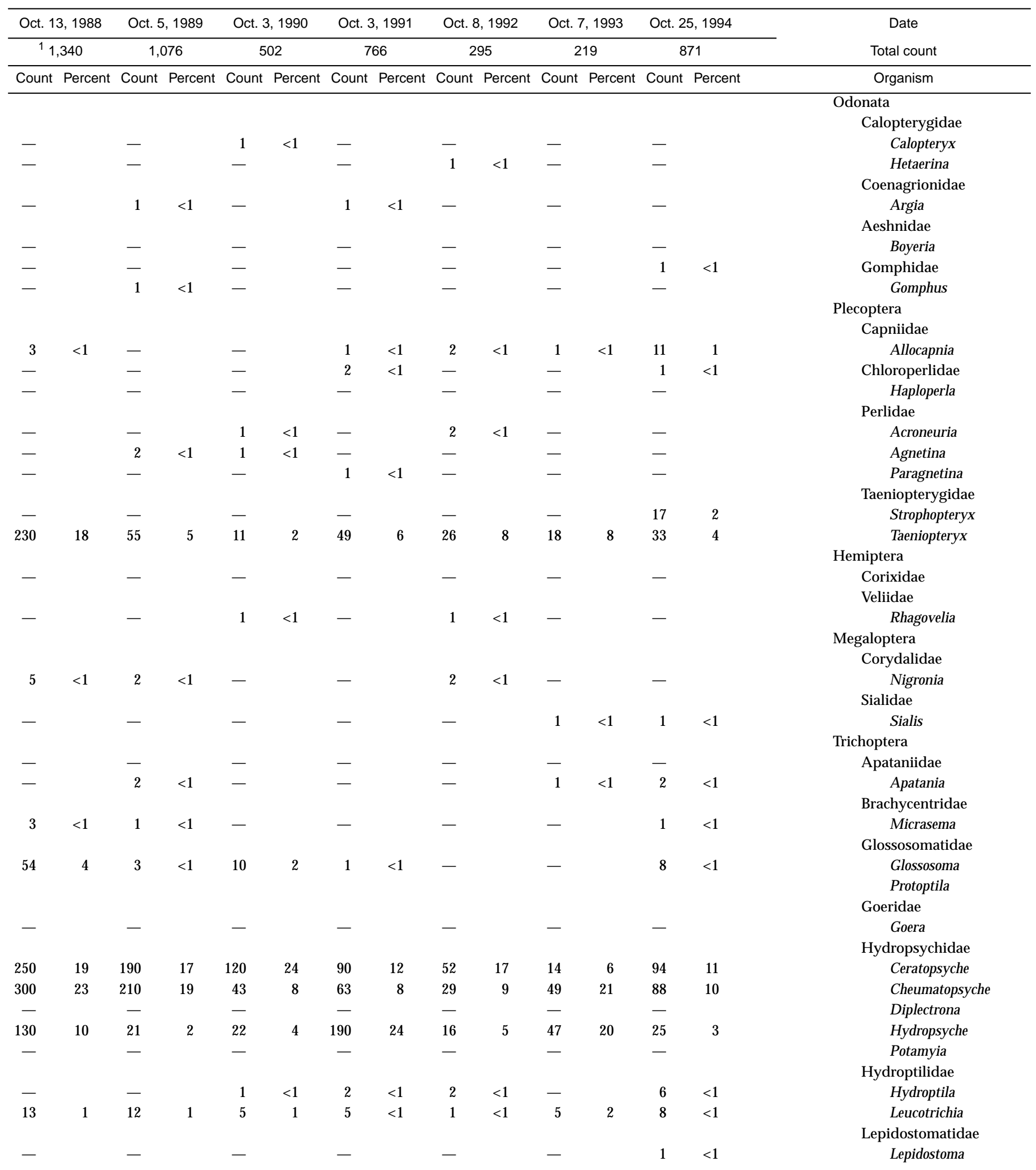


Table 5. Benthic-macroinvertebrate data-Continued

01472174 - Pickering Creek near Chester Springs, Pa. (Site 2)—Continued

\begin{tabular}{|c|c|c|c|c|c|c|c|c|c|c|c|c|c|c|}
\hline \multirow{3}{*}{$\begin{array}{c}\text { Date } \\
\text { Total count } \\
\text { Organism }\end{array}$} & \multirow{2}{*}{\multicolumn{2}{|c|}{$\begin{array}{c}\text { Oct. } 16,1981 \\
{ }^{1} 747\end{array}$}} & \multirow{2}{*}{\multicolumn{2}{|c|}{$\begin{array}{c}\text { Oct. } 18,1982 \\
11,084\end{array}$}} & \multirow{2}{*}{\multicolumn{2}{|c|}{$\begin{array}{c}\text { Oct. } 18,1983 \\
526\end{array}$}} & \multirow{2}{*}{\multicolumn{2}{|c|}{$\begin{array}{c}\text { Oct. } 5,1984 \\
11,350\end{array}$}} & \multirow{2}{*}{\multicolumn{2}{|c|}{$\begin{array}{c}\text { Oct. } 8,1985 \\
595\end{array}$}} & \multirow{2}{*}{\multicolumn{2}{|c|}{$\begin{array}{c}\text { Oct. } 7,1986 \\
488\end{array}$}} & \multirow{2}{*}{\multicolumn{2}{|c|}{$\frac{\text { Oct. 9, } 1987}{170}$}} \\
\hline & & & & & & & & & & & & & & \\
\hline & Count & Percent & Count & Percent & Count & Percent & Count & Percent & Count & Percent & Count & Percent & Count & Percent \\
\hline \multicolumn{15}{|l|}{ Trichoptera } \\
\hline \multicolumn{15}{|l|}{ Leptoceridae } \\
\hline Mystacides & 3 & $<1$ & - & & - & & - & & - & & 1 & $<1$ & - & \\
\hline Oecetis & - & & 3 & $<1$ & - & & 3 & $<1$ & - & & - & & - & \\
\hline \multicolumn{15}{|l|}{ Philopotamidae } \\
\hline Chimarra & - & & - & & 27 & 5 & 80 & 6 & 25 & 4 & 18 & 4 & - & \\
\hline Dolophilodes & - & & - & & - & & - & & - & & - & & - & \\
\hline Wormaldia & - & & - & & - & & - & & - & & - & & - & \\
\hline \multicolumn{15}{|l|}{ Polycentropodidae } \\
\hline Nyctiophylax & - & & - & & - & & - & & & & - & & 1 & $<1$ \\
\hline Polycentropus & - & & 8 & $<1$ & 5 & 1 & 5 & $<1$ & - & & 1 & $<1$ & - & \\
\hline \multicolumn{15}{|l|}{ Psychomyiidae } \\
\hline Psychomyia & 53 & 7 & 180 & 16 & 8 & 2 & - & & - & & 1 & $<1$ & 1 & $<1$ \\
\hline \multicolumn{15}{|l|}{ Coleoptera } \\
\hline Curculionidae & - & & - & & - & & - & & - & & - & & - & \\
\hline \multicolumn{15}{|l|}{ Dryopidae } \\
\hline Helichus & - & & - & & - & & - & & 2 & $<1$ & 1 & $<1$ & - & \\
\hline \multicolumn{15}{|l|}{ Elmidae } \\
\hline Dubiraphia & 3 & $<1$ & 5 & $<1$ & - & & - & & - & & & & & \\
\hline Optioservus & 19 & 3 & 32 & 3 & 40 & 8 & 35 & 3 & 19 & 3 & 6 & 1 & 1 & $<1$ \\
\hline Oulimnius & - & & 3 & $<1$ & 5 & 1 & - & & 1 & $<1$ & 1 & $<1$ & - & \\
\hline Promoresia & - & & - & & - & & - & & 1 & $<1$ & & & & \\
\hline Stenelmis & - & & 8 & $<1$ & - & & 8 & $<1$ & 6 & 1 & 5 & 1 & - & \\
\hline \multicolumn{15}{|l|}{ Psephenidae } \\
\hline Psephenus & 3 & $<1$ & 3 & $<1$ & - & & - & & - & & - & & - & \\
\hline \multicolumn{15}{|l|}{ Diptera } \\
\hline \multicolumn{15}{|l|}{ Athericidae } \\
\hline Atherix & - & & - & & - & & - & & 1 & $<1$ & - & & - & \\
\hline Blephariceridae & - & & - & & - & & - & & - & & - & & - & \\
\hline Chironomidae & 420 & 56 & 260 & 24 & 48 & 9 & 160 & 11 & 13 & 2 & 120 & 24 & 12 & 7 \\
\hline \multicolumn{15}{|l|}{ Dixidae } \\
\hline Dixa & - & & - & & - & & - & & - & & - & & - & \\
\hline Empididae & & & & & & & & & & & & & & \\
\hline Hemerodromia & - & & 8 & $<1$ & 3 & $<1$ & 5 & $<1$ & 4 & $<1$ & 1 & $<1$ & - & \\
\hline Simuliidae & & & & & & & & & & & & & & \\
\hline Simulium & - & & 3 & $<1$ & - & & - & & 17 & 3 & 30 & 6 & - & \\
\hline Tipulidae & & & & & & & & & & & & & & \\
\hline Antocha & 43 & 6 & 93 & 8 & 16 & 3 & - & & 4 & $<1$ & 20 & 4 & 1 & $<1$ \\
\hline Hexatoma & 3 & $<1$ & - & & 3 & $<1$ & - & & - & & - & & - & \\
\hline Tipula & - & & 一 & & - & & - & & - & & - & & - & \\
\hline
\end{tabular}

${ }^{1}$ Extrapolated from a 3/8 subsample. 


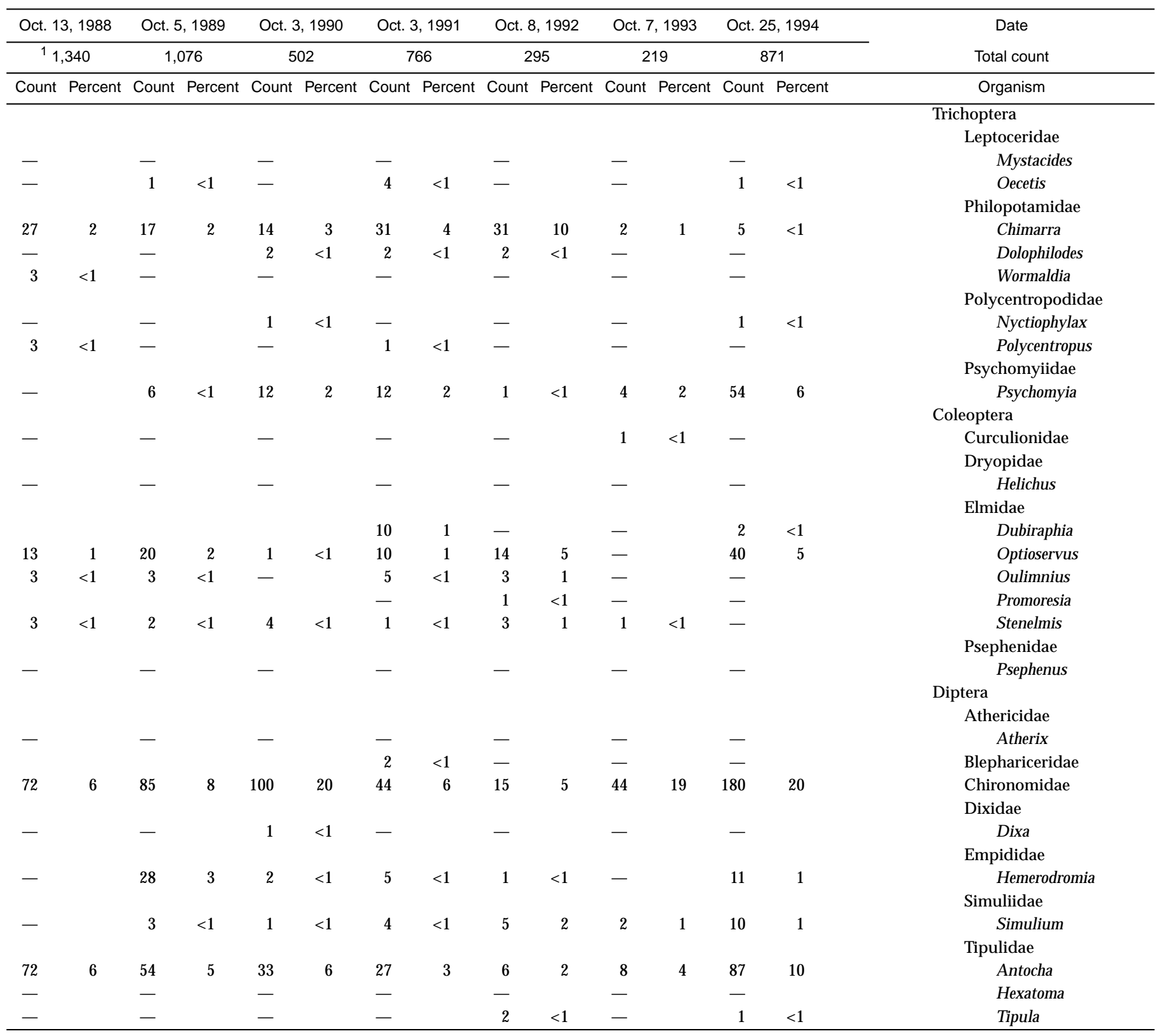


Table 5. Benthic-macroinvertebrate data-Continued

$[<$, less than; - , not found]

014721854 - Pickering Creek at Merlin, Pa. (Site 3)

\begin{tabular}{|c|c|c|c|c|c|c|c|c|c|c|c|c|c|c|}
\hline \multirow{3}{*}{$\begin{array}{cc}\text { Date } \\
\text { Total count } \\
\text { Organism }\end{array}$} & \multirow{2}{*}{\multicolumn{2}{|c|}{$\begin{array}{c}\text { Oct. } 15,1981 \\
{ }^{1} 1,757\end{array}$}} & \multirow{2}{*}{\multicolumn{2}{|c|}{$\frac{\text { Oct. } 18,1982}{2,123}$}} & \multirow{2}{*}{\multicolumn{2}{|c|}{$\begin{array}{c}\text { Oct. } 17,1983 \\
{ }^{1} 935\end{array}$}} & \multirow{2}{*}{\multicolumn{2}{|c|}{$\frac{\text { Oct. } 5,1984}{{ }^{1} 2,005}$}} & \multirow{2}{*}{\multicolumn{2}{|c|}{$\frac{\text { Oct. } 7,1985}{912}$}} & \multirow{2}{*}{\multicolumn{2}{|c|}{$\begin{array}{c}\text { Oct. } 8,1986 \\
1,049\end{array}$}} & \multirow{2}{*}{\multicolumn{2}{|c|}{$\frac{\text { Oct. } 8,1987}{1,396}$}} \\
\hline & & & & & & & & & & & & & & \\
\hline & Count & Percent & Count & Percent & Count & Percent & Count & Percent & Count & Percent & Count & Percent & Count & Percent \\
\hline \multicolumn{15}{|l|}{ Platyhelminthes (flatworms) } \\
\hline \multicolumn{15}{|l|}{ Turbellaria } \\
\hline \multicolumn{15}{|l|}{ Tricladida } \\
\hline Planariidae & - & & - & & 8 & $<1$ & - & & 5 & $<1$ & 4 & $<1$ & - & \\
\hline Nematoda (nematodes) & - & & - & & - & & - & & - & & 3 & $<1$ & - & \\
\hline \multicolumn{15}{|l|}{ Nemertea (proboscis worms) } \\
\hline \multicolumn{15}{|l|}{ Enopla } \\
\hline \multicolumn{15}{|l|}{ Hoplonemertea } \\
\hline \multicolumn{15}{|l|}{ Tetrastemmatidae } \\
\hline Prostoma & - & & - & & - & & - & & 1 & $<1$ & - & & - & \\
\hline \multicolumn{15}{|l|}{ Mollusca (molluscs) } \\
\hline Gastropoda & & & & & & & & & & & & & & \\
\hline Basommatophora & & & & & & & & & & & & & & \\
\hline Ancylidae & & & & & & & & & & & & & & \\
\hline Ferrissia & - & & - & & - & & 16 & 1 & 10 & 1 & 2 & $<1$ & 79 & 6 \\
\hline Lymnaeidae & & & & & & & & & & & & & & \\
\hline Lymnaea & - & & - & & - & & - & & 1 & $<1$ & - & & - & \\
\hline Annelida (segmented worms) & & & & & & & & & & & & & & \\
\hline Oligochaeta & & & & & & & & & & & & & & \\
\hline Lumbriculida & & & & & & & & & & & & & & \\
\hline Lumbriculidae & 3 & $<1$ & - & & - & & - & & 1 & $<1$ & - & & - & \\
\hline Tubificida & & & & & & & & & & & & & & \\
\hline Naididae & - & & 3 & $<1$ & - & & 29 & 2 & 8 & $<1$ & 11 & 1 & 250 & 18 \\
\hline Arthropoda (arthropods) & & & & & & & & & & & & & & \\
\hline Acariformes & & & & & & & & & & & & & & \\
\hline Hydrachnidia & - & & - & & - & & - & & 4 & $<1$ & 10 & $<1$ & - & \\
\hline Crustacea & & & & & & & & & & & & & & \\
\hline Cyclopoida & - & & - & & - & & - & & - & & - & & - & \\
\hline Insecta & & & & & & & & & & & & & & \\
\hline Ephemeroptera & & & & & & & & & & & & & & \\
\hline Baetidae & & & & & & & & & & & & & & \\
\hline Baetis & 8 & $<1$ & 8 & $<1$ & - & & 21 & 2 & 3 & $<1$ & 4 & $<1$ & 4 & $<1$ \\
\hline Pseudocloeon & - & & - & & - & & 8 & $<1$ & - & & - & & - & \\
\hline Caenidae & & & & & & & & & & & & & & \\
\hline Caenis & - & & - & & - & & - & & - & & - & & - & \\
\hline Ephemerellidae & & & & & & & & & & & & & & \\
\hline Ephemerella & 72 & 4 & 110 & 5 & 80 & 9 & 64 & 5 & 34 & 4 & 81 & 7 & 23 & 2 \\
\hline Heptageniidae & & & & & & & & & & & & & & \\
\hline Stenacron & - & & - & & - & & - & & 1 & $<1$ & - & & - & \\
\hline Stenonema & 88 & 5 & 99 & 5 & 32 & 3 & 59 & 4 & 82 & 9 & 31 & 3 & 41 & 3 \\
\hline Isonychiidae & & & & & & & & & & & & & & \\
\hline Isonychia & 11 & $<1$ & 35 & 2 & - & & 13 & $<1$ & 22 & 2 & 8 & $<1$ & 19 & 1 \\
\hline Leptohyphidae & & & & & & & & & & & & & & \\
\hline Tricorythodes & - & & 5 & $<1$ & 3 & $<1$ & 5 & $<1$ & - & & 3 & $<1$ & 2 & $<1$ \\
\hline Odonata & & & & & & & & & & & & & & \\
\hline Coenagrionidae & & & & & & & & & & & & & & \\
\hline Argia & - & & - & & - & & - & & - & & - & & 2 & $<1$ \\
\hline Gomphidae & - & & - & & - & & - & & 1 & $<1$ & 1 & $<1$ & 1 & $<1$ \\
\hline Gomphus & - & & - & & - & & - & & - & & - & & - & \\
\hline
\end{tabular}




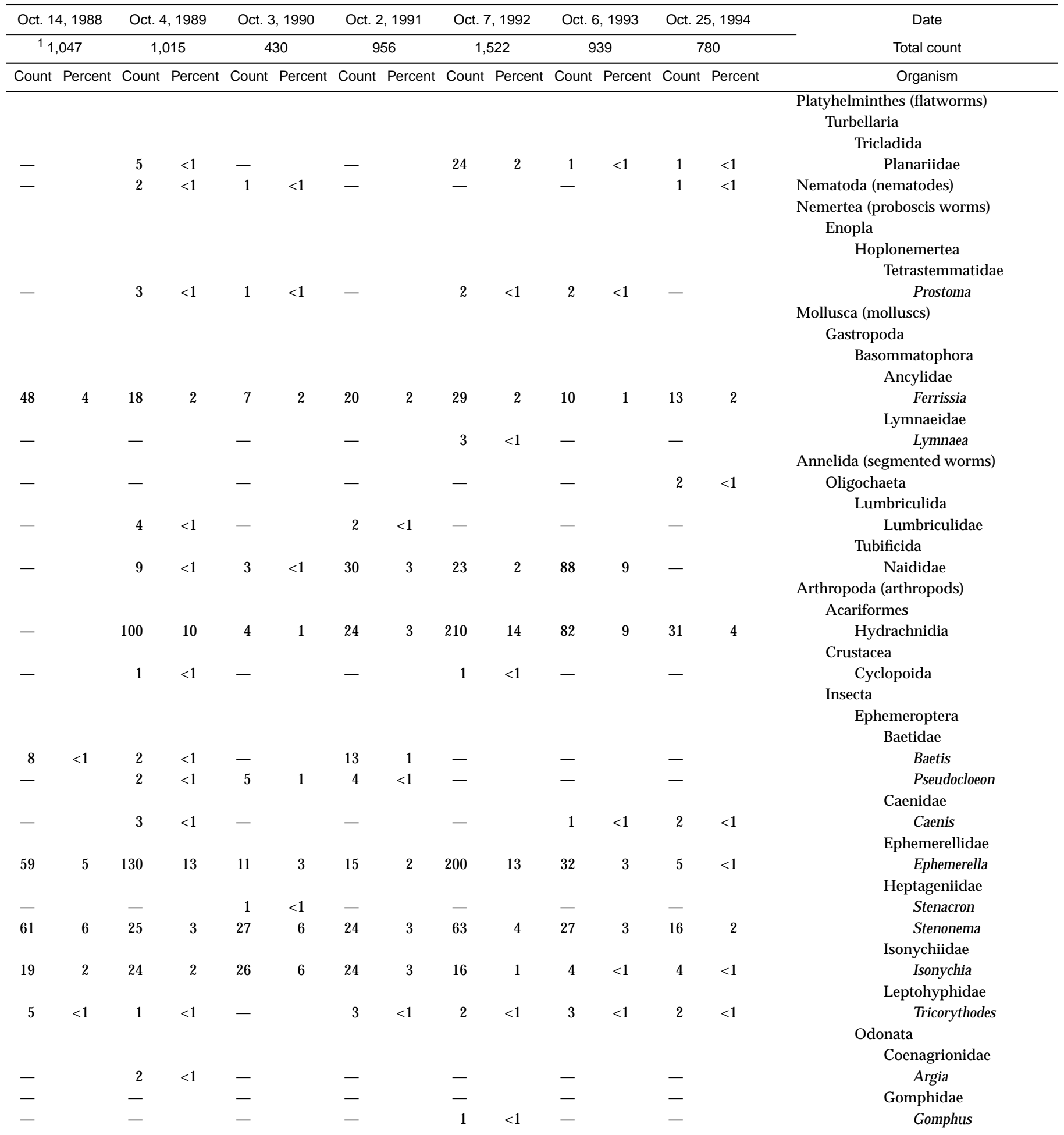


Table 5. Benthic-macroinvertebrate data-Continued

014721854 - Pickering Creek at Merlin, Pa. (Site 3)—Continued

\begin{tabular}{|c|c|c|c|c|c|c|c|c|c|c|c|c|c|c|}
\hline \multirow{3}{*}{$\begin{array}{c}\text { Date } \\
\text { Total count } \\
\text { Organism }\end{array}$} & \multirow{2}{*}{\multicolumn{2}{|c|}{$\begin{array}{c}\text { Oct. } 15,1981 \\
11,757\end{array}$}} & \multirow{2}{*}{\multicolumn{2}{|c|}{$\begin{array}{c}\text { Oct. } 18,1982 \\
2,123\end{array}$}} & \multirow{2}{*}{\multicolumn{2}{|c|}{$\begin{array}{c}\text { Oct. } 17,1983 \\
{ }^{1} 935\end{array}$}} & \multirow{2}{*}{\multicolumn{2}{|c|}{$\begin{array}{c}\text { Oct. 5, } 1984 \\
{ }^{1} 2,005\end{array}$}} & \multirow{2}{*}{\multicolumn{2}{|c|}{$\begin{array}{c}\text { Oct. } 7,1985 \\
912\end{array}$}} & \multirow{2}{*}{\multicolumn{2}{|c|}{$\begin{array}{c}\text { Oct. } 8,1986 \\
1,049\end{array}$}} & \multirow{2}{*}{\multicolumn{2}{|c|}{$\begin{array}{c}\text { Oct. } 8,1987 \\
1,396\end{array}$}} \\
\hline & & & & & & & & & & & & & & \\
\hline & Count & Percent & Count & Percent & Count & Percent & Count & Percent & Count & Percent & Count & Percent & Count & Percent \\
\hline \multicolumn{15}{|l|}{ Plecoptera } \\
\hline \multicolumn{15}{|l|}{ Capniidae } \\
\hline Allocapnia & 3 & $<1$ & - & & 3 & $<1$ & - & & - & & - & & - & \\
\hline Chloroperlidae & - & & - & & - & & - & & - & & - & & - & \\
\hline \multicolumn{15}{|l|}{ Perlidae } \\
\hline Acroneuria & - & & 5 & $<1$ & - & & - & & 1 & $<1$ & 2 & $<1$ & 1 & $<1$ \\
\hline Agnetina & - & & - & & - & & - & & - & & - & & - & \\
\hline Paragnetina & - & & - & & - & & - & & - & & - & & 1 & $<1$ \\
\hline \multicolumn{15}{|l|}{ Taeniopterygidae } \\
\hline Taeniopteryx & 69 & 4 & 43 & 2 & 29 & 3 & 13 & $<1$ & 14 & 2 & 38 & 3 & 38 & 3 \\
\hline \multicolumn{15}{|l|}{ Hemiptera } \\
\hline Corixidae & & & & & & & & & & & & & & \\
\hline Sigara & - & & - & & - & & - & & - & & 1 & $<1$ & - & \\
\hline Gerridae & & & & & & & & & & & & & & \\
\hline Metrobates & - & & - & & - & & - & & - & & - & & - & \\
\hline Veliidae & & & & & & & & & & & & & & \\
\hline Rhagovelia & - & & - & & - & & - & & - & & 1 & $<1$ & - & \\
\hline Megaloptera & & & & & & & & & & & & & & \\
\hline Corydalidae & & & & & & & & & & & & & & \\
\hline Corydalus & - & & - & & - & & - & & - & & - & & - & \\
\hline Nigronia & 3 & $<1$ & - & & 5 & $<1$ & - & & - & & 1 & $<1$ & 3 & $<1$ \\
\hline Sialidae & & & & & & & & & & & & & & \\
\hline Sialis & 5 & $<1$ & - & & - & & - & & - & & - & & - & \\
\hline Trichoptera & & & & & & & & & & & & & & \\
\hline Apataniidae & & & & & & & & & & & & & & \\
\hline Apatania & - & & - & & - & & - & & - & & 17 & 2 & 5 & $<1$ \\
\hline Brachycentridae & & & & & & & & & & & & & & \\
\hline Brachycentrus & & & & & & & & & & & & & & \\
\hline Micrasema & 27 & 2 & 8 & $<1$ & 69 & 7 & 16 & 1 & 13 & 1 & 2 & $<1$ & 7 & $<1$ \\
\hline Glossosomatidae & & & & & & & & & & & & & & \\
\hline Glossosoma & 3 & $<1$ & 59 & 3 & 3 & $<1$ & 16 & 1 & 2 & $<1$ & - & & 3 & $<1$ \\
\hline Protoptila & - & & - & & - & & 11 & $<1$ & - & & - & & - & \\
\hline Goeridae & & & & & & & & & & & & & & \\
\hline Goera & - & & - & & - & & 3 & $<1$ & 69 & 8 & - & & - & \\
\hline Hydropsychidae & & & & & & & & & & & & & & \\
\hline Ceratopsyche & 350 & 19 & 300 & 14 & 130 & 14 & 120 & 9 & 79 & 9 & 24 & 2 & 210 & 15 \\
\hline Cheumatopsyche & 110 & 6 & 93 & 4 & 77 & 8 & 120 & 9 & 300 & 33 & 18 & 2 & 43 & 3 \\
\hline Hydropsyche & 43 & 2 & 43 & 2 & 27 & 3 & 13 & $<1$ & 6 & $<1$ & 2 & $<1$ & 27 & 2 \\
\hline Macrostemum & - & & - & & 3 & $<1$ & - & & - & & - & & 2 & $<1$ \\
\hline Hydroptilidae & & & & & & & & & & & & & & \\
\hline Hydroptila & 21 & 1 & 56 & 3 & 29 & 3 & - & & 17 & 2 & 10 & $<1$ & 22 & 2 \\
\hline Leucotrichia & 13 & $<1$ & 480 & 23 & 140 & 15 & 370 & 26 & 36 & 4 & 85 & 8 & 46 & 3 \\
\hline Leptoceridae & & & & & & & & & & & & & & \\
\hline Mystacides & 11 & $<1$ & 11 & $<1$ & - & & - & & 7 & $<1$ & 4 & $<1$ & 4 & $<1$ \\
\hline Oecetis & - & & - & & 8 & $<1$ & 3 & $<1$ & 2 & $<1$ & 2 & $<1$ & 2 & $<1$ \\
\hline Philopotamidae & & & & & & & & & & & & & & \\
\hline Chimarra & - & & 5 & $<1$ & - & & - & & 1 & $<1$ & 2 & $<1$ & - & \\
\hline Dolophilodes & - & & - & & - & & - & & - & & - & & - & \\
\hline Polycentropodidae & & & & & & & & & & & & & & \\
\hline Neureclipsis & 13 & $<1$ & - & & 8 & $<1$ & - & & 9 & 1 & - & & 6 & $<1$ \\
\hline Nyctiophylax & 5 & $<1$ & 8 & $<1$ & 16 & 2 & 13 & $<1$ & 16 & 2 & 1 & $<1$ & 2 & $<1$ \\
\hline Polycentropus & - & & 5 & $<1$ & 61 & 6 & - & & - & & 1 & $<1$ & 1 & $<1$ \\
\hline Psychomyiidae & & & & & & & & & & & & & & \\
\hline Psychomyia & 5 & $<1$ & 3 & $<1$ & - & & 8 & $<1$ & 7 & $<1$ & - & & 15 & 1 \\
\hline
\end{tabular}




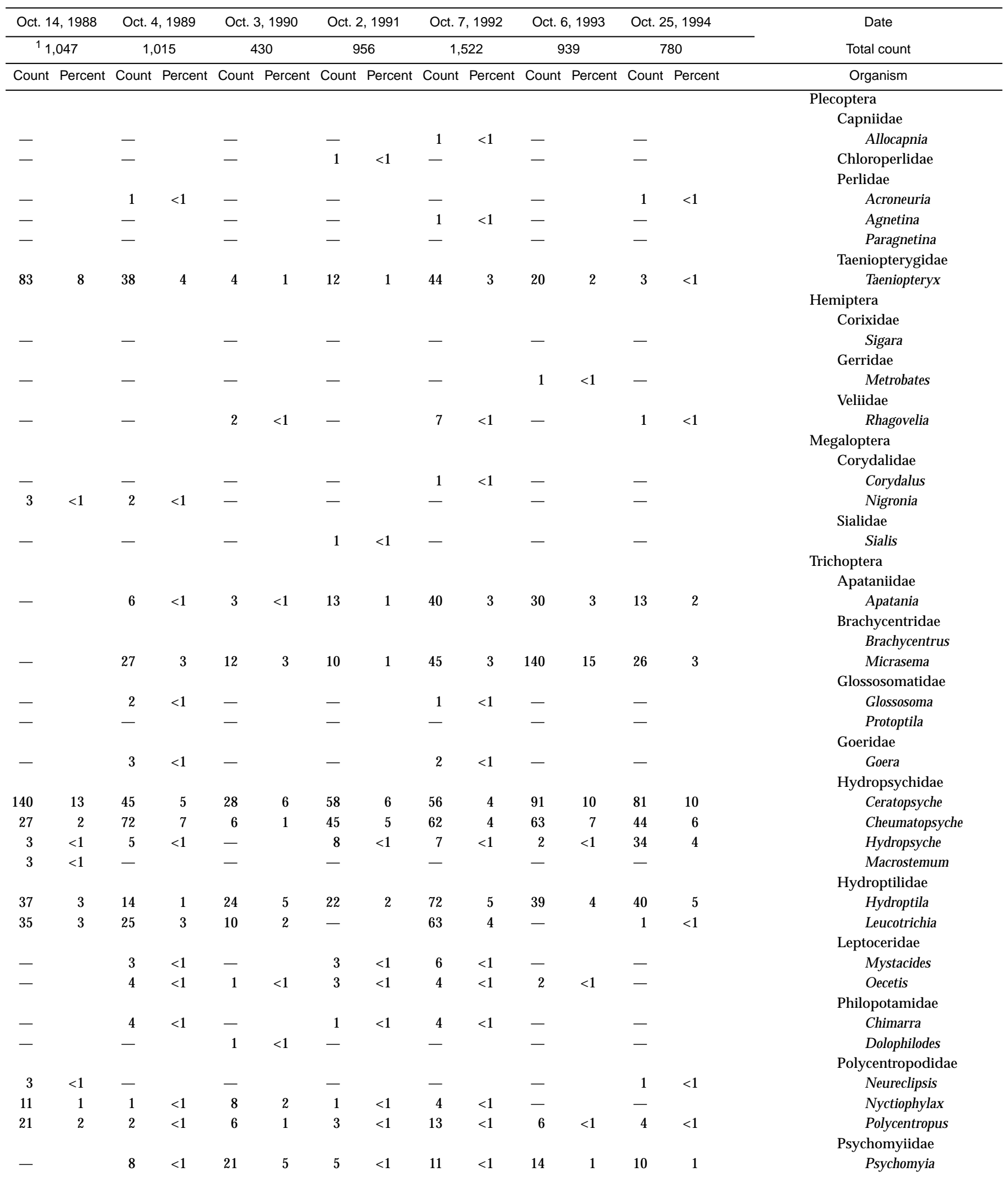


Table 5. Benthic-macroinvertebrate data-Continued

014721854 - Pickering Creek at Merlin, Pa. (Site 3)—Continued

\begin{tabular}{|c|c|c|c|c|c|c|c|c|c|c|c|c|c|c|}
\hline \multirow{3}{*}{$\begin{array}{c}\text { Date } \\
\text { Total count } \\
\text { Organism }\end{array}$} & \multirow{2}{*}{\multicolumn{2}{|c|}{$\begin{array}{c}\text { Oct. } 15,1981 \\
11,757\end{array}$}} & \multirow{2}{*}{\multicolumn{2}{|c|}{$\begin{array}{c}\text { Oct. } 18,1982 \\
2,123\end{array}$}} & \multirow{2}{*}{\multicolumn{2}{|c|}{$\begin{array}{c}\text { Oct. } 17,1983 \\
{ }^{1} 935\end{array}$}} & \multirow{2}{*}{\multicolumn{2}{|c|}{$\begin{array}{c}\text { Oct. 5, } 1984 \\
{ }^{1} 2,005\end{array}$}} & \multirow{2}{*}{\multicolumn{2}{|c|}{$\begin{array}{c}\text { Oct. 7, } 1985 \\
912\end{array}$}} & \multirow{2}{*}{\multicolumn{2}{|c|}{$\begin{array}{c}\text { Oct. } 8,1986 \\
1,049\end{array}$}} & \multirow{2}{*}{\multicolumn{2}{|c|}{$\begin{array}{c}\text { Oct. } 8,1987 \\
1,396\end{array}$}} \\
\hline & & & & & & & & & & & & & & \\
\hline & Count & Percent & Count & Percent & Count & Percent & Count & Percent & Count & Percent & Count & Percent & Count & Percent \\
\hline \multicolumn{15}{|l|}{ Lepidoptera } \\
\hline \multicolumn{15}{|l|}{ Pyralidae } \\
\hline Petrophila & - & & - & & - & & - & & 2 & $<1$ & - & & 3 & $<1$ \\
\hline \multicolumn{15}{|l|}{ Coleoptera } \\
\hline \multicolumn{14}{|l|}{ Elmidae } & \\
\hline Ancyronyx & - & & - & & - & & - & & - & & - & & - & \\
\hline A.variegata & - & & - & & - & & - & & - & & - & & - & \\
\hline \multicolumn{15}{|l|}{ Macronychus } \\
\hline M. glabratus & - & & - & & - & & - & & - & & - & & 1 & $<1$ \\
\hline Optioserous & 8 & $<1$ & 16 & $<1$ & 3 & $<1$ & 3 & $<1$ & 17 & 2 & 19 & 2 & 9 & $<1$ \\
\hline Oulimnius & 3 & $<1$ & 5 & $<1$ & - & - & - & & 1 & $<1$ & 1 & $<1$ & - & \\
\hline Promoresia & - & & - & & 3 & $<1$ & 3 & $<1$ & 10 & 1 & - & & - & \\
\hline Stenelmis & - & & 5 & $<1$ & 8 & $<1$ & - & & 6 & $<1$ & - & & 14 & 1 \\
\hline \multicolumn{15}{|l|}{ Psephenidae } \\
\hline Psephenus & - & & 3 & $<1$ & - & & - & & - & & - & & 1 & $<1$ \\
\hline Hymenoptera & - & & - & & - & & - & & 1 & $<1$ & - & & - & \\
\hline \multicolumn{15}{|l|}{ Diptera } \\
\hline \multicolumn{15}{|l|}{ Athericidae } \\
\hline Atherix & - & & 3 & $<1$ & - & & - & & - & & - & & - & \\
\hline \multicolumn{15}{|l|}{ Empididae } \\
\hline $\begin{array}{l}\text { Hemerodromia } \\
\text { Simuliidae }\end{array}$ & 5 & $<1$ & 3 & $<1$ & - & & - & & - & & 1 & $<1$ & 2 & $<1$ \\
\hline Simulium & 24 & 1 & 21 & 1 & - & & - & & - & & 1 & $<1$ & 1 & $<1$ \\
\hline Syrphidae & - & & - & & - & & - & & - & & 1 & $<1$ & - & \\
\hline \multicolumn{15}{|l|}{ Tipulidae } \\
\hline Antocha & 16 & $<1$ & 45 & 2 & 16 & 2 & 48 & 3 & 51 & 6 & 88 & 8 & 93 & 7 \\
\hline Tipula & - & & - & & - & & - & & 1 & $<1$ & - & & - & \\
\hline
\end{tabular}

${ }^{1}$ Extrapolated from a 3/8 subsample. 


\begin{tabular}{|c|c|c|c|c|c|c|c|c|c|c|c|c|c|c|}
\hline \multirow{2}{*}{\multicolumn{2}{|c|}{$\frac{\text { Oct. } 14,1988}{{ }^{1} 1,047}$}} & \multicolumn{2}{|c|}{ Oct. 4, 1989} & \multicolumn{2}{|c|}{ Oct. 3, 1990} & \multicolumn{2}{|c|}{ Oct. 2, 1991} & \multicolumn{2}{|c|}{ Oct. 7, 1992} & \multicolumn{2}{|c|}{ Oct. 6, 1993} & \multicolumn{2}{|c|}{ Oct. 25, 1994} & \multirow{3}{*}{$\begin{array}{c}\text { Date } \\
\text { Total count }\end{array}$} \\
\hline & & \multicolumn{2}{|c|}{1,015} & \multicolumn{2}{|c|}{430} & \multicolumn{2}{|c|}{956} & \multicolumn{2}{|c|}{1,522} & \multicolumn{2}{|c|}{939} & \multicolumn{2}{|c|}{780} & \\
\hline Count & Percent & Count & Percent & Count & Percent & Count & Percent & Count & Percent & Count & Percent & Count & Percent & \\
\hline & & & & & & & & & & & & & & Pyralidae \\
\hline \multirow[t]{2}{*}{11} & 1 & 12 & 1 & 9 & 2 & 2 & $<1$ & 10 & $<1$ & 15 & 2 & 7 & $<1$ & Petrophila \\
\hline & & & & & & & & & & & & & & Coleoptera \\
\hline 3 & $<1$ & - & & - & & - & & - & & - & & - & & Ancyronyx \\
\hline- & & - & & - & & - & & - & & - & & 3 & $<1$ & A.variegata \\
\hline \multirow[t]{2}{*}{ - } & & 3 & $<1$ & - & & 18 & 2 & 25 & 2 & 16 & 2 & - & & Dubiraphia \\
\hline & & & & & & & & & & & & & & Macronychus \\
\hline - & & - & & - & & - & & - & & - & & - & & M. glabratus \\
\hline 6 & $<1$ & 26 & 3 & 9 & 2 & 9 & $<1$ & 32 & 2 & 7 & $<1$ & 3 & $<1$ & Optioservus \\
\hline - & & 1 & $<1$ & - & & - & & 1 & $<1$ & - & & - & & Psephenus \\
\hline \multirow[t]{3}{*}{-} & & - & & - & & - & & - & & - & & - & & Hymenoptera \\
\hline & & & & & & & & & & & & & & Diptera \\
\hline & & & & & & & & & & & & & & Athericidae \\
\hline - & & - & & 1 & $<1$ & - & & - & & - & & - & & Atherix \\
\hline \multirow[t]{2}{*}{310} & 28 & 280 & 28 & 96 & 22 & 500 & 52 & 290 & 19 & 190 & 20 & 340 & 43 & Chironomidae \\
\hline & & & & & & & & & & & & & & Empididae \\
\hline \multirow[t]{2}{*}{3} & $<1$ & 47 & 5 & - & & - & & 6 & $<1$ & 5 & $<1$ & 3 & $<1$ & Hemerodromia \\
\hline & & & & & & & & & & & & & & Simuliidae \\
\hline - & & 7 & $<1$ & - & & 42 & 4 & 1 & $<1$ & - & & - & & Simulium \\
\hline \multirow{2}{*}{ - } & & - & & - & & - & & - & & - & & - & & Syrphidae \\
\hline & & & & & & & & & & & & & & Tipulidae \\
\hline
\end{tabular}


Table 5. Benthic-macroinvertebrate data-Continued

$[<$, less than; - , not found]

014721884 - Pickering Creek at Charlestown Road Bridge at Charlestown, Pa. (Site 4)

\begin{tabular}{|c|c|c|c|c|c|c|c|c|c|c|c|c|c|c|}
\hline \multirow{3}{*}{$\begin{array}{c}\text { Date } \\
\text { Total count } \\
\text { Organism }\end{array}$} & \multirow{2}{*}{\multicolumn{2}{|c|}{$\begin{array}{c}\text { Oct. } 15,1981 \\
3,611\end{array}$}} & \multirow{2}{*}{\multicolumn{2}{|c|}{$\begin{array}{c}\text { Oct. } 19,1982 \\
1,887\end{array}$}} & \multirow{2}{*}{\multicolumn{2}{|c|}{$\begin{array}{c}\text { Oct. } 17,1983 \\
{ }^{1} 1,316\end{array}$}} & \multirow{2}{*}{\multicolumn{2}{|c|}{$\begin{array}{c}\text { Oct. 9, } 1984 \\
1,943\end{array}$}} & \multirow{2}{*}{\multicolumn{2}{|c|}{$\frac{\text { Oct. } 7,1985}{557}$}} & \multirow{2}{*}{\multicolumn{2}{|c|}{$\begin{array}{c}\text { Oct. 6, } 1986 \\
2,593\end{array}$}} & \multirow{2}{*}{\multicolumn{2}{|c|}{$\begin{array}{c}\text { Oct. } 8,1987 \\
2,312\end{array}$}} \\
\hline & & & & & & & & & & & & & & \\
\hline & Count & Percent & Count & Percent & Count & Percent & Count & Percent & Count & Percent & Count & Percent & Count & Percent \\
\hline \multicolumn{15}{|l|}{ Platyhelminthes (flatworms) } \\
\hline \multicolumn{15}{|l|}{ Turbellaria } \\
\hline \multicolumn{15}{|l|}{ Tricladida } \\
\hline Planariidae & 16 & $<1$ & 3 & $<1$ & 16 & 1 & 3 & $<1$ & 15 & 3 & 13 & $<1$ & 86 & 4 \\
\hline Nematoda (nematodes) & - & & - & & - & & - & & - & & - & & - & \\
\hline \multicolumn{15}{|l|}{ Nemertea (proboscis worms) } \\
\hline \multicolumn{15}{|l|}{ Enopla } \\
\hline Hoplonemertea & & & & & & & & & & & & & & \\
\hline Tetrastemmatidae & & & & & & & & & & & & & & \\
\hline Prostoma & - & & - & & - & & - & & - & & 3 & $<1$ & - & \\
\hline Mollusca (molluscs) & & & & & & & & & & & & & & \\
\hline Gastropoda & & & & & & & & & & & & & & \\
\hline Mesogastropoda & & & & & & & & & & & & & & \\
\hline Hydrobiidae & & & & & & & & & & & & & & \\
\hline Amnicola & - & & - & & - & & - & & - & & 1 & $<1$ & 4 & $<1$ \\
\hline Basommatophora & & & & & & & & & & & & & & \\
\hline Ancylidae & & & & & & & & & & & & & & \\
\hline Ferrissia & 8 & $<1$ & - & & - & & - & & - & & 10 & $<1$ & 17 & $<1$ \\
\hline Planorbidae & & & & & & & & & & & & & & \\
\hline Gyraulus & - & & - & & - & & - & & - & & - & & - & \\
\hline Helisoma & - & & - & & - & & - & & 2 & $<1$ & 1 & $<1$ & - & \\
\hline Bivalvia & & & & & & & & & & & & & & \\
\hline Veneroida & & & & & & & & & & & & & & \\
\hline Sphaeriidae & - & & - & & - & & - & & - & & - & & - & \\
\hline Annelida (segmented worms) & & & & & & & & & & & & & & \\
\hline Oligochaeta & - & & - & & - & & - & & 1 & $<1$ & - & & - & \\
\hline Lumbriculida & & & & & & & & & & & & & & \\
\hline Lumbriculidae & - & & - & & - & & - & & - & & - & & - & \\
\hline Tubificida & & & & & & & & & & & & & & \\
\hline Naididae & 2 & $<1$ & - & & - & & 3 & $<1$ & - & & - & & - & \\
\hline Arthropoda (arthropods) & & & & & & & & & & & & & & \\
\hline Acariformes & & & & & & & & & & & & & & \\
\hline Hydrachnidia & - & & - & & 3 & $<1$ & 3 & $<1$ & 2 & $<1$ & 9 & $<1$ & - & \\
\hline Crustacea & & & & & & & & & & & & & & \\
\hline Cyclopoida & - & & - & & - & & - & & - & & - & & - & \\
\hline Amphipoda & & & & & & & & & & & & & & \\
\hline Crangonyctidae & & & & & & & & & & & & & & \\
\hline Crangonyx & - & & - & & - & & - & & - & & - & & - & \\
\hline Insecta & & & & & & & & & & & & & & \\
\hline Ephemeroptera & & & & & & & & & & & & & & \\
\hline Baetidae & & & & & & & & & & & & & & \\
\hline Baetis & 130 & 4 & 13 & $<1$ & 13 & 1 & 53 & 3 & 4 & $<1$ & 43 & 2 & 76 & 3 \\
\hline Pseudocloeon & 6 & $<1$ & - & & - & & 21 & 1 & 2 & $<1$ & 14 & $<1$ & 84 & 4 \\
\hline Caenidae & & & & & & & & & & & & & & \\
\hline Caenis & - & & - & & - & & - & & - & & - & & 10 & $<1$ \\
\hline Ephemerellidae & & & & & & & & & & & & & & \\
\hline Ephemerella & 83 & 2 & 24 & 1 & 59 & 5 & 110 & 6 & 29 & 5 & 180 & 7 & 390 & 17 \\
\hline Heptageniidae & & & & & & & & & & & & & & \\
\hline Epeorus & - & & - & & - & & 3 & $<1$ & - & & - & & - & \\
\hline Stenonema & 32 & $<1$ & 64 & 3 & 100 & 8 & 51 & 3 & 27 & 5 & 45 & 2 & 20 & $<1$ \\
\hline Isonychiidae & & & & & & & & & & & & & & \\
\hline Isonychia & 64 & 2 & 21 & 1 & 16 & 1 & - & & 32 & 6 & 25 & $<1$ & 43 & 2 \\
\hline Leptohyphidae & & & & & & & & & & & & & & \\
\hline Tricorythodes & - & & 3 & $<1$ & - & & - & & - & & - & & 2 & $<1$ \\
\hline
\end{tabular}




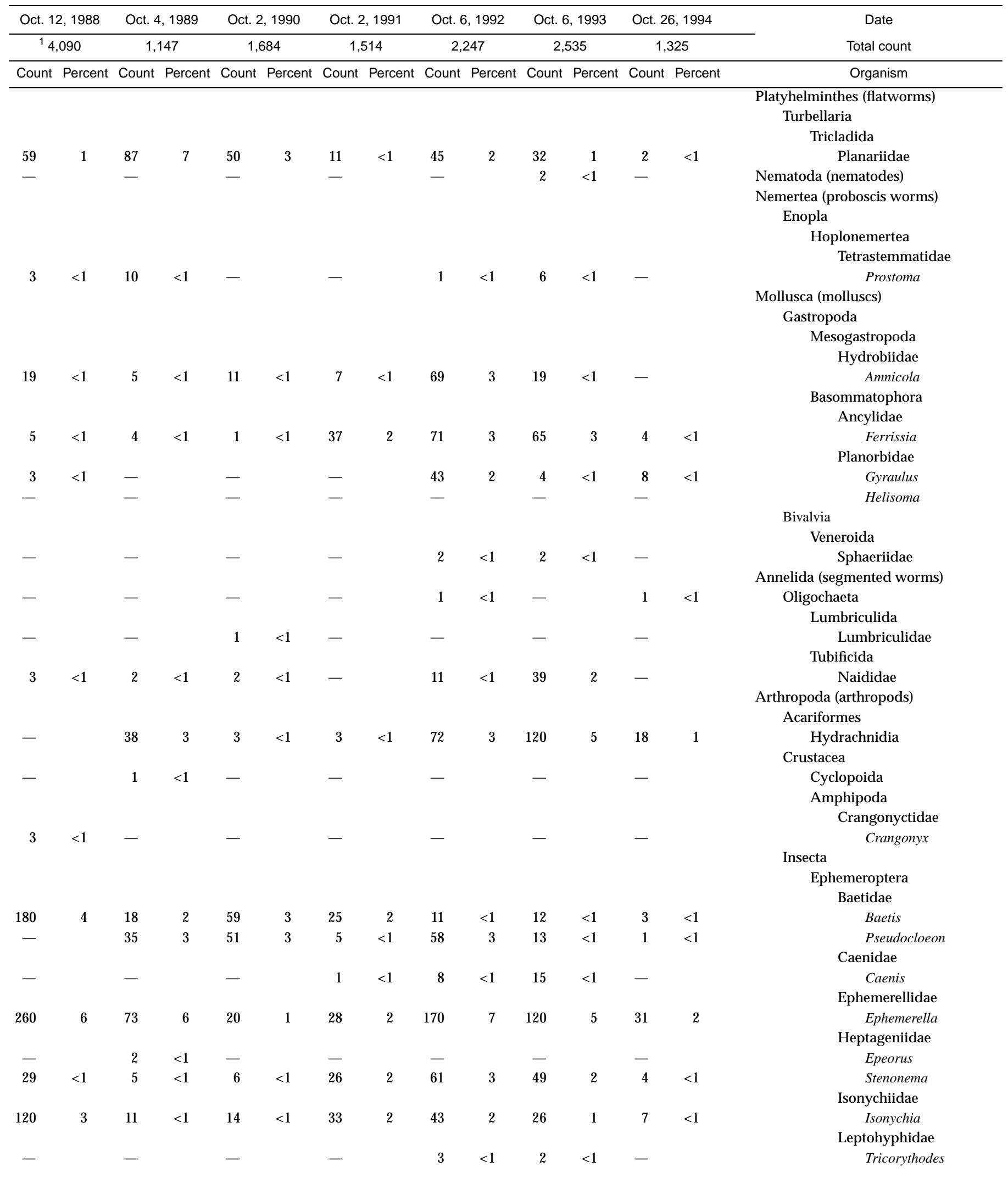


Table 5. Benthic-macroinvertebrate data-Continued

014721884 - Pickering Creek at Charlestown Road Bridge at Charlestown, Pa. (Site 4)—Continued

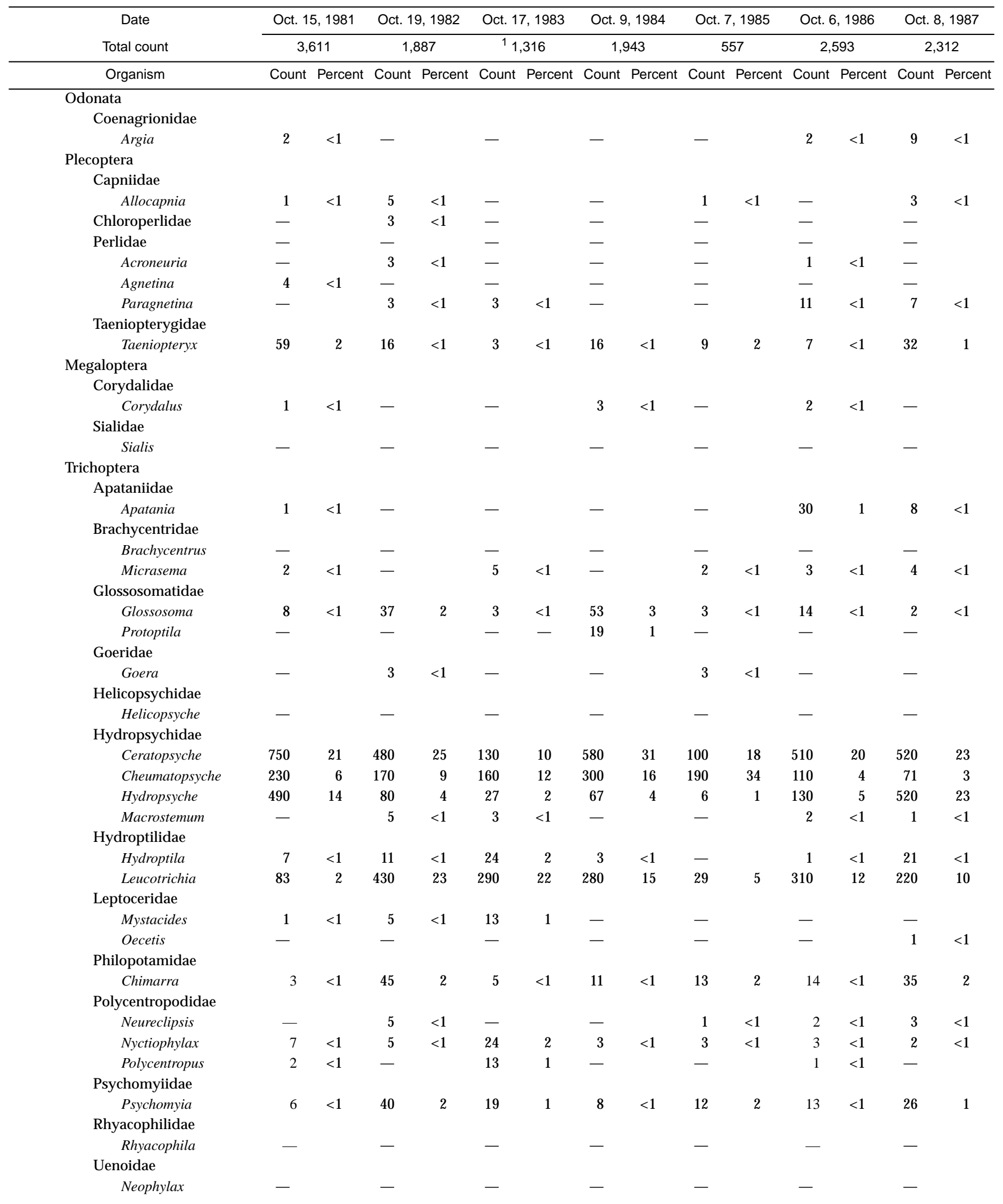




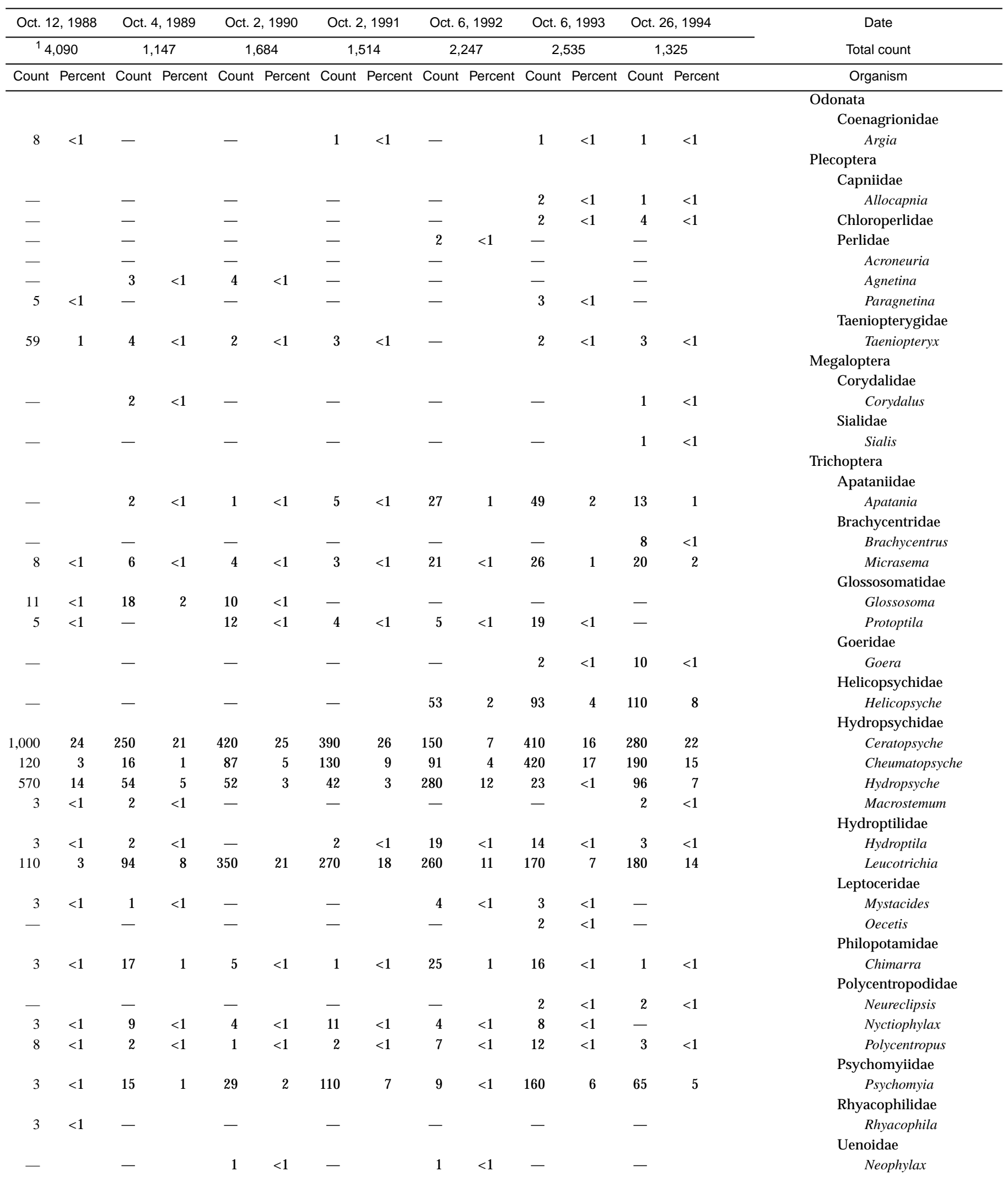


Table 5. Benthic-macroinvertebrate data-Continued

014721884 - Pickering Creek at Charlestown Road Bridge at Charlestown, Pa. (Site 4)-Continued

\begin{tabular}{|c|c|c|c|c|c|c|c|c|c|c|c|c|c|c|}
\hline \multirow{3}{*}{$\begin{array}{c}\text { Date } \\
\text { Total count } \\
\text { Organism }\end{array}$} & \multirow{2}{*}{\multicolumn{2}{|c|}{$\begin{array}{c}\text { Oct. } 15,1981 \\
3,611\end{array}$}} & \multirow{2}{*}{\multicolumn{2}{|c|}{$\begin{array}{c}\text { Oct. } 19,1982 \\
1,887\end{array}$}} & \multirow{2}{*}{\multicolumn{2}{|c|}{$\begin{array}{c}\text { Oct. } 17,1983 \\
1_{1,316}\end{array}$}} & \multirow{2}{*}{\multicolumn{2}{|c|}{$\begin{array}{c}\text { Oct. } 9,1984 \\
1,943\end{array}$}} & \multirow{2}{*}{\multicolumn{2}{|c|}{$\begin{array}{c}\text { Oct. } 7,1985 \\
557\end{array}$}} & \multirow{2}{*}{\multicolumn{2}{|c|}{$\begin{array}{c}\text { Oct. } 6,1986 \\
2,593\end{array}$}} & \multirow{2}{*}{\multicolumn{2}{|c|}{$\begin{array}{c}\text { Oct. 8, } 1987 \\
2,312\end{array}$}} \\
\hline & & & & & & & & & & & & & & \\
\hline & Count & Percent & Count & Percent & Count & Percent & Count & Percent & Count & Percent & Count & Percent & Count & Percent \\
\hline \multicolumn{15}{|l|}{ Lepidoptera } \\
\hline \multicolumn{15}{|l|}{ Pyralidae } \\
\hline Petrophila & - & & - & & - & & - & & - & & - & & - & \\
\hline \multicolumn{15}{|l|}{ Coleoptera } \\
\hline \multicolumn{15}{|l|}{ Dryopidae } \\
\hline Helichus & - & & - & & - & & - & & - & & - & & 1 & $<1$ \\
\hline \multicolumn{15}{|l|}{ Elmidae } \\
\hline \multicolumn{15}{|l|}{ Ancyronyx } \\
\hline A.variegata & - & & - & & - & & - & & - & & - & & - & \\
\hline Dubiraphia & - & & - & & - & & - & & - & & 1 & $<1$ & - & \\
\hline Optioservus & - & & 3 & $<1$ & 16 & 1 & 11 & $<1$ & 5 & $<1$ & 12 & $<1$ & 8 & $<1$ \\
\hline Oulimnius & 2 & $<1$ & 3 & $<1$ & - & & - & & - & & - & & - & \\
\hline Promoresia & - & & - & & - & & - & & - & & 1 & $<1$ & 1 & $<1$ \\
\hline Stenelmis & 2 & $<1$ & 3 & $<1$ & - & & - & & - & & 3 & $<1$ & 10 & $<1$ \\
\hline \multicolumn{15}{|l|}{ Psephenidae } \\
\hline \multicolumn{15}{|l|}{ Ectopria } \\
\hline E. nervosa & - & & - & & - & & - & & - & & - & & - & \\
\hline Psephenus & - & & - & & 5 & $<1$ & 3 & $<1$ & - & & - & & 1 & $<1$ \\
\hline \multicolumn{15}{|l|}{ Diptera } \\
\hline Chironomidae & 1,500 & 42 & 300 & 16 & 280 & 22 & 280 & 15 & 31 & 6 & 1,000 & 38 & - & \\
\hline \multicolumn{15}{|l|}{ Empididae } \\
\hline Hemerodromia & 5 & $<1$ & 5 & $<1$ & 3 & $<1$ & 3 & $<1$ & 2 & $<1$ & 7 & $<1$ & 2 & $<1$ \\
\hline \multicolumn{15}{|l|}{ Simuliidae } \\
\hline Simulium & 63 & 2 & 27 & 1 & 8 & $<1$ & 24 & 1 & 15 & 3 & 4 & $<1$ & 13 & $<1$ \\
\hline \multicolumn{15}{|l|}{ Tipulidae } \\
\hline Antocha & 41 & 1 & 72 & 4 & 75 & 6 & 32 & 2 & 18 & 3 & 55 & 2 & 59 & 3 \\
\hline
\end{tabular}

\footnotetext{
${ }^{1}$ Extrapolated from a 3/8 subsample.
} 


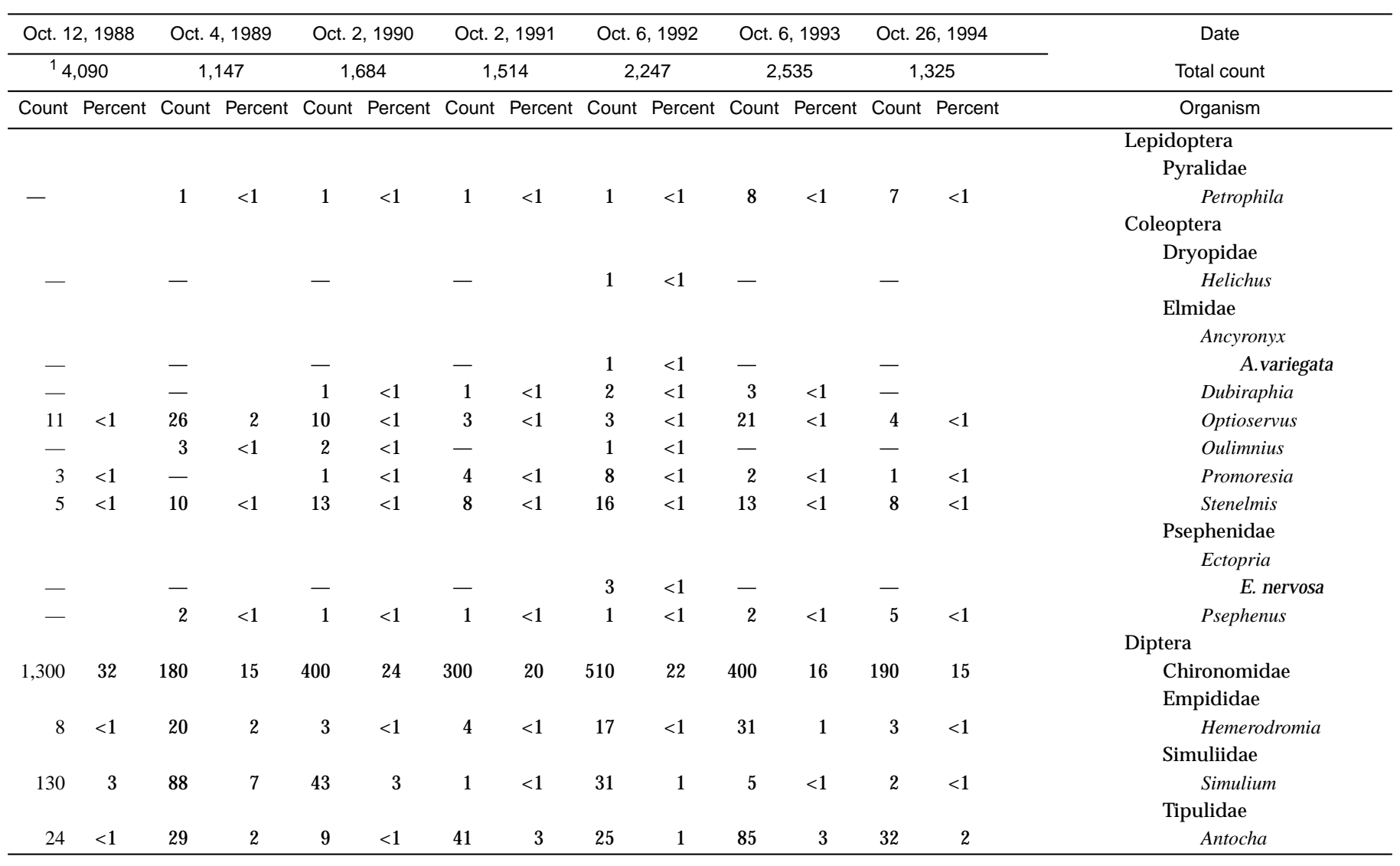


Table 5. Benthic-macroinvertebrate data-Continued

$[<$, less than; - , not found]

01472190 - Pickering Creek near Phoenixville, Pa. (Site 5)

\begin{tabular}{|c|c|c|c|c|c|c|c|c|c|c|c|c|c|c|}
\hline \multirow{3}{*}{$\begin{array}{c}\text { Date } \\
\text { Total count } \\
\text { Organism }\end{array}$} & \multirow{2}{*}{\multicolumn{2}{|c|}{$\frac{\text { Oct. } 15,1981}{2,081}$}} & \multirow{2}{*}{\multicolumn{2}{|c|}{$\frac{\text { Nov. 2, } 1982}{3,232}$}} & \multirow{2}{*}{\multicolumn{2}{|c|}{$\frac{\text { Oct. } 18,1983}{2,183}$}} & \multirow{2}{*}{\multicolumn{2}{|c|}{$\frac{\text { Oct. 22, } 1984}{1,513}$}} & \multirow{2}{*}{\multicolumn{2}{|c|}{$\frac{\text { Oct. } 8,1985}{438}$}} & \multirow{2}{*}{\multicolumn{2}{|c|}{$\begin{array}{c}\text { Oct. } 6,1986 \\
1,150\end{array}$}} & \multirow{2}{*}{\multicolumn{2}{|c|}{$\frac{\text { Oct. } 13,1987}{2,029}$}} \\
\hline & & & & & & & & & & & & & & \\
\hline & Count & Percent & Count & Percent & Count & Percent & Count & Percent & Count & Percent & Count & Percent & Count & Percent \\
\hline \multicolumn{15}{|l|}{ Platyhelminthes (flatworms) } \\
\hline \multicolumn{15}{|l|}{ Turbellaria } \\
\hline \multicolumn{15}{|l|}{ Tricladida } \\
\hline Planariidae & - & & - & & - & & - & & 1 & $<1$ & 11 & $<1$ & - & \\
\hline Nematoda (nematodes) & - & & 2 & $<1$ & 1 & $<1$ & - & & - & & 1 & $<1$ & - & \\
\hline \multicolumn{15}{|l|}{ Nemertea (proboscis worms) } \\
\hline \multicolumn{15}{|l|}{ Enopla } \\
\hline \multicolumn{15}{|l|}{ Hoplonemertea } \\
\hline Tetrastemmatidac & & & & & & & & & & & & & & \\
\hline Prostoma & - & & - & & 3 & $<1$ & - & & - & & - & & 1 & $<1$ \\
\hline Mollusca (molluscs) & & & & & & & & & & & & & & \\
\hline Gastropoda & & & & & & & & & & & & & & \\
\hline Mesogastropoda & & & & & & & & & & & & & & \\
\hline Hydrobiidae & & & & & & & & & & & & & & \\
\hline Amnicola & - & & - & & - & & - & & - & & - & & - & \\
\hline Basommatophora & & & & & & & & & & & & & & \\
\hline Ancylidae & & & & & & & & & & & & & & \\
\hline Ferrissia & 20 & $<1$ & 7 & $<1$ & 6 & $<1$ & - & & 9 & 2 & 17 & 1 & 150 & 8 \\
\hline Lymnaeidae & & & & & & & & & & & & & & \\
\hline Lymnaea & - & & 1 & $<1$ & - & & - & & - & & - & & - & \\
\hline Planorbidae & & & & & & & & & & & & & & \\
\hline Gyraulus & - & & - & & - & & - & & - & & - & & - & \\
\hline Helisoma & - & & - & & - & & - & & - & & 1 & $<1$ & - & \\
\hline Bivalvia & & & & & & & & & & & & & & \\
\hline Veneroida & & & & & & & & & & & & & & \\
\hline Sphaeriidae & - & & - & & - & & - & & - & & - & & - & \\
\hline Annelida (segmented worms) & & & & & & & & & & & & & & \\
\hline Oligochaeta & - & & - & & - & & - & & - & & - & & - & \\
\hline Lumbriculida & & & & & & & & & & & & & & \\
\hline Lumbriculidae & 1 & $<1$ & 1 & $<1$ & 3 & $<1$ & - & & - & & 1 & $<1$ & - & \\
\hline Tubificida & & & & & & & & & & & & & & \\
\hline Naididae & - & & 17 & $<1$ & 25 & 1 & - & & - & & 2 & $<1$ & - & \\
\hline Tubificidae & - & & - & & - & & - & & - & & 1 & $<1$ & - & \\
\hline Arthropoda (arthropods) & & & & & & & & & & & & & & \\
\hline Acariformes & & & & & & & & & & & & & & \\
\hline Hydrachnidia & - & & - & & - & & - & & 1 & $<1$ & 12 & 1 & 3 & $<1$ \\
\hline Crustacea & & & & & & & & & & & & & & \\
\hline Cyclopoida & - & & - & & - & & - & & - & & - & & 1 & $<1$ \\
\hline Amphipoda & 1 & $<1$ & - & & - & & - & & - & & - & & - & \\
\hline Isopoda & & & & & & & & & & & & & & \\
\hline Asellidae & & & & & & & & & & & & & & \\
\hline Caecidotea & - & & 1 & $<1$ & - & & - & & - & & - & & - & \\
\hline Decapoda & & & & & & & & & & & & & & \\
\hline Cambaridae & & & & & & & & & & & & & & \\
\hline Cambarus & - & & - & & - & & - & & - & & 1 & $<1$ & - & \\
\hline Insecta & & & & & & & & & & & & & & \\
\hline Ephemeroptera & & & & & & & & & & & & & & \\
\hline Baetidae & & & & & & & & & & & & & & \\
\hline Baetis & 5 & $<1$ & 1 & $<1$ & - & & 7 & $<1$ & - & & 13 & 1 & 19 & $<1$ \\
\hline Pseudocloeon & 7 & $<1$ & 6 & $<1$ & 8 & $<1$ & 2 & $<1$ & 1 & $<1$ & 10 & $<1$ & 18 & $<1$ \\
\hline Caenidae & & & & & & & & & & & & & & \\
\hline Caenis & 3 & $<1$ & - & & - & & 1 & $<1$ & - & & 2 & $<1$ & 5 & $<1$ \\
\hline
\end{tabular}




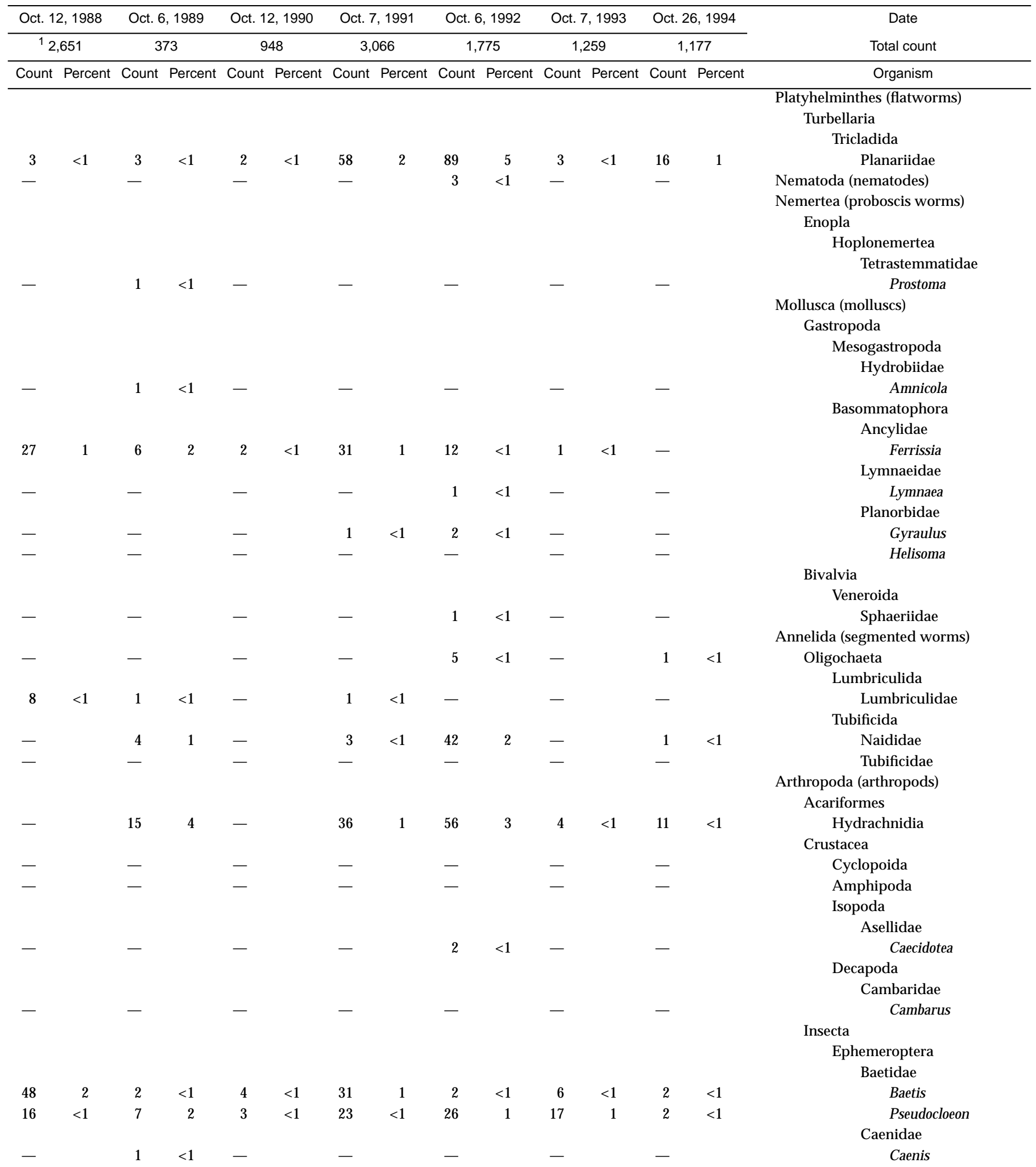


Table 5. Benthic-macroinvertebrate data-Continued

01472190 - Pickering Creek near Phoenixville, Pa. (Site 5)—Continued

\begin{tabular}{|c|c|c|c|c|c|c|c|c|c|c|c|c|c|c|}
\hline \multirow{3}{*}{$\begin{array}{c}\text { Date } \\
\text { Total count } \\
\text { Organism }\end{array}$} & \multirow{2}{*}{\multicolumn{2}{|c|}{$\begin{array}{c}\text { Oct. } 15,1981 \\
2,081\end{array}$}} & \multirow{2}{*}{\multicolumn{2}{|c|}{$\begin{array}{c}\text { Nov. 2, } 1982 \\
3,232\end{array}$}} & \multirow{2}{*}{\multicolumn{2}{|c|}{$\begin{array}{c}\text { Oct. } 18,1983 \\
2,183\end{array}$}} & \multirow{2}{*}{\multicolumn{2}{|c|}{$\begin{array}{c}\text { Oct. } 22,1984 \\
1,513\end{array}$}} & \multirow{2}{*}{\multicolumn{2}{|c|}{$\begin{array}{c}\text { Oct. } 8,1985 \\
438\end{array}$}} & \multirow{2}{*}{\multicolumn{2}{|c|}{$\begin{array}{c}\text { Oct. } 6,1986 \\
1,150\end{array}$}} & \multirow{2}{*}{\multicolumn{2}{|c|}{$\begin{array}{c}\text { Oct. } 13,1987 \\
2,029\end{array}$}} \\
\hline & & & & & & & & & & & & & & \\
\hline & Count & Percent & Count & Percent & Count & Percent & Count & Percent & Count & Percent & Count & Percent & Count & Percent \\
\hline \multicolumn{15}{|l|}{ Ephemeroptera } \\
\hline \multicolumn{15}{|l|}{ Ephemerellidae } \\
\hline Ephemerella & 120 & 6 & 220 & 7 & 200 & 9 & 200 & 13 & 45 & 10 & 64 & 5 & 63 & 3 \\
\hline \multicolumn{15}{|l|}{ Heptageniidae } \\
\hline Epeorus & - & & 3 & $<1$ & - & & 6 & $<1$ & - & & - & & - & \\
\hline Stenonema & 69 & 3 & 58 & 2 & 60 & 3 & 76 & 5 & 19 & 4 & 17 & 1 & 59 & 3 \\
\hline \multicolumn{15}{|l|}{ Isonychiidae } \\
\hline Isonychia & 14 & $<1$ & 3 & $<1$ & 11 & $<1$ & 5 & $<1$ & 4 & 1 & 14 & 1 & 58 & 3 \\
\hline \multicolumn{15}{|l|}{ Leptohyphidae } \\
\hline Tricorythodes & - & & - & & - & & - & & - & & - & & - & \\
\hline Odonata & & & & & & & & & & & & & & \\
\hline Coenagrionidae & & & & & & & & & & & & & & \\
\hline Argia & 4 & $<1$ & - & & 1 & $<1$ & 1 & $<1$ & - & & - & & 1 & $<1$ \\
\hline Plecoptera & & & & & & & & & & & & & & \\
\hline Capniidae & & & & & & & & & & & & & & \\
\hline Allocapnia & 3 & $<1$ & 10 & $<1$ & 11 & $<1$ & 25 & 2 & 1 & $<1$ & - & & 4 & $<1$ \\
\hline Chloroperlidae & - & & - & & 2 & $<1$ & 6 & $<1$ & 1 & $<1$ & - & & - & \\
\hline Nemouridae & - & & - & & - & & - & & - & & - & & - & \\
\hline Perlidae & & & & & & & & & & & & & & \\
\hline Acroneuria & 1 & $<1$ & - & & - & & - & & 2 & $<1$ & 4 & $<1$ & 2 & $<1$ \\
\hline Agnetina & - & & - & & - & & - & & - & & - & & - & \\
\hline Paragnetina & - & & 1 & $<1$ & - & & - & & - & & 1 & $<1$ & 4 & $<1$ \\
\hline Taeniopterygidae & & & & & & & & & & & & & & \\
\hline Taeniopteryx & 29 & 1 & 32 & 1 & 7 & $<1$ & 1 & $<1$ & 9 & 2 & 14 & 1 & 48 & 2 \\
\hline Hemiptera & & & & & & & & & & & & & & \\
\hline Veliidae & & & & & & & & & & & & & & \\
\hline Rhagovelia & - & & - & & 3 & $<1$ & - & & - & & - & & 1 & $<1$ \\
\hline Megaloptera & & & & & & & & & & & & & & \\
\hline Corydalidae & & & & & & & & & & & & & & \\
\hline Corydalus & - & & 2 & $<1$ & 2 & $<1$ & 1 & $<1$ & 1 & $<1$ & - & & 1 & $<1$ \\
\hline Trichoptera & & & & & & & & & & & & & & \\
\hline Apataniidae & & & & & & & & & & & & & & \\
\hline Apatania & 1 & $<1$ & - & & - & & - & & - & & 5 & $<1$ & - & \\
\hline Brachycentridae & & & & & & & & & & & & & & \\
\hline Micrasema & 8 & $<1$ & 29 & $<1$ & 190 & 9 & 4 & $<1$ & 3 & $<1$ & 42 & 3 & 12 & $<1$ \\
\hline Glossosomatidae & & & & & & & & & & & & & & \\
\hline Glossosoma & 3 & $<1$ & 52 & 2 & 8 & $<1$ & 100 & 7 & 1 & $<1$ & 8 & $<1$ & 12 & $<1$ \\
\hline Protoptila & 4 & $<1$ & 6 & $<1$ & 48 & 2 & 37 & 2 & - & & - & & - & \\
\hline Goeridae & & & & & & & & & & & & & & \\
\hline Goera & - & & 2 & $<1$ & 3 & $<1$ & - & & - & & - & & - & \\
\hline Helicopsychidae & & & & & & & & & & & & & & \\
\hline Helicopsyche & - & & - & & - & & - & & 1 & $<1$ & 1 & $<1$ & - & \\
\hline Hydropsychidae & & & & & & & & & & & & & & \\
\hline Ceratopsyche & 140 & 7 & 460 & 14 & 380 & 17 & 290 & 19 & 120 & 27 & 160 & 13 & 310 & 16 \\
\hline Cheumatopsyche & 130 & 6 & 87 & 3 & 160 & 7 & 93 & 6 & 53 & 12 & 14 & 1 & 40 & 2 \\
\hline Hydropsyche & 200 & 10 & 74 & 2 & 46 & 2 & 47 & 3 & - & & 11 & $<1$ & 31 & 2 \\
\hline Macrostemum & 5 & $<1$ & 1 & $<1$ & 4 & $<1$ & 3 & $<1$ & - & & - & & 5 & $<1$ \\
\hline Hydroptilidae & & & & & & & & & & & & & & \\
\hline Hydroptila & 8 & $<1$ & 13 & $<1$ & 6 & $<1$ & 1 & $<1$ & 1 & $<1$ & - & & 21 & 1 \\
\hline Leucotrichia & 210 & 10 & 950 & 30 & 520 & 24 & 260 & 17 & 72 & 16 & 84 & 7 & 430 & 22 \\
\hline Lepidostomatidae & & & & & & & & & & & & & & \\
\hline Lepidostoma & - & & - & & - & & - & & - & & - & & - & \\
\hline Leptoceridae & & & & & & & & & & & & & & \\
\hline Mystacides & - & & - & & 6 & $<1$ & - & & - & & - & & 1 & $<1$ \\
\hline Oecetis & - & & - & & - & & - & & - & & 1 & $<1$ & 1 & $<1$ \\
\hline
\end{tabular}




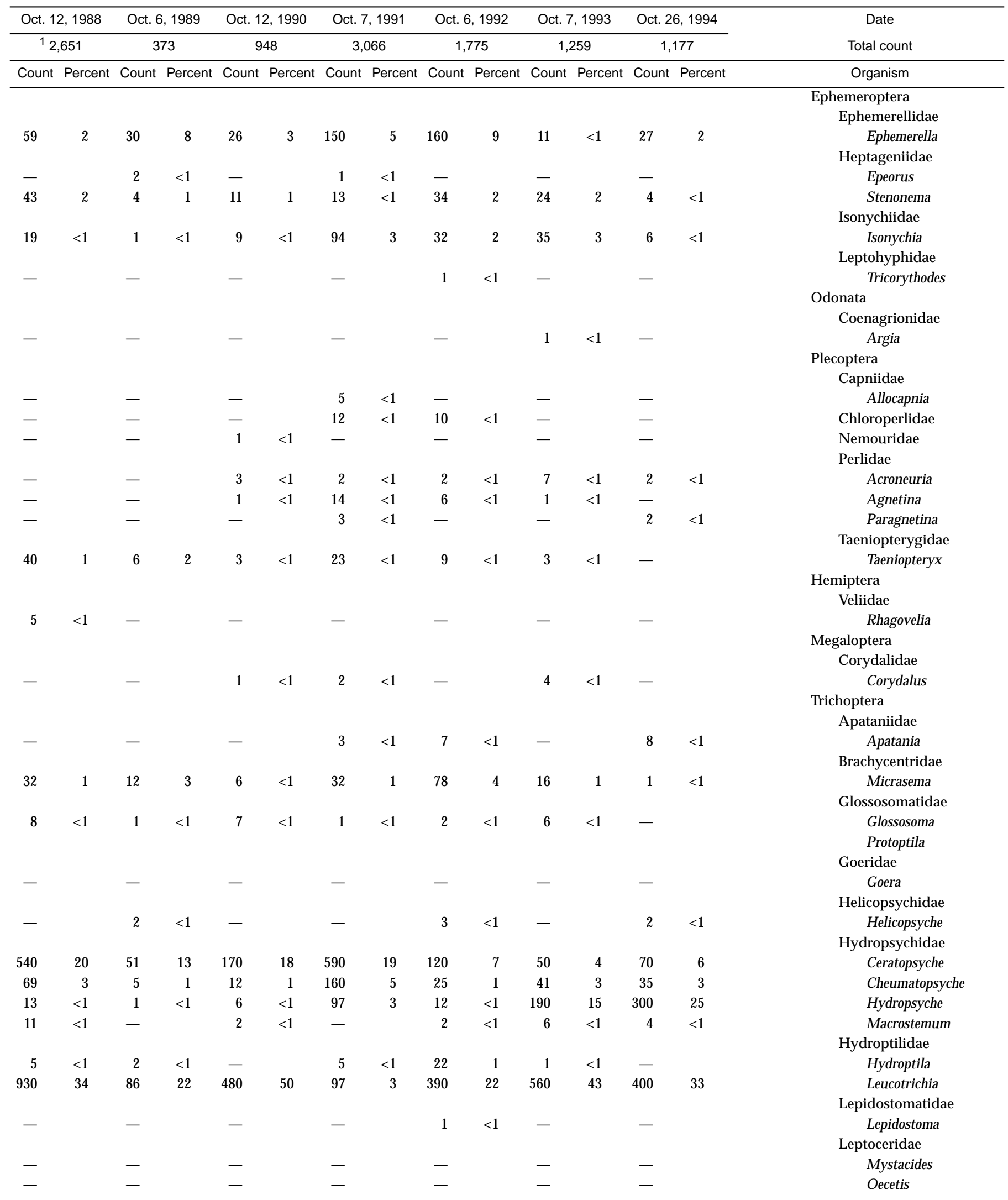


Table 5. Benthic-macroinvertebrate data-Continued

01472190 - Pickering Creek near Phoenixville, Pa. (Site 5)—Continued

\begin{tabular}{|c|c|c|c|c|c|c|c|c|c|c|c|c|c|c|}
\hline \multirow{3}{*}{$\begin{array}{c}\text { Date } \\
\text { Total count } \\
\text { Organism }\end{array}$} & \multirow{2}{*}{\multicolumn{2}{|c|}{$\begin{array}{c}\text { Oct. } 15,1981 \\
2,081\end{array}$}} & \multirow{2}{*}{\multicolumn{2}{|c|}{$\begin{array}{c}\text { Nov. 2, } 1982 \\
3,232\end{array}$}} & \multirow{2}{*}{\multicolumn{2}{|c|}{$\frac{\text { Oct. } 18,1983}{2,183}$}} & \multirow{2}{*}{\multicolumn{2}{|c|}{$\frac{\text { Oct. } 22,1984}{1,513}$}} & \multirow{2}{*}{\multicolumn{2}{|c|}{$\frac{\text { Oct. 8, } 1985}{438}$}} & \multirow{2}{*}{\multicolumn{2}{|c|}{$\begin{array}{c}\text { Oct. } 6,1986 \\
1,150\end{array}$}} & \multirow{2}{*}{\multicolumn{2}{|c|}{$\frac{\text { Oct. } 13,1987}{2,029}$}} \\
\hline & & & & & & & & & & & & & & \\
\hline & Count & Percent & Count & Percent & Count & Percent & Count & Percent & Count & Percent & Count & Percent & Count & Percent \\
\hline \multicolumn{15}{|l|}{ Trichoptera } \\
\hline \multicolumn{15}{|l|}{ Philopotamidae } \\
\hline Chimarra & 4 & $<1$ & 22 & $<1$ & 9 & $<1$ & 27 & 2 & 1 & $<1$ & 1 & $<1$ & 7 & $<1$ \\
\hline Wormaldia & - & & - & & - & & - & & - & & - & & - & \\
\hline \multicolumn{15}{|l|}{ Polycentropodidae } \\
\hline Neureclipsis & - & & - & & - & & 1 & $<1$ & - & & - & & 10 & $<1$ \\
\hline Nyctiophylax & 19 & $<1$ & 24 & $<1$ & 29 & 1 & 7 & $<1$ & 3 & $<1$ & 1 & $<1$ & 4 & $<1$ \\
\hline Polycentropus & - & & 2 & $<1$ & 5 & $<1$ & - & & - & & - & & - & \\
\hline \multicolumn{15}{|l|}{ Psychomyiidae } \\
\hline Psychomyia & 29 & 1 & 30 & $<1$ & 8 & $<1$ & 3 & $<1$ & 29 & 6 & 64 & 5 & 160 & 8 \\
\hline \multicolumn{15}{|l|}{ Uenoidae } \\
\hline Neophylax & - & & 17 & $<1$ & - & & - & & - & & - & & - & \\
\hline \multicolumn{15}{|l|}{ Lepidoptera } \\
\hline \multicolumn{15}{|l|}{ Pyralidae } \\
\hline Petrophila & 2 & $<1$ & 3 & $<1$ & 1 & $<1$ & - & & 3 & $<1$ & - & & 31 & 2 \\
\hline \multicolumn{15}{|l|}{ Coleoptera } \\
\hline \multicolumn{15}{|l|}{ Elmidae } \\
\hline \multicolumn{15}{|l|}{ Ancyronyx } \\
\hline A.variegata & - & & - & & - & & - & & - & & - & & - & \\
\hline Dubiraphia & - & & - & & - & & - & & - & & - & & - & \\
\hline Macronychus & - & & - & & - & & - & & - & & - & & - & \\
\hline M. glabratus & - & & - & & - & & - & & - & & - & & - & \\
\hline Optioservus & 2 & $<1$ & 5 & $<1$ & 14 & $<1$ & 3 & $<1$ & 11 & 2 & 29 & 2 & 3 & $<1$ \\
\hline Oulimnius & - & & 5 & $<1$ & 6 & $<1$ & - & & - & & 3 & $<1$ & 3 & $<1$ \\
\hline Promoresia & - & & - & & - & & - & & - & & 1 & $<1$ & - & \\
\hline Stenelmis & - & & - & & 15 & $<1$ & 1 & $<1$ & 2 & $<1$ & 5 & $<1$ & 1 & $<1$ \\
\hline \multicolumn{15}{|l|}{ Psephenidae } \\
\hline \multicolumn{15}{|l|}{ Ectopria } \\
\hline E. nervosa & - & & - & & - & & - & & - & & - & & - & \\
\hline Psephenus & 5 & $<1$ & 9 & $<1$ & 9 & $<1$ & 2 & $<1$ & 6 & 1 & 21 & 2 & 7 & $<1$ \\
\hline Diptera & & & & & & & & & & & & & & \\
\hline Athericidae & & & & & & & & & & & & & & \\
\hline Atherix & - & & - & & - & & - & & - & & - & & - & \\
\hline Chironomidae & 1,000 & 48 & 870 & 27 & 230 & 10 & 240 & 16 & 11 & 2 & 370 & 31 & 380 & 19 \\
\hline Empididae & & & & & & & & & & & & & & \\
\hline Hemerodromia & 2 & $<1$ & 4 & $<1$ & 3 & $<1$ & 2 & $<1$ & 3 & $<1$ & 11 & $<1$ & 2 & $<1$ \\
\hline Simuliidae & & & & & & & & & & & & & & \\
\hline Simulium & - & & 2 & $<1$ & - & & 3 & $<1$ & 1 & $<1$ & 1 & $<1$ & - & \\
\hline Tipulidae & & & & & & & & & & & & & & \\
\hline Antocha & 32 & 2 & 200 & 6 & 140 & 6 & 58 & 4 & 23 & 5 & 130 & 11 & 120 & 6 \\
\hline Tipula & - & & - & & - & & - & & - & & 1 & $<1$ & - & \\
\hline
\end{tabular}

${ }^{1}$ Extrapolated from a 3/8 subsample. 


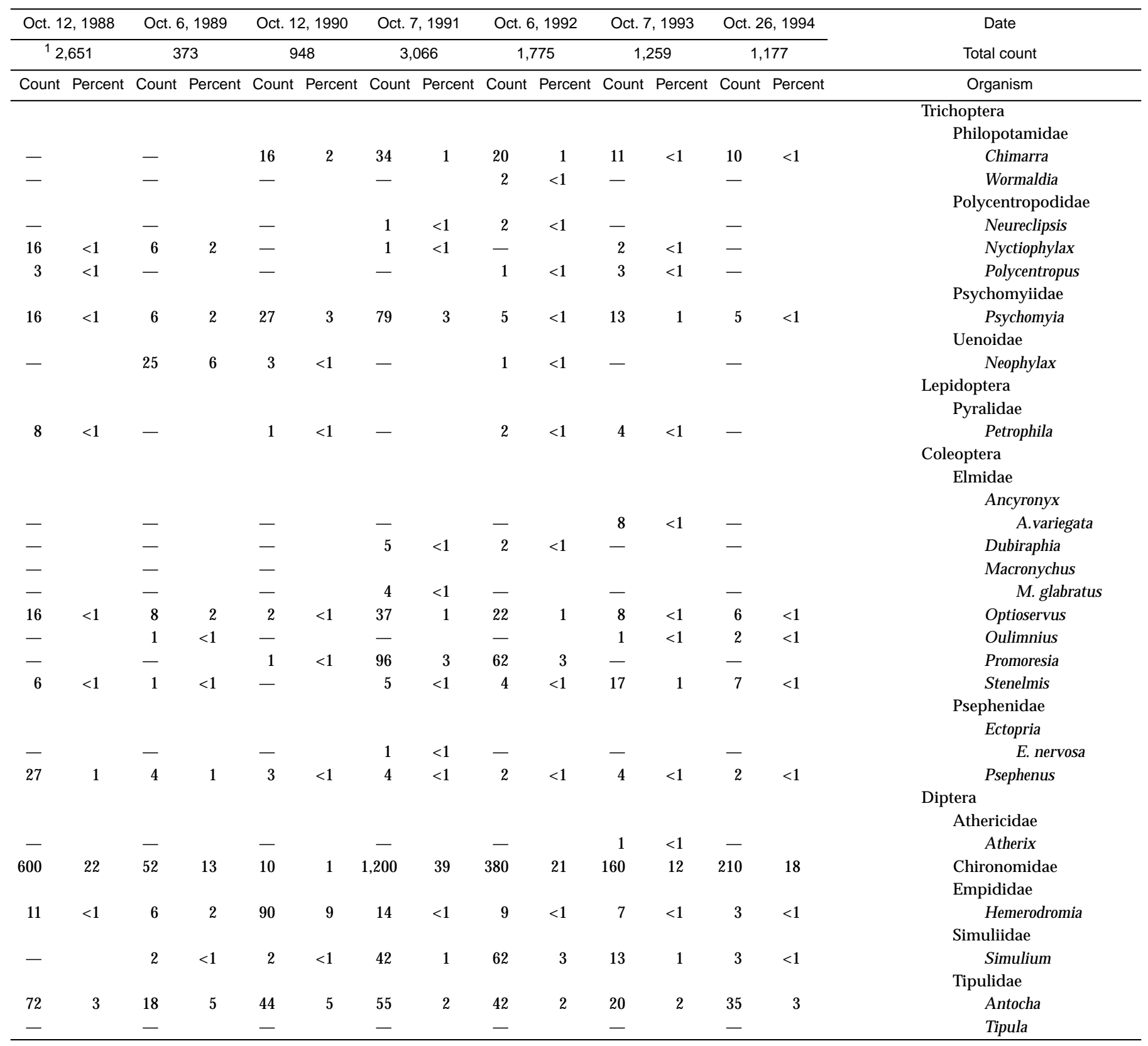


Table 5. Benthic-macroinvertebrate data-Continued

$[<$, less than; - , not found]

01473167 - Little Valley Creek at Howellville, Pa. (Site 49)

\begin{tabular}{|c|c|c|c|c|c|c|c|c|c|c|c|c|c|c|}
\hline \multirow{3}{*}{ 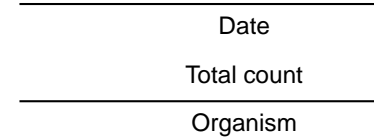 } & \multirow{2}{*}{\multicolumn{2}{|c|}{$\begin{array}{c}\text { Oct. } 16,1981 \\
2,871\end{array}$}} & \multirow{2}{*}{\multicolumn{2}{|c|}{$\frac{\text { Oct. } 15,1982}{2,454}$}} & \multirow{2}{*}{\multicolumn{2}{|c|}{$\begin{array}{c}\text { Oct. } 21,1983 \\
1,231\end{array}$}} & \multirow{2}{*}{\multicolumn{2}{|c|}{$\frac{\text { Oct. 9, } 1984}{1,218}$}} & \multirow{2}{*}{\multicolumn{2}{|c|}{$\frac{\text { Oct. 9, } 1985}{551}$}} & \multirow{2}{*}{\multicolumn{2}{|c|}{$\begin{array}{c}\text { Nov. } 6,1986 \\
1,102\end{array}$}} & \multirow{2}{*}{\multicolumn{2}{|c|}{$\begin{array}{c}\text { Nov. } 16,1987 \\
1,357\end{array}$}} \\
\hline & & & & & & & & & & & & & & \\
\hline & Count & Percent & Count & Percent & Count & Percent & Count & Percent & Count & Percent & Count & Percent & Count & Percent \\
\hline \multicolumn{15}{|l|}{ Platyhelminthes (flatworms) } \\
\hline \multicolumn{15}{|l|}{ Turbellaria } \\
\hline \multicolumn{15}{|l|}{ Tricladida } \\
\hline Planariidae & 9 & $<1$ & 7 & $<1$ & 24 & 2 & 31 & 3 & 5 & $<1$ & 14 & 1 & 19 & 1 \\
\hline \multicolumn{15}{|l|}{ Mollusca (molluscs) } \\
\hline \multicolumn{15}{|l|}{ Gastropoda } \\
\hline \multicolumn{15}{|l|}{ Basommatophora } \\
\hline Ancylidae & & & & & & & & & & & & & & \\
\hline Ferrissia & - & & - & & 1 & $<1$ & - & & 1 & $<1$ & - & & - & \\
\hline Annelida (segmented worms) & & & & & & & & & & & & & & \\
\hline Oligochaeta & 29 & 1 & 3 & $<1$ & 3 & $<1$ & - & & - & & - & & - & \\
\hline Lumbriculida & & & & & & & & & & & & & & \\
\hline Lumbriculidae & - & & - & & - & & - & & - & & - & & 5 & $<1$ \\
\hline Tubificida & & & & & & & & & & & & & & \\
\hline Naididae & - & & - & & - & & - & & - & & - & & - & \\
\hline Arthropoda (arthropods) & & & & & & & & & & & & & & \\
\hline Acariformes & & & & & & & & & & & & & & \\
\hline Hydrachnidia & - & & 3 & $<1$ & 3 & $<1$ & 6 & $<1$ & 2 & $<1$ & 1 & $<1$ & - & \\
\hline Crustacea & & & & & & & & & & & & & & \\
\hline Amphipoda & & & & & & & & & & & & & & \\
\hline Gammaridae & & & & & & & & & & & & & & \\
\hline Gammarus & 43 & 1 & 160 & 7 & 99 & 8 & 8 & $<1$ & 24 & 4 & 130 & 12 & 190 & 14 \\
\hline Isopoda & & & & & & & & & & & & & & \\
\hline Asellidae & - & & - & & - & & - & & 1 & $<1$ & - & & - & \\
\hline Lirceus & 2 & $<1$ & 9 & $<1$ & 2 & $<1$ & 8 & $<1$ & 5 & $<1$ & 70 & 6 & 12 & $<1$ \\
\hline Decapoda & & & & & & & & & & & & & & \\
\hline Cambaridae & & & & & & & & & & & & & & \\
\hline Cambarus & - & & 1 & $<1$ & - & & - & & - & & - & & - & \\
\hline Insecta & & & & & & & & & & & & & & \\
\hline Ephemeroptera & & & & & & & & & & & & & & \\
\hline Baetidae & & & & & & & & & & & & & & \\
\hline Baetis & 310 & 11 & 350 & 14 & 140 & 11 & 83 & 7 & 31 & 6 & 220 & 20 & 30 & 2 \\
\hline Pseudocloeon & - & & - & & - & & - & & 64 & 11 & - & & 73 & 5 \\
\hline Ephemerellidae & & & & & & & & & & & & & & \\
\hline Ephemerella & 300 & 10 & 190 & 8 & 490 & 40 & 480 & 40 & 150 & 27 & 230 & 21 & 430 & 31 \\
\hline Heptageniidae & & & & & & & & & & & & & & \\
\hline Stenonema & - & & - & & - & & - & & - & & 1 & $<1$ & - & \\
\hline Plecoptera & & & & & & & & & & & & & & \\
\hline Capniidae & & & & & & & & & & & & & & \\
\hline Allocapnia & - & & - & & - & & - & & - & & - & & - & \\
\hline Taeniopterygidae & & & & & & & & & & & & & & \\
\hline Taeniopteryx & - & & 1 & $<1$ & - & & - & & - & & - & & - & \\
\hline Hemiptera & & & & & & & & & & & & & & \\
\hline Corixidae & & & & & & & & & & & & & & \\
\hline Trichocorixa & 2 & $<1$ & - & & - & & - & & - & & - & & - & \\
\hline Veliidae & & & & & & & & & & & & & & \\
\hline Rhagovelia & 1 & $<1$ & - & & - & & 1 & $<1$ & - & & - & & - & \\
\hline Trichoptera & & & & & & & & & & & & & & \\
\hline Brachycentridae & & & & & & & & & & & & & & \\
\hline Micrasema & - & & - & & - & & - & & - & & - & & - & \\
\hline Glossosomatidae & & & & & & & & & & & & & & \\
\hline Glossosoma & 28 & $<1$ & 140 & 6 & 19 & 2 & 98 & 8 & 2 & $<1$ & 32 & 3 & 130 & 9 \\
\hline
\end{tabular}




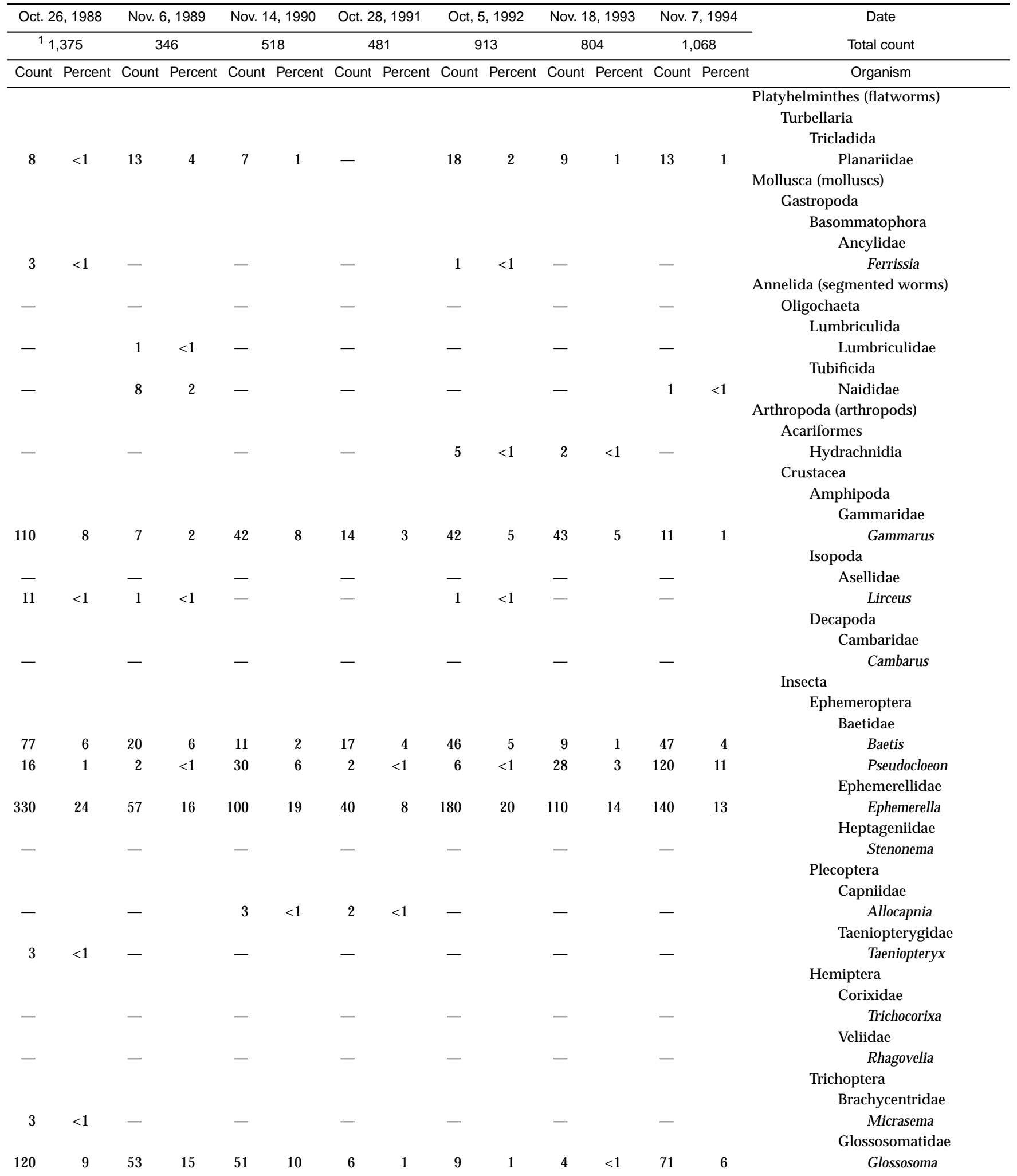


Table 5. Benthic-macroinvertebrate data-Continued

01473167 - Little Valley Creek at Howellville, Pa. (Site 49)—Continued

\begin{tabular}{|c|c|c|c|c|c|c|c|c|c|c|c|c|c|c|}
\hline \multirow{3}{*}{$\begin{array}{c}\text { Date } \\
\text { Total count } \\
\text { Organism }\end{array}$} & \multirow{2}{*}{\multicolumn{2}{|c|}{$\begin{array}{c}\text { Oct. } 16,1981 \\
2,871\end{array}$}} & \multicolumn{2}{|c|}{ Oct. 15,1982} & \multicolumn{2}{|c|}{ Oct. 21,1983} & \multicolumn{2}{|c|}{ Oct. 9, 1984} & \multicolumn{2}{|c|}{ Oct. 9, 1985} & \multicolumn{2}{|c|}{ Nov. 6,1986} & \multicolumn{2}{|c|}{ Nov. 16,1987} \\
\hline & & & 2,4 & 454 & \multicolumn{2}{|c|}{1,231} & \multicolumn{2}{|c|}{1,218} & \multicolumn{2}{|c|}{551} & \multicolumn{2}{|c|}{1,102} & \multicolumn{2}{|c|}{1,357} \\
\hline & Count & Percent & Count & Percent & Count & Percent & Count & Percent & Count & Percent & Count & Percent & Count & Percent \\
\hline \multicolumn{15}{|l|}{ Trichoptera } \\
\hline \multicolumn{15}{|l|}{ Hydropsychidae } \\
\hline Ceratopsyche & 390 & 13 & 690 & 28 & 190 & 15 & 200 & 17 & 170 & 30 & 200 & 18 & 160 & 11 \\
\hline Cheumatopsyche & 88 & 3 & 16 & $<1$ & - & & 4 & $<1$ & 14 & 3 & 2 & $<1$ & 11 & $<1$ \\
\hline Hydropsyche & 530 & 18 & 120 & 5 & 140 & 11 & 48 & 4 & 11 & 2 & 47 & 4 & 120 & 9 \\
\hline \multicolumn{15}{|l|}{ Hydroptilidae } \\
\hline Hydroptila & - & & - & & 1 & $<1$ & - & & - & & - & & - & \\
\hline Leucotrichia & 1 & $<1$ & - & & - & & - & & - & & - & & - & \\
\hline \multicolumn{15}{|l|}{ Leptoceridae } \\
\hline Oecetis & - & & - & & - & & - & & - & & - & & - & \\
\hline \multicolumn{15}{|l|}{ Philopotamidae } \\
\hline Dolophilodes & - & & 1 & $<1$ & - & & - & & - & & - & & - & \\
\hline \multicolumn{15}{|l|}{ Psychomyiidae } \\
\hline Psychomyia & 1 & $<1$ & 1 & $<1$ & 4 & $<1$ & - & & - & & - & & - & \\
\hline Lepidoptera & - & & - & & - & & 1 & $<1$ & - & & - & & - & \\
\hline \multicolumn{15}{|l|}{ Coleoptera } \\
\hline Chrysomelidae & - & & 1 & $<1$ & - & & - & & - & & - & & - & \\
\hline Donacia & - & & - & & 1 & $<1$ & - & & - & & - & & - & \\
\hline Curculionidae & - & & - & & - & & - & & - & & - & & - & \\
\hline \multicolumn{15}{|l|}{ Dryopidae } \\
\hline Helichus & - & & - & & - & & - & & 1 & $<1$ & - & & - & \\
\hline Elmidae & & & & & & & & & & & & & & \\
\hline Dubiraphia & - & & - & & - & & - & & - & & - & & - & \\
\hline Optioservus & 14 & $<1$ & 7 & $<1$ & 8 & $<1$ & 27 & 2 & 7 & 1 & 58 & 5 & 84 & 6 \\
\hline Oulimnius & - & & - & & - & & - & & 2 & $<1$ & 1 & $<1$ & - & \\
\hline Stenelmis & 2 & $<1$ & - & & - & & 4 & $<1$ & - & & - & & 8 & $<1$ \\
\hline Hymenoptera & & & & & & & & & & & & & & \\
\hline Ichneumonidae & - & & 1 & $<1$ & - & & - & & - & & - & & - & \\
\hline Diptera & & & & & & & & & & & & & & \\
\hline Chironomidae & 1,000 & 34 & 660 & 27 & 73 & 6 & 200 & 17 & 41 & 7 & 33 & 3 & 53 & 4 \\
\hline Empididae & & & & & & & & & & & & & & \\
\hline Chelifera & - & & - & & - & & - & & - & & - & & - & \\
\hline Hemerodromia & 8 & $<1$ & 8 & $<1$ & - & & - & & - & & - & & - & \\
\hline Simuliidae & & & & & & & & & & & & & & \\
\hline Simulium & 3 & $<1$ & - & & 3 & $<1$ & 3 & $<1$ & 15 & 3 & 36 & 3 & - & \\
\hline Tipulidae & & & & & & & & & & & & & & \\
\hline Antocha & 110 & 4 & 85 & 3 & 30 & 3 & 16 & 1 & 4 & $<1$ & 26 & 2 & 32 & 2 \\
\hline Tipula & - & & - & & - & & - & & 1 & $<1$ & - & & - & \\
\hline
\end{tabular}

${ }^{1}$ Extrapolated from a 3/8 subsample. 


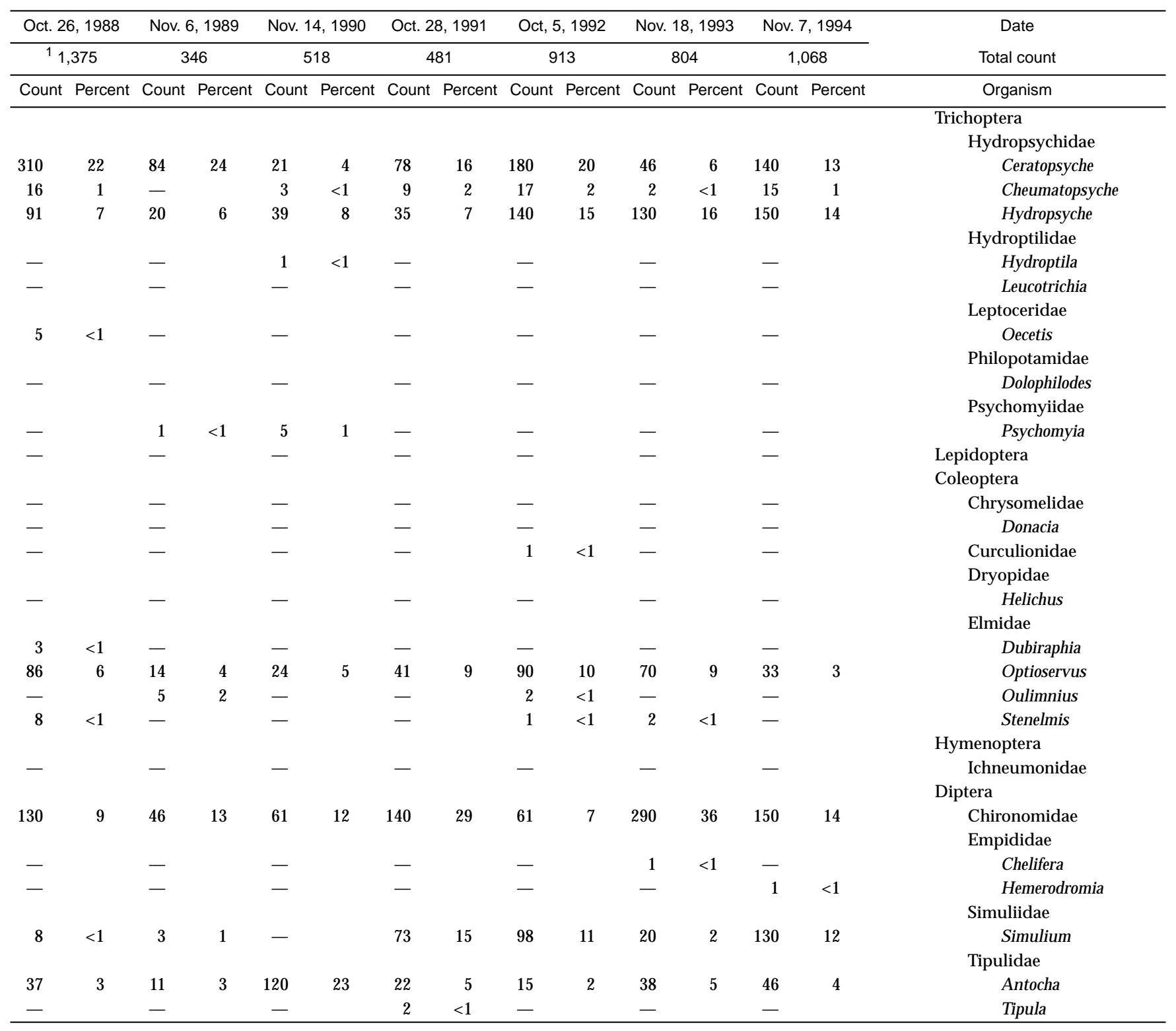


Table 5. Benthic-macroinvertebrate data-Continued

$[<$, less than; - , not found]

01473168 - Valley Creek near Valley Forge, Pa. (Site 50)

\begin{tabular}{|c|c|c|c|c|c|c|c|c|c|c|c|c|c|c|}
\hline \multirow{3}{*}{$\begin{array}{c}\text { Date } \\
\text { Total count } \\
\text { Organism }\end{array}$} & \multirow{2}{*}{\multicolumn{2}{|c|}{$\begin{array}{c}\text { Oct. } 16,1981 \\
2,183\end{array}$}} & \multirow{2}{*}{\multicolumn{2}{|c|}{$\frac{\text { Oct. } 15,1982}{3,144}$}} & \multirow{2}{*}{\multicolumn{2}{|c|}{$\frac{\text { Oct. } 21,1983}{1,745}$}} & \multirow{2}{*}{\multicolumn{2}{|c|}{$\frac{\text { Oct. 9, } 1984}{2,073}$}} & \multirow{2}{*}{\multicolumn{2}{|c|}{$\frac{\text { Oct. 9, } 1985}{1,354}$}} & \multirow{2}{*}{\multicolumn{2}{|c|}{$\begin{array}{c}\text { Nov. } 7,1986 \\
1,820\end{array}$}} & \multirow{2}{*}{\multicolumn{2}{|c|}{$\begin{array}{c}\text { Nov. } 16,1987 \\
1,625\end{array}$}} \\
\hline & & & & & & & & & & & & & & \\
\hline & Count & Percent & Count & Percent & Count & Percent & Count & Percent & Count & Percent & Count & Percent & Count & Percent \\
\hline \multicolumn{15}{|l|}{ Platyhelminthes (flatworms) } \\
\hline \multicolumn{15}{|l|}{ Turbellaria } \\
\hline \multicolumn{15}{|l|}{ Tricladida } \\
\hline Planariidae & 24 & 1 & 80 & 3 & 31 & 2 & 120 & 6 & 47 & 3 & 75 & 4 & 87 & 5 \\
\hline Nematoda (nematodes) & - & & - & & - & & - & & - & & - & & 3 & $<1$ \\
\hline \multicolumn{15}{|l|}{ Nemertea (proboscis worms) } \\
\hline \multicolumn{15}{|l|}{ Enopla } \\
\hline \multicolumn{15}{|l|}{ Hoplonemertea } \\
\hline \multicolumn{15}{|l|}{ Tetrastemmatidae } \\
\hline Prostoma & - & & - & & - & & - & & - & & - & & - & \\
\hline Mollusca (molluscs) & & & & & & & & & & & & & & \\
\hline Gastropoda & & & & & & & & & & & & & & \\
\hline Basommatophora & & & & & & & & & & & & & & \\
\hline Ancylidae & & & & & & & & & & & & & & \\
\hline Ferrissia & 17 & $<1$ & 3 & $<1$ & 7 & $<1$ & 5 & $<1$ & 10 & $<1$ & 1 & $<1$ & 1 & $<1$ \\
\hline Lymnaeidae & & & & & & & & & & & & & & \\
\hline Lymnaea & - & & - & & - & & - & & - & & - & & 1 & $<1$ \\
\hline Planorbidae & - & & - & & 1 & $<1$ & - & & - & & - & & - & \\
\hline Gyraulus & - & & - & & - & & - & & - & & - & & - & \\
\hline Annelida (segmented worms) & & & & & & & & & & & & & & \\
\hline Oligochaeta & - & & 38 & 1 & - & & 1 & $<1$ & - & & - & & - & \\
\hline Lumbriculida & & & & & & & & & & & & & & \\
\hline Lumbriculidae & - & & - & & - & & - & & - & & - & & - & \\
\hline Tubificida & & & & & & & & & & & & & & \\
\hline Naididae & 34 & 2 & - & & - & & - & & 3 & $<1$ & 1 & $<1$ & 19 & 1 \\
\hline Tubificidae & - & & - & & - & & - & & 1 & $<1$ & - & & 5 & $<1$ \\
\hline Hirudinea & & & & & & & & & & & & & & \\
\hline Pharyngobdellida & & & & & & & & & & & & & & \\
\hline Erpobdellidae & - & & 1 & $<1$ & - & & - & & - & & - & & - & \\
\hline Arthropoda (arthropods) & & & & & & & & & & & & & & \\
\hline Acariformes & & & & & & & & & & & & & & \\
\hline Hydrachnidia & - & & 8 & $<1$ & - & & - & & - & & - & & 1 & $<1$ \\
\hline Crustacea & & & & & & & & & & & & & & \\
\hline Amphipoda & & & & & & & & & & & & & & \\
\hline Gammaridae & & & & & & & & & & & & & & \\
\hline Gammarus & 42 & 2 & 7 & $<1$ & 17 & 1 & 2 & $<1$ & 34 & 2 & 16 & $<1$ & 15 & $<1$ \\
\hline Isopoda & & & & & & & & & & & & & & \\
\hline Asellidae & & & & & & & & & & & & & & \\
\hline Lirceus & 110 & 5 & 740 & 24 & 410 & 24 & 480 & 123 & 320 & 23 & 470 & 26 & 220 & 14 \\
\hline Decapoda & & & & & & & & & & & & & & \\
\hline Cambaridae & - & & - & & - & & - & & - & & - & & - & \\
\hline Insecta & & & & & & & & & & & & & & \\
\hline Ephemeroptera & & & & & & & & & & & & & & \\
\hline Baetidae & & & & & & & & & & & & & & \\
\hline Baetis & 110 & 5 & 69 & 2 & 41 & 2 & 150 & 7 & 62 & 4 & 16 & $<1$ & 42 & 3 \\
\hline Pseudocloeon & - & & - & & - & & - & & - & & - & & - & \\
\hline Ephemerellidae & & & & & & & & & & & & & & \\
\hline Ephemerella & - & & 1 & $<1$ & 2 & $<1$ & 4 & $<1$ & 1 & $<1$ & 2 & $<1$ & 7 & $<1$ \\
\hline Heptageniidae & & & & & & & & & & & & & & \\
\hline Stenonema & - & & - & & - & & - & & - & & - & & - & \\
\hline Leptophlebiidae & - & & - & & - & & - & & - & & - & & - & \\
\hline
\end{tabular}




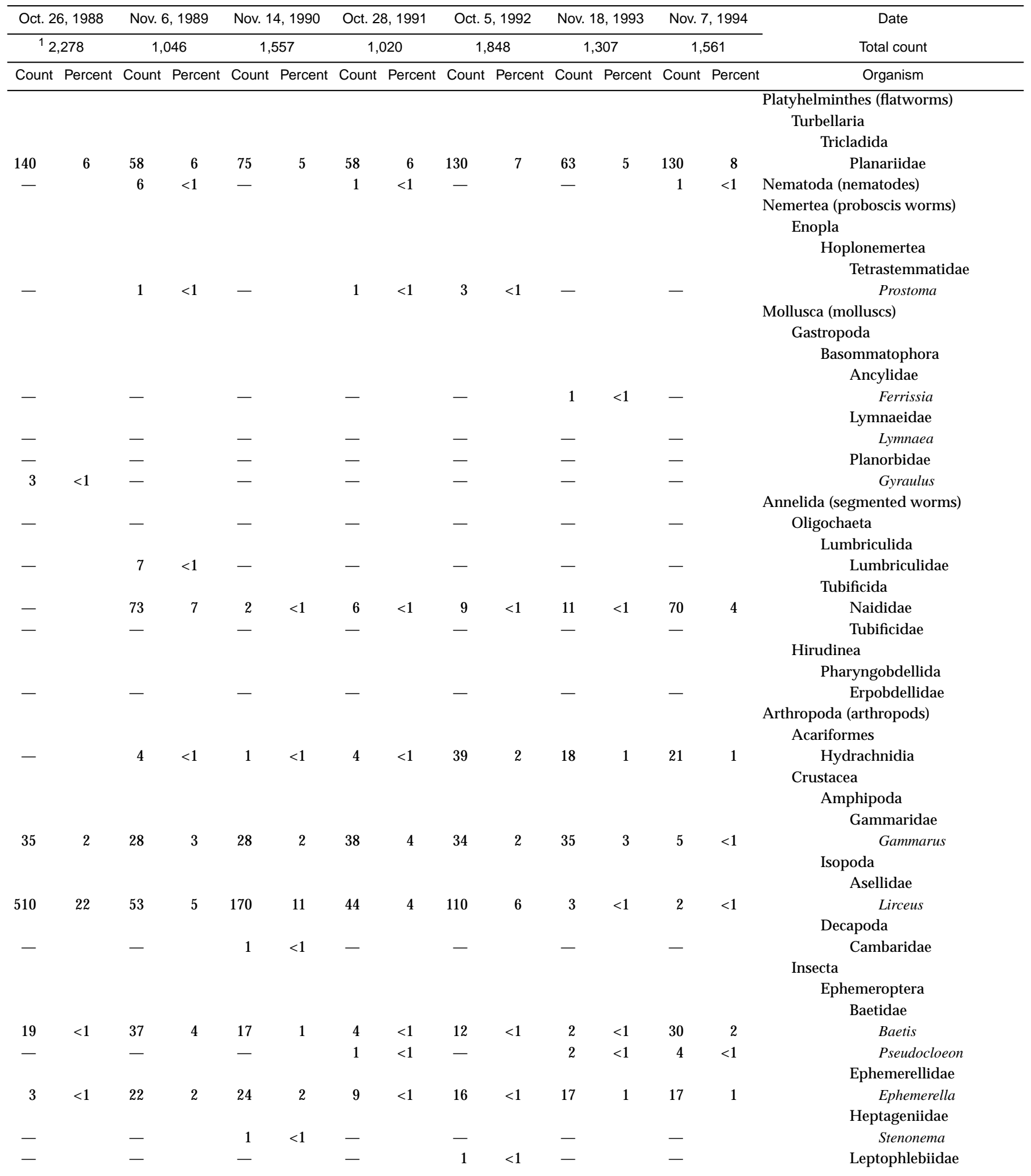


Table 5. Benthic-macroinvertebrate data-Continued

01473168 - Valley Creek near Valley Forge, Pa. (Site 50)—Continued

\begin{tabular}{|c|c|c|c|c|c|c|c|c|c|c|c|c|c|c|}
\hline \multirow{3}{*}{$\begin{array}{c}\text { Date } \\
\text { Total count } \\
\text { Organism }\end{array}$} & \multirow{2}{*}{\multicolumn{2}{|c|}{$\begin{array}{c}\text { Oct. } 16,1981 \\
2,183\end{array}$}} & \multirow{2}{*}{\multicolumn{2}{|c|}{ Oct. 15,1982}} & \multicolumn{2}{|c|}{ Oct. 21,1983} & \multicolumn{2}{|c|}{ Oct. 9, 1984} & \multicolumn{2}{|c|}{ Oct. 9, 1985} & \multicolumn{2}{|c|}{ Nov. 7, 1986} & \multicolumn{2}{|c|}{ Nov. 16,1987} \\
\hline & & & & & 1,7 & 745 & 2,0 & 73 & & 354 & 1,8 & 320 & & 625 \\
\hline & Count & Percent & Count & Percent & Count & Percent & Count & Percent & Count & Percent & Count & Percent & Count & Percent \\
\hline \multicolumn{15}{|l|}{ Hemiptera } \\
\hline Corixidae & - & & - & & - & & - & & - & & - & & - & \\
\hline Sigara & 1 & $<1$ & - & & - & & - & & - & & - & & - & \\
\hline \multicolumn{15}{|l|}{ Trichoptera } \\
\hline \multicolumn{15}{|l|}{ Glossosomatidae } \\
\hline Glossosoma & 1 & $<1$ & 4 & $<1$ & - & & 9 & $<1$ & - & & 3 & $<1$ & 2 & $<1$ \\
\hline \multicolumn{15}{|l|}{ Hydropsychidae } \\
\hline Ceratopsyche & 340 & 15 & 860 & 28 & 370 & 22 & 200 & 10 & 160 & 11 & 590 & 33 & 210 & 13 \\
\hline Cheumatopsyche & 120 & 5 & 44 & 1 & 48 & 3 & 6 & $<1$ & 20 & 1 & 8 & $<1$ & 13 & $<1$ \\
\hline Hydropsyche & 120 & 5 & 410 & 13 & 500 & 29 & 220 & 10 & 62 & 4 & 150 & 8 & 270 & 17 \\
\hline \multicolumn{15}{|l|}{ Hydroptilidae } \\
\hline Hydroptila & 4 & $<1$ & - & & - & & - & & - & & - & & - & \\
\hline Leucotrichia & - & & 1 & $<1$ & - & & 1 & $<1$ & - & & 1 & $<1$ & - & \\
\hline \multicolumn{15}{|l|}{ Philopotamidae } \\
\hline Chimarra & - & & - & & 4 & $<1$ & 1 & $<1$ & 7 & $<1$ & 27 & 2 & 2 & $<1$ \\
\hline \multicolumn{15}{|l|}{ Psychomyiidae } \\
\hline Psychomyia & - & & - & & - & & - & & - & & - & & 1 & $<1$ \\
\hline Coleoptera & 1 & $<1$ & - & & - & & 1 & $<1$ & 3 & $<1$ & - & & - & \\
\hline \multicolumn{15}{|l|}{ Dryopidae } \\
\hline Helichus & - & & - & & - & & - & & - & & - & & - & \\
\hline \multicolumn{15}{|l|}{ Elmidae } \\
\hline Ancyronyx & - & & - & & - & & - & & - & & - & & - & \\
\hline Optioservus & 17 & $<1$ & 20 & $<1$ & 15 & $<1$ & 22 & 1 & 44 & 3 & 47 & 3 & 67 & 4 \\
\hline Oulimnius & - & & - & & - & & - & & - & & - & & - & \\
\hline Promoresia & - & & - & & - & & - & & - & & - & & - & \\
\hline Stenelmis & 9 & $<1$ & 13 & $<1$ & 8 & $<1$ & 7 & $<1$ & 10 & $<1$ & 1 & $<1$ & 38 & 2 \\
\hline \multicolumn{15}{|l|}{ Psephenidae } \\
\hline Ectopria & - & & - & & - & & - & & - & & - & & - & \\
\hline Psephenus & - & & - & & - & & - & & - & & - & & - & \\
\hline Hymenoptera & 1 & $<1$ & - & & - & & 1 & $<1$ & & & & & & \\
\hline \multicolumn{15}{|l|}{ Diptera } \\
\hline Chironomidae & 1,100 & 50 & 640 & 21 & 160 & 9 & 720 & 34 & 490 & 35 & 120 & 7 & 350 & 22 \\
\hline \multicolumn{15}{|l|}{ Empididae } \\
\hline Hemerodromia & 6 & $<1$ & 3 & $<1$ & 1 & $<1$ & 1 & $<1$ & 2 & $<1$ & 2 & $<1$ & - & \\
\hline \multicolumn{15}{|l|}{ Simuliidae } \\
\hline Simulium & 6 & $<1$ & 2 & $<1$ & - & & 22 & 1 & 5 & $<1$ & 110 & 6 & 21 & 1 \\
\hline Tipulidae & & & & & & & & & & & & & & \\
\hline Antocha & 120 & 5 & 200 & 6 & 130 & 8 & 100 & 5 & 73 & 5 & 180 & 10 & 250 & 16 \\
\hline
\end{tabular}

${ }^{1}$ Extrapolated from a 3/8 subsample. 


\begin{tabular}{|c|c|c|c|c|c|c|c|c|c|c|c|c|c|c|}
\hline \multicolumn{2}{|c|}{ Oct. 26,1988} & \multicolumn{2}{|c|}{ Nov. 6, 1989} & \multicolumn{2}{|c|}{ Nov. 14, 1990} & \multicolumn{2}{|c|}{ Oct. 28, 1991} & \multicolumn{2}{|c|}{ Oct. 5, 1992} & \multicolumn{2}{|c|}{ Nov. 18, 1993} & \multicolumn{2}{|c|}{ Nov. 7, 1994} & \multirow{2}{*}{$\begin{array}{c}\text { Date } \\
\text { Total count }\end{array}$} \\
\hline \multicolumn{2}{|c|}{${ }^{1} 2,278$} & \multicolumn{2}{|c|}{1,046} & \multicolumn{2}{|c|}{1,557} & \multicolumn{2}{|c|}{1,020} & \multicolumn{2}{|c|}{1,848} & \multicolumn{2}{|c|}{1,307} & \multicolumn{2}{|c|}{1,561} & \\
\hline Count & Percent & Count & Percent & Count & Percent & Count & Percent & Count & Percent & Count & Percent & Count & Percent & Organism \\
\hline & & & & & & & & & & & & & & Hemiptera \\
\hline - & & 1 & $<1$ & - & & - & & - & & - & & - & & Corixidae \\
\hline \multirow{3}{*}{-} & & - & & - & & - & & - & & - & & - & & Sigara \\
\hline & & & & & & & & & & & & & & Trichoptera \\
\hline & & & & & & & & & & & & & & Glossosomatidae \\
\hline \multirow[t]{2}{*}{-} & & 10 & 1 & 2 & $<1$ & - & & 1 & $<1$ & - & & 9 & $<1$ & Glossosoma \\
\hline & & & & & & & & & & & & & & Hydropsychidae \\
\hline 290 & 13 & 110 & 11 & 300 & 19 & 92 & 9 & 140 & 7 & 120 & 9 & 170 & 11 & Ceratopsyche \\
\hline 27 & 1 & 2 & $<1$ & 8 & $<1$ & 17 & 2 & 20 & 1 & 10 & $<1$ & 17 & 1 & Cheumatopsyche \\
\hline \multirow[t]{2}{*}{510} & 22 & 82 & 8 & 260 & 16 & 120 & 12 & 280 & 15 & 120 & 9 & 110 & 7 & Hydropsyche \\
\hline & & & & & & & & & & & & & & Hydroptilidae \\
\hline - & & - & & - & & 1 & $<1$ & - & & - & & - & & Hydroptila \\
\hline \multirow[t]{2}{*}{ - } & & - & & - & & - & & 2 & $<1$ & 1 & $<1$ & 1 & $<1$ & Leucotrichia \\
\hline & & & & & & & & & & & & & & Philopotamidae \\
\hline \multirow[t]{2}{*}{3} & $<1$ & 2 & $<1$ & - & & 11 & 1 & 19 & 1 & 52 & 4 & 37 & 2 & Chimarra \\
\hline & & & & & & & & & & & & & & Psychomyiidae \\
\hline- & & - & & - & & - & & - & & - & & - & & Psychomyia \\
\hline \multirow[t]{2}{*}{ - } & & - & & - & & - & & - & & - & & - & & Coleoptera \\
\hline & & & & & & & & & & & & & & Dryopidae \\
\hline- & & - & & - & & - & & 1 & $<1$ & - & & - & & Helichus \\
\hline & & & & & & & & & & & & & & Elmidae \\
\hline - & & - & & - & & 2 & $<1$ & - & & - & & - & & Ancyronyx \\
\hline 67 & 3 & 54 & 5 & 51 & 3 & 100 & 10 & 370 & 19 & 81 & 6 & 160 & 10 & Optioservus \\
\hline - & & - & & - & & - & & - & & 5 & $<1$ & 1 & $<1$ & Oulimnius \\
\hline - & & - & & - & & - & & - & & 1 & $<1$ & - & & Promoresia \\
\hline 35 & 2 & 21 & 2 & 10 & $<1$ & - & & 57 & 3 & 5 & $<1$ & 9 & $<1$ & Stenelmis \\
\hline & & & & & & & & & & & & & & Psephenidae \\
\hline - & & - & & 1 & $<1$ & - & & - & & - & & - & & Ectopria \\
\hline - & & - & & - & & - & & 1 & $<1$ & - & & 1 & $<1$ & Psephenus \\
\hline - & & - & & - & & - & & - & & - & & - & & Hymenoptera \\
\hline & & & & & & & & & & & & & & Diptera \\
\hline 550 & 24 & 300 & 30 & 440 & 27 & 340 & 34 & 470 & 25 & 620 & 48 & 530 & 33 & Chironomidae \\
\hline & & & & & & & & & & & & & & Empididae \\
\hline - & & 2 & $<1$ & - & & 1 & $<1$ & 6 & $<1$ & 6 & $<1$ & 6 & $<1$ & Hemerodromia \\
\hline & & & & & & & & & & & & & & Simuliidae \\
\hline 27 & 1 & 33 & 3 & 26 & 2 & 30 & 3 & 91 & 5 & 14 & 1 & 120 & 8 & Simulium \\
\hline & & & & & & & & & & & & & & Tipulidae \\
\hline 59 & 3 & 140 & 14 & 140 & 9 & 140 & 14 & 36 & 2 & 120 & 9 & 110 & 7 & Antocha \\
\hline
\end{tabular}


Table 5. Benthic-macroinvertebrate data-Continued

$[<$, less than; - , not found]

01475300 - Darby Creek at Waterloo Mills near Devon, Pa. (Site 17)

\begin{tabular}{|c|c|c|c|c|c|c|c|c|c|c|c|c|c|c|}
\hline \multirow{3}{*}{$\begin{array}{cc}\text { Date } \\
\text { Total count } \\
\text { Organism }\end{array}$} & \multirow{2}{*}{\multicolumn{2}{|c|}{$\frac{\text { Oct. } 19,1981}{524}$}} & \multirow{2}{*}{\multicolumn{2}{|c|}{$\frac{\text { Oct. } 13,1982}{215}$}} & \multirow{2}{*}{\multicolumn{2}{|c|}{$\frac{\text { Oct. } 27,1983}{403}$}} & \multirow{2}{*}{\multicolumn{2}{|c|}{$\frac{\text { Oct. } 15,1984}{1,208}$}} & \multirow{2}{*}{\multicolumn{2}{|c|}{$\frac{\text { Oct. 31, } 1985}{968}$}} & \multirow{2}{*}{\multicolumn{2}{|c|}{$\frac{\text { Nov. } 14,1986}{706}$}} & \multirow{2}{*}{\multicolumn{2}{|c|}{$\frac{\text { Oct. } 15,1987}{1,115}$}} \\
\hline & & & & & & & & & & & & & & \\
\hline & Count & Percent & Count & Percent & Count & Percent & Count & Percent & Count & Percent & Count & Percent & Count & Percent \\
\hline \multicolumn{15}{|l|}{ Platyhelminthes (flatworms) } \\
\hline \multicolumn{15}{|l|}{ Turbellaria } \\
\hline \multicolumn{15}{|l|}{ Tricladida } \\
\hline Planariidae & 3 & $<1$ & 3 & 2 & 4 & 1 & 6 & $<1$ & 3 & $<1$ & 28 & 4 & 5 & $<1$ \\
\hline Nematoda (nematodes) & - & & - & & - & & - & & - & & - & & - & \\
\hline \multicolumn{15}{|l|}{ Nemertea (proboscis worms) } \\
\hline \multicolumn{15}{|l|}{ Enopla } \\
\hline \multicolumn{15}{|l|}{ Hoplonemertea } \\
\hline Tetrastemmatida & & & & & & & & & & & & & & \\
\hline Prostoma & - & & - & & 1 & $<1$ & - & & - & & 2 & $<1$ & - & \\
\hline Mollusca (molluscs) & & & & & & & & & & & & & & \\
\hline Gastropoda & - & & - & & - & & - & & - & & - & & - & \\
\hline Basommatophora & & & & & & & & & & & & & & \\
\hline Ancylidae & & & & & & & & & & & & & & \\
\hline Ferrissia & - & & - & & - & & - & & - & & 1 & $<1$ & - & \\
\hline Lymnaeidae & & & & & & & & & & & & & & \\
\hline Lymnaea & - & & - & & - & & - & & - & & - & & - & \\
\hline Planorbidae & & & & & & & & & & & & & & \\
\hline Gyraulus & - & & - & & - & & - & & - & & - & & - & \\
\hline Helisoma & - & & - & & - & & - & & - & & 1 & $<1$ & - & \\
\hline Bivalvia & & & & & & & & & & & & & & \\
\hline Veneroida & & & & & & & & & & & & & & \\
\hline Sphaeriidae & - & & - & & - & & - & & - & & - & & - & \\
\hline Annelida (segmented worms) & & & & & & & & & & & & & & \\
\hline Oligochaeta & - & & - & & - & & 1 & $<1$ & - & & - & & - & \\
\hline Lumbriculida & & & & & & & & & & & & & & \\
\hline Lumbriculidae & - & & - & & - & & - & & 1 & $<1$ & - & & 4 & $<1$ \\
\hline Tubificida & & & & & & & & & & & & & & \\
\hline Naididae & 1 & $<1$ & - & & 2 & $<1$ & - & & - & & - & & 29 & 3 \\
\hline Tubificidae & - & & - & & - & & - & & - & & - & & 1 & $<1$ \\
\hline Arthropoda (arthropods) & & & & & & & & & & & & & & \\
\hline Acariformes & & & & & & & & & & & & & & \\
\hline Hydrachnidia & - & & 1 & $<1$ & 1 & $<1$ & 3 & $<1$ & 1 & $<1$ & - & & 17 & 2 \\
\hline Crustacea & & & & & & & & & & & & & & \\
\hline Cladocera & - & & - & & - & & - & & - & & - & & - & \\
\hline Cyclopoida & - & & - & & - & & - & & - & & - & & - & \\
\hline Cyclopidae & - & & - & & - & & - & & - & & - & & 1 & $<1$ \\
\hline Amphipoda & & & & & & & & & & & & & & \\
\hline Gammaridae & & & & & & & & & & & & & & \\
\hline Gammarus & 3 & $<1$ & 1 & $<1$ & - & & 2 & $<1$ & 1 & $<1$ & 5 & $<1$ & - & \\
\hline Isopoda & & & & & & & & & & & & & & \\
\hline Asellidae & & & & & & & & & & & & & & \\
\hline Caecidotea & - & & - & & - & & - & & - & & - & & - & \\
\hline Decapoda & & & & & & & & & & & & & & \\
\hline Cambaridae & - & & - & & - & & - & & - & & - & & - & \\
\hline Podocopa & - & & - & & - & & - & & - & & - & & - & \\
\hline Insecta & & & & & & & & & & & & & & \\
\hline Ephemeroptera & & & & & & & & & & & & & & \\
\hline Baetidae & & & & & & & & & & & & & & \\
\hline Baetis & 5 & 1 & - & & 1 & $<1$ & 19 & 2 & 4 & $<1$ & 1 & $<1$ & - & \\
\hline Pseudocloeon & - & & - & & - & & - & & - & & - & & 8 & $<1$ \\
\hline Ephemerellidae & & & & & & & & & & & & & & \\
\hline Ephemerella & 6 & 1 & 3 & 2 & 8 & 2 & 24 & 2 & 12 & 1 & 12 & 2 & 27 & 2 \\
\hline
\end{tabular}




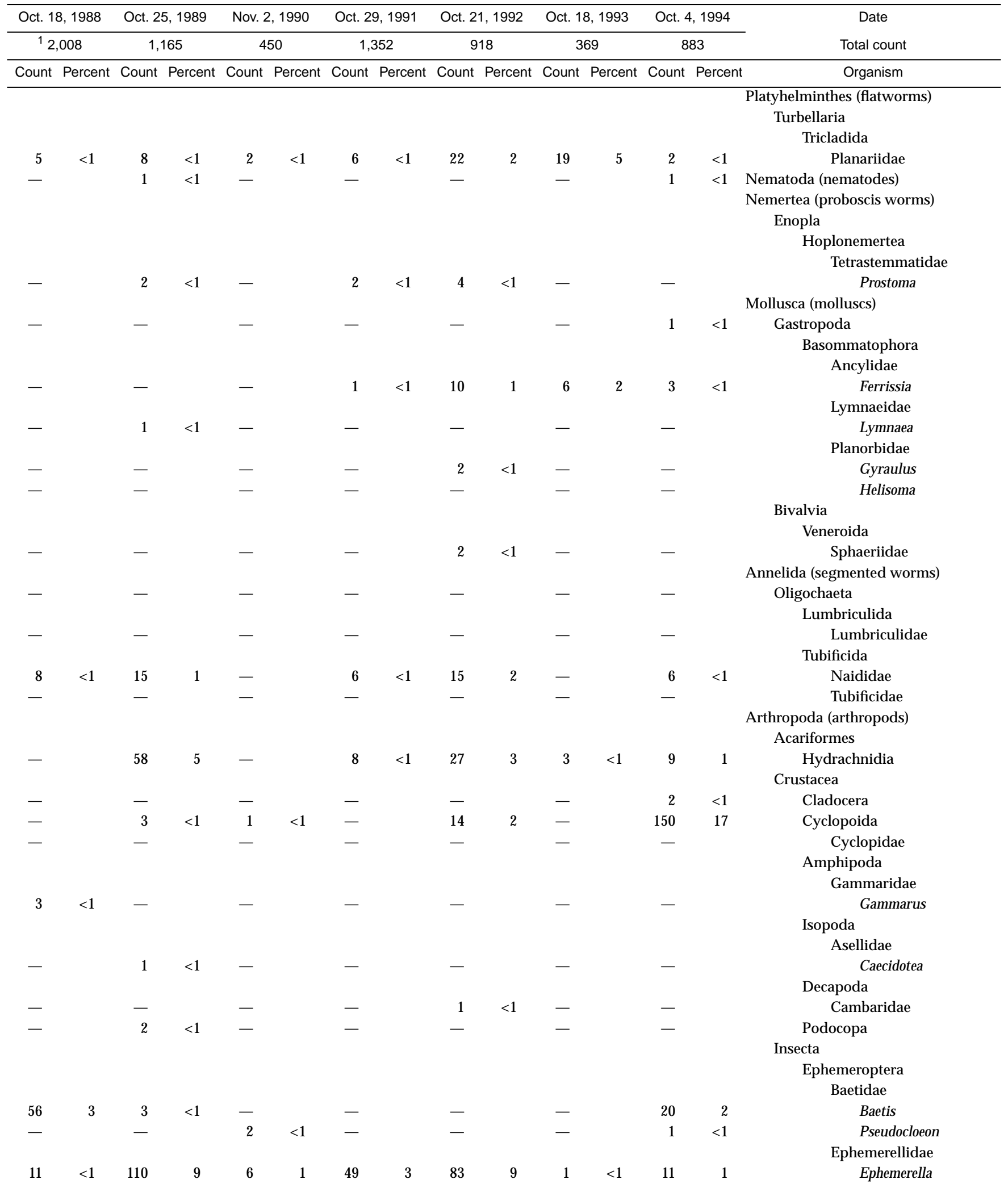


Table 5. Benthic-macroinvertebrate data—Continued

01475300 - Darby Creek at Waterloo Mills near Devon, Pa. (Site 17)—Continued

\begin{tabular}{|c|c|c|c|c|c|c|c|c|c|c|c|c|c|c|}
\hline \multirow{3}{*}{$\begin{array}{c}\text { Date } \\
\text { Total count } \\
\text { Organism }\end{array}$} & \multirow{2}{*}{\multicolumn{2}{|c|}{$\frac{\text { Oct. } 19,1981}{524}$}} & \multirow{2}{*}{\multicolumn{2}{|c|}{$\begin{array}{c}\text { Oct. } 13,1982 \\
215\end{array}$}} & \multirow{2}{*}{\multicolumn{2}{|c|}{$\frac{\text { Oct. } 27,1983}{403}$}} & \multirow{2}{*}{\multicolumn{2}{|c|}{$\begin{array}{c}\text { Oct. } 15,1984 \\
1,208\end{array}$}} & \multirow{2}{*}{\multicolumn{2}{|c|}{$\frac{\text { Oct. } 31,1985}{968}$}} & \multirow{2}{*}{\multicolumn{2}{|c|}{$\begin{array}{c}\text { Nov. } 14,1986 \\
706\end{array}$}} & \multirow{2}{*}{\multicolumn{2}{|c|}{$\begin{array}{c}\text { Oct. } 15,1987 \\
1,115\end{array}$}} \\
\hline & & & & & & & & & & & & & & \\
\hline & Count & Percent & Count & Percent & Count & Percent & Count & Percent & Count & Percent & Count & Percent & Count & Percent \\
\hline \multicolumn{15}{|l|}{ Ephemeroptera } \\
\hline \multicolumn{15}{|l|}{ Heptageniidae } \\
\hline Stenacron & - & & - & & - & & - & & - & & - & & - & \\
\hline Stenonema & 30 & 6 & 15 & 7 & 55 & 13 & 46 & 4 & 32 & 3 & 51 & 7 & 70 & 6 \\
\hline \multicolumn{15}{|l|}{ Isonychiidae } \\
\hline Isonychia & - & & - & & 2 & $<1$ & 21 & 2 & 6 & $<1$ & 12 & 2 & 39 & 4 \\
\hline \multicolumn{15}{|l|}{ Leptohyphidae } \\
\hline Tricorythodes & - & & - & & - & & - & & - & & - & & - & \\
\hline \multicolumn{15}{|l|}{ Leptophlebiidae } \\
\hline Paraleptophlebia & - & & - & & - & & - & & - & & - & & - & \\
\hline Odonata & & & & & & & & & & & & & & \\
\hline Coenagrionidae & & & & & & & & & & & & & & \\
\hline Argia & - & & - & & 1 & $<1$ & - & & - & & - & & - & \\
\hline Aeshnidae & & & & & & & & & & & & & & \\
\hline Boyeria & 1 & $<1$ & - & & - & & - & & - & & - & & - & \\
\hline Gomphidae & & & & & & & & & & & & & & \\
\hline Gomphus & - & & - & & - & & - & & - & & - & & - & \\
\hline Plecoptera & & & & & & & & & & & & & & \\
\hline Capniidae & & & & & & & & & & & & & & \\
\hline Allocapnia & 9 & 2 & - & & - & & 15 & 1 & 2 & $<1$ & - & & - & \\
\hline Chloroperlidae & - & & - & & - & & - & & - & & - & & - & \\
\hline Taeniopterygidae & & & & & & & & & & & & & & \\
\hline Taeniopteryx & - & & - & & - & & - & & - & & - & & - & \\
\hline Hemiptera & & & & & & & & & & & & & & \\
\hline Gerridae & & & & & & & & & & & & & & \\
\hline Gerris & - & & - & & - & & - & & - & & - & & - & \\
\hline Veliidae & & & & & & & & & & & & & & \\
\hline Rhagovelia & - & & - & & 6 & 2 & - & & - & & - & & - & \\
\hline Megaloptera & & & & & & & & & & & & & & \\
\hline Corydalidae & & & & & & & & & & & & & & \\
\hline Corydalus & - & & - & & - & & 2 & $<1$ & - & & 1 & $<1$ & 2 & $<1$ \\
\hline Nigronia & 1 & $<1$ & - & & 1 & $<1$ & 1 & $<1$ & - & & 2 & $<1$ & - & \\
\hline Sialidae & & & & & & & & & & & & & & \\
\hline Sialis & - & & - & & - & & - & & - & & - & & 1 & $<1$ \\
\hline Trichoptera & & & & & & & & & & & & & & \\
\hline Glossosomatidae & & & & & & & & & & & & & & \\
\hline Glossosoma & 9 & 2 & 4 & 2 & 13 & 3 & 49 & 4 & 23 & 2 & 31 & 4 & 30 & 3 \\
\hline Hydropsychidae & & & & & & & & & & & & & & \\
\hline Ceratopsyche & 24 & 5 & 17 & 8 & 77 & 19 & 140 & 12 & 69 & 7 & 87 & 12 & 240 & 22 \\
\hline Cheumatopsyche & 41 & 8 & 19 & 9 & 100 & 24 & 140 & 12 & 92 & 9 & 59 & 8 & 70 & 6 \\
\hline Diplectrona & - & & - & & - & & - & & - & & - & & - & \\
\hline Hydropsyche & 39 & 7 & 10 & 5 & 4 & 1 & 52 & 4 & 19 & 2 & 59 & 8 & 130 & 12 \\
\hline Hydroptilidae & & & & & & & & & & & & & & \\
\hline Agraylea & - & & - & & - & & 1 & $<1$ & - & & - & & - & \\
\hline Hydroptila & 38 & 7 & 5 & 3 & 15 & 4 & 20 & 2 & 2 & $<1$ & 14 & 2 & 5 & $<1$ \\
\hline Leucotrichia & - & & 3 & 2 & 1 & $<1$ & 200 & 17 & 260 & 27 & 14 & 2 & 17 & 2 \\
\hline Leptoceridae & & & & & & & & & & & & & & \\
\hline Oecetis & - & & - & & - & & - & & - & & - & & - & \\
\hline Triaenodes & - & & - & & - & & - & & - & & - & & - & \\
\hline Philopotamidae & & & & & & & & & & & & & & \\
\hline Chimarra & 37 & 7 & 18 & 8 & 30 & 7 & 70 & 6 & 68 & 7 & 160 & 23 & 9 & $<1$ \\
\hline Dolophilodes & - & & - & & - & & - & & - & & - & & - & \\
\hline Wormaldia & - & & - & & - & & - & & - & & - & & - & \\
\hline Psychomyiidae & & & & & & & & & & & & & & \\
\hline Psychomyia & - & & - & & - & & - & & - & & - & & - & \\
\hline
\end{tabular}




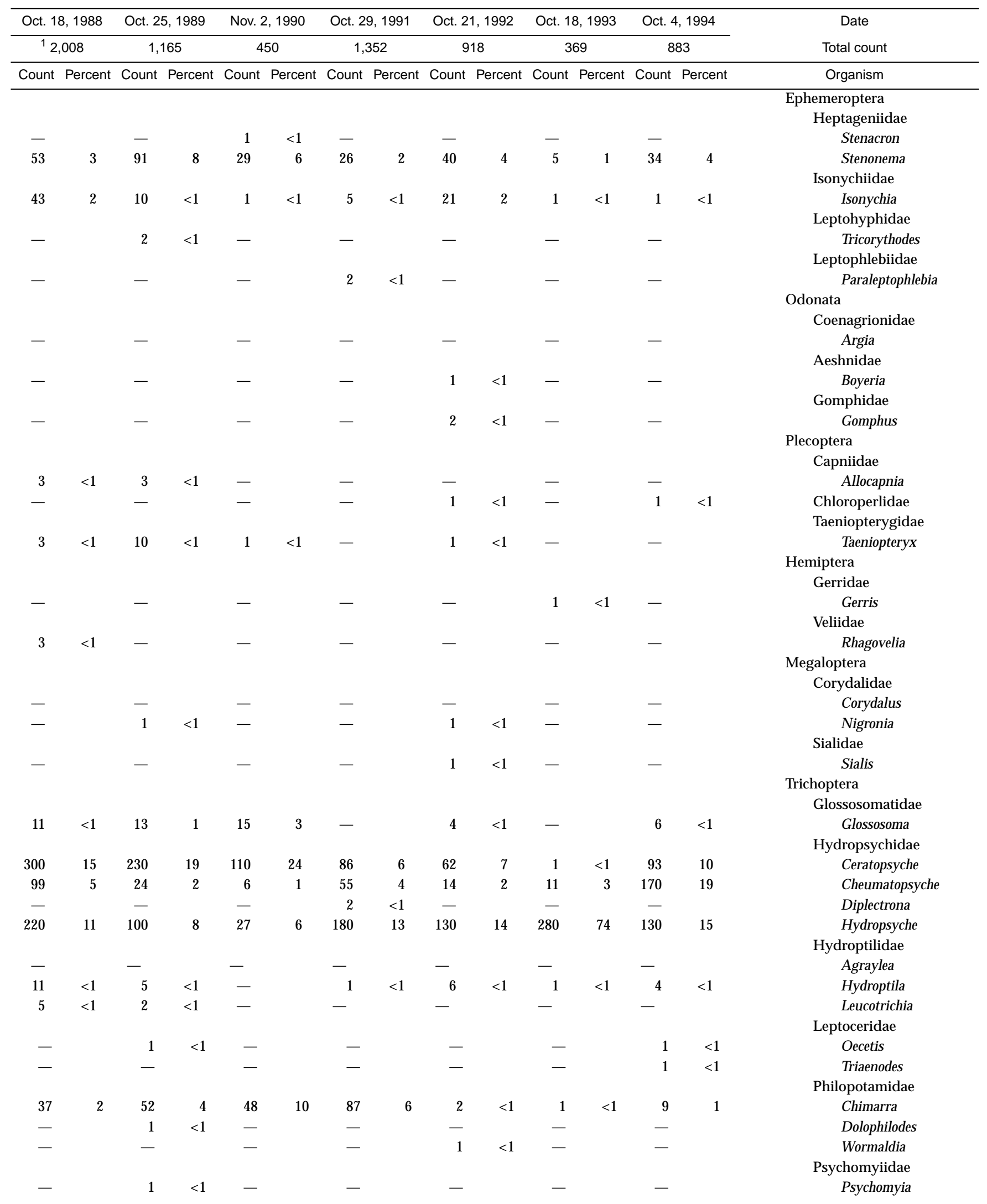


Table 5. Benthic-macroinvertebrate data-Continued

01475300 - Darby Creek at Waterloo Mills near Devon, Pa. (Site 17)—Continued

\begin{tabular}{|c|c|c|c|c|c|c|c|c|c|c|c|c|c|c|}
\hline \multirow{3}{*}{$\begin{array}{c}\text { Date } \\
\text { Total count } \\
\text { Organism }\end{array}$} & \multirow{2}{*}{\multicolumn{2}{|c|}{$\frac{\text { Oct. } 19,1981}{524}$}} & \multirow{2}{*}{\multicolumn{2}{|c|}{$\frac{\text { Oct. } 13,1982}{215}$}} & \multirow{2}{*}{\multicolumn{2}{|c|}{$\frac{\text { Oct. } 27,1983}{403}$}} & \multirow{2}{*}{\multicolumn{2}{|c|}{$\frac{\text { Oct. } 15,1984}{1,208}$}} & \multirow{2}{*}{\multicolumn{2}{|c|}{$\frac{\text { Oct. 31, } 1985}{968}$}} & \multirow{2}{*}{\multicolumn{2}{|c|}{$\frac{\text { Nov. } 14,1986}{706}$}} & \multirow{2}{*}{\multicolumn{2}{|c|}{$\frac{\text { Oct. } 15,1987}{1,115}$}} \\
\hline & & & & & & & & & & & & & & \\
\hline & Count & Percent & Count & Percent & Count & Percent & Count & Percent & Count & Percent & Count & Percent & Count & Percent \\
\hline \multicolumn{15}{|l|}{ Trichoptera } \\
\hline \multicolumn{15}{|l|}{ Rhyacophilidae } \\
\hline Rhyacophila & - & & - & & - & & - & & 1 & $<1$ & 1 & $<1$ & - & \\
\hline \multicolumn{15}{|l|}{ Uenoidae } \\
\hline Neophylax & - & & - & & - & & - & & - & & - & & - & \\
\hline \multicolumn{15}{|l|}{ Coleoptera } \\
\hline \multicolumn{15}{|l|}{ Elmidae } \\
\hline Ancyronyx & - & & - & & 1 & $<1$ & 3 & $<1$ & - & & - & & - & \\
\hline \multicolumn{15}{|l|}{ Macronychus } \\
\hline M. glabratus & - & & - & & 1 & $<1$ & - & & - & & - & & - & \\
\hline Microcylloepus & - & & - & & - & & - & & - & & - & & - & \\
\hline Optioservus & 27 & 5 & 19 & 9 & 6 & 2 & 25 & 2 & 38 & 4 & 14 & 2 & 36 & 3 \\
\hline Oulimnius & 2 & $<1$ & 9 & 4 & 4 & 1 & 17 & 1 & 16 & 2 & 1 & $<1$ & 22 & 2 \\
\hline Stenelmis & 36 & 7 & 18 & 8 & 17 & 4 & 39 & 3 & 35 & 4 & 1 & $<1$ & 23 & 2 \\
\hline \multicolumn{15}{|l|}{ Psephenidae } \\
\hline \multicolumn{15}{|l|}{ Ectopria } \\
\hline E. nervosa & - & & - & & 2 & $<1$ & - & & 1 & $<1$ & - & & - & \\
\hline Psephenus & 17 & 3 & 12 & 5 & 4 & 1 & 19 & 2 & 53 & 5 & 15 & 2 & 110 & 10 \\
\hline \multicolumn{15}{|l|}{ Diptera } \\
\hline Chironomidae & 170 & 32 & 51 & 23 & 41 & 10 & 240 & 20 & 170 & 18 & 77 & 11 & 150 & 14 \\
\hline \multicolumn{15}{|l|}{ Empididae } \\
\hline Chelifera & - & & - & & - & & - & & - & & - & & - & \\
\hline Hemerodromia & 5 & 1 & 1 & $<1$ & - & & 6 & $<1$ & 6 & $<1$ & - & & 7 & $<1$ \\
\hline \multicolumn{15}{|l|}{ Simuliidae } \\
\hline Simulium & 19 & 4 & 3 & 2 & 1 & $<1$ & 22 & 2 & 20 & 2 & 25 & 4 & 13 & 1 \\
\hline \multicolumn{15}{|l|}{ Tipulidae } \\
\hline Antocha & 1 & $<1$ & 3 & 2 & 4 & 1 & 25 & 2 & 33 & 3 & 32 & 5 & 49 & 4 \\
\hline Tipula & - & & - & & - & & - & & - & & - & & - & \\
\hline
\end{tabular}

${ }^{1}$ Extrapolated from a 3/8 subsample. 


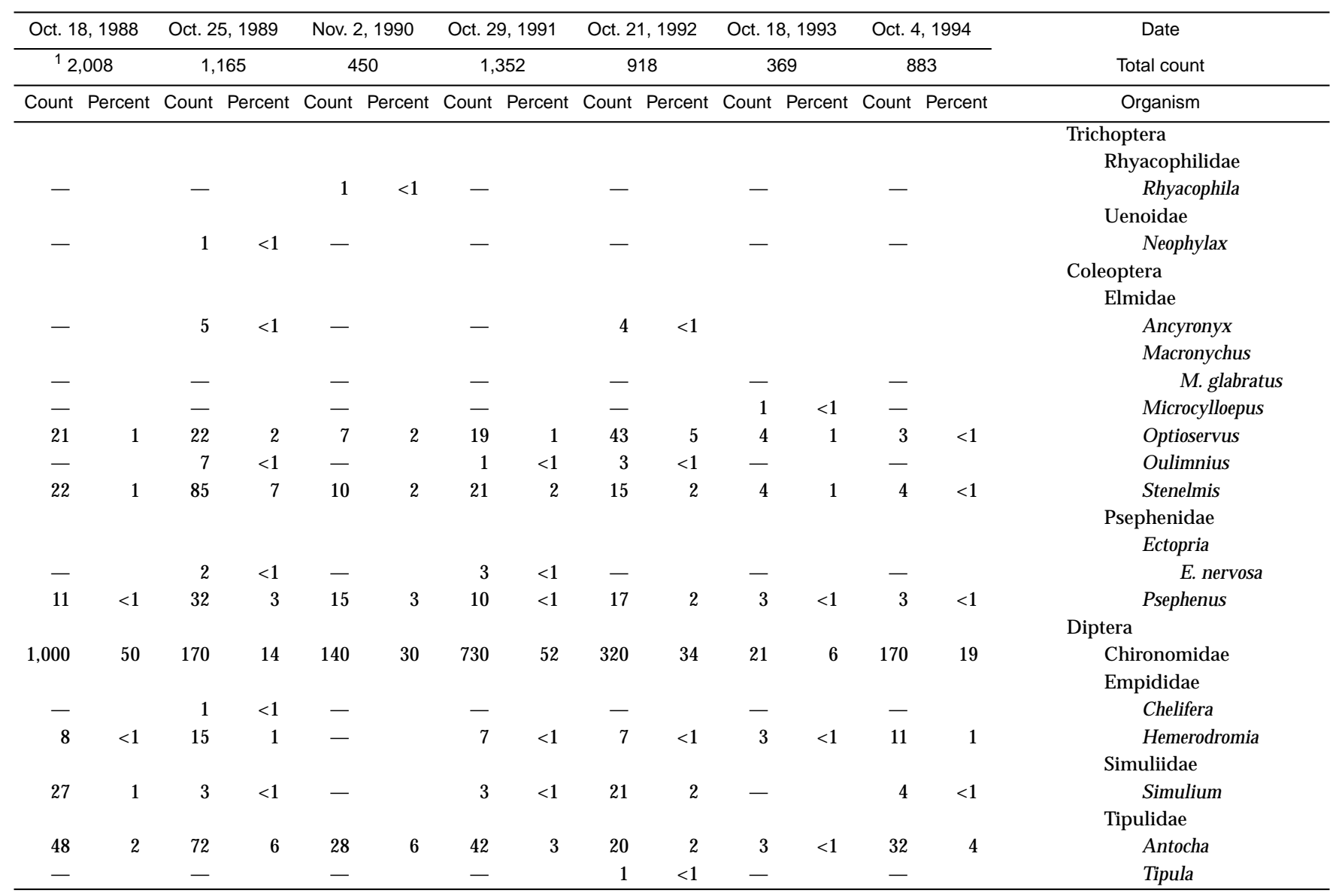


Table 5. Benthic-macroinvertebrate data-Continued

$[<$, less than; - , not found]

01475830 - Crum Creek near Paoli, Pa. (Site 18)

\begin{tabular}{|c|c|c|c|c|}
\hline \multirow{3}{*}{$\begin{array}{cc}\text { Date } \\
\text { Total count }\end{array}$} & \multirow{2}{*}{\multicolumn{2}{|c|}{$\begin{array}{c}\text { Oct. } 26,1981 \\
1,133\end{array}$}} & \multirow{2}{*}{\multicolumn{2}{|c|}{$\begin{array}{c}\text { Oct. } 13,1982 \\
581\end{array}$}} \\
\hline & & & & \\
\hline & Count & Percent & Count & Percent \\
\hline \multicolumn{5}{|l|}{ Platyhelminthes (flatworms) } \\
\hline \multicolumn{5}{|l|}{ Turbellaria } \\
\hline \multicolumn{5}{|l|}{ Tricladida } \\
\hline Planariidae & 6 & $<1$ & 9 & 2 \\
\hline \multicolumn{5}{|l|}{ Mollusca (molluscs) } \\
\hline \multicolumn{5}{|l|}{ Gastropoda } \\
\hline \multicolumn{5}{|l|}{ Basommatophora } \\
\hline \multicolumn{5}{|l|}{ Ancylidae } \\
\hline Ferrissia & 4 & $<1$ & 3 & $<1$ \\
\hline \multicolumn{5}{|l|}{ Lymnaeidae } \\
\hline Lymnaea & 2 & $<1$ & - & \\
\hline \multicolumn{5}{|l|}{ Annelida (segmented worms) } \\
\hline \multicolumn{5}{|l|}{ Oligochaeta } \\
\hline \multicolumn{5}{|l|}{ Tubificida } \\
\hline Naididae & - & & 6 & 1 \\
\hline \multicolumn{5}{|l|}{ Arthropoda (arthropods) } \\
\hline \multicolumn{5}{|l|}{ Acariformes } \\
\hline Hydrachnidia & 25 & 2 & 39 & 7 \\
\hline \multicolumn{5}{|l|}{ Crustacea } \\
\hline \multicolumn{5}{|l|}{ Decapoda } \\
\hline \multicolumn{5}{|l|}{ Cambaridae } \\
\hline Procambarus & - & & 1 & $<1$ \\
\hline \multicolumn{5}{|l|}{ Insecta } \\
\hline Ephemeroptera & & & & \\
\hline Baetidae & & & & \\
\hline Baetis & 4 & $<1$ & - & \\
\hline Pseudocloeon & 2 & $<1$ & - & \\
\hline Ephemerellidae & & & & \\
\hline Ephemerella & 87 & 8 & 26 & 4 \\
\hline Heptageniidae & & & & \\
\hline Stenonema & 160 & 15 & 75 & 13 \\
\hline Isonychiidae & & & & \\
\hline Isonychia & 82 & 7 & 8 & 1 \\
\hline Odonata & & & & \\
\hline Coenagrionidae & & & & \\
\hline Argia & 1 & $<1$ & 1 & $<1$ \\
\hline Plecoptera & & & & \\
\hline Perlidae & & & & \\
\hline Paragnetina & 2 & $<1$ & 1 & $<1$ \\
\hline Taeniopterygidae & & & & \\
\hline Taeniopteryx & 5 & $<1$ & - & \\
\hline Megaloptera & & & & \\
\hline Corydalidae & & & & \\
\hline Corydalus & 1 & $<1$ & 1 & $<1$ \\
\hline Trichoptera & & & & \\
\hline Glossosomatidae & & & & \\
\hline Glossosoma & 2 & $<1$ & 1 & $<1$ \\
\hline Hydropsychidae & & & & \\
\hline Ceratopsyche & 100 & 9 & 28 & 5 \\
\hline Cheumatopsyche & 73 & 7 & 32 & 5 \\
\hline Hydropsyche & 100 & 9 & 40 & 7 \\
\hline
\end{tabular}


Table 5. Benthic-macroinvertebrate data-Continued

01475830 - Crum Creek near Paoli, Pa. (Site 18)—Continued

\begin{tabular}{|c|c|c|c|c|}
\hline Date & \multicolumn{2}{|c|}{ Oct. 26, 1981} & \multicolumn{2}{|c|}{ Oct. 13, 1982} \\
\hline Total count & \multicolumn{2}{|c|}{1,133} & \multicolumn{2}{|c|}{581} \\
\hline Organism & Count & Percent & Count & Percent \\
\hline \multicolumn{5}{|l|}{ Trichoptera } \\
\hline \multicolumn{5}{|l|}{ Hydroptilidae } \\
\hline Hydroptila & 23 & 2 & 30 & 5 \\
\hline Leucotrichia & 11 & 1 & 63 & 11 \\
\hline \multicolumn{5}{|l|}{ Philopotamidae } \\
\hline Chimarra & 12 & 1 & 2 & $<1$ \\
\hline \multicolumn{5}{|l|}{ Lepidoptera } \\
\hline Noctuidae & - & & 1 & $<1$ \\
\hline \multicolumn{5}{|l|}{ Pyralidae } \\
\hline Petrophila & 53 & 5 & 52 & 9 \\
\hline \multicolumn{5}{|l|}{ Coleoptera } \\
\hline \multicolumn{5}{|l|}{ Elmidae } \\
\hline Optioservus & 2 & $<1$ & 4 & $<1$ \\
\hline Stenelmis & 4 & $<1$ & 6 & 1 \\
\hline \multicolumn{5}{|l|}{ Psephenidae } \\
\hline \multicolumn{5}{|l|}{ Ectopria } \\
\hline E. nervosa & 1 & $<1$ & - & \\
\hline Psephenus & 3 & $<1$ & 1 & $<1$ \\
\hline \multicolumn{5}{|l|}{ Diptera } \\
\hline \multicolumn{5}{|l|}{ Empididae } \\
\hline Hemerodromia & 25 & 2 & 13 & 2 \\
\hline \multicolumn{5}{|l|}{ Simuliidae } \\
\hline Simulium & 30 & 3 & 1 & $<1$ \\
\hline \multicolumn{5}{|l|}{ Tipulidae } \\
\hline Antocha & 33 & 3 & 17 & 3 \\
\hline
\end{tabular}


Table 5. Benthic-macroinvertebrate data-Continued

$[<$, less than; - , not found]

01475840 - Crum Creek at Whitehorse, Pa. (Site 19)

\begin{tabular}{|c|c|c|c|c|c|c|c|c|c|c|c|c|c|c|}
\hline \multirow{3}{*}{$\begin{array}{c}\text { Date } \\
\text { Total count } \\
\text { Organism }\end{array}$} & \multirow{2}{*}{\multicolumn{2}{|c|}{$\begin{array}{c}\text { Oct. } 26,1981 \\
992\end{array}$}} & \multirow{2}{*}{\multicolumn{2}{|c|}{$\begin{array}{c}\text { Oct. } 13,1982 \\
1,636\end{array}$}} & \multirow{2}{*}{\multicolumn{2}{|c|}{$\begin{array}{c}\text { Oct. } 27,1983 \\
525\end{array}$}} & \multirow{2}{*}{\multicolumn{2}{|c|}{$\begin{array}{c}\text { Oct. } 25,1984 \\
1,222\end{array}$}} & \multirow{2}{*}{\multicolumn{2}{|c|}{$\frac{\text { Oct. } 15,1985}{568}$}} & \multirow{2}{*}{\multicolumn{2}{|c|}{$\begin{array}{c}\text { Oct. 9, } 1986 \\
907\end{array}$}} & \multirow{2}{*}{\multicolumn{2}{|c|}{$\begin{array}{c}\text { Nov. 2, } 1987 \\
1,285\end{array}$}} \\
\hline & & & & & & & & & & & & & & \\
\hline & Count & Percent & Count & Percent & Count & Percent & Count & Percent & Count & Percent & Count & Percent & Count & Percent \\
\hline \multicolumn{15}{|l|}{ Platyhelminthes (flatworms) } \\
\hline \multicolumn{15}{|l|}{ Turbellaria } \\
\hline \multicolumn{15}{|l|}{ Tricladida } \\
\hline Planariidae & 6 & $<1$ & 50 & 3 & 12 & 2 & 6 & $<1$ & 1 & $<1$ & 1 & $<1$ & 8 & $<1$ \\
\hline Nematoda (nematodes) & - & & 2 & $<1$ & 2 & $<1$ & - & & - & & - & & - & \\
\hline \multicolumn{15}{|l|}{ Nemertea (proboscis worms) } \\
\hline \multicolumn{15}{|l|}{ Enopla } \\
\hline \multicolumn{15}{|l|}{ Hoplonemertea } \\
\hline \multicolumn{15}{|c|}{ Tetrastemmatidae } \\
\hline Prostoma & - & & 7 & $<1$ & - & & - & & - & & - & & - & \\
\hline \multicolumn{15}{|l|}{ Mollusca (molluscs) } \\
\hline \multicolumn{15}{|l|}{ Gastropoda } \\
\hline \multicolumn{15}{|l|}{ Basommatophora } \\
\hline Ancylidae & & & & & & & & & & & & & & \\
\hline Ferrissia & 9 & $<1$ & 11 & $<1$ & 2 & $<1$ & 7 & $<1$ & 6 & 1 & 36 & 4 & 19 & 1 \\
\hline Lymnaeidae & & & & & & & & & & & & & & \\
\hline Lymnaea & 1 & $<1$ & - & & - & & - & & - & & - & & 2 & $<1$ \\
\hline Physidae & & & & & & & & & & & & & & \\
\hline Physa & - & & - & & 1 & $<1$ & - & & - & & - & & - & \\
\hline Planorbidae & & & & & & & & & & & & & & \\
\hline Helisoma & - & & - & & - & & - & & - & & - & & 2 & $<1$ \\
\hline Bivalvia & & & & & & & & & & & & & & \\
\hline Veneroida & & & & & & & & & & & & & & \\
\hline Sphaeriidae & - & & - & & - & & - & & - & & - & & - & \\
\hline Pisidium & - & & - & & - & & - & & - & & - & & - & \\
\hline Sphaerium & 3 & $<1$ & - & & - & & - & & - & & - & & - & \\
\hline Annelida (segmented worms & & & & & & & & & & & & & & \\
\hline Oligochaeta & - & & - & & - & & - & & - & & - & & - & \\
\hline Lumbriculida & & & & & & & & & & & & & & \\
\hline Lumbriculidae & 5 & $<1$ & - & & - & & 1 & $<1$ & - & & - & & - & \\
\hline Tubificida & & & & & & & & & & & & & & \\
\hline Naididae & 22 & 2 & 98 & 6 & 3 & $<1$ & 7 & $<1$ & 2 & $<1$ & 1 & $<1$ & 150 & 12 \\
\hline Tubificidae & - & & - & & - & & - & & - & & - & & 3 & $<1$ \\
\hline Arthropoda (arthropods) & & & & & & & & & & & & & & \\
\hline Acariformes & & & & & & & & & & & & & & \\
\hline Hydrachnidia & 1 & $<1$ & 4 & $<1$ & - & & - & & 3 & $<1$ & 1 & $<1$ & 87 & 7 \\
\hline Crustacea & & & & & & & & & & & & & & \\
\hline Cyclopoida & - & & - & & - & & - & & - & & - & & - & \\
\hline Isopoda & & & & & & & & & & & & & & \\
\hline Asellidae & & & & & & & & & & & & & & \\
\hline Caecidotea & - & & - & & 1 & $<1$ & - & & - & & - & & - & \\
\hline Decapoda & & & & & & & & & & & & & & \\
\hline Cambaridae & - & & 1 & $<1$ & - & & - & & - & & - & & - & \\
\hline Cambarus & 1 & $<1$ & - & & - & & - & & - & & - & & - & \\
\hline Podocopa & - & & - & & - & & - & & - & & - & & - & \\
\hline
\end{tabular}
Insecta

Ephemeroptera

Baetidae

Baetis

Pseudocloeon

Caenidae

Caenis

Ephemerellidae

Ephemerella

$\begin{array}{rrrrrrrrrrrrrr}4 & <1 & 5 & <1 & - & & 2 & <1 & 2 & <1 & 12 & 1 & 10 & <1 \\ 5 & <1 & - & & 1 & <1 & - & & 3 & <1 & - & & - & \\ 1 & <1 & - & & 2 & <1 & - & & - & & - & & 4 & <1 \\ 29 & 3 & 67 & 4 & 19 & 4 & 34 & 3 & 20 & 3 & 21 & 2 & 40 & 3\end{array}$




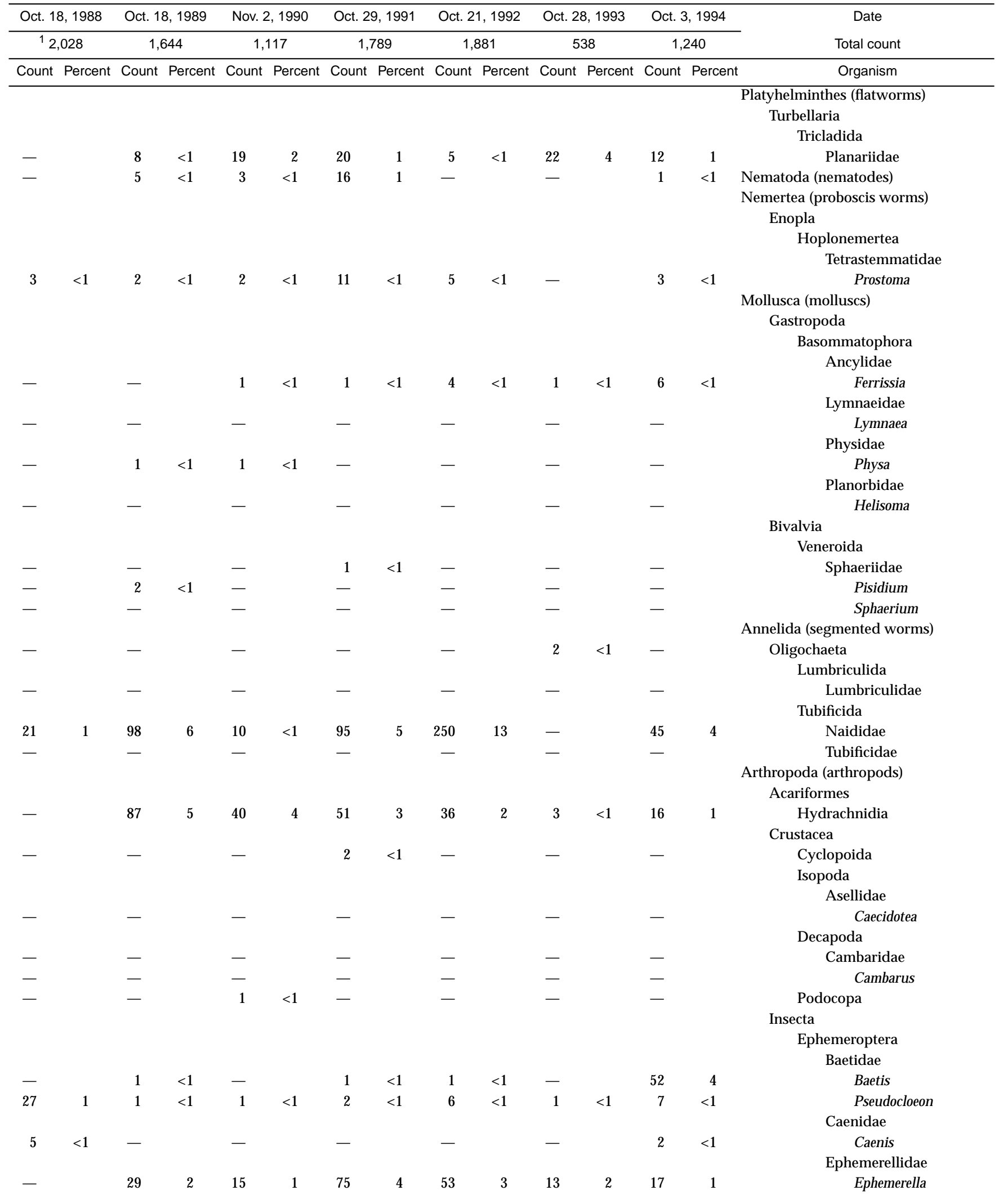


Table 5. Benthic-macroinvertebrate data-Continued

01475840 - Crum Creek at Whitehorse, Pa. (Site 19)—Continued

\begin{tabular}{|c|c|c|c|c|c|c|c|c|c|c|c|c|c|c|}
\hline \multirow{3}{*}{$\begin{array}{c}\text { Date } \\
\text { Total count } \\
\text { Organism }\end{array}$} & \multirow{2}{*}{\multicolumn{2}{|c|}{$\begin{array}{c}\text { Oct. } 26,1981 \\
992\end{array}$}} & \multirow{2}{*}{\multicolumn{2}{|c|}{$\begin{array}{c}\text { Oct. } 13,1982 \\
1,636\end{array}$}} & \multirow{2}{*}{\multicolumn{2}{|c|}{$\begin{array}{c}\text { Oct. } 27,1983 \\
525\end{array}$}} & \multirow{2}{*}{\multicolumn{2}{|c|}{$\begin{array}{c}\text { Oct. } 25,1984 \\
1,222\end{array}$}} & \multirow{2}{*}{\multicolumn{2}{|c|}{$\frac{\text { Oct. } 15,1985}{568}$}} & \multirow{2}{*}{\multicolumn{2}{|c|}{$\begin{array}{c}\text { Oct. 9, } 1986 \\
907\end{array}$}} & \multirow{2}{*}{\multicolumn{2}{|c|}{$\begin{array}{c}\text { Nov. 2, } 1987 \\
1,285\end{array}$}} \\
\hline & & & & & & & & & & & & & & \\
\hline & Count & Percent & Count & Percent & Count & Percent & Count & Percent & Count & Percent & Count & Percent & Count & Percent \\
\hline \multicolumn{15}{|l|}{ Ephemeroptera } \\
\hline \multicolumn{15}{|l|}{ Heptageniidae } \\
\hline Epeorus & 1 & $<1$ & - & & 5 & 1 & - & & - & & - & & 35 & 3 \\
\hline Stenonema & 55 & 6 & 51 & 3 & 24 & 4 & 39 & 3 & 25 & 4 & 33 & 4 & 39 & 3 \\
\hline \multicolumn{15}{|l|}{ Isonychiidae } \\
\hline Isonychia & 17 & 2 & 14 & $<1$ & 19 & 4 & 27 & 2 & 8 & 1 & 19 & 2 & 21 & 2 \\
\hline \multicolumn{15}{|l|}{ Leptohyphidae } \\
\hline Tricorythodes & - & & 2 & $<1$ & 1 & $<1$ & - & & - & & - & & - & \\
\hline \multicolumn{15}{|l|}{ Leptophlebiidae } \\
\hline Paraleptophlebia & - & & - & & - & & - & & - & & - & & - & \\
\hline Odonata & & & & & & & & & & & & & & \\
\hline Coenagrionidae & & & & & & & & & & & & & & \\
\hline Argia & - & & 1 & $<1$ & - & & - & & - & & - & & 1 & $<1$ \\
\hline Aeshnidae & & & & & & & & & & & & & & \\
\hline Aeshna & 1 & $<1$ & 1 & $<1$ & - & & - & & - & & - & & - & \\
\hline Gomphidae & 1 & $<1$ & - & & - & & - & & - & & - & & - & \\
\hline Plecoptera & & & & & & & & & & & & & & \\
\hline Capniidae & & & & & & & & & & & & & & \\
\hline Allocapnia & - & & - & & - & & - & & 3 & $<1$ & - & & 18 & 1 \\
\hline Chloroperlidae & - & & - & & - & & - & & - & & - & & 12 & $<1$ \\
\hline Perlidae & & & & & & & & & & & & & & \\
\hline Acroneuria & - & & - & & - & & - & & - & & 2 & $<1$ & - & \\
\hline Agnetina & - & & 2 & $<1$ & - & & - & & - & & - & & - & \\
\hline Neoperla & - & & - & & - & & - & & - & & - & & - & \\
\hline Paragnetina & 2 & $<1$ & - & & - & & - & & - & & - & & - & \\
\hline Taeniopterygidae & & & & & & & & & & & & & & \\
\hline Taeniopteryx & 1 & $<1$ & 1 & $<1$ & 2 & $<1$ & 1 & $<1$ & - & & 2 & $<1$ & 55 & 4 \\
\hline Hemiptera & & & & & & & & & & & & & & \\
\hline Veliidae & & & & & & & & & & & & & & \\
\hline Rhagovelia & 1 & $<1$ & 3 & $<1$ & - & & - & & - & & - & & - & \\
\hline Megaloptera & & & & & & & & & & & & & & \\
\hline Corydalidae & & & & & & & & & & & & & & \\
\hline Corydalus & 1 & $<1$ & - & & - & & 6 & $<1$ & 1 & $<1$ & - & & - & \\
\hline Nigronia & 1 & $<1$ & - & & 1 & $<1$ & - & & - & & - & & - & \\
\hline Sialidae & & & & & & & & & & & & & & \\
\hline Sialis & - & & - & & - & & - & & - & & - & & - & \\
\hline Trichoptera & & & & & & & & & & & & & & \\
\hline Apataniidae & & & & & & & & & & & & & & \\
\hline Apatania & - & & - & & - & & - & & - & & - & & 1 & $<1$ \\
\hline Brachycentridae & & & & & & & & & & & & & & \\
\hline Micrasema & - & & - & & - & & - & & - & & - & & 1 & $<1$ \\
\hline Glossosomatidae & & & & & & & & & & & & & & \\
\hline Glossosoma & 1 & $<1$ & 1 & $<1$ & - & & 5 & $<1$ & 3 & $<1$ & 1 & $<1$ & 3 & $<1$ \\
\hline Hydropsychidae & & & & & & & & & & & & & & \\
\hline Ceratopsyche & 160 & 16 & 270 & 17 & 43 & 8 & 210 & 18 & 36 & 6 & 48 & 5 & 200 & 15 \\
\hline Cheumatopsyche & 68 & 7 & 55 & 3 & 8 & 2 & 130 & 11 & 35 & 6 & 7 & $<1$ & 9 & $<1$ \\
\hline Hydropsyche & 32 & 3 & 67 & 4 & 1 & $<1$ & 10 & $<1$ & 1 & $<1$ & 24 & 3 & 40 & 3 \\
\hline Hydroptilidae & & & & & & & & & & & & & & \\
\hline Hydroptila & 65 & 7 & 3 & $<1$ & 14 & 3 & 19 & 2 & 2 & $<1$ & 7 & $<1$ & 14 & 1 \\
\hline Leucotrichia & 63 & 6 & 290 & 18 & 35 & 6 & 420 & 35 & 100 & 17 & 420 & 46 & 170 & 13 \\
\hline Leptoceridae & & & & & & & & & & & & & & \\
\hline Mystacides & - & & - & & - & & - & & - & & - & & - & \\
\hline Philopotamidae & & & & & & & & & & & & & & \\
\hline Chimarra & 49 & 5 & 35 & 2 & 3 & $<1$ & 12 & 1 & 3 & $<1$ & 11 & 1 & 14 & 1 \\
\hline
\end{tabular}




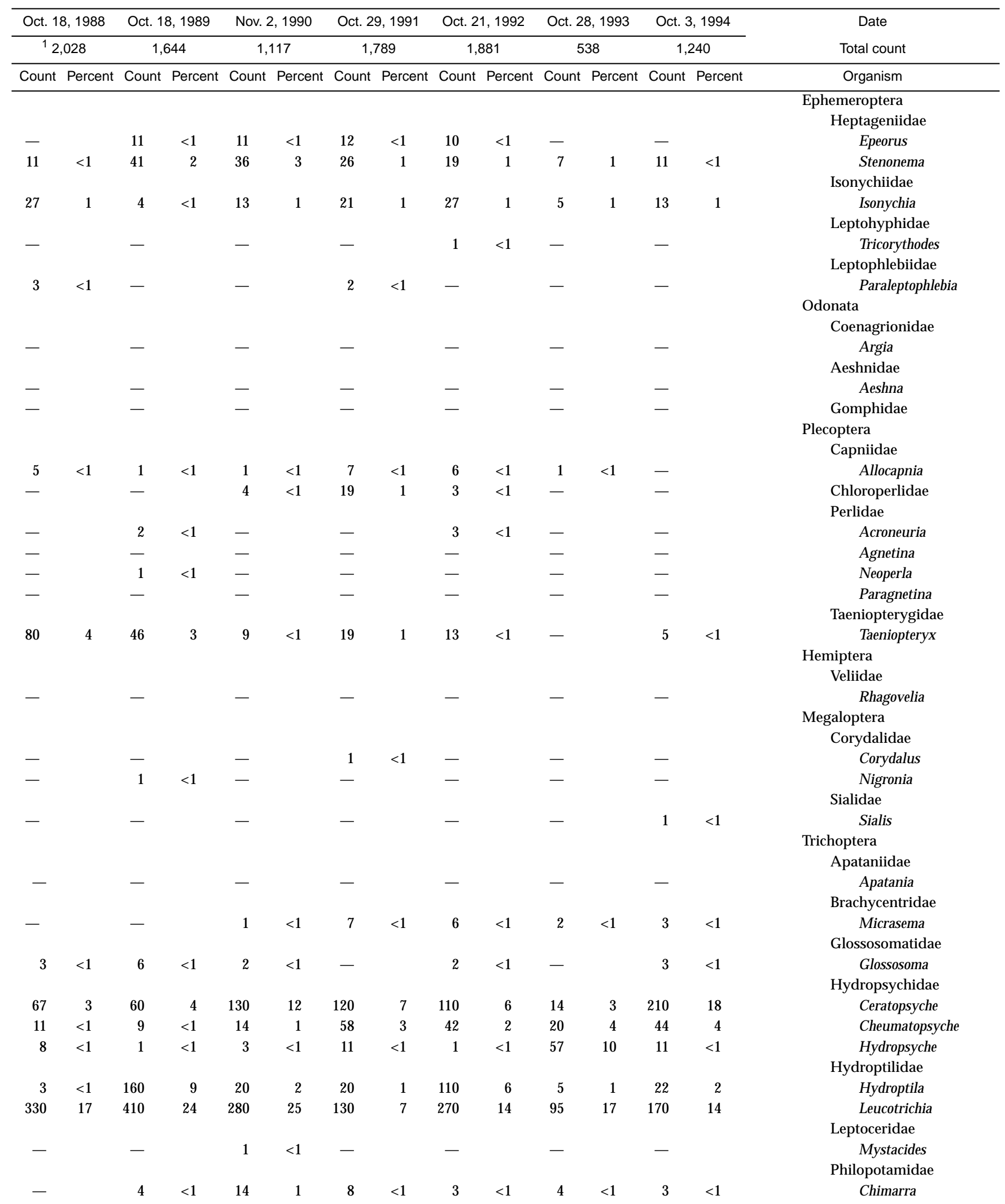


Table 5. Benthic-macroinvertebrate data-Continued

01475840 - Crum Creek at Whitehorse, Pa. (Site 19)—Continued

\begin{tabular}{|c|c|c|c|c|c|c|c|c|c|c|c|c|c|c|}
\hline \multirow{3}{*}{$\begin{array}{c}\text { Date } \\
\text { Total count } \\
\text { Organism }\end{array}$} & \multirow{2}{*}{\multicolumn{2}{|c|}{$\begin{array}{c}\text { Oct. 26, } 1981 \\
992\end{array}$}} & \multirow{2}{*}{\multicolumn{2}{|c|}{$\begin{array}{c}\text { Oct. } 13,1982 \\
1,636\end{array}$}} & \multirow{2}{*}{\multicolumn{2}{|c|}{$\begin{array}{c}\text { Oct. } 27,1983 \\
525\end{array}$}} & \multirow{2}{*}{\multicolumn{2}{|c|}{$\begin{array}{c}\text { Oct. } 25,1984 \\
1,222\end{array}$}} & \multirow{2}{*}{\multicolumn{2}{|c|}{$\begin{array}{c}\text { Oct. } 15,1985 \\
568\end{array}$}} & \multirow{2}{*}{\multicolumn{2}{|c|}{$\begin{array}{c}\text { Oct. 9, } 1986 \\
907\end{array}$}} & \multirow{2}{*}{\multicolumn{2}{|c|}{$\begin{array}{c}\text { Nov. 2, } 1987 \\
1,285\end{array}$}} \\
\hline & & & & & & & & & & & & & & \\
\hline & Count & Percent & Count & Percent & Count & Percent & Count & Percent & Count & Percent & Count & Percent & Count & Percent \\
\hline \multicolumn{15}{|l|}{ Trichoptera } \\
\hline \multicolumn{15}{|l|}{ Polycentropodidae } \\
\hline Neureclipsis & - & & - & & - & & - & & - & & 1 & $<1$ & - & \\
\hline Polycentropus & - & & 2 & $<1$ & 2 & $<1$ & - & & - & & 1 & $<1$ & - & \\
\hline \multicolumn{15}{|l|}{ Psychomyiidae } \\
\hline Psychomyia & - & & - & & - & & - & & 1 & $<1$ & - & & - & \\
\hline \multicolumn{15}{|l|}{ Rhyacophilidae } \\
\hline Rhyacophila & - & & 2 & $<1$ & 1 & $<1$ & - & & - & & - & & - & \\
\hline \multicolumn{15}{|l|}{ Uenoidae } \\
\hline Neophylax & - & & - & & - & & - & & - & & - & & - & \\
\hline \multicolumn{15}{|l|}{ Lepidoptera } \\
\hline Petrophila & 24 & 2 & 31 & 2 & 62 & 11 & 24 & 2 & 5 & $<1$ & 39 & 4 & 24 & 2 \\
\hline \multicolumn{15}{|l|}{ Coleoptera } \\
\hline Dubiraphia & - & & - & & - & & - & & - & & - & & - & \\
\hline Optioservus & 15 & 2 & 17 & 1 & 7 & 1 & 15 & 1 & 16 & 3 & 4 & $<1$ & 14 & 1 \\
\hline Oulimnius & - & & - & & - & & 7 & $<1$ & 1 & $<1$ & - & & - & \\
\hline Stenelmis & 6 & $<1$ & 7 & $<1$ & 1 & $<1$ & 7 & $<1$ & 2 & $<1$ & 5 & $<1$ & 5 & $<1$ \\
\hline \multicolumn{15}{|l|}{ Psephenidae } \\
\hline Ectopria & 2 & $<1$ & 2 & $<1$ & - & & - & & - & & - & & - & \\
\hline Psephenus & 2 & $<1$ & 4 & $<1$ & - & & 7 & $<1$ & 6 & 1 & 3 & $<1$ & - & \\
\hline Hymenoptera & - & & - & & - & & - & & - & & 4 & $<1$ & - & \\
\hline \multicolumn{15}{|l|}{ Diptera } \\
\hline \multicolumn{15}{|l|}{ Athericidae } \\
\hline Atherix & - & & - & & - & & - & & - & & - & & - & \\
\hline $\begin{array}{l}\text { Chironomidae } \\
\text { Empididae }\end{array}$ & 270 & 27 & 450 & 28 & 200 & 37 & 160 & 13 & 250 & 43 & 140 & 15 & 150 & 12 \\
\hline $\begin{array}{l}\text { Hemerodromia } \\
\text { Simuliidae }\end{array}$ & \multicolumn{13}{|c|}{ Simuliidae } & $<1$ \\
\hline $\begin{array}{l}\text { Simulium } \\
\text { Tipulidae }\end{array}$ & 5 & $<1$ & 46 & 3 & 2 & $<1$ & 2 & $<1$ & 12 & 2 & 11 & 1 & 28 & 2 \\
\hline Antocha & 47 & 5 & 19 & 1 & 49 & 9 & 60 & 5 & 18 & 3 & 49 & 5 & 100 & 8 \\
\hline
\end{tabular}

${ }^{1}$ Extrapolated from a 3/8 subsample. 


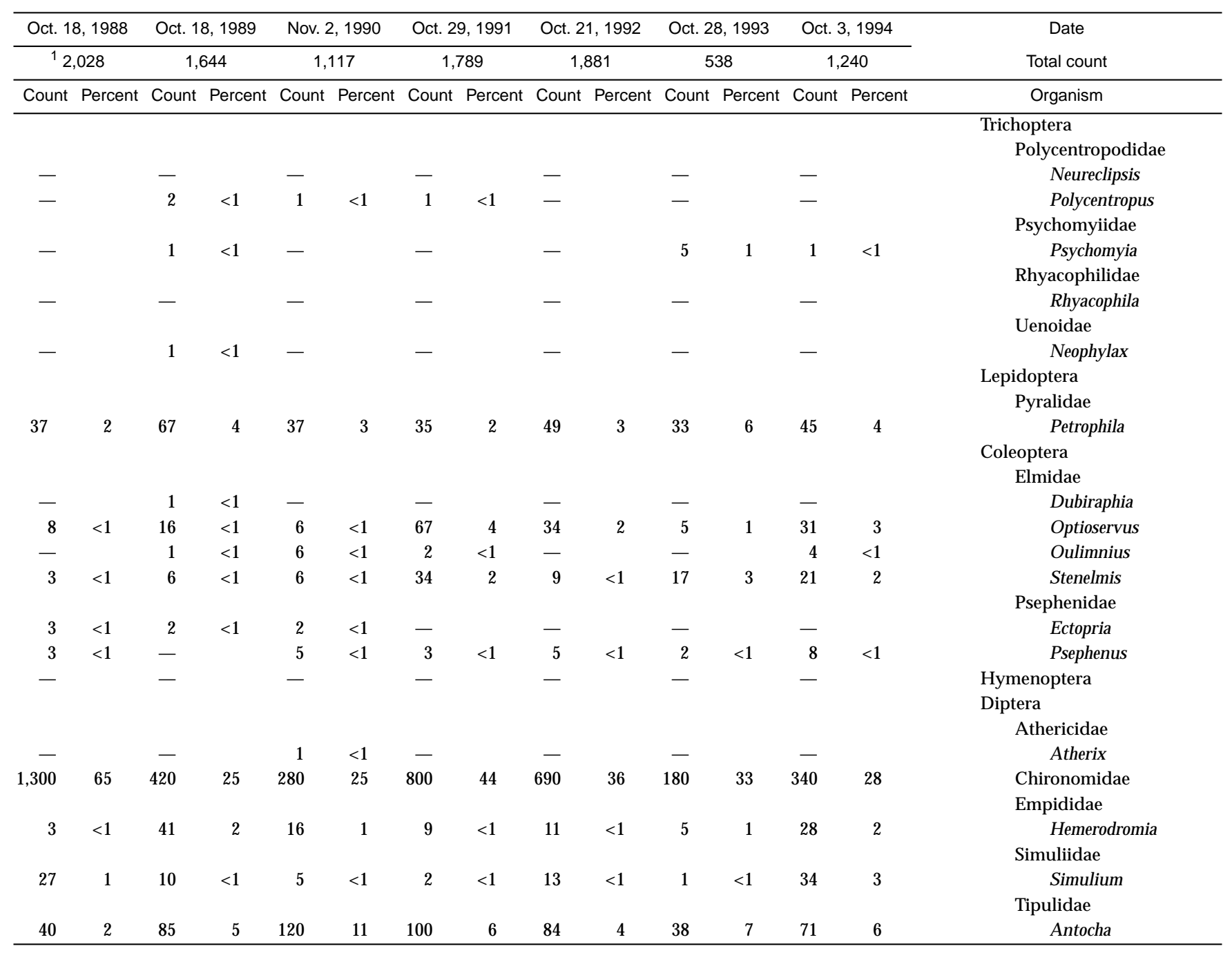


Table 5. Benthic-macroinvertebrate data-Continued

$[<$, less than; - , not found]

01476430 - Ridley Creek at Goshenville, Pa. (Site 20)

\begin{tabular}{|c|c|c|c|c|c|c|c|c|c|c|c|c|c|c|}
\hline \multirow{3}{*}{$\begin{array}{c}\text { Date } \\
\text { Total count } \\
\text { Organism }\end{array}$} & \multirow{2}{*}{\multicolumn{2}{|c|}{$\frac{\text { Nov. } 5,1981}{241}$}} & \multirow{2}{*}{\multicolumn{2}{|c|}{$\frac{\text { Oct. } 14,1982}{{ }^{1} 1,345}$}} & \multirow{2}{*}{\multicolumn{2}{|c|}{$\frac{\text { Oct. } 27,1983}{{ }^{1} 855}$}} & \multirow{2}{*}{\multicolumn{2}{|c|}{$\begin{array}{c}\text { Oct. } 25,1984 \\
{ }^{1} 1,688\end{array}$}} & \multirow{2}{*}{\multicolumn{2}{|c|}{$\frac{\text { Oct. } 15,1985}{722}$}} & \multirow{2}{*}{\multicolumn{2}{|c|}{$\begin{array}{c}\text { Oct. 9, } 1986 \\
980\end{array}$}} & \multirow{2}{*}{\multicolumn{2}{|c|}{$\frac{\text { Oct. } 26,1987}{1,881}$}} \\
\hline & & & & & & & & & & & & & & \\
\hline & Count & Percent & Count & Percent & Count & Percent & Count & Percent & Count & Percent & Count & Percent & Count & Percent \\
\hline \multicolumn{15}{|l|}{ Platyhelminthes (flatworms) } \\
\hline \multicolumn{15}{|l|}{ Turbellaria } \\
\hline \multicolumn{15}{|l|}{ Tricladida } \\
\hline Planariidae & 1 & $<1$ & 8 & $<1$ & 5 & $<1$ & - & & 41 & 6 & 36 & 4 & 35 & 2 \\
\hline Nematoda (nematodes) & - & & - & & - & & - & & - & & - & & 7 & $<1$ \\
\hline \multicolumn{15}{|l|}{ Nemertea (proboscis worms) } \\
\hline \multicolumn{15}{|l|}{ Enopla } \\
\hline \multicolumn{15}{|l|}{ Hoplonemertea } \\
\hline Tetrastemmatidae & & & & & & & & & & & & & & \\
\hline Prostoma & 2 & 1 & 3 & $<1$ & - & & 3 & $<1$ & - & & 3 & $<1$ & - & \\
\hline Mollusca (molluscs) & & & & & & & & & & & & & & \\
\hline Gastropoda & & & & & & & & & & & & & & \\
\hline Basommatophora & & & & & & & & & & & & & & \\
\hline Ancylidae & & & & & & & & & & & & & & \\
\hline Ferrissia & - & & 3 & $<1$ & - & & - & & - & & - & & 20 & 1 \\
\hline Lymnaeidae & & & & & & & & & & & & & & \\
\hline Lymnaea & 1 & $<1$ & - & & - & & - & & - & & - & & - & \\
\hline Physidae & & & & & & & & & & & & & & \\
\hline Physa & 6 & 3 & - & & 3 & $<1$ & - & & - & & - & & 4 & $<1$ \\
\hline Planorbidae & & & & & & & & & & & & & & \\
\hline Gyraulus & 1 & $<1$ & - & & - & & - & & - & & - & & - & \\
\hline Helisoma & - & & - & & - & & - & & - & & - & & 1 & $<1$ \\
\hline Bivalvia & & & & & & & & & & & & & & \\
\hline Veneroida & & & & & & & & & & & & & & \\
\hline Sphaeriidae & - & & - & & - & & - & & - & & - & & 6 & $<1$ \\
\hline Pisidium & - & & 5 & $<1$ & 5 & $<1$ & 5 & $<1$ & - & & - & & - & \\
\hline Sphaerium & - & & - & & - & & - & & - & & - & & - & \\
\hline Annelida (segmented worms) & & & & & & & & & & & & & & \\
\hline Oligochaeta & & & & & & & & & & & & & & \\
\hline Lumbriculida & & & & & & & & & & & & & & \\
\hline Lumbriculidae & - & & - & & 5 & $<1$ & 8 & $<1$ & - & & - & & - & \\
\hline Tubificida & & & & & & & & & & & & & & \\
\hline Naididae & - & & - & & - & & - & & - & & - & & 94 & 5 \\
\hline Tubificidae & 3 & 1 & - & & - & & - & & - & & - & & 6 & $<1$ \\
\hline Arthropoda (arthropods) & & & & & & & & & & & & & & \\
\hline Acariformes & & & & & & & & & & & & & & \\
\hline Hydrachnidia & - & & 3 & $<1$ & - & & - & & 8 & 1 & 26 & 3 & 58 & 3 \\
\hline Crustacea & & & & & & & & & & & & & & \\
\hline Cyclopoida & - & & - & & - & & - & & - & & - & & - & \\
\hline Cyclopidae & - & & - & & - & & - & & - & & - & & 3 & $<1$ \\
\hline Amphipoda & & & & & & & & & & & & & & \\
\hline Crangonyctidae & & & & & & & & & & & & & & \\
\hline Crangonyx & - & & - & & - & & - & & - & & - & & - & \\
\hline Gammaridae & & & & & & & & & & & & & & \\
\hline Gammarus & - & & - & & - & & - & & - & & - & & - & \\
\hline Talitridae & & & & & & & & & & & & & & \\
\hline Hyallela & & & & & & & & & & & & & & \\
\hline H. azteca & - & & - & & - & & - & & - & & - & & 11 & $<1$ \\
\hline Isopoda & & & & & & & & & & & & & & \\
\hline Asellidae & & & & & & & & & & & & & & \\
\hline Caecidotea & 1 & $<1$ & - & & 3 & $<1$ & - & & - & & - & & - & \\
\hline Podocopa & - & & - & & - & & - & & - & & - & & - & \\
\hline
\end{tabular}




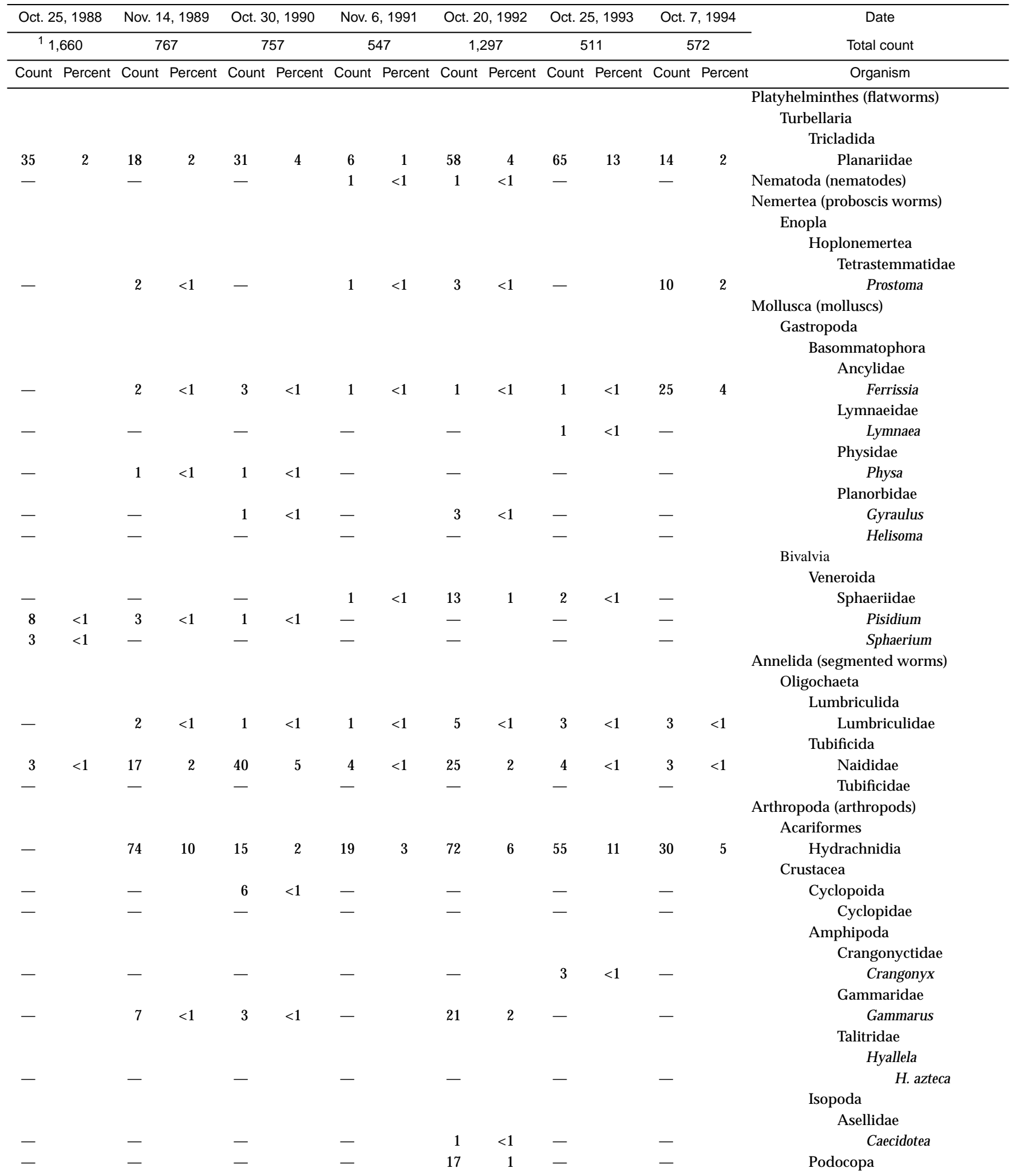


Table 5. Benthic-macroinvertebrate data-Continued

01476430 - Ridley Creek at Goshenville, Pa. (Site 20)—Continued

\begin{tabular}{|c|c|c|c|c|c|c|c|c|c|c|c|c|c|c|}
\hline \multirow{3}{*}{$\begin{array}{c}\text { Date } \\
\text { Total count } \\
\text { Organism }\end{array}$} & \multirow{2}{*}{\multicolumn{2}{|c|}{$\frac{\text { Nov. } 5,1981}{241}$}} & \multirow{2}{*}{\multicolumn{2}{|c|}{$\begin{array}{c}\text { Oct. } 14,1982 \\
11,345\end{array}$}} & \multirow{2}{*}{\multicolumn{2}{|c|}{$\begin{array}{c}\text { Oct. } 27,1983 \\
{ }^{1} 855\end{array}$}} & \multirow{2}{*}{\multicolumn{2}{|c|}{$\begin{array}{c}\text { Oct. } 25,1984 \\
{ }^{1} 1,688\end{array}$}} & \multirow{2}{*}{\multicolumn{2}{|c|}{$\frac{\text { Oct. } 15,1985}{722}$}} & \multirow{2}{*}{\multicolumn{2}{|c|}{$\begin{array}{c}\text { Oct. 9, } 1986 \\
980\end{array}$}} & \multirow{2}{*}{\multicolumn{2}{|c|}{$\begin{array}{c}\text { Oct. } 26,1987 \\
1,881\end{array}$}} \\
\hline & & & & & & & & & & & & & & \\
\hline & Count & Percent & Count & Percent & Count & Percent & Count & Percent & Count & Percent & Count & Percent & Count & Percent \\
\hline \multicolumn{15}{|l|}{ Insecta } \\
\hline \multicolumn{15}{|l|}{ Ephemeroptera } \\
\hline \multicolumn{15}{|l|}{ Baetidae } \\
\hline Baetis & - & & 3 & $<1$ & - & & 3 & $<1$ & 5 & $<1$ & 38 & 4 & 4 & $<1$ \\
\hline Pseudocloeon & - & & 3 & $<1$ & - & & - & & - & & - & & - & \\
\hline \multicolumn{15}{|l|}{ Ephemerellidae } \\
\hline Ephemerella & 14 & 6 & 32 & 2 & 130 & 15 & 130 & 8 & 17 & 2 & 57 & 6 & 120 & 6 \\
\hline \multicolumn{15}{|l|}{ Heptageniidae } \\
\hline Stenacron & - & & - & & - & & - & & - & & - & & - & \\
\hline Stenonema & 17 & 7 & 48 & 3 & 35 & 4 & 19 & 1 & 16 & 2 & 73 & 7 & 79 & 4 \\
\hline \multicolumn{15}{|l|}{ Isonychiidae } \\
\hline Isonychia & - & & - & & 5 & $<1$ & 3 & $<1$ & - & & - & & 3 & $<1$ \\
\hline Leptohyphidae & & & & & & & & & & & & & & \\
\hline Tricorythodes & - & & - & & - & & 3 & $<1$ & - & & - & & - & \\
\hline Odonata & & & & & & & & & & & & & & \\
\hline Coenagrionidae & & & & & & & & & & & & & & \\
\hline Argia & 1 & $<1$ & - & & - & & - & & - & & 2 & $<1$ & 2 & $<1$ \\
\hline Enallagma & - & & - & & - & & - & & - & & - & & - & \\
\hline Aeshnidae & & & & & & & & & & & & & & \\
\hline Aeshna & - & & - & & - & & - & & - & & - & & - & \\
\hline Boyeria & - & & - & & - & & - & & 1 & $<1$ & - & & - & \\
\hline Plecoptera & & & & & & & & & & & & & & \\
\hline Taeniopterygidae & & & & & & & & & & & & & & \\
\hline Taeniopteryx & 1 & $<1$ & 3 & $<1$ & - & & - & & 1 & $<1$ & 1 & $<1$ & 20 & 1 \\
\hline Hemiptera & & & & & & & & & & & & & & \\
\hline Veliidae & & & & & & & & & & & & & & \\
\hline Rhagovelia & - & & - & & - & & - & & - & & 1 & $<1$ & - & \\
\hline Megaloptera & & & & & & & & & & & & & & \\
\hline Corydalidae & & & & & & & & & & & & & & \\
\hline Nigronia & 1 & $<1$ & 3 & $<1$ & 3 & $<1$ & - & & - & & 1 & $<1$ & - & \\
\hline Sialidae & & & & & & & & & & & & & & \\
\hline Sialis & 2 & 1 & - & & - & & - & & - & & - & & - & \\
\hline Trichoptera & & & & & & & & & & & & & & \\
\hline Brachycentridae & & & & & & & & & & & & & & \\
\hline Micrasema & - & & - & & - & & 3 & $<1$ & - & & - & & - & \\
\hline Glossosomatidae & & & & & & & & & & & & & & \\
\hline Glossosoma & 1 & $<1$ & 5 & $<1$ & 3 & $<1$ & 21 & 1 & 1 & $<1$ & 2 & $<1$ & 1 & $<1$ \\
\hline Hydropsychidae & & & & & & & & & & & & & & \\
\hline Ceratopsyche & 12 & 5 & 220 & 16 & 150 & 17 & 290 & 17 & 90 & 12 & 99 & 10 & 220 & 12 \\
\hline Cheumatopsyche & 23 & 9 & 290 & 21 & 40 & 5 & 400 & 24 & 83 & 11 & 18 & 2 & 58 & 3 \\
\hline Hydropsyche & 14 & 6 & 45 & 3 & 35 & 4 & 100 & 6 & 31 & 4 & 220 & 22 & 310 & 16 \\
\hline Hydroptilidae & & & & & & & & & & & & & & \\
\hline Hydroptila & 2 & 1 & 48 & 3 & 13 & 2 & 11 & $<1$ & 4 & $<1$ & 25 & 3 & 100 & 5 \\
\hline Leucotrichia & - & & 130 & 9 & - & & 3 & $<1$ & 12 & 2 & 73 & 7 & 56 & 3 \\
\hline Leptoceridae & & & & & & & & & & & & & & \\
\hline Mystacides & - & & - & & - & & - & & - & & - & & - & \\
\hline Oecetis & - & & 5 & $<1$ & - & & - & & - & & - & & - & \\
\hline Philopotamidae & & & & & & & & & & & & & & \\
\hline Chimarra & - & & 53 & 4 & 37 & 4 & 29 & 2 & 7 & 1 & 49 & 5 & 2 & $<1$ \\
\hline Wormaldia & - & & - & & - & & - & & - & & - & & - & \\
\hline Polycentropodidae & & & & & & & & & & & & & & \\
\hline Polycentropus & 2 & 1 & 11 & $<1$ & - & & - & & - & & 2 & $<1$ & - & \\
\hline
\end{tabular}




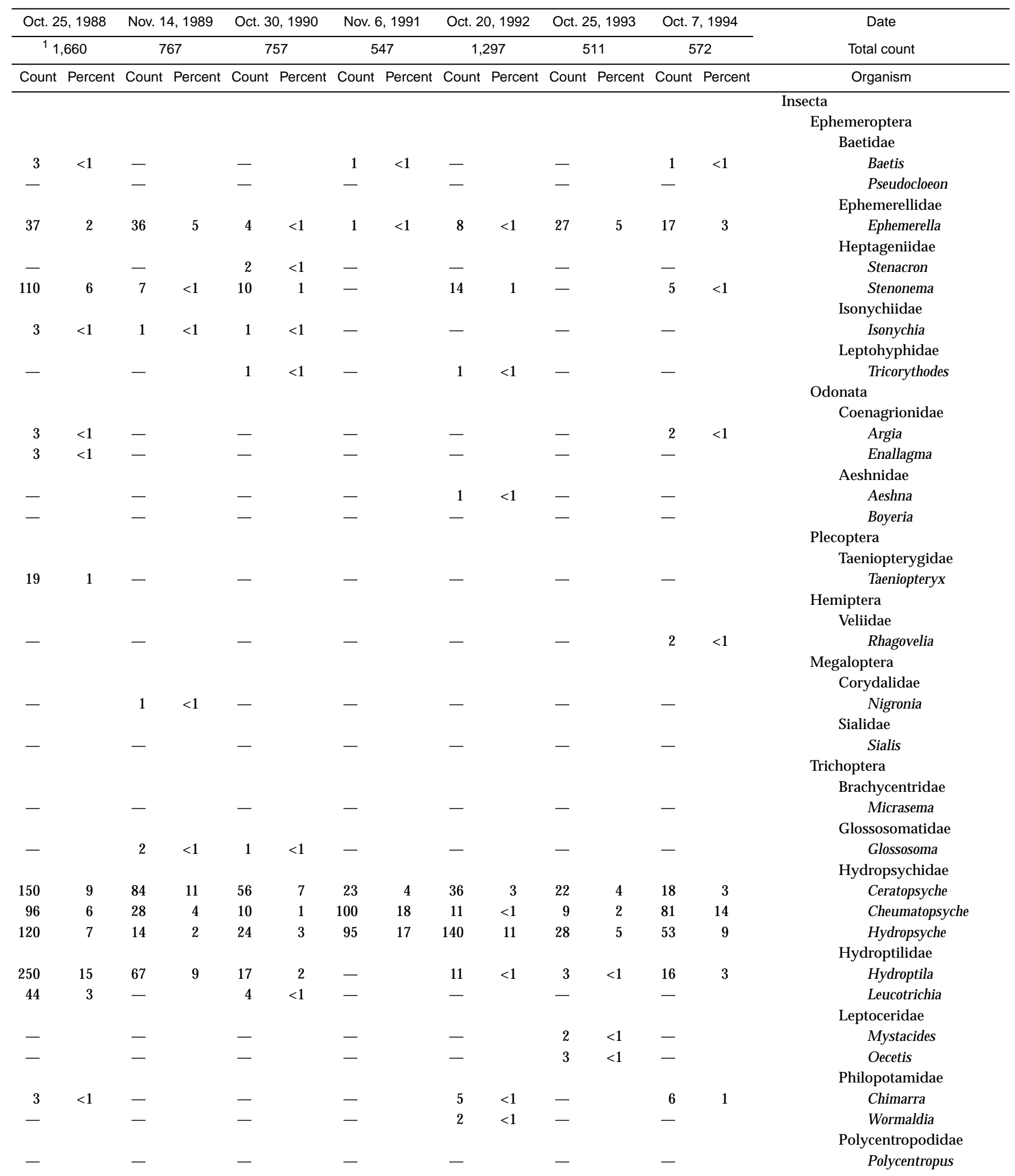


Table 5. Benthic-macroinvertebrate data-Continued

01476430 - Ridley Creek at Goshenville, Pa. (Site 20)—Continued

\begin{tabular}{|c|c|c|c|c|c|c|c|c|c|c|c|c|c|c|}
\hline \multirow{3}{*}{$\begin{array}{c}\text { Date } \\
\text { Total count } \\
\text { Organism }\end{array}$} & \multirow{2}{*}{\multicolumn{2}{|c|}{$\begin{array}{c}\text { Nov. } 5,1981 \\
241\end{array}$}} & \multirow{2}{*}{\multicolumn{2}{|c|}{$\begin{array}{c}\text { Oct. } 14,1982 \\
{ }^{1} 1,345\end{array}$}} & \multirow{2}{*}{\multicolumn{2}{|c|}{$\begin{array}{c}\text { Oct. } 27,1983 \\
{ }^{1} 855\end{array}$}} & \multirow{2}{*}{\multicolumn{2}{|c|}{$\begin{array}{c}\text { Oct. } 25,1984 \\
11,688\end{array}$}} & \multirow{2}{*}{\multicolumn{2}{|c|}{$\frac{\text { Oct. } 15,1985}{722}$}} & \multirow{2}{*}{\multicolumn{2}{|c|}{$\begin{array}{c}\text { Oct. 9, } 1986 \\
980\end{array}$}} & \multirow{2}{*}{\multicolumn{2}{|c|}{$\begin{array}{c}\text { Oct. } 26,1987 \\
1,881\end{array}$}} \\
\hline & & & & & & & & & & & & & & \\
\hline & Count & Percent & Count & Percent & Count & Percent & Count & Percent & Count & Percent & Count & Percent & Count & Percent \\
\hline \multicolumn{15}{|l|}{ Trichoptera } \\
\hline \multicolumn{15}{|l|}{ Psychomyiidae } \\
\hline Psychomyia & 2 & 1 & 110 & 8 & - & & - & & - & & - & & - & \\
\hline \multicolumn{15}{|l|}{ Rhyacophilidae } \\
\hline $\begin{array}{l}\text { Rhyacophila } \\
\text { Uenoidae }\end{array}$ & \multicolumn{13}{|c|}{ Uenoidae } & \\
\hline Neophylax & - & & - & & - & & - & & - & & - & & - & \\
\hline \multicolumn{15}{|l|}{ Lepidoptera } \\
\hline \multicolumn{15}{|l|}{ Noctuidae } \\
\hline Archanara & - & & - & & - & & - & & - & & - & & - & \\
\hline \multicolumn{15}{|l|}{ Coleoptera } \\
\hline $\begin{array}{l}\text { Curculionidae } \\
\text { Elmidae }\end{array}$ & - & & - & & - & & - & & - & & - & & - & \\
\hline Ancyronyx & - & & - & & - & & - & & & & - & & - & \\
\hline A. variegata & - & & - & & - & & - & & - & & - & & - & \\
\hline Dubiraphia & 2 & 1 & - & & - & & - & & - & & - & & - & \\
\hline Optioservus & 1 & $<1$ & 56 & 4 & 13 & 2 & 8 & $<1$ & 1 & $<1$ & 4 & $<1$ & 16 & $<1$ \\
\hline Oulimnius & - & & 3 & $<1$ & - & & - & & - & & - & & - & \\
\hline Promoresia & - & & 3 & $<1$ & - & & - & & - & & - & & - & \\
\hline Stenelmis & 1 & $<1$ & 5 & $<1$ & 3 & $<1$ & - & & - & & - & & - & \\
\hline \multicolumn{15}{|l|}{ Psephenidae } \\
\hline \multicolumn{15}{|l|}{ Ectopria } \\
\hline \multicolumn{15}{|l|}{ E. nervosa } \\
\hline Psephenus & - & & - & & - & & - & & - & & - & & - & \\
\hline Hymenoptera & - & & - & & - & & - & & - & & 2 & $<1$ & - & \\
\hline \multicolumn{15}{|l|}{ Diptera } \\
\hline $\begin{array}{l}\text { Chironomidae } \\
\text { Empididae }\end{array}$ & \multicolumn{10}{|c|}{ Empididae } & 82 & 8 & 250 & 13 \\
\hline Chelifera & - & & - & & - & & - & & - & & - & & - & \\
\hline Hemerodromia & 4 & 2 & 11 & $<1$ & 11 & 1 & 3 & $<1$ & 4 & $<1$ & 10 & 1 & 13 & $<1$ \\
\hline $\begin{array}{l}\text { Ephydridae } \\
\text { Psychodidae }\end{array}$ & - & \multicolumn{9}{|c|}{ Psychodidae } & - & & 2 & $<1$ \\
\hline $\begin{array}{l}\text { Telmatoscopus } \\
\text { Simuliidae }\end{array}$ & \multicolumn{13}{|c|}{ Simuliidae } & \\
\hline Simulium & 80 & 32 & 27 & 2 & 130 & 15 & 290 & 17 & 47 & 6 & 58 & 6 & 240 & 13 \\
\hline \multicolumn{15}{|l|}{ Tipulidae } \\
\hline Antocha & 7 & 3 & 69 & 5 & 27 & 3 & 96 & 6 & 73 & 10 & 96 & 10 & 140 & 7 \\
\hline Tipula & - & & - & & - & & - & & - & & 1 & $<1$ & - & \\
\hline
\end{tabular}

${ }^{1}$ Extrapolated from a 3/8 subsample. 


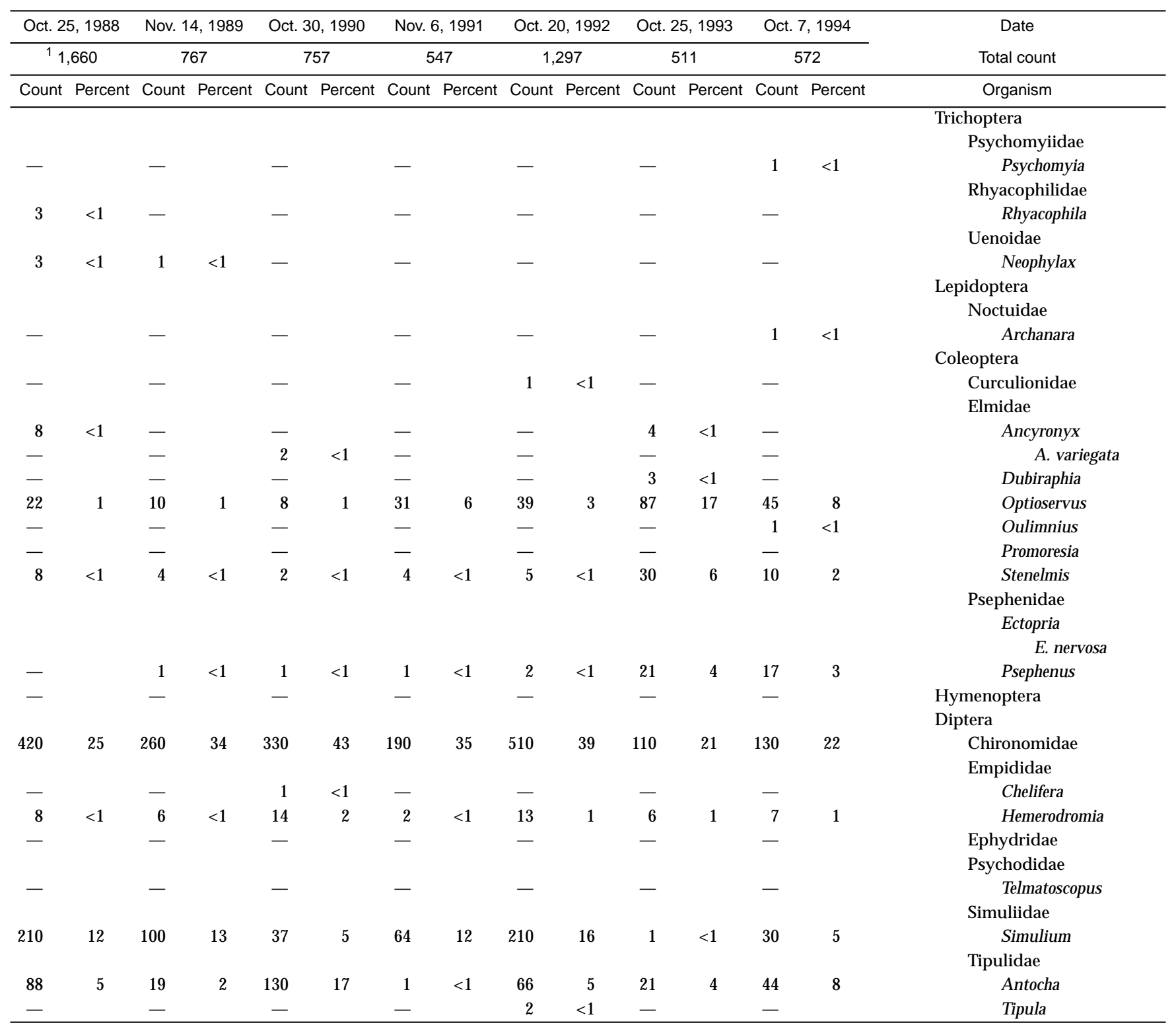


Table 5. Benthic-macroinvertebrate data-Continued

$[<$, less than; - , not found]

01476435 - Ridley Creek at Dutton Mill near West Chester, Pa. (Site 21)

\begin{tabular}{|c|c|c|c|c|c|c|c|c|c|c|c|c|c|c|}
\hline \multirow{3}{*}{ 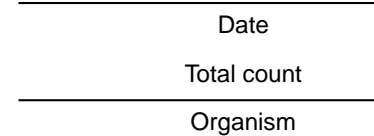 } & \multirow{2}{*}{\multicolumn{2}{|c|}{$\begin{array}{c}\text { Nov. } 5,1981 \\
1,407\end{array}$}} & \multirow{2}{*}{\multicolumn{2}{|c|}{$\begin{array}{c}\text { Oct. } 14,1982 \\
11,578\end{array}$}} & \multirow{2}{*}{\multicolumn{2}{|c|}{$\begin{array}{c}\text { Oct. } 27,1983 \\
{ }^{1} 1,697\end{array}$}} & \multirow{2}{*}{\multicolumn{2}{|c|}{$\begin{array}{c}\text { Oct. } 15,1984 \\
{ }^{1} 3,842\end{array}$}} & \multirow{2}{*}{\multicolumn{2}{|c|}{$\begin{array}{c}\text { Oct. } 15,1985 \\
1,617\end{array}$}} & \multirow{2}{*}{\multicolumn{2}{|c|}{$\begin{array}{c}\text { Oct. } 9,1986 \\
1,629\end{array}$}} & \multirow{2}{*}{\multicolumn{2}{|c|}{$\begin{array}{c}\text { Oct. } 15,1987 \\
1,198\end{array}$}} \\
\hline & & & & & & & & & & & & & & \\
\hline & Count & Percent & Count & Percent & Count & Percent & Count & Percent & Count & Percent & Count & Percent & Count & Percent \\
\hline \multicolumn{15}{|l|}{ Platyhelminthes (flatworms) } \\
\hline \multicolumn{15}{|l|}{ Turbellaria } \\
\hline \multicolumn{15}{|l|}{ Tricladida } \\
\hline Planariidae & 31 & 2 & - & & 61 & 4 & 27 & $<1$ & 37 & 2 & 50 & 3 & 10 & $<1$ \\
\hline Nematoda (nematodes) & - & & - & & - & & - & & - & & - & & - & \\
\hline \multicolumn{15}{|l|}{ Nemertea (proboscis worms) } \\
\hline \multicolumn{15}{|l|}{ Enopla } \\
\hline Hoplonemertea & & & & & & & & & & & & & & \\
\hline Tetrastemmatida & & & & & & & & & & & & & & \\
\hline Prostoma & 2 & $<1$ & 3 & $<1$ & - & & - & & 5 & $<1$ & 2 & $<1$ & - & \\
\hline Mollusca (molluscs) & & & & & & & & & & & & & & \\
\hline Gastropoda & & & & & & & & & & & & & & \\
\hline Basommatophora & & & & & & & & & & & & & & \\
\hline Ancylidae & & & & & & & & & & & & & & \\
\hline Ferrissia & 2 & $<1$ & - & & - & & 21 & $<1$ & 5 & $<1$ & 13 & $<1$ & 47 & 4 \\
\hline Lymnaeidae & & & & & & & & & & & & & & \\
\hline Lymnaea & - & & - & & - & & - & & - & & 1 & $<1$ & - & \\
\hline Physidae & & & & & & & & & & & & & & \\
\hline Physa & - & & - & & - & & - & & - & & - & & - & \\
\hline Planorbidae & & & & & & & & & & & & & & \\
\hline Gyraulus & - & & - & & - & & - & & - & & - & & - & \\
\hline Bivalvia & & & & & & & & & & & & & & \\
\hline Veneroida & & & & & & & & & & & & & & \\
\hline Sphaeriidae & - & & - & & - & & - & & 10 & $<1$ & 8 & $<1$ & - & \\
\hline Pisidium & 3 & $<1$ & - & & 5 & $<1$ & - & & - & & - & & - & \\
\hline Sphaerium & - & & - & & - & & - & & - & & - & & - & \\
\hline Annelida (segmented worms) & & & & & & & & & & & & & & \\
\hline Oligochaeta & & & & & & & & & & & & & & \\
\hline Lumbriculida & & & & & & & & & & & & & & \\
\hline Lumbriculidae & - & & 3 & $<1$ & - & & 3 & $<1$ & - & & - & & 1 & $<1$ \\
\hline Tubificida & & & & & & & & & & & & & & \\
\hline Naididae & 1 & $<1$ & - & & - & & - & & - & & - & & 2 & $<1$ \\
\hline Tubificidae & - & & 3 & $<1$ & - & & - & & - & & - & & - & \\
\hline Arthropoda (arthropods) & & & & & & & & & & & & & & \\
\hline Acariformes & & & & & & & & & & & & & & \\
\hline Hydrachnidia & - & & 3 & $<1$ & 3 & $<1$ & - & & 3 & $<1$ & 140 & 9 & 16 & 1 \\
\hline Crustacea & & & & & & & & & & & & & & \\
\hline Cyclopoida & - & & - & & - & & - & & - & & - & & - & \\
\hline Cyclopidae & - & & - & & - & & - & & - & & - & & 1 & $<1$ \\
\hline Amphipoda & & & & & & & & & & & & & & \\
\hline Crangonyctidae & & & & & & & & & & & & & & \\
\hline Crangonyx & - & & - & & - & & - & & - & & - & & - & \\
\hline Isopoda & & & & & & & & & & & & & & \\
\hline Asellidae & & & & & & & & & & & & & & \\
\hline Caecidotea & - & & - & & 5 & $<1$ & - & & - & & - & & - & \\
\hline Insecta & & & & & & & & & & & & & & \\
\hline Ephemeroptera & & & & & & & & & & & & & & \\
\hline Baetidae & & & & & & & & & & & & & & \\
\hline Baetis & - & & 35 & 2 & 5 & $<1$ & 64 & 2 & 4 & $<1$ & 18 & 1 & 10 & $<1$ \\
\hline Pseudocloeon & - & & 19 & 1 & 35 & 2 & 80 & 2 & - & & - & & 42 & 3 \\
\hline Caenidae & & & & & & & & & & & & & & \\
\hline Caenis & - & & - & & - & & - & & - & & - & & - & \\
\hline Ephemerellidae & & & & & & & & & & & & & & \\
\hline Ephemerella & 110 & 8 & 64 & 4 & 260 & 15 & 200 & 5 & 100 & 6 & 72 & 5 & 27 & 2 \\
\hline
\end{tabular}




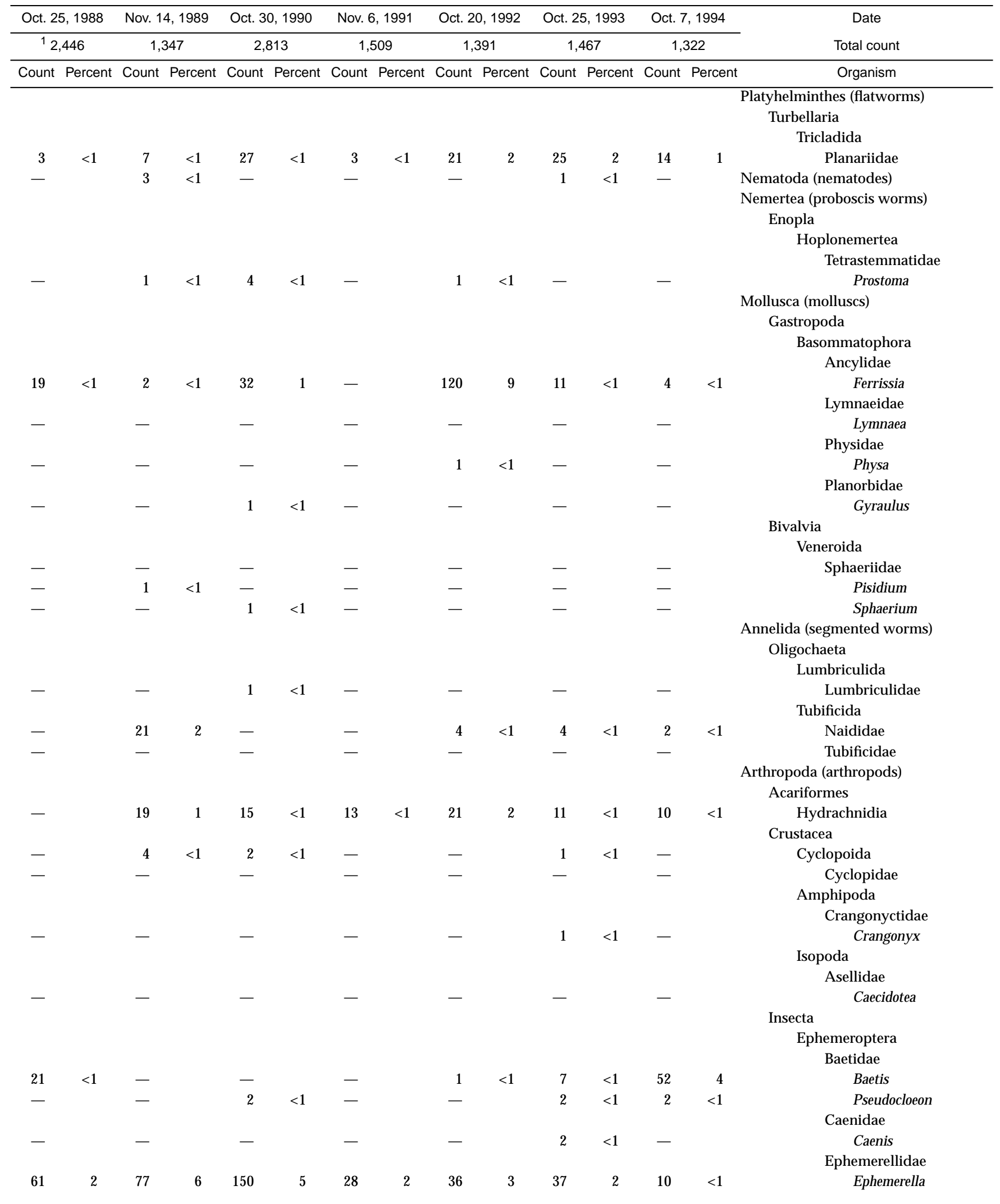


Table 5. Benthic-macroinvertebrate data-Continued

01476435 - Ridley Creek at Dutton Mill near West Chester, Pa. (Site 21)—Continued

\begin{tabular}{|c|c|c|c|c|c|c|c|c|c|c|c|c|c|c|}
\hline \multirow{3}{*}{$\begin{array}{c}\text { Date } \\
\text { Total count } \\
\text { Organism }\end{array}$} & \multirow{2}{*}{\multicolumn{2}{|c|}{$\begin{array}{c}\text { Nov. } 5,1981 \\
1,407\end{array}$}} & \multirow{2}{*}{\multicolumn{2}{|c|}{$\begin{array}{c}\text { Oct. } 14,1982 \\
{ }^{1} 1,578\end{array}$}} & \multirow{2}{*}{\multicolumn{2}{|c|}{$\begin{array}{c}\text { Oct. } 27,1983 \\
{ }^{1} 1,697\end{array}$}} & \multirow{2}{*}{\multicolumn{2}{|c|}{$\begin{array}{c}\text { Oct. } 15,1984 \\
{ }^{1} 3,842\end{array}$}} & \multirow{2}{*}{\multicolumn{2}{|c|}{$\begin{array}{c}\text { Oct. } 15,1985 \\
1,617\end{array}$}} & \multirow{2}{*}{\multicolumn{2}{|c|}{$\begin{array}{c}\text { Oct. 9, } 1986 \\
1,629\end{array}$}} & \multirow{2}{*}{\multicolumn{2}{|c|}{$\begin{array}{c}\text { Oct. } 15,1987 \\
1,198\end{array}$}} \\
\hline & & & & & & & & & & & & & & \\
\hline & Count & Percent & Count & Percent & Count & Percent & Count & Percent & Count & Percent & Count & Percent & Count & Percent \\
\hline \multicolumn{15}{|l|}{ Ephemeroptera } \\
\hline \multicolumn{15}{|l|}{ Heptageniidae } \\
\hline Epeorus & 2 & $<1$ & 5 & $<1$ & 5 & $<1$ & 3 & $<1$ & - & & - & & - & \\
\hline Stenonema & 44 & 3 & 91 & 6 & 170 & 10 & 91 & 2 & 38 & 2 & 78 & 5 & 51 & 4 \\
\hline \multicolumn{15}{|l|}{ Isonychiidae } \\
\hline Isonychia & 3 & $<1$ & - & & 21 & 1 & 72 & 2 & 41 & 3 & 99 & 6 & 37 & 3 \\
\hline \multicolumn{15}{|l|}{ Leptohyphidae } \\
\hline Tricorythodes & - & & - & & 3 & $<1$ & - & & - & & - & & 1 & $<1$ \\
\hline Leptophlebiidae & - & & - & & - & & - & & - & & - & & - & \\
\hline \multicolumn{15}{|l|}{ Odonata } \\
\hline Coenagrionidae & & & & & & & & & & & & & & \\
\hline Argia & - & & 3 & $<1$ & 3 & $<1$ & - & & - & & - & & - & \\
\hline Aeshnidae & & & & & & & & & & & & & & \\
\hline Boyeria & - & & - & & - & & - & & - & & - & & - & \\
\hline Macromiidae & & & & & & & & & & & & & & \\
\hline Macromia & - & & - & & 1 & $<1$ & - & & - & & - & & - & \\
\hline Plecoptera & & & & & & & & & & & & & & \\
\hline Capniidae & & & & & & & & & & & & & & \\
\hline Allocapnia & - & & - & & - & & - & & - & & - & & - & \\
\hline Chloroperlidae & - & & - & & - & & - & & - & & - & & - & \\
\hline Nemouridae & 1 & $<1$ & - & & - & & - & & - & & - & & - & \\
\hline Perlidae & & & & & & & & & & & & & & \\
\hline Acroneuria & 3 & $<1$ & - & & - & & 3 & $<1$ & - & & - & & - & \\
\hline Agnetina & - & & 5 & $<1$ & - & & - & & - & & - & & - & \\
\hline Paragnetina & 1 & $<1$ & - & & 3 & $<1$ & - & & - & & - & & - & \\
\hline Taeniopterygidae & & & & & & & & & & & & & & \\
\hline Taeniopteryx & 7 & $<1$ & 3 & $<1$ & 8 & $<1$ & 13 & $<1$ & 17 & 1 & 2 & $<1$ & 95 & 8 \\
\hline Hemiptera & & & & & & & & & & & & & & \\
\hline Veliidae & & & & & & & & & & & & & & \\
\hline Microvelia & - & & - & & - & & - & & - & & - & & - & \\
\hline Megaloptera & & & & & & & & & & & & & & \\
\hline Corydalidae & & & & & & & & & & & & & & \\
\hline Corydalus & 2 & $<1$ & - & & 5 & $<1$ & - & & - & & 3 & $<1$ & - & \\
\hline Nigronia & - & & - & & 3 & $<1$ & - & & - & & - & & - & \\
\hline Trichoptera & & & & & & & & & & & & & & \\
\hline Brachycentridae & & & & & & & & & & & & & & \\
\hline Micrasema & 1 & $<1$ & - & & - & & 3 & $<1$ & 4 & $<1$ & 19 & 1 & 1 & $<1$ \\
\hline Glossosomatidae & & & & & & & & & & & & & & \\
\hline Glossosoma & 1 & $<1$ & 3 & $<1$ & 3 & $<1$ & 16 & $<1$ & - & & - & & - & \\
\hline Hydropsychidae & & & & & & & & & & & & & & \\
\hline Ceratopsyche & 180 & 13 & 420 & 26 & 310 & 18 & 1000 & 26 & 440 & 27 & 260 & 16 & 240 & 20 \\
\hline Cheumatopsyche & 240 & 17 & 59 & 4 & 270 & 16 & 660 & 17 & 260 & 16 & 27 & 2 & 18 & 2 \\
\hline Hydropsyche & 10 & $<1$ & 11 & $<1$ & 24 & 1 & 91 & 2 & 36 & 2 & 100 & 6 & 78 & 7 \\
\hline Hydroptilidae & & & & & & & & & & & & & & \\
\hline Hydroptila & 4 & $<1$ & 3 & $<1$ & 3 & $<1$ & - & & 5 & $<1$ & 4 & $<1$ & 1 & $<1$ \\
\hline Leucotrichia & 210 & 15 & 130 & 8 & 11 & $<1$ & 140 & 4 & 4 & $<1$ & 120 & 8 & 8 & $<1$ \\
\hline Philopotamidae & & & & & & & & & & & & & & \\
\hline Chimarra & 79 & 6 & 72 & 5 & 61 & 4 & 80 & 2 & 24 & 2 & 2 & $<1$ & 3 & $<1$ \\
\hline Dolophilodes & - & & - & & - & & - & & - & & - & & - & \\
\hline Polycentropodidae & & & & & & & & & & & & & & \\
\hline Neureclipsis & 3 & $<1$ & - & & - & & - & & - & & - & & - & \\
\hline Polycentropus & 4 & $<1$ & 3 & $<1$ & - & & 3 & $<1$ & 1 & $<1$ & 1 & $<1$ & - & \\
\hline Psychomyiidae & & & & & & & & & & & & & & \\
\hline Psychomyia & 29 & 2 & 3 & $<1$ & - & & - & & 1 & $<1$ & - & & - & \\
\hline
\end{tabular}




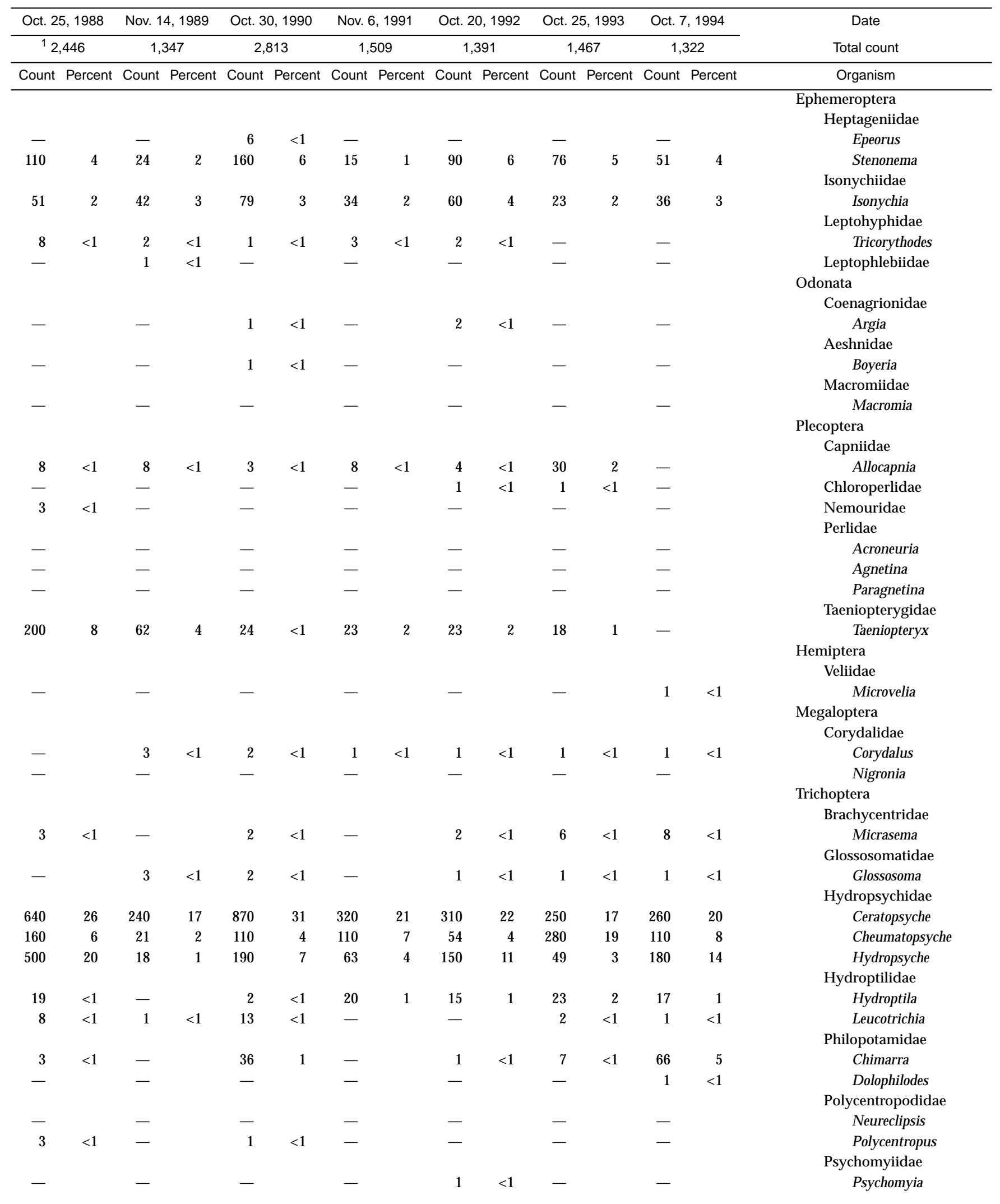


Table 5. Benthic-macroinvertebrate data-Continued

01476435 - Ridley Creek at Dutton Mill near West Chester, Pa. (Site 21)—Continued

\begin{tabular}{|c|c|c|c|c|c|c|c|c|c|c|c|c|c|c|}
\hline \multirow{3}{*}{$\begin{array}{c}\text { Date } \\
\text { Total count } \\
\text { Organism }\end{array}$} & \multirow{2}{*}{\multicolumn{2}{|c|}{$\begin{array}{c}\text { Nov. } 5,1981 \\
1,407\end{array}$}} & \multirow{2}{*}{\multicolumn{2}{|c|}{$\begin{array}{c}\text { Oct. } 14,1982 \\
11,578\end{array}$}} & \multirow{2}{*}{\multicolumn{2}{|c|}{$\begin{array}{c}\text { Oct. } 27,1983 \\
11,697 \\
\end{array}$}} & \multirow{2}{*}{\multicolumn{2}{|c|}{$\begin{array}{c}\text { Oct. } 15,1984 \\
{ }^{1} 3,842 \\
\end{array}$}} & \multirow{2}{*}{\multicolumn{2}{|c|}{$\begin{array}{c}\text { Oct. } 15,1985 \\
1,617\end{array}$}} & \multirow{2}{*}{\multicolumn{2}{|c|}{$\begin{array}{c}\text { Oct. 9, } 1986 \\
1,629\end{array}$}} & \multirow{2}{*}{\multicolumn{2}{|c|}{$\frac{\text { Oct. } 15,1987}{1,198}$}} \\
\hline & & & & & & & & & & & & & & \\
\hline & Count & Percent & Count & Percent & Count & Percent & Count & Percent & Count & Percent & Count & Percent & Count & Percent \\
\hline \multicolumn{15}{|l|}{ Trichoptera } \\
\hline \multicolumn{15}{|l|}{ Uenoidae } \\
\hline Neophylax & 1 & $<1$ & - & & - & & - & & - & & - & & - & \\
\hline \multicolumn{15}{|l|}{ Lepidoptera } \\
\hline \multicolumn{15}{|l|}{ Pyralidae } \\
\hline Petrophila & 37 & 3 & - & & 3 & $<1$ & 3 & $<1$ & 1 & $<1$ & 2 & $<1$ & 1 & $<1$ \\
\hline \multicolumn{15}{|l|}{ Coleoptera } \\
\hline \multicolumn{15}{|l|}{ Elmidae } \\
\hline Ancyronyx & - & & - & & - & & - & & - & & - & & - & \\
\hline A.variegata & - & & - & & - & & - & & - & & - & & - & \\
\hline Dubiraphia & - & & - & & 3 & $<1$ & - & & - & & - & & - & \\
\hline Optioservus & 8 & $<1$ & 16 & 1 & 6 & $<1$ & 21 & $<1$ & 10 & $<1$ & 6 & $<1$ & 5 & $<1$ \\
\hline Oulimnius & - & & - & & - & & - & & - & & 2 & $<1$ & - & \\
\hline Stenelmis & 6 & $<1$ & 3 & $<1$ & 13 & $<1$ & 30 & $<1$ & 4 & $<1$ & 8 & $<1$ & 2 & $<1$ \\
\hline \multicolumn{15}{|l|}{ Psephenidae } \\
\hline Psephenus & - & & - & & - & & - & & - & & - & & - & \\
\hline Hymenoptera & - & & - & & - & & - & & 2 & $<1$ & 1 & $<1$ & - & \\
\hline \multicolumn{15}{|l|}{ Diptera } \\
\hline Chironomidae & 160 & 11 & 430 & 27 & 290 & 17 & 680 & 18 & 400 & 25 & 410 & 26 & 310 & 26 \\
\hline \multicolumn{15}{|l|}{ Empididae } \\
\hline Chelifera & - & & - & & - & & - & & - & & - & & - & \\
\hline Hemerodromia & 7 & $<1$ & - & & - & & 3 & $<1$ & 6 & $<1$ & 14 & $<1$ & 3 & $<1$ \\
\hline Ephydridae & - & & 3 & $<1$ & 3 & $<1$ & - & & - & & 5 & $<1$ & - & \\
\hline \multicolumn{15}{|l|}{ Simuliidae } \\
\hline Simulium & 170 & 12 & 180 & 11 & 96 & 6 & 530 & 14 & 120 & 8 & 63 & 4 & 110 & 9 \\
\hline \multicolumn{15}{|l|}{ Tipulidae } \\
\hline Antocha & 45 & 3 & 5 & $<1$ & 5 & $<1$ & 5 & $<1$ & 39 & 2 & 99 & 6 & 78 & 7 \\
\hline Tipula & - & & - & & - & & - & & - & & - & & - & \\
\hline
\end{tabular}

\footnotetext{
${ }^{1}$ Extrapolated from a 3/8 subsample.
} 


\begin{tabular}{|c|c|c|c|c|c|c|c|c|c|c|c|c|c|c|}
\hline \multirow{2}{*}{\multicolumn{2}{|c|}{$\frac{\text { Oct. } 25,1988}{{ }^{1} 2,446}$}} & \multirow{2}{*}{\multicolumn{2}{|c|}{ Nov. 14, 1989}} & \multicolumn{2}{|c|}{ Oct. 30, 1990} & \multicolumn{2}{|c|}{ Nov. 6, 1991} & \multicolumn{2}{|c|}{ Oct. 20, 1992} & \multicolumn{2}{|c|}{ Oct. 25, 1993} & \multicolumn{2}{|c|}{ Oct. 7, 1994} & \multirow{3}{*}{$\begin{array}{c}\text { Date } \\
\text { Total count } \\
\text { Organism }\end{array}$} \\
\hline & & & & 2,8 & 313 & & 509 & & 391 & & 467 & & 322 & \\
\hline \multirow[t]{3}{*}{ Count } & Percent & Count & Percent & Count & Percent & Count & Percent & Count & Percent & Count & Percent & Count & Percent & \\
\hline & & & & & & & & & & & & & & Trichoptera \\
\hline & & & & & & & & & & & & & & Uenoidae \\
\hline \multirow[t]{3}{*}{-} & & - & & - & & - & & - & & - & & - & & Neophylax \\
\hline & & & & & & & & & & & & & & Lepidoptera \\
\hline & & & & & & & & & & & & & & Pyralidae \\
\hline \multirow[t]{3}{*}{3} & $<1$ & - & & 1 & $<1$ & 2 & $<1$ & 1 & $<1$ & - & & 2 & $<1$ & Petrophila \\
\hline & & & & & & & & & & & & & & Coleoptera \\
\hline & & & & & & & & & & & & & & Elmidae \\
\hline - & & - & & - & & - & & 2 & $<1$ & 3 & $<1$ & - & & Ancyronyx \\
\hline - & & 3 & $<1$ & 3 & $<1$ & - & & - & & - & & - & & A.variegata \\
\hline - & & 1 & $<1$ & - & & - & & - & & 1 & $<1$ & - & & Dubiraphia \\
\hline 6 & $<1$ & 4 & $<1$ & 11 & $<1$ & 54 & 4 & 11 & $<1$ & 88 & 6 & 11 & $<1$ & Optioservus \\
\hline- & & - & & - & & - & & - & & 2 & $<1$ & - & & Oulimnius \\
\hline \multirow[t]{2}{*}{11} & $<1$ & 1 & $<1$ & 12 & $<1$ & 6 & $<1$ & 2 & $<1$ & 50 & 3 & 5 & $<1$ & Stenelmis \\
\hline & & & & & & & & & & & & & & Psephenidae \\
\hline \multirow{2}{*}{-} & & - & & 4 & $<1$ & 3 & $<1$ & - & & 3 & $<1$ & 5 & $<1$ & Psephenus \\
\hline & & - & & - & & - & & - & & - & & - & & $\begin{array}{l}\text { Hymenoptera } \\
\text { Diptera }\end{array}$ \\
\hline 460 & 18 & 610 & 44 & 880 & 31 & 750 & 50 & 390 & 28 & 350 & 23 & 340 & 26 & $\begin{array}{l}\text { Chironomidae } \\
\text { Empididae }\end{array}$ \\
\hline - & & - & & 1 & $<1$ & - & & - & & - & & - & & Chelifera \\
\hline 3 & $<1$ & 21 & 2 & 23 & $<1$ & 8 & $<1$ & 3 & $<1$ & 5 & $<1$ & 18 & 1 & Hemerodromia \\
\hline- & & - & & - & & - & & - & & - & & - & & Ephydridae \\
\hline 43 & 2 & 110 & 8 & 29 & 1 & 44 & 3 & 17 & 1 & 26 & 2 & 65 & 5 & $\begin{array}{l}\text { Simuliidae } \\
\text { Simulium } \\
\text { Tipulidae }\end{array}$ \\
\hline 100 & 4 & 37 & 3 & 110 & 4 & 1 & $<1$ & 43 & 3 & 69 & 5 & 49 & 4 & Antocha \\
\hline - & & - & & 1 & $<1$ & - & & - & & 1 & $<1$ & - & & Tipula \\
\hline
\end{tabular}


Table 5. Benthic-macroinvertebrate data-Continued

$[<$, less than; - , not found]

01476790 - East Branch Chester Creek at Green Hill, Pa. (Site 22)

\begin{tabular}{|c|c|c|c|c|c|c|c|c|c|c|c|c|c|c|}
\hline \multirow{3}{*}{$\begin{array}{cc}\text { Date } \\
\text { Total count }\end{array}$} & \multirow{2}{*}{\multicolumn{2}{|c|}{$\begin{array}{c}\text { Nov. } 27,1981 \\
323\end{array}$}} & \multirow{2}{*}{\multicolumn{2}{|c|}{$\frac{\text { Oct. } 15,1982}{464}$}} & \multirow{2}{*}{\multicolumn{2}{|c|}{$\frac{\text { Oct. } 26,1983}{319}$}} & \multirow{2}{*}{\multicolumn{2}{|c|}{$\frac{\text { Oct. } 11,1984}{519}$}} & \multirow{2}{*}{\multicolumn{2}{|c|}{$\frac{\text { Oct. } 16,1985}{247}$}} & \multirow{2}{*}{\multicolumn{2}{|c|}{$\frac{\text { Oct. 15, } 1986}{338}$}} & \multirow{2}{*}{\multicolumn{2}{|c|}{$\frac{\text { Nov. 9, } 1987}{1,304}$}} \\
\hline & & & & & & & & & & & & & & \\
\hline & Count & Percent & Count & Percent & Count & Percent & Count & Percent & Count & Percent & Count & Percent & Count & Percent \\
\hline \multicolumn{15}{|l|}{ Platyhelminthes (flatworms) } \\
\hline \multicolumn{15}{|l|}{ Turbellaria } \\
\hline \multicolumn{15}{|l|}{ Tricladida } \\
\hline Planariidae & - & & - & & - & & 1 & $<1$ & - & & - & & 16 & 1 \\
\hline Nematoda (nematodes) & - & & - & & - & & - & & - & & - & & $<1$ & 1 \\
\hline \multicolumn{15}{|l|}{ Nemertea (proboscis worms) } \\
\hline \multicolumn{15}{|l|}{ Enopla } \\
\hline \multicolumn{15}{|l|}{ Hoplonemertea } \\
\hline \multicolumn{15}{|l|}{ Tetrastemmatidae } \\
\hline Prostoma & - & & - & & - & & - & & - & & - & & - & \\
\hline \multicolumn{15}{|l|}{ Mollusca (molluscs) } \\
\hline Gastropoda & & & & & & & & & & & & & & \\
\hline Basommatophora & & & & & & & & & & & & & & \\
\hline Lymnaeidae & & & & & & & & & & & & & & \\
\hline Lymnaea & - & & - & & - & & - & & - & & - & & - & \\
\hline Physidae & & & & & & & & & & & & & & \\
\hline Physa & 1 & $<1$ & - & & 5 & 2 & - & & - & & 4 & 1 & 2 & $<1$ \\
\hline Bivalvia & & & & & & & & & & & & & & \\
\hline Veneroida & & & & & & & & & & & & & & \\
\hline Sphaeriidae & 1 & $<1$ & - & & - & & - & & - & & - & & 2 & $<1$ \\
\hline Pisidium & - & & - & & - & & - & & - & & - & & - & \\
\hline Annelida (segmented worms) & & & & & & & & & & & & & & \\
\hline Oligochaeta & & & & & & & & & & & & & & \\
\hline Lumbriculida & & & & & & & & & & & & & & \\
\hline Lumbriculidae & 1 & $<1$ & - & & - & & - & & - & & - & & - & \\
\hline Tubificida & & & & & & & & & & & & & & \\
\hline Naididae & 3 & 1 & - & & - & & - & & - & & 1 & $<1$ & 390 & 30 \\
\hline Tubificidae & - & & - & & - & & - & & - & & - & & 1 & $<1$ \\
\hline Arthropoda (arthropods) & & & & & & & & & & & & & & \\
\hline Acariformes & & & & & & & & & & & & & & \\
\hline Hydrachnidia & - & & 1 & $<1$ & 3 & 1 & 1 & $<1$ & - & & 1 & $<1$ & 35 & 3 \\
\hline Crustacea & & & & & & & & & & & & & & \\
\hline Cyclopoida & - & & - & & - & & - & & - & & - & & - & \\
\hline Cyclopidae & & & & & & & & & & & & & & \\
\hline Amphipoda & & & & & & & & & & & & & & \\
\hline Gammaridae & & & & & & & & & & & & & & \\
\hline Gammarus & - & & - & & 1 & $<1$ & - & & - & & - & & - & \\
\hline Isopoda & & & & & & & & & & & & & & \\
\hline Asellidae & & & & & & & & & & & & & & \\
\hline Caecidotea & 9 & 3 & 4 & $<1$ & 6 & 2 & 4 & $<1$ & - & & 4 & 1 & 3 & $<1$ \\
\hline Lirceus & - & & 4 & $<1$ & - & & - & & - & & - & & - & \\
\hline Podocopa & - & & - & & - & & - & & - & & - & & - & \\
\hline Insecta & & & & & & & & & & & & & & \\
\hline Ephemeroptera & & & & & & & & & & & & & & \\
\hline Baetidae & & & & & & & & & & & & & & \\
\hline Baetis & 15 & 5 & 51 & 11 & 1 & $<1$ & 32 & 6 & 7 & 3 & 18 & 5 & 91 & 7 \\
\hline Pseudocloeon & - & & - & & - & & - & & - & & - & & 96 & 7 \\
\hline Ephemerellidae & & & & & & & & & & & & & & \\
\hline Ephemerella & 28 & 8 & 75 & 16 & 4 & 1 & 21 & 4 & 19 & 8 & 2 & $<1$ & 130 & 10 \\
\hline
\end{tabular}




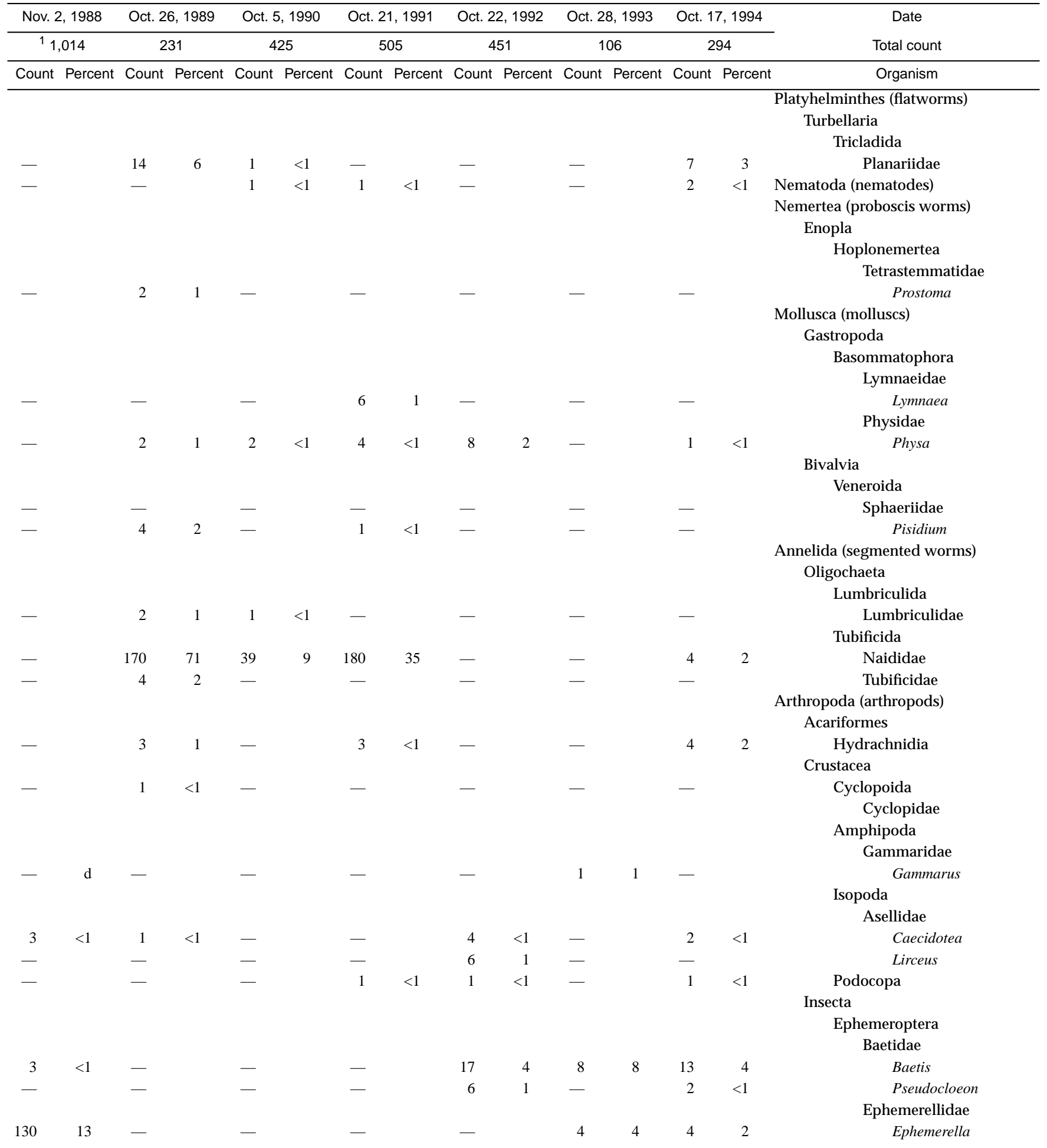


Table 5. Benthic-macroinvertebrate data-Continued

01476790 - East Branch Chester Creek at Green Hill, Pa. (Site 22)—Continued

\begin{tabular}{|c|c|c|c|c|c|c|c|c|c|c|c|c|c|c|}
\hline \multirow{3}{*}{$\begin{array}{c}\text { Date } \\
\text { Total count } \\
\text { Organism }\end{array}$} & \multirow{2}{*}{\multicolumn{2}{|c|}{$\begin{array}{c}\text { Nov. 27, } 1981 \\
323\end{array}$}} & \multirow{2}{*}{\multicolumn{2}{|c|}{$\begin{array}{c}\text { Oct. } 15,1982 \\
464\end{array}$}} & \multirow{2}{*}{\multicolumn{2}{|c|}{$\begin{array}{c}\text { Oct. 26, } 1983 \\
319\end{array}$}} & \multirow{2}{*}{\multicolumn{2}{|c|}{$\begin{array}{c}\text { Oct. } 11,1984 \\
519\end{array}$}} & \multirow{2}{*}{\multicolumn{2}{|c|}{$\begin{array}{c}\text { Oct. } 16,1985 \\
247\end{array}$}} & \multirow{2}{*}{\multicolumn{2}{|c|}{$\begin{array}{c}\text { Oct. } 15,1986 \\
338\end{array}$}} & \multirow{2}{*}{\multicolumn{2}{|c|}{$\begin{array}{c}\text { Nov. } 9,1987 \\
1,304\end{array}$}} \\
\hline & & & & & & & & & & & & & & \\
\hline & Count & Percent & Count & Percent & Count & Percent & Count & Percent & Count & Percent & Count & Percent & Count & Percent \\
\hline \multicolumn{15}{|l|}{ Ephemeroptera } \\
\hline \multicolumn{15}{|l|}{ Heptageniidae } \\
\hline Stenonema & 47 & 14 & 82 & 17 & 54 & 16 & 36 & 7 & 36 & 14 & 51 & 15 & 28 & 2 \\
\hline \multicolumn{15}{|l|}{ Isonychiidae } \\
\hline $\begin{array}{c}\text { Isonychia } \\
\text { Leptohyphidae }\end{array}$ & \multicolumn{13}{|c|}{ Leptohyphidae } & \\
\hline $\begin{array}{l}\text { Tricorythodes } \\
\text { Leptophlebiidae }\end{array}$ & - & & - & & - & & - & & - & & - & & - & \\
\hline Paraleptophlebia & - & & - & & - & & - & & - & & - & & - & \\
\hline \multicolumn{14}{|l|}{ Odonata } & Calopterygidae \\
\hline Calopteryx & - & & - & & 1 & $<1$ & - & & - & & - & & - & \\
\hline \multicolumn{14}{|l|}{ Plecoptera } & Capniidae \\
\hline Allocapnia & - & & 1 & $<1$ & 33 & 10 & 36 & 7 & 16 & 6 & 100 & 29 & 100 & 8 \\
\hline $\begin{array}{l}\text { Chloroperlidae } \\
\text { Perlodidae }\end{array}$ & - & & - & & - & & - & & - & & - & & 3 & $<1$ \\
\hline Isoperla & - & & - & & - & & - & & - & & - & & - & \\
\hline \multicolumn{15}{|l|}{ Hemiptera } \\
\hline Rhagovelia & 2 & $<1$ & 4 & $<1$ & - & & 5 & 1 & - & & - & & 1 & $<1$ \\
\hline \multicolumn{15}{|l|}{ Megaloptera } \\
\hline Sialis & - & & - & & - & & - & & - & & - & & 1 & $<1$ \\
\hline \multicolumn{14}{|l|}{ Trichoptera } & \\
\hline $\begin{array}{c}\text { Apatania } \\
\text { Glossosomatidae }\end{array}$ & 3 & 1 & - & & - & & - & & - & & - & & 14 & 1 \\
\hline $\begin{array}{c}\text { Glossosoma } \\
\text { Hydropsychidae }\end{array}$ & 57 & 17 & 39 & 8 & 64 & 19 & 160 & 31 & 39 & 16 & 23 & 7 & 86 & 7 \\
\hline Ceratopsyche & 53 & 16 & 55 & 12 & 63 & 19 & 75 & 14 & 24 & 10 & 30 & 9 & 24 & 2 \\
\hline Cheumatopsyche & 7 & 2 & 35 & 7 & 17 & 5 & 20 & 4 & 23 & 9 & 16 & 5 & 5 & $<1$ \\
\hline Diplectrona & - & & - & & - & & - & & - & & - & & - & \\
\hline Hydropsyche & 19 & 6 & 23 & 5 & 17 & 5 & 44 & 8 & 22 & 9 & 11 & 3 & 84 & 6 \\
\hline $\begin{array}{c}\text { Potamyia } \\
\text { Hydroptilidae }\end{array}$ & - & & - & & - & & - & & - & & - & & - & \\
\hline Hydroptila & - & & - & & - & & - & & - & & - & & - & \\
\hline $\begin{array}{l}\text { Leucotrichia } \\
\text { Leptoceridae }\end{array}$ & - & & - & & - & & - & & - & & - & & - & \\
\hline $\begin{array}{c}\text { Mystacides } \\
\text { Philopotamidae }\end{array}$ & - & & - & & - & & - & & - & & - & & 1 & $<1$ \\
\hline Chimarra & - & & - & & - & & - & & - & & - & & - & \\
\hline Dolophilodes & 2 & $<1$ & 2 & $<1$ & 6 & 2 & 4 & $<1$ & 1 & $<1$ & 1 & $<1$ & 2 & $<1$ \\
\hline Polycentropodidae & & & & & & & & & & & & & & \\
\hline $\begin{array}{l}\text { Polycentropus } \\
\text { Rhyacophilidae }\end{array}$ & - & & - & & - & & - & & - & & - & & - & \\
\hline $\begin{array}{l}\text { Rhyacophila } \\
\text { Uenoidae }\end{array}$ & 2 & $<1$ & 2 & $<1$ & - & & - & & - & & 1 & $<1$ & 1 & $<1$ \\
\hline Neophylax & 6 & 2 & - & & 1 & $<1$ & - & & - & & - & & 7 & $<1$ \\
\hline
\end{tabular}




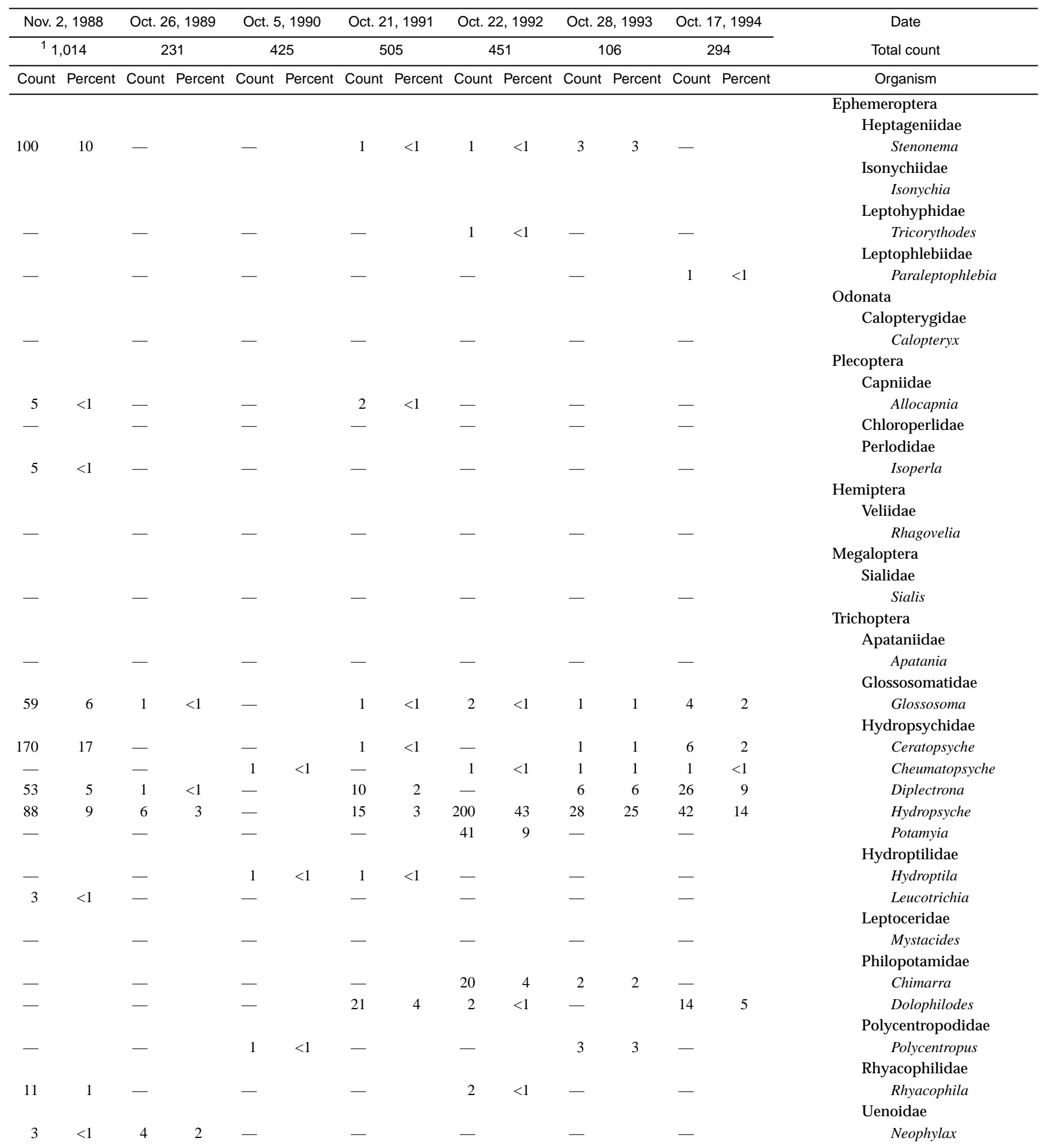


Table 5. Benthic-macroinvertebrate data-Continued

01476790 - East Branch Chester Creek at Green Hill, Pa. (Site 22)—Continued

\begin{tabular}{|c|c|c|c|c|c|c|c|c|c|c|c|c|c|c|}
\hline \multirow{3}{*}{$\begin{array}{c}\text { Date } \\
\text { Total count } \\
\text { Organism }\end{array}$} & \multirow{2}{*}{\multicolumn{2}{|c|}{$\begin{array}{c}\text { Nov. } 27,1981 \\
323\end{array}$}} & \multicolumn{2}{|c|}{ Oct. 15,1982} & \multicolumn{2}{|c|}{ Oct. 26,1983} & \multicolumn{2}{|c|}{ Oct. 11,1984} & \multicolumn{2}{|c|}{ Oct. 16,1985} & \multicolumn{2}{|c|}{ Oct. 15,1986} & \multicolumn{2}{|c|}{ Nov. 9, 1987} \\
\hline & & & & 64 & & 19 & & 19 & \multicolumn{2}{|c|}{247} & \multicolumn{2}{|c|}{338} & \multicolumn{2}{|c|}{1,304} \\
\hline & Count & Percent & Count & Percent & Count & Percent & Count & Percent & Count & Percent & Count & Percent & Count & Percent \\
\hline \multicolumn{15}{|l|}{ Coleoptera } \\
\hline $\begin{array}{l}\text { Curculionidae } \\
\text { Elmidae }\end{array}$ & - & & - & & - & & 1 & $<1$ & - & & - & & - & \\
\hline Ancyronyx & - & & - & & - & & - & & - & & - & & - & \\
\hline A.variegata & - & & - & & - & & - & & - & & - & & - & \\
\hline Dubiraphia & 1 & $<1$ & - & & - & & - & & - & & - & & - & \\
\hline Optioservus & 29 & 9 & 37 & 8 & 9 & 3 & 17 & 3 & 37 & 15 & 14 & 4 & 42 & 3 \\
\hline Oulimnius & 1 & $<1$ & 2 & $<1$ & 3 & 1 & 2 & $<1$ & 2 & 1 & 3 & 1 & 9 & $<1$ \\
\hline Promoresia & 1 & $<1$ & - & & 1 & $<1$ & - & & - & & - & & - & \\
\hline Stenelmis & - & & - & & - & & - & & - & & - & & - & \\
\hline \multicolumn{15}{|l|}{ Hydrophilidae } \\
\hline Helophorus & - & & - & & - & & - & & - & & - & & - & \\
\hline \multicolumn{15}{|l|}{ Psephenidae } \\
\hline Psephenus & - & & - & & - & & - & & - & & - & & - & \\
\hline Hymenoptera & - & & 1 & $<1$ & - & & - & & - & & 3 & 1 & - & \\
\hline \multicolumn{15}{|l|}{ Diptera } \\
\hline Chironomidae & 24 & 7 & 35 & 7 & 23 & 7 & 39 & 8 & 12 & 5 & 17 & 5 & 110 & 8 \\
\hline \multicolumn{15}{|l|}{ Empididae } \\
\hline Chelifera & - & & - & & - & & - & & - & & - & & - & \\
\hline Clinocera & - & & - & & - & & - & & - & & - & & - & \\
\hline Hemerodromia & - & & - & & - & & - & & - & & - & & 3 & $<1$ \\
\hline \multicolumn{15}{|l|}{ Simuliidae } \\
\hline Simulium & 3 & 1 & 2 & $<1$ & 1 & $<1$ & 17 & 3 & - & & 1 & $<1$ & 2 & $<1$ \\
\hline Tipulidae & - & & - & & - & & 1 & $<1$ & - & & - & & - & \\
\hline Antocha & 5 & 2 & 10 & 2 & 5 & 2 & - & & 9 & 4 & 35 & 10 & 12 & $<1$ \\
\hline Hexatoma & - & & - & & - & & - & & - & & - & & - & \\
\hline Tipula & 3 & 1 & - & & 1 & $<1$ & 2 & $<1$ & - & & 2 & $<1$ & 2 & $<1$ \\
\hline
\end{tabular}

${ }^{1}$ Extrapolated from a 3/8 subsample. 


\begin{tabular}{|c|c|c|c|c|c|c|c|c|c|c|c|c|c|c|}
\hline \multirow{2}{*}{\multicolumn{2}{|c|}{$\begin{array}{c}\text { Nov. } 2,1988 \\
{ }^{1} 1,014\end{array}$}} & \multirow{2}{*}{\multicolumn{2}{|c|}{$\frac{\text { Oct. 26, } 1989}{231}$}} & \multirow{2}{*}{\multicolumn{2}{|c|}{$\frac{\text { Oct. } 5,1990}{425}$}} & \multirow{2}{*}{\multicolumn{2}{|c|}{$\frac{\text { Oct. 21, } 1991}{505}$}} & \multirow{2}{*}{\multicolumn{2}{|c|}{$\frac{\text { Oct. 22, } 1992}{451}$}} & \multirow{2}{*}{\multicolumn{2}{|c|}{$\frac{\text { Oct. } 28,1993}{106}$}} & \multirow{2}{*}{\multicolumn{2}{|c|}{$\frac{\text { Oct. } 17,1994}{294}$}} & \multirow{3}{*}{$\begin{array}{c}\text { Date } \\
\text { Total count } \\
\text { Organism }\end{array}$} \\
\hline & & & & & & & & & & & & & & \\
\hline Count & Percent & Count & Percent & Count & Percent & Count & Percent & Count & Percent & Count & Percent & Count & Percent & \\
\hline & & & & & & & & & & & & & & Coleoptera \\
\hline- & & - & & - & & - & & - & & - & & - & & $\begin{array}{l}\text { Curculionidae } \\
\text { Elmidae }\end{array}$ \\
\hline- & & - & & - & & - & & - & & - & & 1 & $<1$ & Ancyronyx \\
\hline- & & 1 & $<1$ & - & & - & & - & & - & & - & & A.variegata \\
\hline - & & - & & - & & - & & - & & 1 & 1 & - & & Dubiraphia \\
\hline 75 & 8 & 6 & 3 & 1 & $<1$ & 2 & $<1$ & - & & - & & 1 & $<1$ & Optioservus \\
\hline- & & - & & - & & - & & - & & - & & - & & Oulimnius \\
\hline - & & - & & - & & - & & - & & - & & - & & Promoresia \\
\hline- & & 1 & $<1$ & 3 & $<1$ & - & & - & & 3 & 3 & 2 & $<1$ & $\begin{array}{c}\text { Stenelmis } \\
\end{array}$ \\
\hline- & & - & & 1 & $<1$ & - & & - & & - & & - & & $\begin{array}{l}\text { Helophorus } \\
\text { Psephenidae }\end{array}$ \\
\hline- & & 1 & $<1$ & - & & - & & - & & - & & - & & Psephenus \\
\hline- & & - & & - & & - & & - & & - & & - & & $\begin{array}{l}\text { Hymenoptera } \\
\text { Diptera }\end{array}$ \\
\hline 280 & 28 & 3 & 1 & 320 & 74 & 170 & 33 & 120 & 26 & 35 & 32 & 110 & 37 & $\begin{array}{l}\text { Chironomidae } \\
\text { Empididae }\end{array}$ \\
\hline- & & - & & 1 & $<1$ & 10 & 2 & - & & - & & - & & Chelifera \\
\hline - & & - & & - & & 2 & $<1$ & - & & - & & - & & Clinocera \\
\hline 5 & $<1$ & 1 & $<1$ & - & & 5 & 1 & - & & - & & - & & $\begin{array}{l}\text { Hemerodromia } \\
\text { Simuliidae }\end{array}$ \\
\hline 5 & $<1$ & 2 & 1 & 49 & 11 & 63 & 12 & 16 & 3 & 9 & 9 & 42 & 14 & Simulium \\
\hline - & & - & & - & & - & & - & & - & & - & & Tipulidae \\
\hline 13 & 1 & - & & 1 & $<1$ & 2 & $<1$ & 2 & $<1$ & - & & - & & Antocha \\
\hline 3 & $<1$ & - & & - & & - & & - & & - & & - & & Hexatoma \\
\hline - & & 1 & $<1$ & 2 & $<1$ & 3 & $<1$ & 1 & $<1$ & - & & 4 & 2 & Tipula \\
\hline
\end{tabular}


Table 5. Benthic-macroinvertebrate data-Continued

$[<$, less than; - , not found]

01476830 - East Branch Chester Creek at Milltown, Pa. (Site 23)

\begin{tabular}{|c|c|c|c|c|c|c|c|c|c|c|c|c|c|c|}
\hline \multirow{3}{*}{$\begin{array}{cc}\text { Date } \\
\text { Total count } \\
\text { Organism }\end{array}$} & \multirow{2}{*}{\multicolumn{2}{|c|}{$\begin{array}{c}\text { Oct. } 27,1981 \\
1,371\end{array}$}} & \multirow{2}{*}{\multicolumn{2}{|c|}{$\begin{array}{c}\text { Oct. } 22,1982 \\
1,700\end{array}$}} & \multirow{2}{*}{\multicolumn{2}{|c|}{$\begin{array}{c}\text { Oct. } 26,1983 \\
1,247\end{array}$}} & \multirow{2}{*}{\multicolumn{2}{|c|}{$\frac{\text { Oct. } 11,1984}{1,085}$}} & \multirow{2}{*}{\multicolumn{2}{|c|}{$\frac{\text { Oct. 16, } 1985}{991}$}} & \multirow{2}{*}{\multicolumn{2}{|c|}{$\begin{array}{c}\text { Oct. } 15,1986 \\
518\end{array}$}} & \multirow{2}{*}{\multicolumn{2}{|c|}{$\begin{array}{c}\text { Nov. } 9,1987 \\
2,252\end{array}$}} \\
\hline & & & & & & & & & & & & & & \\
\hline & Count & Percent & Count & Percent & Count & Percent & Count & Percent & Count & Percent & Count & Percent & Count & Percent \\
\hline \multicolumn{15}{|l|}{ Platyhelminthes (flatworms) } \\
\hline \multicolumn{15}{|l|}{ Turbellaria } \\
\hline \multicolumn{15}{|l|}{ Tricladida } \\
\hline Planariidae & 6 & $<1$ & 7 & $<1$ & 4 & $<1$ & 5 & $<1$ & 15 & 2 & - & & 7 & $<1$ \\
\hline Nematoda (nematodes) & - & & - & & - & & - & & - & & - & & 1 & $<1$ \\
\hline \multicolumn{15}{|l|}{ Nemertea (proboscis worms) } \\
\hline \multicolumn{15}{|l|}{ Enopla } \\
\hline \multicolumn{15}{|l|}{ Hoplonemertea } \\
\hline Tetrastemmatidae & & & & & & & & & & & & & & \\
\hline Prostoma & - & & - & & - & & - & & - & & - & & - & \\
\hline Mollusca (molluscs) & & & & & & & & & & & & & & \\
\hline Gastropoda & & & & & & & & & & & & & & \\
\hline Basommatophora & & & & & & & & & & & & & & \\
\hline Ancylidae & & & & & & & & & & & & & & \\
\hline Ferrissia & 31 & 2 & 19 & 1 & 16 & 1 & 15 & 1 & 24 & 2 & 56 & 11 & 110 & 5 \\
\hline Lymnaeidae & & & & & & & & & & & & & & \\
\hline Lymnaea & - & & - & & - & & - & & - & & - & & - & \\
\hline Physidae & & & & & & & & & & & & & & \\
\hline Physa & 1 & $<1$ & - & & 1 & $<1$ & 1 & $<1$ & - & & 1 & $<1$ & 3 & $<1$ \\
\hline Planorbidae & & & & & & & & & & & & & & \\
\hline Helisoma & 1 & $<1$ & - & & - & & - & & - & & - & & - & \\
\hline Bivalvia & & & & & & & & & & & & & & \\
\hline Veneroida & & & & & & & & & & & & & & \\
\hline Sphaeriidae & - & & - & & - & & - & & - & & - & & - & \\
\hline Annelida (segmented worms) & & & & & & & & & & & & & & \\
\hline Oligochaeta & - & & 13 & $<1$ & 10 & $<1$ & 3 & $<1$ & 2 & $<1$ & - & & - & \\
\hline Lumbriculida & & & & & & & & & & & & & & \\
\hline Lumbriculidae & 1 & $<1$ & - & & - & & - & & - & & - & & - & \\
\hline Tubificida & & & & & & & & & & & & & & \\
\hline Naididae & 25 & 2 & - & & - & & - & & - & & - & & 160 & 7 \\
\hline Tubificidae & - & & - & & - & & - & & - & & - & & 1 & $<1$ \\
\hline Arthropoda (arthropods) & & & & & & & & & & & & & & \\
\hline Acariformes & & & & & & & & & & & & & & \\
\hline Hydrachnidia & - & & 1 & $<1$ & 1 & $<1$ & - & & 4 & $<1$ & - & & 27 & 1 \\
\hline Crustacea & & & & & & & & & & & & & & \\
\hline Amphipoda & & & & & & & & & & & & & & \\
\hline Gammaridae & & & & & & & & & & & & & & \\
\hline Gammarus & - & & - & & - & & - & & - & & - & & - & \\
\hline Isopoda & & & & & & & & & & & & & & \\
\hline Asellidae & & & & & & & & & & & & & & \\
\hline Caecidotea & 1 & $<1$ & - & & 1 & $<1$ & - & & - & & - & & 2 & $<1$ \\
\hline Lirceus & - & & - & & 1 & $<1$ & - & & - & & - & & - & \\
\hline Podocopa & - & & 1 & $<1$ & - & & - & & - & & - & & - & \\
\hline Insecta & & & & & & & & & & & & & & \\
\hline Ephemeroptera & & & & & & & & & & & & & & \\
\hline Baetidae & & & & & & & & & & & & & & \\
\hline Baetis & - & & 9 & $<1$ & 4 & $<1$ & 100 & 9 & 26 & 3 & - & & 11 & $<1$ \\
\hline Pseudocloeon & 1 & $<1$ & - & & - & & - & & - & & - & & - & \\
\hline Ephemerellidae & & & & & & & & & & & & & & \\
\hline Ephemerella & 3 & $<1$ & 1 & $<1$ & - & & 1 & $<1$ & 2 & $<1$ & - & & 17 & $<1$ \\
\hline Ephemeridae & & & & & & & & & & & & & & \\
\hline Ephemera & - & & - & & - & & - & & 1 & $<1$ & - & & - & \\
\hline
\end{tabular}




\begin{tabular}{|c|c|c|c|c|c|c|c|c|c|c|c|c|c|c|}
\hline \multirow{2}{*}{\multicolumn{2}{|c|}{$\begin{array}{c}\text { Nov. 2, } 1988 \\
{ }^{1} 2,477\end{array}$}} & \multirow{2}{*}{\multicolumn{2}{|c|}{$\begin{array}{c}\text { Oct. } 26,1989 \\
4,174\end{array}$}} & \multirow{2}{*}{\multicolumn{2}{|c|}{$\begin{array}{c}\text { Oct. 5, } 1990 \\
2,625 \\
\end{array}$}} & \multirow{2}{*}{\multicolumn{2}{|c|}{$\begin{array}{c}\text { Oct. } 21,1991 \\
1,731 \\
\end{array}$}} & \multirow{2}{*}{\multicolumn{2}{|c|}{$\begin{array}{c}\text { Oct. } 23,1992 \\
2,926 \\
\end{array}$}} & \multirow{2}{*}{\multicolumn{2}{|c|}{$\begin{array}{c}\text { Oct. 26, } 1993 \\
693\end{array}$}} & \multirow{2}{*}{\multicolumn{2}{|c|}{$\begin{array}{c}\text { Oct. 21, } 1994 \\
2,643\end{array}$}} & \multirow{3}{*}{$\begin{array}{c}\text { Date } \\
\text { Total count } \\
\text { Organism }\end{array}$} \\
\hline & & & & & & & & & & & & & & \\
\hline Count & Percent & Count & Percent & Count & Percent & Count & Percent & Count & Percent & Count & Percent & Count & Percent & \\
\hline & & & & & & & & & & & & & & $\begin{array}{l}\text { Platyhelminthes (flatworms) } \\
\text { Turbellaria } \\
\text { Tricladida }\end{array}$ \\
\hline 16 & $<1$ & 110 & 3 & 45 & 2 & 9 & $<1$ & 36 & 1 & - & & 18 & $<1$ & Planariidae \\
\hline- & & 5 & $<1$ & 2 & $<1$ & - & & 2 & $<1$ & - & & 2 & $<1$ & $\begin{array}{l}\text { Nematoda (nematodes) } \\
\text { Nemertea (proboscis worms) } \\
\text { Enopla } \\
\text { Hoplonemertea } \\
\text { Tetrastemmatidae }\end{array}$ \\
\hline- & & 8 & $<1$ & 2 & $<1$ & - & & 9 & $<1$ & - & & 11 & $<1$ & $\begin{array}{r}\text { Prostoma } \\
\text { Mollusca (molluscs) } \\
\text { Gastropoda } \\
\text { Basommatophora } \\
\text { Ancylidae }\end{array}$ \\
\hline- & & - & & - & & - & & - & & - & & - & & $\begin{array}{r}\text { Ferrissia } \\
\text { Lymnaeidae }\end{array}$ \\
\hline- & & 1 & $<1$ & - & & - & & - & & - & & - & & $\begin{array}{l}\text { Lymnaea } \\
\text { Physidae }\end{array}$ \\
\hline- & & - & & - & & - & & 1 & $<1$ & - & & - & & $\begin{array}{c}\text { Physa } \\
\text { Planorbidae }\end{array}$ \\
\hline- & & - & & - & & - & & - & & - & & - & & Bivalvia Helisoma \\
\hline- & & - & & - & & - & & 1 & $<1$ & - & & - & & $\begin{array}{c}\text { Veneroida } \\
\text { Sphaeriidae } \\
\text { Annelida (segmented worms) }\end{array}$ \\
\hline - & & - & & - & & - & & - & & - & & - & & $\begin{array}{l}\text { Oligochaeta } \\
\text { Lumbriculida }\end{array}$ \\
\hline- & & 2 & $<1$ & - & & - & & - & & - & & - & & $\begin{array}{l}\text { Lumbriculidae } \\
\text { Tubificida }\end{array}$ \\
\hline- & & 480 & 11 & 10 & $<1$ & 1 & $<1$ & 75 & 3 & - & & 64 & 2 & Naididae \\
\hline - & & - & & - & & - & & - & & - & & - & & $\begin{array}{l}\text { Tubificidae } \\
\text { Arthropoda (arthropods) } \\
\text { Acariformes }\end{array}$ \\
\hline- & & 190 & 5 & 58 & 2 & 8 & $<1$ & 140 & 5 & 17 & 2 & 56 & 2 & $\begin{array}{l}\text { Hydrachnidia } \\
\text { Crustacea } \\
\text { Amphipoda } \\
\text { Gammaridae }\end{array}$ \\
\hline- & & - & & - & & - & & 1 & $<1$ & - & & - & & $\begin{array}{l}\text { Gammarus } \\
\text { Isopoda } \\
\text { Asellidae }\end{array}$ \\
\hline- & & 1 & $<1$ & - & & - & & - & & - & & - & & Caecidotea \\
\hline- & & - & & - & & - & & - & & - & & - & & Lirceus \\
\hline- & & - & & 10 & $<1$ & - & & - & & - & & - & & $\begin{array}{l}\text { Podocopa } \\
\text { Insecta } \\
\text { Ephemeroptera } \\
\text { Baetidae }\end{array}$ \\
\hline 3 & $<1$ & 12 & $<1$ & 55 & 2 & 6 & $<1$ & 2 & $<1$ & 2 & $<1$ & 4 & $<1$ & Baetis \\
\hline- & & - & & - & & 3 & $<1$ & 3 & $<1$ & 1 & $<1$ & - & & $\begin{array}{l}\text { Pseudocloeon } \\
\text { Ephemerellidae }\end{array}$ \\
\hline 16 & $<1$ & 42 & 1 & 13 & $<1$ & 6 & $<1$ & 85 & 3 & 5 & $<1$ & 21 & $<1$ & $\begin{array}{l}\text { Ephemerella } \\
\text { Ephemeridae }\end{array}$ \\
\hline- & & - & & 1 & $<1$ & - & & - & & - & & - & & Ephemera \\
\hline
\end{tabular}


Table 5. Benthic-macroinvertebrate data-Continued

01476830 - East Branch Chester Creek at Milltown, Pa. (Site 23)—Continued

\begin{tabular}{|c|c|c|c|c|c|c|c|c|c|c|c|c|c|c|}
\hline \multirow{3}{*}{$\begin{array}{c}\text { Date } \\
\text { Total count } \\
\text { Organism }\end{array}$} & \multirow{2}{*}{\multicolumn{2}{|c|}{$\begin{array}{c}\text { Oct. } 27,1981 \\
1,371\end{array}$}} & \multirow{2}{*}{\multicolumn{2}{|c|}{$\begin{array}{c}\text { Oct. } 22,1982 \\
1,700\end{array}$}} & \multirow{2}{*}{\multicolumn{2}{|c|}{$\begin{array}{c}\text { Oct. } 26,1983 \\
1,247\end{array}$}} & \multirow{2}{*}{\multicolumn{2}{|c|}{$\begin{array}{c}\text { Oct. } 11,1984 \\
1,085\end{array}$}} & \multirow{2}{*}{\multicolumn{2}{|c|}{$\begin{array}{c}\text { Oct. 16, } 1985 \\
991\end{array}$}} & \multirow{2}{*}{\multicolumn{2}{|c|}{$\begin{array}{c}\text { Oct. } 15,1986 \\
518\end{array}$}} & \multirow{2}{*}{\multicolumn{2}{|c|}{$\begin{array}{c}\text { Nov. } 9,1987 \\
2,252\end{array}$}} \\
\hline & & & & & & & & & & & & & & \\
\hline & Count & Percent & Count & Percent & Count & Percent & Count & Percent & Count & Percent & Count & Percent & Count & Percent \\
\hline \multicolumn{15}{|l|}{ Ephemeroptera } \\
\hline \multicolumn{15}{|l|}{ Heptageniidae } \\
\hline Stenacron & - & & - & & - & & - & & - & & 20 & 4 & - & \\
\hline Stenonema & 69 & 5 & 110 & 6 & 63 & 5 & 76 & 7 & 58 & 6 & 12 & 2 & 130 & 6 \\
\hline \multicolumn{15}{|l|}{ Leptohyphidae } \\
\hline Tricorythodes & - & & 5 & $<1$ & 1 & $<1$ & - & & - & & 1 & $<1$ & 3 & $<1$ \\
\hline Leptophlebiidae & - & & - & & - & & 1 & $<1$ & - & & - & & - & \\
\hline Paraleptophlebia & - & & - & & - & & - & & - & & - & & - & \\
\hline \multicolumn{15}{|l|}{ Odonata } \\
\hline \multicolumn{15}{|l|}{ Coenagrionidae } \\
\hline Argia & - & & 1 & $<1$ & 1 & $<1$ & - & & - & & - & & - & \\
\hline Gomphidae & - & & - & & - & & - & & - & & - & & - & \\
\hline \multicolumn{15}{|l|}{ Plecoptera } \\
\hline \multicolumn{15}{|l|}{ Capniidae } \\
\hline Allocapnia & - & & - & & - & & - & & - & & - & & 2 & $<1$ \\
\hline \multicolumn{15}{|l|}{ Taeniopterygidae } \\
\hline Taeniopteryx & - & & - & & - & & - & & - & & - & & 2 & $<1$ \\
\hline Hemiptera & & & & & & & & & & & & & & \\
\hline Corixidae & & & & & & & & & & & & & & \\
\hline Trichocorixa & - & & 1 & $<1$ & 11 & $<1$ & 3 & $<1$ & - & & - & & - & \\
\hline Veliidae & & & & & & & & & & & & & & \\
\hline Rhagovelia & - & & - & & 2 & $<1$ & - & & - & & - & & - & \\
\hline Megaloptera & & & & & & & & & & & & & & \\
\hline Corydalidae & & & & & & & & & & & & & & \\
\hline Corydalus & - & & - & & 1 & $<1$ & - & & - & & - & & - & \\
\hline Nigronia & - & & - & & 1 & $<1$ & - & & - & & - & & - & \\
\hline Trichoptera & & & & & & & & & & & & & & \\
\hline Glossosomatidae & & & & & & & & & & & & & & \\
\hline Glossosoma & - & & - & & - & & 1 & $<1$ & - & & - & & 2 & $<1$ \\
\hline Hydropsychidae & & & & & & & & & & & & & & \\
\hline Ceratopsyche & 360 & 26 & 300 & 18 & 150 & 12 & 140 & 13 & 150 & 15 & 44 & 8 & 220 & 10 \\
\hline Cheumatopsyche & 100 & 7 & 64 & 4 & 28 & 2 & 22 & 2 & 31 & 3 & 1 & $<1$ & 19 & $<1$ \\
\hline Diplectrona & - & & - & & - & & - & & - & & - & & - & \\
\hline Hydropsyche & 16 & 1 & 84 & 5 & 38 & 3 & 35 & 3 & 10 & 1 & 2 & $<1$ & 52 & 2 \\
\hline Hydroptilidae & & & & & & & & & & & & & & \\
\hline Hydroptila & 200 & 14 & 290 & 17 & 220 & 17 & 70 & 6 & 20 & 2 & 2 & $<1$ & 46 & 2 \\
\hline Leucotrichia & 10 & $<1$ & 100 & 6 & 57 & 4 & 250 & 23 & 80 & 8 & 2 & $<1$ & 370 & 16 \\
\hline Leptoceridae & & & & & & & & & & & & & & \\
\hline Mystacides & - & & - & & - & & - & & - & & - & & - & \\
\hline Oecetis & - & & - & & - & & 1 & $<1$ & 1 & $<1$ & - & & - & \\
\hline Triaenodes & - & & - & & - & & - & & - & & - & & - & \\
\hline Philopotamidae & & & & & & & & & & & & & & \\
\hline Chimarra & 3 & $<1$ & 13 & $<1$ & 1 & $<1$ & 11 & 1 & 23 & 2 & - & & 6 & $<1$ \\
\hline Polycentropodidae & & & & & & & & & & & & & & \\
\hline Polycentropus & 1 & $<1$ & - & & 1 & $<1$ & 1 & $<1$ & - & & 1 & $<1$ & - & \\
\hline Psychomyiidae & & & & & & & & & & & & & & \\
\hline Psychomyia & 1 & $<1$ & 14 & $<1$ & 95 & 7 & 61 & 6 & 120 & 12 & 190 & 37 & 660 & 29 \\
\hline Lepidoptera & & & & & & & & & & & & & & \\
\hline Noctuidae & 1 & $<1$ & - & & - & & - & & - & & - & & - & \\
\hline
\end{tabular}




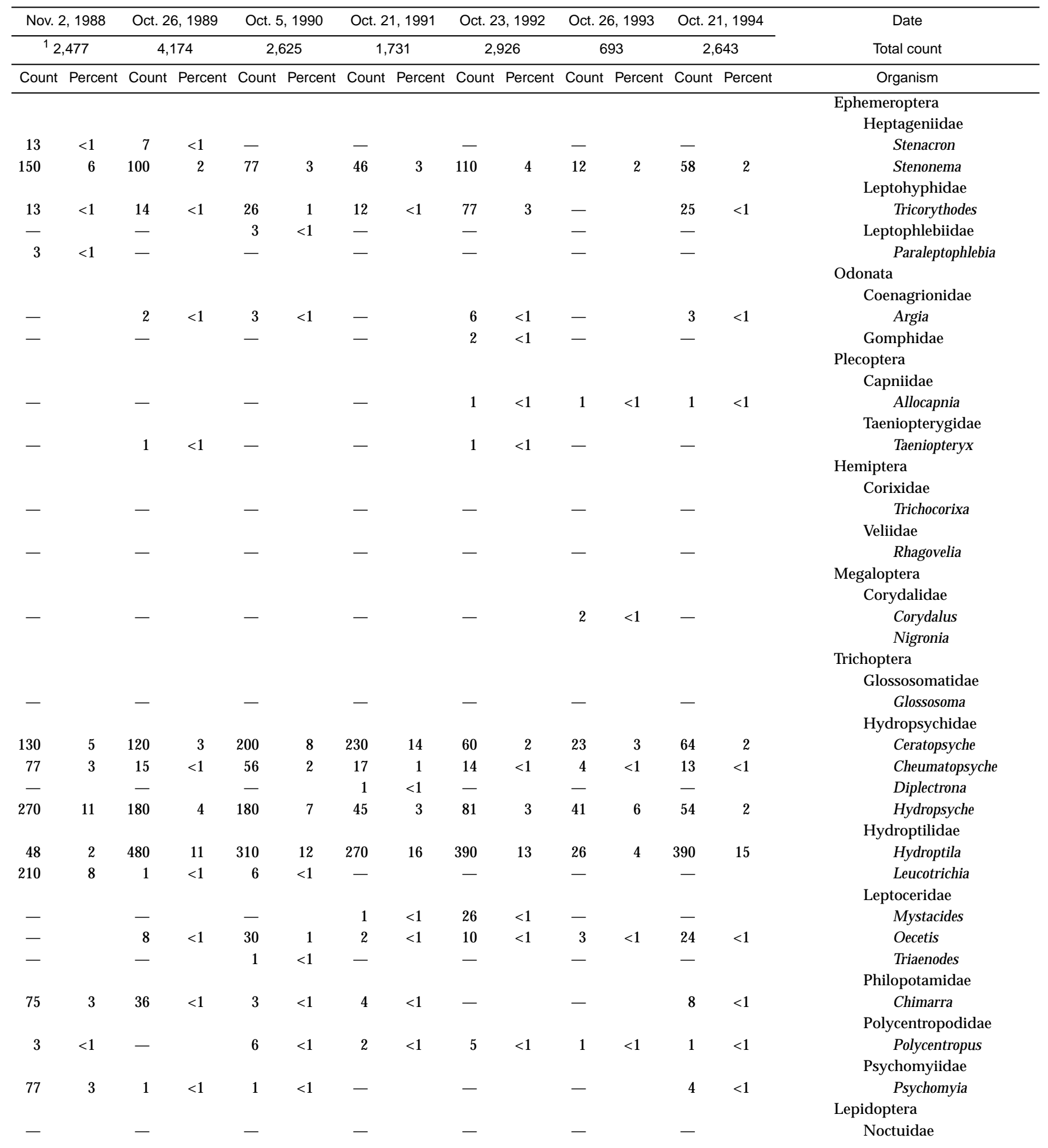


Table 5. Benthic-macroinvertebrate data-Continued

01476830 - East Branch Chester Creek at Milltown, Pa. (Site 23)—Continued

\begin{tabular}{|c|c|c|c|c|c|c|c|c|c|c|c|c|c|c|}
\hline \multirow{3}{*}{$\begin{array}{c}\text { Date } \\
\text { Total count } \\
\text { Organism }\end{array}$} & \multirow{2}{*}{\multicolumn{2}{|c|}{$\begin{array}{c}\text { Oct. } 27,1981 \\
1,371\end{array}$}} & \multirow{2}{*}{\multicolumn{2}{|c|}{$\begin{array}{c}\text { Oct. 22, } 1982 \\
1,700\end{array}$}} & \multirow{2}{*}{\multicolumn{2}{|c|}{$\begin{array}{c}\text { Oct. } 26,1983 \\
1,247 \\
\end{array}$}} & \multirow{2}{*}{\multicolumn{2}{|c|}{$\begin{array}{c}\text { Oct. } 11,1984 \\
1,085\end{array}$}} & \multirow{2}{*}{\multicolumn{2}{|c|}{$\begin{array}{c}\text { Oct. 16, } 1985 \\
991\end{array}$}} & \multirow{2}{*}{\multicolumn{2}{|c|}{$\begin{array}{c}\text { Oct. } 15,1986 \\
518 \\
\end{array}$}} & \multirow{2}{*}{\multicolumn{2}{|c|}{$\begin{array}{c}\text { Nov. 9, } 1987 \\
2,252\end{array}$}} \\
\hline & & & & & & & & & & & & & & \\
\hline & Count & Percent & Count & Percent & Count & Percent & Count & Percent & Count & Percent & Count & Percent & Count & Percent \\
\hline \multicolumn{15}{|l|}{ Coleoptera } \\
\hline $\begin{array}{l}\text { Curculionidae } \\
\text { Elmidae }\end{array}$ & - & & 1 & $<1$ & - & & - & & - & & - & & - & \\
\hline Ancyronyx & - & & - & & - & & - & & - & & - & & - & \\
\hline A.variegata & - & & - & & - & & - & & - & & - & & 1 & $<1$ \\
\hline Dubiraphia & 1 & $<1$ & 1 & $<1$ & 2 & $<1$ & 1 & $<1$ & 1 & $<1$ & 2 & $<1$ & - & \\
\hline \multicolumn{15}{|l|}{ Macronychus } \\
\hline M. glabratus & - & & - & & - & & 1 & $<1$ & - & & - & & - & \\
\hline Optioservus & 4 & $<1$ & 11 & $<1$ & 13 & 1 & 6 & $<1$ & 11 & 1 & 1 & $<1$ & 26 & 1 \\
\hline Oulimnius & 2 & $<1$ & 1 & $<1$ & - & & 2 & $<1$ & - & & - & & 2 & $<1$ \\
\hline Stenelmis & 12 & $<1$ & 23 & 1 & 63 & 5 & 12 & 1 & 21 & 2 & 17 & 3 & 31 & 1 \\
\hline \multicolumn{15}{|l|}{ Hydrophilidae } \\
\hline \multicolumn{15}{|l|}{ Psephenidae } \\
\hline Psephenus & - & & - & & - & & - & & 1 & $<1$ & - & & 11 & $<1$ \\
\hline $\begin{array}{l}\text { Hymenoptera } \\
\text { Diptera }\end{array}$ & 1 & $<1$ & - & & - & & - & & 1 & $<1$ & - & & - & \\
\hline $\begin{array}{l}\text { Chironomidae } \\
\text { Dixidae }\end{array}$ & \multicolumn{13}{|c|}{ Dixidae } & 10 \\
\hline $\begin{array}{c}\text { Dixa } \\
\text { Empididae }\end{array}$ & \multicolumn{13}{|c|}{ Empididae } & \\
\hline $\begin{array}{l}\text { Hemerodromia } \\
\text { Simuliidae }\end{array}$ & 15 & \multicolumn{5}{|c|}{ Simuliidae } & 8 & $<1$ & 6 & $<1$ & - & & 21 & $<1$ \\
\hline $\begin{array}{l}\text { Simulium } \\
\text { Tipulidae }\end{array}$ & 21 & 2 & 9 & $<1$ & 6 & $<1$ & 61 & 6 & 63 & 6 & 34 & 7 & 49 & 2 \\
\hline Antocha & 64 & 5 & 36 & 2 & 49 & 4 & 6 & $<1$ & 150 & 15 & 11 & 2 & 30 & 1 \\
\hline Dicranota & - & & - & & - & & - & & - & & - & & - & \\
\hline Tipula & - & & - & & - & & - & & - & & - & & - & \\
\hline
\end{tabular}

${ }^{1}$ Extrapolated from a 3/8 subsample. 


\begin{tabular}{|c|c|c|c|c|c|c|c|c|c|c|c|c|c|c|}
\hline \multicolumn{2}{|c|}{ Nov. 2, 1988} & \multicolumn{2}{|c|}{ Oct. 26,1989} & \multicolumn{2}{|c|}{ Oct. 5, 1990} & \multicolumn{2}{|c|}{ Oct. 21, 1991} & \multicolumn{2}{|c|}{ Oct. 23, 1992} & \multicolumn{2}{|c|}{ Oct. 26,1993} & \multicolumn{2}{|c|}{ Oct. 21, 1994} & \multirow{2}{*}{$\begin{array}{c}\text { Date } \\
\text { Total count }\end{array}$} \\
\hline \multicolumn{2}{|c|}{${ }^{1} 2,477$} & \multicolumn{2}{|c|}{4,174} & \multicolumn{2}{|c|}{2,625} & \multicolumn{2}{|c|}{1,731} & \multicolumn{2}{|c|}{2,926} & \multicolumn{2}{|c|}{693} & \multicolumn{2}{|c|}{2,643} & \\
\hline Count & Percent & Count & Percent & Count & Percent & Count & Percent & Count & Percent & Count & Percent & Count & Percent & Organism \\
\hline & & & & & & & & & & & & & & Coleoptera \\
\hline - & & - & & - & & - & & - & & - & & - & & $\begin{array}{l}\text { Curculionidae } \\
\text { Elmidae }\end{array}$ \\
\hline 3 & $<1$ & - & & - & & 2 & $<1$ & 3 & $<1$ & - & & - & & Ancyronyx \\
\hline - & & 7 & $<1$ & 2 & $<1$ & - & & - & & - & & - & & A.variegata \\
\hline - & & 8 & $<1$ & 1 & $<1$ & - & & 42 & 1 & - & & 5 & $<1$ & $\begin{array}{l}\text { Dubiraphia } \\
\text { Macronychus }\end{array}$ \\
\hline - & & - & & - & & - & & 3 & $<1$ & - & & - & & M. glabratus \\
\hline 35 & 1 & 51 & 1 & 38 & 1 & 28 & 2 & 110 & 4 & 14 & 2 & 62 & 2 & Optioservus \\
\hline - & & 7 & $<1$ & 1 & $<1$ & 6 & $<1$ & 8 & $<1$ & 3 & $<1$ & 10 & $<1$ & Oulimnius \\
\hline 29 & 1 & 32 & $<1$ & 78 & 3 & 22 & 1 & 290 & 10 & 2 & $<1$ & 93 & 4 & $\begin{array}{c}\text { Stenelmis } \\
\text { Hydrophilidae }\end{array}$ \\
\hline - & & - & & - & & - & & 4 & $<1$ & - & & 1 & $<1$ & $\begin{array}{c}\text { Berosus } \\
\text { Psephenidae }\end{array}$ \\
\hline 19 & $<1$ & 44 & 1 & 62 & 2 & 29 & 2 & 57 & 2 & 10 & 1 & 31 & 1 & Psephenus \\
\hline - & & - & & - & & - & & - & & - & & - & & $\begin{array}{l}\text { Hymenoptera } \\
\text { Diptera }\end{array}$ \\
\hline 960 & 38 & 1,700 & 40 & 1,300 & 50 & 880 & 52 & 1,200 & 41 & 480 & 69 & 1,500 & 58 & $\begin{array}{l}\text { Chironomidae } \\
\text { Dixidae }\end{array}$ \\
\hline - & & - & & - & & - & & - & & - & & - & & $\begin{array}{c}\text { Dixa } \\
\text { Empididae }\end{array}$ \\
\hline 3 & $<1$ & 130 & 3 & 26 & 1 & 13 & $<1$ & 23 & $<1$ & 10 & 1 & 73 & 3 & $\begin{array}{l}\text { Hemerodromia } \\
\text { Simuliidae }\end{array}$ \\
\hline 310 & 12 & 350 & 8 & 3 & $<1$ & 20 & 1 & 30 & 1 & - & & 27 & 1 & $\begin{array}{l}\text { Simulium } \\
\text { Tipulidae }\end{array}$ \\
\hline 11 & $<1$ & 29 & $<1$ & 16 & $<1$ & 68 & 4 & 16 & $<1$ & 36 & 5 & 19 & $<1$ & Antocha \\
\hline 3 & $<1$ & - & & - & & - & & 1 & $<1$ & - & & - & & Dicranota \\
\hline - & & - & & - & & - & & 1 & $<1$ & - & & 1 & $<1$ & Tipula \\
\hline
\end{tabular}


Table 5. Benthic-macroinvertebrate data-Continued

$[<$, less than; - , not found]

01476835 - East Branch Chester Creek at Westtown, Pa. (Site 24)

\begin{tabular}{|c|c|c|c|c|c|c|c|c|c|c|c|c|c|c|}
\hline \multirow{3}{*}{$\begin{array}{c}\text { Date } \\
\text { Total count } \\
\text { Organism }\end{array}$} & \multirow{2}{*}{\multicolumn{2}{|c|}{$\begin{array}{c}\text { Oct. } 27,1981 \\
1,783\end{array}$}} & \multirow{2}{*}{\multicolumn{2}{|c|}{$\frac{\text { Oct. 22, } 1982}{3,535}$}} & \multirow{2}{*}{\multicolumn{2}{|c|}{$\begin{array}{c}\text { Oct. } 26,1983 \\
2,250\end{array}$}} & \multirow{2}{*}{\multicolumn{2}{|c|}{$\begin{array}{c}\text { Oct. 11, } 1984 \\
2,424\end{array}$}} & \multirow{2}{*}{\multicolumn{2}{|c|}{$\frac{\text { Oct. } 16,1985}{1,365}$}} & \multirow{2}{*}{\multicolumn{2}{|c|}{$\frac{\text { Oct. } 16,1986}{1,026}$}} & \multirow{2}{*}{\multicolumn{2}{|c|}{$\frac{\text { Nov. 5, } 1987}{2,592}$}} \\
\hline & & & & & & & & & & & & & & \\
\hline & Count & Percent & Count & Percent & Count & Percent & Count & Percent & Count & Percent & Count & Percent & Count & Percent \\
\hline \multicolumn{15}{|l|}{ Platyhelminthes (flatworms) } \\
\hline \multicolumn{15}{|l|}{ Turbellaria } \\
\hline \multicolumn{15}{|l|}{ Tricladida } \\
\hline Planariidae & 16 & $<1$ & 33 & $<1$ & 65 & 3 & 43 & 2 & 13 & $<1$ & 8 & $<1$ & 77 & 3 \\
\hline Nematoda (nematodes) & - & & - & & - & & - & & - & & - & & 3 & $<1$ \\
\hline \multicolumn{15}{|l|}{ Nemertea (proboscis worms) } \\
\hline \multicolumn{15}{|l|}{ Enopla } \\
\hline \multicolumn{15}{|l|}{ Hoplonemertea } \\
\hline \multicolumn{15}{|l|}{ Tetrastemmatidae } \\
\hline Prostoma & - & & - & & - & & 1 & $<1$ & - & & - & & - & \\
\hline \multicolumn{15}{|l|}{ Mollusca (molluscs) } \\
\hline \multicolumn{15}{|l|}{ Gastropoda } \\
\hline Basommatophora & & & & & & & & & & & & & & \\
\hline Ancylidae & & & & & & & & & & & & & & \\
\hline Ferrissia & 32 & 2 & 1 & $<1$ & - & & 13 & $<1$ & 1 & $<1$ & - & & 4 & $<1$ \\
\hline Physidae & & & & & & & & & & & & & & \\
\hline Physa & 2 & $<1$ & - & & - & & - & & - & & - & & - & \\
\hline Planorbidae & & & & & & & & & & & & & & \\
\hline Gyraulus & - & & - & & - & & - & & - & & - & & - & \\
\hline Helisoma & 4 & $<1$ & - & & - & & - & & - & & - & & - & \\
\hline Bivalvia & & & & & & & & & & & & & & \\
\hline Veneroida & & & & & & & & & & & & & & \\
\hline Sphaeriidae & - & & - & & - & & - & & 1 & $<1$ & - & & - & \\
\hline Pisidium & - & & - & & - & & - & & - & & - & & - & \\
\hline Annelida (segmented worms) & & & & & & & & & & & & & & \\
\hline Oligochaeta & 7 & $<1$ & 2 & $<1$ & - & & 1 & $<1$ & - & & - & & - & \\
\hline Lumbriculida & & & & & & & & & & & & & & \\
\hline Lumbriculidae & - & & - & & - & & - & & - & & - & & - & \\
\hline Tubificida & & & & & & & & & & & & & & \\
\hline Naididae & - & & - & & - & & - & & - & & - & & 78 & 3 \\
\hline Hirudinea & & & & & & & & & & & & & & \\
\hline Pharyngobdellida & & & & & & & & & & & & & & \\
\hline Erpobdellidae & - & & - & & - & & - & & - & & 1 & $<1$ & - & \\
\hline Arthropoda (arthropods) & & & & & & & & & & & & & & \\
\hline Acariformes & & & & & & & & & & & & & & \\
\hline Hydrachnidia & 2 & $<1$ & 1 & $<1$ & 2 & $<1$ & 1 & $<1$ & 1 & $<1$ & - & & 31 & 1 \\
\hline Crustacea & & & & & & & & & & & & & & \\
\hline Cyclopoida & - & & - & & - & & - & & - & & - & & - & \\
\hline Amphipoda & & & & & & & & & & & & & & \\
\hline Gammaridae & & & & & & & & & & & & & & \\
\hline Gammarus & - & & - & & 1 & $<1$ & - & & - & & - & & - & \\
\hline Talitridae & & & & & & & & & & & & & & \\
\hline Hyallela & & & & & & & & & & & & & & \\
\hline H. azteca & - & & - & & - & & - & & - & & - & & 4 & $<1$ \\
\hline Isopoda & & & & & & & & & & & & & & \\
\hline Asellidae & - & & - & & 1 & $<1$ & - & & - & & - & & - & \\
\hline Podocopa & - & & - & & - & & - & & - & & - & & - & \\
\hline
\end{tabular}

Insecta

Ephemeroptera

Baetidae

$$
\text { Baetis }
$$

Pseudocloeon

Ephemerellidae

Ephemerella

$\begin{array}{rrrrr}26 & 1 & 40 & 1 & 15 \\ 9 & <1 & - & & \\ 2 & <1 & 2 & <1\end{array}$




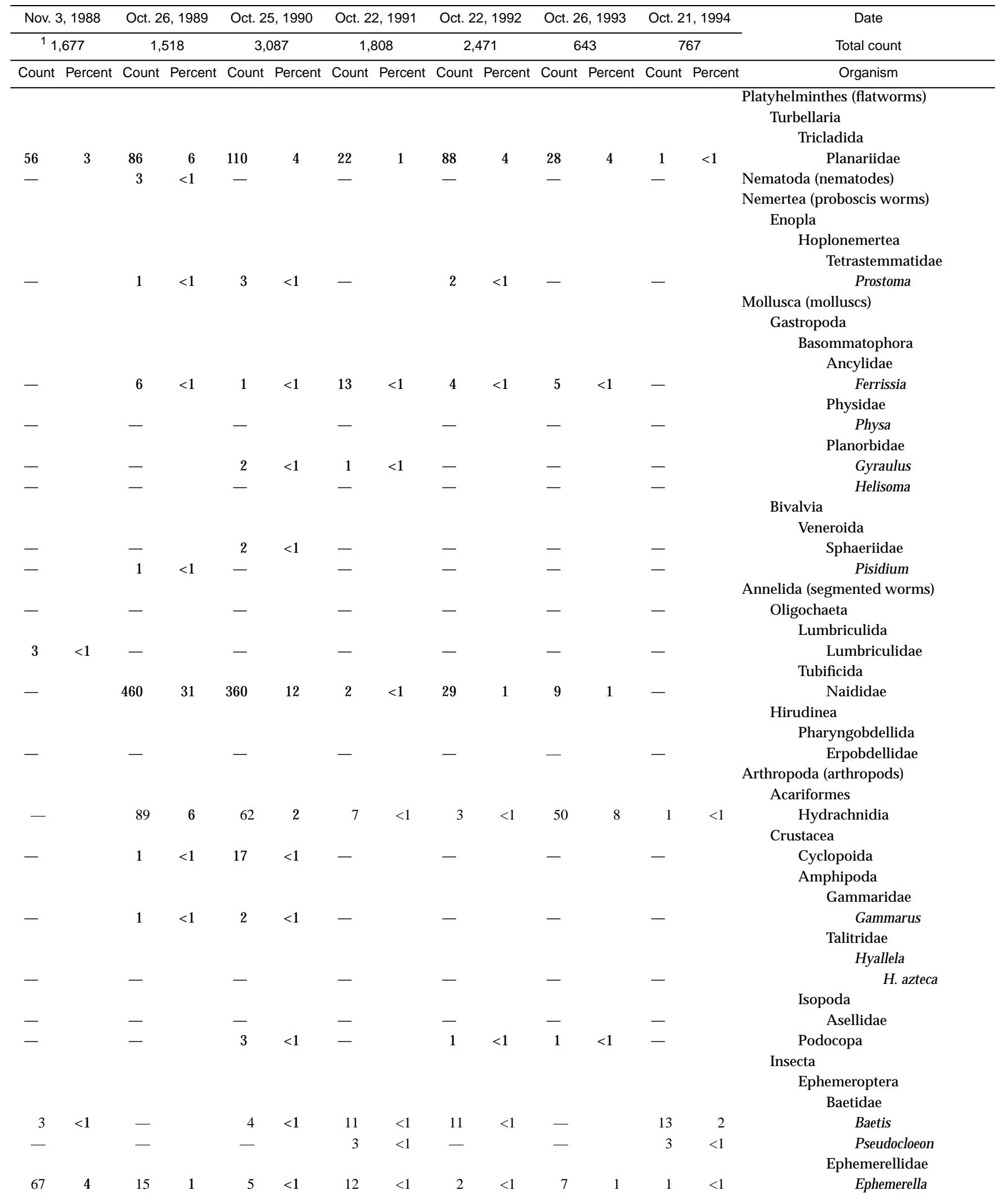


Table 5. Benthic-macroinvertebrate data-Continued

01476835 - East Branch Chester Creek at Westtown, Pa. (Site 24)—Continued

\begin{tabular}{|c|c|c|c|c|c|c|c|c|c|c|c|c|c|c|}
\hline \multirow{3}{*}{$\begin{array}{c}\text { Date } \\
\text { Total count } \\
\text { Organism }\end{array}$} & \multirow{2}{*}{\multicolumn{2}{|c|}{$\begin{array}{c}\text { Oct. } 27,1981 \\
1,783\end{array}$}} & \multicolumn{2}{|c|}{ Oct. 22, 1982} & \multicolumn{2}{|c|}{ Oct. 26,1983} & \multicolumn{2}{|c|}{ Oct. 11,1984} & \multicolumn{2}{|c|}{ Oct. 16,1985} & \multicolumn{2}{|c|}{ Oct. 16,1986} & \multicolumn{2}{|c|}{ Nov. 5, 1987} \\
\hline & & & & 535 & \multicolumn{2}{|c|}{2,250} & \multicolumn{2}{|c|}{2,424} & \multicolumn{2}{|c|}{1,365} & \multicolumn{2}{|c|}{1,026} & \multicolumn{2}{|c|}{2,592} \\
\hline & Count & Percent & Count & Percent & Count & Percent & Count & Percent & Count & Percent & Count & Percent & Count & Percent \\
\hline Ephemeroptera & & & & & & & & & & & & & & \\
\hline Heptageniidae & & & & & & & & & & & & & & \\
\hline Stenonema & 73 & 4 & 79 & 2 & 120 & 5 & 110 & 5 & 12 & $<1$ & 51 & 5 & 60 & 2 \\
\hline Leptohyphidae & & & & & & & & & & & & & & \\
\hline Tricorythodes & 13 & $<1$ & 22 & $<1$ & 24 & 1 & 1 & $<1$ & - & & 1 & $<1$ & 4 & $<1$ \\
\hline Leptophlebiidae & - & & - & & 1 & $<1$ & - & & - & & - & & - & \\
\hline Paraleptophlebia & - & & - & & - & & - & & - & & - & & - & \\
\hline Odonata & & & & & & & & & & & & & & \\
\hline Coenagrionidae & & & & & & & & & & & & & & \\
\hline Argia & 1 & $<1$ & - & & - & & 1 & $<1$ & - & & - & & - & \\
\hline Plecoptera & & & & & & & & & & & & & & \\
\hline Capniidae & & & & & & & & & & & & & & \\
\hline Allocapnia & 2 & $<1$ & - & & 2 & $<1$ & - & & 3 & $<1$ & - & & - & \\
\hline Megaloptera & & & & & & & & & & & & & & \\
\hline Corydalidae & & & & & & & & & & & & & & \\
\hline Corydalus & - & & - & & 1 & $<1$ & 1 & $<1$ & - & & - & & - & \\
\hline Nigronia & 3 & $<1$ & - & & - & & - & & - & & - & & - & \\
\hline Trichoptera & & & & & & & & & & & & & & \\
\hline Apataniidae & & & & & & & & & & & & & & \\
\hline Apatania & - & & - & & - & & - & & - & & - & & - & \\
\hline Glossosomatidae & & & & & & & & & & & & & & \\
\hline Glossosoma & 1 & $<1$ & - & & - & & 1 & $<1$ & - & & - & & - & \\
\hline Hydropsychidae & & & & & & & & & & & & & & \\
\hline Ceratopsyche & 150 & 8 & 380 & 11 & 600 & 26 & 440 & 18 & 41 & 3 & 260 & 26 & 180 & 7 \\
\hline Cheumatopsyche & 120 & 7 & 240 & 7 & 370 & 16 & 160 & 7 & 71 & 5 & 86 & 9 & 41 & 2 \\
\hline Hydropsyche & 72 & 4 & 180 & 5 & 96 & 4 & 180 & 7 & 20 & 1 & 200 & 20 & 220 & 8 \\
\hline Hydroptilidae & & & & & & & & & & & & & & \\
\hline Hydroptila & 180 & 10 & 69 & 2 & 120 & 5 & 4 & $<1$ & 4 & $<1$ & 3 & $<1$ & 79 & 3 \\
\hline Leucotrichia & 85 & 5 & 120 & 3 & 56 & 2 & 540 & 22 & 27 & 2 & 14 & 1 & 62 & 2 \\
\hline Leptoceridae & & & & & & & & & & & & & & \\
\hline Oecetis & - & & - & & 1 & $<1$ & 2 & $<1$ & - & & - & & 1 & $<1$ \\
\hline Philopotamidae & & & & & & & & & & & & & & \\
\hline Chimarra & 4 & $<1$ & 16 & $<1$ & 4 & $<1$ & 17 & $<1$ & 2 & $<1$ & 88 & 9 & 180 & 7 \\
\hline Wormaldia & - & & - & & - & & - & & - & & - & & - & \\
\hline Polycentropodidae & & & & & & & & & & & & & & \\
\hline Polycentropus & - & & - & & 1 & $<1$ & - & & - & & - & & - & \\
\hline Psychomyiidae & & & & & & & & & & & & & & \\
\hline Psychomyia & - & & - & & - & & 1 & $<1$ & 2 & $<1$ & - & & 6 & $<1$ \\
\hline Lepidoptera & & & & & & & & & & & & & & \\
\hline Pyralidae & & & & & & & & & & & & & & \\
\hline Petrophila & 2 & $<1$ & 3 & $<1$ & 9 & $<1$ & 29 & 1 & 5 & $<1$ & 2 & $<1$ & 4 & $<1$ \\
\hline Coleoptera & & & & & & & & & & & & & & \\
\hline Elmidae & & & & & & & & & & & & & & \\
\hline Ancyronyx & - & & - & & - & & - & & - & & - & & - & \\
\hline A.variegata & - & & - & & - & & - & & - & & - & & 2 & $<1$ \\
\hline Dubiraphia & - & & - & & - & & - & & 1 & $<1$ & - & & 2 & $<1$ \\
\hline Macronychus & - & & 1 & $<1$ & - & & 1 & $<1$ & 1 & $<1$ & - & & - & \\
\hline Optioservus & 2 & $<1$ & 3 & $<1$ & 13 & $<1$ & 9 & $<1$ & 11 & $<1$ & 16 & 2 & 34 & 1 \\
\hline Oulimnius & - & & - & & 1 & $<1$ & - & & - & & - & & 3 & $<1$ \\
\hline Promoresia & - & & - & & - & & - & & - & & - & & - & \\
\hline Stenelmis & 15 & $<1$ & 31 & $<1$ & 27 & 1 & 46 & 2 & 36 & 3 & 49 & 5 & 38 & 1 \\
\hline Hydrophilidae & & & & & & & & & & & & & & \\
\hline Berosus & - & & - & & - & & - & & - & & - & & - & \\
\hline Psephenidae & & & & & & & & & & & & & & \\
\hline Psephenus & - & & - & & 1 & $<1$ & - & & 1 & $<1$ & - & & 3 & $<1$ \\
\hline
\end{tabular}




\begin{tabular}{|c|c|c|c|c|c|c|c|c|c|c|c|c|c|c|}
\hline \multirow{2}{*}{\multicolumn{2}{|c|}{$\begin{array}{c}\text { Nov. 3, } 1988 \\
11,677\end{array}$}} & \multicolumn{2}{|c|}{ Oct. 26, 1989} & \multicolumn{2}{|c|}{ Oct. 25,1990} & \multicolumn{2}{|c|}{ Oct. 22, 1991} & \multicolumn{2}{|c|}{ Oct. 22, 1992} & \multicolumn{2}{|c|}{ Oct. 26, 1993} & \multicolumn{2}{|c|}{ Oct. 21, 1994} & \multirow{2}{*}{$\begin{array}{c}\text { Date } \\
\text { Total count }\end{array}$} \\
\hline & & & 518 & 3,0 & 887 & & 308 & & 471 & 64 & 43 & & 67 & \\
\hline \multirow[t]{3}{*}{ Count } & Percent & Count & Percent & Count & Percent & Count & Percent & Count & Percent & Count & Percent & Count & Percent & Organism \\
\hline & & & & & & & & & & & & & & Ephemeroptera \\
\hline & & & & & & & & & & & & & & Heptageniidae \\
\hline \multirow[t]{2}{*}{43} & 3 & 4 & $<1$ & 44 & 1 & 46 & 3 & 13 & $<1$ & 13 & 2 & 13 & 2 & Stenonema \\
\hline & & & & & & & & & & & & & & Leptohyphidae \\
\hline \multirow{2}{*}{11} & $<1$ & - & & 5 & $<1$ & 2 & $<1$ & - & & - & & - & & Tricorythodes \\
\hline & & - & & 2 & $<1$ & - & & - & & - & & - & & Leptophlebiidae \\
\hline \multirow{3}{*}{-} & & - & & - & & - & & - & & - & & 1 & $<1$ & Paraleptophlebia \\
\hline & & & & & & & & & & & & & & Odonata \\
\hline & & & & & & & & & & & & & & Coenagrionidae \\
\hline \multirow[t]{3}{*}{-} & & 1 & $<1$ & - & & - & & - & & - & & 1 & $<1$ & Argia \\
\hline & & & & & & & & & & & & & & Plecoptera \\
\hline & & & & & & & & & & & & & & Capniidae \\
\hline - & & - & & - & & - & & 1 & $<1$ & - & & - & & Allocapnia \\
\hline & & & & & & & & & & & & & & Megaloptera \\
\hline & & & & & & & & & & & & & & Corydalidae \\
\hline - & & - & & - & & - & & - & & - & & - & & Corydalus \\
\hline - & & - & & - & & - & & - & & - & & - & & Nigronia \\
\hline & & & & & & & & & & & & & & Trichoptera \\
\hline & & & & & & & & & & & & & & Apataniidae \\
\hline 3 & $<1$ & - & & - & & - & & - & & - & & - & & Apatania \\
\hline & & & & & & & & & & & & & & Glossosomatidae \\
\hline - & & - & & 2 & $<1$ & - & & - & & - & & - & & Glossosoma \\
\hline & & & & & & & & & & & & & & Hydropsychidae \\
\hline 100 & 6 & 23 & 2 & 110 & 4 & 150 & 8 & 78 & 3 & 87 & 13 & 61 & 8 & Ceratopsyche \\
\hline 59 & 3 & 22 & 1 & 550 & 18 & 130 & 7 & 43 & 2 & 53 & 8 & 53 & 7 & Cheumatopsyche \\
\hline 360 & 21 & 160 & 11 & 350 & 11 & 340 & 19 & 410 & 16 & 92 & 14 & 97 & 13 & Hydropsyche \\
\hline & & & & & & & & & & & & & & Hydroptilidae \\
\hline 3 & $<1$ & 10 & $<1$ & 79 & 3 & 16 & $<1$ & 30 & 1 & 5 & $<1$ & 1 & $<1$ & Hydroptila \\
\hline 11 & $<1$ & 2 & $<1$ & - & & 14 & $<1$ & 1 & $<1$ & 5 & $<1$ & 10 & 1 & Leucotrichia \\
\hline & & & & & & & & & & & & & & Leptoceridae \\
\hline - & & - & & - & & 1 & $<1$ & - & & 1 & $<1$ & - & & Oecetis \\
\hline & & & & & & & & & & & & & & Philopotamidae \\
\hline 29 & 2 & 1 & $<1$ & 10 & $<1$ & 21 & 1 & 4 & $<1$ & 3 & $<1$ & 9 & 1 & Chimarra \\
\hline - & & - & & - & & - & & - & & - & & 1 & $<1$ & Wormaldia \\
\hline & & & & & & & & & & & & & & Polycentropodidae \\
\hline - & & - & & - & & - & & - & & - & & - & & Polycentropus \\
\hline & & & & & & & & & & & & & & Psychomyiidae \\
\hline - & & - & & - & & 58 & 3 & 4 & $<1$ & - & & 1 & $<1$ & Psychomyia \\
\hline & & & & & & & & & & & & & & Lepidoptera \\
\hline & & & & & & & & & & & & & & Pyralidae \\
\hline 3 & $<1$ & - & & - & & - & & - & & - & & - & & Petrophila \\
\hline & & & & & & & & & & & & & & Coleoptera \\
\hline & & & & & & & & & & & & & & Elmidae \\
\hline- & & - & & - & & 7 & $<1$ & - & & 2 & $<1$ & 2 & $<1$ & Ancyronyx \\
\hline- & & 4 & $<1$ & 5 & $<1$ & - & & - & & - & & - & & A.variegata \\
\hline- & & - & & 3 & $<1$ & - & & - & & - & & - & & Dubiraphia \\
\hline- & & - & & - & & - & & - & & - & & - & & Macronychus \\
\hline 75 & 4 & 37 & 2 & 51 & 2 & 25 & 1 & 78 & 3 & 40 & 6 & 33 & 4 & Optioservus \\
\hline- & & 2 & $<1$ & 3 & $<1$ & 4 & $<1$ & 1 & $<1$ & 9 & 1 & - & & Oulimnius \\
\hline 5 & $<1$ & - & & - & & - & & - & & - & & - & & Promoresia \\
\hline 32 & 2 & 25 & 2 & 61 & 2 & 44 & 2 & 36 & 1 & 38 & 6 & 6 & $<1$ & Stenelmis \\
\hline & & & & & & & & & & & & & & Hydrophilidae \\
\hline- & & - & & 1 & $<1$ & - & & - & & 1 & $<1$ & - & & Berosus \\
\hline & & & & & & & & & & & & & & Psephenidae \\
\hline 3 & $<1$ & 14 & $<1$ & 8 & $<1$ & 9 & $<1$ & - & & 18 & 3 & 2 & $<1$ & Psephenus \\
\hline
\end{tabular}


Table 5. Benthic-macroinvertebrate data-Continued

01476835 - East Branch Chester Creek at Westtown, Pa. (Site 24)—Continued

\begin{tabular}{|c|c|c|c|c|c|c|c|c|c|c|c|c|c|c|}
\hline \multirow{3}{*}{$\begin{array}{c}\text { Date } \\
\text { Total count } \\
\text { Organism }\end{array}$} & \multirow{2}{*}{\multicolumn{2}{|c|}{$\frac{\text { Oct. } 27,1981}{1,783}$}} & \multicolumn{2}{|c|}{ Oct. 22, 1982} & \multicolumn{2}{|c|}{ Oct. 26, 1983} & \multicolumn{2}{|c|}{ Oct. 11,1984} & \multicolumn{2}{|c|}{ Oct. 16,1985} & \multicolumn{2}{|c|}{ Oct. 16, 1986} & \multicolumn{2}{|c|}{ Nov. 5, 1987} \\
\hline & & & \multicolumn{2}{|c|}{3,535} & \multicolumn{2}{|c|}{2,250} & \multicolumn{2}{|c|}{2,424} & \multicolumn{2}{|c|}{1,365} & \multicolumn{2}{|c|}{1,026} & \multicolumn{2}{|c|}{2,592} \\
\hline & Count & Percent & Count & Percent & Count & Percent & Count & Percent & Count & Percent & Count & Percent & Count & Percent \\
\hline Hymenoptera & - & & - & & 2 & $<1$ & 1 & $<1$ & 2 & $<1$ & - & & - & \\
\hline \multicolumn{15}{|l|}{ Diptera } \\
\hline Ceratopogonidae & - & & - & & - & & - & & - & & - & & - & \\
\hline Chironomidae & 450 & 25 & 700 & 20 & 330 & 14 & 400 & 17 & 260 & 19 & 56 & 6 & 230 & 9 \\
\hline \multicolumn{15}{|l|}{ Empididae } \\
\hline Hemerodromia & 55 & 3 & 2 & $<1$ & 6 & $<1$ & 19 & $<1$ & - & & 1 & $<1$ & 8 & $<1$ \\
\hline \multicolumn{15}{|l|}{ Simuliidae } \\
\hline Simulium & 440 & 24 & 1,600 & 46 & 310 & 13 & 230 & 9 & 780 & 56 & 150 & 15 & 1,100 & 42 \\
\hline \multicolumn{15}{|l|}{ Tipulidae } \\
\hline Antocha & 15 & $<1$ & 10 & $<1$ & 51 & 2 & 51 & 2 & 63 & 5 & 16 & 2 & 77 & 3 \\
\hline
\end{tabular}

${ }^{1}$ Extrapolated from a 3/8 subsample. 


\begin{tabular}{|c|c|c|c|c|c|c|c|c|c|c|c|c|c|c|}
\hline \multicolumn{2}{|c|}{ Nov. 3, 1988} & \multicolumn{2}{|c|}{ Oct. 26, 1989} & \multicolumn{2}{|c|}{ Oct. 25,1990} & \multicolumn{2}{|c|}{ Oct. 22, 1991} & \multicolumn{2}{|c|}{ Oct. 22, 1992} & \multicolumn{2}{|c|}{ Oct. 26,1993} & \multicolumn{2}{|c|}{ Oct. 21, 1994} & \multirow{2}{*}{$\begin{array}{c}\text { Date } \\
\text { Total count }\end{array}$} \\
\hline${ }^{1} 1$ & 677 & & 518 & & 87 & & 308 & & 471 & & 43 & & 67 & \\
\hline Count & Percent & Count & Percent & Count & Percent & Count & Percent & Count & Percent & Count & Percent & Count & Percent & Organism \\
\hline- & & - & & - & & - & & - & & - & & - & & $\begin{array}{l}\text { Hymenoptera } \\
\text { Diptera }\end{array}$ \\
\hline - & & - & & 3 & $<1$ & - & & - & & - & & - & & Ceratopogonidae \\
\hline 510 & 30 & 250 & 17 & 1,000 & 32 & 680 & 38 & 950 & 38 & 80 & 12 & 220 & 29 & $\begin{array}{l}\text { Chironomidae } \\
\text { Empididae }\end{array}$ \\
\hline 5 & $<1$ & 17 & 1 & 33 & 1 & 7 & $<1$ & 8 & $<1$ & 16 & 2 & 2 & $<1$ & $\begin{array}{l}\text { Hemerodromia } \\
\text { Simuliidae }\end{array}$ \\
\hline 280 & 16 & 230 & 15 & 100 & 3 & 93 & 5 & 580 & 23 & 5 & $<1$ & 210 & 27 & $\begin{array}{l}\text { Simulium } \\
\text { Tipulidae }\end{array}$ \\
\hline 16 & $<1$ & 53 & 4 & 96 & 3 & 90 & 5 & 94 & 4 & 75 & 12 & 25 & 3 & Antocha \\
\hline
\end{tabular}


Table 5. Benthic-macroinvertebrate data-Continued

$[<$, less than; - , not found]

01476840 - Goose Creek tributary to East Branch Chester Creek near West Chester, Pa. (Site 25)

\begin{tabular}{|c|c|c|c|c|c|c|c|c|c|c|}
\hline \multirow{3}{*}{$\begin{array}{c}\text { Date } \\
\text { Total count } \\
\text { Organism }\end{array}$} & \multirow{2}{*}{\multicolumn{2}{|c|}{$\frac{\text { Oct. } 27,1981}{356}$}} & \multirow{2}{*}{\multicolumn{2}{|c|}{$\begin{array}{c}\text { Oct. } 22,1982 \\
19,644\end{array}$}} & \multirow{2}{*}{\multicolumn{2}{|c|}{$\frac{\text { Nov. } 4,1988}{{ }^{2} 587}$}} & \multirow{2}{*}{\multicolumn{2}{|c|}{$\frac{\text { Oct. } 25,1989}{3,091}$}} & \multirow{2}{*}{\multicolumn{2}{|c|}{$\frac{\text { Oct. } 25,1990}{1,111}$}} \\
\hline & & & & & & & & & & \\
\hline & Count & Percent & Count & Percent & Count & Percent & Count & Percent & Count & Percent \\
\hline \multicolumn{11}{|l|}{ Platyhelminthes (flatworms) } \\
\hline \multicolumn{11}{|l|}{ Turbellaria } \\
\hline \multicolumn{11}{|l|}{ Tricladida } \\
\hline Planariidae & - & & - & & 11 & 2 & 91 & 3 & 73 & 7 \\
\hline Nematoda & - & & - & & - & & - & & - & \\
\hline \multicolumn{11}{|l|}{ Nemertea (proboscis worms) } \\
\hline \multicolumn{11}{|l|}{ Enopla } \\
\hline \multicolumn{11}{|l|}{ Hoplonemertea } \\
\hline \multicolumn{11}{|l|}{ Tetrastemmatidae } \\
\hline Prostoma & - & & - & & - & & - & & - & \\
\hline \multicolumn{11}{|l|}{ Mollusca (molluscs) } \\
\hline \multicolumn{11}{|l|}{ Gastropoda } \\
\hline \multicolumn{11}{|l|}{ Basommatophora } \\
\hline Ancylidae & & & & & & & & & & \\
\hline Ferrissia & - & & - & & - & & 7 & $<1$ & 3 & $<1$ \\
\hline Physidae & & & & & & & & & & \\
\hline Physa & 71 & 20 & 88 & $<1$ & - & & - & & - & \\
\hline Bivalvia & & & & & & & & & & \\
\hline Veneroida & & & & & & & & & & \\
\hline Sphaeriidae & - & & - & & - & & - & & 2 & $<1$ \\
\hline Annelida (segmented worms) & & & & & & & & & & \\
\hline Oligochaeta & - & & 440 & 5 & - & & - & & - & \\
\hline Lumbriculida & & & & & & & & & & \\
\hline Lumbriculidae & - & & - & & - & & - & & 7 & $<1$ \\
\hline Tubificida & & & & & & & & & & \\
\hline Naididae & - & & - & & 5 & $<1$ & 450 & 15 & 1 & $<1$ \\
\hline Tubificidae & 9 & 3 & - & & - & & 74 & 2 & - & \\
\hline Arthropoda (arthropods) & & & & & & & & & & \\
\hline Acariformes & & & & & & & & & & \\
\hline Hydrachnidia & - & & - & & - & & 7 & $<1$ & 42 & 4 \\
\hline Crustacea & & & & & & & & & & \\
\hline Cyclopoida & - & & - & & - & & 1 & $<1$ & 2 & $<1$ \\
\hline Isopoda & & & & & & & & & & \\
\hline Asellidae & & & & & & & & & & \\
\hline Caecidotea & 2 & $<1$ & - & & 3 & $<1$ & 21 & $<1$ & 27 & 2 \\
\hline Podocopa & - & & - & & - & & - & & 110 & 10 \\
\hline Insecta & & & & & & & & & & \\
\hline Ephemeroptera & & & & & & & & & & \\
\hline Baetidae & & & & & & & & & & \\
\hline Baetis & 2 & $<1$ & 4 & $<1$ & - & & - & & - & - \\
\hline Pseudocloeon & - & & - & & 3 & $<1$ & - & & - & \\
\hline Ephemerellidae & & & & & & & & & & \\
\hline Ephemerella & - & & - & & - & & - & & - & \\
\hline Heptageniidae & & & & & & & & & & \\
\hline Epeorus & - & & - & & - & & - & & - & \\
\hline Stenonema & - & & 4 & $<1$ & - & & - & & - & \\
\hline Leptohyphidae & & & & & & & & & & \\
\hline Tricorythodes & - & & - & & - & & - & & 1 & $<1$ \\
\hline Odonata & & & & & & & & & & \\
\hline Gomphidae & - & & - & & - & & - & & - & \\
\hline Hemiptera & & & & & & & & & & \\
\hline Corixidae & - & & - & & - & & - & & - & \\
\hline
\end{tabular}




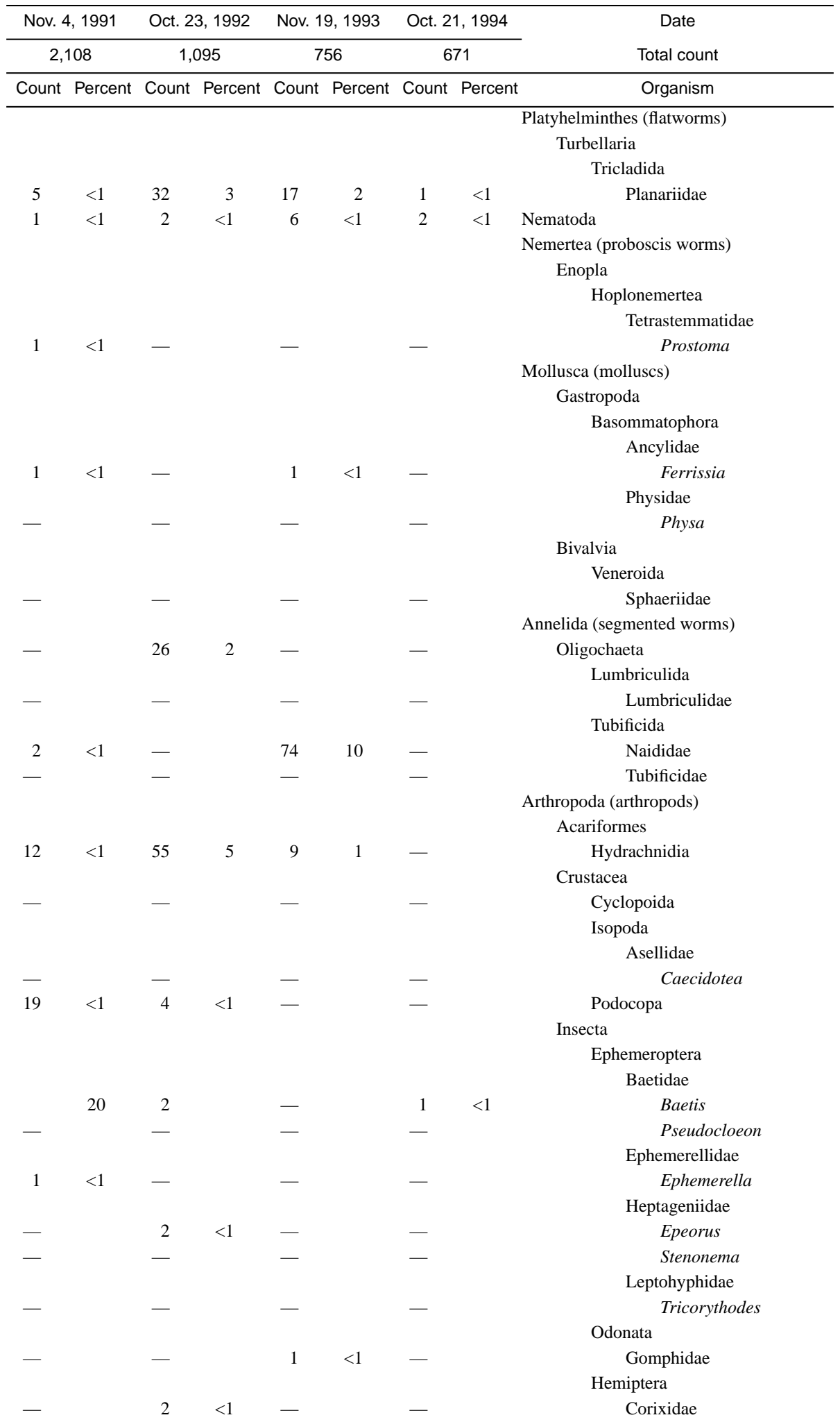


Table 5. Benthic-macroinvertebrate data—Continued

01476840 - Goose Creek tributary to East Branch Chester Creek near West Chester, Pa. (Site 25)—Continued

\begin{tabular}{|c|c|c|c|c|c|c|c|c|c|c|}
\hline \multirow{3}{*}{$\begin{array}{c}\text { Date } \\
\text { Total count } \\
\text { Organism }\end{array}$} & \multirow{2}{*}{\multicolumn{2}{|c|}{$\frac{\text { Oct. } 27,1981}{356}$}} & \multirow{2}{*}{\multicolumn{2}{|c|}{$\begin{array}{c}\text { Oct. 22, } 1982 \\
{ }^{1} 9,644\end{array}$}} & \multirow{2}{*}{\multicolumn{2}{|c|}{$\frac{\text { Nov. } 4,1988}{{ }^{2} 587}$}} & \multirow{2}{*}{\multicolumn{2}{|c|}{$\frac{\text { Oct. } 25,1989}{3,091}$}} & \multirow{2}{*}{\multicolumn{2}{|c|}{$\frac{\text { Oct. } 25,1990}{1,111}$}} \\
\hline & & & & & & & & & & \\
\hline & Count & Percent & Count & Percent & Count & Percent & Count & Percent & Count & Percent \\
\hline \multicolumn{11}{|l|}{ Trichoptera } \\
\hline \multicolumn{11}{|l|}{ Hydropsychidae } \\
\hline Ceratopsyche & 4 & 1 & 4 & $<1$ & 11 & 2 & - & & 3 & $<1$ \\
\hline Cheumatopsyche & - & & - & & 3 & $<1$ & - & & 1 & $<1$ \\
\hline Diplectrona & - & & - & & 一 & & 1 & $<1$ & - & \\
\hline Hydropsyche & - & & - & & 150 & 25 & 3 & $<1$ & 15 & 1 \\
\hline \multicolumn{11}{|l|}{ Hydroptilidae } \\
\hline Agraylea & - & & - & & - & & - & & 1 & $<1$ \\
\hline Hydroptila & 2 & $<1$ & 一 & & 5 & $<1$ & 1 & $<1$ & 16 & 1 \\
\hline Leucotrichia & - & & - & & 一 & & 1 & $<1$ & - & \\
\hline \multicolumn{11}{|l|}{ Lepidoptera } \\
\hline \multicolumn{11}{|l|}{ Noctuidae } \\
\hline Archanara & - & & 一 & & 一 & & 1 & $<1$ & - & \\
\hline \multicolumn{11}{|l|}{ Coleoptera } \\
\hline \multicolumn{11}{|l|}{ Elmidae } \\
\hline Optioservus & - & & - & & - & & - & & - & \\
\hline Stenelmis & - & & 4 & $<1$ & 3 & $<1$ & 2 & $<1$ & 7 & $<1$ \\
\hline \multicolumn{11}{|l|}{ Psephenidae } \\
\hline Psephenus & - & & 一 & & 一 & & 一 & & - & \\
\hline \multicolumn{11}{|l|}{ Diptera } \\
\hline Chironomidae & 230 & 64 & 2,300 & 24 & 160 & 27 & 490 & 16 & 190 & 17 \\
\hline \multicolumn{11}{|l|}{ Empididae } \\
\hline Hemerodromia & - & & - & & 3 & $<1$ & 140 & 5 & 9 & $<1$ \\
\hline \multicolumn{11}{|l|}{ Psychodidae } \\
\hline Telmatoscopus & 1 & $<1$ & 一 & & 一 & & 一 & & - & \\
\hline \multicolumn{11}{|l|}{ Simuliidae } \\
\hline Simulium & 35 & 10 & 6,800 & 71 & 230 & 39 & 1,800 & 58 & 600 & 55 \\
\hline \multicolumn{11}{|l|}{ Tipulidae } \\
\hline Antocha & - & & 一 & & 一 & & 一 & & - & \\
\hline Tipula & - & & - & & - & & 1 & $<1$ & 1 & $<1$ \\
\hline
\end{tabular}

${ }^{1}$ Extrapolated from a 3/8 subsample.

${ }^{2}$ Extrapolated from a 1/4 subsample. 


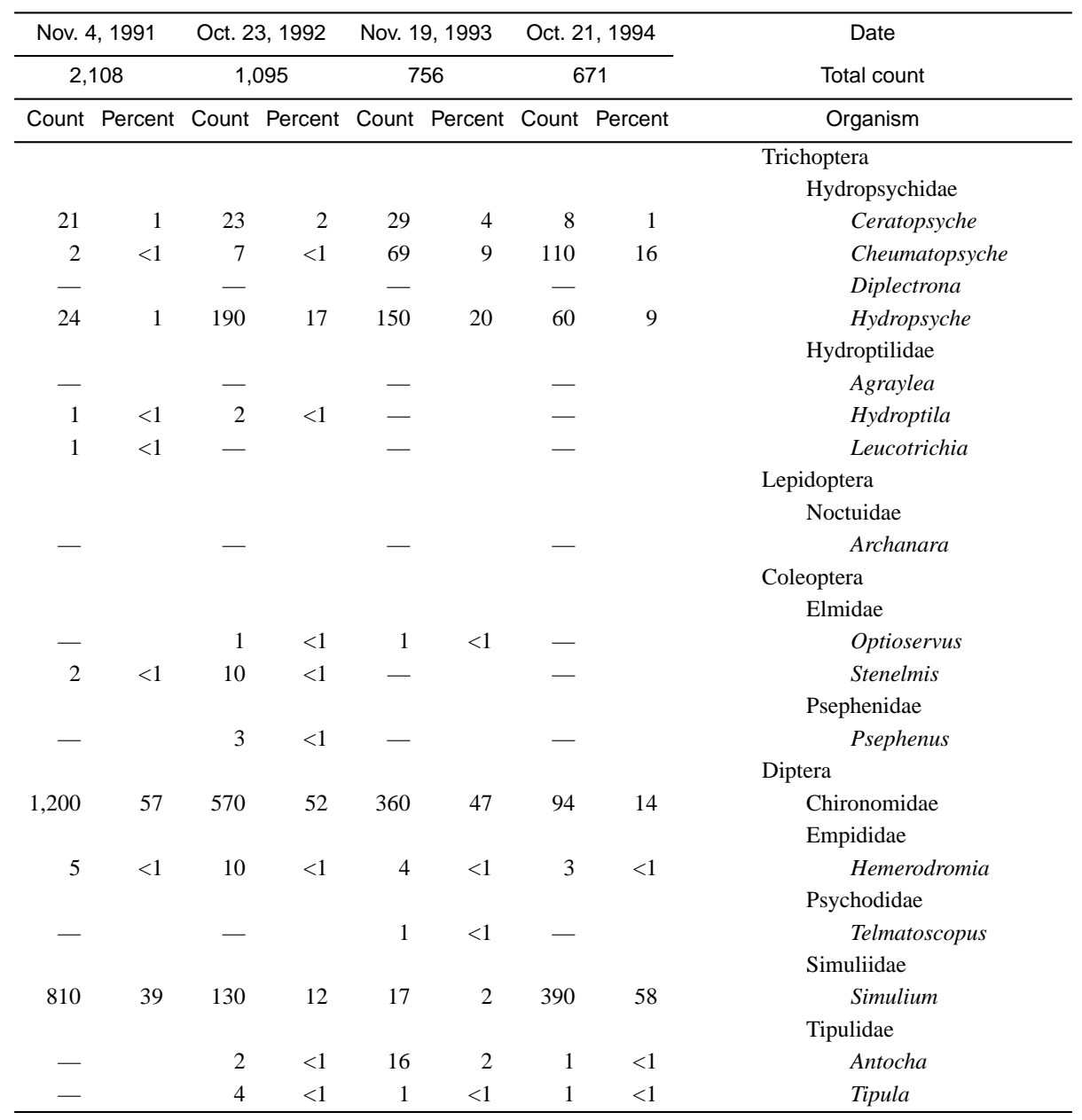


Table 5. Benthic-macroinvertebrate data-Continued

$[<$, less than; - , not found]

01476848 - East Branch Chester Creek below Goose Creek near West Chester, Pa. (Site 51)

\begin{tabular}{|c|c|c|c|c|c|c|c|c|c|c|c|c|c|c|}
\hline \multirow{3}{*}{$\begin{array}{c}\text { Date } \\
\text { Total count } \\
\text { Organism }\end{array}$} & \multirow{2}{*}{\multicolumn{2}{|c|}{$\begin{array}{c}\text { Oct. } 26,1983 \\
2,869\end{array}$}} & \multirow{2}{*}{\multicolumn{2}{|c|}{$\frac{\text { Oct. 11, } 1984}{2,874}$}} & \multirow{2}{*}{\multicolumn{2}{|c|}{$\frac{\text { Oct. 28, } 1985}{4,236}$}} & \multirow{2}{*}{\multicolumn{2}{|c|}{$\frac{\text { Oct. } 16,1986}{1,514}$}} & \multirow{2}{*}{\multicolumn{2}{|c|}{$\begin{array}{c}\text { Nov. } 15,1987 \\
12,174\end{array}$}} & \multirow{2}{*}{\multicolumn{2}{|c|}{$\frac{\text { Nov. 3, } 1988}{{ }^{1} 3,963}$}} & \multirow{2}{*}{\multicolumn{2}{|c|}{$\frac{\text { Oct. 25, } 1989}{926}$}} \\
\hline & & & & & & & & & & & & & & \\
\hline & Count & Percent & Count & Percent & Count & Percent & Count & Percent & Count & Percent & Count & Percent & Count & Percent \\
\hline \multicolumn{15}{|l|}{ Platyhelminthes (flatworms) } \\
\hline \multicolumn{15}{|l|}{ Turbellaria } \\
\hline \multicolumn{15}{|l|}{ Tricladida } \\
\hline Planariidae & 195 & 7 & 351 & 12 & 32 & $<1$ & 17 & 1 & 69 & $<1$ & 16 & $<1$ & - & \\
\hline Nematoda (nematodes) & 2 & $<1$ & 4 & $<1$ & - & & - & & - & & - & & - & \\
\hline \multicolumn{15}{|l|}{ Nemertea (proboscis worms) } \\
\hline \multicolumn{15}{|l|}{ Enopla } \\
\hline \multicolumn{15}{|l|}{ Hoplonemertea } \\
\hline Tetrastemmatida & & & & & & & & & & & & & & \\
\hline Prostoma & 1 & $<1$ & 1 & $<1$ & 8 & $<1$ & - & & - & & 8 & $<1$ & 1 & $<1$ \\
\hline Mollusca (molluscs) & & & & & & & & & & & & & & \\
\hline Gastropoda & & & & & & & & & & & & & & \\
\hline Basommatophora & & & & & & & & & & & & & & \\
\hline Ancylidae & & & & & & & & & & & & & & \\
\hline Ferrissia & - & & - & & 32 & $<1$ & 1 & $<1$ & 20 & $<1$ & - & & 9 & 1 \\
\hline Lymnaeidae & & & & & & & & & & & & & & \\
\hline Lymnaea & - & & - & & - & & - & & - & & - & & 1 & $<1$ \\
\hline Physidae & & & & & & & & & & & & & & \\
\hline Physa & 18 & $<1$ & - & & - & & - & & - & & - & & 2 & $<1$ \\
\hline Planorbidae & & & & & & & & & & & & & & \\
\hline Gyraulus & - & & - & & - & & - & & - & & - & & 1 & $<1$ \\
\hline Helisoma & - & & - & & 8 & $<1$ & 3 & $<1$ & 1 & $<1$ & - & & - & \\
\hline Bivalvia & & & & & & & & & & & & & & \\
\hline Veneroida & & & & & & & & & & & & & & \\
\hline Sphaeriidae & - & & - & & 16 & $<1$ & 53 & 4 & 30 & $<1$ & - & & - & \\
\hline Pisidium & - & & - & & - & & - & & - & & 5 & $<1$ & - & \\
\hline Annelida (segmented worms) & & & & & & & & & & & & & & \\
\hline Oligochaeta & - & & - & & - & & - & & - & & - & & - & \\
\hline Lumbriculida & & & & & & & & & & & & & & \\
\hline Lumbriculidae & - & & - & & - & & - & & - & & - & & 3 & $<1$ \\
\hline Tubificida & & & & & & & & & & & & & & \\
\hline Naididae & 110 & 4 & 190 & 7 & - & & - & & 7,200 & 60 & 960 & 24 & 300 & 32 \\
\hline Tubificidae & 380 & 13 & 190 & 7 & 1,400 & 33 & 7 & $<1$ & 120 & 1 & 27 & $<1$ & - & \\
\hline Hirudinea & & & & & & & & & & & & & & \\
\hline Pharyngobdellida & & & & & & & & & & & & & & \\
\hline Erpobdellidae & - & & - & & 8 & $<1$ & 1 & $<1$ & 1 & $<1$ & - & & - & \\
\hline Rhynchobdellida & & & & & & & & & & & & & & \\
\hline Glossiphoniidae & 1 & $<1$ & - & & - & & - & & - & & - & & - & \\
\hline Arthropoda (arthropods) & & & & & & & & & & & & & & \\
\hline Acariformes & & & & & & & & & & & & & & \\
\hline Hydrachnidia & 1 & $<1$ & 4 & $<1$ & 8 & $<1$ & 1 & $<1$ & 4 & $<1$ & - & & 78 & 8 \\
\hline Crustacea & & & & & & & & & & & & & & \\
\hline Cyclopoida & - & & - & & - & & - & & - & & - & & 1 & $<1$ \\
\hline Amphipoda & & & & & & & & & & & & & & \\
\hline Gammaridae & & & & & & & & & & & & & & \\
\hline Gammarus & 2 & $<1$ & - & & 8 & $<1$ & - & & - & & - & & - & \\
\hline Isopoda & & & & & & & & & & & & & & \\
\hline Asellidae & & & & & & & & & & & & & & \\
\hline Caecidotea & 1,000 & 34 & 18 & $<1$ & 180 & 4 & 93 & 6 & 51 & $<1$ & - & & 1 & $<1$ \\
\hline Decapoda & & & & & & & & & & & & & & \\
\hline Cambaridae & - & & 1 & $<1$ & - & & - & & - & & - & & - & \\
\hline Podocopa & 79 & 3 & - & & 16 & $<1$ & 4 & $<1$ & 20 & $<1$ & - & & - & \\
\hline
\end{tabular}




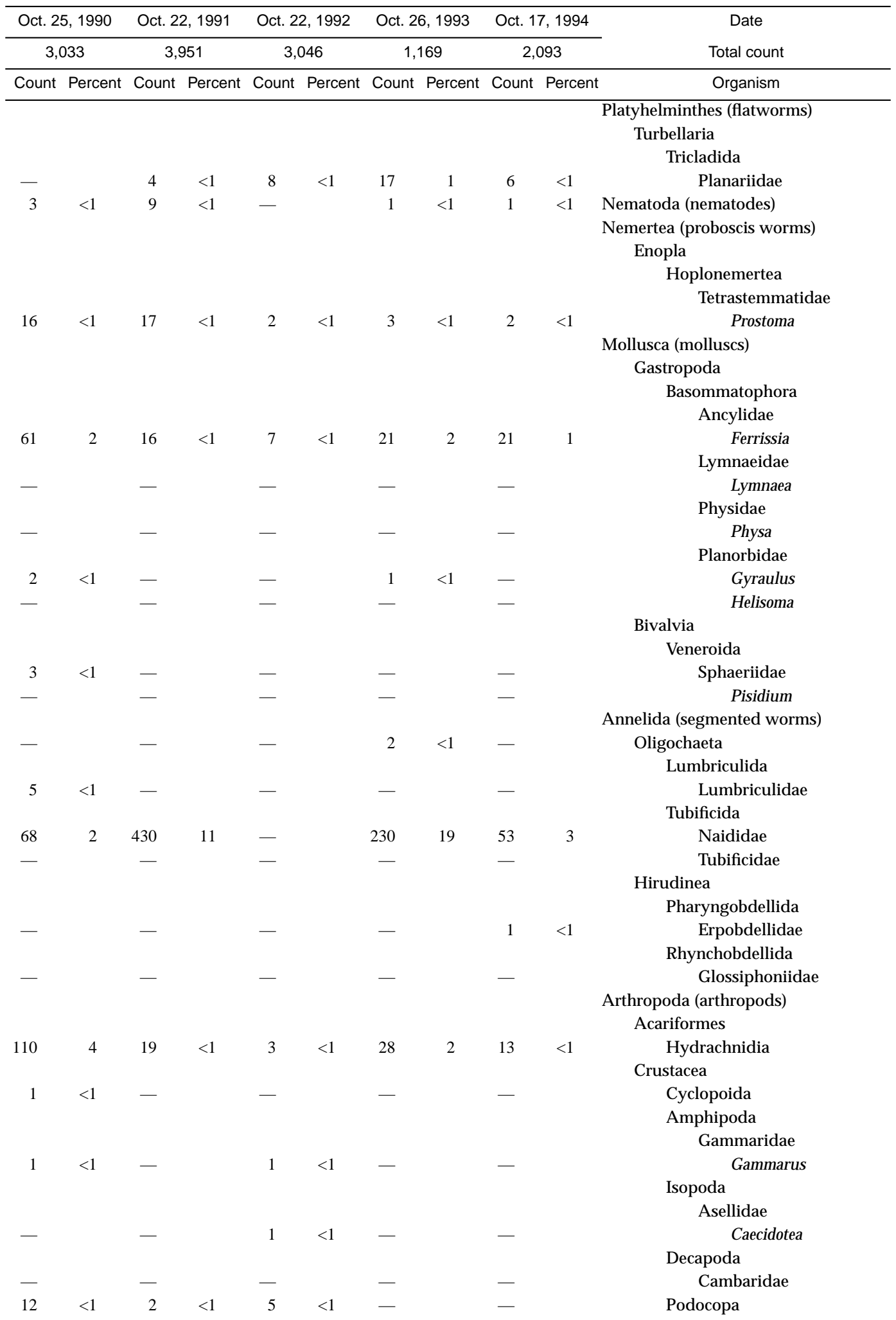


Table 5. Benthic-macroinvertebrate data-Continued

01476848 - East Branch Chester Creek below Goose Creek near West Chester, Pa. (Site 51)—Continued

\begin{tabular}{|c|c|c|c|c|c|c|c|c|c|c|c|c|c|c|}
\hline \multirow{3}{*}{$\begin{array}{c}\text { Date } \\
\text { Total count } \\
\text { Organism }\end{array}$} & \multirow{2}{*}{\multicolumn{2}{|c|}{$\begin{array}{c}\text { Oct. } 26,1983 \\
2,869\end{array}$}} & \multirow{2}{*}{\multicolumn{2}{|c|}{$\begin{array}{c}\text { Oct. } 11,1984 \\
2,874\end{array}$}} & \multirow{2}{*}{\multicolumn{2}{|c|}{$\begin{array}{c}\text { Oct. } 28,1985 \\
4,236\end{array}$}} & \multirow{2}{*}{\multicolumn{2}{|c|}{$\begin{array}{c}\text { Oct. } 16,1986 \\
1,514\end{array}$}} & \multirow{2}{*}{\multicolumn{2}{|c|}{$\begin{array}{c}\text { Nov. } 15,1987 \\
12,174\end{array}$}} & \multirow{2}{*}{\multicolumn{2}{|c|}{$\begin{array}{c}\text { Nov. 3, } 1988 \\
13,963\end{array}$}} & \multirow{2}{*}{\multicolumn{2}{|c|}{$\begin{array}{c}\text { Oct. } 25,1989 \\
926\end{array}$}} \\
\hline & & & & & & & & & & & & & & \\
\hline & Count & Percent & Count & Percent & Count & Percent & Count & Percent & Count & Percent & Count & Percent & Count & Percent \\
\hline \multicolumn{15}{|l|}{ Insecta } \\
\hline \multicolumn{15}{|l|}{ Ephemeroptera } \\
\hline \multicolumn{15}{|l|}{ Baetidae } \\
\hline Baetis & - & & 3 & $<1$ & - & & 1 & $<1$ & - & & - & & - & \\
\hline Pseudocloeon & - & & - & & - & & - & & - & & - & & - & \\
\hline \multicolumn{15}{|l|}{ Ephemerellidae } \\
\hline Ephemerella & - & & - & & - & & - & & - & & 3 & $<1$ & 2 & $<1$ \\
\hline \multicolumn{15}{|l|}{ Heptageniidae } \\
\hline Stenonema & 3 & $<1$ & 1 & $<1$ & - & & 3 & $<1$ & 1 & $<1$ & 21 & $<1$ & 3 & $<1$ \\
\hline \multicolumn{15}{|l|}{ Isonychiidae } \\
\hline Isonychia & - & & - & & - & & - & & - & & - & & - & \\
\hline \multicolumn{15}{|l|}{ Leptohyphidae } \\
\hline Tricorythodes & 3 & $<1$ & - & & - & & 1 & $<1$ & - & & 3 & $<1$ & 4 & $<1$ \\
\hline \multicolumn{15}{|l|}{ Odonata } \\
\hline \multicolumn{15}{|l|}{ Coenagrionidae } \\
\hline Argia & - & & - & & - & & 2 & $<1$ & - & & - & & - & \\
\hline Enallagma & - & & - & & - & & - & & - & & - & & 1 & $<1$ \\
\hline \multicolumn{15}{|l|}{ Plecoptera } \\
\hline Capniidae & & & & & & & & & & & & & & \\
\hline Allocapnia & - & & - & & - & & - & & - & & - & & - & \\
\hline Megaloptera & & & & & & & & & & & & & & \\
\hline Corydalidae & & & & & & & & & & & & & & \\
\hline Corydalus & - & & - & & - & & - & & 1 & $<1$ & - & & - & \\
\hline Sialidae & & & & & & & & & & & & & & \\
\hline Sialis & - & & - & & - & & - & & - & & - & & - & \\
\hline Trichoptera & & & & & & & & & & & & & & \\
\hline Glossosomatidae & & & & & & & & & & & & & & \\
\hline Glossosoma & - & & - & & - & & - & & - & & - & & - & \\
\hline Helicopsychidae & & & & & & & & & & & & & & \\
\hline Helicopsyche & - & & - & & - & & - & & - & & - & & - & \\
\hline Hydropsychidae & & & & & & & & & & & & & & \\
\hline Ceratopsyche & 11 & $<1$ & 430 & 15 & 8 & $<1$ & 110 & 7 & 60 & $<1$ & 260 & 7 & 58 & 6 \\
\hline Cheumatopsyche & 16 & $<1$ & 63 & 2 & - & & 28 & 2 & - & & 160 & 4 & 9 & 1 \\
\hline Hydropsyche & 40 & 1 & 140 & 5 & - & & 490 & 33 & 750 & 6 & 1,500 & 38 & 220 & 23 \\
\hline Hydroptilidae & & & & & & & & & & & & & & \\
\hline Hydroptila & - & & - & & 8 & $<1$ & - & & 17 & $<1$ & - & & 72 & 8 \\
\hline Leucotrichia & - & & 2 & $<1$ & - & & - & & - & & - & & - & \\
\hline Leptoceridae & & & & & & & & & & & & & & \\
\hline Oecetis & - & & - & & - & & - & & - & & - & & - & \\
\hline Psychomyiidae & & & & & & & & & & & & & & \\
\hline Psychomyia & - & & - & & - & & - & & - & & - & & - & \\
\hline Lepidoptera & & & & & & & & & & & & & & \\
\hline Pyralidae & & & & & & & & & & & & & & \\
\hline Petrophila & - & & 3 & $<1$ & - & & - & & - & & - & & - & \\
\hline
\end{tabular}




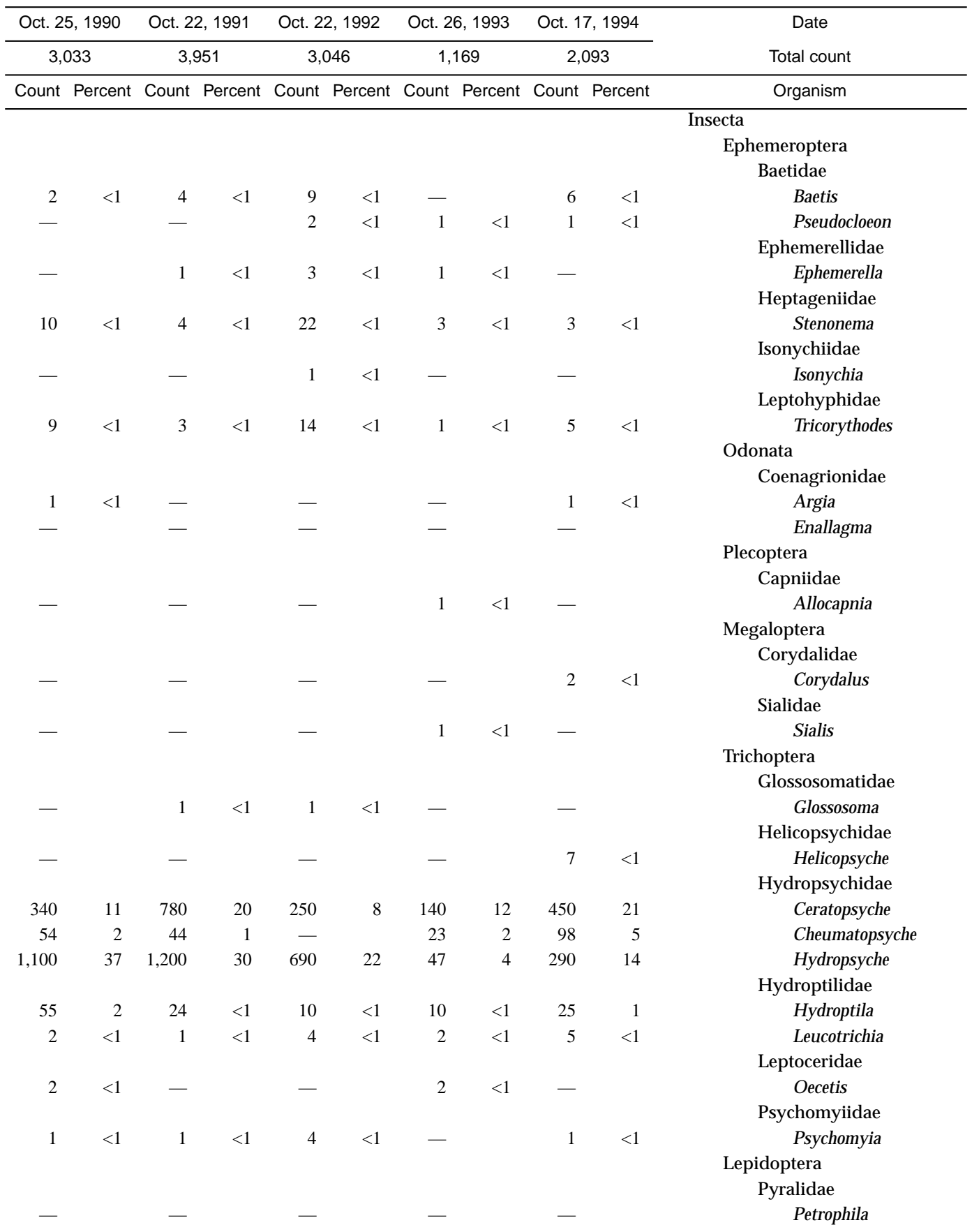


Table 5. Benthic-macroinvertebrate data—Continued

01476848 - East Branch Chester Creek below Goose Creek near West Chester, Pa. (Site 51)—Continued

\begin{tabular}{|c|c|c|c|c|c|c|c|c|c|c|c|c|c|c|}
\hline \multirow{3}{*}{$\begin{array}{c}\text { Date } \\
\text { Total count } \\
\text { Organism }\end{array}$} & \multirow{2}{*}{\multicolumn{2}{|c|}{$\frac{\text { Oct. } 26,1983}{2,869}$}} & \multirow{2}{*}{\multicolumn{2}{|c|}{$\frac{\text { Oct. } 11,1984}{2,874}$}} & \multirow{2}{*}{\multicolumn{2}{|c|}{$\frac{\text { Oct. 28, } 1985}{4,236}$}} & \multirow{2}{*}{\multicolumn{2}{|c|}{$\frac{\text { Oct. } 16,1986}{1,514}$}} & \multirow{2}{*}{\multicolumn{2}{|c|}{$\frac{\text { Nov. } 15,1987}{12,174}$}} & \multirow{2}{*}{\multicolumn{2}{|c|}{$\begin{array}{c}\text { Nov. 3, } 1988 \\
{ }^{1} 3,963\end{array}$}} & \multirow{2}{*}{\multicolumn{2}{|c|}{$\frac{\text { Oct. } 25,1989}{926}$}} \\
\hline & & & & & & & & & & & & & & \\
\hline & Count & Percent & Count & Percent & Count & Percent & Count & Percent & Count & Percent & Count & Percent & Count & Percent \\
\hline \multicolumn{15}{|l|}{ Coleoptera } \\
\hline Curculionidae & - & & 1 & $<1$ & - & & - & & - & & - & & - & \\
\hline Dytiscidae & 1 & $<1$ & - & & - & & - & & - & & - & & - & \\
\hline \multicolumn{15}{|l|}{ Elmidae } \\
\hline Ancyronyx & - & & - & & - & & 1 & $<1$ & - & & - & & 3 & $<1$ \\
\hline Dubiraphia & - & & - & & 8 & $<1$ & - & & - & & - & & 1 & $<1$ \\
\hline Optioservus & 1 & $<1$ & 3 & $<1$ & - & & 2 & $<1$ & 1 & $<1$ & 13 & $<1$ & 4 & $<1$ \\
\hline Oulimnius & - & & - & & - & & - & & - & & - & & 6 & $<1$ \\
\hline Promoresia & - & & - & & - & & - & & - & & - & & - & \\
\hline Stenelmis & 4 & $<1$ & 30 & 1 & 72 & 2 & 25 & 2 & 44 & $<1$ & 170 & 4 & 22 & 2 \\
\hline \multicolumn{15}{|l|}{ Hydrophilidae } \\
\hline Berosus & - & & - & & - & & - & & - & & - & & - & \\
\hline \multicolumn{15}{|l|}{ Psephenidae } \\
\hline Psephenus & - & & - & & - & & - & & 一 & & - & & 1 & $<1$ \\
\hline Hymenoptera & - & & 2 & $<1$ & 8 & $<1$ & 1 & $<1$ & - & & - & & - & \\
\hline \multicolumn{15}{|l|}{ Diptera } \\
\hline Chironomidae & 920 & 32 & 950 & 33 & 1,100 & 26 & 590 & 39 & 2,900 & 24 & 440 & 11 & 55 & 6 \\
\hline \multicolumn{15}{|l|}{ Empididae } \\
\hline Clinocera & - & & - & & - & & - & & - & & - & & - & \\
\hline Hemerodromia & 1 & $<1$ & 18 & $<1$ & 16 & $<1$ & 2 & $<1$ & 24 & $<1$ & 8 & $<1$ & 28 & 3 \\
\hline \multicolumn{15}{|l|}{ Simuliidae } \\
\hline Simulium & 75 & 3 & 470 & 16 & 1,300 & 31 & 78 & 5 & 860 & 7 & 340 & 9 & 32 & 3 \\
\hline \multicolumn{15}{|l|}{ Tipulidae } \\
\hline Antocha & - & & - & & - & & - & & - & & 29 & $<1$ & 8 & $<1$ \\
\hline Hexatoma & - & & - & & - & & - & & - & & - & & - & \\
\hline Tipula & - & & - & & - & & - & & - & & - & & - & \\
\hline
\end{tabular}

\footnotetext{
${ }^{1}$ Extrapolated from a 3/8 subsample.
} 


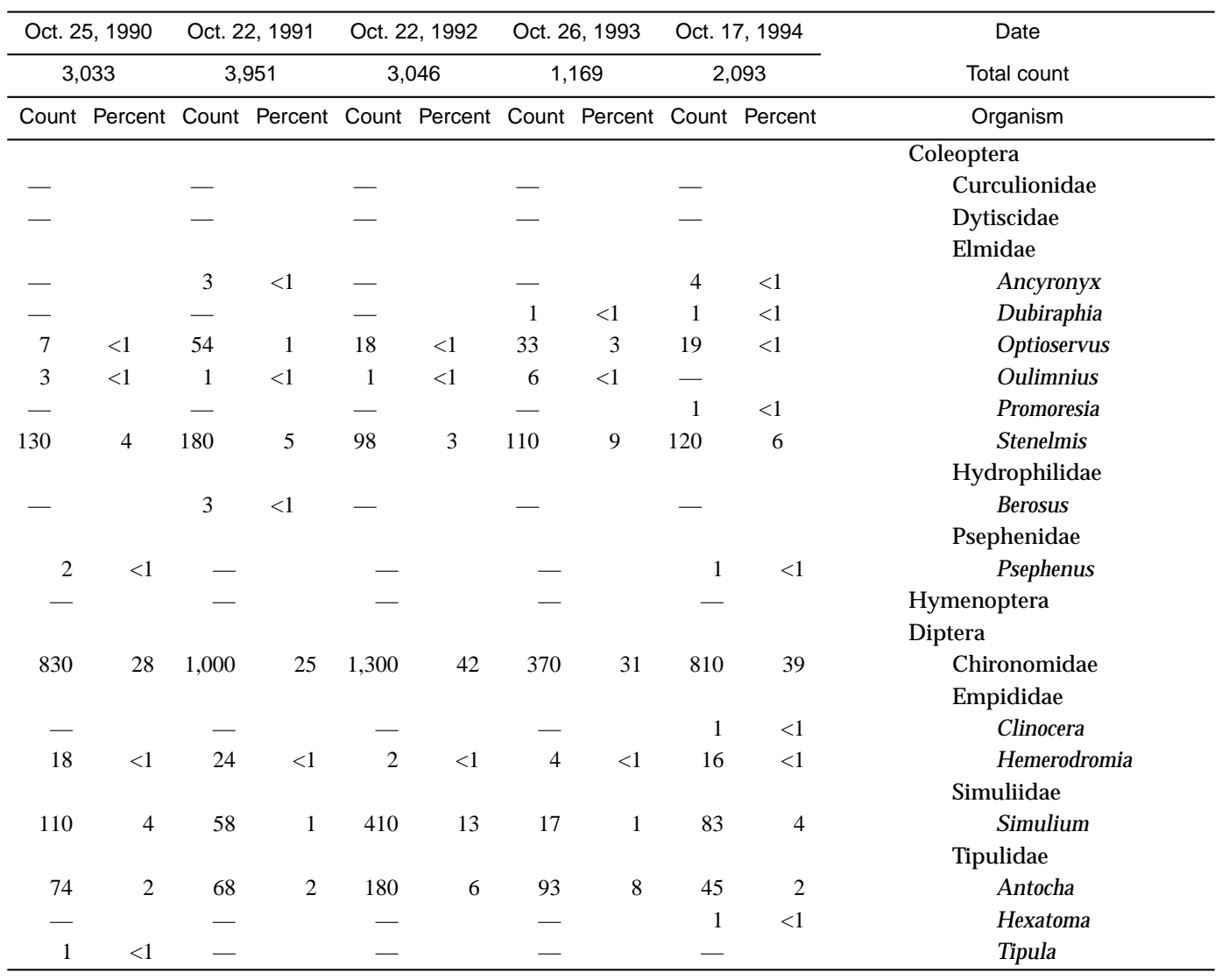


Table 5. Benthic-macroinvertebrate data-Continued

' $[<$, less than; - , not found]

01478120 - East Branch White Clay Creek at Avondale, Pa. (Site 28)

\begin{tabular}{|c|c|c|c|c|c|c|c|c|c|c|c|c|c|c|}
\hline \multirow{3}{*}{$\begin{array}{cc}\text { Date } \\
\text { Total count } \\
\text { Organism }\end{array}$} & \multirow{2}{*}{\multicolumn{2}{|c|}{$\frac{\text { Oct. 30, } 1981}{836}$}} & \multirow{2}{*}{\multicolumn{2}{|c|}{$\frac{\text { Oct. 20, } 1982}{1,295}$}} & \multirow{2}{*}{\multicolumn{2}{|c|}{$\begin{array}{c}\text { Nov. } 1,1983 \\
1,368\end{array}$}} & \multirow{2}{*}{\multicolumn{2}{|c|}{$\frac{\text { Oct. } 19,1984}{932}$}} & \multirow{2}{*}{\multicolumn{2}{|c|}{$\frac{\text { Oct. } 25,1985}{1,007}$}} & \multirow{2}{*}{\multicolumn{2}{|c|}{$\frac{\text { Oct. 30, } 1986}{1,025}$}} & \multirow{2}{*}{\multicolumn{2}{|c|}{$\frac{\text { Nov. } 17,1987}{4,223}$}} \\
\hline & & & & & & & & & & & & & & \\
\hline & Count & Percent & Count & Percent & Count & Percent & Count & Percent & Count & Percent & Count & Percent & Count & Percent \\
\hline \multicolumn{15}{|l|}{ Platyhelminthes (flatworms) } \\
\hline \multicolumn{15}{|l|}{ Turbellaria } \\
\hline \multicolumn{15}{|l|}{ Tricladida } \\
\hline Planariidae & 95 & 11 & 46 & 4 & 11 & $<1$ & - & & 27 & 3 & 4 & $<1$ & 25 & $<1$ \\
\hline Nematoda (nematodes) & - & & - & & - & & - & & - & & - & & - & \\
\hline \multicolumn{15}{|l|}{ Nemertea (proboscis worms) } \\
\hline \multicolumn{15}{|l|}{ Enopla } \\
\hline Hoplonemertea & & & & & & & & & & & & & & \\
\hline Tetrastemmatidae & & & & & & & & & & & & & & \\
\hline Prostoma & - & & - & & - & & - & & - & & - & & - & \\
\hline Mollusca (molluscs) & & & & & & & & & & & & & & \\
\hline Gastropoda & & & & & & & & & & & & & & \\
\hline Mesogastropoda & & & & & & & & & & & & & & \\
\hline Hydrobiidae & & & & & & & & & & & & & & \\
\hline Amnicola & - & & - & & - & & - & & - & & - & & - & \\
\hline Basommatophora & & & & & & & & & & & & & & \\
\hline Ancylidae & & & & & & & & & & & & & & \\
\hline Ferrissia & 1 & $<1$ & 3 & $<1$ & 1 & $<1$ & - & & 1 & $<1$ & - & & 1 & $<1$ \\
\hline Planorbidae & & & & & & & & & & & & & & \\
\hline Gyraulus & - & & - & & - & & - & & - & & - & & - & \\
\hline Bivalvia & & & & & & & & & & & & & & \\
\hline Veneroida & & & & & & & & & & & & & & \\
\hline Sphaeriidae & & & & & & & & & & & & & & \\
\hline Pisidium & - & & - & & - & & - & & - & & - & & - & \\
\hline Annelida (segmented worms) & & & & & & & & & & & & & & \\
\hline Oligochaeta & - & & - & & - & & - & & 11 & 1 & - & & - & \\
\hline Lumbriculida & & & & & & & & & & & & & & \\
\hline Lumbriculidae & - & & - & & - & & - & & - & & - & & - & \\
\hline Tubificida & & & & & & & & & & & & & & \\
\hline Naididae & 29 & 3 & 84 & 6 & - & & - & & - & & 5 & $<1$ & 1,300 & 31 \\
\hline Arthropoda (arthropods) & & & & & & & & & & & & & & \\
\hline Acariformes & & & & & & & & & & & & & & \\
\hline Hydrachnidia & 45 & 5 & 65 & 5 & 2 & $<1$ & 2 & $<1$ & 4 & $<1$ & 4 & $<1$ & - & \\
\hline Crustacea & & & & & & & & & & & & & & \\
\hline Amphipoda & & & & & & & & & & & & & & \\
\hline Gammaridae & & & & & & & & & & & & & & \\
\hline Gammarus & - & & - & & - & & - & & - & & - & & 1 & $<1$ \\
\hline Isopoda & & & & & & & & & & & & & & \\
\hline Asellidae & & & & & & & & & & & & & & \\
\hline Caecidotea & - & & 2 & $<1$ & 2 & $<1$ & - & & - & & - & & 1 & $<1$ \\
\hline Podocopa & - & & - & & - & & - & & - & & - & & - & \\
\hline Insecta & & & & & & & & & & & & & & \\
\hline Ephemeroptera & & & & & & & & & & & & & & \\
\hline Baetidae & & & & & & & & & & & & & & \\
\hline Baetis & - & & - & & 1 & $<1$ & 2 & $<1$ & - & & 1 & $<1$ & - & \\
\hline Pseudocloeon & - & & - & & 1 & $<1$ & 2 & $<1$ & 8 & $<1$ & - & & - & \\
\hline Ephemerellidae & & & & & & & & & & & & & & \\
\hline Ephemerella & - & & - & & - & & - & & - & & - & & 3 & $<1$ \\
\hline Heptageniidae & & & & & & & & & & & & & & \\
\hline Epeorus & - & & - & & - & & - & & - & & - & & - & \\
\hline Stenacron & - & & - & & - & & - & & - & & - & & - & \\
\hline Stenonema & 12 & 1 & 10 & $<1$ & 13 & $<1$ & 7 & $<1$ & 2 & $<1$ & 19 & 2 & 11 & $<1$ \\
\hline Isonychiidae & & & & & & & & & & & & & & \\
\hline Isonychia & - & & - & & - & & 1 & $<1$ & 5 & $<1$ & 5 & $<1$ & 5 & $<1$ \\
\hline
\end{tabular}




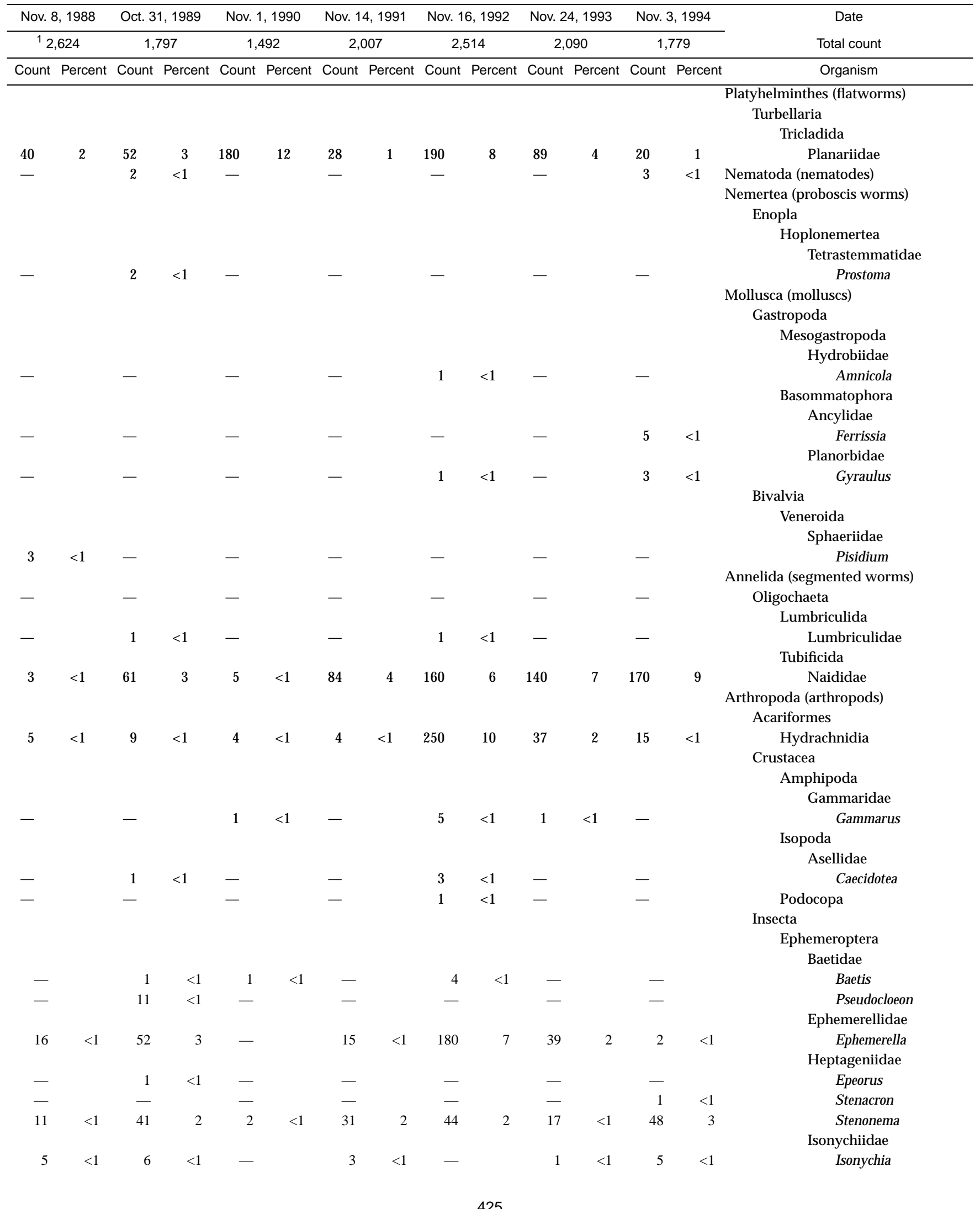


Table 5. Benthic-macroinvertebrate data—Continued

01478120 - East Branch White Clay Creek at Avondale, Pa. (Site 28)—Continued

\begin{tabular}{|c|c|c|c|c|c|c|c|c|c|c|c|c|c|c|}
\hline \multirow{3}{*}{$\begin{array}{c}\text { Date } \\
\text { Total count } \\
\text { Organism }\end{array}$} & \multirow{2}{*}{\multicolumn{2}{|c|}{$\begin{array}{c}\text { Oct. 30, } 1981 \\
836\end{array}$}} & \multicolumn{2}{|c|}{ Oct. 20, 1982} & \multicolumn{2}{|c|}{ Nov. 1,1983} & \multicolumn{2}{|c|}{ Oct. 19,1984} & \multicolumn{2}{|c|}{ Oct. 25,1985} & \multicolumn{2}{|c|}{ Oct. 30,1986} & \multicolumn{2}{|c|}{ Nov. 17,1987} \\
\hline & & & & 295 & \multicolumn{2}{|c|}{1,368} & \multicolumn{2}{|c|}{932} & \multicolumn{2}{|c|}{1,007} & \multicolumn{2}{|c|}{1,025} & \multicolumn{2}{|c|}{4,223} \\
\hline & Count & Percent & Count & Percent & Count & Percent & Count & Percent & Count & Percent & Count & Percent & Count & Percent \\
\hline \multicolumn{15}{|l|}{ Ephemeroptera } \\
\hline Leptohyphidae & & & & & & & & & & & & & & \\
\hline Tricorythodes & - & & 1 & $<1$ & - & & - & & - & & - & & - & \\
\hline Leptophlebiidae & - & & - & & - & & - & & - & & - & & - & \\
\hline Odonata & & & & & & & & & & & & & & \\
\hline Coenagrionidae & & & & & & & & & & & & & & \\
\hline Argia & 3 & $<1$ & 1 & $<1$ & - & & - & & - & & - & & - & \\
\hline Plecoptera & & & & & & & & & & & & & & \\
\hline Capniidae & & & & & & & & & & & & & & \\
\hline Allocapnia & - & & - & & - & & 一 & & 1 & $<1$ & - & & 1 & $<1$ \\
\hline Nemouridae & - & & - & & - & & - & & - & & - & & - & \\
\hline Taeniopterygidae & & & & & & & & & & & & & & \\
\hline Taeniopteryx & - & & 1 & $<1$ & 1 & $<1$ & 6 & $<1$ & 10 & 1 & 5 & $<1$ & - & \\
\hline Hemiptera & & & & & & & & & & & & & & \\
\hline Veliidae & & & & & & & & & & & & & & \\
\hline Rhagovelia & - & & - & & 1 & $<1$ & - & & - & & - & & - & \\
\hline Trichoptera & & & & & & & & & & & & & & \\
\hline Brachycentridae & & & & & & & & & & & & & & \\
\hline Micrasema & - & & - & & - & & - & & - & & - & & - & \\
\hline Glossosomatidae & & & & & & & & & & & & & & \\
\hline Glossosoma & - & & - & & - & & - & & - & & - & & - & \\
\hline Hydropsychidae & & & & & & & & & & & & & & \\
\hline Ceratopsyche & 51 & 6 & 42 & 3 & 360 & 26 & 140 & 15 & 220 & 22 & 180 & 18 & 37 & $<1$ \\
\hline Cheumatopsyche & 10 & 1 & 4 & $<1$ & 44 & 3 & 30 & 3 & 48 & 5 & 7 & $<1$ & 29 & $<1$ \\
\hline Hydropsyche & 36 & 4 & 45 & 3 & 260 & 19 & 34 & 4 & 44 & 4 & 60 & 6 & 270 & 6 \\
\hline Hydroptilidae & & & & & & & & & & & & & & \\
\hline Hydroptila & - & & 3 & $<1$ & - & & - & & 7 & $<1$ & 12 & 1 & - & \\
\hline Leucotrichia & 130 & 15 & 330 & 25 & 310 & 22 & 3 & $<1$ & 11 & 1 & 3 & $<1$ & - & \\
\hline Leptoceridae & & & & & & & & & & & & & & \\
\hline Mystacides & - & & - & & - & & - & & - & & - & & - & \\
\hline Philopotamidae & & & & & & & & & & & & & & \\
\hline Chimarra & - & & - & & - & & - & & - & & - & & - & \\
\hline Psychomyiidae & & & & & & & & & & & & & & \\
\hline Psychomyia & - & & - & & - & & - & & - & & - & & - & \\
\hline Coleoptera & & & & & & & & & & & & & & \\
\hline Dryopidae & & & & & & & & & & & & & & \\
\hline Helichus & 1 & $<1$ & - & & - & & - & & - & & - & & - & \\
\hline Elmidae & & & & & & & & & & & & & & \\
\hline Dubiraphia & - & & - & & - & & - & & - & & - & & - & \\
\hline Macronychus & - & & 1 & $<1$ & - & & - & & - & & - & & - & \\
\hline Microcylloepus & - & & - & & - & & - & & - & & - & & 1 & $<1$ \\
\hline Optioservus & 56 & 7 & 28 & 2 & 17 & 1 & 4 & $<1$ & 14 & 1 & 5 & $<1$ & 43 & 1 \\
\hline Oulimnius & - & & - & & - & & - & & - & & - & & - & \\
\hline Stenelmis & 10 & 1 & 8 & $<1$ & - & & - & & 3 & $<1$ & - & & 2 & $<1$ \\
\hline Hydrophilidae & 1 & $<1$ & - & & - & & 1 & $<1$ & - & & - & & - & \\
\hline Berosus & - & & 1 & $<1$ & - & & - & & - & & - & & - & \\
\hline Psephenidae & & & & & & & & & & & & & & \\
\hline Psephenus & - & & - & & - & & - & & - & & - & & 1 & $<1$ \\
\hline Hymenoptera & - & & - & & - & & - & & 1 & $<1$ & 2 & $<1$ & - & \\
\hline Diptera & & & & & & & & & & & & & & \\
\hline $\begin{array}{l}\text { Chironomidae } \\
\text { Empididae }\end{array}$ & 280 & 33 & 500 & 38 & 170 & 12 & 530 & 56 & 450 & 45 & 430 & 43 & 1,900 & 45 \\
\hline $\begin{array}{l}\text { Hemerodromia } \\
\text { Muscidae }\end{array}$ & 16 & 2 & 32 & 2 & 1 & $<1$ & - & & 2 & $<1$ & 1 & $<1$ & - & \\
\hline Limnophora & - & & 1 & $<1$ & - & & - & & - & & - & & - & \\
\hline
\end{tabular}




\begin{tabular}{|c|c|c|c|c|c|c|c|c|c|c|c|c|c|c|}
\hline \multirow{2}{*}{\multicolumn{2}{|c|}{$\begin{array}{c}\text { Nov. } 8,1988 \\
{ }^{1} 2,624\end{array}$}} & \multicolumn{2}{|c|}{ Oct. 31, 1989} & \multicolumn{2}{|c|}{ Nov. 1,1990} & \multicolumn{2}{|c|}{ Nov. 14,1991} & \multicolumn{2}{|c|}{ Nov. 16, 1992} & \multicolumn{2}{|c|}{ Nov. 24,1993} & \multicolumn{2}{|c|}{ Nov. 3, 1994} & \multirow{2}{*}{$\begin{array}{c}\text { Date } \\
\text { Total count }\end{array}$} \\
\hline & & & 797 & & 492 & & 007 & 2,5 & 514 & & 090 & 1,7 & 779 & \\
\hline \multirow[t]{3}{*}{ Count } & Percent & Count & Percent & Count & Percent & Count & Percent & Count & Percent & Count & Percent & Count & Percent & Organism \\
\hline & & & & & & & & & & & & & & Ephemeroptera \\
\hline & & & & & & & & & & & & & & Leptohyphidae \\
\hline \multirow{4}{*}{-} & & - & & - & & - & & 22 & $<1$ & 1 & $<1$ & 1 & $<1$ & Tricorythodes \\
\hline & & - & & - & & - & & - & & - & & 1 & $<1$ & Leptophlebiidae \\
\hline & & & & & & & & & & & & & & Odonata \\
\hline & & & & & & & & & & & & & & Coenagrionidae \\
\hline \multirow[t]{3}{*}{ - } & & - & & - & & - & & - & & - & & - & & Argia \\
\hline & & & & & & & & & & & & & & Plecoptera \\
\hline & & & & & & & & & & & & & & Capniidae \\
\hline - & & 1 & $<1$ & - & & - & & - & & - & & - & & Allocapnia \\
\hline \multirow[t]{2}{*}{-} & & 1 & $<1$ & - & & - & & - & & - & & 1 & $<1$ & Nemouridae \\
\hline & & & & & & & & & & & & & & Taeniopterygidae \\
\hline \multirow[t]{2}{*}{ - } & & 11 & $<1$ & - & & 6 & $<1$ & 1 & $<1$ & 5 & $<1$ & 4 & $<1$ & Taeniopteryx \\
\hline & & & & & & & & & & & & & & $\begin{array}{l}\text { Hemiptera } \\
\text { Veliidae }\end{array}$ \\
\hline- & & - & & - & & - & & - & & - & & - & & Rhagovelia \\
\hline & & & & & & & & & & & & & & Trichoptera \\
\hline & & & & & & & & & & & & & & Brachycentridae \\
\hline - & & - & & - & & - & & - & & 1 & $<1$ & - & & Micrasema \\
\hline & & & & & & & & & & & & & & Glossosomatidae \\
\hline 3 & $<1$ & - & & - & & 1 & $<1$ & 1 & $<1$ & 2 & $<1$ & - & & Glossosoma \\
\hline & & & & & & & & & & & & & & Hydropsychidae \\
\hline 370 & 14 & 440 & 24 & 220 & 15 & 170 & 9 & 150 & 6 & 170 & 8 & 220 & 12 & Ceratopsyche \\
\hline 140 & 5 & 110 & 6 & 68 & 5 & 35 & 2 & 33 & 1 & 33 & 2 & 42 & 2 & Cheumatopsyche \\
\hline 180 & 7 & 190 & 11 & 150 & 10 & 150 & 8 & 160 & 6 & 160 & 8 & 79 & 4 & Hydropsyche \\
\hline & & & & & & & & & & & & & & Hydroptilidae \\
\hline 8 & $<1$ & - & & 6 & $<1$ & 56 & 3 & 170 & 7 & 12 & $<1$ & 21 & 1 & Hydroptila \\
\hline 16 & $<1$ & 3 & $<1$ & 7 & $<1$ & 110 & 6 & 12 & $<1$ & 27 & 1 & - & & Leucotrichia \\
\hline & & & & & & & & & & & & & & Leptoceridae \\
\hline - & & - & & - & & - & & - & & - & & 1 & $<1$ & Mystacides \\
\hline & & & & & & & & & & & & & & Philopotamidae \\
\hline- & & - & & 1 & $<1$ & 4 & $<1$ & 52 & 2 & 3 & $<1$ & - & & Chimarra \\
\hline & & & & & & & & & & & & & & Psychomyiidae \\
\hline- & & 3 & $<1$ & - & & - & & 1 & $<1$ & 7 & $<1$ & 2 & $<1$ & Psychomyia \\
\hline & & & & & & & & & & & & & & Coleoptera \\
\hline & & & & & & & & & & & & & & Dryopidae \\
\hline - & & - & & - & & - & & - & & - & & - & & Helichus \\
\hline & & & & & & & & & & & & & & Elmidae \\
\hline - & & - & & - & & - & & 1 & $<1$ & 1 & $<1$ & - & & Dubiraphia \\
\hline- & & - & & - & & - & & - & & - & & - & & Macronychus \\
\hline - & & - & & - & & - & & - & & - & & - & & Microcylloepus \\
\hline 40 & 2 & 42 & 2 & 20 & 1 & 14 & $<1$ & 39 & 2 & 59 & 3 & 18 & 1 & Optioservus \\
\hline - & & 1 & $<1$ & - & & - & & - & & 2 & $<1$ & 2 & $<1$ & Oulimnius \\
\hline 5 & $<1$ & 12 & $<1$ & 2 & $<1$ & - & & 11 & $<1$ & 2 & $<1$ & 3 & $<1$ & Stenelmis \\
\hline - & & - & & - & & - & & - & & - & & - & & Hydrophilidae \\
\hline - & & - & & - & & - & & - & & - & & - & & Berosus \\
\hline & & & & & & & & & & & & & & Psephenidae \\
\hline- & & 3 & $<1$ & 2 & $<1$ & - & & - & & 5 & $<1$ & - & & Psephenus \\
\hline - & & - & & - & & - & & - & & - & & - & & Hymenoptera \\
\hline & & & & & & & & & & & & & & Diptera \\
\hline 1,300 & 50 & 410 & 23 & 560 & 37 & 770 & 39 & 650 & 26 & 820 & 39 & 660 & 37 & Chironomidae \\
\hline & & & & & & & & & & & & & & Empididae \\
\hline 8 & $<1$ & 22 & 1 & 5 & $<1$ & 12 & $<1$ & 18 & $<1$ & 7 & $<1$ & 19 & 1 & Hemerodromia \\
\hline & & & & & & & & & & & & & & Muscidae \\
\hline - & & - & & - & & - & & - & & - & & - & & Limnophora \\
\hline
\end{tabular}


Table 5. Benthic-macroinvertebrate data—Continued

01478120 - East Branch White Clay Creek at Avondale, Pa. (Site 28)—Continued

\begin{tabular}{|c|c|c|c|c|c|c|c|c|c|c|c|c|c|c|}
\hline \multirow{3}{*}{$\begin{array}{c}\text { Date } \\
\text { Total count } \\
\text { Organism }\end{array}$} & \multirow{2}{*}{\multicolumn{2}{|c|}{$\frac{\text { Oct. } 30,1981}{836}$}} & \multicolumn{2}{|c|}{ Oct. 20, 1982} & \multicolumn{2}{|c|}{ Nov. 1, 1983} & \multicolumn{2}{|c|}{ Oct. 19,1984} & \multicolumn{2}{|c|}{ Oct. 25,1985} & \multicolumn{2}{|c|}{ Oct. 30,1986} & \multicolumn{2}{|c|}{ Nov. 17,1987} \\
\hline & & & \multicolumn{2}{|c|}{1,295} & \multicolumn{2}{|c|}{1,368} & \multicolumn{2}{|c|}{932} & \multicolumn{2}{|c|}{1,007} & \multicolumn{2}{|c|}{1,025} & \multicolumn{2}{|c|}{4,223} \\
\hline & Count & Percent & Count & Percent & Count & Percent & Count & Percent & Count & Percent & Count & Percent & Count & Percent \\
\hline \multicolumn{15}{|l|}{ Diptera } \\
\hline Psychodidae & - & & - & & - & & - & & 3 & $<1$ & - & & - & \\
\hline Telmatoscopus & - & & - & & - & & 1 & $<1$ & - & & - & & - & \\
\hline \multicolumn{15}{|l|}{ Simuliidae } \\
\hline Simulium & 9 & 1 & 13 & 1 & 3 & $<1$ & 19 & 2 & 15 & 2 & 12 & 1 & 52 & 1 \\
\hline \multicolumn{15}{|l|}{ Tipulidae } \\
\hline Antocha & 51 & 6 & 74 & 6 & 170 & 12 & 150 & 16 & 120 & 12 & 270 & 27 & 540 & 13 \\
\hline Dicranota & - & & - & & - & & - & & - & & - & & - & \\
\hline Tipula & - & & - & & 一 & & - & & 一 & & - & & - & \\
\hline
\end{tabular}

${ }^{1}$ Extrapolated from a 3/8 subsample. 


\begin{tabular}{|c|c|c|c|c|c|c|c|c|c|c|c|c|c|c|}
\hline \multicolumn{2}{|c|}{ Nov. 8, 1988} & \multicolumn{2}{|c|}{ Oct. 31,1989} & \multicolumn{2}{|c|}{ Nov. 1, 1990} & \multicolumn{2}{|c|}{ Nov. 14, 1991} & \multicolumn{2}{|c|}{ Nov. 16,1992} & \multicolumn{2}{|c|}{ Nov. 24,1993} & \multicolumn{2}{|c|}{ Nov. 3, 1994} & Date \\
\hline \multicolumn{2}{|c|}{${ }^{1} 2,624$} & \multicolumn{2}{|c|}{1,797} & \multicolumn{2}{|c|}{1,492} & \multicolumn{2}{|c|}{2,007} & \multicolumn{2}{|c|}{2,514} & \multicolumn{2}{|c|}{2,090} & \multicolumn{2}{|c|}{1,779} & Total count \\
\hline \multirow[t]{2}{*}{ Count } & Percent & Count & Percent & Count & Percent & Count & Percent & Count & Percent & Count & Percent & Count & Percent & Organism \\
\hline & & & & & & & & & & & & \multicolumn{3}{|c|}{ Diptera } \\
\hline- & & - & & - & & - & & - & & - & & - & & Psychodidae \\
\hline- & & - & & - & & - & & - & & - & & - & & Telmatoscopus \\
\hline & & & & & & & & & & & & & & Simuliidae \\
\hline 21 & $<1$ & 38 & 2 & 17 & 1 & 14 & $<1$ & 3 & $<1$ & 9 & $<1$ & 22 & 1 & Simulium \\
\hline & & & & & & & & & & & & & & Tipulidae \\
\hline 450 & 17 & 270 & 15 & 240 & 16 & 500 & 25 & 350 & 14 & 440 & 21 & 410 & 23 & Antocha \\
\hline- & & - & & - & & - & & - & & - & & 1 & $<1$ & Dicranota \\
\hline- & & - & & 1 & $<1$ & - & & - & & - & & - & & Tipula \\
\hline
\end{tabular}


Table 5. Benthic-macroinvertebrate data-Continued

$[<$, less than; - , not found]

01478190 - Middle Branch White Clay Creek near Wickerton, Pa. (Site 29)

\begin{tabular}{|c|c|c|c|c|c|c|c|c|c|c|c|c|c|c|}
\hline \multirow{3}{*}{$\begin{array}{c}\text { Date } \\
\text { Total count } \\
\text { Organism }\end{array}$} & \multirow{2}{*}{\multicolumn{2}{|c|}{$\frac{\text { Oct. } 29,1981}{780}$}} & \multirow{2}{*}{\multicolumn{2}{|c|}{$\begin{array}{c}\text { Oct. } 20,1982 \\
1,697\end{array}$}} & \multirow{2}{*}{\multicolumn{2}{|c|}{$\frac{\text { Nov. 2, } 1983}{833}$}} & \multirow{2}{*}{\multicolumn{2}{|c|}{$\frac{\text { Oct. } 18,1984}{1,742}$}} & \multirow{2}{*}{\multicolumn{2}{|c|}{$\frac{\text { Oct. } 25,1985}{1,265}$}} & \multirow{2}{*}{\multicolumn{2}{|c|}{$\frac{\text { Dec. 2, } 1986}{898}$}} & \multirow{2}{*}{\multicolumn{2}{|c|}{$\frac{\text { Oct. } 29,1987}{1,314}$}} \\
\hline & & & & & & & & & & & & & & \\
\hline & Count & Percent & Count & Percent & Count & Percent & Count & Percent & Count & Percent & Count & Percent & Count & Percent \\
\hline \multicolumn{15}{|l|}{ Platyhelminthes (flatworms) } \\
\hline \multicolumn{15}{|l|}{ Turbellaria } \\
\hline \multicolumn{15}{|l|}{ Tricladida } \\
\hline Planariidae & 160 & 21 & 2 & $<1$ & 10 & 1 & 16 & $<1$ & 24 & 2 & 13 & 1 & 2 & $<1$ \\
\hline Nematoda (nematodes) & - & & - & & - & & - & & - & & - & & - & \\
\hline \multicolumn{15}{|l|}{ Nemertea (proboscis worms) } \\
\hline \multicolumn{15}{|l|}{ Enopla } \\
\hline Hoplonemertea & & & & & & & & & & & & & & \\
\hline Tetrastemmatidae & & & & & & & & & & & & & & \\
\hline Prostoma & - & & 1 & $<1$ & 1 & $<1$ & - & & - & & - & & - & \\
\hline Mollusca (molluscs) & & & & & & & & & & & & & & \\
\hline Gastropoda & & & & & & & & & & & & & & \\
\hline Basommatophora & & & & & & & & & & & & & & \\
\hline Ancylidae & & & & & & & & & & & & & & \\
\hline Ferrissia & - & & - & & - & & - & & - & & 1 & $<1$ & - & \\
\hline Physidae & & & & & & & & & & & & & & \\
\hline Physa & - & & 1 & $<1$ & - & & - & & - & & - & & - & \\
\hline Planorbidae & & & & & & & & & & & & & & \\
\hline Gyraulus & - & & - & & - & & - & & - & & - & & - & \\
\hline Helisoma & - & & - & & - & & - & & - & & 1 & $<1$ & - & \\
\hline Mesogastropoda & & & & & & & & & & & & & & \\
\hline Hydrobiidae & & & & & & & & & & & & & & \\
\hline Amnicola & - & & - & & - & & - & & - & & - & & - & \\
\hline Bivalvia & & & & & & & & & & & & & & \\
\hline Veneroida & & & & & & & & & & & & & & \\
\hline Sphaeriidae & - & & - & & - & & - & & - & & - & & - & \\
\hline Pisidium & - & & - & & - & & - & & - & & - & & - & \\
\hline Annelida (segmented worms) & & & & & & & & & & & & & & \\
\hline Oligochaeta & & & & & & & & & & & & & & \\
\hline Lumbriculida & & & & & & & & & & & & & & \\
\hline Lumbriculidae & - & & - & & - & & - & & 1 & $<1$ & - & & - & \\
\hline Tubificida & & & & & & & & & & & & & & \\
\hline Naididae & 23 & 3 & - & & - & & - & & 5 & $<1$ & 9 & 1 & 11 & $<1$ \\
\hline Tubificidae & - & & - & & - & & - & & - & & - & & 2 & $<1$ \\
\hline Arthropoda (arthropods) & & & & & & & & & & & & & & \\
\hline Acariformes & & & & & & & & & & & & & & \\
\hline Hydrachnidia & 9 & 1 & 6 & $<1$ & 2 & $<1$ & - & & 10 & $<1$ & - & & - & \\
\hline Crustacea & & & & & & & & & & & & & & \\
\hline Cyclopoida & - & & - & & - & & - & & - & & - & & - & \\
\hline Isopoda & & & & & & & & & & & & & & \\
\hline Asellidae & & & & & & & & & & & & & & \\
\hline Caecidotea & 4 & $<1$ & - & & - & & - & & 1 & $<1$ & - & & 3 & $<1$ \\
\hline Insecta & & & & & & & & & & & & & & \\
\hline Ephemeroptera & & & & & & & & & & & & & & \\
\hline Baetidae & & & & & & & & & & & & & & \\
\hline Baetis & - & & 1 & $<1$ & - & & 14 & $<1$ & 6 & $<1$ & 2 & $<1$ & 1 & $<1$ \\
\hline Pseudocloeon & - & & - & & - & & 2 & $<1$ & - & & - & & - & \\
\hline Ephemerellidae & & & & & & & & & & & & & & \\
\hline Ephemerella & - & & - & & 1 & $<1$ & 2 & $<1$ & 4 & $<1$ & 2 & $<1$ & 6 & $<1$ \\
\hline Heptageniidae & & & & & & & & & & & & & & \\
\hline Epeorus & - & & - & & - & & - & & - & & - & & - & \\
\hline Stenonema & 1 & $<1$ & 6 & $<1$ & 25 & 3 & 32 & 2 & 22 & 2 & 7 & $<1$ & - & \\
\hline Isonychiidae & & & & & & & & & & & & & & \\
\hline Isonychia & - & & 1 & $<1$ & 9 & 1 & 4 & $<1$ & 4 & $<1$ & 3 & $<1$ & 10 & $<1$ \\
\hline
\end{tabular}




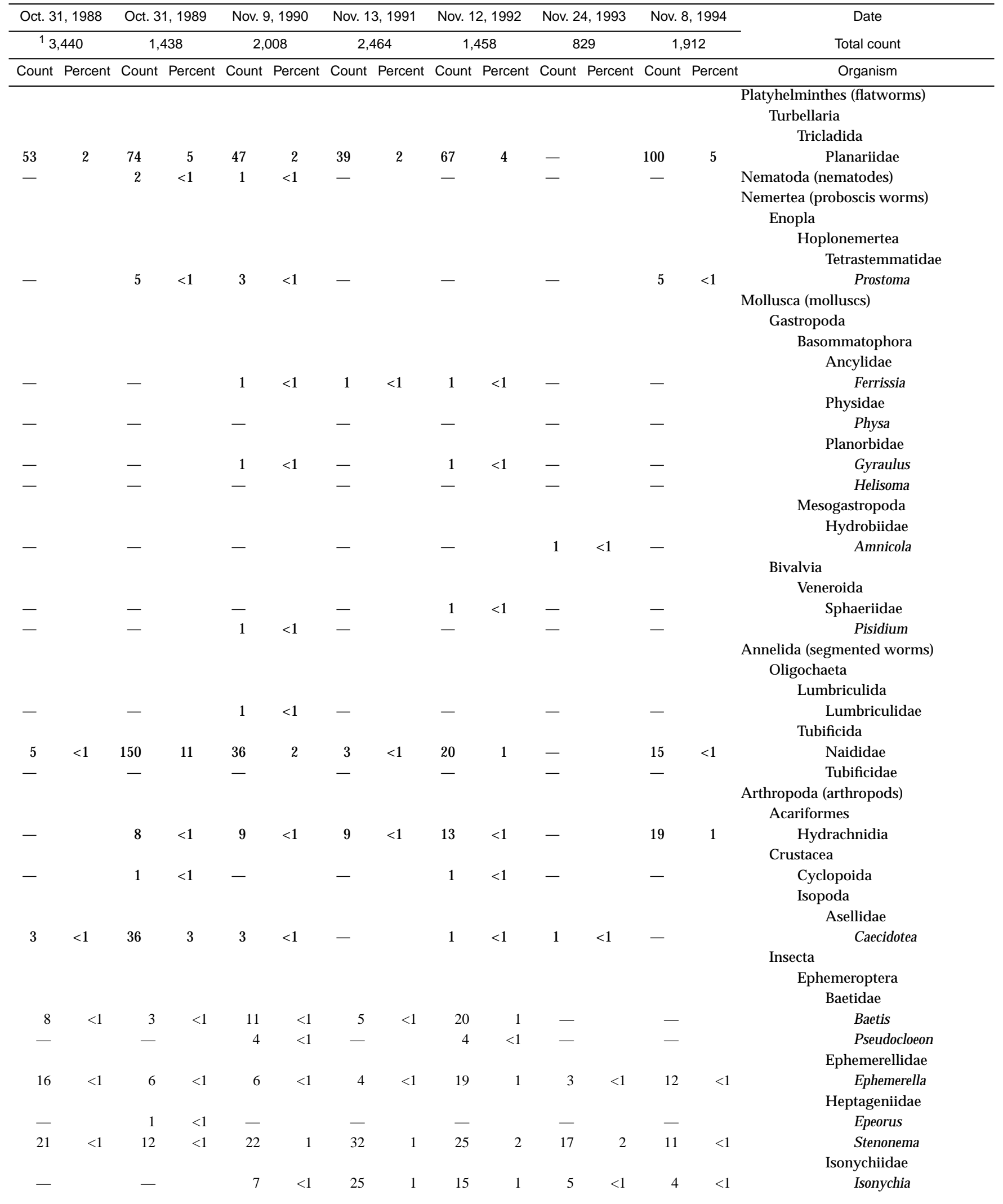


Table 5. Benthic-macroinvertebrate data-Continued

01478190 - Middle Branch White Clay Creek near Wickerton, Pa. (Site 29)—Continued

\begin{tabular}{|c|c|c|c|c|c|c|c|c|c|c|c|c|c|c|}
\hline \multirow{2}{*}{$\begin{array}{c}\text { Date } \\
\text { Total count }\end{array}$} & \multicolumn{2}{|c|}{ Oct. 29, 1981} & \multicolumn{2}{|c|}{ Oct. 20, 1982} & \multicolumn{2}{|c|}{ Nov. 2, 1983} & \multicolumn{2}{|c|}{ Oct. 18,1984} & \multicolumn{2}{|c|}{ Oct. 25,1985} & \multicolumn{2}{|c|}{ Dec. 2, 1986} & \multicolumn{2}{|c|}{ Oct. 29,1987} \\
\hline & \multicolumn{2}{|c|}{780} & \multicolumn{2}{|c|}{1,697} & \multicolumn{2}{|c|}{833} & \multicolumn{2}{|c|}{1,742} & \multicolumn{2}{|c|}{1,265} & \multicolumn{2}{|c|}{898} & & 314 \\
\hline Organism & Count & Percent & Count & Percent & Count & Percent & Count & Percent & Count & Percent & Count & Percent & Count & Percent \\
\hline Ephemeroptera & & & & & & & & & & & & & & \\
\hline Potamanthidae & & & & & & & & & & & & & & \\
\hline Anthopotamus & - & & - & & - & & - & & - & & - & & - & \\
\hline Plecoptera & & & & & & & & & & & & & & \\
\hline Capniidae & & & & & & & & & & & & & & \\
\hline Allocapnia & - & & - & & - & & - & & - & & - & & 1 & $<1$ \\
\hline Megaloptera & & & & & & & & & & & & & & \\
\hline Corydalidae & & & & & & & & & & & & & & \\
\hline Corydalus & - & & - & & - & & - & & - & & - & & - & \\
\hline Nigronia & 1 & $<1$ & - & & - & & - & & 1 & $<1$ & - & & 2 & $<1$ \\
\hline Trichoptera & & & & & & & & & & & & & & \\
\hline Apataniidae & & & & & & & & & & & & & & \\
\hline Apatania & - & & - & & - & & - & & - & & - & & - & \\
\hline Glossosomatidae & & & & & & & & & & & & & & \\
\hline Glossosoma & - & & - & & - & & 7 & $<1$ & 2 & $<1$ & - & & - & \\
\hline Hydropsychidae & & & & & & & & & & & & & & \\
\hline Ceratopsyche & 21 & 3 & 130 & 8 & 120 & 14 & 460 & 27 & 180 & 14 & 89 & 10 & 35 & 3 \\
\hline Cheumatopsyche & 80 & 10 & 440 & 26 & 180 & 21 & 150 & 9 & 64 & 5 & 210 & 23 & 71 & 5 \\
\hline Hydropsyche & 61 & 8 & 600 & 35 & 200 & 24 & 230 & 14 & 110 & 8 & 140 & 15 & 270 & 21 \\
\hline Hydroptilidae & & & & & & & & & & & & & & \\
\hline Hydroptila & 1 & $<1$ & 2 & $<1$ & 3 & $<1$ & 1 & $<1$ & 10 & $<1$ & 5 & $<1$ & 9 & $<1$ \\
\hline Leucotrichia & - & & 10 & $<1$ & 34 & 4 & 4 & $<1$ & 8 & $<1$ & 18 & 2 & 20 & 2 \\
\hline Leptoceridae & & & & & & & & & & & & & & \\
\hline Oecetis & - & & - & & - & & - & & - & & - & & - & \\
\hline Philopotamidae & & & & & & & & & & & & & & \\
\hline Chimarra & - & & - & & - & & 4 & $<1$ & 4 & $<1$ & 5 & $<1$ & - & \\
\hline Wormaldia & - & & - & & - & & - & & - & & - & & - & \\
\hline Polycentropodidae & & & & & & & & & & & & & & \\
\hline Polycentropus & - & & - & & - & & - & & 1 & $<1$ & - & & - & \\
\hline Psychomyiidae & & & & & & & & & & & & & & \\
\hline Psychomyia & - & & - & & - & & - & & - & & - & & - & \\
\hline Uenoidae & & & & & & & & & & & & & & \\
\hline Neophylax & - & & - & & - & & - & & - & & - & & - & \\
\hline Coleoptera & & & & & & & & & & & & & & \\
\hline Dryopidae & & & & & & & & & & & & & & \\
\hline Helichus & - & & 1 & $<1$ & - & & - & & - & & - & & - & \\
\hline Elmidae & & & & & & & & & & & & & & \\
\hline Ancyronyx & - & & - & & - & & - & & - & & - & & - & \\
\hline A. variegata & - & & - & & - & & - & & - & & 2 & $<1$ & - & \\
\hline Dubiraphia & - & & - & & - & & - & & - & & 2 & $<1$ & - & \\
\hline Microcylloepus & - & & - & & - & & - & & - & & - & & 1 & $<1$ \\
\hline Optioservus & 3 & $<1$ & 18 & 1 & 10 & 1 & 18 & 1 & 34 & 3 & 48 & 5 & 68 & 5 \\
\hline Oulimnius & - & & - & & - & & - & & 7 & $<1$ & 2 & $<1$ & 1 & $<1$ \\
\hline Stenelmis & 2 & $<1$ & 11 & $<1$ & - & & 7 & $<1$ & 12 & $<1$ & 22 & 2 & 47 & 4 \\
\hline Psephenidae & & & & & & & & & & & & & & \\
\hline Psephenus & - & & - & & - & & - & & - & & 1 & $<1$ & 2 & $<1$ \\
\hline Diptera & - & & - & & 1 & $<1$ & - & & - & & - & & - & \\
\hline Ceratopogonidae & - & & - & & - & & - & & - & & - & & 1 & $<1$ \\
\hline Chironomidae & 190 & 24 & 310 & 18 & 110 & 13 & 620 & 36 & 520 & 40 & 140 & 15 & 520 & 40 \\
\hline Empididae & & & & & & & & & & & & & & \\
\hline Hemerodromia & 150 & 19 & 15 & $<1$ & 6 & $<1$ & 4 & $<1$ & 34 & 3 & 8 & $<1$ & 1 & $<1$ \\
\hline Simuliidae & & & & & & & & & & & & & & \\
\hline Simulium & 73 & 9 & 32 & 2 & 1 & $<1$ & 27 & 2 & 1 & $<1$ & 8 & $<1$ & - & \\
\hline
\end{tabular}




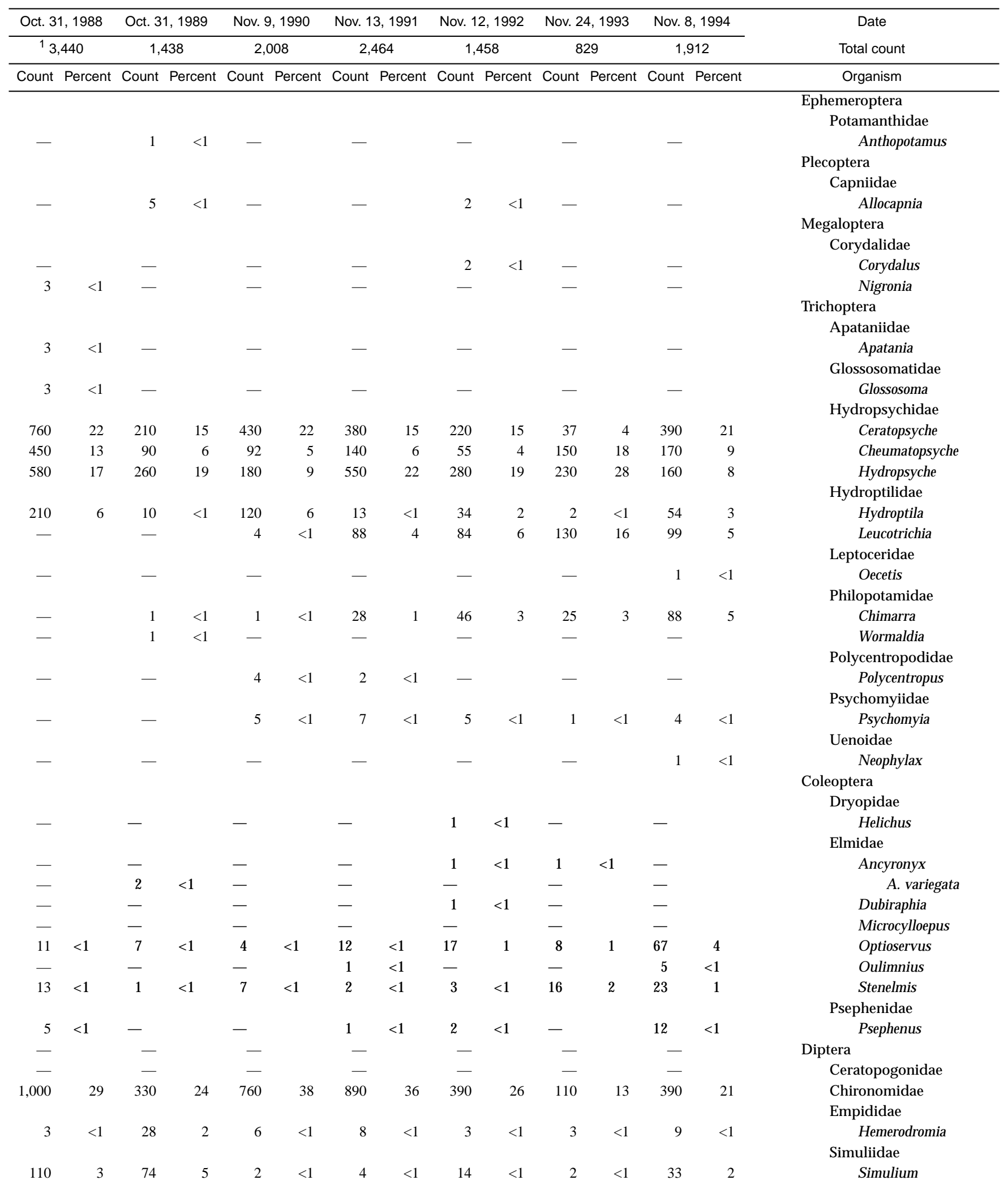


Table 5. Benthic-macroinvertebrate data—Continued

01478190 - Middle Branch White Clay Creek near Wickerton, Pa. (Site 29)—Continued

\begin{tabular}{|c|c|c|c|c|c|c|c|c|c|c|c|c|c|c|}
\hline \multirow{3}{*}{$\begin{array}{c}\text { Date } \\
\text { Total count } \\
\text { Organism }\end{array}$} & \multirow{2}{*}{\multicolumn{2}{|c|}{$\begin{array}{c}\text { Oct. } 29,1981 \\
780\end{array}$}} & \multicolumn{2}{|c|}{ Oct. 20, 1982} & \multicolumn{2}{|c|}{ Nov. 2, 1983} & \multicolumn{2}{|c|}{ Oct. 18,1984} & \multicolumn{2}{|c|}{ Oct. 25,1985} & \multicolumn{2}{|c|}{ Dec. 2, 1986} & \multicolumn{2}{|c|}{ Oct. 29,1987} \\
\hline & & & \multicolumn{2}{|c|}{1,697} & \multicolumn{2}{|c|}{833} & \multicolumn{2}{|c|}{1,742} & \multicolumn{2}{|c|}{1,265} & \multicolumn{2}{|c|}{898} & \multicolumn{2}{|c|}{1,314} \\
\hline & Count & Percent & Count & Percent & Count & Percent & Count & Percent & Count & Percent & Count & Percent & Count & Percent \\
\hline \multicolumn{15}{|l|}{ Diptera } \\
\hline \multicolumn{15}{|l|}{ Tipulidae } \\
\hline Antocha & - & & 110 & 6 & 120 & 14 & 140 & 8 & 200 & 15 & 160 & 18 & 230 & 18 \\
\hline Hexatoma & - & & - & & - & & - & & - & & - & & - & \\
\hline Tipula & 1 & $<1$ & - & & - & & - & & - & & - & & - & \\
\hline
\end{tabular}

${ }^{1}$ Extrapolated from a 3/8 subsample. 


\begin{tabular}{|c|c|c|c|c|c|c|c|c|c|c|c|c|c|c|}
\hline \multicolumn{2}{|c|}{ Oct. 31,1988} & \multicolumn{2}{|c|}{ Oct. 31, 1989} & \multicolumn{2}{|c|}{ Nov. 9, 1990} & \multicolumn{2}{|c|}{ Nov. 13, 1991} & \multicolumn{2}{|c|}{ Nov. 12, 1992} & \multicolumn{2}{|c|}{ Nov. 24, 1993} & \multicolumn{2}{|c|}{ Nov. 8, 1994} & \multirow{2}{*}{$\begin{array}{l}\text { Date } \\
\text { Total count }\end{array}$} \\
\hline \multicolumn{2}{|c|}{${ }^{1} 3,440$} & \multicolumn{2}{|c|}{1,438} & \multicolumn{2}{|c|}{2,008} & \multicolumn{2}{|c|}{2,464} & \multicolumn{2}{|c|}{1,458} & \multicolumn{2}{|c|}{829} & \multicolumn{2}{|c|}{1,912} & \\
\hline Count & Percent & Count & Percent & Count & Percent & Count & Percent & Count & Percent & Count & Percent & Count & Percent & Organism \\
\hline & & & & & & & & & & & & & & tera \\
\hline & & & & & & & & & & & & & & Tipulidae \\
\hline 180 & 5 & 120 & 9 & 240 & 12 & 220 & 9 & 110 & 7 & 87 & 10 & 240 & 13 & Antocha \\
\hline 3 & $<1$ & - & & - & & - & & - & & - & & - & & Hexatoma \\
\hline - & & - & & - & & - & & - & & - & & - & & Tipula \\
\hline
\end{tabular}


Table 5. Benthic-macroinvertebrate data-Continued

$[<$, less than; - , not found]

01478220 - West Branch White Clay Creek near Chesterville, Pa. (Site 30)

\begin{tabular}{|c|c|c|c|c|c|c|c|c|c|c|c|c|c|c|}
\hline \multirow{3}{*}{ 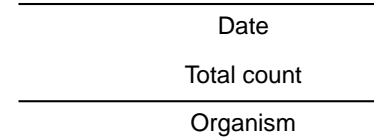 } & \multirow{2}{*}{\multicolumn{2}{|c|}{$\begin{array}{c}\text { Oct. } 29,1981 \\
1,216\end{array}$}} & \multirow{2}{*}{\multicolumn{2}{|c|}{$\begin{array}{c}\text { Oct. } 20,1982 \\
2,270\end{array}$}} & \multirow{2}{*}{\multicolumn{2}{|c|}{$\frac{\text { Nov. 2, } 1983}{794}$}} & \multirow{2}{*}{\multicolumn{2}{|c|}{$\begin{array}{c}\text { Oct. } 18,1984 \\
1,232\end{array}$}} & \multirow{2}{*}{\multicolumn{2}{|c|}{$\frac{\text { Oct. } 25,1985}{836}$}} & \multirow{2}{*}{\multicolumn{2}{|c|}{$\begin{array}{c}\text { Nov. } 25,1986 \\
1,079\end{array}$}} & \multirow{2}{*}{\multicolumn{2}{|c|}{$\frac{\text { Oct. } 29,1987}{1,665}$}} \\
\hline & & & & & & & & & & & & & & \\
\hline & Count & Percent & Count & Percent & Count & Percent & Count & Percent & Count & Percent & Count & Percent & Count & Percent \\
\hline \multicolumn{15}{|l|}{ Cnidaria (cnidarians) } \\
\hline \multicolumn{15}{|l|}{ Hydrozoa } \\
\hline \multicolumn{15}{|l|}{ Hydroida } \\
\hline \multicolumn{15}{|l|}{ Hydridae } \\
\hline Hydra & 1 & $<1$ & - & & - & & - & & - & & - & & - & \\
\hline \multicolumn{15}{|l|}{ Platyhelminthes (flatworms) } \\
\hline \multicolumn{15}{|l|}{ Turbellaria } \\
\hline Tricladida & & & & & & & & & & & & & & \\
\hline Planariidae & 2 & $<1$ & 2 & $<1$ & 14 & 2 & 1 & $<1$ & 2 & $<1$ & 4 & $<1$ & 1 & $<1$ \\
\hline Nematoda (nematodes) & - & & - & & - & & - & & - & & & & - & \\
\hline Nemertea (proboscis worms) & & & & & & & & & & & & & & \\
\hline Enopla & & & & & & & & & & & & & & \\
\hline Hoplonemertea & & & & & & & & & & & & & & \\
\hline Tetrastemmatidae & & & & & & & & & & & & & & \\
\hline Prostoma & - & & - & & 4 & $<1$ & 1 & $<1$ & 5 & $<1$ & - & & 2 & $<1$ \\
\hline Mollusca (molluscs) & & & & & & & & & & & & & & \\
\hline Gastropoda & & & & & & & & & & & & & & \\
\hline Basommatophora & & & & & & & & & & & & & & \\
\hline Ancylidae & & & & & & & & & & & & & & \\
\hline Ferrissia & - & & 1 & $<1$ & - & & 1 & $<1$ & 1 & $<1$ & - & & - & \\
\hline Physidae & & & & & & & & & & & & & & \\
\hline Physa & - & & - & & 1 & $<1$ & - & & - & & - & & - & \\
\hline Planorbidae & & & & & & & & & & & & & & \\
\hline Helisoma & 1 & $<1$ & - & & - & & - & & - & & - & & - & \\
\hline Annelida (segmented worms) & & & & & & & & & & & & & & \\
\hline Oligochaeta & - & & - & & 4 & $<1$ & 1 & $<1$ & - & & - & & - & \\
\hline Lumbriculida & & & & & & & & & & & & & & \\
\hline Lumbriculidae & - & & - & & - & & - & & 1 & $<1$ & 1 & $<1$ & - & \\
\hline Tubificida & & & & & & & & & & & & & & \\
\hline Naididae & 4 & $<1$ & - & & - & & - & & - & & - & & 8 & $<1$ \\
\hline Arthropoda (arthropods) & & & & & & & & & & & & & & \\
\hline Acariformes & & & & & & & & & & & & & & \\
\hline Hydrachnidia & 14 & 1 & 25 & 1 & 48 & 6 & - & & 6 & $<1$ & 1 & $<1$ & - & \\
\hline Crustacea & & & & & & & & & & & & & & \\
\hline Isopoda & & & & & & & & & & & & & & \\
\hline Asellidae & & & & & & & & & & & & & & \\
\hline Caecidotea & - & & - & & - & & - & & - & & - & & - & \\
\hline Insecta & & & & & & & & & & & & & & \\
\hline Ephemeroptera & & & & & & & & & & & & & & \\
\hline Baetidae & & & & & & & & & & & & & & \\
\hline Baetis & 1 & $<1$ & - & & - & & 19 & 2 & - & & 1 & $<1$ & 5 & $<1$ \\
\hline Pseudocloeon & 8 & $<1$ & 24 & 1 & 2 & $<1$ & 34 & 3 & 7 & $<1$ & - & & 17 & 1 \\
\hline Caenidae & & & & & & & & & & & & & & \\
\hline Caenis & - & & - & & 1 & $<1$ & - & & - & & - & & - & \\
\hline Ephemerellidae & & & & & & & & & & & & & & \\
\hline Ephemerella & 2 & $<1$ & 2 & $<1$ & - & & 13 & 1 & 16 & 2 & 27 & 2 & 30 & 2 \\
\hline Heptageniidae & & & & & & & & & & & & & & \\
\hline Epeorus & - & & - & & - & & - & & - & & - & & - & \\
\hline Stenonema & 5 & $<1$ & 19 & $<1$ & 21 & 3 & 29 & 2 & 32 & 4 & 21 & 2 & 65 & 4 \\
\hline Isonychiidae & & & & & & & & & & & & & & \\
\hline Isonychia & 5 & $<1$ & 7 & $<1$ & 12 & 2 & 14 & 1 & 19 & 2 & 27 & 2 & 110 & 6 \\
\hline Leptophlebiidae & & & & & & & & & & & & & & \\
\hline Habrophlebia & - & & - & & - & & - & & 1 & $<1$ & - & & - & \\
\hline
\end{tabular}




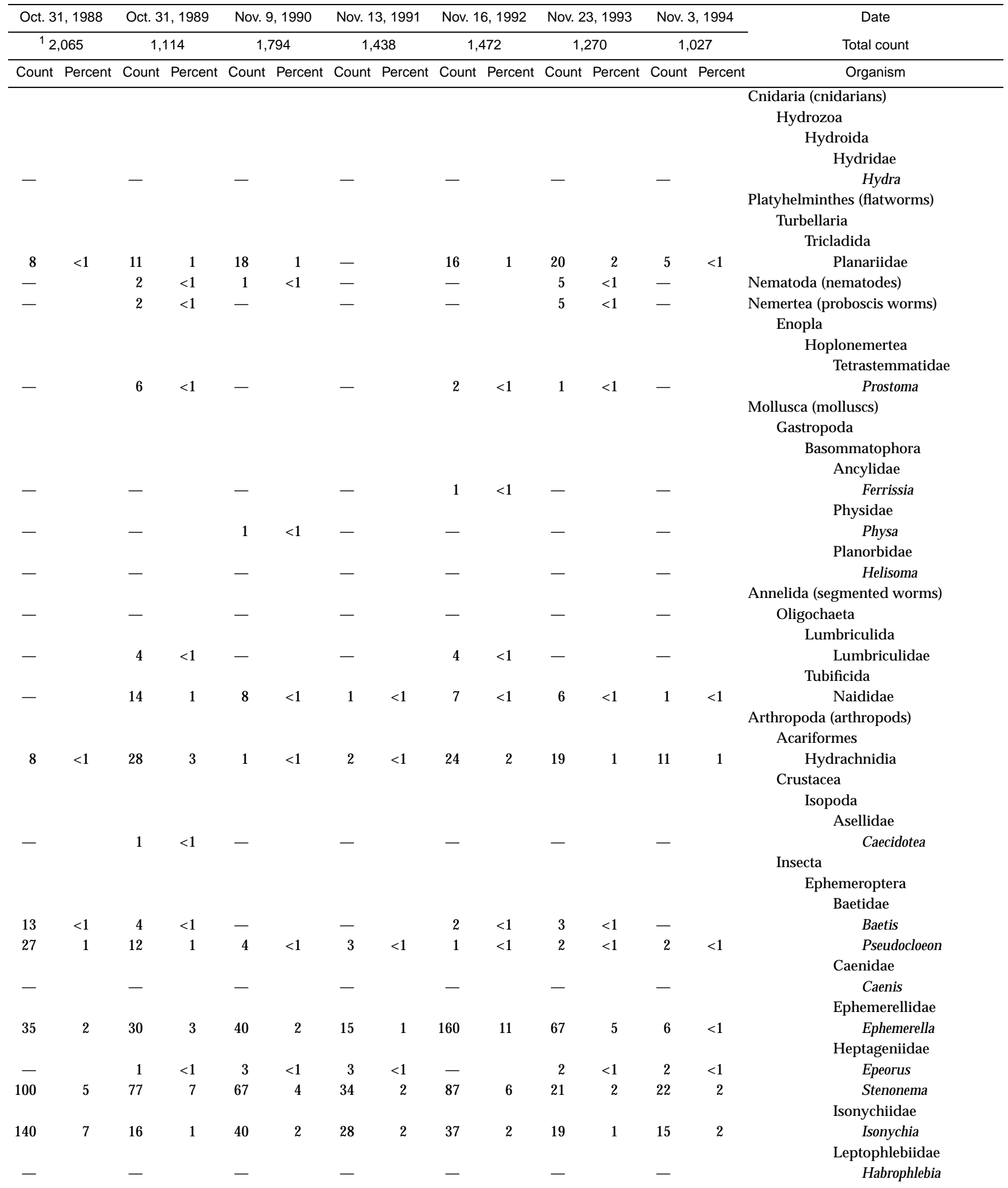


Table 5. Benthic-macroinvertebrate data-Continued

01478220 - West Branch White Clay Creek near Chesterville, Pa. (Site 30)

\begin{tabular}{|c|c|c|c|c|c|c|c|c|c|c|c|c|c|c|}
\hline \multirow{3}{*}{$\begin{array}{c}\text { Date } \\
\text { Total count } \\
\text { Organism }\end{array}$} & \multirow{2}{*}{\multicolumn{2}{|c|}{$\begin{array}{c}\text { Oct. } 29,1981 \\
1,216\end{array}$}} & \multirow{2}{*}{\multicolumn{2}{|c|}{$\begin{array}{c}\text { Oct. } 20,1982 \\
2,270\end{array}$}} & \multirow{2}{*}{\multicolumn{2}{|c|}{$\begin{array}{c}\text { Nov. } 2,1983 \\
794\end{array}$}} & \multirow{2}{*}{\multicolumn{2}{|c|}{$\begin{array}{c}\text { Oct. } 18,1984 \\
1,232\end{array}$}} & \multirow{2}{*}{\multicolumn{2}{|c|}{$\begin{array}{c}\text { Oct. } 25,1985 \\
836\end{array}$}} & \multirow{2}{*}{\multicolumn{2}{|c|}{$\begin{array}{c}\text { Nov. } 25,1986 \\
1,079\end{array}$}} & \multirow{2}{*}{\multicolumn{2}{|c|}{$\begin{array}{c}\text { Oct. } 29,1987 \\
1,665\end{array}$}} \\
\hline & & & & & & & & & & & & & & \\
\hline & Count & Percent & Count & Percent & Count & Percent & Count & Percent & Count & Percent & Count & Percent & Count & Percent \\
\hline \multicolumn{15}{|l|}{ Odonata } \\
\hline \multicolumn{15}{|l|}{ Aeshnidae } \\
\hline Boyeria & - & & - & & 1 & $<1$ & - & & 1 & $<1$ & - & & - & \\
\hline \multicolumn{15}{|l|}{ Plecoptera } \\
\hline \multicolumn{15}{|l|}{ Capniidae } \\
\hline Allocapnia & - & & - & & - & & - & & 2 & $<1$ & 2 & $<1$ & 4 & $<1$ \\
\hline Chloroperlidae & - & & - & & - & & - & & - & & - & & - & \\
\hline Nemouridae & - & & - & & - & & - & & - & & - & & - & \\
\hline \multicolumn{15}{|l|}{ Peltoperlidae } \\
\hline Peltoperla & - & & 1 & $<1$ & - & & - & & - & & - & & - & \\
\hline Taeniopterygidae & & & & & & & & & & & & & & \\
\hline Taeniopteryx & - & & 1 & $<1$ & - & & - & & 1 & $<1$ & 3 & $<1$ & 6 & $<1$ \\
\hline Hemiptera & & & & & & & & & & & & & & \\
\hline Corixidae & - & & - & & - & & - & & - & & - & & - & \\
\hline Megaloptera & & & & & & & & & & & & & & \\
\hline Corydalidae & & & & & & & & & & & & & & \\
\hline Corydalus & - & & 1 & $<1$ & - & & - & & - & & - & & - & \\
\hline Nigronia & 1 & $<1$ & 2 & $<1$ & 1 & $<1$ & 1 & $<1$ & - & & - & & - & \\
\hline Trichoptera & & & & & & & & & & & & & & \\
\hline Apataniidae & & & & & & & & & & & & & & \\
\hline Apatania & - & & - & & - & & - & & - & & - & & - & \\
\hline Brachycentridae & & & & & & & & & & & & & & \\
\hline Micrasema & - & & - & & - & & - & & - & & - & & - & \\
\hline Glossosomatidae & & & & & & & & & & & & & & \\
\hline Glossosoma & - & & 3 & $<1$ & 2 & $<1$ & 6 & $<1$ & 2 & $<1$ & 5 & $<1$ & 1 & $<1$ \\
\hline Hydropsychidae & & & & & & & & & & & & & & \\
\hline Ceratopsyche & 340 & 28 & 110 & 5 & 58 & 7 & 130 & 11 & 140 & 17 & 190 & 17 & 210 & 12 \\
\hline Cheumatopsyche & 200 & 17 & 140 & 6 & 4 & $<1$ & 100 & 8 & 47 & 6 & 110 & 10 & 130 & 8 \\
\hline Hydropsyche & 72 & 6 & 110 & 5 & 32 & 4 & 110 & 9 & 56 & 7 & 210 & 19 & 250 & 15 \\
\hline Hydroptilidae & & & & & & & & & & & & & & \\
\hline Hydroptila & 2 & $<1$ & 1 & $<1$ & 1 & $<1$ & - & & 6 & $<1$ & 1 & $<1$ & 19 & 1 \\
\hline Leucotrichia & 10 & $<1$ & 1,400 & 61 & 110 & 14 & 450 & 38 & - & & 160 & 15 & 220 & 13 \\
\hline Leptoceridae & & & & & & & & & & & & & & \\
\hline Oecetis & - & & - & & - & & - & & - & & - & & - & \\
\hline Philopotamidae & & & & & & & & & & & & & & \\
\hline Chimarra & - & & 1 & $<1$ & - & & 4 & $<1$ & 8 & 1 & 12 & 1 & 9 & $<1$ \\
\hline Dolophilodes & - & & - & & - & & - & & 1 & $<1$ & - & & - & \\
\hline Wormaldia & - & & - & & - & & - & & - & & - & & - & \\
\hline Polycentropodidae & & & & & & & & & & & & & & \\
\hline Neureclipsis & - & & - & & - & & - & & - & & - & & - & \\
\hline Polycentropus & - & & - & & - & & - & & 1 & $<1$ & - & & - & \\
\hline Psychomyiidae & & & & & & & & & & & & & & \\
\hline Psychomyia & - & & - & & - & & - & & - & & - & & - & \\
\hline Uenoidae & & & & & & & & & & & & & & \\
\hline Neophylax & - & & - & & - & & - & & - & & - & & - & \\
\hline Coleoptera & & & & & & & & & & & & & & \\
\hline Elmidae & & & & & & & & & & & & & & \\
\hline Ancyronyx & - & & - & & 1 & $<1$ & - & & - & & 2 & $<1$ & - & \\
\hline Dubiraphia & - & & - & & - & & - & & - & & - & & - & \\
\hline Microcylloepus & - & & - & & - & & - & & - & & - & & - & \\
\hline Optioservus & 13 & 1 & 17 & $<1$ & 18 & 2 & 27 & 2 & 26 & 3 & 29 & 3 & 9 & $<1$ \\
\hline Oulimnius & - & & - & & - & & 1 & $<1$ & 7 & $<1$ & 9 & $<1$ & - & \\
\hline Stenelmis & 1 & $<1$ & 2 & $<1$ & 1 & $<1$ & 5 & $<1$ & 3 & $<1$ & 1 & $<1$ & 4 & $<1$ \\
\hline Psephenidae & & & & & & & & & & & & & & \\
\hline Psephenus & - & & - & & - & & - & & 1 & $<1$ & - & & 1 & $<1$ \\
\hline
\end{tabular}




\begin{tabular}{|c|c|c|c|c|c|c|c|c|c|c|c|c|c|c|}
\hline \multirow{2}{*}{\multicolumn{2}{|c|}{$\begin{array}{c}\text { Oct. 31, } 1988 \\
12,065\end{array}$}} & \multicolumn{2}{|c|}{ Oct. 31, 1989} & \multicolumn{2}{|c|}{ Nov. 9, 1990} & \multicolumn{2}{|c|}{ Nov. 13,1991} & \multicolumn{2}{|c|}{ Nov. 16, 1992} & \multicolumn{2}{|c|}{ Nov. 23, 1993} & \multicolumn{2}{|c|}{ Nov. 3, 1994} & \multirow{3}{*}{$\begin{array}{c}\text { Date } \\
\text { Total count }\end{array}$} \\
\hline & & \multicolumn{2}{|c|}{1,114} & \multicolumn{2}{|c|}{1,794} & \multicolumn{2}{|c|}{1,438} & \multicolumn{2}{|c|}{1,472} & \multicolumn{2}{|c|}{1,270} & & 027 & \\
\hline Count & Percent & Count & Percent & Count & Percent & Count & Percent & Count & Percent & Count & Percent & Count & Percent & \\
\hline & & & & & & & & & & & & & & Odonata \\
\hline & & & & & & & & & & & & & & Aeshnidae \\
\hline- & & - & & - & & - & & - & & - & & - & & Boyeria \\
\hline & & & & & & & & & & & & & & Plecoptera \\
\hline & & & & & & & & & & & & & & Capniidae \\
\hline 3 & $<1$ & 15 & 1 & 6 & $<1$ & 9 & $<1$ & 8 & $<1$ & 2 & $<1$ & - & & Allocapnia \\
\hline - & & - & & - & & 2 & $<1$ & 1 & $<1$ & - & & 1 & $<1$ & Chloroperlidae \\
\hline- & & 7 & $<1$ & - & & - & & - & & - & & - & & Nemouridae \\
\hline & & & & & & & & & & & & & & Peltoperlidae \\
\hline- & & - & & - & & - & & - & & - & & - & & Peltoperla \\
\hline & & & & & & & & & & & & & & Taeniopterygidae \\
\hline 3 & $<1$ & - & & 3 & $<1$ & 12 & $<1$ & 7 & $<1$ & 18 & 1 & 3 & $<1$ & Taeniopteryx \\
\hline & & & & & & & & & & & & & & Hemiptera \\
\hline- & & - & & - & & - & & 1 & $<1$ & - & & - & & Corixidae \\
\hline & & & & & & & & & & & & & & Megaloptera \\
\hline & & & & & & & & & & & & & & Corydalidae \\
\hline- & & - & & - & & - & & - & & - & & - & & Corydalus \\
\hline- & & 1 & $<1$ & - & & 2 & $<1$ & 2 & $<1$ & - & & - & & Nigronia \\
\hline & & & & & & & & & & & & & & Trichoptera \\
\hline & & & & & & & & & & & & & & Apataniidae \\
\hline- & & 5 & $<1$ & - & & - & & - & & - & & - & & Apatania \\
\hline & & & & & & & & & & & & & & Brachycentridae \\
\hline 5 & $<1$ & - & & - & & - & & - & & - & & - & & Micrasema \\
\hline & & & & & & & & & & & & & & Glossosomatidae \\
\hline- & & 7 & $<1$ & 8 & $<1$ & 1 & $<1$ & 8 & $<1$ & 2 & $<1$ & 2 & $<1$ & Glossosoma \\
\hline & & & & & & & & & & & & & & Hydropsychidae \\
\hline 360 & 17 & 210 & 19 & 290 & 16 & 150 & 11 & 160 & 11 & 160 & 12 & 270 & 27 & Ceratopsyche \\
\hline 100 & 5 & 64 & 6 & 140 & 8 & 31 & 2 & 45 & 3 & 15 & 1 & 78 & 8 & Cheumatopsyche \\
\hline 270 & 13 & 83 & 8 & 130 & 7 & 270 & 19 & 160 & 11 & 97 & 7 & 92 & 9 & Hydropsyche \\
\hline & & & & & & & & & & & & & & Hydroptilidae \\
\hline 5 & $<1$ & 1 & $<1$ & 52 & 3 & 4 & $<1$ & 3 & $<1$ & - & & 5 & $<1$ & Hydroptila \\
\hline 580 & 28 & 75 & 7 & 350 & 19 & 280 & 20 & 150 & 10 & 16 & 1 & 6 & $<1$ & Leucotrichia \\
\hline & & & & & & & & & & & & & & Leptoceridae \\
\hline- & & - & & - & & 1 & $<1$ & - & & 2 & $<1$ & - & & Oecetis \\
\hline & & & & & & & & & & & & & & Philopotamidae \\
\hline 21 & 1 & 23 & 2 & 14 & $<1$ & 6 & $<1$ & 25 & 2 & 50 & 4 & 10 & 1 & Chimarra \\
\hline- & & - & & - & & - & & - & & - & & - & & Dolophilodes \\
\hline- & & 1 & $<1$ & - & & - & & - & & - & & - & & Wormaldia \\
\hline & & & & & & & & & & & & & & Polycentropodidae \\
\hline- & & - & & 1 & $<1$ & 5 & $<1$ & 2 & $<1$ & 1 & $<1$ & - & & Neureclipsis \\
\hline- & & - & & - & & - & & - & & - & & 1 & $<1$ & Polycentropus \\
\hline & & & & & & & & & & & & & & Psychomyiidae \\
\hline- & & - & & - & & - & & - & & 1 & $<1$ & 1 & $<1$ & Psychomyia \\
\hline & & & & & & & & & & & & & & Uenoidae \\
\hline- & & - & & 2 & $<1$ & - & & 10 & $<1$ & 1 & $<1$ & - & & Neophylax \\
\hline & & & & & & & & & & & & & & Coleoptera \\
\hline & & & & & & & & & & & & & & Elmidae \\
\hline- & & - & & - & & - & & - & & - & & - & & Ancyronyx \\
\hline- & & - & & - & & - & & 1 & $<1$ & - & & - & & Dubiraphia \\
\hline 3 & $<1$ & - & & - & & - & & - & & - & & - & & Microcylloepus \\
\hline 13 & $<1$ & 27 & 2 & 10 & $<1$ & 6 & $<1$ & 47 & 3 & 10 & $<1$ & 3 & $<1$ & Optioservus \\
\hline- & & 7 & $<1$ & 1 & $<1$ & 1 & $<1$ & 4 & $<1$ & 2 & $<1$ & - & & Oulimnius \\
\hline 3 & $<1$ & 5 & $<1$ & 1 & $<1$ & - & & 3 & $<1$ & 2 & $<1$ & 2 & $<1$ & Stenelmis \\
\hline & & & & & & & & & & & & & & Psephenidae \\
\hline- & & 7 & $<1$ & 2 & $<1$ & - & & 1 & $<1$ & 2 & $<1$ & 1 & $<1$ & Psephenus \\
\hline
\end{tabular}


Table 5. Benthic-macroinvertebrate data-Continued

01478220 - West Branch White Clay Creek near Chesterville, Pa. (Site 30)

\begin{tabular}{|c|c|c|c|c|c|c|c|c|c|c|c|c|c|c|}
\hline \multirow{3}{*}{$\begin{array}{c}\text { Date } \\
\text { Total count } \\
\text { Organism }\end{array}$} & \multirow{2}{*}{\multicolumn{2}{|c|}{$\begin{array}{c}\text { Oct. } 29,1981 \\
1,216\end{array}$}} & \multicolumn{2}{|c|}{ Oct. 20, 1982} & \multicolumn{2}{|c|}{ Nov. 2, 1983} & \multicolumn{2}{|c|}{ Oct. 18,1984} & \multicolumn{2}{|c|}{ Oct. 25, 1985} & \multicolumn{2}{|c|}{ Nov. 25, 1986} & \multicolumn{2}{|c|}{ Oct. 29, 1987} \\
\hline & & & \multicolumn{2}{|c|}{2,270} & \multicolumn{2}{|c|}{794} & \multicolumn{2}{|c|}{1,232} & \multicolumn{2}{|c|}{836} & \multicolumn{2}{|c|}{1,079} & \multicolumn{2}{|c|}{1,665} \\
\hline & Count & Percent & Count & Percent & Count & Percent & Count & Percent & Count & Percent & Count & Percent & Count & Percent \\
\hline \multicolumn{15}{|l|}{ Diptera } \\
\hline \multicolumn{15}{|l|}{ Athericidae } \\
\hline Atherix & - & & - & & 一 & & - & & - & & 一 & & - & \\
\hline Chironomidae & 340 & 28 & 260 & 11 & 240 & 30 & 170 & 14 & 410 & 49 & 94 & 9 & 290 & 17 \\
\hline \multicolumn{15}{|l|}{ Empididae } \\
\hline Clinocera & - & & 一 & & 一 & & - & & - & & - & & - & \\
\hline Hemerodromia & 27 & 2 & 11 & $<1$ & 8 & 1 & 3 & $<1$ & 3 & $<1$ & 11 & 1 & 11 & $<1$ \\
\hline \multicolumn{15}{|l|}{ Simuliidae } \\
\hline Simulium & 130 & 11 & - & & 一 & & 2 & $<1$ & 3 & $<1$ & 8 & $<1$ & 3 & $<1$ \\
\hline \multicolumn{15}{|l|}{ Tipulidae } \\
\hline Antocha & 37 & 3 & 130 & 6 & 210 & 26 & 110 & 9 & 28 & 3 & 150 & 14 & 260 & 15 \\
\hline Tipula & - & & - & & - & & - & & - & & - & & - & \\
\hline
\end{tabular}

${ }^{1}$ Extrapolated from a 3/8 subsample. 


\begin{tabular}{|c|c|c|c|c|c|c|c|c|c|c|c|c|c|c|}
\hline \multicolumn{2}{|c|}{ Oct. 31,1988} & \multicolumn{2}{|c|}{ Oct. 31, 1989} & \multicolumn{2}{|c|}{ Nov. 9, 1990} & \multicolumn{2}{|c|}{ Nov. 13, 1991} & \multicolumn{2}{|c|}{ Nov. 16, 1992} & \multicolumn{2}{|c|}{ Nov. 23, 1993} & \multicolumn{2}{|c|}{ Nov. 3, 1994} & \multirow{2}{*}{$\begin{array}{l}\text { Date } \\
\text { Total count }\end{array}$} \\
\hline \multicolumn{2}{|c|}{${ }^{1} 2,065$} & \multicolumn{2}{|c|}{1,114} & \multicolumn{2}{|c|}{1,794} & \multicolumn{2}{|c|}{1,438} & \multicolumn{2}{|c|}{1,472} & \multicolumn{2}{|c|}{1,270} & \multicolumn{2}{|c|}{1,027} & \\
\hline \multirow[t]{3}{*}{ Count } & Percent & Count & Percent & Count & Percent & Count & Percent & Count & Percent & Count & Percent & Count & Percent & Organism \\
\hline & & & & & & & & & & & & \multicolumn{3}{|c|}{ Diptera } \\
\hline & & & & & & & & & & & & & & Athericidae \\
\hline- & & - & & - & & - & & - & & 1 & $<1$ & - & & Atherix \\
\hline \multirow[t]{2}{*}{240} & \multirow[t]{3}{*}{11} & \multirow[t]{2}{*}{240} & \multirow[t]{2}{*}{22} & \multirow[t]{2}{*}{450} & \multirow[t]{2}{*}{25} & \multirow[t]{2}{*}{470} & \multirow[t]{2}{*}{34} & \multirow[t]{2}{*}{350} & \multirow[t]{2}{*}{23} & \multirow[t]{2}{*}{580} & \multirow[t]{2}{*}{45} & \multirow[t]{2}{*}{190} & \multirow[t]{2}{*}{19} & Chironomidae \\
\hline & & & & & & & & & & & & & & Empididae \\
\hline - & & - & & - & & - & & - & & 3 & $<1$ & - & & Clinocera \\
\hline \multirow[t]{2}{*}{5} & \multirow[t]{2}{*}{$<1$} & \multirow[t]{2}{*}{48} & 4 & 10 & $<1$ & 11 & $<1$ & 17 & 1 & 9 & $<1$ & 8 & $<1$ & Hemerodromia \\
\hline & & & & & & & & & & & & & & Simuliidae \\
\hline 3 & $<1$ & 14 & 1 & 1 & $<1$ & 6 & $<1$ & 6 & $<1$ & 33 & 3 & - & & Simulium \\
\hline & & & & & & & & & & & & & & Tipulidae \\
\hline 120 & 6 & 67 & 6 & 140 & 8 & 84 & 6 & 120 & 8 & 98 & 8 & 290 & 29 & Antocha \\
\hline- & & 1 & $<1$ & - & & 1 & $<1$ & - & & - & & - & & Tipula \\
\hline
\end{tabular}


Table 5. Benthic-macroinvertebrate data-Continued

$[<$, less than; - , not found]

01479680 - West Branch Red Clay Creek at Kennett Square, Pa. (Site 27)

\begin{tabular}{|c|c|c|c|c|c|c|c|c|c|c|c|c|c|c|}
\hline \multirow{3}{*}{$\begin{array}{c}\text { Date } \\
\text { Total count } \\
\text { Organism }\end{array}$} & \multirow{2}{*}{\multicolumn{2}{|c|}{$\frac{\text { Oct. 30, } 1981}{211}$}} & \multirow{2}{*}{\multicolumn{2}{|c|}{$\begin{array}{c}\text { Nov. } 1,1982 \\
777\end{array}$}} & \multirow{2}{*}{\multicolumn{2}{|c|}{$\frac{\text { Nov. 1, } 1983}{84}$}} & \multirow{2}{*}{\multicolumn{2}{|c|}{$\begin{array}{c}\text { Oct. } 19,1984 \\
468\end{array}$}} & \multirow{2}{*}{\multicolumn{2}{|c|}{$\frac{\text { Oct. 18, } 1985}{326}$}} & \multirow{2}{*}{\multicolumn{2}{|c|}{$\frac{\text { Nov. } 18,1986}{107}$}} & \multirow{2}{*}{\multicolumn{2}{|c|}{$\frac{\text { Oct. } 30,1987}{267}$}} \\
\hline & & & & & & & & & & & & & & \\
\hline & Count & Percent & Count & Percent & Count & Percent & Count & Percent & Count & Percent & Count & Percent & Count & Percent \\
\hline \multicolumn{15}{|l|}{ Platyhelminthes (flatworms) } \\
\hline \multicolumn{15}{|l|}{ Turbellaria } \\
\hline \multicolumn{15}{|l|}{ Tricladida } \\
\hline Planariidae & 16 & 7 & 110 & 14 & 8 & 10 & - & & 6 & 2 & 8 & 8 & 17 & 6 \\
\hline Nematoda (nematodes) & - & & - & & - & & 4 & 1 & - & & - & & - & \\
\hline \multicolumn{15}{|l|}{ Nemertea (proboscis worms) } \\
\hline \multicolumn{15}{|l|}{ Enopla } \\
\hline Hoplonemertea & & & & & & & & & & & & & & \\
\hline Tetrastemmatidae & & & & & & & & & & & & & & \\
\hline Prostoma & 1 & $<1$ & 25 & 3 & 9 & 11 & 1 & $<1$ & 12 & 4 & 3 & 3 & - & \\
\hline Nematomorpha & - & & - & & - & & - & & - & & - & & - & \\
\hline Mollusca (molluscs) & & & & & & & & & & & & & & \\
\hline Gastropoda & & & & & & & & & & & & & & \\
\hline Basommatophora & & & & & & & & & & & & & & \\
\hline Ancylidae & & & & & & & & & & & & & & \\
\hline Ferrissia & - & & 1 & $<1$ & 8 & 10 & 37 & 8 & 110 & 33 & 6 & 6 & 35 & 13 \\
\hline Lymnaeidae & & & & & & & & & & & & & & \\
\hline Lymnaea & - & & - & & 2 & 3 & - & & 1 & $<1$ & - & & - & \\
\hline Physidae & & & & & & & & & & & & & & \\
\hline Physa & - & & - & & 1 & 2 & - & & - & & - & & 1 & $<1$ \\
\hline Planorbidae & & & & & & & & & & & & & & \\
\hline Gyraulus & - & & - & & - & & - & & - & & - & & - & \\
\hline Helisoma & 1 & $<1$ & - & & - & & - & & 1 & $<1$ & - & & 3 & 1 \\
\hline Bivalvia & & & & & & & & & & & & & & \\
\hline Veneroida & & & & & & & & & & & & & & \\
\hline Sphaeriidae & & & & & & & & & & & & & & \\
\hline Pisidium & - & & - & & - & & - & & - & & - & & - & \\
\hline Annelida (segmented worms) & & & & & & & & & & & & & & \\
\hline Oligochaeta & - & & - & & - & & 130 & 28 & - & & - & & - & \\
\hline Lumbriculida & & & & & & & & & & & & & & \\
\hline Lumbriculidae & - & & - & & - & & - & & - & & - & & - & \\
\hline Tubificida & & & & & & & & & & & & & & \\
\hline Naididae & - & & - & & - & & - & & 6 & 2 & 3 & 3 & 78 & 29 \\
\hline Tubificidae & - & & 3 & $<1$ & - & & - & & - & & - & & - & \\
\hline Arthropoda (arthropods) & & & & & & & & & & & & & & \\
\hline Acariformes & & & & & & & & & & & & & & \\
\hline Hydrachnidia & 1 & $<1$ & 24 & 3 & - & & - & & 2 & $<1$ & 3 & 3 & 15 & 6 \\
\hline Crustacea & & & & & & & & & & & & & & \\
\hline Cladocera & - & & - & & - & & - & & - & & - & & - & \\
\hline Cyclopoida & - & & - & & - & & - & & - & & - & & - & \\
\hline Amphipoda & & & & & & & & & & & & & & \\
\hline Gammaridae & & & & & & & & & & & & & & \\
\hline Gammarus & - & & - & & - & & - & & - & & - & & - & \\
\hline Isopoda & & & & & & & & & & & & & & \\
\hline Asellidae & & & & & & & & & & & & & & \\
\hline Caecidotea & - & & 3 & $<1$ & - & & - & & - & & - & & - & \\
\hline Podocopa & - & & 110 & 14 & - & & - & & - & & - & & - & \\
\hline Insecta & & & & & & & & & & & & & & \\
\hline Ephemeroptera & & & & & & & & & & & & & & \\
\hline Baetidae & & & & & & & & & & & & & & \\
\hline Baetis & - & & - & & - & & - & & - & & - & & - & \\
\hline Pseudocloeon & - & & - & & - & & - & & - & & - & & - & \\
\hline Ephemerellidae & & & & & & & & & & & & & & \\
\hline Ephemerella & - & & - & & - & & - & & - & & - & & - & \\
\hline
\end{tabular}




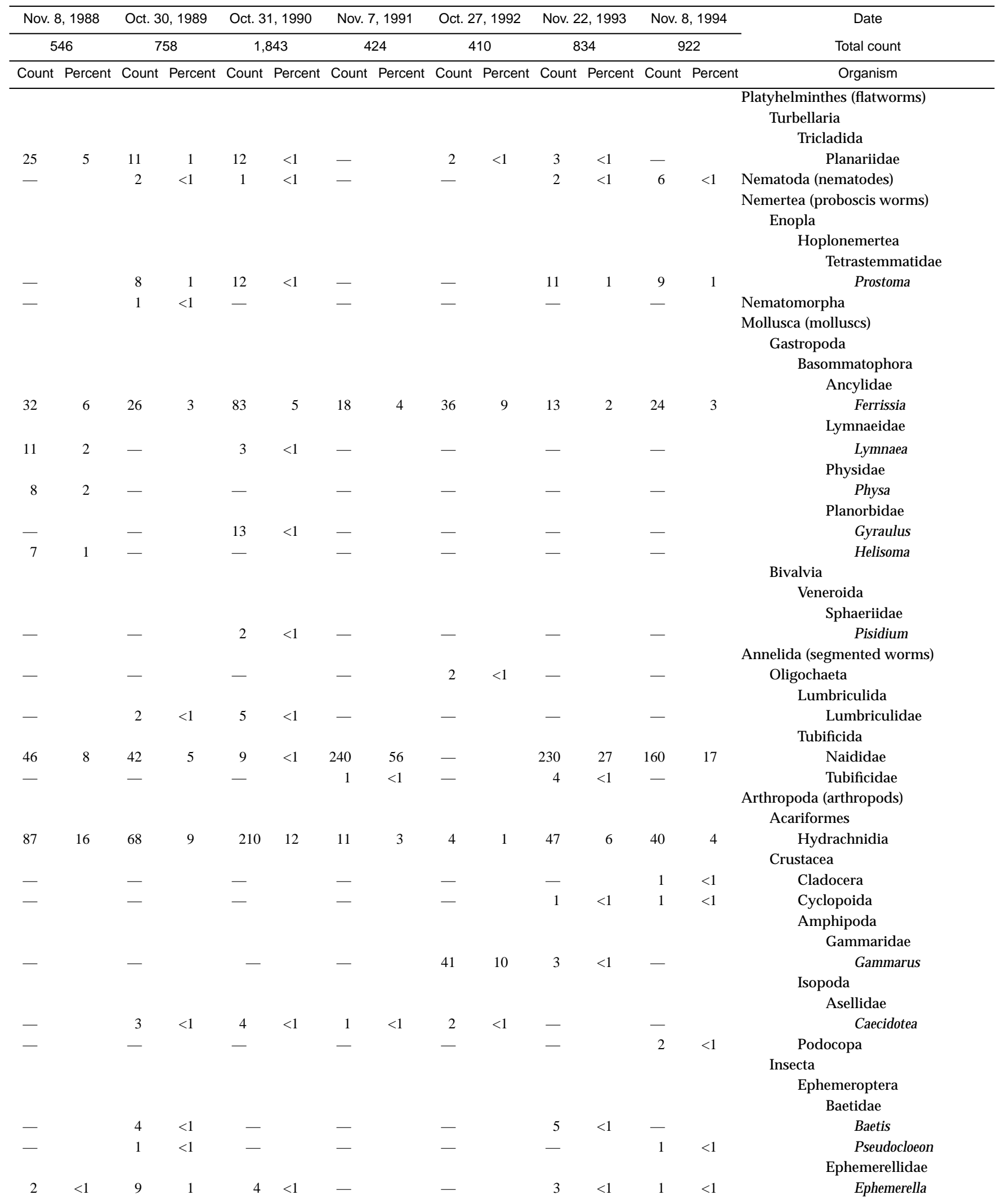


Table 5. Benthic-macroinvertebrate data—Continued

01479680 - West Branch Red Clay Creek at Kennett Square, Pa. (Site 27)—Continued

\begin{tabular}{|c|c|c|c|c|c|c|c|c|c|c|c|c|c|c|}
\hline \multirow{3}{*}{$\begin{array}{c}\text { Date } \\
\text { Total count } \\
\text { Organism }\end{array}$} & \multirow{2}{*}{\multicolumn{2}{|c|}{$\frac{\text { Oct. 30, } 1981}{211}$}} & \multirow{2}{*}{\multicolumn{2}{|c|}{$\begin{array}{c}\text { Nov. } 1,1982 \\
777\end{array}$}} & \multirow{2}{*}{\multicolumn{2}{|c|}{$\frac{\text { Nov. } 1,1983}{84}$}} & \multirow{2}{*}{\multicolumn{2}{|c|}{$\begin{array}{c}\text { Oct. } 19,1984 \\
468\end{array}$}} & \multirow{2}{*}{\multicolumn{2}{|c|}{$\frac{\text { Oct. } 18,1985}{326}$}} & \multirow{2}{*}{\multicolumn{2}{|c|}{$\begin{array}{c}\text { Nov. } 18,1986 \\
107\end{array}$}} & \multirow{2}{*}{\multicolumn{2}{|c|}{$\frac{\text { Oct. } 30,1987}{267}$}} \\
\hline & & & & & & & & & & & & & & \\
\hline & Count & Percent & Count & Percent & Count & Percent & Count & Percent & Count & Percent & Count & Percent & Count & Percent \\
\hline \multicolumn{15}{|l|}{ Ephemeroptera } \\
\hline \multicolumn{15}{|l|}{ Heptageniidae } \\
\hline Stenonema & - & & - & & - & & - & & 1 & $<1$ & - & & - & \\
\hline \multicolumn{15}{|l|}{ Isonychiidae } \\
\hline $\begin{array}{c}\text { Isonychia } \\
\text { Leptohyphidae }\end{array}$ & - & & - & & - & & - & & - & & 1 & 1 & - & \\
\hline Tricorythodes & - & & - & & - & & - & & - & & - & & - & \\
\hline \multicolumn{15}{|l|}{ Odonata } \\
\hline \multicolumn{14}{|l|}{ Plecoptera } & \\
\hline \multicolumn{15}{|l|}{ Capniidae } \\
\hline $\begin{array}{c}\text { Allocapnia } \\
\text { Taeniopterygidae }\end{array}$ & - & & - & & - & & - & & - & & - & & - & \\
\hline Taeniopteryx & - & & - & & - & & - & & - & & - & & - & \\
\hline $\begin{array}{l}\text { Hemiptera } \\
\text { Veliidae }\end{array}$ & & & & & & & & & & & & & & \\
\hline Microvelia & - & & - & & - & & - & & 2 & $<1$ & - & & - & \\
\hline $\begin{array}{l}\text { Megaloptera } \\
\text { Corydalidae }\end{array}$ & & & & & & & & & & & & & & \\
\hline Nigronia & - & & - & & - & & - & & - & & - & & - & \\
\hline Trichoptera & & & & & & & & & & & & & & \\
\hline Brachycentridae & & & & & & & & & & & & & & \\
\hline Brachycentrus & - & & - & & - & & - & & - & & - & & - & \\
\hline Glossosomatidae & & & & & & & & & & & & & & \\
\hline $\begin{array}{c}\text { Glossosoma } \\
\text { Hydropsychidae }\end{array}$ & - & & - & & - & & - & & - & & - & & - & \\
\hline Hydropsychidae & & & & & & & & & & & & & & \\
\hline Ceratopsyche & - & & 2 & $<1$ & 4 & 5 & - & & - & & - & & - & \\
\hline Cheumatopsyche & 2 & 1 & - & & - & & - & & 7 & 2 & - & & 1 & $<1$ \\
\hline Hydropsyche & - & & - & & - & & - & & - & & - & & - & \\
\hline Hydroptilidae & & & & & & & & & & & & & & \\
\hline Hydroptila & - & & - & & - & & - & & - & & - & & - & \\
\hline Leucotrichia & - & & - & & - & & - & & - & & - & & - & \\
\hline Polycentropodidae & & & & & & & & & & & & & & \\
\hline Polycentropus & - & & - & & - & & - & & - & & - & & - & \\
\hline Psychomyiidae & & & & & & & & & & & & & & \\
\hline Psychomyia & - & & - & & - & & - & & - & & - & & - & \\
\hline Coleoptera & & & & & & & & & & & & & & \\
\hline Elmidae & & & & & & & & & & & & & & \\
\hline Ancyronyx & & & & & & & & & & & & & & \\
\hline A.variegata & - & & - & & - & & - & & - & & - & & - & \\
\hline Dubiraphia & - & & - & & - & & - & & - & & 1 & 1 & 1 & $<1$ \\
\hline Macronychus & - & & - & & - & & - & & - & & - & & 1 & $<1$ \\
\hline Optioservus & 4 & 2 & 3 & $<1$ & 7 & 8 & 8 & 2 & 20 & 6 & 22 & 20 & 8 & 3 \\
\hline Oulimnius & - & & - & & - & & - & & 2 & $<1$ & - & & 1 & $<1$ \\
\hline Stenelmis & 1 & $<1$ & 2 & $<1$ & - & & 1 & $<1$ & 3 & 1 & - & & - & \\
\hline Psephenidae & & & & & & & & & & & & & & \\
\hline Psephenus & - & & - & & - & & - & & 1 & $<1$ & - & & - & \\
\hline Diptera & & & & & & & & & & & & & & \\
\hline Chironomidae & 130 & 59 & 310 & 40 & 36 & 40 & 240 & 51 & 130 & 39 & 59 & 54 & 78 & 29 \\
\hline Empididae & & & & & & & & & & & & & & \\
\hline Clinocera & - & & - & & - & & - & & - & & - & & - & \\
\hline Hemerodromia & 1 & $<1$ & 44 & 6 & 4 & 5 & 5 & 1 & 3 & 1 & - & & 5 & 2 \\
\hline Muscidae & & & & & & & & & & & & & & \\
\hline Limnophora & 1 & $<1$ & - & & - & & - & & - & & - & & - & \\
\hline
\end{tabular}




\begin{tabular}{|c|c|c|c|c|c|c|c|c|c|c|c|c|c|c|}
\hline \multirow{2}{*}{\multicolumn{2}{|c|}{$\begin{array}{c}\text { Nov. } 8,1988 \\
546\end{array}$}} & \multirow{2}{*}{\multicolumn{2}{|c|}{$\begin{array}{c}\text { Oct. } 30,1989 \\
758\end{array}$}} & \multirow{2}{*}{\multicolumn{2}{|c|}{$\frac{\text { Oct. } 31,1990}{1,843}$}} & \multirow{2}{*}{\multicolumn{2}{|c|}{$\begin{array}{c}\text { Nov. } 7,1991 \\
424\end{array}$}} & \multirow{2}{*}{\multicolumn{2}{|c|}{$\frac{\text { Oct. } 27,1992}{410}$}} & \multirow{2}{*}{\multicolumn{2}{|c|}{$\begin{array}{c}\text { Nov. 22, } 1993 \\
834\end{array}$}} & \multirow{2}{*}{\multicolumn{2}{|c|}{$\frac{\text { Nov. 8, } 1994}{922}$}} & \multirow{3}{*}{$\begin{array}{c}\text { Date } \\
\text { Total count } \\
\text { Organism }\end{array}$} \\
\hline & & & & & & & & & & & & & & \\
\hline \multirow[t]{3}{*}{ Count } & Percent & Count & Percent & Count & Percent & Count & Percent & Count & Percent & Count & Percent & Count & Percent & \\
\hline & & & & & & & & & & & & & & Ephemeroptera \\
\hline & & & & & & & & & & & & & & Heptageniidae \\
\hline \multirow[t]{2}{*}{ - } & & 11 & 1 & 2 & $<1$ & - & & 2 & $<1$ & 3 & $<1$ & - & & Stenonema \\
\hline & & & & & & & & & & & & & & Isonychiidae \\
\hline \multirow[t]{2}{*}{ - } & & 2 & $<1$ & - & & - & & - & & - & & - & & Isonychia \\
\hline & & & & & & & & & & & & & & Leptohyphidae \\
\hline \multirow[t]{2}{*}{ - } & & - & & 2 & $<1$ & - & & - & & - & & - & & Tricorythodes \\
\hline & & & & & & & & & & & & & & Odonata \\
\hline \multirow[t]{3}{*}{ - } & & - & & - & & - & & - & & - & & - & & Coenagrionidae \\
\hline & & & & & & & & & & & & & & Plecoptera \\
\hline & & & & & & & & & & & & & & Capniidae \\
\hline - & & 1 & $<1$ & - & & - & & - & & - & & - & & Allocapnia \\
\hline & & & & & & & & & & & & & & Taeniopterygidae \\
\hline - & & 1 & $<1$ & - & & - & & - & & - & & - & & Taeniopteryx \\
\hline & & & & & & & & & & & & & & Hemiptera \\
\hline & & & & & & & & & & & & & & Veliidae \\
\hline - & & - & & - & & - & & - & & - & & - & & Microvelia \\
\hline & & & & & & & & & & & & & & Megaloptera \\
\hline & & & & & & & & & & & & & & Corydalidae \\
\hline - & & - & & - & & - & & - & & 1 & $<1$ & - & & Nigronia \\
\hline & & & & & & & & & & & & & & Trichoptera \\
\hline & & & & & & & & & & & & & & Brachycentridae \\
\hline - & & - & & - & & - & & - & & - & & 1 & $<1$ & Brachycentrus \\
\hline & & & & & & & & & & & & & & Glossosomatidae \\
\hline - & & 2 & $<1$ & - & & - & & - & & - & & - & & Glossosoma \\
\hline & & & & & & & & & & & & & & Hydropsychidae \\
\hline 3 & $<1$ & 130 & 17 & 28 & 2 & 2 & $<1$ & - & & 18 & 2 & 8 & $<1$ & Ceratopsyche \\
\hline 1 & $<1$ & 41 & 5 & 11 & $<1$ & 4 & 1 & - & & 19 & 2 & 4 & $<1$ & Cheumatopsyche \\
\hline - & & 100 & 13 & 17 & $<1$ & 21 & 5 & 170 & 41 & 23 & 3 & 11 & 1 & Hydropsyche \\
\hline & & & & & & & & & & & & & & Hydroptilidae \\
\hline - & & 2 & $<1$ & - & & - & & 2 & $<1$ & 1 & $<1$ & 1 & $<1$ & Hydroptila \\
\hline - & & 1 & $<1$ & - & & - & & - & & - & & - & & Leucotrichia \\
\hline & & & & & & & & & & & & & & Polycentropodidae \\
\hline - & & 1 & $<1$ & - & & - & & - & & - & & - & & Polycentropus \\
\hline & & & & & & & & & & & & & & Psychomyiidae \\
\hline - & & 1 & $<1$ & - & & - & & - & & - & & - & & Psychomyia \\
\hline & & & & & & & & & & & & & & Coleoptera \\
\hline & & & & & & & & & & & & & & Elmidae \\
\hline & & & & & & & & & & & & & & Ancyronyx \\
\hline - & & - & & - & & - & & - & & 1 & $<1$ & 2 & $<1$ & A.variegata \\
\hline 1 & $<1$ & 1 & $<1$ & 1 & $<1$ & - & & - & & 2 & $<1$ & 1 & $<1$ & Dubiraphia \\
\hline - & & - & & - & & - & & - & & - & & - & & Macronychus \\
\hline 15 & 3 & 16 & 2 & 10 & $<1$ & 2 & $<1$ & 8 & 2 & 9 & 1 & 10 & 1 & Optioservus \\
\hline - & & 7 & $<1$ & - & & - & & - & & - & & 1 & $<1$ & Oulimnius \\
\hline 3 & $<1$ & 11 & 1 & 11 & $<1$ & 2 & $<1$ & 2 & $<1$ & 3 & $<1$ & 2 & $<1$ & Stenelmis \\
\hline & & & & & & & & & & & & & & Psephenidae \\
\hline - & & 4 & $<1$ & - & & - & & - & & 2 & $<1$ & - & & Psephenus \\
\hline & & & & & & & & & & & & & & Diptera \\
\hline 67 & 12 & 98 & 13 & 1,200 & 67 & 100 & 23 & 56 & 14 & 300 & 36 & 530 & 57 & Chironomidae \\
\hline & & & & & & & & & & & & & & Empididae \\
\hline - & & - & & - & & - & & - & & 2 & $<1$ & - & & Clinocera \\
\hline 8 & 2 & 45 & 6 & 6 & $<1$ & 2 & $<1$ & - & & 9 & 1 & 15 & 2 & Hemerodromia \\
\hline & & & & & & & & & & & & & & Muscidae \\
\hline - & & - & & - & & - & & - & & - & & - & & Limnophora \\
\hline
\end{tabular}


Table 5. Benthic-macroinvertebrate data-Continued

01479680 - West Branch Red Clay Creek at Kennett Square, Pa. (Site 27)—Continued

\begin{tabular}{|c|c|c|c|c|c|c|c|c|c|c|c|c|c|c|}
\hline \multirow{3}{*}{$\begin{array}{c}\text { Date } \\
\text { Total count } \\
\text { Organism }\end{array}$} & \multirow{2}{*}{\multicolumn{2}{|c|}{$\frac{\text { Oct. } 30,1981}{211}$}} & \multicolumn{2}{|c|}{ Nov. 1, 1982} & \multicolumn{2}{|c|}{ Nov. 1, 1983} & \multicolumn{2}{|c|}{ Oct. 19,1984} & \multicolumn{2}{|c|}{ Oct. 18,1985} & \multicolumn{2}{|c|}{ Nov. 18, 1986} & \multicolumn{2}{|c|}{ Oct. 30,1987} \\
\hline & & & \multicolumn{2}{|c|}{777} & \multicolumn{2}{|c|}{84} & \multicolumn{2}{|c|}{468} & \multicolumn{2}{|c|}{326} & \multicolumn{2}{|c|}{107} & \multicolumn{2}{|c|}{267} \\
\hline & Count & Percent & Count & Percent & Count & Percent & Count & Percent & Count & Percent & Count & Percent & Count & Percent \\
\hline \multicolumn{15}{|l|}{ Diptera } \\
\hline \multicolumn{15}{|l|}{ Simuliidae } \\
\hline Simulium & 53 & 24 & 140 & 18 & 4 & 5 & 6 & 1 & 18 & 5 & 1 & 1 & 20 & 7 \\
\hline Stratiomyidae & - & & - & & - & & - & & - & & - & & - & \\
\hline Tipulidae & - & & - & & - & & - & & - & & - & & - & \\
\hline Antocha & - & & - & & - & & 36 & 8 & 1 & $<1$ & - & & 3 & 1 \\
\hline Tipula & - & & - & & - & & - & & - & & - & & - & \\
\hline
\end{tabular}




\begin{tabular}{|c|c|c|c|c|c|c|c|c|c|c|c|c|c|c|}
\hline \multicolumn{2}{|c|}{ Nov. 8, 1988} & \multicolumn{2}{|c|}{ Oct. 30, 1989} & \multicolumn{2}{|c|}{ Oct. 31, 1990} & \multicolumn{2}{|c|}{ Nov. 7, 1991} & \multicolumn{2}{|c|}{ Oct. 27,1992} & \multicolumn{2}{|c|}{ Nov. 22, 1993} & \multicolumn{2}{|c|}{ Nov. 8, 1994} & Date \\
\hline \multicolumn{2}{|c|}{546} & \multicolumn{2}{|c|}{758} & \multicolumn{2}{|c|}{1,843} & \multicolumn{2}{|c|}{424} & \multicolumn{2}{|c|}{410} & \multicolumn{2}{|c|}{834} & \multicolumn{2}{|c|}{922} & Total count \\
\hline \multirow[t]{3}{*}{ Count } & Percent & Count & Percent & Count & Percent & Count & Percent & Count & Percent & Count & Percent & Count & Percent & Organism \\
\hline & & & & & & & & & & & & \multicolumn{3}{|c|}{ Diptera } \\
\hline & & & & & & & & & & & & & & Simuliidae \\
\hline 220 & 40 & 6 & $<1$ & 110 & 6 & 6 & 2 & 8 & 2 & 33 & 4 & 10 & 1 & Simulium \\
\hline - & & - & & - & & - & & - & & 1 & $<1$ & - & & Stratiomyidae \\
\hline - & & - & & 1 & $<1$ & - & & - & & 一 & & 一 & & Tipulidae \\
\hline 10 & 2 & 100 & 13 & 85 & 5 & 14 & 3 & 75 & 18 & 85 & 10 & 81 & 9 & Antocha \\
\hline- & & - & & 1 & $<1$ & - & & - & & - & & 一 & & Tipula \\
\hline
\end{tabular}


Table 5. Benthic-macroinvertebrate data-Continued

$[<$, less than; - , not found]

01479800 - East Branch Red Clay Creek near Five Point, Pa. (Site 26)

\begin{tabular}{|c|c|c|c|c|c|c|c|c|c|c|c|c|c|c|}
\hline \multirow{3}{*}{$\begin{array}{c}\text { Date } \\
\text { Total count } \\
\text { Organism }\end{array}$} & \multirow{2}{*}{\multicolumn{2}{|c|}{$\frac{\text { Oct. } 30,1981}{1,055}$}} & \multirow{2}{*}{\multicolumn{2}{|c|}{$\begin{array}{c}\text { Nov. } 1,1982 \\
285\end{array}$}} & \multirow{2}{*}{\multicolumn{2}{|c|}{$\frac{\text { Nov. } 1,1983}{577}$}} & \multirow{2}{*}{\multicolumn{2}{|c|}{$\frac{\text { Oct. } 19,1984}{2,375}$}} & \multirow{2}{*}{\multicolumn{2}{|c|}{$\frac{\text { Oct. } 18,1985}{627}$}} & \multirow{2}{*}{\multicolumn{2}{|c|}{$\frac{\text { Nov. } 18,1986}{34}$}} & \multirow{2}{*}{\multicolumn{2}{|c|}{$\frac{\text { Nov. } 17,1987}{577}$}} \\
\hline & & & & & & & & & & & & & & \\
\hline & Count & Percent & Count & Percent & Count & Percent & Count & Percent & Count & Percent & Count & Percent & Count & Percent \\
\hline \multicolumn{15}{|l|}{ Platyhelminthes (flatworms) } \\
\hline \multicolumn{15}{|l|}{ Turbellaria } \\
\hline \multicolumn{15}{|l|}{ Tricladida } \\
\hline Planariidae & 6 & $<1$ & 3 & 1 & 5 & $<1$ & - & & 1 & $<1$ & - & & - & \\
\hline Nematoda (nematodes) & - & & - & & - & & - & & - & & - & & - & \\
\hline \multicolumn{15}{|l|}{ Nemertea (proboscis worms) } \\
\hline \multicolumn{15}{|l|}{ Enopla } \\
\hline \multicolumn{15}{|l|}{ Hoplonemertea } \\
\hline Tetrastemmatidae & & & & & & & & & & & & & & \\
\hline Prostoma & 16 & 1 & 11 & 4 & 8 & 1 & 2 & $<1$ & 9 & 2 & - & & - & \\
\hline Mollusca (molluscs) & & & & & & & & & & & & & & \\
\hline Gastropoda & & & & & & & & & & & & & & \\
\hline Basommatophora & & & & & & & & & & & & & & \\
\hline Ancylidae & & & & & & & & & & & & & & \\
\hline Ferrissia & 53 & 5 & 28 & 10 & 2 & $<1$ & 6 & $<1$ & 17 & 3 & 1 & 4 & 5 & $<1$ \\
\hline Physidae & & & & & & & & & & & & & & \\
\hline Physa & 59 & 5 & 9 & 3 & 1 & $<1$ & 1 & $<1$ & - & & - & & 1 & $<1$ \\
\hline Planorbidae & & & & & & & & & & & & & & \\
\hline Helisoma & 2 & $<1$ & - & & - & & - & & - & & - & & - & \\
\hline Annelida (segmented worms) & & & & & & & & & & & & & & \\
\hline Oligochaeta & - & & - & & - & & 2,000 & 83 & - & & - & & - & \\
\hline Tubificida & & & & & & & & & & & & & & \\
\hline Naididae & 30 & 3 & 10 & 3 & 5 & $<1$ & - & & 19 & 3 & 1 & 4 & 38 & 7 \\
\hline Tubificidae & - & & - & & - & & - & & - & & - & & - & \\
\hline Arthropoda (arthropods) & & & & & & & & & & & & & & \\
\hline Acariformes & & & & & & & & & & & & & & \\
\hline Hydrachnidia & 39 & 4 & 11 & 4 & 3 & $<1$ & 7 & $<1$ & 50 & 8 & 1 & 4 & 3 & $<1$ \\
\hline Crustacea & & & & & & & & & & & & & & \\
\hline Cyclopoida & - & & - & & - & & - & & - & & - & & - & \\
\hline Amphipoda & & & & & & & & & & & & & & \\
\hline Crangonyctidae & & & & & & & & & & & & & & \\
\hline Crangonyx & - & & - & & - & & - & & - & & - & & - & \\
\hline Isopoda & & & & & & & & & & & & & & \\
\hline Asellidae & & & & & & & & & & & & & & \\
\hline Caecidotea & - & & - & & - & & - & & - & & - & & 1 & $<1$ \\
\hline Podocopa & 1 & $<1$ & 1 & $<1$ & 1 & $<1$ & - & & - & & - & & - & \\
\hline Insecta & & & & & & & & & & & & & & \\
\hline Ephemeroptera & & & & & & & & & & & & & & \\
\hline Baetidae & & & & & & & & & & & & & & \\
\hline Baetis & - & & - & & - & & - & & - & & - & & - & \\
\hline Ephemerellidae & & & & & & & & & & & & & & \\
\hline Ephemerella & - & & - & & - & & - & & - & & - & & 2 & $<1$ \\
\hline Heptageniidae & & & & & & & & & & & & & & \\
\hline Stenonema & - & & 1 & $<1$ & - & & - & & - & & - & & - & \\
\hline Odonata & & & & & & & & & & & & & & \\
\hline Calopterygidae & & & & & & & & & & & & & & \\
\hline Hetaerina & - & & - & & - & & - & & - & & - & & - & \\
\hline Coenagrionidae & & & & & & & & & & & & & & \\
\hline Argia & - & & - & & 1 & $<1$ & - & & - & & - & & - & \\
\hline Plecoptera & & & & & & & & & & & & & & \\
\hline Taeniopterygidae & & & & & & & & & & & & & & \\
\hline Taeniopteryx & - & & - & & - & & - & & - & & 1 & 4 & - & \\
\hline
\end{tabular}




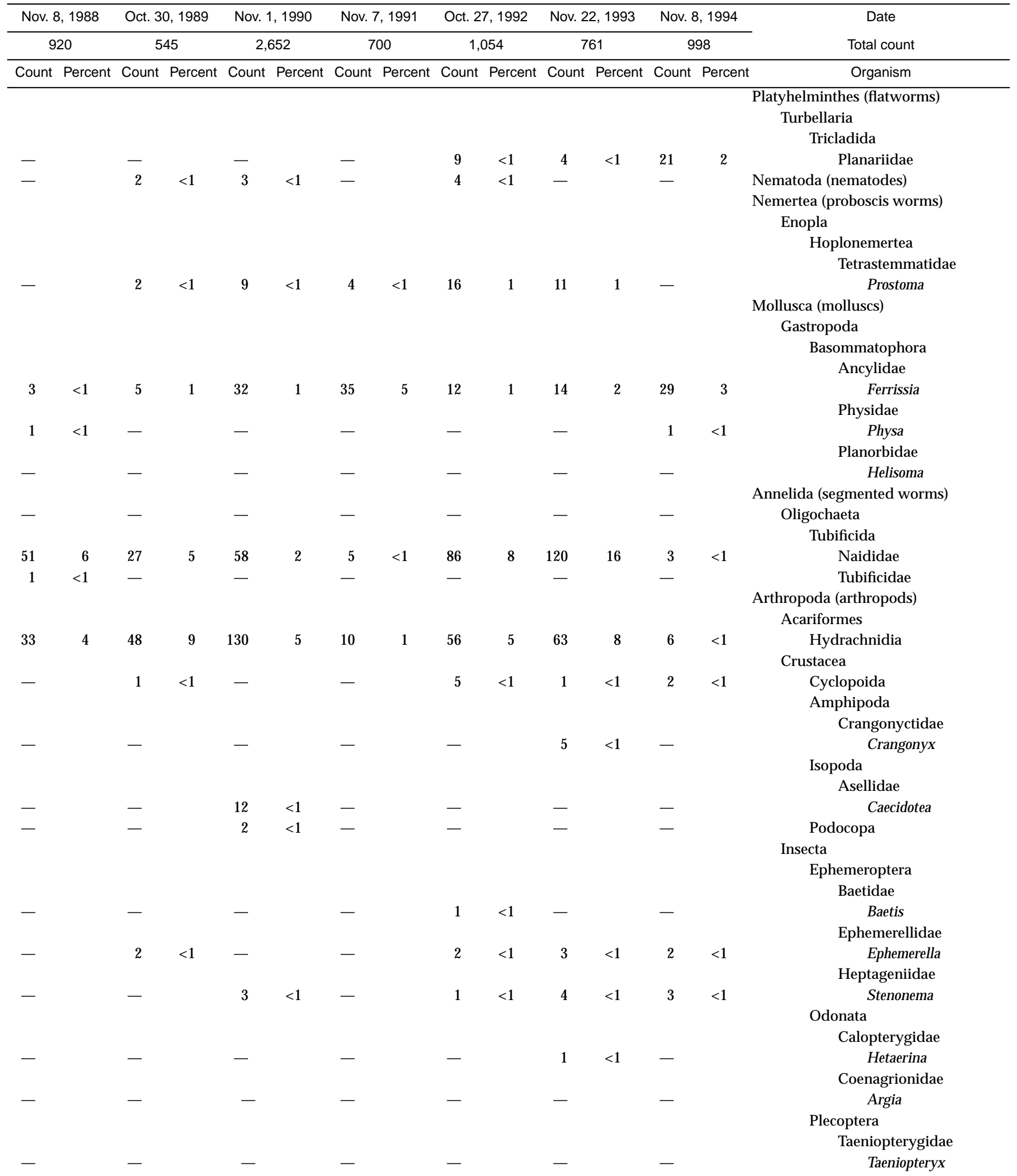


Table 5. Benthic-macroinvertebrate data—Continued

01479800 - East Branch Red Clay Creek near Five Point, Pa. (Site 26)—Continued

\begin{tabular}{|c|c|c|c|c|c|c|c|c|c|c|c|c|c|c|}
\hline \multirow{3}{*}{$\begin{array}{c}\text { Date } \\
\text { Total count } \\
\text { Organism }\end{array}$} & \multirow{2}{*}{\multicolumn{2}{|c|}{$\frac{\text { Oct. 30, } 1981}{1,055}$}} & \multirow{2}{*}{\multicolumn{2}{|c|}{$\begin{array}{c}\text { Nov. } 1,1982 \\
285\end{array}$}} & \multicolumn{2}{|c|}{ Nov. 1,1983} & \multicolumn{2}{|c|}{ Oct. 19,1984} & \multicolumn{2}{|c|}{ Oct. 18,1985} & \multicolumn{2}{|c|}{ Nov. 18,1986} & \multicolumn{2}{|c|}{ Nov. 17,1987} \\
\hline & & & & & 57 & 77 & & 375 & & 27 & & 4 & & 77 \\
\hline & Count & Percent & Count & Percent & Count & Percent & Count & Percent & Count & Percent & Count & Percent & Count & Percent \\
\hline \multicolumn{15}{|l|}{ Hemiptera } \\
\hline \multicolumn{15}{|l|}{ Veliidae } \\
\hline Rhagovelia & - & & - & & - & & - & & - & & - & & - & \\
\hline \multicolumn{15}{|l|}{ Megaloptera } \\
\hline \multicolumn{15}{|l|}{ Corydalidae } \\
\hline Nigronia & - & & - & & - & & - & & 1 & $<1$ & 1 & 4 & 3 & $<1$ \\
\hline \multicolumn{15}{|l|}{ Trichoptera } \\
\hline \multicolumn{15}{|l|}{ Glossosomatidae } \\
\hline Glossosoma & - & & - & & - & & - & & - & & - & & - & \\
\hline \multicolumn{15}{|l|}{ Hydropsychidae } \\
\hline Ceratopsyche & - & & 31 & 11 & 400 & 68 & 1 & $<1$ & - & & - & & - & \\
\hline Cheumatopsyche & - & & 6 & 2 & 25 & 4 & - & & - & & - & & 1 & $<1$ \\
\hline Hydropsyche & - & & 3 & 1 & - & & - & & 2 & $<1$ & - & & 14 & 2 \\
\hline \multicolumn{15}{|l|}{ Hydroptilidae } \\
\hline Hydroptila & - & & - & & - & & - & & - & & - & & - & \\
\hline Leucotrichia & - & & - & & - & & - & & 1 & $<1$ & - & & - & \\
\hline Philopotamidae & & & & & & & & & & & & & & \\
\hline Chimarra & - & & - & & - & & - & & - & & - & & - & \\
\hline Coleoptera & & & & & & & & & & & & & & \\
\hline Dryopidae & & & & & & & & & & & & & & \\
\hline Helichus & 1 & $<1$ & - & & - & & - & & - & & - & & - & \\
\hline Elmidae & & & & & & & & & & & & & & \\
\hline Ancyronyx & - & & - & & - & & - & & - & & - & & - & \\
\hline A.variegata & - & & - & & - & & - & & - & & - & & - & \\
\hline Dubiraphia & - & & - & & - & & - & & - & & - & & - & \\
\hline Optioserous & 3 & $<1$ & 6 & 2 & 12 & 2 & 17 & $<1$ & 23 & 4 & 13 & 34 & 5 & $<1$ \\
\hline Oulimnius & - & & - & & - & & - & & 1 & $<1$ & - & & 1 & $<1$ \\
\hline Stenelmis & - & & - & & - & & 1 & $<1$ & - & & - & & 1 & $<1$ \\
\hline Hydrophilidae & & & & & & & & & & & & & & \\
\hline Berosus & - & & - & & - & & - & & - & & - & & - & \\
\hline Psephenidae & & & & & & & & & & & & & & \\
\hline Ectopria & & & & & & & & & & & & & & \\
\hline E. nervosa & - & & - & & - & & - & & 1 & $<1$ & - & & - & \\
\hline Psephenus & - & & - & & - & & - & & - & & - & & 2 & $<1$ \\
\hline Hymenoptera & - & & - & & - & & - & & 2 & $<1$ & 1 & 4 & - & \\
\hline Diptera & 2 & $<1$ & - & & - & & - & & - & & - & & - & \\
\hline Athericidae & & & & & & & & & & & & & & \\
\hline Atherix & - & & - & & 2 & $<1$ & - & & - & & - & & - & \\
\hline Chironomidae & 280 & 25 & 110 & 38 & 68 & 12 & 250 & 10 & 390 & 62 & 12 & 32 & 210 & 36 \\
\hline Empididae & & & & & & & & & & & & & & \\
\hline Chelifera & - & & - & & - & & - & & - & & - & & - & \\
\hline Clinocera & - & & - & & - & & - & & - & & - & & - & \\
\hline Hemerodromia & 63 & 6 & 15 & 5 & 8 & 1 & 1 & $<1$ & 24 & 4 & - & & 2 & $<1$ \\
\hline Simuliidae & & & & & & & & & & & & & & \\
\hline Simulium & 500 & 45 & 35 & 12 & 25 & 4 & 6 & $<1$ & 24 & 4 & 1 & 4 & 230 & 40 \\
\hline Tipulidae & & & & & & & & & & & & & & \\
\hline Antocha & - & & 5 & 2 & 10 & 2 & 83 & 3 & 62 & 10 & 2 & 7 & 58 & 10 \\
\hline Tipula & - & & - & & 1 & $<1$ & - & & - & & - & & - & \\
\hline
\end{tabular}




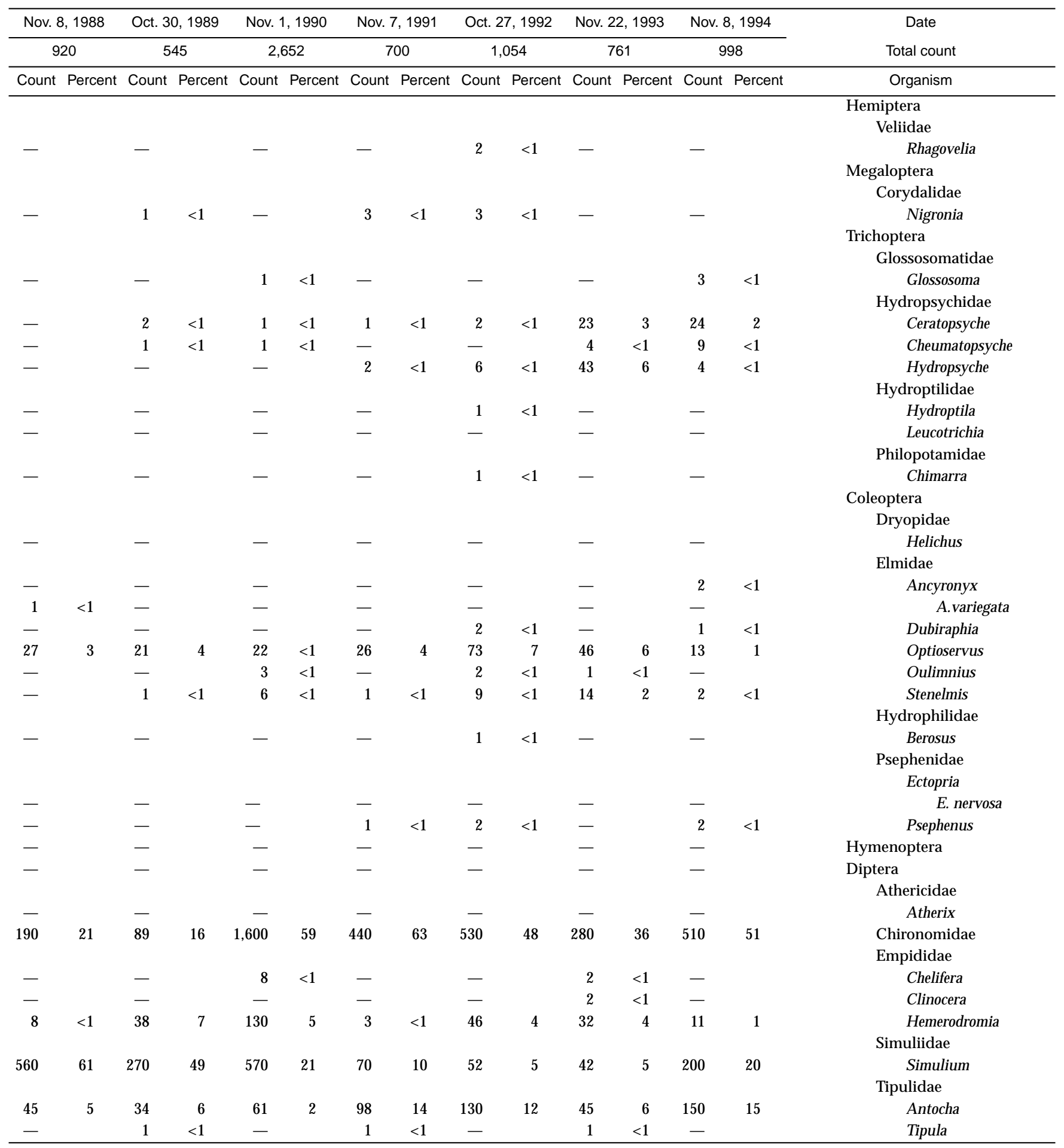


Table 5. Benthic-macroinvertebrate data-Continued

$[<$, less than; - , not found]

01480434 - West Branch Brandywine Creek at Rock Run, Pa. (Site 37)

\begin{tabular}{|c|c|c|c|c|c|c|c|c|c|c|c|c|c|c|}
\hline \multirow{3}{*}{$\begin{array}{cc}\text { Date } \\
\text { Total count }\end{array}$} & \multirow{2}{*}{\multicolumn{2}{|c|}{$\frac{\text { Nov. 2, } 1981}{551}$}} & \multirow{2}{*}{\multicolumn{2}{|c|}{$\begin{array}{c}\text { Oct. } 27,1982 \\
1,086\end{array}$}} & \multirow{2}{*}{\multicolumn{2}{|c|}{$\begin{array}{c}\text { Nov. } 4,1983 \\
1,241\end{array}$}} & \multirow{2}{*}{\multicolumn{2}{|c|}{$\begin{array}{c}\text { Oct. } 30,1984 \\
1,052\end{array}$}} & \multirow{2}{*}{\multicolumn{2}{|c|}{$\begin{array}{c}\text { Oct. } 21,1985 \\
1,711\end{array}$}} & \multirow{2}{*}{\multicolumn{2}{|c|}{$\frac{\text { Nov. } 17,1986}{646}$}} & \multirow{2}{*}{\multicolumn{2}{|c|}{$\begin{array}{c}\text { Oct. } 22,1987 \\
1,278\end{array}$}} \\
\hline & & & & & & & & & & & & & & \\
\hline & Count & Percent & Count & Percent & Count & Percent & Count & Percent & Count & Percent & Count & Percent & Count & Percent \\
\hline \multicolumn{15}{|l|}{ Platyhelminthes (flatworms) } \\
\hline \multicolumn{15}{|l|}{ Turbellaria } \\
\hline \multicolumn{15}{|l|}{ Tricladida } \\
\hline Planariidae & - & & 8 & $<1$ & - & & - & & 4 & $<1$ & 6 & $<1$ & 3 & $<1$ \\
\hline Nematoda (nematodes) & - & & - & & - & & - & & - & & - & & - & \\
\hline \multicolumn{15}{|l|}{ Nemertea (proboscis worms) } \\
\hline \multicolumn{15}{|l|}{ Enopla } \\
\hline \multicolumn{15}{|l|}{ Hoplonemertea } \\
\hline Tetrastemmatidae & & & & & & & & & & & & & & \\
\hline Prostoma & - & & - & & - & & 1 & $<1$ & - & & - & & - & \\
\hline Mollusca (molluscs) & & & & & & & & & & & & & & \\
\hline Gastropoda & & & & & & & & & & & & & & \\
\hline Basommatophora & & & & & & & & & & & & & & \\
\hline Ancylidae & & & & & & & & & & & & & & \\
\hline Ferrissia & 8 & 2 & 37 & 3 & 28 & 2 & 4 & $<1$ & 5 & $<1$ & 9 & 1 & 1 & $<1$ \\
\hline Lymnaeidae & & & & & & & & & & & & & & \\
\hline Lymnaea & - & & - & & - & & - & & - & & 1 & $<1$ & - & \\
\hline Physidae & & & & & & & & & & & & & & \\
\hline Physa & - & & - & & - & & - & & 2 & $<1$ & 2 & $<1$ & - & \\
\hline Bivalvia & & & & & & & & & & & & & & \\
\hline Veneroida & & & & & & & & & & & & & & \\
\hline Sphaeriidae & - & & - & & - & & - & & - & & - & & 1 & $<1$ \\
\hline Pisidium & - & & - & & - & & - & & - & & - & & - & \\
\hline Annelida (segmented worms) & & & & & & & & & & & & & & \\
\hline Oligochaeta & & & & & & & & & & & & & & \\
\hline Tubificida & & & & & & & & & & & & & & \\
\hline Naididae & - & & 1 & $<1$ & - & & - & & 2 & $<1$ & - & & 3 & $<1$ \\
\hline Arthropoda (arthropods) & & & & & & & & & & & & & & \\
\hline Acariformes & & & & & & & & & & & & & & \\
\hline Hydrachnidia & - & & - & & 1 & $<1$ & 2 & $<1$ & 4 & $<1$ & 2 & $<1$ & 25 & 2 \\
\hline Crustacea & & & & & & & & & & & & & & \\
\hline Decapoda & & & & & & & & & & & & & & \\
\hline Cambaridae & & & & & & & & & & & & & & \\
\hline Cambarus & - & & - & & 1 & $<1$ & - & & - & & - & & - & \\
\hline Podocopa & - & & - & & - & & - & & - & & - & & - & \\
\hline Insecta & & & & & & & & & & & & & & \\
\hline Ephemeroptera & & & & & & & & & & & & & & \\
\hline Baetidae & & & & & & & & & & & & & & \\
\hline Baetis & - & & 1 & $<1$ & 1 & $<1$ & 3 & $<1$ & 14 & $<1$ & 1 & $<1$ & 2 & $<1$ \\
\hline Pseudocloeon & - & & 2 & $<1$ & - & & 3 & $<1$ & 9 & $<1$ & - & & 11 & $<1$ \\
\hline Caenidae & & & & & & & & & & & & & & \\
\hline Caenis & - & & - & & - & & - & & - & & - & & 1 & $<1$ \\
\hline Ephemerellidae & & & & & & & & & & & & & & \\
\hline Ephemerella & 15 & 3 & 28 & 3 & 28 & 2 & 24 & 2 & 51 & 3 & 25 & 4 & 81 & 6 \\
\hline Heptageniidae & & & & & & & & & & & & & & \\
\hline Epeorus & 3 & $<1$ & 14 & 1 & 9 & $<1$ & 27 & 2 & - & & - & & - & \\
\hline Stenacron & - & & - & & - & & - & & - & & 1 & $<1$ & - & \\
\hline Stenonema & 80 & 14 & 110 & 10 & 50 & 4 & 62 & 6 & 63 & 4 & 54 & 8 & 92 & 7 \\
\hline Isonychiidae & & & & & & & & & & & & & & \\
\hline Isonychia & 44 & 8 & 87 & 8 & 27 & 2 & 26 & 2 & 92 & 5 & 64 & 10 & 86 & 7 \\
\hline Leptohyphidae & & & & & & & & & & & & & & \\
\hline Tricorythodes & - & & - & & - & & - & & - & & - & & 4 & $<1$ \\
\hline Leptophlebiidae & - & & - & & - & & - & & - & & - & & - & \\
\hline
\end{tabular}




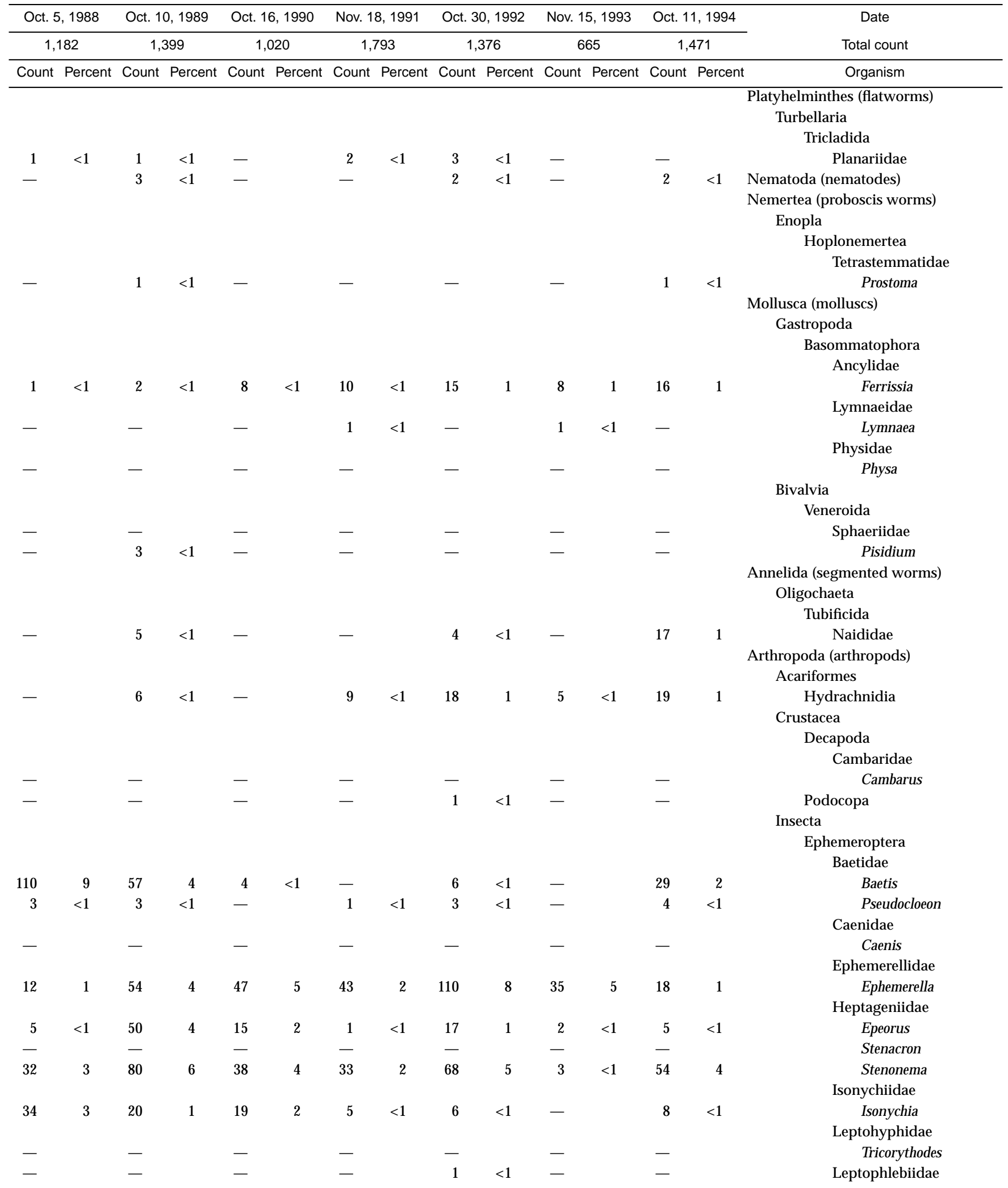


Table 5. Benthic-macroinvertebrate data-Continued

01480434 - West Branch Brandywine Creek at Rock Run, Pa. (Site 37)—Continued

\begin{tabular}{|c|c|c|c|c|c|c|c|c|c|c|c|c|c|c|}
\hline \multirow{3}{*}{$\begin{array}{c}\text { Date } \\
\text { Total count } \\
\text { Organism }\end{array}$} & \multirow{2}{*}{\multicolumn{2}{|c|}{$\begin{array}{c}\text { Nov. 2, } 1981 \\
551\end{array}$}} & \multicolumn{2}{|c|}{ Oct. 27, 1982} & \multicolumn{2}{|c|}{ Nov. 4, 1983} & \multicolumn{2}{|c|}{ Oct. 30,1984} & \multicolumn{2}{|c|}{ Oct. 21,1985} & \multicolumn{2}{|c|}{ Nov. 17,1986} & \multicolumn{2}{|c|}{ Oct. 22, 1987} \\
\hline & & & & 086 & 1,2 & 241 & 1, & 052 & & 711 & & 46 & & 278 \\
\hline & Count & Percent & Count & Percent & Count & Percent & Count & Percent & Count & Percent & Count & Percent & Count & Percent \\
\hline \multicolumn{15}{|l|}{ Odonata } \\
\hline \multicolumn{15}{|l|}{ Coenagrionidae } \\
\hline Argia & - & & - & & 2 & $<1$ & - & & - & & 1 & $<1$ & - & \\
\hline \multicolumn{15}{|l|}{ Plecoptera } \\
\hline \multicolumn{15}{|l|}{ Capniidae } \\
\hline Allocapnia & 2 & $<1$ & - & & - & & 1 & $<1$ & 4 & $<1$ & - & & 7 & $<1$ \\
\hline Chloroperlidae & 3 & $<1$ & 2 & $<1$ & 1 & $<1$ & - & & - & & - & & 10 & $<1$ \\
\hline Nemouridae & 2 & $<1$ & - & & - & & - & & - & & - & & - & \\
\hline \multicolumn{15}{|l|}{ Perlidae } \\
\hline Acroneuria & - & & 4 & $<1$ & 2 & $<1$ & 3 & $<1$ & 3 & $<1$ & - & & 3 & $<1$ \\
\hline Agnetina & - & & - & & - & & 1 & $<1$ & - & & - & & - & \\
\hline Paragnetina & - & & 3 & $<1$ & 1 & $<1$ & - & & 2 & $<1$ & 1 & $<1$ & 2 & $<1$ \\
\hline Taeniopterygidae & & & & & & & & & & & & & & \\
\hline Strophopteryx & 2 & $<1$ & - & & 2 & $<1$ & - & & - & & - & & - & \\
\hline Taeniopteryx & 45 & 8 & 45 & 4 & 10 & $<1$ & 3 & $<1$ & 45 & 3 & 4 & $<1$ & 21 & 2 \\
\hline Hemiptera & & & & & & & & & & & & & & \\
\hline Veliidae & & & & & & & & & & & & & & \\
\hline Microvelia & - & & - & & - & & - & & - & & 1 & $<1$ & - & \\
\hline Rhagovelia & - & & - & & - & & 1 & $<1$ & - & & - & & - & \\
\hline Megaloptera & & & & & & & & & & & & & & \\
\hline Corydalidae & & & & & & & & & & & & & & \\
\hline Corydalus & 2 & $<1$ & 2 & $<1$ & 2 & $<1$ & 5 & $<1$ & 1 & $<1$ & - & & 3 & $<1$ \\
\hline Trichoptera & & & & & & & & & & & & & & \\
\hline Apataniidae & & & & & & & & & & & & & & \\
\hline Apatania & - & & - & & - & & - & & - & & - & & 2 & $<1$ \\
\hline Brachycentridae & & & & & & & & & & & & & & \\
\hline Micrasema & 1 & $<1$ & 1 & $<1$ & - & & 1 & $<1$ & 1 & $<1$ & 10 & 2 & - & \\
\hline Glossosomatidae & & & & & & & & & & & & & & \\
\hline Glossosoma & 1 & $<1$ & 1 & $<1$ & 4 & $<1$ & 3 & $<1$ & 2 & $<1$ & 13 & 2 & 2 & $<1$ \\
\hline Protoptila & - & & - & & - & & - & & - & & - & & - & \\
\hline Helicopsychidae & & & & & & & & & & & & & & \\
\hline Helicopsyche & - & & - & & - & & - & & - & & - & & - & \\
\hline Hydropsychidae & & & & & & & & & & & & & & \\
\hline Ceratopsyche & 25 & 4 & 56 & 5 & 120 & 10 & 100 & 9 & 250 & 15 & 99 & 15 & 49 & 4 \\
\hline Cheumatopsyche & 100 & 18 & 64 & 6 & 32 & 3 & 90 & 8 & 87 & 5 & 14 & 2 & 12 & $<1$ \\
\hline Hydropsyche & 2 & $<1$ & 7 & $<1$ & 18 & 2 & 12 & 1 & 31 & 2 & 60 & 9 & 29 & 2 \\
\hline Macrostemum & - & & - & & - & & - & & - & & - & & - & \\
\hline Hydroptilidae & & & & & & & & & & & & & & \\
\hline Hydroptila & 5 & $<1$ & 3 & $<1$ & 1 & $<1$ & 1 & $<1$ & - & & 2 & $<1$ & 2 & $<1$ \\
\hline Leucotrichia & 2 & $<1$ & 240 & 22 & 750 & 63 & 420 & 38 & 410 & 24 & 100 & 15 & 240 & 18 \\
\hline Leptoceridae & & & & & & & & & & & & & & \\
\hline Oecetis & - & & - & & - & & - & & - & & - & & - & \\
\hline Philopotamidae & & & & & & & & & & & & & & \\
\hline Chimarra & 19 & 3 & 6 & $<1$ & 18 & 2 & 28 & 3 & 9 & $<1$ & 21 & 3 & 10 & $<1$ \\
\hline Polycentropodidae & & & & & & & & & & & & & & \\
\hline Neureclipsis & - & & - & & 1 & $<1$ & 1 & $<1$ & - & & 1 & $<1$ & - & \\
\hline Nyctiophylax & 1 & $<1$ & 2 & $<1$ & 3 & $<1$ & - & & 1 & $<1$ & 1 & $<1$ & - & \\
\hline Polycentropus & - & & 1 & $<1$ & - & & - & & 1 & $<1$ & - & & - & \\
\hline Psychomyiidae & & & & & & & & & & & & & & \\
\hline Psychomyia & 20 & 4 & 4 & $<1$ & - & & 13 & 1 & 14 & $<1$ & 1 & $<1$ & 7 & $<1$ \\
\hline Uenoidae & & & & & & & & & & & & & & \\
\hline Neophylax & - & & - & & - & & - & & - & & 1 & $<1$ & - & \\
\hline Lepidoptera & & & & & & & & & & & & & & \\
\hline Noctuidae & - & & - & & - & & - & & - & & - & & 1 & $<1$ \\
\hline Archanara & - & & - & & - & & - & & - & & - & & - & \\
\hline
\end{tabular}




\begin{tabular}{|c|c|c|c|c|c|c|c|c|c|c|c|c|c|c|}
\hline \multirow{2}{*}{\multicolumn{2}{|c|}{$\begin{array}{c}\text { Oct. } 5,1988 \\
1,182\end{array}$}} & \multicolumn{2}{|c|}{ Oct. 10,1989} & \multicolumn{2}{|c|}{ Oct. 16,1990} & \multicolumn{2}{|c|}{ Nov. 18,1991} & \multicolumn{2}{|c|}{ Oct. 30,1992} & \multicolumn{2}{|c|}{ Nov. 15,1993} & \multicolumn{2}{|c|}{ Oct. 11,1994} & \multirow{3}{*}{$\begin{array}{c}\text { Date } \\
\text { Total count }\end{array}$} \\
\hline & & \multicolumn{2}{|c|}{1,399} & \multicolumn{2}{|c|}{1,020} & \multicolumn{2}{|c|}{1,793} & \multicolumn{2}{|c|}{1,376} & \multicolumn{2}{|c|}{665} & 1,4 & 471 & \\
\hline Count & Percent & Count & Percent & Count & Percent & Count & Percent & Count & Percent & Count & Percent & Count & Percent & \\
\hline & & & & & & & & & & & & & & Odonata \\
\hline & & & & & & & & & & & & & & Coenagrionidae \\
\hline- & & - & & - & & - & & - & & 1 & $<1$ & - & & Argia \\
\hline & & & & & & & & & & & & & & Plecoptera \\
\hline & & & & & & & & & & & & & & Capniidae \\
\hline 1 & $<1$ & 1 & $<1$ & - & & 2 & $<1$ & - & & 7 & 1 & - & & Allocapnia \\
\hline - & & - & & 2 & $<1$ & 6 & $<1$ & 15 & 1 & 3 & $<1$ & 2 & $<1$ & Chloroperlidae \\
\hline - & & - & & - & & - & & - & & - & & - & & Nemouridae \\
\hline & & & & & & & & & & & & & & Perlidae \\
\hline 2 & $<1$ & 5 & $<1$ & 3 & $<1$ & - & & 5 & $<1$ & - & & - & & Acroneuria \\
\hline - & & - & & 1 & $<1$ & 4 & $<1$ & 5 & $<1$ & - & & 2 & $<1$ & Agnetina \\
\hline 3 & $<1$ & - & & - & & 2 & $<1$ & - & & - & & - & & Paragnetina \\
\hline & & & & & & & & & & & & & & Taeniopterygidae \\
\hline - & & - & & - & & - & & - & & 18 & 3 & - & & Strophopteryx \\
\hline 27 & 2 & 4 & $<1$ & 3 & $<1$ & 10 & $<1$ & 2 & $<1$ & 1 & $<1$ & 5 & $<1$ & Taeniopteryx \\
\hline & & & & & & & & & & & & & & Hemiptera \\
\hline & & & & & & & & & & & & & & Veliidae \\
\hline - & & - & & - & & - & & - & & - & & - & & Microvelia \\
\hline 3 & $<1$ & - & & - & & - & & - & & - & & - & & Rhagovelia \\
\hline & & & & & & & & & & & & & & Megaloptera \\
\hline & & & & & & & & & & & & & & Corydalidae \\
\hline 2 & $<1$ & 1 & $<1$ & - & & - & & - & & 1 & $<1$ & - & & Corydalus \\
\hline & & & & & & & & & & & & & & Trichoptera \\
\hline & & & & & & & & & & & & & & Apataniidae \\
\hline - & & - & & 5 & $<1$ & 17 & $<1$ & 30 & 2 & 11 & 2 & 3 & $<1$ & Apatania \\
\hline & & & & & & & & & & & & & & Brachycentridae \\
\hline - & & 5 & $<1$ & 13 & 1 & 22 & 1 & 26 & 2 & 20 & 3 & 34 & 2 & Micrasema \\
\hline & & & & & & & & & & & & & & Glossosomatidae \\
\hline - & & 6 & $<1$ & 1 & $<1$ & - & & 9 & $<1$ & 2 & $<1$ & 1 & $<1$ & Glossosoma \\
\hline - & & 1 & $<1$ & - & & 2 & $<1$ & - & & 1 & $<1$ & - & & Protoptila \\
\hline & & & & & & & & & & & & & & Helicopsychidae \\
\hline - & & - & & - & & - & & 2 & $<1$ & 1 & $<1$ & - & & Helicopsyche \\
\hline & & & & & & & & & & & & & & Hydropsychidae \\
\hline 96 & 8 & 170 & 12 & 120 & 12 & 180 & 10 & 75 & 5 & 66 & 10 & 49 & 3 & Ceratopsyche \\
\hline 26 & 2 & 36 & 3 & 34 & 3 & 110 & 6 & 51 & 4 & 24 & 4 & 33 & 2 & Cheumatopsyche \\
\hline 17 & 1 & 31 & 2 & 4 & $<1$ & 110 & 6 & 70 & 5 & 13 & 2 & 120 & 8 & Hydropsyche \\
\hline - & & 1 & $<1$ & - & & 1 & $<1$ & - & & - & & - & & Macrostemum \\
\hline & & & & & & & & & & & & & & Hydroptilidae \\
\hline - & & - & & 3 & $<1$ & 2 & $<1$ & - & & - & & - & & Hydroptila \\
\hline 610 & 51 & 260 & 19 & 410 & 41 & 50 & 3 & 260 & 19 & 130 & 19 & 390 & 26 & Leucotrichia \\
\hline & & & & & & & & & & & & & & Leptoceridae \\
\hline- & & - & & - & & 1 & $<1$ & - & & - & & - & & Oecetis \\
\hline & & & & & & & & & & & & & & Philopotamidae \\
\hline 25 & 2 & 30 & 2 & 14 & 1 & 13 & $<1$ & 24 & 2 & 6 & $<1$ & 2 & $<1$ & Chimarra \\
\hline & & & & & & & & & & & & & & Polycentropodidae \\
\hline - & & - & & 1 & $<1$ & - & & - & & - & & - & & Neureclipsis \\
\hline - & & - & & - & & 1 & $<1$ & - & & - & & - & & Nyctiophylax \\
\hline- & & - & & 1 & $<1$ & - & & 1 & $<1$ & - & & - & & Polycentropus \\
\hline & & & & & & & & & & & & & & Psychomyiidae \\
\hline 2 & $<1$ & 4 & $<1$ & 11 & 1 & 3 & $<1$ & 4 & $<1$ & 6 & $<1$ & 20 & 1 & Psychomyia \\
\hline & & & & & & & & & & & & & & Uenoidae \\
\hline - & & - & & - & & - & & - & & - & & - & & Neophylax \\
\hline & & & & & & & & & & & & & & Lepidoptera \\
\hline- & & - & & - & & - & & - & & - & & - & & Noctuidae \\
\hline- & & 2 & $<1$ & - & & - & & - & & - & & - & & Archanara \\
\hline
\end{tabular}


Table 5. Benthic-macroinvertebrate data-Continued

01480434 - West Branch Brandywine Creek at Rock Run, Pa. (Site 37)—Continued

\begin{tabular}{|c|c|c|c|c|c|c|c|c|c|c|c|c|c|c|}
\hline \multirow{3}{*}{$\begin{array}{c}\text { Date } \\
\text { Total count } \\
\text { Organism }\end{array}$} & \multirow{2}{*}{\multicolumn{2}{|c|}{$\begin{array}{c}\text { Nov. } 2,1981 \\
551\end{array}$}} & \multirow{2}{*}{\multicolumn{2}{|c|}{$\frac{\text { Oct. } 27,1982}{1,086}$}} & \multirow{2}{*}{\multicolumn{2}{|c|}{$\begin{array}{c}\text { Nov. } 4,1983 \\
1,241 \\
\end{array}$}} & \multirow{2}{*}{\multicolumn{2}{|c|}{$\begin{array}{c}\text { Oct. } 30,1984 \\
1,052 \\
\end{array}$}} & \multirow{2}{*}{\multicolumn{2}{|c|}{$\begin{array}{c}\text { Oct. } 21,1985 \\
1,711 \\
\end{array}$}} & \multirow{2}{*}{\multicolumn{2}{|c|}{$\begin{array}{c}\text { Nov. } 17,1986 \\
646\end{array}$}} & \multirow{2}{*}{\multicolumn{2}{|c|}{$\begin{array}{c}\text { Oct. } 22,1987 \\
1,278\end{array}$}} \\
\hline & & & & & & & & & & & & & & \\
\hline & Count & Percent & Count & Percent & Count & Percent & Count & Percent & Count & Percent & Count & Percent & Count & Percent \\
\hline \multicolumn{15}{|l|}{ Coleoptera } \\
\hline \multicolumn{15}{|l|}{ Elmidae } \\
\hline Microcylloepus & - & & - & & - & & - & & - & & - & & - & \\
\hline Optioservus & 6 & 1 & 2 & $<1$ & 21 & 2 & 11 & 1 & 7 & $<1$ & 10 & 2 & 19 & 1 \\
\hline Oulimnius & - & & - & & - & & - & & - & & - & & - & \\
\hline Promoresia & 1 & $<1$ & - & & - & & - & & 2 & $<1$ & 7 & 1 & 2 & $<1$ \\
\hline Stenelmis & 1 & $<1$ & 4 & $<1$ & 1 & $<1$ & - & & 4 & $<1$ & 11 & 2 & 4 & $<1$ \\
\hline \multicolumn{15}{|l|}{ Psephenidae } \\
\hline Psephenus & 1 & $<1$ & - & & 11 & $<1$ & - & & - & & 1 & $<1$ & 2 & $<1$ \\
\hline \multicolumn{15}{|l|}{ Diptera } \\
\hline Ceratopogonidae & - & & - & & - & & - & & - & & - & & - & \\
\hline Chironomidae & 120 & 21 & 280 & 25 & 82 & 7 & 180 & 16 & 500 & 29 & 96 & 15 & 530 & 41 \\
\hline \multicolumn{15}{|l|}{ Empididae } \\
\hline Chelifera & - & & - & & - & & - & & - & & - & & - & \\
\hline Hemerodromia & 1 & $<1$ & 5 & $<1$ & 2 & $<1$ & 2 & $<1$ & 1 & $<1$ & 2 & $<1$ & 2 & $<1$ \\
\hline \multicolumn{15}{|l|}{ Simuliidae } \\
\hline Simulium & 4 & $<1$ & 2 & $<1$ & 2 & $<1$ & 9 & $<1$ & 55 & 3 & 8 & 1 & 5 & $<1$ \\
\hline \multicolumn{15}{|l|}{ Tipulidae } \\
\hline Antocha & 35 & 6 & 64 & 6 & 10 & $<1$ & 15 & 1 & 35 & 2 & 16 & 2 & 4 & $<1$ \\
\hline
\end{tabular}




\begin{tabular}{|c|c|c|c|c|c|c|c|c|c|c|c|c|c|c|}
\hline \multicolumn{2}{|c|}{ Oct. 5, 1988} & \multicolumn{2}{|c|}{ Oct. 10, 1989} & \multicolumn{2}{|c|}{ Oct. 16, 1990} & \multicolumn{2}{|c|}{ Nov. 18, 1991} & \multicolumn{2}{|c|}{ Oct. 30, 1992} & \multicolumn{2}{|c|}{ Nov. 15, 1993} & \multicolumn{2}{|c|}{ Oct. 11, 1994} & Date \\
\hline \multicolumn{2}{|c|}{1,182} & \multicolumn{2}{|c|}{1,399} & \multicolumn{2}{|c|}{1,020} & \multicolumn{2}{|c|}{1,793} & \multicolumn{2}{|c|}{1,376} & \multicolumn{2}{|c|}{665} & \multicolumn{2}{|c|}{1,471} & Total count \\
\hline Count & Percent & Count & Percent & Count & Percent & Count & Percent & Count & Percent & Count & Percent & Count & Percent & Organism \\
\hline & & & & & & & & & & & & & & eoptera \\
\hline & & & & & & & & & & & & & & Elmidae \\
\hline 4 & $<1$ & - & & - & & 3 & $<1$ & - & & - & & 1 & $<1$ & Microcylloepus \\
\hline 12 & 1 & 9 & $<1$ & 7 & $<1$ & 8 & $<1$ & 30 & 2 & 12 & 2 & 26 & 2 & Optioservus \\
\hline - & & 5 & $<1$ & - & & 1 & $<1$ & 1 & $<1$ & 2 & $<1$ & - & & Oulimnius \\
\hline - & & - & & - & & 25 & 1 & 17 & 1 & 1 & $<1$ & 3 & $<1$ & Promoresia \\
\hline 5 & $<1$ & 2 & $<1$ & 13 & 1 & 40 & 2 & 8 & $<1$ & - & & 9 & $<1$ & Stenelmis \\
\hline & & & & & & & & & & & & & & Psephenidae \\
\hline 14 & 1 & 23 & 2 & 3 & $<1$ & 2 & $<1$ & 7 & $<1$ & 16 & 2 & 18 & 1 & Psephenus \\
\hline & & & & & & & & & & & & & & tera \\
\hline - & & - & & - & & - & & 1 & $<1$ & - & & - & & Ceratopogonidae \\
\hline 110 & 9 & 470 & 34 & 180 & 18 & 1,000 & 56 & 390 & 28 & 210 & 31 & 490 & 33 & Chironomidae \\
\hline & & & & & & & & & & & & & & Empididae \\
\hline - & & - & & 一 & & 1 & $<1$ & - & & - & & - & & Chelifera \\
\hline 2 & $<1$ & 12 & $<1$ & 1 & $<1$ & 3 & $<1$ & 9 & $<1$ & 4 & $<1$ & 6 & $<1$ & Hemerodromia \\
\hline & & & & & & & & & & & & & & Simuliidae \\
\hline 13 & 1 & 11 & $<1$ & 1 & $<1$ & 4 & $<1$ & 16 & 1 & 2 & $<1$ & 5 & $<1$ & Simulium \\
\hline & & & & & & & & & & & & & & Tipulidae \\
\hline 10 & $<1$ & 25 & 2 & 58 & 6 & 65 & 4 & 64 & 5 & 53 & 8 & 79 & 5 & Antocha \\
\hline
\end{tabular}


Table 5. Benthic-macroinvertebrate data-Continued

$[<$, less than; - , not found]

01480629 - Buck Run at Doe Run, Pa. (Site 46)

\begin{tabular}{|c|c|c|c|c|c|c|c|c|c|c|c|c|c|c|}
\hline \multirow{3}{*}{$\begin{array}{cc}\text { Date } \\
\text { Total count }\end{array}$} & \multirow{2}{*}{\multicolumn{2}{|c|}{$\begin{array}{c}\text { Nov. } 5,1981 \\
1,026\end{array}$}} & \multirow{2}{*}{\multicolumn{2}{|c|}{$\frac{\text { Oct. } 28,1982}{{ }^{1} 1,647}$}} & \multirow{2}{*}{\multicolumn{2}{|c|}{$\begin{array}{c}\text { Oct. } 28,1983 \\
{ }^{1} 1,846\end{array}$}} & \multirow{2}{*}{\multicolumn{2}{|c|}{$\frac{\text { Oct. } 31,1984}{{ }^{1} 2,272}$}} & \multirow{2}{*}{\multicolumn{2}{|c|}{$\frac{\text { Oct. } 29,1985}{1,091}$}} & \multirow{2}{*}{\multicolumn{2}{|c|}{$\frac{\text { Oct. } 30,1986}{1,769}$}} & \multirow{2}{*}{\multicolumn{2}{|c|}{$\begin{array}{c}\text { Nov. } 19,1987 \\
1,644\end{array}$}} \\
\hline & & & & & & & & & & & & & & \\
\hline & Count & Percent & Count & Percent & Count & Percent & Count & Percent & Count & Percent & Count & Percent & Count & Percent \\
\hline \multicolumn{15}{|l|}{ Platyhelminthes (flatworms) } \\
\hline \multicolumn{15}{|l|}{ Turbellaria } \\
\hline \multicolumn{15}{|l|}{ Tricladida } \\
\hline Planariidae & 23 & 2 & 11 & $<1$ & 24 & 1 & 13 & $<1$ & 91 & 8 & 8 & $<1$ & 88 & 5 \\
\hline Nematoda (nematodes) & - & & - & & - & & - & & - & & - & & 5 & $<1$ \\
\hline \multicolumn{15}{|l|}{ Nemertea (proboscis worms) } \\
\hline \multicolumn{15}{|l|}{ Enopla } \\
\hline \multicolumn{15}{|l|}{ Hoplonemertea } \\
\hline Tetrastemmatida & & & & & & & & & & & & & & \\
\hline Prostoma & 1 & $<1$ & - & & - & & 3 & $<1$ & 8 & $<1$ & - & & - & \\
\hline Mollusca (molluscs) & & & & & & & & & & & & & & \\
\hline Gastropoda & & & & & & & & & & & & & & \\
\hline Basommatophora & & & & & & & & & & & & & & \\
\hline Ancylidae & & & & & & & & & & & & & & \\
\hline Ferrissia & 13 & 1 & 53 & 3 & 29 & 2 & 19 & $<1$ & 89 & 8 & 51 & 3 & 5 & $<1$ \\
\hline Lymnaeidae & & & & & & & & & & & & & & \\
\hline Lymnaea & - & & - & & - & & - & & - & & - & & - & \\
\hline Physidae & & & & & & & & & & & & & & \\
\hline Physa & - & & - & & - & & - & & - & & - & & - & \\
\hline Planorbidae & & & & & & & & & & & & & & \\
\hline Gyraulus & - & & - & & - & & - & & - & & - & & - & \\
\hline Helisoma & - & & - & & - & & - & & - & & 8 & $<1$ & 1 & $<1$ \\
\hline Bivalvia & & & & & & & & & & & & & & \\
\hline Veneroida & & & & & & & & & & & & & & \\
\hline Sphaeriidae & - & & - & & - & & - & & - & & 7 & $<1$ & 2 & $<1$ \\
\hline Pisidium & - & & 5 & $<1$ & 3 & $<1$ & - & & - & & - & & - & \\
\hline Sphaerium & - & & - & & - & & 3 & $<1$ & - & & - & & - & \\
\hline Annelida (segmented worms) & & & & & & & & & & & & & & \\
\hline Oligochaeta & & & & & & & & & & & & & & \\
\hline Lumbriculida & & & & & & & & & & & & & & \\
\hline Lumbriculidae & - & & - & & - & & - & & - & & - & & - & \\
\hline Tubificida & & & & & & & & & & & & & & \\
\hline Naididae & 21 & 2 & - & & 16 & $<1$ & - & & - & & - & & 2 & $<1$ \\
\hline Tubificidae & - & & - & & - & & - & & - & & - & & 1 & $<1$ \\
\hline Arthropoda (arthropods) & & & & & & & & & & & & & & \\
\hline Acariformes & & & & & & & & & & & & & & \\
\hline Hydrachnidia & - & & - & & - & & 3 & $<1$ & 2 & $<1$ & - & & 8 & $<1$ \\
\hline Crustacea & & & & & & & & & & & & & & \\
\hline Cyclopoida & - & & - & & - & & - & & - & & - & & - & \\
\hline Isopoda & & & & & & & & & & & & & & \\
\hline Asellidae & & & & & & & & & & & & & & \\
\hline Caecidotea & 1 & $<1$ & 8 & $<1$ & - & & - & & 2 & $<1$ & - & & - & \\
\hline Podocopa & - & & - & & - & & - & & - & & - & & - & \\
\hline Insecta & & & & & & & & & & & & & & \\
\hline Ephemeroptera & & & & & & & & & & & & & & \\
\hline Baetidae & & & & & & & & & & & & & & \\
\hline Baetis & - & & 3 & $<1$ & - & & - & & - & & - & & - & \\
\hline Pseudocloeon & 2 & $<1$ & - & & - & & 13 & $<1$ & 44 & 4 & 5 & $<1$ & - & \\
\hline Ephemerellidae & & & & & & & & & & & & & & \\
\hline Ephemerella & 7 & $<1$ & - & & 43 & 2 & 37 & 2 & 46 & 4 & 21 & 1 & 39 & 2 \\
\hline Heptageniidae & & & & & & & & & & & & & & \\
\hline Epeorus & - & & - & & - & & - & & - & & - & & - & \\
\hline Stenonema & 180 & 18 & 130 & 8 & 88 & 5 & 59 & 3 & 41 & 4 & 19 & 1 & 32 & 2 \\
\hline
\end{tabular}




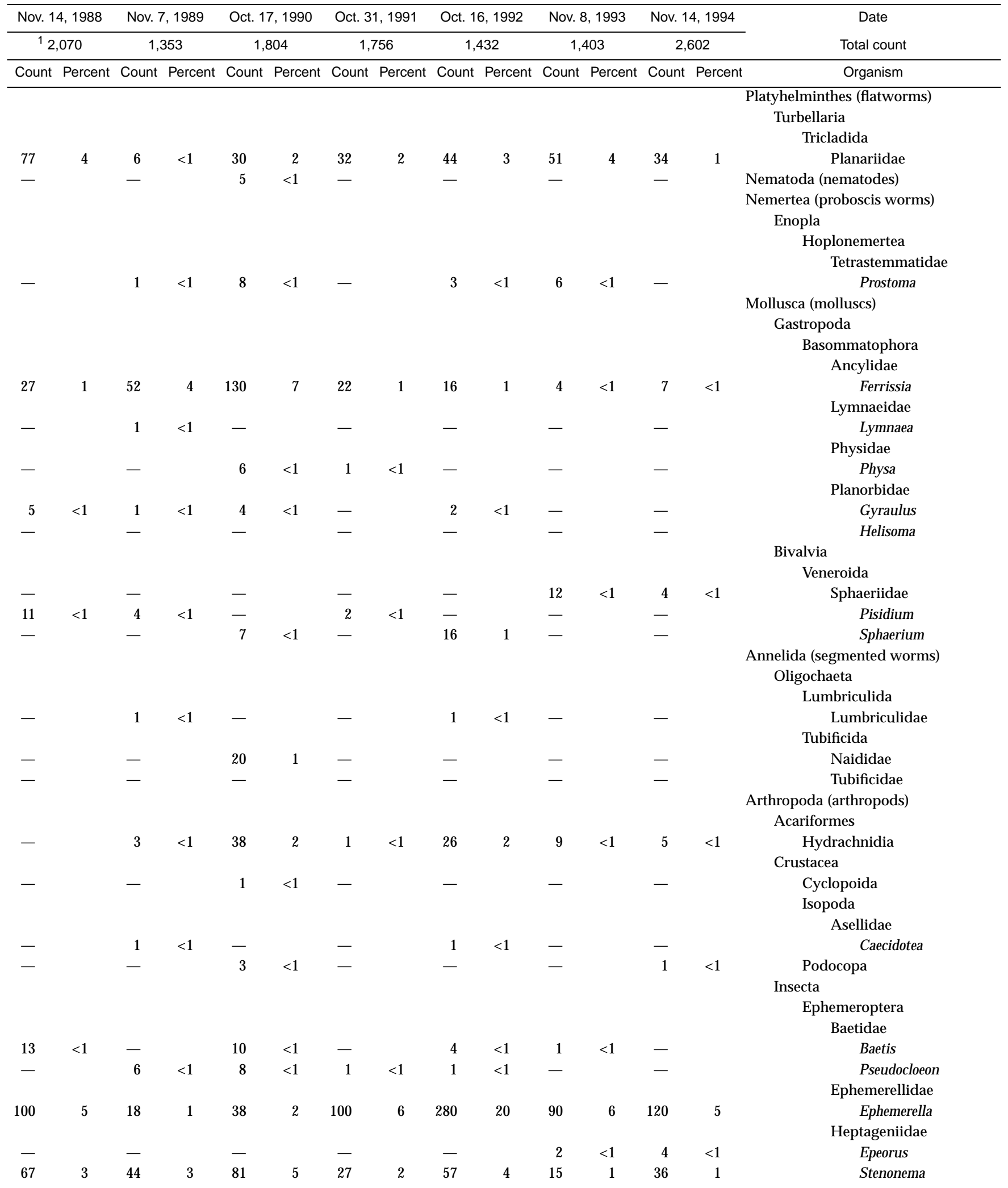


Table 5. Benthic-macroinvertebrate data-Continued

01480629 - Buck Run at Doe Run, Pa. (Site 46)—Continued

\begin{tabular}{|c|c|c|c|c|c|c|c|c|c|c|c|c|c|c|}
\hline \multirow{3}{*}{$\begin{array}{c}\text { Date } \\
\text { Total count } \\
\text { Organism }\end{array}$} & \multirow{2}{*}{\multicolumn{2}{|c|}{$\begin{array}{c}\text { Nov. } 5,1981 \\
1,026\end{array}$}} & \multirow{2}{*}{\multicolumn{2}{|c|}{$\begin{array}{c}\text { Oct. } 28,1982 \\
{ }^{1} 1,647\end{array}$}} & \multirow{2}{*}{\multicolumn{2}{|c|}{$\begin{array}{c}\text { Oct. } 28,1983 \\
{ }^{1} 1,846\end{array}$}} & \multirow{2}{*}{\multicolumn{2}{|c|}{$\begin{array}{c}\text { Oct. 31, } 1984 \\
{ }^{1} 2,272\end{array}$}} & \multirow{2}{*}{\multicolumn{2}{|c|}{$\begin{array}{c}\text { Oct. } 29,1985 \\
1,091\end{array}$}} & \multirow{2}{*}{\multicolumn{2}{|c|}{$\begin{array}{c}\text { Oct. } 30,1986 \\
1,769\end{array}$}} & \multirow{2}{*}{\multicolumn{2}{|c|}{$\begin{array}{c}\text { Nov. } 19,1987 \\
1,644\end{array}$}} \\
\hline & & & & & & & & & & & & & & \\
\hline & Count & Percent & Count & Percent & Count & Percent & Count & Percent & Count & Percent & Count & Percent & Count & Percent \\
\hline \multicolumn{15}{|l|}{ Ephemeroptera } \\
\hline \multicolumn{15}{|l|}{ Isonychiidae } \\
\hline Isonychia & 7 & $<1$ & 80 & 5 & 69 & 4 & 110 & 5 & 68 & 6 & 170 & 9 & 16 & $<1$ \\
\hline \multicolumn{15}{|l|}{ Leptohyphidae } \\
\hline Tricorythodes & - & & - & & - & & - & & - & & - & & - & \\
\hline \multicolumn{15}{|l|}{ Odonata } \\
\hline \multicolumn{15}{|l|}{ Coenagrionidae } \\
\hline Argia & - & & - & & 3 & $<1$ & - & & - & & 1 & $<1$ & 1 & $<1$ \\
\hline Aeshnidae & & & & & & & & & & & & & & \\
\hline Boyeria & - & & - & & - & & - & & 1 & $<1$ & - & & - & \\
\hline Gomphidae & - & & - & & - & & - & & - & & - & & - & \\
\hline Plecoptera & & & & & & & & & & & & & & \\
\hline Capniidae & & & & & & & & & & & & & & \\
\hline Allocapnia & - & & - & & - & & - & & - & & - & & 1 & $<1$ \\
\hline Chloroperlidae & - & & - & & - & & - & & - & & 1 & $<1$ & - & \\
\hline Perlidae & - & & - & & - & & - & & - & & - & & - & \\
\hline Taeniopterygidae & & & & & & & & & & & & & & \\
\hline Taeniopteryx & - & & - & & - & & - & & 1 & $<1$ & 4 & $<1$ & 6 & $<1$ \\
\hline Hemiptera & & & & & & & & & & & & & & \\
\hline Veliidae & & & & & & & & & & & & & & \\
\hline Rhagovelia & 1 & $<1$ & - & & - & & - & & - & & - & & - & \\
\hline Megaloptera & & & & & & & & & & & & & & \\
\hline Corydalidae & & & & & & & & & & & & & & \\
\hline Corydalus & - & & - & & - & & - & & - & & - & & - & \\
\hline Trichoptera & & & & & & & & & & & & & & \\
\hline Apataniidae & & & & & & & & & & & & & & \\
\hline Apatania & - & & - & & - & & - & & - & & - & & 1 & $<1$ \\
\hline Brachycentridae & & & & & & & & & & & & & & \\
\hline Micrasema & - & & - & & - & & - & & - & & - & & - & \\
\hline Glossosomatidae & & & & & & & & & & & & & & \\
\hline Glossosoma & - & & - & & - & & 11 & $<1$ & - & & 1 & $<1$ & - & \\
\hline Protoptila & - & & - & & - & & - & & - & & - & & - & \\
\hline Hydropsychidae & & & & & & & & & & & & & & \\
\hline Ceratopsyche & 120 & 12 & 110 & 6 & 110 & 6 & 310 & 13 & 190 & 17 & 220 & 12 & 76 & 4 \\
\hline Cheumatopsyche & 21 & 2 & 3 & $<1$ & 5 & $<1$ & 3 & $<1$ & 12 & 1 & 8 & $<1$ & 6 & $<1$ \\
\hline Hydropsyche & - & & - & & 8 & $<1$ & 8 & $<1$ & 18 & 2 & 91 & 5 & 110 & 6 \\
\hline Hydroptilidae & & & & & & & & & & & & & & \\
\hline Hydroptila & 5 & $<1$ & - & & 3 & $<1$ & - & & - & & 1 & $<1$ & 2 & $<1$ \\
\hline Leucotrichia & 400 & 40 & 900 & 53 & 1,300 & 72 & 980 & 43 & 87 & 8 & 870 & 48 & 710 & 42 \\
\hline Leptoceridae & & & & & & & & & & & & & & \\
\hline Mystacides & - & & - & & - & & - & & - & & - & & - & \\
\hline Oecetis & - & & - & & - & & - & & - & & - & & - & \\
\hline Philopotamidae & & & & & & & & & & & & & & \\
\hline Chimarra & - & & - & & 3 & $<1$ & 13 & $<1$ & 1 & $<1$ & 5 & $<1$ & - & \\
\hline Dolophilodes & - & & - & & - & & - & & - & & 1 & $<1$ & - & \\
\hline Polycentropodidae & & & & & & & & & & & & & & \\
\hline Neureclipsis & - & & - & & - & & - & & - & & - & & - & \\
\hline Polycentropus & - & & - & & - & & - & & - & & - & & - & \\
\hline Psychomyiidae & & & & & & & & & & & & & & \\
\hline Psychomyia & - & & - & & - & & - & & - & & - & & - & \\
\hline Uenoidae & & & & & & & & & & & & & & \\
\hline Neophylax & - & & - & & - & & - & & - & & - & & - & \\
\hline Lepidoptera & & & & & & & & & & & & & & \\
\hline Noctuidae & - & & - & & - & & - & & - & & - & & - & \\
\hline Archanara & - & & - & & - & & - & & - & & - & & - & \\
\hline
\end{tabular}




\begin{tabular}{|c|c|c|c|c|c|c|c|c|c|c|c|c|c|c|}
\hline \multirow{2}{*}{\multicolumn{2}{|c|}{$\begin{array}{c}\text { Nov. } 14,1988 \\
{ }^{1} 2,070\end{array}$}} & \multirow{2}{*}{\multicolumn{2}{|c|}{$\begin{array}{c}\text { Nov. } 7,1989 \\
1,353\end{array}$}} & \multirow{2}{*}{\multicolumn{2}{|c|}{$\begin{array}{c}\text { Oct. } 17,1990 \\
1,804\end{array}$}} & \multirow{2}{*}{\multicolumn{2}{|c|}{$\begin{array}{c}\text { Oct. 31, } 1991 \\
1756\end{array}$}} & \multicolumn{2}{|c|}{ Oct. 16,1992} & \multicolumn{2}{|c|}{ Nov. 8,1993} & \multicolumn{2}{|c|}{ Nov. 14,1994} & \multirow{3}{*}{$\begin{array}{c}\text { Date } \\
\text { Total count } \\
\text { Organism }\end{array}$} \\
\hline & & & & & & & & & 432 & & 403 & 2,6 & 602 & \\
\hline Count & Percent & Count & Percent & Count & Percent & Count & Percent & Count & Percent & Count & Percent & Count & Percent & \\
\hline 88 & 4 & 60 & 4 & 32 & 2 & 23 & 1 & 34 & 2 & 35 & 3 & 50 & 2 & $\begin{array}{c}\text { Ephemeroptera } \\
\text { Isonychiidae } \\
\text { Isonychia } \\
\text { Leptohyphidae }\end{array}$ \\
\hline- & & - & & 2 & $<1$ & 1 & $<1$ & - & & - & & - & & $\begin{array}{l}\text { Tricorythodes } \\
\text { Odonata }\end{array}$ \\
\hline 3 & $<1$ & - & & 4 & $<1$ & 1 & $<1$ & 2 & $<1$ & - & & - & & $\begin{array}{l}\text { Coenagrionidae } \\
\text { Argia } \\
\text { Aeshnidae }\end{array}$ \\
\hline- & & - & & - & & - & & - & & - & & - & & Boyeria \\
\hline- & & - & & - & & - & & - & & 1 & $<1$ & - & & $\begin{array}{l}\text { Gomphidae } \\
\text { Plecoptera } \\
\text { Capniidae }\end{array}$ \\
\hline- & & - & & - & & - & & - & & - & & - & & Allocapnia \\
\hline- & & - & & - & & 1 & $<1$ & - & & - & & - & & Chloroperlidae \\
\hline- & & - & & - & & - & & - & & - & & 1 & $<1$ & $\begin{array}{l}\text { Perlidae } \\
\text { Taeniopterygidae }\end{array}$ \\
\hline 11 & $<1$ & - & & 1 & $<1$ & - & & 1 & $<1$ & 1 & $<1$ & 1 & $<1$ & $\begin{array}{l}\text { Taeniopteryx } \\
\text { Hemiptera } \\
\text { Veliidae }\end{array}$ \\
\hline- & & - & & - & & - & & - & & - & & - & & $\begin{array}{l}\text { Rhagovelia } \\
\text { Megaloptera } \\
\text { Corydalidae }\end{array}$ \\
\hline- & & 1 & $<1$ & - & & - & & - & & 1 & $<1$ & - & & $\begin{array}{l}\text { Corydalus } \\
\text { Trichoptera } \\
\text { Apataniidae }\end{array}$ \\
\hline- & & - & & - & & - & & - & & - & & - & & $\begin{array}{c}\text { Apatania } \\
\text { Brachycentridae }\end{array}$ \\
\hline- & & - & & - & & 1 & $<1$ & - & & - & & - & & $\begin{array}{c}\text { Micrasema } \\
\text { Glossosomatidae }\end{array}$ \\
\hline 8 & $<1$ & 3 & $<1$ & 11 & $<1$ & - & & 1 & $<1$ & 3 & $<1$ & - & & Glossosoma \\
\hline- & & - & & 1 & $<1$ & - & & - & & - & & - & & $\begin{array}{c}\text { Protoptila } \\
\text { Hydropsychidae }\end{array}$ \\
\hline 140 & 7 & 120 & 9 & 170 & 9 & 78 & 4 & 110 & 8 & 140 & 10 & 70 & 3 & Ceratopsyche \\
\hline 11 & $<1$ & 6 & $<1$ & 11 & $<1$ & 3 & $<1$ & 1 & $<1$ & 7 & $<1$ & 33 & 1 & Cheumatopsyche \\
\hline 200 & 10 & 180 & 13 & 220 & 12 & 190 & 11 & 85 & 6 & 82 & 6 & 890 & 34 & $\begin{array}{l}\text { Hydropsyche } \\
\text { Hydroptilidae }\end{array}$ \\
\hline 5 & $<1$ & 4 & $<1$ & 6 & $<1$ & 1 & $<1$ & 3 & $<1$ & - & & - & & Hydroptila \\
\hline 740 & 35 & 670 & 48 & 420 & 23 & 980 & 54 & 480 & 34 & 510 & 36 & 630 & 24 & $\begin{array}{l}\text { Leucotrichia } \\
\text { Leptoceridae }\end{array}$ \\
\hline- & & 1 & $<1$ & - & & - & & 24 & 2 & - & & - & & Mystacides \\
\hline 3 & $<1$ & - & & 1 & $<1$ & - & & 2 & $<1$ & 1 & $<1$ & 1 & $<1$ & $\begin{array}{c}\text { Oecetis } \\
\text { Philopotamidae }\end{array}$ \\
\hline 27 & 1 & 2 & $<1$ & 2 & $<1$ & 53 & 3 & 24 & 2 & 85 & 6 & 72 & 3 & Chimarra \\
\hline- & & - & & - & & - & & - & & - & & - & & $\begin{array}{c}\text { Dolophilodes } \\
\text { Polycentropodidae }\end{array}$ \\
\hline 3 & $<1$ & - & & 12 & $<1$ & - & & 1 & $<1$ & 1 & $<1$ & - & & Neureclipsis \\
\hline 3 & $<1$ & 1 & $<1$ & 15 & $<1$ & - & & - & & - & & - & & $\begin{array}{l}\text { Polycentropus } \\
\text { Psychomyiidae }\end{array}$ \\
\hline- & & - & & 1 & $<1$ & - & & - & & 1 & $<1$ & 1 & $<1$ & $\begin{array}{l}\text { Psychomyia } \\
\text { Uenoidae }\end{array}$ \\
\hline- & & - & & - & & - & & - & & 2 & $<1$ & - & & $\begin{array}{l}\text { Neophylax } \\
\text { Lepidoptera }\end{array}$ \\
\hline- & & 1 & $<1$ & - & & - & & - & & - & & - & & Noctuidae \\
\hline- & & - & & - & & - & & 1 & $<1$ & - & & - & & Archanara \\
\hline
\end{tabular}


Table 5. Benthic-macroinvertebrate data-Continued

01480629 - Buck Run at Doe Run, Pa. (Site 46)—Continued

\begin{tabular}{|c|c|c|c|c|c|c|c|c|c|c|c|c|c|c|}
\hline \multirow{3}{*}{$\begin{array}{c}\text { Date } \\
\text { Total count } \\
\text { Organism }\end{array}$} & \multirow{2}{*}{\multicolumn{2}{|c|}{$\begin{array}{c}\text { Nov. } 5,1981 \\
1,026\end{array}$}} & \multirow{2}{*}{\multicolumn{2}{|c|}{$\begin{array}{c}\text { Oct. } 28,1982 \\
11,647 \\
\end{array}$}} & \multirow{2}{*}{\multicolumn{2}{|c|}{$\begin{array}{c}\text { Oct. } 28,1983 \\
11,846 \\
\end{array}$}} & \multirow{2}{*}{\multicolumn{2}{|c|}{$\begin{array}{c}\text { Oct. } 31,1984 \\
{ }^{1} 2,272 \\
\end{array}$}} & \multirow{2}{*}{\multicolumn{2}{|c|}{$\begin{array}{c}\text { Oct. } 29,1985 \\
1,091 \\
\end{array}$}} & \multirow{2}{*}{\multicolumn{2}{|c|}{$\begin{array}{c}\text { Oct. } 30,1986 \\
1,769\end{array}$}} & \multirow{2}{*}{\multicolumn{2}{|c|}{$\begin{array}{c}\text { Nov. } 19,1987 \\
1,644\end{array}$}} \\
\hline & & & & & & & & & & & & & & \\
\hline & Count & Percent & Count & Percent & Count & Percent & Count & Percent & Count & Percent & Count & Percent & Count & Percent \\
\hline \multicolumn{15}{|l|}{ Coleoptera } \\
\hline \multicolumn{15}{|l|}{ Elmidae } \\
\hline Ancyronyx & - & & - & & - & & - & & - & & - & & - & \\
\hline Dubiraphia & - & & - & & - & & - & & - & & - & & - & \\
\hline Optioservus & 3 & $<1$ & 5 & $<1$ & - & & 8 & $<1$ & 6 & $<1$ & 4 & $<1$ & 1 & $<1$ \\
\hline Oulimnius & - & & - & & - & & - & & - & & - & & - & \\
\hline Stenelmis & - & & 3 & $<1$ & - & & 3 & $<1$ & - & & - & & - & \\
\hline \multicolumn{15}{|l|}{ Psephenidae } \\
\hline Psephenus & - & & - & & - & & - & & - & & - & & - & \\
\hline \multicolumn{15}{|l|}{ Diptera } \\
\hline $\begin{array}{l}\text { Chironomidae } \\
\text { Empididae }\end{array}$ & 140 & 14 & 170 & 10 & 88 & 5 & 290 & 13 & 190 & 17 & 55 & 3 & 270 & 16 \\
\hline Hemerodromia & 1 & $<1$ & 5 & $<1$ & - & & 3 & $<1$ & 3 & $<1$ & - & & 1 & $<1$ \\
\hline Ephydridae & - & & - & & - & & - & & - & & - & & - & \\
\hline \multicolumn{15}{|l|}{ Simuliidae } \\
\hline Simulium & 28 & 3 & 51 & 3 & 3 & $<1$ & 290 & 13 & 41 & 4 & 160 & 9 & 190 & 11 \\
\hline Stratiomyidae & - & & - & & - & & - & & - & & - & & - & \\
\hline \multicolumn{15}{|l|}{ Tipulidae } \\
\hline Antocha & 52 & 5 & 110 & 6 & 51 & 3 & 93 & 4 & 150 & 14 & 58 & 3 & 70 & 4 \\
\hline Tipula & - & & - & & - & & - & & - & & - & & - & \\
\hline
\end{tabular}

\footnotetext{
${ }^{1}$ Extrapolated from a 3/8 subsample.
} 


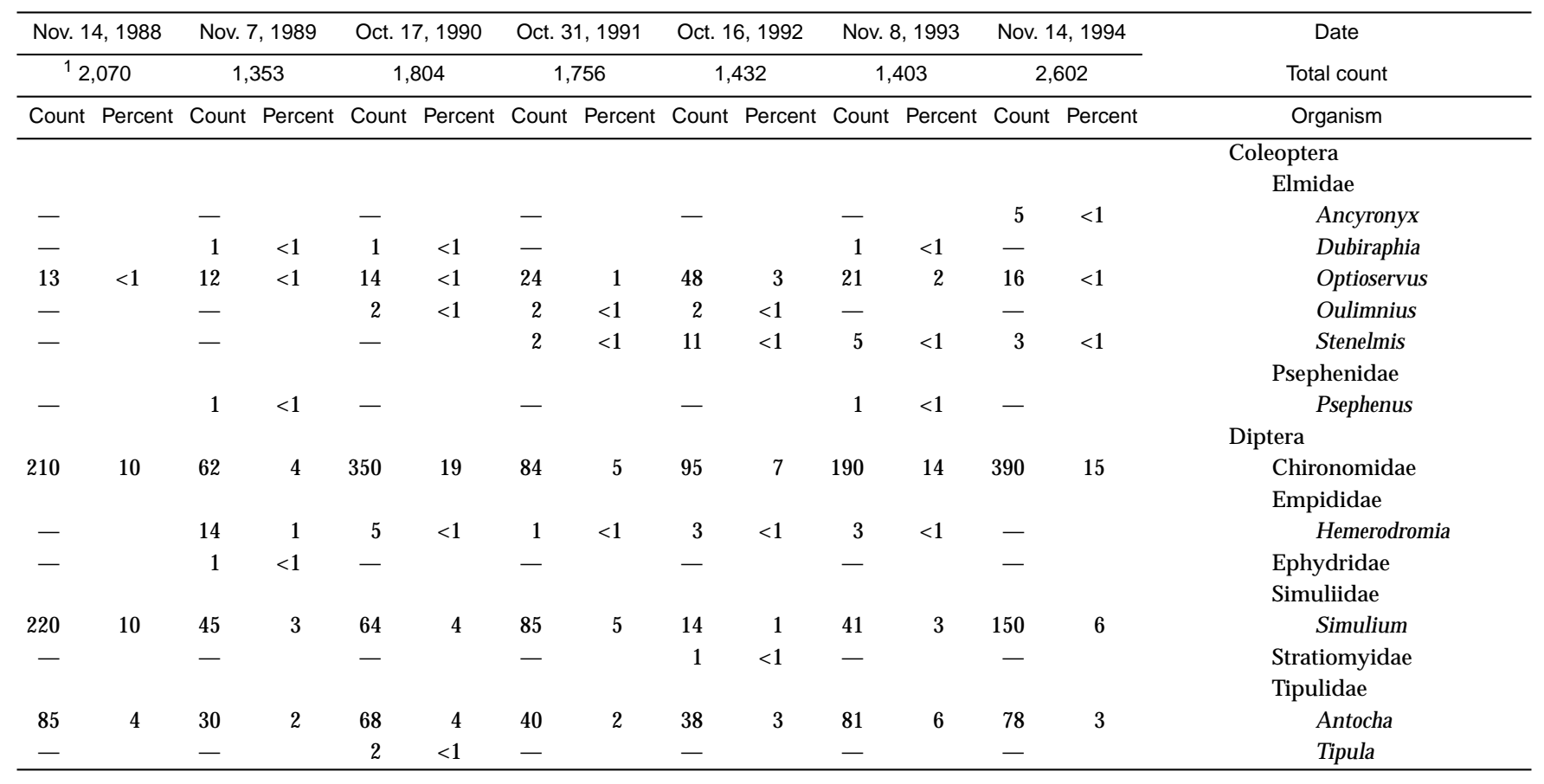


Table 5. Benthic-macroinvertebrate data-Continued

$[<$, less than; - , not found]

01480632 - Doe Run at Springdell, Pa. (Site 45)

\begin{tabular}{|c|c|c|c|c|c|c|c|c|c|c|c|c|c|c|}
\hline \multirow{3}{*}{$\begin{array}{cc}\text { Date } \\
\text { Total count }\end{array}$} & \multirow{2}{*}{\multicolumn{2}{|c|}{$\begin{array}{c}\text { Nov. } 5,1981 \\
11,133\end{array}$}} & \multirow{2}{*}{\multicolumn{2}{|c|}{$\begin{array}{c}\text { Oct. } 28,1982 \\
11,620\end{array}$}} & \multirow{2}{*}{\multicolumn{2}{|c|}{$\begin{array}{c}\text { Oct. } 28,1983 \\
11,405\end{array}$}} & \multirow{2}{*}{\multicolumn{2}{|c|}{$\begin{array}{c}\text { Oct. } 31,1984 \\
11,608\end{array}$}} & \multirow{2}{*}{\multicolumn{2}{|c|}{$\begin{array}{c}\text { Oct. } 29,1985 \\
974\end{array}$}} & \multirow{2}{*}{\multicolumn{2}{|c|}{$\begin{array}{c}\text { Oct. } 30,1986 \\
774\end{array}$}} & \multirow{2}{*}{\multicolumn{2}{|c|}{$\begin{array}{c}\text { Nov. } 19,1987 \\
1,617\end{array}$}} \\
\hline & & & & & & & & & & & & & & \\
\hline & Count & Percent & Count & Percent & Count & Percent & Count & Percent & Count & Percent & Count & Percent & Count & Percent \\
\hline \multicolumn{15}{|l|}{ Platyhelminthes (flatworms) } \\
\hline \multicolumn{15}{|l|}{ Turbellaria } \\
\hline \multicolumn{15}{|l|}{ Tricladida } \\
\hline Planariidae & 43 & 4 & 16 & 1 & 8 & $<1$ & 16 & 1 & 11 & 1 & 13 & 2 & 27 & 2 \\
\hline Nematoda (nematodes) & - & & - & & 5 & $<1$ & - & & - & & - & & 1 & $<1$ \\
\hline \multicolumn{15}{|l|}{ Nemertea (proboscis worms) } \\
\hline \multicolumn{15}{|l|}{ Enopla } \\
\hline \multicolumn{15}{|l|}{ Hoplonemertea } \\
\hline \multicolumn{15}{|l|}{ Tetrastemmatidae } \\
\hline Prostoma & - & & - & & - & & - & & 1 & $<1$ & - & & - & \\
\hline Mollusca (molluscs) & & & & & & & & & & & & & & \\
\hline Gastropoda & & & & & & & & & & & & & & \\
\hline Basommatophora & & & & & & & & & & & & & & \\
\hline Ancylidae & & & & & & & & & & & & & & \\
\hline Ferrissia & 29 & 3 & 11 & $<1$ & 93 & 7 & - & & - & & 31 & 4 & 7 & $<1$ \\
\hline Physidae & & & & & & & & & & & & & & \\
\hline Physa & - & & - & & - & & - & & - & & - & & - & \\
\hline Annelida (segmented worms) & & & & & & & & & & & & & & \\
\hline Oligochaeta & - & & - & & - & & - & & 1 & $<1$ & - & & - & \\
\hline Lumbriculida & & & & & & & & & & & & & & \\
\hline Lumbriculidae & - & & - & & 3 & $<1$ & - & & - & & - & & - & \\
\hline Tubificida & & & & & & & & & & & & & & \\
\hline Naididae & 5 & $<1$ & 11 & $<1$ & 5 & $<1$ & 8 & $<1$ & - & & - & & 10 & $<1$ \\
\hline Arthropoda (arthropods) & & & & & & & & & & & & & & \\
\hline Acariformes & & & & & & & & & & & & & & \\
\hline Hydrachnidia & - & & 5 & $<1$ & 3 & $<1$ & - & & 5 & $<1$ & - & & 15 & $<1$ \\
\hline Crustacea & & & & & & & & & & & & & & \\
\hline Cyclopoida & - & & - & & - & & - & & - & & - & & - & \\
\hline Podocopa & - & & - & & - & & - & & - & & - & & - & \\
\hline Insecta & & & & & & & & & & & & & & \\
\hline Ephemeroptera & & & & & & & & & & & & & & \\
\hline Baetidae & & & & & & & & & & & & & & \\
\hline Baetis & 5 & $<1$ & 3 & $<1$ & - & & 3 & $<1$ & - & & 1 & $<1$ & - & \\
\hline Pseudocloeon & 11 & 1 & 16 & 1 & 13 & $<1$ & 8 & $<1$ & 24 & 2 & 7 & $<1$ & 6 & $<1$ \\
\hline Ephemerellidae & & & & & & & & & & & & & & \\
\hline Ephemerella & 37 & 3 & 40 & 3 & 100 & 7 & 56 & 3 & 7 & $<1$ & 7 & $<1$ & 31 & 2 \\
\hline Heptageniidae & & & & & & & & & & & & & & \\
\hline Epeorus & - & & - & & - & & - & & - & & - & & - & \\
\hline Stenonema & 120 & 11 & 59 & 4 & 40 & 3 & 120 & 8 & 21 & 2 & 24 & 3 & 75 & 5 \\
\hline Isonychiidae & & & & & & & & & & & & & & \\
\hline Isonychia & 72 & 7 & 120 & 8 & 24 & 2 & 40 & 3 & 46 & 5 & 17 & 2 & 42 & 3 \\
\hline Leptohyphidae & & & & & & & & & & & & & & \\
\hline Tricorythodes & - & & - & & - & & - & & - & & - & & 2 & $<1$ \\
\hline Odonata & & & & & & & & & & & & & & \\
\hline Coenagrionidae & & & & & & & & & & & & & & \\
\hline Argia & 3 & $<1$ & 3 & $<1$ & - & & - & & - & & - & & - & \\
\hline Plecoptera & & & & & & & & & & & & & & \\
\hline Capniidae & & & & & & & & & & & & & & \\
\hline Allocapnia & - & & - & & - & & - & & - & & - & & - & \\
\hline Taeniopterygidae & & & & & & & & & & & & & & \\
\hline Taeniopteryx & - & & - & & - & & 3 & $<1$ & - & & 8 & 1 & 6 & $<1$ \\
\hline
\end{tabular}




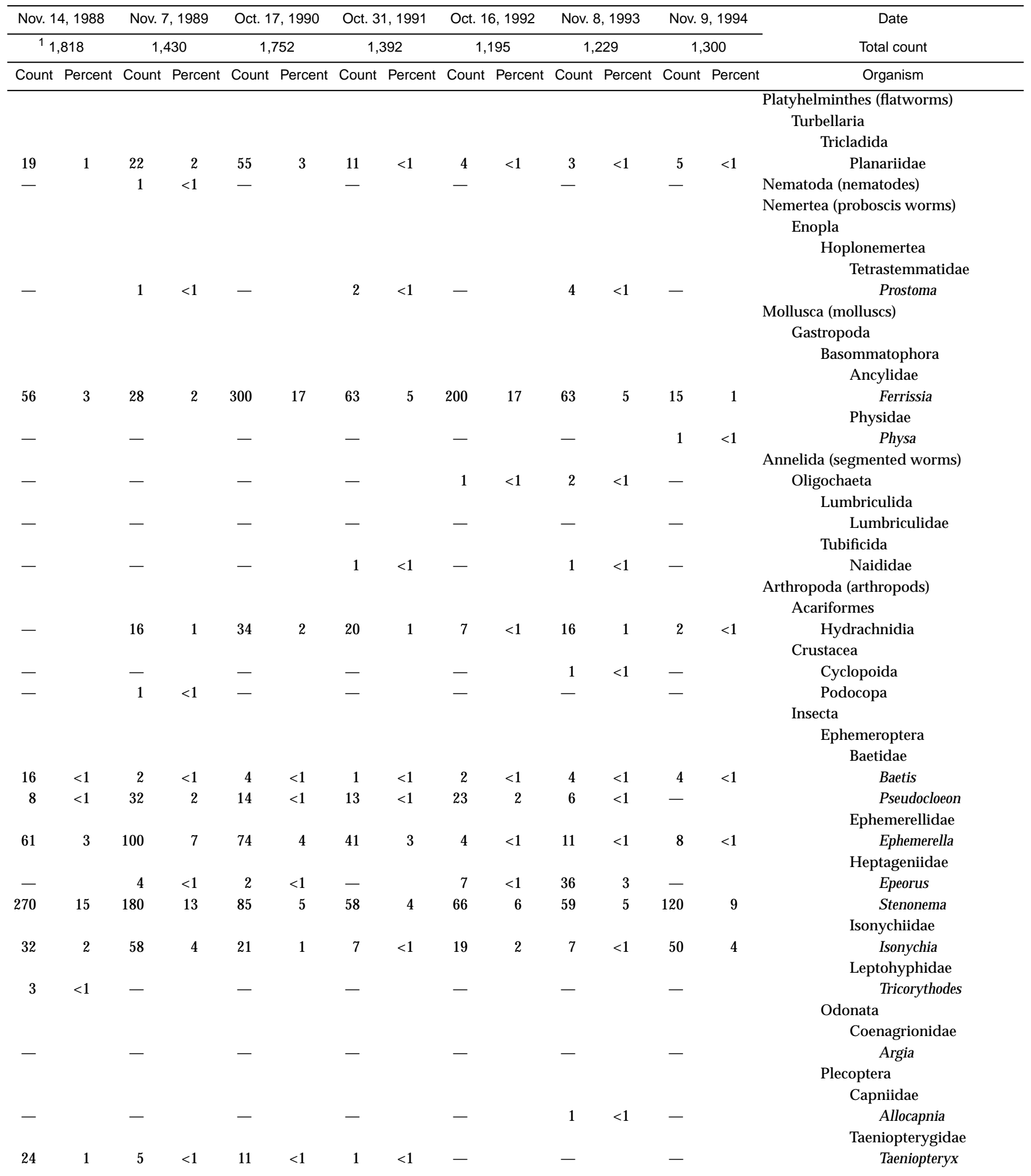


Table 5. Benthic-macroinvertebrate data-Continued

01480632 - Doe Run at Springdell, Pa. (Site 45)

\begin{tabular}{|c|c|c|c|c|c|c|c|c|c|c|c|c|c|c|}
\hline \multirow{3}{*}{$\begin{array}{c}\text { Date } \\
\text { Total count } \\
\text { Organism }\end{array}$} & \multirow{2}{*}{\multicolumn{2}{|c|}{$\begin{array}{c}\text { Nov. } 5,1981 \\
11,133\end{array}$}} & \multirow{2}{*}{\multicolumn{2}{|c|}{$\begin{array}{c}\text { Oct. } 28,1982 \\
{ }^{1} 1,620\end{array}$}} & \multirow{2}{*}{\multicolumn{2}{|c|}{$\begin{array}{c}\text { Oct. } 28,1983 \\
{ }^{1} 1,405 \\
\end{array}$}} & \multirow{2}{*}{\multicolumn{2}{|c|}{$\begin{array}{c}\text { Oct. } 31,1984 \\
11,608 \\
\end{array}$}} & \multirow{2}{*}{\multicolumn{2}{|c|}{$\begin{array}{c}\text { Oct. } 29,1985 \\
974\end{array}$}} & \multirow{2}{*}{\multicolumn{2}{|c|}{$\begin{array}{c}\text { Oct. 30, } 1986 \\
774\end{array}$}} & \multirow{2}{*}{\multicolumn{2}{|c|}{$\begin{array}{c}\text { Nov. } 19,1987 \\
1,617\end{array}$}} \\
\hline & & & & & & & & & & & & & & \\
\hline & Count & Percent & Count & Percent & Count & Percent & Count & Percent & Count & Percent & Count & Percent & Count & Percent \\
\hline \multicolumn{15}{|l|}{ Megaloptera } \\
\hline \multicolumn{15}{|l|}{ Corydalidae } \\
\hline Corydalus & - & & - & & - & & - & & - & & - & & - & \\
\hline \multicolumn{15}{|l|}{ Trichoptera } \\
\hline \multicolumn{15}{|l|}{ Apataniidae } \\
\hline Apatania & - & & - & & - & & - & & 1 & $<1$ & - & & 7 & $<1$ \\
\hline \multicolumn{15}{|l|}{ Glossosomatidae } \\
\hline Glossosoma & 3 & $<1$ & 5 & $<1$ & 8 & $<1$ & 16 & 1 & - & & - & & 2 & $<1$ \\
\hline Protoptila & 3 & $<1$ & - & & - & & - & & - & & - & & - & \\
\hline \multicolumn{15}{|l|}{ Hydropsychidae } \\
\hline Ceratopsyche & 230 & 21 & 120 & 8 & 360 & 26 & 400 & 25 & 430 & 44 & 130 & 17 & 160 & 10 \\
\hline Cheumatopsyche & 140 & 13 & 37 & 2 & 8 & $<1$ & 27 & 2 & 34 & 3 & 1 & $<1$ & 35 & 2 \\
\hline Hydropsyche & 13 & 1 & 13 & $<1$ & 16 & 1 & 5 & $<1$ & 26 & 3 & 44 & 6 & 24 & 2 \\
\hline \multicolumn{15}{|l|}{ Hydroptilidae } \\
\hline Hydroptila & 8 & $<1$ & 11 & $<1$ & 3 & $<1$ & - & & - & & - & & 22 & 1 \\
\hline Leucotrichia & 11 & 1 & 140 & 9 & 390 & 28 & 290 & 18 & 100 & 10 & 270 & 35 & 560 & 35 \\
\hline \multicolumn{15}{|l|}{ Philopotamidae } \\
\hline Chimarra & - & & 21 & 1 & 5 & $<1$ & 21 & 1 & - & & 3 & $<1$ & 22 & 1 \\
\hline Dolophilodes & - & & - & & - & & - & & - & & - & & - & \\
\hline Polycentropodidae & & & & & & & & & & & & & & \\
\hline Neureclipsis & - & & - & & - & & - & & - & & 2 & $<1$ & - & \\
\hline Polycentropus & - & & 3 & $<1$ & - & & - & & - & & - & & - & \\
\hline Psychomyiidae & & & & & & & & & & & & & & \\
\hline Psychomyia & - & & 3 & $<1$ & - & & - & & - & & - & & - & \\
\hline Uenoidae & & & & & & & & & & & & & & \\
\hline Neophylax & 3 & $<1$ & - & & - & & 5 & $<1$ & - & & - & & - & \\
\hline Lepidoptera & & & & & & & & & & & & & & \\
\hline Noctuidae & - & & - & & - & & - & & - & & - & & - & \\
\hline Archanara & - & & - & & - & & - & & - & & - & & - & \\
\hline Pyralidae & & & & & & & & & & & & & & \\
\hline Petrophila & 13 & 1 & 61 & 4 & 21 & 2 & 3 & $<1$ & 2 & $<1$ & 2 & $<1$ & 13 & $<1$ \\
\hline Coleoptera & & & & & & & & & & & & & & \\
\hline Elmidae & & & & & & & & & & & & & & \\
\hline Ancyronyx & - & & - & & - & & - & & - & & - & & - & \\
\hline Dubiraphia & - & & - & & - & & - & & - & & - & & 1 & $<1$ \\
\hline Optioservus & 8 & $<1$ & - & & - & & 24 & 2 & 3 & $<1$ & 2 & $<1$ & 6 & $<1$ \\
\hline Oulimnius & - & & 3 & $<1$ & - & & - & & 1 & $<1$ & - & & - & \\
\hline Stenelmis & 3 & $<1$ & - & & 3 & $<1$ & 3 & $<1$ & - & & - & & - & \\
\hline Psephenidae & & & & & & & & & & & & & & \\
\hline Psephenus & - & & - & & - & & - & & - & & - & & - & \\
\hline Diptera & & & & & & & & & & & & & & \\
\hline Chironomidae & 250 & 23 & 720 & 45 & 230 & 16 & 180 & 11 & 160 & 16 & 110 & 14 & 370 & 23 \\
\hline Empididae & & & & & & & & & & & & & & \\
\hline Hemerodromia & 5 & $<1$ & 11 & $<1$ & 3 & $<1$ & 3 & $<1$ & 4 & $<1$ & - & & 1 & $<1$ \\
\hline Simuliidae & & & & & & & & & & & & & & \\
\hline Simulium & 8 & $<1$ & 8 & $<1$ & 3 & $<1$ & 300 & 19 & 15 & 2 & 37 & 5 & 22 & 1 \\
\hline Tipulidae & & & & & & & & & & & & & & \\
\hline Antocha & 110 & 10 & 180 & 11 & 61 & 4 & 77 & 5 & 82 & 8 & 65 & 8 & 150 & 9 \\
\hline
\end{tabular}

${ }^{1}$ Extrapolated from a 3/8 subsample. 


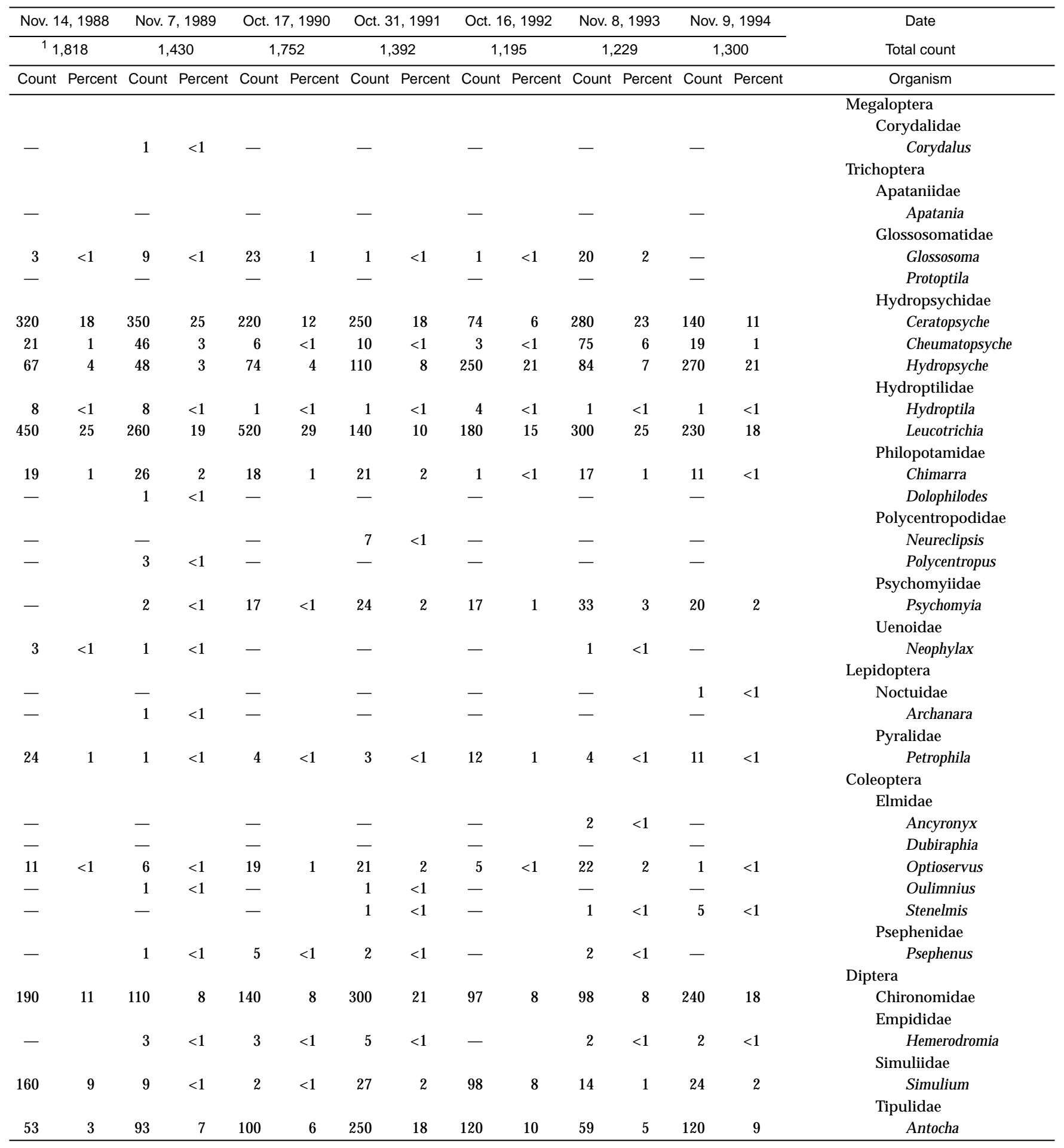


Table 5. Benthic-macroinvertebrate data-Continued

$[<$, less than; - , not found]

01480640 - West Branch Brandywine Creek at Wawaset, Pa. (Site 38)

\begin{tabular}{|c|c|c|c|c|c|c|c|c|c|c|c|c|c|c|}
\hline \multirow{3}{*}{ 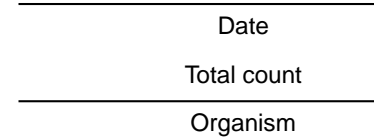 } & \multirow{2}{*}{\multicolumn{2}{|c|}{$\frac{\text { Nov. } 4,1981}{598}$}} & \multirow{2}{*}{\multicolumn{2}{|c|}{$\begin{array}{c}\text { Oct. } 21,1982 \\
1,655\end{array}$}} & \multirow{2}{*}{\multicolumn{2}{|c|}{$\frac{\text { Oct. } 31,1983}{1,110}$}} & \multirow{2}{*}{\multicolumn{2}{|c|}{$\begin{array}{c}\text { Oct. } 16,1984 \\
1,402\end{array}$}} & \multirow{2}{*}{\multicolumn{2}{|c|}{$\begin{array}{c}\text { Oct. } 22,1985 \\
1,085\end{array}$}} & \multirow{2}{*}{\multicolumn{2}{|c|}{$\begin{array}{c}\text { Nov. 3, } 1986 \\
769\end{array}$}} & \multirow{2}{*}{\multicolumn{2}{|c|}{$\begin{array}{c}\text { Nov. } 3,1987 \\
402\end{array}$}} \\
\hline & & & & & & & & & & & & & & \\
\hline & Count & Percent & Count & Percent & Count & Percent & Count & Percent & Count & Percent & Count & Percent & Count & Percent \\
\hline \multicolumn{15}{|l|}{ Platyhelminthes (flatworms) } \\
\hline \multicolumn{15}{|l|}{ Turbellaria } \\
\hline \multicolumn{15}{|l|}{ Tricladida } \\
\hline Planariidae & 17 & 3 & - & & 19 & 2 & 1 & $<1$ & 19 & 2 & 2 & $<1$ & 16 & 4 \\
\hline Nematoda & - & & - & & - & & 1 & $<1$ & - & & - & & - & \\
\hline \multicolumn{15}{|l|}{ Nemertea (proboscis worms) } \\
\hline \multicolumn{15}{|l|}{ Enopla } \\
\hline Hoplonemertea & & & & & & & & & & & & & & \\
\hline Tetrastemmatidae & & & & & & & & & & & & & & \\
\hline Prostoma & 1 & $<1$ & - & & - & & 1 & $<1$ & 1 & $<1$ & - & & - & \\
\hline Mollusca (molluscs) & & & & & & & & & & & & & & \\
\hline Gastropoda & & & & & & & & & & & & & & \\
\hline Mesogastropoda & & & & & & & & & & & & & & \\
\hline Hydrobiidae & & & & & & & & & & & & & & \\
\hline Amnicola & - & & - & & - & & - & & - & & - & & - & \\
\hline Basommatophora & & & & & & & & & & & & & & \\
\hline Ancylidae & & & & & & & & & & & & & & \\
\hline Ferrissia & 7 & 1 & 45 & 3 & 26 & 2 & 6 & $<1$ & 15 & 1 & 6 & $<1$ & 1 & $<1$ \\
\hline Lymnaeidae & & & & & & & & & & & & & & \\
\hline Lymnaea & - & & - & & - & & - & & - & & - & & 1 & $<1$ \\
\hline Physidae & & & & & & & & & & & & & & \\
\hline Physa & - & & - & & - & & - & & - & & 3 & $<1$ & 3 & $<1$ \\
\hline Planorbidae & & & & & & & & & & & & & & \\
\hline Gyraulus & - & & - & & - & & - & & - & & - & & - & \\
\hline Helisoma & - & & - & & - & & - & & - & & - & & - & \\
\hline Bivalvia & & & & & & & & & & & & & & \\
\hline Veneroida & & & & & & & & & & & & & & \\
\hline Sphaeriidae & - & & - & & - & & - & & - & & 3 & $<1$ & - & \\
\hline Annelida (segmented worms) & & & & & & & & & & & & & & \\
\hline Oligochaeta & & & & & & & & & & & & & & \\
\hline Lumbriculida & & & & & & & & & & & & & & \\
\hline Lumbriculidae & - & & - & & - & & - & & - & & - & & - & \\
\hline Tubificida & & & & & & & & & & & & & & \\
\hline Naididae & - & & - & & - & & 2 & $<1$ & - & & - & & - & \\
\hline Hirudinea & & & & & & & & & & & & & & \\
\hline Pharyngobdellida & & & & & & & & & & & & & & \\
\hline Glossiphoniidae & 2 & $<1$ & - & & - & & - & & - & & - & & - & \\
\hline Arthropoda (arthropods) & & & & & & & & & & & & & & \\
\hline Acariformes & & & & & & & & & & & & & & \\
\hline Hydrachnidia & 1 & $<1$ & - & & 2 & $<1$ & 2 & $<1$ & 2 & $<1$ & - & & 8 & 2 \\
\hline Crustacea & & & & & & & & & & & & & & \\
\hline Amphipoda & & & & & & & & & & & & & & \\
\hline Gammaridae & & & & & & & & & & & & & & \\
\hline Gammarus & - & & - & & - & & - & & - & & - & & - & \\
\hline Podocopa & - & & - & & - & & - & & 1 & $<1$ & - & & - & \\
\hline Insecta & & & & & & & & & & & & & & \\
\hline Ephemeroptera & & & & & & & & & & & & & & \\
\hline Baetidae & & & & & & & & & & & & & & \\
\hline Baetis & 6 & 1 & 6 & $<1$ & 1 & $<1$ & 14 & 1 & 11 & 1 & 1 & $<1$ & - & \\
\hline Pseudocloeon & 2 & $<1$ & - & & - & & - & & - & & - & & 10 & 2 \\
\hline Caenidae & & & & & & & & & & & & & & \\
\hline Caenis & - & & - & & 2 & $<1$ & - & & - & & - & & 1 & $<1$ \\
\hline Ephemerellidae & & & & & & & & & & & & & & \\
\hline Ephemerella & 6 & 1 & 14 & $<1$ & 40 & 4 & 3 & $<1$ & 5 & $<1$ & 5 & $<1$ & 10 & 2 \\
\hline
\end{tabular}




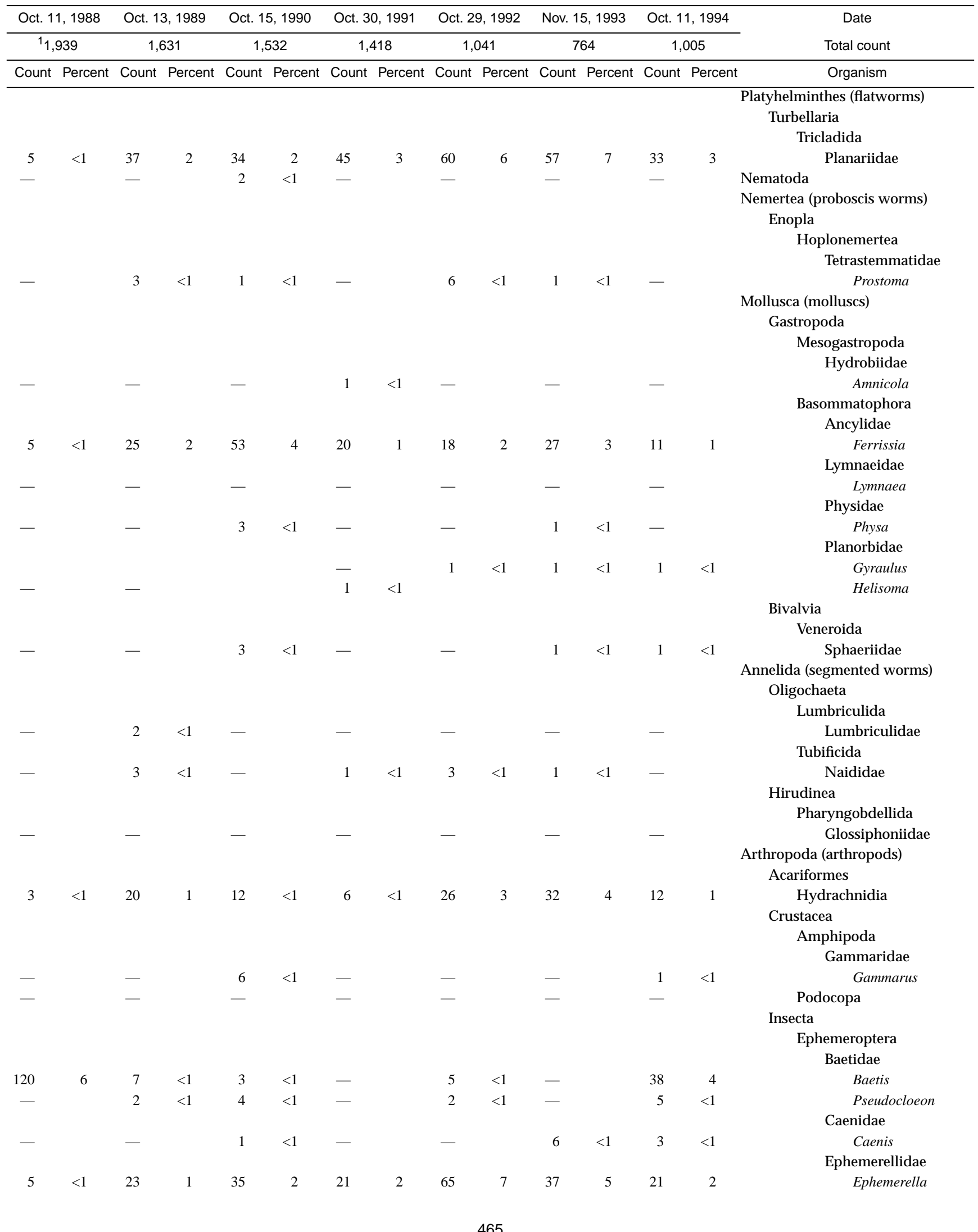


Table 5. Benthic-macroinvertebrate data-Continued

01480640 - West Branch Brandywine Creek at Wawaset, Pa. (Site 38)—Continued

\begin{tabular}{|c|c|c|c|c|c|c|c|c|c|c|c|c|c|c|}
\hline \multirow{3}{*}{$\begin{array}{c}\text { Date } \\
\text { Total count } \\
\text { Organism }\end{array}$} & \multirow{2}{*}{\multicolumn{2}{|c|}{$\begin{array}{c}\text { Nov. } 4,1981 \\
598\end{array}$}} & \multicolumn{2}{|c|}{ Oct. 21,1982} & \multicolumn{2}{|c|}{ Oct. 31,1983} & \multicolumn{2}{|c|}{ Oct. 16,1984} & \multicolumn{2}{|c|}{ Oct. 22, 1985} & \multicolumn{2}{|c|}{ Nov. 3, 1986} & \multicolumn{2}{|c|}{ Nov. 3, 1987} \\
\hline & & & & & & 110 & & 402 & & 085 & & 769 & & 102 \\
\hline & Count & Percent & Count & Percent & Count & Percent & Count & Percent & Count & Percent & Count & Percent & Count & Percent \\
\hline \multicolumn{15}{|l|}{ Ephemeroptera } \\
\hline \multicolumn{15}{|l|}{ Heptageniidae } \\
\hline Epeorus & - & & - & & - & & - & & - & & - & & - & \\
\hline Stenonema & 130 & 21 & 170 & 10 & 68 & 6 & 41 & 3 & 33 & 3 & 110 & 14 & 52 & 13 \\
\hline \multicolumn{15}{|l|}{ Isonychiidae } \\
\hline Isonychia & 1 & $<1$ & 2 & $<1$ & 7 & $<1$ & 6 & $<1$ & 3 & $<1$ & 13 & 2 & 2 & $<1$ \\
\hline \multicolumn{15}{|l|}{ Leptohyphidae } \\
\hline Tricorythodes & 10 & 2 & 6 & $<1$ & 34 & 3 & 1 & $<1$ & 5 & $<1$ & - & & 7 & 2 \\
\hline \multicolumn{15}{|l|}{ Potamanthidae } \\
\hline $\begin{array}{l}\text { Anthopotamus } \\
\text { Odonata }\end{array}$ & - & & - & & - & & - & & - & & - & & - & \\
\hline \multicolumn{15}{|l|}{ Coenagrionidae } \\
\hline Argia & 2 & $<1$ & - & & 10 & $<1$ & - & & - & & 4 & $<1$ & - & \\
\hline \multicolumn{15}{|l|}{ Plecoptera } \\
\hline Allocapnia & - & & - & & 1 & $<1$ & - & & - & & 1 & $<1$ & 1 & $<1$ \\
\hline $\begin{array}{l}\text { Chloroperlidae } \\
\text { Perlidae }\end{array}$ & \multicolumn{6}{|c|}{ Perlidae } & - & & - & & - & & - & \\
\hline \multicolumn{15}{|l|}{ Taeniopterygidae } \\
\hline Taeniopteryx & 1 & $<1$ & 1 & $<1$ & 1 & $<1$ & - & & - & & - & & - & \\
\hline \multicolumn{15}{|l|}{ Megaloptera } \\
\hline Corydalus & 1 & $<1$ & - & & - & & 1 & $<1$ & - & & - & & - & \\
\hline $\begin{array}{l}\text { Neuroptera } \\
\quad \begin{array}{l}\text { Sisyridae } \\
\text { Climacia }\end{array}\end{array}$ & & & & & & & & & & & & & & \\
\hline C. areolaris & - & & - & & - & & - & & - & & 1 & $<1$ & - & \\
\hline $\begin{array}{l}\text { Trichoptera } \\
\text { Apataniidae }\end{array}$ & & & & & & & & & & & & & & \\
\hline $\begin{array}{c}\text { Apatania } \\
\text { Brachycentridae }\end{array}$ & - & & - & & - & & - & & - & & - & & - & \\
\hline $\begin{array}{c}\text { Micrasema } \\
\text { Glossosomatidae }\end{array}$ & - & & - & & - & & - & & - & & - & & - & \\
\hline Glossosoma & - & & 3 & $<1$ & 13 & 1 & 2 & $<1$ & - & & 3 & $<1$ & 1 & $<1$ \\
\hline $\begin{array}{c}\text { Protoptila } \\
\text { Helicopsychidae }\end{array}$ & - & & - & & - & & - & & - & & - & & - & \\
\hline $\begin{array}{r}\text { Helicopsyche } \\
\text { Hydropsychidae }\end{array}$ & - & & - & & - & & - & & - & & - & & - & \\
\hline Ceratopsyche & 150 & 25 & 480 & 28 & 220 & 20 & 240 & 17 & 190 & 17 & 240 & 31 & 95 & 23 \\
\hline Cheumatopsyche & 120 & 20 & 190 & 11 & 150 & 14 & 200 & 14 & 33 & 3 & 11 & 1 & 11 & 3 \\
\hline Hydropsyche & 4 & $<1$ & 24 & 1 & 6 & $<1$ & 20 & 1 & 13 & 1 & 19 & 2 & 12 & 3 \\
\hline Hydroptilidae & & & & & & & & & & & & & & \\
\hline Hydroptila & 1 & $<1$ & - & & 2 & $<1$ & - & & 1 & $<1$ & - & & - & \\
\hline $\begin{array}{c}\text { Leucotrichia } \\
\text { Lepidostomatidae }\end{array}$ & 54 & 9 & 340 & 20 & 320 & 29 & - & & 3 & $<1$ & 100 & 13 & 17 & 4 \\
\hline $\begin{array}{l}\text { Lepidostoma } \\
\text { Leptoceridae }\end{array}$ & - & & - & & - & & - & & - & & - & & - & \\
\hline Mystacides & - & & - & & - & & - & & - & & - & & - & \\
\hline $\begin{array}{c}\text { Oecetis } \\
\text { Philopotamidae }\end{array}$ & - & & - & & - & & - & & - & & - & & - & \\
\hline Chimarra & 2 & $<1$ & 1 & $<1$ & - & & - & & - & & - & & - & \\
\hline
\end{tabular}




\begin{tabular}{|c|c|c|c|c|c|c|c|c|c|c|c|c|c|c|}
\hline \multirow{2}{*}{\multicolumn{2}{|c|}{$\begin{array}{c}\text { Oct. } 11,1988 \\
11,939\end{array}$}} & \multirow{2}{*}{\multicolumn{2}{|c|}{$\begin{array}{c}\text { Oct. } 13,1989 \\
1,631\end{array}$}} & \multirow{2}{*}{\multicolumn{2}{|c|}{$\begin{array}{c}\text { Oct. } 15,1990 \\
1,532\end{array}$}} & \multicolumn{2}{|c|}{ Oct. 30, 1991} & \multicolumn{2}{|c|}{ Oct. 29, 1992} & \multicolumn{2}{|c|}{ Nov. 15,1993} & \multicolumn{2}{|c|}{ Oct. 11, 1994} & \multirow{3}{*}{$\begin{array}{c}\text { Date } \\
\text { Total count } \\
\text { Organism }\end{array}$} \\
\hline & & & & & & & 418 & & 041 & & 64 & & 005 & \\
\hline Count & Percent & Count & Percent & Count & Percent & Count & Percent & Count & Percent & Count & Percent & Count & Percent & \\
\hline & & & & & & & & & & & & & & $\begin{array}{l}\text { Ephemeroptera } \\
\text { Heptageniidae }\end{array}$ \\
\hline - & & 1 & $<1$ & 2 & $<1$ & - & & - & & 1 & $<1$ & - & & Epeorus \\
\hline 270 & 14 & 49 & 3 & 270 & 18 & 83 & 6 & 79 & 8 & 62 & 8 & 86 & 9 & Stenonema \\
\hline 8 & $<1$ & - & & 7 & $<1$ & 1 & $<1$ & 4 & $<1$ & 1 & $<1$ & 25 & 3 & $\begin{array}{l}\text { Isonychiidae } \\
\text { Isonychia } \\
\text { Leptohyphidae }\end{array}$ \\
\hline - & & - & & 2 & $<1$ & 1 & $<1$ & 4 & $<1$ & 7 & $<1$ & 2 & $<1$ & Tricorythodes \\
\hline - & & - & & - & & - & & - & & - & & 1 & $<1$ & $\begin{array}{l}\text { Leptophlebiidae } \\
\text { Potamanthidae }\end{array}$ \\
\hline - & & - & & - & & - & & - & & 1 & $<1$ & - & & $\begin{array}{l}\text { Anthopotamus } \\
\text { Odonata } \\
\text { Coenagrionidae }\end{array}$ \\
\hline - & & 1 & $<1$ & - & & 4 & $<1$ & - & & 3 & $<1$ & 1 & $<1$ & $\begin{array}{c}\text { Argia } \\
\text { Plecoptera } \\
\text { Capniidae }\end{array}$ \\
\hline - & & - & & - & & - & & - & & - & & - & & Allocapnia \\
\hline- & & 1 & $<1$ & 2 & $<1$ & - & & - & & - & & 2 & $<1$ & $\begin{array}{l}\text { Chloroperlidae } \\
\text { Perlidae }\end{array}$ \\
\hline- & & - & & - & & - & & - & & - & & 1 & $<1$ & $\begin{array}{c}\text { Acroneuria } \\
\text { Taeniopterygidae }\end{array}$ \\
\hline- & & 2 & $<1$ & 1 & $<1$ & - & & - & & - & & - & & $\begin{array}{l}\text { Taeniopteryx } \\
\text { Megaloptera } \\
\text { Corydalidae }\end{array}$ \\
\hline - & & - & & - & & - & & - & & 1 & $<1$ & - & & $\begin{array}{l}\text { Corydalus } \\
\text { Neuroptera } \\
\text { Sisyridae } \\
\text { Climacia }\end{array}$ \\
\hline - & & - & & - & & - & & - & & - & & - & & $\begin{array}{l}\text { C. areolaris } \\
\text { Trichoptera } \\
\text { Apataniidae }\end{array}$ \\
\hline- & & - & & - & & - & & - & & 1 & $<1$ & - & & $\begin{array}{c}\text { Apatania } \\
\text { Brachycentridae }\end{array}$ \\
\hline- & & - & & - & & - & & 1 & $<1$ & - & & - & & $\begin{array}{c}\text { Micrasema } \\
\text { Glossosomatidae }\end{array}$ \\
\hline 3 & $<1$ & 5 & $<1$ & - & & - & & - & & - & & 2 & $<1$ & Glossosoma \\
\hline 3 & $<1$ & 44 & 3 & 4 & $<1$ & 75 & 5 & 10 & 1 & 27 & 3 & 5 & $<1$ & $\begin{array}{c}\text { Protoptila } \\
\text { Helicopsychidae }\end{array}$ \\
\hline- & & - & & 10 & $<1$ & 470 & 34 & 14 & 1 & 120 & 15 & 140 & 14 & $\begin{array}{l}\text { Helicopsyche } \\
\text { Hydropsychidae }\end{array}$ \\
\hline 730 & 38 & 400 & 25 & 480 & 32 & 220 & 16 & 150 & 15 & 54 & 7 & 120 & 12 & Ceratopsyche \\
\hline 280 & 15 & 69 & 4 & 69 & 5 & 52 & 4 & 27 & 3 & 8 & 1 & 110 & 11 & Cheumatopsyche \\
\hline 150 & 8 & 110 & 7 & 76 & 5 & 19 & 1 & 25 & 3 & 4 & $<1$ & 130 & 13 & $\begin{array}{l}\text { Hydropsyche } \\
\text { Hydroptilidae }\end{array}$ \\
\hline - & & - & & 1 & $<1$ & 3 & $<1$ & 2 & $<1$ & 5 & $<1$ & - & & Hydroptila \\
\hline 43 & 2 & 6 & $<1$ & 4 & $<1$ & 18 & 1 & 5 & $<1$ & 17 & 2 & 68 & 7 & $\begin{array}{c}\text { Leucotrichia } \\
\text { Lepidostomatidae }\end{array}$ \\
\hline- & & - & & 1 & $<1$ & 3 & $<1$ & 4 & $<1$ & 5 & $<1$ & 3 & $<1$ & $\begin{array}{l}\text { Lepidostoma } \\
\text { Leptoceridae }\end{array}$ \\
\hline- & & - & & - & & 1 & $<1$ & 3 & $<1$ & & & 1 & $<1$ & Mystacides \\
\hline- & & - & & 5 & $<1$ & 1 & $<1$ & - & & 2 & $<1$ & 6 & $<1$ & $\begin{array}{c}\text { Oecetis } \\
\text { Philopotamidae }\end{array}$ \\
\hline 5 & $<1$ & 8 & $<1$ & - & & 18 & 1 & 16 & 2 & 29 & 4 & 43 & 4 & Chimarra \\
\hline
\end{tabular}


Table 5. Benthic-macroinvertebrate data-Continued

01480640 - West Branch Brandywine Creek at Wawaset, Pa. (Site 38)—Continued

\begin{tabular}{|c|c|c|c|c|c|c|c|c|c|c|c|c|c|c|}
\hline \multirow{3}{*}{$\begin{array}{c}\text { Date } \\
\text { Total count } \\
\text { Organism }\end{array}$} & \multirow{2}{*}{\multicolumn{2}{|c|}{$\begin{array}{c}\text { Nov. } 4,1981 \\
598\end{array}$}} & \multirow{2}{*}{\multicolumn{2}{|c|}{$\begin{array}{c}\text { Oct. } 21,1982 \\
1,655\end{array}$}} & \multirow{2}{*}{\multicolumn{2}{|c|}{$\begin{array}{c}\text { Oct. } 31,1983 \\
1,110\end{array}$}} & \multirow{2}{*}{\multicolumn{2}{|c|}{$\begin{array}{c}\text { Oct. } 16,1984 \\
1,402\end{array}$}} & \multirow{2}{*}{\multicolumn{2}{|c|}{$\begin{array}{c}\text { Oct. } 22,1985 \\
1,085\end{array}$}} & \multirow{2}{*}{\multicolumn{2}{|c|}{$\begin{array}{c}\text { Nov. 3, } 1986 \\
769\end{array}$}} & \multirow{2}{*}{\multicolumn{2}{|c|}{$\begin{array}{c}\text { Nov. 3, } 1987 \\
402\end{array}$}} \\
\hline & & & & & & & & & & & & & & \\
\hline & Count & Percent & Count & Percent & Count & Percent & Count & Percent & Count & Percent & Count & Percent & Count & Percent \\
\hline \multicolumn{15}{|l|}{ Trichoptera } \\
\hline \multicolumn{15}{|l|}{ Polycentropodidae } \\
\hline Neureclipsis & 1 & $<1$ & 6 & $<1$ & - & & - & & - & & 5 & $<1$ & - & \\
\hline Polycentropus & - & & - & & - & & - & & - & & - & & - & \\
\hline \multicolumn{15}{|l|}{ Psychomyiidae } \\
\hline Psychomyia & - & & - & & - & & - & & - & & - & & 1 & $<1$ \\
\hline \multicolumn{15}{|l|}{ Lepidoptera } \\
\hline \multicolumn{15}{|l|}{ Pyralidae } \\
\hline Petrophila & 5 & $<1$ & 9 & $<1$ & 19 & 2 & 9 & $<1$ & 19 & 2 & 26 & 3 & 3 & $<1$ \\
\hline Synclita & - & & 1 & $<1$ & - & & - & & - & & - & & - & \\
\hline \multicolumn{15}{|l|}{ Coleoptera } \\
\hline Curculionidae & - & & - & & - & & - & & - & & - & & - & \\
\hline \multicolumn{15}{|l|}{ Elmidae } \\
\hline Dubiraphia & 1 & $<1$ & - & & 1 & $<1$ & - & & - & & - & & - & \\
\hline Optioservus & - & & - & & 19 & 2 & 1 & $<1$ & 27 & 2 & 17 & 2 & 9 & 2 \\
\hline Oulimnius & 1 & $<1$ & - & & 1 & $<1$ & - & & 4 & $<1$ & - & & - & \\
\hline Stenelmis & 1 & $<1$ & 3 & $<1$ & 1 & $<1$ & 1 & $<1$ & 2 & $<1$ & 1 & $<1$ & - & \\
\hline \multicolumn{15}{|l|}{ Hydrophilidae } \\
\hline Berosus & - & & - & & - & & - & & - & & - & & - & \\
\hline \multicolumn{15}{|l|}{ Psephenidae } \\
\hline Psephenus & 2 & $<1$ & - & & - & & - & & - & & - & & - & \\
\hline Hymenoptera & - & & - & & - & & - & & 1 & $<1$ & 1 & $<1$ & - & \\
\hline \multicolumn{15}{|l|}{ Diptera } \\
\hline \multicolumn{15}{|l|}{ Athericidae } \\
\hline Atherix & - & & - & & - & & - & & - & & - & & - & \\
\hline Chironomidae & 58 & 10 & 240 & 14 & 74 & 7 & 410 & 29 & 630 & 57 & 86 & 11 & 94 & 23 \\
\hline \multicolumn{15}{|l|}{ Empididae } \\
\hline Hemerodromia & 1 & $<1$ & 1 & $<1$ & 1 & $<1$ & - & & 1 & $<1$ & - & & - & \\
\hline \multicolumn{15}{|l|}{ Simuliidae } \\
\hline Simulium & 5 & $<1$ & 71 & 4 & 16 & 1 & 340 & 24 & 26 & 2 & 45 & 6 & 40 & 10 \\
\hline \multicolumn{15}{|l|}{ Tipulidae } \\
\hline Antocha & 4 & $<1$ & 42 & 2 & 56 & 5 & 100 & 7 & 40 & 4 & 66 & 8 & 7 & 2 \\
\hline Tipula & - & & - & & - & & - & & - & & - & & - & \\
\hline
\end{tabular}




\begin{tabular}{|c|c|c|c|c|c|c|c|c|c|c|c|c|c|c|}
\hline \multirow{2}{*}{\multicolumn{2}{|c|}{$\begin{array}{c}\text { Oct. } 11,1988 \\
{ }^{1} 1,939\end{array}$}} & \multirow{2}{*}{\multicolumn{2}{|c|}{$\begin{array}{c}\text { Oct. } 13,1989 \\
1.631\end{array}$}} & \multicolumn{2}{|c|}{ Oct. 15,1990} & \multicolumn{2}{|c|}{ Oct. 30, 1991} & \multicolumn{2}{|c|}{ Oct. 29,1992} & \multicolumn{2}{|c|}{ Nov. 15,1993} & \multicolumn{2}{|c|}{ Oct. 11,1994} & \multirow{2}{*}{$\begin{array}{c}\text { Date } \\
\text { Total count }\end{array}$} \\
\hline & & & & & 532 & & 418 & & 041 & & 64 & & 005 & \\
\hline Count & Percent & Count & Percent & Count & Percent & Count & Percent & Count & Percent & Count & Percent & Count & Percent & Organism \\
\hline & & & & & & & & & & & & & & Trichoptera \\
\hline & & & & & & & & & & & & & & Polycentropodidae \\
\hline 3 & $<1$ & - & & 9 & $<1$ & 2 & $<1$ & & & 1 & $<1$ & 3 & $<1$ & Neureclipsis \\
\hline - & & - & & 4 & $<1$ & - & & - & & - & & - & & Polycentropus \\
\hline & & & & & & & & & & & & & & Psychomyiidae \\
\hline 5 & $<1$ & 28 & 2 & 66 & 4 & 5 & $<1$ & 6 & $<1$ & 13 & 2 & 9 & $<1$ & Psychomyia \\
\hline & & & & & & & & & & & & & & $\begin{array}{l}\text { Lepidoptera } \\
\text { Pyralidae }\end{array}$ \\
\hline 19 & 1 & 9 & $<1$ & 16 & 1 & 11 & $<1$ & 10 & 1 & 5 & $<1$ & 18 & 2 & Petrophila \\
\hline - & & - & & - & & - & & - & & - & & - & & Synclita \\
\hline & & & & & & & & & & & & & & Coleoptera \\
\hline - & & - & & - & & - & & - & & - & & 1 & $<1$ & $\begin{array}{l}\text { Curculionidae } \\
\text { Elmidae }\end{array}$ \\
\hline - & & - & & 2 & $<1$ & - & & - & & 1 & $<1$ & - & & Dubiraphia \\
\hline 16 & $<1$ & 41 & 3 & 19 & 1 & 51 & 4 & 42 & 4 & 22 & 3 & 16 & 2 & Optioservus \\
\hline - & & - & & - & & - & & - & & - & & - & & Oulimnius \\
\hline 11 & $<1$ & 31 & 2 & 9 & $<1$ & 13 & $<1$ & 4 & $<1$ & 6 & $<1$ & 7 & $<1$ & $\begin{array}{c}\text { Stenelmis } \\
\text { Hydrophilidae }\end{array}$ \\
\hline - & & - & & - & & - & & 1 & $<1$ & - & & - & & $\begin{array}{c}\text { Berosus } \\
\text { Psephenidae }\end{array}$ \\
\hline - & & - & & 1 & $<1$ & - & & 1 & $<1$ & 5 & $<1$ & - & & Psephenus \\
\hline- & & - & & - & & - & & - & & - & & - & & $\begin{array}{l}\text { Hymenoptera } \\
\text { Diptera }\end{array}$ \\
\hline & & & & & & & & & & & & & & Athericidae \\
\hline - & & 1 & $<1$ & - & & - & & - & & - & & - & & Atherix \\
\hline 180 & 9 & 610 & 38 & 220 & 15 & 220 & 16 & 340 & 34 & 170 & 22 & 64 & 6 & $\begin{array}{l}\text { Chironomidae } \\
\text { Empididae }\end{array}$ \\
\hline - & & 14 & $<1$ & 1 & $<1$ & - & & 2 & $<1$ & 4 & $<1$ & - & & $\begin{array}{l}\text { Hemerodromia } \\
\text { Simuliidae }\end{array}$ \\
\hline 67 & 4 & 18 & 1 & 18 & 1 & 4 & $<1$ & 59 & 6 & 2 & $<1$ & 3 & $<1$ & $\begin{array}{l}\text { Simulium } \\
\text { Tipulidae }\end{array}$ \\
\hline 8 & $<1$ & 60 & 4 & 76 & 5 & 47 & 3 & 45 & 5 & 23 & 3 & 12 & 1 & Antocha \\
\hline - & & 1 & $<1$ & - & & 1 & $<1$ & 1 & $<1$ & - & & - & & Tipula \\
\hline
\end{tabular}

\footnotetext{
${ }^{1}$ Extrapolated from a 3/8 subsample.
} 
Table 5. Benthic-macroinvertebrate data-Continued

$[<$, less than; - , not found $]$

01480647 - E Br Brandywine Creek near Struble Dam, Pa. (Site 43)

\begin{tabular}{|c|c|c|c|c|}
\hline \multirow{3}{*}{$\begin{array}{c}\text { Date } \\
\text { Total count } \\
\text { Organism }\end{array}$} & \multirow{2}{*}{\multicolumn{2}{|c|}{$\begin{array}{c}\text { Oct. } 22,1981 \\
303\end{array}$}} & \multirow{2}{*}{\multicolumn{2}{|c|}{$\frac{\text { Nov. 3, } 1982}{566}$}} \\
\hline & & & & \\
\hline & Count & Percent & Count & Percent \\
\hline \multicolumn{5}{|l|}{ Platyhelminthes (flatworms) } \\
\hline \multicolumn{5}{|l|}{ Turbellaria } \\
\hline \multicolumn{5}{|l|}{ Tricladida } \\
\hline Planariidae & 150 & 48 & 100 & 18 \\
\hline \multicolumn{5}{|l|}{ Nemertea (proboscis worms) } \\
\hline \multicolumn{5}{|l|}{ Enopla } \\
\hline \multicolumn{5}{|l|}{ Hoplonemertea } \\
\hline \multicolumn{5}{|l|}{ Tetrastemmatidae } \\
\hline Prostoma & 7 & 2 & 9 & 2 \\
\hline \multicolumn{5}{|l|}{ Mollusca (molluscs) } \\
\hline \multicolumn{5}{|l|}{ Gastropoda } \\
\hline \multicolumn{5}{|l|}{ Basommatophora } \\
\hline \multicolumn{5}{|l|}{ Ancylidae } \\
\hline Ferrissia & - & & 3 & $<1$ \\
\hline \multicolumn{5}{|l|}{ Physidae } \\
\hline Physa & 4 & 1 & - & \\
\hline \multicolumn{5}{|l|}{ Bivalvia } \\
\hline \multicolumn{5}{|l|}{ Veneroida } \\
\hline Sphaeriidae & 2 & $<1$ & 14 & 2 \\
\hline \multicolumn{5}{|l|}{ Annelida (segmented worms) } \\
\hline Oligochaeta & 1 & $<1$ & - & \\
\hline \multicolumn{5}{|l|}{ Lumbriculida } \\
\hline Lumbriculidae & - & & 1 & $<1$ \\
\hline \multicolumn{5}{|l|}{ Tubificida } \\
\hline Naididae & 51 & 16 & 13 & 2 \\
\hline \multicolumn{5}{|l|}{ Arthropoda (arthropods) } \\
\hline Acariformes & & & & \\
\hline Hydrachnidia & 4 & 1 & 35 & 6 \\
\hline Crustacea & & & & \\
\hline Amphipoda & & & & \\
\hline Gammaridae & & & & \\
\hline Gammarus & 5 & 2 & - & \\
\hline Podocopa & 35 & 11 & 10 & 2 \\
\hline Insecta & & & & \\
\hline Ephemeroptera & & & & \\
\hline Baetidae & & & & \\
\hline Baetis & 1 & $<1$ & 1 & $<1$ \\
\hline Ephemerellidae & & & & \\
\hline Ephemerella & - & & 3 & $<1$ \\
\hline Odonata & & & & \\
\hline Calopterygidae & & & & \\
\hline Calopteryx & 2 & $<1$ & - & \\
\hline Coenagrionidae & & & & \\
\hline Enallagma & 6 & 2 & - & \\
\hline Megaloptera & & & & \\
\hline Corydalidae & & & & \\
\hline Nigronia & - & & 1 & $<1$ \\
\hline Sialidae & & & & \\
\hline Sialis & 3 & 1 & - & \\
\hline
\end{tabular}


Table 5. Benthic-macroinvertebrate data-Continued

01480647 - E Br Brandywine Creek near Struble Dam, Pa. (Site 43)—Continued

\begin{tabular}{|c|c|c|c|c|}
\hline Date & \multicolumn{2}{|c|}{ Oct. 22,1981} & \multicolumn{2}{|c|}{ Nov. 3, 1982} \\
\hline Total count & \multicolumn{2}{|c|}{303} & \multicolumn{2}{|c|}{566} \\
\hline Organism & Count & Percent & Count & Percen \\
\hline \multicolumn{5}{|l|}{ Trichoptera } \\
\hline \multicolumn{5}{|l|}{ Hydropsychidae } \\
\hline Cheumatopsyche & - & & 54 & 9 \\
\hline Hydropsyche & 7 & 2 & 15 & 3 \\
\hline \multicolumn{5}{|l|}{ Hydroptilidae } \\
\hline Hydroptila & 10 & 3 & 43 & 8 \\
\hline Orthotrichia & - & & 1 & $<1$ \\
\hline \multicolumn{5}{|l|}{ Leptoceridae } \\
\hline Mystacides & - & & 1 & $<1$ \\
\hline Oecetis & 1 & $<1$ & - & \\
\hline Triaenodes & - & & 6 & 1 \\
\hline \multicolumn{5}{|l|}{ Psychomyiidae } \\
\hline Psychomyia & - & & 3 & $<1$ \\
\hline \multicolumn{5}{|l|}{ Coleoptera } \\
\hline \multicolumn{5}{|l|}{ Elmidae } \\
\hline Dubiraphia & 1 & $<1$ & 6 & 1 \\
\hline Optioservus & - & & 3 & $<1$ \\
\hline Stenelmis & 2 & $<1$ & 4 & $<1$ \\
\hline \multicolumn{5}{|l|}{ Diptera } \\
\hline Chironomidae & 7 & 2 & 63 & 11 \\
\hline \multicolumn{5}{|l|}{ Empididae } \\
\hline Hemerodromia & - & & 6 & 1 \\
\hline \multicolumn{5}{|l|}{ Psychodidae } \\
\hline Telmatoscopus & 1 & $<1$ & - & \\
\hline \multicolumn{5}{|l|}{ Simuliidae } \\
\hline Simulium & 2 & $<1$ & 160 & 28 \\
\hline \multicolumn{5}{|l|}{ Tipulidae } \\
\hline Antocha & 1 & $<1$ & 11 & 2 \\
\hline
\end{tabular}


Table 5. Benthic-macroinvertebrate data-Continued

$[<$, less than; - , not found]

01480648 - East Branch Brandywine Creek near Cupola, Pa. (Site 48)

\begin{tabular}{|c|c|c|c|c|c|c|c|c|c|c|c|c|c|c|}
\hline \multirow{3}{*}{$\begin{array}{c}\text { Date } \\
\text { Total count } \\
\text { Organism }\end{array}$} & \multirow{2}{*}{\multicolumn{2}{|c|}{$\begin{array}{c}\text { Oct. } 22,1981 \\
1,310\end{array}$}} & \multirow{2}{*}{\multicolumn{2}{|c|}{$\begin{array}{c}\text { Nov. 3, } 1982 \\
2,529\end{array}$}} & \multirow{2}{*}{\multicolumn{2}{|c|}{$\frac{\text { Nov. 3, } 1983}{733}$}} & \multirow{2}{*}{\multicolumn{2}{|c|}{$\begin{array}{c}\text { Oct. } 17,1984 \\
1,652\end{array}$}} & \multirow{2}{*}{\multicolumn{2}{|c|}{$\frac{\text { Oct. 23, } 1985}{689}$}} & \multirow{2}{*}{\multicolumn{2}{|c|}{$\frac{\text { Oct. } 29,1986}{895}$}} & \multirow{2}{*}{\multicolumn{2}{|c|}{$\begin{array}{c}\text { Oct. 19. } 1987 \\
1,139\end{array}$}} \\
\hline & & & & & & & & & & & & & & \\
\hline & Count & Percent & Count & Percent & Count & Percent & Count & Percent & Count & Percent & Count & Percent & Count & Percent \\
\hline \multicolumn{15}{|l|}{ Platyhelminthes (flatworms) } \\
\hline \multicolumn{15}{|l|}{ Turbellaria } \\
\hline \multicolumn{15}{|l|}{ Tricladida } \\
\hline Planariidae & 10 & $<1$ & 63 & 3 & 41 & 6 & 76 & 4 & 47 & 7 & 3 & $<1$ & 41 & 4 \\
\hline Nematoda (nematodes) & - & & - & & - & & - & & - & & - & & - & \\
\hline \multicolumn{15}{|l|}{ Nemertea (proboscis worms) } \\
\hline \multicolumn{15}{|l|}{ Enopla } \\
\hline \multicolumn{15}{|l|}{ Hoplonemertea } \\
\hline Tetrastemmatidae & & & & & & & & & & & & & & \\
\hline Prostoma & 10 & $<1$ & 13 & $<1$ & 10 & 1 & 6 & $<1$ & 7 & 1 & 1 & $<1$ & - & \\
\hline Mollusca (molluscs) & & & & & & & & & & & & & & \\
\hline Gastropoda & & & & & & & & & & & & & & \\
\hline Basommatophora & & & & & & & & & & & & & & \\
\hline Ancylidae & & & & & & & & & & & & & & \\
\hline Ferrissia & - & & 1 & $<1$ & - & & - & & - & & - & & - & \\
\hline Physidae & & & & & & & & & & & & & & \\
\hline Physa & - & & - & & - & & - & & - & & - & & - & \\
\hline Bivalvia & & & & & & & & & & & & & & \\
\hline Veneroida & & & & & & & & & & & & & & \\
\hline Sphaeriidae & 8 & $<1$ & - & & 1 & $<1$ & - & & 1 & $<1$ & - & & - & \\
\hline Pisidium & - & & - & & - & & - & & - & & - & & - & \\
\hline Annelida (segmented worms) & & & & & & & & & & & & & & \\
\hline Oligochaeta & - & & - & & - & & - & & - & & - & & - & \\
\hline Lumbriculida & & & & & & & & & & & & & & \\
\hline Lumbriculidae & - & & - & & - & & - & & 1 & $<1$ & 2 & $<1$ & 1 & $<1$ \\
\hline Tubificida & & & & & & & & & & & & & & \\
\hline Naididae & 30 & 2 & - & & 9 & 1 & - & & - & & - & & 31 & 3 \\
\hline Tubificidae & - & & - & & - & & - & & - & & - & & - & \\
\hline Arthropoda (arthropods) & & & & & & & & & & & & & & \\
\hline Acariformes & & & & & & & & & & & & & & \\
\hline Hydrachnidia & 31 & 2 & 1 & $<1$ & 3 & $<1$ & - & & 6 & $<1$ & 1 & $<1$ & 8 & $<1$ \\
\hline Crustacea & & & & & & & & & & & & & & \\
\hline Cladocera & - & & - & & - & & - & & - & & - & & - & \\
\hline Cyclopoida & - & & - & & - & & - & & - & & - & & - & \\
\hline Amphipoda & & & & & & & & & & & & & & \\
\hline Gammaridae & & & & & & & & & & & & & & \\
\hline Gammarus & - & & - & & - & & - & & - & & - & & 4 & $<1$ \\
\hline Isopoda & & & & & & & & & & & & & & \\
\hline Asellidae & & & & & & & & & & & & & & \\
\hline Caecidotea & - & & 1 & $<1$ & 1 & $<1$ & - & & 2 & $<1$ & - & & - & \\
\hline Podocopa & 14 & 1 & 1 & $<1$ & 1 & $<1$ & 1 & $<1$ & - & & - & & 3 & $<1$ \\
\hline Insecta & & & & & & & & & & & & & & \\
\hline Ephemeroptera & & & & & & & & & & & & & & \\
\hline Baetidae & & & & & & & & & & & & & & \\
\hline Baetis & 35 & 3 & 52 & 2 & 5 & $<1$ & 9 & $<1$ & 4 & $<1$ & 6 & $<1$ & 13 & 1 \\
\hline Pseudocloeon & 1 & $<1$ & 3 & $<1$ & - & & - & & - & & - & & 5 & $<1$ \\
\hline Ephemerellidae & & & & & & & & & & & & & & \\
\hline Ephemerella & 30 & 2 & 24 & $<1$ & 28 & 4 & 14 & $<1$ & 1 & $<1$ & 2 & $<1$ & 18 & 2 \\
\hline Ephemeridae & & & & & & & & & & & & & & \\
\hline Ephemera & - & & - & & - & & - & & - & & - & & - & \\
\hline Heptageniidae & & & & & & & & & & & & & & \\
\hline Epeorus & 7 & $<1$ & - & & - & & - & & - & & - & & - & \\
\hline Stenonema & 40 & 3 & 110 & 4 & 70 & 9 & 120 & 7 & 46 & 7 & 71 & 8 & 69 & 6 \\
\hline
\end{tabular}




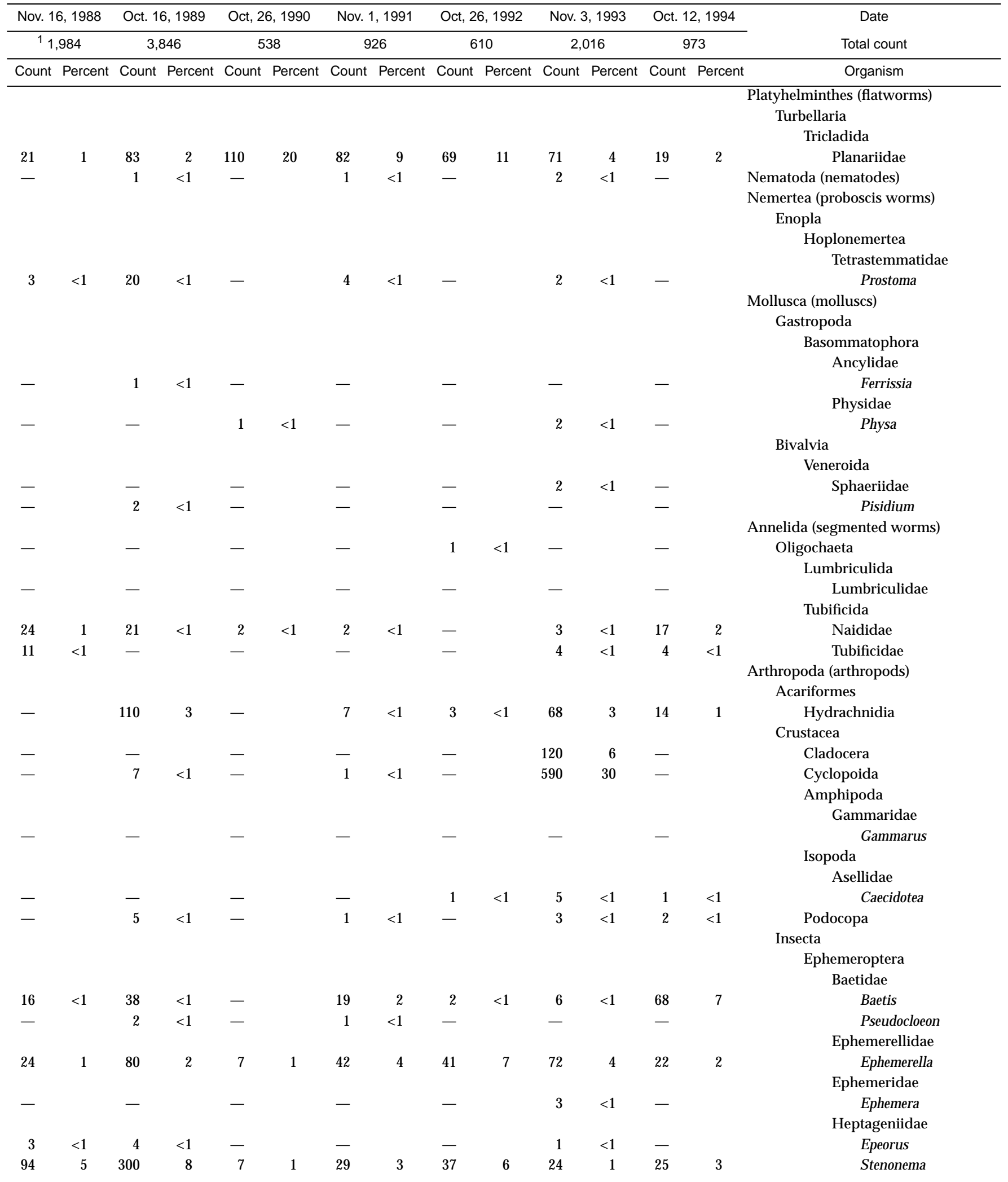


Table 5. Benthic-macroinvertebrate data-Continued

01480648 - East Branch Brandywine Creek near Cupola, Pa. (Site 48)—Continued

\begin{tabular}{|c|c|c|c|c|c|c|c|c|c|c|c|c|c|c|}
\hline \multirow{3}{*}{$\begin{array}{c}\text { Date } \\
\text { Total count } \\
\text { Organism }\end{array}$} & \multirow{2}{*}{\multicolumn{2}{|c|}{$\begin{array}{c}\text { Oct. } 22,1981 \\
1,310\end{array}$}} & \multirow{2}{*}{\multicolumn{2}{|c|}{$\begin{array}{c}\text { Nov. 3, } 1982 \\
2,529\end{array}$}} & \multirow{2}{*}{\multicolumn{2}{|c|}{$\begin{array}{c}\text { Nov. 3, } 1983 \\
733\end{array}$}} & \multirow{2}{*}{\multicolumn{2}{|c|}{$\begin{array}{c}\text { Oct. } 17,1984 \\
1,652\end{array}$}} & \multirow{2}{*}{\multicolumn{2}{|c|}{$\begin{array}{c}\text { Oct. 23, } 1985 \\
689\end{array}$}} & \multirow{2}{*}{\multicolumn{2}{|c|}{$\begin{array}{c}\text { Oct. } 29,1986 \\
895\end{array}$}} & \multirow{2}{*}{\multicolumn{2}{|c|}{$\begin{array}{c}\text { Oct. 19. } 1987 \\
1,139\end{array}$}} \\
\hline & & & & & & & & & & & & & & \\
\hline & Count & Percent & Count & Percent & Count & Percent & Count & Percent & Count & Percent & Count & Percent & Count & Percent \\
\hline \multicolumn{15}{|l|}{ Ephemeroptera } \\
\hline \multicolumn{15}{|l|}{ Isonychiidae } \\
\hline Isonychia & - & & - & & 1 & $<1$ & - & & - & & 2 & $<1$ & - & \\
\hline \multicolumn{15}{|l|}{ Leptohyphidae } \\
\hline Tricorythodes & 3 & $<1$ & 1 & $<1$ & - & & - & & - & & - & & - & \\
\hline Leptophlebiidae & - & & 2 & $<1$ & - & & - & & - & & - & & - & \\
\hline Paraleptophlebia & 7 & $<1$ & - & & - & & - & & - & & - & & - & \\
\hline \multicolumn{15}{|l|}{ Odonata } \\
\hline \multicolumn{15}{|l|}{ Coenagrionidae } \\
\hline Argia & - & & - & & - & & - & & - & & - & & - & \\
\hline Aeshnidae & & & & & & & & & & & & & & \\
\hline Boyeria & - & & - & & 1 & $<1$ & - & & - & & - & & - & \\
\hline Gomphidae & - & & - & & - & & - & & - & & - & & - & \\
\hline Plecoptera & & & & & & & & & & & & & & \\
\hline Capniidae & & & & & & & & & & & & & & \\
\hline Allocapnia & - & & - & & - & & - & & - & & - & & 4 & $<1$ \\
\hline Perlidae & & & & & & & & & & & & & & \\
\hline Agnetina & 2 & $<1$ & 2 & $<1$ & - & & - & & - & & - & & - & \\
\hline Paragnetina & 1 & $<1$ & 4 & $<1$ & 1 & $<1$ & - & & - & & - & & - & \\
\hline Taeniopterygidae & & & & & & & & & & & & & & \\
\hline Taeniopteryx & 4 & $<1$ & 21 & $<1$ & 7 & 1 & 15 & $<1$ & 26 & 4 & 30 & 3 & 36 & 3 \\
\hline Hemiptera & & & & & & & & & & & & & & \\
\hline Veliidae & & & & & & & & & & & & & & \\
\hline Rhagovelia & 5 & $<1$ & 1 & $<1$ & - & & - & & - & & - & & - & \\
\hline Megaloptera & & & & & & & & & & & & & & \\
\hline Corydalidae & & & & & & & & & & & & & & \\
\hline Corydalus & 1 & $<1$ & - & & - & & - & & - & & - & & - & \\
\hline Nigronia & 2 & $<1$ & - & & 3 & $<1$ & - & & - & & - & & 1 & $<1$ \\
\hline Sialidae & & & & & & & & & & & & & & \\
\hline Sialis & - & & - & & - & & - & & 1 & $<1$ & - & & - & \\
\hline Trichoptera & & & & & & & & & & & & & & \\
\hline Apataniidae & & & & & & & & & & & & & & \\
\hline Apatania & - & & 2 & $<1$ & 2 & $<1$ & - & & - & & 1 & $<1$ & 2 & $<1$ \\
\hline Brachycentridae & & & & & & & & & & & & & & \\
\hline Micrasema & 11 & $<1$ & - & & - & & - & & - & & - & & - & \\
\hline Glossosomatidae & & & & & & & & & & & & & & \\
\hline Glossosoma & 9 & $<1$ & 24 & $<1$ & 16 & 2 & 44 & 3 & 7 & 1 & 16 & 2 & 1 & $<1$ \\
\hline Goeridae & & & & & & & & & & & & & & \\
\hline Goera & - & & 1 & $<1$ & - & & - & & - & & 3 & $<1$ & - & \\
\hline Helicopsychidae & & & & & & & & & & & & & & \\
\hline Helicopsyche & - & & - & & - & & - & & - & & - & & - & \\
\hline Hydropsychidae & & & & & & & & & & & & & & \\
\hline Ceratopsyche & 95 & 7 & 320 & 13 & 170 & 23 & 400 & 24 & 58 & 8 & 130 & 14 & 32 & 3 \\
\hline Cheumatopsyche & 82 & 6 & 190 & 8 & 84 & 11 & 130 & 8 & 15 & 2 & 38 & 4 & 26 & 2 \\
\hline Hydropsyche & 180 & 14 & 89 & 4 & 79 & 11 & 410 & 24 & 150 & 21 & 68 & 8 & 130 & 12 \\
\hline Hydroptilidae & & & & & & & & & & & & & & \\
\hline Hydroptila & 57 & 4 & 3 & $<1$ & 2 & $<1$ & - & & 7 & 1 & 13 & 1 & 2 & $<1$ \\
\hline Leucotrichia & 84 & 6 & 680 & 27 & - & & 23 & 1 & 12 & 2 & 15 & 2 & 2 & $<1$ \\
\hline Leptoceridae & & & & & & & & & & & & & & \\
\hline Mystacides & 33 & 3 & 1 & $<1$ & 2 & $<1$ & - & & - & & 8 & $<1$ & - & \\
\hline Oecetis & 5 & $<1$ & - & & 4 & $<1$ & 1 & $<1$ & 2 & $<1$ & - & & - & \\
\hline Limnephilidae & & & & & & & & & & & & & & \\
\hline Hydatophylax & - & & - & & - & & - & & - & & - & & - & \\
\hline Odontoceridae & & & & & & & & & & & & & & \\
\hline Psilotreta & - & & 1 & $<1$ & - & & - & & - & & - & & - & \\
\hline
\end{tabular}




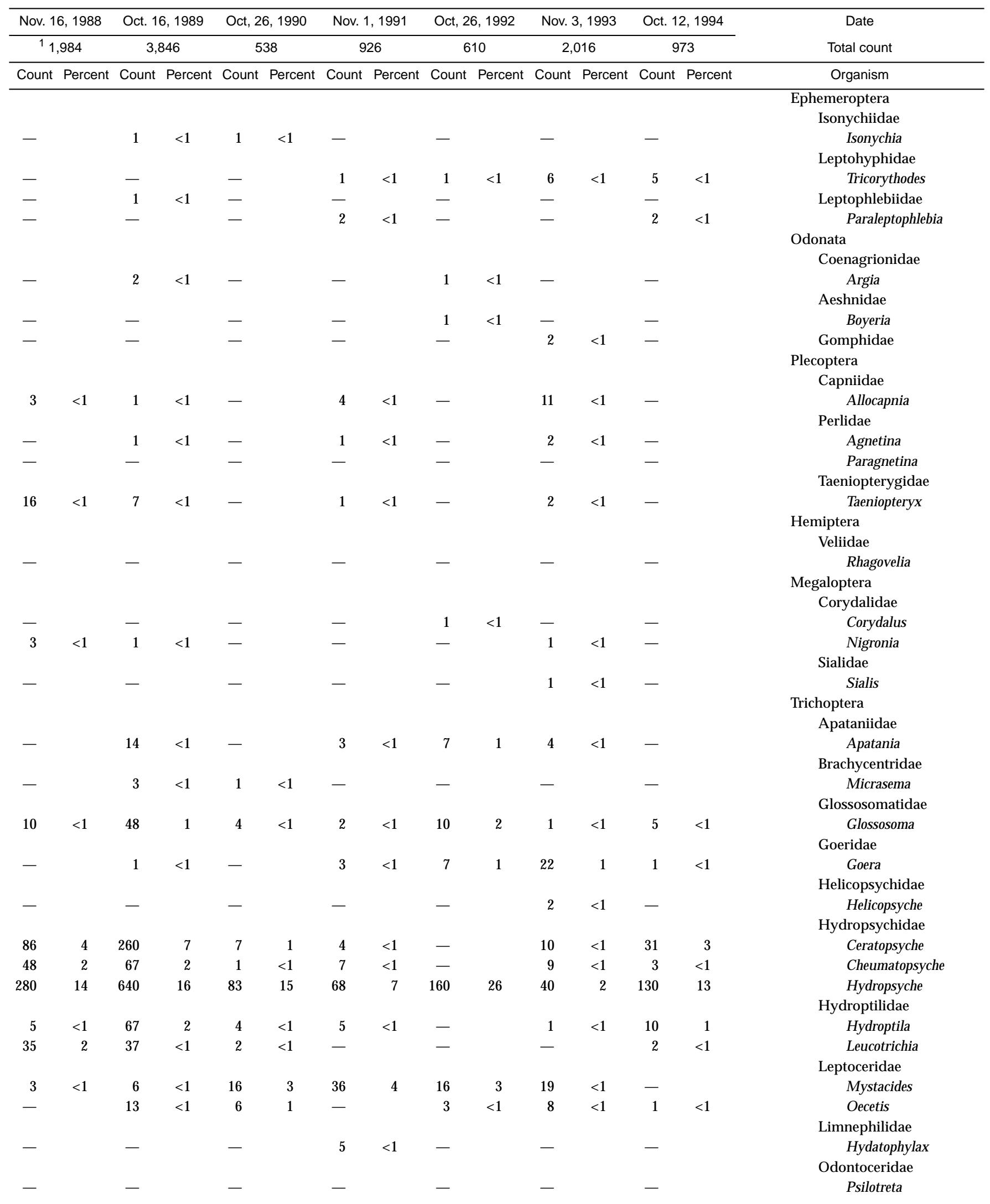


Table 5. Benthic-macroinvertebrate data-Continued

01480648 - East Branch Brandywine Creek near Cupola, Pa. (Site 48)—Continued

\begin{tabular}{|c|c|c|c|c|c|c|c|c|c|c|c|c|c|c|}
\hline \multirow{3}{*}{$\begin{array}{c}\text { Date } \\
\text { Total count } \\
\text { Organism }\end{array}$} & \multirow{2}{*}{\multicolumn{2}{|c|}{$\begin{array}{c}\text { Oct. } 22,1981 \\
1,310\end{array}$}} & \multirow{2}{*}{\multicolumn{2}{|c|}{$\begin{array}{c}\text { Nov. 3, } 1982 \\
2,529\end{array}$}} & \multirow{2}{*}{\multicolumn{2}{|c|}{$\begin{array}{c}\text { Nov. 3, } 1983 \\
733\end{array}$}} & \multirow{2}{*}{\multicolumn{2}{|c|}{$\begin{array}{c}\text { Oct. } 17,1984 \\
1,652\end{array}$}} & \multirow{2}{*}{\multicolumn{2}{|c|}{$\begin{array}{c}\text { Oct. 23, } 1985 \\
689\end{array}$}} & \multirow{2}{*}{\multicolumn{2}{|c|}{$\begin{array}{c}\text { Oct. } 29,1986 \\
895\end{array}$}} & \multirow{2}{*}{\multicolumn{2}{|c|}{$\begin{array}{c}\text { Oct. } 19.1987 \\
1,139\end{array}$}} \\
\hline & & & & & & & & & & & & & & \\
\hline & Count & Percent & Count & Percent & Count & Percent & Count & Percent & Count & Percent & Count & Percent & Count & Percent \\
\hline \multicolumn{15}{|l|}{ Trichoptera } \\
\hline \multicolumn{15}{|l|}{ Philopotamidae } \\
\hline Chimarra & 86 & 7 & 18 & $<1$ & 1 & $<1$ & 1 & $<1$ & 5 & $<1$ & 32 & 4 & 12 & 1 \\
\hline Dolophilodes & - & & - & & - & & 1 & $<1$ & - & & - & & - & \\
\hline \multicolumn{15}{|l|}{ Polycentropodidae } \\
\hline Cyrnellus & 1 & $<1$ & - & & - & & - & & - & & - & & - & \\
\hline Neureclipsis & 1 & $<1$ & - & & 1 & $<1$ & 1 & $<1$ & - & & 1 & $<1$ & - & \\
\hline Nyctiophylax & - & & - & & - & & - & & - & & - & & - & \\
\hline Polycentropus & 1 & $<1$ & - & & - & & 1 & $<1$ & - & & - & & - & \\
\hline \multicolumn{15}{|l|}{ Psychomyiidae } \\
\hline Psychomyia & - & & - & & - & & - & & - & & 2 & $<1$ & - & \\
\hline \multicolumn{15}{|l|}{ Rhyacophilidae } \\
\hline Rhyacophila & 1 & $<1$ & - & & - & & - & & - & & - & & - & \\
\hline \multicolumn{15}{|l|}{ Uenoidae } \\
\hline Neophylax & - & & - & & - & & - & & - & & - & & - & \\
\hline \multicolumn{15}{|l|}{ Lepidoptera } \\
\hline Pyralidae & & & & & & & & & & & & & & \\
\hline Petrophila & - & & - & & - & & - & & - & & - & & - & \\
\hline Coleoptera & & & & & & & & & & & & & & \\
\hline Dryopidae & & & & & & & & & & & & & & \\
\hline Helichus & - & & - & & - & & - & & - & & 1 & $<1$ & - & \\
\hline Elmidae & & & & & & & & & & & & & & \\
\hline Ancyronyx & - & & - & & - & & - & & - & & 3 & $<1$ & - & \\
\hline Dubiraphia & 1 & $<1$ & - & & 6 & $<1$ & - & & - & & - & & 1 & $<1$ \\
\hline Macronychus & & & & & & & & & & & & & & \\
\hline M. glabratus & 1 & $<1$ & - & & - & & - & & 2 & $<1$ & - & & - & \\
\hline Optioservus & 41 & 3 & 23 & $<1$ & 8 & 1 & 2 & $<1$ & 13 & 2 & 76 & 8 & 59 & 5 \\
\hline Oulimnius & - & & - & & - & & - & & - & & 3 & $<1$ & - & \\
\hline Stenelmis & 92 & 7 & 20 & $<1$ & 37 & 5 & 9 & $<1$ & 18 & 3 & 14 & 2 & 37 & 3 \\
\hline Gyrinidae & & & & & & & & & & & & & & \\
\hline Dineutus & - & & - & & - & & - & & - & & - & & - & \\
\hline Hydrophilidae & & & & & & & & & & & & & & \\
\hline Berosus & - & & - & & - & & - & & - & & - & & - & \\
\hline Hydrochara & - & & - & & - & & - & & - & & - & & - & \\
\hline Psephenidae & & & & & & & & & & & & & & \\
\hline Ectopria & - & & - & & - & & - & & - & & - & & - & \\
\hline E. nervosa & - & & - & & - & & - & & - & & 1 & $<1$ & - & \\
\hline Psephenus & 3 & $<1$ & 1 & $<1$ & - & & 2 & $<1$ & 7 & 1 & 10 & 1 & 2 & $<1$ \\
\hline Hymenoptera & - & & - & & - & & - & & 1 & $<1$ & 1 & $<1$ & - & \\
\hline Diptera & & & & & & & & & & & & & & \\
\hline Ceratopogonidae & 1 & $<1$ & - & & - & & - & & - & & - & & - & \\
\hline Chironomidae & 220 & 17 & 220 & 9 & 71 & 10 & 130 & 8 & 160 & 23 & 160 & 18 & 470 & 43 \\
\hline Empididae & & & & & & & & & & & & & & \\
\hline Hemerodromia & 13 & 1 & 10 & $<1$ & 7 & 1 & 2 & $<1$ & 2 & $<1$ & 1 & $<1$ & 1 & $<1$ \\
\hline Ephydridae & - & & - & & - & & - & & - & & - & & 2 & $<1$ \\
\hline Simuliidae & & & & & & & & & & & & & & \\
\hline Simulium & 1 & $<1$ & 560 & 22 & 38 & 5 & 220 & 13 & 59 & 8 & 50 & 6 & 100 & 9 \\
\hline Tipulidae & & & & & & & & & & & & & & \\
\hline Antocha & 50 & 4 & 66 & 3 & 23 & 3 & 34 & 2 & 29 & 4 & 130 & 14 & 25 & 2 \\
\hline Dicranota & - & & - & & - & & - & & - & & - & & - & \\
\hline Tipula & - & & - & & - & & - & & - & & - & & 1 & $<1$ \\
\hline
\end{tabular}

${ }^{1}$ Extrapolated from a 3/8 subsample. 


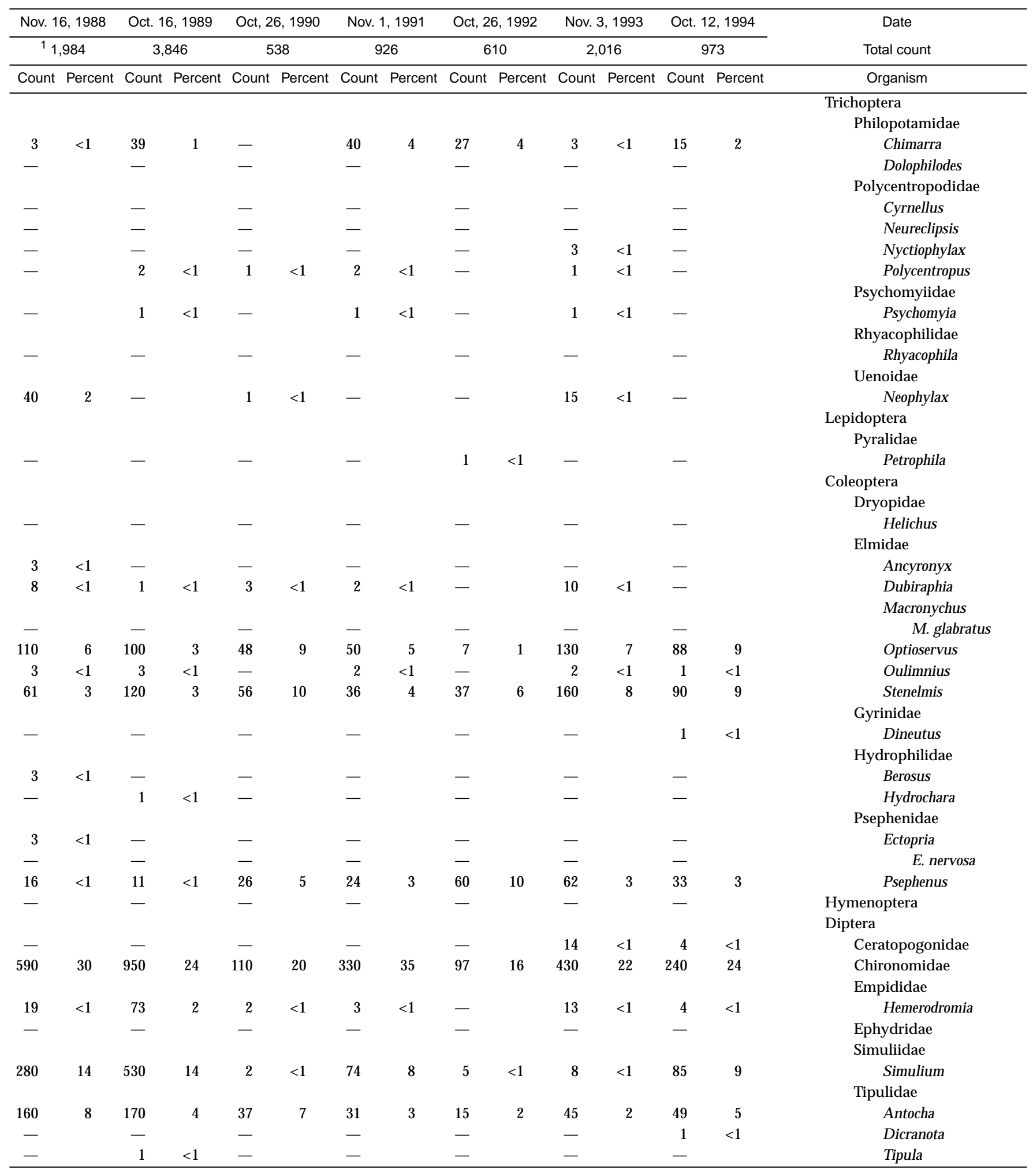


Table 5. Benthic-macroinvertebrate data-Continued

$[<$, less than; - , not found]

01480653 - East Branch Brandywine Creek at Glenmoore, Pa. (Site 42)

\begin{tabular}{|c|c|c|c|c|c|c|c|c|c|c|c|c|c|c|}
\hline \multirow{3}{*}{$\begin{array}{c}\text { Date } \\
\text { Total count } \\
\text { Organism }\end{array}$} & \multirow{2}{*}{\multicolumn{2}{|c|}{$\begin{array}{c}\text { Nov. } 2,1981 \\
752\end{array}$}} & \multicolumn{2}{|c|}{ Nov. 3, 1982} & \multicolumn{2}{|c|}{ Nov. 3, 1983} & \multicolumn{2}{|c|}{ Oct. 17,1984} & \multicolumn{2}{|c|}{ Oct. 23, 1985} & \multicolumn{2}{|c|}{ Dec. 5,1986} & \multicolumn{2}{|c|}{ Oct. 23, 1987} \\
\hline & & & & 708 & & 338 & & 008 & & 361 & & 23 & 1,4 & 435 \\
\hline & Count & Percent & Count & Percent & Count & Percent & Count & Percent & Count & Percent & Count & Percent & Count & Percent \\
\hline \multicolumn{15}{|l|}{ Platyhelminthes (flatworms) } \\
\hline \multicolumn{15}{|l|}{ Turbellaria } \\
\hline \multicolumn{15}{|l|}{ Tricladida } \\
\hline Planariidae & 4 & $<1$ & 1 & $<1$ & 6 & $<1$ & 2 & $<1$ & 23 & 2 & 24 & 3 & 14 & 1 \\
\hline Nematoda (nematodes) & - & & - & & - & & - & & - & & - & & - & \\
\hline \multicolumn{15}{|l|}{ Nemertea (proboscis worms) } \\
\hline \multicolumn{15}{|l|}{ Enopla } \\
\hline \multicolumn{15}{|l|}{ Hoplonemertea } \\
\hline \multicolumn{15}{|l|}{ Tetrastemmatidae } \\
\hline Prostoma & 2 & $<1$ & 5 & $<1$ & 6 & $<1$ & 2 & $<1$ & 1 & $<1$ & - & & - & \\
\hline \multicolumn{15}{|l|}{ Mollusca (molluscs) } \\
\hline Gastropoda & & & & & & & & & & & & & & \\
\hline Basommatophora & & & & & & & & & & & & & & \\
\hline Ancylidae & & & & & & & & & & & & & & \\
\hline Ferrissia & 34 & 4 & 4 & $<1$ & 11 & $<1$ & 14 & 1 & 21 & 2 & 2 & $<1$ & 5 & $<1$ \\
\hline Lymnaeidae & & & & & & & & & & & & & & \\
\hline Lymnaea & - & & 1 & $<1$ & - & & - & & 1 & $<1$ & - & & - & \\
\hline Physidae & & & & & & & & & & & & & & \\
\hline Physa & - & & 6 & $<1$ & - & & - & & - & & 4 & $<1$ & - & \\
\hline Planorbidae & & & & & & & & & & & & & & \\
\hline Gyraulus & - & & - & & - & & - & & - & & - & & - & \\
\hline Helisoma & 4 & $<1$ & - & & 2 & $<1$ & - & & - & & 1 & $<1$ & 1 & $<1$ \\
\hline Bivalvia & & & & & & & & & & & & & & \\
\hline Veneroida & & & & & & & & & & & & & & \\
\hline Sphaeriidae & - & & 6 & $<1$ & - & & - & & - & & - & & - & \\
\hline Pisidium & - & & - & & - & & - & & - & & - & & - & \\
\hline Sphaerium & - & & - & & - & & - & & - & & - & & - & \\
\hline Annelida (segmented worms) & & & & & & & & & & & & & & \\
\hline Oligochaeta & & & & & & & & & & & & & & \\
\hline Lumbriculida & & & & & & & & & & & & & & \\
\hline Lumbriculidae & - & & - & & - & & - & & - & & 2 & $<1$ & - & \\
\hline Tubificida & & & & & & & & & & & & & & \\
\hline Naididae & 3 & $<1$ & 17 & 1 & 16 & 1 & - & & 2 & $<1$ & 4 & $<1$ & - & \\
\hline Tubificidae & 1 & $<1$ & 2 & $<1$ & 2 & $<1$ & - & & - & & - & & - & \\
\hline Arthropoda (arthropods) & & & & & & & & & & & & & & \\
\hline Acariformes & & & & & & & & & & & & & & \\
\hline Hydrachnidia & 14 & 2 & 170 & 10 & 99 & 7 & 3 & $<1$ & 3 & $<1$ & 2 & $<1$ & 35 & 3 \\
\hline Crustacea & & & & & & & & & & & & & & \\
\hline Cladocera & - & & - & & - & & - & & - & & - & & - & \\
\hline Cyclopoida & - & & - & & - & & - & & - & & - & & - & \\
\hline Amphipoda & & & & & & & & & & & & & & \\
\hline Talitridae & & & & & & & & & & & & & & \\
\hline Hyallela & - & & - & & - & & - & & - & & 1 & $<1$ & - & \\
\hline H. azteca & - & & - & & - & & - & & 1 & $<1$ & - & & - & \\
\hline Isopoda & & & & & & & & & & & & & & \\
\hline Asellidae & & & & & & & & & & & & & & \\
\hline Lirceus & - & & - & & - & & - & & - & & 2 & $<1$ & - & \\
\hline Podocopa & - & & 6 & $<1$ & 17 & 1 & - & & 1 & $<1$ & - & & - & \\
\hline
\end{tabular}




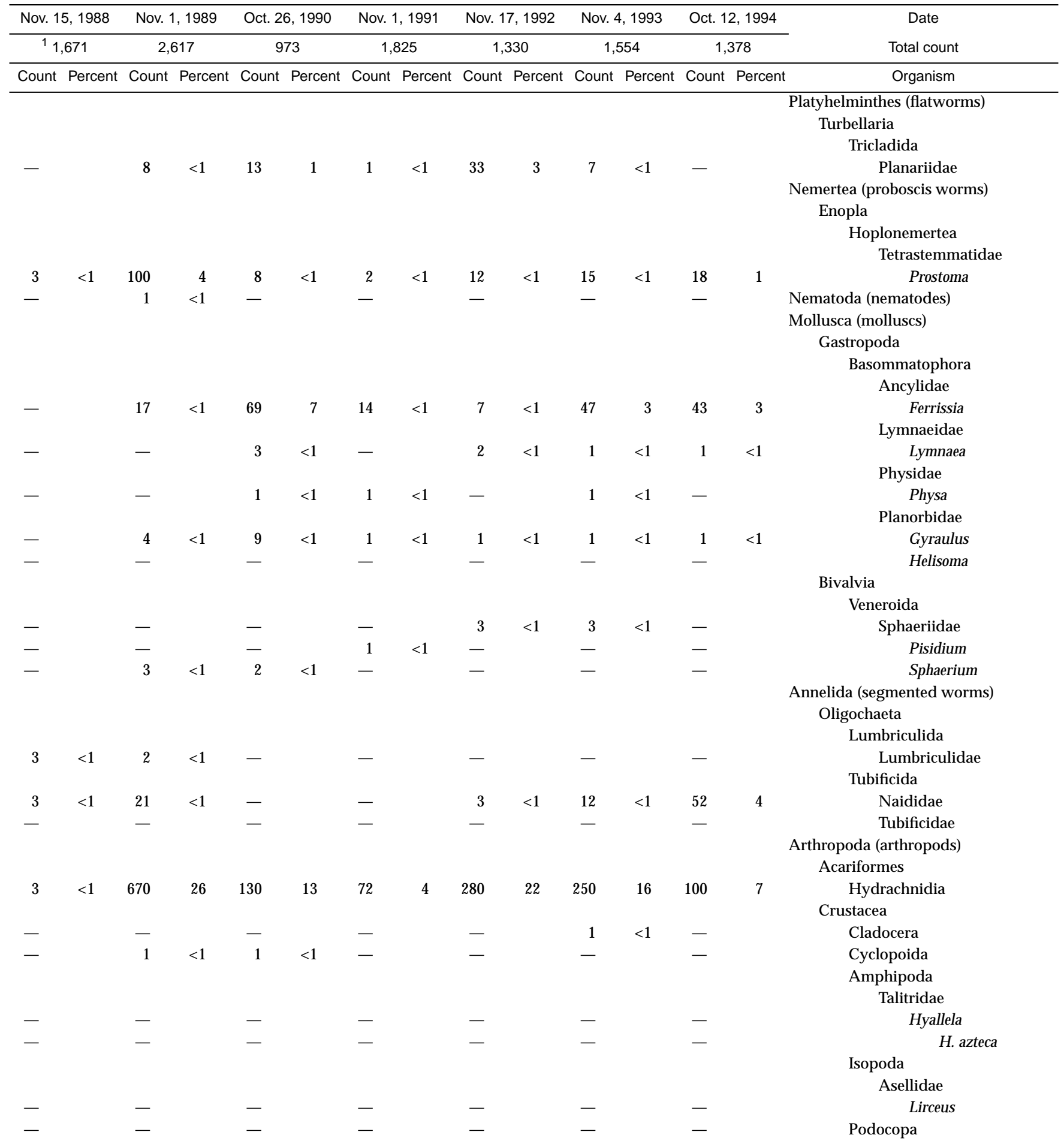


Table 5. Benthic-macroinvertebrate data-Continued

01480653 - East Branch Brandywine Creek at Glenmoore, Pa. (Site 42)—Continued

\begin{tabular}{|c|c|c|c|c|c|c|c|c|c|c|c|c|c|c|}
\hline \multirow{3}{*}{$\begin{array}{c}\text { Date } \\
\text { Total count } \\
\text { Organism }\end{array}$} & \multirow{2}{*}{\multicolumn{2}{|c|}{$\begin{array}{c}\text { Nov. 2, } 1981 \\
752\end{array}$}} & \multicolumn{2}{|c|}{ Nov. 3, 1982} & \multicolumn{2}{|c|}{ Nov. 3, 1983} & \multicolumn{2}{|c|}{ Oct. 17,1984} & \multicolumn{2}{|c|}{ Oct. 23,1985} & \multicolumn{2}{|c|}{ Dec. 5, 1986} & \multicolumn{2}{|c|}{ Oct. 23,1987} \\
\hline & & & \multicolumn{2}{|c|}{1,708} & \multicolumn{2}{|c|}{1,338} & \multicolumn{2}{|c|}{1,008} & \multicolumn{2}{|c|}{1,361} & \multicolumn{2}{|c|}{723} & \multicolumn{2}{|c|}{1,435} \\
\hline & Count & Percent & Count & Percent & Count & Percent & Count & Percent & Count & Percent & Count & Percent & Count & Percent \\
\hline \multicolumn{15}{|l|}{ Insecta } \\
\hline Ephemeroptera & & & & & & & & & & & & & & \\
\hline Baetidae & & & & & & & & & & & & & & \\
\hline Baetis & - & & 1 & $<1$ & 1 & $<1$ & 17 & 2 & 31 & 2 & 2 & $<1$ & 8 & $<1$ \\
\hline Pseudocloeon & 2 & $<1$ & 1 & $<1$ & 2 & $<1$ & 4 & $<1$ & 8 & $<1$ & - & & 7 & $<1$ \\
\hline Caenidae & & & & & & & & & & & & & & \\
\hline Caenis & - & & - & & 14 & 1 & - & & 2 & $<1$ & 14 & 2 & - & \\
\hline Ephemerellidae & & & & & & & & & & & & & & \\
\hline Ephemerella & 6 & $<1$ & 31 & 2 & 43 & 3 & 44 & 4 & 120 & 9 & 65 & 9 & 79 & 6 \\
\hline Heptageniidae & & & & & & & & & & & & & & \\
\hline Epeorus & - & & - & & - & & - & & - & & - & & - & \\
\hline Stenonema & 82 & 11 & 120 & 7 & - & & 34 & 3 & 51 & 4 & 30 & 4 & 65 & 5 \\
\hline Isonychiidae & & & & & & & & & & & & & & \\
\hline Isonychia & - & & 2 & $<1$ & - & & - & & - & & 1 & $<1$ & - & \\
\hline Leptohyphidae & & & & & & & & & & & & & & \\
\hline Tricorythodes & 2 & $<1$ & 1 & $<1$ & 3 & $<1$ & - & & - & & - & & - & \\
\hline Leptophlebiidae & - & & - & & - & & 4 & $<1$ & - & & - & & - & \\
\hline Odonata & & & & & & & & & & & & & & \\
\hline Coenagrionidae & & & & & & & & & & & & & & \\
\hline Argia & - & & - & & - & & - & & 1 & $<1$ & - & & - & \\
\hline Aeshnidae & & & & & & & & & & & & & & \\
\hline Boyeria & - & & - & & - & & 1 & $<1$ & - & & - & & - & \\
\hline Gomphidae & - & & - & & - & & - & & - & & 1 & $<1$ & - & \\
\hline Plecoptera & & & & & & & & & & & & & & \\
\hline Capniidae & & & & & & & & & & & & & & \\
\hline Allocapnia & - & & 5 & $<1$ & 1 & $<1$ & 1 & $<1$ & 5 & $<1$ & 1 & $<1$ & 11 & $<1$ \\
\hline Chloroperlidae & - & & - & & 1 & $<1$ & - & & - & & - & & 2 & $<1$ \\
\hline Haploperla & - & & - & & - & & - & & - & & - & & - & \\
\hline Nemouridae & - & & - & & - & & - & & - & & - & & - & \\
\hline Peltoperlidae & & & & & & & & & & & & & & \\
\hline Peltoperla & - & & - & & - & & - & & - & & - & & - & \\
\hline Perlidae & & & & & & & & & & & & & & \\
\hline Acroneuria & - & & 4 & $<1$ & - & & - & & 6 & $<1$ & 2 & $<1$ & 1 & $<1$ \\
\hline Agnetina & - & & - & & - & & - & & - & & - & & - & \\
\hline Paragnetina & 2 & $<1$ & - & & - & & 4 & $<1$ & - & & - & & - & \\
\hline Taeniopterygidae & & & & & & & & & & & & & & \\
\hline Strophopteryx & - & & - & & - & & - & & - & & 2 & $<1$ & - & \\
\hline Taeniopteryx & 7 & $<1$ & 50 & 3 & 44 & 3 & 33 & 3 & 42 & 3 & 17 & 2 & 98 & 7 \\
\hline Hemiptera & & & & & & & & & & & & & & \\
\hline Veliidae & & & & & & & & & & & & & & \\
\hline Rhagovelia & - & & - & & - & & - & & - & & - & & - & \\
\hline Megaloptera & & & & & & & & & & & & & & \\
\hline Corydalidae & & & & & & & & & & & & & & \\
\hline Chauliodes & 1 & $<1$ & - & & - & & - & & - & & - & & - & \\
\hline Corydalus & - & & - & & - & & - & & 1 & $<1$ & - & & - & \\
\hline Nigronia & - & & 2 & $<1$ & 1 & $<1$ & - & & - & & - & & - & \\
\hline Sialidae & & & & & & & & & & & & & & \\
\hline Sialis & - & & - & & - & & - & & - & & - & & - & \\
\hline Neuroptera & & & & & & & & & & & & & & \\
\hline Sisyridae & & & & & & & & & & & & & & \\
\hline Climacia & - & & 2 & $<1$ & - & & - & & - & & - & & - & \\
\hline
\end{tabular}




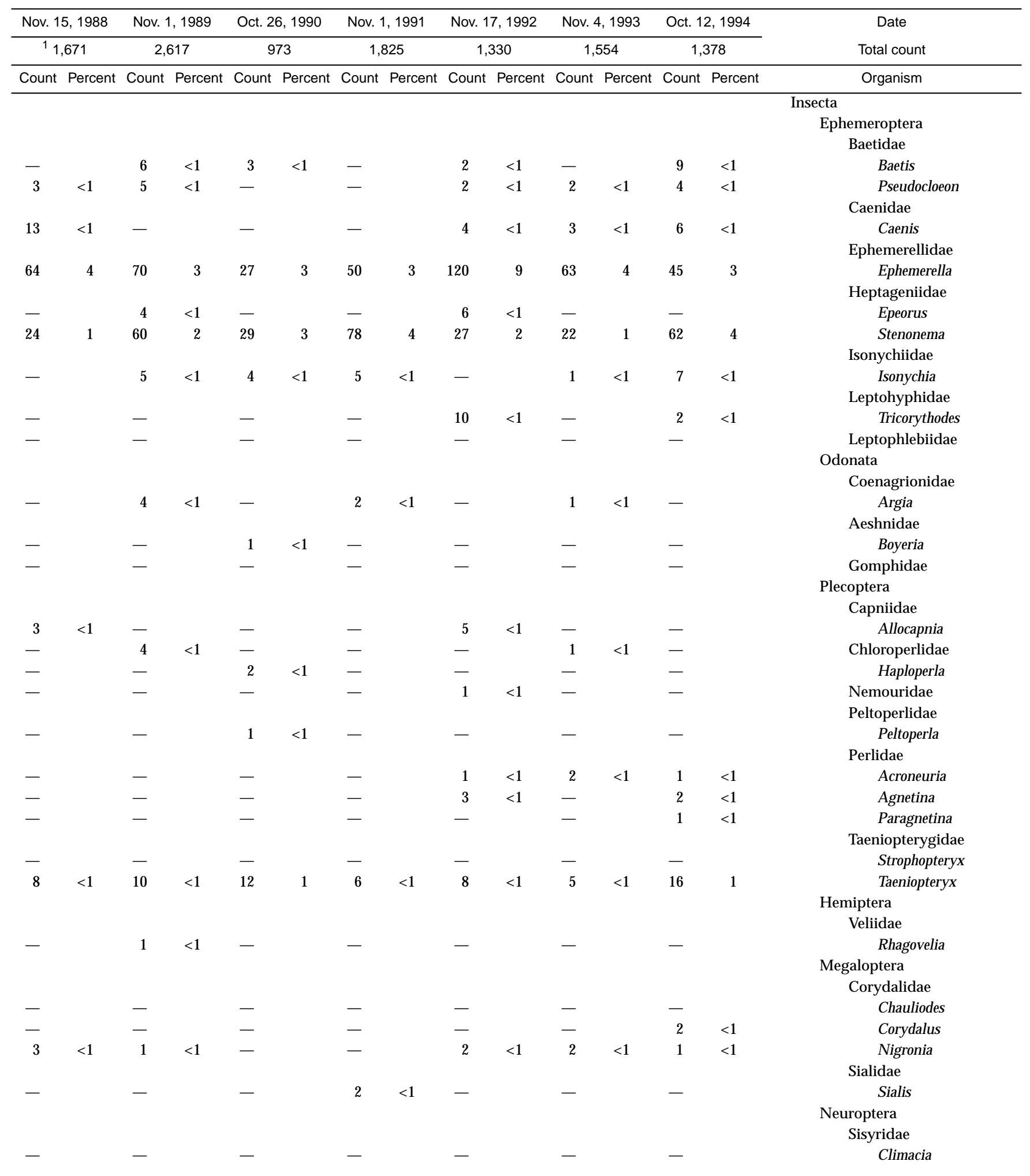


Table 5. Benthic-macroinvertebrate data-Continued

01480653 - East Branch Brandywine Creek at Glenmoore, Pa. (Site 42)—Continued

\begin{tabular}{|c|c|c|c|c|c|c|c|c|c|c|c|c|c|c|}
\hline \multirow{2}{*}{$\begin{array}{c}\text { Date } \\
\text { Total count }\end{array}$} & \multicolumn{2}{|c|}{ Nov. 2,1981} & \multicolumn{2}{|c|}{ Nov. 3, 1982} & \multicolumn{2}{|c|}{ Nov. 3,1983} & \multicolumn{2}{|c|}{ Oct. 17,1984} & \multicolumn{2}{|c|}{ Oct. 23, 1985} & \multicolumn{2}{|c|}{ Dec. 5,1986} & \multicolumn{2}{|c|}{ Oct. 23, 1987} \\
\hline & \multicolumn{2}{|c|}{752} & \multicolumn{2}{|c|}{1,708} & \multicolumn{2}{|c|}{1,338} & \multicolumn{2}{|c|}{1,008} & \multicolumn{2}{|c|}{1,361} & & 23 & & 435 \\
\hline Organism & Count & Percent & Count & Percent & Count & Percent & Count & Percent & Count & Percent & Count & Percent & Count & Percent \\
\hline Trichoptera & & & & & & & & & & & & & & \\
\hline Apataniidae & & & & & & & & & & & & & & \\
\hline Apatania & - & & - & & 3 & $<1$ & - & & - & & 13 & 2 & 13 & $<1$ \\
\hline Brachycentridae & & & & & & & & & & & & & & \\
\hline Micrasema & 11 & 1 & 34 & 2 & 59 & 4 & 6 & $<1$ & 9 & $<1$ & 48 & 6 & 45 & 3 \\
\hline Glossosomatidae & & & & & & & & & & & & & & \\
\hline Glossosoma & 6 & $<1$ & 9 & $<1$ & 11 & $<1$ & 53 & 5 & 24 & 2 & 16 & 2 & - & \\
\hline Protoptila & - & & - & & - & & - & & - & & - & & 1 & $<1$ \\
\hline Goeridae & & & & & & & & & & & & & & \\
\hline Goera & 1 & $<1$ & - & & - & & 12 & 1 & 7 & $<1$ & 20 & 3 & 2 & $<1$ \\
\hline Helicopsychidae & & & & & & & & & & & & & & \\
\hline Helicopsyche & - & & - & & - & & - & & - & & 3 & $<1$ & 8 & $<1$ \\
\hline Hydropsychidae & & & & & & & & & & & & & & \\
\hline Ceratopsyche & 96 & 13 & 110 & 6 & 200 & 14 & 200 & 20 & 240 & 17 & 42 & 6 & 390 & 28 \\
\hline Cheumatopsyche & 75 & 10 & 120 & 7 & 110 & 8 & 92 & 9 & 150 & 11 & 56 & 8 & 78 & 6 \\
\hline Hydropsyche & 240 & 32 & 160 & 9 & 160 & 11 & 26 & 3 & 31 & 2 & 26 & 4 & 86 & 6 \\
\hline Hydroptilidae & & & & & & & & & & & & & & \\
\hline Hydroptila & 8 & 1 & 40 & 2 & 35 & 3 & 4 & $<1$ & 3 & $<1$ & - & & 3 & $<1$ \\
\hline Leucotrichia & 35 & 5 & 300 & 18 & 200 & 14 & 170 & 17 & 71 & 5 & 10 & 1 & 48 & 3 \\
\hline Leptoceridae & & & & & & & & & & & & & & \\
\hline Mystacides & 46 & 6 & 3 & $<1$ & 5 & $<1$ & - & & - & & 3 & $<1$ & - & \\
\hline Oecetis & - & & 1 & $<1$ & 7 & $<1$ & 2 & $<1$ & 3 & $<1$ & 1 & $<1$ & - & \\
\hline Triaenodes & - & & - & & 1 & $<1$ & - & & - & & - & & - & \\
\hline Limnephilidae & & & & & & & & & & & & & & \\
\hline Hydatophylax & - & & - & & - & & - & & - & & - & & - & \\
\hline Philopotamidae & & & & & & & & & & & & & & \\
\hline Chimarra & 1 & $<1$ & 14 & $<1$ & 12 & $<1$ & 7 & $<1$ & 28 & 2 & 13 & 2 & 6 & $<1$ \\
\hline Polycentropodidae & & & & & & & & & & & & & & \\
\hline Neureclipsis & 1 & $<1$ & 9 & $<1$ & 2 & $<1$ & 7 & $<1$ & 4 & $<1$ & 4 & $<1$ & 4 & $<1$ \\
\hline Nyctiophylax & 2 & $<1$ & 4 & $<1$ & 3 & $<1$ & 12 & 1 & 5 & $<1$ & 4 & $<1$ & 5 & $<1$ \\
\hline Polycentropus & 4 & $<1$ & 9 & $<1$ & 17 & 1 & 2 & $<1$ & 4 & $<1$ & - & & - & \\
\hline Psychomyiidae & & & & & & & & & & & & & & \\
\hline Psychomyia & - & & 3 & $<1$ & 2 & $<1$ & - & & - & & - & & - & \\
\hline Rhyacophilidae & & & & & & & & & & & & & & \\
\hline Rhyacophila & - & & - & & 1 & $<1$ & 3 & $<1$ & 13 & $<1$ & - & & 6 & $<1$ \\
\hline R. fuscula & - & & - & & - & & - & & - & & 5 & $<1$ & - & \\
\hline Uenoidae & & & & & & & & & & & & & & \\
\hline Neophylax & - & & - & & - & & - & & - & & 10 & 1 & - & \\
\hline Lepidoptera & & & & & & & & & & & & & & \\
\hline Pyralidae & - & & - & & - & & - & & - & & - & & - & \\
\hline Petrophila & 7 & $<1$ & 2 & $<1$ & - & & - & & - & & - & & - & \\
\hline Coleoptera & & & & & & & & & & & & & & \\
\hline Dryopidae & & & & & & & & & & & & & & \\
\hline Helichus & - & & 1 & $<1$ & - & & - & & - & & - & & - & \\
\hline Elmidae & & & & & & & & & & & & & & \\
\hline Ancyronyx & - & & - & & - & & - & & - & & 1 & $<1$ & - & \\
\hline Dubiraphia & 4 & $<1$ & 12 & $<1$ & 8 & $<1$ & 2 & $<1$ & 1 & $<1$ & 1 & $<1$ & 1 & $<1$ \\
\hline Macronychus & & & & & & & & & & & & & & \\
\hline M. glabratus & - & & - & & - & & - & & - & & - & & - & \\
\hline Optioservus & 10 & 1 & 6 & $<1$ & 16 & 1 & 12 & 1 & 45 & 3 & 34 & 5 & 9 & $<1$ \\
\hline Oulimnius & - & & 2 & $<1$ & 3 & $<1$ & - & & 4 & $<1$ & 1 & $<1$ & 6 & $<1$ \\
\hline Promoresia & - & & 1 & $<1$ & 3 & $<1$ & 1 & $<1$ & 1 & $<1$ & 2 & $<1$ & - & \\
\hline Stenelmis & 8 & 1 & 7 & $<1$ & 12 & $<1$ & 11 & 1 & 7 & $<1$ & 7 & 1 & 16 & 1 \\
\hline Hydrophilidae & & & & & & & & & & & & & & \\
\hline Berosus & - & & - & & 1 & $<1$ & - & & - & & 1 & $<1$ & - & \\
\hline
\end{tabular}




\begin{tabular}{|c|c|c|c|c|c|c|c|c|c|c|c|c|c|c|}
\hline \multirow{2}{*}{\multicolumn{2}{|c|}{$\begin{array}{c}\text { Nov. } 15,1988 \\
11,671\end{array}$}} & \multicolumn{2}{|c|}{ Nov. 1, 1989} & \multicolumn{2}{|c|}{ Oct. 26,1990} & \multicolumn{2}{|c|}{ Nov. 1, 1991} & \multicolumn{2}{|c|}{ Nov. 17,1992} & \multicolumn{2}{|c|}{ Nov. 4, 1993} & \multicolumn{2}{|c|}{ Oct. 12, 1994} & \multirow{2}{*}{$\begin{array}{c}\text { Date } \\
\text { Total count }\end{array}$} \\
\hline & & & 17 & 97 & 73 & & 325 & 1,3 & 330 & $\overline{1,5}$ & 554 & & 378 & \\
\hline \multirow[t]{3}{*}{ Count } & Percent & Count & Percent & Count & Percent & Count & Percent & Count & Percent & Count & Percent & Count & Percent & Organism \\
\hline & & & & & & & & & & & & & & Trichoptera \\
\hline & & & & & & & & & & & & & & Apataniidae \\
\hline \multirow[t]{2}{*}{3} & $<1$ & 78 & 3 & 2 & $<1$ & 13 & $<1$ & 22 & 2 & 32 & 2 & 3 & $<1$ & Apatania \\
\hline & & & & & & & & & & & & & & Brachycentridae \\
\hline \multirow[t]{2}{*}{140} & 8 & 410 & 16 & 43 & 4 & 180 & 10 & 93 & 7 & 270 & 17 & 120 & 9 & Micrasema \\
\hline & & & & & & & & & & & & & & Glossosomatidae \\
\hline 8 & $<1$ & 7 & $<1$ & 2 & $<1$ & 20 & 1 & 9 & $<1$ & 4 & $<1$ & 17 & 1 & Glossosoma \\
\hline \multirow[t]{2}{*}{-} & & - & & - & & - & & - & & 2 & $<1$ & - & & Protoptila \\
\hline & & & & & & & & & & & & & & Goeridae \\
\hline \multirow[t]{2}{*}{-} & & 2 & $<1$ & - & & 4 & $<1$ & 5 & $<1$ & 10 & $<1$ & 1 & $<1$ & Goera \\
\hline & & & & & & & & & & & & & & Helicopsychidae \\
\hline- & & - & & - & & - & & 3 & $<1$ & 9 & $<1$ & - & & Helicopsyche \\
\hline & & & & & & & & & & & & & & Hydropsychidae \\
\hline 250 & 15 & 250 & 10 & 130 & 13 & 230 & 13 & 82 & 6 & 140 & 9 & 160 & 11 & Ceratopsyche \\
\hline 210 & 12 & 51 & 2 & 34 & 3 & 120 & 7 & 23 & 2 & 130 & 8 & 140 & 10 & Cheumatopsyche \\
\hline 120 & 7 & 120 & 5 & 22 & 2 & 92 & 5 & 31 & 2 & 82 & 5 & 58 & 4 & Hydropsyche \\
\hline & & & & & & & & & & & & & & Hydroptilidae \\
\hline 3 & $<1$ & 5 & $<1$ & 1 & $<1$ & - & & 7 & $<1$ & 2 & $<1$ & 1 & $<1$ & Hydroptila \\
\hline 110 & 6 & 16 & $<1$ & 120 & 12 & 35 & 2 & 16 & 1 & 31 & 2 & 110 & 8 & Leucotrichia \\
\hline & & & & & & & & & & & & & & Leptoceridae \\
\hline 5 & $<1$ & - & & - & & 2 & $<1$ & 10 & $<1$ & 1 & $<1$ & 1 & $<1$ & Mystacides \\
\hline- & & 40 & 2 & 5 & $<1$ & 12 & $<1$ & 6 & $<1$ & 10 & $<1$ & 3 & $<1$ & Oecetis \\
\hline- & & - & & - & & - & & - & & - & & - & & Triaenodes \\
\hline & & & & & & & & & & & & & & Limnephilidae \\
\hline- & & - & & - & & - & & 1 & $<1$ & - & & 1 & $<1$ & Hydatophylax \\
\hline & & & & & & & & & & & & & & Philopotamidae \\
\hline- & & 1 & $<1$ & 4 & $<1$ & 19 & 1 & 2 & $<1$ & 3 & $<1$ & 12 & $<1$ & Chimarra \\
\hline & & & & & & & & & & & & & & Polycentropodidae \\
\hline- & & - & & 3 & $<1$ & 14 & $<1$ & 1 & $<1$ & 1 & $<1$ & 4 & $<1$ & Neureclipsis \\
\hline 8 & $<1$ & 9 & $<1$ & 1 & $<1$ & 1 & $<1$ & - & & - & & - & & Nyctiophylax \\
\hline 16 & $<1$ & 3 & $<1$ & 3 & $<1$ & 3 & $<1$ & 1 & $<1$ & - & & 1 & $<1$ & Polycentropus \\
\hline & & & & & & & & & & & & & & Psychomyiidae \\
\hline- & & - & & - & & 3 & $<1$ & - & & 3 & $<1$ & - & & Psychomyia \\
\hline & & & & & & & & & & & & & & Rhyacophilidae \\
\hline 8 & $<1$ & 21 & $<1$ & 3 & $<1$ & 9 & $<1$ & 13 & 1 & 5 & $<1$ & 18 & 1 & Rhyacophila \\
\hline- & & - & & - & & - & & - & & - & & - & & R. fuscula \\
\hline & & & & & & & & & & & & & & Uenoidae \\
\hline 3 & $<1$ & - & & 1 & $<1$ & - & & - & & - & & - & & Neophylax \\
\hline & & & & & & & & & & & & & & Lepidoptera \\
\hline- & & - & & - & & 1 & $<1$ & - & & - & & - & & Pyralidae \\
\hline- & & 1 & $<1$ & - & & - & & - & & 1 & $<1$ & - & & Petrophila \\
\hline & & & & & & & & & & & & & & Coleoptera \\
\hline & & & & & & & & & & & & & & Dryopidae \\
\hline- & & - & & - & & - & & - & & - & & - & & Helichus \\
\hline & & & & & & & & & & & & & & Elmidae \\
\hline- & & - & & - & & - & & 3 & $<1$ & 1 & $<1$ & - & & Ancyronyx \\
\hline 3 & $<1$ & 13 & $<1$ & 5 & $<1$ & 4 & $<1$ & 12 & $<1$ & 1 & $<1$ & 2 & $<1$ & Dubiraphia \\
\hline & & & & & & & & & & & & & & Macronychus \\
\hline- & & - & & - & & 1 & $<1$ & - & & - & & - & & M. glabratus \\
\hline 45 & 3 & 38 & 1 & 27 & 3 & 60 & 3 & 100 & 8 & 95 & 6 & 32 & 2 & Optioservus \\
\hline- & & 4 & $<1$ & 1 & $<1$ & 5 & $<1$ & 1 & $<1$ & 9 & $<1$ & 3 & $<1$ & Oulimnius \\
\hline- & & - & & - & & 1 & $<1$ & 1 & $<1$ & - & & 1 & $<1$ & Promoresia \\
\hline 40 & 2 & 43 & 2 & 25 & 3 & 92 & 5 & 33 & 3 & 57 & 4 & 12 & $<1$ & Stenelmis \\
\hline & & & & & & & & & & & & & & Hydrophilidae \\
\hline- & & - & & - & & - & & - & & - & & - & & Berosus \\
\hline
\end{tabular}


Table 5. Benthic-macroinvertebrate data-Continued

01480653 - East Branch Brandywine Creek at Glenmoore, Pa. (Site 42)—Continued

\begin{tabular}{|c|c|c|c|c|c|c|c|c|c|c|c|c|c|c|}
\hline \multirow{3}{*}{$\begin{array}{c}\text { Date } \\
\text { Total count } \\
\text { Organism }\end{array}$} & \multirow{2}{*}{\multicolumn{2}{|c|}{$\frac{\text { Nov. } 2,1981}{752}$}} & \multicolumn{2}{|c|}{ Nov. 3, 1982} & \multicolumn{2}{|c|}{ Nov. 3, 1983} & \multicolumn{2}{|c|}{ Oct. 17,1984} & \multicolumn{2}{|c|}{ Oct. 23, 1985} & \multicolumn{2}{|c|}{ Dec. 5, 1986} & \multicolumn{2}{|c|}{ Oct. 23, 1987} \\
\hline & & & \multicolumn{2}{|c|}{1,708} & \multicolumn{2}{|c|}{1,338} & \multicolumn{2}{|c|}{1,008} & \multicolumn{2}{|c|}{1,361} & \multicolumn{2}{|c|}{723} & \multicolumn{2}{|c|}{1,435} \\
\hline & Count & Percent & Count & Percent & Count & Percent & Count & Percent & Count & Percent & Count & Percent & Count & Percent \\
\hline \multicolumn{15}{|l|}{ Coleoptera } \\
\hline \multicolumn{15}{|l|}{ Psephenidae } \\
\hline \multicolumn{15}{|l|}{ Ectopria } \\
\hline E. nervosa & - & & - & & - & & - & & - & & - & & - & \\
\hline Psephenus & 5 & $<1$ & 1 & $<1$ & 1 & $<1$ & - & & 2 & $<1$ & 12 & 2 & 10 & $<1$ \\
\hline Hymenoptera & - & & - & & - & & 1 & $<1$ & - & & - & & - & \\
\hline \multicolumn{15}{|l|}{ Diptera } \\
\hline \multicolumn{15}{|l|}{ Athericidae } \\
\hline Atherix & - & & - & & - & & - & & - & & 3 & $<1$ & 1 & $<1$ \\
\hline Chironomidae & 14 & 2 & 310 & 18 & 110 & 8 & 160 & 16 & 320 & 23 & 150 & 20 & 310 & 22 \\
\hline \multicolumn{15}{|l|}{ Empididae } \\
\hline Hemerodromia & 1 & $<1$ & 9 & $<1$ & 3 & $<1$ & 7 & $<1$ & 5 & $<1$ & 2 & $<1$ & 6 & $<1$ \\
\hline Ephydridae & - & & - & & - & & - & & 1 & $<1$ & - & & - & \\
\hline \multicolumn{15}{|l|}{ Simuliidae } \\
\hline Simulium & - & & 20 & 1 & 2 & $<1$ & 20 & 2 & 23 & 2 & 13 & 2 & 4 & $<1$ \\
\hline \multicolumn{15}{|l|}{ Tipulidae } \\
\hline Antocha & 12 & 2 & 84 & 5 & 82 & 6 & 35 & 3 & 40 & 3 & 45 & 6 & 51 & 4 \\
\hline Tipula & 1 & $<1$ & - & & - & & - & & - & & - & & - & \\
\hline
\end{tabular}

${ }^{1}$ Extrapolated from a 3/8 subsample. 


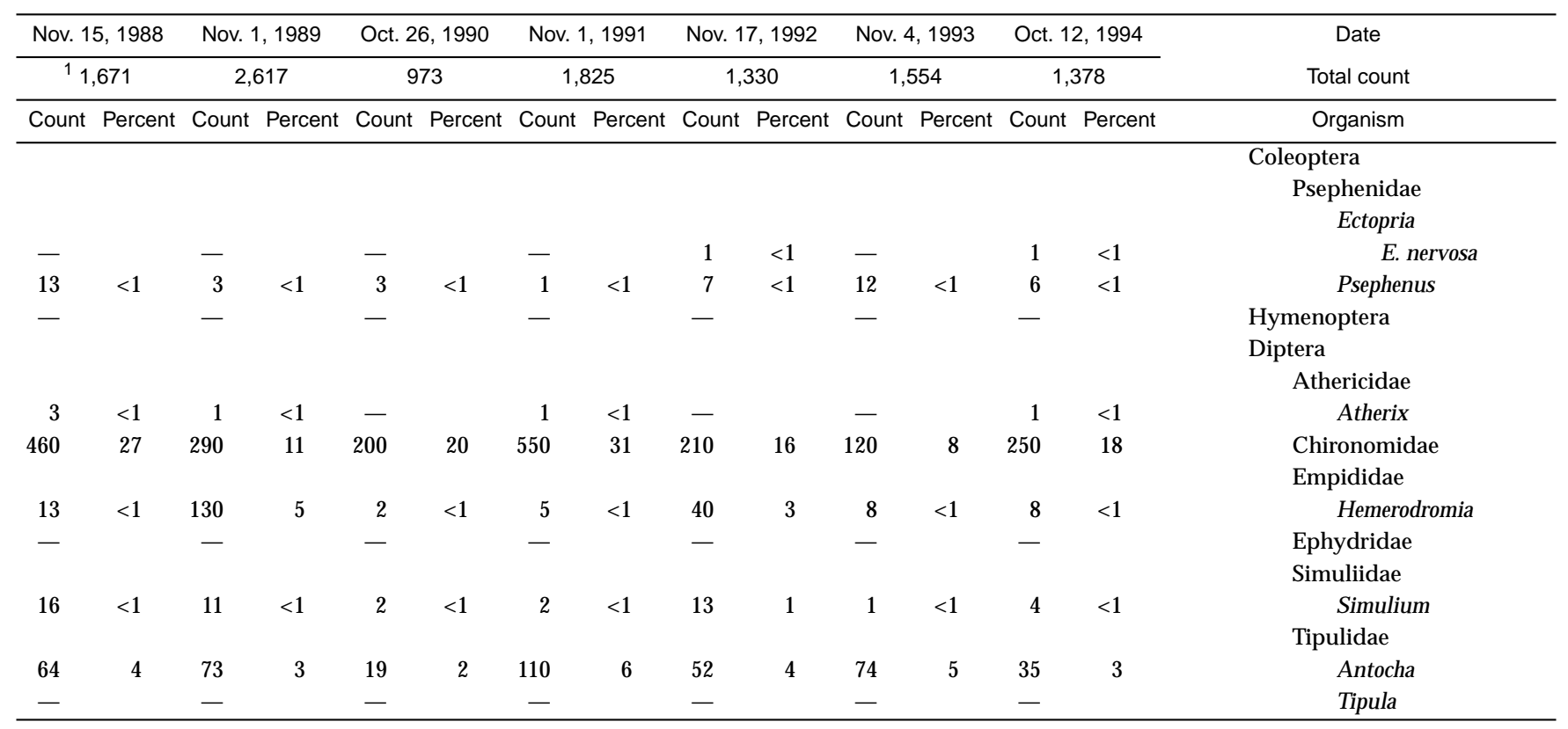


Table 5. Benthic-macroinvertebrate data-Continued

$[<$, less than; - , not found]

01480656 - Indian Run near Springton, Pa. (Site 47)

\begin{tabular}{|c|c|c|c|c|c|c|c|c|c|c|c|c|c|c|}
\hline \multirow{2}{*}{$\begin{array}{c}\text { Date } \\
\text { Total count } \\
\end{array}$} & \multicolumn{2}{|c|}{ Nov. 2, 1981} & \multicolumn{2}{|c|}{ Nov. 3, 1982} & \multicolumn{2}{|c|}{ Nov. 3,1983} & \multicolumn{2}{|c|}{ Oct. 17, 1984} & \multicolumn{2}{|c|}{ Oct. 23, 1985} & \multicolumn{2}{|c|}{ Oct. 29, 1986} & \multicolumn{2}{|c|}{ Oct. 19,1987} \\
\hline & \multicolumn{2}{|c|}{1,050} & \multicolumn{2}{|c|}{1,883} & \multicolumn{2}{|c|}{1,165} & \multicolumn{2}{|c|}{1,027} & \multicolumn{2}{|c|}{729} & \multicolumn{2}{|c|}{688} & \multicolumn{2}{|c|}{640} \\
\hline & Count & Percent & Count & Percent & Count & Percent & Count & Percent & Count & Percent & Count & Percent & Count & Percent \\
\hline \multicolumn{15}{|l|}{ Platyhelminthes (flatworms) } \\
\hline Turbellaria & & & & & & & & & & & & & & \\
\hline Tricladida & & & & & & & & & & & & & & \\
\hline Planariidae & 1 & $<1$ & - & & - & & - & & - & & 1 & $<1$ & 3 & $<1$ \\
\hline Nematoda (nematodes) & - & & - & & - & & 2 & $<1$ & - & & - & & 2 & $<1$ \\
\hline Nemertea (proboscis worms) & & & & & & & & & & & & & & \\
\hline Enopla & & & & & & & & & & & & & & \\
\hline Hoplonemertea & & & & & & & & & & & & & & \\
\hline Tetrastemmatidae & & & & & & & & & & & & & & \\
\hline Prostoma & 1 & $<1$ & - & & - & & - & & - & & - & & - & \\
\hline Mollusca (molluscs) & & & & & & & & & & & & & & \\
\hline Gastropoda & & & & & & & & & & & & & & \\
\hline Basommatophora & & & & & & & & & & & & & & \\
\hline Ancylidae & & & & & & & & & & & & & & \\
\hline Ferrissia & 57 & 5 & 24 & 1 & 17 & 1 & - & & 1 & $<1$ & 16 & 2 & 3 & $<1$ \\
\hline Physidae & & & & & & & & & & & & & & \\
\hline Physa & - & & - & & 1 & $<1$ & - & & - & & - & & - & \\
\hline Bivalvia & & & & & & & & & & & & & & \\
\hline Veneroida & & & & & & & & & & & & & & \\
\hline Sphaeriidae & - & & - & & 1 & $<1$ & - & & - & & - & & - & \\
\hline Sphaerium & - & & - & & - & & - & & - & & - & & - & \\
\hline Annelida (segmented worms) & & & & & & & & & & & & & & \\
\hline Oligochaeta & - & & - & & - & & - & & 1 & $<1$ & - & & - & \\
\hline Tubificida & & & & & & & & & & & & & & \\
\hline Naididae & 18 & 2 & 26 & 1 & 27 & 2 & 23 & 2 & - & & - & & 8 & 1 \\
\hline Tubificidae & 6 & $<1$ & 3 & $<1$ & 3 & $<1$ & - & & - & & - & & 1 & $<1$ \\
\hline Arthropoda (arthropods) & & & & & & & & & & & & & & \\
\hline Acariformes & & & & & & & & & & & & & & \\
\hline Hydrachnidia & 25 & 2 & 10 & $<1$ & 17 & 1 & 12 & 1 & - & & - & & 4 & $<1$ \\
\hline Crustacea & & & & & & & & & & & & & & \\
\hline Decapoda & & & & & & & & & & & & & & \\
\hline Cambaridae & - & & - & & - & & - & & - & & - & & 1 & $<1$ \\
\hline Podocopa & - & & 1 & $<1$ & - & & 1 & $<1$ & - & & - & & - & \\
\hline Insecta & & & & & & & & & & & & & & \\
\hline Ephemeroptera & & & & & & & & & & & & & & \\
\hline Baetidae & & & & & & & & & & & & & & \\
\hline Baetis & 1 & $<1$ & 19 & 1 & - & & 7 & $<1$ & 20 & 3 & 11 & 2 & 7 & 1 \\
\hline Pseudocloeon & - & & - & & 3 & $<1$ & 20 & 2 & 6 & $<1$ & - & & - & \\
\hline Ephemerellidae & & & & & & & & & & & & & & \\
\hline Ephemerella & 310 & 28 & 360 & 19 & 390 & 33 & 200 & 20 & 150 & 20 & 280 & 40 & 50 & 8 \\
\hline Ephemeridae & & & & & & & & & & & & & & \\
\hline Ephemera & - & & - & & - & & - & & - & & 1 & $<1$ & - & \\
\hline Heptageniidae & & & & & & & & & & & & & & \\
\hline Epeorus & - & & 15 & $<1$ & 100 & 8 & 52 & 5 & - & & - & & - & \\
\hline Stenonema & 29 & 3 & 50 & 3 & 54 & 5 & 46 & 5 & 56 & 8 & 71 & 10 & 63 & 10 \\
\hline Isonychiidae & & & & & & & & & & & & & & \\
\hline Isonychia & 1 & $<1$ & 2 & $<1$ & 8 & $<1$ & 1 & $<1$ & 1 & $<1$ & 5 & $<1$ & 1 & $<1$ \\
\hline Leptophlebiidae & 1 & $<1$ & - & & 1 & $<1$ & - & & - & & 2 & $<1$ & - & \\
\hline Paraleptophlebia & - & & 3 & $<1$ & - & & - & & - & & - & & - & \\
\hline
\end{tabular}




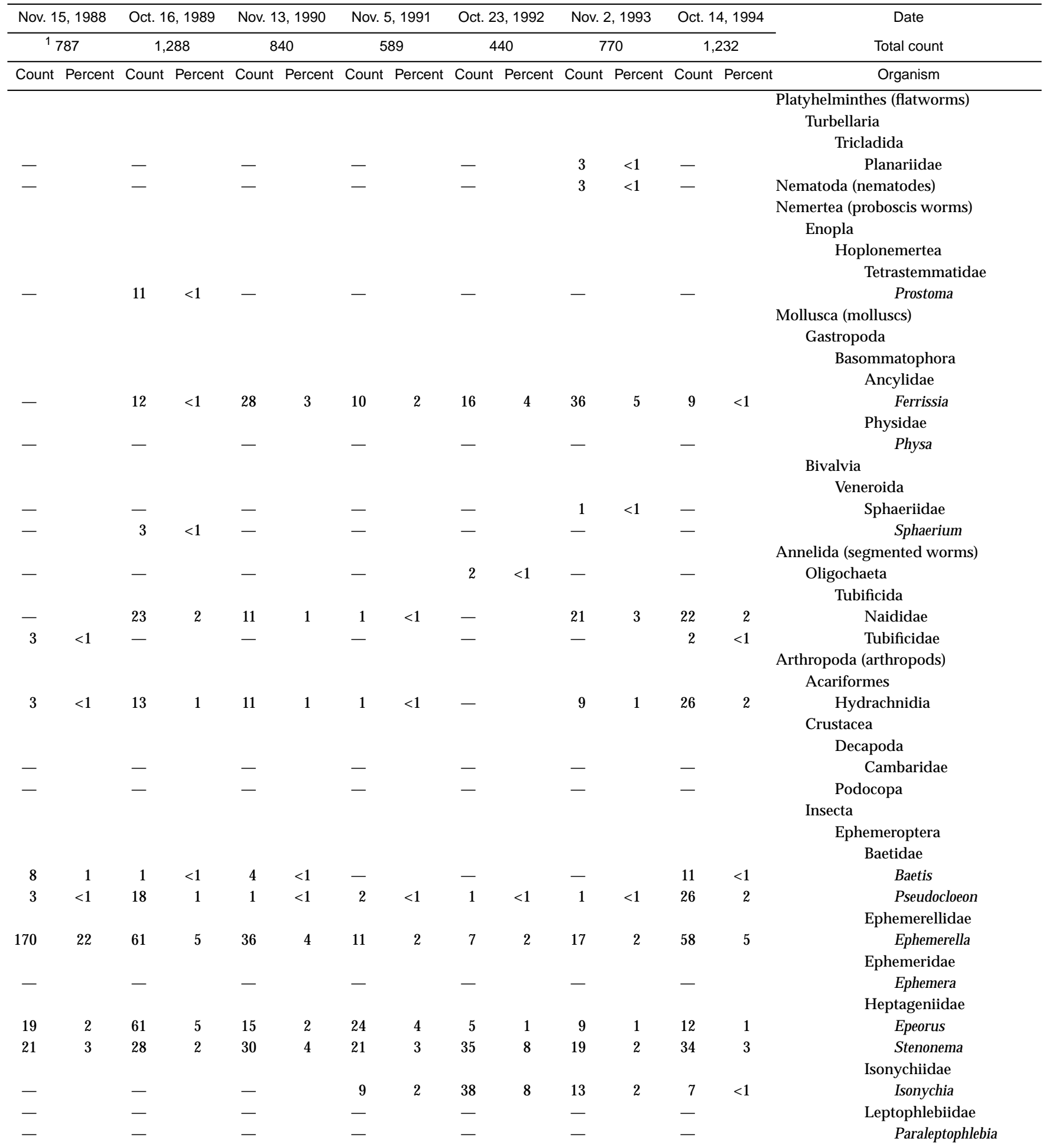


Table 5. Benthic-macroinvertebrate data-Continued

01480656 - Indian Run near Springton, Pa. (Site 47)

\begin{tabular}{|c|c|c|c|c|c|c|c|c|c|c|c|c|c|c|}
\hline \multirow{3}{*}{$\begin{array}{c}\text { Date } \\
\text { Total count } \\
\text { Organism }\end{array}$} & \multirow{2}{*}{\multicolumn{2}{|c|}{$\begin{array}{c}\text { Nov. } 2,1981 \\
1,050\end{array}$}} & \multirow{2}{*}{\multicolumn{2}{|c|}{$\frac{\text { Nov. 3, } 1982}{1,883}$}} & \multirow{2}{*}{\multicolumn{2}{|c|}{$\frac{\text { Nov. 3, } 1983}{1,165}$}} & \multirow{2}{*}{\multicolumn{2}{|c|}{$\begin{array}{c}\text { Oct. } 17,1984 \\
1,027\end{array}$}} & \multirow{2}{*}{\multicolumn{2}{|c|}{$\frac{\text { Oct. } 23,1985}{729}$}} & \multirow{2}{*}{\multicolumn{2}{|c|}{$\begin{array}{c}\text { Oct. } 29,1986 \\
688\end{array}$}} & \multirow{2}{*}{\multicolumn{2}{|c|}{$\begin{array}{c}\text { Oct. } 19,1987 \\
640\end{array}$}} \\
\hline & & & & & & & & & & & & & & \\
\hline & Count & Percent & Count & Percent & Count & Percent & Count & Percent & Count & Percent & Count & Percent & Count & Percent \\
\hline \multicolumn{15}{|l|}{ Odonata } \\
\hline \multicolumn{15}{|l|}{ Aeshnidae } \\
\hline Boyeria & - & & - & & - & & 1 & $<1$ & - & & - & & - & \\
\hline Gomphidae & - & & - & & - & & - & & - & & - & & - & \\
\hline \multicolumn{15}{|l|}{ Plecoptera } \\
\hline \multicolumn{15}{|l|}{ Capniidae } \\
\hline Allocapnia & 17 & 2 & - & & - & & 56 & 6 & 110 & 15 & 3 & $<1$ & 19 & 3 \\
\hline Chloroperlidae & - & & - & & - & & - & & - & & - & & 7 & 1 \\
\hline Leuctridae & - & & - & & - & & - & & - & & - & & - & \\
\hline Nemouridae & - & & - & & - & & - & & - & & - & & - & \\
\hline \multicolumn{15}{|l|}{ Peltoperlidae } \\
\hline Peltoperla & - & & - & & - & & - & & - & & - & & - & \\
\hline Perlidae & & & & & & & & & & & & & & \\
\hline Acroneuria & 2 & $<1$ & 10 & $<1$ & 10 & $<1$ & 5 & $<1$ & - & & 2 & $<1$ & 4 & $<1$ \\
\hline Agnetina & - & & - & & - & & - & & - & & - & & - & \\
\hline Neoperla & - & & - & & - & & - & & - & & - & & - & \\
\hline Paragnetina & - & & - & & - & & - & & 3 & $<1$ & 2 & $<1$ & 2 & $<1$ \\
\hline Taeniopterygidae & & & & & & & & & & & & & & \\
\hline Strophopteryx & - & & - & & - & & - & & - & & - & & - & \\
\hline Taeniopteryx & 1 & $<1$ & 17 & $<1$ & 64 & 5 & - & & - & & 1 & $<1$ & - & \\
\hline Hemiptera & & & & & & & & & & & & & & \\
\hline Veliidae & & & & & & & & & & & & & & \\
\hline Rhagovelia & - & & - & & 1 & $<1$ & - & & - & & - & & 3 & $<1$ \\
\hline Megaloptera & & & & & & & & & & & & & & \\
\hline Corydalidae & & & & & & & & & & & & & & \\
\hline Nigronia & 3 & $<1$ & 2 & $<1$ & 1 & $<1$ & - & & - & & 1 & $<1$ & - & \\
\hline Sialidae & & & & & & & & & & & & & & \\
\hline Sialis & - & & 1 & $<1$ & - & & - & & - & & - & & - & \\
\hline Trichoptera & & & & & & & & & & & & & & \\
\hline Apataniidae & & & & & & & & & & & & & & \\
\hline Apatania & 62 & 6 & 61 & 3 & 20 & 2 & 16 & 2 & 6 & $<1$ & 26 & 4 & 31 & 5 \\
\hline Brachycentridae & & & & & & & & & & & & & & \\
\hline Micrasema & 13 & 1 & 19 & 1 & 8 & $<1$ & 6 & $<1$ & 1 & $<1$ & 2 & $<1$ & - & \\
\hline Glossosomatidae & & & & & & & & & & & & & & \\
\hline Glossosoma & - & & 82 & 4 & 52 & 4 & 75 & 8 & 16 & 2 & 27 & 4 & 15 & 2 \\
\hline Goeridae & & & & & & & & & & & & & & \\
\hline Goera & 10 & $<1$ & 9 & $<1$ & 1 & $<1$ & - & & 2 & $<1$ & 2 & $<1$ & - & \\
\hline Hydropsychidae & & & & & & & & & & & & & & \\
\hline Ceratopsyche & 8 & $<1$ & 47 & 2 & 34 & 3 & 24 & 2 & 41 & 6 & 17 & 2 & 33 & 5 \\
\hline Cheumatopsyche & 24 & 2 & 95 & 5 & 64 & 5 & 140 & 14 & 40 & 5 & 17 & 2 & 13 & 2 \\
\hline Diplectrona & - & & - & & - & & - & & - & & - & & - & \\
\hline Hydropsyche & 12 & 1 & 62 & 3 & 66 & 6 & 16 & 2 & 4 & $<1$ & 4 & $<1$ & 12 & 2 \\
\hline Hydroptilidae & & & & & & & & & & & & & & \\
\hline Hydroptila & 18 & 2 & 3 & $<1$ & - & & 1 & $<1$ & - & & - & & 1 & $<1$ \\
\hline Leucotrichia & 5 & $<1$ & 12 & $<1$ & 7 & $<1$ & 22 & 2 & 6 & $<1$ & 23 & 3 & 3 & $<1$ \\
\hline Lepidostomatidae & & & & & & & & & & & & & & \\
\hline Lepidostoma & - & & - & & - & & - & & - & & - & & - & \\
\hline Leptoceridae & & & & & & & & & & & & & & \\
\hline Mystacides & 7 & $<1$ & 8 & $<1$ & - & & - & & - & & - & & - & \\
\hline Oecetis & 1 & $<1$ & - & & - & & - & & - & & - & & - & \\
\hline Philopotamidae & & & & & & & & & & & & & & \\
\hline Chimarra & 1 & $<1$ & 1 & $<1$ & 14 & 1 & 37 & 4 & 4 & $<1$ & 13 & 2 & 4 & $<1$ \\
\hline Dolophilodes & - & & - & & 3 & $<1$ & 13 & 1 & 10 & 1 & 18 & 3 & 15 & 2 \\
\hline Wormaldia & - & & - & & - & & - & & - & & - & & - & \\
\hline
\end{tabular}




\begin{tabular}{|c|c|c|c|c|c|c|c|c|c|c|c|c|c|c|}
\hline \multirow{2}{*}{\multicolumn{2}{|c|}{$\frac{\text { Nov. } 15,1988}{1787}$}} & \multicolumn{2}{|c|}{ Oct. 16,1989} & \multicolumn{2}{|c|}{ Nov. 13, 1990} & \multicolumn{2}{|c|}{ Nov. 5, 1991} & \multicolumn{2}{|c|}{ Oct. 23, 1992} & \multicolumn{2}{|c|}{ Nov. 2, 1993} & \multicolumn{2}{|c|}{ Oct. 14,1994} & \multirow{2}{*}{$\begin{array}{c}\text { Date } \\
\text { Total count }\end{array}$} \\
\hline & & \multicolumn{2}{|c|}{1,288} & \multicolumn{2}{|c|}{840} & \multicolumn{2}{|c|}{589} & \multicolumn{2}{|c|}{440} & \multicolumn{2}{|c|}{770} & 1,2 & 232 & \\
\hline Count & Percent & Count & Percent & Count & Percent & Count & Percent & Count & Percent & Count & Percent & Count & Percent & Organism \\
\hline & & & & & & & & & & & & & & Odonata \\
\hline & & & & & & & & & & & & & & Aeshnidae \\
\hline- & & - & & - & & - & & - & & - & & - & & Boyeria \\
\hline- & & - & & 1 & $<1$ & - & & - & & - & & - & & Gomphidae \\
\hline & & & & & & & & & & & & & & Plecoptera \\
\hline & & & & & & & & & & & & & & Capniidae \\
\hline 24 & 3 & - & & 14 & 2 & 6 & 1 & 4 & 1 & 36 & 5 & - & & Allocapnia \\
\hline- & & - & & - & & - & & - & & 1 & $<1$ & - & & Chloroperlidae \\
\hline- & & - & & 16 & 2 & 1 & $<1$ & - & & - & & - & & Leuctridae \\
\hline 21 & 3 & - & & - & & - & & - & & - & & - & & Nemouridae \\
\hline & & & & & & & & & & & & & & Peltoperlidae \\
\hline- & & - & & - & & - & & - & & - & & 1 & $<1$ & Peltoperla \\
\hline & & & & & & & & & & & & & & Perlidae \\
\hline 3 & $<1$ & 6 & $<1$ & - & & - & & - & & 1 & $<1$ & 2 & $<1$ & Acroneuria \\
\hline 3 & $<1$ & - & & - & & - & & - & & - & & - & & Agnetina \\
\hline- & & - & & 1 & $<1$ & - & & - & & - & & - & & Neoperla \\
\hline- & & 3 & $<1$ & - & & 1 & $<1$ & - & & - & & - & & Paragnetina \\
\hline & & & & & & & & & & & & & & Taeniopterygidae \\
\hline 37 & 5 & - & & - & & - & & - & & - & & - & & Strophopteryx \\
\hline- & & 140 & 11 & 1 & $<1$ & 3 & $<1$ & 1 & $<1$ & 10 & 1 & 8 & $<1$ & Taeniopteryx \\
\hline & & & & & & & & & & & & & & Hemiptera \\
\hline & & & & & & & & & & & & & & Veliidae \\
\hline- & & - & & - & & - & & - & & 1 & $<1$ & - & & Rhagovelia \\
\hline & & & & & & & & & & & & & & Megaloptera \\
\hline & & & & & & & & & & & & & & Corydalidae \\
\hline- & & - & & - & & - & & - & & - & & - & & Nigronia \\
\hline & & & & & & & & & & & & & & Sialidae \\
\hline- & & - & & - & & - & & - & & - & & - & & Sialis \\
\hline & & & & & & & & & & & & & & Trichoptera \\
\hline & & & & & & & & & & & & & & Apataniidae \\
\hline 32 & 4 & 21 & 2 & 44 & 5 & 20 & 3 & - & & 30 & 4 & 59 & 5 & Apatania \\
\hline & & & & & & & & & & & & & & Brachycentridae \\
\hline- & & 8 & $<1$ & 3 & $<1$ & 3 & $<1$ & 50 & 11 & 1 & $<1$ & 2 & $<1$ & Micrasema \\
\hline & & & & & & & & & & & & & & Glossosomatidae \\
\hline 64 & 8 & 32 & 2 & 16 & 2 & 27 & 5 & 10 & 2 & 42 & 5 & 63 & 5 & Glossosoma \\
\hline & & & & & & & & & & & & & & Goeridae \\
\hline- & & - & & - & & - & & - & & - & & - & & Goera \\
\hline & & & & & & & & & & & & & & Hydropsychidae \\
\hline 99 & 12 & 55 & 4 & 15 & 2 & 26 & 4 & 1 & $<1$ & 83 & 11 & 69 & 6 & Ceratopsyche \\
\hline 32 & 4 & 28 & 2 & 9 & 1 & 28 & 5 & - & & 31 & 4 & 50 & 4 & Cheumatopsyche \\
\hline- & & - & & - & & 5 & $<1$ & 2 & $<1$ & 17 & 2 & - & & Diplectrona \\
\hline 11 & 1 & 140 & 11 & 40 & 5 & 31 & 5 & 75 & 17 & 16 & 2 & 150 & 13 & Hydropsyche \\
\hline & & & & & & & & & & & & & & Hydroptilidae \\
\hline 3 & $<1$ & - & & 3 & $<1$ & - & & 1 & $<1$ & - & & - & & Hydroptila \\
\hline- & & 18 & 1 & 28 & 3 & 43 & 7 & 10 & 2 & 2 & $<1$ & 1 & $<1$ & Leucotrichia \\
\hline & & & & & & & & & & & & & & Lepidostomatidae \\
\hline- & & - & & - & & - & & - & & 6 & $<1$ & - & & Lepidostoma \\
\hline & & & & & & & & & & & & & & Leptoceridae \\
\hline- & & - & & - & & - & & - & & - & & - & & Mystacides \\
\hline- & & - & & - & & - & & - & & - & & - & & Oecetis \\
\hline & & & & & & & & & & & & & & Philopotamidae \\
\hline 11 & 1 & 21 & 2 & 1 & $<1$ & 6 & 1 & 9 & 2 & 6 & $<1$ & 28 & 2 & Chimarra \\
\hline- & & 22 & 2 & - & & - & & - & & - & & 26 & 2 & Dolophilodes \\
\hline 5 & $<1$ & - & & - & & - & & - & & 2 & $<1$ & - & & Wormaldia \\
\hline
\end{tabular}


Table 5. Benthic-macroinvertebrate data-Continued

01480656 - Indian Run near Springton, Pa. (Site 47)

\begin{tabular}{|c|c|c|c|c|c|c|c|c|c|c|c|c|c|c|}
\hline \multirow{3}{*}{$\begin{array}{c}\text { Date } \\
\text { Total count } \\
\text { Organism }\end{array}$} & \multirow{2}{*}{\multicolumn{2}{|c|}{$\begin{array}{c}\text { Nov. } 2,1981 \\
1,050\end{array}$}} & \multirow{2}{*}{\multicolumn{2}{|c|}{$\begin{array}{c}\text { Nov. } 3,1982 \\
1,883\end{array}$}} & \multirow{2}{*}{\multicolumn{2}{|c|}{$\begin{array}{c}\text { Nov. } 3,1983 \\
1,165 \\
\end{array}$}} & \multirow{2}{*}{\multicolumn{2}{|c|}{$\begin{array}{c}\text { Oct. } 17,1984 \\
1,027\end{array}$}} & \multirow{2}{*}{\multicolumn{2}{|c|}{$\begin{array}{c}\text { Oct. 23, } 1985 \\
729\end{array}$}} & \multirow{2}{*}{\multicolumn{2}{|c|}{$\begin{array}{c}\text { Oct. } 29,1986 \\
688\end{array}$}} & \multirow{2}{*}{\multicolumn{2}{|c|}{$\begin{array}{c}\text { Oct. 19, } 1987 \\
640\end{array}$}} \\
\hline & & & & & & & & & & & & & & \\
\hline & Count & Percent & Count & Percent & Count & Percent & Count & Percent & Count & Percent & Count & Percent & Count & Percent \\
\hline \multicolumn{15}{|l|}{ Trichoptera } \\
\hline \multicolumn{15}{|l|}{ Polycentropodidae } \\
\hline Cyrnellus & - & & 7 & $<1$ & - & & - & & - & & - & & - & \\
\hline Neureclipsis & - & & 1 & $<1$ & - & & - & & - & & - & & - & \\
\hline Nyctiophylax & 6 & $<1$ & - & & 1 & $<1$ & 2 & $<1$ & - & & 1 & $<1$ & - & \\
\hline Polycentropus & 7 & $<1$ & 7 & $<1$ & 1 & $<1$ & - & & 1 & $<1$ & 2 & $<1$ & - & \\
\hline \multicolumn{15}{|l|}{ Psychomyiidae } \\
\hline Psychomyia & 96 & 9 & 59 & 3 & 16 & 1 & 5 & $<1$ & 9 & 1 & 29 & 4 & 10 & 2 \\
\hline \multicolumn{15}{|l|}{ Rhyacophilidae } \\
\hline Rhyacophila & 1 & $<1$ & 10 & $<1$ & 5 & $<1$ & 18 & 2 & 9 & 1 & 4 & $<1$ & 6 & 1 \\
\hline \multicolumn{15}{|l|}{ Uenoidae } \\
\hline Neophylax & - & & - & & - & & - & & - & & 3 & $<1$ & - & \\
\hline \multicolumn{15}{|l|}{ Coleoptera } \\
\hline \multicolumn{15}{|l|}{ Elmidae } \\
\hline Ancyronyx & - & & - & & - & & - & & - & & - & & - & \\
\hline Dubiraphia & - & & - & & - & & - & & - & & - & & - & \\
\hline Optioservus & 7 & $<1$ & 27 & 1 & 13 & 1 & - & & 4 & $<1$ & 10 & 1 & 9 & 1 \\
\hline Oulimnius & 2 & $<1$ & 3 & $<1$ & 2 & $<1$ & 5 & $<1$ & 1 & $<1$ & - & & 5 & $<1$ \\
\hline Promoresia & - & & - & & - & & - & & - & & - & & - & \\
\hline Stenelmis & 15 & 1 & 2 & $<1$ & - & & 4 & $<1$ & - & & 1 & $<1$ & 1 & $<1$ \\
\hline \multicolumn{15}{|l|}{ Psephenidae } \\
\hline \multicolumn{15}{|l|}{ Ectopria } \\
\hline E. nervosa & - & & 1 & $<1$ & - & & - & & - & & - & & - & \\
\hline Psephenus & 5 & $<1$ & 3 & $<1$ & 2 & $<1$ & - & & 1 & $<1$ & 3 & $<1$ & 8 & 1 \\
\hline \multicolumn{15}{|l|}{ Diptera } \\
\hline \multicolumn{15}{|l|}{ Athericidae } \\
\hline Atherix & - & & - & & 2 & $<1$ & - & & - & & - & & - & \\
\hline Blephariceridae & - & & - & & - & & - & & - & & - & & - & \\
\hline \multicolumn{15}{|l|}{ Blepharicera } \\
\hline Chironomidae & 170 & 15 & 670 & 35 & 120 & 10 & 180 & 18 & 190 & 26 & 59 & 8 & 250 & 38 \\
\hline \multicolumn{15}{|l|}{ Empididae } \\
\hline Hemerodromia & 7 & $<1$ & 4 & $<1$ & 2 & $<1$ & 1 & $<1$ & - & & - & & 1 & $<1$ \\
\hline Simuliidae & & & & & & & & & & & & & & \\
\hline Simulium & - & & 7 & $<1$ & 7 & $<1$ & 7 & $<1$ & 17 & 2 & 1 & $<1$ & 21 & 3 \\
\hline Tipulidae & - & & - & & - & & - & & - & & - & & - & \\
\hline Antocha & 100 & 9 & 140 & 7 & 27 & 2 & 28 & 3 & 16 & 2 & 30 & 4 & 24 & 4 \\
\hline Hexatoma & - & & - & & - & & 1 & $<1$ & - & & - & & - & \\
\hline Tipula & - & & - & & - & & - & & 3 & $<1$ & - & & - & \\
\hline
\end{tabular}

${ }^{1}$ Extrapolated from a 3/8 subsample. 


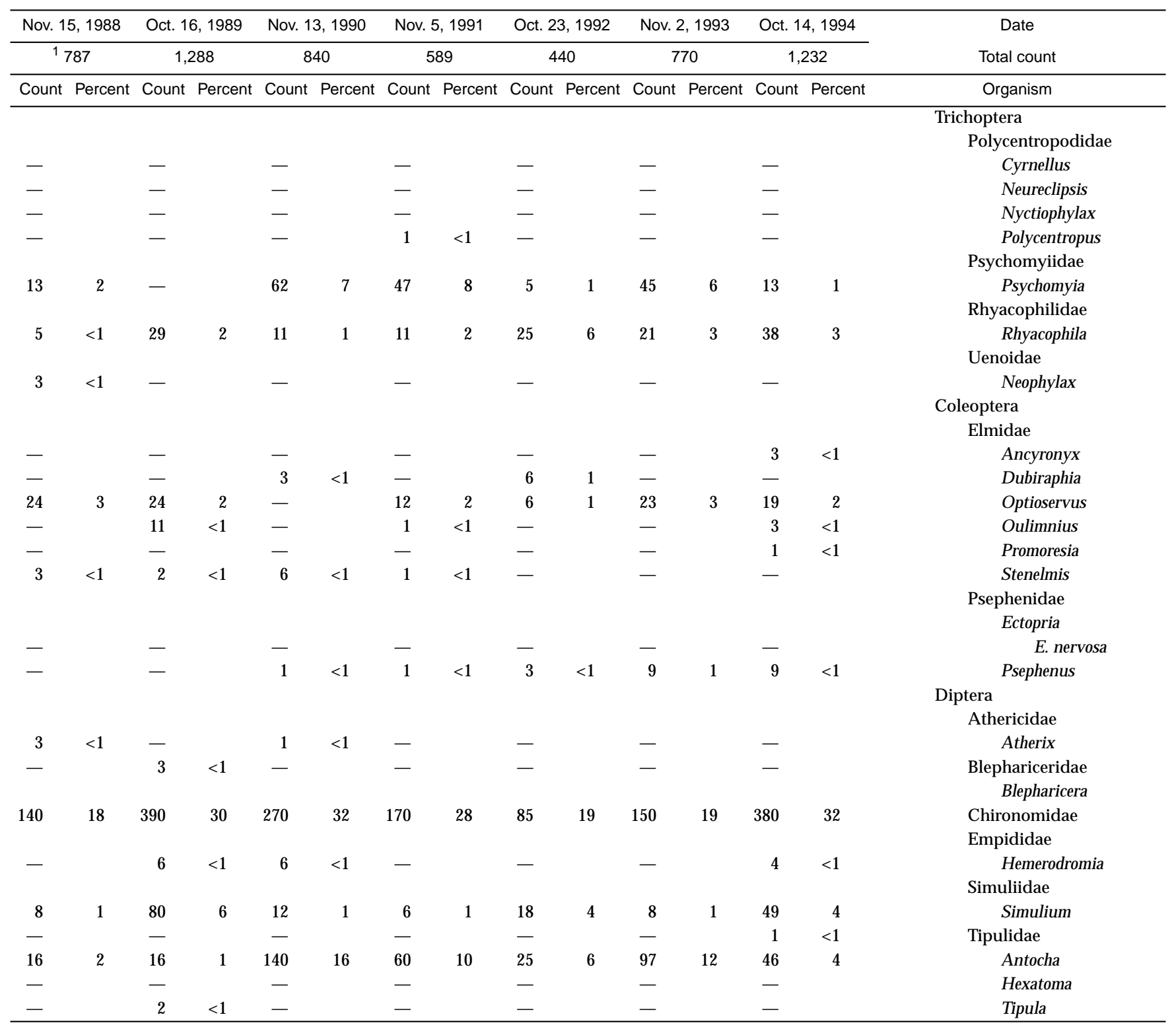


Table 5. Benthic-macroinvertebrate data-Continued

$[<$, less than; - , not found]

01480700 - East Branch Brandywine Creek near Downingtown, Pa. (Site 36)

\begin{tabular}{|c|c|c|c|c|c|c|c|c|c|c|c|c|c|c|}
\hline \multirow{3}{*}{ 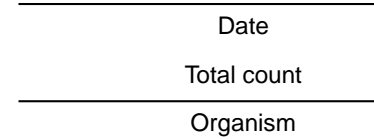 } & \multirow{2}{*}{\multicolumn{2}{|c|}{$\frac{\text { Nov. } 4,1981}{{ }^{1} 2,450}$}} & \multirow{2}{*}{\multicolumn{2}{|c|}{$\begin{array}{c}\text { Oct. } 28,1982 \\
111,821\end{array}$}} & \multirow{2}{*}{\multicolumn{2}{|c|}{$\begin{array}{c}\text { Nov. } 4,1983 \\
{ }^{1} 2,848\end{array}$}} & \multirow{2}{*}{\multicolumn{2}{|c|}{$\frac{\text { Oct. } 30,1984}{{ }^{1} 5,962}$}} & \multirow{2}{*}{\multicolumn{2}{|c|}{$\frac{\text { Oct. } 21,1985}{1,866}$}} & \multirow{2}{*}{\multicolumn{2}{|c|}{$\begin{array}{c}\text { Nov. } 17,1986 \\
2,232\end{array}$}} & \multirow{2}{*}{\multicolumn{2}{|c|}{$\begin{array}{c}\text { Oct. } 20,1987 \\
2,179\end{array}$}} \\
\hline & & & & & & & & & & & & & & \\
\hline & Count & Percent & Count & Percent & Count & Percent & Count & Percent & Count & Percent & Count & Percent & Count & Percent \\
\hline \multicolumn{15}{|l|}{ Platyhelminthes (flatworms) } \\
\hline \multicolumn{15}{|l|}{ Turbellaria } \\
\hline \multicolumn{15}{|l|}{ Tricladida } \\
\hline Planariidae & 45 & 2 & 3 & $<1$ & 8 & $<1$ & - & & 8 & $<1$ & 2 & $<1$ & 6 & $<1$ \\
\hline Nematoda (nematodes) & - & & - & & - & & - & & - & & - & & 2 & $<1$ \\
\hline \multicolumn{15}{|l|}{ Nemertea (proboscis worms) } \\
\hline \multicolumn{15}{|l|}{ Enopla } \\
\hline Hoplonemertea & & & & & & & & & & & & & & \\
\hline Tetrastemmatida & & & & & & & & & & & & & & \\
\hline Prostoma & - & & - & & 8 & $<1$ & 5 & $<1$ & 13 & $<1$ & - & & - & \\
\hline Mollusca (molluscs) & & & & & & & & & & & & & & \\
\hline Gastropoda & & & & & & & & & & & & & & \\
\hline Basommatophora & & & & & & & & & & & & & & \\
\hline Ancylidae & & & & & & & & & & & & & & \\
\hline Ferrissia & 3 & $<1$ & 3 & $<1$ & - & & - & & - & & 2 & $<1$ & 1 & $<1$ \\
\hline Lymnaeidae & & & & & & & & & & & & & & \\
\hline Lymnaea & - & & - & & - & & - & & - & & - & & 1 & $<1$ \\
\hline Planorbidae & & & & & & & & & & & & & & \\
\hline Gyraulus & - & & - & & - & & - & & - & & - & & - & \\
\hline Bivalvia & & & & & & & & & & & & & & \\
\hline Veneroida & & & & & & & & & & & & & & \\
\hline Sphaeriidae & - & & - & & - & & - & & - & & - & & - & \\
\hline Annelida (segmented worms) & & & & & & & & & & & & & & \\
\hline Oligochaeta & - & & - & & - & & - & & - & & - & & - & \\
\hline Lumbriculida & & & & & & & & & & & & & & \\
\hline Lumbriculidae & - & & - & & - & & - & & - & & - & & - & \\
\hline Tubificida & & & & & & & & & & & & & & \\
\hline Naididae & - & & - & & 3 & $<1$ & 3 & $<1$ & - & & - & & 27 & 1 \\
\hline Arthropoda (arthropods) & & & & & & & & & & & & & & \\
\hline Acariformes & & & & & & & & & & & & & & \\
\hline Hydrachnidia & 3 & $<1$ & - & & 5 & $<1$ & 11 & $<1$ & - & & 3 & $<1$ & 35 & 2 \\
\hline Crustacea & & & & & & & & & & & & & & \\
\hline Cladocera & - & & - & & - & & - & & - & & - & & - & \\
\hline Cyclopoida & - & & - & & - & & - & & - & & - & & - & \\
\hline Amphipoda & & & & & & & & & & & & & & \\
\hline Gammaridae & & & & & & & & & & & & & & \\
\hline Gammarus & - & & - & & - & & - & & - & & - & & - & \\
\hline Podocopa & - & & - & & - & & - & & - & & - & & - & \\
\hline Insecta & & & & & & & & & & & & & & \\
\hline Ephemeroptera & & & & & & & & & & & & & & \\
\hline Baetidae & & & & & & & & & & & & & & \\
\hline Baetis & - & & 35 & $<1$ & - & & - & & 110 & 6 & - & & - & \\
\hline Pseudocloeon & 16 & $<1$ & 40 & $<1$ & 32 & 1 & 16 & $<1$ & 23 & 1 & 2 & $<1$ & 33 & 2 \\
\hline Caenidae & & & & & & & & & & & & & & \\
\hline Caenis & - & & - & & - & & - & & - & & - & & - & \\
\hline Ephemerellidae & & & & & & & & & & & & & & \\
\hline Ephemerella & - & & 48 & $<1$ & 83 & 3 & 61 & 1 & 12 & $<1$ & 8 & $<1$ & 11 & $<1$ \\
\hline Heptageniidae & & & & & & & & & & & & & & \\
\hline Epeorus & - & & - & & - & & 3 & $<1$ & - & & - & & - & \\
\hline Stenonema & 75 & 3 & 91 & $<1$ & 51 & 2 & 110 & 2 & 33 & 2 & 31 & 1 & 71 & 3 \\
\hline Isonychiidae & & & & & & & & & & & & & & \\
\hline Isonychia & - & & 8 & $<1$ & - & & - & & - & & - & & - & \\
\hline Leptohyphidae & & & & & & & & & & & & & & \\
\hline Tricorythodes & 3 & $<1$ & 5 & $<1$ & - & & - & & - & & - & & - & \\
\hline
\end{tabular}




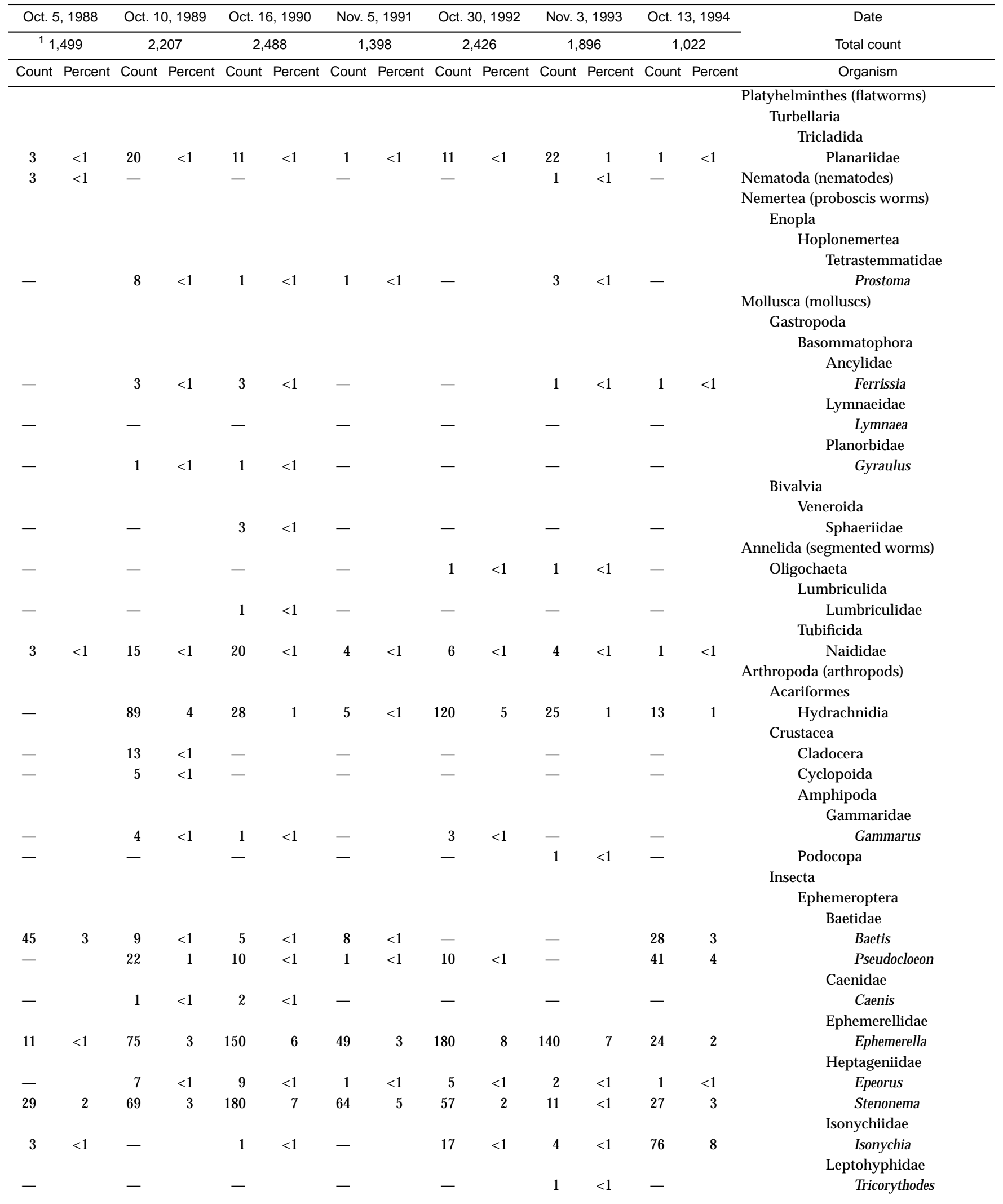


Table 5. Benthic-macroinvertebrate data-Continued

01480700 - East Branch Brandywine Creek near Downingtown, Pa. (Site 36)—Continued

\begin{tabular}{|c|c|c|c|c|c|c|c|c|c|c|c|c|c|c|}
\hline \multirow{3}{*}{$\begin{array}{c}\text { Date } \\
\text { Total count } \\
\text { Organism }\end{array}$} & \multirow{2}{*}{\multicolumn{2}{|c|}{$\begin{array}{c}\text { Nov. } 4,1981 \\
12,450\end{array}$}} & \multirow{2}{*}{\multicolumn{2}{|c|}{$\begin{array}{c}\text { Oct. } 28,1982 \\
{ }^{1} 11,821\end{array}$}} & \multirow{2}{*}{\multicolumn{2}{|c|}{$\begin{array}{c}\text { Nov. } 4,1983 \\
12,848\end{array}$}} & \multirow{2}{*}{\multicolumn{2}{|c|}{$\begin{array}{c}\text { Oct. } 30,1984 \\
15,962\end{array}$}} & \multirow{2}{*}{\multicolumn{2}{|c|}{$\begin{array}{c}\text { Oct. } 21,1985 \\
1,866\end{array}$}} & \multirow{2}{*}{\multicolumn{2}{|c|}{$\begin{array}{c}\text { Nov. } 17,1986 \\
2,232\end{array}$}} & \multirow{2}{*}{\multicolumn{2}{|c|}{$\begin{array}{c}\text { Oct. } 20,1987 \\
2,179\end{array}$}} \\
\hline & & & & & & & & & & & & & & \\
\hline & Count & Percent & Count & Percent & Count & Percent & Count & Percent & Count & Percent & Count & Percent & Count & Percent \\
\hline \multicolumn{15}{|l|}{ Odonata } \\
\hline \multicolumn{15}{|l|}{ Calopterygidae } \\
\hline Hetaerina & - & & - & & - & & 3 & $<1$ & - & & - & & - & \\
\hline \multicolumn{15}{|l|}{ Plecoptera } \\
\hline \multicolumn{15}{|l|}{ Capniidae } \\
\hline Allocapnia & - & & - & & 3 & $<1$ & - & & - & & - & & 4 & $<1$ \\
\hline Chloroperlidae & - & & - & & 8 & $<1$ & 3 & $<1$ & - & & 1 & $<1$ & 5 & $<1$ \\
\hline Nemouridae & - & & - & & - & & 3 & $<1$ & - & & - & & - & \\
\hline \multicolumn{15}{|l|}{ Perlidae } \\
\hline Acroneuria & - & & 3 & $<1$ & 3 & $<1$ & - & & 1 & $<1$ & - & & - & \\
\hline Agnetina & - & & - & & - & & 3 & $<1$ & - & & - & & - & \\
\hline Paragnetina & 19 & $<1$ & 13 & $<1$ & - & & - & & 1 & $<1$ & 3 & $<1$ & 1 & $<1$ \\
\hline \multicolumn{15}{|l|}{ Taeniopterygidae } \\
\hline Taeniopteryx & 75 & 3 & 35 & $<1$ & 37 & 1 & 8 & $<1$ & 16 & $<1$ & 16 & $<1$ & 37 & 2 \\
\hline Hemiptera & & & & & & & & & & & & & & \\
\hline Veliidae & & & & & & & & & & & & & & \\
\hline Rhagovelia & - & & - & & 3 & $<1$ & - & & - & & - & & - & \\
\hline Megaloptera & & & & & & & & & & & & & & \\
\hline Corydalidae & & & & & & & & & & & & & & \\
\hline Corydalus & 8 & $<1$ & - & & 13 & $<1$ & 3 & $<1$ & - & & 2 & $<1$ & 2 & $<1$ \\
\hline Nigronia & 5 & $<1$ & - & & - & & - & & - & & 1 & $<1$ & - & \\
\hline Sialidae & & & & & & & & & & & & & & \\
\hline Sialis & - & & - & & 3 & $<1$ & - & & - & & - & & - & \\
\hline Neuroptera & & & & & & & & & & & & & & \\
\hline Sisyridae & & & & & & & & & & & & & & \\
\hline Climacia & & & & & & & & & & & & & & \\
\hline C. areolaris & - & & - & & - & & - & & 2 & $<1$ & - & & - & \\
\hline Trichoptera & & & & & & & & & & & & & & \\
\hline Apataniidae & & & & & & & & & & & & & & \\
\hline Apatania & - & & - & & - & & 3 & $<1$ & - & & 1 & $<1$ & - & \\
\hline Brachycentridae & & & & & & & & & & & & & & \\
\hline Micrasema & 29 & 1 & - & & 16 & $<1$ & 8 & $<1$ & 15 & $<1$ & 69 & 3 & 20 & $<1$ \\
\hline Glossosomatidae & & & & & & & & & & & & & & \\
\hline Glossosoma & 3 & $<1$ & 13 & $<1$ & 3 & $<1$ & 37 & $<1$ & 7 & $<1$ & 16 & $<1$ & 3 & $<1$ \\
\hline Protoptila & - & & - & & - & & - & & - & & - & & - & \\
\hline Goeridae & & & & & & & & & & & & & & \\
\hline Goera & - & & - & & - & & - & & - & & - & & - & \\
\hline Helicopsychidae & & & & & & & & & & & & & & \\
\hline Helicopsyche & - & & - & & - & & - & & - & & - & & - & \\
\hline Hydropsychidae & & & & & & & & & & & & & & \\
\hline Ceratopsyche & 1,100 & 44 & 1,100 & 9 & 880 & 30 & 500 & 8 & 470 & 25 & 240 & 11 & 320 & 15 \\
\hline Cheumatopsyche & 170 & 7 & 48 & $<1$ & 250 & 9 & 48 & $<1$ & 110 & 6 & 61 & 3 & 48 & 2 \\
\hline Hydropsyche & 140 & 6 & 85 & $<1$ & 200 & 7 & 56 & $<1$ & 92 & 5 & 280 & 13 & 220 & 10 \\
\hline Hydroptilidae & & & & & & & & & & & & & & \\
\hline Hydroptila & - & & - & & 8 & $<1$ & 16 & $<1$ & 1 & $<1$ & 1 & $<1$ & 2 & $<1$ \\
\hline Leucotrichia & 11 & $<1$ & 16 & $<1$ & - & & 290 & 5 & 160 & 8 & 130 & 6 & 190 & 9 \\
\hline Lepidostomatidae & & & & & & & & & & & & & & \\
\hline Lepidostoma & - & & - & & - & & - & & - & & - & & - & \\
\hline Leptoceridae & & & & & & & & & & & & & & \\
\hline Mystacides & - & & - & & - & & - & & - & & - & & - & \\
\hline Oecetis & - & & - & & - & & 5 & $<1$ & 1 & $<1$ & 4 & $<1$ & - & \\
\hline Philopotamidae & & & & & & & & & & & & & & \\
\hline Chimarra & 3 & $<1$ & - & & 11 & $<1$ & - & & 1 & $<1$ & - & & - & \\
\hline
\end{tabular}




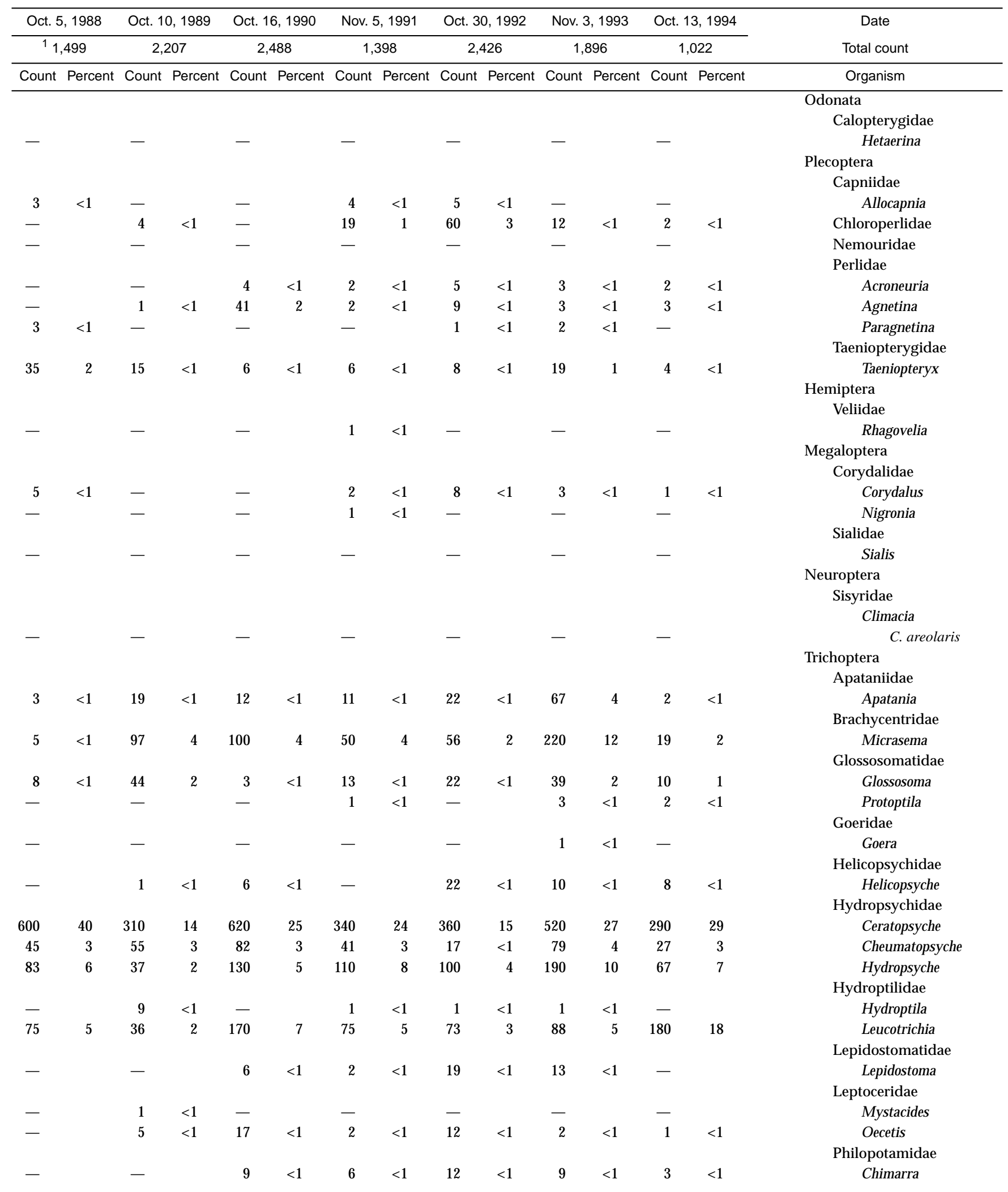


Table 5. Benthic-macroinvertebrate data-Continued

01480700 - East Branch Brandywine Creek near Downingtown, Pa. (Site 36)—Continued

\begin{tabular}{|c|c|c|c|c|c|c|c|c|c|c|c|c|c|c|}
\hline \multirow{3}{*}{$\begin{array}{c}\text { Date } \\
\text { Total count } \\
\text { Organism }\end{array}$} & \multirow{2}{*}{\multicolumn{2}{|c|}{$\begin{array}{c}\text { Nov. } 4,1981 \\
{ }^{1} 2,450\end{array}$}} & \multicolumn{2}{|c|}{ Oct. 28, 1982} & \multicolumn{2}{|c|}{ Nov. 4, 1983} & \multicolumn{2}{|c|}{ Oct. 30, 1984} & \multicolumn{2}{|c|}{ Oct. 21, 1985} & \multicolumn{2}{|c|}{ Nov. 17, 1986} & \multicolumn{2}{|c|}{ Oct. 20, 1987} \\
\hline & & & \multicolumn{2}{|c|}{${ }^{1} 11,821$} & \multicolumn{2}{|c|}{${ }^{1} 2,848$} & \multicolumn{2}{|c|}{${ }^{1} 5,962$} & \multicolumn{2}{|c|}{1,866} & \multicolumn{2}{|c|}{2,232} & \multicolumn{2}{|c|}{2,179} \\
\hline & Count & Percent & Count & Percent & Count & Percent & Count & Percent & Count & Percent & Count & Percent & Count & Percent \\
\hline \multicolumn{15}{|l|}{ Trichoptera } \\
\hline \multicolumn{15}{|l|}{ Polycentropodidae } \\
\hline Neureclipsis & 11 & $<1$ & - & & 3 & $<1$ & 43 & $<1$ & - & & 25 & 1 & 1 & $<1$ \\
\hline Nyctiophylax & 3 & $<1$ & - & & - & & 3 & $<1$ & - & & 1 & $<1$ & 2 & $<1$ \\
\hline Polycentropus & 3 & $<1$ & - & & - & & - & & - & & - & & - & \\
\hline \multicolumn{15}{|l|}{ Psychomyiidae } \\
\hline Psychomyia & - & & - & & - & & 13 & $<1$ & 35 & 2 & 8 & $<1$ & 120 & 5 \\
\hline \multicolumn{15}{|l|}{ Rhyacophilidae } \\
\hline Rhyacophila & - & & - & & - & & 3 & $<1$ & - & & 2 & $<1$ & - & \\
\hline Uenoidae & & & & & & & & & & & & & & \\
\hline Neophylax & - & & - & & - & & - & & - & & - & & - & \\
\hline Lepidoptera & & & & & & & & & & & & & & \\
\hline Pyralidae & & & & & & & & & & & & & & \\
\hline Petrophila & 21 & $<1$ & - & & - & & - & & - & & 1 & $<1$ & 2 & $<1$ \\
\hline Coleoptera & & & & & & & & & & & & & & \\
\hline Dryopidae & & & & & & & & & & & & & & \\
\hline Helichus & - & & - & & - & & - & & - & & - & & - & \\
\hline Elmidae & & & & & & & & & & & & & & \\
\hline Ancyronyx & - & & - & & - & & - & & - & & - & & - & \\
\hline Dubiraphia & 5 & $<1$ & - & & 5 & $<1$ & 5 & $<1$ & 2 & $<1$ & - & & - & \\
\hline Optioservus & 13 & $<1$ & 13 & $<1$ & 32 & 1 & 19 & $<1$ & 10 & $<1$ & - & & 18 & $<1$ \\
\hline Oulimnius & - & & - & & - & & - & & 1 & $<1$ & - & & 8 & $<1$ \\
\hline Promoresia & - & & - & & - & & - & & 2 & $<1$ & 5 & $<1$ & - & \\
\hline Stenelmis & 14 & $<1$ & 3 & $<1$ & 13 & $<1$ & 3 & $<1$ & 3 & $<1$ & - & & - & \\
\hline Hydrophilidae & & & & & & & & & & & & & & \\
\hline Berosus & - & & - & & 3 & $<1$ & - & & - & & - & & - & \\
\hline Psephenidae & & & & & & & & & & & & & & \\
\hline Ectopria & - & & 3 & $<1$ & - & & - & & - & & - & & - & \\
\hline Psephenus & - & & - & & 3 & $<1$ & - & & - & & - & & - & \\
\hline Hymenoptera & - & & - & & - & & - & & 1 & $<1$ & - & & - & \\
\hline Diptera & & & & & & & & & & & & & & \\
\hline Athericidae & & & & & & & & & & & & & & \\
\hline Atherix & - & & - & & - & & - & & - & & - & & - & \\
\hline Chaoboridae & & & & & & & & & & & & & & \\
\hline Chaoborus & - & & - & & - & & - & & - & & - & & - & \\
\hline Chironomidae & 570 & 23 & 10,000 & 83 & 770 & 27 & 3,400 & 57 & 580 & 31 & 400 & 18 & 840 & 38 \\
\hline Empididae & & & & & & & & & & & & & & \\
\hline Hemerodromia & 3 & $<1$ & 19 & $<1$ & 8 & $<1$ & 3 & $<1$ & 4 & $<1$ & 6 & $<1$ & 5 & $<1$ \\
\hline Simuliidae & & & & & & & & & & & & & & \\
\hline Simulium & 83 & 3 & 200 & 2 & 380 & 13 & 1,200 & 20 & 99 & 5 & 780 & 35 & 14 & $<1$ \\
\hline Stratiomyidae & - & & - & & - & & - & & - & & 1 & $<1$ & - & \\
\hline Tipulidae & & & & & & & & & & & & & & \\
\hline Antocha & 16 & $<1$ & 37 & $<1$ & 3 & $<1$ & 75 & 1 & 53 & 3 & 130 & 6 & 130 & 6 \\
\hline Tipula & - & & - & & - & & - & & - & & - & & - & \\
\hline
\end{tabular}

${ }^{1}$ Extrapolated from a 3/8 subsample. 


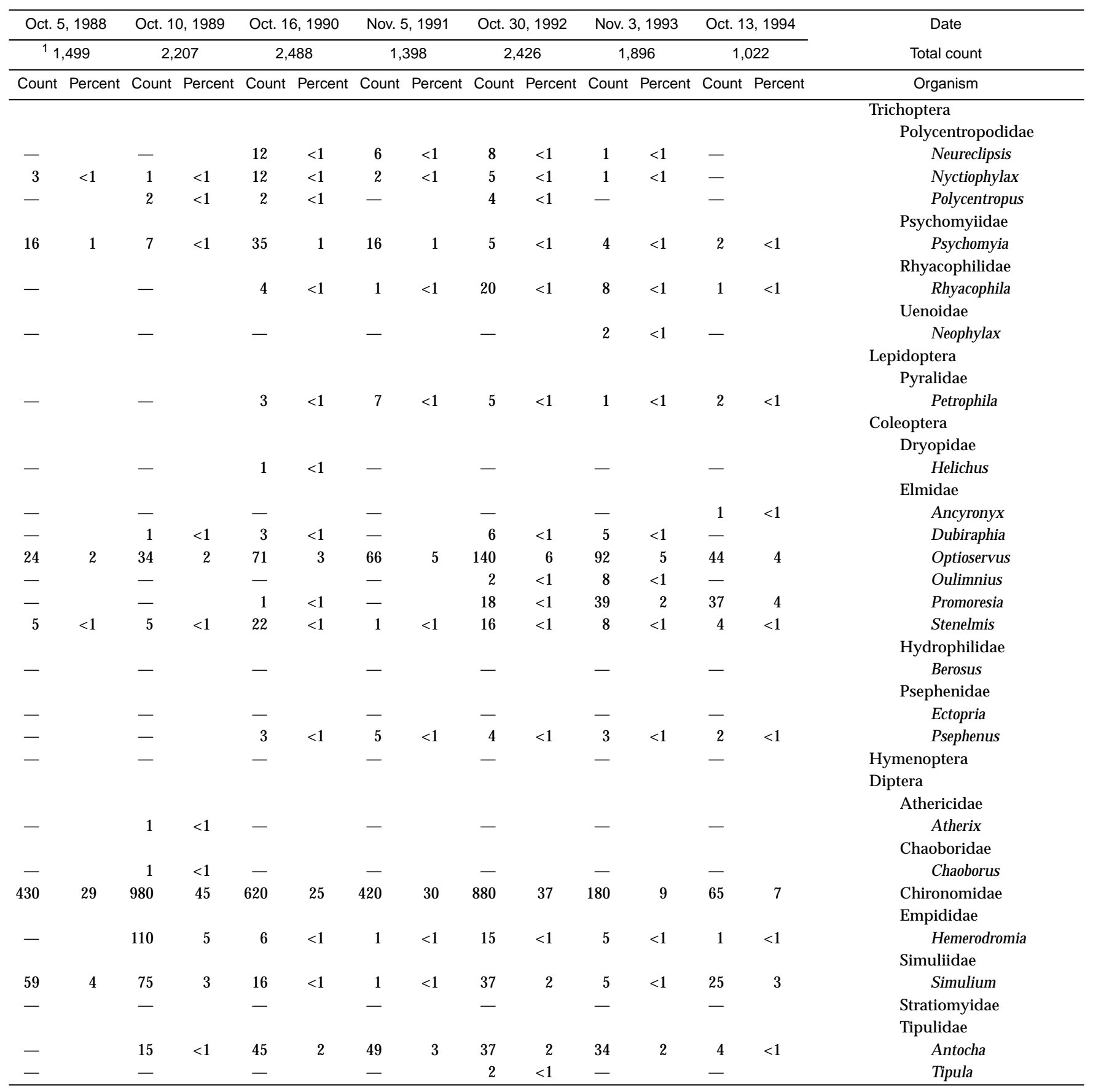


Table 5. Benthic-macroinvertebrate data-Continued

$[<$, less than; - , not found]

01480903 - Valley Creek at Mullsteins Meadows near Downingtown, Pa. (Site 44)

\begin{tabular}{|c|c|c|c|c|c|c|c|c|c|c|c|c|c|c|}
\hline \multirow{3}{*}{ 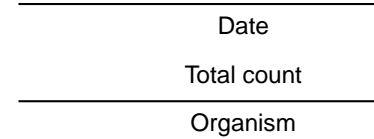 } & \multirow{2}{*}{\multicolumn{2}{|c|}{$\begin{array}{c}\text { Nov. } 4,1981 \\
2,812\end{array}$}} & \multirow{2}{*}{\multicolumn{2}{|c|}{$\begin{array}{c}\text { Oct. } 28,1982 \\
1,556\end{array}$}} & \multirow{2}{*}{\multicolumn{2}{|c|}{$\frac{\text { Oct. } 31,1983}{1,918}$}} & \multirow{2}{*}{\multicolumn{2}{|c|}{$\begin{array}{c}\text { Oct. } 16,1984 \\
1,475\end{array}$}} & \multirow{2}{*}{\multicolumn{2}{|c|}{$\frac{\text { Oct. } 31,1985}{2,091}$}} & \multirow{2}{*}{\multicolumn{2}{|c|}{$\begin{array}{c}\text { Oct. 8, } 1986 \\
1,079\end{array}$}} & \multirow{2}{*}{\multicolumn{2}{|c|}{$\begin{array}{c}\text { Nov. 4, } 1987 \\
2,352\end{array}$}} \\
\hline & & & & & & & & & & & & & & \\
\hline & Count & Percent & Count & Percent & Count & Percent & Count & Percent & Count & Percent & Count & Percent & Count & Percent \\
\hline \multicolumn{15}{|l|}{ Platyhelminthes (flatworms) } \\
\hline \multicolumn{15}{|l|}{ Turbellaria } \\
\hline \multicolumn{15}{|l|}{ Tricladida } \\
\hline Planariidae & 38 & 1 & 27 & 2 & 39 & 2 & 6 & $<1$ & 62 & 3 & 13 & 1 & 21 & $<1$ \\
\hline Nematoda (nematodes) & 1 & $<1$ & 1 & $<1$ & - & & 3 & $<1$ & - & & - & & 1 & $<1$ \\
\hline \multicolumn{15}{|l|}{ Nemertea (proboscis worms) } \\
\hline \multicolumn{15}{|l|}{ Enopla } \\
\hline \multicolumn{15}{|l|}{ Hoplonemertea } \\
\hline \multicolumn{15}{|l|}{ Tetrastemmatidae } \\
\hline Prostoma & - & & - & & - & & - & & 1 & $<1$ & - & & - & \\
\hline Mollusca (molluscs) & & & & & & & & & & & & & & \\
\hline Gastropoda & & & & & & & & & & & & & & \\
\hline Basommatophora & & & & & & & & & & & & & & \\
\hline Ancylidae & & & & & & & & & & & & & & \\
\hline Ferrissia & - & & - & & 1 & $<1$ & - & & - & & 1 & $<1$ & - & \\
\hline Physidae & & & & & & & & & & & & & & \\
\hline Physa & 1 & $<1$ & 16 & 1 & - & & - & & - & & - & & - & \\
\hline Planorbidae & & & & & & & & & & & & & & \\
\hline Helisoma & - & & 3 & $<1$ & - & & - & & - & & - & & - & \\
\hline Annelida (segmented worms) & & & & & & & & & & & & & & \\
\hline Oligochaeta & & & & & & & & & & & & & & \\
\hline Lumbriculida & & & & & & & & & & & & & & \\
\hline Lumbriculidae & - & & - & & - & & - & & - & & - & & - & \\
\hline Tubificida & & & & & & & & & & & & & & \\
\hline Naididae & - & & 4 & $<1$ & - & & 1 & $<1$ & 1 & $<1$ & 2 & $<1$ & 5 & $<1$ \\
\hline Arthropoda (arthropods) & & & & & & & & & & & & & & \\
\hline Acariformes & & & & & & & & & & & & & & \\
\hline Hydrachnidia & 28 & 1 & 6 & $<1$ & 18 & $<1$ & 10 & $<1$ & 1 & $<1$ & 1 & $<1$ & 6 & $<1$ \\
\hline Crustacea & & & & & & & & & & & & & & \\
\hline Cyclopoida & - & & - & & - & & - & & - & & - & & - & \\
\hline Amphipoda & & & & & & & & & & & & & & \\
\hline Gammaridae & & & & & & & & & & & & & & \\
\hline Gammarus & - & & - & & - & & - & & - & & - & & - & \\
\hline Podocopa & 1 & $<1$ & - & & - & & - & & 1 & $<1$ & - & & 1 & $<1$ \\
\hline Insecta & & & & & & & & & & & & & & \\
\hline Ephemeroptera & & & & & & & & & & & & & & \\
\hline Baetidae & & & & & & & & & & & & & & \\
\hline Baetis & 16 & $<1$ & 4 & $<1$ & - & & 30 & 2 & 14 & $<1$ & 26 & 2 & 2 & $<1$ \\
\hline Pseudocloeon & - & & 5 & $<1$ & 1 & $<1$ & 3 & $<1$ & 12 & $<1$ & - & & 21 & $<1$ \\
\hline Caenidae & & & & & & & & & & & & & & \\
\hline Caenis & - & & - & & - & & - & & - & & - & & - & \\
\hline Ephemerellidae & & & & & & & & & & & & & & \\
\hline Ephemerella & 230 & 8 & 180 & 11 & 330 & 17 & 44 & 3 & 260 & 12 & 30 & 3 & 200 & 8 \\
\hline Heptageniidae & & & & & & & & & & & & & & \\
\hline Epeorus & - & & - & & - & & - & & - & & - & & - & \\
\hline Stenonema & 83 & 3 & 90 & 6 & 84 & 4 & 29 & 2 & 31 & 1 & 10 & $<1$ & 31 & 1 \\
\hline Isonychiidae & & & & & & & & & & & & & & \\
\hline Isonychia & 10 & $<1$ & 17 & 1 & 14 & $<1$ & 19 & 1 & 3 & $<1$ & 2 & $<1$ & 3 & $<1$ \\
\hline Leptohyphidae & & & & & & & & & & & & & & \\
\hline Tricorythodes & 3 & $<1$ & 5 & $<1$ & 5 & $<1$ & - & & 3 & $<1$ & - & & 4 & $<1$ \\
\hline Leptophlebiidae & - & & - & & - & & 1 & $<1$ & - & & - & & - & \\
\hline
\end{tabular}




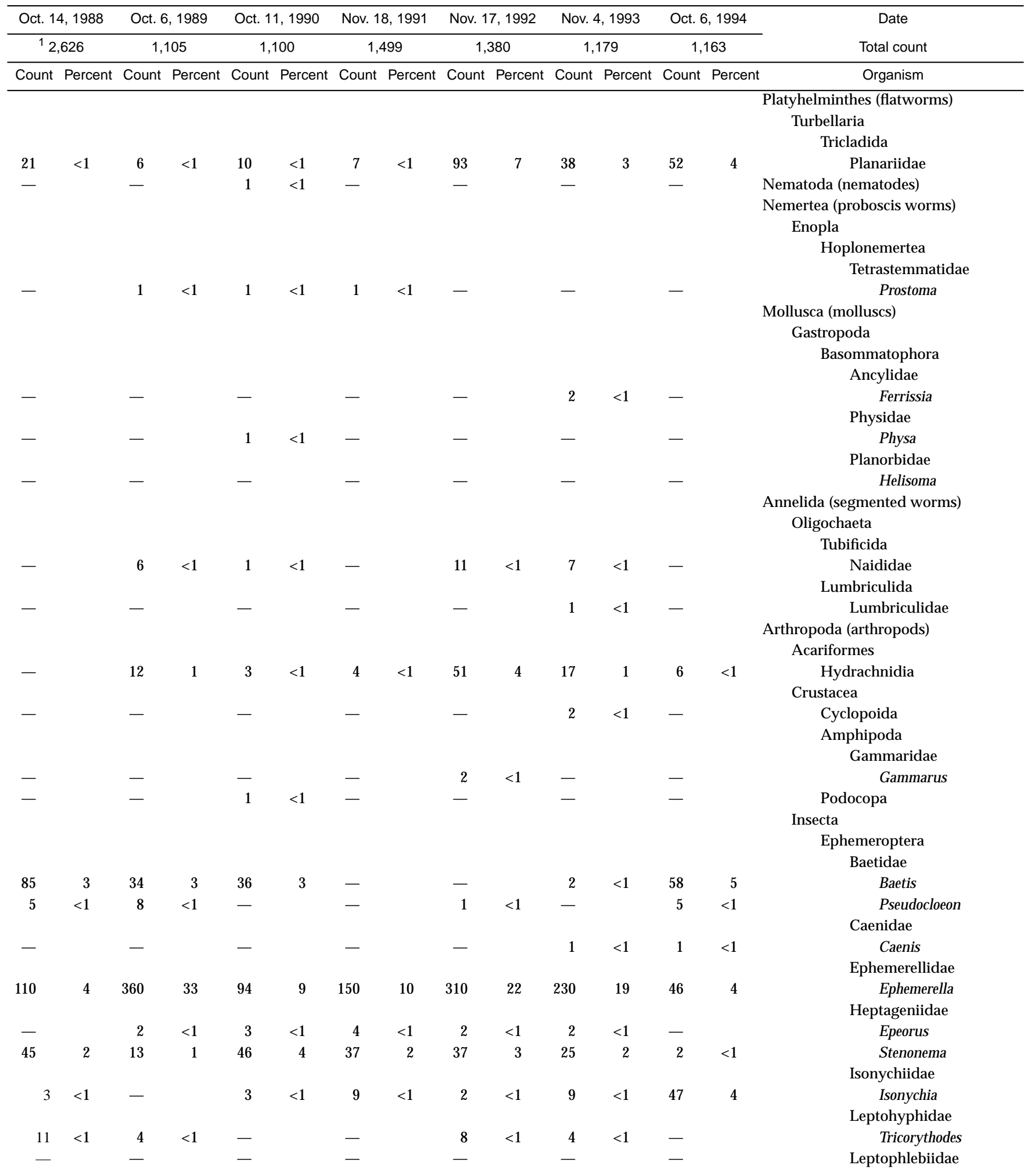


Table 5. Benthic-macroinvertebrate data-Continued

01480903 - Valley Creek at Mullsteins Meadows near Downingtown, Pa. (Site 44)—Continued

\begin{tabular}{|c|c|c|c|c|c|c|c|c|c|c|c|c|c|c|}
\hline \multirow{3}{*}{$\begin{array}{c}\text { Date } \\
\text { Total count } \\
\text { Organism }\end{array}$} & \multirow{2}{*}{\multicolumn{2}{|c|}{$\begin{array}{c}\text { Nov. } 4,1981 \\
2,812\end{array}$}} & \multirow{2}{*}{\multicolumn{2}{|c|}{$\begin{array}{c}\text { Oct. } 28,1982 \\
1,556\end{array}$}} & \multirow{2}{*}{\multicolumn{2}{|c|}{$\frac{\text { Oct. } 31,1983}{1,918}$}} & \multirow{2}{*}{\multicolumn{2}{|c|}{$\begin{array}{c}\text { Oct. } 16,1984 \\
1,475\end{array}$}} & \multirow{2}{*}{\multicolumn{2}{|c|}{$\begin{array}{c}\text { Oct. } 31,1985 \\
2,091\end{array}$}} & \multirow{2}{*}{\multicolumn{2}{|c|}{$\begin{array}{c}\text { Oct. } 8,1986 \\
1,079\end{array}$}} & \multirow{2}{*}{\multicolumn{2}{|c|}{$\begin{array}{c}\text { Nov. 4, } 1987 \\
2,352\end{array}$}} \\
\hline & & & & & & & & & & & & & & \\
\hline & Count & Percent & Count & Percent & Count & Percent & Count & Percent & Count & Percent & Count & Percent & Count & Percent \\
\hline \multicolumn{15}{|l|}{ Odonata } \\
\hline \multicolumn{15}{|l|}{ Coenagrionidae } \\
\hline Argia & 1 & $<1$ & - & & - & & - & & - & & - & & - & \\
\hline \multicolumn{15}{|l|}{ Plecoptera } \\
\hline \multicolumn{15}{|l|}{ Capniidae } \\
\hline Allocapnia & 11 & $<1$ & 2 & $<1$ & 9 & $<1$ & 5 & $<1$ & 68 & 3 & - & & 6 & $<1$ \\
\hline Chloroperlidae & 3 & $<1$ & - & & 6 & $<1$ & 2 & $<1$ & 9 & $<1$ & - & & 7 & $<1$ \\
\hline Perlidae & - & & - & & - & & - & & - & & - & & - & \\
\hline & \multicolumn{13}{|c|}{ Taeniopterygidae } & $<1$ \\
\hline Taeniopteryx & - & & - & & - & & - & & 1 & $<1$ & - & & 2 & $<1$ \\
\hline \multicolumn{15}{|l|}{ Hemiptera } \\
\hline Rhagovelia & - & & - & & - & & - & & - & & - & & - & \\
\hline \multicolumn{14}{|l|}{ Megaloptera } & \\
\hline Corydalus & 1 & $<1$ & 1 & $<1$ & - & & 4 & $<1$ & 2 & $<1$ & 2 & $<1$ & 4 & $<1$ \\
\hline Nigronia & - & & 1 & $<1$ & - & & - & & - & & - & & - & \\
\hline \multicolumn{15}{|l|}{ Trichoptera } \\
\hline $\begin{array}{c}\text { Apatania } \\
\text { Brachycentridae }\end{array}$ & - & & - & & - & & - & & - & & - & & - & \\
\hline $\begin{array}{c}\text { Micrasema } \\
\text { Glossosomatidae }\end{array}$ & - & & - & & - & & - & & - & & - & & - & \\
\hline $\begin{array}{c}\text { Glossosoma } \\
\text { Helicopsychidae }\end{array}$ & 2 & $<1$ & 13 & $<1$ & 20 & 1 & 28 & 2 & 4 & $<1$ & 1 & $<1$ & 2 & $<1$ \\
\hline $\begin{array}{l}\text { Helicopsyche } \\
\text { Hydropsychidae }\end{array}$ & 11 & $<1$ & - & & - & & - & & - & & - & & 6 & $<1$ \\
\hline Ceratoopsyche & 680 & 24 & 250 & 16 & 510 & 27 & 590 & 39 & 400 & 19 & 250 & 23 & 630 & 26 \\
\hline Cheumatopsyche & 220 & 8 & 42 & 3 & 120 & 6 & 90 & 6 & 130 & 6 & 28 & 3 & 60 & 3 \\
\hline Hydropsyche & 76 & 3 & 75 & 5 & 60 & 3 & 88 & 6 & 9 & $<1$ & 50 & 5 & 200 & 8 \\
\hline Hydroptilidae & & & & & & & & & & & & & & \\
\hline Hydroptila & 2 & $<1$ & - & & - & & - & & 2 & $<1$ & - & & 1 & $<1$ \\
\hline $\begin{array}{c}\text { Leucotrichia } \\
\text { Lepidostomatidae }\end{array}$ & 110 & 4 & 410 & 26 & 270 & 14 & 75 & 5 & 63 & 3 & 290 & 26 & 300 & 13 \\
\hline Lepidostoma & - & & - & & - & & - & & - & & - & & - & \\
\hline Leptoceridae & & & & & & & & & & & & & & \\
\hline Mystacides & - & & 1 & $<1$ & - & & - & & - & & - & & - & \\
\hline Oecetis & - & & - & & - & & - & & - & & - & & - & \\
\hline Philopotamidae & & & & & & & & & & & & & & \\
\hline Chimarra & 150 & 5 & 9 & $<1$ & 14 & $<1$ & 21 & 1 & 55 & 3 & 52 & 5 & 26 & 1 \\
\hline Dolophilodes & - & & - & & - & & - & & - & & - & & - & \\
\hline Wormaldia & - & & - & & - & & - & & - & & - & & - & \\
\hline Polycentropodidae & & & & & & & & & & & & & & \\
\hline Nyctiophylax & 8 & $<1$ & 3 & $<1$ & 11 & $<1$ & - & & - & & - & & - & \\
\hline Polycentropus & 1 & $<1$ & - & & 1 & $<1$ & - & & - & & - & & - & \\
\hline Psychomyiidae & & & & & & & & & & & & & & \\
\hline Psychomyia & 4 & $<1$ & 2 & $<1$ & 5 & $<1$ & 1 & $<1$ & 17 & $<1$ & 9 & $<1$ & 8 & $<1$ \\
\hline Lepidoptera & & & & & & & & & & & & & & \\
\hline $\begin{array}{l}\text { Noctuidae } \\
\text { Pyralidae }\end{array}$ & - & & - & & - & & - & & - & & - & & - & \\
\hline Petrophila & - & & - & & 1 & $<1$ & - & & 2 & $<1$ & - & & 1 & $<1$ \\
\hline
\end{tabular}




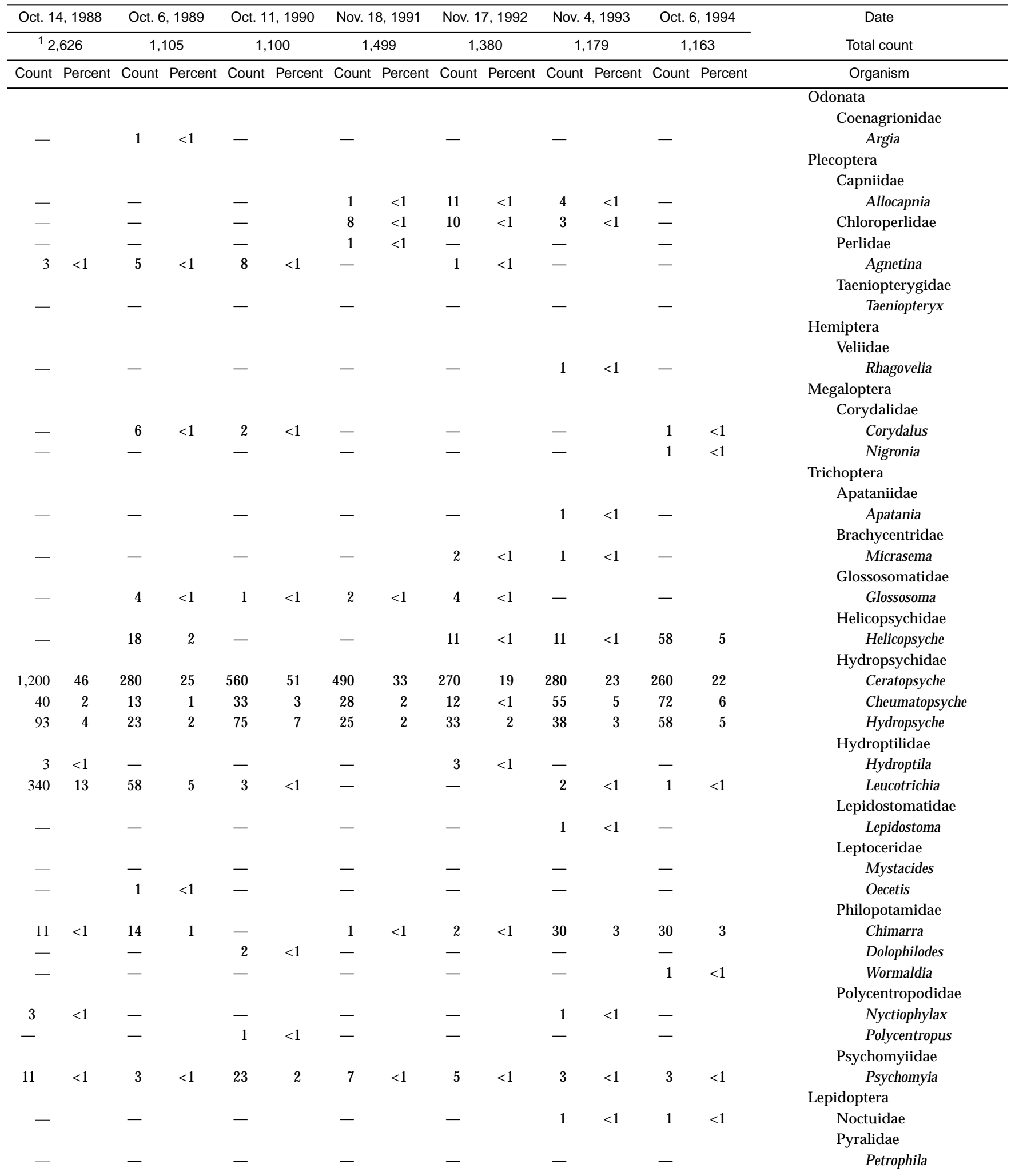


Table 5. Benthic-macroinvertebrate data-Continued

01480903 - Valley Creek at Mullsteins Meadows near Downingtown, Pa. (Site 44)—Continued

\begin{tabular}{|c|c|c|c|c|c|c|c|c|c|c|c|c|c|c|}
\hline \multirow{3}{*}{$\begin{array}{c}\text { Date } \\
\text { Total count } \\
\text { Organism }\end{array}$} & \multirow{2}{*}{\multicolumn{2}{|c|}{$\begin{array}{c}\text { Nov. } 4,1981 \\
2,812\end{array}$}} & \multirow{2}{*}{\multicolumn{2}{|c|}{$\frac{\text { Oct. 28, } 1982}{1,556}$}} & \multirow{2}{*}{\multicolumn{2}{|c|}{$\frac{\text { Oct. } 31,1983}{1,918}$}} & \multirow{2}{*}{\multicolumn{2}{|c|}{$\frac{\text { Oct. } 16,1984}{1,475}$}} & \multirow{2}{*}{\multicolumn{2}{|c|}{$\frac{\text { Oct. } 31,1985}{2,091}$}} & \multirow{2}{*}{\multicolumn{2}{|c|}{$\frac{\text { Oct. } 8,1986}{1,079}$}} & \multirow{2}{*}{\multicolumn{2}{|c|}{$\frac{\text { Nov. 4, } 1987}{2,352}$}} \\
\hline & & & & & & & & & & & & & & \\
\hline & Count & Percent & Count & Percent & Count & Percent & Count & Percent & Count & Percent & Count & Percent & Count & Percent \\
\hline \multicolumn{15}{|l|}{ Coleoptera } \\
\hline \multicolumn{15}{|l|}{ Elmidae } \\
\hline Dubiraphia & - & & - & & - & & - & & - & & - & & - & \\
\hline Optioserous & 48 & 2 & 12 & $<1$ & 75 & 4 & 22 & 1 & 51 & 2 & 36 & 3 & 67 & 3 \\
\hline Oulimnius & - & & - & & - & & - & & 3 & $<1$ & - & & - & \\
\hline Stenelmis & 13 & $<1$ & 1 & $<1$ & 6 & $<1$ & 2 & $<1$ & 6 & $<1$ & 4 & $<1$ & 4 & $<1$ \\
\hline \multicolumn{15}{|l|}{ Psephenidae } \\
\hline Psephenus & - & & 1 & $<1$ & - & & - & & - & & 2 & $<1$ & - & \\
\hline \multicolumn{15}{|l|}{ Diptera } \\
\hline Ceratopogonidae & - & & - & & - & & - & & - & & - & & - & \\
\hline $\begin{array}{l}\text { Chironomidae } \\
\text { Empididae }\end{array}$ & 400 & 14 & 240 & 15 & 220 & 12 & 160 & 11 & 330 & 16 & 41 & 4 & 340 & 14 \\
\hline Hemerodromia & 5 & $<1$ & 3 & $<1$ & 2 & $<1$ & - & & 2 & $<1$ & - & & 2 & $<1$ \\
\hline \multicolumn{15}{|l|}{ Simuliidae } \\
\hline Simulium & 600 & 21 & 120 & 8 & 82 & 4 & 230 & 15 & 500 & 24 & 220 & 20 & 360 & 15 \\
\hline \multicolumn{15}{|l|}{ Tipulidae } \\
\hline Antocha & 42 & 2 & 10 & $<1$ & 14 & $<1$ & 11 & $<1$ & 46 & 2 & 3 & $<1$ & 29 & 1 \\
\hline Tipula & 1 & $<1$ & 1 & $<1$ & - & & - & & 1 & $<1$ & 1 & $<1$ & 1 & $<1$ \\
\hline
\end{tabular}

${ }^{1}$ Extrapolated from a 3/8 subsample. 


\begin{tabular}{|c|c|c|c|c|c|c|c|c|c|c|c|c|c|c|}
\hline \multicolumn{2}{|c|}{ Oct. 14,1988} & \multicolumn{2}{|c|}{ Oct. 6,1989} & \multicolumn{2}{|c|}{ Oct. 11,1990} & \multicolumn{2}{|c|}{ Nov. 18, 1991} & \multicolumn{2}{|c|}{ Nov. 17,1992} & \multicolumn{2}{|c|}{ Nov. 4, 1993} & \multicolumn{2}{|c|}{ Oct. 6,1994} & \multirow{2}{*}{$\begin{array}{c}\text { Date } \\
\text { Total count }\end{array}$} \\
\hline \multicolumn{2}{|c|}{${ }^{1} 2,626$} & \multicolumn{2}{|c|}{1,105} & \multicolumn{2}{|c|}{1,100} & \multicolumn{2}{|c|}{1,499} & \multicolumn{2}{|c|}{1,380} & \multicolumn{2}{|c|}{1,179} & \multicolumn{2}{|c|}{1,163} & \\
\hline \multirow[t]{3}{*}{ Count } & Percent & Count & Percent & Count & Percent & Count & Percent & Count & Percent & Count & Percent & Count & Percent & Organism \\
\hline & & & & & & & & & & & & & \multicolumn{2}{|c|}{ Coleoptera } \\
\hline & & & & & & & & & & & & & \multicolumn{2}{|r|}{ Elmidae } \\
\hline - & & - & & - & & - & & - & & - & & 1 & $<1$ & Dubiraphia \\
\hline 67 & 3 & 31 & 3 & 36 & 3 & 24 & 2 & 140 & 10 & 54 & 5 & 110 & 9 & Optioserous \\
\hline- & & - & & 3 & $<1$ & 3 & $<1$ & - & & - & & - & & Oulimnius \\
\hline \multirow[t]{2}{*}{6} & $<1$ & 15 & 1 & - & & - & & 5 & $<1$ & 6 & $<1$ & 48 & 4 & Stenelmis \\
\hline & & & & & & & & & & & & & & Psephenidae \\
\hline \multirow[t]{2}{*}{8} & $<1$ & 7 & $<1$ & 5 & $<1$ & - & & - & & 4 & $<1$ & 14 & 1 & Psephenus \\
\hline & & & & & & & & & & & & \multicolumn{3}{|c|}{ Diptera } \\
\hline - & & - & & - & & - & & - & & 1 & $<1$ & - & & Ceratopogonidae \\
\hline \multirow[t]{2}{*}{420} & \multirow[t]{4}{*}{16} & \multirow[t]{2}{*}{110} & \multirow[t]{2}{*}{10} & \multirow[t]{2}{*}{110} & \multirow[t]{2}{*}{10} & \multirow[t]{2}{*}{580} & \multirow[t]{4}{*}{39} & \multirow[t]{2}{*}{240} & \multirow[t]{2}{*}{17} & 250 & 21 & 240 & 20 & Chironomidae \\
\hline & & & & & & & & & & & & & & Empididae \\
\hline - & & 8 & $<1$ & - & & - & & 9 & $<1$ & 4 & $<1$ & 3 & $<1$ & Hemerodromia \\
\hline & & & & & & & & & & & & & & Simuliidae \\
\hline 130 & 5 & 54 & 5 & 19 & 2 & 87 & 6 & 49 & 3 & 18 & 2 & 22 & 2 & Simulium \\
\hline & & & & & & & & & & & & & & Tipulidae \\
\hline 11 & $<1$ & 7 & $<1$ & 19 & 2 & 30 & 2 & 56 & 4 & 70 & 6 & 22 & 2 & Antocha \\
\hline - & & 1 & $<1$ & - & & - & & - & & 一 & & 一 & & Tipula \\
\hline
\end{tabular}


Table 5. Benthic-macroinvertebrate data-Continued

$[<$, less than; - , not found]

01480950 - East Branch Brandywine Creek at Wawaset, Pa. (Site 39)

\begin{tabular}{|c|c|c|c|c|c|c|c|c|c|c|c|c|c|c|}
\hline \multirow{3}{*}{$\begin{array}{c}\text { Date } \\
\text { Total count } \\
\text { Organism }\end{array}$} & \multirow{2}{*}{\multicolumn{2}{|c|}{$\begin{array}{c}\text { Nov. 4, } 1981 \\
641\end{array}$}} & \multicolumn{2}{|c|}{ Oct. 21,1982} & \multicolumn{2}{|c|}{ Oct. 31, 1983} & \multicolumn{2}{|c|}{ Oct. 16,1984} & \multicolumn{2}{|c|}{ Oct. 22, 1985} & \multicolumn{2}{|c|}{ Nov. 3, 1986} & \multicolumn{2}{|c|}{ Nov. 4, 1987} \\
\hline & & & \multicolumn{2}{|c|}{2,825} & \multicolumn{2}{|c|}{771} & \multicolumn{2}{|c|}{2,999} & \multicolumn{2}{|c|}{699} & \multicolumn{2}{|c|}{2,583} & & 115 \\
\hline & Count & Percent & Count & Percent & Count & Percent & Count & Percent & Count & Percent & Count & Percent & Count & Percent \\
\hline Platyhelminthes (flatworms) & & & & & & & & & & & & & & \\
\hline Turbellaria & & & & & & & & & & & & & & \\
\hline Tricladida & & & & & & & & & & & & & & \\
\hline Planariidae & 5 & $<1$ & 19 & $<1$ & 110 & 14 & 11 & $<1$ & 13 & 2 & 28 & 1 & 44 & 4 \\
\hline Nematoda & - & & - & & 1 & $<1$ & - & & - & & - & & 2 & $<1$ \\
\hline Nemertea (proboscis worms) & & & & & & & & & & & & & & \\
\hline Enopla & & & & & & & & & & & & & & \\
\hline Hoplonemertea & & & & & & & & & & & & & & \\
\hline Tetrastemmatidae & & & & & & & & & & & & & & \\
\hline Prostoma & - & & - & & - & & 3 & $<1$ & - & & - & & - & \\
\hline Mollusca (molluscs) & & & & & & & & & & & & & & \\
\hline Gastropoda & & & & & & & & & & & & & & \\
\hline Mesogastropoda & & & & & & & & & & & & & & \\
\hline Hydrobiidae & & & & & & & & & & & & & & \\
\hline Amnicola & - & & - & & - & & - & & - & & - & & - & \\
\hline Basommatophora & & & & & & & & & & & & & & \\
\hline Ancylidae & & & & & & & & & & & & & & \\
\hline Ferrissia & 51 & 8 & 31 & 1 & 22 & 3 & 17 & $<1$ & 10 & 1 & 23 & $<1$ & 10 & $<1$ \\
\hline Lymnaeidae & & & & & & & & & & & & & & \\
\hline Lymnaea & 1 & $<1$ & - & & - & & - & & - & & - & & 1 & $<1$ \\
\hline Physidae & & & & & & & & & & & & & & \\
\hline Physa & - & & 12 & $<1$ & 2 & $<1$ & 1 & $<1$ & - & & 2 & $<1$ & - & \\
\hline Planorbidae & & & & & & & & & & & & & & \\
\hline Gyraulus & - & & - & & - & & - & & - & & - & & - & \\
\hline Helisoma & 3 & $<1$ & 2 & $<1$ & 2 & $<1$ & - & & - & & 1 & $<1$ & 2 & $<1$ \\
\hline Planorbula & - & & - & & - & & - & & - & & - & & - & \\
\hline Bivalvia & & & & & & & & & & & & & & \\
\hline Veneroida & & & & & & & & & & & & & & \\
\hline Sphaeriidae & 1 & $<1$ & 5 & $<1$ & 1 & $<1$ & 1 & $<1$ & - & & 1 & $<1$ & - & \\
\hline Pisidium & - & & - & & - & & - & & - & & - & & - & \\
\hline Sphaerium & - & & - & & - & & - & & - & & - & & - & \\
\hline Annelida (segmented worms) & & & & & & & & & & & & & & \\
\hline Oligochaeta & & & & & & & & & & & & & & \\
\hline Tubificida & & & & & & & & & & & & & & \\
\hline Naididae & 26 & 4 & 52 & 2 & 1 & $<1$ & 120 & 4 & - & & 1 & $<1$ & 48 & 4 \\
\hline Stylaria & - & & - & & - & & - & & 2 & $<1$ & - & & - & \\
\hline Tubificidae & 1 & $<1$ & - & & 2 & $<1$ & 1 & $<1$ & 3 & $<1$ & - & & 13 & 1 \\
\hline Hirudinea & 1 & $<1$ & - & & - & & - & & - & & - & & - & \\
\hline Pharyngobdellida & & & & & & & & & & & & & & \\
\hline Erpobdellidae & - & & 1 & $<1$ & - & & - & & - & & - & & - & \\
\hline Arthropoda (arthropods) & & & & & & & & & & & & & & \\
\hline Acariformes & & & & & & & & & & & & & & \\
\hline Hydrachnidia & - & & 30 & 1 & 4 & $<1$ & 8 & $<1$ & 3 & $<1$ & 9 & $<1$ & 33 & 3 \\
\hline Crustacea & & & & & & & & & & & & & & \\
\hline Cladocera & - & & - & & - & & - & & - & & 1 & $<1$ & - & \\
\hline Cyclopoida & & & & & & & & & & & & & & \\
\hline Cyclopidae & - & & 1 & $<1$ & - & & - & & - & & - & & - & \\
\hline Amphipoda & & & & & & & & & & & & & & \\
\hline Crangonyctidae & & & & & & & & & & & & & & \\
\hline Crangonyx & - & & - & & 1 & $<1$ & 4 & $<1$ & - & & - & & - & \\
\hline Gammaridae & & & & & & & & & & & & & & \\
\hline Gammarus & - & & - & & - & & - & & - & & 3 & $<1$ & 5 & $<1$ \\
\hline Talitridae & & & & & & & & & & & & & & \\
\hline Hyallela & & & & & & & & & & & & & & \\
\hline H. azteca & - & & 11 & $<1$ & - & & - & & 1 & $<1$ & 7 & $<1$ & - & \\
\hline
\end{tabular}




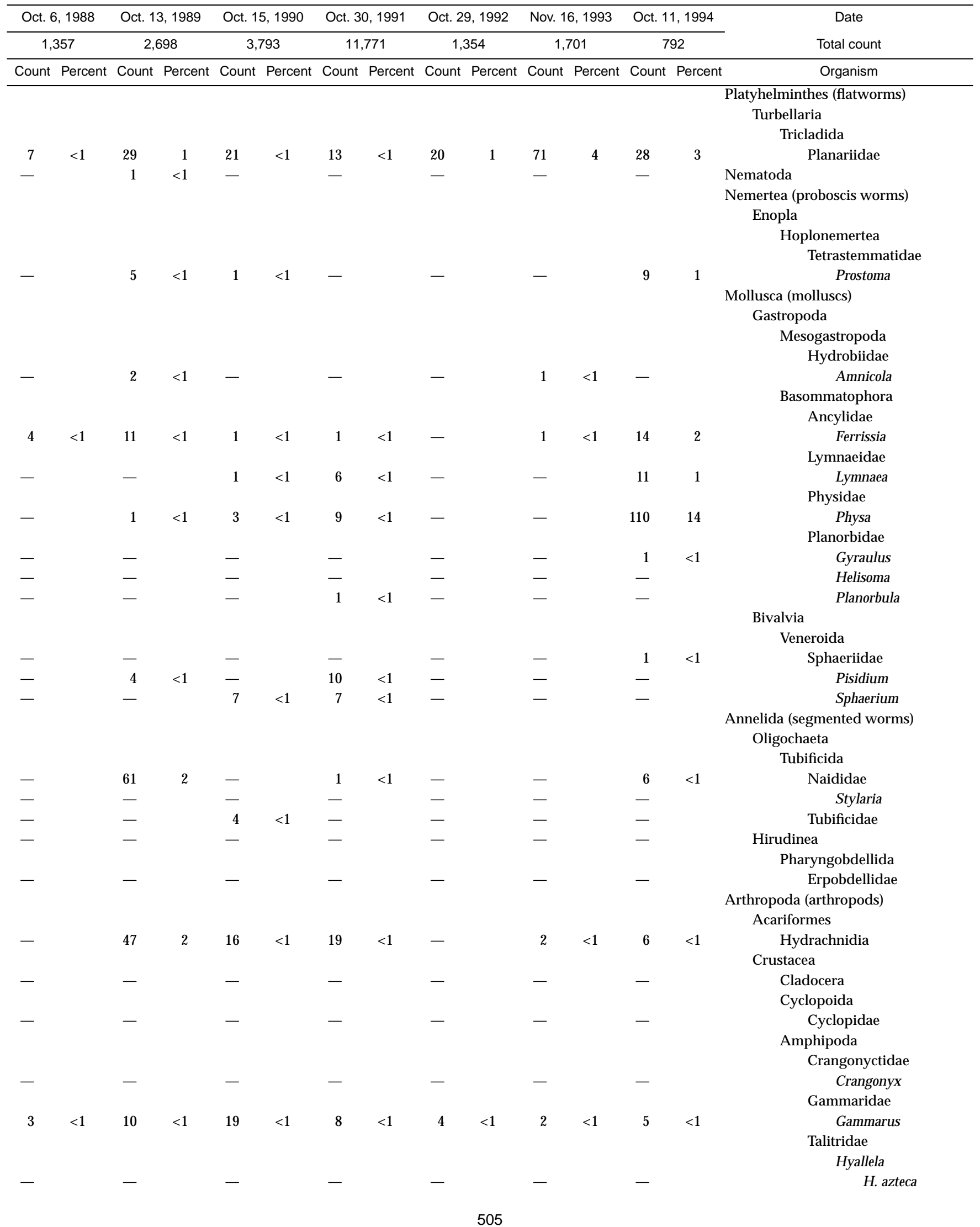


Table 5. Benthic-macroinvertebrate data-Continued

01480950 - East Branch Brandywine Creek at Wawaset, Pa. (Site 39)—Continued

\begin{tabular}{|c|c|c|c|c|c|c|c|c|c|c|c|c|c|c|}
\hline \multirow{3}{*}{$\begin{array}{c}\text { Date } \\
\text { Total count } \\
\text { Organism }\end{array}$} & \multirow{2}{*}{\multicolumn{2}{|c|}{$\begin{array}{c}\text { Nov. } 4,1981 \\
641 \\
\end{array}$}} & \multicolumn{2}{|c|}{ Oct. 21, 1982} & \multicolumn{2}{|c|}{ Oct. 31,1983} & \multicolumn{2}{|c|}{ Oct. 16,1984} & \multicolumn{2}{|c|}{ Oct. 22,1985} & \multicolumn{2}{|c|}{ Nov. 3, 1986} & \multicolumn{2}{|c|}{ Nov. 4, 1987} \\
\hline & & & & 825 & & 71 & 2,9 & 999 & & 99 & & 583 & & 115 \\
\hline & Count & Percent & Count & Percent & Count & Percent & Count & Percent & Count & Percent & Count & Percent & Count & Percent \\
\hline \multicolumn{15}{|l|}{ Decapoda } \\
\hline Cambaridae & - & & - & & - & & - & & - & & - & & - & \\
\hline Orconectes & - & & - & & - & & 1 & $<1$ & - & & - & & - & \\
\hline Podocopa & 17 & 3 & 270 & 10 & 39 & 5 & 1 & $<1$ & - & & 2 & $<1$ & - & \\
\hline \multicolumn{15}{|l|}{ Insecta } \\
\hline \multicolumn{15}{|l|}{ Ephemeroptera } \\
\hline \multicolumn{15}{|l|}{ Baetidae } \\
\hline Baetis & 2 & $<1$ & 27 & $<1$ & - & & 150 & 5 & - & & 2 & $<1$ & - & \\
\hline Pseudocloeon & - & & - & & - & & - & & 9 & 1 & - & & 6 & $<1$ \\
\hline \multicolumn{15}{|l|}{ Caenidae } \\
\hline Caenis & 1 & $<1$ & - & & 1 & $<1$ & 4 & $<1$ & 2 & $<1$ & 3 & $<1$ & 4 & $<1$ \\
\hline Ephemerellidae & & & & & & & & & & & & & & \\
\hline Ephemerella & 9 & 1 & 2 & $<1$ & 6 & $<1$ & 7 & $<1$ & 16 & 2 & 140 & 5 & 18 & 2 \\
\hline Heptageniidae & & & & & & & & & & & & & & \\
\hline Epeorus & - & & - & & - & & - & & - & & - & & - & \\
\hline Stenonema & 19 & 3 & 130 & 5 & 55 & 7 & 260 & 9 & 69 & 10 & 270 & 10 & 56 & 5 \\
\hline Isonychiidae & & & & & & & & & & & & & & \\
\hline Isonychia & - & & - & & - & & - & & - & & 1 & $<1$ & - & \\
\hline Leptohyphidae & & & & & & & & & & & & & & \\
\hline Tricorythodes & 6 & 1 & 12 & $<1$ & 16 & 2 & 4 & $<1$ & 11 & 2 & 11 & $<1$ & 46 & 4 \\
\hline Leptophlebiidae & & & & & & & & & & & & & & \\
\hline Paraleptophlebia & - & & - & & - & & - & & - & & - & & - & \\
\hline Potamanthidae & & & & & & & & & & & & & & \\
\hline Anthopotamus & - & & - & & - & & - & & - & & 1 & $<1$ & 5 & $<1$ \\
\hline Odonata & & & & & & & & & & & & & & \\
\hline Coenagrionidae & & & & & & & & & & & & & & \\
\hline Amphiagrion & - & & - & & 1 & $<1$ & - & & - & & - & & - & \\
\hline Argia & 13 & 2 & 48 & 2 & 2 & $<1$ & - & & 1 & $<1$ & 11 & $<1$ & 3 & $<1$ \\
\hline Enallagma & - & & - & & - & & - & & - & & - & & - & \\
\hline Ischnura & - & & - & & - & & - & & - & & - & & - & \\
\hline Gomphidae & & & & & & & & & & & & & & \\
\hline Stylogomphus & - & & - & & 1 & $<1$ & - & & - & & - & & - & \\
\hline Plecoptera & & & & & & & & & & & & & & \\
\hline Capniidae & & & & & & & & & & & & & & \\
\hline Allocapnia & - & & - & & - & & 1 & $<1$ & 1 & $<1$ & - & & - & \\
\hline Perlidae & & & & & & & & & & & & & & \\
\hline Acroneuria & - & & - & & - & & - & & - & & - & & - & \\
\hline Agnetina & - & & - & & - & & - & & - & & - & & - & \\
\hline Neoperla & - & & - & & - & & - & & - & & - & & - & \\
\hline Paragnetina & - & & - & & - & & 3 & $<1$ & - & & - & & - & \\
\hline Taeniopterygidae & & & & & & & & & & & & & & \\
\hline Taeniopteryx & 1 & $<1$ & 2 & $<1$ & - & & 5 & $<1$ & - & & - & & 1 & $<1$ \\
\hline Hemiptera & & & & & & & & & & & & & & \\
\hline Corixidae & & & & & & & & & & & & & & \\
\hline Sigara & - & & - & & - & & - & & - & & - & & - & \\
\hline Gerridae & & & & & & & & & & & & & & \\
\hline Rheumatobates & - & & - & & - & & 1 & $<1$ & - & & - & & - & \\
\hline Veliidae & & & & & & & & & & & & & & \\
\hline Microvelia & - & & - & & - & & - & & - & & - & & - & \\
\hline Megaloptera & & & & & & & & & & & & & & \\
\hline Corydalidae & & & & & & & & & & & & & & \\
\hline Corydalus & - & & - & & - & & 1 & $<1$ & - & & - & & - & \\
\hline Sialidae & & & & & & & & & & & & & & \\
\hline Sialis & - & & 1 & $<1$ & - & & - & & - & & - & & 1 & $<1$ \\
\hline
\end{tabular}




\begin{tabular}{|c|c|c|c|c|c|c|c|c|c|c|c|c|c|c|}
\hline \multirow{2}{*}{\multicolumn{2}{|c|}{$\begin{array}{c}\text { Oct. 6, } 1988 \\
1,357\end{array}$}} & \multicolumn{2}{|c|}{ Oct. 13, 1989} & \multicolumn{2}{|c|}{ Oct. 15, 1990} & \multicolumn{2}{|c|}{ Oct. 30, 1991} & \multicolumn{2}{|c|}{ Oct. 29, 1992} & \multicolumn{2}{|c|}{ Nov. 16, 1993} & \multicolumn{2}{|c|}{ Oct. 11, 1994} & \multirow{3}{*}{$\begin{array}{c}\text { Date } \\
\text { Total count } \\
\text { Organism }\end{array}$} \\
\hline & & \multicolumn{2}{|c|}{2,698} & \multicolumn{2}{|c|}{3,793} & \multicolumn{2}{|c|}{11,771} & \multicolumn{2}{|c|}{1,354} & \multicolumn{2}{|c|}{1,701} & & 92 & \\
\hline Count & Percent & Count & Percent & Count & Percent & Count & Percent & Count & Percent & Count & Percent & Count & Percent & \\
\hline & & & & & & & & & & & & & & Decapoda \\
\hline- & & - & & - & & 1 & $<1$ & - & & - & & - & & Cambaridae \\
\hline- & & - & & - & & - & & - & & - & & - & & Orconectes \\
\hline - & & - & & 4 & $<1$ & - & & 2 & $<1$ & - & & - & & Podocopa \\
\hline & & & & & & & & & & & & & & Insecta \\
\hline & & & & & & & & & & & & & & Ephemeroptera \\
\hline & & & & & & & & & & & & & & Baetidae \\
\hline 130 & 9 & - & & 13 & $<1$ & 1 & $<1$ & 1 & $<1$ & - & & 11 & 1 & Baetis \\
\hline 10 & $<1$ & - & & 5 & $<1$ & 12 & $<1$ & - & & - & & 2 & $<1$ & Pseudocloeon \\
\hline & & & & & & & & & & & & & & Caenidae \\
\hline - & & 4 & $<1$ & 1 & $<1$ & 1 & $<1$ & - & & - & & 8 & 1 & Caenis \\
\hline & & & & & & & & & & & & & & Ephemerellidae \\
\hline 11 & $<1$ & 110 & 4 & 120 & 3 & 84 & $<1$ & 71 & 5 & 290 & 17 & 6 & $<1$ & Ephemerella \\
\hline & & & & & & & & & & & & & & Heptageniidae \\
\hline 1 & $<1$ & 6 & $<1$ & 4 & $<1$ & - & & - & & - & & - & & Epeorus \\
\hline 250 & 18 & 210 & 8 & 260 & 7 & 100 & $<1$ & 39 & 2 & 59 & 3 & 22 & 3 & Stenonema \\
\hline & & & & & & & & & & & & & & Isonychiidae \\
\hline 1 & $<1$ & 1 & $<1$ & 3 & $<1$ & 4 & $<1$ & - & & 8 & $<1$ & - & & Isonychia \\
\hline & & & & & & & & & & & & & & Leptohyphidae \\
\hline 5 & $<1$ & 4 & $<1$ & 32 & $<1$ & 5 & $<1$ & - & & - & & 10 & 1 & Tricorythodes \\
\hline & & & & & & & & & & & & & & Leptophlebiidae \\
\hline- & & 3 & $<1$ & - & & - & & - & & - & & - & & Paraleptophlebia \\
\hline & & & & & & & & & & & & & & Potamanthidae \\
\hline - & & - & & - & & 1 & $<1$ & - & & - & & 3 & $<1$ & Anthopotamus \\
\hline & & & & & & & & & & & & & & Odonata \\
\hline & & & & & & & & & & & & & & Coenagrionidae \\
\hline - & & - & & - & & - & & - & & - & & - & & Amphiagrion \\
\hline 3 & $<1$ & 4 & $<1$ & - & & 2 & $<1$ & - & & 1 & $<1$ & 7 & $<1$ & Argia \\
\hline- & & - & & - & & 3 & $<1$ & - & & - & & - & & Enallagma \\
\hline- & & - & & - & & - & & - & & 1 & $<1$ & - & & Ischnura \\
\hline & & & & & & & & & & & & & & Gomphidae \\
\hline- & & - & & - & & - & & - & & - & & - & & Stylogomphus \\
\hline & & & & & & & & & & & & & & Plecoptera \\
\hline & & & & & & & & & & & & & & Capniidae \\
\hline - & & - & & - & & - & & - & & - & & - & & Allocapnia \\
\hline & & & & & & & & & & & & & & Perlidae \\
\hline- & & - & & - & & - & & - & & 1 & $<1$ & - & & Acroneuria \\
\hline- & & 1 & $<1$ & - & & - & & - & & - & & - & & Agnetina \\
\hline- & & - & & - & & - & & 1 & $<1$ & - & & - & & Neoperla \\
\hline- & & - & & - & & - & & - & & - & & - & & Paragnetina \\
\hline & & & & & & & & & & & & & & Taeniopterygidae \\
\hline- & & 4 & $<1$ & - & & 1 & $<1$ & - & & - & & - & & Taeniopteryx \\
\hline & & & & & & & & & & & & & & Hemiptera \\
\hline & & & & & & & & & & & & & & Corixidae \\
\hline - & & - & & 5 & $<1$ & - & & - & & - & & - & & Sigara \\
\hline & & & & & & & & & & & & & & Gerridae \\
\hline - & & - & & - & & - & & - & & - & & - & & Rheumatobates \\
\hline & & & & & & & & & & & & & & Veliidae \\
\hline - & & - & & - & & - & & - & & - & & 1 & $<1$ & Microvelia \\
\hline & & & & & & & & & & & & & & Megaloptera \\
\hline & & & & & & & & & & & & & & Corydalidae \\
\hline- & & - & & - & & 1 & $<1$ & - & & 2 & $<1$ & - & & Corydalus \\
\hline & & & & & & & & & & & & & & Sialidae \\
\hline- & & - & & - & & 1 & $<1$ & - & & - & & 1 & $<1$ & Sialis \\
\hline
\end{tabular}


Table 5. Benthic-macroinvertebrate data-Continued

01480950 - East Branch Brandywine Creek at Wawaset, Pa. (Site 39)—Continued

\begin{tabular}{|c|c|c|c|c|c|c|c|c|c|c|c|c|c|c|}
\hline \multirow{3}{*}{$\begin{array}{c}\text { Date } \\
\text { Total count } \\
\text { Organism }\end{array}$} & \multirow{2}{*}{\multicolumn{2}{|c|}{$\begin{array}{c}\text { Nov. 4, } 1981 \\
641\end{array}$}} & \multicolumn{2}{|c|}{ Oct. 21, 1982} & \multirow{2}{*}{\multicolumn{2}{|c|}{$\begin{array}{c}\text { Oct. 31, } 1983 \\
771\end{array}$}} & \multirow{2}{*}{\multicolumn{2}{|c|}{$\begin{array}{c}\text { Oct. } 16,1984 \\
2,999\end{array}$}} & \multirow{2}{*}{\multicolumn{2}{|c|}{$\begin{array}{c}\text { Oct. 22, } 1985 \\
699\end{array}$}} & \multirow{2}{*}{\multicolumn{2}{|c|}{$\begin{array}{c}\text { Nov. 3, } 1986 \\
2,583\end{array}$}} & \multirow{2}{*}{\multicolumn{2}{|c|}{$\begin{array}{c}\text { Nov. } 4,1987 \\
1,115\end{array}$}} \\
\hline & & & & & & & & & & & & & & \\
\hline & Count & Percent & Count & Percent & Count & Percent & Count & Percent & Count & Percent & Count & Percent & Count & Percent \\
\hline \multicolumn{15}{|l|}{ Trichoptera } \\
\hline \multicolumn{15}{|l|}{ Apataniidae } \\
\hline Apatania & - & & - & & - & & - & & - & & - & & - & \\
\hline \multicolumn{15}{|l|}{ Brachycentridae } \\
\hline Brachycentrus & - & & - & & - & & - & & - & & - & & - & \\
\hline Micrasema & 2 & $<1$ & - & & - & & - & & - & & - & & - & \\
\hline \multicolumn{15}{|l|}{ Glossosomatidae } \\
\hline Culoptila & - & & - & & - & & - & & - & & - & & - & \\
\hline Glossosoma & - & & - & & 1 & $<1$ & - & & - & & - & & - & \\
\hline Protoptila & - & & - & & - & & - & & - & & 9 & $<1$ & 1 & $<1$ \\
\hline \multicolumn{15}{|l|}{ Helicopsychidae } \\
\hline Helicopsyche & - & & - & & 1 & $<1$ & - & & - & & 580 & 22 & 320 & 29 \\
\hline \multicolumn{15}{|l|}{ Hydropsychidae } \\
\hline Ceratopsyche & 110 & 17 & 270 & 10 & 140 & 18 & 500 & 17 & 120 & 17 & 230 & 9 & 130 & 12 \\
\hline Cheumatopsyche & 73 & 11 & 310 & 11 & 61 & 8 & 140 & 5 & 46 & 6 & 34 & 1 & 29 & 3 \\
\hline Hydropsyche & 26 & 4 & 54 & 2 & 62 & 8 & 100 & 3 & 13 & 2 & 52 & 2 & 29 & 3 \\
\hline Hydroptilidae & & & & & & & & & & & & & & \\
\hline Hydroptila & 7 & 1 & 77 & 3 & 4 & $<1$ & 2 & $<1$ & - & & 32 & 1 & - & \\
\hline Leucotrichia & 20 & 3 & 14 & $<1$ & 1 & $<1$ & 30 & 1 & 6 & $<1$ & 55 & 2 & 5 & $<1$ \\
\hline Lepidostomatidae & & & & & & & & & & & & & & \\
\hline Lepidostoma & - & & - & & - & & - & & - & & - & & - & \\
\hline Leptoceridae & & & & & & & & & & & & & & \\
\hline Mystacides & - & & - & & 1 & $<1$ & 1 & $<1$ & - & & 9 & $<1$ & 4 & $<1$ \\
\hline Oecetis & 2 & $<1$ & 6 & $<1$ & 1 & $<1$ & 1 & $<1$ & 3 & $<1$ & 4 & $<1$ & 14 & 1 \\
\hline Philopotamidae & & & & & & & & & & & & & & \\
\hline Chimarra & - & & - & & - & & - & & - & & 2 & $<1$ & - & \\
\hline Polycentropodidae & & & & & & & & & & & & & & \\
\hline Neureclipsis & - & & - & & - & & 4 & $<1$ & - & & 2 & $<1$ & 1 & $<1$ \\
\hline Nyctiophylax & - & & - & & - & & - & & - & & - & & - & \\
\hline Polycentropus & - & & - & & - & & - & & 2 & $<1$ & 1 & $<1$ & 1 & $<1$ \\
\hline Psychomyiidae & & & & & & & & & & & & & & \\
\hline Psychomyia & - & & - & & - & & 11 & $<1$ & 8 & 1 & 9 & $<1$ & - & \\
\hline Lepidoptera & & & & & & & & & & & & & & \\
\hline Noctuidae & - & & - & & - & & 1 & $<1$ & - & & - & & - & \\
\hline Pyralidae & & & & & & & & & & & & & & \\
\hline Petrophila & 17 & 3 & 9 & $<1$ & 23 & 3 & 5 & $<1$ & 8 & 1 & 15 & $<1$ & 11 & 1 \\
\hline Coleoptera & & & & & & & & & & & & & & \\
\hline Elmidae & & & & & & & & & & & & & & \\
\hline Ancyronyx & - & & - & & - & & - & & - & & - & & - & \\
\hline A.variegata & 1 & $<1$ & 1 & $<1$ & 1 & $<1$ & - & & - & & 1 & $<1$ & 2 & $<1$ \\
\hline Dubiraphia & - & & 3 & $<1$ & 2 & $<1$ & 1 & $<1$ & - & & 10 & $<1$ & 12 & 1 \\
\hline Macronychus & & & & & & & & & & & & & & \\
\hline M. glabratus & - & & - & & - & & - & & - & & - & & - & \\
\hline Optioserous & 2 & $<1$ & - & & 1 & $<1$ & 5 & $<1$ & - & & 7 & $<1$ & 5 & $<1$ \\
\hline Oulimnius & - & & - & & - & & - & & - & & - & & - & \\
\hline Promoresia & - & & - & & - & & - & & - & & - & & - & \\
\hline Stenelmis & 59 & 9 & 66 & 2 & 64 & 8 & 34 & 1 & 29 & 4 & 120 & 5 & 34 & 3 \\
\hline Hydrophilidae & & & & & & & & & & & & & & \\
\hline Berosus & - & & 2 & $<1$ & 2 & $<1$ & - & & - & & 1 & $<1$ & 2 & $<1$ \\
\hline Psephenidae & & & & & & & & & & & & & & \\
\hline Psephenus & - & & - & & - & & 1 & $<1$ & 1 & $<1$ & 6 & $<1$ & 1 & $<1$ \\
\hline Hymenoptera & - & & 1 & $<1$ & - & & 1 & $<1$ & - & & 1 & $<1$ & - & \\
\hline
\end{tabular}




\begin{tabular}{|c|c|c|c|c|c|c|c|c|c|c|c|c|c|c|}
\hline \multirow{2}{*}{\multicolumn{2}{|c|}{$\begin{array}{c}\text { Oct. } 6,1988 \\
1,357\end{array}$}} & \multicolumn{2}{|c|}{ Oct. 13, 1989} & \multicolumn{2}{|c|}{ Oct. 15,1990} & \multicolumn{2}{|c|}{ Oct. 30, 1991} & \multicolumn{2}{|c|}{ Oct. 29, 1992} & \multicolumn{2}{|c|}{ Nov. 16,1993} & \multicolumn{2}{|c|}{ Oct 11.1994} & \multirow{3}{*}{$\begin{array}{c}\text { Date } \\
\text { Total count } \\
\text { Organism }\end{array}$} \\
\hline & & \multicolumn{2}{|c|}{2,698} & \multicolumn{2}{|c|}{3,793} & \multicolumn{2}{|c|}{11,771} & \multicolumn{2}{|c|}{1,354} & \multicolumn{2}{|c|}{1,701} & \multicolumn{2}{|c|}{792} & \\
\hline Count & Percent & Count & Percent & Count & Percent & Count & Percent & Count & Percent & Count & Percent & Count & Percent & \\
\hline & & & & & & & & & & & & & & Trichoptera \\
\hline & & & & & & & & & & & & & & Apataniidae \\
\hline - & & - & & 1 & $<1$ & 1 & $<1$ & - & & - & & - & & Apatania \\
\hline & & & & & & & & & & & & & & Brachycentridae \\
\hline - & & - & & - & & 一 & & - & & 3 & $<1$ & - & & Brachycentrus \\
\hline - & & - & & - & & 1 & $<1$ & 2 & $<1$ & - & & - & & Micrasema \\
\hline & & & & & & & & & & & & & & Glossosomatidae \\
\hline - & & 220 & 8 & - & & - & & - & & - & & - & & Culoptila \\
\hline 3 & $<1$ & - & & - & & 一 & & - & & 3 & $<1$ & - & & Glossosoma \\
\hline - & & - & & 4 & $<1$ & 77 & $<1$ & - & & - & & 7 & $<1$ & Protoptila \\
\hline & & & & & & & & & & & & & & Helicopsychidae \\
\hline - & & 89 & 3 & 1,300 & 34 & 9,700 & 81 & 300 & 21 & 290 & 17 & 29 & 4 & Helicopsyche \\
\hline & & & & & & & & & & & & & & Hydropsychidae \\
\hline 320 & 23 & 540 & 20 & 420 & 11 & 250 & 2 & 100 & 7 & 51 & 3 & 77 & 10 & Ceratopsyche \\
\hline 120 & 9 & 120 & 4 & 130 & 3 & 150 & 1 & 41 & 3 & 150 & 9 & 25 & 3 & Cheumatopsyche \\
\hline 140 & 10 & 180 & 7 & 69 & 2 & 26 & $<1$ & 110 & 8 & 180 & 11 & 2 & $<1$ & Hydropsyche \\
\hline & & & & & & & & & & & & & & Hydroptilidae \\
\hline - & & 2 & $<1$ & 14 & $<1$ & 57 & $<1$ & 3 & $<1$ & 1 & $<1$ & 5 & $<1$ & Hydroptila \\
\hline 29 & 2 & 1 & $<1$ & - & & 一 & & - & & - & & - & & Leucotrichia \\
\hline & & & & & & & & & & & & & & Lepidostomatidae \\
\hline - & & - & & 4 & $<1$ & 4 & $<1$ & - & & - & & - & & Lepidostoma \\
\hline & & & & & & & & & & & & & & Leptoceridae \\
\hline - & & - & & 9 & $<1$ & 32 & $<1$ & - & & - & & 2 & $<1$ & Mystacides \\
\hline 2 & $<1$ & 4 & $<1$ & 8 & $<1$ & 15 & $<1$ & - & & 2 & $<1$ & 67 & 8 & Oecetis \\
\hline & & & & & & & & & & & & & & Philopotamidae \\
\hline - & & - & & 1 & $<1$ & - & & - & & 1 & $<1$ & 3 & $<1$ & Chimarra \\
\hline & & & & & & & & & & & & & & Polycentropodidae \\
\hline 7 & $<1$ & - & & - & & 一 & & - & & - & & 3 & $<1$ & Neureclipsis \\
\hline 1 & $<1$ & - & & - & & 一 & & - & & - & & - & & Nyctiophylax \\
\hline - & & 2 & $<1$ & 1 & $<1$ & 一 & & - & & - & & 1 & $<1$ & Polycentropus \\
\hline & & & & & & & & & & & & & & Psychomyiidae \\
\hline 5 & $<1$ & 21 & $<1$ & 10 & $<1$ & 2 & $<1$ & - & & - & & - & & Psychomyia \\
\hline & & & & & & & & & & & & & & Lepidoptera \\
\hline - & & - & & - & & - & & - & & - & & - & & Noctuidae \\
\hline & & & & & & & & & & & & & & Pyralidae \\
\hline 65 & 5 & 14 & $<1$ & 4 & $<1$ & 7 & $<1$ & - & & 13 & $<1$ & 12 & 2 & Petrophila \\
\hline & & & & & & & & & & & & & & Coleoptera \\
\hline & & & & & & & & & & & & & & Elmidae \\
\hline - & & - & & - & & 1 & $<1$ & - & & 1 & $<1$ & 4 & $<1$ & Ancyronyx \\
\hline - & & - & & 1 & $<1$ & - & & - & & - & & - & & A.variegata \\
\hline - & & 1 & $<1$ & - & & 3 & $<1$ & 1 & $<1$ & 4 & $<1$ & - & & Dubiraphia \\
\hline & & & & & & & & & & & & & & Macronychus \\
\hline - & & - & & - & & 1 & $<1$ & - & & - & & - & & M. glabratus \\
\hline 1 & $<1$ & 11 & $<1$ & 19 & $<1$ & 62 & $<1$ & 11 & $<1$ & 97 & 6 & 3 & $<1$ & Optioservus \\
\hline- & & - & & 2 & $<1$ & 3 & $<1$ & - & & 2 & $<1$ & - & & Oulimnius \\
\hline - & & - & & - & & - & & - & & 4 & $<1$ & - & & Promoresia \\
\hline 37 & 3 & 110 & 4 & 320 & 8 & 170 & 1 & 6 & $<1$ & 170 & 10 & 14 & 2 & Stenelmis \\
\hline & & & & & & & & & & & & & & Hydrophilidae \\
\hline - & & - & & 1 & $<1$ & 1 & $<1$ & - & & - & & 1 & $<1$ & Berosus \\
\hline & & & & & & & & & & & & & & Psephenidae \\
\hline 1 & $<1$ & 8 & $<1$ & 9 & $<1$ & 4 & $<1$ & - & & 1 & $<1$ & 1 & $<1$ & Psephenus \\
\hline- & & - & & - & & - & & - & & - & & - & & Hymenoptera \\
\hline
\end{tabular}


Table 5. Benthic-macroinvertebrate data-Continued

01480950 - East Branch Brandywine Creek at Wawaset, Pa. (Site 39)—Continued

\begin{tabular}{|c|c|c|c|c|c|c|c|c|c|c|c|c|c|c|}
\hline \multirow{3}{*}{$\begin{array}{c}\text { Date } \\
\text { Total count } \\
\text { Organism }\end{array}$} & \multirow{2}{*}{\multicolumn{2}{|c|}{$\frac{\text { Nov. } 4,1981}{641}$}} & \multirow{2}{*}{\multicolumn{2}{|c|}{$\frac{\text { Oct. 21, } 1982}{2,825}$}} & \multirow{2}{*}{\multicolumn{2}{|c|}{$\frac{\text { Oct. } 31,1983}{771}$}} & \multirow{2}{*}{\multicolumn{2}{|c|}{$\frac{\text { Oct. } 16,1984}{2,999}$}} & \multirow{2}{*}{\multicolumn{2}{|c|}{$\frac{\text { Oct. 22, } 1985}{699}$}} & \multirow{2}{*}{\multicolumn{2}{|c|}{$\frac{\text { Nov. 3, } 1986}{2,583}$}} & \multirow{2}{*}{\multicolumn{2}{|c|}{$\frac{\text { Nov. } 4,1987}{1,115}$}} \\
\hline & & & & & & & & & & & & & & \\
\hline & Count & Percent & Count & Percent & Count & Percent & Count & Percent & Count & Percent & Count & Percent & Count & Percent \\
\hline \multicolumn{15}{|l|}{ Diptera } \\
\hline \multicolumn{14}{|l|}{ Empididae } & 15 \\
\hline Hemerodromia & 1 & $<1$ & 12 & $<1$ & 2 & $<1$ & 7 & $<1$ & 2 & $<1$ & 1 & $<1$ & 3 & $<1$ \\
\hline \multicolumn{14}{|l|}{ Simuliidae } & \\
\hline \multicolumn{14}{|l|}{ Stratiomyidae } & $<1$ \\
\hline \multicolumn{14}{|l|}{ Tabanidae } & \\
\hline Tabanus & - & & - & & - & & - & & - & & - & & - & \\
\hline Tipulidae & - & & - & & - & & - & & - & & - & & - & \\
\hline Antocha & 21 & 3 & 570 & 20 & 7 & $<1$ & 120 & 4 & 47 & 7 & 100 & 4 & 33 & 3 \\
\hline Tipula & - & & 1 & $<1$ & - & & - & & - & & - & & 1 & $<1$ \\
\hline
\end{tabular}




\begin{tabular}{|c|c|c|c|c|c|c|c|c|c|c|c|c|c|c|}
\hline \multicolumn{2}{|c|}{ Oct. 6,1988} & \multicolumn{2}{|c|}{ Oct. 13,1989} & \multicolumn{2}{|c|}{ Oct. 15, 1990} & \multicolumn{2}{|c|}{ Oct. 30, 1991} & \multicolumn{2}{|c|}{ Oct. 29, 1992} & \multicolumn{2}{|c|}{ Nov. 16,1993} & \multicolumn{2}{|c|}{ Oct. 11, 1994} & \multirow{3}{*}{$\begin{array}{c}\text { Date } \\
\text { Total count } \\
\text { Organism }\end{array}$} \\
\hline \multicolumn{2}{|c|}{1,357} & \multicolumn{2}{|c|}{2,698} & \multicolumn{2}{|c|}{3,793} & \multicolumn{2}{|c|}{11,771} & \multicolumn{2}{|c|}{1,354} & \multicolumn{2}{|c|}{1,701} & \multicolumn{2}{|c|}{792} & \\
\hline Count & Percent & Count & Percent & Count & Percent & Count & Percent & Count & Percent & Count & Percent & Count & Percent & \\
\hline & & & & & & & & & & & & & & Diptera \\
\hline 140 & 10 & 610 & 23 & 660 & 17 & 730 & 6 & 480 & 34 & 190 & 11 & 250 & 31 & $\begin{array}{l}\text { Chironomidae } \\
\text { Empididae }\end{array}$ \\
\hline 1 & $<1$ & 32 & 1 & 3 & $<1$ & 2 & $<1$ & - & & 3 & $<1$ & 6 & $<1$ & Hemerodromia \\
\hline - & & - & & - & & - & & - & & - & & - & & $\begin{array}{l}\text { Ephydridae } \\
\text { Simuliidae }\end{array}$ \\
\hline 18 & 1 & 140 & 5 & 2 & $<1$ & 49 & $<1$ & 100 & 7 & 15 & $<1$ & 2 & $<1$ & $\begin{array}{c}\text { Simulium } \\
\text { Stratiomyidae }\end{array}$ \\
\hline - & & - & & - & & - & & - & & - & & - & & $\begin{array}{l}\text { Stratiomys } \\
\text { Tabanidae }\end{array}$ \\
\hline - & & - & & - & & 1 & $<1$ & - & & - & & - & & Tabanus \\
\hline - & & - & & 1 & $<1$ & - & & - & & - & & - & & Tipulidae \\
\hline 42 & 3 & 74 & 3 & 280 & 7 & 130 & 1 & 62 & 4 & 81 & 5 & 16 & 2 & Antocha \\
\hline- & & 1 & $<1$ & - & & - & & - & & - & & - & & Tipula \\
\hline
\end{tabular}


Table 5. Benthic-macroinvertebrate data-Continued

$[<$, less than; - , not found]

01481030 - Brandywine Creek near Chadds Ford, Pa. (Site 40)

\begin{tabular}{|c|c|c|c|c|c|c|c|c|c|c|c|c|c|c|}
\hline \multirow{3}{*}{$\begin{array}{cc}\text { Date } \\
\text { Total count }\end{array}$} & \multirow{2}{*}{\multicolumn{2}{|c|}{$\frac{\text { Nov. } 4,1981}{651}$}} & \multirow{2}{*}{\multicolumn{2}{|c|}{$\frac{\text { Oct. } 21,1982}{1,673}$}} & \multirow{2}{*}{\multicolumn{2}{|c|}{$\frac{\text { Oct. } 31,1983}{1,009}$}} & \multirow{2}{*}{\multicolumn{2}{|c|}{$\frac{\text { Oct. } 15,1984}{1,446}$}} & \multirow{2}{*}{\multicolumn{2}{|c|}{$\frac{\text { Oct. 30, } 1985}{993}$}} & \multirow{2}{*}{\multicolumn{2}{|c|}{$\frac{\text { Dec. } 2,1986}{428}$}} & \multirow{2}{*}{\multicolumn{2}{|c|}{$\frac{\text { Nov. } 20,1987}{1,046}$}} \\
\hline & & & & & & & & & & & & & & \\
\hline & Count & Percent & Count & Percent & Count & Percent & Count & Percent & Count & Percent & Count & Percent & Count & Percent \\
\hline \multicolumn{15}{|l|}{ Platyhelminthes (flatworms) } \\
\hline \multicolumn{15}{|l|}{ Turbellaria } \\
\hline \multicolumn{15}{|l|}{ Tricladida } \\
\hline Planariidae & 67 & 10 & 27 & 2 & 16 & 2 & 18 & 1 & 4 & $<1$ & 32 & 7 & 20 & 2 \\
\hline Nematoda (nematodes) & - & & - & & - & & - & & - & & - & & - & \\
\hline \multicolumn{15}{|l|}{ Nemertea (proboscis worms) } \\
\hline \multicolumn{15}{|l|}{ Enopla } \\
\hline Hoplonemertea & & & & & & & & & & & & & & \\
\hline Tetrastemmatida & & & & & & & & & & & & & & \\
\hline Prostoma & 1 & $<1$ & - & & - & & - & & - & & - & & - & \\
\hline Mollusca (molluscs) & & & & & & & & & & & & & & \\
\hline Gastropoda & & & & & & & & & & & & & & \\
\hline Basommatophora & & & & & & & & & & & & & & \\
\hline Ancylidae & & & & & & & & & & & & & & \\
\hline Ferrissia & 4 & $<1$ & 26 & 2 & 3 & $<1$ & 8 & $<1$ & 38 & 4 & - & & 17 & 2 \\
\hline Physidae & & & & & & & & & & & & & & \\
\hline Physa & - & & - & & - & & - & & - & & 4 & 1 & - & \\
\hline Planorbidae & & & & & & & & & & & & & & \\
\hline Helisoma & - & & - & & 1 & $<1$ & - & & - & & 1 & $<1$ & - & \\
\hline Bivalvia & & & & & & & & & & & & & & \\
\hline Veneroida & & & & & & & & & & & & & & \\
\hline Sphaeriidae & 5 & $<1$ & 5 & $<1$ & 3 & $<1$ & - & & 1 & $<1$ & 20 & 5 & 6 & $<1$ \\
\hline Pisidium & - & & - & & - & & - & & - & & - & & - & \\
\hline Sphaerium & - & & - & & - & & - & & - & & - & & - & \\
\hline Annelida (segmented worms) & & & & & & & & & & & & & & \\
\hline Oligochaeta & & & & & & & & & & & & & & \\
\hline Tubificida & & & & & & & & & & & & & & \\
\hline Naididae & 3 & $<1$ & 10 & $<1$ & 2 & $<1$ & 1 & $<1$ & - & & 1 & $<1$ & 32 & 3 \\
\hline Tubificidae & - & & - & & - & & - & & - & & 1 & $<1$ & - & \\
\hline Arthropoda (arthropods) & & & & & & & & & & & & & & \\
\hline Acariformes & & & & & & & & & & & & & & \\
\hline Hydrachnidia & - & & 1 & $<1$ & 3 & $<1$ & 1 & $<1$ & - & & - & & 35 & 3 \\
\hline Crustacea & & & & & & & & & & & & & & \\
\hline Cyclopoida & - & & - & & - & & - & & - & & - & & - & \\
\hline Amphipoda & & & & & & & & & & & & & & \\
\hline Gammaridae & & & & & & & & & & & & & & \\
\hline Gammarus & - & & - & & - & & - & & - & & 8 & 2 & 1 & $<1$ \\
\hline Isopoda & & & & & & & & & & & & & & \\
\hline Asellidae & & & & & & & & & & & & & & \\
\hline Caecidotea & - & & - & & - & & - & & - & & - & & - & \\
\hline Podocopa & - & & 1 & $<1$ & - & & - & & - & & 1 & $<1$ & - & \\
\hline Insecta & & & & & & & & & & & & & & \\
\hline Ephemeroptera & & & & & & & & & & & & & & \\
\hline Baetidae & & & & & & & & & & & & & & \\
\hline Baetis & 3 & $<1$ & 24 & 1 & 10 & 1 & 46 & 3 & 7 & $<1$ & 3 & $<1$ & - & \\
\hline Pseudocloeon & - & & 4 & $<1$ & - & & - & & 28 & 3 & - & & 1 & $<1$ \\
\hline Caenidae & & & & & & & & & & & & & & \\
\hline Caenis & - & & - & & - & & - & & - & & - & & 1 & $<1$ \\
\hline Ephemerellidae & & & & & & & & & & & & & & \\
\hline Ephemerella & 33 & 5 & 92 & 5 & 93 & 9 & 10 & $<1$ & 65 & 7 & 10 & 2 & 42 & 4 \\
\hline Heptageniidae & & & & & & & & & & & & & & \\
\hline Epeorus & - & & - & & - & & - & & - & & - & & - & \\
\hline Stenacron & - & & - & & - & & - & & - & & - & & - & \\
\hline Stenonema & 100 & 15 & 220 & 13 & 170 & 17 & 130 & 9 & 53 & 5 & 25 & 6 & 39 & 4 \\
\hline
\end{tabular}




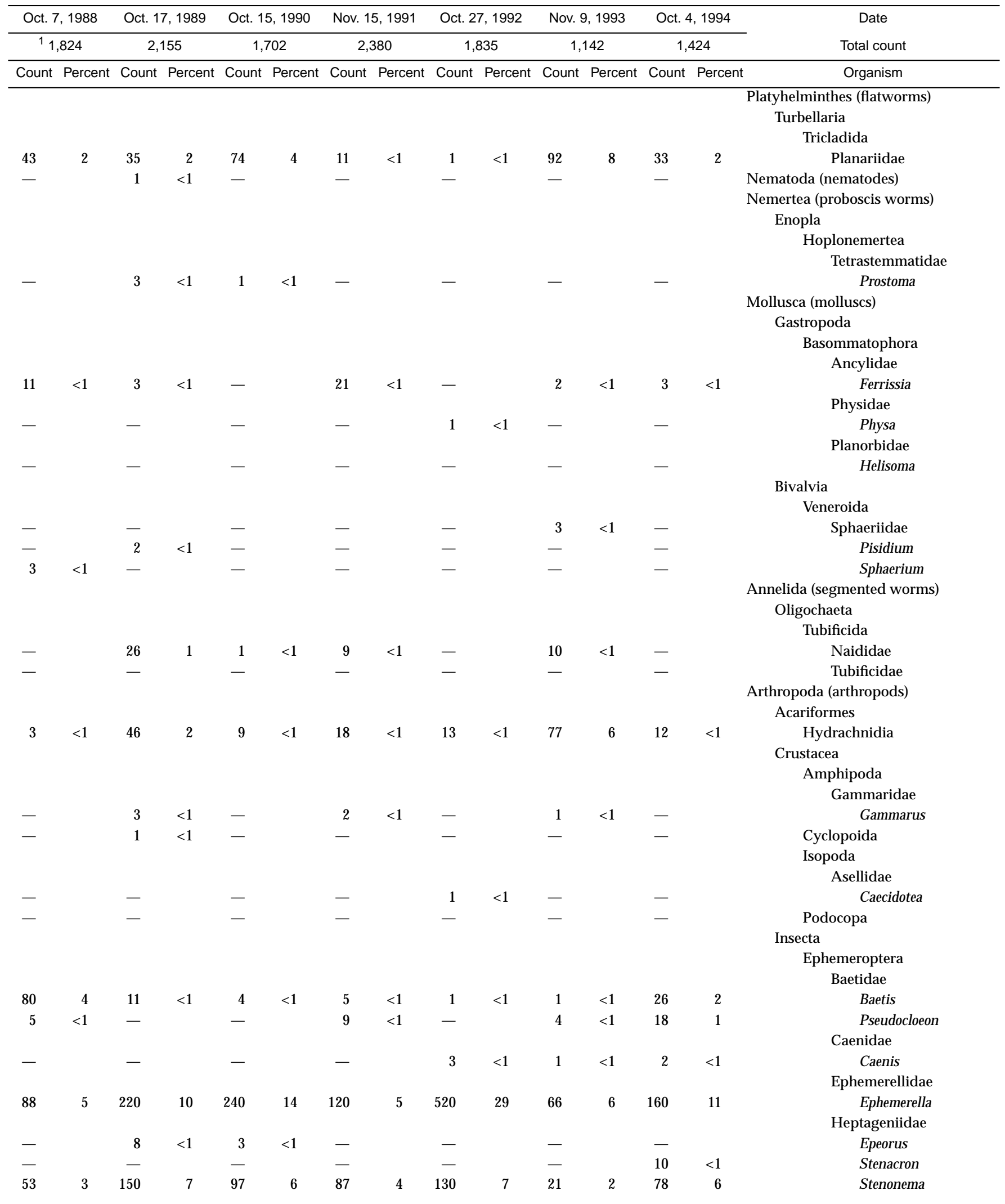


Table 5. Benthic-macroinvertebrate data-Continued

01481030 - Brandywine Creek near Chadds Ford, Pa. (Site 40)—Continued

\begin{tabular}{|c|c|c|c|c|c|c|c|c|c|c|c|c|c|c|}
\hline \multirow{3}{*}{$\begin{array}{c}\text { Date } \\
\text { Total count } \\
\text { Organism }\end{array}$} & \multirow{2}{*}{\multicolumn{2}{|c|}{$\begin{array}{c}\text { Nov. 4, } 1981 \\
651\end{array}$}} & \multirow{2}{*}{\multicolumn{2}{|c|}{ Oct. 21, 1982}} & \multicolumn{2}{|c|}{ Oct. 31,1983} & \multicolumn{2}{|c|}{ Oct. 15,1984} & \multicolumn{2}{|c|}{ Oct. 30,1985} & \multicolumn{2}{|c|}{ Dec. 2,1986} & \multicolumn{2}{|c|}{ Nov. 20, 1987} \\
\hline & & & & & 1, & 009 & 1, & 446 & & 93 & & 28 & & 046 \\
\hline & Count & Percent & Count & Percent & Count & Percent & Count & Percent & Count & Percent & Count & Percent & Count & Percent \\
\hline \multicolumn{15}{|l|}{ Ephemeroptera } \\
\hline \multicolumn{15}{|l|}{ Isonychiidae } \\
\hline Isonychia & 3 & $<1$ & - & & 3 & $<1$ & - & & - & & - & & 2 & $<1$ \\
\hline \multicolumn{15}{|l|}{ Leptohyphidae } \\
\hline Tricorythodes & - & & 6 & $<1$ & 6 & $<1$ & 1 & $<1$ & - & & 1 & $<1$ & 7 & $<1$ \\
\hline \multicolumn{15}{|l|}{ Leptophlebiidae } \\
\hline Paraleptophlebia & - & & - & & - & & - & & - & & - & & - & \\
\hline \multicolumn{15}{|l|}{ Potamanthidae } \\
\hline Anthopotamus & - & & - & & 1 & $<1$ & 1 & $<1$ & - & & 1 & $<1$ & 3 & $<1$ \\
\hline Odonata & & & & & & & & & & & & & & \\
\hline Coenagrionidae & & & & & & & & & & & & & & \\
\hline Argia & - & & - & & 3 & $<1$ & - & & - & & 7 & 2 & 5 & $<1$ \\
\hline Plecoptera & & & & & & & & & & & & & & \\
\hline Capniidae & & & & & & & & & & & & & & \\
\hline Allocapnia & - & & 1 & $<1$ & 2 & $<1$ & - & & - & & - & & - & \\
\hline Chloroperlidae & - & & - & & - & & - & & - & & - & & - & \\
\hline Perlidae & - & & - & & - & & - & & - & & - & & - & \\
\hline Acroneuria & - & & - & & - & & - & & - & & 1 & $<1$ & - & \\
\hline Agnetina & - & & - & & - & & - & & - & & - & & 7 & $<1$ \\
\hline Paragnetina & - & & - & & - & & - & & 2 & $<1$ & - & & - & \\
\hline Taeniopterygidae & & & & & & & & & & & & & & \\
\hline Taeniopteryx & - & & 4 & $<1$ & 3 & $<1$ & - & & 2 & $<1$ & 2 & $<1$ & 2 & $<1$ \\
\hline Hemiptera & & & & & & & & & & & & & & \\
\hline Corixidae & & & & & & & & & & & & & & \\
\hline Sigara & - & & - & & - & & - & & - & & - & & - & \\
\hline Gerridae & & & & & & & & & & & & & & \\
\hline Metrobates & - & & - & & - & & 1 & $<1$ & - & & - & & - & \\
\hline Veliidae & & & & & & & & & & & & & & \\
\hline Rhagovelia & - & & - & & - & & - & & - & & - & & - & \\
\hline Megaloptera & & & & & & & & & & & & & & \\
\hline Corydalidae & & & & & & & & & & & & & & \\
\hline Corydalus & - & & - & & - & & - & & 1 & $<1$ & - & & 1 & $<1$ \\
\hline Nigronia & - & & - & & - & & - & & - & & 1 & $<1$ & - & \\
\hline Trichoptera & & & & & & & & & & & & & & \\
\hline Apataniidae & & & & & & & & & & & & & & \\
\hline Apatania & - & & - & & - & & - & & - & & - & & 1 & $<1$ \\
\hline Glossosomatidae & & & & & & & & & & & & & & \\
\hline Glossosoma & 12 & 2 & 14 & $<1$ & 4 & $<1$ & 3 & $<1$ & 25 & 3 & 2 & $<1$ & 1 & $<1$ \\
\hline Protoptila & - & & - & & - & & - & & - & & - & & 5 & $<1$ \\
\hline Helicopsychidae & & & & & & & & & & & & & & \\
\hline Helicopsyche & - & & - & & - & & - & & - & & - & & - & \\
\hline Hydropsychidae & & & & & & & & & & & & & & \\
\hline Ceratopsyche & 86 & 13 & 180 & 11 & 47 & 5 & 180 & 12 & 100 & 10 & 50 & 11 & 99 & 9 \\
\hline Cheumatopsyche & 80 & 12 & 43 & 3 & 24 & 2 & 74 & 5 & 28 & 3 & 6 & 1 & 24 & 2 \\
\hline Hydropsyche & 3 & $<1$ & 110 & 6 & 6 & $<1$ & 77 & 5 & 5 & $<1$ & 1 & $<1$ & 28 & 3 \\
\hline Hydroptilidae & & & & & & & & & & & & & & \\
\hline Hydroptila & - & & 1 & $<1$ & 3 & $<1$ & - & & 2 & $<1$ & 1 & $<1$ & 1 & $<1$ \\
\hline Leucotrichia & 13 & 2 & 170 & 10 & 120 & 12 & 8 & $<1$ & 150 & 15 & 42 & 10 & 72 & 7 \\
\hline Lepidostomatidae & & & & & & & & & & & & & & \\
\hline Lepidostoma & - & & - & & - & & - & & - & & - & & - & \\
\hline Leptoceridae & & & & & & & & & & & & & & \\
\hline Oecetis & - & & - & & 1 & $<1$ & - & & - & & - & & 1 & $<1$ \\
\hline Philopotamidae & & & & & & & & & & & & & & \\
\hline Chimarra & 4 & $<1$ & 5 & $<1$ & 5 & $<1$ & 1 & $<1$ & 45 & 5 & 50 & 11 & 31 & 3 \\
\hline
\end{tabular}




\begin{tabular}{|c|c|c|c|c|c|c|c|c|c|c|c|c|c|c|}
\hline \multirow{2}{*}{\multicolumn{2}{|c|}{$\frac{\text { Oct. } 7,1988}{{ }^{1} 1,824}$}} & \multirow{2}{*}{\multicolumn{2}{|c|}{$\begin{array}{c}\text { Oct. } 17,1989 \\
2,155\end{array}$}} & \multirow{2}{*}{\multicolumn{2}{|c|}{$\begin{array}{c}\text { Oct. } 15,1990 \\
1,702 \\
\end{array}$}} & \multirow{2}{*}{\multicolumn{2}{|c|}{$\begin{array}{c}\text { Nov. } 15,1991 \\
2,380\end{array}$}} & \multirow{2}{*}{\multicolumn{2}{|c|}{$\begin{array}{c}\text { Oct. } 27,1992 \\
1,835\end{array}$}} & \multirow{2}{*}{\multicolumn{2}{|c|}{$\frac{\text { Nov. 9, } 1993}{1,142}$}} & \multirow{2}{*}{\multicolumn{2}{|c|}{$\frac{\text { Oct. } 4,1994}{1,424}$}} & \multirow{3}{*}{$\begin{array}{c}\text { Date } \\
\text { Total count } \\
\text { Organism }\end{array}$} \\
\hline & & & & & & & & & & & & & & \\
\hline Count & Percent & Count & Percent & Count & Percent & Count & Percent & Count & Percent & Count & Percent & Count & Percent & \\
\hline 8 & $<1$ & 2 & $<1$ & 1 & $<1$ & - & & 14 & $<1$ & 1 & $<1$ & 15 & 1 & $\begin{array}{c}\text { Ephemeroptera } \\
\text { Isonychiidae } \\
\text { Isonychia } \\
\text { Leptohyphidae }\end{array}$ \\
\hline 3 & $<1$ & - & & 18 & 1 & - & & - & & - & & - & & $\begin{array}{l}\text { Tricorythodes } \\
\text { Leptophlebiidae }\end{array}$ \\
\hline- & & 4 & $<1$ & - & & - & & - & & - & & - & & $\begin{array}{l}\text { Paraleptophlebia } \\
\text { Potamanthidae }\end{array}$ \\
\hline 3 & $<1$ & - & & - & & - & & - & & 1 & $<1$ & - & & $\begin{array}{l}\text { Anthopotamus } \\
\text { Odonata } \\
\text { Coenagrionidae }\end{array}$ \\
\hline- & & - & & - & & - & & 1 & $<1$ & - & & 1 & $<1$ & $\begin{array}{l}\text { Argia } \\
\text { Plecoptera } \\
\text { Capniidae }\end{array}$ \\
\hline- & & 2 & $<1$ & 1 & $<1$ & - & & - & & 1 & $<1$ & - & & Allocapnia \\
\hline- & & 7 & $<1$ & 4 & $<1$ & 56 & 2 & - & & 9 & $<1$ & - & & Chloroperlidae \\
\hline- & & - & & - & & - & & 4 & $<1$ & - & & - & & Perlidae \\
\hline- & & - & & - & & - & & - & & - & & - & & Acroneuria \\
\hline- & & - & & - & & - & & - & & - & & - & & Agnetina \\
\hline- & & - & & - & & - & & - & & - & & - & & $\begin{array}{c}\text { Paragnetina } \\
\text { Taeniopterygidae }\end{array}$ \\
\hline 3 & $<1$ & 4 & $<1$ & - & & 2 & $<1$ & - & & - & & 1 & $<1$ & $\begin{array}{l}\text { Taeniopteryx } \\
\text { Hemiptera } \\
\text { Corixidae }\end{array}$ \\
\hline- & & - & & 3 & $<1$ & - & & - & & - & & - & & $\begin{array}{l}\quad \text { Sigara } \\
\text { Gerridae }\end{array}$ \\
\hline- & & - & & - & & - & & - & & - & & - & & $\begin{array}{l}\text { Metrobates } \\
\text { Veliidae }\end{array}$ \\
\hline- & & - & & - & & - & & 1 & $<1$ & - & & - & & $\begin{array}{l}\text { Rhagovelia } \\
\text { Megaloptera } \\
\text { Corydalidae }\end{array}$ \\
\hline- & & - & & - & & - & & - & & - & & - & & Corydalus \\
\hline- & & - & & - & & - & & - & & - & & - & & $\begin{array}{l}\text { Nigronia } \\
\text { Trichoptera } \\
\text { Apataniidae }\end{array}$ \\
\hline- & & - & & - & & - & & - & & - & & - & & $\begin{array}{c}\text { Apatania } \\
\text { Glossosomatidae }\end{array}$ \\
\hline- & & - & & - & & - & & 5 & $<1$ & - & & - & & Glossosoma \\
\hline 99 & 6 & 330 & 15 & 19 & 1 & 58 & 2 & 7 & $<1$ & 77 & 6 & 46 & 3 & $\begin{array}{c}\text { Protoptila } \\
\text { Helicopsychidae }\end{array}$ \\
\hline- & & - & & - & & 310 & 13 & 6 & $<1$ & 180 & 15 & 1 & $<1$ & $\begin{array}{l}\text { Helicopsyche } \\
\text { Hydropsychidae }\end{array}$ \\
\hline 350 & 19 & 240 & 11 & 130 & 8 & 60 & 3 & 68 & 4 & 68 & 6 & 190 & 14 & Ceratopsyche \\
\hline 110 & 6 & 21 & $<1$ & 33 & 2 & 54 & 2 & 100 & 6 & 55 & 5 & 240 & 17 & Cheumatopsyche \\
\hline 37 & 2 & 40 & 2 & 2 & $<1$ & 67 & 3 & 230 & 13 & 31 & 3 & 96 & 7 & $\begin{array}{l}\text { Hydropsyche } \\
\text { Hydroptilidae }\end{array}$ \\
\hline- & & - & & 7 & $<1$ & 8 & $<1$ & - & & 3 & $<1$ & 1 & $<1$ & Hydroptila \\
\hline 290 & 16 & 11 & $<1$ & 4 & $<1$ & 15 & $<1$ & 16 & $<1$ & 63 & 5 & 190 & 14 & $\begin{array}{c}\text { Leucotrichia } \\
\text { Lepidostomatidae }\end{array}$ \\
\hline- & & 55 & 3 & 63 & 4 & 5 & $<1$ & 9 & $<1$ & 5 & $<1$ & 9 & $<1$ & $\begin{array}{l}\text { Lepidostoma } \\
\text { Leptoceridae }\end{array}$ \\
\hline - & & 5 & $<1$ & 4 & $<1$ & 15 & $<1$ & 4 & $<1$ & 10 & $<1$ & 2 & $<1$ & $\begin{array}{c}\text { Oecetis } \\
\text { Philopotamidae }\end{array}$ \\
\hline 53 & 3 & 10 & $<1$ & 110 & 6 & 52 & 2 & 38 & 2 & 58 & 5 & 24 & 2 & Chimarra \\
\hline
\end{tabular}


Table 5. Benthic-macroinvertebrate data-Continued

01481030 - Brandywine Creek near Chadds Ford, Pa. (Site 40)—Continued

\begin{tabular}{|c|c|c|c|c|c|c|c|c|c|c|c|c|c|c|}
\hline \multirow{3}{*}{$\begin{array}{c}\text { Date } \\
\text { Total count } \\
\text { Organism }\end{array}$} & \multirow{2}{*}{\multicolumn{2}{|c|}{$\begin{array}{c}\text { Nov. 4, } 1981 \\
651\end{array}$}} & \multirow{2}{*}{\multicolumn{2}{|c|}{$\frac{\text { Oct. } 21,1982}{1,673}$}} & \multirow{2}{*}{\multicolumn{2}{|c|}{$\frac{\text { Oct. 31, } 1983}{1,009}$}} & \multirow{2}{*}{\multicolumn{2}{|c|}{$\frac{\text { Oct. } 15,1984}{1,446}$}} & \multirow{2}{*}{\multicolumn{2}{|c|}{$\frac{\text { Oct. 30, } 1985}{993}$}} & \multirow{2}{*}{\multicolumn{2}{|c|}{$\frac{\text { Dec. } 2,1986}{428}$}} & \multirow{2}{*}{\multicolumn{2}{|c|}{$\frac{\text { Nov. 20, } 1987}{1,046}$}} \\
\hline & & & & & & & & & & & & & & \\
\hline & Count & Percent & Count & Percent & Count & Percent & Count & Percent & Count & Percent & Count & Percent & Count & Percent \\
\hline \multicolumn{15}{|l|}{ Trichoptera } \\
\hline \multicolumn{15}{|l|}{ Polycentropodidae } \\
\hline Neureclipsis & 2 & $<1$ & 2 & $<1$ & 22 & 2 & 7 & $<1$ & - & & 6 & 1 & 4 & $<1$ \\
\hline Polycentropus & - & & - & & - & & - & & - & & - & & - & \\
\hline \multicolumn{15}{|l|}{ Psychomyiidae } \\
\hline Psychomyia & - & & - & & - & & - & & 1 & $<1$ & - & & 13 & 1 \\
\hline \multicolumn{15}{|l|}{ Lepidoptera } \\
\hline Noctuidae & - & & - & & - & & - & & - & & - & & - & \\
\hline \multicolumn{15}{|l|}{ Pyralidae } \\
\hline Petrophila & 16 & 2 & 58 & 3 & 88 & 9 & 45 & 3 & 92 & 9 & 2 & $<1$ & 51 & 5 \\
\hline \multicolumn{15}{|l|}{ Coleoptera } \\
\hline \multicolumn{15}{|l|}{ Elmidae } \\
\hline Ancyronyx & - & & - & & - & & - & & - & & - & & - & \\
\hline A.variegata & - & & - & & - & & - & & 1 & $<1$ & - & & - & \\
\hline Dubiraphia & - & & - & & 1 & $<1$ & - & & - & & 1 & $<1$ & - & \\
\hline Optioservus & 12 & 2 & 14 & $<1$ & 9 & $<1$ & 3 & $<1$ & 25 & 3 & 9 & 2 & 16 & 1 \\
\hline Stenelmis & 5 & $<1$ & 15 & $<1$ & 23 & 2 & 20 & 1 & 6 & $<1$ & 5 & 1 & 6 & $<1$ \\
\hline \multicolumn{15}{|l|}{ Hydrophilidae } \\
\hline Berosus & - & & - & & - & & - & & - & & 2 & $<1$ & 1 & $<1$ \\
\hline \multicolumn{15}{|l|}{ Psephenidae } \\
\hline Psephenus & - & & - & & - & & - & & - & & 11 & 3 & - & \\
\hline Hymenoptera & - & & 1 & $<1$ & - & & - & & - & & - & & - & \\
\hline \multicolumn{15}{|l|}{ Diptera } \\
\hline \multicolumn{15}{|l|}{ Blephariceridae } \\
\hline Chironomidae & 160 & 24 & 550 & 32 & 310 & 31 & 610 & 41 & 270 & 27 & 43 & 10 & 380 & 35 \\
\hline \multicolumn{15}{|l|}{ Empididae } \\
\hline Hemerodromia & 7 & 1 & 6 & $<1$ & - & & 2 & $<1$ & - & & 1 & $<1$ & 3 & $<1$ \\
\hline Ephydridae & - & & 2 & $<1$ & - & & - & & - & & - & & - & \\
\hline \multicolumn{15}{|l|}{ Simuliidae } \\
\hline Simulium & 28 & 4 & 65 & 4 & 11 & 1 & 150 & 10 & 21 & 2 & 43 & 10 & 53 & 5 \\
\hline \multicolumn{15}{|l|}{ Tipulidae } \\
\hline Antocha & 4 & $<1$ & 16 & $<1$ & 15 & 2 & 49 & 3 & 21 & 2 & 29 & 7 & 37 & 3 \\
\hline Dicranota & - & & - & & - & & - & & - & & - & & - & \\
\hline Tipula & - & & - & & - & & - & & - & & 1 & $<1$ & - & \\
\hline
\end{tabular}

${ }^{1}$ Extrapolated from a 3/8 subsample. 


\begin{tabular}{|c|c|c|c|c|c|c|c|c|c|c|c|c|c|c|}
\hline \multirow{2}{*}{\multicolumn{2}{|c|}{$\begin{array}{c}\text { Oct. } 7,1988 \\
{ }^{1} 1,824\end{array}$}} & \multicolumn{2}{|c|}{ Oct. 17, 1989} & \multicolumn{2}{|c|}{ Oct. 15, 1990} & \multicolumn{2}{|c|}{ Nov. 15, 1991} & \multicolumn{2}{|c|}{ Oct. 27, 1992} & \multicolumn{2}{|c|}{ Nov. 9, 1993} & \multicolumn{2}{|c|}{ Oct. 4, 1994} & \multirow{3}{*}{$\begin{array}{c}\text { Date } \\
\text { Total count } \\
\text { Oraanism }\end{array}$} \\
\hline & & 2,1 & 155 & 1,7 & 02 & 2,3 & 380 & 1,8 & 835 & & 142 & 1,4 & 424 & \\
\hline \multirow{3}{*}{ Count } & Percent & Count & Percent & Count & Percent & Count & Percent & Count & Percent & Count & Percent & Count & Percent & \\
\hline & & & & & & & & & & & & & & Trichoptera \\
\hline & & & & & & & & & & & & & & Polycentropodidae \\
\hline 5 & $<1$ & 8 & $<1$ & 11 & $<1$ & 2 & $<1$ & - & & 1 & $<1$ & 3 & $<1$ & Neureclipsis \\
\hline \multirow[t]{2}{*}{-} & & - & & - & & - & & - & & - & & 1 & $<1$ & Polycentropus \\
\hline & & & & & & & & & & & & & & Psychomyiidae \\
\hline \multirow[t]{2}{*}{13} & $<1$ & 78 & 4 & 37 & 2 & 1 & $<1$ & 2 & $<1$ & 7 & $<1$ & 5 & $<1$ & Psychomyia \\
\hline & & & & & & & & & & & & & & Lepidoptera \\
\hline \multirow[t]{2}{*}{-} & & - & & - & & - & & - & & - & & 1 & $<1$ & Noctuidae \\
\hline & & & & & & & & & & & & & & Pyralidae \\
\hline \multirow[t]{3}{*}{130} & 7 & 22 & 1 & 56 & 3 & 100 & 4 & 97 & 5 & 34 & 3 & 82 & 6 & Petrophila \\
\hline & & & & & & & & & & & & & & Coleoptera \\
\hline & & & & & & & & & & & & & & Elmidae \\
\hline- & & 1 & $<1$ & - & & - & & - & & - & & - & & Ancyronyx \\
\hline- & & - & & - & & - & & - & & - & & - & & A.variegata \\
\hline- & & - & & 2 & $<1$ & - & & - & & 1 & $<1$ & - & & Dubiraphia \\
\hline 8 & $<1$ & 20 & $<1$ & 31 & 2 & 49 & 2 & 55 & 3 & 42 & 3 & 8 & $<1$ & Optioservus \\
\hline \multirow[t]{2}{*}{66} & 4 & 61 & 3 & 35 & 2 & 9 & $<1$ & 24 & 1 & 16 & 1 & 2 & $<1$ & Stenelmis \\
\hline & & & & & & & & & & & & & & Hydrophilidae \\
\hline \multirow[t]{2}{*}{-} & & - & & - & & - & & - & & - & & - & & Berosus \\
\hline & & & & & & & & & & & & & & Psephenidae \\
\hline- & & 2 & $<1$ & - & & - & & - & & - & & - & & Psephenus \\
\hline \multirow[t]{2}{*}{-} & & - & & - & & - & & - & & - & & - & & \multirow{2}{*}{$\begin{array}{l}\text { Hymenoptera } \\
\text { Diptera }\end{array}$} \\
\hline & & & & & & & & & & & & & & \\
\hline- & & - & & - & & 1 & $<1$ & - & & - & & - & & Blephariceridae \\
\hline \multirow[t]{2}{*}{180} & 10 & 660 & 30 & 540 & 32 & 1,200 & 50 & 460 & 26 & 150 & 13 & 150 & 11 & Chironomidae \\
\hline & & & & & & & & & & & & & & Empididae \\
\hline- & & 20 & $<1$ & - & & 2 & $<1$ & - & & 8 & $<1$ & 3 & $<1$ & Hemerodromia \\
\hline \multirow[t]{2}{*}{ - } & & - & & - & & - & & - & & - & & - & & Ephydridae \\
\hline & & & & & & & & & & & & & & Simuliidae \\
\hline \multirow[t]{2}{*}{180} & 10 & 9 & $<1$ & 32 & 2 & 6 & $<1$ & 6 & $<1$ & 16 & 1 & 11 & $<1$ & Simulium \\
\hline & & & & & & & & & & & & & & Tipulidae \\
\hline- & & 34 & 2 & 130 & 8 & 26 & 1 & 18 & 1 & 25 & 2 & - & & Antocha \\
\hline- & & - & & - & & - & & - & & 2 & $<1$ & - & & Dicranota \\
\hline- & & - & & - & & - & & - & & - & & - & & Tipula \\
\hline
\end{tabular}


Table 5. Benthic-macroinvertebrate data-Continued

$[<$, less than; - , not found]

01494900 - East Branch Big Elk Creek at Elkview, Pa. (Site 31)

\begin{tabular}{|c|c|c|c|c|c|c|c|c|c|c|c|c|c|c|}
\hline \multirow{3}{*}{$\begin{array}{cc}\text { Date } \\
\text { Total count }\end{array}$} & \multirow{2}{*}{\multicolumn{2}{|c|}{$\begin{array}{c}\text { Oct. 29, } 1981 \\
846\end{array}$}} & \multirow{2}{*}{\multicolumn{2}{|c|}{$\frac{\text { Nov. } 1,1982}{1,416}$}} & \multirow{2}{*}{\multicolumn{2}{|c|}{$\frac{\text { Nov. 2, } 1983}{1,171}$}} & \multirow{2}{*}{\multicolumn{2}{|c|}{$\frac{\text { Oct. } 18,1984}{1,216}$}} & \multirow{2}{*}{\multicolumn{2}{|c|}{$\frac{\text { Oct. } 17,1985}{546}$}} & \multirow{2}{*}{\multicolumn{2}{|c|}{$\frac{\text { Oct. } 28,1986}{851}$}} & \multirow{2}{*}{\multicolumn{2}{|c|}{$\frac{\text { Oct. } 27,1987}{1.638}$}} \\
\hline & & & & & & & & & & & & & & \\
\hline & Count & Percent & Count & Percent & Count & Percent & Count & Percent & Count & Percent & Count & Percent & Count & Percent \\
\hline \multicolumn{15}{|l|}{ Platyhelminthes (flatworms) } \\
\hline \multicolumn{15}{|l|}{ Turbellaria } \\
\hline \multicolumn{15}{|l|}{ Tricladida } \\
\hline Planariidae & - & & - & & - & & - & & 5 & 1 & 31 & 4 & 5 & $<1$ \\
\hline Nematoda (nematodes) & - & & - & & - & & - & & - & & - & & 4 & $<1$ \\
\hline \multicolumn{15}{|l|}{ Nemertea (proboscis worms) } \\
\hline \multicolumn{15}{|l|}{ Enopla } \\
\hline \multicolumn{15}{|l|}{ Hoplonemertea } \\
\hline \multicolumn{15}{|l|}{ Tetrastemmatidae } \\
\hline Prostoma & - & & - & & - & & 1 & $<1$ & - & & - & & - & \\
\hline Mollusca (molluscs) & & & & & & & & & & & & & & \\
\hline Gastropoda & & & & & & & & & & & & & & \\
\hline Mesogastropoda & & & & & & & & & & & & & & \\
\hline Pleuroceridae & & & & & & & & & & & & & & \\
\hline Goniobasis & - & & - & & - & & - & & - & & - & & - & \\
\hline Basommatophora & & & & & & & & & & & & & & \\
\hline Ancylidae & & & & & & & & & & & & & & \\
\hline Ferrissia & 28 & 3 & 25 & 2 & 7 & $<1$ & 47 & 4 & 9 & 2 & 16 & 2 & 16 & 1 \\
\hline Physidae & & & & & & & & & & & & & & \\
\hline Physa & 1 & $<1$ & 2 & $<1$ & - & & - & & - & & - & & - & \\
\hline Annelida (segmented worms) & & & & & & & & & & & & & & \\
\hline Oligochaeta & - & & - & & - & & - & & - & & - & & - & \\
\hline Lumbriculida & & & & & & & & & & & & & & \\
\hline Lumbriculidae & - & & - & & - & & - & & - & & - & & - & \\
\hline Tubificida & & & & & & & & & & & & & & \\
\hline Naididae & 18 & 2 & 29 & 2 & 4 & $<1$ & 2 & $<1$ & 6 & 1 & 7 & $<1$ & 510 & 32 \\
\hline Arthropoda (arthropods) & & & & & & & & & & & & & & \\
\hline Acariformes & & & & & & & & & & & & & & \\
\hline Hydrachnidia & 1 & $<1$ & 19 & 1 & 17 & 1 & 7 & $<1$ & - & & 6 & $<1$ & 82 & 5 \\
\hline Crustacea & & & & & & & & & & & & & & \\
\hline Podocopa & - & & - & & - & & 1 & $<1$ & - & & - & & 1 & $<1$ \\
\hline Insecta & & & & & & & & & & & & & & \\
\hline Ephemeroptera & & & & & & & & & & & & & & \\
\hline Baetidae & - & & 1 & $<1$ & - & & - & & - & & - & & - & \\
\hline Baetis & 1 & $<1$ & - & & - & & 11 & $<1$ & - & & - & & - & \\
\hline Pseudocloeon & - & & - & & 2 & $<1$ & 11 & $<1$ & - & & - & & - & \\
\hline Caenidae & & & & & & & & & & & & & & \\
\hline Caenis & 3 & $<1$ & 1 & $<1$ & - & & - & & 1 & $<1$ & - & & 1 & $<1$ \\
\hline Ephemerellidae & & & & & & & & & & & & & & \\
\hline Ephemerella & 1 & $<1$ & 10 & $<1$ & 4 & $<1$ & 13 & 1 & - & & 3 & $<1$ & 2 & $<1$ \\
\hline Heptageniidae & & & & & & & & & & & & & & \\
\hline Stenacron & 22 & 3 & - & & 4 & $<1$ & - & & - & & - & & - & \\
\hline Stenonema & 13 & 2 & 13 & $<1$ & 51 & 4 & 15 & 1 & 3 & $<1$ & 3 & $<1$ & - & \\
\hline Isonychiidae & & & & & & & & & & & & & & \\
\hline Isonychia & - & & - & & 4 & $<1$ & 1 & $<1$ & - & & - & & - & \\
\hline Leptohyphidae & & & & & & & & & & & & & & \\
\hline Tricorythodes & 1 & $<1$ & - & & - & & 1 & $<1$ & - & & - & & - & \\
\hline Leptophlebiidae & - & & - & & - & & - & & - & & - & & - & \\
\hline Odonata & & & & & & & & & & & & & & \\
\hline Aeshnidae & & & & & & & & & & & & & & \\
\hline Boyeria & - & & - & & - & & - & & 1 & $<1$ & - & & - & \\
\hline
\end{tabular}




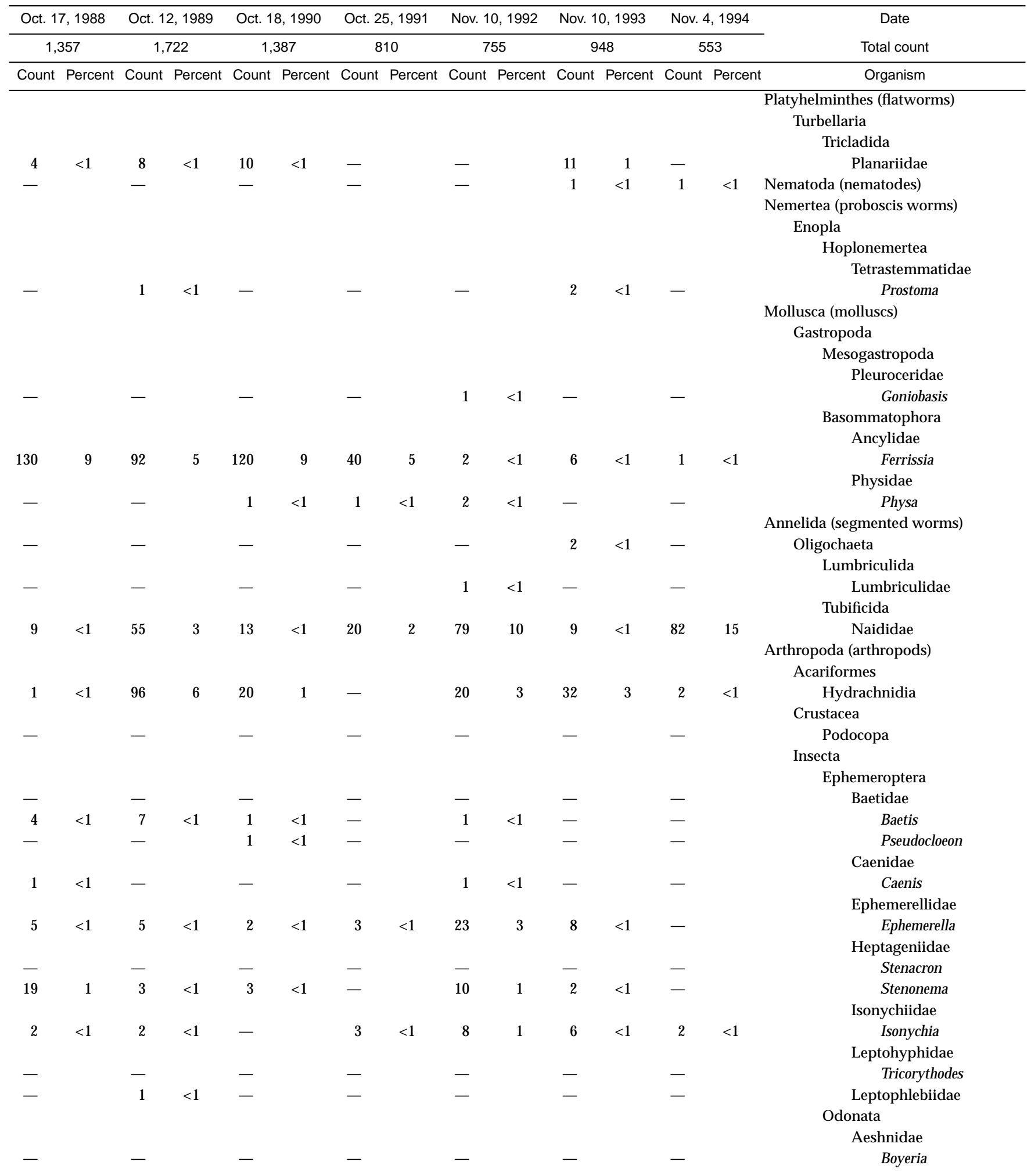


Table 5. Benthic-macroinvertebrate data-Continued

01494900 - East Branch Big Elk Creek at Elkview, Pa. (Site 31)—Continued

\begin{tabular}{|c|c|c|c|c|c|c|c|c|c|c|c|c|c|c|}
\hline \multirow{3}{*}{$\begin{array}{c}\text { Date } \\
\text { Total count } \\
\text { Organism }\end{array}$} & \multirow{2}{*}{\multicolumn{2}{|c|}{$\begin{array}{c}\text { Oct. } 29,1981 \\
846\end{array}$}} & \multicolumn{2}{|c|}{ Nov. 1, 1982} & \multicolumn{2}{|c|}{ Nov. 2, 1983} & \multicolumn{2}{|c|}{ Oct. 18,1984} & \multicolumn{2}{|c|}{ Oct. 17,1985} & \multicolumn{2}{|c|}{ Oct. 28,1986} & \multicolumn{2}{|c|}{ Oct. 27,1987} \\
\hline & & & 1,2 & 416 & \multicolumn{2}{|c|}{1,171} & \multicolumn{2}{|c|}{1,216} & \multicolumn{2}{|c|}{546} & \multicolumn{2}{|c|}{851} & \multicolumn{2}{|c|}{1.638} \\
\hline & Count & Percent & Count & Percent & Count & Percent & Count & Percent & Count & Percent & Count & Percent & Count & Percent \\
\hline \multicolumn{15}{|l|}{ Plecoptera } \\
\hline \multicolumn{15}{|l|}{ Capniidae } \\
\hline Allocapnia & - & & - & & - & & - & & - & & - & & - & \\
\hline Nemouridae & - & & - & & - & & - & & - & & - & & - & \\
\hline Hemiptera & & & & & & & & & & & & & & \\
\hline Veliidae & & & & & & & & & & & & & & \\
\hline Microvelia & - & & - & & - & & - & & 1 & $<1$ & - & & - & \\
\hline Rhagovelia & - & & 1 & $<1$ & - & & - & & 1 & $<1$ & - & & - & \\
\hline Megaloptera & & & & & & & & & & & & & & \\
\hline Corydalidae & & & & & & & & & & & & & & \\
\hline Nigronia & - & & 1 & $<1$ & - & & - & & - & & - & & 1 & $<1$ \\
\hline Trichoptera & & & & & & & & & & & & & & \\
\hline Glossosomatidae & & & & & & & & & & & & & & \\
\hline Glossosoma & - & & - & & 1 & $<1$ & 9 & $<1$ & - & & 2 & $<1$ & - & \\
\hline Hydropsychidae & & & & & & & & & & & & & & \\
\hline Ceratopsyche & 25 & 3 & 95 & 7 & 85 & 7 & 46 & 4 & 50 & 9 & 59 & 7 & 20 & 1 \\
\hline Cheumatopsyche & 110 & 13 & 140 & 10 & 170 & 14 & 160 & 13 & 58 & 11 & 50 & 6 & 2 & $<1$ \\
\hline Hydropsyche & 13 & 2 & 63 & 5 & 88 & 7 & 130 & 11 & 42 & 8 & 170 & 20 & 33 & 2 \\
\hline Hydroptilidae & & & & & & & & & & & & & & \\
\hline Hydroptila & 44 & 5 & 26 & 2 & 7 & $<1$ & - & & 3 & $<1$ & 61 & 7 & 7 & $<1$ \\
\hline Leucotrichia & 8 & 1 & 47 & 3 & 280 & 23 & 320 & 27 & - & & - & & - & \\
\hline Leptoceridae & & & & & & & & & & & & & & \\
\hline Oecetis & - & & 2 & $<1$ & - & & - & & - & & - & & - & \\
\hline Philopotamidae & & & & & & & & & & & & & & \\
\hline Chimarra & 4 & $<1$ & 16 & 1 & 4 & $<1$ & 2 & $<1$ & 1 & $<1$ & 3 & $<1$ & 2 & $<1$ \\
\hline Dolophilodes & - & & - & & - & & - & & - & & - & & - & \\
\hline Polycentropodidae & & & & & & & & & & & & & & \\
\hline Polycentropus & - & & 1 & $<1$ & 4 & $<1$ & - & & - & & - & & - & \\
\hline Rhyacophilidae & & & & & & & & & & & & & & \\
\hline Rhyacophila & - & & - & & - & & - & & - & & - & & - & \\
\hline R. fuscula & - & & - & & - & & 1 & $<1$ & - & & - & & - & \\
\hline Uenoidae & & & & & & & & & & & & & & \\
\hline Neophylax & - & & - & & - & & - & & - & & - & & - & \\
\hline Coleoptera & & & & & & & & & & & & & & \\
\hline $\begin{array}{l}\text { Curculionidae } \\
\text { Dryopidae }\end{array}$ & - & & - & & - & & - & & - & & - & & - & \\
\hline Helichus & - & & - & & - & & - & & - & & 1 & $<1$ & - & \\
\hline Elmidae & & & & & & & & & & & & & & \\
\hline Ancyronyx & 1 & $<1$ & - & & - & & - & & 1 & $<1$ & - & & - & \\
\hline Dubiraphia & - & & - & & - & & - & & - & & - & & 3 & $<1$ \\
\hline Macronychus & & & & & & & & & & & & & & \\
\hline M. glabratus & 1 & $<1$ & - & & 2 & $<1$ & - & & - & & - & & - & \\
\hline Optioservus & 37 & 4 & 29 & 2 & 9 & $<1$ & 19 & 2 & 8 & 2 & 4 & $<1$ & 13 & $<1$ \\
\hline Oulimnius & - & & - & & 1 & $<1$ & - & & 7 & 1 & 4 & $<1$ & 4 & $<1$ \\
\hline Stenelmis & 4 & $<1$ & 8 & $<1$ & 10 & $<1$ & 12 & 1 & 6 & 1 & 14 & 2 & 43 & 3 \\
\hline Gyrinidae & & & & & & & & & & & & & & \\
\hline Dineutus & - & & - & & - & & - & & - & & - & & - & \\
\hline Hydrophilidae & & & & & & & & & & & & & & \\
\hline Hydrobius & - & & - & & - & & - & & 1 & $<1$ & - & & - & \\
\hline Psephenidae & & & & & & & & & & & & & & \\
\hline Psephenus & 7 & $<1$ & 2 & $<1$ & - & & 4 & $<1$ & - & & 2 & $<1$ & - & \\
\hline
\end{tabular}




\begin{tabular}{|c|c|c|c|c|c|c|c|c|c|c|c|c|c|c|}
\hline Oct. 1 & 7,1988 & Oct. 1 & 2, 1989 & Oct. 1 & 8,1990 & Oct. 2 & 5,1991 & Nov. 1 & 0,1992 & Nov. 1 & 0,1993 & Nov. 4 & 4, 1994 & Date \\
\hline & 357 & 1,7 & 722 & & 387 & & 10 & & 55 & & 48 & & 53 & Total count \\
\hline Count & Percent & Count & Percent & Count & Percent & Count & Percent & Count & Percent & Count & Percent & Count & Percent & Organism \\
\hline & & & & & & & & & & & & & & Plecoptera \\
\hline & & & & & & & & & & & & & & Capniidae \\
\hline - & & - & & - & & - & & 1 & $<1$ & - & & - & & Allocapnia \\
\hline 1 & $<1$ & - & & - & & - & & - & & - & & - & & Nemouridae \\
\hline & & & & & & & & & & & & & & Hemiptera \\
\hline & & & & & & & & & & & & & & Veliidae \\
\hline - & & - & & - & & - & & - & & - & & - & & Microvelia \\
\hline - & & - & & - & & - & & - & & - & & - & & Rhagovelia \\
\hline & & & & & & & & & & & & & & Megaloptera \\
\hline & & & & & & & & & & & & & & Corydalidae \\
\hline - & & - & & - & & - & & 1 & $<1$ & - & & 1 & $<1$ & Nigronia \\
\hline & & & & & & & & & & & & & & Trichoptera \\
\hline & & & & & & & & & & & & & & Glossosomatidae \\
\hline - & & 6 & $<1$ & 4 & $<1$ & - & & 10 & 1 & 3 & $<1$ & - & & Glossosoma \\
\hline & & & & & & & & & & & & & & Hydropsychidae \\
\hline 270 & 19 & 71 & 4 & 100 & 7 & 49 & 6 & 38 & 5 & 72 & 8 & 37 & 7 & Ceratopsyche \\
\hline 53 & 4 & 9 & $<1$ & 7 & $<1$ & 4 & $<1$ & 23 & 3 & 74 & 8 & 77 & 14 & Cheumatopsyche \\
\hline 71 & 5 & 370 & 22 & 83 & 6 & 61 & 8 & 67 & 9 & 28 & 3 & 21 & 4 & Hydropsyche \\
\hline & & & & & & & & & & & & & & Hydroptilidae \\
\hline 89 & 6 & 59 & 3 & 18 & 1 & 11 & 1 & 22 & 3 & 11 & 1 & 14 & 3 & Hydroptila \\
\hline 5 & $<1$ & - & & - & & - & & - & & - & & 1 & $<1$ & Leucotrichia \\
\hline & & & & & & & & & & & & & & Leptoceridae \\
\hline - & & 1 & $<1$ & - & & 1 & $<1$ & - & & 2 & $<1$ & 1 & $<1$ & Oecetis \\
\hline & & & & & & & & & & & & & & Philopotamidae \\
\hline 7 & $<1$ & 30 & 2 & 2 & $<1$ & - & & 8 & 1 & 9 & $<1$ & - & & Chimarra \\
\hline - & & - & & 1 & $<1$ & - & & - & & - & & - & & Dolophilodes \\
\hline & & & & & & & & & & & & & & Polycentropodidae \\
\hline 1 & $<1$ & - & & - & & - & & - & & - & & - & & Polycentropus \\
\hline & & & & & & & & & & & & & & Rhyacophilidae \\
\hline - & & - & & - & & - & & - & & 1 & $<1$ & - & & Rhyacophila \\
\hline - & & - & & - & & - & & - & & - & & - & & R. fuscula \\
\hline & & & & & & & & & & & & & & Uenoidae \\
\hline - & & - & & - & & - & & 2 & $<1$ & - & & - & & Neophylax \\
\hline & & & & & & & & & & & & & & Coleoptera \\
\hline - & & - & & - & & - & & - & & 1 & $<1$ & - & & Curculionidae \\
\hline & & & & & & & & & & & & & & Dryopidae \\
\hline - & & - & & 1 & $<1$ & - & & - & & - & & - & & Helichus \\
\hline & & & & & & & & & & & & & & Elmidae \\
\hline - & & 1 & $<1$ & - & & - & & - & & - & & - & & Ancyronyx \\
\hline - & & - & & - & & - & & - & & - & & - & & Dubiraphia \\
\hline & & & & & & & & & & & & & & Macronychus \\
\hline- & & - & & - & & - & & - & & - & & - & & M. glabratus \\
\hline 10 & $<1$ & 15 & $<1$ & 4 & $<1$ & 6 & $<1$ & 25 & 3 & 48 & 5 & 9 & 2 & Optioservus \\
\hline 3 & $<1$ & 2 & $<1$ & - & & - & & - & & 4 & $<1$ & - & & Oulimnius \\
\hline 16 & 1 & 43 & 3 & 8 & $<1$ & 6 & $<1$ & 11 & 1 & 22 & 2 & 3 & $<1$ & Stenelmis \\
\hline & & & & & & & & & & & & & & Gyrinidae \\
\hline 3 & $<1$ & - & & - & & - & & - & & - & & - & & Dineutus \\
\hline & & & & & & & & & & & & & & Hydrophilidae \\
\hline - & & - & & - & & - & & - & & - & & - & & Hydrobius \\
\hline & & & & & & & & & & & & & & Psephenidae \\
\hline 1 & $<1$ & 1 & $<1$ & - & & - & & - & & 1 & $<1$ & - & & Psephenus \\
\hline
\end{tabular}


Table 5. Benthic-macroinvertebrate data-Continued

01494900 - East Branch Big Elk Creek at Elkview, Pa. (Site 31)—Continued

\begin{tabular}{|c|c|c|c|c|c|c|c|c|c|c|c|c|c|c|}
\hline \multirow{3}{*}{$\begin{array}{c}\text { Date } \\
\text { Total count } \\
\text { Organism }\end{array}$} & \multirow{2}{*}{\multicolumn{2}{|c|}{$\frac{\text { Oct. } 29,1981}{846}$}} & \multicolumn{2}{|c|}{ Nov. 1, 1982} & \multicolumn{2}{|c|}{ Nov. 2, 1983} & \multicolumn{2}{|c|}{ Oct. 18,1984} & \multicolumn{2}{|c|}{ Oct. 17,1985} & \multicolumn{2}{|c|}{ Oct. 28,1986} & \multicolumn{2}{|c|}{ Oct. 27,1987} \\
\hline & & & \multicolumn{2}{|c|}{1,416} & \multicolumn{2}{|c|}{1,171} & \multicolumn{2}{|c|}{1,216} & \multicolumn{2}{|c|}{546} & \multicolumn{2}{|c|}{851} & \multicolumn{2}{|c|}{1.638} \\
\hline & Count & Percent & Count & Percent & Count & Percent & Count & Percent & Count & Percent & Count & Percent & Count & Percent \\
\hline \multicolumn{15}{|l|}{ Diptera } \\
\hline Chironomidae & 450 & 53 & 650 & 46 & 280 & 23 & 370 & 31 & 290 & 53 & 340 & 40 & 610 & 38 \\
\hline \multicolumn{15}{|l|}{ Empididae } \\
\hline Hemerodromia & 19 & 2 & 43 & 3 & 17 & 1 & 3 & $<1$ & 11 & 2 & 15 & 2 & 49 & 3 \\
\hline \multicolumn{15}{|l|}{ Simuliidae } \\
\hline Simulium & 3 & $<1$ & 11 & $<1$ & - & & 2 & $<1$ & 3 & $<1$ & - & & - & \\
\hline \multicolumn{15}{|l|}{ Tipulidae } \\
\hline Antocha & 31 & 4 & 180 & 13 & 120 & 10 & 28 & 2 & 38 & 7 & 60 & 7 & 230 & 14 \\
\hline Tipula & - & & 1 & $<1$ & - & & - & & - & & - & & - & \\
\hline
\end{tabular}




\begin{tabular}{|c|c|c|c|c|c|c|c|c|c|c|c|c|c|c|}
\hline \multicolumn{2}{|c|}{ Oct. 17,1988} & \multicolumn{2}{|c|}{ Oct. 12,1989} & \multicolumn{2}{|c|}{ Oct. 18,1990} & \multicolumn{2}{|c|}{ Oct. 25,1991} & \multicolumn{2}{|c|}{ Nov. 10,1992} & \multicolumn{2}{|c|}{ Nov. 10,1993} & \multicolumn{2}{|c|}{ Nov. 4, 1994} & \multirow{2}{*}{$\begin{array}{c}\text { Date } \\
\text { Total count }\end{array}$} \\
\hline \multicolumn{2}{|c|}{1,357} & \multicolumn{2}{|c|}{1,722} & \multicolumn{2}{|c|}{1,387} & \multicolumn{2}{|c|}{810} & \multicolumn{2}{|c|}{755} & \multicolumn{2}{|c|}{948} & \multicolumn{2}{|c|}{553} & \\
\hline Count & Percent & Count & Percent & Count & Percent & Count & Percent & Count & Percent & Count & Percent & Count & Percent & Organism \\
\hline & & & & & & & & & & & & & & tera \\
\hline 440 & 31 & 620 & 36 & 760 & 54 & 510 & 63 & 220 & 29 & 360 & 38 & 160 & 29 & $\begin{array}{l}\text { Chironomidae } \\
\text { Empididae }\end{array}$ \\
\hline 3 & $<1$ & 37 & 2 & 15 & 1 & 8 & 1 & 5 & $<1$ & 13 & 1 & 1 & $<1$ & $\begin{array}{l}\text { Hemerodromia } \\
\text { Simuliidae }\end{array}$ \\
\hline 9 & $<1$ & 17 & 1 & 3 & $<1$ & - & & 4 & $<1$ & - & & - & & $\begin{array}{l}\text { Simulium } \\
\text { Tipulidae }\end{array}$ \\
\hline 200 & 14 & 170 & 10 & 210 & 15 & 87 & 11 & 170 & 22 & 220 & 23 & 140 & 25 & Antocha \\
\hline - & & - & & - & & - & & - & & - & & - & & Tipula \\
\hline
\end{tabular}


Table 5. Benthic-macroinvertebrate data-Continued

$[<$, less than; - , not found]

01494950 - West Branch Big Elk Creek near Oxford, Pa. (Site 32)

\begin{tabular}{|c|c|c|c|c|c|c|c|c|c|c|c|c|c|c|}
\hline \multirow{3}{*}{$\begin{array}{cc}\text { Date } \\
\text { Total count }\end{array}$} & \multirow{2}{*}{\multicolumn{2}{|c|}{$\begin{array}{c}\text { Oct. } 29,1981 \\
1,517\end{array}$}} & \multirow{2}{*}{\multicolumn{2}{|c|}{$\begin{array}{c}\text { Nov. 1, } 1982 \\
2,458\end{array}$}} & \multirow{2}{*}{\multicolumn{2}{|c|}{$\begin{array}{c}\text { Nov. } 2,1983 \\
1,203\end{array}$}} & \multirow{2}{*}{\multicolumn{2}{|c|}{$\begin{array}{c}\text { Oct. } 18,1984 \\
1,875\end{array}$}} & \multirow{2}{*}{\multicolumn{2}{|c|}{$\frac{\text { Oct. } 17,1985}{1,124}$}} & \multirow{2}{*}{\multicolumn{2}{|c|}{$\begin{array}{c}\text { Oct. } 28,1986 \\
1,402\end{array}$}} & \multirow{2}{*}{\multicolumn{2}{|c|}{$\begin{array}{c}\text { Oct. } 27,1987 \\
1,309\end{array}$}} \\
\hline & & & & & & & & & & & & & & \\
\hline & Count & Percent & Count & Percent & Count & Percent & Count & Percent & Count & Percent & Count & Percent & Count & Percent \\
\hline \multicolumn{15}{|l|}{ Platyhelminthes (flatworms) } \\
\hline \multicolumn{15}{|l|}{ Turbellaria } \\
\hline \multicolumn{15}{|l|}{ Tricladida } \\
\hline Planariidae & 14 & $<1$ & 15 & $<1$ & 2 & $<1$ & 2 & $<1$ & 1 & $<1$ & - & & 3 & $<1$ \\
\hline Nematoda & - & & - & & - & & - & & - & & - & & 1 & $<1$ \\
\hline \multicolumn{15}{|l|}{ Nemertea (proboscis worms) } \\
\hline \multicolumn{15}{|l|}{ Enopla } \\
\hline Hoplonemertea & & & & & & & & & & & & & & \\
\hline Tetrastemmatidae & & & & & & & & & & & & & & \\
\hline Prostoma & 3 & $<1$ & 1 & $<1$ & 4 & $<1$ & - & & - & & - & & - & \\
\hline Mollusca (molluscs) & & & & & & & & & & & & & & \\
\hline Gastropoda & & & & & & & & & & & & & & \\
\hline Basommatophora & & & & & & & & & & & & & & \\
\hline Ancylidae & & & & & & & & & & & & & & \\
\hline Ferrissia & - & & 1 & $<1$ & 1 & $<1$ & 1 & $<1$ & - & & - & & - & \\
\hline Physidae & & & & & & & & & & & & & & \\
\hline Physa & 1 & $<1$ & - & & - & & - & & - & & 4 & $<1$ & - & \\
\hline Annelida (segmented worms) & & & & & & & & & & & & & & \\
\hline Oligochaeta & 2 & $<1$ & 10 & $<1$ & 38 & 3 & 2 & $<1$ & - & & - & & - & \\
\hline Lumbriculida & & & & & & & & & & & & & & \\
\hline Lumbriculidae & - & & - & & - & & - & & - & & - & & - & \\
\hline Tubificida & & & & & & & & & & & & & & \\
\hline Naididae & - & & - & & - & & - & & - & & 4 & $<1$ & 94 & 7 \\
\hline Arthropoda (arthropods) & & & & & & & & & & & & & & \\
\hline Acariformes & & & & & & & & & & & & & & \\
\hline Hydrachnidia & 8 & $<1$ & 13 & $<1$ & 12 & 1 & 2 & $<1$ & 2 & $<1$ & 3 & $<1$ & 17 & 1 \\
\hline Crustacea & & & & & & & & & & & & & & \\
\hline Cyclopoida & - & & - & & - & & - & & - & & - & & - & \\
\hline Podocopa & - & & 2 & $<1$ & - & & - & & - & & - & & - & \\
\hline Insecta & & & & & & & & & & & & & & \\
\hline Ephemeroptera & & & & & & & & & & & & & & \\
\hline Baetidae & & & & & & & & & & & & & & \\
\hline Baetis & - & & - & & 3 & $<1$ & 49 & 3 & 12 & 1 & 4 & $<1$ & 1 & $<1$ \\
\hline Pseudocloeon & - & & - & & 1 & $<1$ & - & & - & & - & & 2 & $<1$ \\
\hline Caenidae & & & & & & & & & & & & & & \\
\hline Caenis & - & & - & & - & & - & & - & & - & & 1 & $<1$ \\
\hline Ephemerellidae & & & & & & & & & & & & & & \\
\hline Ephemerella & 34 & 2 & 2 & $<1$ & 3 & $<1$ & 38 & 2 & 17 & 2 & 19 & 1 & 24 & 2 \\
\hline Heptageniidae & & & & & & & & & & & & & & \\
\hline Stenonema & 15 & 1 & 39 & 2 & 22 & 2 & 42 & 2 & 63 & 6 & 48 & 3 & 65 & 5 \\
\hline Isonychiidae & & & & & & & & & & & & & & \\
\hline Isonychia & 2 & $<1$ & - & & 1 & $<1$ & 4 & $<1$ & 4 & $<1$ & 4 & $<1$ & 14 & 1 \\
\hline Leptohyphidae & & & & & & & & & & & & & & \\
\hline Tricorythodes & - & & - & & - & & - & & - & & - & & - & \\
\hline Leptophlebiidae & - & & - & & - & & - & & - & & - & & - & \\
\hline Odonata & & & & & & & & & & & & & & \\
\hline Coenagrionidae & & & & & & & & & & & & & & \\
\hline Argia & - & & 1 & $<1$ & - & & - & & - & & - & & - & \\
\hline Plecoptera & & & & & & & & & & & & & & \\
\hline Capniidae & & & & & & & & & & & & & & \\
\hline Allocapnia & - & & - & & - & & - & & - & & 1 & $<1$ & - & \\
\hline Chloroperlidae & - & & - & & - & & - & & - & & - & & - & \\
\hline Taeniopterygidae & & & & & & & & & & & & & & \\
\hline Taeniopteryx & - & & - & & - & & - & & - & & - & & 1 & $<1$ \\
\hline
\end{tabular}




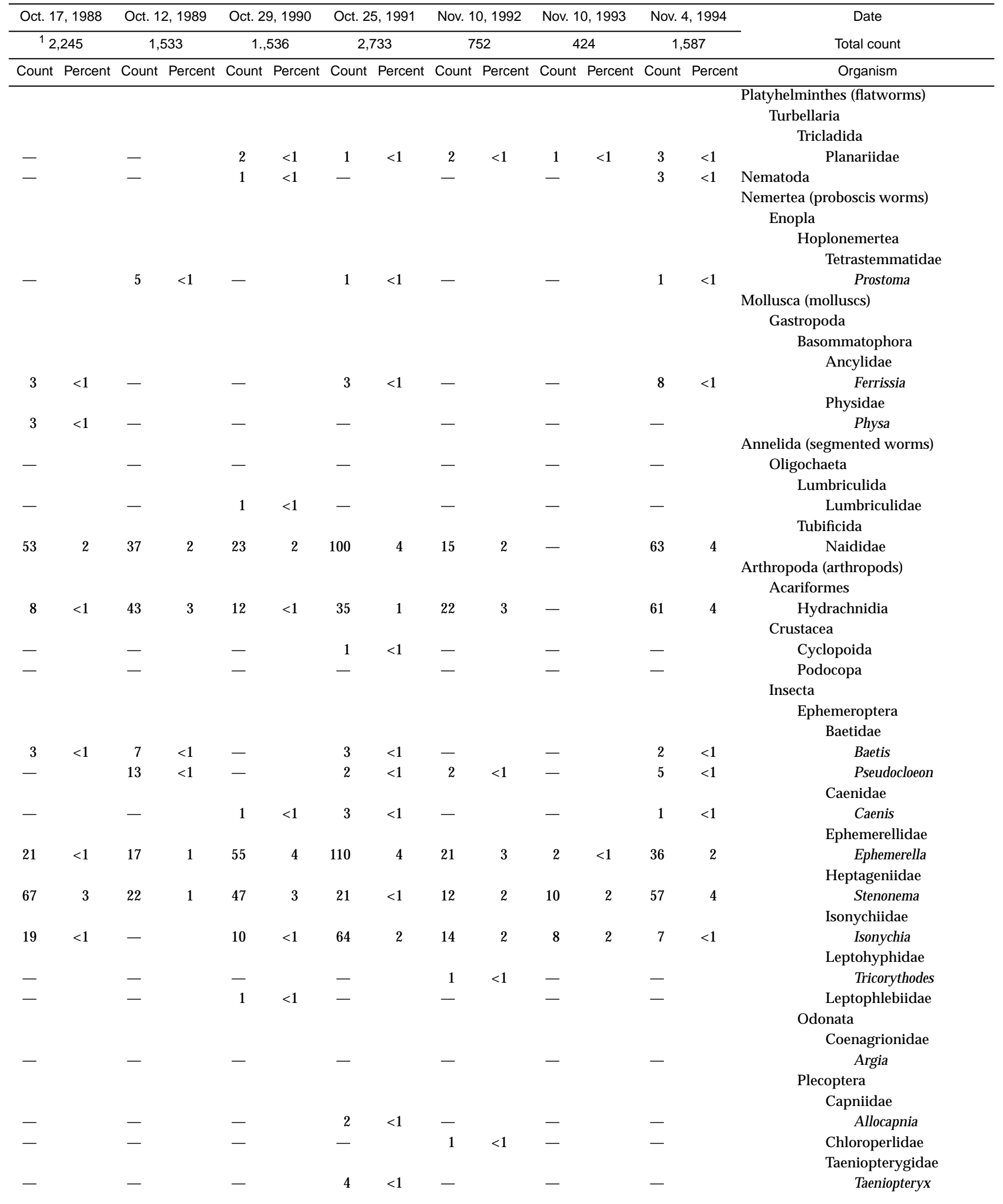


Table 5. Benthic-macroinvertebrate data-Continued

01494950 - West Branch Big Elk Creek near Oxford, Pa. (Site 32)—Continued

\begin{tabular}{|c|c|c|c|c|c|c|c|c|c|c|c|c|c|c|}
\hline \multirow{3}{*}{$\begin{array}{c}\text { Date } \\
\text { Total count } \\
\text { Organism }\end{array}$} & \multirow{2}{*}{\multicolumn{2}{|c|}{$\begin{array}{c}\text { Oct. } 29,1981 \\
1,517\end{array}$}} & \multicolumn{2}{|c|}{ Nov. 1, 1982} & \multicolumn{2}{|c|}{ Nov. 2, 1983} & \multicolumn{2}{|c|}{ Oct. 18,1984} & \multicolumn{2}{|c|}{ Oct. 17,1985} & \multicolumn{2}{|c|}{ Oct. 28,1986} & \multicolumn{2}{|c|}{ Oct. 27,1987} \\
\hline & & & & 458 & & 203 & $1, \varepsilon$ & 875 & 1, & 124 & & 402 & & 309 \\
\hline & Count & Percent & Count & Percent & Count & Percent & Count & Percent & Count & Percent & Count & Percent & Count & Percent \\
\hline \multicolumn{15}{|l|}{ Hemiptera } \\
\hline \multicolumn{15}{|l|}{ Veliidae } \\
\hline Rhagovelia & - & & - & & 2 & $<1$ & - & & - & & - & & - & \\
\hline \multicolumn{15}{|l|}{ Megaloptera } \\
\hline \multicolumn{15}{|l|}{ Corydalidae } \\
\hline Corydalus & 3 & $<1$ & 1 & $<1$ & - & & 4 & $<1$ & - & & 2 & $<1$ & - & \\
\hline Nigronia & 1 & $<1$ & - & & - & & - & & - & & - & & - & \\
\hline \multicolumn{15}{|l|}{ Trichoptera } \\
\hline Apataniidae & & & & & & & & & & & & & & \\
\hline Apatania & - & & - & & - & & - & & 1 & $<1$ & - & & - & \\
\hline Brachycentridae & & & & & & & & & & & & & & \\
\hline Brachycentrus & - & & - & & - & & - & & - & & - & & - & \\
\hline Glossosomatidae & & & & & & & & & & & & & & \\
\hline Glossosoma & 1 & $<1$ & - & & - & & 4 & $<1$ & - & & - & & - & \\
\hline Hydropsychidae & & & & & & & & & & & & & & \\
\hline Ceratopsyche & 120 & 8 & 160 & 6 & 120 & 10 & 470 & 25 & 260 & 24 & 400 & 29 & 210 & 16 \\
\hline Cheumatopsyche & 310 & 21 & 220 & 9 & 180 & 15 & 320 & 17 & 200 & 18 & 120 & 9 & 41 & 3 \\
\hline Hydropsyche & 260 & 17 & 460 & 18 & 84 & 7 & 120 & 6 & 9 & $<1$ & 140 & 10 & 51 & 4 \\
\hline Macrostemum & 1 & $<1$ & - & & 3 & $<1$ & - & & - & & - & & - & \\
\hline Hydroptilidae & & & & & & & & & & & & & & \\
\hline Hydroptila & 62 & 4 & 46 & 2 & 17 & 1 & 3 & $<1$ & 4 & $<1$ & 23 & 2 & 50 & 4 \\
\hline Leucotrichia & 320 & 21 & 860 & 34 & 180 & 15 & 470 & 25 & - & & 180 & 13 & 14 & 1 \\
\hline Leptoceridae & - & & - & & - & & - & & - & & - & & - & \\
\hline Oecetis & 9 & $<1$ & 5 & $<1$ & - & & - & & 2 & $<1$ & - & & - & \\
\hline Philopotamidae & & & & & & & & & & & & & & \\
\hline Chimarra & - & & - & & 4 & $<1$ & - & & 18 & 2 & 22 & 2 & 18 & 1 \\
\hline Dolophilodes & - & & - & & - & & - & & - & & 1 & $<1$ & - & \\
\hline Polycentropodidae & & & & & & & & & & & & & & \\
\hline Neureclipsis & 8 & $<1$ & - & & 4 & $<1$ & - & & - & & - & & - & \\
\hline Polycentropus & 1 & $<1$ & 1 & $<1$ & 1 & $<1$ & - & & 1 & $<1$ & 6 & $<1$ & - & \\
\hline Rhyacophilidae & & & & & & & & & & & & & & \\
\hline Rhyacophila & - & & - & & - & & - & & - & & - & & - & \\
\hline Uenoidae & & & & & & & & & & & & & & \\
\hline Neophylax & 2 & $<1$ & 1 & $<1$ & - & & - & & - & & - & & - & \\
\hline Lepidoptera & & & & & & & & & & & & & & \\
\hline Pyralidae & - & & - & & - & & 1 & $<1$ & - & & - & & - & \\
\hline Coleoptera & & & & & & & & & & & & & & \\
\hline Dryopidae & & & & & & & & & & & & & & \\
\hline Helichus & - & & - & & 2 & $<1$ & - & & - & & - & & - & \\
\hline Dytiscidae & & & & & & & & & & & & & & \\
\hline Agabus & - & & - & & - & & - & & - & & - & & - & \\
\hline Elmidae & & & & & & & & & & & & & & \\
\hline Ancyronyx & - & & - & & - & & - & & - & & - & & - & \\
\hline Dubiraphia & 3 & $<1$ & - & & - & & - & & - & & - & & - & \\
\hline Optioservus & 6 & $<1$ & 9 & $<1$ & 2 & $<1$ & 10 & $<1$ & 5 & $<1$ & 6 & $<1$ & 3 & $<1$ \\
\hline Oulimnius & 1 & $<1$ & - & & - & & 5 & $<1$ & 2 & $<1$ & 10 & $<1$ & - & \\
\hline Stenelmis & 31 & 2 & 17 & $<1$ & 4 & $<1$ & 11 & $<1$ & 2 & $<1$ & 25 & 2 & - & \\
\hline Gyrinidae & & & & & & & & & & & & & & \\
\hline Dineutus & 1 & $<1$ & - & & - & & - & & - & & - & & - & \\
\hline Hydraenidae & & & & & & & & & & & & & & \\
\hline Limnebius & - & & - & & - & & - & & - & & - & & - & \\
\hline Hydrophilidae & & & & & & & & & & & & & & \\
\hline Berosus & - & & - & & - & & - & & - & & - & & - & \\
\hline Psephenidae & & & & & & & & & & & & & & \\
\hline Psephenus & - & & 1 & $<1$ & - & & - & & - & & - & & - & \\
\hline
\end{tabular}




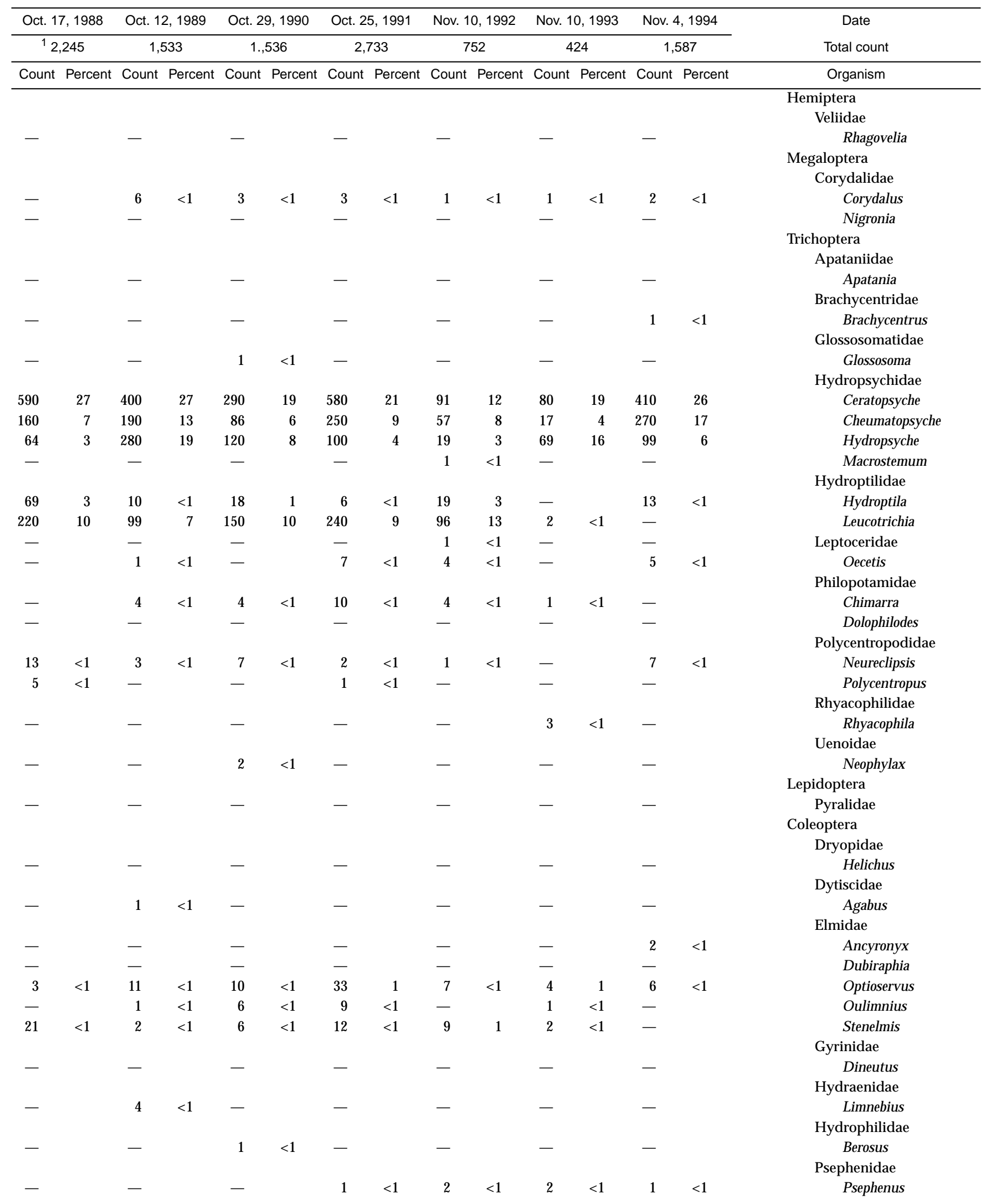


Table 5. Benthic-macroinvertebrate data-Continued

01494950 - West Branch Big Elk Creek near Oxford, Pa. (Site 32)—Continued

\begin{tabular}{|c|c|c|c|c|c|c|c|c|c|c|c|c|c|c|}
\hline \multirow{3}{*}{$\begin{array}{c}\text { Date } \\
\text { Total count } \\
\text { Organism }\end{array}$} & \multicolumn{2}{|c|}{ Oct. 29,1981} & \multicolumn{2}{|c|}{ Nov. 1,1982} & \multicolumn{2}{|c|}{ Nov. 2, 1983} & \multicolumn{2}{|c|}{ Oct. 18,1984} & \multicolumn{2}{|c|}{ Oct. 17,1985} & \multicolumn{2}{|c|}{ Oct. 28,1986} & \multicolumn{2}{|c|}{ Oct. 27,1987} \\
\hline & \multicolumn{2}{|c|}{1,517} & \multicolumn{2}{|c|}{2,458} & \multicolumn{2}{|c|}{1,203} & \multicolumn{2}{|c|}{1,875} & \multicolumn{2}{|c|}{1,124} & \multicolumn{2}{|c|}{1,402} & \multicolumn{2}{|c|}{1,309} \\
\hline & Count & Percent & Count & Percent & Count & Percent & Count & Percent & Count & Percent & Count & Percent & Count & Percent \\
\hline \multicolumn{15}{|l|}{ Coleoptera } \\
\hline \multicolumn{15}{|l|}{ Ptilodactylidae } \\
\hline \multicolumn{15}{|l|}{ Anchytarsus } \\
\hline A. bicolor & - & & - & & 1 & $<1$ & - & & - & & - & & - & \\
\hline Hymenoptera & - & & - & & - & & - & & - & & 1 & $<1$ & - & \\
\hline \multicolumn{15}{|l|}{ Diptera } \\
\hline \multicolumn{15}{|l|}{ Athericidae } \\
\hline Atherix & - & & - & & - & & - & & - & & - & & - & \\
\hline Chironomidae & 140 & 9 & 410 & 16 & 400 & 33 & 270 & 14 & 490 & 45 & 190 & 14 & 610 & 47 \\
\hline \multicolumn{15}{|l|}{ Empididae } \\
\hline Chelifera & - & & - & & - & & - & & - & & - & & - & \\
\hline Hemerodromia & 5 & $<1$ & 9 & $<1$ & 9 & $<1$ & 3 & $<1$ & 3 & $<1$ & 9 & $<1$ & 5 & $<1$ \\
\hline \multicolumn{15}{|l|}{ Simuliidae } \\
\hline Simulium & 3 & $<1$ & 3 & $<1$ & 3 & $<1$ & 28 & 1 & 5 & $<1$ & - & & 8 & $<1$ \\
\hline \multicolumn{15}{|l|}{ Tipulidae } \\
\hline Antocha & 150 & 10 & 170 & 7 & 100 & 8 & 16 & $<1$ & 23 & 2 & 180 & 13 & 76 & 6 \\
\hline Tipula & - & & 1 & $<1$ & - & & - & & - & & - & & - & \\
\hline
\end{tabular}

\footnotetext{
${ }^{1}$ Extrapolated from a 3/8 subsample.
} 


\begin{tabular}{|c|c|c|c|c|c|c|c|c|c|c|c|c|c|c|}
\hline \multirow{2}{*}{\multicolumn{2}{|c|}{$\frac{\text { Oct. } 17,1988}{{ }^{1} 2,245}$}} & \multirow{2}{*}{\multicolumn{2}{|c|}{ Oct. 12, 1989}} & \multicolumn{2}{|c|}{ Oct. 29, 1990} & \multicolumn{2}{|c|}{ Oct. 25, 1991} & \multicolumn{2}{|c|}{ Nov. 10, 1992} & \multicolumn{2}{|c|}{ Nov. 10,1993} & \multicolumn{2}{|c|}{ Nov. 4, 1994} & \multirow{3}{*}{$\begin{array}{c}\text { Date } \\
\text { Total count } \\
\text { Organism }\end{array}$} \\
\hline & & & & & 536 & & 733 & & 52 & & 24 & & 587 & \\
\hline \multirow{3}{*}{ Count } & Percent & Count & Percent & Count & Percent & Count & Percent & Count & Percent & Count & Percent & Count & Percent & \\
\hline & & & & & & & & & & & & & & Coleoptera \\
\hline & & & & & & & & & & & & & & $\begin{array}{r}\text { Ptilodactylidae } \\
\text { Anchytarsus }\end{array}$ \\
\hline - & & - & & - & & - & & - & & - & & - & & A. bicolor \\
\hline- & & - & & - & & - & & - & & - & & - & & $\begin{array}{l}\text { Hymenoptera } \\
\text { Diptera }\end{array}$ \\
\hline- & & - & & - & & - & & - & & - & & 2 & $<1$ & $\begin{array}{r}\text { Athericidae } \\
\text { Atherix }\end{array}$ \\
\hline 620 & 28 & 250 & 17 & 560 & 37 & 810 & 30 & 230 & 30 & 130 & 30 & 380 & 24 & $\begin{array}{l}\text { Chironomidae } \\
\text { Empididae }\end{array}$ \\
\hline - & & - & & - & & - & & - & & - & & 1 & $<1$ & Chelifera \\
\hline 3 & $<1$ & 42 & 3 & 9 & $<1$ & 18 & $<1$ & 5 & $<1$ & 5 & 1 & 13 & $<1$ & $\begin{array}{l}\text { Hemerodromia } \\
\text { Simuliidae }\end{array}$ \\
\hline- & & 4 & $<1$ & - & & 1 & $<1$ & 5 & $<1$ & - & & 8 & $<1$ & $\begin{array}{l}\text { Simulium } \\
\text { Tipulidae }\end{array}$ \\
\hline $\begin{array}{r}300 \\
-\end{array}$ & 14 & $\begin{array}{l}81 \\
-\end{array}$ & 5 & $\begin{array}{l}110 \\
-\end{array}$ & 7 & $\begin{array}{r}290 \\
-\end{array}$ & 11 & $\begin{array}{l}110 \\
-\end{array}$ & 14 & $\begin{array}{l}86 \\
-\end{array}$ & 20 & $\begin{array}{l}120 \\
-\end{array}$ & 8 & $\begin{array}{l}\text { Antocha } \\
\text { Tipula }\end{array}$ \\
\hline
\end{tabular}


Table 5. Benthic-macroinvertebrate data-Continued

$[<$, less than; - , not found]

01578340 - East Branch Octoraro Creek at Christiana, Pa. (Site 33)

\begin{tabular}{|c|c|c|c|c|c|c|c|c|c|c|c|c|c|c|}
\hline \multirow{3}{*}{$\begin{array}{c}\text { Date } \\
\text { Total count } \\
\text { Organism }\end{array}$} & \multirow{2}{*}{\multicolumn{2}{|c|}{$\begin{array}{c}\text { Nov. 3, } 1981 \\
978\end{array}$}} & \multirow{2}{*}{\multicolumn{2}{|c|}{$\begin{array}{c}\text { Oct. } 27,1982 \\
1,670\end{array}$}} & \multirow{2}{*}{\multicolumn{2}{|c|}{$\begin{array}{c}\text { Oct. } 28,1983 \\
856\end{array}$}} & \multirow{2}{*}{\multicolumn{2}{|c|}{$\begin{array}{c}\text { Oct. } 26,1984 \\
1,518\end{array}$}} & \multirow{2}{*}{\multicolumn{2}{|c|}{$\begin{array}{c}\text { Oct. } 24,1985 \\
593\end{array}$}} & \multirow{2}{*}{\multicolumn{2}{|c|}{$\begin{array}{c}\text { Nov. } 20,1986 \\
1,110\end{array}$}} & \multirow{2}{*}{\multicolumn{2}{|c|}{$\begin{array}{c}\text { Nov. } 18,1987 \\
1,421\end{array}$}} \\
\hline & & & & & & & & & & & & & & \\
\hline & Count & Percent & Count & Percent & Count & Percent & Count & Percent & Count & Percent & Count & Percent & Count & Percent \\
\hline \multicolumn{15}{|l|}{ Platyhelminthes (flatworms) } \\
\hline \multicolumn{15}{|l|}{ Turbellaria } \\
\hline \multicolumn{15}{|l|}{ Tricladida } \\
\hline Planariidae & 5 & $<1$ & 10 & $<1$ & 21 & 2 & 38 & 3 & 41 & 7 & 35 & 3 & 39 & 3 \\
\hline Nematoda (nematodes) & - & & 1 & $<1$ & - & & - & & - & & - & & 3 & $<1$ \\
\hline \multicolumn{15}{|l|}{ Mollusca (molluscs) } \\
\hline \multicolumn{15}{|l|}{ Gastropoda } \\
\hline \multicolumn{15}{|l|}{ Basommatophora } \\
\hline Ancylidae & & & & & & & & & & & & & & \\
\hline Ferrissia & 150 & 15 & 140 & 8 & 19 & 2 & - & & 1 & $<1$ & 1 & $<1$ & 1 & $<1$ \\
\hline Physidae & & & & & & & & & & & & & & \\
\hline Physa & - & & - & & - & & - & & - & & - & & - & \\
\hline Planorbidae & & & & & & & & & & & & & & \\
\hline Gyraulus & - & & - & & - & & - & & - & & - & & - & \\
\hline Helisoma & 1 & $<1$ & - & & - & & - & & - & & 1 & $<1$ & - & \\
\hline Bivalvia & & & & & & & & & & & & & & \\
\hline Veneroida & & & & & & & & & & & & & & \\
\hline Sphaeriidae & - & & - & & - & & - & & 1 & $<1$ & 3 & $<1$ & 2 & $<1$ \\
\hline Pisidium & - & & - & & 1 & $<1$ & - & & - & & - & & - & \\
\hline Annelida (segmented worms) & & & & & & & & & & & & & & \\
\hline Oligochaeta & - & & - & & - & & - & & - & & - & & - & \\
\hline Tubificida & & & & & & & & & & & & & & \\
\hline Naididae & 97 & 10 & 61 & 4 & 7 & $<1$ & 3 & $<1$ & 8 & 1 & 2 & $<1$ & 320 & 23 \\
\hline Tubificidae & - & & - & & - & & - & & 4 & $<1$ & - & & - & \\
\hline Hirudinea & & & & & & & & & & & & & & \\
\hline Pharyngobdellida & & & & & & & & & & & & & & \\
\hline Erpobdellidae & - & & 1 & $<1$ & 1 & $<1$ & - & & 1 & $<1$ & - & & - & \\
\hline Arthropoda (arthropods) & & & & & & & & & & & & & & \\
\hline Acariformes & & & & & & & & & & & & & & \\
\hline Hydrachnidia & - & & - & & 1 & $<1$ & - & & 1 & $<1$ & 2 & $<1$ & 48 & 3 \\
\hline Crustacea & & & & & & & & & & & & & & \\
\hline Amphipoda & & & & & & & & & & & & & & \\
\hline Gammaridae & - & & - & & - & & - & & - & & - & & - & \\
\hline Gammarus & - & & - & & - & & - & & - & & - & & - & \\
\hline Isopoda & & & & & & & & & & & & & & \\
\hline Asellidae & - & & - & & - & & - & & - & & - & & - & \\
\hline Caecidotea & 21 & 2 & 110 & 6 & 6 & $<1$ & 32 & 2 & 6 & 1 & 6 & $<1$ & 4 & $<1$ \\
\hline Lirceus & - & & - & & - & & - & & - & & - & & - & \\
\hline Podocopa & - & & - & & - & & - & & - & & - & & - & \\
\hline Insecta & & & & & & & & & & & & & & \\
\hline Ephemeroptera & & & & & & & & & & & & & & \\
\hline Baetidae & & & & & & & & & & & & & & \\
\hline Baetis & - & & 6 & $<1$ & - & & 2 & $<1$ & 3 & $<1$ & - & & 1 & $<1$ \\
\hline Pseudocloeon & - & & - & & - & & 2 & $<1$ & - & & - & & - & \\
\hline Ephemerellidae & & & & & & & & & & & & & & \\
\hline Ephemerella & 1 & $<1$ & 9 & $<1$ & 41 & 5 & 16 & 1 & 61 & 10 & 180 & 16 & 150 & 11 \\
\hline Heptageniidae & & & & & & & & & & & & & & \\
\hline Stenacron & - & & - & & - & & - & & - & & - & & - & \\
\hline Stenonema & 3 & $<1$ & 12 & $<1$ & 12 & 1 & 5 & $<1$ & 7 & 1 & 10 & $<1$ & 4 & $<1$ \\
\hline Isonychiidae & & & & & & & & & & & & & & \\
\hline Isonychia & - & & - & & - & & - & & 1 & $<1$ & 1 & $<1$ & - & \\
\hline Leptohyphidae & & & & & & & & & & & & & & \\
\hline Tricorythodes & - & & - & & - & & - & & - & & - & & - & \\
\hline
\end{tabular}




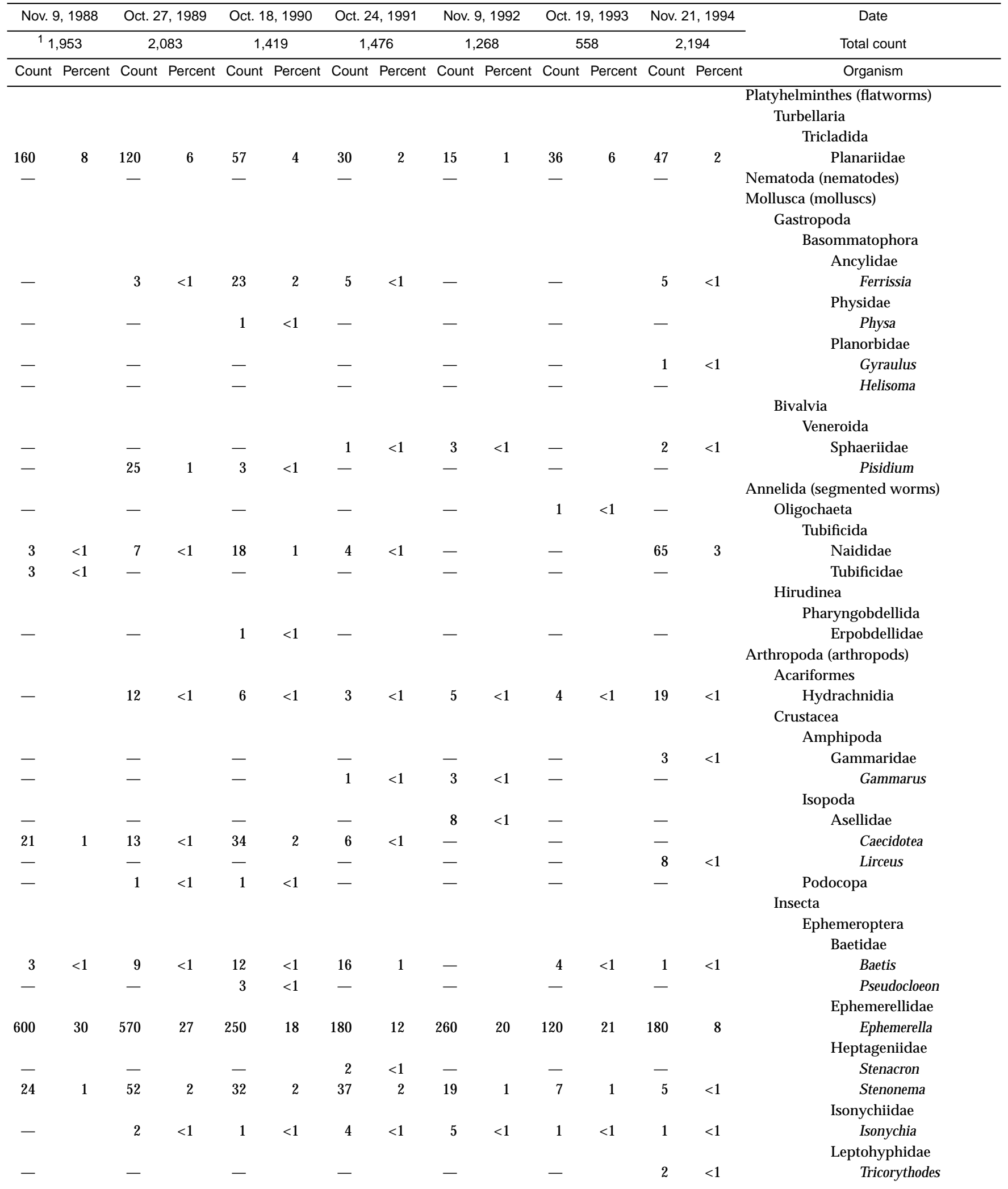


Table 5. Benthic-macroinvertebrate data-Continued

01578340 - East Branch Octoraro Creek at Christiana, Pa. (Site 33)—Continued

\begin{tabular}{|c|c|c|c|c|c|c|c|c|c|c|c|c|c|c|}
\hline \multirow{3}{*}{$\begin{array}{c}\text { Date } \\
\text { Total count } \\
\text { Organism }\end{array}$} & \multirow{2}{*}{\multicolumn{2}{|c|}{$\begin{array}{c}\text { Nov. 3, } 1981 \\
978\end{array}$}} & \multicolumn{2}{|c|}{ Oct. 27,1982} & \multirow{2}{*}{\multicolumn{2}{|c|}{$\begin{array}{c}\text { Oct. 28, } 1983 \\
856\end{array}$}} & \multicolumn{2}{|c|}{ Oct. 26, 1984} & \multicolumn{2}{|c|}{ Oct. 24,1985} & \multicolumn{2}{|c|}{ Nov. 20, 1986} & \multicolumn{2}{|c|}{ Nov. 18,1987} \\
\hline & & & 1,6 & 370 & & & & 518 & $5 \varsigma$ & 93 & & 110 & & 421 \\
\hline & Count & Percent & Count & Percent & Count & Percent & Count & Percent & Count & Percent & Count & Percent & Count & Percent \\
\hline \multicolumn{15}{|l|}{ Odonata } \\
\hline \multicolumn{15}{|l|}{ Coenagrionidae } \\
\hline Argia & - & & - & & - & & - & & - & & - & & 1 & $<1$ \\
\hline \multicolumn{15}{|l|}{ Plecoptera } \\
\hline \multicolumn{15}{|l|}{ Taeniopterygidae } \\
\hline Taeniopteryx & - & & 3 & $<1$ & - & & 7 & $<1$ & - & & 1 & $<1$ & - & \\
\hline \multicolumn{15}{|l|}{ Hemiptera } \\
\hline \multicolumn{15}{|l|}{ Megaloptera } \\
\hline \multicolumn{15}{|l|}{ Corydalidae } \\
\hline Corydalus & - & & - & & - & & - & & - & & - & & - & \\
\hline Nigronia & - & & - & & - & & - & & - & & - & & - & \\
\hline \multicolumn{15}{|l|}{ Sialidae } \\
\hline Sialis & - & & - & & 1 & $<1$ & - & & - & & - & & - & \\
\hline $\begin{array}{l}\text { Neuroptera } \\
\text { Sisyridae } \\
\text { Climacia }\end{array}$ & & & & & & & & & & & & & & \\
\hline C. areolaris & - & & - & & - & & - & & - & & 1 & $<1$ & - & \\
\hline $\begin{array}{l}\text { Trichoptera } \\
\text { Apataniidae }\end{array}$ & & & & & & & & & & & & & & \\
\hline $\begin{array}{c}\text { Apatania } \\
\text { Brachycentridae }\end{array}$ & - & & - & & - & & - & & - & & - & & 6 & $<1$ \\
\hline $\begin{array}{c}\text { Micrasema } \\
\text { Glossosomatidae }\end{array}$ & - & & - & & - & & - & & - & & - & & - & \\
\hline Glossosoma & - & & - & & - & & - & & - & & - & & - & \\
\hline $\begin{array}{l}\text { Hydropsychidae } \\
\text { Ceratopsyche }\end{array}$ & 42 & 4 & 76 & 4 & 28 & 3 & 76 & 5 & 78 & 13 & 100 & 9 & 27 & 2 \\
\hline Cheumatopsyche & 150 & 15 & 110 & 6 & 83 & 10 & 270 & 18 & 77 & 13 & 10 & $<1$ & 36 & 3 \\
\hline Hydropsyche & 89 & 9 & 250 & 15 & 120 & 14 & 220 & 15 & 35 & 6 & 69 & 6 & 71 & 5 \\
\hline Potamyia & - & & 47 & 3 & 1 & $<1$ & - & & - & & - & & - & \\
\hline Hydroptilidae & & & & & & & & & & & & & & \\
\hline Hydroptila & - & & 18 & 1 & 2 & $<1$ & 3 & $<1$ & 2 & $<1$ & 7 & $<1$ & 39 & 3 \\
\hline Leucotrichia & 150 & 15 & 390 & 23 & 340 & 40 & 53 & 4 & 120 & 20 & 65 & 6 & 120 & 9 \\
\hline Leptoceridae & & & & & & & & & & & & & & \\
\hline Ceraclea & - & & - & & - & & - & & - & & - & & - & \\
\hline Oecetis & - & & - & & - & & - & & - & & - & & - & \\
\hline Philopotamidae & & & & & & & & & & & & & & \\
\hline Chimarra & 5 & $<1$ & 4 & $<1$ & 20 & 2 & 10 & $<1$ & 8 & 1 & 130 & 12 & 110 & 8 \\
\hline Wormaldia & - & & - & & - & & - & & - & & - & & - & \\
\hline Polycentropodidae & & & & & & & & & & & & & & \\
\hline Polycentropus & - & & - & & - & & - & & - & & 3 & $<1$ & - & \\
\hline Psychomyiidae & & & & & & & & & & & & & & \\
\hline $\begin{array}{l}\text { Psychomyia } \\
\text { Uenoidae }\end{array}$ & - & & - & & - & & 18 & 1 & 1 & $<1$ & - & & 6 & $<1$ \\
\hline Neophylax & - & & - & & - & & - & & - & & - & & - & \\
\hline Coleoptera & & & & & & & & & & & & & & \\
\hline Curculionidae & - & & - & & 1 & $<1$ & - & & - & & - & & - & \\
\hline Dytiscidae & - & & - & & - & & - & & - & & - & & - & \\
\hline Elmidae & & & & & & & & & & & & & & \\
\hline Ancyronyx & - & & - & & - & & - & & - & & - & & - & \\
\hline Dubiraphia & - & & - & & 1 & $<1$ & - & & - & & 1 & $<1$ & 1 & $<1$ \\
\hline Optioservus & - & & - & & - & & 2 & $<1$ & 1 & $<1$ & 1 & $<1$ & 1 & $<1$ \\
\hline Oulimnius & - & & - & & - & & - & & - & & - & & - & \\
\hline Stenelmis & 20 & 2 & 26 & 2 & 9 & 1 & 18 & 1 & 6 & 1 & 2 & $<1$ & 3 & $<1$ \\
\hline
\end{tabular}




\begin{tabular}{|c|c|c|c|c|c|c|c|c|c|c|c|c|c|c|}
\hline \multirow{2}{*}{\multicolumn{2}{|c|}{$\begin{array}{c}\text { Nov. } 9,1988 \\
11,953\end{array}$}} & \multirow{2}{*}{\multicolumn{2}{|c|}{$\begin{array}{c}\text { Oct. } 27,1989 \\
2,083\end{array}$}} & \multicolumn{2}{|c|}{ Oct. 18,1990} & \multicolumn{2}{|c|}{ Oct. 24, 1991} & \multicolumn{2}{|c|}{ Nov. 9,1992} & \multicolumn{2}{|c|}{ Oct. 19,1993} & \multicolumn{2}{|c|}{ Nov. 21, 1994} & \multirow{3}{*}{$\begin{array}{c}\text { Date } \\
\text { Total count } \\
\text { Organism }\end{array}$} \\
\hline & & & & & 419 & $\overline{1,4}$ & 476 & & 268 & & 58 & & 194 & \\
\hline Count & Percent & Count & Percent & Count & Percent & Count & Percent & Count & Percent & Count & Percent & Count & Percent & \\
\hline & & & & & & & & & & & & & & Odonata \\
\hline & & & & & & & & & & & & & & Coenagrionidae \\
\hline- & & 1 & $<1$ & - & & - & & - & & - & & - & & Argia \\
\hline & & & & & & & & & & & & & & Plecoptera \\
\hline- & & - & & - & & - & & - & & - & & 1 & $<1$ & $\begin{array}{l}\text { Chloroperlidae } \\
\text { Taeniopterygidae }\end{array}$ \\
\hline- & & - & & 1 & $<1$ & - & & - & & - & & 2 & $<1$ & $\begin{array}{l}\text { Taeniopteryx } \\
\text { Hemiptera }\end{array}$ \\
\hline- & & - & & - & & - & & - & & - & & - & & $\begin{array}{l}\text { Saldidae } \\
\text { Megaloptera } \\
\text { Corydalidae }\end{array}$ \\
\hline- & & - & & - & & - & & - & & 1 & $<1$ & - & & Corydalus \\
\hline- & & 2 & $<1$ & - & & - & & - & & - & & - & & $\begin{array}{l}\text { Nigronia } \\
\text { Sialidae }\end{array}$ \\
\hline- & & - & & 1 & $<1$ & - & & - & & 1 & $<1$ & - & & $\begin{array}{c}\text { Sialis } \\
\text { Neuroptera } \\
\text { Sisyridae } \\
\text { Climacia }\end{array}$ \\
\hline- & & - & & - & & - & & - & & - & & - & & $\begin{array}{l}\text { C. areolaris } \\
\text { Trichoptera } \\
\text { Apataniidae }\end{array}$ \\
\hline- & & - & & - & & - & & - & & - & & - & & $\begin{array}{c}\text { Apatania } \\
\text { Brachycentridae }\end{array}$ \\
\hline- & & - & & - & & - & & 5 & $<1$ & 1 & $<1$ & 3 & $<1$ & $\begin{array}{c}\text { Micrasema } \\
\text { Glossosomatidae }\end{array}$ \\
\hline- & & - & & - & & 1 & $<1$ & - & & - & & - & & $\begin{array}{c}\text { Glossosoma } \\
\text { Hydropsychidae }\end{array}$ \\
\hline 37 & 2 & 84 & 4 & 59 & 4 & 9 & $<1$ & - & & 14 & 3 & 55 & 3 & Ceratopsyche \\
\hline 16 & $<1$ & 75 & 4 & 14 & $<1$ & 28 & 2 & 12 & $<1$ & 22 & 4 & 120 & 5 & Cheumatopsyche \\
\hline 210 & 11 & 290 & 14 & 100 & 7 & 110 & 7 & 200 & 15 & 84 & 15 & 100 & 5 & Hydropsyche \\
\hline- & & - & & - & & - & & - & & - & & - & & $\begin{array}{c}\text { Potamyia } \\
\text { Hydroptilidae }\end{array}$ \\
\hline 29 & 1 & 14 & $<1$ & 5 & $<1$ & 8 & $<1$ & 6 & $<1$ & - & & 20 & $<1$ & Hydroptila \\
\hline 310 & 16 & 230 & 11 & 170 & 12 & 210 & 14 & 2 & $<1$ & 3 & $<1$ & 13 & $<1$ & $\begin{array}{l}\text { Leucotrichia } \\
\text { Leptoceridae }\end{array}$ \\
\hline- & & - & & - & & - & & 2 & $<1$ & - & & - & & Ceraclea \\
\hline- & & - & & - & & 1 & $<1$ & - & & - & & - & & $\begin{array}{c}\text { Oecetis } \\
\text { Philopotamidae }\end{array}$ \\
\hline 260 & 13 & 180 & 9 & 170 & 12 & 85 & 6 & 19 & 1 & 54 & 10 & 81 & 4 & Chimarra \\
\hline- & & - & & 1 & $<1$ & - & & - & & - & & - & & $\begin{array}{c}\text { Wormaldia } \\
\text { Polycentropodidae }\end{array}$ \\
\hline- & & 1 & $<1$ & 3 & $<1$ & - & & - & & 1 & $<1$ & - & & $\begin{array}{l}\text { Polycentropus } \\
\text { Psychomyiidae }\end{array}$ \\
\hline- & & 4 & $<1$ & 2 & $<1$ & 1 & $<1$ & - & & - & & - & & $\begin{array}{l}\text { Psychomyia } \\
\text { Uenoidae }\end{array}$ \\
\hline- & & - & & - & & - & & - & & - & & 1 & $<1$ & $\begin{array}{l}\text { Neophylax } \\
\text { Coleoptera }\end{array}$ \\
\hline- & & - & & - & & - & & - & & - & & - & & Curculionidae \\
\hline- & & - & & 1 & $<1$ & - & & - & & - & & - & & $\begin{array}{l}\text { Dytiscidae } \\
\text { Elmidae }\end{array}$ \\
\hline- & & 1 & $<1$ & - & & - & & - & & - & & - & & Ancyronyx \\
\hline 3 & $<1$ & - & & - & & - & & 5 & $<1$ & - & & - & & Dubiraphia \\
\hline- & & 1 & $<1$ & 1 & $<1$ & 1 & $<1$ & - & & - & & 3 & $<1$ & Optioservus \\
\hline- & & 1 & $<1$ & - & & - & & 3 & $<1$ & - & & - & & Oulimnius \\
\hline 35 & 2 & 30 & 1 & 25 & 2 & 20 & 1 & 21 & 2 & 26 & 5 & 9 & $<1$ & Stenelmis \\
\hline
\end{tabular}


Table 5. Benthic-macroinvertebrate data-Continued

01578340 - East Branch Octoraro Creek at Christiana, Pa. (Site 33)—Continued

\begin{tabular}{|c|c|c|c|c|c|c|c|c|c|c|c|c|c|c|}
\hline \multirow{3}{*}{$\begin{array}{c}\text { Date } \\
\text { Total count } \\
\text { Organism }\end{array}$} & \multirow{2}{*}{\multicolumn{2}{|c|}{$\frac{\text { Nov. 3, } 1981}{978}$}} & \multicolumn{2}{|c|}{ Oct. 27, 1982} & \multicolumn{2}{|c|}{ Oct. 28,1983} & \multicolumn{2}{|c|}{ Oct. 26, 1984} & \multicolumn{2}{|c|}{ Oct. 24, 1985} & \multicolumn{2}{|c|}{ Nov. 20, 1986} & \multicolumn{2}{|c|}{ Nov. 18, 1987} \\
\hline & & & \multicolumn{2}{|c|}{1,670} & \multicolumn{2}{|c|}{856} & \multicolumn{2}{|c|}{1,518} & \multicolumn{2}{|c|}{593} & \multicolumn{2}{|c|}{1,110} & \multicolumn{2}{|c|}{1,421} \\
\hline & Count & Percent & Count & Percent & Count & Percent & Count & Percent & Count & Percent & Count & Percent & Count & Percent \\
\hline \multicolumn{15}{|l|}{ Coleoptera } \\
\hline \multicolumn{15}{|l|}{ Psephenidae } \\
\hline Psephenus & 2 & $<1$ & 4 & $<1$ & 11 & 1 & - & & 2 & $<1$ & 3 & $<1$ & 6 & $<1$ \\
\hline \multicolumn{15}{|l|}{ Diptera } \\
\hline \multicolumn{14}{|l|}{ Empididae } & 24 \\
\hline \multicolumn{14}{|l|}{ Simuliidae } & $<1$ \\
\hline Simulium & 6 & $<1$ & 30 & 2 & 1 & $<1$ & 240 & 16 & - & & 18 & 2 & 44 & 3 \\
\hline \multicolumn{15}{|l|}{ Stratiomyidae } \\
\hline Stratiomys & - & & - & & - & & - & & - & & - & & - & \\
\hline \multicolumn{15}{|l|}{ Tipulidae } \\
\hline Antocha & 15 & 2 & 37 & 2 & 8 & $<1$ & 49 & 3 & 4 & $<1$ & 35 & 3 & 30 & 2 \\
\hline Dicranota & 一 & & 一 & & 一 & & - & & 一 & & 一 & & - & \\
\hline
\end{tabular}

${ }^{1}$ Extrapolated from a 3/8 subsample. 


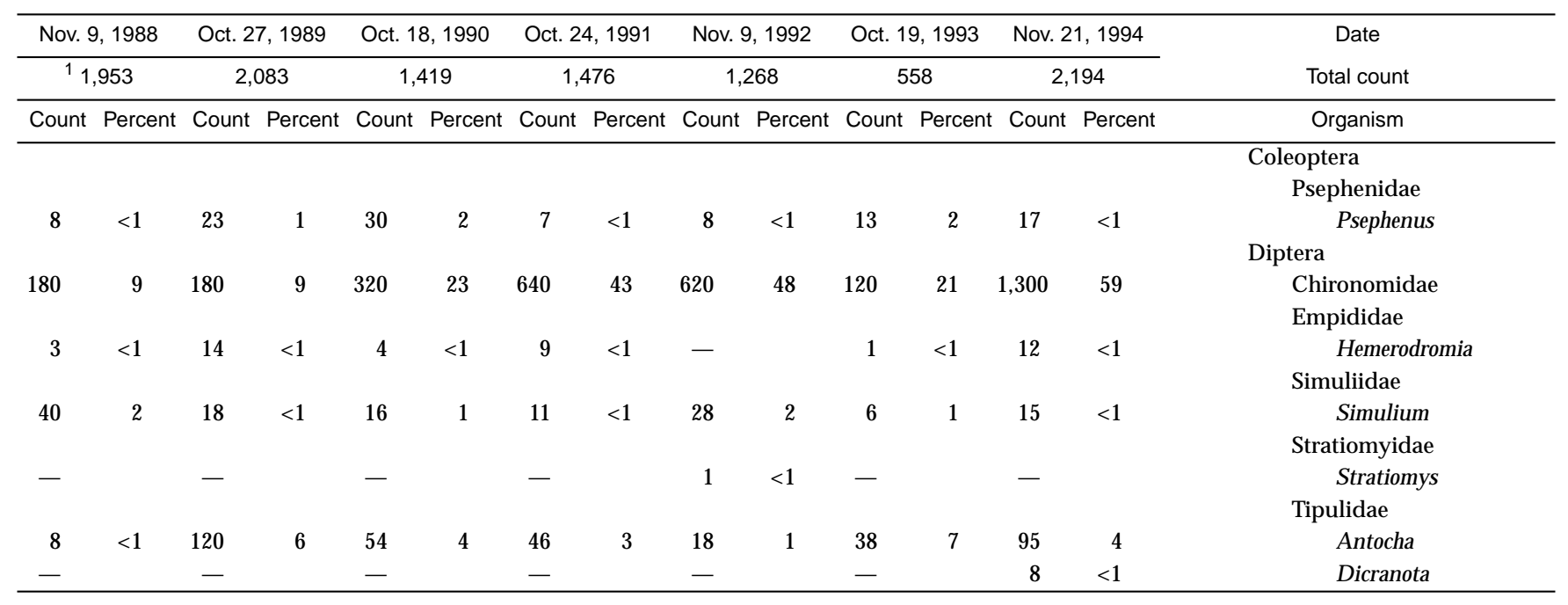


Table 5. Benthic-macroinvertebrate data-Continued

$[<$, less than; - , not found]

01578343 - Valley Creek at Atglen, Pa. (Site 34)

\begin{tabular}{|c|c|c|c|c|c|c|c|c|c|c|c|c|c|c|}
\hline \multirow{3}{*}{$\begin{array}{cc}\text { Date } \\
\text { Total count } \\
\text { Organism }\end{array}$} & \multirow{2}{*}{\multicolumn{2}{|c|}{$\frac{\text { Nov. } 3,1981}{2,173}$}} & \multirow{2}{*}{\multicolumn{2}{|c|}{$\frac{\text { Oct. } 27,1982}{2,478}$}} & \multirow{2}{*}{\multicolumn{2}{|c|}{$\frac{\text { Oct. } 28,1983}{930}$}} & \multirow{2}{*}{\multicolumn{2}{|c|}{$\begin{array}{c}\text { Oct. } 26,1984 \\
2,239\end{array}$}} & \multirow{2}{*}{\multicolumn{2}{|c|}{$\frac{\text { Oct. } 24,1985}{962}$}} & \multirow{2}{*}{\multicolumn{2}{|c|}{$\frac{\text { Nov. } 20,1986}{783}$}} & \multirow{2}{*}{\multicolumn{2}{|c|}{$\frac{\text { Nov. } 18,1987}{2,316}$}} \\
\hline & & & & & & & & & & & & & & \\
\hline & Count & Percent & Count & Percent & Count & Percent & Count & Percent & Count & Percent & Count & Percent & Count & Percent \\
\hline \multicolumn{15}{|l|}{ Platyhelminthes (flatworms) } \\
\hline \multicolumn{15}{|l|}{ Turbellaria } \\
\hline \multicolumn{15}{|l|}{ Tricladida } \\
\hline Planariidae & - & & 1 & $<1$ & - & & - & & 1 & $<1$ & - & & 7 & $<1$ \\
\hline Nematoda (nematodes) & 1 & $<1$ & 1 & $<1$ & - & & - & & - & & - & & 1 & $<1$ \\
\hline \multicolumn{15}{|l|}{ Nemertea (proboscis worms) } \\
\hline \multicolumn{15}{|l|}{ Enopla } \\
\hline Hoplonemertea & & & & & & & & & & & & & & \\
\hline Tetrastemmatida & & & & & & & & & & & & & & \\
\hline Prostoma & - & & - & & - & & - & & 1 & $<1$ & - & & - & \\
\hline Mollusca (molluscs) & & & & & & & & & & & & & & \\
\hline Gastropoda & & & & & & & & & & & & & & \\
\hline Basommatophora & & & & & & & & & & & & & & \\
\hline Ancylidae & & & & & & & & & & & & & & \\
\hline Ferrissia & 32 & 1 & 48 & 2 & 14 & 1 & - & & - & & - & & 1 & $<1$ \\
\hline Physidae & & & & & & & & & & & & & & \\
\hline Physa & 1 & $<1$ & 1 & $<1$ & - & & - & & - & & - & & - & \\
\hline Planorbidae & & & & & & & & & & & & & & \\
\hline Gyraulus & - & & - & & - & & - & & - & & - & & - & \\
\hline Bivalvia & & & & & & & & & & & & & & \\
\hline Veneroida & & & & & & & & & & & & & & \\
\hline Sphaeriidae & - & & - & & - & & - & & - & & - & & 1 & $<1$ \\
\hline Annelida (segmented worms) & & & & & & & & & & & & & & \\
\hline Oligochaeta & & & & & & & & & & & & & & \\
\hline Lumbriculida & & & & & & & & & & & & & & \\
\hline Lumbriculidae & - & & - & & - & & 1 & $<1$ & - & & - & & - & \\
\hline Tubificida & & & & & & & & & & & & & & \\
\hline Naididae & 68 & 3 & 45 & 2 & 10 & 1 & 48 & 2 & 2 & $<1$ & - & & 470 & 20 \\
\hline Tubificidae & - & & 4 & $<1$ & - & & - & & - & & - & & 3 & $<1$ \\
\hline Hirudinea & & & & & & & & & & & & & & \\
\hline Pharynobdellidae & & & & & & & & & & & & & & \\
\hline Erpobdellidae & - & & - & & - & & 1 & $<1$ & - & & - & & - & \\
\hline Arthropoda (arthropods) & & & & & & & & & & & & & & \\
\hline Acariformes & & & & & & & & & & & & & & \\
\hline Hydrachnidia & - & & - & & - & & - & & - & & - & & 56 & 2 \\
\hline Crustacea & & & & & & & & & & & & & & \\
\hline Amphipoda & & & & & & & & & & & & & & \\
\hline Gammaridae & & & & & & & & & & & & & & \\
\hline Gammarus & - & & 1 & $<1$ & - & & - & & 1 & $<1$ & 2 & $<1$ & - & \\
\hline Isopoda & & & & & & & & & & & & & & \\
\hline Asellidae & & & & & & & & & & & & & & \\
\hline Caecidotea & - & & 1 & $<1$ & 8 & $<1$ & 1 & $<1$ & 1 & $<1$ & 4 & $<1$ & 8 & $<1$ \\
\hline Podocopa & - & & - & & - & & - & & - & & - & & 3 & $<1$ \\
\hline Insecta & & & & & & & & & & & & & & \\
\hline Ephemeroptera & & & & & & & & & & & & & & \\
\hline Baetidae & & & & & & & & & & & & & & \\
\hline Baetis & 3 & $<1$ & - & & - & & 5 & $<1$ & 17 & 2 & 4 & $<1$ & - & \\
\hline Pseudocloeon & 1 & $<1$ & 4 & $<1$ & - & & 6 & $<1$ & 2 & $<1$ & 1 & $<1$ & 19 & $<1$ \\
\hline Ephemerellidae & & & & & & & & & & & & & & \\
\hline Ephemerella & 3 & $<1$ & 6 & $<1$ & 4 & $<1$ & 16 & $<1$ & 10 & 1 & 3 & $<1$ & 140 & 6 \\
\hline Heptageniidae & & & & & & & & & & & & & & \\
\hline Stenonema & 170 & 8 & 190 & 8 & 13 & 1 & 110 & 5 & 21 & 2 & 2 & $<1$ & 54 & 2 \\
\hline Isonychiidae & & & & & & & & & & & & & & \\
\hline Isonychia & 9 & $<1$ & 24 & $<1$ & 2 & $<1$ & 15 & $<1$ & 7 & $<1$ & 4 & $<1$ & 34 & 1 \\
\hline
\end{tabular}




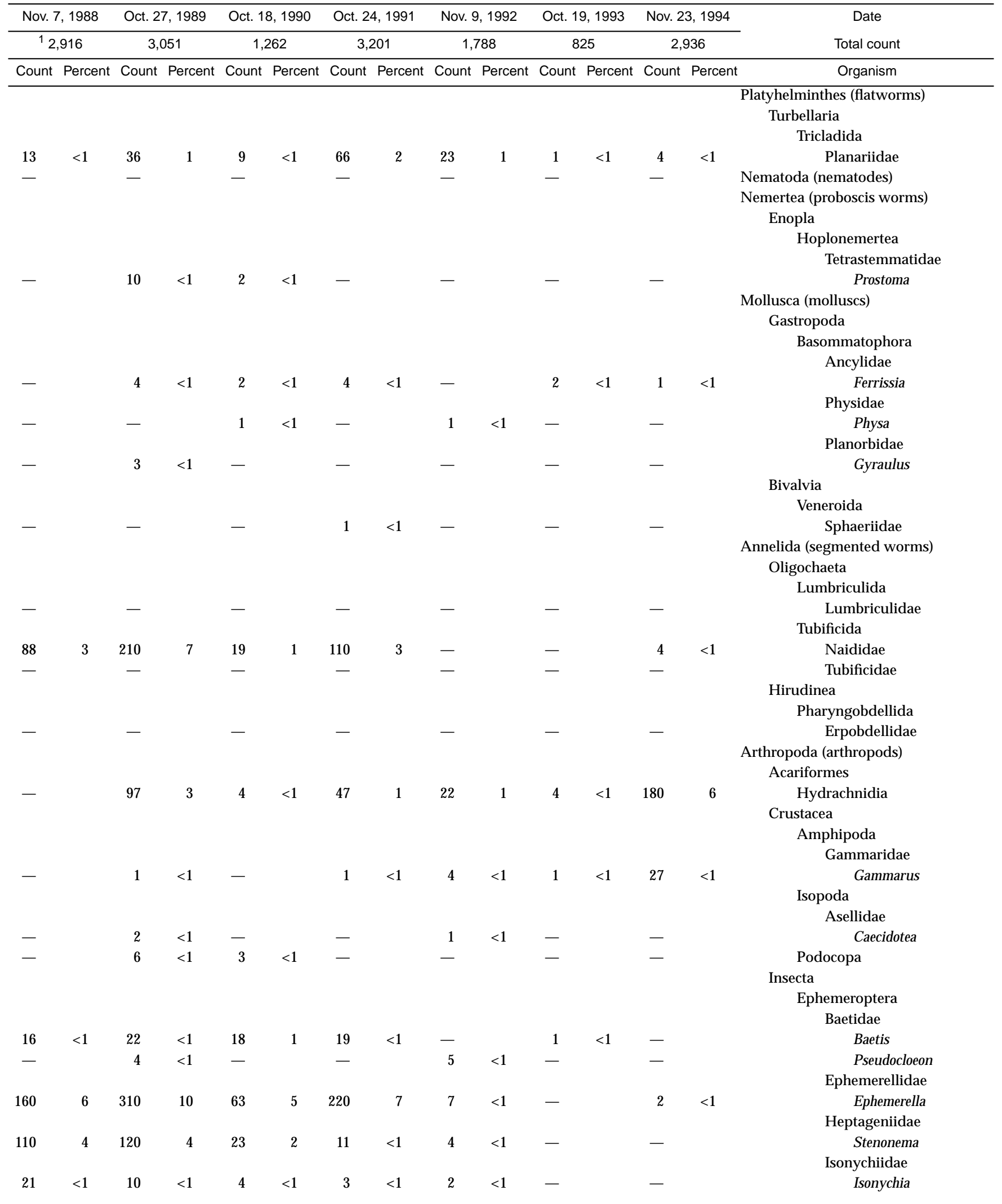


Table 5. Benthic-macroinvertebrate data-Continued

01578343 - Valley Creek at Atglen, Pa. (Site 34)—Continued

\begin{tabular}{|c|c|c|c|c|c|c|c|c|c|c|c|c|c|c|}
\hline \multirow{3}{*}{$\begin{array}{c}\text { Date } \\
\text { Total count } \\
\text { Organism }\end{array}$} & \multirow{2}{*}{\multicolumn{2}{|c|}{$\begin{array}{c}\text { Nov. } 3,1981 \\
2,173\end{array}$}} & \multirow{2}{*}{\multicolumn{2}{|c|}{$\begin{array}{c}\text { Oct. } 27,1982 \\
2,478\end{array}$}} & \multirow{2}{*}{\multicolumn{2}{|c|}{$\begin{array}{c}\text { Oct. 28, } 1983 \\
930\end{array}$}} & \multirow{2}{*}{\multicolumn{2}{|c|}{$\begin{array}{c}\text { Oct. } 26,1984 \\
2,239\end{array}$}} & \multirow{2}{*}{\multicolumn{2}{|c|}{$\frac{\text { Oct. } 24,1985}{962}$}} & \multirow{2}{*}{\multicolumn{2}{|c|}{$\begin{array}{c}\text { Nov. } 20,1986 \\
783\end{array}$}} & \multirow{2}{*}{\multicolumn{2}{|c|}{$\begin{array}{c}\text { Nov. } 18,1987 \\
2,316\end{array}$}} \\
\hline & & & & & & & & & & & & & & \\
\hline & Count & Percent & Count & Percent & Count & Percent & Count & Percent & Count & Percent & Count & Percent & Count & Percent \\
\hline \multicolumn{15}{|l|}{ Ephemeroptera } \\
\hline \multicolumn{15}{|l|}{ Leptohyphidae } \\
\hline Tricorythodes & - & & - & & - & & - & & - & & - & & 4 & $<1$ \\
\hline Leptophlebiidae & - & & - & & - & & - & & - & & - & & - & \\
\hline Paraleptophlebia & - & & - & & - & & - & & 1 & $<1$ & - & & - & \\
\hline \multicolumn{15}{|l|}{ Potamanthidae } \\
\hline Anthopotamus & - & & 4 & $<1$ & - & & - & & - & & - & & - & \\
\hline \multicolumn{15}{|l|}{ Plecoptera } \\
\hline \multicolumn{15}{|l|}{ Capniidae } \\
\hline Allocapnia & - & & - & & 2 & $<1$ & 3 & $<1$ & - & & - & & 1 & $<1$ \\
\hline \multicolumn{15}{|l|}{ Taeniopterygidae } \\
\hline Taeniopteryx & - & & - & & 1 & $<1$ & 3 & $<1$ & 2 & $<1$ & - & & - & \\
\hline \multicolumn{15}{|l|}{ Megaloptera } \\
\hline Corydalidae & & & & & & & & & & & & & & \\
\hline Corydalus & 2 & $<1$ & - & & - & & - & & - & & - & & - & \\
\hline Sialidae & & & & & & & & & & & & & & \\
\hline Sialis & - & & 1 & $<1$ & - & & 1 & $<1$ & - & & - & & - & \\
\hline Trichoptera & & & & & & & & & & & & & & \\
\hline Apataniidae & & & & & & & & & & & & & & \\
\hline Apatania & - & & - & & - & & - & & - & & - & & 2 & $<1$ \\
\hline Glossosomatidae & & & & & & & & & & & & & & \\
\hline Glossosoma & - & & 1 & $<1$ & - & & - & & 5 & $<1$ & 9 & 1 & 1 & $<1$ \\
\hline Hydropsychidae & & & & & & & & & & & & & & \\
\hline Ceratopsyche & 310 & 14 & 370 & 15 & 87 & 9 & 240 & 11 & 180 & 19 & 71 & 9 & 79 & 3 \\
\hline Cheumatopsyche & 460 & 21 & 450 & 18 & 100 & 11 & 210 & 10 & 100 & 10 & 16 & 2 & 140 & 6 \\
\hline Hydropsyche & 300 & 14 & 300 & 12 & 130 & 14 & 96 & 4 & 40 & 4 & 120 & 15 & 200 & 9 \\
\hline Potamyia & - & & - & & 7 & $<1$ & 1 & $<1$ & - & & - & & - & \\
\hline Hydroptilidae & & & & & & & & & & & & & & \\
\hline Hydroptila & - & & 7 & $<1$ & - & & - & & 1 & $<1$ & 1 & $<1$ & 4 & $<1$ \\
\hline Leucotrichia & 90 & 4 & 100 & 4 & 300 & 32 & 170 & 8 & 250 & 26 & 73 & 9 & 230 & 10 \\
\hline Leptoceridae & & & & & & & & & & & & & & \\
\hline Mystacides & - & & - & & - & & - & & - & & - & & - & \\
\hline Philopotamidae & & & & & & & & & & & & & & \\
\hline Chimarra & 1 & $<1$ & 4 & $<1$ & 4 & $<1$ & 6 & $<1$ & 32 & 3 & 53 & 7 & 55 & 2 \\
\hline Dolophilodes & - & & - & & - & & 3 & $<1$ & - & & - & & - & \\
\hline Polycentropodidae & & & & & & & & & & & & & & \\
\hline Polycentropus & - & & 5 & $<1$ & 2 & $<1$ & - & & - & & - & & - & \\
\hline Psychomyiidae & & & & & & & & & & & & & & \\
\hline Psychomyia & 2 & $<1$ & 46 & 2 & 17 & 2 & 2 & $<1$ & 21 & 2 & 12 & 2 & 110 & 5 \\
\hline Coleoptera & & & & & & & & & & & & & & \\
\hline Elmidae & & & & & & & & & & & & & & \\
\hline Ancyronyx & - & & 1 & $<1$ & 1 & $<1$ & - & & - & & - & & - & \\
\hline Dubiraphia & - & & 1 & $<1$ & - & & 1 & $<1$ & - & & - & & - & \\
\hline Microcylloepus & - & & - & & - & & - & & - & & - & & - & \\
\hline Optioservus & - & & - & & 1 & $<1$ & 4 & $<1$ & 1 & $<1$ & 1 & $<1$ & 1 & $<1$ \\
\hline Oulimnius & - & & - & & - & & - & & 2 & $<1$ & - & & - & \\
\hline Stenelmis & 44 & 2 & 130 & 5 & 10 & 1 & 16 & $<1$ & 16 & 2 & 18 & 2 & 20 & $<1$ \\
\hline Hydrophilidae & & & & & & & & & & & & & & \\
\hline Helophorus & - & & - & & - & & 1 & $<1$ & - & & - & & - & \\
\hline Psephenidae & & & & & & & & & & & & & & \\
\hline Psephenus & - & & 1 & $<1$ & 2 & $<1$ & - & & 1 & $<1$ & 2 & $<1$ & 1 & $<1$ \\
\hline
\end{tabular}




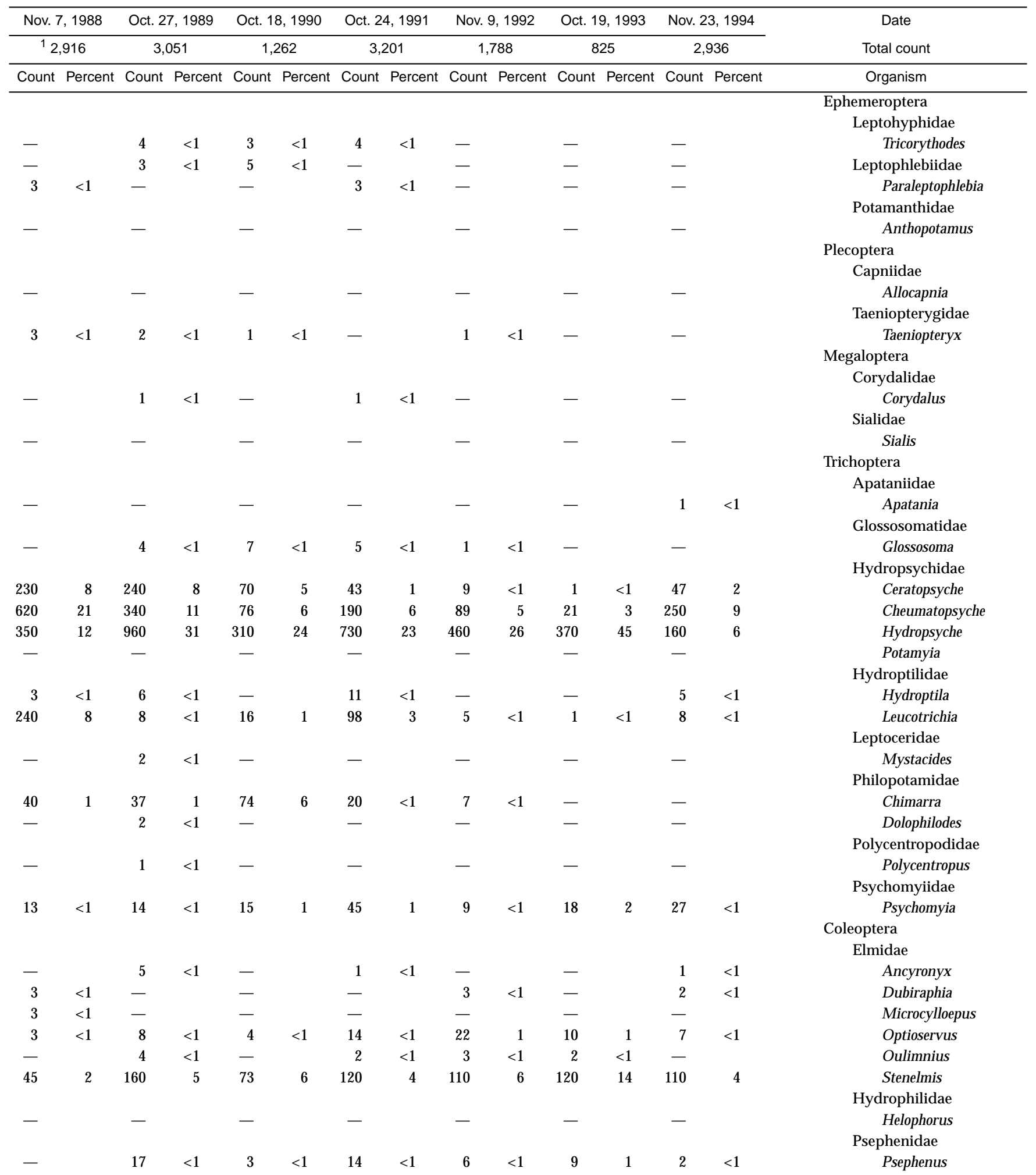


Table 5. Benthic-macroinvertebrate data-Continued

01578343 - Valley Creek at Atglen, Pa. (Site 34)—Continued

\begin{tabular}{|c|c|c|c|c|c|c|c|c|c|c|c|c|c|c|}
\hline Date & \multicolumn{2}{|c|}{ Nov. 3, 1981} & \multicolumn{2}{|c|}{ Oct. 27, 1982} & \multicolumn{2}{|c|}{ Oct. 28, 1983} & \multicolumn{2}{|c|}{ Oct. 26, 1984} & \multicolumn{2}{|c|}{ Oct. 24,1985} & \multicolumn{2}{|c|}{ Nov. 20, 1986} & \multicolumn{2}{|c|}{ Nov. 18,1987} \\
\hline Total count & \multicolumn{2}{|c|}{2,173} & \multicolumn{2}{|c|}{2,478} & \multicolumn{2}{|c|}{930} & \multicolumn{2}{|c|}{2,239} & \multicolumn{2}{|c|}{962} & \multicolumn{2}{|c|}{783} & \multicolumn{2}{|c|}{2,316} \\
\hline Organism & Count & Percent & Count & Percent & Count & Percent & Count & Percent & Count & Percent & Count & Percent & Count & Percent \\
\hline \multicolumn{15}{|l|}{ Diptera } \\
\hline Chironomidae & 370 & 17 & 450 & 18 & 130 & 14 & 640 & 29 & 170 & 18 & 210 & 27 & 440 & 19 \\
\hline \multicolumn{15}{|l|}{ Empididae } \\
\hline Hemerodromia & 14 & $<1$ & 9 & $<1$ & - & & 7 & $<1$ & 2 & $<1$ & 1 & $<1$ & 2 & $<1$ \\
\hline \multicolumn{15}{|l|}{ Simuliidae } \\
\hline Simulium & 250 & 11 & 91 & 4 & 3 & $<1$ & 600 & 27 & 8 & $<1$ & 85 & 11 & 170 & 7 \\
\hline Stratiomyidae & - & & - & & - & & 1 & $<1$ & - & & - & & - & \\
\hline \multicolumn{15}{|l|}{ Tipulidae } \\
\hline Antocha & 42 & 2 & 180 & 7 & 82 & 9 & 30 & 1 & 67 & 7 & 87 & 11 & 59 & 3 \\
\hline Dicranota & - & & - & & - & & - & & - & & 4 & $<1$ & - & \\
\hline Hexatoma & - & & 1 & $<1$ & - & & - & & - & & - & & - & \\
\hline Tipula & - & & - & & - & & 1 & $<1$ & - & & - & & - & \\
\hline
\end{tabular}

${ }^{1}$ Extrapolated from a 3/8 subsample. 


\begin{tabular}{|c|c|c|c|c|c|c|c|c|c|c|c|c|c|c|}
\hline \multicolumn{2}{|c|}{ Nov. 7, 1988} & \multicolumn{2}{|c|}{ Oct. 27,1989} & \multicolumn{2}{|c|}{ Oct. 18,1990} & \multicolumn{2}{|c|}{ Oct. 24,1991} & \multicolumn{2}{|c|}{ Nov. 9, 1992} & \multicolumn{2}{|c|}{ Oct. 19,1993} & \multicolumn{2}{|c|}{ Nov. 23, 1994} & \multirow{2}{*}{$\begin{array}{c}\text { Date } \\
\text { Total count }\end{array}$} \\
\hline \multicolumn{2}{|c|}{${ }^{1} 2,916$} & \multicolumn{2}{|c|}{3,051} & \multicolumn{2}{|c|}{1,262} & \multicolumn{2}{|c|}{3,201} & \multicolumn{2}{|c|}{1,788} & \multicolumn{2}{|c|}{825} & \multicolumn{2}{|c|}{2,936} & \\
\hline Count & Percent & Count & Percent & Count & Percent & Count & Percent & Count & Percent & Count & Percent & Count & Percent & Organism \\
\hline & & & & & & & & & & & & & & tera \\
\hline 520 & 18 & 210 & 7 & 330 & 25 & 1,200 & 38 & 190 & 11 & 150 & 18 & 1,500 & 52 & $\begin{array}{l}\text { Chironomidae } \\
\text { Empididae }\end{array}$ \\
\hline 5 & $<1$ & 46 & 1 & - & & 15 & $<1$ & 3 & $<1$ & 2 & $<1$ & 12 & $<1$ & $\begin{array}{l}\text { Hemerodromia } \\
\text { Simuliidae }\end{array}$ \\
\hline 400 & 14 & 42 & 1 & 53 & 4 & 12 & $<1$ & 680 & 38 & 2 & $<1$ & 260 & 9 & Simulium \\
\hline - & & - & & - & & - & & - & & - & & - & & $\begin{array}{l}\text { Stratiomyidae } \\
\text { Tipulidae }\end{array}$ \\
\hline 24 & $<1$ & 99 & 3 & 73 & 6 & 180 & 6 & 120 & 7 & 110 & 13 & 320 & 11 & Antocha \\
\hline 3 & $<1$ & - & & - & & 10 & $<1$ & - & & - & & 6 & $<1$ & Dicranota \\
\hline- & & 1 & $<1$ & 1 & $<1$ & 1 & $<1$ & 1 & $<1$ & - & & - & & Hexatoma \\
\hline - & & - & & - & & - & & - & & - & & - & & Tipula \\
\hline
\end{tabular}


Table 5. Benthic-macroinvertebrate data-Continued

$[<$, less than; - , not found $]$

01578345 - East Branch Octoraro Creek at Steelville, Pa. (Site 35)

\begin{tabular}{|c|c|c|c|c|}
\hline Date & Nov. 3 & 3,1981 & Oct. 27 & 7,1982 \\
\hline Total count & 1,0 & 041 & & 791 \\
\hline Organism & Count & Percent & Count & Percent \\
\hline Platyhelminthes (flatworms) & 4 & $<1$ & 1 & $<1$ \\
\hline Turbellaria & & & & \\
\hline Tricladida & & & & \\
\hline Planariidae & 3 & $<1$ & 4 & $<1$ \\
\hline Mollusca (molluscs) & & & & \\
\hline Gastropoda & & & & \\
\hline Basommatophora & & & & \\
\hline Ancylidae & & & & \\
\hline Ferrissia & 5 & $<1$ & 24 & 1 \\
\hline Lymnaeidae & & & & \\
\hline Lymnaea & 1 & $<1$ & - & \\
\hline Annelida (segmented worms) & & & & \\
\hline Oligochaeta & - & & 1 & $<1$ \\
\hline Tubificida & & & & \\
\hline Tubificidae & 1 & $<1$ & - & \\
\hline Arthropoda (arthropods) & & & & \\
\hline Acariformes & & & & \\
\hline Hydrachnidia & 58 & 6 & 32 & 2 \\
\hline Crustacea & & & & \\
\hline Isopoda & & & & \\
\hline Asellidae & & & & \\
\hline Caecidotea & 1 & $<1$ & 1 & $<1$ \\
\hline Insecta & & & & \\
\hline Ephemeroptera & & & & \\
\hline Baetidae & & & & \\
\hline Pseudocloeon & 1 & $<1$ & - & \\
\hline Ephemerellidae & & & & \\
\hline Ephemerella & 55 & 6 & 78 & 4 \\
\hline Heptageniidae & & & & \\
\hline Stenonema & 160 & 16 & 110 & 6 \\
\hline Isonychiidae & & & & \\
\hline Isonychia & - & & 10 & $<1$ \\
\hline Plecoptera & & & & \\
\hline Capniidae & & & & \\
\hline Allocapnia & - & & 2 & $<1$ \\
\hline Chloroperlidae & - & & 1 & $<1$ \\
\hline Taeniopterygidae & & & & \\
\hline Strophopteryx & 2 & $<1$ & - & \\
\hline Megaloptera & & & & \\
\hline Corydalidae & & & & \\
\hline Nigronia & - & & 2 & $<1$ \\
\hline Sialidae & & & & \\
\hline Sialis & 3 & $<1$ & - & \\
\hline Trichoptera & & & & \\
\hline Hydropsychidae & & & & \\
\hline Ceratopsyche & 180 & 18 & 220 & 12 \\
\hline Cheumatopsyche & 48 & 5 & 120 & 7 \\
\hline Hydropsyche & 21 & 2 & 35 & 2 \\
\hline Hydroptilidae & & & & \\
\hline Hydroptila & 12 & 1 & 20 & 1 \\
\hline Leucotrichia & 51 & 5 & 400 & 22 \\
\hline Philopotamidae & & & & \\
\hline Chimarra & 6 & $<1$ & 30 & 2 \\
\hline
\end{tabular}


01578345 - East Branch Octoraro Creek at Steelville, Pa. (Site 35)—Continued

\begin{tabular}{|c|c|c|c|c|}
\hline Date & \multicolumn{2}{|c|}{ Nov. 3, 1981} & \multicolumn{2}{|c|}{ Oct. 27, 1982} \\
\hline Total count & \multicolumn{2}{|c|}{1,041} & \multicolumn{2}{|c|}{1,791} \\
\hline Organism & Count & Percent & Count & Percent \\
\hline \multicolumn{5}{|l|}{ Coleoptera } \\
\hline Chrysomelidae & 1 & $<1$ & - & \\
\hline \multicolumn{5}{|l|}{ Elmidae } \\
\hline Dubiraphia & 1 & $<1$ & - & \\
\hline Optioservus & 2 & $<1$ & - & \\
\hline Oulimnius & - & & 1 & $<1$ \\
\hline Stenelmis & 14 & 1 & 3 & $<1$ \\
\hline \multicolumn{5}{|l|}{ Psephenidae } \\
\hline Psephenus & 5 & $<1$ & 1 & $<1$ \\
\hline \multicolumn{5}{|l|}{ Diptera } \\
\hline Chironomidae & 360 & 36 & 530 & 29 \\
\hline \multicolumn{5}{|l|}{ Empididae } \\
\hline Hemerodromia & 2 & $<1$ & 3 & $<1$ \\
\hline \multicolumn{5}{|l|}{ Simuliidae } \\
\hline Simulium & 14 & 1 & 2 & $<1$ \\
\hline \multicolumn{5}{|l|}{ Tipulidae } \\
\hline Antocha & 30 & 3 & 160 & 9 \\
\hline
\end{tabular}


Table 6. Brillouin's diversity index, maximum diversity, minimum diversity, and relative evenness by site $[-$, no data $]$

\section{PIGEON CREEK NEAR BUCKTOWN (SITE 8)}

\begin{tabular}{ccccccr}
\hline Year & $\begin{array}{c}\text { Total } \\
\text { number of } \\
\text { organisms }\end{array}$ & $\begin{array}{c}\text { Total } \\
\text { number } \\
\text { of taxa }\end{array}$ & $\begin{array}{c}\text { Brillouin's } \\
\text { diversity index } \\
(\mathrm{H})\end{array}$ & $\begin{array}{c}\text { Maximum } \\
\text { diversity } \\
\left(\mathrm{H}_{\text {max }}\right)\end{array}$ & $\begin{array}{c}\text { Minimum } \\
\text { diversity } \\
\left(\mathrm{H}_{\min }\right)\end{array}$ & $\begin{array}{c}\text { Evenness } \\
(\mathrm{E})\end{array}$ \\
\hline 1981 & 822 & 28 & 3.11 & 4.77 & 0.32 & 0.63 \\
1982 & 975 & 31 & 3.52 & 4.93 & .30 & .70 \\
\hline
\end{tabular}

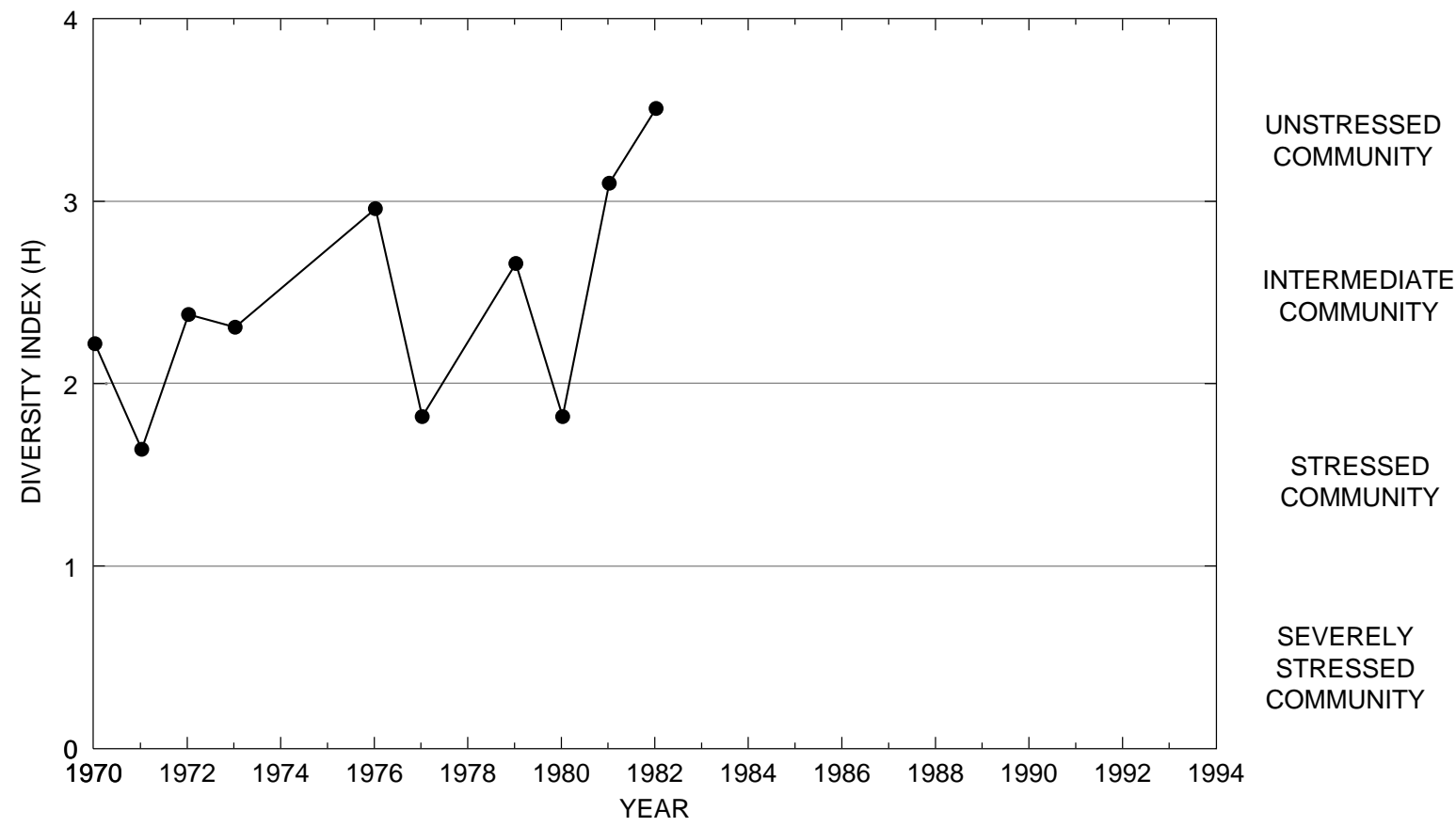


Table 6. Brillouin's diversity index, maximum diversity, minimum diversity, and relative evenness by site-Continued 01472065 PIGEON CREEK AT PORTERS MILL (SITE 9)

\begin{tabular}{ccccccr}
\hline Year & $\begin{array}{c}\text { Total } \\
\text { number of } \\
\text { organisms }\end{array}$ & $\begin{array}{c}\text { Total } \\
\text { number } \\
\text { of taxa }\end{array}$ & $\begin{array}{c}\text { Brillouin's } \\
\text { diversity index } \\
(\mathrm{H})\end{array}$ & $\begin{array}{c}\text { Maximum } \\
\text { diversity } \\
\left(\mathrm{H}_{\text {max }}\right)\end{array}$ & $\begin{array}{c}\text { Minimum } \\
\text { diversity } \\
\left(\mathrm{H}_{\min }\right)\end{array}$ & $\begin{array}{c}\text { Evenness } \\
(\mathrm{E})\end{array}$ \\
\hline 1981 & 482 & 23 & 3.03 & 4.57 & 0.41 & 0.63 \\
1982 & 918 & 24 & 3.30 & 5.50 & .25 & .72 \\
\hline
\end{tabular}

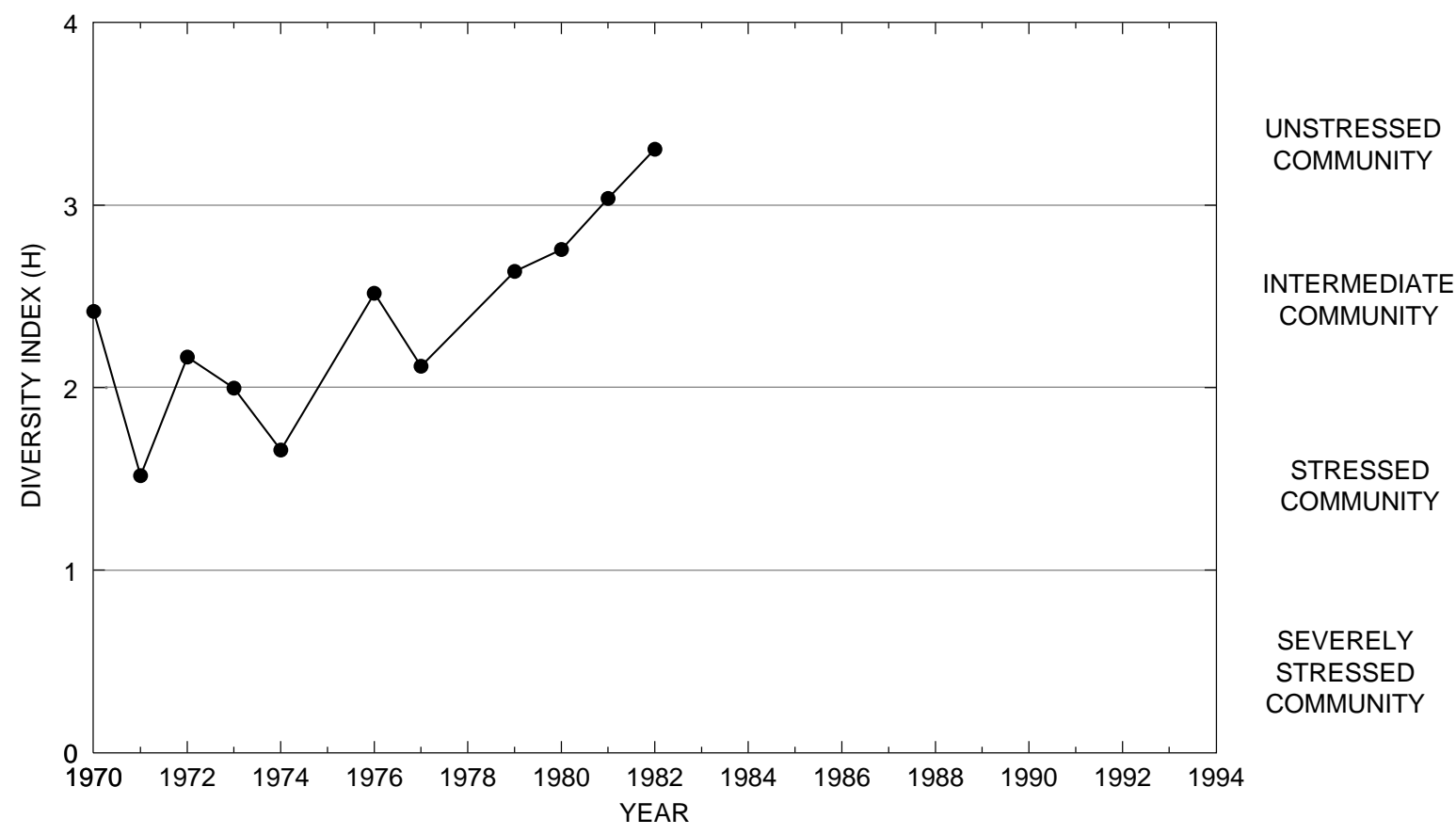


Table 6. Brillouin's diversity index, maximum diversity, minimum diversity, and relative evenness by site—Continued

01472080 PIGEON CREEK NEAR PARKER FORD (SITE 10)

\begin{tabular}{|c|c|c|c|c|c|c|}
\hline Year & $\begin{array}{c}\text { Total } \\
\text { number of } \\
\text { organisms }\end{array}$ & $\begin{array}{c}\text { Total } \\
\text { number } \\
\text { of taxa }\end{array}$ & $\begin{array}{c}\text { Brillouin's } \\
\text { diversity index } \\
\text { (H) }\end{array}$ & $\begin{array}{c}\text { Maximum } \\
\text { diversity } \\
\left(\mathrm{H}_{\max }\right)\end{array}$ & $\begin{array}{c}\text { Minimum } \\
\text { diversity } \\
\left(\mathrm{H}_{\min }\right)\end{array}$ & $\begin{array}{c}\text { Evenness } \\
\text { (E) }\end{array}$ \\
\hline 1981 & 2,785 & 33 & 3.07 & 5.03 & 0.13 & 0.60 \\
\hline 1982 & 1,691 & 30 & 3.39 & 4.86 & .18 & .69 \\
\hline 1983 & 969 & 24 & 3.20 & 4.56 & .23 & .69 \\
\hline 1984 & 1,492 & 29 & 3.50 & 4.83 & .20 & .71 \\
\hline 1985 & 1,032 & 21 & 2.82 & 4.33 & .19 & .63 \\
\hline 1986 & 1,133 & 24 & 3.35 & 4.59 & .21 & .72 \\
\hline 1987 & 2,098 & 39 & 3.86 & 5.29 & .20 & .72 \\
\hline 1988 & ${ }^{1} 2,397$ & 31 & 3.57 & 4.93 & .14 & .71 \\
\hline 1989 & 2,270 & 40 & 3.81 & 5.32 & .19 & .71 \\
\hline 1990 & 1,947 & 32 & 3.68 & 4.95 & .17 & .73 \\
\hline 1991 & 1,705 & 34 & 3.34 & 5.06 & .21 & .65 \\
\hline 1992 & 440 & 30 & 3.08 & 4.90 & .57 & .58 \\
\hline 1993 & 1,161 & 35 & 3.42 & 5.03 & .30 & .66 \\
\hline 1994 & 1,599 & 41 & 3.33 & 5.28 & .26 & .61 \\
\hline
\end{tabular}

${ }^{1}$ Extrapolated from a $3 / 8$ subsample.

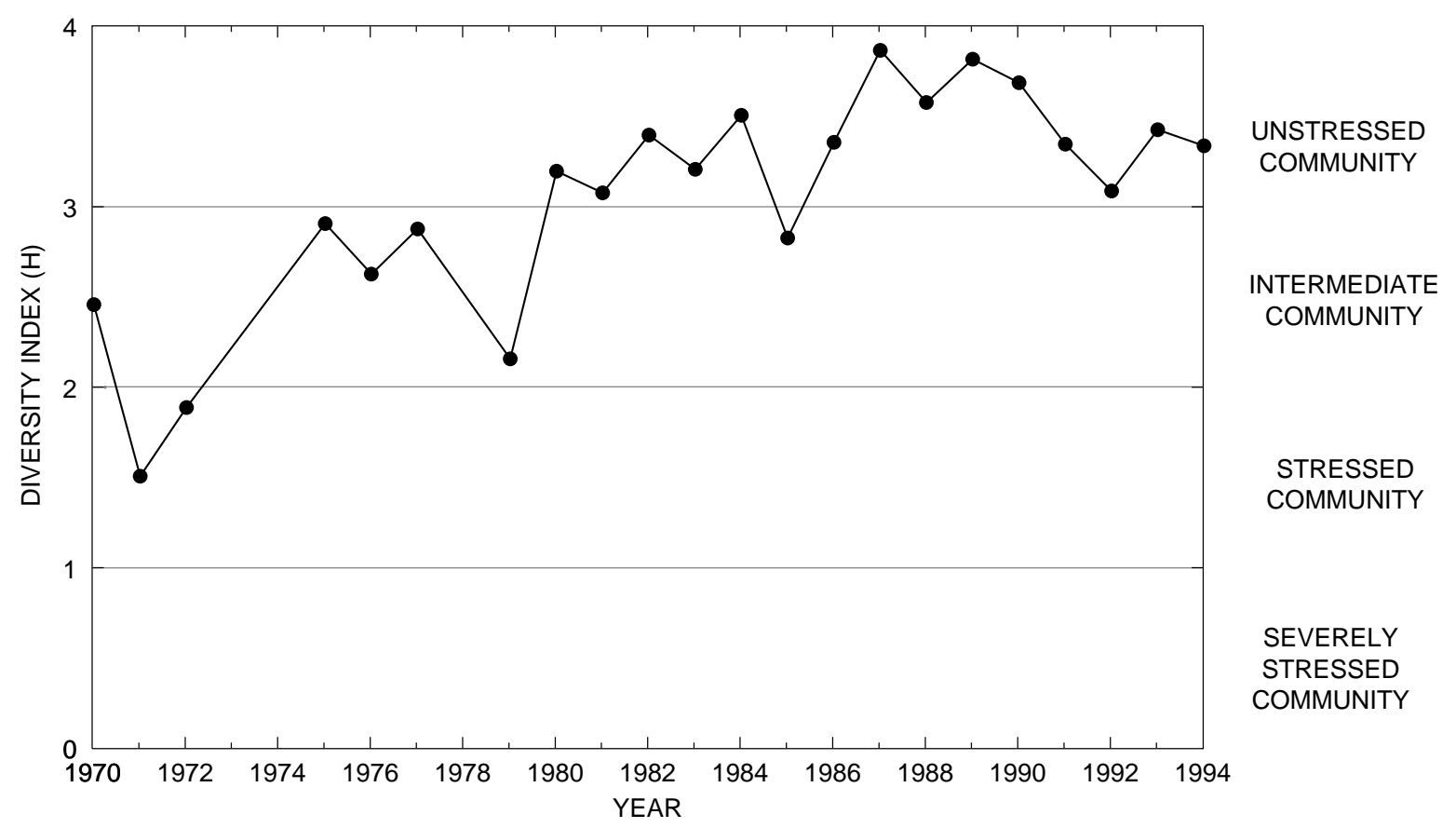


Table 6. Brillouin's diversity index, maximum diversity, minimum diversity, and relative evenness by site—Continued 01472109 STONY RUN NEAR SPRING CITY (SITE 6)

\begin{tabular}{|c|c|c|c|c|c|c|}
\hline Year & $\begin{array}{c}\text { Total } \\
\text { number of } \\
\text { organisms }\end{array}$ & $\begin{array}{c}\text { Total } \\
\text { number } \\
\text { of taxa }\end{array}$ & $\begin{array}{c}\text { Brillouin's } \\
\text { diversity index } \\
\text { (H) }\end{array}$ & $\begin{array}{l}\text { Maximum } \\
\text { diversity } \\
\left(\mathrm{H}_{\max }\right)\end{array}$ & $\begin{array}{c}\text { Minimum } \\
\text { diversity } \\
\left(\mathrm{H}_{\min }\right)\end{array}$ & $\begin{array}{c}\text { Evenness } \\
(\mathrm{E})\end{array}$ \\
\hline 1981 & ${ }^{1} 2,760$ & 32 & 3.08 & 4.95 & 0.13 & 0.61 \\
\hline 1982 & 1,265 & 27 & 3.53 & 4.76 & .21 & .73 \\
\hline 1983 & 2,082 & 37 & 3.33 & 5.16 & .19 & .63 \\
\hline 1984 & 998 & 26 & 3.49 & 4.66 & .25 & .74 \\
\hline 1985 & 550 & 26 & 2.22 & 4.54 & .41 & .44 \\
\hline 1986 & 651 & 38 & 3.60 & 5.08 & .53 & .67 \\
\hline 1987 & 1,467 & 34 & 3.57 & 5.03 & .24 & .70 \\
\hline 1988 & ${ }^{1} 816$ & 24 & 3.29 & 4.50 & .27 & .71 \\
\hline 1989 & 2,122 & 35 & 3.62 & 5.13 & .18 & .70 \\
\hline 1990 & 2,129 & 37 & 3.29 & 5.18 & .19 & .62 \\
\hline 1991 & 1,489 & 35 & 3.61 & 5.08 & .24 & .70 \\
\hline 1992 & 671 & 29 & 3.71 & 4.90 & .39 & .74 \\
\hline 1993 & 993 & 24 & 3.01 & 4.54 & .23 & .64 \\
\hline 1994 & 1,010 & 36 & 3.62 & 5.08 & .34 & .69 \\
\hline
\end{tabular}

${ }^{1}$ Extrapolated from a 3/8 subsample.

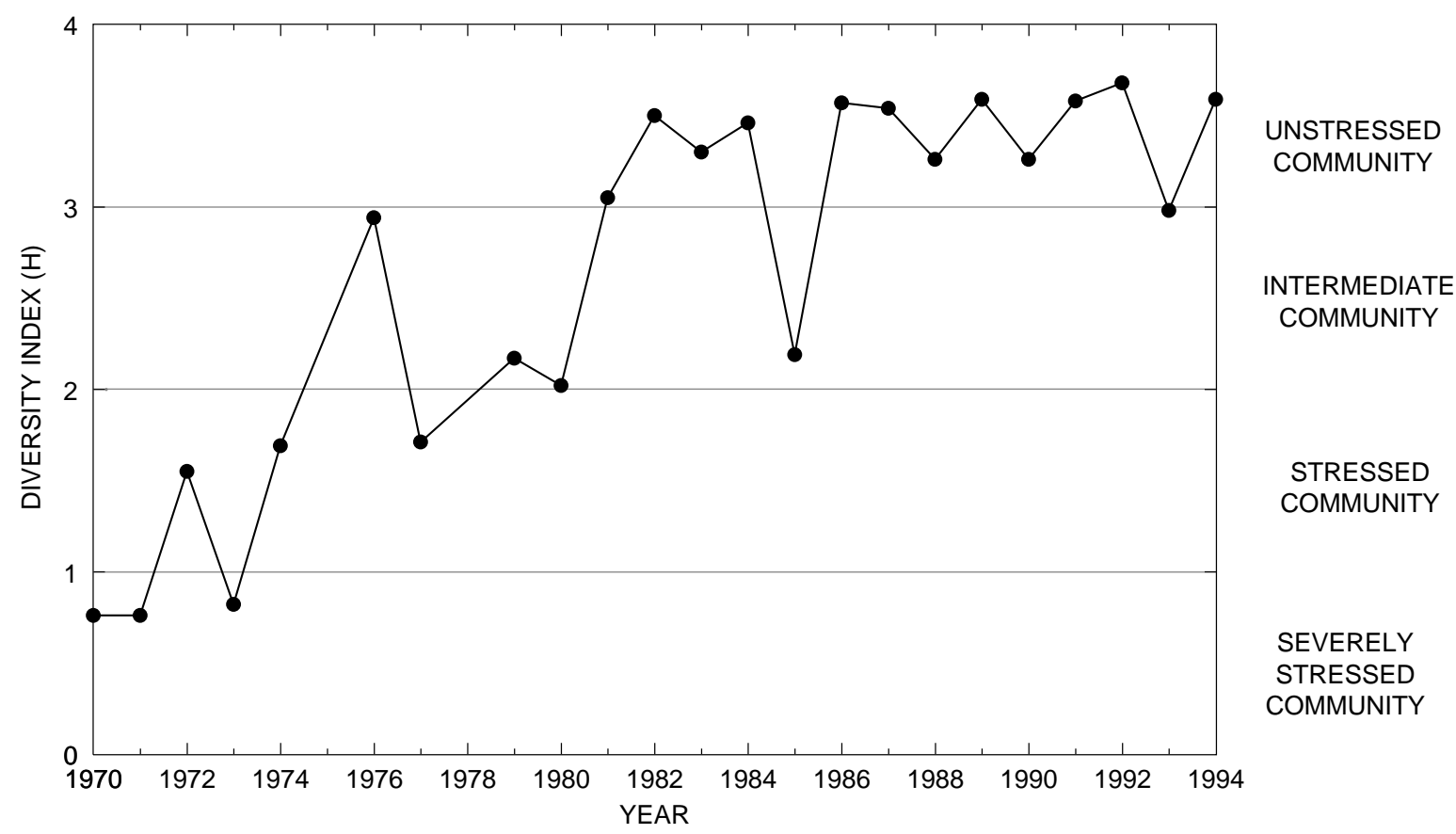


Table 6. Brillouin's diversity index, maximum diversity, minimum diversity, and relative evenness by site-Continued 01472110 STONY RUN AT SPRING CITY (SITE 7)

\begin{tabular}{ccccccr}
\hline Year & $\begin{array}{c}\text { Total } \\
\text { number of } \\
\text { organisms }\end{array}$ & $\begin{array}{c}\text { Total } \\
\text { number } \\
\text { of taxa }\end{array}$ & $\begin{array}{c}\text { Brillouin's } \\
\text { diversity index } \\
(\mathrm{H})\end{array}$ & $\begin{array}{c}\text { Maximum } \\
\text { diversity } \\
\left(\mathrm{H}_{\text {max }}\right)\end{array}$ & $\begin{array}{c}\text { Minimum } \\
\text { diversity } \\
\left(\mathrm{H}_{\text {min }}\right)\end{array}$ & $\begin{array}{c}\text { Evenness } \\
(\mathrm{E})\end{array}$ \\
\hline 1981 & 1,507 & 32 & 3.52 & 4.95 & 0.22 & 0.70 \\
1982 & 1,787 & 27 & 2.97 & 4.70 & .16 & .62 \\
\hline
\end{tabular}

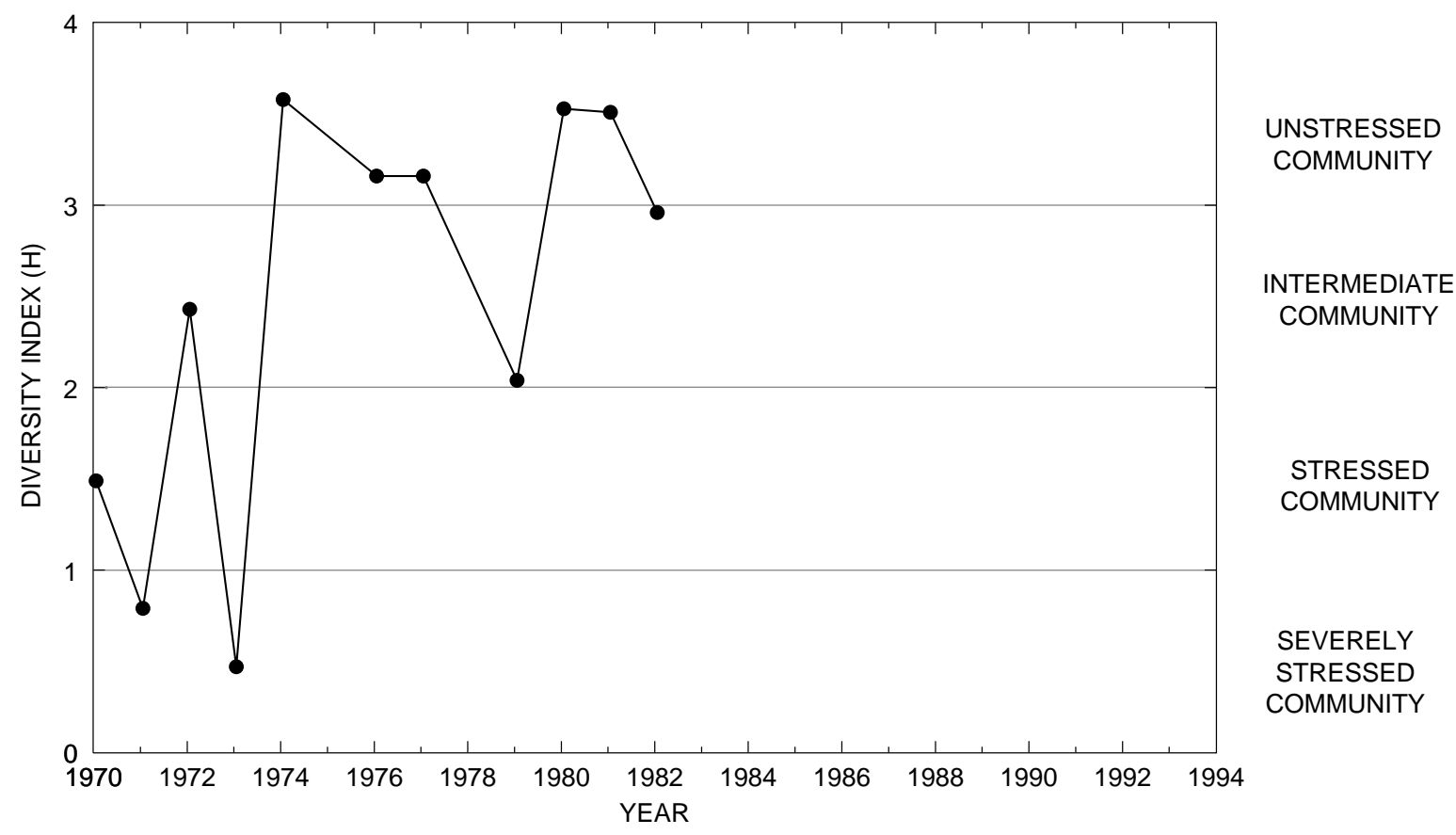


Table 6. Brillouin's diversity index, maximum diversity, minimum diversity, and relative evenness by site-Continued 01472126 FRENCH CREEK AT TRYTHALL (SITE 41)

\begin{tabular}{ccccccc}
\hline Year & $\begin{array}{c}\text { Total } \\
\text { number of } \\
\text { organisms }\end{array}$ & $\begin{array}{c}\text { Total } \\
\text { number } \\
\text { of taxa }\end{array}$ & $\begin{array}{c}\text { Brillouin's } \\
\text { diversity index } \\
(\mathrm{H})\end{array}$ & $\begin{array}{c}\text { Maximum } \\
\text { diversity } \\
\left(\mathrm{H}_{\max }\right)\end{array}$ & $\begin{array}{c}\text { Minimum } \\
\text { diversity } \\
\left(\mathrm{H}_{\min }\right)\end{array}$ & $\begin{array}{c}\text { Evenness } \\
(\mathrm{E})\end{array}$ \\
\hline 1981 & - & - & - & - & - & - \\
1982 & 215 & 24 & 3.02 & 4.62 & 0.82 & 0.58 \\
\hline
\end{tabular}

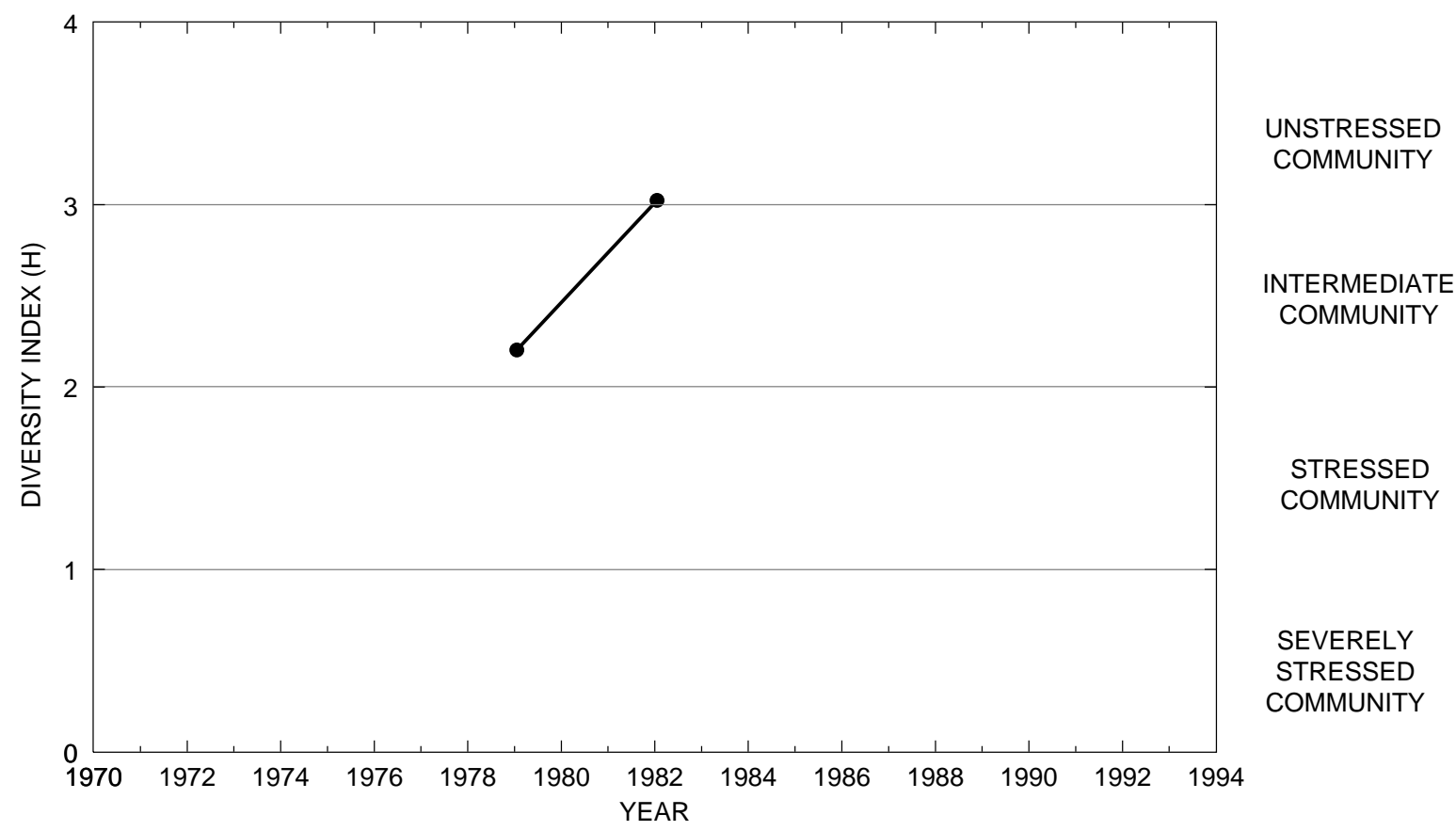


Table 6. Brillouin's diversity index, maximum diversity, minimum diversity, and relative evenness by site—Continued 01472129 FRENCH CREEK NEAR KNAUERTOWN (SITE 11)

\begin{tabular}{ccccccc}
\hline Year & $\begin{array}{c}\text { Total } \\
\text { number of } \\
\text { organisms }\end{array}$ & $\begin{array}{c}\text { Total } \\
\text { number } \\
\text { of taxa }\end{array}$ & $\begin{array}{c}\text { Brillouin's } \\
\text { diversity index } \\
(\mathrm{H})\end{array}$ & $\begin{array}{c}\text { Maximum } \\
\text { diversity } \\
\left(\mathrm{H}_{\max }\right)\end{array}$ & $\begin{array}{c}\text { Minimum } \\
\text { diversity } \\
\left(\mathrm{H}_{\min }\right)\end{array}$ & $\begin{array}{c}\text { Evenness } \\
(\mathrm{E})\end{array}$ \\
\hline 1981 & 1,078 & 36 & 3.83 & 5.20 & 0.33 & 0.72 \\
1982 & 2,186 & 40 & 3.59 & 5.27 & .20 & .67 \\
\hline
\end{tabular}

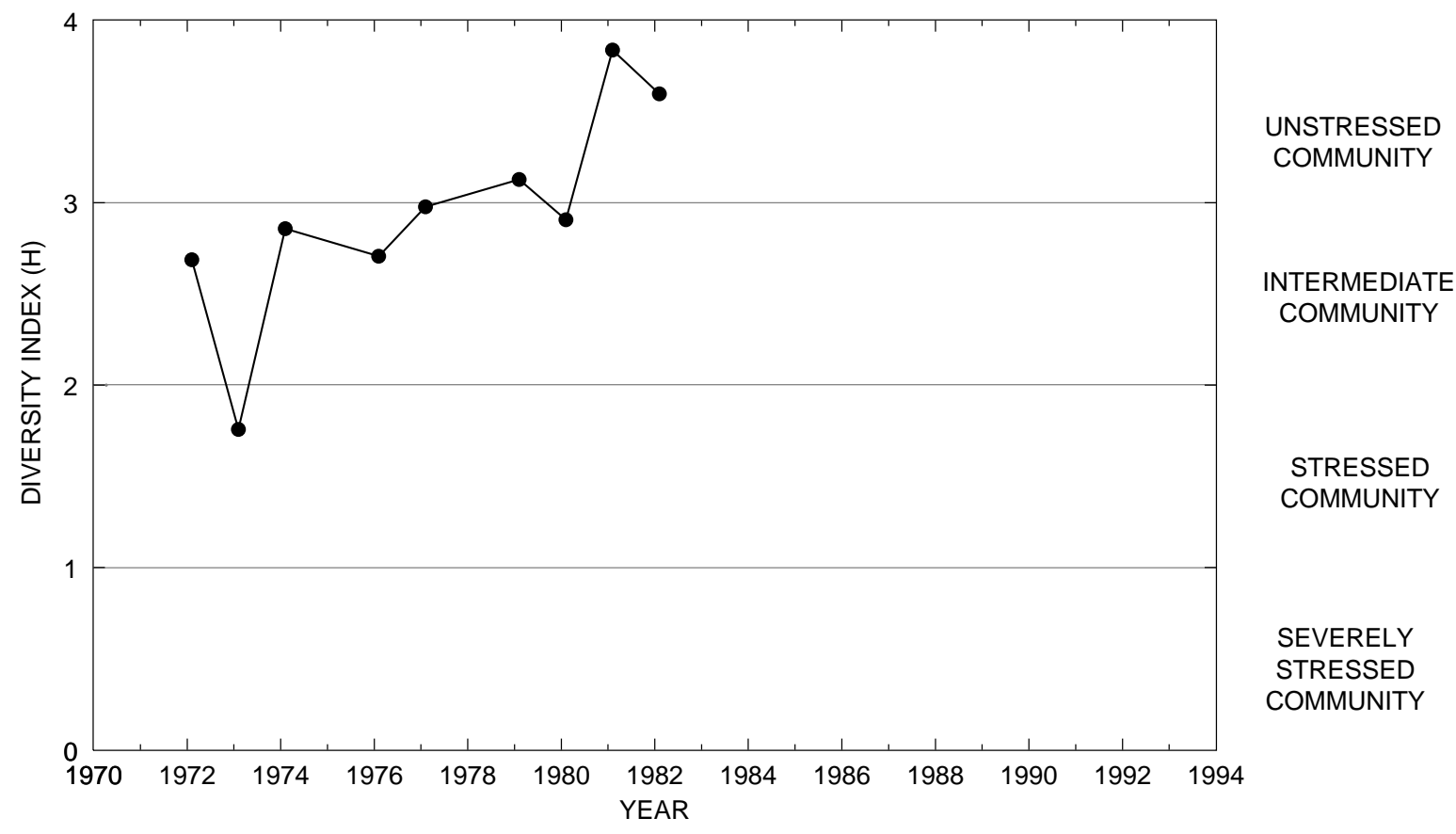


Table 6. Brillouin's diversity index, maximum diversity, minimum diversity, and relative evenness by site—Continued 01472138 FRENCH CREEK NEAR COVENTRYVILLE (SITE 13)

\begin{tabular}{|c|c|c|c|c|c|c|}
\hline Year & $\begin{array}{c}\text { Total } \\
\text { number of } \\
\text { organisms }\end{array}$ & $\begin{array}{c}\text { Total } \\
\text { number } \\
\text { of taxa }\end{array}$ & $\begin{array}{c}\text { Brillouin's } \\
\text { diversity index } \\
\text { (H) }\end{array}$ & $\begin{array}{l}\text { Maximum } \\
\text { diversity } \\
\left(\mathrm{H}_{\max }\right)\end{array}$ & $\begin{array}{c}\text { Minimum } \\
\text { diversity } \\
\left(\mathrm{H}_{\min }\right)\end{array}$ & $\begin{array}{c}\text { Evenness } \\
(\mathrm{E})\end{array}$ \\
\hline 1981 & 1,542 & 43 & 3.88 & 5.44 & 0.29 & 0.70 \\
\hline 1982 & ${ }^{1} 2,380$ & 35 & 3.21 & 5.10 & .16 & .62 \\
\hline 1983 & ${ }^{1} 1,615$ & 38 & 3.82 & 5.19 & .24 & .72 \\
\hline 1984 & ${ }^{1} 1,295$ & 27 & 3.51 & 4.77 & .21 & .72 \\
\hline 1985 & 535 & 36 & 3.18 & 5.21 & .59 & .56 \\
\hline 1986 & 1,395 & 31 & 3.01 & 4.87 & .22 & .60 \\
\hline 1987 & 1,338 & 31 & 2.50 & 4.89 & .23 & .49 \\
\hline 1988 & 1,846 & 31 & 3.12 & 4.94 & .18 & .62 \\
\hline 1989 & 1,643 & 51 & 3.96 & 5.51 & .33 & .69 \\
\hline 1990 & 1,507 & 46 & 3.51 & 5.53 & .31 & .61 \\
\hline 1991 & 597 & 35 & 3.24 & 4.95 & .52 & .61 \\
\hline 1992 & 573 & 29 & 3.49 & 4.88 & .44 & .69 \\
\hline 1993 & 732 & 38 & 3.97 & 5.13 & .48 & .75 \\
\hline 1994 & 1,029 & 32 & 3.31 & 4.91 & .30 & .65 \\
\hline
\end{tabular}

${ }^{1}$ Extrapolated from a $3 / 8$ subsample.

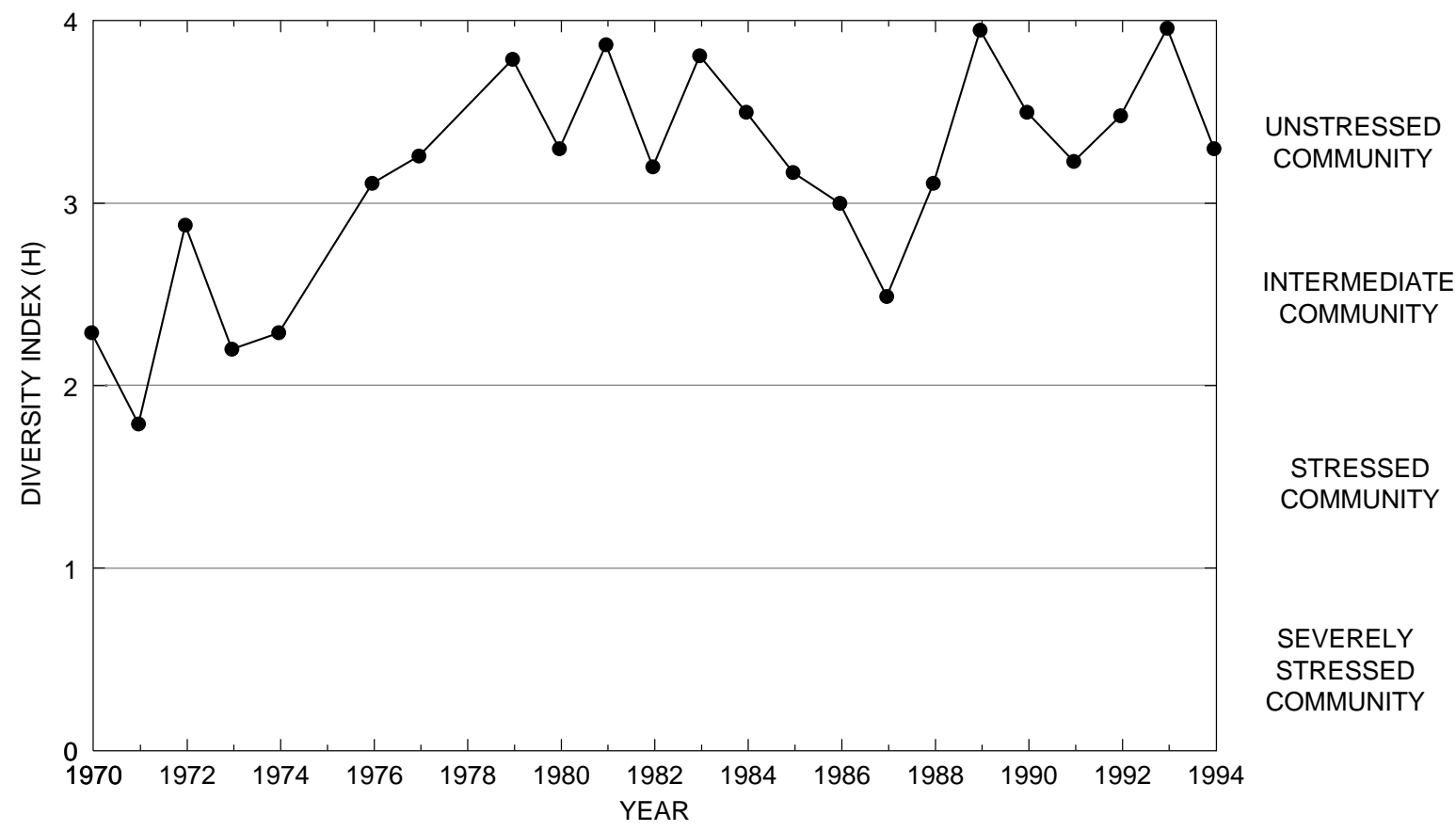


Table 6. Brillouin's diversity index, maximum diversity, minimum diversity, and relative evenness by site-Continued

\section{SOUTH BRANCH FRENCH CREEK AT COVENTRYVILLE (SITE 12)}

\begin{tabular}{|c|c|c|c|c|c|c|}
\hline Year & $\begin{array}{c}\text { Total } \\
\text { number of } \\
\text { organisms }\end{array}$ & $\begin{array}{c}\text { Total } \\
\text { number } \\
\text { of taxa }\end{array}$ & $\begin{array}{l}\text { Brillouin's } \\
\text { diversity index } \\
\text { (H) }\end{array}$ & $\begin{array}{c}\text { Maximum } \\
\text { diversity } \\
\left(\mathrm{H}_{\max }\right)\end{array}$ & $\begin{array}{c}\text { Minimum } \\
\text { diversity } \\
\left(\mathrm{H}_{\min }\right)\end{array}$ & $\begin{array}{c}\text { Evenness } \\
\text { (E) }\end{array}$ \\
\hline 1981 & ${ }^{1} 1,197$ & 32 & 3.41 & 4.91 & 0.27 & 0.68 \\
\hline 1982 & ${ }^{1} 2,649$ & 33 & 3.18 & 5.01 & .14 & .63 \\
\hline 1983 & ${ }^{1} 1,697$ & 31 & 3.26 & 4.91 & .19 & .65 \\
\hline 1984 & ${ }^{1} 1,563$ & 26 & 3.28 & 4.63 & .17 & .70 \\
\hline 1985 & 785 & 34 & 3.75 & 5.13 & .40 & .71 \\
\hline 1986 & 1,312 & 39 & 3.85 & 5.24 & .30 & .72 \\
\hline 1987 & 2,014 & 40 & 3.20 & 5.29 & .21 & .59 \\
\hline 1988 & 3,070 & 40 & 3.73 & 5.31 & .15 & .69 \\
\hline 1989 & 2,447 & 41 & 3.78 & 5.34 & .18 & .70 \\
\hline 1990 & 643 & 36 & 3.86 & 5.20 & .50 & .72 \\
\hline 1991 & 1,737 & 43 & 3.85 & 5.38 & .26 & .70 \\
\hline 1992 & 1,336 & 48 & 3.94 & 5.60 & .36 & .68 \\
\hline 1993 & 1,432 & 42 & 4.03 & 5.29 & .30 & .75 \\
\hline 1994 & 565 & 29 & 3.36 & 4.76 & .45 & .67 \\
\hline
\end{tabular}

${ }^{1}$ Extrapolated from a $3 / 8$ subsample.

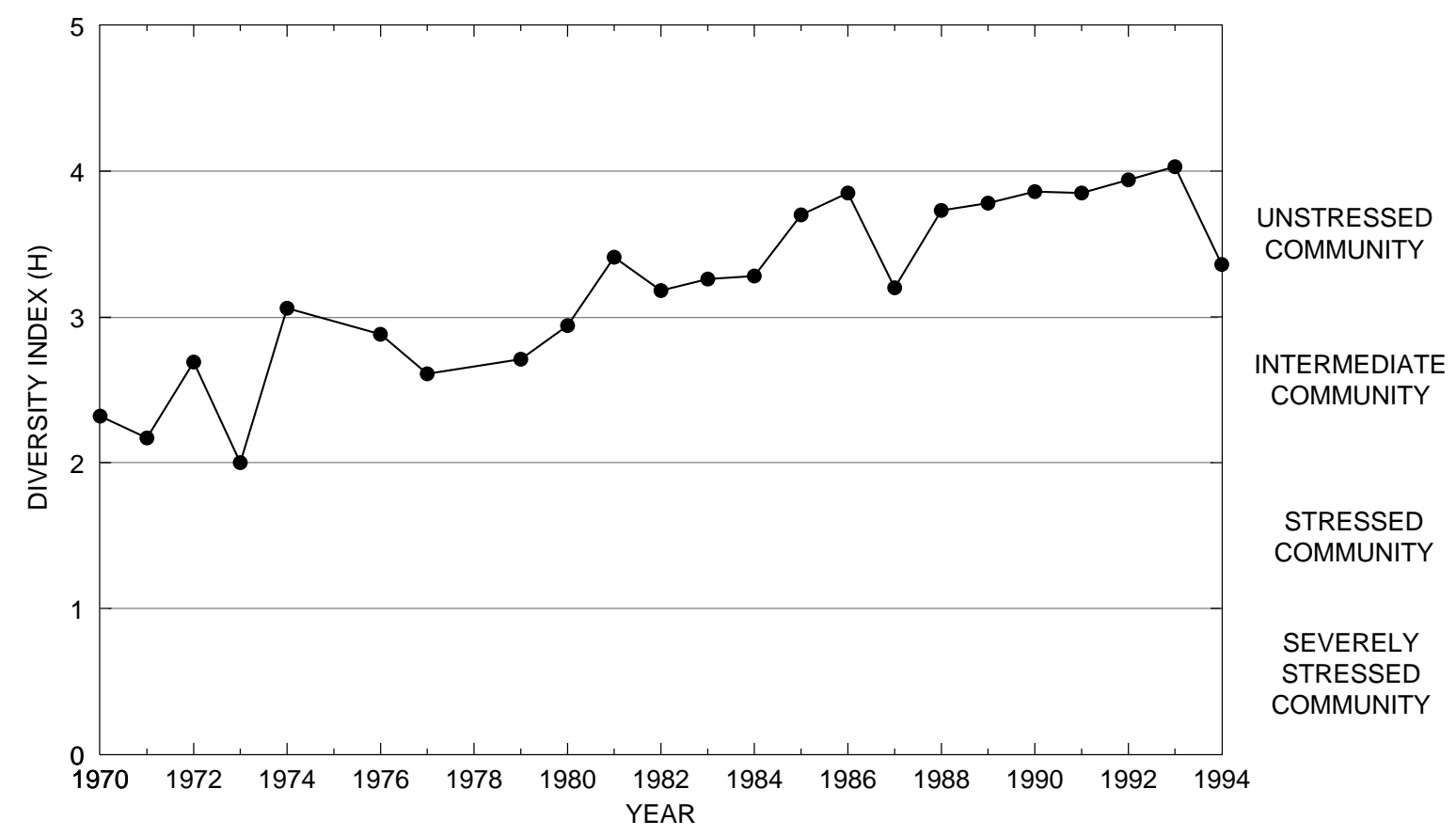


Table 6. Brillouin's diversity index, maximum diversity, minimum diversity, and relative evenness by site-Continued

\section{FRENCH CREEK NEAR PUGHTOWN (SITE 14)}

\begin{tabular}{|c|c|c|c|c|c|c|}
\hline Year & $\begin{array}{c}\text { Total } \\
\text { number of } \\
\text { organisms }\end{array}$ & $\begin{array}{c}\text { Total } \\
\text { number } \\
\text { of taxa }\end{array}$ & $\begin{array}{l}\text { Brillouin's } \\
\text { diversity index } \\
\text { (H) }\end{array}$ & $\begin{array}{c}\text { Maximum } \\
\text { diversity } \\
\left(\mathrm{H}_{\max }\right)\end{array}$ & $\begin{array}{c}\text { Minimum } \\
\text { diversity } \\
\left(\mathrm{H}_{\min }\right)\end{array}$ & $\begin{array}{c}\text { Evenness } \\
\text { (E) }\end{array}$ \\
\hline 1981 & 1,760 & 35 & 3.42 & 5.09 & 0.21 & 0.66 \\
\hline 1982 & 1,543 & 29 & 2.88 & 4.81 & .19 & .58 \\
\hline 1983 & 1,432 & 40 & 3.63 & 5.31 & .29 & .66 \\
\hline 1984 & 1,716 & 31 & 3.20 & 4.93 & .19 & .64 \\
\hline 1985 & 421 & 24 & 3.33 & 4.53 & .47 & .70 \\
\hline 1986 & 1,416 & 32 & 3.32 & 4.96 & .23 & .65 \\
\hline 1987 & 1,331 & 31 & 2.03 & 4.97 & .23 & .38 \\
\hline 1988 & ${ }^{1} 2,589$ & 33 & 3.72 & 5.03 & .14 & .73 \\
\hline 1989 & 1,489 & 38 & 3.98 & 5.15 & .26 & .76 \\
\hline 1990 & 747 & 35 & 3.89 & 5.02 & .43 & .75 \\
\hline 1991 & 1,545 & 36 & 3.56 & 5.10 & .24 & .68 \\
\hline 1992 & 1,025 & 40 & 3.58 & 5.32 & .38 & .65 \\
\hline 1993 & 765 & 34 & 3.25 & 5.02 & .41 & .61 \\
\hline 1994 & 1,212 & 40 & 3.70 & 5.21 & .33 & .69 \\
\hline
\end{tabular}

\footnotetext{
${ }^{1}$ Extrapolated from a $3 / 8$ subsample.
}

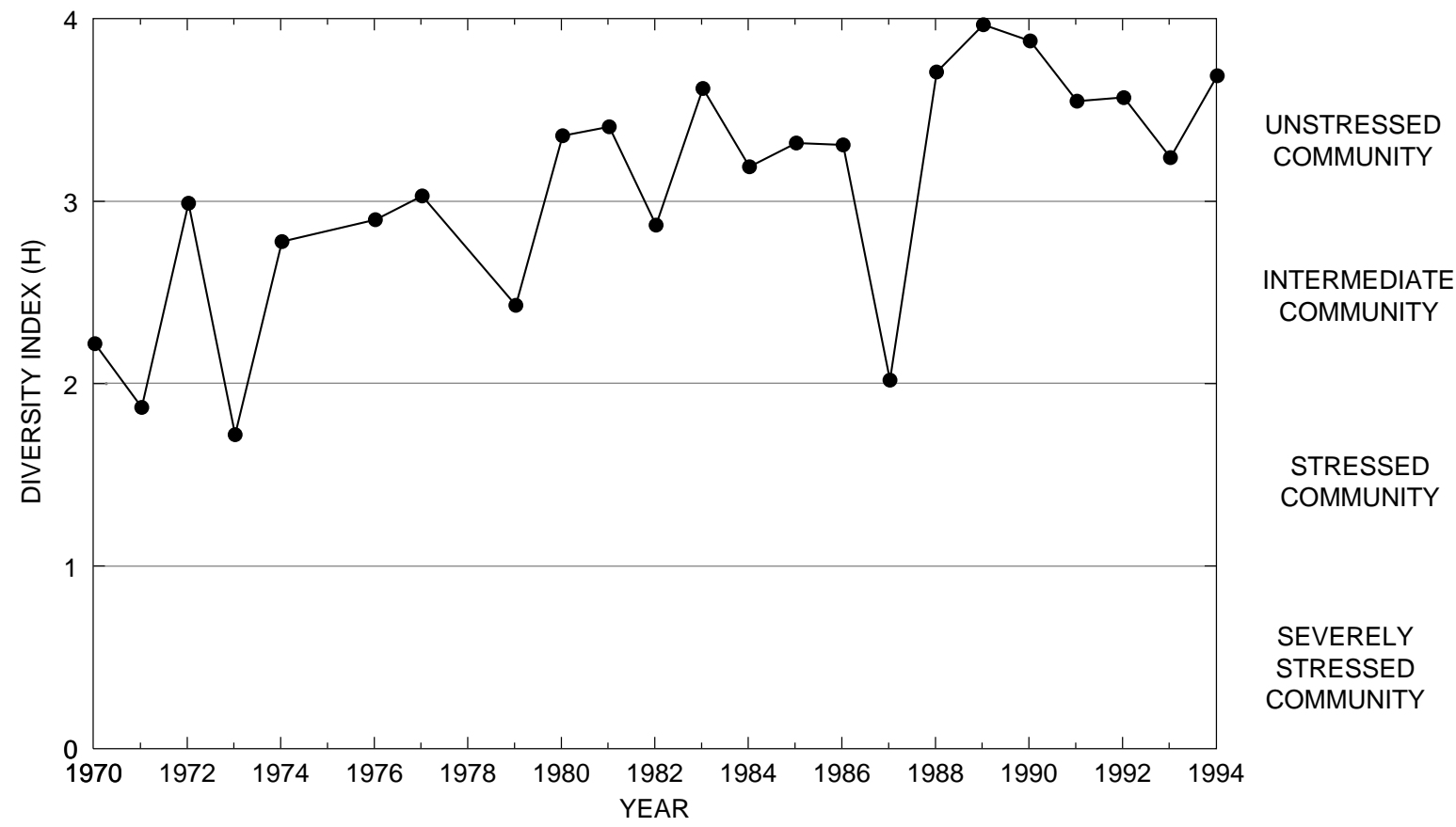


Table 6. Brillouin's diversity index, maximum diversity, minimum diversity, and relative evenness by site-Continued

01472157 FRENCH CREEK NEAR PHOENIXVILLE (SITE 15)

\begin{tabular}{|c|c|c|c|c|c|c|}
\hline Year & $\begin{array}{c}\text { Total } \\
\text { number of } \\
\text { organisms }\end{array}$ & $\begin{array}{c}\text { Total } \\
\text { number } \\
\text { of taxa }\end{array}$ & $\begin{array}{l}\text { Brillouin's } \\
\text { diversity index } \\
\text { (H) }\end{array}$ & $\begin{array}{c}\text { Maximum } \\
\text { diversity } \\
\left(\mathrm{H}_{\max }\right)\end{array}$ & $\begin{array}{c}\text { Minimum } \\
\text { diversity } \\
\left(\mathrm{H}_{\min }\right)\end{array}$ & $\begin{array}{c}\text { Evenness } \\
\text { (E) }\end{array}$ \\
\hline 1981 & ${ }^{1} 3,427$ & 32 & 2.34 & 5.00 & 0.11 & 0.46 \\
\hline 1982 & ${ }^{1} 548$ & 22 & 3.06 & 4.48 & .35 & .66 \\
\hline 1983 & ${ }^{1} 1,141$ & 28 & 2.82 & 4.80 & .24 & .57 \\
\hline 1984 & ${ }^{1} 821$ & 29 & 3.32 & 4.78 & .33 & .67 \\
\hline 1985 & 226 & 30 & 3.92 & 4.77 & .99 & .77 \\
\hline 1986 & 712 & 36 & 3.77 & 5.21 & .46 & .70 \\
\hline 1987 & 600 & 35 & 2.76 & 4.99 & .52 & .50 \\
\hline 1988 & ${ }^{1} 2,496$ & 41 & 3.19 & 5.37 & .18 & .58 \\
\hline 1989 & 203 & 35 & 4.12 & 5.06 & 1.26 & .75 \\
\hline 1990 & 271 & 28 & 3.36 & 4.75 & .80 & .65 \\
\hline 1991 & 1,254 & 38 & 3.14 & 5.29 & .30 & .57 \\
\hline 1992 & 825 & 45 & 3.93 & 5.36 & .52 & .71 \\
\hline 1993 & 587 & 34 & 3.37 & 4.96 & .51 & .64 \\
\hline 1994 & 1,045 & 47 & 4.18 & 5.42 & .44 & .75 \\
\hline
\end{tabular}

${ }^{1}$ Extrapolated from a $3 / 8$ subsample.

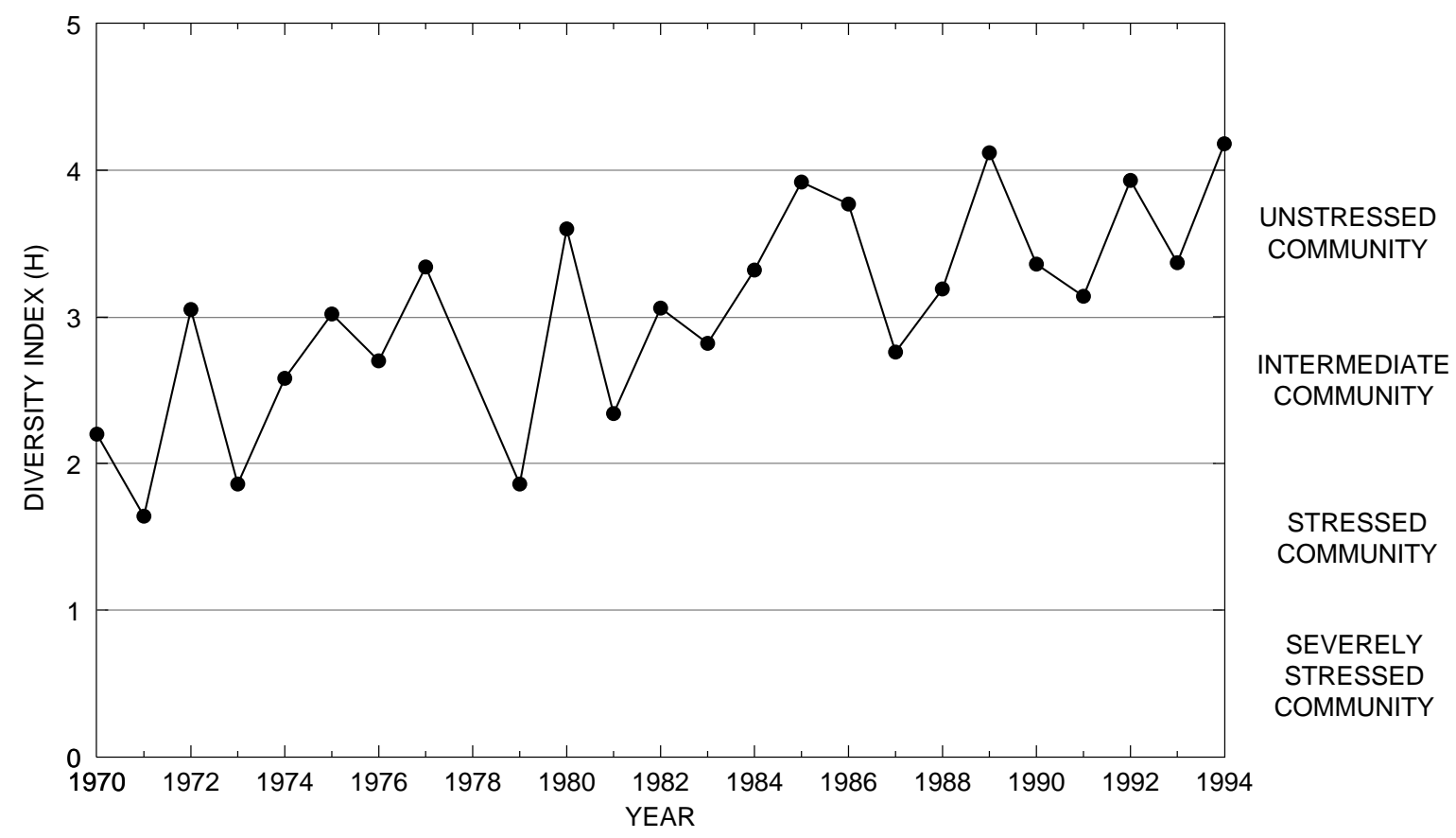


Table 6. Brillouin's diversity index, maximum diversity, minimum diversity, and relative evenness by site-Continued

014721612 FRENCH CREEK AT RAILROAD BRIDGE AT PHOENIXVILLE (SITE 16)

\begin{tabular}{|c|c|c|c|c|c|c|}
\hline Year & $\begin{array}{c}\text { Total } \\
\text { number of } \\
\text { organisms }\end{array}$ & $\begin{array}{c}\text { Total } \\
\text { number } \\
\text { of taxa }\end{array}$ & $\begin{array}{c}\text { Brillouin's } \\
\text { diversity index } \\
\text { (H) }\end{array}$ & $\begin{array}{l}\text { Maximum } \\
\text { diversity } \\
\left(\mathrm{H}_{\max }\right)\end{array}$ & $\begin{array}{c}\text { Minimum } \\
\text { diversity } \\
\left(\mathrm{H}_{\min }\right)\end{array}$ & $\begin{array}{c}\text { Evenness } \\
(\mathrm{E})\end{array}$ \\
\hline 1981 & 240 & 8 & 0.53 & 2.96 & 0.23 & 0.11 \\
\hline 1982 & 619 & 20 & 1.43 & 4.21 & .28 & .29 \\
\hline 1983 & 343 & 24 & 2.82 & 4.44 & .56 & .58 \\
\hline 1984 & 2,247 & 18 & 1.13 & 4.18 & .08 & .26 \\
\hline 1985 & 72 & 21 & 3.11 & 4.03 & 1.66 & .61 \\
\hline 1986 & 605 & 21 & 2.25 & 4.36 & .31 & .48 \\
\hline 1987 & 489 & 25 & 2.75 & 4.61 & .44 & .55 \\
\hline 1988 & ${ }^{1} 1,340$ & 20 & 2.04 & 4.34 & .15 & .45 \\
\hline 1989 & 270 & 36 & 3.84 & 5.01 & 1.03 & .71 \\
\hline 1990 & 113 & 22 & 3.09 & 4.07 & 1.24 & .65 \\
\hline 1991 & 727 & 24 & 2.25 & 4.52 & .30 & .46 \\
\hline 1992 & 115 & 13 & 2.76 & 3.61 & .67 & .71 \\
\hline 1993 & 985 & 33 & 3.02 & 5.05 & .32 & .57 \\
\hline 1994 & 656 & 22 & 2.34 & 4.45 & .30 & .49 \\
\hline
\end{tabular}

${ }^{1}$ Extrapolated from a $3 / 8$ subsample.

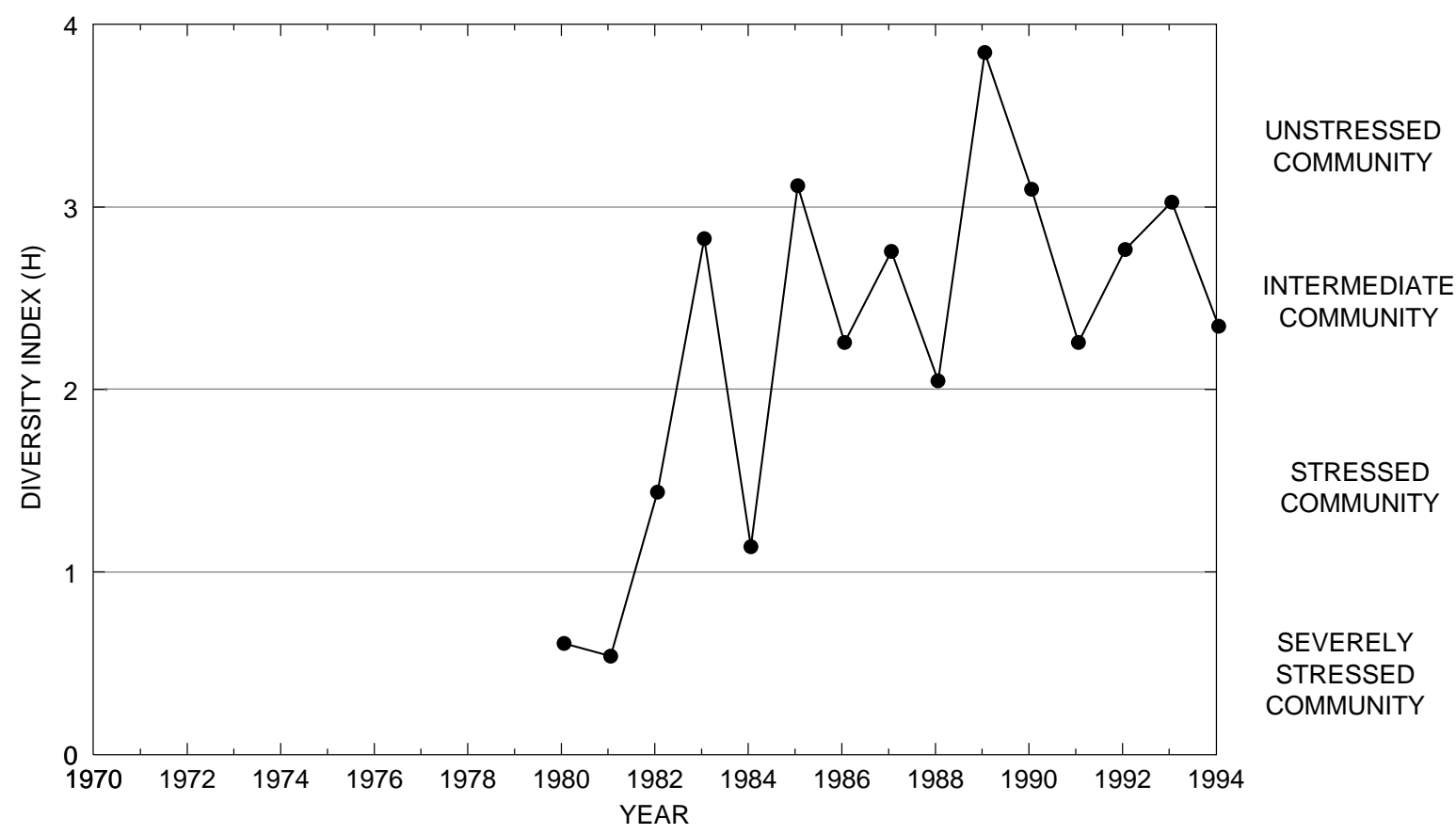


Table 6. Brillouin's diversity index, maximum diversity, minimum diversity, and relative evenness by site-Continued 01472170 PICKERING CREEK NEAR EAGLE (SITE 1)

\begin{tabular}{|c|c|c|c|c|c|c|}
\hline Year & $\begin{array}{c}\text { Total } \\
\text { number of } \\
\text { organisms }\end{array}$ & $\begin{array}{c}\text { Total } \\
\text { number } \\
\text { of taxa }\end{array}$ & $\begin{array}{l}\text { Brillouin's } \\
\text { diversity index } \\
\text { (H) }\end{array}$ & $\begin{array}{l}\text { Maximum } \\
\text { diversity } \\
\left(\mathrm{H}_{\max }\right)\end{array}$ & $\begin{array}{c}\text { Minimum } \\
\text { diversity } \\
\left(\mathrm{H}_{\min }\right)\end{array}$ & $\begin{array}{c}\text { Evenness } \\
\text { (E) }\end{array}$ \\
\hline 1981 & ${ }^{1} 1,301$ & 23 & 2.80 & 4.54 & 0.17 & 0.60 \\
\hline 1982 & ${ }^{1} 2,643$ & 22 & 2.64 & 4.45 & .09 & .58 \\
\hline 1983 & 2,715 & 31 & 2.78 & 4.94 & .13 & .55 \\
\hline 1984 & ${ }^{1} 1,537$ & 23 & 2.78 & 4.55 & .15 & .60 \\
\hline 1985 & 765 & 31 & 3.35 & 4.91 & .38 & .66 \\
\hline 1986 & 1,102 & 32 & 3.43 & 4.93 & .29 & .68 \\
\hline 1987 & 1,431 & 25 & 2.87 & 4.63 & .17 & .61 \\
\hline 1988 & 2,728 & 29 & 3.14 & 4.82 & .12 & .64 \\
\hline 1989 & 1,088 & 32 & 3.70 & 5.02 & .29 & .72 \\
\hline 1990 & 1,000 & 23 & 3.22 & 4.46 & .22 & .71 \\
\hline 1991 & 725 & 29 & 3.41 & 4.87 & .37 & .68 \\
\hline 1992 & 328 & 21 & 3.06 & 4.29 & .51 & .67 \\
\hline 1993 & 872 & 26 & 3.33 & 4.68 & .28 & .69 \\
\hline 1994 & 560 & 27 & 3.61 & 4.70 & .43 & .74 \\
\hline
\end{tabular}

${ }^{1}$ Extrapolated from a $3 / 8$ subsample.

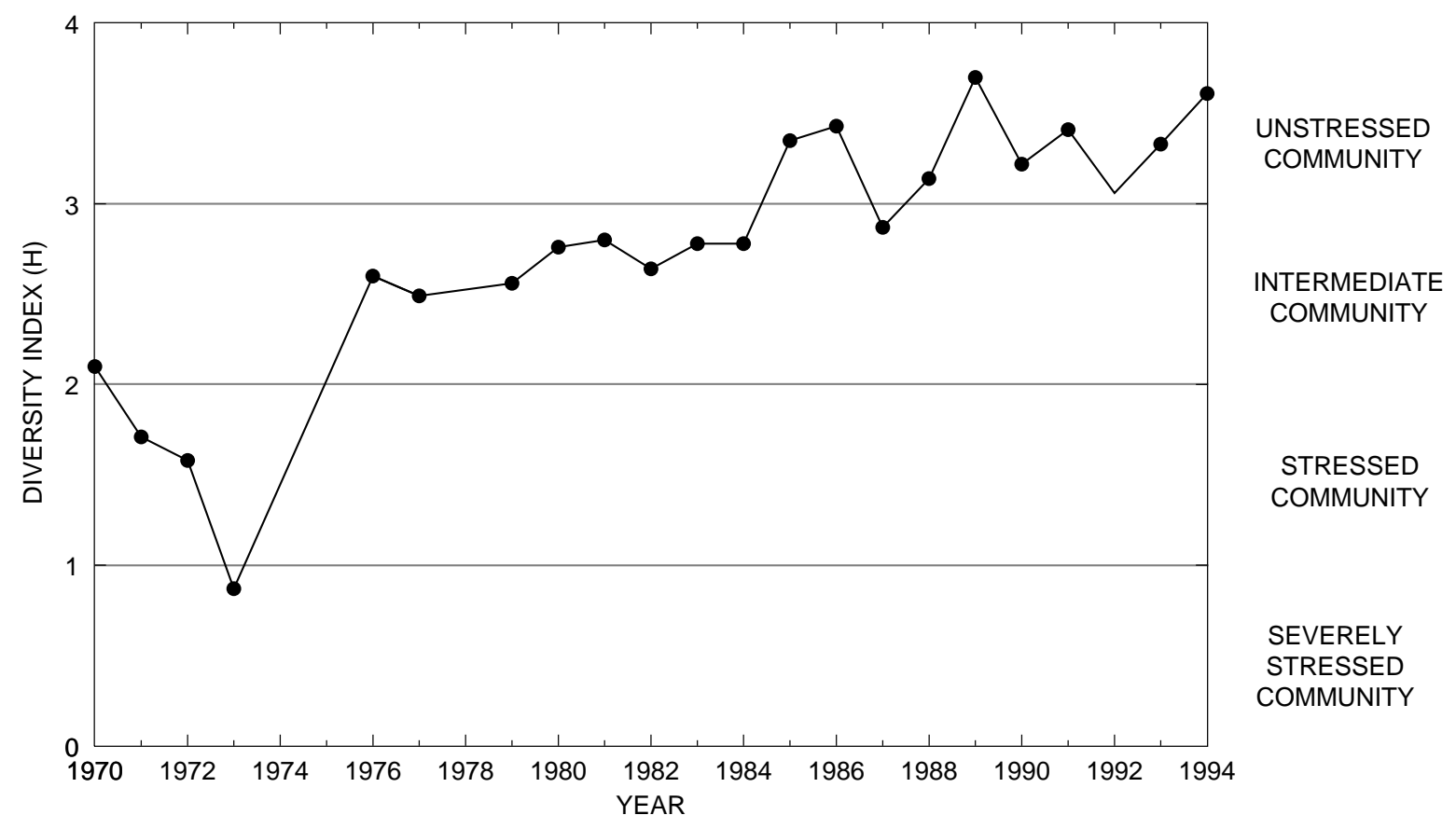


Table 6. Brillouin's diversity index, maximum diversity, minimum diversity, and relative evenness by site-Continued 01472174 PICKERING CREEK NEAR CHESTER SPRINGS (SITE 2)

\begin{tabular}{ccccccc}
\hline Year & $\begin{array}{c}\text { Total } \\
\text { number of } \\
\text { organisms }\end{array}$ & $\begin{array}{c}\text { Total } \\
\text { number } \\
\text { of taxa }\end{array}$ & $\begin{array}{c}\text { Brillouin's } \\
\text { diversity index } \\
(\mathrm{H})\end{array}$ & $\begin{array}{c}\text { Maximum } \\
\text { diversity } \\
\left(\mathrm{H}_{\text {max }}\right)\end{array}$ & $\begin{array}{c}\text { Minimum } \\
\text { diversity } \\
\left(\mathrm{H}_{\text {min }}\right)\end{array}$ & $\begin{array}{c}\text { Evenness } \\
(\mathrm{E})\end{array}$ \\
\hline 1981 & 1747 & 20 & 2.41 & 4.26 & 0.24 & 0.54 \\
1982 & 11,084 & 26 & 3.06 & 4.72 & .23 & .63 \\
1983 & 526 & 24 & 3.80 & 4.62 & .39 & .80 \\
1984 & 11,350 & 21 & 3.17 & 4.36 & .15 & .72 \\
1985 & 595 & 28 & 3.14 & 4.73 & .42 & .63 \\
1986 & 488 & 30 & 3.44 & 4.75 & .53 & .69 \\
1987 & 170 & 18 & 2.42 & 4.04 & .73 & .51 \\
1988 & 1,340 & 24 & 3.29 & 4.60 & .18 & .70 \\
1989 & 1,076 & 35 & 3.67 & 5.13 & .32 & .70 \\
1990 & 502 & 32 & 3.41 & 4.94 & .55 & .65 \\
1991 & 766 & 39 & 3.78 & 5.27 & .47 & .69 \\
1992 & 295 & 35 & 3.90 & 4.97 & .94 & .74 \\
1993 & 219 & 21 & 2.99 & 4.27 & .70 & .64 \\
1994 & 871 & 39 & 3.82 & 5.17 & .43 & .72 \\
\hline
\end{tabular}

${ }^{1}$ Extrapolated from a $3 / 8$ subsample.

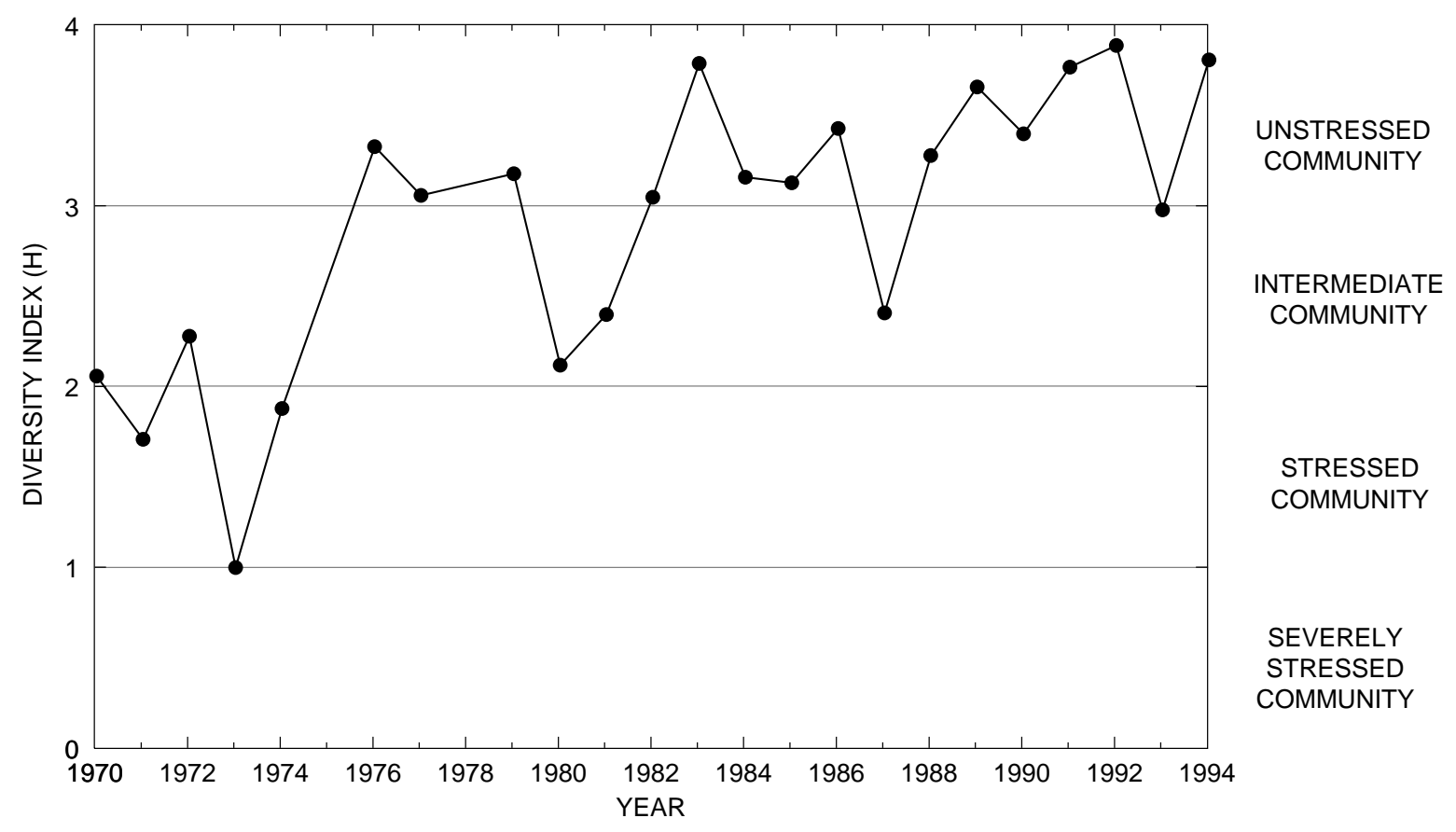


Table 6. Brillouin's diversity index, maximum diversity, minimum diversity, and relative evenness by site-Continued 014721854 PICKERING CREEK AT MERLIN (SITE 3)

\begin{tabular}{|c|c|c|c|c|c|c|}
\hline Year & $\begin{array}{c}\text { Total } \\
\text { number of } \\
\text { organisms }\end{array}$ & $\begin{array}{c}\text { Total } \\
\text { number } \\
\text { of taxa }\end{array}$ & $\begin{array}{c}\text { Brillouin's } \\
\text { diversity index } \\
\text { (H) }\end{array}$ & $\begin{array}{l}\text { Maximum } \\
\text { diversity } \\
\left(\mathrm{H}_{\max }\right)\end{array}$ & $\begin{array}{c}\text { Minimum } \\
\text { diversity } \\
\left(\mathrm{H}_{\min }\right)\end{array}$ & $\begin{array}{c}\text { Evenness } \\
(\mathrm{E})\end{array}$ \\
\hline 1981 & ${ }^{1} 1,757$ & 27 & 2.72 & 4.70 & 0.16 & 0.56 \\
\hline 1982 & 2,123 & 30 & 3.17 & 4.90 & .15 & .63 \\
\hline 1983 & 1935 & 25 & 3.68 & 4.58 & .25 & .79 \\
\hline 1984 & ${ }^{1} 2,005$ & 24 & 3.07 & 4.52 & .17 & .66 \\
\hline 1985 & 912 & 39 & 3.63 & 5.25 & .41 & .67 \\
\hline 1986 & 1,049 & 36 & 2.67 & 5.08 & .33 & .49 \\
\hline 1987 & 1,396 & 38 & 3.34 & 5.24 & .28 & .62 \\
\hline 1988 & ${ }^{1} 1,047$ & 24 & 3.35 & 4.56 & .22 & .72 \\
\hline 1989 & 1,015 & 45 & 3.82 & 5.42 & .43 & .68 \\
\hline 1990 & 430 & 29 & 3.52 & 4.89 & .56 & .68 \\
\hline 1991 & 956 & 33 & 2.98 & 5.08 & .33 & .56 \\
\hline 1992 & 1,522 & 44 & 3.97 & 5.44 & .30 & .72 \\
\hline 1993 & 939 & 30 & 3.72 & 4.80 & .31 & .76 \\
\hline 1994 & 780 & 31 & 3.00 & 4.85 & .37 & .59 \\
\hline
\end{tabular}

${ }^{1}$ Extrapolated from a $3 / 8$ subsample.

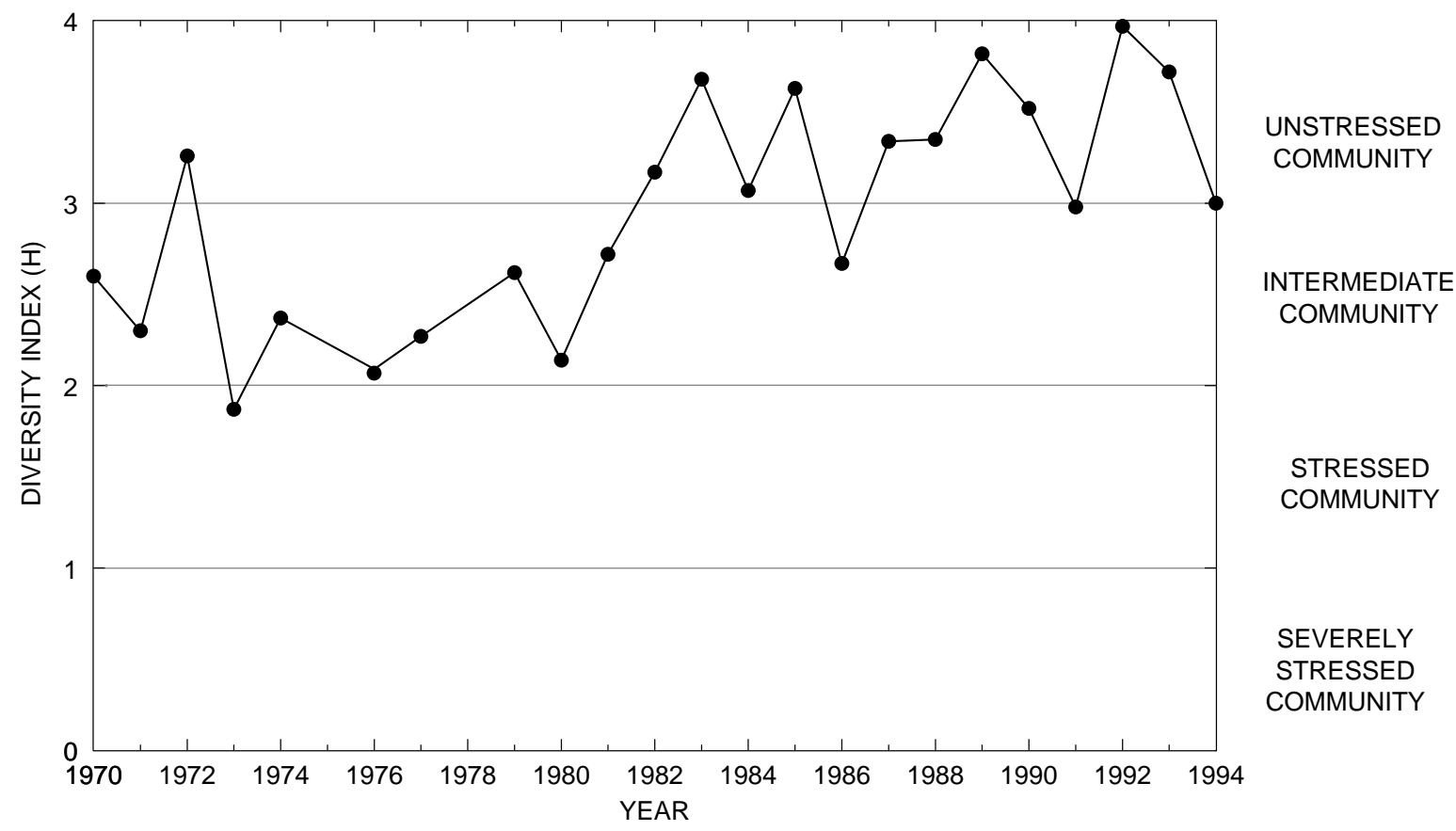


Table 6. Brillouin's diversity index, maximum diversity, minimum diversity, and relative evenness by site—Continued 014721884 PICKERING CREEK AT CHARLESTOWN ROAD AT CHARLESTOWN (SITE 4)

\begin{tabular}{|c|c|c|c|c|c|c|}
\hline Year & $\begin{array}{c}\text { Total } \\
\text { number of } \\
\text { organisms }\end{array}$ & $\begin{array}{c}\text { Total } \\
\text { number } \\
\text { of taxa }\end{array}$ & $\begin{array}{c}\text { Brillouin's } \\
\text { diversity index } \\
\text { (H) }\end{array}$ & $\begin{array}{l}\text { Maximum } \\
\text { diversity } \\
\left(\mathrm{H}_{\max }\right)\end{array}$ & $\begin{array}{c}\text { Minimum } \\
\text { diversity } \\
\left(\mathrm{H}_{\min }\right)\end{array}$ & $\begin{array}{c}\text { Evenness } \\
(\mathrm{E})\end{array}$ \\
\hline 1981 & 3,611 & 32 & 2.68 & 4.96 & 0.10 & 0.53 \\
\hline 1982 & 1,887 & 31 & 3.23 & 4.97 & .17 & .64 \\
\hline 1983 & ${ }^{1} 1,316$ & 27 & 3.42 & 4.72 & .21 & .71 \\
\hline 1984 & 1,943 & 26 & 3.14 & 4.72 & .14 & .66 \\
\hline 1985 & 557 & 27 & 3.26 & 4.72 & .42 & .66 \\
\hline 1986 & 2,593 & 38 & 2.93 & 5.25 & .15 & .54 \\
\hline 1987 & 2,312 & 36 & 3.34 & 5.16 & .17 & .64 \\
\hline 1988 & ${ }^{1} 4,090$ & 36 & 2.99 & 5.17 & .10 & .57 \\
\hline 1989 & 1,147 & 39 & 3.85 & 5.23 & .34 & .72 \\
\hline 1990 & 1,684 & 37 & 3.14 & 5.19 & .23 & .59 \\
\hline 1991 & 1,514 & 34 & 3.21 & 5.05 & .23 & .62 \\
\hline 1992 & 2,247 & 46 & 3.98 & 5.53 & .22 & .71 \\
\hline 1993 & 2,535 & 48 & 3.96 & 5.59 & .21 & .70 \\
\hline 1994 & 1,325 & 40 & 3.50 & 5.32 & .31 & .64 \\
\hline
\end{tabular}

${ }^{1}$ Extrapolated from a $3 / 8$ subsample.

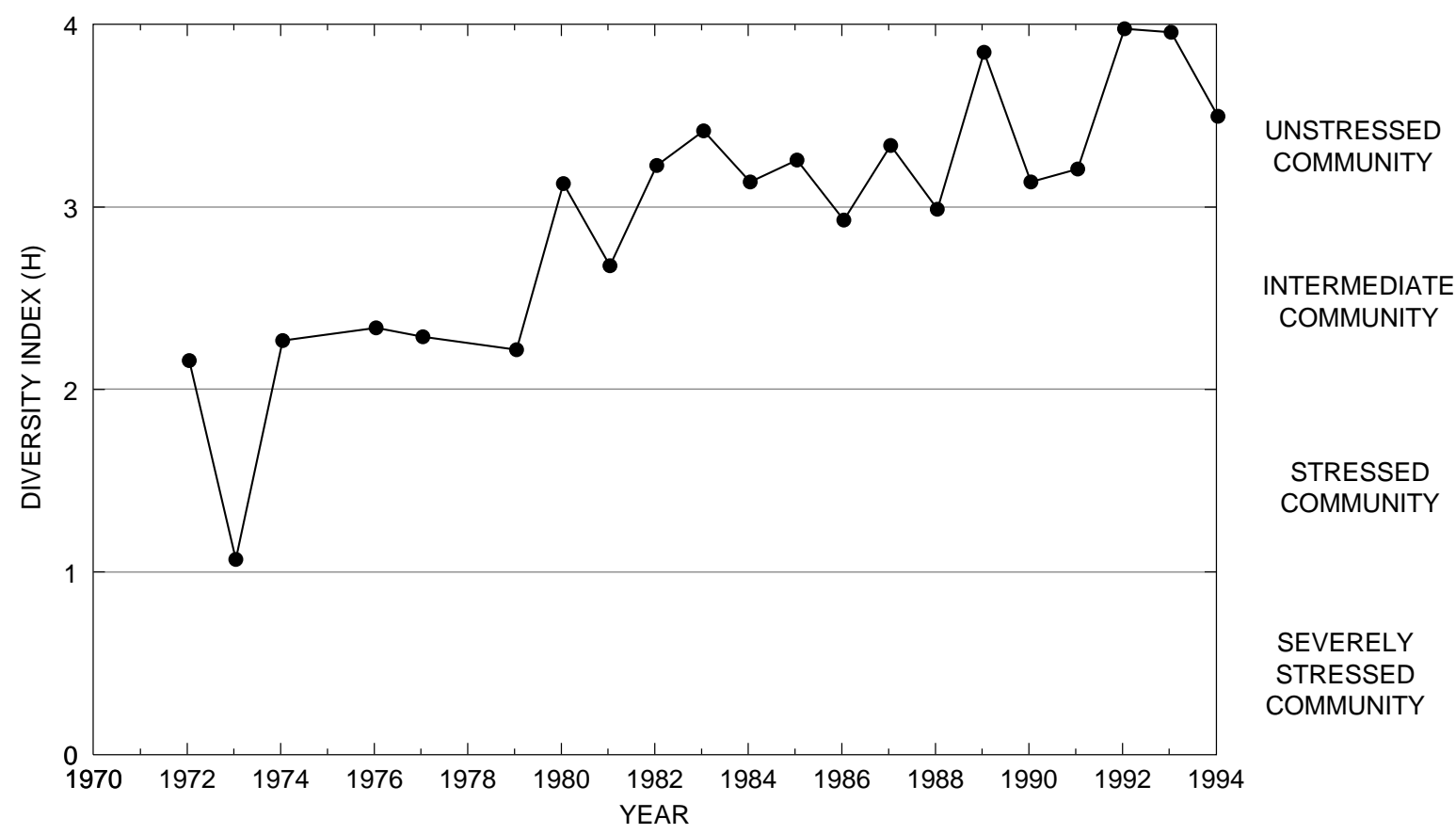


Table 6. Brillouin's diversity index, maximum diversity, minimum diversity, and relative evenness by site-Continued 01472190 PICKERING CREEK NEAR PHOENIXVILLE (SITE 5)

\begin{tabular}{|c|c|c|c|c|c|c|}
\hline Year & $\begin{array}{c}\text { Total } \\
\text { number of } \\
\text { organisms }\end{array}$ & $\begin{array}{c}\text { Total } \\
\text { number } \\
\text { of taxa }\end{array}$ & $\begin{array}{c}\text { Brillouin's } \\
\text { diversity index } \\
\text { (H) }\end{array}$ & $\begin{array}{l}\text { Maximum } \\
\text { diversity } \\
\left(\mathrm{H}_{\max }\right)\end{array}$ & $\begin{array}{c}\text { Minimum } \\
\text { diversity } \\
\left(\mathrm{H}_{\min }\right)\end{array}$ & $\begin{array}{c}\text { Evenness } \\
(\mathrm{E})\end{array}$ \\
\hline 1981 & 2,081 & 32 & 2.77 & 4.98 & 0.17 & 0.54 \\
\hline 1982 & 3,232 & 39 & 3.00 & 5.30 & .14 & .56 \\
\hline 1983 & 2,183 & 38 & 3.50 & 5.18 & .19 & .66 \\
\hline 1984 & 1,513 & 32 & 3.38 & 4.92 & .22 & .67 \\
\hline 1985 & 438 & 30 & 3.32 & 4.81 & .58 & .65 \\
\hline 1986 & 1,150 & 40 & 3.46 & 5.34 & .34 & .62 \\
\hline 1987 & 2,029 & 39 & 3.55 & 5.30 & .21 & .66 \\
\hline 1988 & ${ }^{1} 2,651$ & 28 & 2.83 & 4.81 & .12 & .58 \\
\hline 1989 & 373 & 34 & 3.64 & 5.13 & .75 & .66 \\
\hline 1990 & 948 & 30 & 2.53 & 4.88 & .49 & .49 \\
\hline 1991 & 3,066 & 42 & 3.28 & 5.37 & .16 & .60 \\
\hline 1992 & 1,775 & 47 & 3.78 & 5.78 & .28 & .66 \\
\hline 1993 & 1,259 & 36 & 2.95 & 5.18 & .29 & .55 \\
\hline 1994 & 1,177 & 29 & 2.72 & 4.87 & .24 & .54 \\
\hline
\end{tabular}

${ }^{1}$ Extrapolated from a $3 / 8$ subsample.

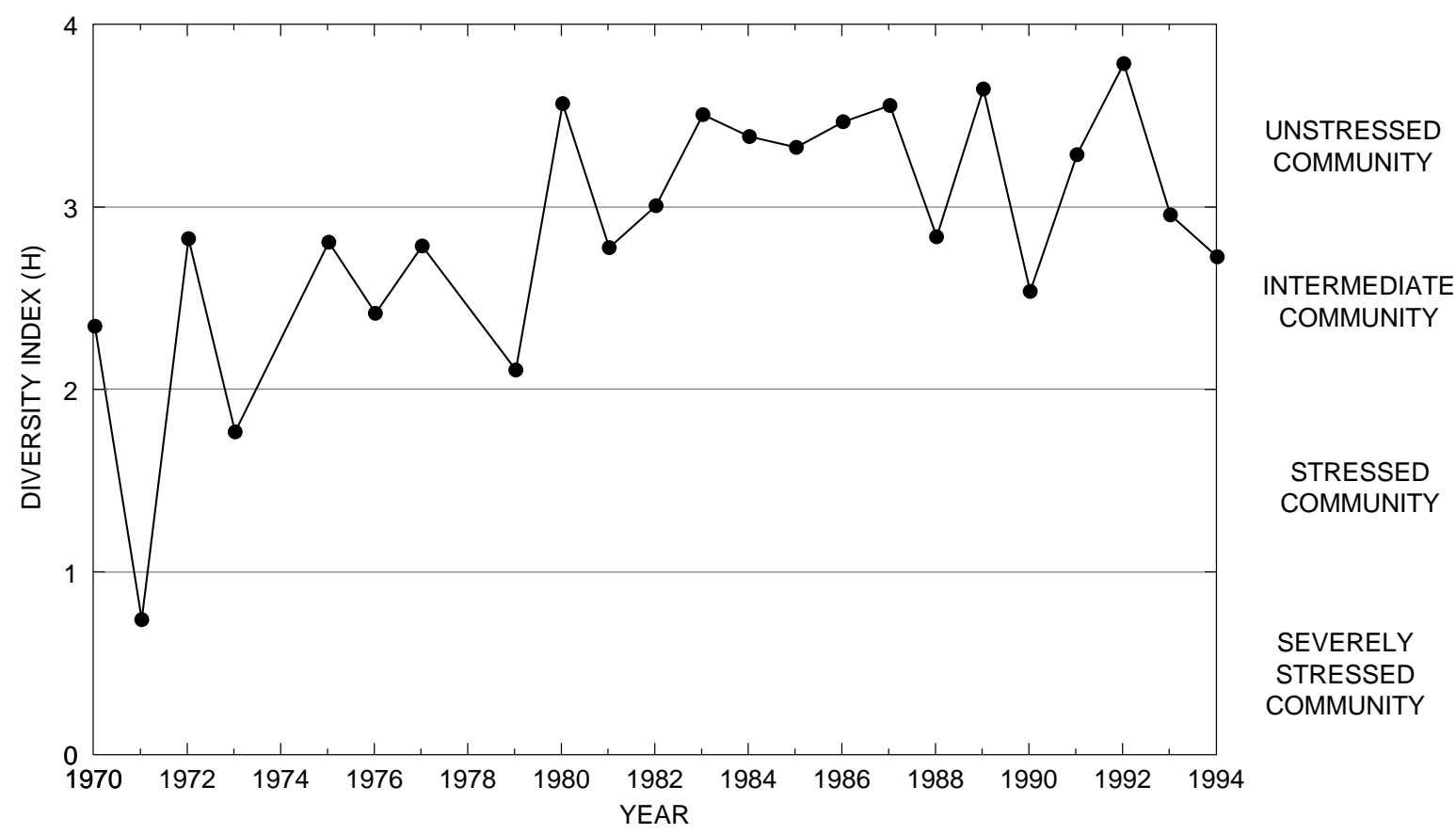


Table 6. Brillouin's diversity index, maximum diversity, minimum diversity, and relative evenness by site—Continued

\section{LITTLE VALLEY CREEK AT HOWELLVILLE (SITE 49)}

\begin{tabular}{|c|c|c|c|c|c|c|}
\hline Year & $\begin{array}{c}\text { Total } \\
\text { number of } \\
\text { organisms }\end{array}$ & $\begin{array}{c}\text { Total } \\
\text { number } \\
\text { of taxa }\end{array}$ & $\begin{array}{l}\text { Brillouin's } \\
\text { diversity index } \\
\text { (H) }\end{array}$ & $\begin{array}{c}\text { Maximum } \\
\text { diversity } \\
\left(\mathrm{H}_{\max }\right)\end{array}$ & $\begin{array}{c}\text { Minimum } \\
\text { diversity } \\
\left(\mathrm{H}_{\min }\right)\end{array}$ & $\begin{array}{c}\text { Evenness } \\
\text { (E) }\end{array}$ \\
\hline 1981 & 2,871 & 20 & 2.70 & 4.31 & 0.08 & 0.62 \\
\hline 1982 & 2,454 & 21 & 2.76 & 4.37 & .09 & .62 \\
\hline 1983 & 1,231 & 18 & 2.66 & 4.13 & .14 & .63 \\
\hline 1984 & 1,218 & 17 & 2.65 & 4.05 & .14 & .64 \\
\hline 1985 & 551 & 20 & 2.82 & 4.27 & .31 & .63 \\
\hline 1986 & 1,102 & 17 & 3.10 & 4.05 & .15 & .75 \\
\hline 1987 & 1,357 & 15 & 3.06 & 3.89 & .11 & .78 \\
\hline 1988 & ${ }^{1} 1,375$ & 20 & 3.17 & 4.32 & .14 & .73 \\
\hline 1989 & 346 & 17 & 3.10 & 4.01 & .39 & .75 \\
\hline 1990 & 518 & 15 & 3.14 & 3.84 & .24 & .80 \\
\hline 1991 & 481 & 14 & 2.95 & 3.78 & .24 & .77 \\
\hline 1992 & 913 & 19 & 3.17 & 4.19 & .19 & .74 \\
\hline 1993 & 804 & 16 & 2.83 & 3.83 & .18 & .71 \\
\hline 1994 & 1,068 & 15 & 3.30 & 3.86 & .13 & .85 \\
\hline
\end{tabular}

${ }^{1}$ Extrapolated from a $3 / 8$ subsample.

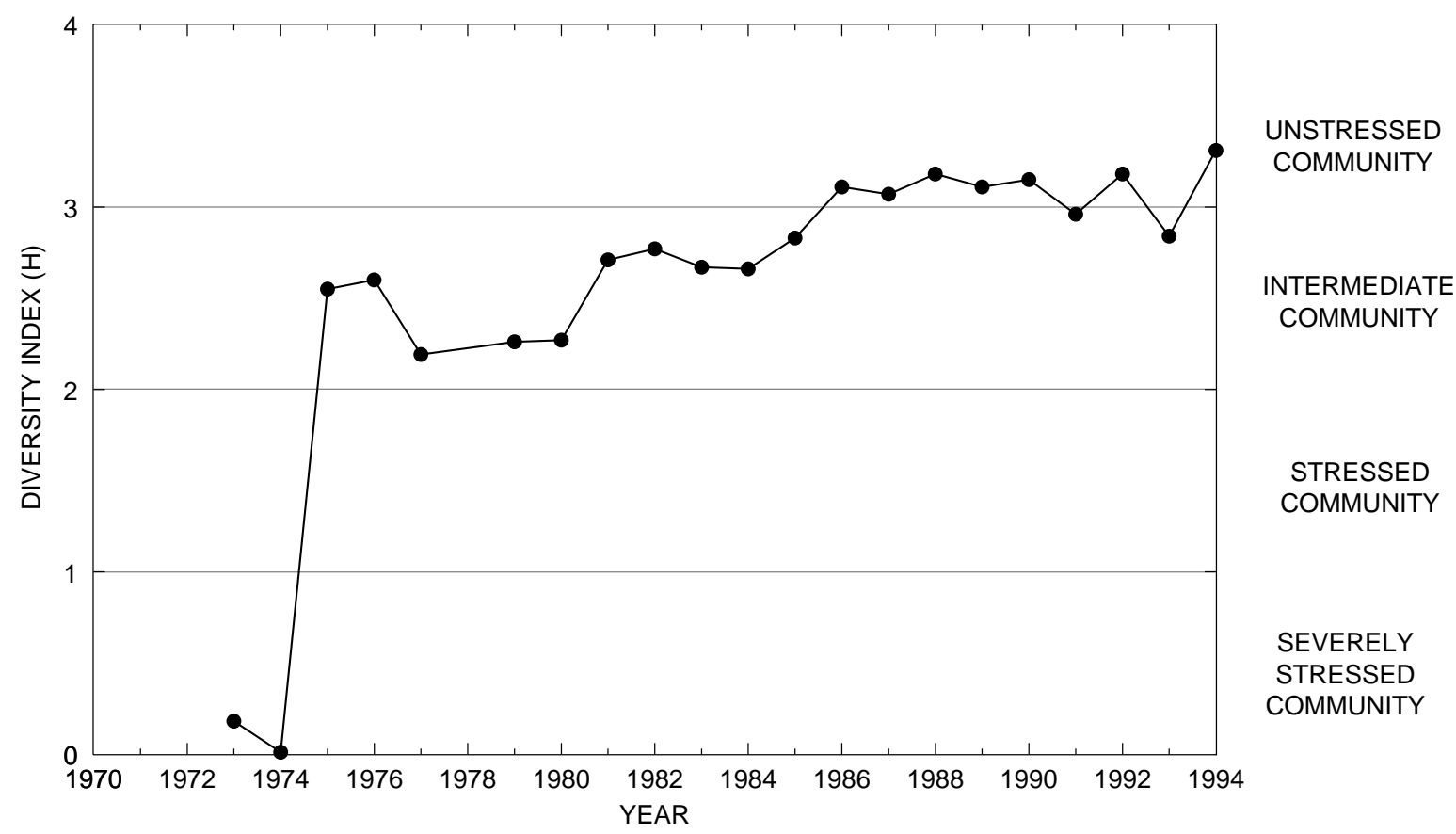


Table 6. Brillouin's diversity index, maximum diversity, minimum diversity, and relative evenness by site-Continued

01473168 VALLEY CREEK NEAR VALLEY FORGE (SITE 50)

\begin{tabular}{|c|c|c|c|c|c|c|}
\hline Year & $\begin{array}{c}\text { Total } \\
\text { number of } \\
\text { organisms }\end{array}$ & $\begin{array}{c}\text { Total } \\
\text { number } \\
\text { of taxa }\end{array}$ & $\begin{array}{c}\text { Brillouin's } \\
\text { diversity index } \\
\text { (H) }\end{array}$ & $\begin{array}{l}\text { Maximum } \\
\text { diversity } \\
\left(\mathrm{H}_{\max }\right)\end{array}$ & $\begin{array}{c}\text { Minimum } \\
\text { diversity } \\
\left(\mathrm{H}_{\min }\right)\end{array}$ & $\begin{array}{c}\text { Evenness } \\
(\mathrm{E})\end{array}$ \\
\hline 1981 & 2,183 & 20 & 2.51 & 4.29 & 0.10 & 0.58 \\
\hline 1982 & 3,144 & 20 & 2.67 & 4.33 & .07 & .61 \\
\hline 1983 & 1,745 & 16 & 2.66 & 3.96 & .09 & .66 \\
\hline 1984 & 2,073 & 21 & 2.68 & 4.35 & .11 & .61 \\
\hline 1985 & 1,354 & 19 & 2.77 & 4.25 & .14 & .64 \\
\hline 1986 & 1,820 & 19 & 2.77 & 4.20 & .11 & .65 \\
\hline 1987 & 1,625 & 22 & 3.13 & 4.47 & .14 & .69 \\
\hline 1988 & $1_{2,278}$ & 15 & 2.78 & 3.92 & .07 & .71 \\
\hline 1989 & 1,046 & 22 & 3.37 & 4.43 & .20 & .75 \\
\hline 1990 & 1,557 & 19 & 2.90 & 4.27 & .12 & .67 \\
\hline 1991 & 1,020 & 21 & 3.02 & 4.38 & .20 & .68 \\
\hline 1992 & 1,848 & 23 & 3.20 & 4.50 & .13 & .70 \\
\hline 1993 & 1,307 & 22 & 2.71 & 4.46 & .17 & .59 \\
\hline 1994 & 1,561 & 23 & 3.15 & 4.55 & .15 & .68 \\
\hline
\end{tabular}

${ }^{1}$ Extrapolated from a $3 / 8$ subsample.

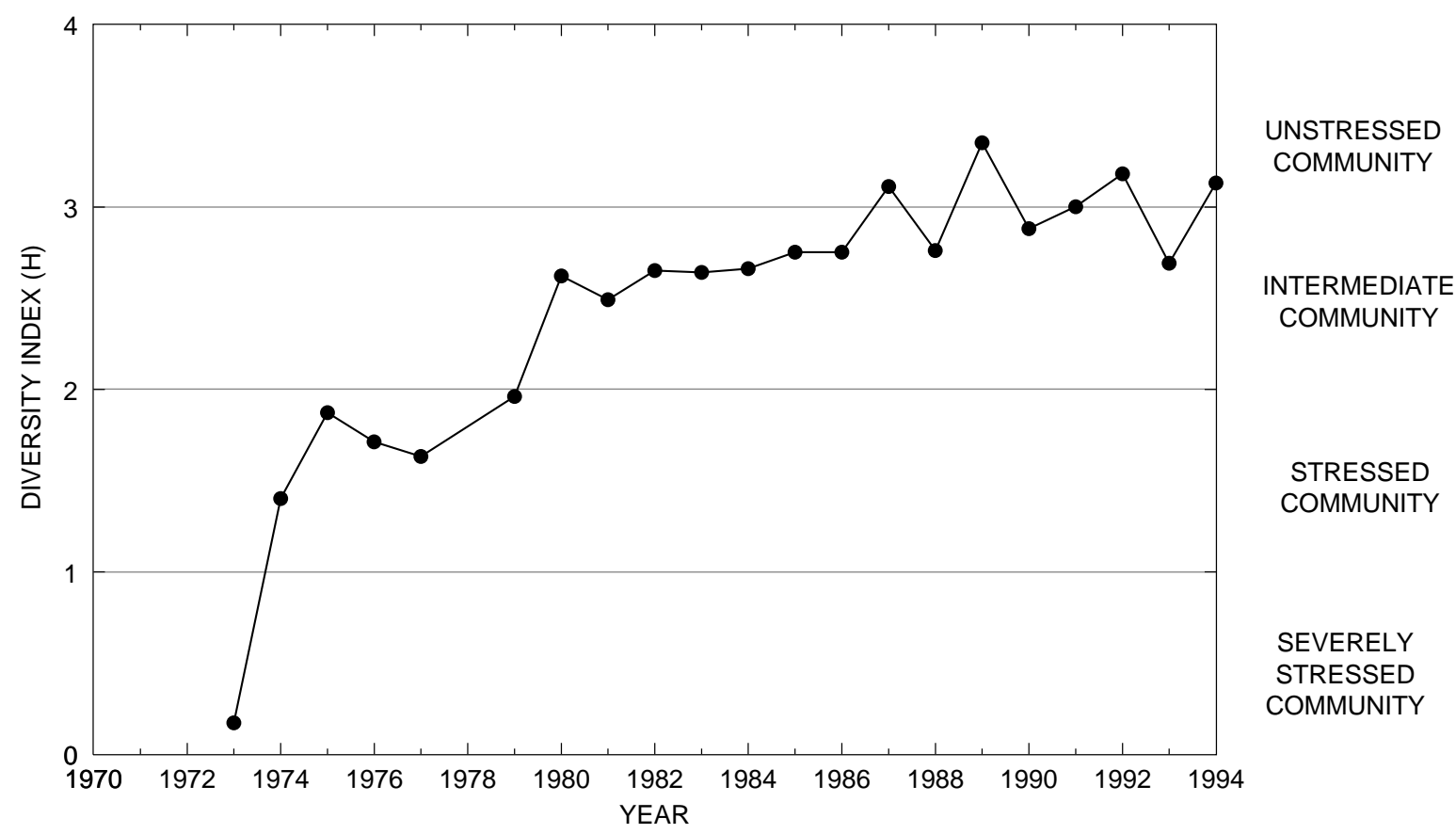


Table 6. Brillouin's diversity index, maximum diversity, minimum diversity, and relative evenness by site—Continued

01475300 DARBY CREEK AT WATERLOO MILLS NEAR DEVON (SITE 17)

\begin{tabular}{|c|c|c|c|c|c|c|}
\hline Year & $\begin{array}{c}\text { Total } \\
\text { number of } \\
\text { organisms }\end{array}$ & $\begin{array}{c}\text { Total } \\
\text { number } \\
\text { of taxa }\end{array}$ & $\begin{array}{c}\text { Brillouin's } \\
\text { diversity index } \\
\text { (H) }\end{array}$ & $\begin{array}{l}\text { Maximum } \\
\text { diversity } \\
\left(\mathrm{H}_{\max }\right)\end{array}$ & $\begin{array}{c}\text { Minimum } \\
\text { diversity } \\
\left(\mathrm{H}_{\min }\right)\end{array}$ & $\begin{array}{c}\text { Evenness } \\
(\mathrm{E})\end{array}$ \\
\hline 1981 & 524 & 23 & 3.35 & 4.57 & 0.38 & 0.71 \\
\hline 1982 & 215 & 20 & 3.44 & 4.30 & .68 & .76 \\
\hline 1983 & 403 & 28 & 3.26 & 4.71 & .58 & .65 \\
\hline 1984 & 1,208 & 28 & 3.68 & 4.73 & .23 & .77 \\
\hline 1985 & 968 & 26 & 3.42 & 4.62 & .26 & .73 \\
\hline 1986 & 706 & 26 & 3.57 & 4.62 & .33 & .76 \\
\hline 1987 & 1,115 & 27 & 3.70 & 4.70 & .24 & .78 \\
\hline 1988 & ${ }^{1} 2,008$ & 24 & 2.60 & 4.59 & .12 & .56 \\
\hline 1989 & 1,165 & 39 & 3.75 & 5.32 & .33 & .69 \\
\hline 1990 & 450 & 19 & 2.89 & 4.21 & .35 & .66 \\
\hline 1991 & 1,352 & 24 & 2.47 & 4.57 & .18 & .52 \\
\hline 1992 & 918 & 35 & 3.40 & 5.04 & .36 & .65 \\
\hline 1993 & 369 & 19 & 1.51 & 4.20 & .41 & .29 \\
\hline 1994 & 883 & 29 & 3.19 & 4.80 & .31 & .64 \\
\hline
\end{tabular}

${ }^{1}$ Extrapolated from a $3 / 8$ subsample.

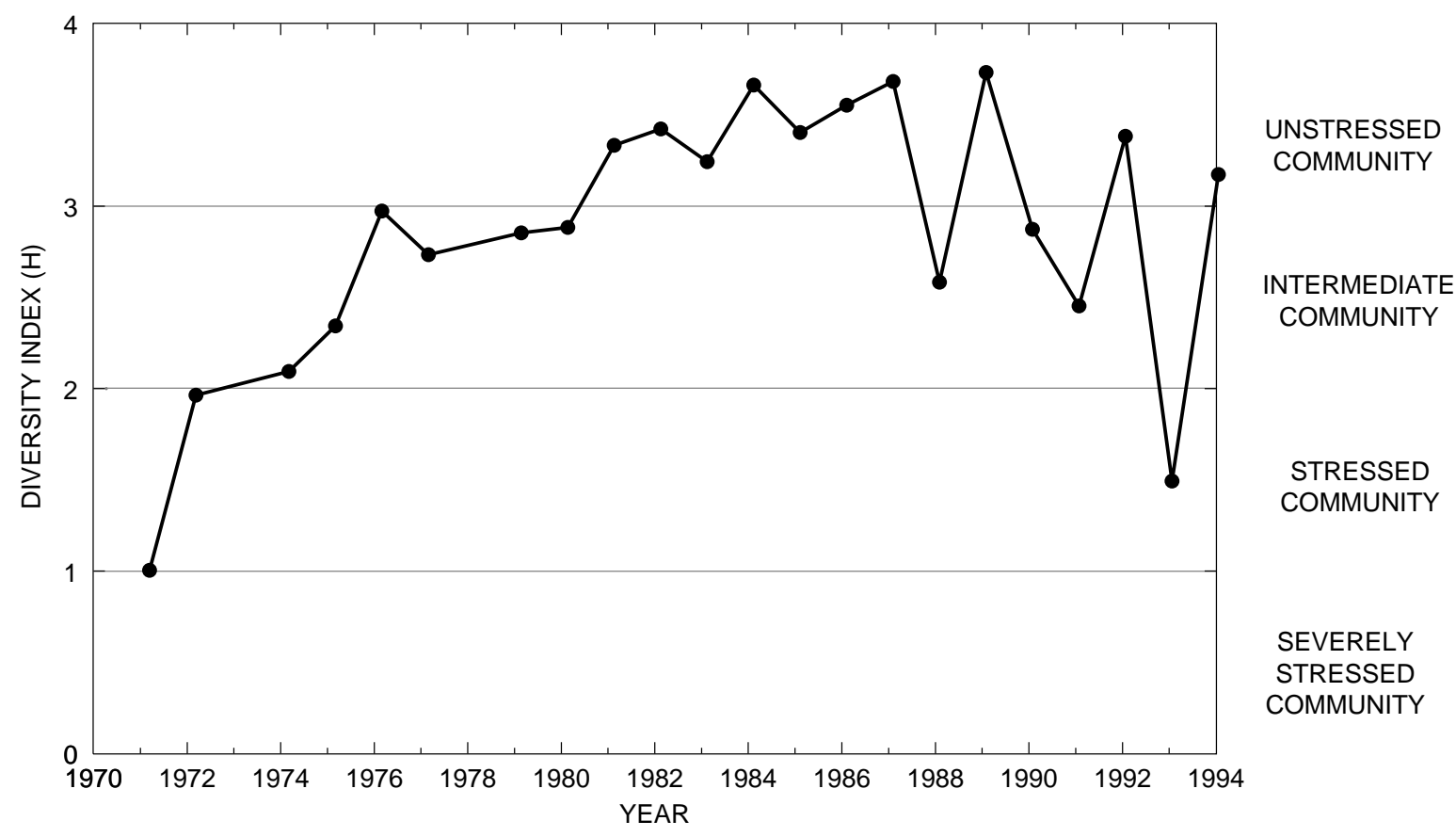


Table 6. Brillouin's diversity index, maximum diversity, minimum diversity, and relative evenness by site—Continued 01475830 CRUM CREEK NEAR PAOLI (SITE 18)

\begin{tabular}{ccccccc}
\hline Year & $\begin{array}{c}\text { Total } \\
\text { number of } \\
\text { organisms }\end{array}$ & $\begin{array}{c}\text { Total } \\
\text { number } \\
\text { of taxa }\end{array}$ & $\begin{array}{c}\text { Brillouin's } \\
\text { diversity index } \\
(\mathrm{H})\end{array}$ & $\begin{array}{c}\text { Maximum } \\
\text { diversity } \\
\left(\mathrm{H}_{\text {max }}\right)\end{array}$ & $\begin{array}{c}\text { Minimum } \\
\text { diversity } \\
\left(\mathrm{H}_{\text {min }}\right)\end{array}$ & $\begin{array}{c}\text { Evenness } \\
(\mathrm{E})\end{array}$ \\
\hline 1981 & 1,133 & 29 & 3.53 & 4.78 & 0.25 & 0.73 \\
1982 & 581 & 27 & 3.62 & 4.68 & .41 & .75 \\
\hline
\end{tabular}

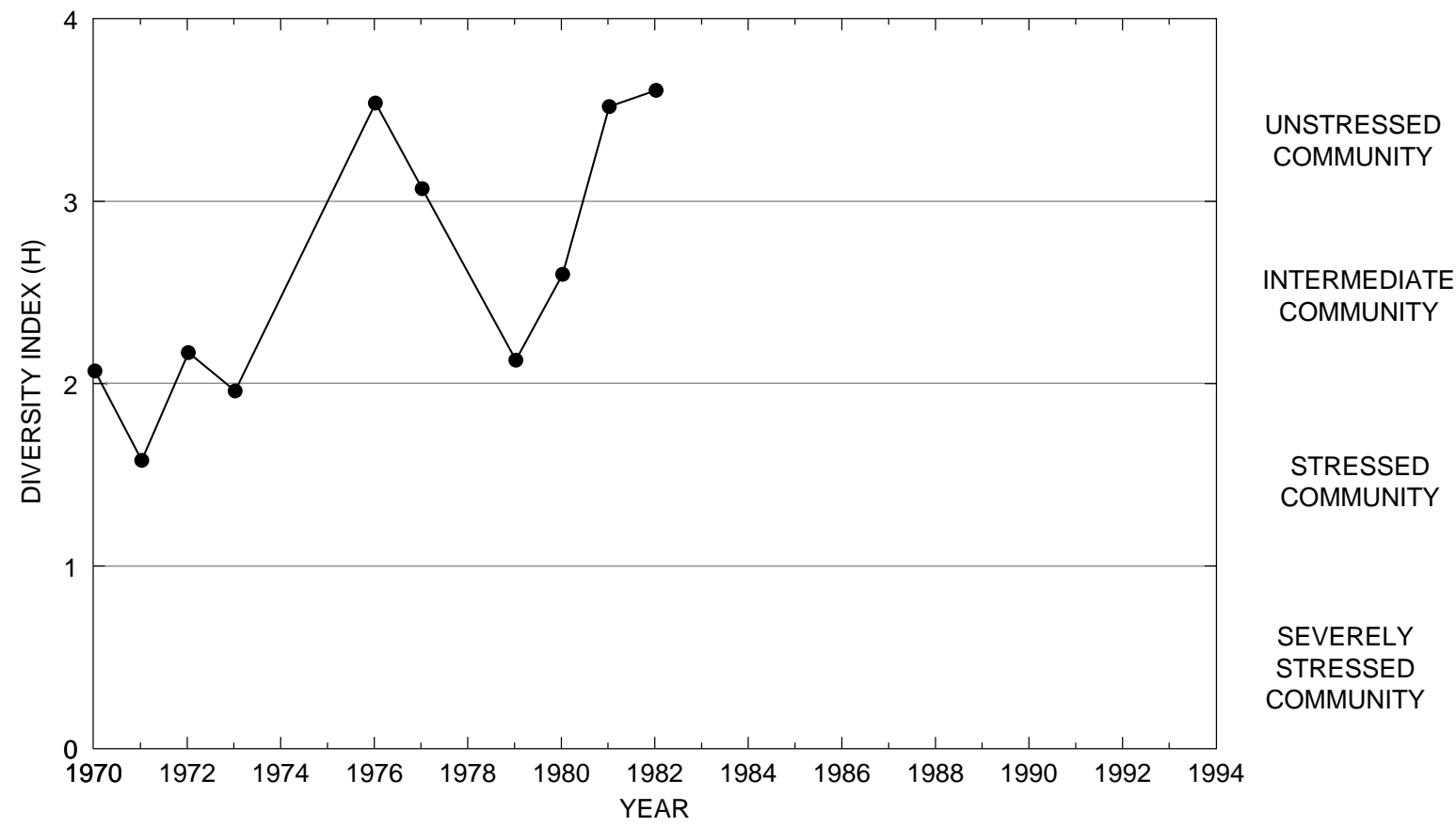


Table 6. Brillouin's diversity index, maximum diversity, minimum diversity, and relative evenness by site-Continued

01475840 CRUM CREEK AT WHITEHORSE (SITE 19)

\begin{tabular}{|c|c|c|c|c|c|c|}
\hline Year & $\begin{array}{c}\text { Total } \\
\text { number of } \\
\text { organisms }\end{array}$ & $\begin{array}{c}\text { Total } \\
\text { number } \\
\text { of taxa }\end{array}$ & $\begin{array}{l}\text { Brillouin's } \\
\text { diversity index } \\
\text { (H) }\end{array}$ & $\begin{array}{c}\text { Maximum } \\
\text { diversity } \\
\left(\mathrm{H}_{\max }\right)\end{array}$ & $\begin{array}{c}\text { Minimum } \\
\text { diversity } \\
\left(\mathrm{H}_{\min }\right)\end{array}$ & $\begin{array}{c}\text { Evenness } \\
\text { (E) }\end{array}$ \\
\hline 1981 & 992 & 38 & 3.61 & 5.14 & 0.37 & 0.68 \\
\hline 1982 & 1,636 & 35 & 3.38 & 5.11 & .22 & .65 \\
\hline 1983 & 525 & 30 & 3.12 & 4.85 & .50 & .60 \\
\hline 1984 & 1,222 & 26 & 3.07 & 4.73 & .21 & .63 \\
\hline 1985 & 568 & 28 & 2.85 & 4.73 & .43 & .56 \\
\hline 1986 & 907 & 28 & 2.85 & 4.78 & .29 & .57 \\
\hline 1987 & 1,285 & 33 & 3.91 & 5.08 & .26 & .76 \\
\hline 1988 & ${ }^{1} 2,028$ & 24 & 2.01 & 4.59 & .13 & .42 \\
\hline 1989 & 1,644 & 38 & 3.33 & 5.19 & .24 & .62 \\
\hline 1990 & 1,117 & 37 & 3.30 & 5.12 & .33 & .62 \\
\hline 1991 & 1,789 & 36 & 3.24 & 5.20 & .21 & .61 \\
\hline 1992 & 1,881 & 32 & 3.18 & 4.99 & .18 & .62 \\
\hline 1993 & 538 & 25 & 3.14 & 4.62 & .40 & .65 \\
\hline 1994 & 1,240 & 32 & 3.54 & 4.97 & .26 & .70 \\
\hline
\end{tabular}

${ }^{1}$ Extrapolated from a $3 / 8$ subsample.

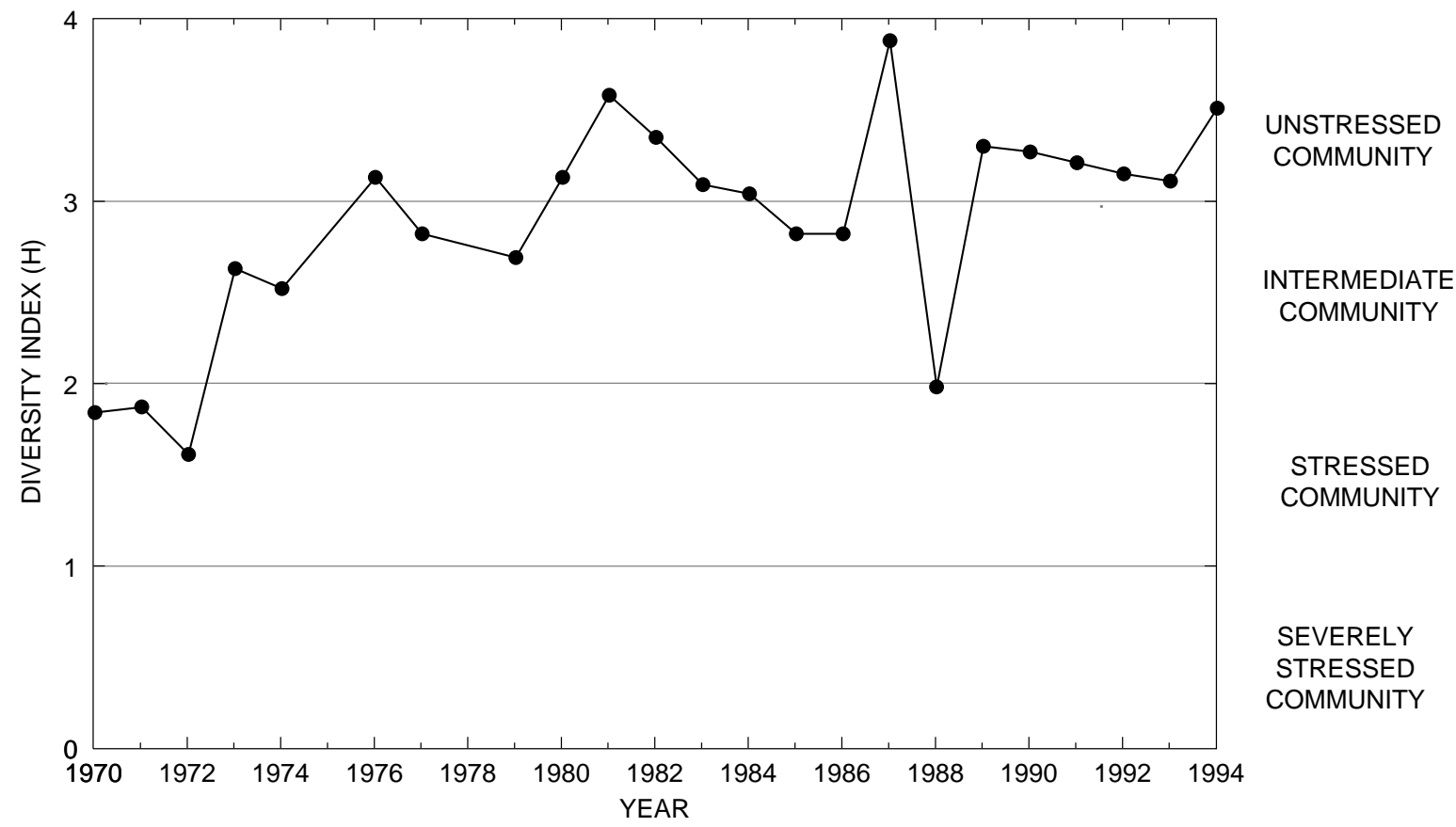


Table 6. Brillouin's diversity index, maximum diversity, minimum diversity, and relative evenness by site—Continued 01476430 RIDLEY CREEK AT GOSHENVILLE (SITE 20)

\begin{tabular}{|c|c|c|c|c|c|c|}
\hline Year & $\begin{array}{c}\text { Total } \\
\text { number of } \\
\text { organisms }\end{array}$ & $\begin{array}{c}\text { Total } \\
\text { number } \\
\text { of taxa }\end{array}$ & $\begin{array}{c}\text { Brillouin's } \\
\text { diversity index } \\
\text { (H) }\end{array}$ & $\begin{array}{l}\text { Maximum } \\
\text { diversity } \\
\left(\mathrm{H}_{\max }\right)\end{array}$ & $\begin{array}{c}\text { Minimum } \\
\text { diversity } \\
\left(\mathrm{H}_{\min }\right)\end{array}$ & $\begin{array}{c}\text { Evenness } \\
(\mathrm{E})\end{array}$ \\
\hline 1981 & 241 & 27 & 3.14 & 4.78 & 0.85 & 0.58 \\
\hline 1982 & ${ }^{1} 1,345$ & 29 & 3.60 & 4.81 & .22 & .74 \\
\hline 1983 & ${ }^{1} 855$ & 22 & 3.31 & 4.45 & .24 & .73 \\
\hline 1984 & ${ }^{1} 1,688$ & 21 & 3.02 & 4.42 & .13 & .67 \\
\hline 1985 & 722 & 19 & 2.89 & 4.27 & .24 & .66 \\
\hline 1986 & 980 & 26 & 3.61 & 4.68 & .25 & .76 \\
\hline 1987 & 1,881 & 30 & 3.73 & 4.90 & .17 & .75 \\
\hline 1988 & ${ }^{1} 1,660$ & 26 & 3.39 & 4.65 & .16 & .72 \\
\hline 1989 & 767 & 26 & 3.16 & 4.66 & .31 & .65 \\
\hline 1990 & 757 & 30 & 2.88 & 4.81 & .37 & .56 \\
\hline 1991 & 547 & 20 & 2.65 & 4.27 & .31 & .59 \\
\hline 1992 & 1,297 & 31 & 3.06 & 4.87 & .24 & .61 \\
\hline 1993 & 511 & 24 & 3.40 & 4.50 & .40 & .73 \\
\hline 1994 & 572 & 26 & 3.64 & 4.56 & .40 & .78 \\
\hline
\end{tabular}

${ }^{1}$ Extrapolated from a 3/8 subsample.

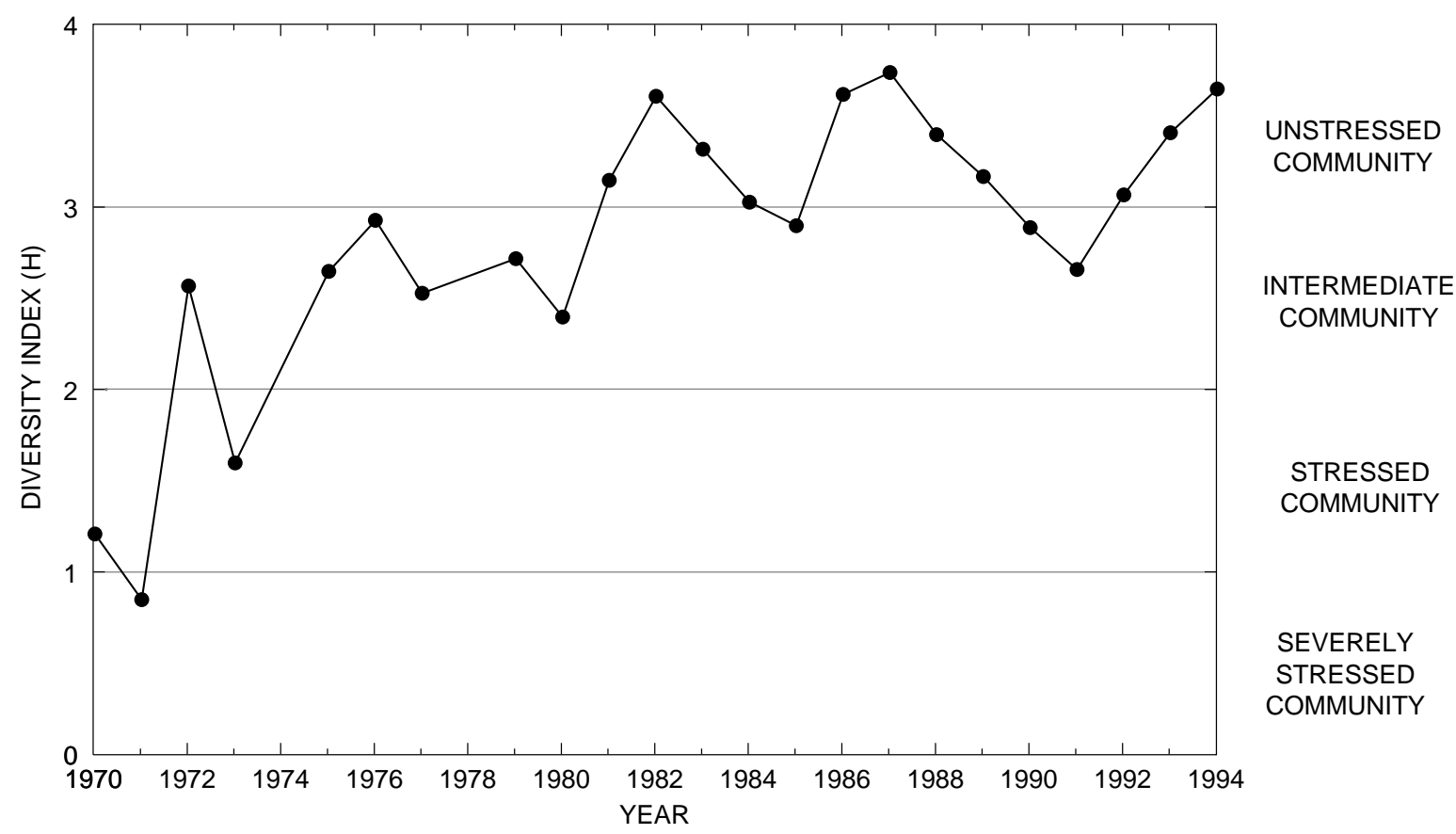


Table 6. Brillouin's diversity index, maximum diversity, minimum diversity, and relative evenness by site—Continued

01476435 RIDLEY CREEK AT DUTTON MILL NEAR WEST CHESTER (SITE 21)

\begin{tabular}{|c|c|c|c|c|c|c|}
\hline Year & $\begin{array}{c}\text { Total } \\
\text { number of } \\
\text { organisms }\end{array}$ & $\begin{array}{c}\text { Total } \\
\text { number } \\
\text { of taxa }\end{array}$ & $\begin{array}{l}\text { Brillouin's } \\
\text { diversity index } \\
\text { (H) }\end{array}$ & $\begin{array}{c}\text { Maximum } \\
\text { diversity } \\
\left(\mathrm{H}_{\max }\right)\end{array}$ & $\begin{array}{c}\text { Minimum } \\
\text { diversity } \\
\left(\mathrm{H}_{\min }\right)\end{array}$ & $\begin{array}{c}\text { Evenness } \\
\text { (E) }\end{array}$ \\
\hline 1981 & 1,407 & 33 & 3.52 & 5.02 & 0.24 & 0.69 \\
\hline 1982 & ${ }^{1} 1,578$ & 27 & 3.02 & 4.76 & .17 & .62 \\
\hline 1983 & ${ }^{1} 1,697$ & 32 & 3.34 & 5.02 & .20 & .65 \\
\hline 1984 & ${ }^{1} 3,842$ & 26 & 3.15 & 4.68 & .08 & .67 \\
\hline 1985 & 1,617 & 27 & 3.04 & 4.77 & .17 & .62 \\
\hline 1986 & 1,629 & 30 & 3.54 & 4.88 & .19 & .71 \\
\hline 1987 & 1,198 & 27 & 3.35 & 4.71 & .22 & .70 \\
\hline 1988 & ${ }^{1} 2,446$ & 25 & 3.07 & 4.66 & .11 & .65 \\
\hline 1989 & 1,347 & 29 & 2.77 & 4.84 & .22 & .55 \\
\hline 1990 & 2,813 & 39 & 2.94 & 5.30 & .16 & .54 \\
\hline 1991 & 1,509 & 21 & 2.45 & 4.37 & .14 & .55 \\
\hline 1992 & 1,391 & 32 & 3.20 & 4.96 & .23 & .63 \\
\hline 1993 & 1,467 & 36 & 3.45 & 5.17 & .25 & .65 \\
\hline 1994 & 1,322 & 28 & 3.32 & 4.73 & .21 & .69 \\
\hline
\end{tabular}

${ }^{1}$ Extrapolated from a $3 / 8$ subsample.

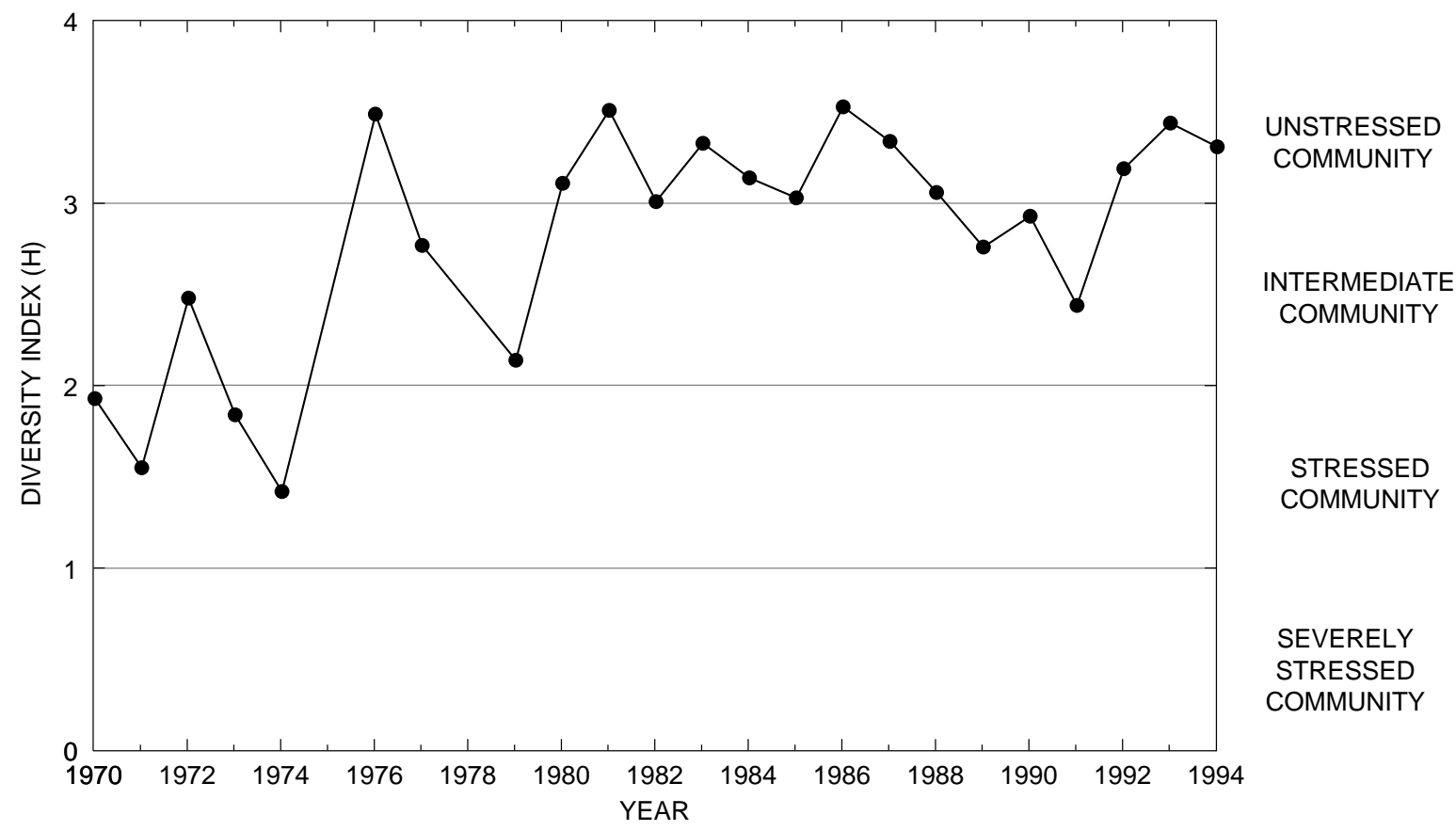


Table 6. Brillouin's diversity index, maximum diversity, minimum diversity, and relative evenness by site—Continued

01476790 EAST BRANCH CHESTER CREEK AT GREEN HILL (SITE 22)

\begin{tabular}{|c|c|c|c|c|c|c|}
\hline Year & $\begin{array}{c}\text { Total } \\
\text { number of } \\
\text { organisms }\end{array}$ & $\begin{array}{c}\text { Total } \\
\text { number } \\
\text { of taxa }\end{array}$ & $\begin{array}{c}\text { Brillouin's } \\
\text { diversity index } \\
\text { (H) }\end{array}$ & $\begin{array}{c}\text { Maximum } \\
\text { diversity } \\
\left(\mathrm{H}_{\max }\right)\end{array}$ & $\begin{array}{c}\text { Minimum } \\
\text { diversity } \\
\left(\mathrm{H}_{\min }\right)\end{array}$ & $\begin{array}{c}\text { Evenness } \\
\text { (E) }\end{array}$ \\
\hline 1981 & 323 & 25 & 3.44 & 4.68 & 0.62 & 0.70 \\
\hline 1982 & 464 & 20 & 3.32 & 4.23 & .36 & .77 \\
\hline 1983 & 319 & 22 & 3.20 & 4.39 & .54 & .69 \\
\hline 1984 & 519 & 21 & 3.21 & 4.36 & .35 & .71 \\
\hline 1985 & 247 & 13 & 3.21 & 3.54 & .38 & .89 \\
\hline 1986 & 338 & 21 & 3.17 & 4.25 & .49 & .71 \\
\hline 1987 & 1,304 & 32 & 3.46 & 5.01 & .25 & .67 \\
\hline 1988 & ${ }^{1} 1,014$ & 19 & 3.06 & 4.18 & .18 & .72 \\
\hline 1989 & 231 & 22 & 1.70 & 4.29 & .72 & .28 \\
\hline 1990 & 425 & 16 & 1.25 & 3.93 & .31 & .26 \\
\hline 1991 & 505 & 23 & 2.44 & 4.55 & .39 & .49 \\
\hline 1992 & 451 & 19 & 2.37 & 4.20 & .35 & .52 \\
\hline 1993 & 106 & 15 & 2.62 & 3.59 & .88 & .64 \\
\hline 1994 & 294 & 23 & 2.93 & 4.46 & .62 & .60 \\
\hline
\end{tabular}

${ }^{1}$ Extrapolated from a $3 / 8$ subsample.

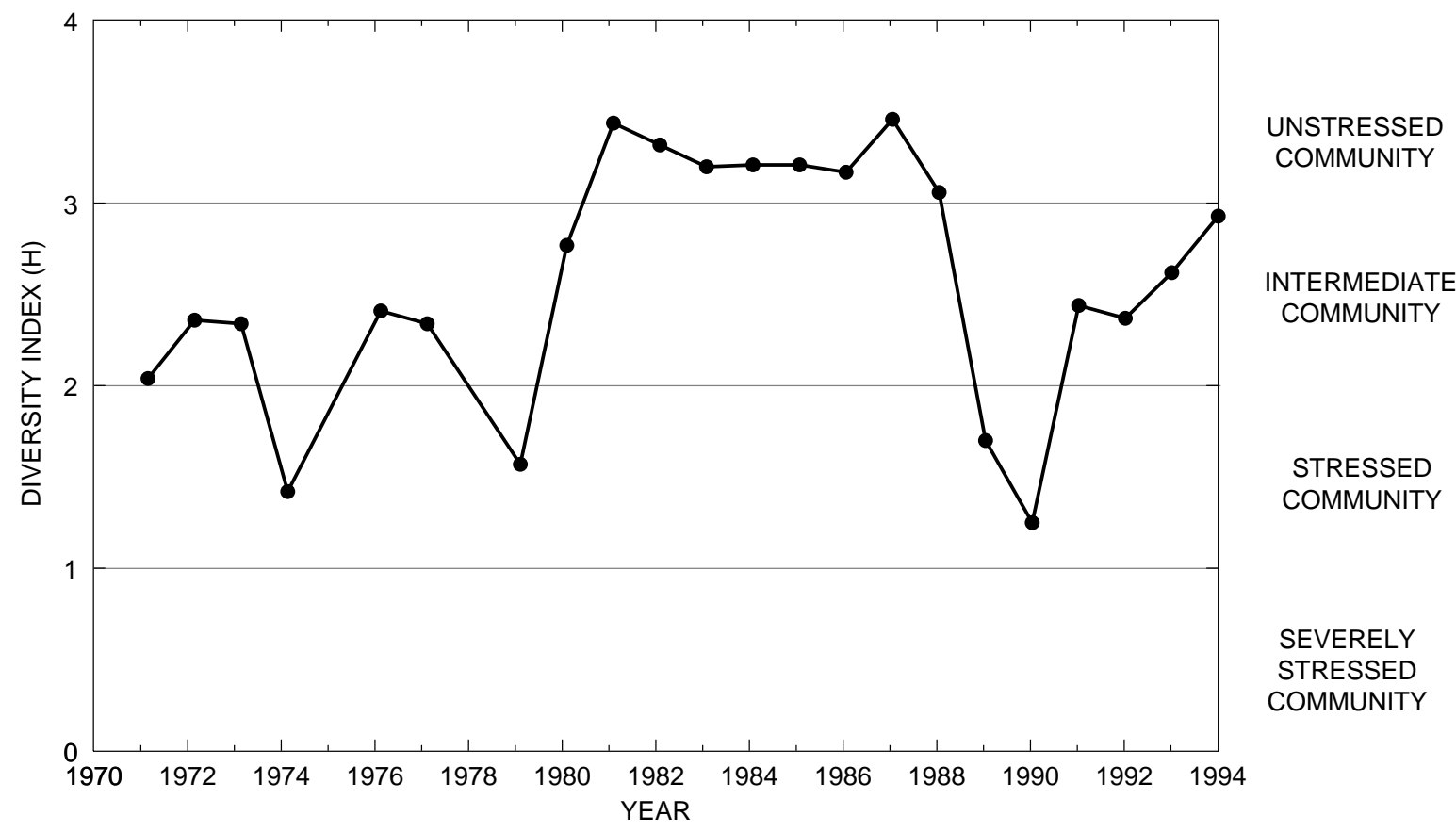


Table 6. Brillouin's diversity index, maximum diversity, minimum diversity, and relative evenness by site—Continued

01476830 EAST BRANCH CHESTER CREEK AT MILLTOWN (SITE 23)

\begin{tabular}{|c|c|c|c|c|c|c|}
\hline Year & $\begin{array}{c}\text { Total } \\
\text { number of } \\
\text { organisms }\end{array}$ & $\begin{array}{c}\text { Total } \\
\text { number } \\
\text { of taxa }\end{array}$ & $\begin{array}{c}\text { Brillouin's } \\
\text { diversity index } \\
\text { (H) }\end{array}$ & $\begin{array}{c}\text { Maximum } \\
\text { diversity } \\
\left(\mathrm{H}_{\max }\right)\end{array}$ & $\begin{array}{c}\text { Minimum } \\
\text { diversity } \\
\left(\mathrm{H}_{\min }\right)\end{array}$ & $\begin{array}{c}\text { Evenness } \\
(\mathrm{E})\end{array}$ \\
\hline 1981 & 1,371 & 28 & 2.84 & 4.73 & 0.20 & 0.58 \\
\hline 1982 & 1,700 & 27 & 2.98 & 4.70 & .16 & .62 \\
\hline 1983 & 1,247 & 31 & 3.16 & 4.90 & .25 & .63 \\
\hline 1984 & 1,085 & 29 & 3.36 & 4.82 & .26 & .68 \\
\hline 1985 & 991 & 25 & 3.51 & 4.55 & .24 & .76 \\
\hline 1986 & 518 & 19 & 2.66 & 4.12 & .32 & .62 \\
\hline 1987 & 2,252 & 31 & 3.72 & 4.92 & .15 & .75 \\
\hline 1988 & ${ }^{1} 2,477$ & 24 & 3.06 & 4.60 & .10 & .66 \\
\hline 1989 & 4,174 & 33 & 3.10 & 5.06 & .09 & .60 \\
\hline 1990 & 2,625 & 33 & 2.80 & 5.05 & .14 & .54 \\
\hline 1991 & 1,731 & 26 & 2.48 & 4.68 & .16 & .51 \\
\hline 1992 & 2,926 & 38 & 3.16 & 5.21 & .14 & .60 \\
\hline 1993 & 693 & 20 & 1.91 & 4.28 & .26 & .41 \\
\hline 1994 & 2,643 & 30 & 2.54 & 4.92 & .13 & .50 \\
\hline
\end{tabular}

${ }^{1}$ Extrapolated from a $3 / 8$ subsample.

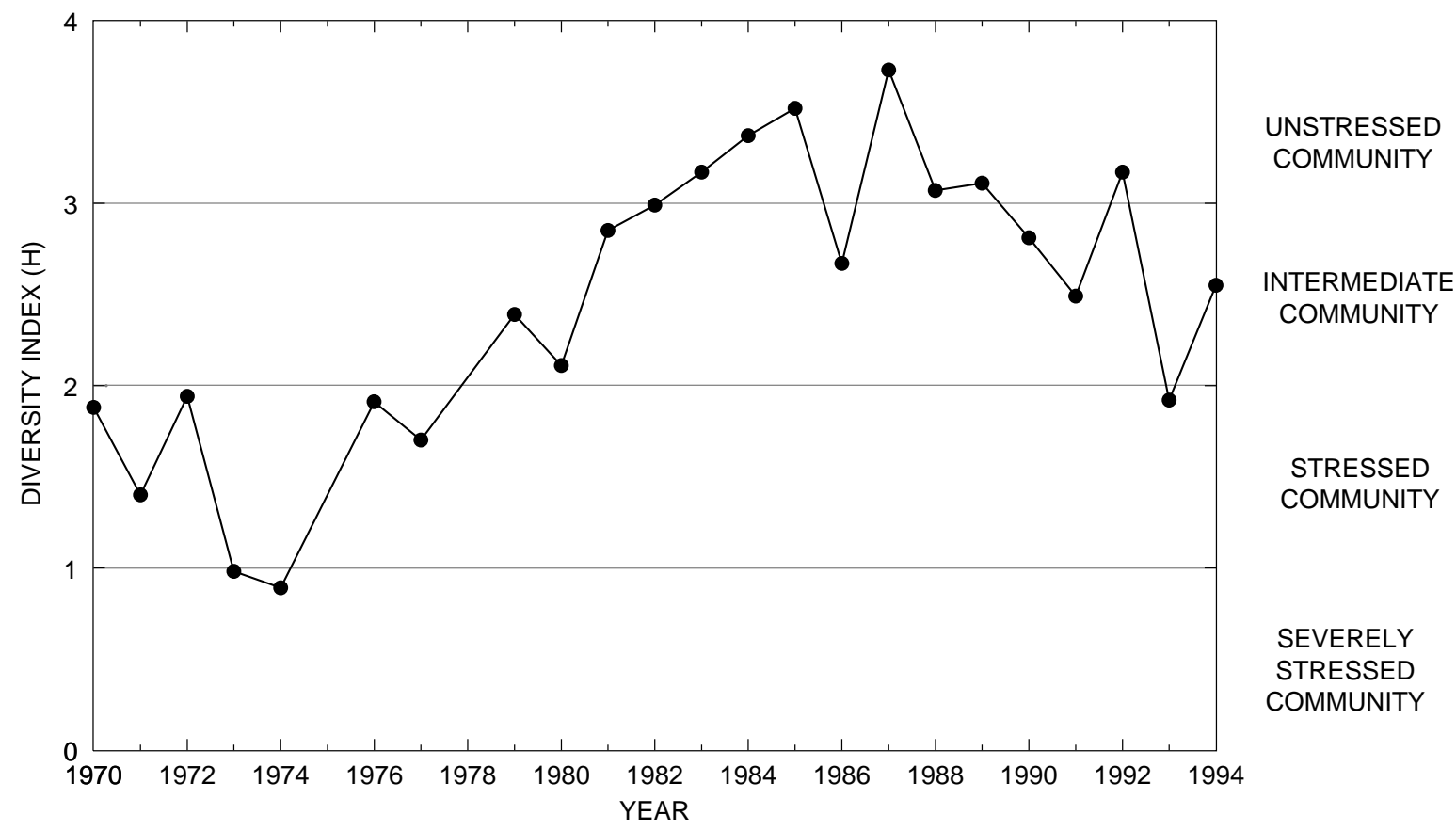


Table 6. Brillouin's diversity index, maximum diversity, minimum diversity, and relative evenness by site—Continued

01476835 EAST BRANCH CHESTER CREEK AT WESTTOWN (SITE 24)

\begin{tabular}{|c|c|c|c|c|c|c|}
\hline Year & $\begin{array}{c}\text { Total } \\
\text { number of } \\
\text { organisms }\end{array}$ & $\begin{array}{c}\text { Total } \\
\text { number } \\
\text { of taxa }\end{array}$ & $\begin{array}{c}\text { Brillouin's } \\
\text { diversity index } \\
\text { (H) }\end{array}$ & $\begin{array}{l}\text { Maximum } \\
\text { diversity } \\
\left(\mathrm{H}_{\max }\right)\end{array}$ & $\begin{array}{c}\text { Minimum } \\
\text { diversity } \\
\left(\mathrm{H}_{\min }\right)\end{array}$ & $\begin{array}{c}\text { Evenness } \\
(\mathrm{E})\end{array}$ \\
\hline 1981 & 1,783 & 28 & 3.21 & 4.83 & 0.16 & 0.65 \\
\hline 1982 & 3,535 & 22 & 2.52 & 4.45 & .07 & .56 \\
\hline 1983 & 2,250 & 30 & 3.19 & 4.85 & .14 & .65 \\
\hline 1984 & 2,424 & 30 & 3.30 & 4.86 & .13 & .67 \\
\hline 1985 & 1,365 & 25 & 2.18 & 4.60 & .18 & .45 \\
\hline 1986 & 1,026 & 19 & 3.10 & 4.27 & .18 & .71 \\
\hline 1987 & 2,592 & 29 & 3.15 & 4.87 & .12 & .64 \\
\hline 1988 & ${ }^{1} 1,677$ & 22 & 3.01 & 4.47 & .13 & .66 \\
\hline 1989 & 1,518 & 27 & 3.12 & 4.71 & .18 & .65 \\
\hline 1990 & 3,087 & 33 & 3.16 & 5.01 & .12 & .62 \\
\hline 1991 & 1,808 & 27 & 3.07 & 4.76 & .16 & .63 \\
\hline 1992 & 2,471 & 24 & 2.62 & 4.59 & .10 & .56 \\
\hline 1993 & 643 & 24 & 3.65 & 4.60 & .33 & .78 \\
\hline 1994 & 767 & 24 & 2.84 & 4.51 & .28 & .60 \\
\hline
\end{tabular}

${ }^{1}$ Extrapolated from a $3 / 8$ subsample.

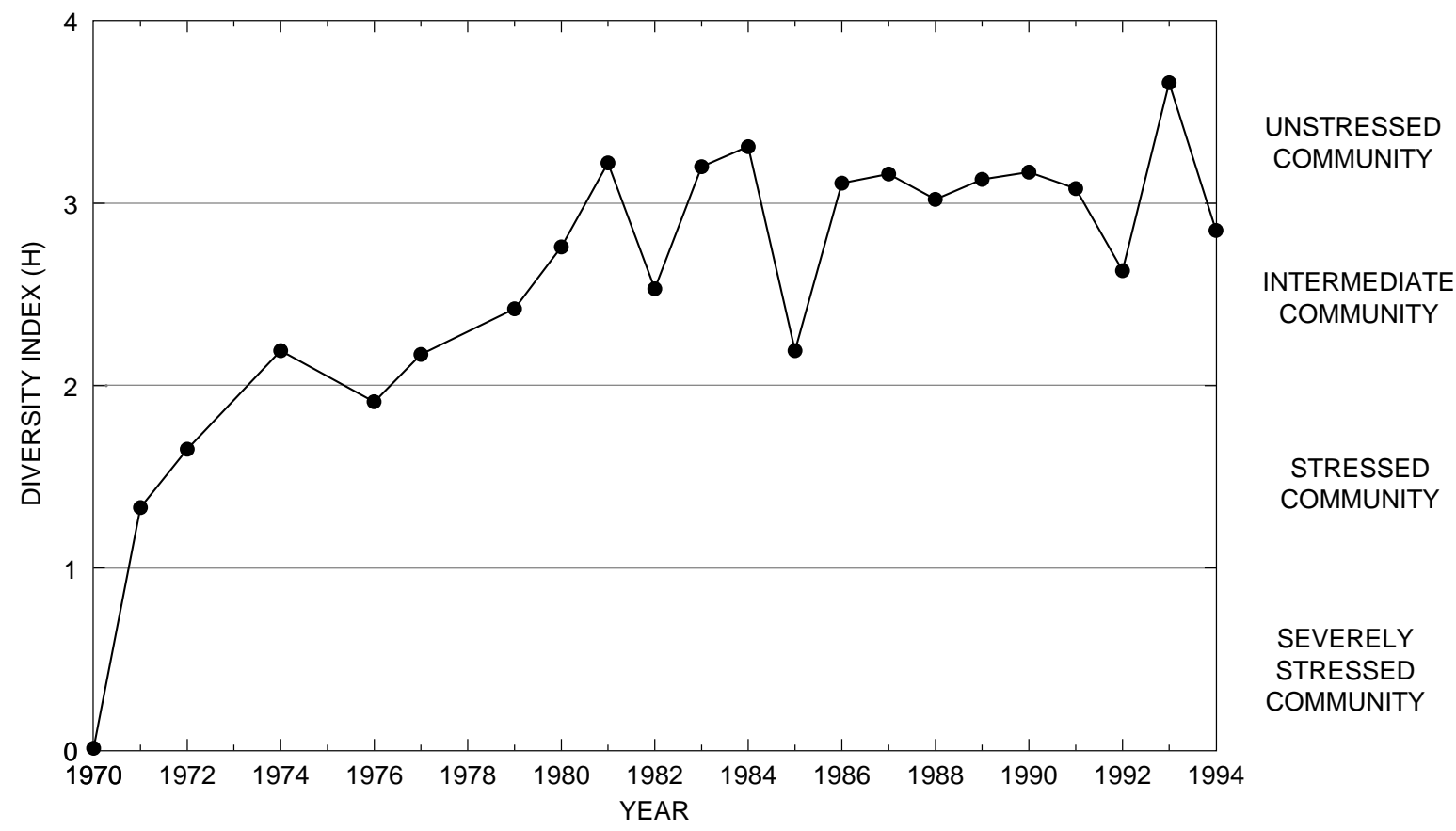


Table 6. Brillouin's diversity index, maximum diversity, minimum diversity, and relative evenness by site-Continued 01476840 GOOSE CREEK TRIBUTARY TO EAST BRANCH CHESTER CREEK NEAR WEST CHESTER (SITE 25)

\begin{tabular}{|c|c|c|c|c|c|c|}
\hline Year & $\begin{array}{c}\text { Total } \\
\text { number of } \\
\text { organisms }\end{array}$ & $\begin{array}{c}\text { Total } \\
\text { number } \\
\text { of taxa }\end{array}$ & $\begin{array}{l}\text { Brillouin's } \\
\text { diversity index } \\
\text { (H) }\end{array}$ & $\begin{array}{c}\text { Maximum } \\
\text { diversity } \\
\left(\mathrm{H}_{\max }\right)\end{array}$ & $\begin{array}{c}\text { Minimum } \\
\text { diversity } \\
\left(\mathrm{H}_{\min }\right)\end{array}$ & $\begin{array}{c}\text { Evenness } \\
\text { (E) }\end{array}$ \\
\hline 1981 & 356 & 9 & 1.50 & 3.13 & 0.19 & 0.45 \\
\hline 1982 & ${ }^{1} 9,644$ & 8 & 1.13 & 3.00 & .01 & .37 \\
\hline 1983 & - & - & - & - & - & - \\
\hline 1984 & - & - & - & - & - & - \\
\hline 1985 & - & - & - & - & - & - \\
\hline 1986 & - & - & - & - & - & - \\
\hline 1987 & - & - & - & - & - & - \\
\hline 1988 & 2587 & 12 & 2.02 & 3.56 & .17 & .55 \\
\hline 1989 & 3,091 & 17 & 1.86 & 4.09 & .06 & .45 \\
\hline 1990 & 1,111 & 20 & 2.21 & 4.32 & .17 & .49 \\
\hline 1991 & 2,108 & 17 & 1.31 & 4.08 & .08 & .31 \\
\hline 1992 & 1,095 & 20 & 2.31 & 4.32 & .18 & .52 \\
\hline 1993 & 765 & 16 & 2.34 & 3.92 & .19 & .58 \\
\hline 1994 & 671 & 11 & 1.86 & 3.46 & .14 & .52 \\
\hline
\end{tabular}

${ }^{1}$ Extrapolated from a $1 / 4$ subsample.

${ }^{2}$ Extrapolated from a 3/8 subsample.

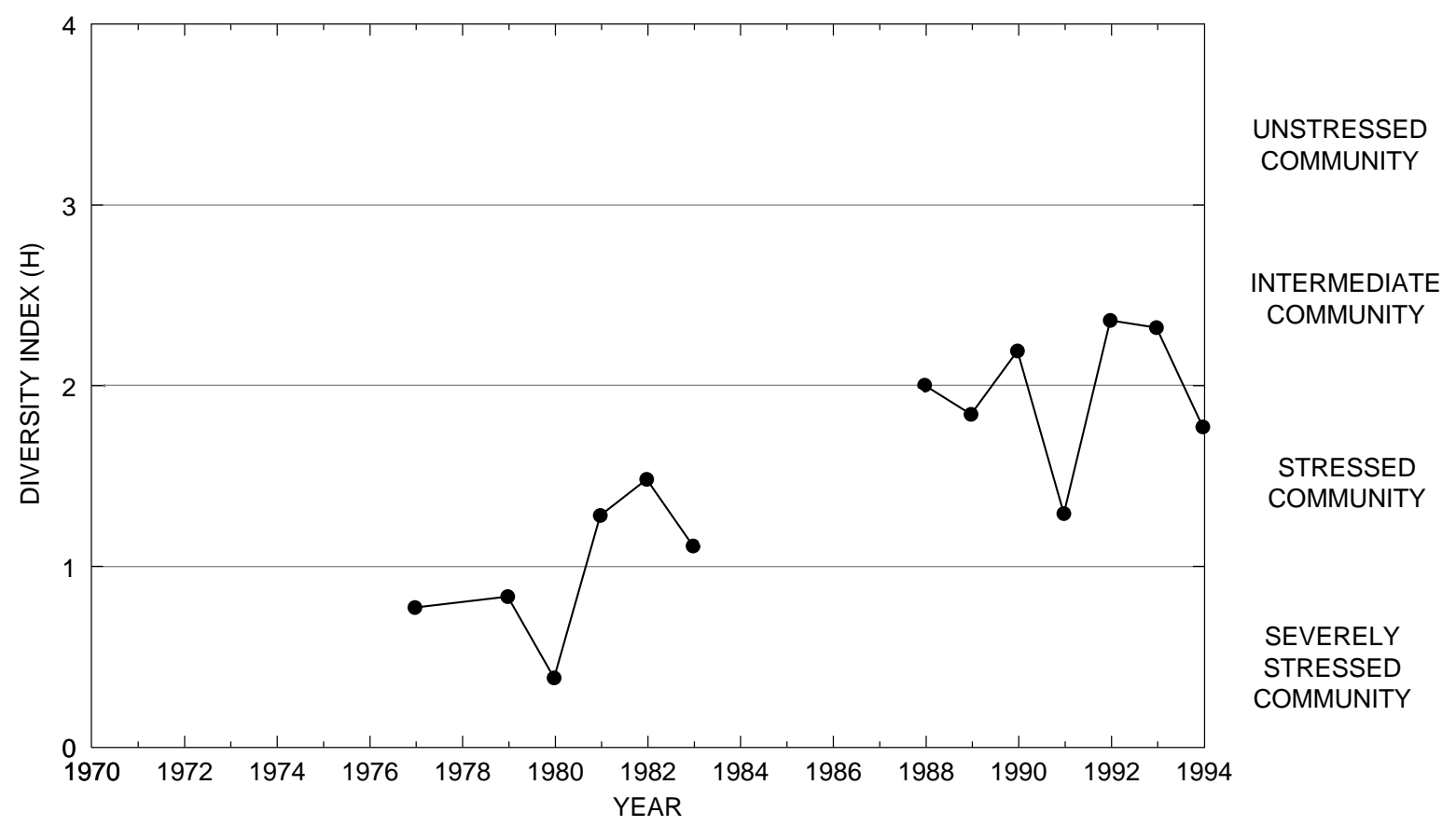


Table 6. Brillouin's diversity index, maximum diversity, minimum diversity, and relative evenness by site—Continued 01476848 EAST BRANCH CHESTER CREEK BELOW GOOSE CREEK NEAR WEST CHESTER (SITE 51)

\begin{tabular}{ccccccc}
\hline Year & $\begin{array}{c}\text { Total } \\
\text { number of } \\
\text { organisms }\end{array}$ & $\begin{array}{c}\text { Total } \\
\text { number } \\
\text { of taxa }\end{array}$ & $\begin{array}{c}\text { Brillouin's } \\
\text { diversity index } \\
(\mathrm{H})\end{array}$ & $\begin{array}{c}\text { Maximum } \\
\text { diversity } \\
\left(\mathrm{H}_{\text {max }}\right)\end{array}$ & $\begin{array}{c}\text { Minimum } \\
\text { diversity } \\
\left(\mathrm{H}_{\text {min }}\right)\end{array}$ & $\begin{array}{c}\text { Evenness } \\
(\mathrm{E})\end{array}$ \\
\hline 1981 & - & - & - & - & - & - \\
1982 & - & - & - & - & - & - \\
1983 & 2,869 & 22 & 2.41 & 4.44 & 0.08 & 0.53 \\
1984 & 2,874 & 22 & 2.81 & 4.47 & .08 & .62 \\
1985 & 4,236 & 19 & 2.18 & 4.24 & .05 & .51 \\
1986 & 1,514 & 23 & 2.39 & 4.47 & .15 & .52 \\
1987 & 12,174 & 20 & 1.75 & 4.33 & .02 & .40 \\
1988 & 13,963 & 17 & 2.58 & 4.09 & .05 & .63 \\
1989 & 926 & 28 & 2.97 & 4.75 & .28 & .60 \\
1990 & 3,033 & 31 & 2.77 & 4.54 & .11 & .55 \\
1991 & 3,951 & 27 & 2.64 & 4.76 & .08 & .55 \\
1992 & 3,046 & 26 & 2.40 & 4.70 & .10 & .50 \\
1993 & 1,169 & 28 & 3.04 & 4.79 & .24 & .62 \\
1994 & 2,093 & 32 & 2.77 & 5.02 & .16 & .54 \\
\hline
\end{tabular}

${ }^{1}$ Extrapolated from a $3 / 8$ subsample.

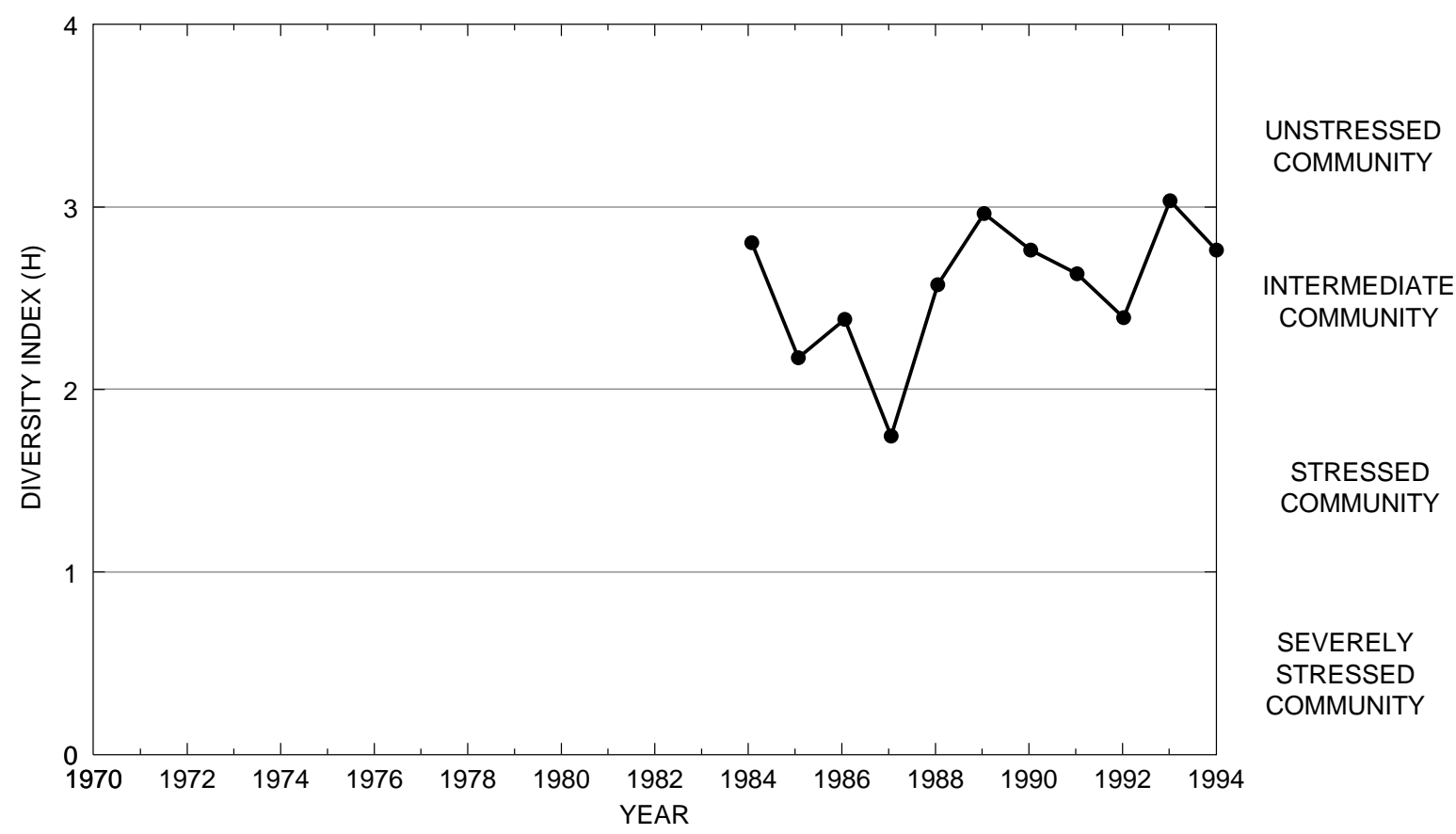


Table 6. Brillouin's diversity index, maximum diversity, minimum diversity, and relative evenness by site—Continued 01478120 EAST BRANCH WHITE CLAY CREEK NEAR AVONDALE (SITE 28)

\begin{tabular}{|c|c|c|c|c|c|c|}
\hline Year & $\begin{array}{c}\text { Total } \\
\text { number of } \\
\text { organisms }\end{array}$ & $\begin{array}{c}\text { Total } \\
\text { number } \\
\text { of taxa }\end{array}$ & $\begin{array}{c}\text { Brillouin's } \\
\text { diversity index } \\
\text { (H) }\end{array}$ & $\begin{array}{c}\text { Maximum } \\
\text { diversity } \\
\left(\mathrm{H}_{\max }\right)\end{array}$ & $\begin{array}{c}\text { Minimum } \\
\text { diversity } \\
\left(\mathrm{H}_{\min }\right)\end{array}$ & $\begin{array}{c}\text { Evenness } \\
(\mathrm{E})\end{array}$ \\
\hline 1981 & 836 & 18 & 3.06 & 4.14 & 0.20 & 0.73 \\
\hline 1982 & 1,295 & 23 & 2.74 & 4.50 & .18 & .59 \\
\hline 1983 & 1,368 & 18 & 2.61 & 4.19 & .13 & .61 \\
\hline 1984 & 932 & 16 & 1.96 & 3.93 & .16 & .48 \\
\hline 1985 & 1,007 & 22 & 2.53 & 4.49 & .21 & .54 \\
\hline 1986 & 1,026 & 19 & 2.26 & 4.23 & .18 & .51 \\
\hline 1987 & 4,223 & 19 & 2.02 & 4.26 & .05 & .47 \\
\hline 1988 & ${ }^{1} 2,624$ & 19 & 2.31 & 4.26 & .08 & .53 \\
\hline 1989 & 1,797 & 29 & 3.16 & 4.79 & .17 & .65 \\
\hline 1990 & 1,492 & 20 & 2.60 & 4.29 & .13 & .59 \\
\hline 1991 & 2,007 & 19 & 2.70 & 4.25 & .10 & .63 \\
\hline 1992 & 2,514 & 29 & 3.43 & 4.83 & .13 & .70 \\
\hline 1993 & 2,090 & 27 & 2.83 & 4.72 & .12 & .61 \\
\hline 1994 & 1,779 & 28 & 2.74 & 4.79 & .16 & .56 \\
\hline
\end{tabular}

${ }^{1}$ Extrapolated from a $3 / 8$ subsample.

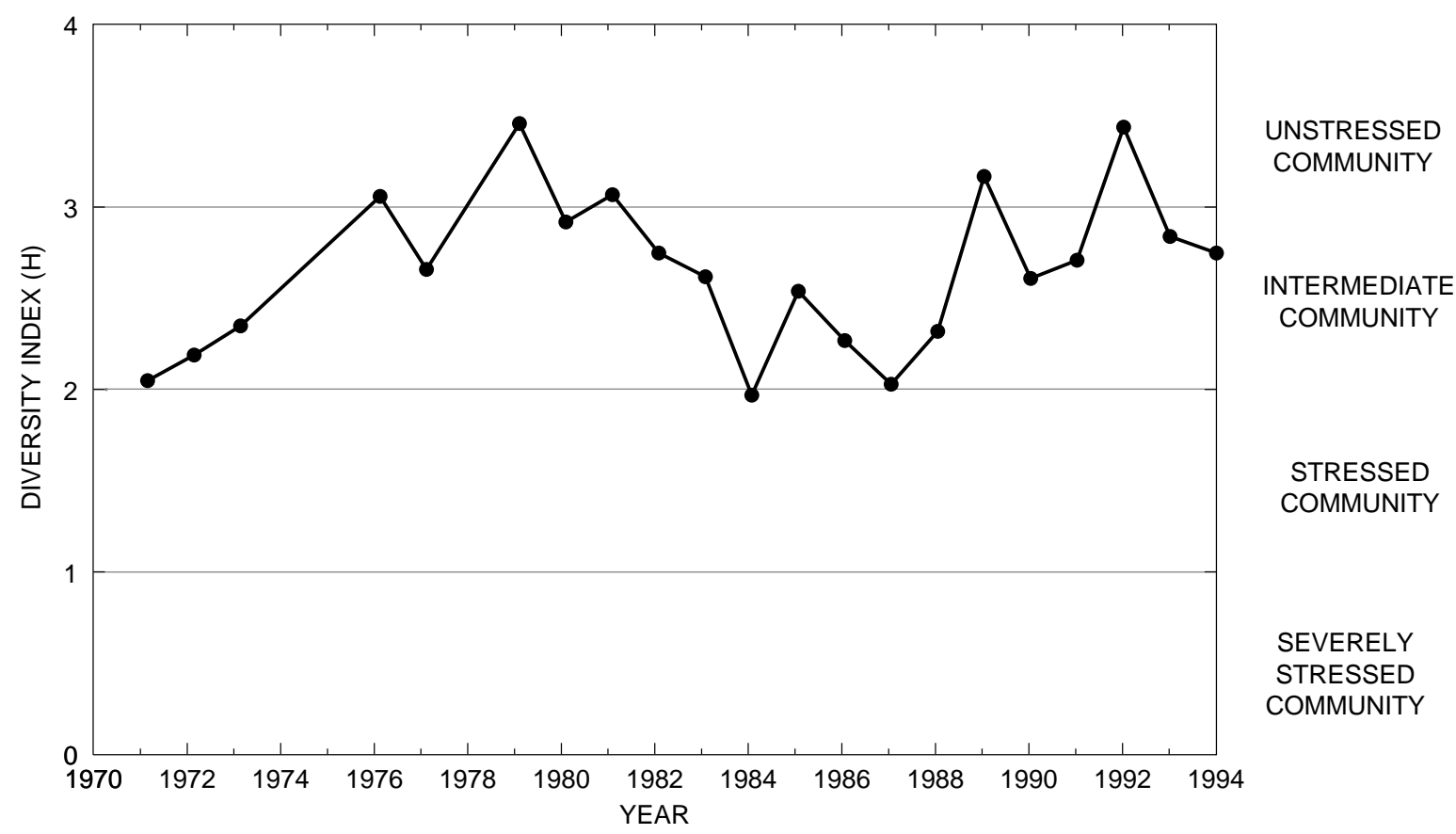


Table 6. Brillouin's diversity index, maximum diversity, minimum diversity, and relative evenness by site—Continued

01478190 MIDDLE BRANCH WHITE CLAY CREEK NEAR WICKERTON (SITE 29)

\begin{tabular}{|c|c|c|c|c|c|c|}
\hline Year & $\begin{array}{c}\text { Total } \\
\text { number of } \\
\text { organisms }\end{array}$ & $\begin{array}{c}\text { Total } \\
\text { number } \\
\text { of taxa }\end{array}$ & $\begin{array}{c}\text { Brillouin's } \\
\text { diversity index } \\
\text { (H) }\end{array}$ & $\begin{array}{l}\text { Maximum } \\
\text { diversity } \\
\left(\mathrm{H}_{\max }\right)\end{array}$ & $\begin{array}{c}\text { Minimum } \\
\text { diversity } \\
\left(\mathrm{H}_{\min }\right)\end{array}$ & $\begin{array}{c}\text { Evenness } \\
\text { (E) }\end{array}$ \\
\hline 1981 & 780 & 16 & 2.82 & 4.00 & 0.18 & 0.69 \\
\hline 1982 & 1,697 & 19 & 2.43 & 4.23 & .11 & .56 \\
\hline 1983 & 833 & 17 & 2.82 & 4.12 & .19 & .67 \\
\hline 1984 & 1,742 & 19 & 2.54 & 4.25 & .11 & .59 \\
\hline 1985 & 1,265 & 25 & 2.77 & 4.57 & .19 & .59 \\
\hline 1986 & 898 & 24 & 3.07 & 4.59 & .25 & .65 \\
\hline 1987 & 1,314 & 23 & 2.56 & 4.48 & .17 & .55 \\
\hline 1988 & ${ }^{1} 3,440$ & 21 & 2.74 & 4.37 & .07 & .62 \\
\hline 1989 & 1,438 & 26 & 3.23 & 4.66 & .18 & .68 \\
\hline 1990 & 2,008 & 29 & 2.74 & 4.83 & .15 & .55 \\
\hline 1991 & 2,464 & 24 & 2.68 & 4.57 & .11 & .58 \\
\hline 1992 & 1,458 & 32 & 3.30 & 4.98 & .22 & .65 \\
\hline 1993 & 829 & 19 & 2.88 & 4.19 & .21 & .67 \\
\hline 1994 & 1,912 & 24 & 3.41 & 4.58 & .13 & .74 \\
\hline
\end{tabular}

${ }^{1}$ Extrapolated from a $3 / 8$ subsample.

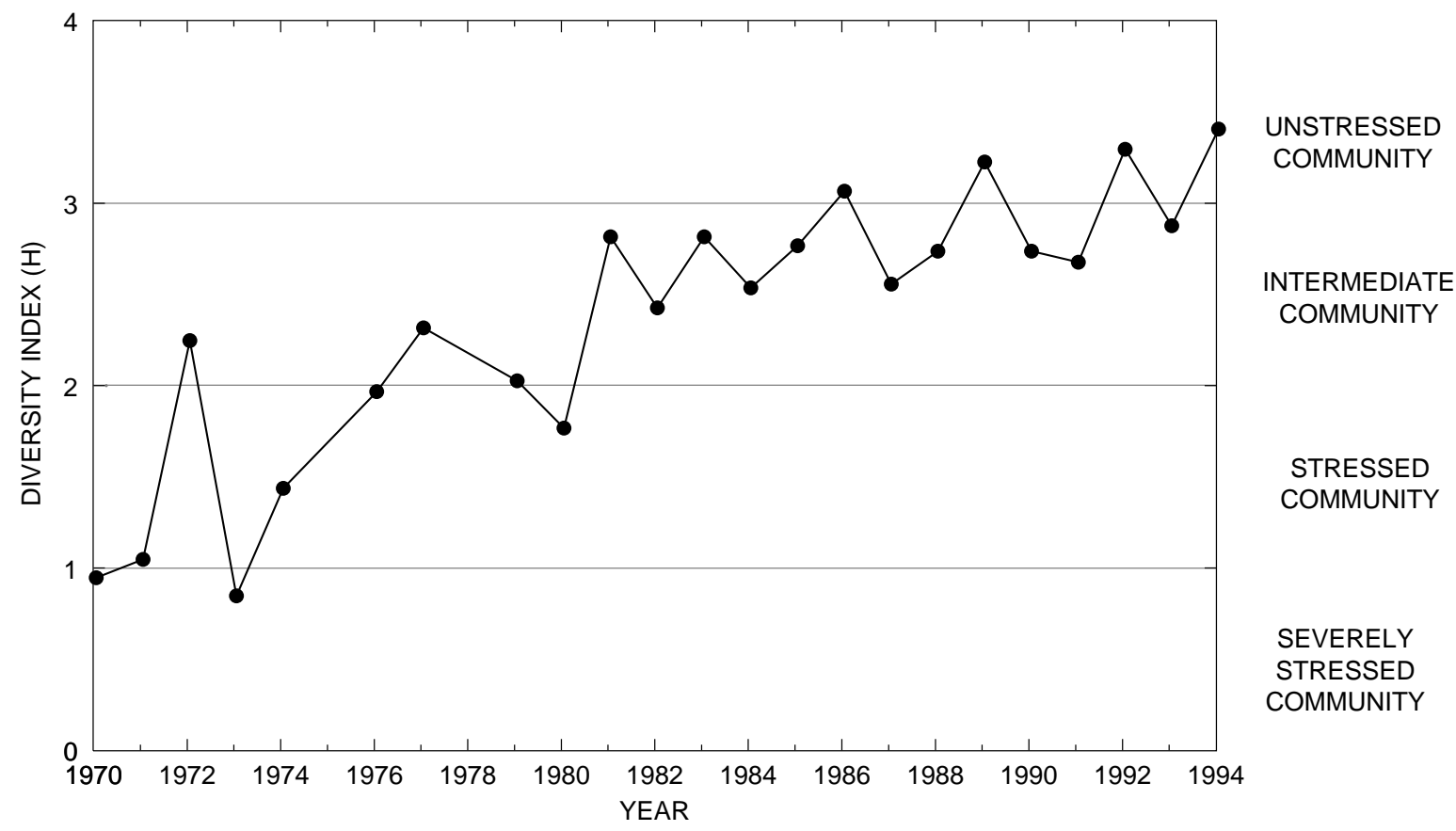


Table 6. Brillouin's diversity index, maximum diversity, minimum diversity, and relative evenness by site—Continued

01478220 WEST BRANCH WHITE CLAY CREEK NEAR CHESTERVILLE (SITE 30)

\begin{tabular}{|c|c|c|c|c|c|c|}
\hline Year & $\begin{array}{c}\text { Total } \\
\text { number of } \\
\text { organisms }\end{array}$ & $\begin{array}{c}\text { Total } \\
\text { number } \\
\text { of taxa }\end{array}$ & $\begin{array}{c}\text { Brillouin's } \\
\text { diversity index } \\
\text { (H) }\end{array}$ & $\begin{array}{c}\text { Maximum } \\
\text { diversity } \\
\left(\mathrm{H}_{\max }\right)\end{array}$ & $\begin{array}{c}\text { Minimum } \\
\text { diversity } \\
\left(\mathrm{H}_{\mathrm{min}}\right)\end{array}$ & $\begin{array}{c}\text { Evenness } \\
(\mathrm{E})\end{array}$ \\
\hline 1981 & 1,216 & 22 & 2.70 & 4.42 & 0.18 & 0.59 \\
\hline 1982 & 2,270 & 23 & 2.08 & 4.50 & .11 & .45 \\
\hline 1983 & 794 & 23 & 2.82 & 4.50 & .27 & .60 \\
\hline 1984 & 1,232 & 23 & 2.94 & 4.45 & .18 & .65 \\
\hline 1985 & 836 & 29 & 2.65 & 4.84 & .33 & .52 \\
\hline 1986 & 1,079 & 24 & 3.22 & 4.56 & .21 & .69 \\
\hline 1987 & 1,665 & 24 & 3.27 & 4.58 & .15 & .71 \\
\hline 1988 & ${ }^{1} 2,065$ & 23 & 3.13 & 4.48 & .12 & .69 \\
\hline 1989 & 1,114 & 34 & 3.74 & 5.08 & .30 & .72 \\
\hline 1990 & 1,794 & 29 & 3.55 & 4.87 & .16 & .72 \\
\hline 1991 & 1,438 & 27 & 2.82 & 4.82 & .19 & .58 \\
\hline 1992 & 1,472 & 34 & 3.54 & 5.07 & .23 & .68 \\
\hline 1993 & 1,270 & 33 & 2.93 & 4.98 & .26 & .57 \\
\hline 1994 & 1,027 & 25 & 2.73 & 4.68 & .23 & .56 \\
\hline
\end{tabular}

${ }^{1}$ Extrapolated from a $3 / 8$ subsample.

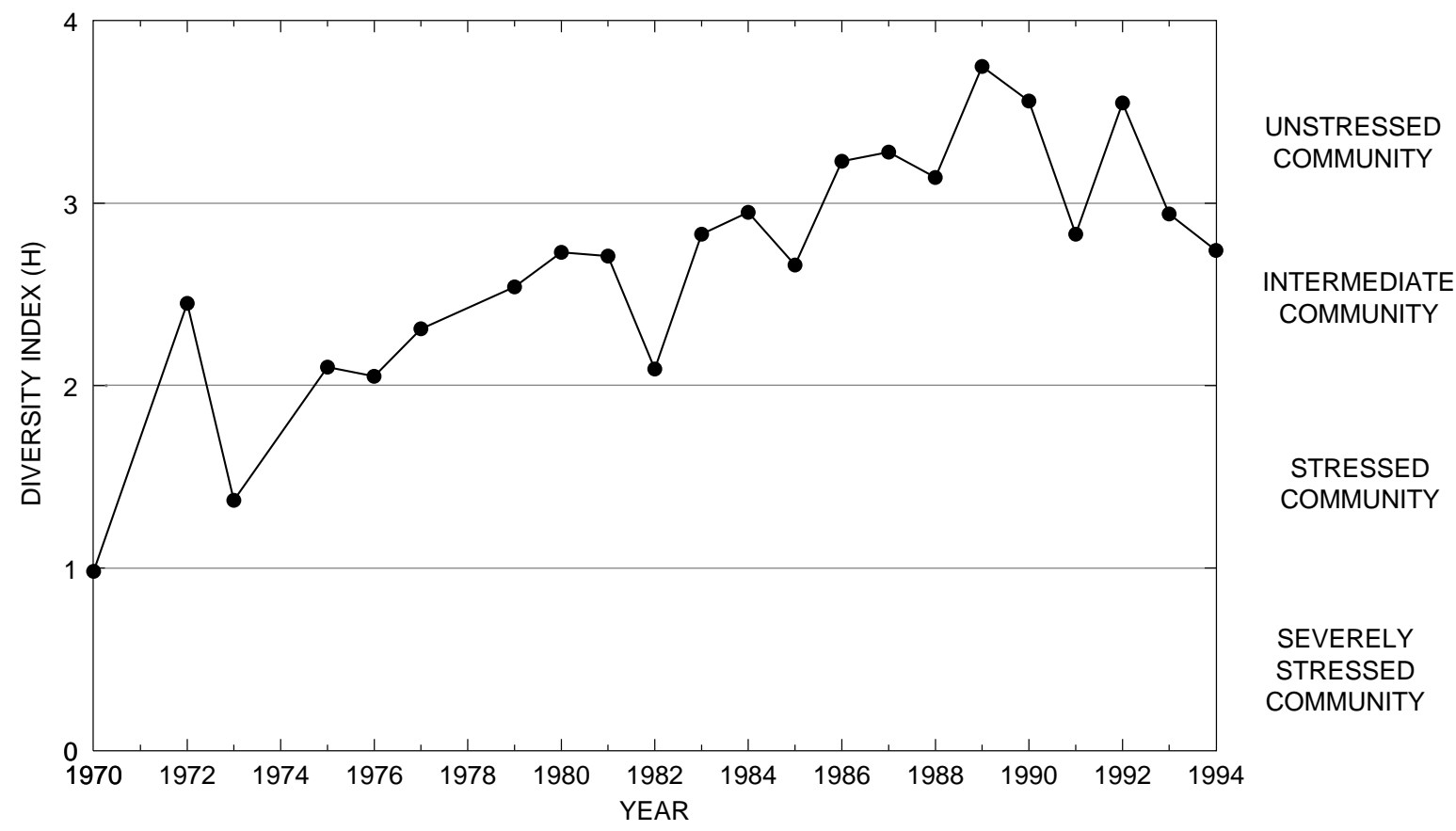


Table 6. Brillouin's diversity index, maximum diversity, minimum diversity, and relative evenness by site—Continued 01479680 WEST BRANCH RED CLAY CREEK AT KENNETT SQUARE (SITE 27)

\begin{tabular}{|c|c|c|c|c|c|c|}
\hline Year & $\begin{array}{c}\text { Total } \\
\text { number of } \\
\text { organisms }\end{array}$ & $\begin{array}{c}\text { Total } \\
\text { number } \\
\text { of taxa }\end{array}$ & $\begin{array}{l}\text { Brillouin's } \\
\text { diversity index } \\
\text { (H) }\end{array}$ & $\begin{array}{c}\text { Maximum } \\
\text { diversity } \\
\left(\mathrm{H}_{\max }\right)\end{array}$ & $\begin{array}{c}\text { Minimum } \\
\text { diversity } \\
\left(\mathrm{H}_{\min }\right)\end{array}$ & $\begin{array}{c}\text { Evenness } \\
\text { (E) }\end{array}$ \\
\hline 1981 & 211 & 11 & 1.51 & 3.32 & 0.37 & 0.39 \\
\hline 1982 & 777 & 13 & 2.42 & 3.71 & .15 & .64 \\
\hline 1983 & 84 & 11 & 2.45 & 3.39 & .75 & .64 \\
\hline 1984 & 468 & 10 & 1.88 & 3.35 & .17 & .54 \\
\hline 1985 & 326 & 18 & 2.31 & 4.04 & .43 & .52 \\
\hline 1986 & 107 & 10 & 1.90 & 3.31 & .56 & .49 \\
\hline 1987 & 267 & 15 & 2.61 & 3.92 & .42 & .63 \\
\hline 1988 & 546 & 17 & 2.75 & 4.13 & .27 & .64 \\
\hline 1989 & 758 & 33 & 3.63 & 4.90 & .40 & .72 \\
\hline 1990 & 1,843 & 26 & 2.01 & 4.64 & .15 & .41 \\
\hline 1991 & 424 & 14 & 1.94 & 3.69 & .27 & .49 \\
\hline 1992 & 410 & 14 & 2.42 & 3.78 & .27 & .61 \\
\hline 1993 & 834 & 28 & 2.78 & 4.84 & .31 & .55 \\
\hline 1994 & 922 & 24 & 2.15 & 4.52 & .25 & .44 \\
\hline
\end{tabular}

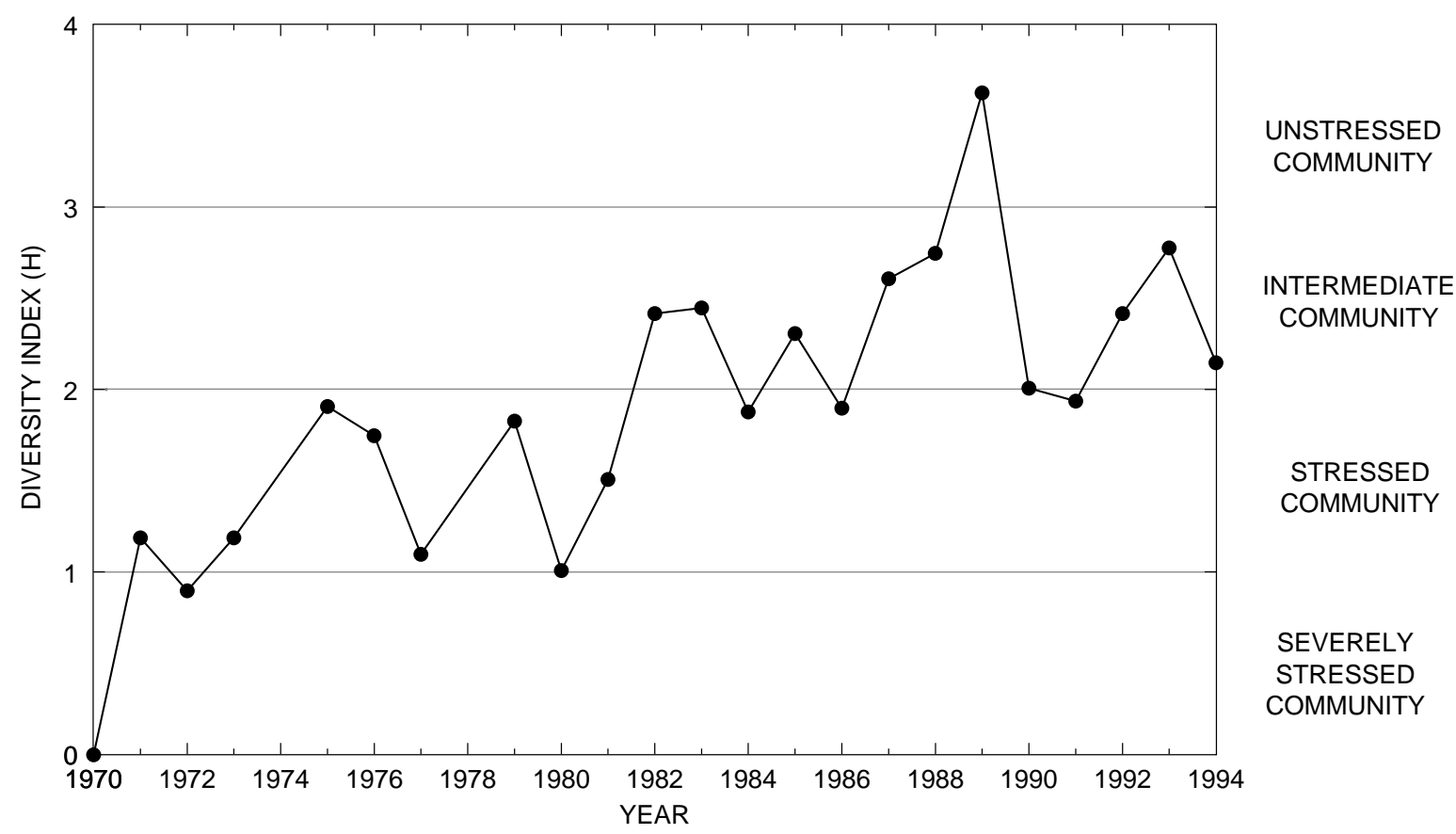


Table 6. Brillouin's diversity index, maximum diversity, minimum diversity, and relative evenness by site-Continued

01479800 EAST BRANCH RED CLAY CREEK NEAR FIVE POINT (SITE 26)

\begin{tabular}{|c|c|c|c|c|c|c|}
\hline Year & $\begin{array}{c}\text { Total } \\
\text { number of } \\
\text { organisms }\end{array}$ & $\begin{array}{c}\text { Total } \\
\text { number } \\
\text { of taxa }\end{array}$ & $\begin{array}{c}\text { Brillouin's } \\
\text { diversity index } \\
\text { (H) }\end{array}$ & $\begin{array}{l}\text { Maximum } \\
\text { diversity } \\
\left(\mathrm{H}_{\max }\right)\end{array}$ & $\begin{array}{c}\text { Minimum } \\
\text { diversity } \\
\left(\mathrm{H}_{\min }\right)\end{array}$ & $\begin{array}{c}\text { Evenness } \\
(\mathrm{E})\end{array}$ \\
\hline 1981 & 1,055 & 14 & 2.21 & 3.82 & 0.12 & 0.56 \\
\hline 1982 & 285 & 16 & 2.90 & 3.96 & .43 & .70 \\
\hline 1983 & 577 & 17 & 1.73 & 3.98 & .25 & .39 \\
\hline 1984 & 2,375 & 12 & .85 & 3.59 & .05 & .23 \\
\hline 1985 & 627 & 16 & 2.03 & 3.92 & .22 & .49 \\
\hline 1986 & 34 & 10 & 1.92 & 3.00 & 1.30 & .37 \\
\hline 1987 & 577 & 17 & 2.08 & 4.11 & .25 & .47 \\
\hline 1988 & 920 & 11 & 1.77 & 3.45 & .11 & .50 \\
\hline 1989 & 545 & 17 & 2.34 & 3.99 & .27 & .56 \\
\hline 1990 & 2,652 & 19 & 1.86 & 4.23 & .08 & .43 \\
\hline 1991 & 700 & 15 & 1.82 & 3.88 & .19 & .44 \\
\hline 1992 & 1,054 & 26 & 2.58 & 4.67 & .24 & .53 \\
\hline 1993 & 761 & 23 & 3.05 & 4.44 & .28 & .67 \\
\hline 1994 & 998 & 21 & 2.19 & 4.37 & .20 & .48 \\
\hline
\end{tabular}

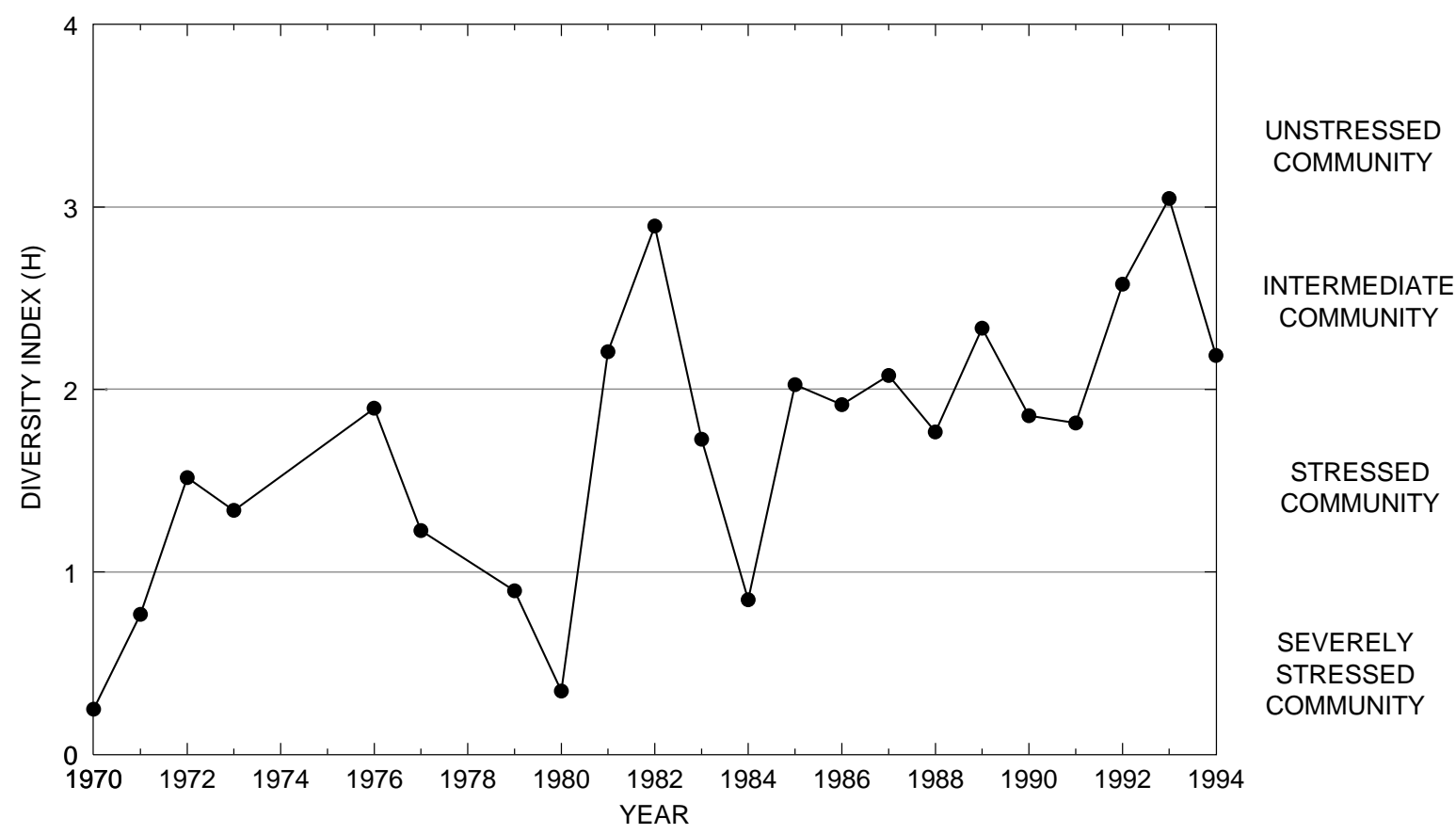


Table 6. Brillouin's diversity index, maximum diversity, minimum diversity, and relative evenness by site—Continued

01480434 WEST BRANCH BRANDYWINE CREEK AT ROCK RUN (SITE 37)

\begin{tabular}{|c|c|c|c|c|c|c|}
\hline Year & $\begin{array}{c}\text { Total } \\
\text { number of } \\
\text { organisms }\end{array}$ & $\begin{array}{c}\text { Total } \\
\text { number } \\
\text { of taxa }\end{array}$ & $\begin{array}{l}\text { Brillouin's } \\
\text { diversity index } \\
\text { (H) }\end{array}$ & $\begin{array}{c}\text { Maximum } \\
\text { diversity } \\
\left(\mathrm{H}_{\max }\right)\end{array}$ & $\begin{array}{c}\text { Minimum } \\
\text { diversity } \\
\left(\mathrm{H}_{\min }\right)\end{array}$ & $\begin{array}{c}\text { Evenness } \\
\text { (E) }\end{array}$ \\
\hline 1981 & 551 & 29 & 3.36 & 4.75 & 0.46 & 0.68 \\
\hline 1982 & 1,086 & 31 & 3.28 & 4.94 & .28 & .64 \\
\hline 1983 & 1,241 & 31 & 2.36 & 4.87 & .25 & .46 \\
\hline 1984 & 1,052 & 30 & 2.95 & 4.81 & .28 & .59 \\
\hline 1985 & 1,711 & 32 & 3.20 & 4.95 & .20 & .63 \\
\hline 1986 & 646 & 34 & 3.66 & 4.92 & .47 & .72 \\
\hline 1987 & 1,278 & 36 & 2.95 & 5.14 & .28 & .55 \\
\hline 1988 & 1,182 & 28 & 2.68 & 4.78 & .23 & .54 \\
\hline 1989 & 1,399 & 36 & 3.25 & 5.07 & .26 & .62 \\
\hline 1990 & 1,020 & 29 & 2.93 & 4.78 & .27 & .59 \\
\hline 1991 & 1,793 & 38 & 2.55 & 5.20 & .22 & .47 \\
\hline 1992 & 1,376 & 38 & 3.61 & 5.15 & .28 & .68 \\
\hline 1993 & 665 & 31 & 3.27 & 4.87 & .42 & .64 \\
\hline 1994 & 1,471 & 32 & 3.10 & 5.03 & .22 & .60 \\
\hline
\end{tabular}

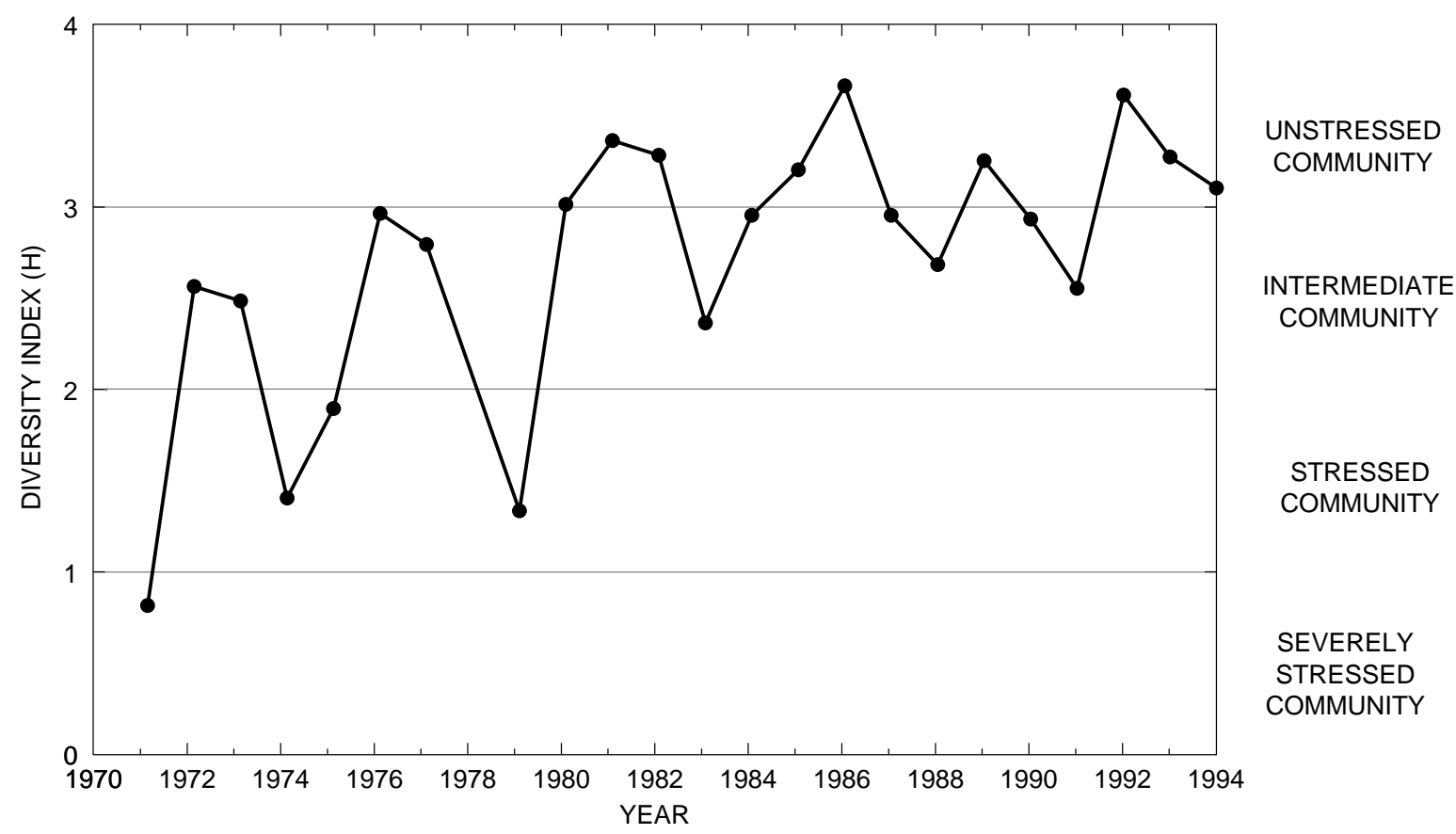


Table 6. Brillouin's diversity index, maximum diversity, minimum diversity, and relative evenness by site—Continued

01480629 BUCK RUN AT DOE RUN (SITE 46)

\begin{tabular}{|c|c|c|c|c|c|c|}
\hline Year & $\begin{array}{c}\text { Total } \\
\text { number of } \\
\text { organisms }\end{array}$ & $\begin{array}{c}\text { Total } \\
\text { number } \\
\text { of taxa }\end{array}$ & $\begin{array}{c}\text { Brillouin's } \\
\text { diversity index } \\
\text { (H) }\end{array}$ & $\begin{array}{l}\text { Maximum } \\
\text { diversity } \\
\left(\mathrm{H}_{\max }\right)\end{array}$ & $\begin{array}{c}\text { Minimum } \\
\text { diversity } \\
\left(\mathrm{H}_{\min }\right)\end{array}$ & $\begin{array}{c}\text { Evenness } \\
(\mathrm{E})\end{array}$ \\
\hline 1981 & 1,026 & 19 & 2.68 & 4.26 & 0.18 & 0.61 \\
\hline 1982 & ${ }^{1} 1,647$ & 16 & 2.34 & 4.00 & .10 & .57 \\
\hline 1983 & ${ }^{1} 1,846$ & 17 & 1.80 & 4.05 & .09 & .43 \\
\hline 1984 & ${ }^{1} 2,272$ & 21 & 2.63 & 4.41 & .10 & .59 \\
\hline 1985 & 1,091 & 21 & 3.43 & 4.42 & .18 & .77 \\
\hline 1986 & 1,769 & 23 & 2.55 & 4.47 & .13 & .56 \\
\hline 1987 & 1,644 & 25 & 2.69 & 4.66 & .16 & .56 \\
\hline 1988 & ${ }^{1} 2,070$ & 24 & 3.20 & 5.54 & .12 & .70 \\
\hline 1989 & 1,353 & 32 & 2.68 & 4.98 & .24 & .51 \\
\hline 1990 & 1,804 & 39 & 3.53 & 5.24 & .23 & .66 \\
\hline 1991 & 1,756 & 26 & 2.46 & 4.67 & .15 & .51 \\
\hline 1992 & 1,432 & 34 & 3.24 & 5.01 & .24 & .63 \\
\hline 1993 & 1,403 & 31 & 3.15 & 4.87 & .22 & .63 \\
\hline 1994 & 2,602 & 24 & 2.80 & 4.59 & .10 & .60 \\
\hline
\end{tabular}

${ }^{1}$ Extrapolated from a $3 / 8$ subsample.

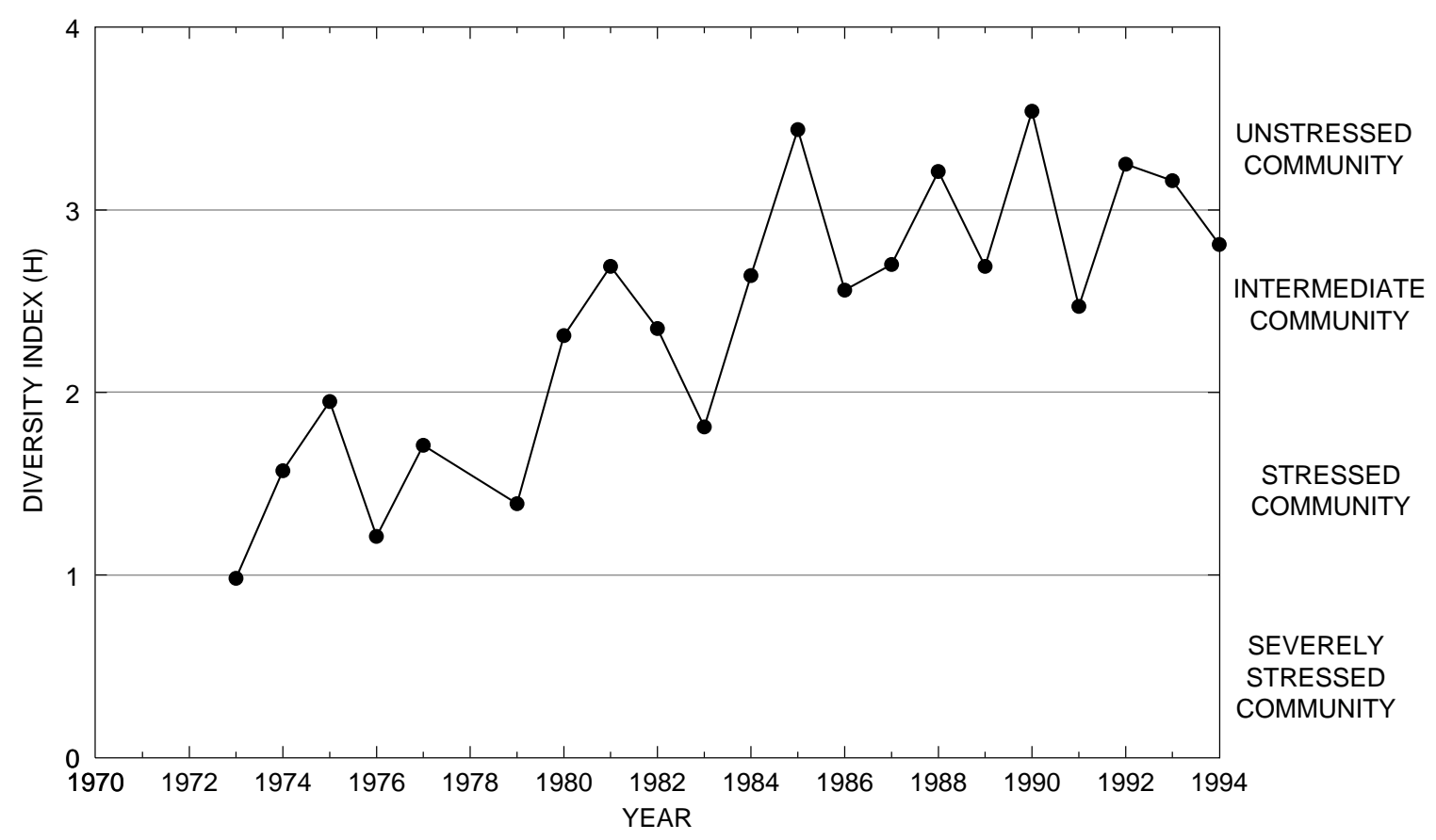


Table 6. Brillouin's diversity index, maximum diversity, minimum diversity, and relative evenness by site—Continued 01480632 DOE RUN AT SPRINGDELL (SITE 45)

\begin{tabular}{|c|c|c|c|c|c|c|}
\hline Year & $\begin{array}{c}\text { Total } \\
\text { number of } \\
\text { organisms }\end{array}$ & $\begin{array}{c}\text { Total } \\
\text { number } \\
\text { of taxa }\end{array}$ & $\begin{array}{c}\text { Brillouin's } \\
\text { diversity index } \\
\text { (H) }\end{array}$ & $\begin{array}{c}\text { Maximum } \\
\text { diversity } \\
\left(\mathrm{H}_{\max }\right)\end{array}$ & $\begin{array}{c}\text { Minimum } \\
\text { diversity } \\
\left(\mathrm{H}_{\min }\right)\end{array}$ & $\begin{array}{c}\text { Evenness } \\
(\mathrm{E})\end{array}$ \\
\hline 1981 & ${ }^{1} 1,133$ & 24 & 3.30 & 4.60 & 0.21 & 0.71 \\
\hline 1982 & ${ }^{1} 1,620$ & 25 & 2.93 & 4.58 & .16 & .63 \\
\hline 1983 & ${ }^{1} 1,405$ & 23 & 2.93 & 4.55 & .16 & .63 \\
\hline 1984 & ${ }^{1} 1,608$ & 22 & 3.11 & 4.46 & .14 & .69 \\
\hline 1985 & 974 & 20 & 2.67 & 4.24 & .19 & .61 \\
\hline 1986 & 774 & 19 & 2.92 & 4.25 & .22 & .67 \\
\hline 1987 & 1,617 & 26 & 3.00 & 4.66 & .16 & .63 \\
\hline 1988 & ${ }^{1} 1,818$ & 22 & 3.30 & 4.42 & .13 & .74 \\
\hline 1989 & 1,430 & 34 & 3.44 & 5.12 & .24 & .66 \\
\hline 1990 & 1,752 & 25 & 3.28 & 4.60 & .15 & .70 \\
\hline 1991 & 1,392 & 29 & 3.33 & 4.88 & .21 & .67 \\
\hline 1992 & 1,195 & 23 & 3.29 & 4.52 & .19 & .71 \\
\hline 1993 & 1,229 & 32 & 3.45 & 4.92 & .26 & .68 \\
\hline 1994 & 1,300 & 23 & 3.14 & 4.51 & .17 & .69 \\
\hline
\end{tabular}

${ }^{1}$ Extrapolated from a $3 / 8$ subsample.

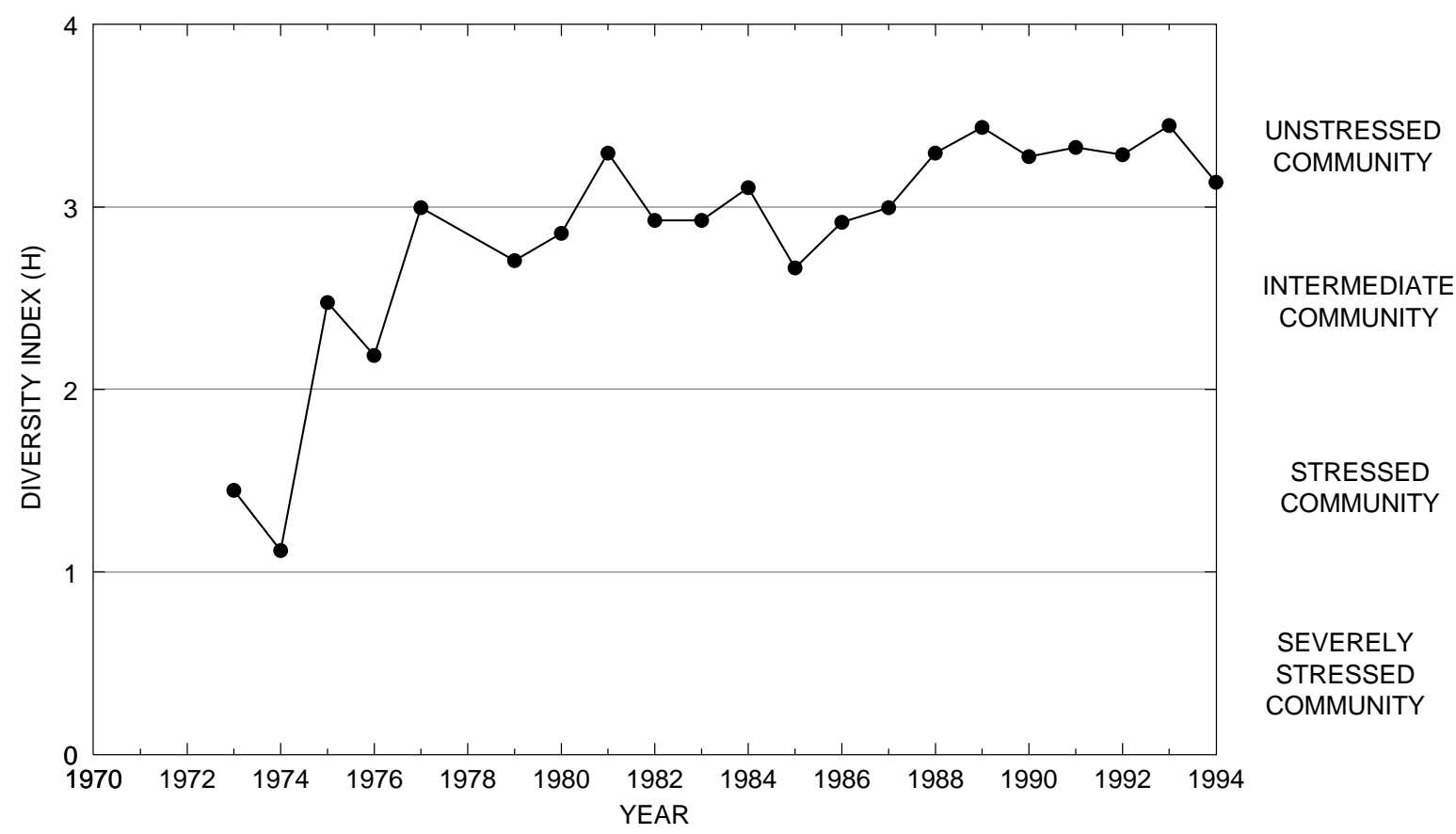


Table 6. Brillouin's diversity index, maximum diversity, minimum diversity, and relative evenness by site-Continued

01480640 WEST BRANCH BRANDYWINE CREEK AT WAWASET (SITE 38)

\begin{tabular}{|c|c|c|c|c|c|c|}
\hline Year & $\begin{array}{c}\text { Total } \\
\text { number of } \\
\text { organisms }\end{array}$ & $\begin{array}{c}\text { Total } \\
\text { number } \\
\text { of taxa }\end{array}$ & $\begin{array}{c}\text { Brillouin's } \\
\text { diversity index } \\
\text { (H) }\end{array}$ & $\begin{array}{l}\text { Maximum } \\
\text { diversity } \\
\left(\mathrm{H}_{\max }\right)\end{array}$ & $\begin{array}{c}\text { Minimum } \\
\text { diversity } \\
\left(\mathrm{H}_{\min }\right)\end{array}$ & $\begin{array}{c}\text { Evenness } \\
(\mathrm{E})\end{array}$ \\
\hline 1981 & 598 & 31 & 2.95 & 4.90 & 0.46 & 0.56 \\
\hline 1982 & 1,655 & 21 & 2.87 & 4.40 & .13 & .64 \\
\hline 1983 & 1,110 & 27 & 3.21 & 4.78 & .24 & .66 \\
\hline 1984 & 1,402 & 22 & 2.61 & 4.48 & .16 & .57 \\
\hline 1985 & 1,085 & 24 & 2.24 & 4.62 & .21 & .46 \\
\hline 1986 & 769 & 24 & 3.09 & 4.52 & .28 & .66 \\
\hline 1987 & 402 & 23 & 3.20 & 4.46 & .47 & .69 \\
\hline 1988 & ${ }^{1} 1,939$ & 22 & 2.84 & 4.43 & .12 & .63 \\
\hline 1989 & 1,631 & 31 & 3.02 & 4.95 & .20 & .59 \\
\hline 1990 & 1,532 & 39 & 3.30 & 5.23 & .26 & .61 \\
\hline 1991 & 1,418 & 31 & 3.19 & 4.94 & .22 & .63 \\
\hline 1992 & 1,041 & 34 & 3.46 & 5.07 & .32 & .66 \\
\hline 1993 & 764 & 39 & 3.79 & 5.28 & .47 & .69 \\
\hline 1994 & 1,005 & 37 & 3.88 & 5.11 & .36 & .74 \\
\hline
\end{tabular}

${ }^{1}$ Extrapolated from a $3 / 8$ subsample.

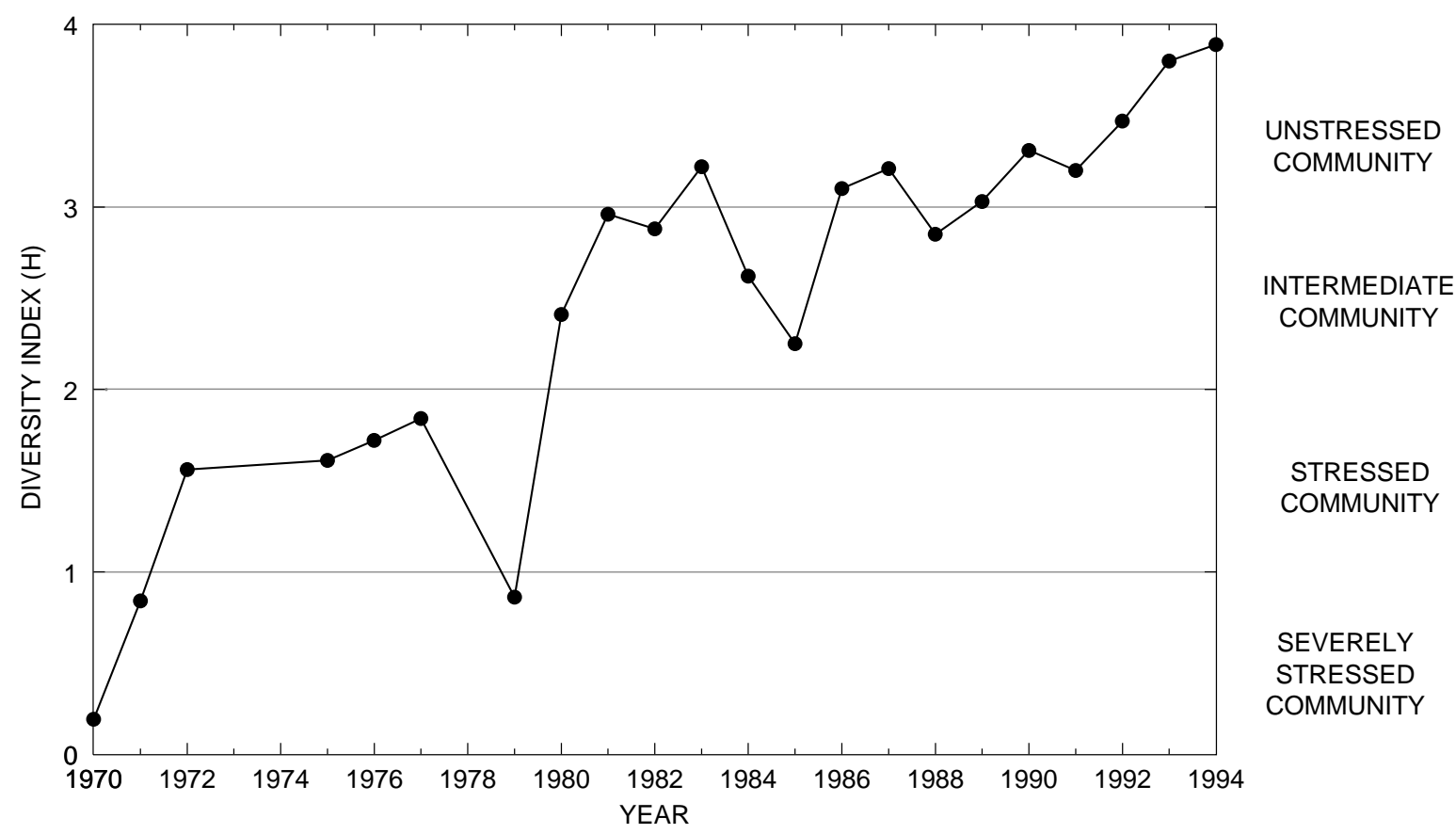


Table 6. Brillouin's diversity index, maximum diversity, minimum diversity, and relative evenness by site—Continued 01480647 EAST BRANCH BRANDYWINE CREEK NEAR STRUBLE DAM (SITE 43)

\begin{tabular}{ccccccc}
\hline Year & $\begin{array}{c}\text { Total } \\
\text { number of } \\
\text { organisms }\end{array}$ & $\begin{array}{c}\text { Total } \\
\text { number } \\
\text { of taxa }\end{array}$ & $\begin{array}{c}\text { Brillouin's } \\
\text { diversity index } \\
(\mathrm{H})\end{array}$ & $\begin{array}{c}\text { Maximum } \\
\text { diversity } \\
\left(\mathrm{H}_{\text {max }}\right)\end{array}$ & $\begin{array}{c}\text { Minimum } \\
\text { diversity } \\
\left(\mathrm{H}_{\text {min }}\right)\end{array}$ & $\begin{array}{c}\text { Evenness } \\
(\mathrm{E})\end{array}$ \\
\hline 1981 & 303 & 22 & 2.50 & 4.39 & 0.58 & 0.50 \\
1982 & 566 & 25 & 3.24 & 4.67 & .38 & .67 \\
\hline
\end{tabular}

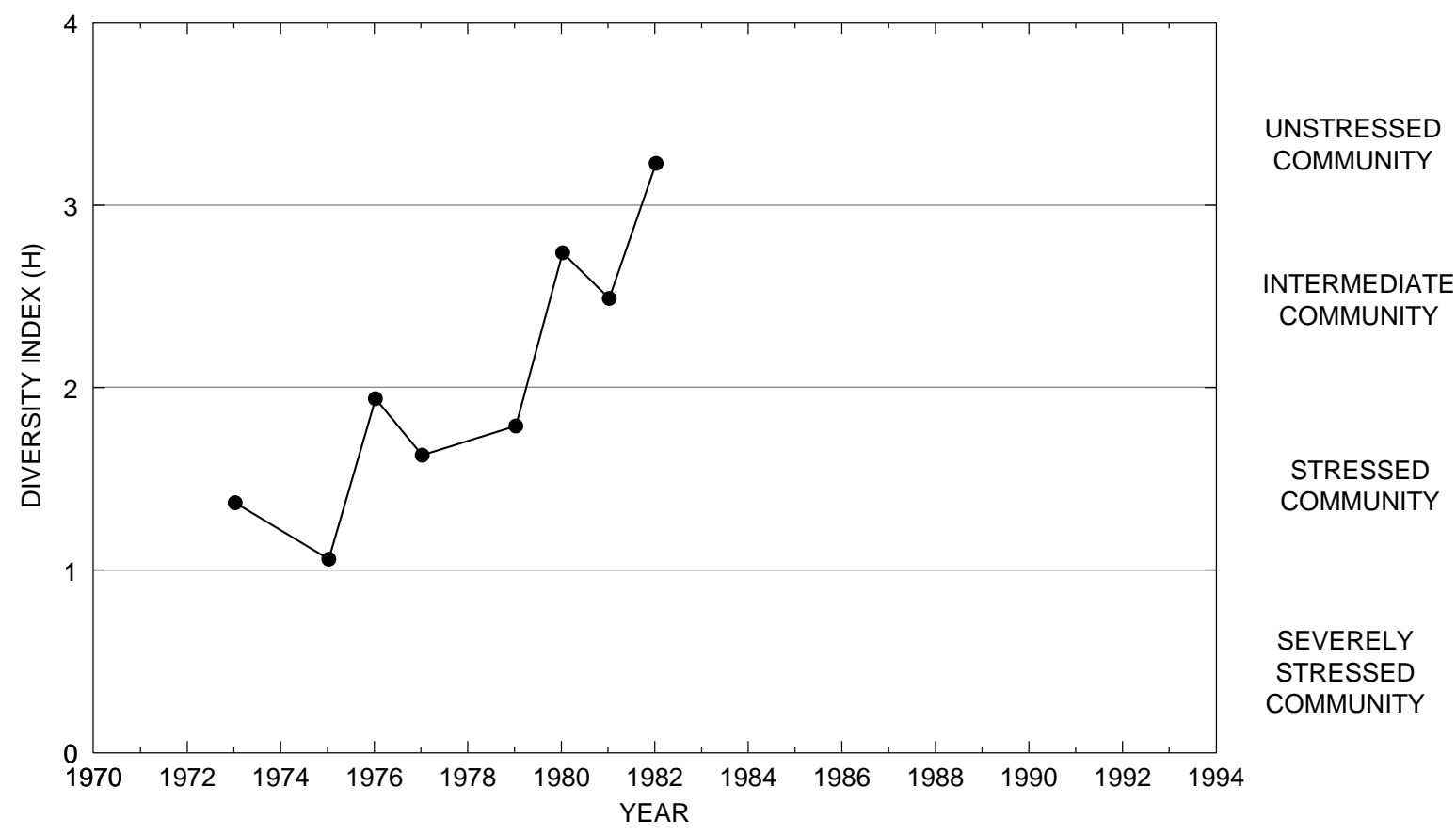


Table 6. Brillouin's diversity index, maximum diversity, minimum diversity, and relative evenness by site—Continued

\section{EAST BRANCH BRANDYWINE CREEK NEAR CUPOLA (SITE 48)}

\begin{tabular}{|c|c|c|c|c|c|c|}
\hline Year & $\begin{array}{c}\text { Total } \\
\text { number of } \\
\text { organisms }\end{array}$ & $\begin{array}{c}\text { Total } \\
\text { number } \\
\text { of taxa }\end{array}$ & $\begin{array}{c}\text { Brillouin's } \\
\text { diversity index } \\
\text { (H) }\end{array}$ & $\begin{array}{l}\text { Maximum } \\
\text { diversity } \\
\left(\mathrm{H}_{\max }\right)\end{array}$ & $\begin{array}{c}\text { Minimum } \\
\text { diversity } \\
\left(\mathrm{H}_{\min }\right)\end{array}$ & $\begin{array}{c}\text { Evenness } \\
(\mathrm{E})\end{array}$ \\
\hline 1981 & 1,310 & 43 & 4.10 & 5.37 & 0.33 & 0.75 \\
\hline 1982 & 2,529 & 35 & 3.21 & 5.08 & .15 & .62 \\
\hline 1983 & 733 & 32 & 3.61 & 5.03 & .40 & .69 \\
\hline 1984 & 1,652 & 24 & 3.04 & 4.58 & .15 & .65 \\
\hline 1985 & 689 & 28 & 3.43 & 4.75 & .37 & .70 \\
\hline 1986 & 895 & 33 & 3.64 & 4.94 & .35 & .72 \\
\hline 1987 & 1,139 & 31 & 3.15 & 4.96 & .27 & .61 \\
\hline 1988 & ${ }^{1} 1,984$ & 32 & 3.43 & 4.94 & .17 & .68 \\
\hline 1989 & 3,846 & 46 & 3.61 & 5.51 & .14 & .65 \\
\hline 1990 & 538 & 25 & 3.20 & 4.59 & .40 & .67 \\
\hline 1991 & 926 & 37 & 3.43 & 5.09 & .38 & .65 \\
\hline 1992 & 610 & 25 & 3.31 & 4.58 & .36 & .70 \\
\hline 1993 & 2,016 & 49 & 3.49 & 5.55 & .26 & .61 \\
\hline 1994 & 973 & 31 & 3.59 & 4.87 & .31 & .72 \\
\hline
\end{tabular}

${ }^{1}$ Extrapolated from a $3 / 8$ subsample.

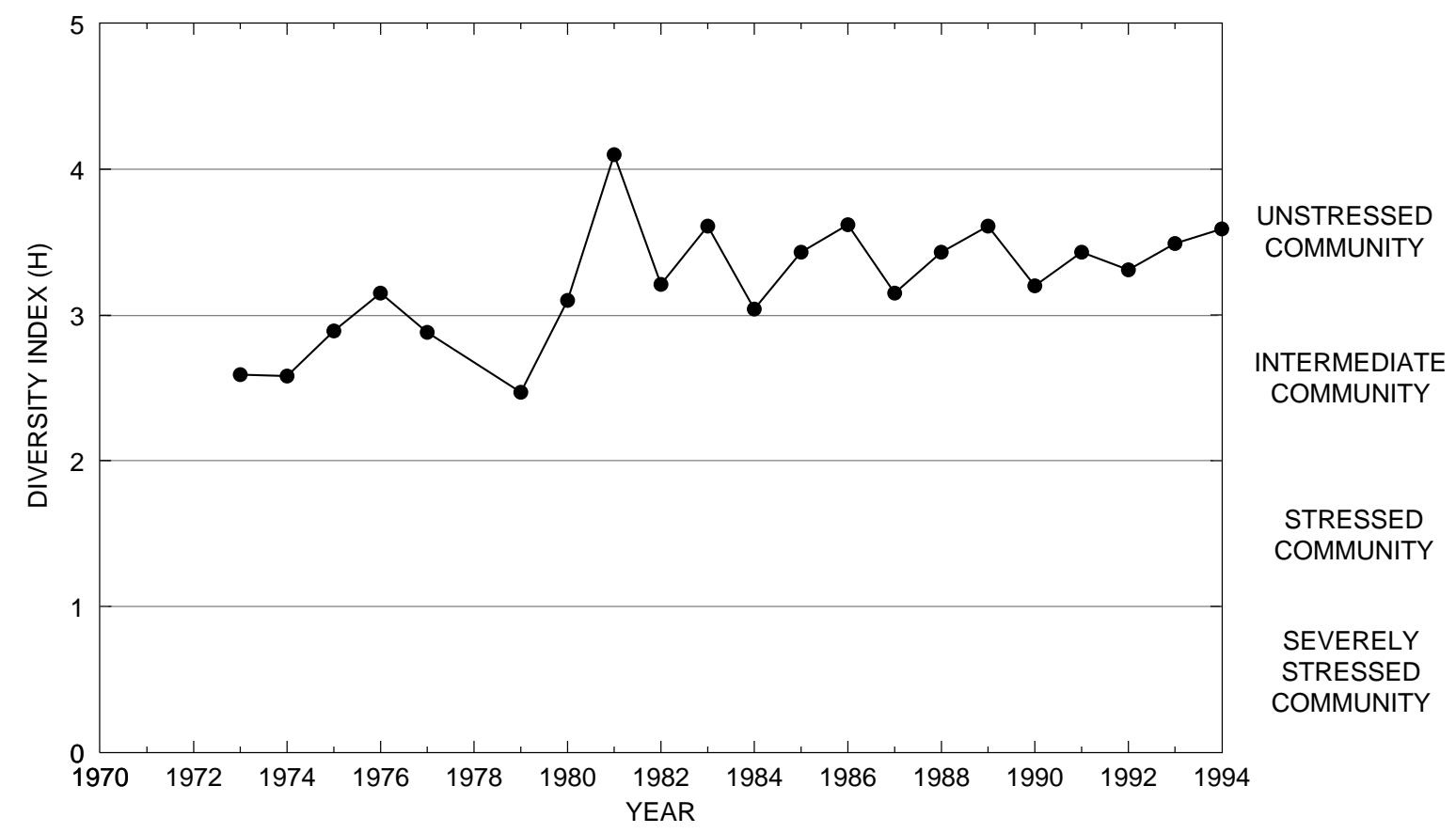


Table 6. Brillouin's diversity index, maximum diversity, minimum diversity, and relative evenness by site—Continued 01480653 EAST BRANCH BRANDYWINE CREEK AT GLENMOORE (SITE 42)

\begin{tabular}{|c|c|c|c|c|c|c|}
\hline Year & $\begin{array}{c}\text { Total } \\
\text { number of } \\
\text { organisms }\end{array}$ & $\begin{array}{c}\text { Total } \\
\text { number } \\
\text { of taxa }\end{array}$ & $\begin{array}{l}\text { Brillouin's } \\
\text { diversity index } \\
\text { (H) }\end{array}$ & $\begin{array}{c}\text { Maximum } \\
\text { diversity } \\
\left(\mathrm{H}_{\max }\right)\end{array}$ & $\begin{array}{l}\text { Minimum } \\
\text { diversity } \\
\left(\mathrm{H}_{\text {min }}\right)\end{array}$ & $\begin{array}{c}\text { Evenness } \\
(\mathrm{E})\end{array}$ \\
\hline 1981 & 752 & 36 & 3.43 & 5.18 & 0.44 & 0.63 \\
\hline 1982 & 1,708 & 47 & 3.81 & 5.51 & .30 & .67 \\
\hline 1983 & 1,338 & 45 & 3.93 & 5.50 & .34 & .70 \\
\hline 1984 & 1,008 & 36 & 3.69 & 5.20 & .35 & .69 \\
\hline 1985 & 1,361 & 43 & 3.73 & 5.41 & .32 & .67 \\
\hline 1986 & 723 & 48 & 4.20 & 5.63 & .62 & .72 \\
\hline 1987 & 1,435 & 36 & 3.49 & 5.20 & .25 & .65 \\
\hline 1988 & ${ }^{1} 1,671$ & 33 & 3.45 & 5.01 & .21 & .68 \\
\hline 1989 & 2,617 & 46 & 3.70 & 5.55 & .19 & .66 \\
\hline 1990 & 973 & 41 & 3.73 & 5.31 & .41 & .68 \\
\hline 1991 & 1,825 & 42 & 3.56 & 5.36 & .24 & .65 \\
\hline 1992 & 1,330 & 50 & 3.99 & 5.60 & .38 & .69 \\
\hline 1993 & 1,554 & 48 & 3.91 & 5.52 & .32 & .69 \\
\hline 1994 & 1,378 & 47 & 3.99 & 5.47 & .35 & .71 \\
\hline
\end{tabular}

${ }^{1}$ Extrapolated from a $3 / 8$ subsample.

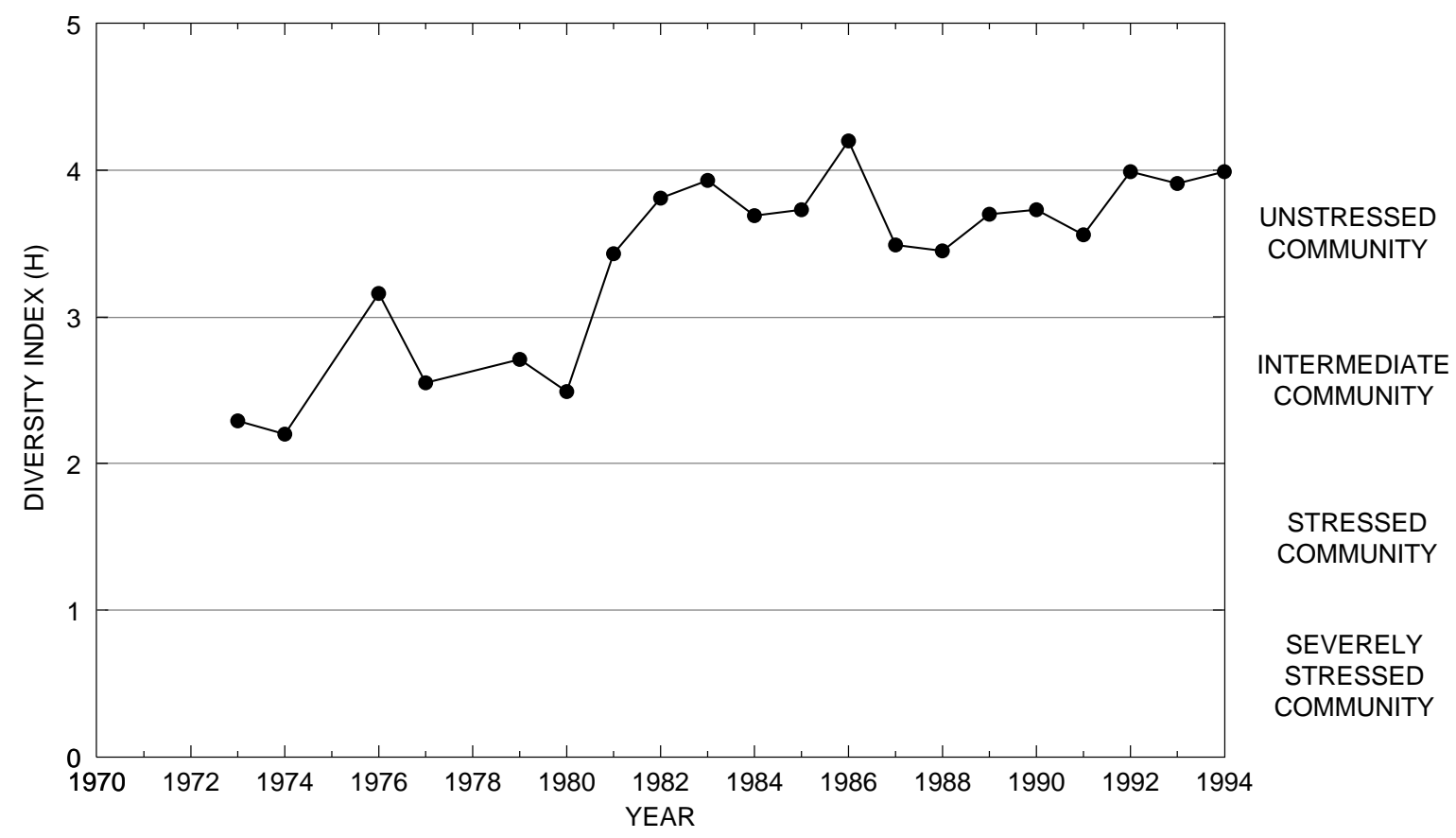


Table 6. Brillouin's diversity index, maximum diversity, minimum diversity, and relative evenness by site—Continued 01480656 INDIAN RUN NEAR SPRINGTON (SITE 47)

\begin{tabular}{|c|c|c|c|c|c|c|}
\hline Year & $\begin{array}{c}\text { Total } \\
\text { number of } \\
\text { organisms }\end{array}$ & $\begin{array}{c}\text { Total } \\
\text { number } \\
\text { of taxa }\end{array}$ & $\begin{array}{c}\text { Brillouin's } \\
\text { diversity index } \\
\text { (H) }\end{array}$ & $\begin{array}{l}\text { Maximum } \\
\text { diversity } \\
\left(\mathrm{H}_{\max }\right)\end{array}$ & $\begin{array}{c}\text { Minimum } \\
\text { diversity } \\
\left(\mathrm{H}_{\min }\right)\end{array}$ & $\begin{array}{c}\text { Evenness } \\
(\mathrm{E})\end{array}$ \\
\hline 1981 & 1,050 & 37 & 3.51 & 5.16 & 0.34 & 0.66 \\
\hline 1982 & 1,883 & 40 & 3.35 & 5.24 & .23 & .62 \\
\hline 1983 & 1,165 & 38 & 3.57 & 2.25 & .32 & .66 \\
\hline 1984 & 1,027 & 33 & 3.74 & 4.95 & .31 & .74 \\
\hline 1985 & 729 & 29 & 3.26 & 4.73 & .37 & .66 \\
\hline 1986 & 688 & 34 & 3.28 & 4.95 & .45 & .63 \\
\hline 1987 & 640 & 35 & 3.42 & 5.02 & .49 & .65 \\
\hline 1988 & ${ }^{1} 787$ & 29 & 3.67 & 4.77 & .34 & .75 \\
\hline 1989 & 1,288 & 32 & 3.72 & 4.91 & .25 & .75 \\
\hline 1990 & 840 & 32 & 3.49 & 4.89 & .36 & .69 \\
\hline 1991 & 589 & 31 & 3.64 & 4.81 & .46 & .73 \\
\hline 1992 & 440 & 25 & 3.56 & 4.61 & .48 & .75 \\
\hline 1993 & 770 & 34 & 3.99 & 5.08 & .41 & .77 \\
\hline 1994 & 1,232 & 34 & 3.73 & 5.02 & .27 & .73 \\
\hline
\end{tabular}

${ }^{1}$ Extrapolated from a $3 / 8$ subsample.

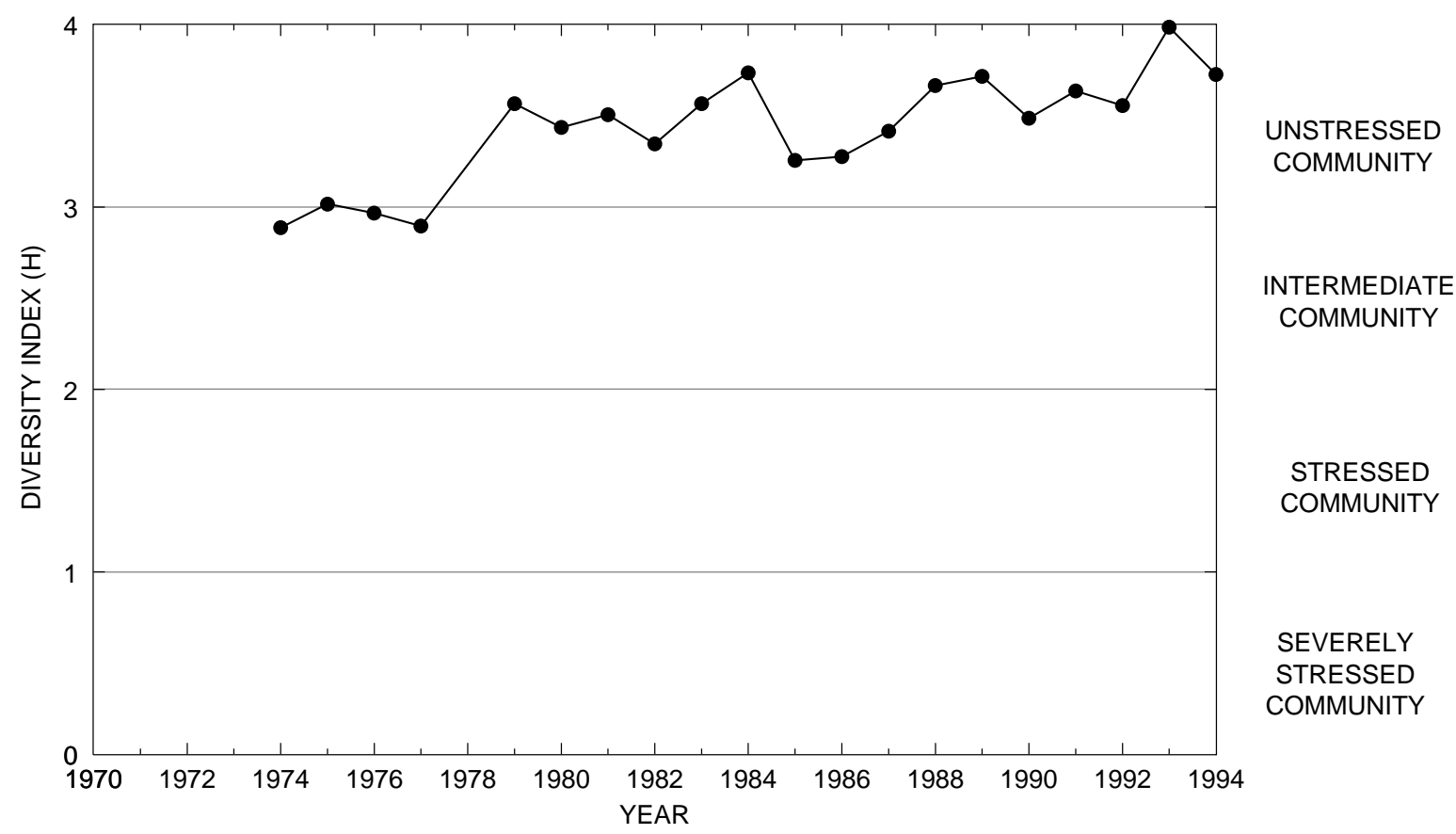


Table 6. Brillouin's diversity index, maximum diversity, minimum diversity, and relative evenness by site—Continued 01480700 EAST BRANCH BRANDYWINE CREEK NEAR DOWNINGTOWN (SITE 36)

\begin{tabular}{|c|c|c|c|c|c|c|}
\hline Year & $\begin{array}{c}\text { Total } \\
\text { number of } \\
\text { organisms }\end{array}$ & $\begin{array}{c}\text { Total } \\
\text { number } \\
\text { of taxa }\end{array}$ & $\begin{array}{c}\text { Brillouin's } \\
\text { diversity index } \\
\text { (H) }\end{array}$ & $\begin{array}{l}\text { Maximum } \\
\text { diversity } \\
\left(\mathrm{H}_{\max }\right)\end{array}$ & $\begin{array}{c}\text { Minimum } \\
\text { diversity } \\
\left(\mathrm{H}_{\min }\right)\end{array}$ & $\begin{array}{c}\text { Evenness } \\
(\mathrm{E})\end{array}$ \\
\hline 1981 & ${ }^{1} 2,450$ & 28 & 2.65 & 4.81 & 0.12 & 0.54 \\
\hline 1982 & ${ }^{1} 11,821$ & 23 & .94 & 4.52 & .02 & .20 \\
\hline 1983 & ${ }^{1} 2,848$ & 31 & 2.84 & 4.95 & .12 & .56 \\
\hline 1984 & ${ }^{1} 5,962$ & 33 & 2.13 & 5.03 & .07 & .42 \\
\hline 1985 & 1,866 & 30 & 3.06 & 4.91 & .17 & .61 \\
\hline 1986 & 2,232 & 31 & 2.92 & 4.90 & .15 & .58 \\
\hline 1987 & 2,179 & 31 & 3.06 & 4.93 & .15 & .61 \\
\hline 1988 & ${ }^{1} 1,499$ & 24 & 2.65 & 4.56 & .16 & .57 \\
\hline 1989 & 2,207 & 41 & 3.17 & 5.36 & .20 & .58 \\
\hline 1990 & 2,488 & 46 & 3.51 & 5.46 & .20 & .63 \\
\hline 1991 & 1,398 & 41 & 3.26 & 5.27 & .30 & .60 \\
\hline 1992 & 2,426 & 46 & 3.55 & 5.50 & .21 & .63 \\
\hline 1993 & 1,896 & 49 & 3.70 & 5.61 & .28 & .64 \\
\hline 1994 & 1,022 & 38 & 3.54 & 5.27 & .36 & .65 \\
\hline
\end{tabular}

${ }^{1}$ Extrapolated from a 3/8 subsample.

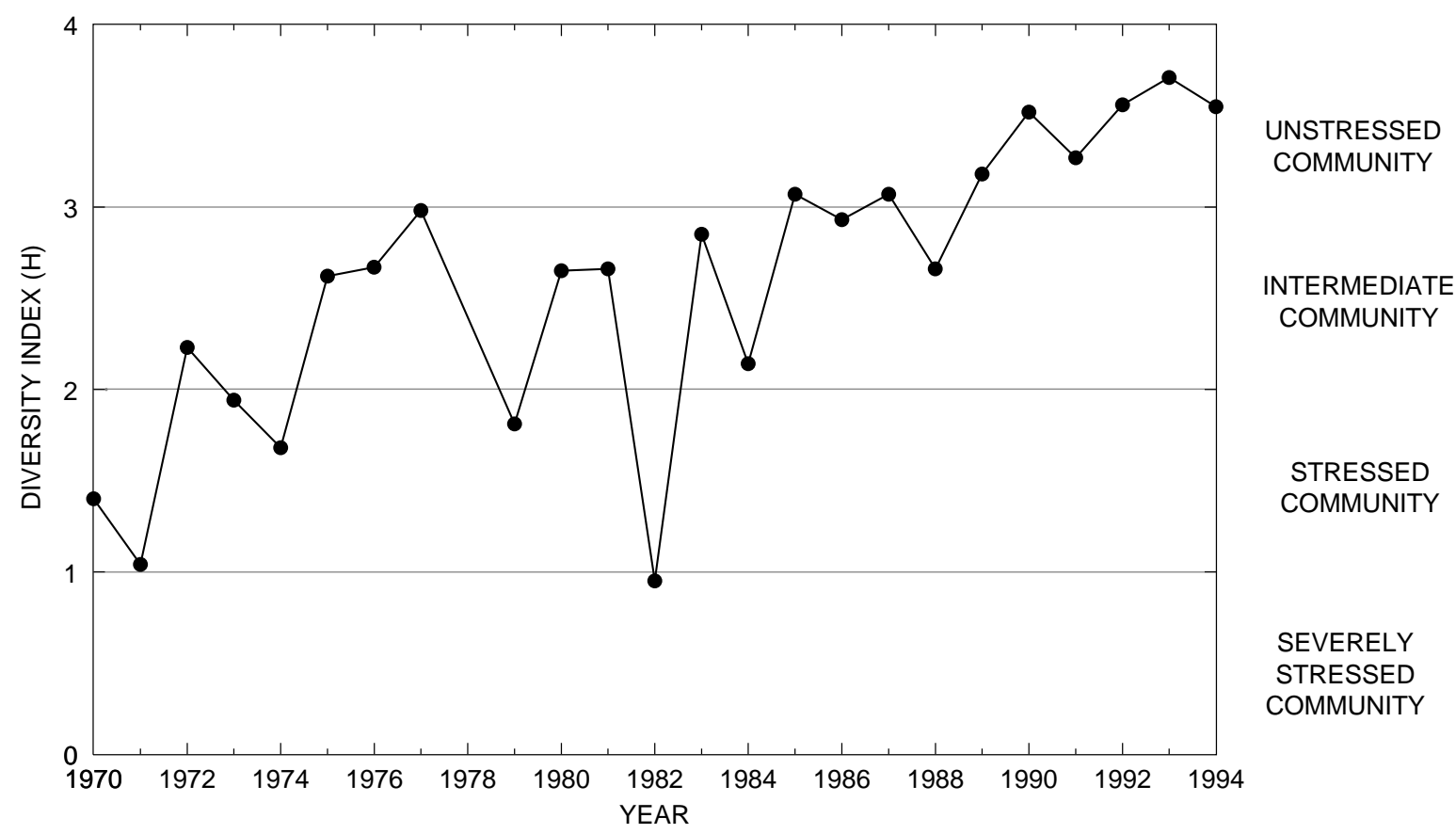


Table 6. Brillouin's diversity index, maximum diversity, minimum diversity, and relative evenness by site—Continued 01480903 VALLEY CREEK AT MULLSTEINS MEADOW NEAR DOWNINGTOWN (SITE 44)

\begin{tabular}{|c|c|c|c|c|c|c|}
\hline Year & $\begin{array}{c}\text { Total } \\
\text { number of } \\
\text { organisms }\end{array}$ & $\begin{array}{c}\text { Total } \\
\text { number } \\
\text { of taxa }\end{array}$ & $\begin{array}{c}\text { Brillouin's } \\
\text { diversity index } \\
\text { (H) }\end{array}$ & $\begin{array}{l}\text { Maximum } \\
\text { diversity } \\
\left(\mathrm{H}_{\max }\right)\end{array}$ & $\begin{array}{c}\text { Minimum } \\
\text { diversity } \\
\left(\mathrm{H}_{\min }\right)\end{array}$ & $\begin{array}{c}\text { Evenness } \\
(\mathrm{E})\end{array}$ \\
\hline 1981 & 2,812 & 33 & 2.29 & 5.02 & 0.13 & 0.65 \\
\hline 1982 & 1,556 & 33 & 3.23 & 4.98 & .22 & .63 \\
\hline 1983 & 1,918 & 26 & 3.25 & 4.70 & .14 & .68 \\
\hline 1984 & 1,475 & 25 & 2.96 & 4.67 & .17 & .62 \\
\hline 1985 & 2,091 & 33 & 3.27 & 5.03 & .17 & .64 \\
\hline 1986 & 1,079 & 24 & 2.96 & 4.50 & .21 & .64 \\
\hline 1987 & 2,352 & 33 & 3.16 & 5.01 & .15 & .62 \\
\hline 1988 & ${ }^{1} 2,626$ & 22 & 2.65 & 4.46 & .09 & .59 \\
\hline 1989 & 1,105 & 30 & 3.10 & 4.93 & .26 & .61 \\
\hline 1990 & 1,100 & 28 & 2.68 & 4.84 & .25 & .53 \\
\hline 1991 & 1,499 & 21 & 2.40 & 4.34 & .14 & .54 \\
\hline 1992 & 1,380 & 28 & 3.28 & 4.76 & .20 & .67 \\
\hline 1993 & 1,179 & 36 & 3.27 & 5.14 & .30 & .61 \\
\hline 1994 & 1,163 & 27 & 3.49 & 4.68 & .23 & .73 \\
\hline
\end{tabular}

${ }^{1}$ Extrapolated from a $3 / 8$ subsample.

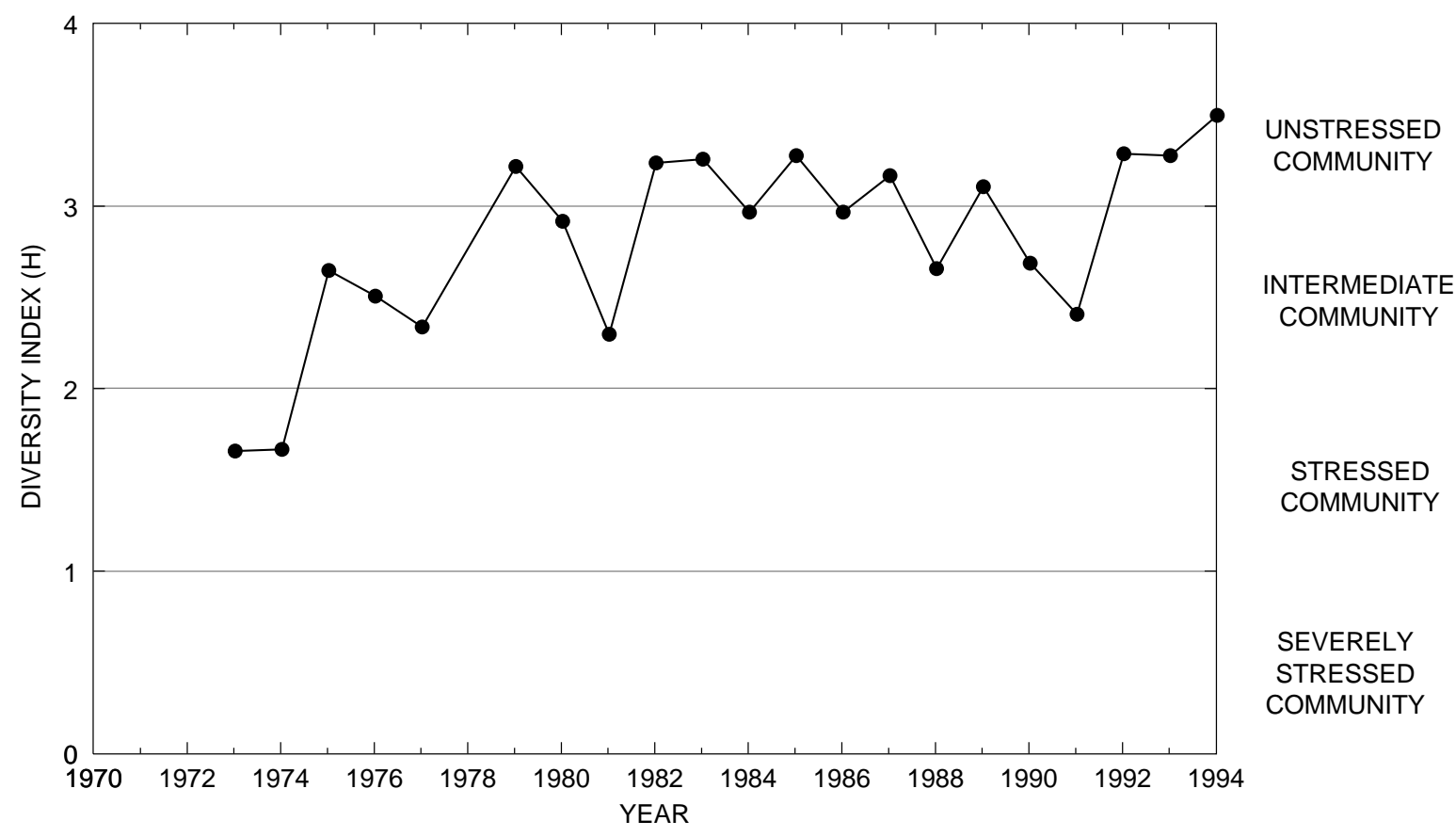


Table 6. Brillouin's diversity index, maximum diversity, minimum diversity, and relative evenness by site—Continued 01480950 EAST BRANCH BRANDYWINE CREEK AT WAWASET (SITE 39)

\begin{tabular}{|c|c|c|c|c|c|c|}
\hline Year & $\begin{array}{c}\text { Total } \\
\text { number of } \\
\text { organisms }\end{array}$ & $\begin{array}{c}\text { Total } \\
\text { number } \\
\text { of taxa }\end{array}$ & $\begin{array}{c}\text { Brillouin's } \\
\text { diversity index } \\
\text { (H) }\end{array}$ & $\begin{array}{c}\text { Maximum } \\
\text { diversity } \\
\left(\mathrm{H}_{\max }\right)\end{array}$ & $\begin{array}{c}\text { Minimum } \\
\text { diversity } \\
\left(\mathrm{H}_{\min }\right)\end{array}$ & $\begin{array}{c}\text { Evenness } \\
(\mathrm{E})\end{array}$ \\
\hline 1981 & 641 & 31 & 3.63 & 4.93 & 0.44 & 0.71 \\
\hline 1982 & 2,825 & 36 & 3.49 & 5.13 & .14 & .67 \\
\hline 1983 & 771 & 36 & 3.49 & 5.07 & .44 & .66 \\
\hline 1984 & 2,999 & 42 & 3.06 & 5.37 & .16 & .56 \\
\hline 1985 & 699 & 27 & 3.00 & 4.80 & .35 & .60 \\
\hline 1986 & 2,583 & 44 & 3.22 & 5.46 & .19 & .57 \\
\hline 1987 & 1,115 & 40 & 3.64 & 5.32 & .35 & .66 \\
\hline 1988 & 1,357 & 28 & 3.29 & 4.77 & .21 & .68 \\
\hline 1989 & 2,698 & 40 & 3.62 & 5.28 & .17 & .67 \\
\hline 1990 & 3,793 & 44 & 3.09 & 5.46 & .14 & .55 \\
\hline 1991 & 11,771 & 50 & 1.28 & 5.63 & .06 & .22 \\
\hline 1992 & 1,354 & 19 & 2.83 & 4.23 & .14 & .66 \\
\hline 1993 & 1,701 & 33 & 3.47 & 5.00 & .20 & .68 \\
\hline 1994 & 792 & 41 & 3.63 & 5.23 & .49 & .66 \\
\hline
\end{tabular}

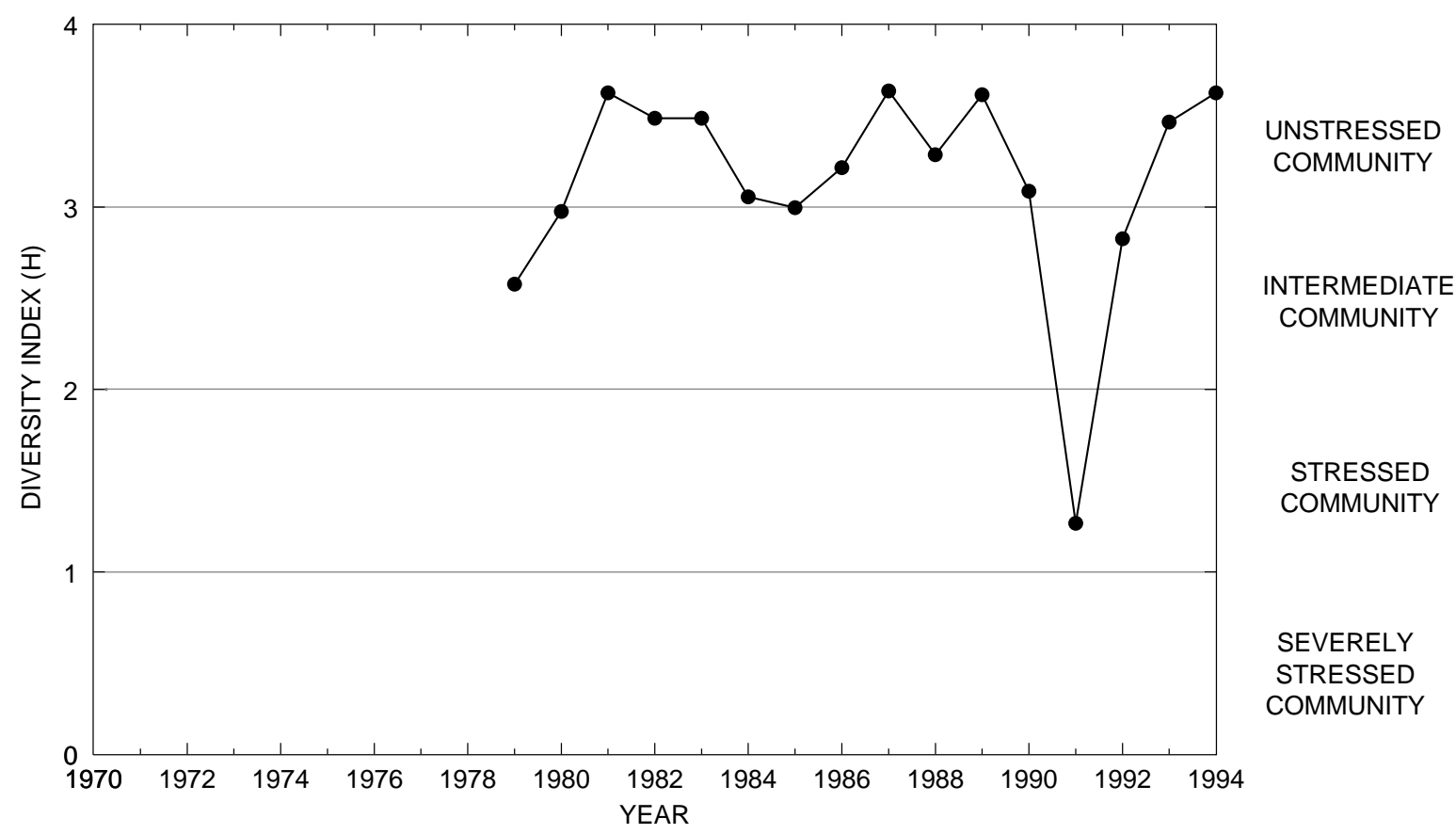


Table 6. Brillouin's diversity index, maximum diversity, minimum diversity, and relative evenness by site-Continued 01481030 BRANDYWINE CREEK NEAR CHADDS FORD (SITE 40)

\begin{tabular}{|c|c|c|c|c|c|c|}
\hline Year & $\begin{array}{c}\text { Total } \\
\text { numberof } \\
\text { organisms }\end{array}$ & $\begin{array}{c}\text { Total } \\
\text { number } \\
\text { of taxa }\end{array}$ & $\begin{array}{c}\text { Brillouin's } \\
\text { diversity index } \\
\text { (H) }\end{array}$ & $\begin{array}{l}\text { Maximum } \\
\text { diversity } \\
\left(\mathrm{H}_{\max }\right)\end{array}$ & $\begin{array}{c}\text { Minimum } \\
\text { diversity } \\
\left(\mathrm{H}_{\min }\right)\end{array}$ & $\begin{array}{c}\text { Evenness } \\
(\mathrm{E})\end{array}$ \\
\hline 1981 & 651 & 23 & 3.28 & 4.45 & 0.32 & 0.72 \\
\hline 1982 & 1,673 & 30 & 3.28 & 4.88 & .19 & .66 \\
\hline 1983 & 1,009 & 32 & 3.24 & 5.01 & .30 & .62 \\
\hline 1984 & 1,446 & 24 & 2.86 & 4.52 & .17 & .62 \\
\hline 1985 & 993 & 25 & 3.41 & 4.68 & .24 & .72 \\
\hline 1986 & 428 & 36 & 3.92 & 5.19 & .71 & .72 \\
\hline 1987 & 1,046 & 37 & 3.53 & 5.14 & .34 & .66 \\
\hline 1988 & ${ }^{1} 1,824$ & 25 & 3.64 & 4.65 & .14 & .78 \\
\hline 1989 & 2,155 & 37 & 3.43 & 5.16 & .18 & .65 \\
\hline 1990 & 1,702 & 31 & 3.45 & 4.96 & .19 & .68 \\
\hline 1991 & 2,380 & 31 & 2.88 & 4.91 & .14 & .57 \\
\hline 1992 & 1,835 & 29 & 3.08 & 4.83 & .16 & .62 \\
\hline 1993 & 1,142 & 36 & 4.02 & 5.16 & .31 & .76 \\
\hline 1994 & 1,424 & 32 & 3.63 & 4.93 & .23 & .72 \\
\hline
\end{tabular}

${ }^{1}$ Extrapolated from a $3 / 8$ subsample.

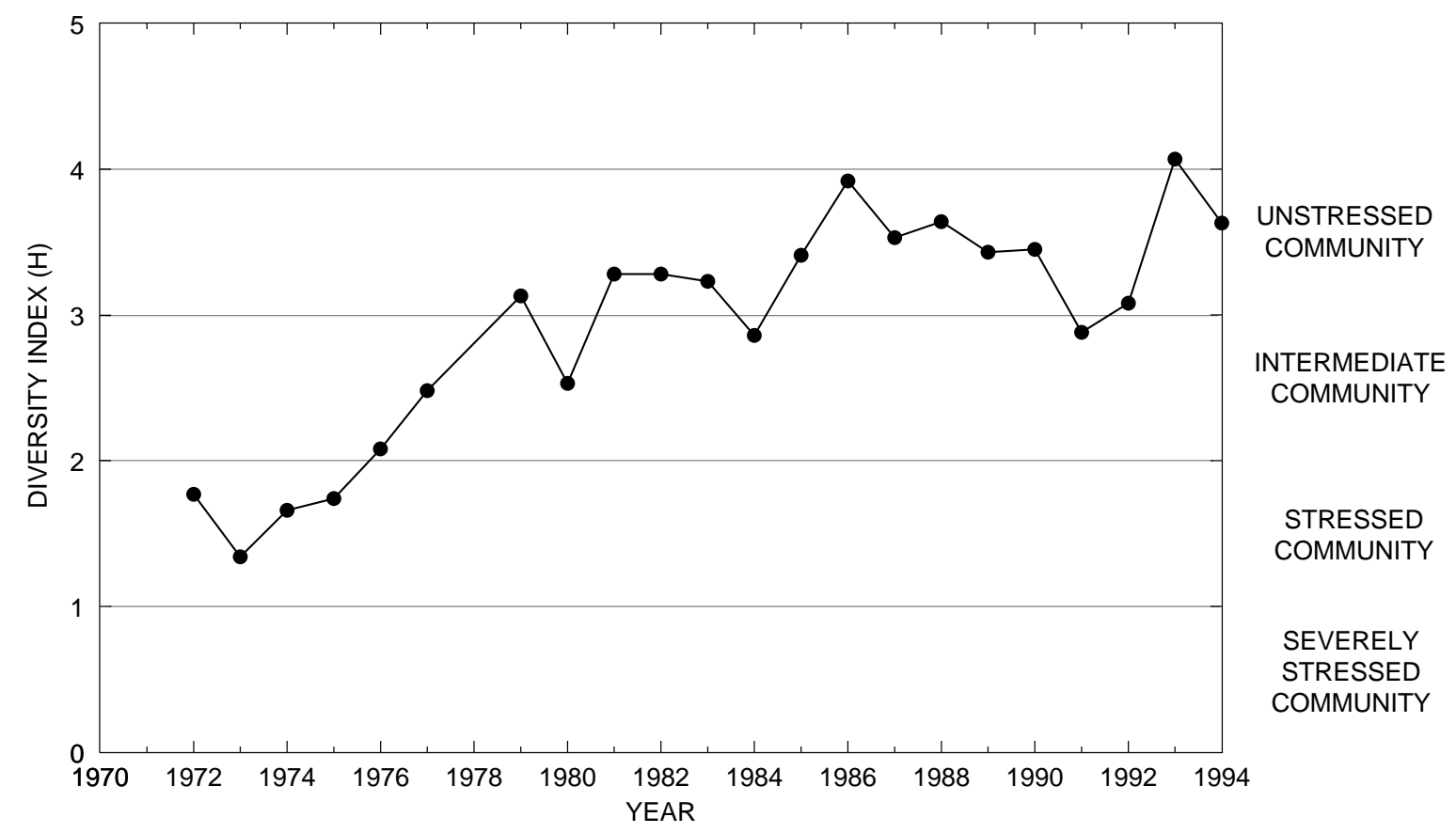


Table 6. Brillouin's diversity index, maximum diversity, minimum diversity, and relative evenness by site—Continued

01494900 EAST BRANCH BIG ELK CREEK AT ELKVIEW (SITE 31)

\begin{tabular}{|c|c|c|c|c|c|c|}
\hline Year & $\begin{array}{c}\text { Total } \\
\text { number of } \\
\text { organisms }\end{array}$ & $\begin{array}{c}\text { Total } \\
\text { number } \\
\text { of taxa }\end{array}$ & $\begin{array}{c}\text { Brillouin's } \\
\text { diversity index } \\
\text { (H) }\end{array}$ & $\begin{array}{c}\text { Maximum } \\
\text { diversity } \\
\left(\mathrm{H}_{\max }\right)\end{array}$ & $\begin{array}{c}\text { Minimum } \\
\text { diversity } \\
\left(\mathrm{H}_{\min }\right)\end{array}$ & $\begin{array}{c}\text { Evenness } \\
(\mathrm{E})\end{array}$ \\
\hline 1981 & 846 & 25 & 2.55 & 4.67 & 0.28 & 0.52 \\
\hline 1982 & 1,416 & 26 & 2.84 & 4.66 & .18 & .59 \\
\hline 1983 & 1,171 & 23 & 3.01 & 4.45 & .19 & .66 \\
\hline 1984 & 1,216 & 25 & 2.85 & 4.63 & .26 & .60 \\
\hline 1985 & 546 & 22 & 2.42 & 4.50 & .35 & .50 \\
\hline 1986 & 851 & 20 & 2.79 & 4.27 & .22 & .63 \\
\hline 1987 & 1,638 & 21 & 2.41 & 4.35 & .13 & .54 \\
\hline 1988 & 1,357 & 26 & 2.90 & 4.73 & .19 & .60 \\
\hline 1989 & 1,722 & 26 & 2.98 & 4.71 & .16 & .62 \\
\hline 1990 & 1,387 & 23 & 2.25 & 4.46 & .17 & .49 \\
\hline 1991 & 810 & 15 & 1.96 & 3.84 & .17 & .49 \\
\hline 1992 & 755 & 26 & 3.16 & 4.59 & .32 & .66 \\
\hline 1993 & 948 & 26 & 2.86 & 4.68 & .26 & .59 \\
\hline 1994 & 553 & 17 & 2.61 & 4.12 & .26 & .61 \\
\hline
\end{tabular}

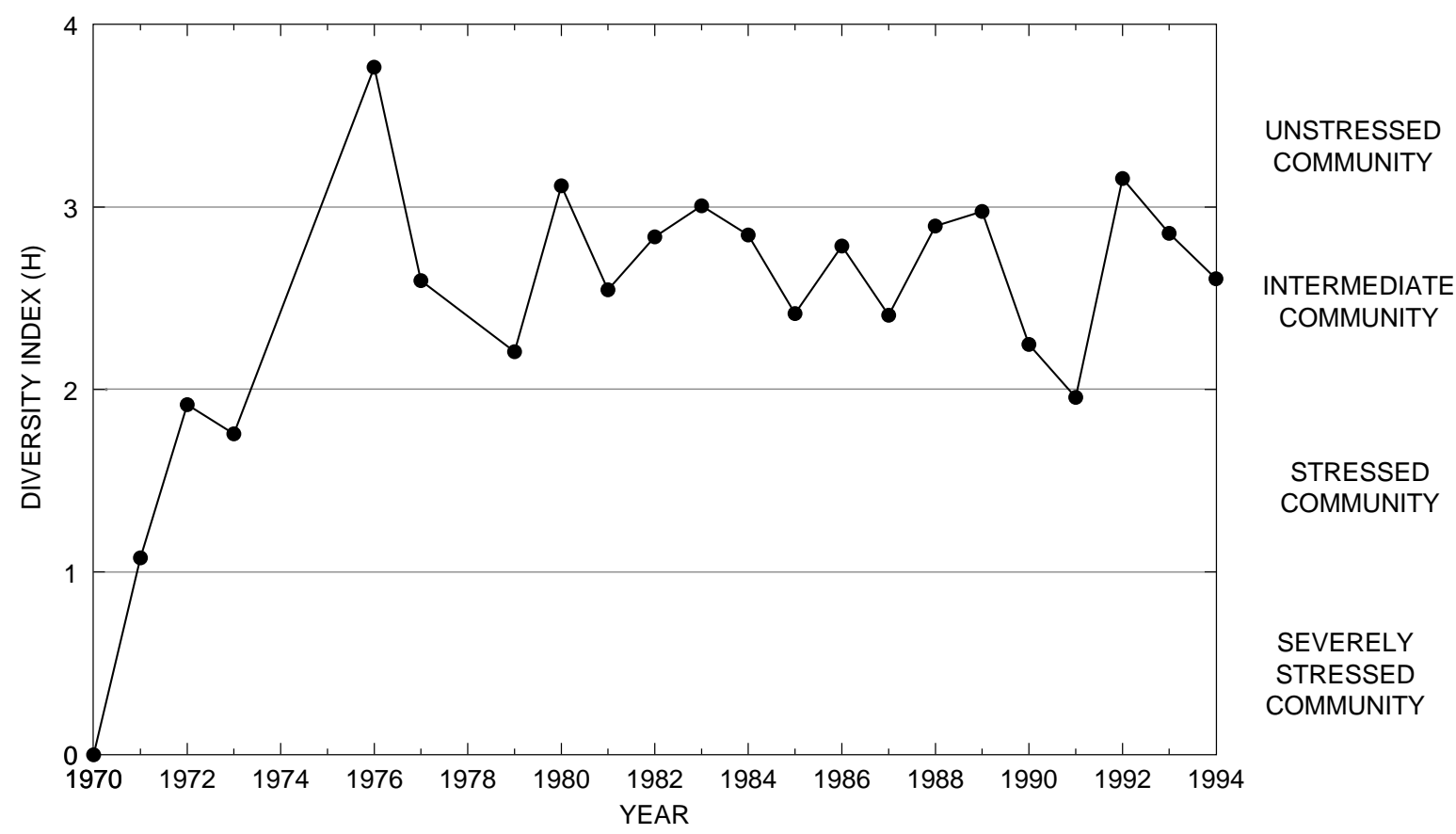


Table 6. Brillouin's diversity index, maximum diversity, minimum diversity, and relative evenness by site-Continued

01494950 WEST BRANCH BIG ELK CREEK NEAR OXFORD (SITE 32)

\begin{tabular}{|c|c|c|c|c|c|c|}
\hline Year & $\begin{array}{c}\text { Total } \\
\text { number of } \\
\text { organisms }\end{array}$ & $\begin{array}{c}\text { Total } \\
\text { number } \\
\text { of taxa }\end{array}$ & $\begin{array}{c}\text { Brillouin's } \\
\text { diversity index } \\
\text { (H) }\end{array}$ & $\begin{array}{l}\text { Maximum } \\
\text { diversity } \\
\left(\mathrm{H}_{\max }\right)\end{array}$ & $\begin{array}{c}\text { Minimum } \\
\text { diversity } \\
\left(\mathrm{H}_{\min }\right)\end{array}$ & $\begin{array}{c}\text { Evenness } \\
(\mathrm{E})\end{array}$ \\
\hline 1981 & 1,517 & 30 & 3.16 & 4.84 & 0.20 & 0.64 \\
\hline 1982 & 2,458 & 26 & 2.73 & 4.69 & .11 & .57 \\
\hline 1983 & 1,203 & 28 & 2.96 & 4.80 & .23 & .60 \\
\hline 1984 & 1,875 & 23 & 2.81 & 4.49 & .13 & .62 \\
\hline 1985 & 1,124 & 21 & 2.31 & 4.32 & .18 & .52 \\
\hline 1986 & 1,402 & 24 & 3.11 & 4.55 & .17 & .67 \\
\hline 1987 & 1,309 & 22 & 2.71 & 4.43 & .17 & .60 \\
\hline 1988 & ${ }^{1} 2,245$ & 20 & 2.90 & 4.29 & .09 & .67 \\
\hline 1989 & 1,533 & 25 & 3.13 & 4.61 & .17 & .67 \\
\hline 1990 & 1,536 & 27 & 2.95 & 4.75 & .18 & .61 \\
\hline 1991 & 2,733 & 32 & 3.09 & 4.98 & .13 & .61 \\
\hline 1992 & 752 & 27 & 3.30 & 4.64 & .33 & .69 \\
\hline 1993 & 424 & 18 & 2.61 & 4.14 & .35 & .60 \\
\hline 1994 & 1,587 & 29 & 3.03 & 4.85 & .19 & .61 \\
\hline
\end{tabular}

${ }^{1}$ Extrapolated from a $3 / 8$ subsample.

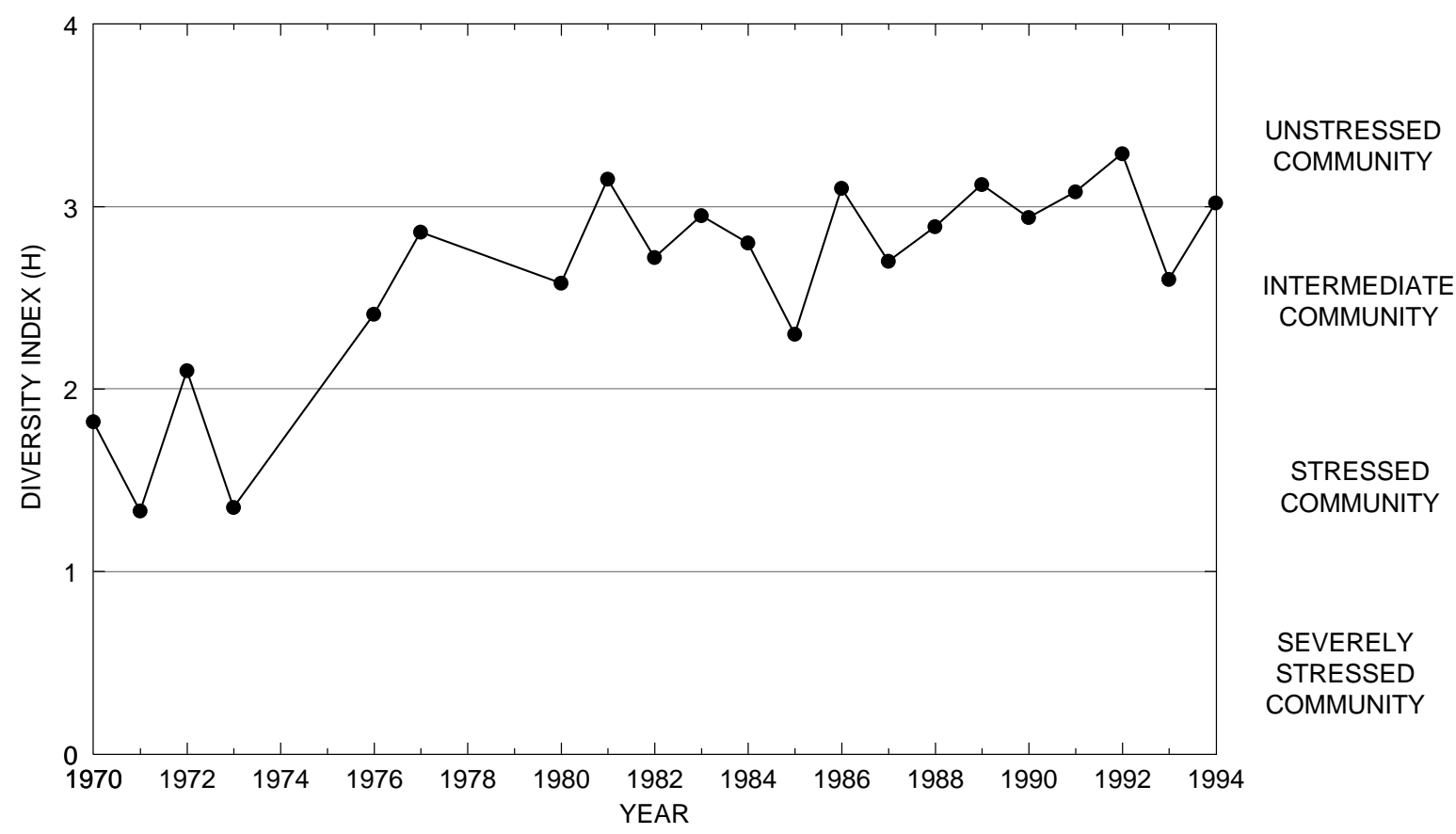


Table 6. Brillouin's diversity index, maximum diversity, minimum diversity, and relative evenness by site—Continued

01578340 EAST BRANCH OCTORARO CREEK AT CHRISTIANA (SITE 33)

\begin{tabular}{|c|c|c|c|c|c|c|}
\hline Year & $\begin{array}{c}\text { Total } \\
\text { number of } \\
\text { organisms }\end{array}$ & $\begin{array}{c}\text { Total } \\
\text { number } \\
\text { of taxa }\end{array}$ & $\begin{array}{c}\text { Brillouin's } \\
\text { diversity index } \\
\text { (H) }\end{array}$ & $\begin{array}{l}\text { Maximum } \\
\text { diversity } \\
\left(\mathrm{H}_{\max }\right)\end{array}$ & $\begin{array}{c}\text { Minimum } \\
\text { diversity } \\
\left(\mathrm{H}_{\min }\right)\end{array}$ & $\begin{array}{c}\text { Evenness } \\
(\mathrm{E})\end{array}$ \\
\hline 1981 & 978 & 18 & 3.09 & 4.12 & 0.17 & 0.74 \\
\hline 1982 & 1,670 & 24 & 3.36 & 4.58 & .15 & .72 \\
\hline 1983 & 856 & 25 & 2.86 & 4.54 & .27 & .61 \\
\hline 1984 & 1,518 & 21 & 2.97 & 4.41 & .14 & .66 \\
\hline 1985 & 593 & 25 & 3.17 & 4.64 & .37 & .65 \\
\hline 1986 & 1,110 & 27 & 2.88 & 4.78 & .24 & .58 \\
\hline 1987 & 1,421 & 27 & 3.31 & 4.70 & .19 & .69 \\
\hline 1988 & ${ }^{1} 1,953$ & 20 & 3.02 & 4.33 & .11 & .69 \\
\hline 1989 & 2,083 & 30 & 3.42 & 4.89 & .15 & .69 \\
\hline 1990 & 1,419 & 33 & 3.49 & 4.95 & .24 & .69 \\
\hline 1991 & 1,476 & 28 & 2.82 & 4.74 & .19 & .58 \\
\hline 1992 & 1,268 & 23 & 2.32 & 4.46 & .18 & .50 \\
\hline 1993 & 558 & 22 & 3.17 & 4.39 & .34 & .70 \\
\hline 1994 & 2,194 & 31 & 2.44 & 4.97 & .15 & .48 \\
\hline
\end{tabular}

${ }^{1}$ Extrapolated from a $3 / 8$ subsample.

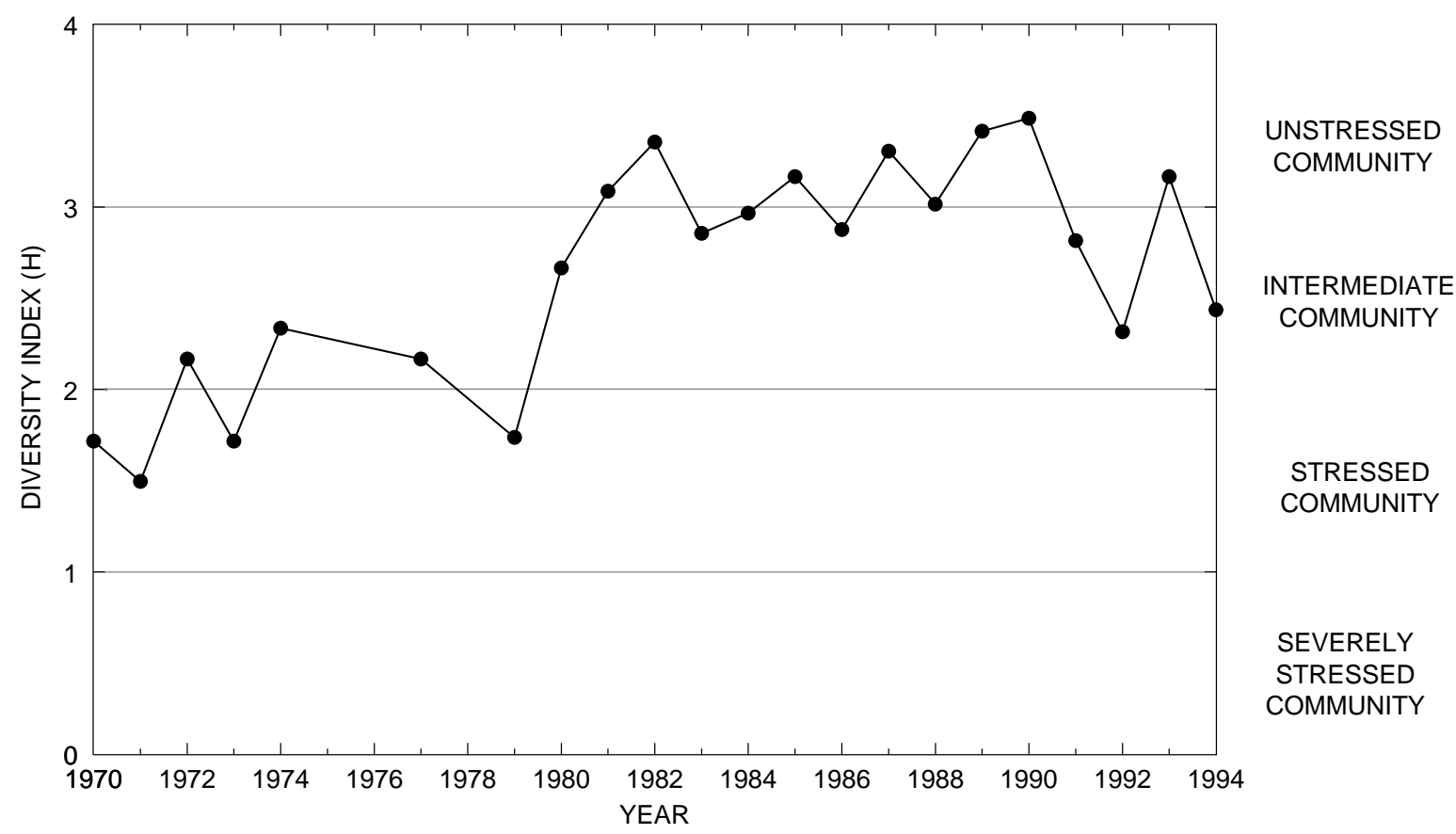


Table 6. Brillouin's diversity index, maximum diversity, minimum diversity, and relative evenness by site—Continued 01578343 VALLEY CREEK AT ATGLEN (SITE 34)

\begin{tabular}{|c|c|c|c|c|c|c|}
\hline Year & $\begin{array}{c}\text { Total } \\
\text { number of } \\
\text { organisms }\end{array}$ & $\begin{array}{c}\text { Total } \\
\text { number } \\
\text { of taxa }\end{array}$ & $\begin{array}{c}\text { Brillouin's } \\
\text { diversity index } \\
\text { (H) }\end{array}$ & $\begin{array}{l}\text { Maximum } \\
\text { diversity } \\
\left(\mathrm{H}_{\max }\right)\end{array}$ & $\begin{array}{c}\text { Minimum } \\
\text { diversity } \\
\left(\mathrm{H}_{\min }\right)\end{array}$ & $\begin{array}{c}\text { Evenness } \\
(\mathrm{E})\end{array}$ \\
\hline 1981 & 2,173 & 21 & 3.12 & 4.35 & 0.10 & 0.71 \\
\hline 1982 & 2,478 & 32 & 3.37 & 5.02 & .14 & .66 \\
\hline 1983 & 930 & 23 & 2.97 & 4.53 & .23 & .64 \\
\hline 1984 & 2,239 & 30 & 2.90 & 4.85 & .14 & .59 \\
\hline 1985 & 962 & 28 & 3.12 & 4.77 & .28 & .63 \\
\hline 1986 & 783 & 23 & 3.16 & 4.53 & .27 & .68 \\
\hline 1987 & 2,316 & 31 & 3.54 & 4.94 & .15 & .71 \\
\hline 1988 & ${ }^{1} 2,916$ & 24 & 3.28 & 4.60 & .09 & .71 \\
\hline 1989 & 3,051 & 39 & 3.46 & 5.25 & .14 & .65 \\
\hline 1990 & 1,262 & 28 & 3.30 & 4.72 & .22 & .68 \\
\hline 1991 & 3,201 & 32 & 2.97 & 4.97 & .11 & .59 \\
\hline 1992 & 1,788 & 27 & 2.67 & 4.73 & .16 & .54 \\
\hline 1993 & 825 & 18 & 2.29 & 4.11 & .20 & .53 \\
\hline 1994 & 2,936 & 23 & 2.49 & 4.50 & .09 & .55 \\
\hline
\end{tabular}

${ }^{1}$ Extrapolated from a $3 / 8$ subsample.

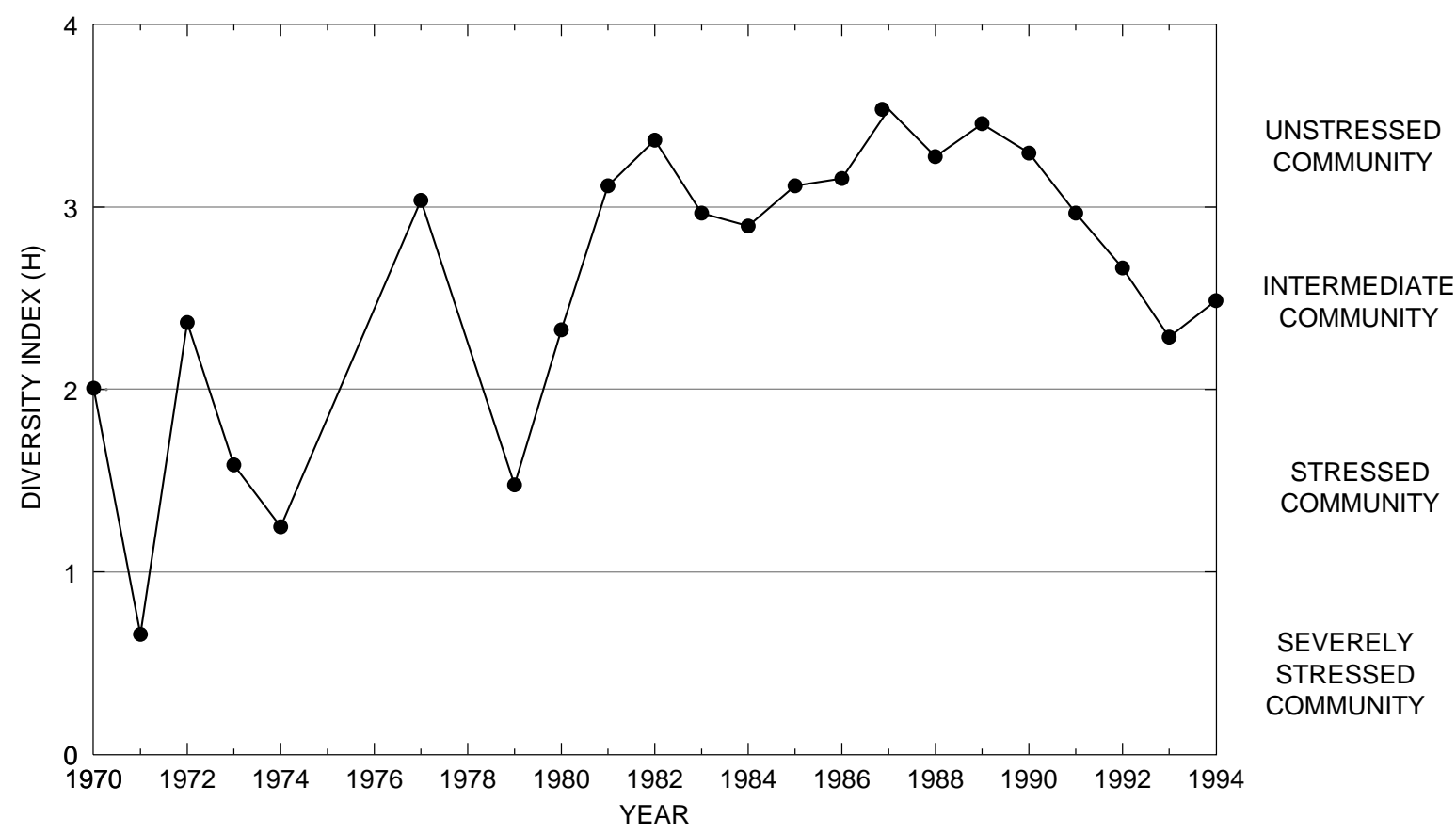


Table 6. Brillouin's diversity index, maximum diversity, minimum diversity, and relative evenness by site—Continued

01578345 EAST BRANCH OCTORARO CREEK AT STEELVILLE (SITE 35)

\begin{tabular}{ccccccr}
\hline Year & $\begin{array}{c}\text { Total } \\
\text { number of } \\
\text { organisms }\end{array}$ & $\begin{array}{c}\text { Total } \\
\text { number } \\
\text { of taxa }\end{array}$ & $\begin{array}{c}\text { Brillouin's } \\
\text { diversity index } \\
(\mathrm{H})\end{array}$ & $\begin{array}{c}\text { Maximum } \\
\text { diversity } \\
\left(\mathrm{H}_{\text {max }}\right)\end{array}$ & $\begin{array}{c}\text { Minimum } \\
\text { diversity } \\
\left(\mathrm{H}_{\min }\right)\end{array}$ & $\begin{array}{c}\text { Evenness } \\
(\mathrm{E})\end{array}$ \\
\hline 1981 & 1,041 & 27 & 2.99 & 4.74 & 0.25 & 0.61 \\
1982 & 1,791 & 25 & 2.99 & 4.60 & .15 & .64 \\
\hline
\end{tabular}

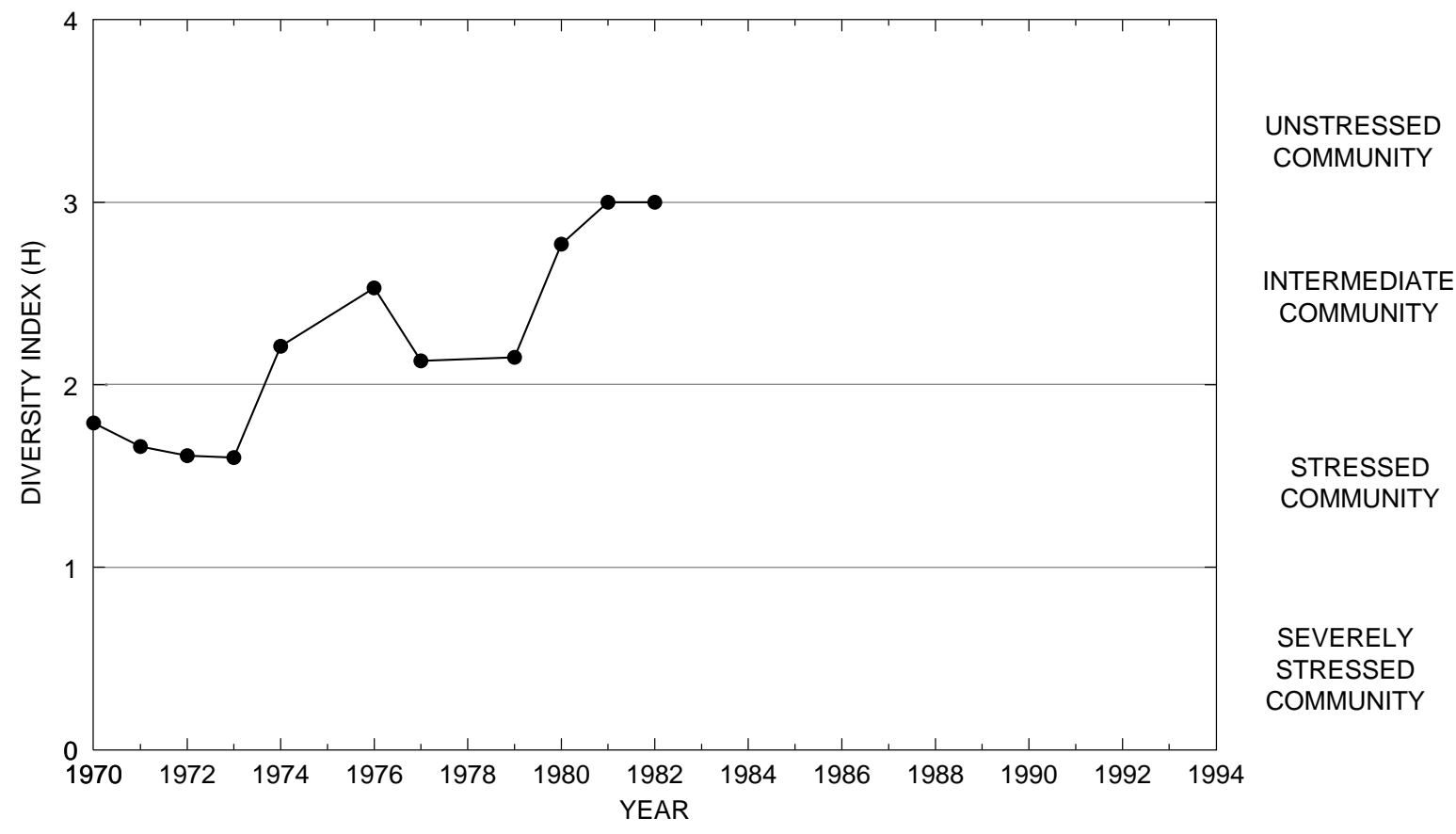


Table 7. Median, mean, standard deviation, and standard error values of Brillouin's diversity index by site

$[-$, no data $]$

\begin{tabular}{|c|c|c|c|c|c|c|}
\hline $\begin{array}{l}\text { Station } \\
\text { number }\end{array}$ & $\begin{array}{c}\text { Site } \\
\text { number }\end{array}$ & $\begin{array}{c}\text { Number of } \\
\text { samples }\end{array}$ & Median & Mean & $\begin{array}{l}\text { Standard } \\
\text { deviation }\end{array}$ & $\begin{array}{l}\text { Standard } \\
\text { error }\end{array}$ \\
\hline 01472054 & 8 & 2 & 3.32 & 3.32 & 0.29 & 0.15 \\
\hline 01472065 & 9 & 2 & 3.17 & 3.17 & .19 & .10 \\
\hline 01472080 & 10 & 14 & 3.37 & 3.39 & .29 & .75 \\
\hline 01472109 & 6 & 14 & 3.51 & 3.36 & .39 & .10 \\
\hline 01472110 & 7 & 2 & 3.25 & 3.25 & .39 & .20 \\
\hline 01472126 & 41 & 1 & - & - & - & - \\
\hline 01472129 & 11 & 2 & 3.71 & 3.71 & .17 & .09 \\
\hline 01473138 & 13 & 14 & 3.40 & 3.41 & .42 & .11 \\
\hline 01472140 & 12 & 14 & 3.71 & 3.60 & .30 & .08 \\
\hline 01472154 & 14 & 14 & 3.49 & 3.39 & .49 & .13 \\
\hline 01472157 & 15 & 14 & 3.34 & 3.38 & .55 & .14 \\
\hline 014721612 & 16 & 14 & 2.55 & 2.38 & .88 & .23 \\
\hline 01472170 & 1 & 14 & 3.18 & 3.15 & .34 & .09 \\
\hline 01472174 & 2 & 14 & 3.35 & 3.31 & .48 & .13 \\
\hline 014721854 & 3 & 14 & 3.35 & 3.33 & .41 & .11 \\
\hline 014721884 & 4 & 14 & 3.25 & 3.33 & .39 & .10 \\
\hline 01472190 & 5 & 14 & 3.30 & 3.19 & .39 & .10 \\
\hline 01473167 & 49 & 14 & 3.00 & 2.96 & .22 & .06 \\
\hline 01473168 & 50 & 14 & 2.78 & 2.88 & .25 & .07 \\
\hline 01475300 & 17 & 14 & 3.38 & 3.15 & .61 & .16 \\
\hline 01475830 & 18 & 2 & 3.58 & 3.58 & .06 & .03 \\
\hline 01475840 & 19 & 14 & 3.21 & 3.18 & .44 & .11 \\
\hline 01476430 & 20 & 14 & 3.24 & 3.25 & .33 & .09 \\
\hline 01476435 & 21 & 14 & 3.18 & 3.15 & .30 & .08 \\
\hline 01476790 & 22 & 14 & 3.12 & 2.83 & .66 & .17 \\
\hline 01476830 & 23 & 14 & 3.02 & 2.95 & .46 & .12 \\
\hline 01476830 & 24 & 14 & 3.11 & 3.01 & .37 & .09 \\
\hline 01456840 & 25 & 9 & 1.86 & 1.84 & .45 & .14 \\
\hline 01476848 & 51 & 12 & 2.61 & 2.53 & .38 & .11 \\
\hline 01478120 & 28 & 14 & 2.65 & 2.64 & .41 & .11 \\
\hline 01478190 & 29 & 14 & 2.82 & 2.86 & .29 & .08 \\
\hline 01478220 & 30 & 14 & 2.94 & 3.01 & .44 & .11 \\
\hline 01479680 & 27 & 14 & 2.37 & 2.34 & .52 & .13 \\
\hline 01479800 & 26 & 14 & 2.06 & 2.10 & .54 & .14 \\
\hline 01480434 & 37 & 14 & 3.15 & 3.13 & .44 & .11 \\
\hline 01480629 & 46 & 14 & 2.69 & 2.80 & .47 & .12 \\
\hline 01480632 & 45 & 14 & 3.21 & 3.15 & .23 & .06 \\
\hline 01480640 & 38 & 14 & 3.14 & 3.12 & .43 & .11 \\
\hline 01480647 & 43 & 2 & 2.87 & 2.87 & .52 & .26 \\
\hline 01480648 & 48 & 14 & 3.43 & 3.44 & .27 & .07 \\
\hline 01480653 & 42 & 14 & 3.73 & 3.76 & .23 & .06 \\
\hline
\end{tabular}


Table 7. Median, mean, standard deviation, and standard error values of Brillouin's diversity index by site-Continued

\begin{tabular}{ccccccc}
\hline $\begin{array}{c}\text { Station } \\
\text { number }\end{array}$ & $\begin{array}{c}\text { Site } \\
\text { number }\end{array}$ & $\begin{array}{c}\text { Number of } \\
\text { samples }\end{array}$ & Median & Mean & $\begin{array}{c}\text { Standard } \\
\text { deviation }\end{array}$ & $\begin{array}{c}\text { Standard } \\
\text { error }\end{array}$ \\
\hline 01480656 & 47 & 14 & 3.57 & 3.57 & 0.20 & 0.05 \\
01480700 & 36 & 14 & 3.06 & 2.93 & .71 & .18 \\
01480903 & 44 & 14 & 3.13 & 3.00 & .36 & .09 \\
01480950 & 39 & 14 & 3.38 & 3.20 & .62 & .16 \\
01481030 & 40 & 14 & 3.42 & 3.41 & .35 & .09 \\
01494900 & 31 & 14 & 2.81 & 2.69 & .33 & .09 \\
01494950 & 32 & 14 & 2.96 & 2.91 & .26 & .07 \\
01578340 & 33 & 14 & 3.06 & 3.02 & .35 & .09 \\
01578343 & 34 & 14 & 3.12 & 3.05 & .36 & .09 \\
01578345 & 35 & 2 & 2.99 & 2.99 & .00 & .00 \\
\hline
\end{tabular}


Acroneuria sp.

Aeshna sp.

Agabus sp.

Agnetina sp.

Agraylea sp.

Allocapnia sp.

Amnicola sp.

Amphiagrion sp.

Anchytarsus bicolor

Ancyronyx sp.

Ancyronyx variegata

Anthopotamus sp.

Antocha sp.

Apatania sp.

Archanara sp.

Argia sp

Atherix sp.

Baetis sp.

Berosus sp.

Blephariceridae

Blepharicera sp.

Boyeria sp.

Brachycentrus sp.

Branchiobdellida

Caecidotea sp.

Caenis $\mathrm{sp}$

Calopteryx $\mathrm{sp}$.

Cambaridae

Cambarus sp.

Ceraclea sp.

Ceratopogonidae

Ceratopsyche $\mathrm{sp}$.

Chaoborus $\mathrm{sp}$.

Chauliodes $\mathrm{sp}$.

Chelifera sp.

Cheumatopsyche sp.

Chimarra sp.

Chironomidae

Chloroperlidae

Chrysomelidae

Cladocera

Climacia sp.

Climacia areolaris

Clinocera sp.

Coenagrionidae

Corixidae

Corydalus sp.

Crangonyx sp.

Culoptila sp.

Curculionidae

Cyclopidae 
Table 8. Alphabetic checklist of taxa reported from Chester County Biological Monitoring Network, 1981-94-Continued

Dicranota sp.

Dineutus sp.

Diplectrona $s p$.

Dixa sp.

Dolophilodes sp.

Dryopidae

Dubiraphia sp.

Dytiscidae

Ectopria sp.

Ectopria nervosa

Empididae

Enallagma sp.

Epeorus sp.

Ephemera sp.

Ephemerella sp.

Ephydridae

Erpobdellidae

Ferrissia sp.

Gammaridae

Gammarus sp.

Gerridae

Gerris sp.

Glossiphoniidae

Glossosoma sp.

Goera sp.

Gomphidae

Gomphus sp.

Goniobasis sp.

Gyraulus sp.

Gyrinidae 
Table 8. Alphabetic checklist of taxa reported from Chester County Biological Monitoring Network, 1981-94-Continued

Habrophlebia sp.

Haploperla sp.

Helichus sp.

Helicopsyche sp.

Helisoma sp.

Helophorus sp.

Hemerodromia sp.

Hemiptera

Heptagenia sp.

Hetaerina $\mathrm{sp}$.

Hexagenia sp.

Hexatoma sp.

Hirudinea

Hirudinidae

Hyallela azteca

Hydatophylax sp.

Hydra sp.

Hydrachnidia

Hydrobius sp.

Hydrochara sp.

Hydrophilidae

Hydropsyche sp.

Hydroptila sp.

Ichneumonidae

Ischnura sp.

Isonychia sp.

Isoperla sp.

Lepidostoma sp.

Leptophlebiidae

Leucotrichia sp.

Limnophora sp.

Lirceus sp.

Lumbriculidae

Lymnaea sp.

Macromia $\mathrm{sp}$.

Macronychus sp.

Macronychus glabratus

Macrostemum sp.

Manayunkia speciosa

Mesovelia sp.

Metrobates sp.

Micrasema sp.

Microcylloepus sp.

Microvelia sp.

Muscidae

Musculium sp.

Mystacides $s p$. 
Table 8. Alphabetic checklist of taxa reported from Chester County Biological Monitoring Network, 1981-94-Continued

Naididae

Nematoda

Nematomorpha

Nemouridae

Neoperla sp.

Neophylax sp.

Neureclipsis sp.

Nigronia $s p$.

Noctuidae

Nyctiophylax sp.

Ochrotrichia sp.

Oecetis sp.

Oligochaeta

Ophiogomphus sp.

Optioservus sp.

Orconectes sp.

Oulimnius sp.

Paragnetina sp.

Paraleptophlebia sp.

Peltoperla sp.

Petrophila sp.

Physa sp.

Pisidium sp.

Planariidae

Planorbidae

Planorbula sp.

Podocopa

Polycentropus sp.

Polychaeta

Potamyia sp.

Procambarus sp.

Promoresia sp.

Prosimulium sp.

Prostoma sp.

Protoptila sp.

Psephenus sp.

Pseudocleon sp.

Psilotreta sp.

Psychomyia sp.

Pyralidae

Rhagovelia sp.

Rheumatobates sp.

Rhyacophila sp.

Rhyacophila fuscula 
Table 8. Alphabetic checklist of taxa reported from Chester County Biological Monitoring Network, 1981-94-Continued

Sabellidae

Saldidae

Sialis sp.

Sigara sp.

Simulium sp.

Sisyridae

Sphaeriidae

Sphaerium sp.

Stenacron $\underline{\mathrm{sp}}$.

Stenelmis $\mathrm{sp}$.

Stenonema sp.

Stratiomyidae

Stratiomys sp.

Strophopteryx sp.

Stylaria sp.

Stylogomphus sp.

Synclita sp.

Syrphidae

Tabanus sp.

Taeniopteryx sp.

Telmatoscopus sp.

Tipula sp.

Trepobates sp.

Triaenodes sp.

Trichocorixa sp.

Tricorythodes sp.

Tubificidae

Wormaldia sp. 
Table 9. Systematic checklist of taxa reported from Chester County Biological Monitoring Network, 1981-94

\author{
Cinidaria (Hydroids) \\ Hydra sp. \\ Platyhelminthes (Flatworms) \\ Planariidae \\ Nematoda (Round Worms) \\ Nematomorpha (Horsehair Worms) \\ Nemertea (Proboscis worms) \\ Prostoma sp. \\ Gastropoda (Snails) \\ Amnicola sp. \\ Ferrissia sp. \\ Goniobasis $\mathrm{sp}$. \\ Gyraulus sp. \\ Helisoma sp. \\ Lymnaea sp. \\ Physa sp. \\ Planorbidae \\ Planorbula sp. \\ Bivalvia (Clams) \\ Musculium sp. \\ Pisidium sp. \\ Sphaeriidae \\ Sphaerium sp. \\ Annelida (Segmented worms) \\ Branchiobdellida \\ Erpobdellidae \\ Hirudinea \\ Hirudinidae \\ Glossiphoniidae \\ Lumbriculidae \\ Manayunkia speciosa \\ Naididae \\ Oligochaeta \\ Polychaeta \\ Sabellidae \\ Stylaria sp. \\ Tubificidae \\ Acariformes (Water mites) \\ Hydrachnidia \\ Cladocera (Water fleas)
}


Table 9. Systematic checklist of taxa reported from Chester County Biological Monitoring Network, 1981-94-Continued

Cyclopoida (Copepods)

Cyclopidae

Amphipoda (Scuds)

Crangonyx sp.

Gammaridae

Gammarus sp.

Hyallela azteca

Isopoda (Sow bugs)

Caecidotea sp.

Lirceus sp.

Decapoda (Crayfish)

Cambaridae

Cambarus sp.

Orconectes sp.

Procambarus sp.

Podocopa (Seed shrimps)

Ephemeroptera (Mayflies)

Anthopotamus sp.

Baetis sp.

Caenis sp.

Epeorus sp.

Ephemera sp.

Ephemerella sp.

Habrophlebia sp.

Heptagenia sp.

Hexagenia sp.

Isonychia sp.

Leptophlebiidae

Paraleptophlebia sp.

Pseudocloeon sp.

Stenacron $\mathrm{sp}$.

Stenonema sp.

Tricorythodes $\mathrm{sp}$. 
Table 9. Systematic checklist of taxa reported from Chester County Biological Monitoring Network, 1981-94-Continued

Odonata (Dragonflies and Damselflies)

Aeshna sp.

Amphiagrion sp.

Argia sp.

Boyeria sp.

Calopteryx sp.

Coenagrionidae

Enallagma sp.

Gomphidae

Gomphus sp.

Hetaerina $s p$.

Ischnura sp.

Macromia sp.

Ophiogomphus sp.

Stylogomphus sp.

Plecoptera (Stoneflies)

Acroneuria sp.

Agnetina sp.

Allocapnia sp.

Chloroperlidae

Haploperla sp.

Isoperla sp.

Nemouridae

Neoperla sp.

Paragnetina sp.

Peltoperla sp.

Strophopteryx sp.

Taeniopteryx sp.

Hemiptera (True Bugs)

Corixidae

Gerridae

Gerris sp.

Mesovelia sp.

Metrobates sp.

Microvelia sp.

Rhagovelia sp.

Rheumatobates $\mathrm{sp}$.

Saldidae

Sigara sp.

Trepobates sp.

Trichocorixa sp. 
Table 9. Systematic checklist of taxa reported from Chester County Biological Monitoring Network, 1981-94-Continued

Megaloptera (Alderflies and Dobsonflies)

Chauliodes sp.

Corydalus sp.

Nigronia sp.

Sialis sp.

Neuroptera (Spongillaflies)

Climacia sp.

C. areolaris

Sisyridae

Trichoptera (Caddisflies)

Agraylea sp.

Apatania sp.

Brachycentrus sp.

Ceraclea sp.

Ceratopsyche sp.

Cheumatopsyche sp.

Chimarra sp.

Culoptila sp.

Diplectrona sp.

Dolophilodes sp.

Glossosoma sp.

Goera sp.

Helicopsyche $\mathrm{sp}$.

Hydatophylax sp.

Hydropsyche sp.

Hydroptila sp.

Lepidostoma sp.

Leucotrichia sp.

Macrostemum sp.

Micrasema sp.

Mystacides $\mathrm{sp}$.

Neophylax sp.

Neureclipsis sp.

Nyctiophylax sp.

Ochrotrichia sp.

Oecetis $\mathrm{sp}$.

Polycentropus $\mathrm{sp}$.

Potamyia sp.

Protoptila sp.

Psilotreta sp.

Psychomyia sp.

Rhyacophila sp.

Rhyacophila fuscula

Triaenodes sp.

Wormaldia sp. 
Table 9. Systematic checklist of taxa reported from Chester County Biological Monitoring Network, 1981-94-Continued

\author{
Lepidoptera (Butterflies and Moths) \\ Archanara sp. \\ Noctuidae \\ Petrophila sp. \\ Pyralidae \\ Synclita sp. \\ Coleoptera (Beetles) \\ Agabus sp. \\ Anchytarsus bicolor \\ Ancyronyx sp. \\ Ancyronyx variegata \\ Berosus sp. \\ Chrysomelidae \\ Curculionidae \\ Dineutus sp. \\ Dryopidae \\ Dubiraphia sp. \\ Dytiscidae \\ Ectopria sp. \\ Ectopria nervosa \\ Gyrinidae \\ Helichus sp. \\ Helophorus sp. \\ Hydrobius sp. \\ Hydrochara sp. \\ Hydrophilidae \\ Macronychus sp. \\ Macronychus glabratus \\ Microcylloepus sp. \\ Optioservus sp. \\ Oulimnius sp. \\ Promoresia sp. \\ Psephenus sp. \\ Stenelmis sp.
}

Hymenoptera (Wasps)

Ichneumonidae 
Table 9. Systematic checklist of taxa reported from Chester County Biological Monitoring Network, 1981-94-Continued

Diptera (Flies)

Antocha sp.

Atherix sp.

Blephariceridae

Blephariceria sp.

Ceratopogonidae

Chaoborus sp.

Chelifera sp.

Chironomidae

Clinocera $s p$.

Dicranota sp.

Dixa sp.

Empididae

Ephydridae

Hemerodromia sp.

Hexatoma sp.

Limnophora sp.

Muscidae

Prosimulium sp.

Simulium sp.

Stratiomyidae

Stratiomys sp.

Syrphidae

Tabanus sp.

Telmatoscopus sp.

Tipula sp. 